\title{
Analysis of Accident Sequences and Source Terms at Treatment and Storage Facilities for Waste Generated by U.S. Department of Energy Waste Management Operations
}

\section{Volume 1: Sections 1-9}

by C. Mueller, B. Nabelssi, J. Roglans-Ribas, S. Folga, A. Policastro, W. Freeman, * R. Jackson, ${ }^{\star}$ J. Mishima, ${ }^{\star}$ and S. Turner*

Environmental Assessment Division, Argonne National Laboratory, 9700 South Cass Avenue, Argonne, Illinois 60439

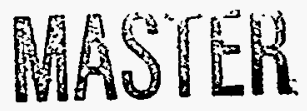

December 1996

DISTRIBUTION OF THIS DOCUABENT IS UNLIMITED

Work sponsored by United States Department of Energy, Assistant Secretary for Environmental Management

* Freeman is affiliated with the University of Illinois at Chicago; Jackson and Turner with Science Applications International Corporation, Golden, Colorado; and Mishima with Science Applications International Corporation, Richland, Washington. 


\section{DISCLAIMER}

This report was prepared as an account of work sponsored by an agency of the United States Government. Neither the United States Government nor any agency thereof, nor any of their employees, makes any warranty, express or implied, or assumes any legal liability or responsibility for the accuracy, completeness; or usefulness of any information, apparatus, product, or process disclosed, or represents that its use would not infringe privately owned rights. Reference herein to any specific commercial product, process, or service by trade name, trademark, manufacturer, or otherwise does not necessarily constitute or imply its endorsement, recommendation, or favoring by the United States Government or any agency thereof. The views and opinions of authors expressed herein do not necessarily state or reflect those of the United States Government or any agency thereof. 


\section{DISCLAIMER}

Portions of this document may be illegible electronic image products. Images are produced from the best available original document. 


\section{VOLUME 1}

\section{CONTENTS}

VOLUME 2 CONTENTS $\ldots \ldots \ldots \ldots \ldots \ldots \ldots \ldots \ldots \ldots \ldots \ldots \ldots \ldots \ldots \ldots \ldots$ viii

VOLUME 3 CONTENTS $\ldots \ldots \ldots \ldots \ldots \ldots \ldots \ldots \ldots \ldots \ldots \ldots \ldots \ldots \ldots$

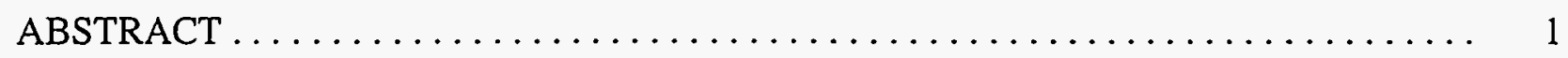

1 INTRODUCTION AND OVERVIEW $\ldots \ldots \ldots \ldots \ldots \ldots \ldots \ldots \ldots \ldots \ldots \ldots$

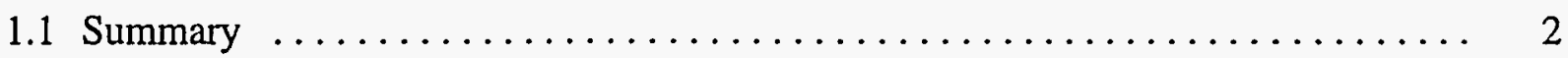

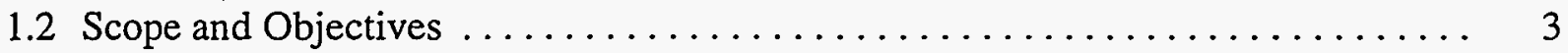

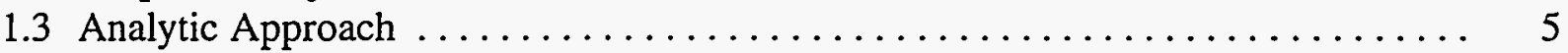

1.4 Organization of Report $\ldots \ldots \ldots \ldots \ldots \ldots \ldots \ldots \ldots \ldots \ldots \ldots \ldots \ldots \ldots \ldots$

2 METHODOLOGY AND COMPUTATIONAL FRAMEWORK

FOR ACCIDENT ANALYSIS $\ldots \ldots \ldots \ldots \ldots \ldots \ldots \ldots \ldots \ldots \ldots \ldots \ldots \ldots$

2.1 Overview $\ldots \ldots \ldots \ldots \ldots \ldots \ldots \ldots \ldots \ldots \ldots \ldots \ldots \ldots \ldots \ldots$

2.2 Selection of Risk-Dominant Operations, Facilities, and Related

Types of Accidents . . . . . . . . . . . . . . . .

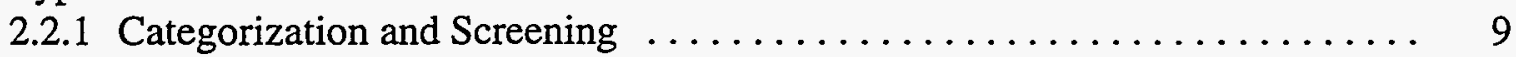

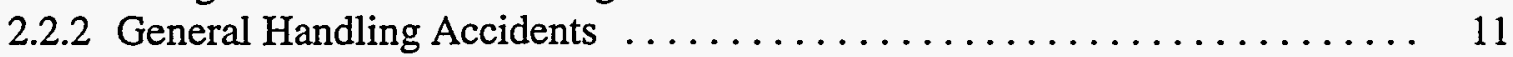

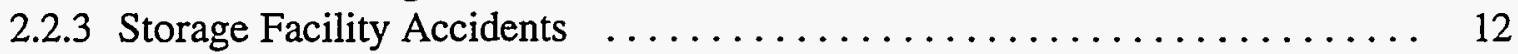

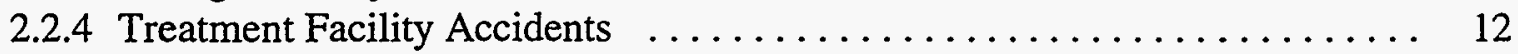

2.3 Development of Risk-Dominant Accident Sequences . . . . . . . . . . . . 15

2.3.1 Selection and Categorization of Accident Initiators $\ldots \ldots \ldots \ldots \ldots \ldots \ldots$

2.3.2 Specification and Evaluation of Accident Sequences . . . . . . . . . 21

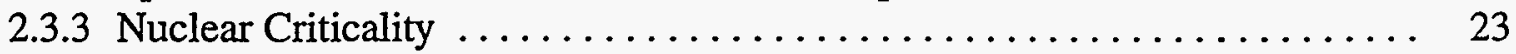

2.4 Development of Source Terms for Accident Sequences . . . . . . . . . . . . . 24

2.4 .1 Radiological Source Terms .............................. 24

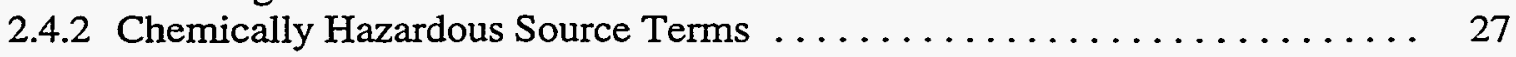

2.5 General Facility Modeling and Inventory Assumptions $\ldots \ldots \ldots \ldots \ldots \ldots$

2.5.1 DOE Design and Performance Criteria .................. 28

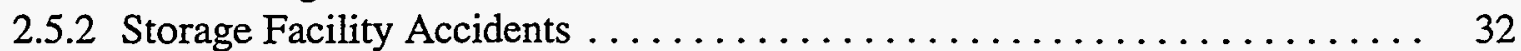

2.5.3 Treatment Facility Accidents . . . . . . . . . . . . . . . . . . 33

2.6 Evaluation of Source Term Parameters and Frequencies . . . . . . . . . . . . 37

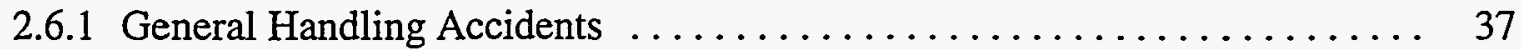

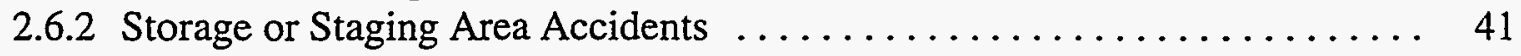

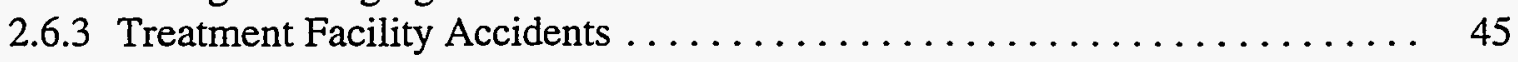

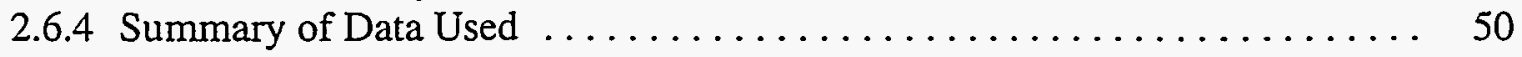




\section{CONTENTS (Cont.)}

2.7 Selection and Calculation of Final Source Terms $\ldots \ldots \ldots \ldots \ldots \ldots \ldots \ldots, 50$

2.8 Uncertainty in Facility Accident Analysis . . . . . . . . . . . . . . . 52

3 ACCIDENT ANALYSIS FOR HIGH-LEVEL WASTE $\ldots \ldots \ldots \ldots \ldots \ldots \ldots \ldots$

3.1 Overview of High-Level Waste Management $\ldots \ldots \ldots \ldots \ldots \ldots \ldots \ldots \ldots$

3.2 Risk-Dominant Accidents and Modeling Assumptions .............. 58

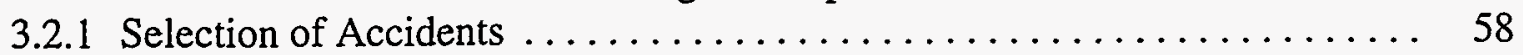

3.2.2 Source Term Modeling Assumptions $\ldots \ldots \ldots \ldots \ldots \ldots \ldots \ldots \ldots, 61$

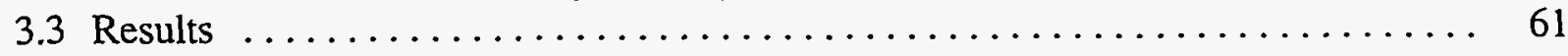

4 ACCIDENT ANALYSIS FOR TRANSURANIC WASTE $\ldots \ldots \ldots \ldots \ldots \ldots \ldots$

4.1 Overview of Transuranic Waste Management $\ldots \ldots \ldots \ldots \ldots \ldots \ldots \ldots . \ldots 7$

4.2 Risk-Dominant Accidents and Modeling Assumptions ............... 73

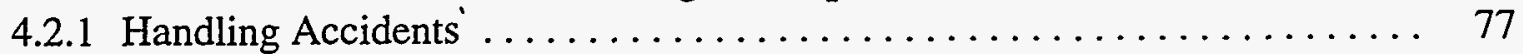

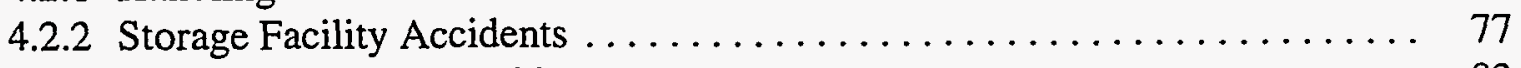

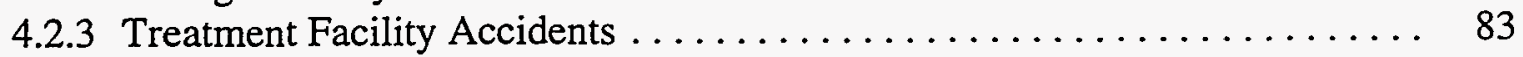

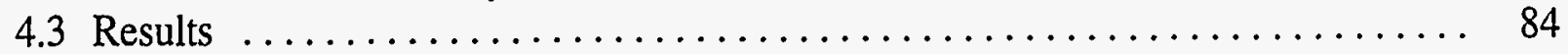

5 ACCIDENT ANALYSIS FOR LOW-LEVEL WASTE $\ldots \ldots \ldots \ldots \ldots \ldots \ldots . . \ldots$

5.1 Overview of Low-Level Waste Management $\ldots \ldots \ldots \ldots \ldots \ldots \ldots \ldots . . \ldots$

5.2 Risk-Dominant Accidents and Modeling Assumptions ............... 93

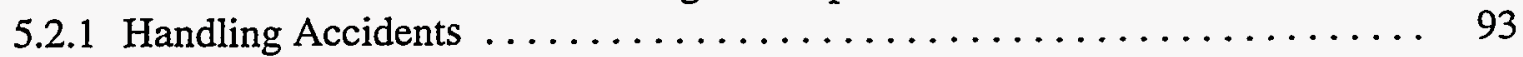

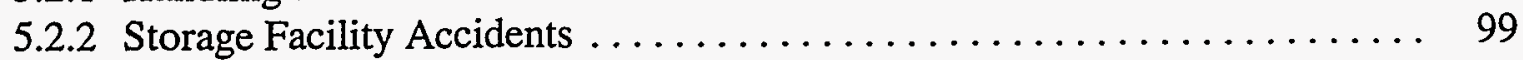

5.2.3 Treatment Facility and Inventory Modeling Assumptions ........... 99

5.2 .4 Disposal Facility Accidents $\ldots \ldots \ldots \ldots \ldots \ldots \ldots \ldots \ldots \ldots \ldots \ldots \ldots \ldots$

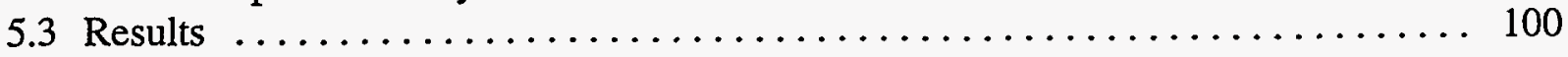

6 ACCIDENT ANALYSIS FOR LOW-LEVEL MIXED WASTE $\ldots \ldots \ldots \ldots \ldots \ldots$

6.1 Overview of Low-Level Mixed Waste Management ............... 108

6.2 Risk-Dominant Accidents and Modeling Assumptions ............... 113

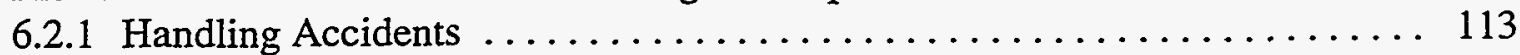

6.2 .2 Storage Facility Accidents .......................... 121

6.2.3 Treatment Facility and Inventory Modeling Assumptions ........... 123

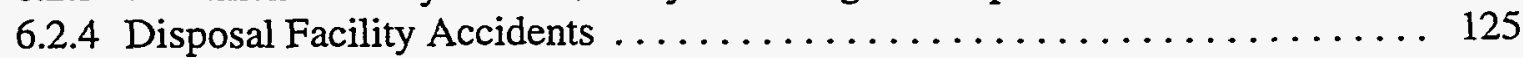

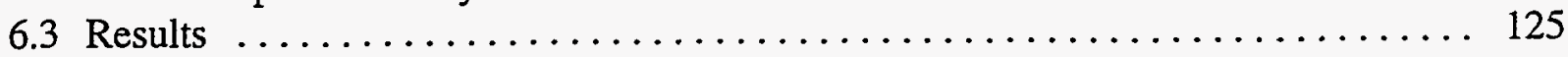




\section{CONTENTS (Cont.)}

\section{ACCIDENT ANALYSIS FOR GREATER-THAN-CLASS-C}

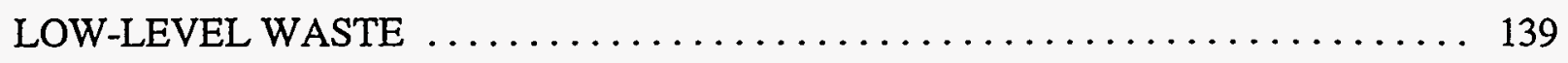

7.1 Overview of Greater-Than-Class-C Low-Level Waste Management . . . . . . . . 139

7.2 Accident Considerations and Conclusions Relating to Source Terms ......... 140

8 ACCIDENT ANALYSIS FOR HAZARDOUS WASTE $\ldots \ldots \ldots \ldots \ldots \ldots \ldots \ldots$

8.1 Overview of Hazardous Waste Management $\ldots \ldots \ldots \ldots \ldots \ldots \ldots \ldots \ldots . \ldots \ldots$

8.2 Risk-Dominant Accidents and Facility Modeling Assumptions . . . . . . . . . . 142

8.2.1 Packaged Waste Storage and Handling Operations . . . . . . . . . . . 148

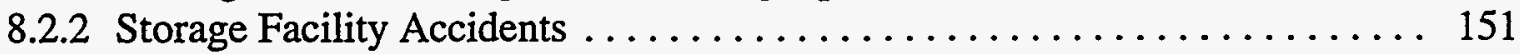

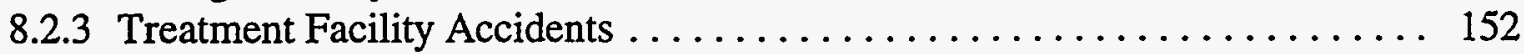

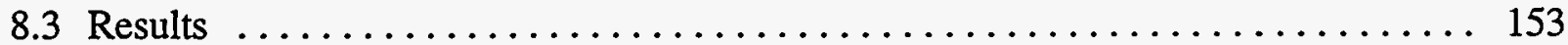

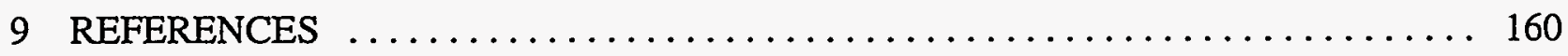

\section{FIGURES}

1.1 Overview of Facility Accident Analysis Interactions for the WM PEIS $\ldots \ldots \ldots \ldots$. 6

2.1 Major Components and Related Input and Output of Data

for Facility Accident Analysis $\ldots \ldots \ldots \ldots \ldots \ldots \ldots \ldots \ldots \ldots \ldots \ldots, 8$

2.2 Screening of Risk-Dominant Accident Sequences $\ldots \ldots \ldots \ldots \ldots \ldots \ldots \ldots$

2.3 Conceptual Flow Diagram for Source Term Development $\ldots \ldots \ldots \ldots \ldots \ldots \ldots .25$

2.4 DOE Performance Goals for Hazard Category 1, 2, and 3 Facilities ......... 31

2.5 Typical Design for Hazardous Waste Storage Facility $\ldots \ldots \ldots \ldots \ldots \ldots \ldots \ldots$

2.6 Plan of Generic Incineration Facility Assumed for Accident Analysis . . . . . . . . 35

2.7 Computational Framework for Facility Accident Analysis Source Terms $\ldots \ldots \ldots \quad 52$

4.1 TRUW Management Technologies and Flow Paths to Meet WIPP-WAC . . . . . . 70

4.2 TRUW Management Technologies and Flow Paths to Minimize Gas Generation ................................. 71 


\section{FIGURES (Cont.)}

4.3 TRUW Management Technologies and Flow Paths to Meet

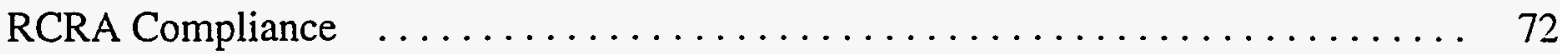

5.1 LLW Management Technologies and Flow Paths $\ldots \ldots \ldots \ldots \ldots \ldots \ldots . . \ldots 4$

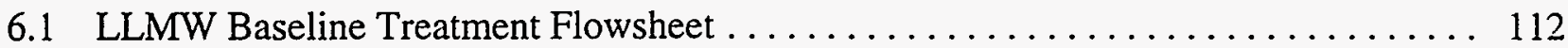

\section{TABLES}

2.1 Risk-Dominant Accident-Initiator Categories for Waste Management Operations and Facilities $\ldots \ldots \ldots \ldots \ldots \ldots \ldots \ldots \ldots \ldots \ldots \ldots \ldots \ldots \ldots \ldots \ldots, 18$

2.2 Frequency Categories Traditionally Considered in Safety Documentation ........ 19

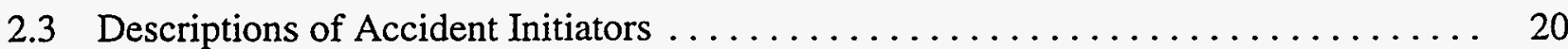

2.4 Frequency and Source Term Parameters for General Handling and Internal Facility Accidents $\ldots \ldots \ldots \ldots \ldots \ldots \ldots \ldots \ldots, 51$

2.5 Representative Accidents Analyzed for Source Term Development .......... 53

3.1 Interim Storage Facilities for HLW Canisters $\ldots \ldots \ldots \ldots \ldots \ldots \ldots \ldots \ldots$

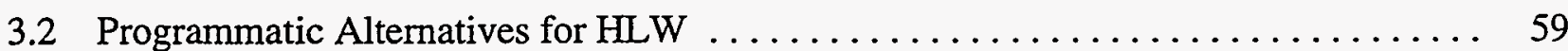

3.3 Dimensions, Weights, and Radioactivities of HLW Canisters .............. 62

3.4 Respirable Airborne Release Fraction as a Function of Filtration

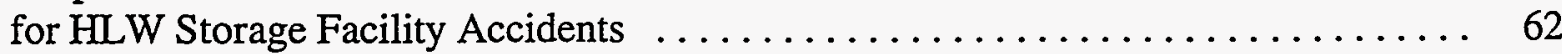

3.5 Mapping of HLW Treatability Categories with Accident Analysis Physical Forms

3.6 Frequencies and Source Term Parameters for WM HLW Storage

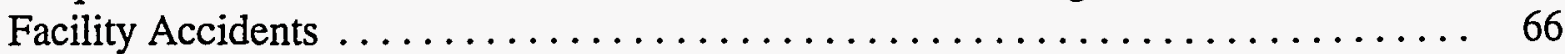

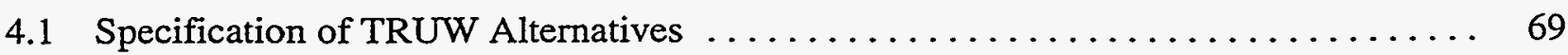

4.2 Mapping of TRUW Treatability Categories with Accident Analysis

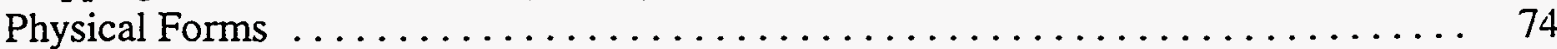




\section{TABLES (Cont.)}

4.3 Representative Accidents and Source Term Parameters from Recent

DOE Safety Analysis Documents Relevant to TRUW Storage $\ldots \ldots \ldots \ldots \ldots \ldots .78$

4.4 Summary of WM TRUW Accidents Analyzed $\ldots \ldots \ldots \ldots \ldots \ldots \ldots \ldots \ldots$

4.5 Frequencies and Source Term Parameters for WM TRUW

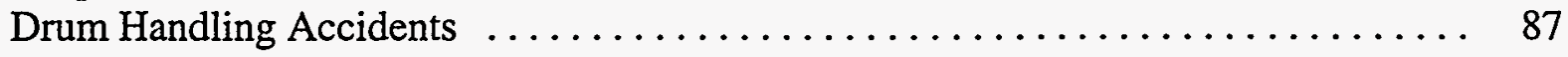

4.6 Summary of Source Terms for TRUW Incineration Facility Accidents $\ldots \ldots \ldots \ldots 88$

5.1 Programmatic Alternatives for LLW Management $\ldots \ldots \ldots \ldots \ldots \ldots \ldots . . \ldots 1$

5.2 Mapping of LLW Treatability Categories with Accident Analysis

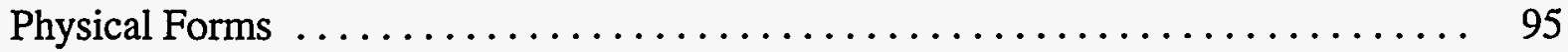

5.3 Summary of WM LLW Accidents Analyzed $\ldots \ldots \ldots \ldots \ldots \ldots \ldots \ldots \ldots \ldots$

5.4 Frequencies and Source Term Parameters for WM LLW

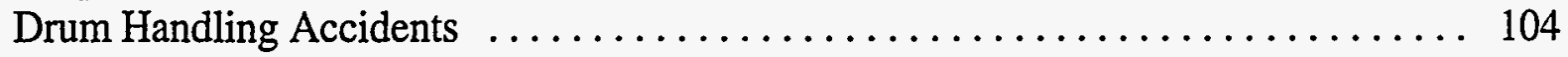

5.5 Frequencies and Source Term Parameters for WM LLW

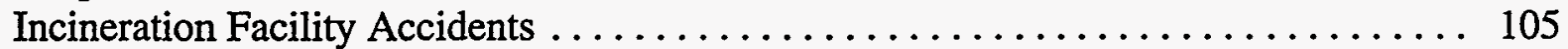

6.1 Specification of LLMW Alternatives $\ldots \ldots \ldots \ldots \ldots \ldots \ldots \ldots \ldots \ldots \ldots \ldots$

6.2 Generic Treatment Categories and Descriptions $\ldots \ldots \ldots \ldots \ldots \ldots \ldots \ldots \ldots \ldots$

6.3 Mapping of LLMW Treatability Categories with Accident Analysis

Physical Forms . .................................... 114

6.4 Chemical Releases Analyzed for LLMW $\ldots \ldots \ldots \ldots \ldots \ldots \ldots \ldots \ldots \ldots \ldots \ldots$

6.5 Representative Accidents and Source Term Parameters from Recent

DOE Safety Analysis Documents Relevant to LLMW ................ 122

6.6 Summary of WM LLMW Radiological Accidents Analyzed $\ldots \ldots \ldots \ldots \ldots \ldots$

6.7 Frequencies and Radiological Source Term Parameters

for WM LLMW Drum Handling Accidents . . . . . . . . . . . . . . . . 131

6.8 Frequencies and Radiological Source Term Parameters

for WM LLMW Non-Alpha Incineration Facility Accidents . . . . . . . . . . . . 133 


\section{TABLES (Cont.)}

6.9 Frequencies and Radiological Source Term Parameters

for WM LLMW Alpha-Incineration Facility Accidents ................ 137

8.1 Specification of HW Alternatives $\ldots \ldots \ldots \ldots \ldots \ldots \ldots \ldots \ldots \ldots \ldots \ldots \ldots \ldots \ldots \ldots$

8.2 Airborne Release Assumptions for Representative HW Accidents ........... 145

8.3 Site-Dependent Annual Frequencies of Representative HW

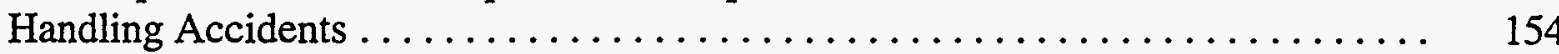

8.4 Frequencies and Source Term Parameters for WM HW

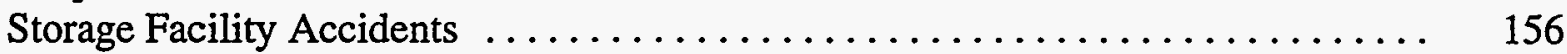

8.5 Frequencies and Source Term Parameters for WM HW

Incineration Facility Accidents . . . . . . . . . . . . . . . . . . . . . 159

VOLUME 2 CONTENTS

APPENDIX A: CHEMICAL SOURCE TERMS FOR LOW-LEVEL MIXED

WASTE ACCIDENTS $\ldots \ldots \ldots \ldots \ldots \ldots \ldots \ldots \ldots \ldots \ldots \ldots \ldots \ldots \ldots \ldots$ A-1

APPENDIX B: RADIONUCLIDE RELEASES FROM ACCIDENTS...$\ldots \ldots \ldots$. B-1

B.1 Introduction $\ldots \ldots \ldots \ldots \ldots \ldots \ldots \ldots \ldots \ldots \ldots \ldots \ldots \ldots \ldots \ldots \ldots$, B-9

B.2 Radionuclide Releases from $\mathrm{HLW}$ Accidents $\ldots \ldots \ldots \ldots \ldots \ldots$ B-11

B.3 Radionuclide Releases from TRUW Accidents .............. B-15

B.4 Radionuclide Releases from LLW Accidents . . . . . . . . . . . . B-29

B.5 Radionuclide Releases from Alpha-LLMW

Treatment Accidents .......................... B-64

B.6 Radionuclide Releases from Non-Alpha LLMW

Treatment Accidents ........................... B-79

B.7 Radionuclide Releases from LLMW Drum

Handling Accidents . . . . . . . . . . . . . . . . . . . . 


\section{TABLES}

A.1 Frequencies and Chemical Source Terms for WM-LLMW

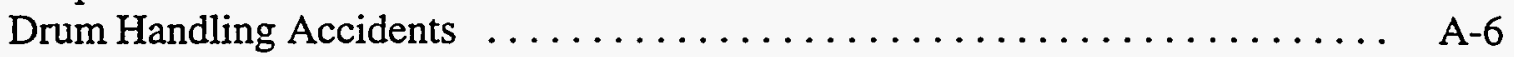

A.2 Frequencies and Chemical Source Terms for WM-LLMW Non-Alpha

Incineration Facility Accidents . . . . . . . . . . . . . . . . . . . . . .

A.3 Frequencies and Chemical Source Terms for WM-LLMW Alpha

Incineration Facility Accidents . . . . . . . . . . . . . . . . . . $\ldots \ldots$

B.1 Accident Identification $\ldots \ldots \ldots \ldots \ldots \ldots \ldots \ldots \ldots \ldots \ldots \ldots \ldots \ldots \ldots \ldots \ldots \ldots$

B.2.1 High-Level Waste, All Cases: Hanford $\ldots \ldots \ldots \ldots \ldots \ldots \ldots \ldots \ldots$ B-11

B.2.2 High-Level Waste, All Cases: Savannah River Site $\ldots \ldots \ldots \ldots \ldots \ldots \ldots$ B-12

B.2.3 High-Level Waste, All Cases: West Valley Demonstration Project ......... B-13

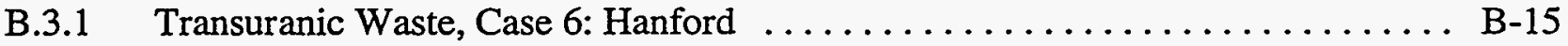

B.3.2 Transuranic Waste, Case 6: Idaho National Engineering Laboratory ......... B-16

B.3.3 Transuranic Waste, Case 6: Los Alamos National Laboratory ............. B-17

B.3.4 Transuranic Waste, Case 6: Rocky Flats Plant $\ldots \ldots \ldots \ldots \ldots \ldots \ldots \ldots$ B-18

B.3.5 Transuranic Waste, Case 6: Savannah River Site .................. B-19

B.3.6 Transuranic Waste, Case 8: Hanford $\ldots \ldots \ldots \ldots \ldots \ldots \ldots \ldots \ldots \ldots$ B-20

B.3.7 Transuranic Waste, Case 8: Idaho National Engineering Laboratory ......... B-21

B.3.8 Transuranic Waste, Case 8: Savannah River Site $\ldots \ldots \ldots \ldots \ldots \ldots \ldots \ldots$ B-22

B.3.9 Transuranic Waste, Case 9: Waste Isolation Pilot Plant $\ldots \ldots \ldots \ldots \ldots \ldots$ B-23

B.3.10 Transuranic Waste, Case 15: Hanford $\ldots \ldots \ldots \ldots \ldots \ldots \ldots \ldots \ldots \ldots$ B-24

B.3.11 Transuranic Waste, Case 15: Oak Ridge National Laboratory ............ B-25

B.3.12 Transuranic Waste Drum Handling Accidents for All Cases:

Argonne National Laboratory-West . . . . . . . . . . . . . . . . . . . B-26

B.3.13 Transuranic Waste Drum Handling Accidents for All Cases: Hanford . . . . . . . B-26 


\section{TABLES (Cont.)}

B.3.14 Transuranic Waste Drum Handling Accidents for All Cases:

Los Alamos National Laboratory $\ldots \ldots \ldots \ldots \ldots \ldots \ldots \ldots \ldots \ldots \ldots \ldots$

B.3.15 Transuranic Waste Drum Handling Accidents for All Cases:

Lawrence Livermore National Laboratory $\ldots \ldots \ldots \ldots \ldots \ldots \ldots \ldots$ B-27

B.3.16 Transuranic Waste Drum Handling Accidents for All Cases:

Rocky Flats Plant $\ldots \ldots \ldots \ldots \ldots \ldots \ldots \ldots \ldots \ldots \ldots \ldots \ldots \ldots \ldots \ldots \ldots \ldots \ldots$

B.3.17 Transuranic Waste Drum Handling Accidents for All Cases:

Savannah River Site $\ldots \ldots \ldots \ldots \ldots \ldots \ldots \ldots \ldots \ldots \ldots \ldots \ldots \ldots \ldots \ldots \ldots \ldots$

B.4.1 Low-Level Waste, Case 1: Idaho National Engineering Laboratory ......... B-29

B.4.2 Low-Level Waste, Case 1: Savannah River Site .................. B-30

B.4.3 Low-Level Waste, Case 9: Fernald Environmental Management Project ...... B-31

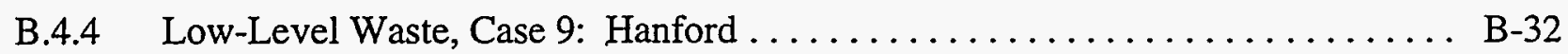

B.4.5 Low-Level Waste, Case 9: Idaho National Engineering Laboratory ......... B-33

B.4.6 Low-Level Waste, Case 9: Lawrence Livermore National Laboratory ........ B-34

B.4.7 Low-Level Waste, Case 9: Los Alamos National Laboratory ............ B-35

B.4.8 Low-Level Waste, Case 9: Oak Ridge National Laboratory $\ldots \ldots \ldots \ldots \ldots$ B-36

B.4.9 Low-Level Waste, Case 9: Paducah Gaseous Diffusion Plant $\ldots \ldots \ldots \ldots$ B-37

B.4.10 Low-Level Waste, Case 9: Portsmouth Gaseous Diffusion Plant $\ldots \ldots \ldots \ldots$ B-38

B.4.11 Low-Level Waste, Case 9: Rocky Flats Environmental Technology Site ...... B-39

B.4.12 Low-Level Waste, Case 9: Savannah River Site $\ldots \ldots \ldots \ldots \ldots \ldots \ldots$ B-40

B.4.13 Low-Level Waste, Case 12: Hanford $\ldots \ldots \ldots \ldots \ldots \ldots \ldots \ldots \ldots \ldots \ldots \ldots \ldots$

B.4.14 Low-Level Waste, Case 12: Idaho National Engineering Laboratory . ....... B-42

B.4.15 Low-Level Waste, Case 12: Los Alamos National Laboratory ........... B-43

B.4.16 Low-Level Waste, Case 12: Oak Ridge National Laboratory . ........... B-44 


\section{TABLES (Cont.)}

B.4.17 Low-Level Waste, Case 12: Portsmouth Gaseous Diffusion Plant . . . . . . . . B-45

B.4.18 Low-Level Waste, Case 12: Rocky Flats Environmental Technology Site . . . . B B-46

B.4.19 Low-Level Waste, Case 12: Rocky Flats Environmental Technology Site . . . . B B-47

B.4.20 Low-Level Waste, Case 12: Savannah River Site ................. B-48

B.4.21 Low-Level Waste, Case 19: Hanford $\ldots \ldots \ldots \ldots \ldots \ldots \ldots \ldots \ldots \ldots$ B-49

B.4.22 Low-Level Waste, Case 19: Idaho National Engineering Laboratory . . . . . . . B-50

B.4.23 Low-Level Waste, Case 19: Idaho National Engineering Laboratory . . . . . . . B-51

B.4.24 Low-Level Waste, Case 19: Oak Ridge National Laboratory $\ldots \ldots \ldots \ldots \ldots$ B-52

B.4.25 Low-Level Waste, Case 19: Savannah River Site ................ B-53

B.4.26 Low-Level Waste, Case 21: Hanford $\ldots \ldots \ldots \ldots \ldots \ldots \ldots \ldots \ldots \ldots \ldots \ldots \ldots$

B.4.27 Low-Level Waste, Case 21: Hanford $\ldots \ldots \ldots \ldots \ldots \ldots \ldots \ldots \ldots \ldots$ B-55

B.4.28 Low-Level Waste, All Cases: Hanford $\ldots \ldots \ldots \ldots \ldots \ldots \ldots \ldots \ldots$ B-56

B.4.29 Low-Level Waste, All Cases: Idaho National Engineering Laboratory . . . . . . B-57

B.4.30 Low-Level Waste, All Cases: Los Alamos National Laboratory $\ldots \ldots \ldots \ldots$ B-58

B.4.31 Low-Level Waste, All Cases: Lawrence Livermore National Laboratory . . . . . B-59

B.4.32 Low-Level Waste, All Cases: Oak Ridge National Laboratory . . . . . . . . . . B-60

B.4.33 Low-Level Waste, All Cases: Paducah Gaseous Diffusion Plant . . . . . . . . . B-61

B.4.34 Low-Level Waste, All Cases: Pantex Plant $\ldots \ldots \ldots \ldots \ldots \ldots \ldots$ B-61

B.4.35 Low-Level Waste, All Cases: Portsmouth Gaseous Diffusion Plant ......... B-62

B.4.36 Low-Level Waste, All Cases: Rocky Flats Plant ................. B-62

B.4.37 Low-Level Waste, All Cases: Savannah River Site $\ldots \ldots \ldots \ldots \ldots \ldots$ B-63 


\section{TABLES (Cont.)}

B.5.1 Low-Level Mixed Waste, Case 2: Idaho National Engineering Laboratory .... . B-64

B.5.2 Low-Level Mixed Waste, Case 2: Los Alamos National Laboratory . . . . . . . . B-65

B.5.3 Low-Level Mixed Waste, Case 2: Lawrence Livermore National Laboratory $\ldots \ldots \ldots \ldots \ldots \ldots \ldots \ldots \ldots \ldots \ldots \ldots \ldots \ldots \ldots \ldots$

B.5.4 Low-Level Mixed Waste, Case 2: Rocky Flats Environmental Technology Site $\ldots \ldots \ldots \ldots \ldots \ldots \ldots \ldots \ldots \ldots \ldots \ldots \ldots \ldots \ldots \ldots \ldots$

B.5.5 Low-Level Mixed Waste, Case 2: Savannah River Site .............. B-67

B.5.6 Low-Level Mixed Waste, Case 4: Idaho National Engineering Laboratory .... . B-68

B.5.7 Low-Level Mixed Waste, Case 4: Lawrence Livermore National Laboratory $\ldots \ldots \ldots \ldots \ldots \ldots \ldots \ldots \ldots \ldots \ldots \ldots \ldots \ldots$

B.5.8 Low-Level Mixed Waste, Case 4: Los Alamos National Laboratory . . . . . . . . B-69

B.5.9 Low-Level Mixed Waste, Case 4: Rocky Flats Environmental Technology Site $\ldots \ldots \ldots \ldots \ldots \ldots \ldots \ldots \ldots \ldots \ldots \ldots \ldots \ldots \ldots \ldots \ldots \ldots$

B.5.10 Low-Level Mixed Waste, Case 4: Savannah River Site .............. B-71

B.5.11 Low-Level Mixed Waste, Case 7: Idaho National Engineering Laboratory .... B B-72

B.5.12 Low-Level Mixed Waste, Case 7: Los Alamos National Laboratory . . . . . . . B B-73

B.5.13 Low-Level Mixed Waste, Case 7: Rocky Flats Environmental

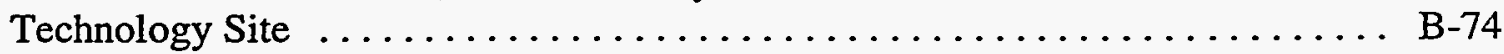

B.5.14 Low-Level Mixed Waste, Case 7: Savannah River Site ............ B-74

B.5.15 Low-Level Mixed Waste, Case 15: Idaho National Engineering Laboratory $\ldots \ldots \ldots \ldots \ldots \ldots \ldots \ldots \ldots \ldots \ldots \ldots \ldots \ldots \ldots \ldots \ldots$

B.5.16 Low-Level Mixed Waste, Case 15: Savannah River Site $\ldots \ldots \ldots \ldots \ldots$ B-76

B.5.17 Low-Level Mixed Waste, Case 17: Hanford $\ldots \ldots \ldots \ldots \ldots \ldots \ldots \ldots$ B-77

B.5.18 Low-Level Mixed Waste, Case 26: Idaho National Engineering Laboratory $\ldots \ldots \ldots \ldots \ldots \ldots \ldots \ldots \ldots \ldots \ldots \ldots \ldots \ldots \ldots \ldots$ 


\section{TABLES (Cont.)}

B.6.1 Low-Level Mixed Waste, Case 1: Idaho National Engineering Laboratory .... B-79

B.6.2 Low-Level Mixed Waste, Case 1: Oak Ridge National Laboratory ......... B-80

B.6.3 Low-Level Mixed Waste, Case 1: Savannah River Site $\ldots \ldots \ldots \ldots \ldots$ B-81

B.6.4 Low-Level Mixed Waste, Case 2: Argonne National Laboratory-East . . . . . . B B-82

B.6.5 Low-Level Mixed Waste, Case 2: Brookhaven National Laboratory . . . . . . . B B-83

B.6.6 Low-Level Mixed Waste, Case 2: Energy Technology Engineering Center .... . B-84

B.6.7 Low-Level Mixed Waste, Case 2: Fernald Environmental Management Project ............................ B-85

B.6.8 Low-Level Mixed Waste, Case 2: Hanford $\ldots \ldots \ldots \ldots \ldots \ldots \ldots \ldots$ B-86

B.6.9 Low-Level Mixed Waste, Case 2: Idaho National Engineering Laboratory .... B B-87

B.6.10 Low-Level Mixed Waste, Case 2: Knolls Atomic Power

Laboratory, Schenectady ....................... B-8

B.6.11 Low-Level Mixed Waste, Case 2: Nevada Test Site $\ldots \ldots \ldots \ldots \ldots$ B-89

B.6.12 Low-Level Mixed Waste, Case 2: Oak Ridge National Laboratory . . . . . . . B B-90

B.6.13 Low-Level Mixed Waste, Case 2: Paducah Gaseous Diffusion Plant ........ B-91

B.6.14 Low-Level Mixed Waste, Case 2: Pantex Plant $\ldots \ldots \ldots \ldots \ldots \ldots \ldots$ B-92

B.6.15 Low-Level Mixed Waste, Case 2: Portsmouth Gaseous Diffusion Plant ...... B-92

B.6.16 Low-Level Mixed Waste, Case 2: Sandia National Laboratories-

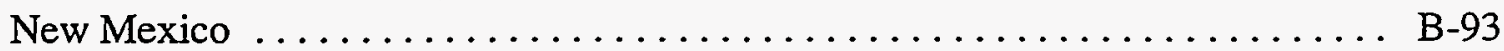

B.6.17 Low-Level Mixed Waste, Case 2: Savannah River Site $\ldots \ldots \ldots \ldots \ldots$ B-94

B.6.18 Low-Level Mixed Waste, Case 4: Energy Technology Engineering Center .... . B-95

B.6.19 Low-Level Mixed Waste, Case 4: Fernald Environmental

Management Project .............................. B-96

B.6.20 Low-Level Mixed Waste, Case 4: Hanford . . . . . . . . . . . . . B-97 


\section{TABLES (Cont.)}

B.6.21 Low-Level Mixed Waste, Case 4: Idaho National Engineering Laboratory . . . . B-98

B.6.22 Low-Level Mixed Waste, Case 4: Lawrence Livermore

National Laboratory $\ldots \ldots \ldots \ldots \ldots \ldots \ldots \ldots \ldots \ldots \ldots \ldots \ldots \ldots . \ldots \ldots$

B.6.23 Low-Level Mixed Waste, Case 4: Los Alamos National Laboratory ........ B-100

B.6.24 Low-Level Mixed Waste, Case 4: Oak Ridge National Laboratory ........ B-101

B.6.25 Low-Level Mixed Waste, Case 4: Paducah Gaseous Diffusion Plant ........ B-102

B.6.26 Low-Level Mixed Waste, Case 4: Pantex Plant $\ldots \ldots \ldots \ldots \ldots \ldots \ldots \ldots$ B-103

B.6.27 Low-Level Mixed Waste, Case 4: Portsmouth Gaseous Diffusion Plant ..... B-104

B.6.28 Low-Level Mixed Waste, Case 4: Rocky Flats Environmental

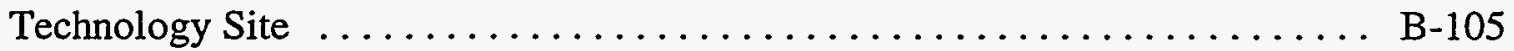

B.6.29 Low-Level Mixed Waste, Case 4: Savannah River Site .............. B-106

B.6.30 Low-Level Mixed Waste, Case 7: Hanford $\ldots \ldots \ldots \ldots \ldots \ldots \ldots \ldots$ B-107

B.6.31 Low-Level Mixed Waste, Cạse 7: Idaho National

Engineering Laboratory $\ldots \ldots \ldots \ldots \ldots \ldots \ldots \ldots \ldots \ldots \ldots \ldots \ldots \ldots \ldots \ldots$

B.6.32 Low-Level Mixed Waste, Case 7: Los Alamos National Laboratory ........ B-109

B.6.33 Low-Level Mixed Waste, Case 7: Oak Ridge National Laboratory ....... B-110

B.6.34 Low-Level Mixed Waste, Case 7: Portsmouth Gaseous Diffusion Plant ..... B-111

B.6.35 Low-Level Mixed Waste, Case 7: Rocky Flats Environmental

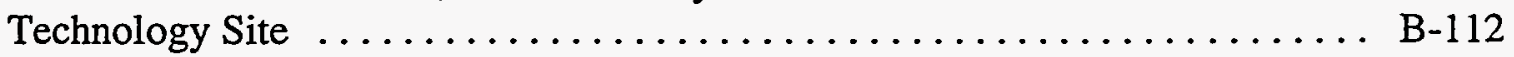

B.6.36 Low-Level Mixed Waste, Case 7: Savannah River Site ............ B-113

B.6.37 Low-Level Mixed Waste, Case 15: Hanford ................. B-114

B.6.38 Low-Level Mixed Waste, Case 15: Idaho National

Engineering Laboratory $\ldots \ldots \ldots \ldots \ldots \ldots \ldots \ldots \ldots \ldots \ldots \ldots \ldots \ldots \ldots \ldots \ldots$

B.6.39 Low-Level Mixed Waste, Case 15: Oak Ridge National Laboratory . . . . . . . B-116 


\section{TABLES (Cont.)}

B.6.40 Low-Level Mixed Waste, Case 15: Savannah River Site .............. B-117

B.6.41 Low-Level Mixed Waste, Case 17: Hanford $\ldots \ldots \ldots \ldots \ldots \ldots \ldots \ldots$ B-118

B.6.42 Low-Level Mixed Waste, Case 26: Hanford ................... B-119

B.6.43 Low-Level Mixed Waste, Case 26: Idaho National

Engineering Laboratory $\ldots \ldots \ldots \ldots \ldots \ldots \ldots \ldots \ldots \ldots \ldots \ldots \ldots \ldots \ldots \ldots$

B.6.44 Low-Level Mixed Waste, Case 26: Oak Ridge National Laboratory ........ B-121

B.6.45 Low-Level Mixed Waste, Case 26: Savannah River Site ............ B-122

B.7.1 Low-Level Mixed Waste, All Cases: Ames Laboratory $\ldots \ldots \ldots \ldots \ldots$ B-123

B.7.2 Low-Level Mixed Waste, All Cases: Argonne National Laboratory-East . . . . B-123

B.7.3 Low-Level Mixed Waste, All Cases: Argonne National Laboratory-West . . . . B-124

B.7.4 Low-Level Mixed Waste, All Cases: Bettis Atomic Power Laboratory . . . . . . B-124

B.7.5 Low-Level Mixed Waste, All Cases: Battelle Columbus Laboratory . . . . . . B B-125

B.7.6 Low-Level Mixed Waste, All Cases: Brookhaven National Laboratory . . . . . . B-125

B.7.7 Low-Level Mixed Waste, All Cases: Charleston Naval Shipyard . . . . . . . . B B-126

B.7.8 Low-Level Mixed Waste, All Cases: Colonie Interim Storage . . . . . . . . B B-126

B.7.9 Low-Level Mixed Waste, All Cases: Energy Technology

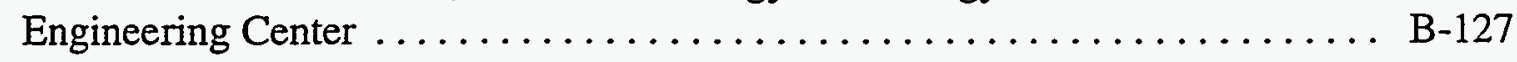

B.7.10 Low-Level Mixed Waste, All Cases: Fernald Environmental

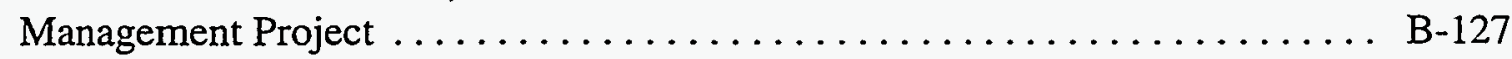

B.7.11 Low-Level Mixed Waste, All Cases: General Atomics . . . . . . . . . . . B B-128

B.7.12 Low-Level Mixed Waste, All Cases: Grand Junction Project Office . . . . . . . B-128

B.7.13 Low-Level Mixed Waste, All Cases: Hanford ................. B-129

B.7.14 Low-Level Mixed Waste, All Cases: Idaho National

Engineering Laboratory $\ldots \ldots \ldots \ldots \ldots \ldots \ldots \ldots \ldots \ldots \ldots \ldots \ldots \ldots \ldots \ldots \ldots$ 


\section{TABLES (Cont.)}

B.7.15 Low-Level Mixed Waste, All Cases: Inhalation Toxicology

Research Institute .............................. B-130

B.7.16 Low-Level Mixed Waste, All Cases: Knolls Atomic Power Laboratory . . . . . B-130

B.7.17 Low-Level Mixed Waste, All Cases: Kansas City Plant ............... B-131

B.7.18 Low-Level Mixed Waste, All Cases: Knolls-Kesselring Site . . . . . . . . . . B-131

B.7.19 Low-Level Mixed Waste, All Cases: Knolls-Windsor Site . . . . . . . . . . . . B-132

B.7.20 Low-Level Mixed Waste, All Cases: Los Alamos National Laboratory . . . . . . B-132

B.7.21 Low-Level Mixed Waste, All Cases: Lawrence Berkeley Laboratory . . . . . . . B-133

B.7.22 Low-Level Mixed Waste, All Cases: Laboratory for Energy-Related

Health Research . .................................. B-133

B.7.23 Low-Level Mixed Waste, All Cases: Lawrence Livermore

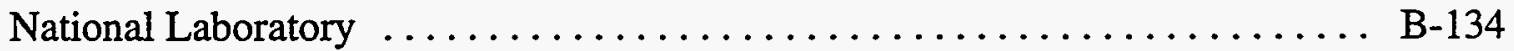

B.7.24 Low-Level Mixed Waste, All Cases: Mare Island Naval Shipyard . . . . . . . . B-134

B.7.25 Low-Level Mixed Waste, All Cases: Mound Plant ................. B-135

B.7.26 Low-Level Mixed Waste, All Cases: Norfolk Naval Shipyard .......... B-135

B.7.27 Low-Level Mixed Waste, All Cases: Nevada Test Site .............. . B-136

B.7.28 Low-Level Mixed Waste, All Cases: Oak Ridge National Laboratory . . . . . . . B-136

B.7.29 Low-Level Mixed Waste, All Cases: Paducah Gaseous Diffusion Plant . . . . . B-137

B.7.30 Low-Level Mixed Waste, All Cases: Pantex Plant $\ldots \ldots \ldots \ldots \ldots \ldots$. . . . . . . . . .

B.7.31 Low-Level Mixed Waste, All Cases: Pearl Harbor Naval Shipyard ........ B-138

B.7.32 Low-Level Mixed Waste, All Cases: Portsmouth Naval Shipyard . . . . . . . . B-138

B.7.33 Low-Level Mixed Waste, All Cases: Portsmouth

Gaseous Diffusion Plant ............................. B-139 


\section{TABLES (Cont.)}

B.7.34 Low-Level Mixed Waste, All Cases: Princeton Plasma

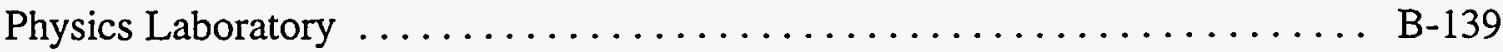

B.7.35 Low-Level Mixed Waste, All Cases: Puget Sound Naval Shipyard ........ B-140

B.7.36 Low-Level Mixed Waste, All Cases: Rocky Flats Plant ............. B-140

B.7.37 Low-Level Mixed Waste, All Cases: Reactive Materials, Inc. . . . . . . . . . . B-141

B.7.38 Low-Level Mixed Waste, All Cases: Sandia National

Laboratories-New Mexico ............................. B-141

B.7.39 Low-Level Mixed Waste, All Cases: Sandia National

Laboratories-California ............................ B-142

B.7.40 Low-Level Mixed Waste, All Cases: Savannah River Site . . . . . . . . . . . . B-142

B.7.41 Low-Level Mixed Waste, All Cases: University of Missouri, Columbia . . . . . B-143

B.7.42 Low-Level Mixed Waste, All Cases: West Valley Demonstration Project .... . B-143

\section{VOLUME 3 CONTENTS}

APPENDIX C: REFERENCE DATA ON FIRES, EXPLOSIONS, AND

CRITICALITIES IN NUCLEAR AND CHEMICAL

PROCESSING AND WASTE MANAGEMENT FACILITIES

C.1 Introduction and Summary $\ldots \ldots \ldots \ldots \ldots \ldots \ldots \ldots \ldots \ldots \ldots \ldots \ldots \ldots$

C.2 Recent Explosions or Fires at Hazardous Waste

Incineration Facilities $\ldots \ldots \ldots \ldots \ldots \ldots \ldots \ldots \ldots \ldots \ldots \ldots \ldots \ldots \ldots$

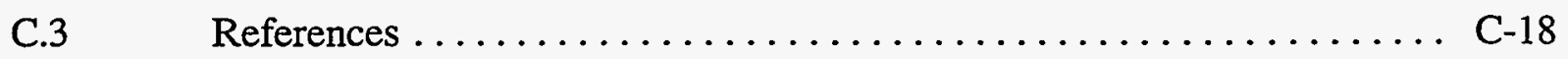

APPENDIX D: REFERENCE DATA ON RESPIRABLE AIRBORNE RELEASE

FRACTIONS AND LEAK PATH FACTORS

D.1 Respirable Airborne Release Fraction $\ldots \ldots \ldots \ldots \ldots \ldots \ldots \ldots \ldots$ D-9

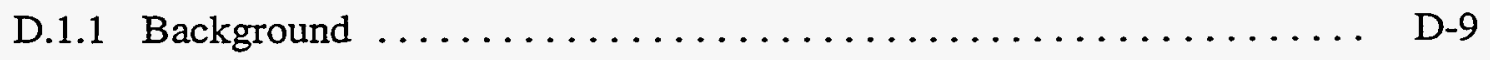




\section{VOLUME 3 CONTENTS (Cont.)}

D.1.2 Airborne Release Fractions, Respirable Fractions, and Respirable Airborne Release Fractions . . . . . . . . . . D-10

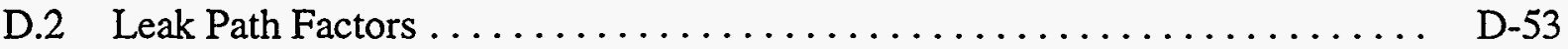

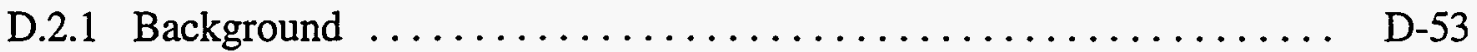

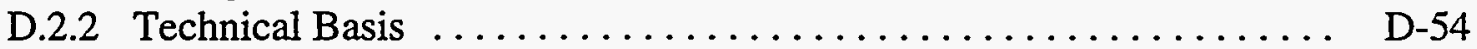

D.2.3 Application to WM PEIS ....................... D-54

D.3 Mapping of WM PEIS Treatability Categories with Physical

Form Categories for Accident Analysis . . . . . . . . . . . . . . . D 55

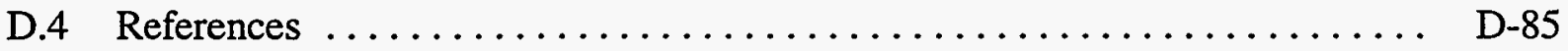

APPENDIX E: REFERENCE DATA ON NATURAL PHENOMENA

FREQUENCIES AND RELATED DESIGN

SPECIFICATIONS OF DOE FACILITIES

APPENDIX F: EVALUATION OF AIR CRASH ACCIDENTS FOR

U.S. DEPARTMENT OF ENERGY WASTE

MANAGEMENT FACILITIES

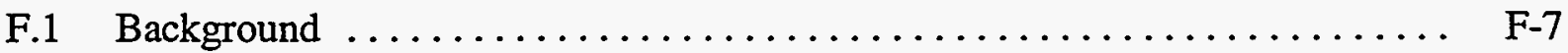

F.2 Methodology $\ldots \ldots \ldots \ldots \ldots \ldots \ldots \ldots \ldots \ldots \ldots \ldots \ldots \ldots \ldots \ldots \ldots \ldots \ldots \ldots \ldots \ldots$

F.2.1 Crash Probability Estimates $\ldots \ldots \ldots \ldots \ldots \ldots \ldots \ldots \ldots \ldots \ldots \ldots \ldots \ldots \ldots \ldots \ldots$

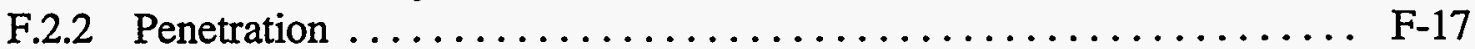

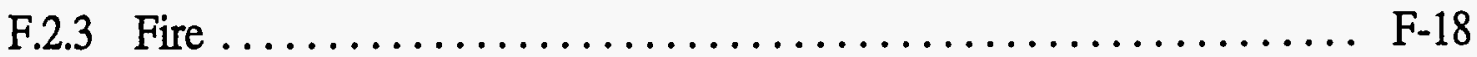

F.2.4 Presence of Radioactive Material $\ldots \ldots \ldots \ldots \ldots \ldots \ldots \ldots \ldots \ldots \ldots$

F.3 Summary of Aircraft Crash Frequencies per Unit

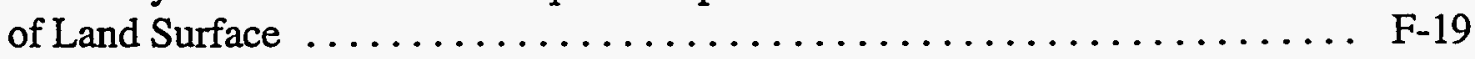

F.4 Aircraft Crash Frequency for WM PEIS Facilities $\ldots \ldots \ldots \ldots \ldots \ldots \ldots$ F-19

F.4.1 Facility Target Area ....................... F-20

F.4.2 Frequency of Aircraft Crashes against Facilities at DOE Sites ........ F-23

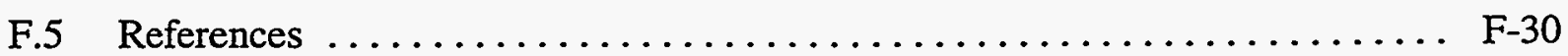




\section{CONTENTS (Cont.)}

\section{APPENDIX G: MODELING OF EXTERNAL EVENTS}

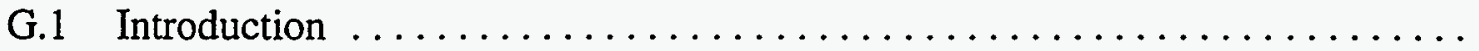

G.2 Storage Facility Accidents $\ldots \ldots \ldots \ldots \ldots \ldots \ldots \ldots \ldots \ldots \ldots \ldots \ldots \ldots \ldots$ G-8

G.2.1 Specification and Frequency Evaluation of Accident Sequences ..... G-8

G.2.2 Evaluation of Source Term Parameters ................. G-16

G.3 Treatment Facility Accidents $\ldots \ldots \ldots \ldots \ldots \ldots \ldots \ldots \ldots \ldots \ldots \ldots \ldots \ldots \ldots \ldots$

G.3.1 Specification and Frequency Evaluation of Accident Sequences ..... G-17

G.3.2 Evaluation of Source Term Parameters for Treatment Facilities ....... G-23

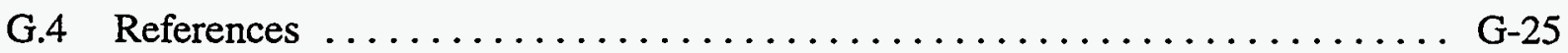

APPENDIX H: REFERENCE DATA ON AIRBORNE RELEASES FOR ACCIDENTS INVOLVING HAZARDOUS CHEMICALS

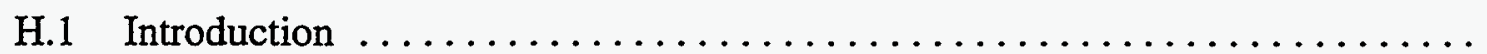

H.2 Handling Accident in Which Aqueous Ammonia Is Spilled

H.3 Handling Accident in Which Hydrochloric Acid Is Spilled

H.4 Handling Accident in Which Aqueous Hydrogen

Fluoride Is Spilled

H.5 Handling Accident in Which Nitric Acid Is Spilled

H.6 Handling Accident in Which an Aromatic Hydrocarbon Spills and Burns .

H.7 Handling Accident in Which a Flammable Liquid Spills, Ignites, and Burns, Causing the Rupture of Other Containers

H.8 Handling Accident in Which a Flammable Liquid Spills and Ignites; the Fire Engulfs Nearby Drums and Initiates Reactions That Release Highly Toxic Vapors 


\section{CONTENTS (Cont.)}

H.9 Larger Accident in Which a Flammable Liquid Spills

and Ignites; the Fire Engulfs Nearby Drums and

Initiates Reactions That Release Toxic Vapors

H.10 Heat from the Fire Causes an Explosion in a Compressed

Gas Container, Resulting in Venting of a Toxic Gas

H.11 Accidental Co-confinement of Oxidizing and Reducing

Agents, Leading to a Reaction Generating Heat That

Ignites Packaging and Breaches a Nearby Drum

H.12 Accidental Confinement of Water with Alkali Metals, Alkali-metal Hydrides, or Alkaline-Earth Oxides, Giving

Reactions Generating Heat, Igniting Packaging, and

Breaching Nearby Drums

H.13 Accidental Rupture of Compressed Gas Due to Valve

Failure, Resulting in Releases of Toxic Gas

H.14 Explosion of a Stored Chemical $\ldots \ldots \ldots \ldots \ldots \ldots \ldots \ldots \ldots \ldots \ldots$

H.15 Handling Accidents in Which a Spilled Waste

Releases a Mutagenic, Teratogenic, or Carcinogenic

Substance

H.16 Handling Accident Spill That Ignites Flammable Liquids, Thereby Breaching Nearby Drums with CadmiumContaining Compounds

H.17 Handling Accident Spill That Ignites Flammable Liquid;

The Fire Breaches Nearby Drums Containing Dichromate

Salts 


\section{FIGURES}

E.1 Relationship among Hazard Class/Category, SSC Performance

Category, and Pertinent DOE Orders and Standards $\ldots \ldots \ldots \ldots \ldots \ldots \ldots$ E-8

F.1 Generic Representation of Takeoff and Landing Sectors $\ldots \ldots \ldots \ldots \ldots \ldots \ldots$ F-9

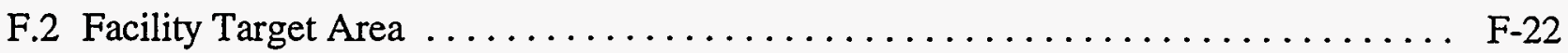

G.1 Event Tree for Small-Aircraft Impact on Generic Storage Facility

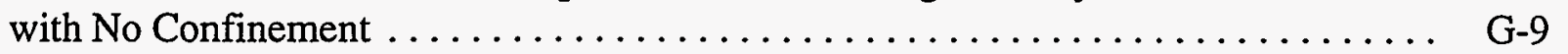

G.2 Event Tree for Large-Aircraft Impact on Generic Storage Facility

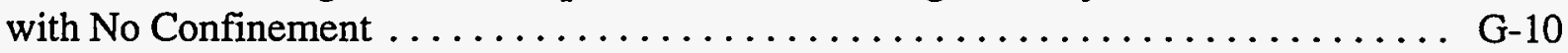

G.3 Event Tree for Seismic Challenge to Generic Storage Facility

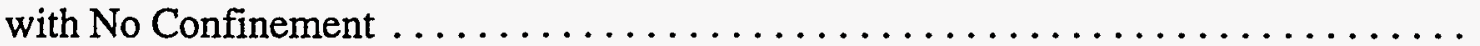

G.4 Event Tree for Small-Aircraft Impact on Generic DOE Hazard

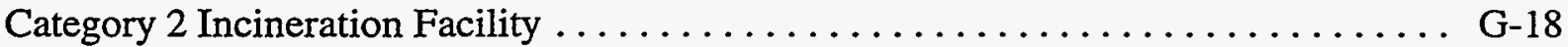

G.5 Event Tree for Large-Aircraft Impact on Generic DOE Hazard

Category 2 Incineration Facility $\ldots \ldots \ldots \ldots \ldots \ldots \ldots \ldots \ldots \ldots \ldots \ldots \ldots \ldots \ldots \ldots \ldots$

G.6 Event Tree for Seismic Challenge to Generic DOE Hazard

Category 2 Incineration Facility . .

\section{TABLES}

C.1 Postulated Fires and Explosions in Treatment, Storage, and Disposal

Facilities

C.2 Summary of Fire and Explosion Sources

C.3 Postulated Criticalities in Treatment, Storage, and Disposal

Facilities

C.4 Summary of Criticality Accident Fission Yields

C.5 Summary of Fires, Explosions, and Incidents of Drum

Overpressurization . 


\section{TABLES (Cont.)}

D.1 Summary of Release Fraction Parameters Abstracted from

Elder et al. (1986) ............................... D

D.2 WM PEIS Waste RARFs: Physical Type or Subcategory versus Stress $\ldots \ldots \ldots$ D-58

D.3 WM PEIS Waste RARFs for LLW, LLMW, and

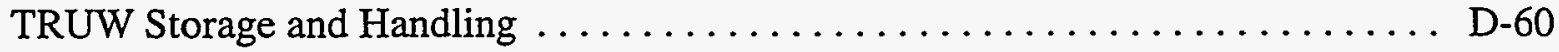

D.4 WM PEIS Waste RARFs for LLW Processing by Incineration $\ldots \ldots \ldots \ldots \ldots$ D-63

D.5 WM PEIS Waste RARFs for HLW Processing and Storage $\ldots \ldots \ldots \ldots \ldots$ D-68

D.6 Threshold Values of Differential Pressure Required to Structurally

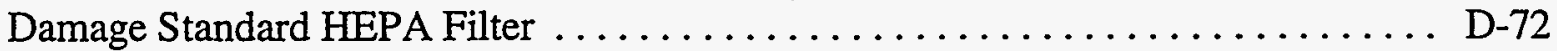

D.7 Effects of Environmental Filter Parameters on Aerosol Penetration

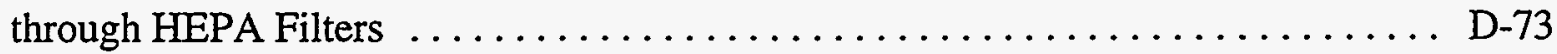

D.8 Summary of Reduction and Removal Factors Abstracted from

Elder et al. (1986) ................................. D

D.9 Mapping of WM PEIS Treatability Categories for LLW with Accident

Analysis Physical Forms . . . . . . . . . . . . . . . . . . . . . .

D.10 Mapping of WM PEIS Treatability Categories for TRUW with Accident

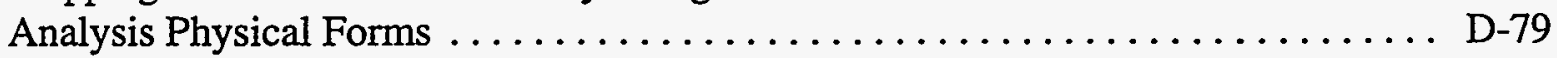

D.11 Mapping of WM PEIS Treatability Categories for HLW with Accident

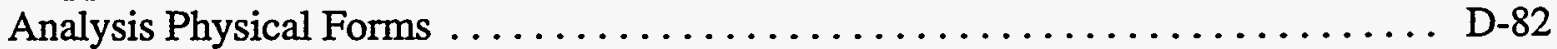

E.1 Natural Phenomena Hazards Performance Goals for Systems, Structures,

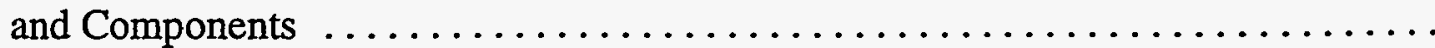

E.2 Natural Phenomena Frequency and Intensity Data for DOE Sites $\ldots \ldots \ldots \ldots$ E-9

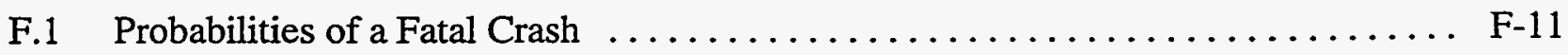

F.2 Principal DOE Waste Management Sites $\ldots \ldots \ldots \ldots \ldots \ldots \ldots \ldots \ldots \ldots \ldots \ldots \ldots \ldots \ldots$ F-13

F.3 Airports near DOE Sites and their Potentials to Increase

Aircraft Accident Frequencies 


\section{TABLES (Cont.)}

F.4 Estimated Annual Overflight Frequencies of DOE Sites $\ldots \ldots \ldots \ldots \ldots \ldots$ F-15

F.5 Estimated Annual Crash Probabilities at DOE Sites from Commercial Aviation Operations at Nearby Airports $\ldots \ldots \ldots \ldots \ldots \ldots \ldots \ldots \ldots \ldots \ldots \ldots \ldots$

F.6 Estimated Annual Federal Airway Commercial Crash Probabilities .......... F-16

F.7 Estimated Annual Crash Probabilities at DOE Sites from General Aviation Operations at Nearby Airports $\ldots \ldots \ldots \ldots \ldots \ldots \ldots \ldots \cdot$ F-18

F.8 General Aviation Building Penetration Probabilities $\ldots \ldots \ldots \ldots \ldots \ldots \ldots$ F-18

F.9 Summary of Annual Aircraft Crash Frequencies for DOE Sites ........... F-20

F.10 Summary of Annual Aircraft Crash Frequency Per Square Mile Grouped into APLL and APLS Crashes $\ldots \ldots \ldots \ldots \ldots \ldots \ldots \ldots \ldots$ F-21

F.11 Effective Area Estimates for LLW, LLMW, TRUW, HLW, and HW Facilities . . . . . . . . . . . . . . . . . . . . . . . .

F.12 Airplane Impacts Initiating Event Frequency: LLW Storage . . . . . . . . . . F F-25

F.13 Airplane Impacts Initiating Event Frequency: LLW Incineration

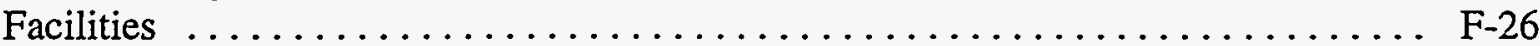

F.14 Airplane Impacts Initiating Event Frequency: HLW Facilities $\ldots \ldots \ldots \ldots \ldots$ F-26

F.15 Airplane Impacts Initiating Event Frequency: HW

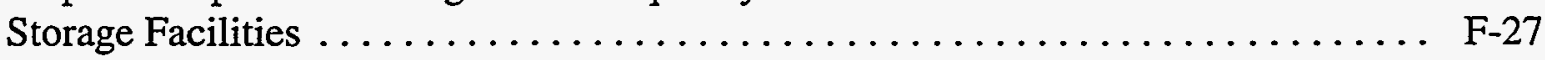

F.16 Airplane Impacts Initiating Event Frequency: HW Treatment Facilities . . . . . . . . . . . . . . . . . . . . . . . .

F.17 Airplane Impacts Initiating Event Frequency: LLMW

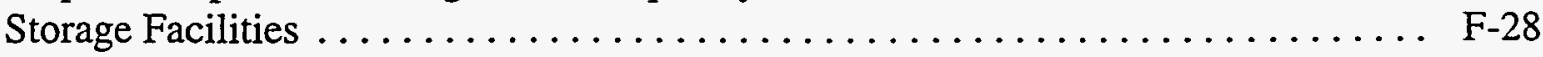

F.18 Airplane Impacts Initiating Event Frequency: LLMW

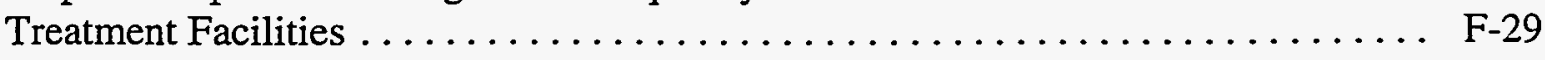

F.19 Airplane Impacts Initiating Event Frequency: TRUW

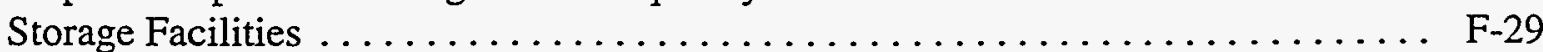




\section{TABLES (Cont.)}

F.20 Airplane Impacts Initiating Event Frequency: TRUW

Treatment Facilities . . . . . . . . . . . . .

G.1 Approximate Distribution of Incinerator Ash in the Generic Facility $\ldots \ldots \ldots$ G-24 


\title{
ANALYSIS OF ACCIDENT SEQUENCES AND SOURCE TERMS AT TREATMENT AND STORAGE FACILITIES FOR WASTE GENERATED BY U.S. DEPARTMENT OF ENERGY WASTE MANAGEMENT OPERATIONS
}

by

\author{
C. Mueller, B. Nabelssi, J. Roglans-Ribas, S. Folga, \\ A. Policastro, W. Freeman, R. Jackson, J. Mishima, and S. Turner
}

\begin{abstract}
This report documents the methodology, computational framework, and results of facility accident analyses performed for the U.S. Department of Energy (DOE) Waste Management Programmatic Environmental Impact Statement (WM PEIS). The accident sequences potentially important to human health risk are specified, their frequencies assessed, and the resultant radiological and chemical source terms evaluated. A personal-computer-based computational framework and database have been developed that provide these results as input to the WM PEIS for the calculation of human health risk impacts.
\end{abstract}

The methodology is in compliance with the most recent guidance from DOE. It considers the spectrum of accident sequences that could occur in activities covered by the WM PEIS and uses a graded approach emphasizing the risk-dominant scenarios to facilitate discrimination among the various WM PEIS alternatives. Although it allows reasonable estimates of the risk impacts associated with each alternative, the main goal of the accident analysis methodology is to allow reliable estimates of the relative risks among the alternatives. Rather than developing all accident sequences in detail, the accident models are systematically applied to approximate the key source term parameters as functions of (1) the phenomenology and severity of the accident, (2) the process parameters, (3) the characteristics of the facility, and (4) the properties of the waste types. This procedure allows many of the uncertainties in the data, which are reflected in estimates of absolute risk, to be canceled out in estimates of relative risk, thus providing a sufficient and scrutable basis for discriminating among alternatives.

The WM PEIS addresses management of five waste streams in the DOE complex: low-level waste (LLW), hazardous waste (HW), high-level waste (HLW), low-level mixed waste (LLMW), and transuranic waste (TRUW). Currently projected waste generation rates, storage inventories, and treatment process throughputs have been calculated for each of the waste streams. This 
report summarizes the accident analyses and aggregates the key results for each of the waste streams. Source terms are estimated, and results are presented for each of the major DOE sites and facilities by WM PEIS alternative for each waste stream. Key assumptions in the development of the source terms are identified. The appendixes identify the potential atmospheric release of each toxic chemical or radionuclide for each accident scenario studied. They also discuss specific accident analysis data and guidance used or consulted in this report.

\section{INTRODUCTION AND OVERVIEW}

\subsection{SUMMARY}

This report documents the methodology, computational framework, and results of facility accident analysis performed for the U.S. Department of Energy (DOE) Waste Management Programmatic Environmental Impact Statement (WM PEIS) (DOE 1996). The objective of the WM PEIS is to examine the potential impacts, including human health and environmental consequences, of an integrated program for managing wastes under the aegis of the Office of the Assistant Secretary for Environmental Management. Facility accident analysis specifically addresses potential radiological and hazardous releases to the environment during plausible facility accidents.

The output of the facility accident analyses consists of a specification for each waste type of the accident sequences potentially important to human health risk, an assessment of the frequencies of these accidents, and an evaluation of the radiological and chemical source terms resulting from these accidents. A radiological source term is defined by specifying the amount in curies ( $\mathrm{Ci}$ ) of each radionuclide released during an accident, where release is conservatively assumed to be instantaneous. A chemical source term is defined by specifying the release rate and duration for each toxic chemical released during an accident. The frequencies of the accidents and the results of the source term evaluation are provided as input to the WM PEIS for calculation of the human health and risk impacts of the identified waste management alternatives.

The accident sequences analyzed were selected for their potential importance to human health. In light of the lack of specific process and facility design information, (including intrasite locations and associated location characteristics of treatment, storage, and disposal [TSD] facilities), the analyses focused on accidents with potential releases to the atmosphere. Although disposal alternatives are included in the WM PEIS waste management options, the details of ultimate disposal are not addressed. Consequently, accidents were not developed for this phase of waste management.

Numerous DOE waste management sites were analyzed in this study. However, generic DOE storage and treatment facility characteristics were assumed in developing the accident 
sequences for all sites. Facility waste inventories assumed for each DOE site were derived from the storage inventories, generation rates, and treatment throughputs developed in the WM PEIS. Site safety documentation was used to help identify the frequencies and potential risk importance of accident initiators affected by site characteristics such as seismic or tornadic vulnerability or proximity to airports. However, existing facility documentation and accident data were used only for general guidance in source term development; thus, the accident analyses herein may not necessarily duplicate the results produced in individual site EISs or safety documents where specific facilities are assessed.

\subsection{SCOPE AND OBJECTIVES}

The requirements on the scope of the accident analysis are driven by the scope of the WM PEIS and by DOE guidance discussed subsequently. The WM PEIS addresses strategic alternatives for management of five different types of waste in the DOE complex: low-level waste (LLW), hazardous waste (HW), high-level waste (HLW), low-level mixed waste (LLMW), and transuranic waste (TRUW). For each waste type, four categorical strategies have been devised for the consolidation of wastes for treatment and storage: (1) no action, where existing sites will generally store and treat their own wastes consistent with currently approved plans; (2) centralization, where from one to a few DOE sites will be used to treat, store, and dispose of a given waste type from the entire DOE complex; (3) regionalization, where several sites distributed throughout the country will be used to treat, store, and dispose of that waste type for their geographic regions; and (4) decentralization, where regionalization is extended to include more sites. Alternatives for consolidation of waste involve both existing and conceptual-design facilities at DOE sites throughout the country. Moreover, a number of technologies for waste treatment and options for storage are to be assessed for each type of waste.

The most recent guidance (DOE 1993a) from the Office of National Environmental Policy Act (NEPA) Oversight within DOE calls for consideration of the spectrum of accident scenarios that could occur in activities encompassed by the actions evaluated in the WM PEIS. This guidance also calls for a graded approach emphasizing the risk-dominant scenarios. Determination of risk dominance requires assessment of both the likelihood and the severity of plausible accident scenarios that could present a significant health hazard to either the workforce or the public. The spectrum of accident scenarios includes all accidents important to risk, from low-frequency events with potentially high consequences (as typified by accident sequences associated with natural phenomena such as earthquakes) to relatively high-frequency events with very low consequences (as typified by routine industrial accidents).

The broad scope of the WM PEIS and the recent NEPA guidance result in a very large number of combinations of possible TSD options, existing or new facilities, and related possible accident scenarios to be evaluated for assessing management alternatives for each waste type. 
Accordingly, one obvious objective of the methodology for accident analysis was the development of a strategy that would enable focus on the risk-dominant sites and facilities for the storage and treatment operations and on the alternatives for waste consolidation under consideration in the WM PEIS for each waste type.

A second objective was to develop a methodology for accident analysis that would allow sufficient discrimination of risk impacts among the various options and alternatives to support the WM PEIS decision-making process. Although the methodology must provide reasonable estimates of the risk impacts associated with each alternative, providing reliable estimates of the relative risks among the alternatives is more important. To accomplish these goals, the accident models must be adequate to approximate the key source term parameters as a function of the phenomenology and severity of the accident, the process parameters, the characteristics of the facility, and the properties of the waste types. Although developing all accidents in detail is not necessary, systematically applying the underlying approximate models is necessary. Many of the uncertainties in the data that are reflected in estimates of absolute risk tend to be canceled in estimates of relative risk. Thus, systematic application of the models is required to provide a sufficient and scrutable basis for estimating relative risk and discriminating among alternatives.

A consistent database must also be applied. The WM PEIS includes options for consolidating waste from both new and existing sites and facilities. Current safety analyses, environmental assessments, and EISs provide much site-specific information, but they have been developed over many years, while the underlying technology base and the related regulatory guidance have improved. The scope and supporting levels of detail in site safety reports vary widely. Thus, a third objective was to support the data requirements for the implementation of the computational framework by appropriately combining existing documentation on the safety of facilities with the most recent guidance on accident modeling.

The last objective was to provide an automated capability to facilitate the overwhelming number of calculations in the accident analysis that are required to provide and evaluate the relative risk of the many combinations of process technology, facility selection, and site consolidation strategies in the WM PEIS alternatives for each waste type. The purpose is not only to provide baseline accident frequency and source term estimates, as required for the WM PEIS, but also to provide a capability for sensitivity analysis that can be used in the review process. Accident frequencies, radiological and chemical release source terms, and health effects on various populations are all sensitive to waste throughput. To allow accident risk to be characterized as a function of the throughput of a given waste type at each facility, thereby facilitating comparative evaluations, the requirements included integrating the computational packages of the accident analysis with the databases storing the data on the waste inventory and interfacing with the computer codes for health effects. 


\subsection{ANALYTIC APPROACH}

To meet these objectives, an integrated approach was developed that includes the following interrelated elements:

- Selection of storage and treatment operations and related facility configurations across the DOE complex that have large and potentially hazardous inventories of radioactive or chemically toxic wastes vis-à-vis the attendant vulnerabilities and demographics of the facilities,

- Development and probabilistic evaluation of a uniform set of the risk-dominant sequences of accidents,

- Determination of the evolution and final compositions of radiologically or chemically hazardous material source terms predicted to be released from these sequences.

A personal-computer-based computational framework and database system (WASTE_ACC) has been developed to automate these elements and provide source term input for the health effects analyses (Nabelssi et al. 1996). The current report discusses the aspects of accident analysis through source term generation.

The source terms were subsequently used for assessment of the radiological or toxicological health effects and risks of accidents to the general public and to the workforces. This assessment is discussed elsewhere in the WM PEIS. In addition to source term development, the main elements in assessing risk include (1) development or integration of existing site-specific demographics and meteorological data and calculation of attendant unit-risk factors and (2) assessment of the radiological or toxicological consequences of accident releases to the general public and to the workforces by combining the source term and unit-risk information.

Figure 1.1 illustrates the integration of these elements into a systematic approach for performing risk impact analysis for the WM PEIS. The waste management alternatives discussed in the WM PEIS include siting options for storing and treating each waste type prior to disposal. Storage inventories and treatment throughput for each site affected by a given alternative are then defined by the current inventories, existing and projected waste generation rates, and the disposition of the waste. The volume and radionuclide composition of each waste are tracked in a relational database as the waste is processed to final disposal. Details of the methodology and computational framework developed to implement or link these elements for the accident analysis are described in Section 2. The source terms for all accidents analyzed are provided in the appendices. 


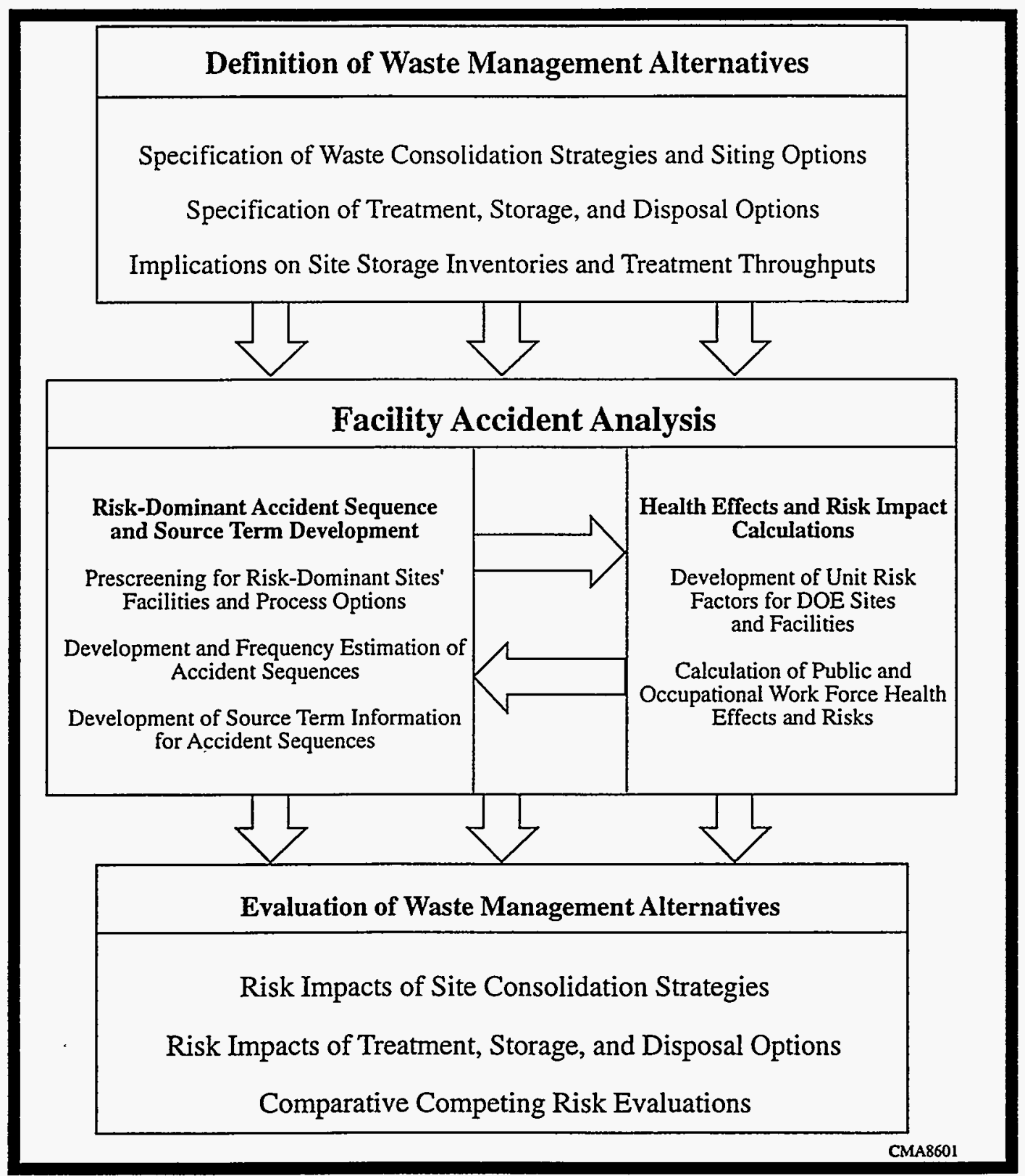

FIGURE 1.1 Overview of Facility Accident Analysis Interactions for the WM PEIS

Implementation of the phased approach is being accomplished through the collaborative efforts of interdisciplinary teams from Argonne National Laboratory-East (ANL-E) and Oak Ridge National Laboratory (ORNL). Risk-dominant accident sequences and associated source term information were selected and developed by ANL-E as the first part of the analysis. The unit-risk factors outlined above were developed by ORNL as the second part of the analysis and transmitted to ANL-E for use in the screening phases to establish the reference accident sequences. The potential source terms for the dominant risk accident sequences were then calculated by ANL-E and transmitted to ORNL for the health effects calculations. 


\subsection{ORGANIZATION OF REPORT}

Section 2 describes the overall methodology for the accident analysis and the integration of the computational components into a complete analytical framework. It also describes the use and integration of generic and site-specific accident analysis data, with waste stream inventory data, storage and treatment process characterizations, and site and facility demographics information developed in the WM PEIS to provide a complete accident analysis data package.

Currently projected waste generation rates, storage inventories, and treatment process throughputs have been calculated. Specific results are presented in this report for each of the waste streams in the WM PEIS. Sections 3 through 8 summarize the accident analyses and aggregate the key results for each of the waste streams. Source terms are estimated and the results presented for each of the major DOE sites and facilities by consolidation alternative for each waste stream. Key assumptions in the development of the source terms are identified. Appendixes A and B (Volume 2) are compilations of the chemical and radiological source terms that identify the potential atmospheric release of each toxic chemical or radionuclide for each accident sequence studied.

Section 9 lists the reference materials used for this report. They include DOE orders and standards, U.S. Nuclear Regulatory Commission (NRC) regulations, NEPA documentation, technical reports developed in support of this regulatory guidance, site-specific safety analysis and environmental impact documentation, and related supporting technical reports that were used in support of the WM PEIS accident analysis.

Appendixes $\mathrm{C}$ through $\mathrm{H}$ (Volume 3 ) discuss specific accident analysis data and guidance used or consulted in this report. 


\section{METHODOLOGY AND COMPUTATIONAL FRAMEWORK FOR ACCIDENT ANALYSIS}

\subsection{OVERVIEW}

This section describes the methodology and computational framework for the facility accident analysis for the WM PEIS. Figure 2.1 illustrates the major components, related input and output of data from the facility accident analysis and presents an overview of the interactions of the analysis with other elements of the WM PEIS. Implementation of this analysis framework included selection and development of the accident sequences and associated output for the source terms. Unit-risk factors developed as part of the WM PEIS effort were used to screen accident sequences for risk dominance. A unit-risk factor is a consequence associated with a unit release of a radionuclide to the environment from a facility or a given site for a given receptor.

This chapter is organized to reflect the integrated approach depicted in Figure 2.1. Sections 2.2 through 2.4 explain how the illustrated program elements are applied to the WM PEIS accident analysis. The general discussion in the sections is applicable to the overall WM PEIS

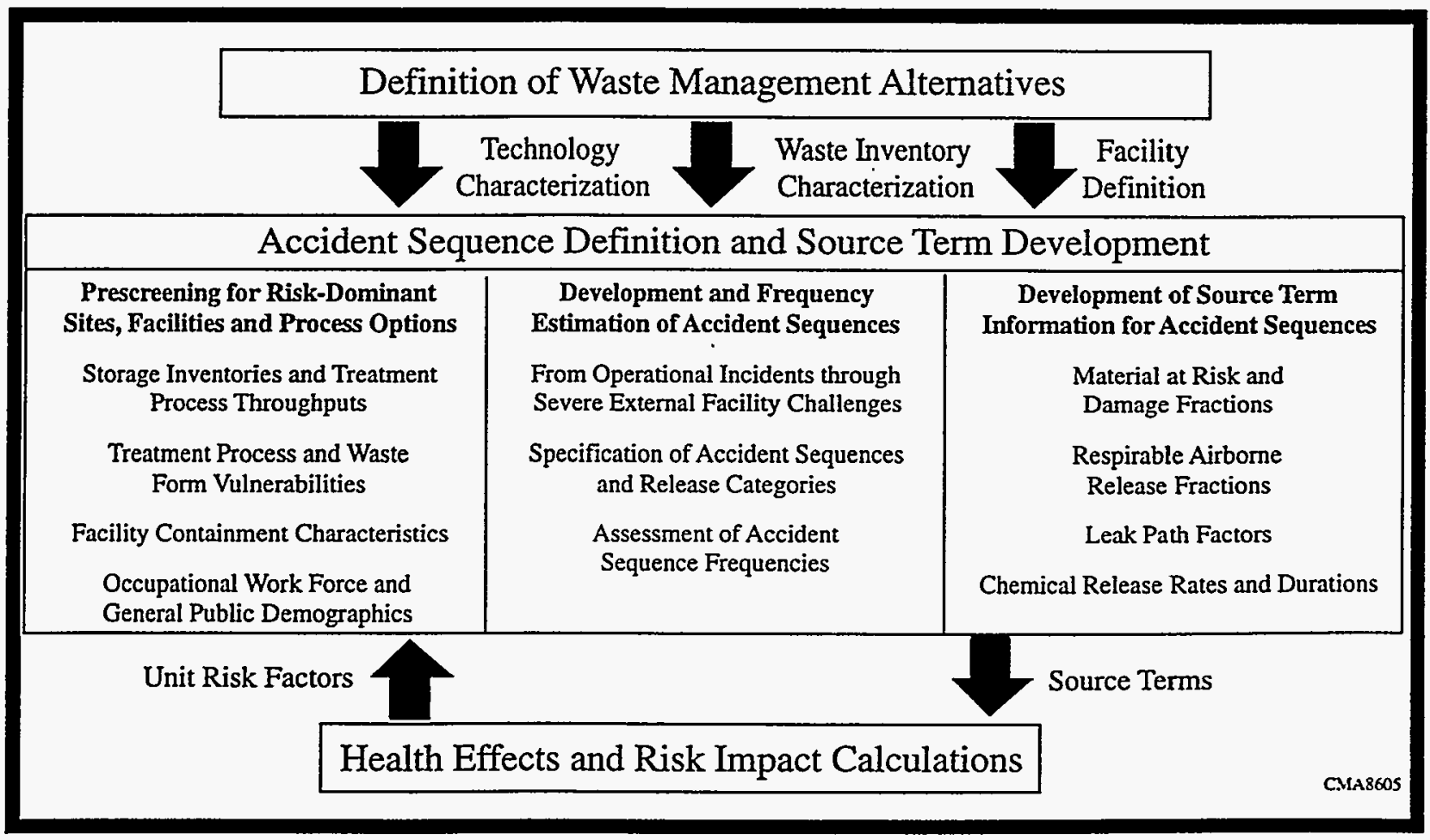

FIGURE 2.1 Major Components and Related Input and Output of Data for Facility Accident Analysis 
accident analyses for all waste types. Sections 2.5 and 2.6 discuss the general modeling assumptions and the data used to evaluate the frequencies for the various accidents and to determine the appropriate source terms for specific accidents, facilities, and waste types. Much of the information presented in these sections has been based on and is primarily applicable to LLW, LLMW, and TRUW. Variations in specific methods and applications of data for other waste types are sometimes necessary because of differences in the types of activities envisioned in the alternatives and because of differences in the type and level of detail in the data. These variations are included in the chapters related to those waste types.

\subsection{SELECTION OF RISK-DOMINANT OPERATIONS, FACILITIES, AND RELATED TYPES OF ACCIDENTS}

A review of the alternatives for WM and of the storage and treatment processes was performed to focus the analysis of the large number of processes and facility configurations possible within the WM alternatives on only those configurations with accidental radiological or chemical releases potentially important to overall risk. This section first describes the process of categorization and then describes the three classes of accidents selected: (1) general handling accidents, (2) accidents at storage facilities, and (3) accidents involving treatment processes and facilities.

\subsubsection{Categorization and Screening}

Waste management activities were categorized as falling within three operational regimes: (1) current or pretreatment storage, which includes placement in and retrieval from storage and transfer to facilities for pretreatment or treatment; (2) processing, which includes pretreatment (which applies only to HLW) and treatment; and (3) interim or predisposal storage. Because of the more stable nature of wastes in their final forms before disposal, the last operational regime was judged to pose a much smaller risk than current storage and processing; and effort on analysis and modeling was directed accordingly. As a result, among the waste types, accidents affecting storage before final disposal were analyzed only for HLW.

Facilities considered in the WM PEIS also include operating and preoperational facilities and conceptual-design facilities. The inventories in storage, the throughputs for treatment, and the sizing of the facility are all functions of the alternatives being investigated by the WM PEIS. Criteria were developed to help identify and classify potentially risk-dominant facilities and storage or treatment operations for each waste stream by their characteristics with respect to accidental radiological or chemical releases. These criteria included the amount and composition of the material at risk (MAR); the vulnerability of this material to airborne releases; the containment characteristics of the facility; and the demographics of the operation, facility, site, and general population. 
Only airborne releases were considered, on the basis of evidence in existing DOE safety analyses that airborne pathways dominate the accident consequences and drive the facility risks. Releases via surface runoff or to the ground cause long-term risks, which are not strong discriminators for WM PEIS alternatives. The only reasonable threats that could cause immediate and appreciable effects via nonairborne pathways are criticalities involving the various waste types. However, facilities handling materials with high fissile content will have rigorous procedures and checks to prevent inadvertent criticalities. Regulations require facilities and processes used to handle fissile materials to be designed so that at least two separate events must occur before a condition exists that could result in a criticality, which would be a highly improbable event. As such, releases via nonairborne pathways are not considered.

Amount and Composition of MAR. Each alternative for waste consolidation discussed in the WM PEIS implicitly defines unique pretreatment and post-treatment inventories and throughputs for treatment of each waste type at each DOE site. Specification of the storage inventories and treatment throughputs by volume, by physical and chemical form, and by radionuclide or chemical composition of the wastes was obtained from the WM database (Kotek et al. 1996). Accordingly, for each alternative for each waste type, the DOE sites for storage and treatment were ranked by the curie and radiation hazard content of treatability categories for that waste type to determine those sites with the largest curie inventories of potentially risk-dominant waste. A similar review of ranking was done to determine sites with the greatest chemical inventories within the waste type (process chemical accidents that could not be strongly correlated with waste inventories or throughputs were not analyzed). These rankings led to the restriction of analyses for any given waste type to those sites with sufficient inventories to justify development of distinct source terms.

Vulnerability of MAR. A major focus of the screening was the vulnerability of the MAR in storage and treatment processes to potential fire or explosion accident sequences. The physical and chemical stability of the waste was reviewed to preclude unnecessary analysis of storage or process operations involving highly stable wastes that would require extremely severe and improbable conditions to attain significant airborne releases. The packaging of the wastes and the overall configuration of the containment facility were also reviewed. As a result, only selected WM operations and treatment technologies were analyzed for source term development.

Characteristics of Facility Containment. Facilities considered in the WM PEIS range from outdoor storage pads with no capability for containment to facilities that have the structural capability to withstand the forces from significant natural phenomena. The containment characteristics of the existing or proposed storage or treatment facilities were judged by their hazard category or natural phenomena hazards (NPH) performance category (PC) and by implied attendant 
operational and emergency procedures and structural capabilities. This process led to the restriction of analyses herein to generic facilities with characteristics typical of either DOE Hazard Category 2 facilities or general-use facilities. (Hazard category and NPH PC are discussed and defined in Section 2.5.1).

Demographics. The hazard to the workforce is directly related to the radiological or chemical inventory involved in the accident, the number of workers affected, and the proximity of these workers to the point of release. Estimates of the population of workers for each treatment technology and facility were developed in the WM PEIS as a function of the throughput of the waste inventory to be processed. Consideration of these populations and their proximity to the point of release vis-à-vis the appropriate radiological or hazardous material inventories of the MAR provided an initial identification of those processes and facilities potentially dominating the risk to the worker population.

The demographics for the general public were included as an input to the development of the health effects and risk impact analysis but were not specifically used to select accidents used in the analysis.

Review of the operations and facilities against these criteria led to the establishment of three broad classes of accidents as determined by their release characteristics and the facilities and populations affected. These classes include (1) general handling accidents involving a breach of the waste packaging, (2) accidents at storage facilities, and (3) accidents involving treatment (or pretreatment) processes and facilities. Within these classes, individual operations or facilities were then reviewed to better define potentially risk-dominant operations or facility configurations. Facility configurations analyzed were limited to those with either confinement and filtration characteristics typical of DOE Hazard Category 2 or to those with no confinement or filtration at all. Within each broad class of accidents, the dominant accident considerations were developed as follows.

\subsubsection{General Handling Accidents}

General handling accidents were defined as a distinct class, because hands-on operational accidents are expected to dominate the radiological and chemical risk to workers (because of the relatively high frequency of such accidents and the proximity of the workers to any release). Such operations include handling in storage and staging areas, packaging and unpackaging, movement of waste within treatment facilities, and some treatment operations. These operations are prone to mechanical stresses in industrial accidents, such as drops and spills of a container or punctures by a forklift; however, airborne releases resulting from breaches in a container are relatively insignificant compared with releases involving fires or explosions. As a result, these handling accidents usually constitute little hazard to the general public. 


\subsubsection{Storage Facility Accidents}

Accidents at storage facilities were selected as a separate class because they potentially involve large quantities of MAR. Moreover, many storage facilities provide little or no formal containment or containment that would likely be breached in the event of severe thermal or structural challenges. Severe accidents (such as fires) in a storage area may result in significant risk to on-site personnel and the general population for many DOE sites.

In addition to potential importance to risk, two other criteria were used to determine which storage facilities and related accidents should be analyzed or reviewed: (1) their potential for discriminating among WM PEIS alternatives and (2) quantity and quality of information available for input to analysis. As a result, storage prior to treatment of LLMW, LLW, and TRUW was not analyzed because the results will not help to discriminate among alternatives. This is a result of the underlying assumption used in the WM PEIS analyses that all sites will accumulate or at least not reduce their waste inventories for roughly 10 years, at which time complexwide treatment will begin. Thus, all sites will achieve their maximum inventories (leading to maximum potential releases), independent of alternative in about 10 years. Nevertheless, because recent DOE safety or NEPA information on storage facility accidents provides guidance on the potential risk impacts applicable to LLW, LLMW, and TRUW storage, the information will be discussed in the appropriate sections for these waste streams.

Calculations of cost and risk impacts for current storage of $\mathrm{HLW}$ are not within the scope of the WM PEIS, and, as a result, no analyses have been performed. However, the storage of vitrified HLW was analyzed because it could be a factor in discriminating among alternatives for HLW management. For the other waste streams, accidents were not analyzed for storage facilities housing solidified, vitrified, or otherwise highly stable wastes prior to disposal because of their low potential for risk-significant releases.

Finally, the characteristics of current or pretreatment storage for hazardous wastes do vary by alternative. Thus, HW storage accidents have been generically analyzed and will be discussed.

\subsubsection{Treatment Facility Accidents}

Accidents involving treatment processes and facilities were identified as a separate class of accidents. Unlike storage accidents, where the overriding concern relates to the large amount of MAR, treatment introduces different safety considerations, such as the joint presence of high process temperatures and pressures, combustible materials, and feed lines of natural gas or fuel. Moreover, the MAR may not only involve substantial inventories but may also have physical or chemical or highly concentrated toxicological or radiological characteristics that pose a threat to both the immediate workforce of the facility and the populations surrounding the facility. As a result, the 
facilities for treatment typically have containment structural design and filtration capabilities commensurate with these hazards.

Treatment operations were reviewed, and many were excluded from detailed investigation on the basis of the absence of sufficient radiological and hazardous material concentrations or lack of sufficient mechanistic stresses and energies capable of creating a risk-dominant airborne release. These operations included evaporative processes and solidifying operations such as grouting and cementation (EG\&G 1992a,b). In general, benign operations, such as packaging and nonthermal size-reduction activities (including shredding, compaction, and supercompaction) were excluded from consideration as large-scale accidents. Technologies for mercury $(\mathrm{Hg})$ separation were excluded because of their relatively low-energy operating characteristics. Thermal desorption of residues, sludges, and resins or of debris wastes involves combustible material; however, the process was excluded because it operates at lower temperatures and pressures than incineration, and the output product is much less dispersible than the ash from incineration.

Other high temperature or pressure processes were more closely reviewed in light of the potential energy source for dispersing airborne radioactive or toxic material and for challenging a facility's integrity and capability for filtration. Similarly, operations involving or being performed in the presence of combustible materials or involving feed lines of natural gas or fuel were reviewed in light of the potential for ignition and subsequent fire or explosions. Thus, thermal or heataccumulating processes (such as fractionation by using ion-exchange columns, metal melting, incineration, wet-air oxidation, and vitrification) were identified for their potential for major airborne release. These processes are discussed subsequently.

Ion Exchange. Ion exchange is a standard technology for removing dissolved ionic material, radionuclides, and toxic pollutants. Ions in an aqueous phase displace complementary ions from ion-exchange sites on the surface of an insoluble support material. Depleted resins are removed, replaced, or regenerated. Regeneration involves displacing contaminant ions with fresh complementary ions by washing with solutions of sulfuric acid or sodium hydroxide. The dominant accident considered in the literature is an explosion of the ion-exchange column, where self-heating of the ion-exchange resin results in fire or explosion, with attendant discharge of the radionuclide-loaded resin to the surroundings as a radioactive and chemically toxic aerosol. Abnormal conditions causing self-heating of the resin include introduction of a solution with a high concentration of nitric acid (which would result in a highly exothermic reaction), column overloading, presence of dry resin in the column, and high column temperatures (leading to ignition) (Ayer et al. 1988). This accident was predicted to have no impact on the operation of the ventilation system of the facility (Mishima et al. 1986). 
Metal Melting. Metal melting is used to prepare, melt, and cast incoming scrap, and ferrous and nonferrous bulk metals. The incoming metal is shredded and then transported to a furnace where it is melted and cast into ingots. Any combustible material in the incoming feed is thermally destroyed in a secondary combustion chamber (SCC). Highly radioactive materials tend to collect in the slag, which is skimmed from the top of the melt and poured into crucible molds. The cast slag is stored before final disposal, and the cast metal is sent to a fabrication plant for reuse into overpack containers and shielded caskets. The accident of concern is overpressurization and rupture of the combustion chamber with dispersal of the contents, particularly the radioactive slag.

Incineration. Incineration is a means of reducing the volume of combustible solid waste and destroying organic liquid waste. Key characteristics of the incineration process with implications for potential airborne release include high temperature, the presence of combustible materials, the potential for rupture of the vessel, elevated concentrations of radioactivity in the ash by-product, and the high dispersibility of the ash. Because incineration often results in a volume reduction factor of roughly 100 , the ash by-product could have a concentration of heavy-metal radionuclides roughly two orders of magnitude greater than the input feed waste. Accidents of concern for an incineration facility include explosions of the incinerator or fires involving the feedstock, the ash residue, or the residues in the filtration system. Feedstock fires may pose a toxicological risk for LLMW and TRUW because of the relatively high concentrations of organic materials.

Wet-Air Oxidation. Wet-air oxidation is the aqueous-phase oxidation of suspended organic substances by using elevated temperatures and pressures. Water $\left(\mathrm{H}_{2} \mathrm{O}\right)$ catalyzes oxidation so that reactions proceed at much lower temperatures $\left(175-340^{\circ} \mathrm{C}\left[347-644^{\circ} \mathrm{F}\right]\right)$ than are required for oxidation in open-flame combustion such as incineration. Although the pressures (2-20 MPa [20-200 atm]) are higher than those in other thermal treatment processes, the MAR is more dilute and is in an aqueous noncombustible liquid form. Rupture of the oxidation vessel followed by a pressurized release is considered plausible but was judged to be relatively insignificant in terms of radiological risk to the public or to occupational workforces. Potential accident impacts from wet-air oxidation are generally enveloped by incineration, a competing technology.

Vitrification. In vitrification, prepared wastes are mixed with glass-forming materials and transferred to the meiter that melts the material at a nominal temperature of $1,150^{\circ} \mathrm{C}\left(2,102{ }^{\circ} \mathrm{F}\right)$. The final product of vitrification is a molten borosilicate glass. The key accident in vitrification is rupture of a vessel from a steam explosion due to the interaction of molten glass with water. This accident could affect the integrity of the cell in which the melter is located and damage the off-gas filtration units and adjacent areas of the facility. 
A comparison of the characteristics of the identified treatment processes led to the selection of incineration as the technology most likely to dominate risk to facility staff and the site, as well as to the surrounding general populations, for LLW, LLMW, TRUW, and HW. As discussed previously, the characteristics of radioactive release from wet-air oxidation are clearly enveloped by those for incineration, a competing technology. Nevertheless, because some of the treatment trains for LLMW sites have greater volumes of waste to be treated by wet-air oxidation than by incineration, source terms were developed, as appropriate, for tank ruptures with pressurized releases.

Although accidents with fractionation and with vitrification may be important in assessing pretreatment or treatment operations for HLW, these accidents do not affect WM PEIS decisions with respect to HLW alternatives. Vitrification of LLW incineration ash, sludges and resins, or wastes resulting from HLW partitioning is a process comparable to incineration in terms of the temperature, potential for pressurization, and the combustible-material hazards. Dispersibility of the feedstock would be equivalent to the feedstock for incineration, and the forms of the vitrification material (molten and solidified borosilicate glass) would be less dispersible by several orders of magnitude than ash from a kiln or from a SCC. Similarly, the dispersibility of the contents of the radioactive slag in metal melting is also very low relative to the ashes in the incineration process.

In summary, source term analyses for treatment operations were generally focused on incineration accidents. Accidents associated with other types of treatment were generally not considered because of the low vulnerability and dispersibility of MAR, as discussed above. Further, the throughputs for other treatment processes are generally low compared with incineration.

\subsection{DEVELOPMENT OF RISK-DOMINANT ACCIDENT SEQUENCES}

This part of the analysis involved the development of a framework that would accommodate the spectrum of accidents possible over the range of DOE facilities managing the different waste types. Orders, standards, and other regulatory guidance from DOE, the NRC, and the U.S. Environmental Protection Agency (EPA 1993), as well as key supporting documents, were reviewed to identify the spectrum of accidents, accident initiators, and potential releases routinely evaluated in safety analyses. The DOE Defense Programs Safety Survey Report (DOE 1993f) and the Idaho National Engineering Laboratory (INEL) and spent nuclear fuel (SNF) EIS (EG\&G 1994a) were also reviewed to provide guidance for the selection and evaluation of accident sequences. Finally, recent safety analysis reports (SARs) and other facility-specific analyses were reviewed for applicability to both specific facilities and related generic facilities.

Probabilistic risk assessment techniques were used to structure the computational framework for operational events and to track the progression of accidents for external events. Potential accident initiators were first reviewed and grouped into categories for analysis of 
subsequent accident progression (see Section 2.3.1). A generic set of accident sequences was then developed to follow the progression of accidents into various source term categories organized by release characteristics and severity levels (see Section 2.3.2). Nuclear criticality events were considered independently (see Section 2.3.3).

\subsubsection{Selection and Categorization of Accident Initiators}

The selection of accident initiators was based primarily on the expected importance to human health risk of the potential radiological or chemical releases. Populations at risk include the workforce in the facility where the accident occurs, the on-site population, and the general population surrounding the site. In general, operational safeguards and equipment are in place to ensure that the impacts of all events on the public health are extremely limited, except in the most severe (and unlikely) accident situations. Higher frequency operational events, such as spills or drops, are expected to dominate the risks to workers, but the limited amount of material generally ensures that such events contribute little risk to public health. The less-frequent severe accidents have large inventories at risk, and the potential exists for breaching multiple containment barriers and filtering systems and disrupting standard emergency procedures. As a result, the low frequency of such accidents is offset by their larger consequences; typically, severe accidents are predicted to dominate overall risks to public health. With different populations at risk, a spectrum of accidents covering a wide range of frequencies and expected consequences must be considered. The accidents considered meet the "reasonably foreseeable" criteria recommended by DOE (DOE 1993a).

To facilitate subsequent analyses, all generic accident initiators were first categorized on the basis of the nature of the initiator and the potential magnitude of releases. These categories included (1) operational events initiated from within the facility (internal events) and (2) external challenges to the facility. Internal events were subdivided to account for mechanically induced breaches of waste containers, fires, and explosions - all resulting from human errors, equipment failures, or industrial accidents internal to the facility. The external events were subdivided to consider accidents from (1) generally man-made events, such as aircraft crashes and fires and explosions on-site or at adjacent facilities, and (2) potentially catastrophic natural phenomena (e.g., earthquakes, extreme winds or tornadoes, floods, and volcanoes) with likely implications for other facilities at the site.

These accident initiator categories were then mapped into the risk-dominant WM operations or facility configurations identified in Section 2.2. The screening process used to intercompare the process and facility characteristics with generic accident consideration is illustrated in Figure 2.2. Table 2.1 shows the matrix of accident categories analyzed for the storage and treatment facilities and for general waste-handling operations. 


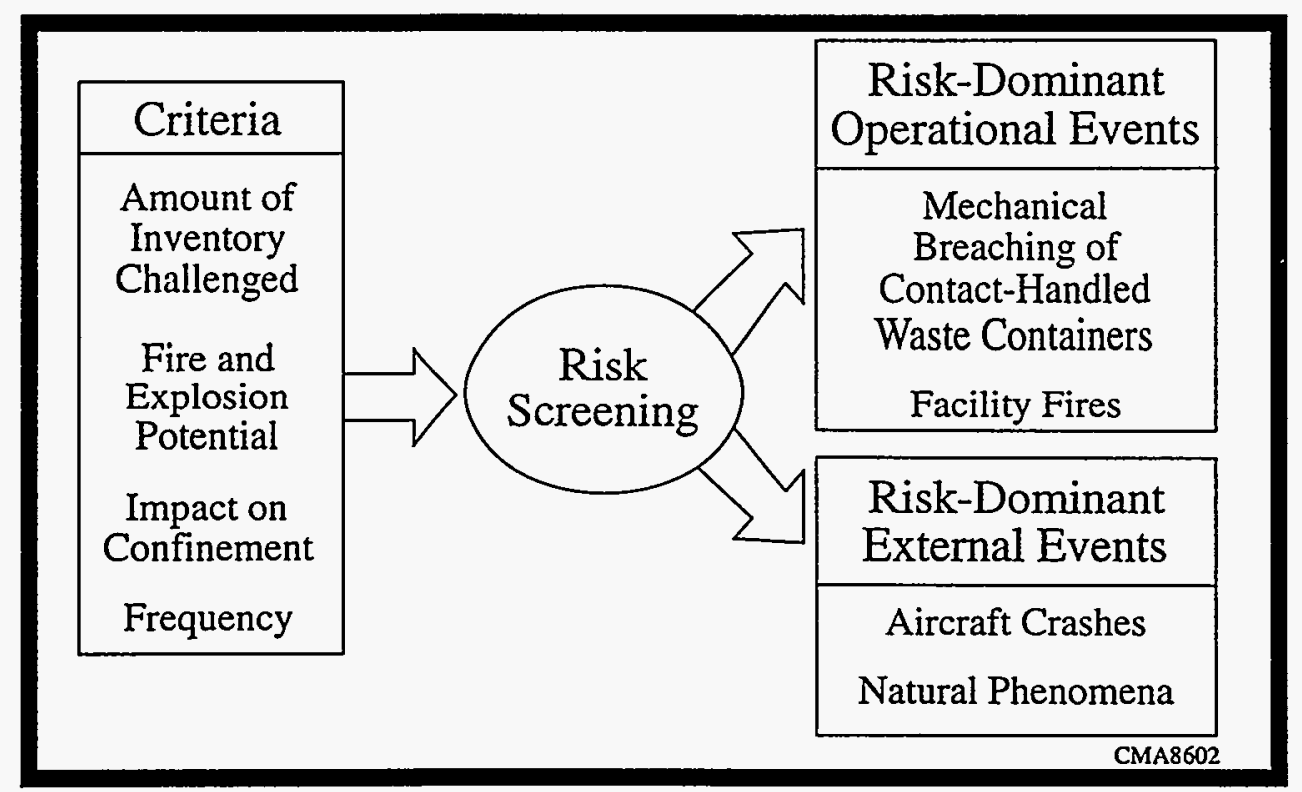

FIGURE 2.2 Screening of Risk-Dominant Accident Sequences

Finally, the accident sequences emerging from the initiators were classified by the frequency categories traditionally considered in safety documentation (Table 2.2). Although the descriptive terminologies of these categories have changed over the years in safety documentation, the frequency ranges have remained the same. Risk-dominant accident sequences from each of the frequency ranges shown were assessed in a manner consistent with recent NEPA guidance (DOE 1993a), in light of their potential for affecting different populations; however, accident initiators leading to sequences with nominal frequencies less than $1.0 \mathrm{E}-06 / \mathrm{yr}$ were generally ignored unless (1) the predicted consequences were so high that the risk (product of frequency and consequence) was likely to be dominant or (2) the uncertainty in the estimated frequency of the sequence was so large that a significant chance existed that the true frequency was greater than $1.0 \mathrm{E}-06 / \mathrm{yr}$. The final risk-dominant accident sequences selected were at or near the maximum "reasonably foreseeable" accidents.

Qualitative descriptions of the types of events composing the accident initiator categories are found in Table 2.3. Surrogate accident initiators were defined for the aforementioned subcategories of internal accidents on the basis of their expected frequency, dominant accident stress mechanisms, and potential consequences. Accident initiators were assigned frequencies appropriate to the process and facility configuration being evaluated, as reflected in the most recent safety documentation for DOE facilities managing nuclear waste and $\mathrm{HW}$.

External event initiators for man-made challenges include impacts of aircraft and fires or explosions in adjoining or nearby facilities that would challenge the primary facility. Although the expected frequency of an aircraft impact is intuitively very low for most DOE facilities, certain 
TABLE 2.1 Risk-Dominant Accident-Initiator Categories for Waste Management Operations and Facilities

\begin{tabular}{|c|c|c|c|c|c|}
\hline \multirow[b]{2}{*}{$\begin{array}{c}\text { Function or } \\
\text { Operation }\end{array}$} & \multirow[b]{2}{*}{$\begin{array}{c}\text { Containment } \\
\text { Characteristics of Facility }\end{array}$} & \multicolumn{2}{|c|}{ Internal Operational Accidents } & \multicolumn{2}{|c|}{$\begin{array}{l}\text { External Challenges to } \\
\text { Facility }\end{array}$} \\
\hline & & $\begin{array}{c}\text { Operational } \\
\text { Breaches of } \\
\text { Waste Packaging }\end{array}$ & $\begin{array}{l}\text { Operating } \\
\text { Fires or } \\
\text { Explosions }\end{array}$ & Man-Made & $\begin{array}{c}\text { Natural } \\
\text { Phenomena }\end{array}$ \\
\hline $\begin{array}{l}\text { General waste-handling } \\
\text { operations }\end{array}$ & Not relevant & $x^{a}$ & $x$ & $N A^{b}$ & NA \\
\hline Large-scale storage & Less than Hazard Category $2^{c}$ & Included above & $x$ & $x$ & $x$ \\
\hline Treatment or pretreatment & Hazard Category 2 & Included above & $x$ & $x$ & $x$ \\
\hline
\end{tabular}

$x=$ risk-dominant accident initiator.

b $\mathrm{NA}=$ not applicable.

c See Figure 2.4 for definitions of hazard categories. 
TABLE 2.2 Frequency Categories Traditionally Considered in Safety Documentation

\begin{tabular}{|c|c|c|}
\hline $\begin{array}{l}\text { Frequency } \\
\text { Category }^{\mathrm{a}}\end{array}$ & Frequency $(/ \mathrm{yr})$ & Definition \\
\hline Likely & $>1.0 \mathrm{E}-02$ & $\begin{array}{l}\text { May be expected to occur once or more during the } \\
\text { lifetime of the facility }\end{array}$ \\
\hline Unlikely & $\begin{array}{l}1.0 \mathrm{E}-02 \text { to } \\
1.0 \mathrm{E}-04\end{array}$ & $\begin{array}{l}\text { Not expected but may occur during the lifetime of } \\
\text { the facility }\end{array}$ \\
\hline Extremely unlikely & $\begin{array}{l}1.0 \mathrm{E}-04 \text { to } \\
1.0 \mathrm{E}-06\end{array}$ & $\begin{array}{l}\text { Will probably not occur during the lifetime of the } \\
\text { facility }\end{array}$ \\
\hline Not credible & $<1.0 \mathrm{E}-06$ & Has extremely low probability of occurring \\
\hline
\end{tabular}

a Although the descriptive terminologies of these categories have changed over the years in safety documentation, the frequency ranges have remained the same.

facilities are located relatively close to airports or are in or near flight patterns for commercial, regional, or military airports. For these sites, aircraft crashes with attendant fires or explosions involving aviation fuel could dominate public risk. Impacts from small and large aircraft will have different frequencies and consequences and are considered independently. Frequencies for air crashes were derived for each site (see Appendix $F$ of this document) from either site-specific documentation or generic guidance, depending on the proximity to airports and the exposure to flight patterns. In general, derived frequencies of aircraft crashes were well below 1.0E-06/yr. Frequencies for fires and explosions were generally derived from generic data. Appendix $\mathrm{C}$ of this document summarizes fire and explosion information used for guidance.

Natural phenomena considered as external accident initiators included earthquakes, floods, extreme winds or tornadoes, and volcanic activity; however, source terms were not developed for catastrophic flooding accidents because subsequent significant airborne releases are both implausible and enveloped in magnitude by airborne releases resulting from other catastrophic natural phenomena in the same frequency range. This is especially true since liquid HLW storage is not included in the analysis.

Source terms were also not developed for volcanic activity because such activity is believed to pose a credible threat to waste management facilities at only three major sites, Hanford, Los Alamos National Laboratory (LANL), and INEL. Eruption of the active volcanoes near the Hanford site or LANL would only result in ashfall, the potential effects of which are overwhelmed by analogous effects for earthquakes in the same frequency category. Although INEL is considered 


\title{
TABLE 2.3 Descriptions of Accident Initiators
}

\author{
Internal Operational Events (Generally with No Public Health Consequences)
}

Representative Industrial Accidents

Breach of primary containment of waste by an operational event, such as a handling accident, vehicular impact, improper system operation, system malfunction, or component failure, or resulting from failure of a support system such as a loss of power. Breach of containment by a small fire or process explosions originating inside the facility are included. Large-scale fires from industrial accidents are also considered, independent of large-scale fires and explosions that challenge the facility from outside and which are treated separately. To the extent possible, initiation frequencies are taken or derived from information in the SARs or supporting documentation. Frequencies of fires and explosions accompanying or subsequent to the breach are based on the combustibility of involved materials or the presence of combustible materials within the facility and are conditioned on the frequencies of events precipitating the accident sequence.

\section{Severe External Challenges to the Facility (Other than Catastrophic Natural Phenomena)}

Fire or Explosion

A fire or explosion originating outside the facility challenges the facility. Examples of initiators include explosions of fuel or volatile chemical tanks or trucks and fires impacting nearby facilities, fires in adjoining facilities, explosions of natural gas or process chemical lines or tanks, and naturally caused fires, such as prairie fires. If the facility is breached, concurrent (common cause) or subsequent accident events challenge the primary waste-containment barriers within the facility.

Impact of Aircraft

An aircraft or major aircraft component (engine) impacts the facility. If the facility is breached, concurrent (common cause) or subsequent accident events challenge the primary waste-containment barriers within the facility. The initiating frequency of impact reflects missiles posing a credible threat to secondary confinement and primary containment. Impacts from small and large aircraft will have different frequencies and consequences and are considered independently.

\section{Catastrophic Challenges to the Site and Facility from Natural Phenomena}

Earhquake

An earthquake exceeding the design basis for the facility occurs. Concurrent (common cause) or subsequent accident events challenge the primary waste-containment barriers within the facility.

Flood

A flood exceeding the design basis for the facility occurs. Concurrent (common cause) or subsequent accident events challenge the primary waste-containment barriers within the facility. Because subsequent significant airborne releases are both implausible and enveloped in magnitude by airborne releases resulting from other natural phenomena in the same frequency range, airbome source terms for flooding are not developed in this report. Dominance by airborne releases is especially truce since liquid HLW storage is not considered in the analysis.

Extreme Winds or Tornado

Extreme winds or tomadoes exceeding the design basis for the facility occur. Concurrent (common cause) or subsequent accident events challenge the waste-containment barriers within the facility.

Volcanic Activity

A volcanic eruption occurs, with ashfall or lava flow (or both). Breach of primary containment may be caused by an operational accident or malfunction due to loss of power or by impacts of structural failure due to heavy ashfall or lava flow. Concurrent (common cause) or subsequent accident events challenge the primary waste-containment barriers within the facility. Because volcanic activity is of concern at very few sites and because potential subsequent source term releases are enveloped either by analogous releases following other natural phenomena in the same frequency range or by the effects of the eruption itself, source terms from volcanic activity are not developed in this report.

\section{Criticality}

\section{Nuclear Criticality}

A nuclear criticality occurs within a storage facility or process vessel. Concurrent (common cause) or subsequent accident events challenge the primary waste-containment barriers within the facility. 
vulnerable to lava flow, the airborne releases of radiological waste are expected to be comparable to those from large-scale facility fires (EG\&G 1994a). Thus, for the analyses herein, seismic events are analyzed as an enveloping scenario for floods and most volcanic activities, and large-scale facility fires envelop the lava flow accidents at the INEL.

Seismic events are also used as the surrogate initiator for extreme winds or tornadoes. Existing analyses in DOE SARs and in the DOE Defense Programs Safety Survey (DOE 1993f) show that seismic events generally bound the risks of winds or tornadoes, including the risks from wind-driven projectiles. With respect to such projectiles, unpublished preliminary analyses for TRUW drums stored on outdoor pads at the Savannah River Site (SRS) show that damage from projectiles could exceed damage caused by seismic events primarily because of the stability of the drum-stacking arrangement and the lack of protection against projectiles. To appropriately account for potential damage by projectiles to unprotected outdoor storage areas, the damage assumed for seismic events in the WM PEIS is conservatively defined to have higher damage ratios than those used in the aforementioned SRS report in order to envelop the damage caused by high winds or wind-driven projectiles.

Frequencies of occurrence for natural phenomena were generally taken from DOE design and evaluation guidance regarding natural phenomena (see Appendix $\mathrm{E}$ of this document); however, the frequencies of loss of integrity of a facility from the challenges of natural phenomena were determined in accordance with DOE facility NPH design performance goals, as discussed in Section 2.5.1.

\subsubsection{Specification and Evaluation of Accident Sequences}

For the internal accident initiators defined in Table 2.3, the plausible accident scenarios and the associated frequencies were based on existing accident analyses in SARs and EISs for DOE facilities. These existing analyses for DOE facilities with waste management activities constitute a significant resource of information on accident assessment, and many of the analyses have been reviewed by peers and approved by DOE. These analyses included scenarios that are very similar to those needed for the WM PEIS and that could be used to estimate accident frequencies. In many cases, the existing analyses included probabilities for failure that were based on experience or on data on plant failures. The use of existing scenario frequencies precluded the need to estimate numerous event tree conditional probabilities for equipment failures and human errors that constitute the accident sequences.

High- and low-frequency estimates were taken from existing accident analyses with accident initiators, facility types, hazardous material types, and circumstances similar to accidents considered in the WM PEIS evaluation. The frequency selected for the WM PEIS evaluation was based on the overall similarity of the existing analysis to the analysis in question. In some cases, 
adjustments were made to include or remove frequency contributions from preventive and mitigative features that may or may not be included in the WM PEIS alternative. In most cases, the frequencies used in the WM PEIS were toward the high end of the frequencies reported in existing analyses, as discussed in Section 2.6.

For the external initiators, the analyses from existing SARs and EISs were sparse and often outdated. Because external events are rare, the facilities have no experience with the direct impact of external forces or experience such as that of the nuclear utility Seismic Qualification Users Group (SQUG); consequently, analysis on the basis of experimental data could not be achieved. Event trees were developed to project the progression of the accidents associated with external initiators through plausible generic sequences. The extent of any release is a function of (1) the accident-related stresses affecting and rendering airborne the material involved in the accident and (2) the response of the containment barriers and filtration systems (if any). Accident stress mechanisms can be categorized as mechanical, fire-driven, or explosion-driven mechanisms; branches of event trees were specifically defined to delineate fire and explosion categories for which experimental information is available to support the associated estimates of the release fraction.

The containment response is a function of the structural strength and operational status and efficiency of the buildings, equipment, and materials providing containment or filtering (or both), as well as the emergency response capabilities of the mitigative systems and relevant personnel. Accordingly, event tree branches were similarly defined to incorporate the key accident containment and filter failures affecting the amount of airborne activity released to the atmosphere. This structuring of the event trees to incorporate stresses and responses of containment allowed a step-bystep characterization of the likelihood of the sequence and the magnitude of the release as the accident sequence progressed.

The accident sequences were developed and analyzed for accident categories applicable to facilities. They (1) provide a uniform treatment of accident analysis to a wide range of facilities with similar design characteristics across the DOE complex and (2) reduce the number of actual analyses performed to a manageable level. To implement this approach, existing facilities were generally mapped into a DOE-STD-1027-92 Hazard Category (DOE 1992b) (see Section 2.5.1) and into DOESTD-1021-93 facility NPH PCs (DOE 1993b). In general, conceptual treatment process facilities were assumed to be Hazard Category 2. A no-confinement category was assigned to concrete pads used for packaged storage, weather protection sheds, Butler buildings, and facilities providing no real barriers to release, up to and including general-use buildings. This treatment is appropriate for catastrophic releases and conservative for more benign sequences.

A generic matrix of release characteristics was then developed as a function of the event tree branches to facilitate the tracking of potential source terms through the accident sequences. This approach enabled the determination of the fractional release of each radionuclide or toxic chemical in the original inventory available for release (the airborne release fraction [ARF]) at each point in 
the progression of the accident. Each accident sequence is then terminated in a generic release category. This approach adapts the source term treatment used in the DOE Defense Programs Safety Survey Report (DOE 1993f) to accident progression analysis (see Section 2.4). The approach also allows the evaluation of contributions from both the accident initiation and the subsequent accident sequence in determining the overall ARF.

The final step in evaluation involved the integration of the radionuclide or chemical compositions of the waste process inventories of MAR in the accidents with the accident data to derive the source terms. Preliminary estimates of the effects on health were obtained by combining the information on source term with the unit-risk factors for each site. With this information, a reduced set of risk-dominant source terms covering the plausible frequency spectrum was developed for final calculations of health effects and risk.

\subsubsection{Nuclear Criticality}

On the basis of existing safety analyses, criticalities were judged to be incredible for LLW and LLMW storage, treatment, and post-treatment storage. The safety analysis of the Consolidated Incineration Facility (CIF) at SRS (DuPont 1987) considered nuclear criticality as implausible on the basis of the design-basis feedstocks and as incredible on the basis of the large number of independent operator errors and other failures necessary to introduce an unsafe quantity of fissile material into the incinerator and processes. The numerous combinations of failures in the waste packaging, classification, and handling processes required to both introduce sufficient fissile material into a LLW or LLMW storage or process facility and create a critical geometry or arrangement of the waste storage arrays simply rule out a credible criticality before or after treatment for these waste types.

Because the WM PEIS addresses only the shipping and interim storage options related to canisters of vitrified $\mathrm{HLW}$, for which no plausible mechanisms exist to achieve criticality, source term analysis for HLW criticality is unwarranted.

A nuclear criticality in a TRUW solid-waste storage-and-handling facility (e.g., Waste Receiving and Processing Facility [WRAP] Module 2 [DOE 1991c] and the Radioactive Waste Management Complex [RWMC] [EG\&G 1993b]) is also judged to be incredible because of the low density and inventory of fissile material in the solid wastes, coupled with the dispersed geometry. Nuclear criticality can be conceived in some aqueous processing alternatives, depending on the dissolution of fissile material in the throughput of the process, the design of the vessel, and the flowsheet parameters (see Appendix C); however, this criticality would require numerous breakdowns of administrative and accountability controls or unforeseen design deficiencies in the processing system (or both). 
DOE requires specific analyses to estimate the frequency of criticality for such processes. If the analysis indicates credibility (>1.0E-06/yr), DOE then requires specific design provisions to preclude or mitigate the effects. With these safeguards in place, accidents of nuclear criticality have been ruled out as not being sufficiently important to risk to justify source term analysis for TRUW. Accidents of nuclear criticality are not discussed further in this report.

\subsection{DEVELOPMENT OF SOURCE TERMS FOR ACCIDENT SEQUENCES}

\subsubsection{Radiological Source Terms}

The method used to estimate radiological source terms is similar to that used in the DOE Defense Programs Safety Survey Report (DOE 1993f). The source term associated with each accident is the product of four factors that vary for each radionuclide within the inventory affected by the accident:

$$
\text { Source term }=M A R \times D F \times R A R F \times L P F \text {, }
$$

where $M A R$ is the material at risk, $D F$ is the damage fraction, $R A R F$ is the respirable airborne release fraction, and $L P F$ is the leak path factor.

Figure 2.3 illustrates the evolution and development of the source term components from accident initiation through delivery to the atmosphere. While the disaggregation of the source term into these components broadly follows the treatment used in the DOE Defense Programs Safety Survey Report (DOE 1993f), the treatment of the components has been extended, as discussed in Section 2.3.2, to allow the tracking of these parameters at each point in the accident sequence.

All accident sequences culminated in fractional release categories defined to accommodate the various combinations of generic sets of DF, RARF, and LPF. The source term total release fraction (TRF) is defined as follows:

$$
T R F=D F \times R A R F \times L P F,
$$

and provides the fraction of each radionuclide or toxic material in the MAR that escapes the confinement and is available for atmospheric transport. This term, multiplied by the MAR, provides the source term used in the calculations of health effects and risk (see Section 2.2). 


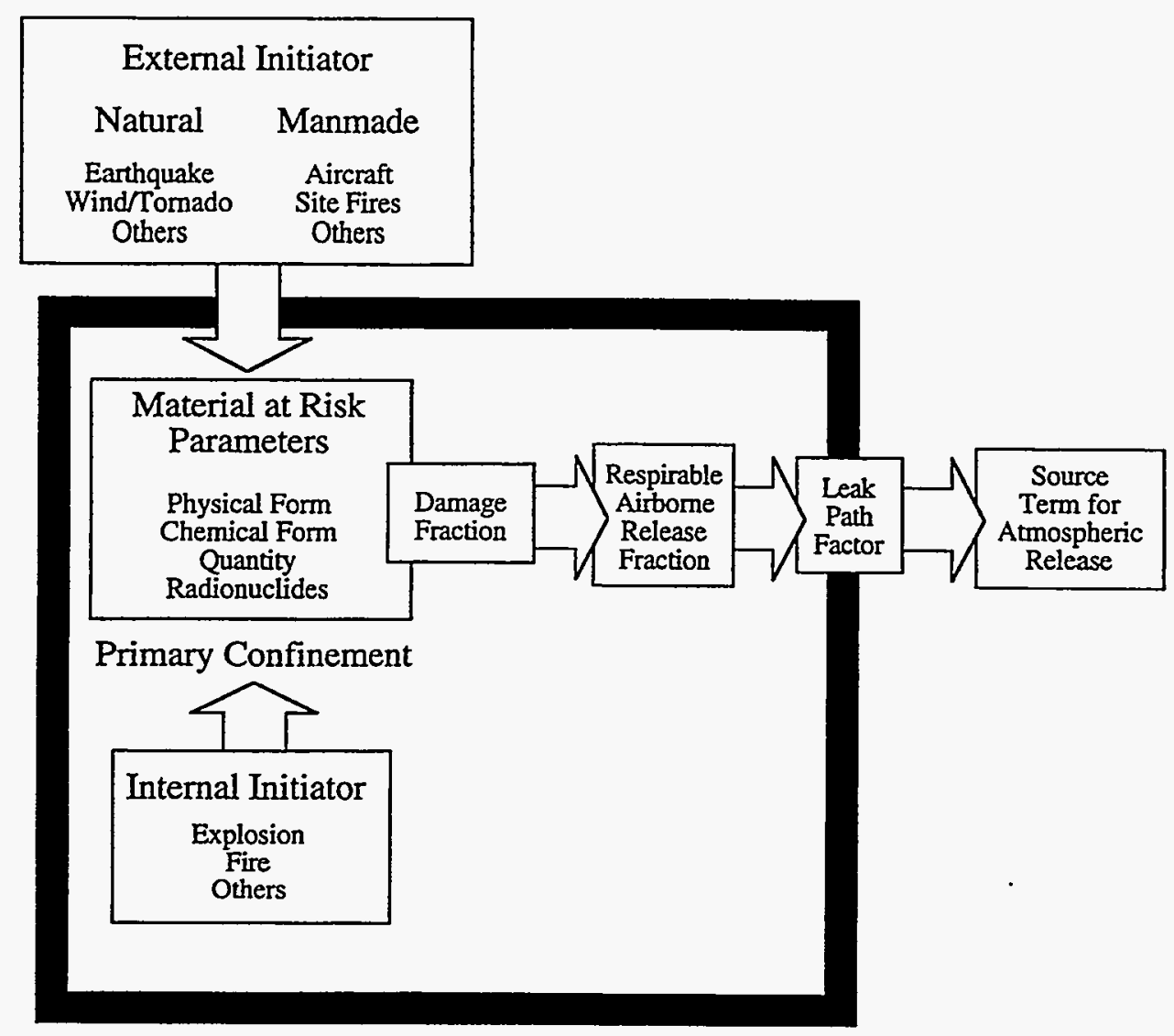

FIGURE 2.3 Conceptual Flow Diagram for Source Term Development

\subsubsection{Material at Risk and Damage Fraction}

The MAR is the total inventory of waste in a facility or particular operation with the potential of being impacted. The MAR is a function not only of the configurations of the process and facility but also of the severity of the accidents challenging the process or facility; for example, catastrophic accident initiators such as earthquakes clearly have the potential to affect greater inventories of waste than do industrial accidents and thus have greater MARs.

The DF refers to the fraction of MAR involved in the accident sequence and actually susceptible to airborne release. The DF is a function of the severity of the initiator and is generally small for operational events if the MAR is large and larger for more severe events, such as external challenges to a facility from natural phenomena. The DF is also a function of the process and facility characteristics and of the subsequent phenomena encountered in the accident sequence, such as fires or explosions that have the capability of challenging or propagating to additional inventories of the MAR. More benign sequences without such mechanisms have sequence DFs that are zero or very 
small. Damage fractions were assigned as a function of the severity of the accident sequence, the physical and chemical forms of the MAR, and the vulnerability of the containment of the MAR.

\subsubsection{Respirable Airborne Release Fraction}

The ARF is the fraction of the potentially available inventory of the radionuclides rendered airborne at the point of the accident. The ARF is a joint function of the original physical form of the waste and the accident mechanisms and concomitant stresses acting to create airborne materials. The airborne release of radioactive materials depends on the ability of an accident sequence to overcome the barriers between the radioactive material and the ambient environment and to subdivide and suspend the radioactive material. Liquids or solids must be either fragmented or deagglomerated and suspended. All materials in the gaseous state (noncondensable gases and vapors under ambient conditions) were assumed to be transportable and respirable. The ARF is also a function of the physical or chemical properties of the individual radionuclides or chemical species. The respirable airborne release fraction (RARF) is the product of the ARF and the respirable fraction (RF). The RF for particulates is conservatively defined as the fraction of particulates with aerodynamic equivalent diameters below $10 \mu \mathrm{m}$. The aerodynamic equivalent diameter is the sphere of material with a density of $1 \mathrm{~g} / \mathrm{cm}^{3}$ that has the same terminal velocity as the particle.

Many experiments and analyses have been conducted to provide both bounding ranges and best estimates of the release fractions of various radionuclides as a function of their chemical and physical form under a variety of accident stresses. The RARFs used in the accident sequences herein were derived by multiplying the ARF and RF for the applicable stress provided in DOE (1994), which examines experimental data for the airborne release of materials under five types of stress: (1) explosions (shock and blast effects), (2) fires, (3) venting of pressurized liquids and powders (or venting of pressurized volume above solids), (4) crush-impact (either fragmentation by the impact of a falling, hard, unyielding object or the impact of a falling material on a hard, unyielding surface), and (5) aerodynamic entrainment or resuspension. Where ARFs and RFs were unavailable for the type of material or the level of stress, values were derived by assessing the effect of some characteristic of the initiator or materials involved (e.g., the effect of viscosity on the fragmentation and suspension of liquids in free-fall spill or pressurized release).

Matrices were developed for each waste type to account for the physical and chemical characteristics of the MAR by mapping the treatability categories into the physical forms for which airborne release data were developed. These matrices and results for the RARFs developed for the various physical forms of waste encountered in DOE waste management as a function of the stresses encountered in the potential accident sequences are shown in Appendix D and the results sections. This treatment allows the analyses of the stresses encountered in the initiating events and the accident sequences to be evaluated independently, which in turn allows the step-by-step buildup of 
the source term to be tracked and integrated with the response of the protection systems to facilitate calculations of health effects for both the occupational workforce and the public.

\subsubsection{Leak Path Factor}

The leak path factor (LPF) is the fraction of the airborne inventory that passes through the containment barriers and filters to escape to the atmosphere. The LPF is a function of the physical form of the nuclide being released, the susceptibility of the nuclide to removal or reduction phenomena (such as precipitation or agglomeration) and to subsequent capture within the containment walls or filtering systems, and the effectiveness of the filtration systems in place. Incontainment transport and filter effectiveness can be heavily dependent on the accident sequence, as well as on the structural characteristics and physical design of the facility. The LPFs were assigned on the basis of the integrity of the containment (if any) and the functionality of filtration systems in the facilities for the accident sequences. The more severe accident sequences generally involved breach of confinement, for which a conservative LPF of unity was assigned. Appendix D provides LPFs as a function of the effectiveness of the filters used in DOE facilities and the intracontainment transport properties of gases and particulates; it also summarizes the values used herein.

\subsubsection{Chemically Hazardous Source Terms}

Chemical source terms were specifically developed for two waste types, HW and LLMW. All accidents were divided into three general categories, each having subcategories and including sublethal and lethal endpoints:

1. Spills resulting in partial vaporization of the waste ("spill only"),

2. Spills followed by ignition of the waste ("spill plus fire"), and

3. "Other event combinations":

- Spills followed by ignition of the waste and an induced explosion in a waste container ("spill plus fire plus explosion"),

- Facility fires resulting in a waste container breach ("fire only"),

- Mechanical failure of a compressed gas container resulting in an explosion ("spill and explosion"), or 
- Explosion from exposure of reactive material to air followed by fire ("fire and explosion").

The MAR and DF for the various chemical accident sequences were based on the same considerations as discussed for the radiological accidents.

In general, these accidents involve chemical or physical change in materials affected by the initial incident. The chemical and physical properties of the MAR were reviewed, and toxic gaseous products were identified for the accident sequences. The masses of these products were estimated from the mass of the reactants and the stoichiometry of the reactions. Rates of releases were generally estimated by assuming exponential decay with time. Obviously, the exact course of an accident is shaped by a multitude of factors, including (but not limited to) temperature, humidity, pooling versus spreading of spills, the exact composition/concentration of reactive materials (often . unknown), and the proximity and nature of nearby reactive materials (including packaging, shelving, and flooring). Details on the selection of the accident scenarios, the chemistry involved in their progress, and the estimation of the release rates of the toxic gases are provided in Sections 6 and 8 for LLMW and HW.

\subsection{GENERAL FACILITY MODELING AND INVENTORY ASSUMPTIONS}

As discussed in Section 2.2.1, the accidents considered in the WM PEIS accident analysis include general handling accidents, storage facility accidents, and accidents involving treatment processes or facilities. To appropriately evaluate these accidents, descriptions and assumptions concerning the design and configuration of storage facilities and processing facilities must be established. This section discusses the generic DOE design and performance criteria and the design aspects and associated modeling assumptions of storage facilities, processing facilities, and waste packages that are the basis for the accident evaluation.

\subsubsection{DOE Design and Performance Criteria}

To understand how the facilities for TSD operations are affected by the various accident initiators discussed in Section 2.3.1, an understanding of how DOE facilities are designed and evaluated is necessary. DOE has established general design criteria (GDC) for all types of facilities (DOE 1989). The GDC in DOE Order 6430.1A provide the minimum requirements for the design, construction, and maintenance of facilities; these GDC must be followed for all new construction, including modifications of facilities. For facilities constructed before 1989, similar predecessor GDC were used; however, compliance was less strictly enforced, and the GDC were somewhat less stringent and specific. In the last few years, much emphasis has been placed on achieving compliance through facility upgrades or demonstrating that noncompliance with a particular criterion 
does not cause undue risk. An implied assumption exists throughout the WM PEIS accident analysis that WM facilities involved in all of the alternatives conform to DOE Order 6430.1A, including the requirements for a higher design pedigree (such as control system redundancy or natural phenomena resistant design) for systems, structures, and components (SSCs) that perform a safety function.

The "graded approach" for facility design, as applied by DOE Order 6430.1A and other DOE orders and standards, is a particularly important design concept that affects the results and assumptions in the WM PEIS accident analysis. The graded approach is a commonsense concept that the design pedigree, as well as the operational maintenance and surveillance, for SSCs should be commensurate with the importance that the SSCs have with respect to the protection of the on-site workers, the public, and the environment. To achieve the appropriate design pedigree and to select appropriately stringent criteria from DOE Order 6430.1A, the DOE classifies facilities by using criteria in DOE Standard DOE-STD-1027-92 (DOE 1992b). This standard categorizes nuclear facilities into Hazard Categories 1, 2, or 3 on the basis of the effects of unmitigated releases of hazardous materials. Category 1 facilities are the most hazardous and are considered to have the potential to cause significant off-site effects. Category 3 facilities are the least hazardous and do not have the potential to cause off-site effects or more than minor on-site effects. Analogous categories for nonnuclear facilities (no radiological hazards) are also established and are referred to as high-, moderate-, or low-hazard facilities.

It is reasonable to assume that the safety significant aspects of the facility design (i.e., those that may affect the WM PEIS analysis) comply with the GDC, since compliance must be demonstrated as part of the authorization basis for facility operations. As such, noncompliant features that may threaten the safety envelope documented in the authorization basis are reviewed for their safety impact, and modifications and retrofits are made as necessary. The GDC are also considered in the safety review of design changes to ensure that compliance is achieved and the authorization basis maintained. Facility compliance to the GDC ensures that the facility safety envelope is maintained and that assuming GDC compliance for the WM PEIS accident analysis is reasonable and justified.

An assumption or assertion that a facility is in a particular hazard category implies that the facility has a design pedigree commensurate with the level of risk posed by the facility. However, the assumption of a higher design pedigree does not in itself ensure that risks to the public and workers are appropriately controlled. The assumption of a design pedigree simply implies that SSCs are designed to prevent accidents or to mitigate the consequences accidents. The assessment that risks are adequately controlled is documented in safety analysis documentation that uses risk-based methods to demonstrate that appropriate programmatic functions and controls are used in concert with the facility design to achieve acceptable risk performance.

To achieve a performance goal of not exceeding a certain annual probability of loss of function in a facility, the facility (and related SSCs) must be designed to withstand a certain 
magnitude of hazard (the design-basis natural phenomena event). Report UCRL-15910 (Kennedy and Short 1990) provides guidelines for selecting the natural phenomena design basis and the maximum acceptable annual probability of exceedance of the hazard to achieve a predetermined performance goal for a facility. In the WM PEIS, a facility of a particular hazard category is assigned a performance goal as defined in DOE-STD-1021-93 (DOE 1993b). The design-basis hazard magnitude for earthquakes and winds corresponding to the hazard annual probability of exceedance (listed in UCRL-15910) is obtained from site-specific hazard curves reported in the Natural Phenomena Hazards Modeling Project (Coats and Murray 1984). For example, for a Hazard Category 2 facility, the performance goal is 1.0E-04 (for loss of function); and based on UCRL15910 , the recommended maximum annual probability of exceedance of a seismic hazard to meet such a performance goal is 1.0E-03. Thus, for a given site such as ANL-E, the peak ground acceleration corresponding to an annual probability of exceedance of $1.0 \mathrm{E}-03$ is $0.12 \mathrm{~g}$ (Coats and Murray 1984), where $g$ is the gravity acceleration. Therefore, a Hazard Category 2 facility at ANL-E with a $0.12 \mathrm{~g}$ seismic design basis has an annual probability of exceedance (beyond seismic design basis) of $1.0 \mathrm{E}-03$ and an annual probability of loss of function of $1.0 \mathrm{E}-04$ (beyond performance goal).

Figure 2.4, abstracted from DOE-STD-1021-93 (DOE 1993b), depicts the performance goals of $1.0 \mathrm{E}-05,1.0 \mathrm{E}-04$, and $5.0 \mathrm{E}-04$, assumed herein to represent frequencies of facility containment failure under challenge from natural phenomena for Hazard Category 1, 2, and 3 buildings, respectively. This figure also shows the relationship between the criteria of resistance to natural phenomena and the PCs and performance goals. The DOE orders and standards to implement the use of these criteria, including DOE Orders 5480.23 (DOE 1993e), 5481.1B (DOE 1987a), 6430.1A (DOE 1989), and 5480.28 (DOE 1993c, formerly 5480.NPH), are also shown. The primary DOE standards for performing structural design and evaluation with respect to natural phenomena resistance are DOE-STD-1021-93 (DOE 1993b) and DOE-STD-1020-92 (DOE 1993d), formerly UCRL-15910 (Kennedy and Short 1990).

In general, the facility categories referenced in the WM PEIS refer to the hazard category that is established by using criteria from DOE-STD-1027-92 (DOE 1992b). Most of the facilities considered in the WM PEIS alternatives are Hazard Category 2 or 3, or general-use facilities. Treatment facilities were assumed to be Hazard Category 2 for accident analyses. Storage facilities were conservatively assumed to have no containment. 


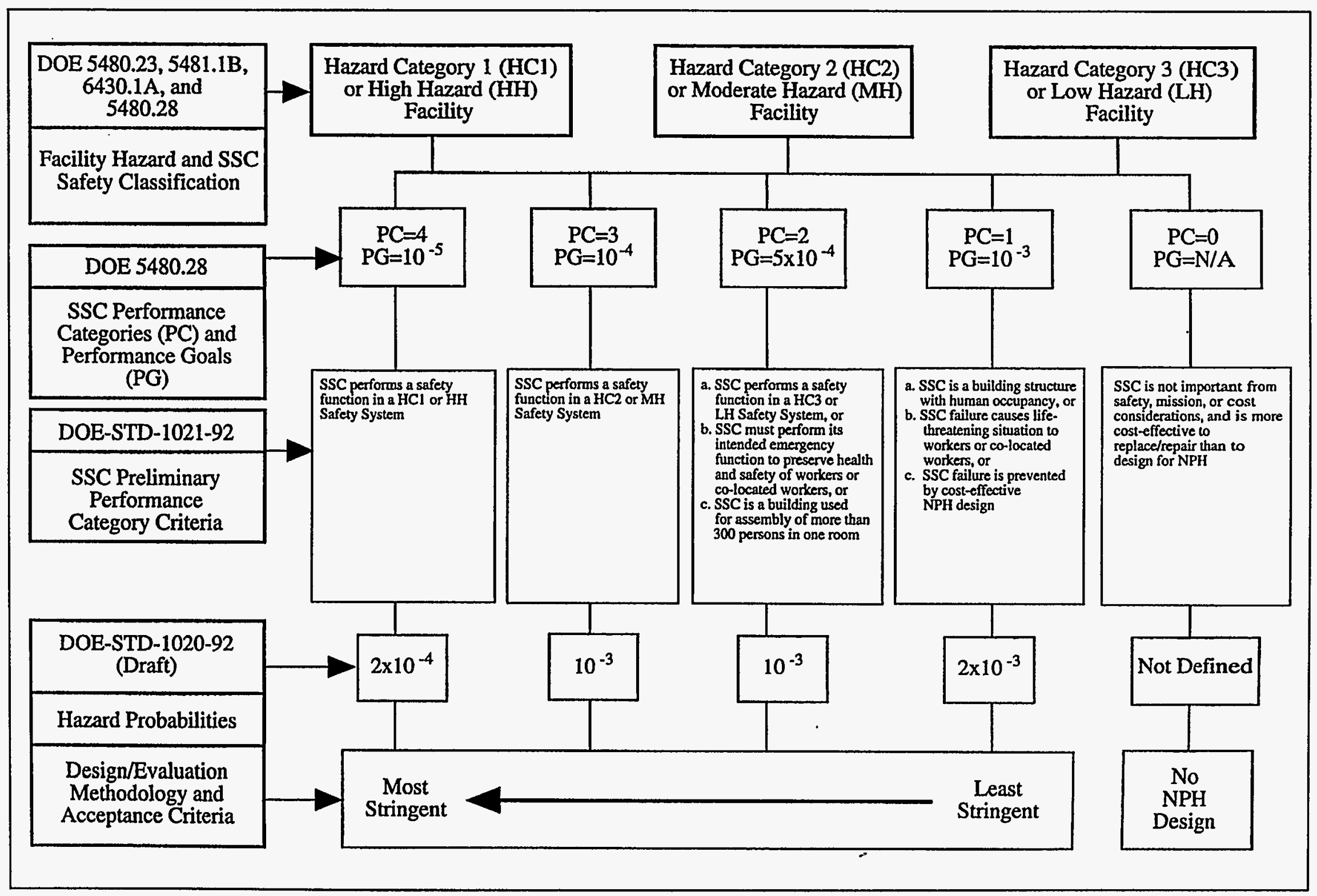

FIGURE 2.4 DOE Performance Goals for Hazard Category 1, 2, and 3 Facilities (DOE 1993b) 


\subsubsection{Storage Facility Accidents}

\subsubsection{Low-Level Waste, Low-Level Mixed Waste, and Transuranic Waste}

The underlying assumption used in the WM PEIS is that all sites will accumulate or at least not reduce these waste inventories for roughly 10 years, at which time complexwide treatment will begin. Thus, all sites will achieve their maximum inventories (leading to maximum potential releases), independent of alternative in about 10 years. This condition applies to all analyses of storage facility accidents and offers no discrimination. Hence, accidents during current storage of LLMW, LLW, and TRUW were not analyzed. However, to provide guidance on the likely impacts of storage facility accidents, a review of recent DOE NEPA guidance or safety documentation is provided in the individual sections for LLMW, LLW, and TRUW. Although not relevant in the discrimination of WM PEIS alternatives, this guidance facilitates qualitative comparisons of the relative impacts of storing wastes in their current form versus treating these wastes prior to disposal.

Current storage for these waste streams is accomplished in a variety of ways. Low-level waste is generally packaged in drums or containers and stored on outdoor concrete or asphalt pads or in weather protection sheds pending treatment or shallow land disposal. Low-level mixed waste is generally packaged in drums or containers and stored in Resource Conservation and Recovery Act (RCRA)-compliant weather-protective sheds pending treatment. Transuranic waste is generally packaged in drums or containers and stored in concrete structures, in weather-protective sheds, in earthen berms, or in below-grade caissons (remote-handled [RH] TRUW). Most contact-handled (CH) TRUW, which dominates the total TRUW inventories, is stored in facilities with minimal containment, although DOE sites are moving toward qualified TRUW storage.

\subsubsection{High-Level Waste}

Most DOE HLW is stored in large underground tanks at Hanford and Savannah River; much smaller amounts are stored at INEL and at the West Valley Demonstration Project (WVDP). Because calculation of the cost and risk impacts of current storage of $\mathrm{HLW}$ is not within the scope of the WM PEIS, no analyses of these storage facilities were performed. However, the storage of vitrified HLW was analyzed because it could be a factor in discriminating among alternatives for HLW management. These analyses are described in the section on HLW.

\subsubsection{Hazardous Waste}

Hazardous waste is generally packaged in 208-L (55-gal) drums and stored in RCRA-compliant staging areas or weather protection sheds before off-site shipment for commercial 
treatment and disposal. An HW storage facility (HWSF) typically has over 100 different chemicals that may include chlorinated solvents, acids, bases, photographic chemicals, ignitable solids and liquids, compressed gases, metallic salts, lab-packed wastes, polychlorinated biphenyls, asbestos, and other regulated wastes. With explosives generally prohibited, the potential hazardous characteristics include volatility, flammability, dispersibility, and toxicity; and the HW is characterized and segregated on the basis of toxicity, corrosivity, reactivity, and ignitability. Most HWSFs have containment berm areas and individual storage cells that permit waste segregation according to RCRA and EPA criteria; some HWSFs have the capability of fire detection and suppression, and some have forced ventilation. Because of the great diversity of storage-facility designs among the DOE sites, a generic facility configuration with design characteristics such as storage arrays and segregation (as illustrated in Figure 2.5) was assumed in the analyses. No credit was taken for containment or filtration.

\subsubsection{Treatment Facility Accidents}

The configuration of the generic treatment facility for the WM PEIS accident analysis consists of a series of linked process modules, each providing a specific treatment process. Modules providing common service to the process modules consist of (1) front-end support, providing waste receipt and lag storage; (2) treatment receiving and inspection; (3) container open, dump, and sort;

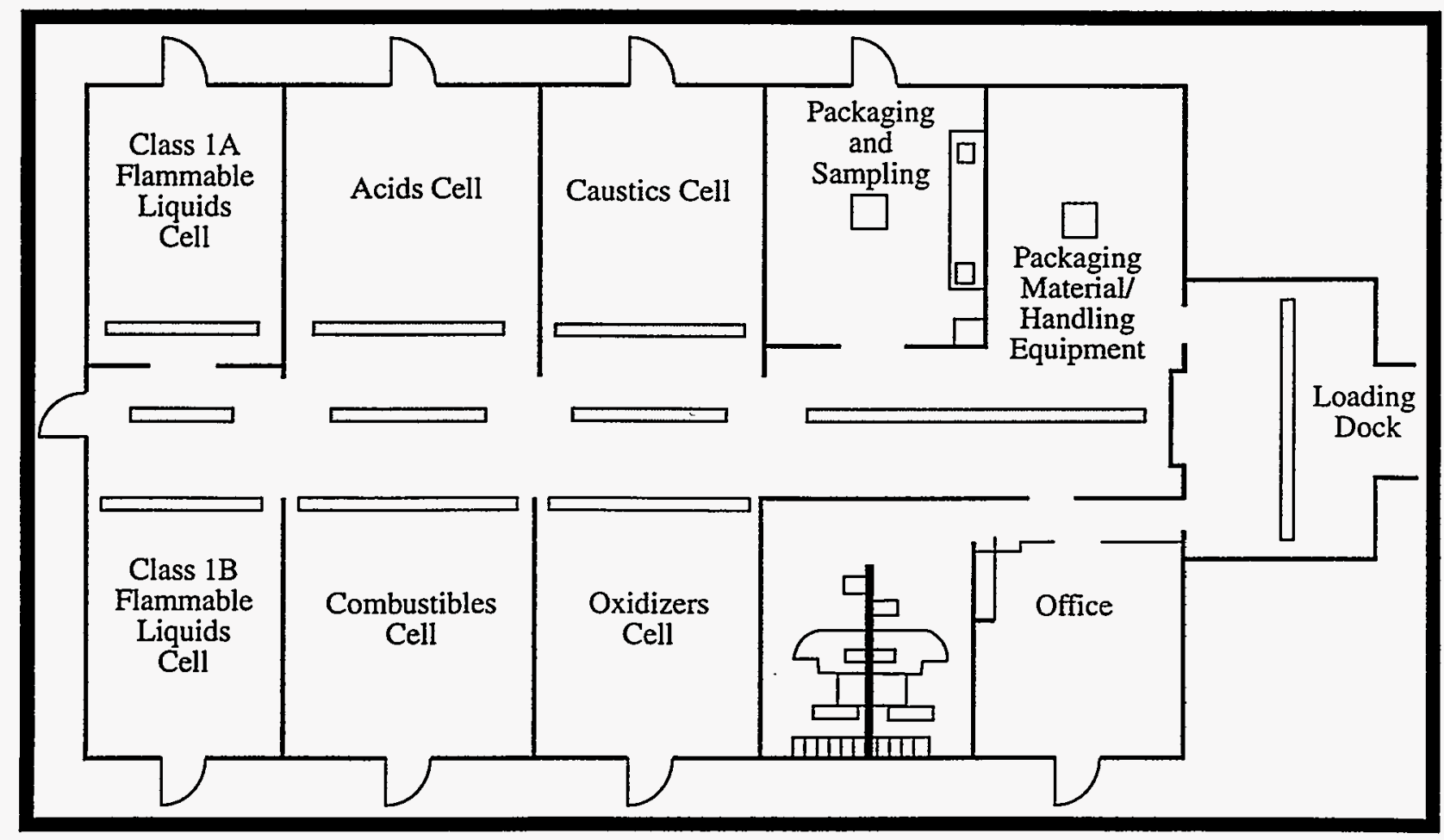

FIGURE 2.5 Typical Design for Hazardous Waste Storage Facility 
(4) certification and shipping; and (5) back-end interim storage before disposal. Process modules consist of specific treatment operations and process support services. The treatment facility is assumed to consist of process trains for both $\mathrm{RH}$ and $\mathrm{CH}$ operations, with similar unit operations, differing only in the degree of shielding and the degree of contact operations and maintenance. The RCRA contaminant removal technologies entail modules for (1) sorting and segregation (e.g., before incineration); (2) removal or destruction of aqueous organics before evaporation; (3) metal removal; (4) metal recovery; (5) mercury removal and recovery; and (6) stabilization of various waste constituents by immobilization, conversion to stable forms, or removal.

As discussed in Section 2.2.4, a generic incineration facility was selected for the evaluation of LLW, LLMW, and TRUW accidents. The RH and $\mathrm{CH}$ incineration portions of the facility shown in Figure 2.6 have the following general functional areas: a receiving, storage, and feed area; the incinerator area housing the rotary kiln and an off-gas SCC; an incinerator off-gas treatment area; a liquid treatment area; a solidification area (when cement solidification is applied to the ash); and facility and process exhaust air treatment, including the high-efficiency particulate air (HEPA) filtration systems. The receiving and storage area contains waste in various (but mostly solid) physical forms. Waste is fed to the incinerator after preparation (sorting or shredding, or both, as required). All combustible materials are destroyed, leaving a solid (ash) residue. The ash is generally solidified or packaged (or both) before transportation and disposal.

Incineration off-gas treatment includes a condenser and fume scrubber and generates a liquid waste stream of condensate and spent gaseous scrubber solution. In the liquid treatment area, dissolved and suspended solids are removed, liquid residue is prepared for immobilization, and treated wastewater is recycled to the system. In the solidification system, the sludge from the liquid residue and the ash resulting from the incineration are mixed with concrete and immobilized. Waste in the other areas is in the form of ash. In the CIF at SRS, wet ash is found in all ash areas except the two combustion chambers (DuPont 1987). Dry ash is generated in other DOE incinerators and, because of its greater dispersibility, is assumed here for source term development.

The incineration facility also produces a residual gaseous waste stream. The incinerator offgas treatment unit is designed to remove particulates, sulfur dioxide $\left(\mathrm{SO}_{2}\right)$, hydrogen chloride $(\mathrm{HCl})$, and nitrogen oxides $\left(\mathrm{NO}_{\mathrm{x}}\right)$. The off-gas from incineration contains carbon monoxide $(\mathrm{CO}), \mathrm{SO}_{2}$, and $\mathrm{NO}_{\mathrm{x}}$. Acid gases are typically removed by scrubbing. Radioactivity and some toxic metals are released directly in off-gas as volatilized compounds and radionuclides (iodine, ruthenium, and cesium) or radioactive gases (carbon monoxide $\left[\mathrm{CO}_{2}\right], \mathrm{H}_{2} \mathrm{O}$, and $\mathrm{SO}_{2}$ formed with carbon 14 [C-14], tritium [H-3], and sulfur 35 [S-35], respectively). Some fission products are also released indirectly in combination with particulates that are removed by off-gas scrubbing and filtering.

Detailed modeling of facilities was beyond the scope of the WM PEIS. Accordingly, a treatment facility with generic confinement characteristics defined previously was used to assess accidents to envelop the releases from accidents in the treatment process. A DOE Hazard Category 


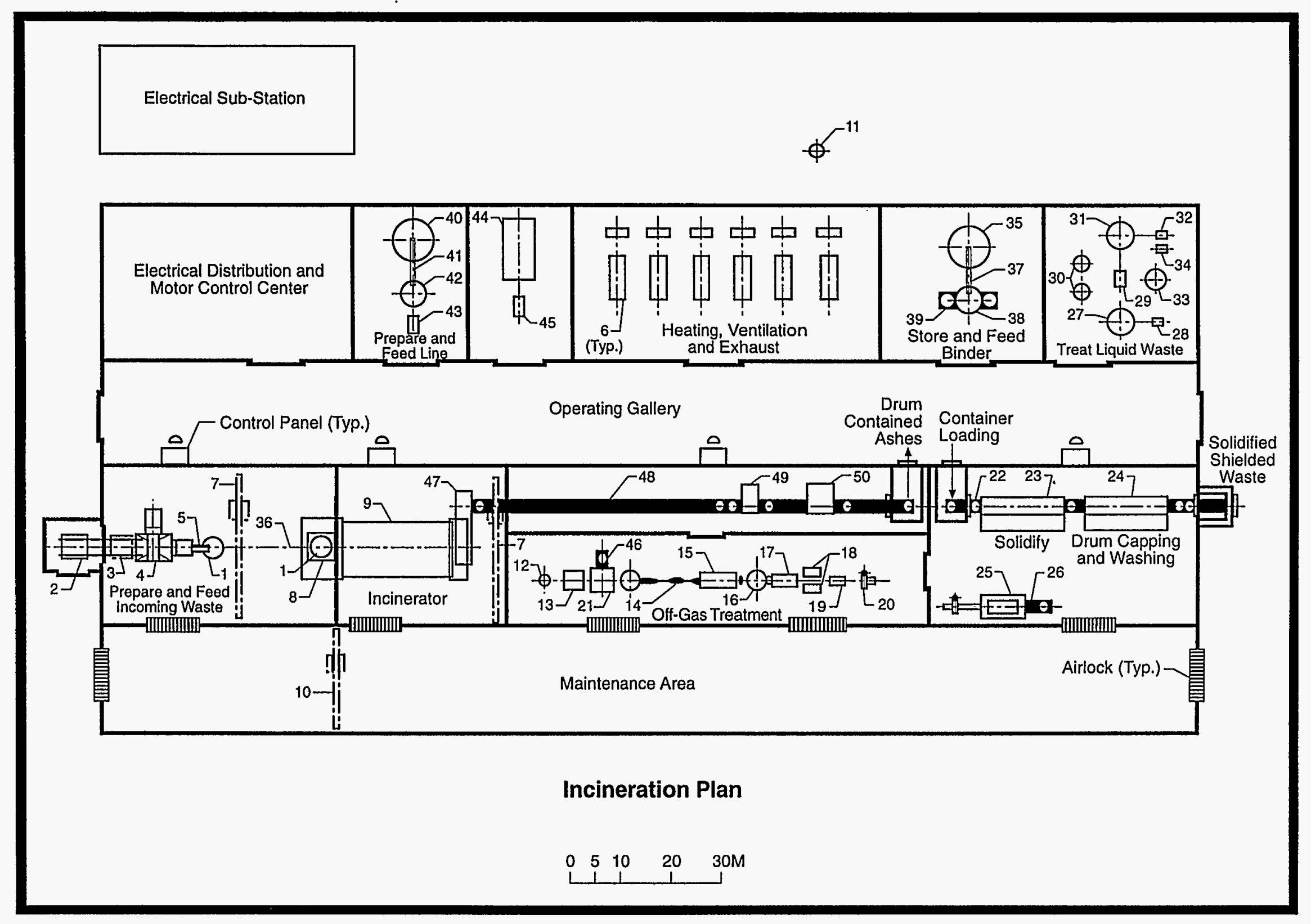




\section{Figure 2.6: Key to Equipment}
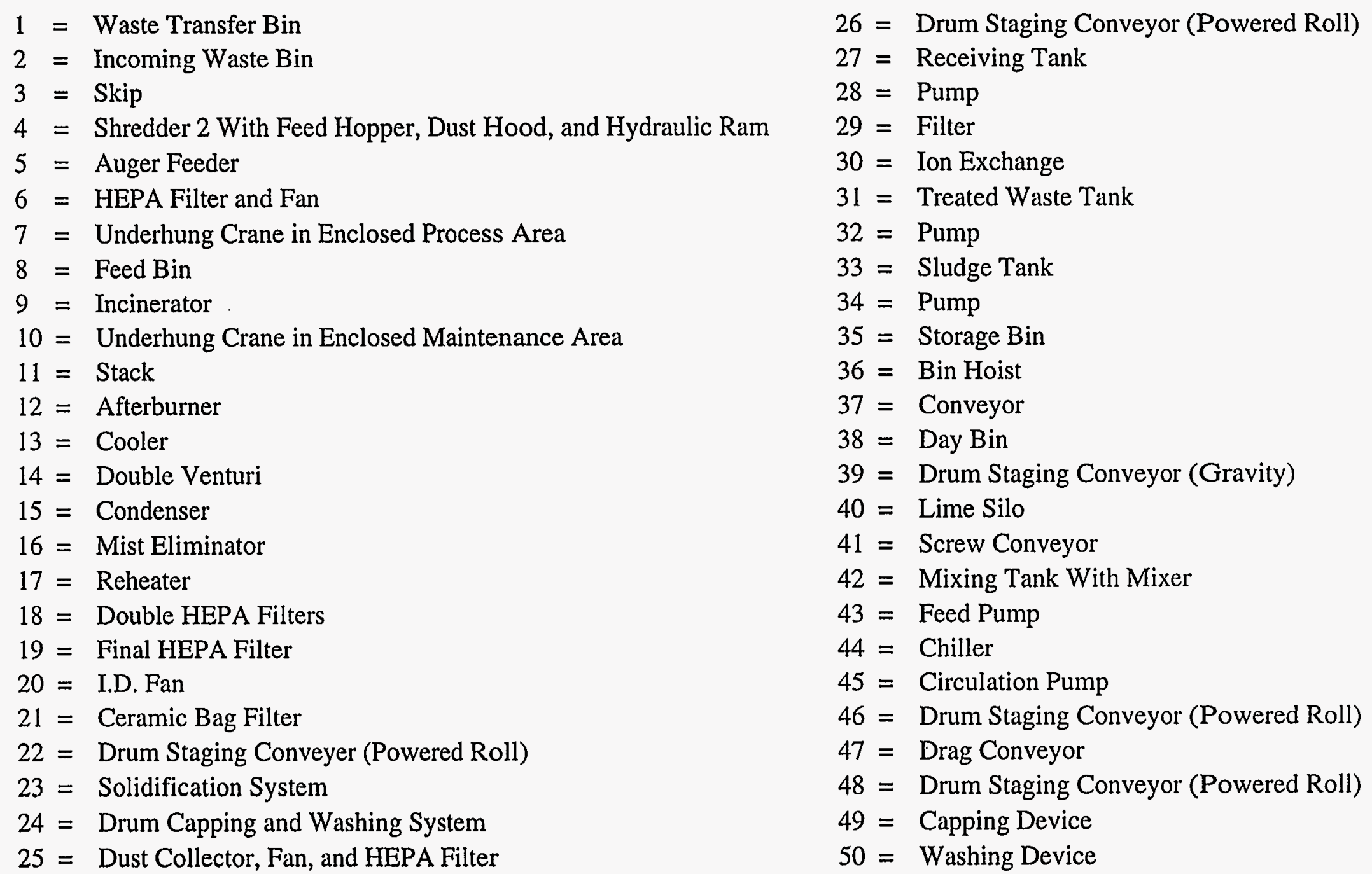
of 2 and the associated performance requirements for its systems were assumed. Double-HEPAfiltration SSCs were assumed to be in place. The waste inventory at the time of the accident was based on the facility throughput at each site and included unique volumetric inventories and physical, chemical, and radiological compositions for each site for each alternative.

\subsection{EVALUATION OF SOURCE TERM PARAMETERS AND FREQUENCIES}

This section discusses the development of the frequency and source term data generally used across the waste types. The evaluation of the frequencies and source term parameters required not only generic data applicable to broad classes of accidents but also data specific to the various waste types to account for differences in the physical and chemical forms, the packaging used as primary containment, and the facilities used to store or treat that waste type. The final selection of data used for facility accidents for each waste type is discussed in further detail in the chapters describing the analyses for that waste type (Sections 3 through 8).

\subsubsection{General Handling Accidents}

The dominant contributor to worker risk from radiological or chemically hazardous releases is expected to result from mechanical breaches of waste containers in handling accidents. This expectation stems from the relatively high frequency of such occurrences and the proximity of the worker to the point of release in such operational incidents. Handling accidents include container breaches caused by package drops, by forklift or other vehicular impacts, by crane drops or crushing, and by overpressurization. The use of heavy equipment poses a potential for damage to waste packages either because of package handling or inadvertent collisions. For many facilities, such as WRAP (DOE 1991b,c) at Hanford and the RWMC (EG\&G 1993b) at INEL, cranes are used to move drums and boxes, with the height of movement generally exceeding the nominal 1.2-m (4-ft) height design specification for drum integrity (Type A package; Code of Federal Regulations, Title 49 [49 CFR Part 173]) in the event of a drum drop. In all facilities, crushing of drums or boxes caused by impact with trucks, forklifts, and other equipment is possible. Although one waste container would generally be breached in an accident, the rupture of multiple containers could occur in instances when several containers are handled at a time.

Handling accidents during treatment processes entail minor hazards to the operating staff. Hazards include puncture wounds during waste sorting, minor contamination from glove failures, and minor spread of contamination from treatment equipment pressurization and off-gas treatment confinement failures (e.g., corrosion, gasket failures). The risk from exposure to radiation from these operational incidents is judged to be enveloped by the analysis for general handling accidents herein. 
The frequencies for chemical spills involving HW or LLMW were derived by using site-specific inventories of individual representative chemicals, along with the assumptions identified previously on frequencies of breach per operation. Conditional probabilities of fire or explosion of chemically reactive or combustible chemicals are also developed. These discussions are included in the sections on HW and LLMW accident analyses.

\subsubsection{Evaluation of Source Term Parameters}

For fall or crush damage scenarios in operations with stacked arrays, the MAR will generally vary from one to four packages, depending on the method of stacking and the arrangement of the array. Storage packages are typically (1) type A (49 CFR) plastic-lined, carbon steel, 208-L (55-gal) drums; (2) plastic-lined wooden boxes $(120 \times 120 \times 210 \mathrm{~cm}[4 \times 4 \times 7 \mathrm{ft}]$ or $60 \times 120 \times 210 \mathrm{~cm}$ [ $2 \times 4 \times 7 \mathrm{ft}$ ]); (3) TRUPACT-II standard waste boxes (metal boxes measuring $120 \times 120 \times 210 \mathrm{~cm}$ [ $4 \times 4 \times 7 \mathrm{ft}])$; or (4) ST -5 metal boxes $(120 \times 120 \times 120 \mathrm{~cm}[4 \times 4 \times 6 \mathrm{ft}])$. The Waste Isolation Pilot Plant (WIPP) final SAR (DOE 1990b) assumes that $25 \%$ of the package contents are spilled (i.e., a damage fraction of $2.5 \mathrm{E}-01$ ) for events dislodging the drum lid and that $10 \%$ of the waste package(s) are inadvertently punctured with forklift tines.

In the majority of handling accidents or hands-on processing incidents, the MAR would be limited to a single package. For more severe sequences involving an array of several containers being dropped or impacted in a single accident, the MAR would depend on the configuration but would be limited to the maximum number of packages in the array. Because the accident releases of greatest overall risk to the workforce involve single-drum handling operations where the worker is in contact with or very near to a breached package, a MAR of one drum is specified to calculate source terms for general handling accidents for all waste types.

The DF of the MAR subjected to spill, crush-impact, or overpressurization would depend on the location of the breach, the physical form of the MAR, and the severity of the accident stress. Liquids and volatiles would be free to flow out of a breached container, whereas most solid material would remain inside. Breached containers of LLW, LLMW, and TRUW are assumed to hold solid wastes, with a single-container DF of $2.5 \mathrm{E}-01$. Breached containers of $\mathrm{HW}$ are assumed to hold liquid, with a single-container DF of 1 for the representative handling accidents analyzed herein.

The physical and chemical composition of the MAR in storage was defined by weighting the relative treatability category inventories at each site. 


\subsubsection{Evaluation of Frequencies}

Numerous frequency estimates for waste package breaches in a facility are reported although facility inventories are generally not reported in existing safety analyses. The SAR for the RWMC (EG\&G 1993b) estimates an annual frequency of external drum breach of $1.4 \mathrm{E}+00 / \mathrm{yr}$ per facility. The EIS for new production reactor capacity (DOE 1991d) estimates a total annual frequency of externally induced drum breaches of $2.0 \mathrm{E}-02 / \mathrm{yr}$ and a rate of vehicular crashes of $1.8 \mathrm{E}-02 / \mathrm{yr}$. Published joint probabilities for a drop from a crane and for the drum or container to breach range from 1.2E-01 to 8.0E-02/yr per facility. The various WRAP studies (DOE 1991b,c; WHC $1991 \mathrm{a}, \mathrm{b}$,$) assume that 10 \%$ of dropped containers are breached. A low value $(8.0 \mathrm{E}-02 / \mathrm{yr})$ has been estimated for damaging packages during loading drums into TRUPACT containers, which is similar to an estimate for breaching drums during railcar loading (1.1E-01/yr). A higher value of $1.2 \mathrm{E}-01 / \mathrm{yr}$ was estimated for damage during the retrieval and restorage of buried TRUW drums and boxes at INEL (DOE 1992a). This value is assumed to be more applicable to TRUW because of the large number of package movements required in the operations of the storage facilities. A frequency of 7.5E-02/yr has been estimated for puncturing up to two packages with forklift tines or, in some fashion, damaging one or more waste packages during heavy-equipment operation (e.g., dislodging the top tiers of a four-package-high array).

The approach used herein was to develop an estimate of the frequency of mechanical breaches for general handling operations on a per-operation basis, with an operation defined as picking up, moving, and setting down a container. The SAR for the HWSF (EG\&G 1990) uses an estimated frequency of 1 drum breached per 10,000 operations, on the basis of analyses at the Rocky Flats Environmental Technology Site (RFETS). A fault tree analysis of container rupture at the HWSF resulted in a probability of $3.0 \mathrm{E}-03$ of an operation error, with a conditional probability between $2.0 \mathrm{E}-03$ and $1.0 \mathrm{E}-02$ for drum breach after an impact, depending on the type of container, or $1.0 \mathrm{E}-01$ for drum piercing. Although several handling errors are considered, this analysis leads to a frequency of rupture between $6.0 \mathrm{E}-01$ and $3.0 \mathrm{E}+00$ for every 10,000 operations. The WIPP fire hazards analysis (DOE 1991a) used a frequency of 5.0E-05 failures per forklift operation when a crew of two is performing the handling operations. A value of $1.5 \mathrm{E}-04$ accidents per forklift operation, with a conditional probability of $2.5 \mathrm{E}-01$ for drum rupture, leading to a breach frequency of 4.0E-05, was used in a probabilistic safety analysis of a LANL facility (Sasser 1992). The LLMW systems analysis (EG\&G 1992c, 1993a) used a value of 1.0E-03 drum breaches per operation but included very minor breaches and spills. Finally, analysis of actual event data at the SRS resulted in a forklift drum drop probability of 5.0E-05 per operation and a drum piercing probability of 3.0E-05 per operation (WSRC 1994b).

On the basis of all of these studies, a probability of $1.0 \mathrm{E}-04$ per operation for significant drum breaches, consistent with the aforementioned estimates of source term parameters, was used in the analysis herein. To apply this operational failure probability to storage area facilities, residency times in the interim storage area, which vary greatly, must be considered. Most areas are 
simply staging areas for treatment or disposal operations. Generally, for such staging areas, two handling operations would occur, one for receiving and one for removal. Thus, the expected annual frequency $\left(f_{m b}\right)$ of a container breach for waste product $x$ caused by a handling accident is

$$
f_{m b}=0.0002 \times n_{x},
$$

where $n_{x}$ is the number of waste containers of waste product $x$ received annually. To convert this value to a throughput number, a conservative assumption was made that the complete inventory turns over each year. Then the expected annual frequency of significant mechanical breaches is given by

$$
f_{m b}=0.0002 \times N
$$

where $N$ is the capacity of the facility in number of drums.

The previous frequency estimate should envelop frequencies of breach of postprocessing storage containers that contain immobilized residues from treatment. With the exception of potential gas generation and pressure buildup, no significant breach mechanisms are present. For miscellaneous TRUW solids, the SAR for the RWMC (EG\&G 1993b) includes a facility frequency estimate of 2.1E-02 events per year for severe internal stresses such as a hydrogen pressure buildup from radiolysis of cellulose material or other gas-generating mechanisms. Thus, the operational estimate of Equation 2.4 envelops this facility estimate.

The frequencies for container damage internal to a treatment facility would also be expected to be lower than those for lag storage because of the significantly lower inventory of drums and reduced drum vulnerability during handling. The estimate for metal-box drop and breach was 1.0E-02/yr for WRAP Module 2 (DOE 1991c). A value of 3.8E-02/yr is estimated for the crane-drop scenario for the WRAP Module 1 facility (WHC 1991b). For processing facilities, fewer drums and other packages are handled per year than would be the case for the range of potential operations of the lag storage areas (e.g., consolidation of the contents of a number of waste pads onto a new pad). Furthermore, the operating conditions internal to a processing facility are superior to those for outside pads in terms of equipment reliability and working environment.

An approach similar to that discussed previously is used for estimating container breaches from operational events involving canisters of vitrified HLW. The glass product is noncombustible, and the stainless steel canister used as a container for the glass offers a high degree of protection from external incidents (e.g., the HLW canisters are designed to be dropped from a height of $9 \mathrm{~m}$ [30 ft] without loss of integrity). Beyond $9 \mathrm{~m}$ ( $30 \mathrm{ft}$ ), the integrity of the canisters is uncertain (e.g.,

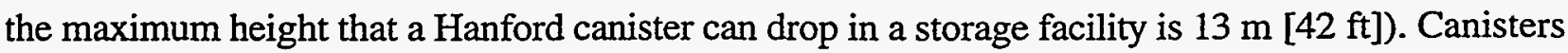
are probably most vulnerable to damage during transfer from the on-site canister transporter into the vault tube (Braun et al. 1993). On the basis of this observation, the only accident analyzed for the 
glass storage facility is an operational event involving the crush impact of a glass canister. Given that a simple drop of a canister (from a height less than $9 \mathrm{~m}[30 \mathrm{ft}]$ ) would not result in a breach, canister rupture would require the drop of a heavy structure (e.g., crane or concrete cover) on top of a canister during handling.

The estimated frequency for a canister breach for the Hanford glass storage facility, which would handle approximately 370 canisters, is $4.0 \mathrm{E}-03 / \mathrm{yr}$ (Braun et al. 1993). By assuming that the annual frequency of a canister breach depends on the number of canisters, which is taken to be equal to the annual rate of canister production, frequency for an HLW breach is

$$
f_{H L W}=0.004 / 370=0.00001 / \text { Canister } \text {. }
$$

Thus, the frequency for canister break at SRS is approximately 4E-03/yr, on the basis of an annual production rate of 410 canisters per year. The WVDP will handle approximately 100 canisters per year, and the annual frequency for canister break is therefore $1 \mathrm{E}-03 / \mathrm{yr}$. The preliminary design at Hanford assumes a production rate of 890 canisters per year, leading to a frequency of $9 \mathrm{E}-03 / \mathrm{yr}$.

The frequencies for chemical spills involving HW or LLMW are derived using site-specific inventories of individual representative chemicals, along with the assumptions identified above on frequencies of breach per operation. Conditional probabilities of fire or explosion of chemically reactive or combustible chemicals are also developed. These discussions are included in the sections on HW and LLMW accident analyses.

\subsubsection{Storage or Staging Area Accidents}

The major concern with storage and some staging facilities is the large inventory of waste in a centralized area and releases during accidents involving fires or explosions. The sections that follow summarize the accident types considered that would affect either dedicated storage areas or areas for staging waste prior to treatment. The discussion is generic in that it is not tied to a specific treatment process or waste type. The final determination of source term parameters for $\mathrm{HW}$ storage accidents is discussed in the section addressing that waste type. Both internally initiated accident sequences and external events were taken into account.

\subsubsection{Internally Initiated Fires}

Internally generated facility fires generally occur because of ignition of fuel sources, combustion of rubbish, or spontaneous combustion of the contents of a waste package. Combustible or flammable fuel sources include diesel fuel or gasoline for tractors, trucks, or other vehicles, and 
natural gas or fuel supplied to a storage area for space heating. Combustible rubbish fires generally result from poor housekeeping and are probably the principal cause of minor facility fires. Spontaneous combustion of the contents of a waste package has been reported (DOE 1990a) but is considered unlikely.

Design and operational safeguards are in place to prevent propagation from a localized source, such as a single package or drum or a rubbish pile, to a much larger inventory. Packages for combustible materials are either steel drums, fire-resistant boxes, or fire-protected shipping containers. Moreover, sites are generally bound by RCRA to segregate storage by waste form compatibility and RCRA category; therefore, combustibles are segregated. Finally, most facilities have fire detection and suppression capabilities from fire watch or operator surveillance, automatic sprinkler systems, fire barriers, or on-site fire department response (or some combination of these types of protection). As a result, fires can be categorized as either local fires involving very limited inventories of wastes or, at the other end of the spectrum, as major facility fires induced by forces that provide a source of fuel (such as gasoline) and that also disable or overwhelm any available safeguards. Accidents affecting staging-area waste packages can generally be enveloped by those affecting storage areas because of the similarity of the primary containment (packaging), and are included herein.

Evaluation of Source Term Parameters. The MAR in all storage scenarios is limited to the number of packages exposed to the fire, which depends on the storage configuration and the detection of and response to the fires. The DF is a strong function of the packaging and the physical form (and combustibility) of the MAR. Two categories of fires were considered: waste-container fires and facility fires. The former were assumed to have a MAR equivalent to the contents of a single 208-L (55-gal) drum and to have a DF of 1 . The representative fire in a storage facility was assumed to encompass the spectrum of undetected or unsuppressed fires, and the entire facility's inventory of waste was assumed to constitute the MAR. A DF of 1.0E-01 was assumed as a generic value to account for segregation and separation of waste packages in the facility and for the nature of the waste packaging as described previously.

Evaluation of Frequencies. Reported fire-initiator frequencies for drum storage (DOE 1990b; Salazar and Lane 1992; EG\&G 1993b) for operationally related events range from $1.0 \mathrm{E}-03 / \mathrm{yr}$ to $2.0 \mathrm{E}-04 / \mathrm{yr}$. The higher value is estimated for general miscellaneous combustibles. The lower value is also fairly typical of estimates for scenarios involving ignition of leaking fuel or natural gas. Because some references distinguish between operationally generated waste and the packaged waste being stored, the upper value is probably associated with poor housekeeping. For fire initiating in a waste package, frequencies on the order of 9.2E-04/yr have been reported for the RWMC (EG\&G 1993b). This range of values is inferred to apply to storage situations involving minimal intervention by operators. Fire frequencies associated with fuel from transport vehicles, 
cranes, and forklifts range from 3.3E-03/yr to 8.3E-04/yr for initiation (Davis and Satterwhite 1989; EG\&G 1993b). Fires resulting from subsequent ignition upon violent breach of TRUW drums can be envisioned because of hydrogen buildup from alpha activity in contact with cellulose material (DOE 1990a). Although the frequencies for waste-package damage scenarios are variously estimated, conditional probabilities for ignition and fire following package breach are not reported but would be higher for TRUW than for LLW and LLMW, for which hydrogen buildup is much less likely.

Because of the relative infrequency of a single-container fire and the much greater consequences of fully developed facility fires, only the latter were analyzed for source term development for the WM PEIS. The estimated annual frequency for a fully developed facility fire with the source term parameters defined previously is $1.0 \mathrm{E}-04 / \mathrm{yr}$. This frequency is the product of a generic facility fire frequency of $1.0 \mathrm{E}-02 / \mathrm{yr}$ and a fire suppression system failure probability of 1.0E-02 (DOE 1982b). This value is consistent with existing documentation and is judged to be reasonable in light of the existing preventive and mitigative safeguards discussed previously.

\subsubsection{Internally Initiated Explosions}

Explosion scenarios for packaged wastes can be postulated for LLMW, TRUW, and HW. Most LLMW accident analyses focus on storage of miscellaneous organic liquid waste (e.g., benzene at the SRS [WSRC 1994a]), where blankets of inert gas serve to preclude ignition and detonation. Most TRUW analyses focus on the accumulation of hydrogen or methane from radiolysis of organics, with subsequent ignition and detonation. Inadvertent chemical reactions are considered for HW but should be unlikely because waste sorting and segregation at the point of generation act to preclude combining reactive materials and oxidants. Storage activities are generally not climate controlled, but heating gas is a candidate source for explosion where some control is maintained. Postprocessing storage is less of a problem than pretreatment storage because of the greater stability of the final forms (e.g., grout).

Damage to packages from an explosion is governed by projectile behavior and the location and configuration of the package. One type of array is a four-tier-high stack of two pallets, each holding a two-drum-high, tightly packed array of four drums (Salazar and Lane 1992). Here, the number of drums that could be directly affected by projectile impact would be five, although the array could be toppled, or other ancillary damage (e.g., to adjacent arrays) could be envisioned. A similar rationale applied to waste boxes would indicate two affected adjacent boxes.

Evaluation of Source Term Parameters. The MAR for an explosion would generally be

limited to a single package because very little explosive energy is typically associated with currently generated wastes, and extrapolation of scenarios to include high-energy projectiles is difficult. The 
DF for explosions internal to a container would be 1 (i.e., the entire contents of the package are assumed to be affected). This damage is judged to conservatively envelop any projectile damage to nearby packages. For external explosions, projectile damage to a waste package is similar to puncture of a package; and a damage ratio of $2.5 \mathrm{E}-01$ or $1.0 \mathrm{E}+00$ would be expected, depending on whether the contents are solid or liquid.

Evaluation of Frequencies. The WRAP Module 1 at the Hanford site (WHC 1991a) considered various potential explosions for CH-TRUW and LLW operations and assigned a frequency range of $1.0 \mathrm{E}-06 / \mathrm{yr}$ to $1.0 \mathrm{E}-04 / \mathrm{yr}$ for a drum exploding because of hydrogen buildup during storage in the shipping and receiving area (after receipt). Presumably, the hydrogen resulted from radiolytic decomposition of water or hydrocarbons, which is plausible for TRUW but unlikely for LLMW. A glove box (sorting area) explosion frequency of 6.3E-05/yr was estimated for opening a RH-TRUW drum containing a hydrogen-air mixture with failure to vent, failure to detect, and ignition.

Because of the relative infrequency of single-container explosions, the lack of any known large-scale explosions, and the similar airborne releases in severe fire scenarios, radiological source terms for explosions in storage and staging areas were not judged sufficiently important to risk to justify source term development. Moreover, this risk is considered to be enveloped by that of facility fires. Explosions from chemical reactions were identified with the release rates discussed in Section 8.

\subsubsection{External Event Accident Sequences}

External event challenges are important to the human health risk from radiological releases insofar as they have the potential to create fires or explosions that can disperse and render airborne radioactive waste materials. As discussed in Section 2.3.1, plausible external accident initiators leading to direct fire and explosion scenarios include impacts from military, general aviation, or commercial aircraft; impacts from large trucks carrying fuel or chemicals; and fuel or process chemical fires and explosions in nearby facilities or storage tanks. Natural phenomena such as earthquakes can cause natural gas, fuel, or process chemical fires and explosions in nearby facilities. The severity of such phenomena makes mitigation by on-site fire brigades unlikely.

Event trees described in Appendix $G$ are used to model the accidents caused by external events and to project the progression of the accidents through plausible generic sequences. The event tree methods are based on accepted probabilistic risk assessment methods and are consistent with methods prescribed by the NRC, the American Institute of Chemical Engineers, and the DOE. Accident sequences are developed for aircraft impacts (small and large aircraft are considered separately) and seismic events. As discussed in Section 2.3.1, the safety impacts of aircraft accidents 
envelop impacts for other man-made severe external challenges, and the damage and safety impacts from seismic events generally envelop effects from other natural phenomena. These accident initiators and the associated accident sequences are developed for the designs for the generic facilities described in Section 2.5. The results are covered in the chapters on specific waste types.

\subsubsection{Treatment Facility Accidents}

The major concern with treatment facilities is fire- or explosion-driven releases of process inventories that are often much more concentrated than the inventories of waste in current storage. This section summarizes the accident types considered for analysis and the development of appropriate source term and frequency parameters. The external events were primarily analyzed for their potential to initiate the same process accidents that could arise from operational causes. External initiators can trigger accident sequences of the same type as operational events, mainly spills and fires. Spills and fires induced by external events are expected to affect a larger amount of waste. Therefore, operational events will not represent the limiting accidents. Event trees were also developed in Appendix $G$ to structure and facilitate the evaluation of the external event sequences

for treatment facilities. As for storage facilities, the results for the internal and external events are shown in the sections for each waste type.

\subsubsection{Treatment Process Incidents}

In general, the processes of the generic treatment facility described in Section 2.5 entail minor hazards to the operating staff, including puncture wounds during waste sorting, minor contamination from glove failures, and minor spread of contamination from the events of treatment equipment pressurization, from spills, and from off-gas treatment confinement failures (corrosion, gasket failures, etc.). Such minor operational incidents in treatment have been folded into general handling accidents and, as a result, are not discussed further.

\subsubsection{Off-Gas System Failures}

Potential on-site and off-site effects may result from failure of the off-gas treatment system to perform as designed or from introduction, into the off-gas treatment, of species for which the treatment steps are ineffective (e.g., noble gases, volatile radionuclides such as $\mathrm{H}-3$, or hightemperature conversion of dichlorodifluoromethane.[Freon] to phosgene); but off-gas events tend to be minor because of the high gas sweep-rate and the inertness of the off-gas constituents relative to the chemically reactive radionuclides and hazardous materials given off during facility fires or explosions. The on- and off-site risks from such accidents are enveloped by potential facility fires or explosions that involve chemically reactive releases of nuclides and chemicals that have extended 
residence times in the body. Thus, abnormal operation of the off-gas systems is not considered further.

\subsubsection{Treatment Process Vessel Accidents}

Aqueous processes to remove RCRA contaminants entail storage in tanks, transfer pumps, vessels and pipe lines, and reaction vessels. The class of accidents associated with storage and related transfer operations was determined in Section 2.6.2 to be unimportant to risk for LLMW and TRUW and irrelevant to WM PEIS alternatives for HLW management. On the basis of inventories of the various waste types and identified treatment technologies, wet-air oxidation of LLMW was selected as a potentially risk-dominant process. However, details of the process and related system descriptions were inadequately specified in the WM PEIS to allow detailed accident analyses.

Consequently, source terms for wet-air oxidation were analyzed by using MAR and facility containment parameters consistent with those used to analyze accidents involving incineration facilities (discussed below). This approach allows an order-of-magnitude scoping of the risks of wet air oxidation process accidents and provides a reasonable relative risk comparison with incineration accidents. The MAR was assumed to be the entire contents of the vessel $(D F=1)$, which was assumed to hold $1 \%$ of the annual wet-air oxidation throughput at the site. The radiological composition at each site for each alternative was obtained from the waste management database (Kotek et al. 1996). An earthquake was the only plausible accident capable of rupturing the process vessel and at the same time defeating the facility containment integrity and filtration systems. For conservatism, the airborne release was assumed to be pressurized, with RARFs chosen accordingly.

\subsubsection{Treatment Facility Fires}

Two categories of fires at treatment facilities have been considered: (1) operation-specific fires developed from consideration of the characteristics of a particular treatment technology or the related process and facility characteristics, and (2) generic fires. Existing on-site safety documentation has been reviewed to develop the source terms and frequencies associated with plausible accident sequences for the first category, which includes fires in incinerator facilities. The CIF analysis (DuPont 1989) treats the fire initiator potential of the incinerator system as governed by the nature of the feedstocks and attributes the initiation of fire to (1) spontaneous combustion of solid waste in lag storage or (2) ignition of contaminated organic liquids in storage. The Waste Experimental Reduction Facility (WERF) (EG\&G 1993b) analysis considered a fire in the baghouse of the filtration system. Both analyses were used to define a reference scenario, as discussed below.

Facility or facility operations characteristics other than those associated with the treatment process can clearly be correlated with the occurrence of fire. These characteristics include the 
presence of highly combustible materials (or materials that can undergo spontaneous combustion, such as dried tetraphenylborate salts), the existence of activities involving these materials (such as machining of pyrophorics), maintenance activities (such as welding) that involve fuel and ignition sources, and building characteristics such as the heating and electrical distribution systems (especially switchgear). The assumption is that these characteristics are reflected in the generic database used to establish the generic data on fire frequency discussed below. Site-specific analyses include ignition of the contents of a breached drum and general room fires (Salazar and Lane 1992). In general, existing LLW and TRUW safety analyses seem to focus less on facility fires than on other accidents; for example, analyses for the various Hanford WRAP modules mention but do not analyze fires. Engineering judgment, which is based, in part, on the information developed herein and largely presented in Appendix $\mathrm{C}$, has been used to assign reasonable source term and frequency parameters to generic facility fires.

Evaluation of Source Term Parameters. The representative incineration-facility fire used to envelop radioactive releases is based largely on information for the WERF (EG\&G 1993b). The assumption that a fire starts in the baghouse of the filtration system and propagates to the HEPA filters is plausible because of the high temperatures of the material entering the baghouse. The fire causes the housing seals to fail on the baghouse and the filters, thereby yielding a direct release of fly ash to the atmosphere. The total ash inventory accumulated in the baghouse and the HEPA filters is assumed to constitute the MAR. It has been assumed that the ash fed to the baghouse during the fire, if the facility has not shut down, is a small fraction of the ash accumulated in the baghouse, and it is therefore neglected in the calculations. The MAR was estimated by averaging the fractions of the total facility ash inventories in the CIF and the Process Experiment Pilot Plant (PREPP) actually present in the baghouse and HEPA filters, a value of roughly 3.0E-02 (DuPont 1989). All of the baghouse and HEPA filter ash was assumed to be affected by the fire, resulting in a DF of 1 . Any subsequent explosions of accumulated waste ready to be incinerated were judged to be enveloped by the dispersion of ash. A more detailed description of the external events analyses can be found in Appendix G.

The representative incineration-facility fire for HW used to envelop hazardous releases assumes that the fire engulfs the feedstock. For further information, refer to the HW analysis in Section 8.

Evaluation of Frequencies. Fire frequencies for production operations are based on occurrences in the SRS data bank for the operations in the SRS 200 Area, and on other industrial experience. The frequency of spontaneous ignition of accumulated combustibles (poor housekeeping) is 5.0E-01/yr if (1) pyrophorics or (2) nitric acid and cellulose are available. The CIF analysis (DuPont 1989) assigned a value of $2.6 \mathrm{E}-02 / \mathrm{yr}$ for fire initiation in the lag storage area for cardboard boxes, on the basis of general experience with spontaneous combustion for $\mathrm{F}$ and $\mathrm{H}$ 
Canyon operations. The SAR for the CIF also addressed the possibility of a fire involving waste organic feedstock (5.0E-03 per tank per year, with three tanks). Maintenance activities, depending on the circumstances (confined-space welding, use of greenhouses, etc.), initiate fires with a frequency of $3.0 \mathrm{E}-01 / \mathrm{yr}$ to $2.0 \mathrm{E}-01 / \mathrm{yr}$. Fires from electrical shorts have similar frequencies. The expected frequency for a process-related fire in a canyon facility has been estimated to be $1.5 \mathrm{E}-02 / \mathrm{yr}$ on the basis of experience with the $\mathrm{F}$ and $\mathrm{H}$ Canyons of the SRS (WSRC 1994a).

Analysis of actual event data at the SRS indicates a failure probability for manual fire suppression of 1.0E-01 to 5.0E-01 per demand, assuming the fire is detected (WSRC 1994b). Most SARs use a reasonably conservative value of $1.0 \mathrm{E}-02$ per demand for failure of automatic fire suppression systems on the basis of the DOE study (DOE 1982b). More recent analyses of Hazard Category 2 facilities indicate a greater reliability for wet pipe sprinkler systems. Typical site-specific values range from $5.0 \mathrm{E}-02$ to $1.0 \mathrm{E}-03$ per demand for a fire department to fail to respond. Also, the SRS data indicate a probability range of $3.0 \mathrm{E}-02$ to $3.0 \mathrm{E}-01$ for the fire department to successfully put out the fire. Because this analysis presumes either automatic or manual fire detection and notification, either or both are required for any credit to be taken.

The EIS for the WIPP (DOE 1990a) applies a frequency of 1.0E-03/yr for a fully developed fire in an operating area, as derived from RWMC documentation. The previously cited Electric Power Research Institute study (EPRI 1979) estimates 1.0E-02/yr for a fully developed fire (on the basis of a generalized fire initiator of $1.0 \mathrm{E}-01 / \mathrm{yr}$ ). General estimates of fire initiator frequencies (for TRUW processing and handling activities) for RFETS range from 5.0E-02/yr to 5.0E-01/yr on the basis of facility-specific experience (e.g., Building 910 [EG\&G 1992a]). The RWMC analyses (EG\&G 1993b) are predominantly focused on fires initiated by helicopter crashes (in various locations), typically with a frequency of $1.2 \mathrm{E}-05 / \mathrm{yr}$ to $5.4 \mathrm{E}-05 / \mathrm{yr}$. Other sites are more concerned with external challenges from aircraft crashes and earthquakes. Aircraft fuel, ruptures of natural gas pipelines, and spilled organic liquids in storage facilities constitute the combustible or ignitable source for these challenges.

The estimated frequency for a fully developed facility fire used herein is $1.0 \mathrm{E}-03$, consistent with WIPP estimates. This includes a generic fire frequency of $1.0 \mathrm{E}-01$ and a fire suppression system failure probability of $1.0 \mathrm{E}-02$. In light of safeguards associated with Hazard Category 2 facilities, this estimate is judged to be conservative. For the HW feedstock fire, refer to the HW analysis in Section 8.

\subsubsection{Treatment Facility Incinerator Explosions}

Except for incineration and wet-air oxidation (of mainly aqueous wastes, with less severe consequences), no significant explosion initiators were identified for processing. Failure of a wet-oxidation unit would result in a pressurized spray release. Nitrated organic reactions at high 
temperatures in evaporators and dryers were discounted in the SARs for RFETS Buildings 910 and 374 (EG\&G 1992a,b) because (1) alkaline solutions do not react significantly, (2) heavy metals are absent, and (3) processes are at low pressure. In general, the accident literature for evaporation focuses primarily on accidents involving loss of filtration; however, unlike many processing activities, incineration has a potential for accumulations and leaks of combustible gas, with a possibility for explosions.

Evaluation of Source Term Parameters. The assumption is that the explosion (which could potentially occur because of the existence of fuel, oxygen, and high temperatures) takes place inside the rotary kiln incinerator. The MAR was derived by averaging the ash inventory at the CIF and PREPP in the kiln incinerator and was determined to be $12 \%$ of the total ash inventory existing in the facility. All of the waste present in the rotary kiln incinerator was conservatively assumed to be affected by the explosion, for a DF of 1 .

Evaluation of Frequencies. The safety analysis for the CIF, which is designed to accommodate LLW but includes various RCRA wastes as candidate feedstocks, estimates an annual frequency of $1.5 \mathrm{E}-02 / \mathrm{yr}$ for explosions in the rotary kiln assembly and the SCC, respectively. Because it envelops the other estimates, the CIF-estimated frequency of $1.5 \mathrm{E}-02 / \mathrm{yr}$ is used herein. A frequency of 2.9E-04/yr for an explosion during RWMC processing activities was estimated (no unit operation is specified), with a frequency for a facility room fuel-air explosion estimated at 2.0E-04/yr (previously reported values were as low as 5.0E-07/yr). A more refined and detailed analysis estimated that conditions conducive to an explosive event exceeding the $100-\mathrm{kPa}$ (15-psig) capability of the vessels could occur at a frequency approaching 3.0E-02/yr. Such overpressures could potentially rupture the vessels and release the contents. Various INEL studies cite an explosion frequency of $1.0 \mathrm{E}-04 / \mathrm{yr}$, derived primarily from earlier analyses to support operations of the RWMC/Solid Waste Experimental Power Plant (SWEPP) with TRUW solid feedstock (EG\&G 1993b).

The post-treatment stored waste may be presumed to be more stable (depending on the method of immobilization) and more robustly packaged. The only qualitatively defined scenario entails a propane gas leak with ignition. The SAR for RFETS Building 910 assigned a conservative value of $4.4 \mathrm{E}-02 / \mathrm{yr}$ for a heating gas-line rupture and ignition to impact postprocessing material stored in the processing facility. Because the source term for this accident is much smaller than that for the rotary kiln explosion, this sequence was not developed further. 


\subsubsection{Summary of Data Used}

A summary of the key generic source term and frequency parameters discussed in the preceding sections is presented in Table 2.4. Although the values actually applied for the accidents for individual waste types are summarized in Sections 3-8, these values are largely based on this table. The MAR units in the facility inventory were converted to $\mathrm{Ci}$ for each waste type and DOE site with the information provided in the WM PEIS waste characterization database. The activity was then distributed into the corresponding radionuclides in the source term files used for consequence calculations.

\subsection{SELECTION AND CALCULATION OF FINAL SOURCE TERMS}

The source term information discussed previously was combined with selected unit-risk factors to develop preliminary screening estimates of the impacts of the accident sequences in order to determine the risk-dominant scenarios. Unit-risk factors were developed to estimate the health effects on the exposed populations from releases of unit amounts of radionuclides or hazardous chemicals (see WM PEIS Appendix D). This involved (1) the development of or integration of existing information on the site-, facility-, and treatment-specific demographics to characterize the workforce and general population potentially exposed to hazardous material and (2) the development of the meteorologic and release dynamics and characterization data necessary for calculating the transport of radioactive or toxicological plumes to the exposed population. Final source terms for the scenarios most risk-dominant to public rịsk were then developed based on importance to risk to the maximally exposed individual (MEI) at the site boundary. The final risk-dominant accident sequences selected were at or near the maximum "reasonably foreseeable" accidents.

The calculation of the source terms merged the frequencies and source term parameters for the accident sequences with the inventory characterization for the MAR. The computational framework and interaction of the code packages is illustrated in Figure 2.7. Preliminary results of the operational and external event accident sequences described previously were screened for each waste type for the sites defined in the various alternatives for waste management. Ranking of the accident sequences for risk dominance at each site was performed using the frequency-weighted dose to the MEI as the screening criterion. Source terms were also selected from risk-dominant sequences in the following annual frequency categories: $>1.0 \mathrm{E}-02$, between $1.0 \mathrm{E}-02$ and $1.0 \mathrm{E}-04$, between $1.0 \mathrm{E}-04$ and $1.0 \mathrm{E}-06$, and $<1.0 \mathrm{E}-06$. The selected source terms were then used to perform the health effects calculations for radiological and chemical releases from facility accidents. The complete set of sequences, with classification of their frequency categories, is shown in Sections 3-8. A representative list of sequences is presented in Table 2.5. The final calculation of the health effects for both general and workforce populations by using the source terms described herein is reported in WM PEIS Appendix D (DOE 1996). 
TABLE 2.4 Frequency and Source Term Parameters for General Handling and Internal Facility Accidents

\begin{tabular}{|c|c|c|c|c|c|c|}
\hline \multirow[b]{3}{*}{ Event } & \multirow{2}{*}{\multicolumn{2}{|c|}{$\begin{array}{l}\text { Reported Annual } \\
\text { Frequencies }\end{array}$}} & \multirow{3}{*}{$\begin{array}{l}\text { WM PEIS } \\
\text { Frequency } \\
\text { Estimate } \\
\text { per Year }\end{array}$} & \multicolumn{3}{|c|}{$\begin{array}{l}\text { Reported or Representative } \\
\text { Source Term Parameters }\end{array}$} \\
\hline & & & & \multirow[b]{2}{*}{ MAR } & \multirow{2}{*}{$\begin{array}{l}\text { MAR } \\
\text { Units }\end{array}$} & \multirow[b]{2}{*}{ DF } \\
\hline & Low & High & & & & \\
\hline \multicolumn{7}{|l|}{ General Handling Accidents } \\
\hline \multicolumn{7}{|l|}{ Packaged Wastes } \\
\hline Crane drop with impact and breach & $8.0 \mathrm{E}-02$ & $1.2 \mathrm{E}-01$ & - & 1 & Package $^{b}$ & $2.5 \mathrm{E}-01$ or $1.0 \mathrm{E}+00^{\mathrm{C}}$ \\
\hline Forklift puncture with impact, breach, and spill & $-\mathbf{a}^{\mathbf{a}}$ & $7.5 \mathrm{E}-02$ & - & 2 & Package & $1.0 \mathrm{E}-01$ or $1.0 \mathrm{E}+00^{\mathrm{c}}$ \\
\hline Internal overpressurization and breach & - & 2.1E-02 & - & 1 & Package & - \\
\hline Toppled stacked array & - & $7.5 \mathrm{E}-02$ & - & 4 & Drum & $2.5 \mathrm{E}-01$ or $1.0 \mathrm{E}+00^{\mathrm{c}}$ \\
\hline Representative breach and rupture & - & - & $2.5 \mathrm{E}-04^{\mathrm{d}}$ & 1 & Drum & 2.5E-01 or $1.0 E+00^{c}$ \\
\hline \multicolumn{7}{|l|}{ Flres in Storage or Staging Areas ${ }^{e}$} \\
\hline Spontaneous-combustion fire & $2.6 \mathrm{E}-02$ & $5.0 \mathrm{E}-01$ & $\mathbf{f}$ & $1.0 \mathrm{E}+\infty$ & Drum & $1.0 \mathrm{E}+00$ \\
\hline Small fuel or chemical fire & $8.3 E-04$ & $3.3 E-03$ & f & 2 & Drum & $1.0 \mathrm{E}+00$ \\
\hline Facility fire & $2.0 \mathrm{E}-04$ & $1.0 \mathrm{E}-03$ & f & $\mathbf{g}$ & Drum & $1.0 \mathrm{E}+00$ \\
\hline Local manual-suppression failure & $1.0 \mathrm{E}-01 / \mathrm{d}^{\mathrm{h}}$ & $5.0 \mathrm{E}-0 \mathrm{l} / \mathrm{d}$ & - & - & - & - \\
\hline Automatic-suppression failure & - & $1.0 \mathrm{E}-02 / \mathrm{d}$ & - & - & - & - \\
\hline Fire brigade response failure & $3.0 \mathrm{E}-02 / \mathrm{d}$ & $3.0 \mathrm{E}-01 / \mathrm{d}$ & - & - & - & - \\
\hline $\begin{array}{l}\text { Representative facility fire } \\
\text { without mitigation }\end{array}$ & - & - & $1.0 \mathrm{E}-04$ & $\mathbf{g}$ & Drum & $1.0 E-01$ \\
\hline \multicolumn{7}{|l|}{ Explosions in Storage or Staging Areas } \\
\hline \multicolumn{7}{|l|}{ Packaged Waste (LLMW and TRUW only) } \\
\hline Spontaneous combustion or explosion & $1.0 \mathrm{E}-06$ & $1.0 \mathrm{E}-04$ & - & 1 & Drum & $1.0 \mathrm{E}+00$ \\
\hline Representative explosion & - & - & f & - & - & - \\
\hline \multicolumn{7}{|l|}{ Fires in Treatment Facillties } \\
\hline \multicolumn{7}{|l|}{ Facility fire } \\
\hline Local manual-suppression failure & $1.0 \mathrm{E}-01 / \mathrm{d}$ & $5.0 \mathrm{E}-01 / \mathrm{d}$ & - & - & - & - \\
\hline Automatic-suppression failure & - & $1.0 \mathrm{E}-02 / \mathrm{d}$ & - & - & - & - \\
\hline Fire brigade response failure & $3.0 \mathrm{E}-02 / \mathrm{d}$ & $3.0 \mathrm{E}-01 / \mathrm{d}$ & - & - & - & - \\
\hline \multicolumn{7}{|l|}{ Representative facility fire } \\
\hline without mitigation & - & - & $1.0 \mathrm{E}-03$ & 1 & $\begin{array}{c}\text { Baghouse } \\
\text { and HEPA } \\
\text { ash } \\
\text { inventory }\end{array}$ & $1.0 \mathrm{E}+00$ \\
\hline Explosions in Treatment Facilities & & & & & - & \\
\hline Spontaneous combustion or explosion & $1.0 \mathrm{E}-04$ & $1.5 \mathrm{E}-02$ & - & 1 & $\begin{array}{c}\text { Incinerator } \\
\text { kiln ash } \\
\text { inventory }\end{array}$ & $1.0 E+\infty$ \\
\hline Representative explosion & - & - & $1.5 \mathrm{E}-02$ & 1 & $\begin{array}{l}\text { Incinerator } \\
\text { kiln ash } \\
\text { inventory }\end{array}$ & $1.0 \mathrm{E}+\infty$ \\
\hline
\end{tabular}

A hyphen indicates data not available.

b A type A (49 CFR) 208-L (55-gal) plastic-lined carbon steel drum was chosen as the representative waste package for MAR calculations in determining source terms for all packaged waste breach or rupture events.

c Waste packages containing liquids were assigned a DF of $1.0 \mathrm{E}+00$.

d Per operation.

e Because of the focus of the WM PEIS alternatives and the low overall risk relative to drum or canister storage accidents in the WM PEIS program, source term analyses were not performed for tank storage.

- Because of the combined relative infrequency and low health impact of individual container fires and explosions, only facility fires were analyzed in the WM PEIS.

8 Total number of waste drums in facility.

h $\mathbf{d}=$ per demand. 


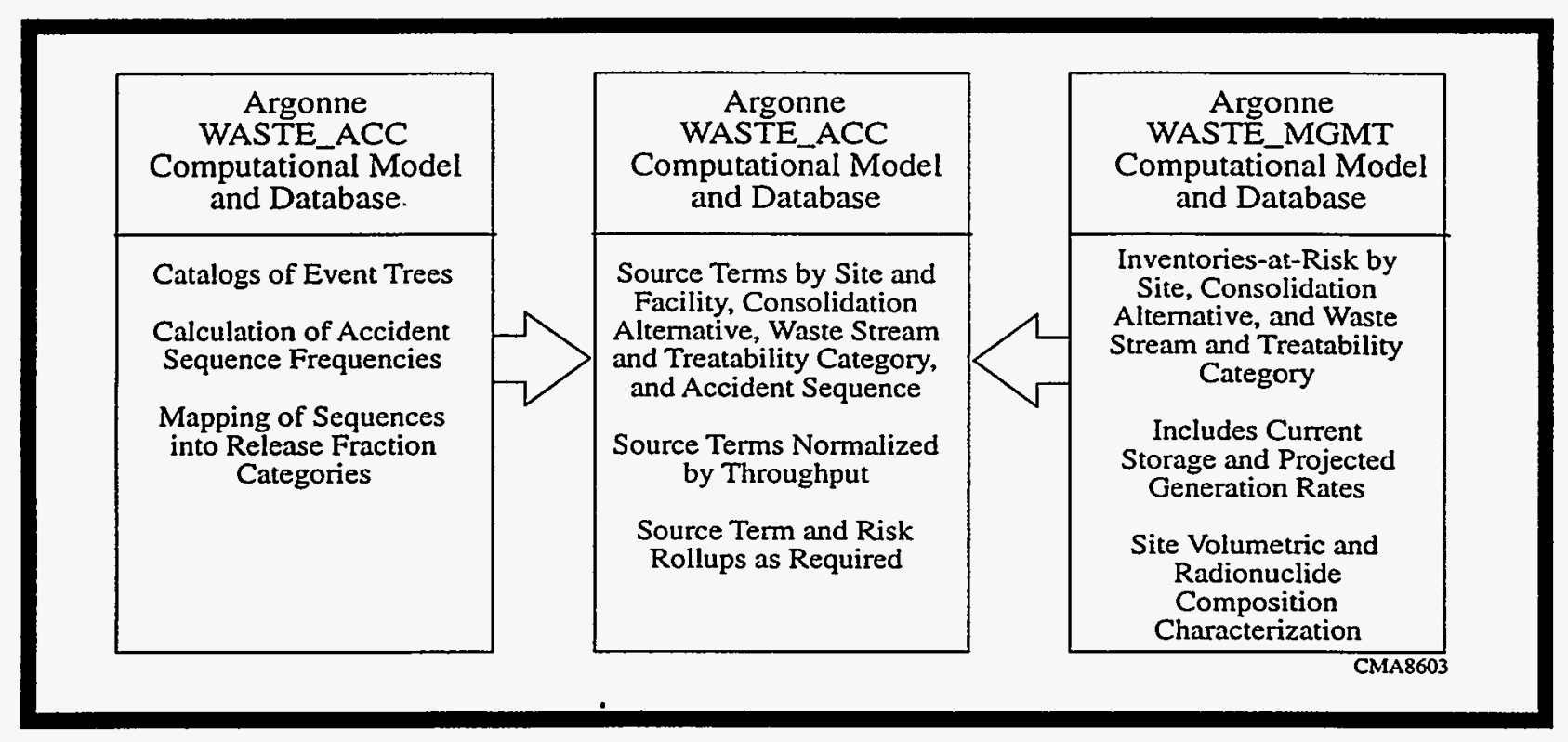

FIGURE 2.7 Computational Framework for Facility Accident Analysis Source Terms

\subsection{UNCERTAINTY IN FACILITY ACCIDENT ANALYSIS}

Considerable uncertainties exist in various aspects of the facility accident analysis. The uncertainties range from issues pertaining to completeness of the analysis to numerical uncertainties in the parameters used in estimating the accident sequence frequency and the airborne release source terms.

Uncertainties in the representativeness and completeness of the accident analysis arise from inherent limitations of the accident sequence modeling and the incomplete knowledge of the facilities and operations involved. Representativeness was addressed by reviewing existing safety analysis documentation and selecting accidents that were similar to or which bounded those found in the literature for the relevant operations, processes, and facilities. The issue of completeness was addressed by selecting surrogate accidents representative of classes of accidents and bounding the product of the frequency and the severity of the surrogates so that the risk from each class of accidents was enveloped.

The numerical estimates of the frequency of the different accident sequences analyzed are also uncertain. Uncertainties exist in both the frequency of the initiating events and in the conditional probabilities of the accident progression path. The numerical estimates were generally conservatively obtained by DOE or NRC safety guidance or site-specific safety documentation. Event trees were used to help organize the information, structure the sequences, and automate the calculations. Uncertainties in the frequencies of the sequences are expected to range from factors of from 3 to 10 for anticipated accident sequences (i.e., those with annual frequencies greater than $1.0 \mathrm{E}-02$ per year) 
TABLE 2.5 Representative Accidents Analyzed for Source Term Development

\begin{tabular}{|c|c|c|c|}
\hline Type of Facility and Accident & Frequency & $\mathrm{MAR} \times \mathrm{DF}$ & Notes \\
\hline \multicolumn{4}{|l|}{ Operational Handling } \\
\hline Drum breach & $2.0 \mathrm{E}-04 / \mathrm{drum} / \mathrm{yr}$ & $\begin{array}{l}25 \% \text { of drum ( } 100 \% \text { for liquid } \\
\text { waste) }\end{array}$ & \\
\hline \multicolumn{4}{|l|}{ Storage or Staging Area ${ }^{a}$} \\
\hline Facility fire & $1.0 \mathrm{E}-04 / \mathrm{yr}$ & $\begin{array}{l}10 \% \text { of combustible drums in } \\
\text { facility }\end{array}$ & $\begin{array}{l}\text { Not applied to drums with } \\
\text { vitrified, solidified, or } \\
\text { otherwise highly stable waste } \\
\text { or to noncombustible liquid } \\
\text { waste }\end{array}$ \\
\hline \multicolumn{4}{|l|}{ External Events } \\
\hline $\begin{array}{l}\text { Small- or large- } \\
\text { aircraft impact }\end{array}$ & $\begin{array}{l}\text { Site-, aircraft-, and accident- } \\
\text { sequence-specific }\end{array}$ & $\begin{array}{l}\text { Aircraft- and accident- } \\
\text { sequence-specific }\end{array}$ & $\begin{array}{l}\text { Event tree sequences for both } \\
\text { small and large aircraft } \\
\text { screened on risk to identify } \\
\text { single sequence }\end{array}$ \\
\hline Earhquaake ${ }^{b}$ or tomado & $\begin{array}{l}\text { Site- }{ }^{c} \text { and accident-sequence- } \\
\text { specific }\end{array}$ & Accident-sequence-specific & $\begin{array}{l}\text { Event tree sequences screened } \\
\text { on risk to identify single } \\
\text { sequence }\end{array}$ \\
\hline \multicolumn{4}{|l|}{ Treatment Facility $^{d}$} \\
\hline \multicolumn{4}{|l|}{ Operational Events } \\
\hline Facility fire & $1.0 \mathrm{E}-03 / \mathrm{yr}$ & $\begin{array}{l}\text { Ash in baghouse and HEPA } \\
\text { filters ( } 3 \% \text { of facility waste } \\
\text { inventory or } 0.03 \% \text { of } \\
\text { throughput) }\end{array}$ & Not for HW stream \\
\hline Facility explosion & $1.5 \mathrm{E}-02 / \mathrm{yr}$ & $\begin{array}{l}\text { Ash in kiln (12\% of facility } \\
\text { waste inventory or } 0.12 \% \text { of } \\
\text { throughput) }\end{array}$ & Not for HW stream \\
\hline \multicolumn{4}{|l|}{ External Events } \\
\hline $\begin{array}{l}\text { Small- or large- } \\
\text { aircraft impact }\end{array}$ & $\begin{array}{l}\text { Site-, aircraft-, and accident- } \\
\text { sequence-specific }\end{array}$ & $\begin{array}{l}\text { Aircraft- and accident- } \\
\text { sequence-specific }\end{array}$ & $\begin{array}{l}\text { Event tree sequences for both } \\
\text { small and large aircraft } \\
\text { screened on risk to identify } \\
\text { single sequence }\end{array}$ \\
\hline Earthquake & Accident-sequence-specific & Accident-sequence-specific & $\begin{array}{l}\text { Event tree sequences screened } \\
\text { on risk to identify single } \\
\text { sequence }\end{array}$ \\
\hline
\end{tabular}

a Used for screening only.

b Earthquake used to upper bound consequences of tornado.

c Frequency was assigned as the larger of those for a $0.15-\mathrm{g}$ earthquake or a $113-\mathrm{km} / \mathrm{h}(70-\mathrm{mph})$ wind. ( $g=$ acceleration due to gravity.)

d Applied only to incinerators at each DOE site. Vitrification accidents were screened for LLW, and wet-air oxidation accidents were screened for LLMW. 
to from 2 to 3 orders of magnitude for end of spectrum accident sequences with frequencies near or less than 1.0E-05, such as those initiated by beyond-design-basis earthquakes (BDBEs).

The uncertainties in the source term calculations apply to both the radiological and the chemical releases. The radiological source terms were calculated as the product of four contributing factors, namely MAR, DF, RARF, and LPF, all of which are affected by uncertainties. Uncertainties in the MAR and DF arise from lack of precise knowledge of the waste stream inventory amounts, physical characteristics, radiological profiles, and operational and containment configurations of the treatment and storage of waste streams under potential accident environments. Estimates of the current inventory radioactivity contents (i.e., reflecting both amount and composition) are probably uncertain by factors of from 2 to 100, depending on the type of waste, where it was generated, and its current disposition. Minimally conservative assumptions were used in developing the MAR. Damage fractions were chosen by using generally conservative assumptions based on existing safety guidance and general knowledge of the physical characteristics of the MAR and the likely configurations and containment properties of the relevant storage and treatment facilities.

The RARF was conservatively adapted from the waste streams subjected to the dominant accident stresses encountered during the postulated sequences by assigning high or bounding values from the RARFs compiled in DOE (1994). The uncertainties caused by imprecise knowledge of accident stresses and imprecise extrapolation of experimental values, which themselves are uncertain, suggest uncertainty ranges from factors of 3 to 10 for high RARF values (say greater than $1.0 \mathrm{E}-02$ ) to orders of magnitude of RARF values of less than 1.0E-04. Uncertainties in the physical compositions and containment configurations of the MAR suggest an additional order of magnitude in the RARF uncertainty. Conservative values for RARF were used in the analysis.

The LPF uncertainties for sequences with full or partial filtration exist due to incomplete knowledge of leak paths and filtration efficiency during accident conditions. For sequences in which the containment structure is damaged, a LPF of unity is conservatively assumed.

The chemical release source term uncertainties in the MAR and DF parallel those for the radiological release source terms. Uncertainties due to the completeness of the HW database, which was developed from actual shipping manifests, are expected to be small, roughly a factor of two. For the hazardous component of mixed waste and TRUW, the chemical breakdown was more generic and was not available on a drum basis as it was for HW, suggesting an order of magnitude uncertainty. For the hazardous component of mixed waste and TRUW, only a small number of accident release types were identified because of the generic nature of the chemical profile available for those mixed waste types. This uncertainty is expected to add another order of magnitude. Uncertainties in the estimated chemical source terms are expected to have a variability of about one order of magnitude because chemical reactions can take place in different ways, depending upon temperatures, the presence of catalysts, and the precise chemical concentrations of constituents, parameters for which there is limited information only. 
Recognizing that the uncertainties in the various source term factors are often interdependent, the uncertainty in source term estimates covers several orders of magnitude. Reasonable predictions of the distribution of source terms cannot be quantitatively established without a much greater level of knowledge of the waste stream inventories, the future generation of wastes within each category, and the actual characterization of the operations, processes, facility configurations, and operating and safety procedures invoked. Developing this level of knowledge is beyond the scope of the WM PEIS.

Although the absolute values of the source term estimates range in uncertainty to several orders of magnitude, the comparisons among the source terms are much less uncertain. Considerable effort was expended to assure that the accident analysis approach and underlying assumptions were consistently applied for all waste streams, types of accidents considered, and operations, processes, and facilities evaluated. Thus, the relative health and risk impacts that are ultimately derived from and calculated for different facility accident sequences are judged to provide useful information in discriminating among strategic alternatives. 


\section{ACCIDENT ANALYSIS FOR HIGH-LEVEL WASTE}

\subsection{OVERVIEW OF HIGH-LEVEL WASTE MANAGEMENT}

As defined by the Nuclear Waste Policy Act, HLW is:

(1) the highly radioactive material resulting from the reprocessing of spent nuclear fuel, including the liquid waste produced directly in reprocessing and any solid material derived from such liquid waste that contains fission products in sufficient concentrations and (2) other highly radioactive material that the Nuclear Regulatory Commission (NRC), consistent with existing law, determines by rule to require permanent isolation. (U.S. Congress 1983)

These wastes contain transuranic elements and fission products that are highly radioactive, heat-generating, and long-lived.

The two primary sources of HLW in the United States are (1) defense wastes generated from the reprocessing of SNF and weapons production targets and (2) commercial wastes generated from the power reactor fuel cycle. Spent nuclear fuel was reprocessed for defense purposes at three sites: SRS, INEL, and Hanford. SNF was commercially reprocessed at WVDP.

DOE Order 5820.2A (DOE 1988), "Radioactive Waste Management," requires proper handling and storage of HLW. It also requires each generator of HLW to develop a technology for permanent disposal of HLW in a geologic repository, when one becomes available. HLW is currently stored in underground tanks. An evaluation of various HLW treatment technologies resulted in the selection of vitrification as the technology best suited for treating the majority of DOE HLW. The DOE approach to ending the current storage of HLW is to immobilize that part of the waste that is highly radioactive in a more stable glass form by using high-temperature vitrification to produce glass logs that are sealed in canisters. A glass made of boron and silicon (i.e., borosilicate glass) was chosen as the protective material for HLW immobilization because of (1) its long-term stability, (2) its resistance to the stresses of disposal in a repository, (3) its capability to withstand leaching under conditions that could potentially exist in a repository, and (4) its suitability for largescale, remote operations with highly radioactive waste.

HLW management follows six implementation phases: current storage, retrieval, pretreatment, treatment, interim canister storage, and geologic repository disposal. Current storage, retrieval, pretreatment, treatment, and geologic repository disposal are outside the scope of the WM PEIS; therefore, accidents during these implementation phases are not considered. The required waste management facilities include expanded interim storage facilities under the various alternatives at Hanford, SRS, and WVDP. 
Three of the HLW sites (WVDP, SRS, and Hanford) plan to use cylindrical stainless steel canisters, $61 \mathrm{~cm}(24 \mathrm{in}$.) in diameter and $300 \mathrm{~cm}$ (118 in.) long, filled with borosilicate glass to about $85 \%$ of the canister volume. The canister designs for Hanford and SRS are identical; the WVDP design has a smaller wall thickness and a wider fill neck. Based on the current design, the canisters will be fabricated from $304 \mathrm{~L}$ stainless steel.

Canisters of vitrified HLW from Hanford, SRS, and WVDP will be placed in an interim on-site storage facility awaiting transport to a geologic repository. Comparison of the interim storage facilities at the three sites is given in Table 3.1. Canisters produced at WVDP will be placed in storage racks that hold four canisters each, then transported in these racks to the on-site Waste Canister Storage Facility (WCSF). The immobilized HLW will be temporarily stored in a previously decontaminated and refurnished process cell known as the Chemical Process Cell (CPC), which will be modified for HLW interim storage. The racks will be stored on two levels to provide a storage area for failed equipment. The storage area has capacity for 344 canisters and will be equipped with two coolers to remove the decay heat.

The interim canister storage facility at SRS is designed to hold canisters in vertically sealed cavities within a concrete structure forming the storage vault (i.e., a concrete modular vault). The Glass Waste Storage Building (GWSB) at SRS will be an air-cooled dry storage vault. It consists of rows of tubes or vaults placed below grade into which the canisters are lowered. No canisters are stacked within the storage tubes. Concrete plugs provide a cover for the tubes. Storage capacity is currently provided for 2,286 canisters, the output from approximately five years of vitrification operations at the Defense Waste Processing Facility (DWPF). The storage capacity of the existing facility was predicated upon the assumption that a geologic repository would be available when 1992

TABLE 3.1 Interim Storage Facilities for HLW Canisters

\begin{tabular}{lccc}
\hline \multicolumn{1}{c}{ Variable } & WVDP & SRS & Hanford \\
\hline Facility name & WCSF & GWSB & $\mathrm{TBD}^{\mathrm{a}}$ \\
Storage capacity & 344 & $2,565^{\mathrm{b}}$ & 15,000 \\
(HLW canisters) & & & \\
Storage method & Process cell & Modular concrete & Modular concrete \\
& & vault & vault \\
Footprint $\left(\mathrm{m}^{2}\right)$ & 190 & 4,343 & 12,200 \\
Vault volume $\left(\mathrm{m}^{3}\right)$ & 2,490 & 63,404 & 141,000 \\
Cooling method & Air cooler & Exhaust fans & Natural convection \\
\hline
\end{tabular}

a $\mathrm{TBD}=$ to be determined. Conceptual facility under design.

b Storage capacity for an additional 2,268 canisters will also be required. 
fresh waste would be processed. Additional storage capacity for 2,286 HLW canisters will be required to assure interim storage of all SRS HLW canisters.

The previous design for the Hanford Waste Vitrification Plant (HWVP) was estimated to produce about 2,000 canisters of glass from high-activity waste from the Hanford double-shell tanks (DSTs). The number of glass canisters from single-shell tank (SST) wastes depends upon the pretreatment process to be selected; a maximum of 60,000 canisters have been projected for minimal pretreatment (GAO 1993). This analysis assumes that a total estimated 15,000 HLW canisters will be produced from all the HLW at Hanford. The vitrified HLW waste canisters are to be placed in interim storage on-site. This is similar to storage at SRS, except that three canisters are stacked per storage tube and a thermosyphon ventilation system would be used to remove decay heat in the Hanford design. As currently designed, the conceptual facility will be able to store 15,000 canisters containing vitrified $\mathrm{HLW}$. Detailed descriptions of $\mathrm{HLW}$ treatment processes and facilities be found in the report by Folga et al. (1996a).

Table 3.2 shows the HLW alternatives considered in the WM PEIS.

The Decentralized Alternative would provide on-site interim storage for all treated $\mathrm{HLW}$ awaiting shipment to a geologic repository for permanent disposal. The regional consolidation alternatives call for the vitrified-HLW canisters produced at one or more sites to be transported for interim storage at another site. Centralization at one site (Hanford) is also considered.

\subsection{RISK-DOMINANT ACCIDENTS AND MODELING ASSUMPTIONS}

\subsubsection{Selection of Accidents}

Accidents with the potential to produce significant off-site consequences were identified by using available safety documentation. Although HLW contains various hazardous components, the primary risk is from radiological hazards. Because of the stable nature of vitrified waste, chemical releases do not occur in interim storage, which is the only waste management phase of relevance to the WM PEIS.

Nuclear criticality was discounted because of the low concentration of fissionable material in the canister and the absence of a mechanism for accumulating a critical mass. This supposition was supported by safety documentation. The effective multiplication factor for criticality in an interim storage facility is required by 10 CFR 60.131(b)(7) (NRC 1994) to be at least $5 \%$ below unity. Reported values for SRS canisters show a large margin of subcriticality (McDonell and Jantzen 1986). Because the inventories of fissionable radionuclides at Hanford and WVDP are lower than at SRS, an even greater margin would be expected. 
TABLE 3.2 Programmatic Alternatives for HLW

No Action Alternative

- Store HLW canisters at Hanford, SRS, INEL, and WVDP in existing and approved storage facilities

- Continue current treatment approaches at each site

- Continue interim storage of liquid and calcine HLW at INEL

- Continue activities necessary for ultimate disposal of HLW in a geologic repository

Decentralized Alternative

- Continue storage of HLW at Hanford, SRS, INEL, and WVDP

- Continue current treatment approaches at each site

- Continue interim storage of stabilized (vitrified or glass-ceramic) HLW at each site

- Continue activities necessary for ultimate disposal of HLW in a geologic repository

Regionalized 1 Alternative

- Same as Decentralized Alternative, except provide interim storage facilities at SRS for WVDP vitrified HLW canisters

Regionalized 2 Alternative

- Same as Decentralized Alternative, except provide interim storage facilities at Hanford for WVDP vitrified HLW canisters

Centralized Alternative

- Same as Regionalized 1, except provide interim storage facilities at Hanford for WVDP, INEL, and SRS HLW canisters 
Radiological releases from severe fires and explosions were considered first. DOE Order 5480.7A (DOE 1987b) establishes requirements for an improved level of risk for fire protection for all facilities for which either loss of value or risk to health and safety would be of concern. The safety analysis reports for the various HLW interim storage facilities (Herborn and Smith 1990; WSRC 1990; WVNS 1994) do not consider the risk of fire within an interim storage facility, generally because there is no significant accumulation of combustibles in the vicinity to support significant fire propagation. Thus, a major destructive fire was judged to be unimportant to risk. Similarly, since a large source of combustible material would not be available for ignition and/or chemical reaction, the possibility of a catastrophic operational explosion was discounted. An aircraft crash with a resulting aviation fuel fire was also discounted because it would have a frequency of less than $1.0 \mathrm{E}-06 / \mathrm{yr}$ and limited radiological consequences given the containment of the encapsulated radioactive materials (Mishima et al. 1986).

Natural phenomena were also considered; the limiting accident was an earthquake. Braun et al. (1993) estimated an annual frequency of 3.37E-08 for an earthquake-induced canister drop with subsequent airborne release for interim storage at Hanford (this scenario assumed full filtration; loss of filtration would result in an even lower frequency estimate). In general, natural-phenomena, such as tornadoes and earthquakes, were discounted as important contributors to the overall risk of HLW interim storage operations (Braun et al. 1993) because of the high integrity of the HLW canisters as well as the low probability of occurrence.

Review of the available safety documentation (DOE 1982a,b; Machida et al. 1989; Mishima et al. 1986; WSRC 1990) suggests that the risk-dominant accident during interim glass canister storage is the breaching of an immobilized canister during handling operations, including a canister drop from the shielded canister transporter (SCT) into the vault tube during transfer and canister damage during transfer because of movement of the cask relative to the vault tube opening (Braun et al. 1993). A rupture could also occur from a cell cover dropping on an encapsulated canister. (Since a cell cover weighs approximately 30 tons, canister rupture is expected following a direct hit.) The initiating event is attributable to operator error in handling or to handling equipment failure (NRC 1988). Particulates would then be generated that are small enough to be suspended, and hence, could be exhausted to the atmosphere. It is not expected that the energetics of the accident would severely degrade the facility filtration. At the time of rupture, each canister is assumed to be full.

The estimated frequency for a HLW canister drop with subsequent release at the Hanford glass storage facility, which would handle approximately 370 canisters/yr, is $4.0 \mathrm{E}-03 / \mathrm{yr}$ (Braun et al. 1993). The frequency of a canister breach depends on the number of handling operations, which is taken to be equal to the annual canister production rate:

$$
\text { Frequency }\left(\mathrm{yr}^{-1}\right)=\left(4 \times 10^{-3} / \mathrm{yr}\right) \times \text { Canister Production Rate } 370 \text {. }
$$


This analysis assumes a canister loading rate of 790 canisters per year for Hanford; therefore, the initiating frequency for a canister drop at Hanford is estimated to be about $8.0 \mathrm{E}-03 / \mathrm{yr}$. Given the above, the initiating frequency for a canister drop accident at SRS is estimated to be $4.0 \mathrm{E}-03 / \mathrm{yr}$, based on an annual production rate of 410 canisters per year. (The frequency of a canister rupture at SRS is estimated in WSRC [1990] to be 2.0E-03/yr; the value used in this analysis can, therefore, be considered to be conservative.) WVDP will handle only approximately 100 canisters/yr, and the annual frequency is therefore reduced to $1.0 \mathrm{E}-03$.

\subsubsection{Source Term Modeling Assumptions}

Site-specific compositions were assumed for the MAR (taken to be the contents of one canister). A full canister of glass in general contains between 1,650 to $1,900 \mathrm{~kg}$ of glass (see Table 3.3). It is also assumed in this analysis that the mechanical impact from the canister drop accident results in fracturing the vitrified-HLW and breaking the canister. The glass particles are released from the damaged canister (damage fraction of unity) and dispersed into the vault. The majority of the glass fragments are too heavy to remain airborne; a fraction (1.5E-04) of the glass lies within the respirable range $(<10 \mu \mathrm{m})$. The RARF for glass that has been subjected to a crush/impact accident stress as a function of filtration is shown in Table 3.4. The RARF is, in general, a function of the physical characteristics of the waste and the accident stress to which it is subjected. The mapping of the $\mathrm{HLW}$ treatability categories (which are based on the physical characteristics of the waste form) with the accident analysis physical forms is shown in Table 3.5.

The analysis of emissions from the Interim Fuel Storage Facility (IFSF) at INEL assumes that all emissions are ground releases because the release point is not greater than 2.5 times the associated building height (DOE 1993g). Because stack locations and heights cannot be defined until a conceptual design has been completed, ground releases were assumed here with both full filtration and loss of filtration. While these two sequences are to be applied for public risk estimation, worker risk is based on unfiltered releases.

\subsection{RESULTS}

Preliminary results of the accident sequences described above were reviewed for risk dominance by using the frequency-weighted dose to the MEI and then grouped into four annual frequencies: anticipated $(>1.0 \mathrm{E}-02)$, unlikely (between $1.0 \mathrm{E}-04$ and $1.0 \mathrm{E}-02$ ), very unlikely (between 1.0E-06 and 1.0E-04), and extremely unlikely $(<1.0 \mathrm{E}-06)$ as a function of site. Representative source terms for the important sequences were then selected as the bases for human health effects calculations. Table 3.6 shows the source term parameters and frequency groups for interim storage accidents for all WM PEIS alternatives. Detailed radionuclide releases are provided in Appendix B. 
TABLE 3.3 Dimensions, Weights, and Radioactivities of HLW Canisters

\begin{tabular}{lccc}
\hline \multicolumn{1}{c}{ Variable } & WVDP & SRS & Hanford \\
\hline & 61 & 61 & 61 \\
Outer diameter (cm) & 300 & 300 & 300 \\
Overall height (cm) & SS; ${ }^{\mathrm{a}} 304 \mathrm{~L}$ & $\mathrm{SS} ; 304 \mathrm{~L}$ & $\mathrm{SS} ; 304 \mathrm{~L}$ \\
Material of construction & 0.34 & 0.95 & 0.95 \\
Nominal wall thickness (cm) & & & \\
Weight (kg) & 252 & 500 & 500 \\
$\quad$ Canister & 1,900 & 1,682 & 1,650 \\
$\quad$ Glass or ceramic & 2,152 & 2,182 & 2,150 \\
$\quad$ Total & 104,300 & 234,400 & 137,000 \\
Radioactivity per canister (Ci) & & & \\
$\quad$ (January 1990) & 311 & 709 & 389 \\
$\begin{array}{l}\text { Decay heat per canister }(\mathrm{W})^{\mathrm{b}} \\
\quad \text { (January 1990) }\end{array}$ & & & \\
\hline
\end{tabular}

a $\mathrm{SS}=$ single shell.

b $\mathrm{W}=$ watt(s).

TABLE 3.4 Respirable Airborne Release Fraction as a Function of Filtration for HLW Storage Facility Accidents ${ }^{2}$

\begin{tabular}{rccc}
\hline Variable & Loss of Filtration & Partial Filtration & Full Filtration \\
\hline RARF & $1.5 \mathrm{E}-04$ & $1.5 \mathrm{E}-07$ & $3.0 \mathrm{E}-10$ \\
\hline
\end{tabular}

a Double banks of HEPA filtration are assumed; for full filtration, efficiency of first bank is $99.9 \%$; efficiency of second bank is $99.8 \%$. 
TABLE 3.5 Mapping of HLW Treatability Categories with Accident Analysis Physical Forms ${ }^{\mathrm{a}}$

\begin{tabular}{|c|c|c|c|c|}
\hline Site $^{b}$ & TSD Function & MAR Based on Contents of: ${ }^{b}$ & Accident Physical Form & Comments/Assumptions \\
\hline Hanford & $\begin{array}{l}\text { Current tank } \\
\text { storage }\end{array}$ & One DST & Aqueous slurry & $\begin{array}{l}\text { DST waste consists of mixtures of HLW, TRUW, and } \\
\text { LLW existing as crystallized salts or oxides, and is } \\
\text { considered to be aqueous slurry (ORNL 1992). }\end{array}$ \\
\hline Hanford & Retrieval & Retrieval line & Aqueous solution & $\begin{array}{l}\text { Hydraulic retrieval assumed, which involves the addition } \\
\text { of water to mobilize waste prior to transport. }\end{array}$ \\
\hline Hanford & Pretreatment & $\mathrm{CPF}$ & Aqueous solution & $\begin{array}{l}\text { Review of conceptual Hanford pretreatment facility design } \\
\text { (Boomer 1992) indicated that the majority of the HLW } \\
\text { within the facility is an aqueous solution. }\end{array}$ \\
\hline Hanford & Pretreatment & $\begin{array}{l}\text { Fully loaded cesium ion- } \\
\text { exchange column }\end{array}$ & $\begin{array}{l}\text { Combustible solids - } \\
\text { polyethylene }\end{array}$ & $\begin{array}{l}\text { Radioactive cesium (Cs) assumed to be removed by a } \\
\text { Duolite-like ion-exchange resin made of polyethylene. }\end{array}$ \\
\hline Hanford & Pretreatment & 3.8- $\mathrm{m}^{3}$ DCRT & aqueous slurry & $\begin{array}{l}\text { Slurry is formed from retrieved waste due to recirculation } \\
\text { (concentration factor of approximately } 3 x \text { ). }\end{array}$ \\
\hline Hanford & Treatment & Vitrification melter & Viscous (molten) liquid & $\begin{array}{l}\text { Molten glass spill due to failure of melter drain system; } \\
\text { MAR consists of borosilicate glass similar in behavior to } \\
\text { molten lava. }\end{array}$ \\
\hline Hanford & Treatment & Vitrification melter & Viscous (molten) liquid & $\begin{array}{l}\text { Steam-glass explosion due to failure of cooling system; } \\
\text { MAR consists of borosilicate glass similar in behavior to } \\
\text { molten lava. }\end{array}$ \\
\hline Hanlord & Treatment & HWVP & Aqueous slurry & $\begin{array}{l}\text { External event assumed to result in rupture of all waste } \\
\text { holding tanks and spillage of molten glass; molten glass } \\
\text { spill neglected on the basis of Herborn and Smith (1990) } \\
\text { because of low inventory in comparison with entire } \\
\text { facility and low release fraction. }\end{array}$ \\
\hline
\end{tabular}


TABLE 3.5 (Cont.)

\begin{tabular}{|c|c|c|c|c|}
\hline Site $^{b}$ & TSD Function & MAR Based on Contents of: & Accident Physical Form & Comments/Assumptions \\
\hline Hanford & $\begin{array}{l}\text { Glass canister } \\
\text { storage }\end{array}$ & One HLW glass canister & Brittle solids (glass) & $\begin{array}{l}\text { Brittle (glass) solids surrogate for borosilicate-lype glass } \\
\text { produced during vitrification. }\end{array}$ \\
\hline SRS & $\begin{array}{l}\text { Current tank } \\
\text { storage }\end{array}$ & One Type-III tank & Aqueous solution & $\begin{array}{l}\text { Majority of the SRS HLW inventory }(\approx 45 \%) \text { associated with an } \\
\text { alkaline liquid with a high-salt solution and many crystallized } \\
\text { salt solids. }\end{array}$ \\
\hline SRS & Retrieval & Retrieval line & Aqueous solution & $\begin{array}{l}\text { Hydraulic retrieval assumed, which involves the addition of } \\
\text { water to mobilize waste prior to transport. }\end{array}$ \\
\hline SRS & Pretreatment & One Type-III tank & Aqueous solution & $\begin{array}{l}\text { Based on material characteristics for in-tank precipitation process } \\
\text { given in Choi and Fowler (1990). }\end{array}$ \\
\hline SRS & Pretreatment & Salt cake tank & Aqueous slurry & $\begin{array}{l}\text { Salt cake tank contains washed sludge waste assumed to be } \\
\text { equivalent in physical form to an aqueous slurry. }\end{array}$ \\
\hline SRS & Treatment & SRE & $\begin{array}{l}\text { Superheated aqueous } \\
\text { solution }\end{array}$ & $\begin{array}{l}\text { Dominant accident scenario in literature involves release of } \\
\text { evaporator contents at high pressure and temperature (WSRC } \\
\text { 1990). }\end{array}$ \\
\hline SRS & Treatment & SRAT & Aqueous slurry & $\begin{array}{l}\text { SRAT contains washed sludge, which is assumed to be } \\
\text { equivalent in physical form to an aqueous slurry. }\end{array}$ \\
\hline SRS & Treatment & Vitrification melter & Viscous (molten) liquid & $\begin{array}{l}\text { Steam-glass explosion due to failure of cooling system; MAR } \\
\text { consists of borosilicate glass similar in behavior to molten lava. }\end{array}$ \\
\hline SRS & Treatment & DWPF & Aqueous slurry & $\begin{array}{l}\text { External event assumed to result in rupture of all waste holding } \\
\text { tanks and spillage of molten glass; molten glass spill neglected } \\
\text { on the basis of WSRC (1994a) because of low inventory in } \\
\text { comparison with entire facility and low release fraction. }\end{array}$ \\
\hline SRS & $\begin{array}{l}\text { Glass canister } \\
\text { storage }\end{array}$ & One HLW glass canister & Brittle solids (glass) & $\begin{array}{l}\text { Brittle (glass) solids surrogate for borosilicate-type glass } \\
\text { produced during vitrification. }\end{array}$ \\
\hline
\end{tabular}


TABLE 3.5 (Cont.)

\begin{tabular}{|c|c|c|c|c|}
\hline Site $^{b}$ & TSD Function & MAR Based on Contents of: ${ }^{b}$ & Accident Physical Form & Comments/Assumptions \\
\hline WVDP & Pretreatment & Tank 8D-2 & Aqueous slurry & $\begin{array}{l}\text { Tank } 8 D-2 \text { contains washed sludge waste assumed to be } \\
\text { equivalent in physical form to an aqueous slurry. }\end{array}$ \\
\hline WVDP & Treatment & CFMUT & Aqueous slurry & Based on waste description given in Barnes et al. (1988). \\
\hline WVDP & Treatment & Vitrification melter & Viscous (molten) liquid & $\begin{array}{l}\text { Steam-glass explosion due to failure of cooling system; MAR } \\
\text { consists of borosilicate glass similar in behavior to molten lava. }\end{array}$ \\
\hline WVDP & Treatment & Vitrification facility & Aqueous slurry & $\begin{array}{l}\text { External event assumed to result in rupture of all waste holding } \\
\text { tanks and spillage of molten glass; molten glass spill neglected } \\
\text { due to low inventory in comparison with entire facility and low } \\
\text { release fraction. }\end{array}$ \\
\hline WVDP & $\begin{array}{l}\text { Glass canister } \\
\text { storage }\end{array}$ & One HLW glass canister & Brittle solids (glass) & $\begin{array}{l}\text { Brittle (glass) solids surrogate for borosilicate-type glass } \\
\text { produced during vitrification. }\end{array}$ \\
\hline
\end{tabular}

a Abbreviations: $C F M U T=$ Concentrated Feed Makeup Tank; $C P F=$ Conceptual Pretreatment Facility; $D S T=$ Double-shell tank; $D C R T=$ Double-Containment Receiver Tank; DWPF = Defense Waste Processing Facility; HWVP = Hanford Waste Vitrification Plant; MAR = material at risk; SRAT = Slurry Receipt and Adjustment Tank; SRE = Slurry Mix Evaporator.

b HLW accident analysis for INEL not included because of nonexistent safety documentation for the immobilization process and possible conflicts with the accident analysis for the INEL sitewide EIS. 
TABLE 3.6 Frequencies and Source Term Parameters for WM HLW Storage Facility Accidents

\begin{tabular}{|c|c|c|c|c|c|c|c|c|c|c|}
\hline \multirow[b]{2}{*}{$\begin{array}{l}\text { WM PEIS } \\
\text { Alternative }\end{array}$} & \multirow[b]{2}{*}{ Site } & \multirow[b]{2}{*}{ Accident } & \multicolumn{4}{|c|}{ Frequency Bin (/yr) } & \multicolumn{3}{|c|}{ Source Term Parameters } & \multirow{2}{*}{$\begin{array}{l}\text { Total } \\
\text { Release } \\
\text { (Ci) }\end{array}$} \\
\hline & & & $>1.0 \mathrm{E}-02$ & $\begin{array}{c}1.0 \mathrm{E}-04 \text { to } \\
1.0 \mathrm{E}-02\end{array}$ & $\begin{array}{c}1.0 \mathrm{E}-06 \text { to } \\
1.0 \mathrm{E}-04\end{array}$ & $<1.0 \mathrm{E}-06$ & $\begin{array}{c}\text { VMAR } \\
\left(\mathrm{m}^{3}\right)\end{array}$ & $\begin{array}{c}\text { MAR } \\
\text { (Ci) }\end{array}$ & DF & \\
\hline All & Hanford & Glass canister crush, fully filtered release & $N A^{a}$ & $x$ & NA & NA & $6.2 \mathrm{E}-01$ & $1.4 \mathrm{E}+05$ & 1.0 & 4.IE-05 \\
\hline All & Hanford & Glass canister crush, unfiltered release & NA & NA & NA & $x$ & $6.2 \mathrm{E}-01$ & $1.4 \mathrm{E}+05$ & 1.0 & $2.1 \mathrm{E}+01$ \\
\hline All & SRS & Glass canister crush, fully filtered release & NA & $x$ & NA & NA & $6.2 \mathrm{E}-01$ & $2.3 \mathrm{E}+05$ & 1.0 & $7.0 \mathrm{E}-05$ \\
\hline All & SRS & Glass canister crush, unfiltered release & NA & NA & NA & $x$ & $6.2 \mathrm{E}-01$ & $2.3 \mathrm{E}+05$ & 1.0 & $3.5 \mathrm{E}+01$ \\
\hline All & WVDP & Glass canister crush, fully filtered release & NA & $x$ & NA & $\mathrm{NA}$ & $6.2 \mathrm{E}-01$ & $1.1 \mathrm{E}+05$ & 1.0 & 3.3E-0.5 \\
\hline All & WVDP & Glass canister crush, unfiltered release & NA & NA & NA & $x$ & $6.2 \mathrm{E}-01$ & $1.1 \mathrm{E}+05$ & 1.0 & $1.7 \mathrm{E}+01$ \\
\hline
\end{tabular}

a $\mathrm{NA}=$ not applicable. 


\section{ACCIDENT ANALYSIS FOR TRANSURANIC WASTE}

\subsection{OVERVIEW OF TRANSURANIC WASTE MANAGEMENT}

TRUW is waste contaminated with alpha-emitting transuranium radionuclides with half-lives greater than 20 years and waste concentrations $>100 \mathrm{nCi} / \mathrm{g}$ at the time of assay. Packaged TRUW with surface dose rates $<200 \mathrm{mrem} / \mathrm{h}$ is categorized as $\mathrm{CH}$; packaged TRUW with surface dose rates $>200 \mathrm{mrem} / \mathrm{h}$ is categorized as RH. TRUW results from a variety of activities, including the processing and handling of plutonium and plutonium-contaminated materials. Principal sources are research and development, special nuclear materials recovery, weapons manufacturing, decontamination and decommissioning (D\&D), and disposition of plutonium bearing residues. Most residue is in solid form, such as contaminated protective clothing, paper trash, glassware, tools, and machine parts. Some liquids and sludges result from chemical processing. Approximately $60 \%$ of the stored TRUW generated before 1989 and $10-30 \%$ of the newly generated TRUW contains hazardous components regulated under RCRA.

Most TRUW is stored at nine DOE sites (Hanford, SRS, ORR, INEL, Nevada Test Site [NTS], RFETS, the Mound Plant, LANL, and Lawrence Livermore National Laboratory [LLNL]). More than $95 \%$ was generated at Hanford, LANL, ORR, RFETS, and SRS. TRUW is currently generated at more than 30 sites and placed into interim retrievable storage awaiting disposal treatment. Most storage involves solid CH-TRUW in 208-L (55-gal) drums or standard waste boxes on asphalt pads within weather-protected structures, earthen berms, or concrete structures. The sites with the most significant processing needs are Hanford, INEL, LANL, SRS, and RFETS.

Under the current program, retrievably stored TRUW (TRUW not disposed of before implementation of a 1970 Atomic Energy Commission determination to store TRUW) is to be retrieved and stored. Newly generated TRUW is to be prepared (characterized, segregated, packaged, and/or certified for transport and disposal) and stored for transport to the planned geologic repository at WIPP in New Mexico. DOE has entered a WIPP test phase to evaluate long-term repository performance and subsequent acceptability for disposal. During this phase, limited quantities also may be stored at WIPP. Additional storage facilities may be required, depending on the timing of retrieval operations and the WIPP schedule. Other sites that generate TRUW, including TRUW from D\&D, will have to store it on-site, contract for commercial storage, or transport it to one of the nine current storage sites. All sites are responsible for minimizing the quantities generated.

The current strategy is to treat TRUW to meet WIPP Waste Acceptance Criteria (WAC) and dispose of it at WIPP under the RCRA no migration determination rule. However, treatment might be required to comply with regulatory requirements in 40 CFR Part 268 concerning hazardous constituents or under 40 CFR Part 191 concerning radiological components (EPA 1993). These requirements depend on results of (1) the test phase, (2) a WIPP disposal performance assessment, 
and (3) the establishment of EPA criteria for compliance certification. DOE does not currently plan to meet RCRA Part 268 and 40 CFR Part 191 until results are available and an evaluation of alternatives is completed. However, the WM PEIS will evaluate system configuration alternatives to provide advanced planning information and will evaluate a longer period of interim storage if WIPP is either delayed or not operated.

Four alternatives are considered in the WM PEIS:

\section{No Action (Existing and Approved)}

- Continue to characterize and prepare newly generated and stored TRUW where existing and approved facilities are available.

- Continue storing TRUW in existing storage facilities.

\section{Decentralization}

- Process and package newly generated and stored TRUW to meet WIPP-WAC at all sites and ship from smaller sites for interim storage.

\section{Regionalization}

- Treat TRUW to either an intermediate level to reduce gas generation or to meet RCRA Land Disposal Restrictions (LDRs) at regional centers.

\section{Centralization}

- Treat TRUW to either an intermediate level to reduce gas generation or to meet RCRA LDRs at one site.

Table 4.1 shows the specification of TRUW alternatives. Decentralization and regionalization each have several cases that may result in distinct inventories for treatment at each site. In addition, three levels of treatment options are considered. In the first option, TRUW is treated to meet the minimum requirement for WIPP-WAC; namely, liquid absorption, compaction, immobilization, and repackaging. The second option considers an intermediate treatment level beyond WIPP-WAC that includes shredding, grouting, and changing containers to reduce gas generation. In the third option, TRUW is treated to meet LDRs with technologies similar to those for LLMW. Figures 4.1 through 4.3 show flowsheets for these treatment options for representative physical waste types and treatability categories. Detailed descriptions of TRUW treatment processes can be found in Hong et al. (1996). For all alternatives, aqueous liquid is treated on-site before any shipping takes place. The volumes, physical characteristics as defined by treatability categories, and 


\section{TABLE 4.1 Specification of TRUW Alternatives}

\begin{tabular}{|c|c|c|c|c|c|c|c|c|c|c|c|c|c|c|c|c|c|c|}
\hline Alternative & Action & 苞 & $\begin{array}{l}\text { 总 } \\
\text { 蛋 } \\
\end{array}$ & $\underline{9}$ & 岁 & 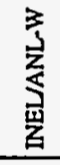 & 点 & 总 & $\frac{2}{3}$ & 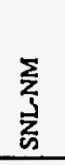 & 宦 & 岕 & 岁 & $\begin{array}{l}\text { Dू } \\
\text { 总 }\end{array}$ & $\sum_{3}^{\circ}$ & 农 & 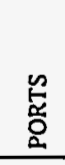 & $\begin{array}{l}\text { 잉 } \\
\text { D }\end{array}$ \\
\hline $\begin{array}{l}\text { No Action: CH-TRUW } \\
\text { Treat to current WIPP_WAC_ and store }\end{array}$ & $\begin{array}{l}\text { Treat at all } \\
\text { Store at all }\end{array}$ & $\begin{array}{l}T \\
S\end{array}$ & $\begin{array}{l}T \\
S\end{array}$ & $\begin{array}{l}T \\
\underline{S}\end{array}$ & $\begin{array}{l}T \\
S\end{array}$ & $\begin{array}{l}\mathrm{T} \\
\mathbf{S}\end{array}$ & $\begin{array}{l}\mathrm{T} \\
\underline{\mathrm{s}}\end{array}$ & $\begin{array}{l}\mathrm{T} \\
\mathbf{S}\end{array}$ & $\begin{array}{l}T \\
\text { S } \\
\underline{T}\end{array}$ & $\begin{array}{l}T \\
\underline{S}\end{array}$ & $\begin{array}{l}T \\
S \\
S\end{array}$ & $\begin{array}{l}\mathbf{T} \\
\mathbf{S}\end{array}$ & $\begin{array}{l}\mathrm{T} \\
\mathrm{S} \\
\end{array}$ & $\begin{array}{l}\mathrm{T} \\
\mathbf{S} \\
-\end{array}$ & $\begin{array}{l}\mathrm{r} \\
\mathbf{S}\end{array}$ & $\begin{array}{l}r \\
\text { I }\end{array}$ & $\begin{array}{l}\mathrm{T} \\
\mathbf{S} \\
-\underline{n}\end{array}$ & $\begin{array}{l}T \\
S\end{array}$ \\
\hline $\begin{array}{l}\text { Decentralized treatment: } \mathrm{CH} \\
\text { Treat to current WIPP-WAC and store. }\end{array}$ & $\begin{array}{l}\text { Treat at all } \\
\text { Store at } 10\end{array}$ & \begin{tabular}{c} 
NA \\
$\vdots$ \\
\hdashline
\end{tabular} & $\begin{array}{l}T \\
S\end{array}$ & $\begin{array}{c}T \\
\text { NA }\end{array}$ & $\begin{array}{l}\mathrm{T} \\
\mathbf{S}\end{array}$ & $\begin{array}{l}T \\
\underline{S} \\
-\end{array}$ & $\begin{array}{l}T \\
S \\
-\end{array}$ & $\begin{array}{c}\mathrm{T} \\
\mathrm{NA}\end{array}$ & $\begin{array}{l}T \\
S\end{array}$ & $\begin{array}{c}\mathrm{T} \\
\mathrm{NA}\end{array}$ & $\begin{array}{l}T \\
S \\
-S\end{array}$ & $\begin{array}{l}T \\
\mathbf{S}\end{array}$ & $\begin{array}{l}\mathrm{T} \\
\mathrm{S}\end{array}$ & $\begin{array}{l}\mathrm{T} \\
\mathbf{S}\end{array}$ & $\begin{array}{c}\mathrm{T} \\
\text { NA } \\
\text { NA. }\end{array}$ & $\begin{array}{l}\mathrm{T} \\
\mathrm{S}\end{array}$ & $\begin{array}{c}T \\
\text { NA }\end{array}$ & $\begin{array}{c}\mathrm{T} \\
\text { NA }\end{array}$ \\
\hline $\begin{array}{l}\text { Regionalized treatment: } \mathrm{CH} \\
\text { Treat to reduce gas generation }\end{array}$ & Treat at 5 & = & $\mathrm{T}$ & NA & NA & $T$ & $\mathrm{NA}$ & NA & $T$ & NA & $\mathbf{T}$ & $\mathbf{T}$ & $\mathrm{NA}$ & NA & NA & NA & NA & NA \\
\hline $\begin{array}{l}\text { Treat to LDRs } \\
\text { Treat to LDRs }\end{array}$ & $\begin{array}{l}\text { Treat at } 5 \\
\text { Treat at } 3\end{array}$ & 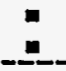 & $\begin{array}{l}\mathrm{T} \\
\mathrm{T} \\
-\end{array}$ & $\begin{array}{l}\text { NA } \\
\text { NA. }\end{array}$ & $\begin{array}{l}\text { NA } \\
\text { NA }\end{array}$ & $\begin{array}{l}T \\
T \\
-\end{array}$ & $\begin{array}{l}\text { NA } \\
\text { NA }\end{array}$ & $\begin{array}{l}\text { NA } \\
\text { NA }\end{array}$ & $\begin{array}{c}T \\
\text { NA }\end{array}$ & $\begin{array}{l}\text { NA } \\
\text { NA }\end{array}$ & $\begin{array}{c}T \\
\text { NA }\end{array}$ & $\begin{array}{l}T \\
T\end{array}$ & $\begin{array}{l}\mathrm{NA} \\
\mathrm{NA}\end{array}$ & $\begin{array}{l}\text { NA } \\
\text { NA }\end{array}$ & $\begin{array}{l}\text { NA } \\
\text { NA }\end{array}$ & $\begin{array}{l}\text { NA } \\
\text { NA. }\end{array}$ & $\begin{array}{l}\text { NA } \\
\text { NA }\end{array}$ & $\begin{array}{l}\mathrm{NA} \\
\mathrm{NA}\end{array}$ \\
\hline $\begin{array}{l}\text { Centralized treatment: } \mathrm{CH} \\
\text { Treat to LDRs }\end{array}$ & Treat at 1 & $\mathrm{~T}$ & $\begin{array}{l}\text { NA } \\
\text { NA }\end{array}$ & $\begin{array}{l}\text { NA } \\
\text { NA }\end{array}$ & $\begin{array}{l}\text { NA } \\
\text { NA }\end{array}$ & $\begin{array}{l}\text { NA } \\
\text { NA }\end{array}$ & $\begin{array}{l}\text { NA } \\
\text { NA. }\end{array}$ & $\begin{array}{l}\mathrm{NA} \\
\text { NA }\end{array}$ & $\begin{array}{l}\text { NA } \\
\text { NA }\end{array}$ & $\begin{array}{l}\mathrm{NA} \\
\mathrm{NA}\end{array}$ & $\begin{array}{l}\mathrm{NA} \\
\text { NA }\end{array}$ & $\begin{array}{l}\text { NA } \\
\text { NA }\end{array}$ & $\begin{array}{l}\text { NA } \\
\text { NA }\end{array}$ & $\begin{array}{l}\text { NA } \\
\text { NA }\end{array}$ & $\begin{array}{l}\text { NA } \\
\text { NA }\end{array}$ & $\begin{array}{l}N A \\
\text { NA }\end{array}$ & $\begin{array}{l}\text { NA } \\
\text { NA. }\end{array}$ & $\begin{array}{l}\mathrm{NA} \\
\mathrm{NA}\end{array}$ \\
\hline $\begin{array}{l}\text { No Action: RH-TRUW } \\
\text { Treas cocurrent WIPP-WAC and store }\end{array}$ & $\begin{array}{l}\text { Treat at } 5 \\
\text { Store at } 5\end{array}$ & $\begin{array}{l}\text { NA } \\
\text { NA }\end{array}$ & $\underline{T}$ & $\begin{array}{l}\text { NA } \\
\text { NA }\end{array}$ & $\begin{array}{l}\text { NA } \\
\text { NA }\end{array}$ & $\begin{array}{l}\mathbf{T} \\
\mathbf{S} \\
-\end{array}$ & $\begin{array}{l}N A \\
N A\end{array}$ & $\begin{array}{l}\text { NA } \\
\text { NA. }\end{array}$ & $\begin{array}{l}\mathrm{T} \\
\mathbf{S}\end{array}$ & $\begin{array}{l}\mathrm{NA} \\
\mathrm{NA}\end{array}$ & $\begin{array}{l}\text { NA } \\
\text { NA }\end{array}$ & $\begin{array}{l}N A \\
\text { NA }\end{array}$ & $\begin{array}{l}T \\
\mathbf{S}\end{array}$ & $\begin{array}{l}\text { NA } \\
\text { NA }\end{array}$ & $\begin{array}{l}\text { NA } \\
\text { NA }\end{array}$ & $\begin{array}{l}\mathrm{T} \\
\mathbf{S} \\
-\underline{S}\end{array}$ & $\begin{array}{l}\text { NA } \\
\text { NA }\end{array}$ & $\begin{array}{l}\mathrm{NA} \\
\mathrm{NA}\end{array}$ \\
\hline $\begin{array}{l}\text { Decentralized treatment: RH } \\
\text { Treat to current WIPP-WAC and store }\end{array}$ & $\begin{array}{l}\text { Treat at } 5 \\
\text { Store at } 5\end{array}$ & $\begin{array}{l}\text { NA } \\
=\end{array}$ & $\begin{array}{l}T \\
S \\
S\end{array}$ & $\begin{array}{l}\text { NA } \\
\text { NA }\end{array}$ & $\begin{array}{l}\text { NA } \\
\text { NA }\end{array}$ & $\begin{array}{l}T \\
S\end{array}$ & $\begin{array}{l}\text { NA } \\
\text { NA }\end{array}$ & $\begin{array}{l}\mathrm{NA} \\
\mathrm{NA}\end{array}$ & $\begin{array}{l}\mathrm{T} \\
\underline{s}\end{array}$ & $\begin{array}{l}N A \\
\text { NA }\end{array}$ & $\begin{array}{l}\text { NA } \\
\text { NA }\end{array}$ & $\begin{array}{l}\mathrm{NA} \\
\mathrm{NA}\end{array}$ & $\begin{array}{l}\mathrm{T} \\
\mathbf{S}\end{array}$ & $\begin{array}{l}\text { NA } \\
\text { NA }\end{array}$ & $\begin{array}{l}\text { NA } \\
\text { NA }\end{array}$ & $\begin{array}{l}T \\
-\underline{S}\end{array}$ & $\begin{array}{l}\mathrm{NA} \\
\text { NA. }\end{array}$ & $\begin{array}{l}\text { NA } \\
\text { NA }\end{array}$ \\
\hline $\begin{array}{l}\text { Regionalized treatment: } \mathrm{RH} \\
\text { Treat to reduce gas generation }\end{array}$ & Treat at 2 & 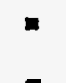 & $T$ & NA & NA & NA & $\mathrm{NA}$ & $N A$ & NA & $\mathrm{NA}$ & NA & NA & NA & $\mathrm{NA}$ & NA & $\mathbf{T}$ & $N A$ & NA \\
\hline Treat to LDRs & Treat at 2 & - & $\mathbf{T}$ & $\mathrm{NA}$ & $\mathrm{NA}$ & $\mathrm{NA}$ & $\mathrm{NA}$ & $\mathrm{NA}$ & NA & NA & NA & $\mathrm{NA}$ & NA & $\mathrm{NA}$ & NA & $\mathrm{T}$ & $\mathrm{NA}$ & NA \\
\hline
\end{tabular}

a Abbreviations: $A N L-W=$ Argonne National Laboratory-West; ETEC $=$ Energy Technology Engineering Center; LBL $=$ Lawrence Berkeley Laboratory; Mound $=$ Mound Plant; NA $=$ not applicable; ORR $=$ Oak Ridge Reservation: $S=$ storage; SNL-M = Sandia National Laboratories-New Mexico; $T=$ treatment; UofMO = University of Missouri, and $n=$ final disposition at WIPP.

The WM PEIS considers a range of treatment actions for four alternatives: no action, decentralized, regionalized, and centralized, all of which address both $\mathrm{CH}$-TRUW and RH-TRUW. There are combinations of three treatment options within the main alternatives: (1) treatment that meets WIPP-WAC, (2) treatment to reduce gas generation by using shredding, grouting, and nonsteel containers, thereby exceeding current WIPP.WAC requirements but not meeting LDRs, and (3) treatment to a level that meets or exceeds LDR requirements.

Under the No Action Alternative, DOE will continue to characterize and prepare newly generated and retrievably stored CH-and RH-TRUW where existing and approved facilities are available. The Decentralized Alternative also represents the current program and assumes treatment to meet current WIPP-WAC, storage for an interim period at selected sites, and evenlually disposal at WIPP. The Regionalized Alternative includes treatment to LDR at five, three, or two sites, with final disposition at WIPP. Treatment to reduce gas generation is considered for CH-TRUW at five sites and for RH-TRUW at two sites. Under the centralized alternative, CH-TRUW assumes both treatment and disposal at WIPP. 


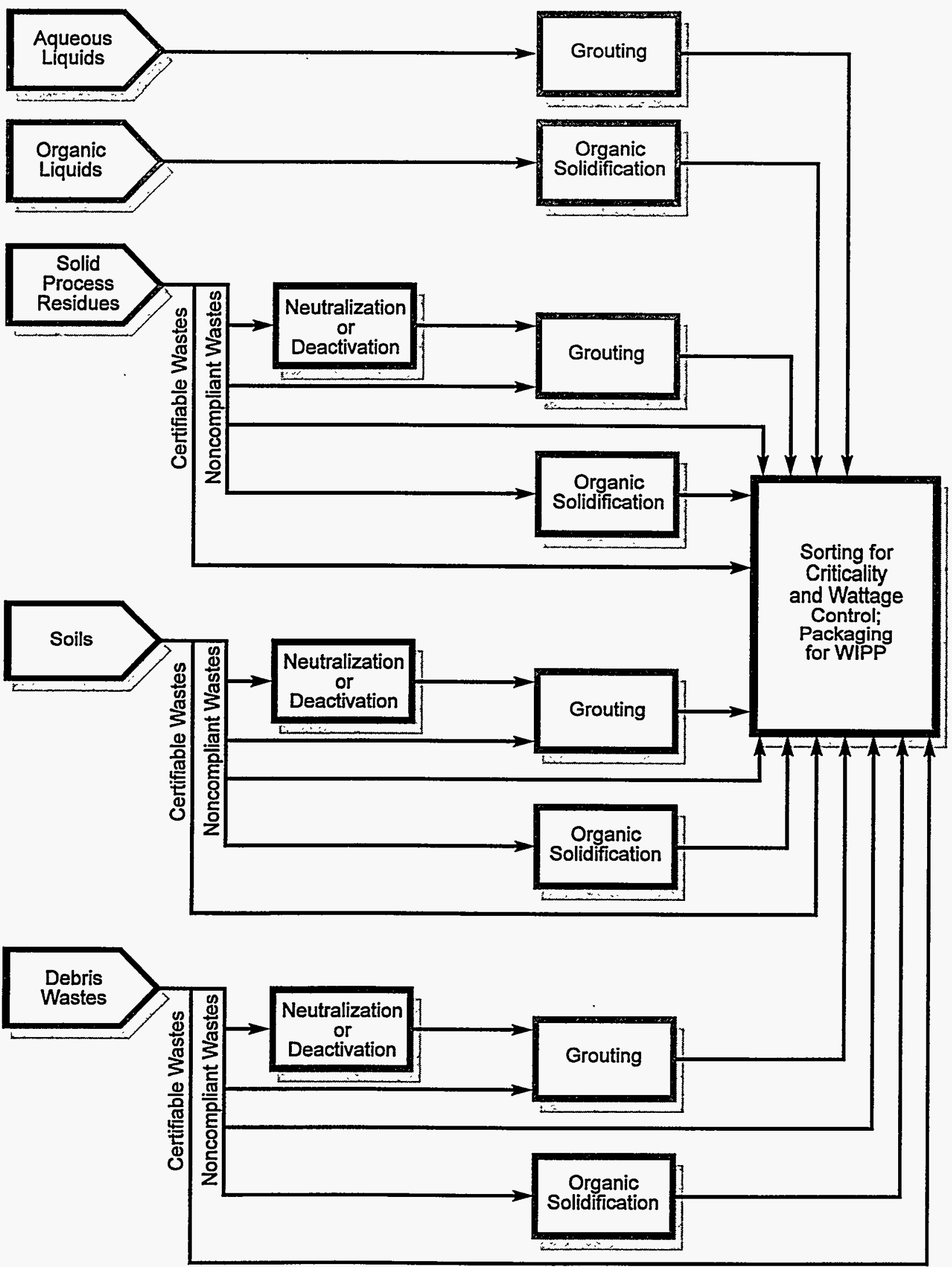

FIGURE 4.1 TRUW Management Technologies and Flow Paths to Meet WIPP-WAC 


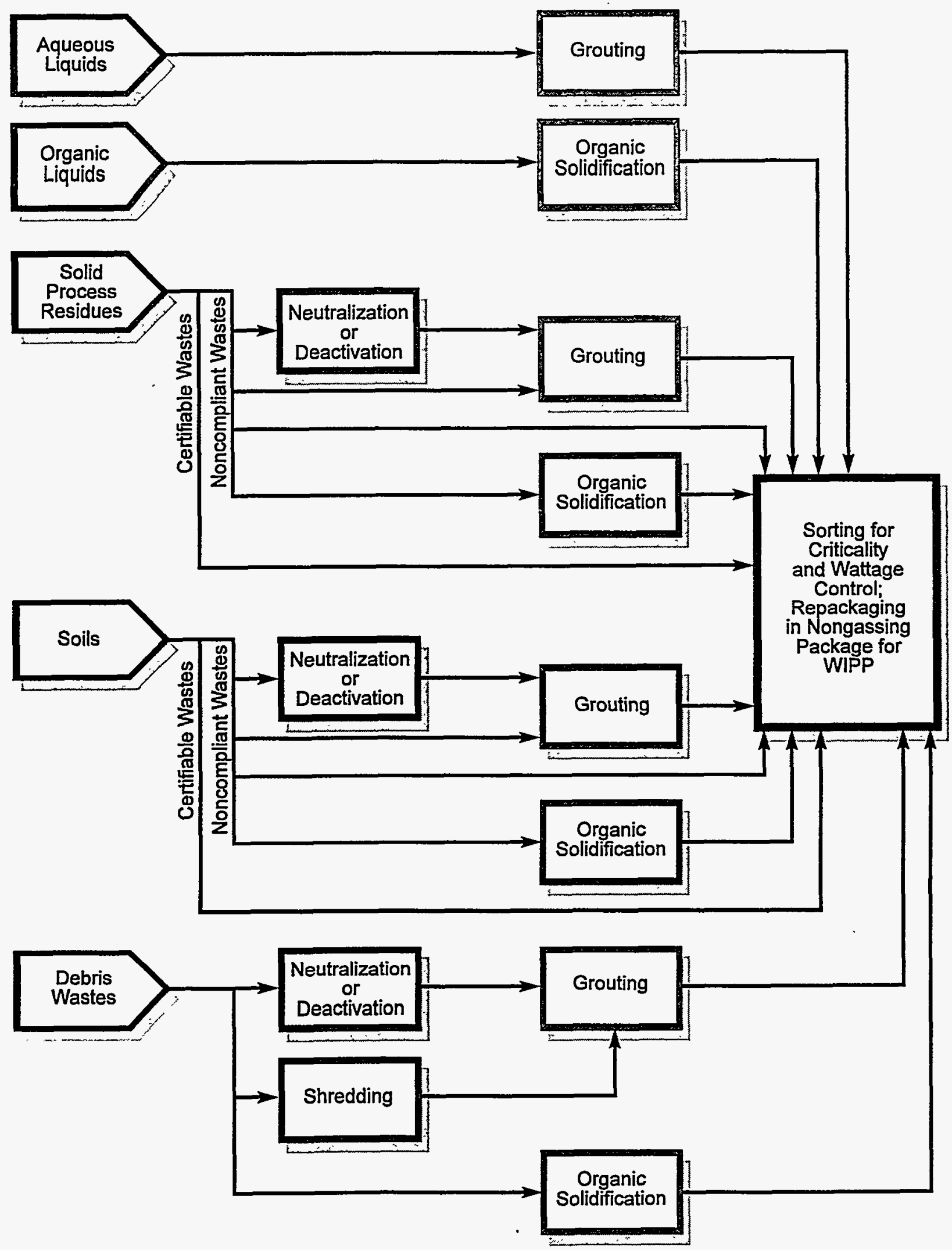

FIGURE 4.2 TRUW Management Technologies and Flow Paths to Minimize Gas Generation 


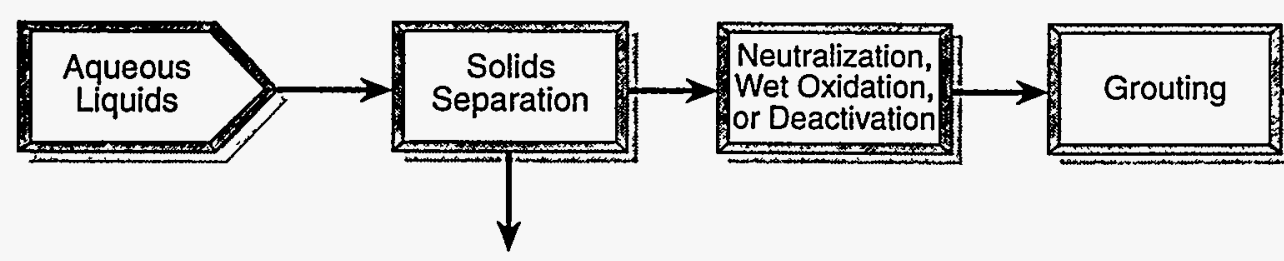

Wet Solids to Residues

Treatment

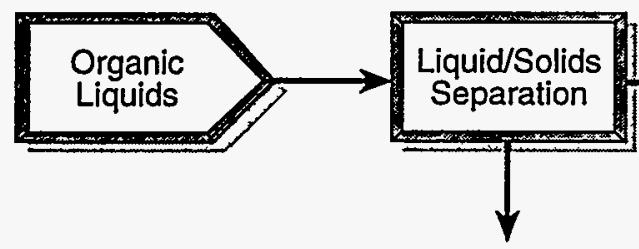

Wet Solids to Residues

Treatment

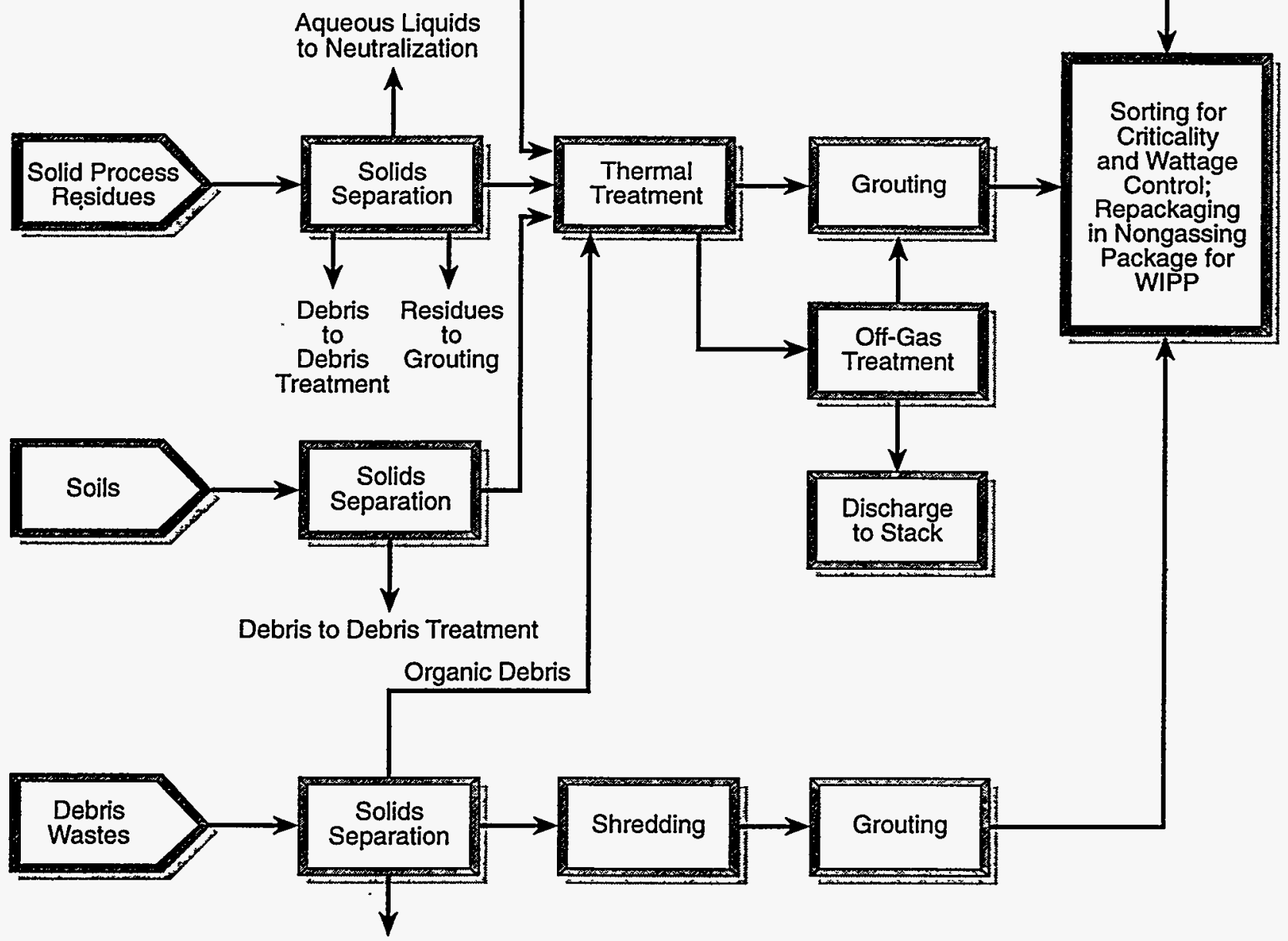

Aqueous Liquids

to Neutralization

FIGURE 4.3 TRUW Management Technologies and Flow Paths to Meet RCRA Compliance 
radiological and chemical compositions of the sites' TRUW inventories have been compiled in the ANL-E computational database.

Several treatment technologies are used, depending primarily on the physical characteristics of the waste, with nine representative technologies considered in the WM PEIS: (1) organic destruction, (2) aqueous liquid (wastewater) treatment, (3) metal (wastewater metal) removal, (4) neutralization (acid or base additions to neutralize waste streams), (5) stabilization, (6) metal recovery, (7) mercury recovery, (8) decontamination, and (9) deactivation of reactives. These technologies are similar to those applied for LLMW and use the same generic facility assumptions to model existing and projected treatment installations for both LLMW and TRUW. Detailed descriptions of treatment technologies can be found in Hong et al. (1996).

\subsection{RISK-DOMINANT ACCIDENTS AND MODELING ASSUMPTIONS}

Accident selection has been based on potential risk dominance; the general modeling assumptions and related source term parameters are used as described in Section 2 and presented in detail in Folga (1996b). The RARFs are a function of the physical form of the material rendered airborne, which varies by treatability category for each waste type. A matrix has been developed for each waste type to map the treatability categories into the physical forms for which airborne release data (Appendix D) were developed. The TRUW mapping, shown in Table 4.2, is based on the WM PEIS waste and process descriptions (Feizollahi and Shropshire 1992; Hong et al. 1996).

A hazard unique to TRUW aqueous processing steps is nuclear criticality through separation and accumulation of fissile materials. In general, a nuclear criticality in solid TRUW storage and handling is judged to be incredible (e.g., WRAP2, RWMC) because of the unfavorable geometry and low fissile material density and inventory. Nuclear criticality may be a plausible accident in some aqueous processing alternatives, depending on fissile material dissolution in the process, process throughput, vessel design, and flowsheet parameters. However, DOE requires analysis to determine frequency estimates and, if the analysis indicates credibility $(>1.0 \mathrm{E}-06 / \mathrm{yr})$, specific design provisions to preclude or mitigate the effects of a criticality. Because nuclear criticality prevention design provisions are incorporated into the process at an early phase and a criticality poses less public exposure risk than other accidents with greater potential for radiological releases, nuclear criticality is not further analyzed. 


\section{TABLE 4.2 Mapping of TRUW Treatability Categories with Accident Analysis Physical Forms}

\begin{tabular}{|c|c|c|}
\hline TRUW Treatability Category & Accident Physical Form & Comments/Assumptions \\
\hline Organic liquid & $\begin{array}{l}\text { Organic combustible } \\
\text { solution }\end{array}$ & $\begin{array}{l}\text { Input waste form consists of flammable components (i.e, petroleum distillates, solvents) with } \\
\text { low amounts of suspended solids. }\end{array}$ \\
\hline Aqueous liquid & Aqueous solution & Input waste form is a dilute aqueous TRUW solution. \\
\hline Organic sludges/particulates & Organic combustible slurry & $\begin{array}{l}\text { Assumes a homogeneous mixture of solid particulates and an organic solution, with the } \\
\text { particulate surfaces "wetted" by the solution. If, however, the particulates are NOT in intimate } \\
\text { contact with the solution so that they can be considered easily dispersible, then the accident } \\
\text { category of "Combustible Powder" may be more appropriate. }\end{array}$ \\
\hline Inorganic sludges/particulates & Aqueous slurry & $\begin{array}{l}\text { Based on logic of previous treatability category. If, however, the particulates are NOT in } \\
\text { intimate contact with the solution so that they can be considered easily dispersible, then the } \\
\text { accident category of "Noncombustible Powder" may be more appropriate. }\end{array}$ \\
\hline Cemented solids & $\begin{array}{l}\text { Noncombustible aggregated } \\
\text { solid }\end{array}$ & $\begin{array}{l}\text { Noncombustible aggregated solids surrogate for cemented solids; would expect minimal risk } \\
\text { from any potential current storage accidents, unless the cohesiveness of the cement has been } \\
\text { degraded. }\end{array}$ \\
\hline Organic debris & Dry active waste & Based on waste form description (ORNL 1994). \\
\hline Inorganic debris & Inert metal & $\begin{array}{l}\text { Waste includes construction materials, equipment, and structures. Assumes that } \\
\text { decontamination of waste has been performed so that the remaining radioactivity is due to } \\
\text { induced activity. }\end{array}$ \\
\hline Heterogeneous debris & Inert metal & Logic used for "Inorganic Debris" also applied to this treatability category. \\
\hline Soils with $<50 \%$ debris & Noncombustible powder & $\begin{array}{l}\text { Based on Mishima's original accident categories, which were taken from the WRAP II safety } \\
\text { documentation (WHC 1991b). }\end{array}$ \\
\hline Soils without debris & Noncombustible powder & As above. \\
\hline
\end{tabular}


TABLE 4.2 (Cont.)

TRUW Treatability Category $\quad$ Accident Physical Form

Lab packs with metals

Dry active waste

Lab packs without metals

Reactive metals

Explosives

Compressed gases

Mercury, liquid
Dry active waste

Reactive metal

Combustible powder

Waste-form dependent

Waste-form dependent
Comments/Assumptions

Mishima's RARFs for dry active waste were developed from available data for combustible trash and "lab packs;" assume that the presence of RCRA toxic metals will not significantly affect the release characteristics of this treatability category (DOE 1994).

Mishima's RARFs for dry active waste were developed from available data for combustible trash and "lab packs."

By definition.

When the accident physical forms were initially developed, the WM PEIS treatability categories for TRUW did not include this treatability category. Further information on the nature of contamination is required; it may, however, be expected that the explosive material has a fine layer of surface contamination. In this case, the "Combustible Powder" accident physical form may be applicable. For assessment of shock-induced explosions, the TNT equivalent of various explosives given in Table 3.4 of NUREG-1320 (NRC 1988) may be used. However, it should be noted that the release of energy may be great enough to cause failure of containment boundaries and lead to opening of alternative flow paths during an accident, affecting the LPF.

The release category is dependent on the compressed gas(es); if the gas is a noncondensible or a noble gas, then the "Noble Gas" category should be applied. A similar situation applies for halogens and condensible vapors.

When the accident physical forms were initially developed, the WM PEIS treatability categories for TRUW did not include this treatability category. It is assumed that the solution and not the mercury itself is radioactively contaminated. One significant mercury-containing solution is the LLMW stream generated at SRS during reprocessing and other waste processing steps. The SRS stream is an organic liquid containing small amounts of mercury; in this case, the "Organic Combustible Solution" accident physical form may be applicable. Aqueous solutions containing mercury are also present; in this case, the appropriate accident physical form would be "Aqueous Liquids, Solutions." 
TABLE 4.2 (Cont.)

TRUW Treatability Category

Lead, elemental

Waste-form dependent

Beryllium, dust

Batteries, lead-acid, cadmium

Other/multiple

Accident Physical Form
Comments/Assumptions

When the accident physical forms were initially developed, the WM PEIS treatability categories for TRUW did not include this treatability category. This treatability category may in general contain both surface contamination and induced lead. In the case of surface contamination (of radionuclides other than lead), the "Noncombustible Powder" accident physical form may be applied. If, however, this stream contains significant amounts of induced activity, then the "Inert Metal" physical form may be more appropriate for accident stresses that do not involve high temperatures (e.g., mechanical releases).

\section{See above.}

Assumes that neither the lead nor the cadmium are radioactive, and that the majority of the radioactivity is associated with surface contamination.

Limited information is available on the physical properties of this treatability category. The appropriate accident physical form would be determined from the treatment processes used to immobilize this waste stream; if supercompaction is used, "Inert Metal" may be appropriate. If liquid/solid separation is required, the waste may be considered to be an "Organic Solution" if combustible liquids are present, or an "Aqueous Slurry" if the liquid is not combustible. 


\subsubsection{Handling Accidents}

Handling accidents during the staging and storage of $\mathrm{CH}$ waste are expected to dominate the risk of exposure for workers because of the high frequency of such accidents and the proximity of the workers during hands-on operations. The frequencies of accidents at a given site would be a strong function of waste throughput at that site. The assumption used (see Section 2) is that two severe breaches of containment occur per year for each inventory of 10,000 drums handled. It is assumed for the results herein that handling breaches fall in the $>0.01 / \mathrm{yr}$ frequency category.

Representative radiological accident scenarios assume that a single drum is affected, such that $25 \%$ of its contents are rendered airborne ( $\mathrm{DF}=2.5 \mathrm{E}-01$ ). The composition of the representative drum is taken as a volume-weighted average of the treatability category compositions (excluding aqueous streams) at each site.

\subsubsection{Storage Facility Accidents}

Accidents and source terms for current storage were not analyzed explicitly. Unlike treatment that will predominantly use new facilities that will have common characteristics, current (pretreatment) storage will consist predominantly of preexisting facilities (storage buildings or enclosures) that vary greatly in the amounts and types of wastes that they can store, the configurations in which they can store wastes, and their containment and confinement characteristics.

However, current SARs and DOE site EISs predict consequences for a range of selected waste storage accidents of varying frequency. Table 4.3 gives a brief summary of some of these accidents, the assumptions used by the sites in preparing the analyses, and release- or health effectsrelated results, all of which are discussed below.

Table 4.3 includes accident results from recent analyses such as the LANL Preliminary Safety Analysis Report for the Retrieval of Transuranic Waste (PSAR) (Benchmark 1994) and the INEL SAR for the Waste Storage Facility (EG\&G 1994b). The LANL PSAR analyzed three credible accidents, including drum spill due to failure during handling, puncture of a crate by a forklift, and breaching of multiple drums in storage due to earthquake-caused toppling from storage arrays. In addition, LANL analyzed one beyond-design-basis accident defined as a single drum fire in the retrieval dome. LANL estimates that only about $0.4 \%$ of the drums contain a potential source of hydrogen that could lead to a fire or explosion. LANL neither analyzed a fire in the storage dome nor provided a rationale for not doing so. The source terms for accidents involving multiple containers are evaluated on the basis of the assumption that the contents of the containers are distributed the same as those of the entire population of containers (average drums). The toppling accident due to an earthquake is assumed to only involve drums stacked on the third level. 
TABLE 4.3 Representative Accidents and Source Term Parameters from Recent DOE Safety Analysis Documents Relevant to TRUW Storage

\begin{tabular}{|c|c|c|c|c|c|}
\hline Safety Document & Scenario & $\mathrm{DF}^{\mathrm{a}}$ & ARF or RARF & Release & Consequence \\
\hline \multirow{2}{*}{$\begin{array}{l}\text { LANL PSAR for } \\
\text { Retrieval of TRUW } \\
\text { (Benchmark 1994) }\end{array}$} & 1. Drum spill at retrieval dome & $5.0 \mathrm{E}-01$ & $\begin{array}{l}1.0 \mathrm{E}-03 \text { to } \\
5.0 \mathrm{E}-05\end{array}$ & $\begin{array}{l}8.7 \mathrm{E}-04 \\
\mathrm{PE}-\mathrm{Ci}\end{array}$ & $\begin{array}{l}1.7 \mathrm{E}-02 \text { rem } \\
(\mathrm{MEI})^{\mathrm{d}}\end{array}$ \\
\hline & $\begin{array}{l}\text { 2. Forklift puncture } \\
\text { of crate in storage dome } \\
\text { ( } 4 \text { drums) }\end{array}$ & $5.0 \mathrm{E}-02$ & $\begin{array}{l}1.0 \mathrm{E}-03 \text { to } \\
5.0 \mathrm{E}-05\end{array}$ & $\begin{array}{l}2.9 \mathrm{E}-04 \\
\mathrm{PE}-\mathrm{Ci}\end{array}$ & $\begin{array}{l}6.8 \mathrm{E}-03 \mathrm{rem} \\
(\mathrm{MEI})\end{array}$ \\
\hline & $\begin{array}{l}\text { 3. Design-basis earthquake in } \\
\text { the storage dome with } \\
\text { multiple drum spill ( } 3 \% \text { of } \\
16,655 \text { drums in the facility } \\
\text { spilled) }\end{array}$ & $5.0 \mathrm{E}-01$ & $\begin{array}{l}1.0 \mathrm{E}-03 \text { to } \\
5.0 \mathrm{E}-05\end{array}$ & $\begin{array}{l}1.2 \mathrm{E}-02 \\
\mathrm{PE}-\mathrm{Ci}\end{array}$ & $\begin{array}{l}2.9 \mathrm{E}-02 \text { rem } \\
(\mathrm{MEI})\end{array}$ \\
\hline & $\begin{array}{l}\text { 4. Drum fire in the retrieval } \\
\text { dome (beyond-design-basis } \\
\text { accident) }\end{array}$ & 1.0 & $5.0 \mathrm{E}-04$ & $\begin{array}{l}1.5 E-01 \\
P E-C i\end{array}$ & $1.4 \mathrm{rem}(\mathrm{MEI})$ \\
\hline \multirow[t]{3}{*}{$\begin{array}{l}\text { INEL SAR for Waste } \\
\text { Storage Facility } \\
\text { (EG\&G 1994b) }\end{array}$} & $\begin{array}{l}\text { 1. Drum fire/explosion } \\
\text { (maximum credible } \\
\text { design basis accident) }\end{array}$ & 1.0 & $1.0 \mathrm{E}-03$ & $1.2 \mathrm{E}-03 \mathrm{Ci}$ & $\begin{array}{l}5.0 \mathrm{E}-02 \text { rem } \\
(\mathrm{MEI})\end{array}$ \\
\hline & $\begin{array}{l}\text { 2. Box spill } \\
\text { ( } 1 \text { box }=15 \text { drums })\end{array}$ & $1.0 \mathrm{E}-01$ & $1.0 \mathrm{E}-04$ & $1.8 \mathrm{E}-03 \mathrm{Ci}$ & $\begin{array}{l}4.2 \text { rem } \\
\text { (worker) }\end{array}$ \\
\hline & $\begin{array}{l}\text { 3. Beyond design basis tornado } \\
\text { with breach } \\
\text { of } 1,440 \text { drums and } \\
576 \text { boxes }\end{array}$ & $\begin{array}{l}1.0 \mathrm{E}-01 \text { (drums) } \\
1.0 \text { (boxes) }\end{array}$ & $1.0 \mathrm{E}-04$ & $1.2 \mathrm{Ci}$ & $\begin{array}{l}9.7 \mathrm{E}-02 \text { rem } \\
(\mathrm{MEI})\end{array}$ \\
\hline \multirow[t]{2}{*}{$\begin{array}{l}\text { SRS Draft EIS } \\
\text { (DOE 1995) }\end{array}$} & $\begin{array}{l}\text { 1. Drum rupture } \\
\text { and fire }\end{array}$ & Not available & Not available & Not available & $\begin{array}{l}7.2 \mathrm{E}-04 \mathrm{rem} \\
(\mathrm{MEI})\end{array}$ \\
\hline & 2. Drum fire in culvert & Not available & Not available & Not available & $\begin{array}{l}2.4 \mathrm{E}-01 \mathrm{rem} \\
(\mathrm{MEI})\end{array}$ \\
\hline
\end{tabular}


TABLE 4.3 (Cont.)

\begin{tabular}{|c|c|c|c|c|c|}
\hline Safety Document & Scenario & $\mathrm{DF}^{\mathrm{a}}$ & ARF or RARFb & Release & Consequence \\
\hline & $\begin{array}{l}\text { 3. Fire caused by } \\
\text { vehicle crash } \\
\text { ( } 28 \text { drums) }\end{array}$ & Not available & Not available & Not available & $\begin{array}{l}\text { 4.4E-02 rem } \\
\text { (MEI) }\end{array}$ \\
\hline & $\begin{array}{l}\text { 4. Drum deflagration in culvert } \\
\text { during drum retrieval }\end{array}$ & Not available & Not available & Not available & $\begin{array}{l}\text { 5.7E-02 rem } \\
(\mathrm{MEI})\end{array}$ \\
\hline \multirow{2}{*}{$\begin{array}{l}\text { ORNL SAR for } \\
\text { Waste Storage } \\
\text { Facility, Bldg. } 7574 \\
\text { (ORNL 1994) }\end{array}$} & $\begin{array}{l}\text { 1. Earthquake with spill of } \\
\text { drums ( } 67 \% \text { of } 1,200 \text { drums } \\
\text { breached) }\end{array}$ & $\begin{array}{l}25 \%(10 \% \text { of } \\
\text { inner packages, if } \\
\text { doubly packaged })\end{array}$ & $\begin{array}{l}8.8 \mathrm{E}-07 \text { to } \\
1.0 \mathrm{E}-03\end{array}$ & \multirow{2}{*}{$\begin{array}{l}\text { Not available } \\
\text { Not available }\end{array}$} & $\begin{array}{l}\text { 5.0E-01 rem } \\
\text { (MEI) }\end{array}$ \\
\hline & 2. Fire (12 drums) & $\begin{array}{l}1.0 \text { (liquid) } \\
0.5 \text { (solid) }\end{array}$ & $\begin{array}{l}1.1 \mathrm{E}-01 \text { (liquid) } \\
\text { to } 5.3 \mathrm{E}-04 \text { (solid) }\end{array}$ & & $\begin{array}{l}\text { 1.0E-01 rem } \\
\text { (MEI) }\end{array}$ \\
\hline $\begin{array}{l}\text { Hazard Classification } \\
\text { and Preliminary } \\
\text { Safety Evaluation } \\
\text { (PSE) for WRAP } \\
\text { Module } 2 \text { (WHC } \\
\text { 1991a) }\end{array}$ & $\begin{array}{l}\text { 1. Seismic impacts with fire in } \\
\text { incoming storage area (size } \\
\text { reduction) }\end{array}$ & 1.0 & $5.3 \mathrm{E}-04$ & $\begin{array}{l}\text { 2.1E-01 } \\
\mathrm{PE}-\mathrm{Ci}\end{array}$ & $\begin{array}{l}3.0 \mathrm{E}-01 \mathrm{rcm} \\
(\mathrm{MEI})\end{array}$ \\
\hline \multirow[t]{2}{*}{$\begin{array}{l}\text { WRAP PSE } \\
\text { (WHC 1991b) }\end{array}$} & $\begin{array}{l}\text { 1. Seismic impacts with fire } \\
\text { in shipping and receiving } \\
\text { area ( } 19 \% \text { of } 100 \text { drums }\end{array}$ & $1.9 \mathrm{E}-01$ & $5.3 \mathrm{E}-04$ & $\begin{array}{l}5.9 E-01 \\
\text { PE-Ci }\end{array}$ & Not available \\
\hline & $\begin{array}{l}\text { and } 4 \text { boxes }) \\
\text { 2. Drum/package spill } \\
\text { ( } 2 \text { drums) }\end{array}$ & $\begin{array}{l}0.5 \text { (1st drum) } \\
0.25 \text { (2nd drum) }\end{array}$ & $\begin{array}{l}1.0 \mathrm{E}-04 \\
(1.0 \mathrm{E}-07 \text { if } \\
\text { filtered })\end{array}$ & $\begin{array}{l}3.7 \mathrm{E}-06 \\
\mathrm{PE}-\mathrm{Ci}\end{array}$ & $\begin{array}{l}\text { 6.0E-03 rem } \\
(\mathrm{MEI})\end{array}$ \\
\hline \multirow[t]{2}{*}{$\begin{array}{l}\text { INEL EIS } \\
\text { (EG\&G 1994a) }\end{array}$} & $\begin{array}{l}\text { 1. Lava flow in TSA } \\
\text { (52,000 stored drums and } \\
\left.5.5 \mathrm{E}+04 \mathrm{~m}^{3} \text { soil covered }\right)\end{array}$ & 0.25 to 0.75 & $\begin{array}{l}1.0 \mathrm{E}-04 \text { to } \\
1.0 \mathrm{E}-07\end{array}$ & $2.7 \mathrm{Ci}$ & Not available \\
\hline & $\begin{array}{l}\text { 2. Aircraft crash into } \\
\text { HFEF WIPP waste } \\
\text { ( } 46 \text { drums) }\end{array}$ & $5.0 \mathrm{E}-01$ & $2.5 \mathrm{E}-04$ & $1.4 \mathrm{E}-02 \mathrm{Ci}$ & Not available \\
\hline
\end{tabular}




\section{TABLE 4.3 (Cont.)}

\begin{tabular}{|c|c|c|c|c|c|}
\hline Safety Document & Scenario & $\mathrm{DF}^{\mathrm{a}}$ & ARF or RARF ${ }^{b}$ & Release & Consequence \\
\hline \multirow[t]{5}{*}{$\begin{array}{l}\text { RWMC SAR } \\
\text { (EG\&G 1993b) }\end{array}$} & $\begin{array}{l}\text { 1. Earthquake-initiated breach } \\
\text { at TSA }(65,443 \text { drums) }\end{array}$ & $1.0 \mathrm{E}-02$ & $1.0 \mathrm{E}-03$ & $7.4 \mathrm{E}-01 \mathrm{Ci}$ & $\begin{array}{l}1.8 \mathrm{E}+00 \text { rem } \\
(\mathrm{MEI})\end{array}$ \\
\hline & $\begin{array}{l}\text { 2. Fuel air explosion and fire at } \\
\text { TSA }\end{array}$ & $\begin{array}{l}2.01 \mathrm{E}-01 \\
\text { (explosion) }\end{array}$ & $\begin{array}{l}1.0 \mathrm{E}-03 \\
\text { (explosion) }\end{array}$ & $1.3 \mathrm{E}+01 \mathrm{Ci}$ & $\begin{array}{l}3.2 \mathrm{E}+01 \mathrm{rem} \\
(\mathrm{MEl})\end{array}$ \\
\hline & 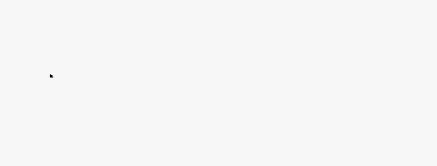 & $5.0 \mathrm{E}-02$ (fire) & $\begin{array}{l}5.0 \mathrm{E}-04 \\
\text { (combustibles) } \\
1.0 \mathrm{E}-05 \\
\text { (noncombustibles) }\end{array}$ & & \\
\hline & $\begin{array}{l}\text { 3. Medium fire at ASB II } \\
\text { caused by propane pipe leak } \\
(9,455 \text { drums })\end{array}$ & $1.0 \mathrm{E}-02$ & $\begin{array}{l}5.0 \mathrm{E}-04 \\
\text { (combustibles) } \\
1.0 \mathrm{E}-05 \\
\text { (noncombustibles) }\end{array}$ & $2.0 \mathrm{E}-02 \mathrm{Ci}$ & $\begin{array}{l}4.8 \mathrm{E}-02 \text { rem } \\
(\mathrm{MEI})\end{array}$ \\
\hline & $\begin{array}{l}\text { 4. Helicopter crash causing a } \\
\text { large fire at ASB II } \\
(9,455 \text { drums })\end{array}$ & $5.0 \mathrm{E}-02$ & $\begin{array}{l}5.0 \mathrm{E}-04 \\
\text { (combustibles) } \\
1.0 \mathrm{E}-05 \\
\text { (noncombustibles) }\end{array}$ & $9.7 \mathrm{E}-02 \mathrm{Ci}$ & $\begin{array}{l}\text { 2.3E-01 rem } \\
(\mathrm{MEI})\end{array}$ \\
\hline
\end{tabular}

a $\mathrm{DF}=$ damage fraction.

b $A R F=$ airborne release fraction; $R A R F=$ respirable airborne release fraction.

c $\mathrm{PE}-\mathrm{Ci}=\mathrm{Pu}-239$-equivalent curies.

d Maximally exposed individual off site.

c $T S A=$ TRUW Storage Area.

f $\mathrm{HFEF}=$ Hot Fuel Examination Facility at ANL-W.

b ASB II = Air Support Building II. 
Furthermore, to determine the number of drums at risk, the number of containers stacked at the third level is reduced by almost $90 \%$ due to interferences in the storage dome. Throughout the PSAR, inventories are expressed in terms of plutonium ( $\mathrm{Pu}-239)$-equivalent curies (PE-Ci). Consequences to the MEI at the site boundary were as follows: $1.7 \mathrm{E}-02,6.8 \mathrm{E}-03,2.9 \mathrm{E}-02$, and 1.4 rem for drum spill, forklift puncture in crate, multiple drum spill caused by earthquake, and drum fire, respectively. The drum spill and forklift puncture in the crate were considered to be anticipated accidents with frequencies greater than $1.0 \mathrm{E}-02 / \mathrm{yr}$. The earthquake accident was considered to be unlikely, with a frequency range between $1.0 \mathrm{E}-02$ and $1.0 \mathrm{E}-04 / \mathrm{yr}$. The beyond-design-basis drum fire was not considered credible, because of a frequency of less than $1.0 \mathrm{E}-06 / \mathrm{yr}$.

The INEL SAR for the Waste Storage Facility identifies three bounding accidents, including a drum fire and explosion, a box spill, and a tornado causing the breach of a large number of waste containers. An earthquake accident is identified but judged to be bounded by the tornado accident. The average concentration of the drums was $0.16 \mathrm{Ci} / \mathrm{ft}^{3}$ (total drum activity of $1.176 \mathrm{Ci}$ ). However, for the box spill accident, the content is taken to be 10 times higher. It is estimated that $99 \%$ of the boxes at $\mathbb{N E L}$ are below this value (a box is equivalent to 15 drums in volume). A box spill accident is estimated to have a frequency of $1.2 \mathrm{E}-01 / \mathrm{yr}$. The drum fire and explosion accident is considered to be the maximum bounding accident within design basis and is estimated to have a frequency of $2.0 \mathrm{E}-06 / \mathrm{yr}$. The tornado accident is considered to be a beyond-design-basis accident with a frequency of $1.0 \mathrm{E}-07 / \mathrm{yr}$. The consequence to the MEI at the site boundary for a tornado accident is estimated to be $9.7 \mathrm{E}-02 \mathrm{rem}$.

The accidents considered in the DOE Programmatic Spent Nuclear Fuel and INEL Environmental Restoration and Waste Management EIS (EG\&G 1994a) involving TRUW were a lava flow over the entire RWMC and an aircraft crash. The molten lava flow caused by a volcanic eruption was determined to be a reasonable foreseeable bounding accident with an estimated frequency of $2.0 \mathrm{E}-05 / \mathrm{yr}$. Although the RWMC includes waste management operations involving LLMW, LLW, and TRUW, the results shown in Table F.4-1 are for CH-TRUW stored in the Transuranic Storage Area (TSA) inside the inflated Air Support Weather Shield buildings. TRUW at TSA consists of approximately $10,400 \mathrm{~m}^{3}$ stored in drums $\left(52,000\right.$ drums) and $55,000 \mathrm{~m}^{3}$ of soilcovered waste. The waste is assumed to come into direct contact with the lava. A two-phased release is assumed to take place. In the first phase, the combustible fraction of the waste is assumed to burn with a release fraction similar to a sustained fire. In the second phase, the remaining waste (noncombustible) is assumed to be mixed with the molten lava resulting in a release similar to offgassing from a vitrification process. The aircraft accident in the INEL EIS assumes that a large commercial jet crashes into the Hot Fuel Examination Facility (HFEF) at ANL-W. This accident is considered to be the bounding externally initiated event because it could cause a major breach of barriers, involve large MARs, and have a high-energy impact resulting in a fire. The frequency of this accident is estimated to be in the range of $1.0 \mathrm{E}-06$ to $1.0 \mathrm{E}-08$ per year. The waste present in the HFEF includes 20 fresh fuel assemblies, 50 stored subassemblies, and 46 drums of WIPP TRUW. 
However, the results presented in Table 4.3 are pertinent to WIPP TRUW only. The number of drums affected by the crash is assumed to be 23, with an ARF of 5.0E-04 and a RF of 5.0E-01.

The SRS EIS (DOE 1995) identifies four representative bounding accidents associated with management of TRUW. These accidents include an internally induced drum rupture and fire, a drum fire in the culvert, a vehicle crash causing a drum fire, and a deflagration event in the culvert during TRUW retrieval activities involving a single drum. The SRS EIS reports consequence results for these accidents but does not include releases and source term parameters such as DFs, ARF, and RARF. All these accidents except the vehicle crash involve a single drum, on the basis of the assumption that the other drums are sealed with a gasket and the lids are secured with metal ring clamps, and, therefore, the fire would not propagate to these drums. The internally induced drum rupture and fire is assumed to occur because of overpressurization due to gas buildup from radiolytic decomposition of cellulosic waste and the ignition of the generated hydrogen. The frequency of such an accident is estimated to be $2.1 \mathrm{E}-02 / \mathrm{yr}$. The drum fire in the culvert is also assumed to be caused by hydrogen gas generated through radiolytic decomposition of organic waste and is estimated to have a frequency of $8.1 \mathrm{E}-04 / \mathrm{yr}$. The vehicle crash with resulting fire at the TRUW storage pads is assumed to involve 28 drums with an estimated frequency of $6.5 \mathrm{E}-05 / \mathrm{yr}$. The drum deflagration in the culvert is assumed to be caused by a flammable gas mixture of hydrogen and air that could exist inside a drum as the result of radiolysis of polyethylene wrappings. This accident is estimated to have a frequency of $1.0 \mathrm{E}-02 / \mathrm{yr}$.

The ORNL SAR for the Waste Storage Facility, Building 7574 (ORNL 1994) identifies two events as the worst-case bounding accidents: spill of drums caused by earthquake and fire inside the building affecting a stack of drums. Building 7574 at ORNL is used to store TRUW and solid LLW. The waste may contain liquids and powders. Some of the waste may be placed in plastic liners inside the drums. The maximum number of drums that can be stored in the building is 1,200 . These drums are stored in an array of four drums per pallet and stacked three pallets high. In the earthquake accident, only $67 \%$ of the total number of drums is assumed to be breached (the second and third levels). Twenty-five percent of the drum content is assumed to be spilled. If the waste is placed in a plastic liner, then only $10 \%$ is assumed to be spilled. The frequency of an earthquake causing waste containers to fall is considered to be in the range of $1.0 \mathrm{E}-02$ to $1.0 \mathrm{E}-04$ per year. The consequence to an individual at the boundary of the site is estimated to be less than $0.5 \mathrm{rem}$ for this accident. The fire accident inside the building is assumed to affect up to one stack of 12 drums. Liquid waste is considered to be flammable and to burn completely. The remainder of the waste is assumed to be $50 \%$ combustible. The frequency of a fire accident is considered to be in the range of $1.0 \mathrm{E}-02$ to $1.0 \mathrm{E}-04 / \mathrm{yr}$. The consequence from such an accident to the individual at the boundary of the site is estimated to be less than 0.1 rem. Release in terms of curies is not reported in this SAR.

The WRAP facilities, as originally configured, were designed to be constructed as a series of modules, including units to process $\mathrm{CH}$ (Module 1)- and RH (Module 2)-TRUW waste. A subsequent project reconfiguration resulted in redefinition of the module missions such that 
Module 2 would have been intended to handle and treat radioactive mixed waste (as discussed below). A Hazard Classification and Preliminary Safety Evaluation (WHC 1991a) identified and analyzed a set of accident scenarios to characterize the range of potential hazards for the WRAP Module 1 operation. Consistent with DOE guidance on hazard class determination, the range of accidents analyzed included worst-case scenarios resulting in completely unmitigated releases. The accident scenarios addressed both waste treatment and packaged waste lag storage and included drum spill, metal box drop and breach, liquid spill from waste pump, drop of a failed HWVP melter, and the most applicable one to the WM PEIS, a design-basis earthquake (DBE). The applicable portion of the WRAP 2 scenario is the earthquake-initiated fire in the size reduction area (the Incoming Storage area). A release fraction of 5.3E-04 is assumed for the fire affecting 30 drums in the lag storage area. A maximally exposed off-site individual is estimated to receive a dose of $0.3 \mathrm{rem}$ with an accident frequency of 1.0E-03/yr. No credit is taken in for HEPA filtration.

In a precursor report (WHC 1991b), the prototype concept of a WRAP facility was analyzed for the effects of a DBE. In the preconceptual design phase, the WRAP I module was scoped to handle and process CH TRUW. The Shipping and Receiving area was scoped to provide lag storage for 100 drums and 4 boxes. The waste packages are damaged by falling girders and portions of the roof. On the basis of estimates of debris and the geometry of the storage array, 19\% of the waste packages are estimated to be breached. The resulting fire is assumed to result in a release fraction of 5.3E-04. Aggregate dose consequences were estimated for the total facility release, but no estimates were provided for the contribution from lag storage.

In reviewing the cited analyses, it was observed that there is considerable variation in the assumptions used by the various DOE sites to develop accidents and associated source term parameters. However, it appears from the analyses that overall, the risks to the public health resulting from storage facility accidents would be small, although the predicted releases are greater than those from LLMW accidents (see Section 6).

It should be noted that explicitly analyzing risks from storage would not help to discriminate among alternatives because of the assumption used in the WM PEIS for estimating the treatment throughputs, which dictate the inventories to be stored prior to treatment. This assumption is that all sites will accumulate or at least not reduce these inventories for roughly 10 years, at which time complexwide treatment will begin. Thus, all sites will achieve their maximum inventories (leading to maximum potential releases during a storage facility accident) independent of alternative.

\subsubsection{Treatment Facility Accidents}

Assessments have shown that incineration is the treatment technology most likely to dominate risk to facility and site staff, as well as to the surrounding general populations. Severe radiological accidents investigated herein focus on sequences involving fire and explosions capable 
of producing large airborne releases of the highly dispersible ash present in the various components of incinerators.

A generic treatment facility, consisting of a series of linked process modules, each providing a specific treatment process, was defined to assess the releases from accidents (see Section 2). A DOE Hazard Category of 2 and concomitant structural performance requirements on its systems were assumed. Double HEPA filtration systems were assumed to be in place (see Section 2). The inventory was based on the facility throughput at each site. Volumetric inventories and physical and radiological compositions for each waste treatability category were considered at each site for each alternative.

Accidents investigated included operation-induced facility fires and external-event-induced fires and explosions. Treatment facility accident sequences analyzed include:

- A fire in the baghouse area of an incineration facility causing a complete failure of the filtration systems ( $\mathrm{LPF}=1$ ), with a damage fraction of $3.0 \mathrm{E}-02$ of the total amount of ash existing in the facility available for release at the time of the accident $(\mathrm{DF}=3.0 \mathrm{E}-02)$;

- A rotary kiln explosion caused by combustible gas buildup that affects the ash existing in the rotary kiln (a damage fraction of 1.2E-01 of the total in the facility available for release at the time of the accident; $\mathrm{DF}=1.2 \mathrm{E}-01$ ) and partially degrades the filtration system of the facility $(\mathrm{LPF}=1.0 \mathrm{E}-03)$; and

- External events leading to a fire. External-event source term parameters vary according to the particular sequence.

All accidents are assumed to be ground-level releases without filtration with the exception of the rotary kiln explosion accident where a stack emission and partial HEPA filtration is assumed with a remaining efficiency of $99.9 \%(\mathrm{LPF}=1.0 \mathrm{E}-03)$.

\subsection{RESULTS}

Preliminary results for the accident sequences described above were reviewed to determine the risk for risk-dominant sequences by using the frequency-weighted dose to the MEI. The results were then grouped into four annual frequency categories: likely $(>1.0 \mathrm{E}-02)$, unlikely (between $1.0 \mathrm{E}-02$ and $1.0 \mathrm{E}-04$ ), extremely unlikely (between $1.0 \mathrm{E}-04$ and $1.0 \mathrm{E}-06$ ), and not credible $(<1.0 \mathrm{E}-06)$. Representative source terms for the important sequences were then selected as the bases for health effects calculations. Of the treatment technologies, only source terms for incineration 
facility accidents are provided because incineration facility accidents were found to bound other treatment accidents, including wet-air oxidation.

Table 4.4 gives the WM TRUW facility accidents that. were considered for analysis. The cases analyzed are described as follows:

- Case 6 (Regionalized 2). Five sites (Hanford, INEL, LANL, RFETS, and SRS) treat CH-TRUW to LDR levels. Disposal of treated TRUW is at WIPP.

- Case 8 (Regionalized 3). Three sites (Hanford, INEL, and SRS) treat CH-TRUW to LDR levels. Disposal of treated TRUW is at WIPP.

- Case 9 (Centralized). One site (WIPP) treats CH-TRUW to LDR levels. Disposal of treated TRUW is at WIPP.

- Case 15 (Remote-handled). Two sites (Hanford and ORR) treat RH-TRUW to LDR levels. Disposal of treated TRUW is at WIPP.

Table 4.5 summarizes the radiological source terms and frequencies for drum handling accidents at TRUW facilities. Table 4.6 summarizes the radiological source terms and frequencies for incineration facility accidents. Detailed radionuclide releases are provided in Appendix B. 
TABLE 4.4 Summary of WM TRUW Accidents Analyzed ${ }^{a}$

\begin{tabular}{|c|c|c|c|c|c|c|c|c|}
\hline \multirow[b]{2}{*}{ Function } & \multirow[b]{2}{*}{$\begin{array}{c}\text { WM PEIS } \\
\text { Alternative }\end{array}$} & \multirow[b]{2}{*}{ Site } & \multicolumn{3}{|c|}{ Operational Events } & \multicolumn{3}{|c|}{ External Events } \\
\hline & & & $\begin{array}{l}\text { Handling } \\
\text { Breaches }\end{array}$ & $\begin{array}{l}\text { Facility } \\
\text { Fire }\end{array}$ & $\begin{array}{l}\text { Facility } \\
\text { Explosion }\end{array}$ & Seismic & $\begin{array}{l}\text { Large } \\
\text { Aircraft }\end{array}$ & $\begin{array}{c}\text { Small } \\
\text { Aircraft }\end{array}$ \\
\hline \multirow[t]{9}{*}{ Drum handling } & All & ANL-W & $\mathrm{X}$ & - & - & - & - & - \\
\hline & All & Hanford & $\mathrm{X}$ & - & - & - & - & - \\
\hline & All & INĖL & $\mathrm{X}$ & - & - & - & - & - \\
\hline & All & LANL & $\mathrm{X}$ & - & - & - & - & - \\
\hline & All & LLNL & $X$ & - & - & - & - & - \\
\hline & All & Mound & $\mathrm{X}$ & - & - & - & - & - \\
\hline & All & ORNL & $\mathrm{X}$ & - & - & - & - & - \\
\hline & All & RFETS & $\mathrm{X}$ & - & - & - & - & - \\
\hline & All & SRS & $\mathrm{X}$ & - & - & - & - & - \\
\hline \multirow[t]{9}{*}{$\alpha$-Incineration ${ }^{b}$} & 6 & Hanford & - & $\mathrm{X}$ & $\mathrm{X}$ & $\mathrm{X}$ & - & - \\
\hline & 6 & INEL & - & $\mathrm{x}$ & $x$ & $\mathrm{x}$ & - & - \\
\hline & 6 & LANL & - & $X$ & $\mathrm{x}$ & $\mathrm{x}$ & - & - \\
\hline & 6 & RFETS & - & $\mathrm{x}$ & $\mathrm{x}$ & $\mathrm{x}$ & - & - \\
\hline & 6 & SRS & - & $\mathrm{X}$ & $\mathrm{x}$ & $\mathrm{x}$ & - & - \\
\hline & 8 & Hanford & - & $\mathrm{x}$ & $\mathrm{x}$ & $\mathrm{x}$ & - & - \\
\hline & 8 & INEL & - & $\mathrm{X}$ & $\mathrm{x}$ & $\mathrm{x}$ & - & - \\
\hline & 8 & SRS & - & $\mathrm{X}$ & $\mathrm{X}$ & $x$ & - & - \\
\hline & 9 & WIPP & - & $\mathrm{X}$ & $\mathrm{x}$ & $\mathbf{x}$ & - & - \\
\hline \multirow[t]{2}{*}{ r-Incineration ${ }^{c}$} & 15 & Hanford & - & $\mathrm{x}$ & $\mathrm{X}$ & $\mathrm{x}$ & - & - \\
\hline & 15 & ORNL & - & $x$ & $\mathrm{x}$ & $\mathrm{x}$ & - & - \\
\hline
\end{tabular}

a Only one source term, generally corresponding to the risk-dominant sequence for each accident initiator, was considered. The WM PEIS cases analyzed are described as follows:

- Case 6 (Regionalized 2). Five sites (Hanford, INEL, LANL, RFETS, and SRS) treat CH-TRUW to LDR levels. Disposal of treated TRUW is at WIPP.

- Case 8 (Regionalized 3). Three sites (Hanford, INEL, and SRS) treat CH-TRUW to LDR levels. Disposal of treated TRUW is at WIPP.

- Case 9 (Centralized). One site (WIPP) treats CH-TRUW to LDR levels. Disposal of treated TRUW is at WIPP.

- Case 15 (Remote-handled). Two sites (Hanford and ORR) treat RH-TRUW to LDR levels. Disposal of treated TRUW is at WIPP.

b $\alpha$-Incineration refers to incineration of waste categorized as alpha-emitting.

c r-Incineration refers to incineration of $\mathrm{RH}$ waste. 
TABLE 4.5 Frequencies and Source Term Parameters for WM TRUW Drum Handling Accidents

\begin{tabular}{|c|c|c|c|c|c|c|c|c|c|}
\hline \multirow[b]{2}{*}{$\begin{array}{l}\text { WM PEIS } \\
\text { Alternative }\end{array}$} & \multirow[b]{2}{*}{ Site } & \multicolumn{4}{|c|}{ Frequency $\mathrm{Bin}(/ \mathrm{yr})$} & \multicolumn{3}{|c|}{ Source Term Parameters } & \multirow{2}{*}{$\begin{array}{c}\text { Total } \\
\text { Release } \\
\text { (Ci) }\end{array}$} \\
\hline & & $>1.0 \mathrm{E}-0.2$ & $\begin{array}{c}1.0 \mathrm{E}-0.4 \text { to } \\
1.0 \mathrm{E}-0.2\end{array}$ & $\begin{array}{c}1.0 \mathrm{E}-0.6 \text { to } \\
1.0 \mathrm{E}-0.4\end{array}$ & $<1.0 \mathrm{E}-0.6$ & $\begin{array}{l}\operatorname{VMAR}^{\mathrm{a}} \\
\left(\mathrm{m}^{3}\right)\end{array}$ & $\begin{array}{c}\text { MAR } \\
(\mathrm{Ci})\end{array}$ & DF & \\
\hline All & ANL-W & $\mathrm{X}$ & $N A^{b}$ & NA & NA & $2.0 \mathrm{E}-01$ & $1.2 E+00$ & 0.25 & $2.0 \mathrm{E}-04$ \\
\hline All & Hanford & $\mathrm{X}$ & NA & NA & NA & $2.0 \mathrm{E}-01$ & $3.0 \mathrm{E}+00$ & 0.25 & $4.2 \mathrm{E}-04$ \\
\hline All & LANL & $\mathrm{X}$ & NA & NA & NA & $2.0 \mathrm{E}-01$ & $3.6 E+00$ & 0.25 & $7.9 \mathrm{E}-04$ \\
\hline All & LLNL & $\mathrm{X}$ & NA & NA & NA & $2.0 \mathrm{E}-01$ & $4.0 \mathrm{E}+00$ & 0.25 & $1.0 \mathrm{E}-03$ \\
\hline All & RFETS & $\mathrm{x}$ & NA & NA & $\mathrm{NA}$ & $2.0 \mathrm{E}-01$ & $6.1 E+00$ & 0.25 & $1.4 \mathrm{E}-03$ \\
\hline All & SRS & $\mathrm{X}$ & NA & NA & NA & $2.0 \mathrm{E}-01$ & $2.2 \mathrm{E}+01$ & 0.25 & $2.7 E-03$ \\
\hline
\end{tabular}

a $\mathrm{VMAR}=$ volume of material at risk.

b $\mathrm{NA}=$ not applicable. 
TABLE 4.6 Summary of Source Terms for TRUW Incineration Facility Accidents

\begin{tabular}{|c|c|c|c|c|c|c|c|}
\hline Site & Accident & $\begin{array}{c}\text { VMAR } \\
\left(\mathrm{m}^{3}\right)\end{array}$ & $\begin{array}{c}\text { MAR } \\
(\mathrm{Ci})\end{array}$ & $\mathrm{TRF}^{\mathrm{a}}$ & $\begin{array}{c}\text { Source } \\
\text { Term (Ci) }\end{array}$ & $\begin{array}{c}\text { Frequency } \\
\text { (/yr) }\end{array}$ & $\begin{array}{l}\text { Frequency } \\
\text { Category }\end{array}$ \\
\hline \multicolumn{8}{|c|}{ Case 6 (Regionalized 2) } \\
\hline Hanford & Explosion in the rotary kiln & $1.9 \mathrm{E}-01$ & $7.4 \mathrm{E}+01$ & $8.4 \mathrm{E}-06$ & $6.2 \mathrm{E}-04$ & $1.5 \mathrm{E}-02$ & I \\
\hline Hanford & Fire in the baghouse area & $1.9 \mathrm{E}-01$ & $7.4 \mathrm{E}+01$ & $1.8 \mathrm{E}-06$ & $1.3 \mathrm{E}-04$ & $1.0 \mathrm{E}-03$ & II \\
\hline Hanford & Earthquake with fireball blasting HEPA filter & $1.9 \mathrm{E}-01$ & $7.4 \mathrm{E}+01$ & $4.6 \mathrm{E}-04$ & $3.4 \mathrm{E}-02$ & $1.2 \mathrm{E}-05$ & III \\
\hline INEL & Explosion in the rotary kiln & $1.0 \mathrm{E}+00$ & $2.1 \mathrm{E}+02$ & $8.4 \mathrm{E}-06$ & $1.8 \mathrm{E}-03$ & $1.5 \mathrm{E}-02$ & I \\
\hline INEL & Fire in the baghouse area & $1.0 \mathrm{E}+00$ & $2.1 \mathrm{E}+02$ & $1.8 \mathrm{E}-06$ & $3.8 \mathrm{E}-04$ & $1.0 \mathrm{E}-03$ & II \\
\hline INEL & Earthquake with fireball blasting HEPA filter & $1.0 \mathrm{E}+00$ & $2.1 \mathrm{E}+02$ & $4.6 \mathrm{E}-04$ & $9.7 \mathrm{E}-02$ & $1.2 \mathrm{E}-05$ & III \\
\hline LANL & Explosion in the rotary kiln & $6.2 \mathrm{E}-01$ & $2.1 \mathrm{E}+02$ & $8.4 \mathrm{E}-06$ & $1.7 \mathrm{E}-03$ & $1.5 \mathrm{E}-02$ & 1 \\
\hline LANL & Fire in the baghouse area & $6.2 \mathrm{E}-01$ & $2.1 \mathrm{E}+02$ & $1.8 \mathrm{E}-06$ & $3.7 \mathrm{E}-04$ & $1.0 \mathrm{E}-03$ & II \\
\hline LANL & Earthquake with fireball blasting HEPA filter & $6.2 \mathrm{E}-01$ & $2.1 \mathrm{E}+02$ & $4.6 E-04$ & $9.5 \mathrm{E}-02$ & $1.2 \mathrm{E}-05$ & III \\
\hline RFETS & Explosion in the rotary kiln & $8.8 \mathrm{E}-02$ & $5.3 \mathrm{E}+01$ & $8.4 \mathrm{E}-06$ & $4.4 \mathrm{E}-04$ & $1.5 \mathrm{E}-02$ & 1 \\
\hline RFETS & Fire in the baghouse area & $8.8 \mathrm{E}-02$ & $5.3 \mathrm{E}+01$ & $1.8 \mathrm{E}-06$ & $9.5 \mathrm{E}-0.5$ & $1.0 \mathrm{E}-03$ & 11 \\
\hline RFETS & Earthquake with fireball blasting HEPA filter & $8.8 \mathrm{E}-02$ & $5.3 \mathrm{E}+01$ & $4.6 \mathrm{E}-04$ & $2.4 \mathrm{E}-02$ & $1.2 \mathrm{E}-05$ & III \\
\hline SRS & Explosion in the rotary kiln & $1.6 \mathrm{E}-02$ & $1.1 \mathrm{E}+00$ & $8.4 \mathrm{E}-06$ & $9.2 \mathrm{E}-06$ & $1.5 \mathrm{E}-02$ & I \\
\hline SRS & Fire in the baghouse area & $1.6 \mathrm{E}-02$ & $1.1 \mathrm{E}+00$ & $1.8 \mathrm{E}-06$ & $2.0 \mathrm{E}-06$ & $1.0 \mathrm{E}-03$ & II \\
\hline SRS & Earthquake with fireball blasting HEPA filter & $1.6 \mathrm{E}-02$ & $1.1 \mathrm{E}+00$ & $4.6 \mathrm{E}-04$ & $5.0 \mathrm{E}-04$ & $1.2 \mathrm{E}-05$ & III \\
\hline
\end{tabular}


TABLE 4.6 (Cont.)

\begin{tabular}{|c|c|c|c|c|c|c|c|}
\hline Site & Accident & $\begin{array}{c}\text { VMAR } \\
\left(\mathrm{m}^{3}\right)\end{array}$ & $\begin{array}{c}\text { MAR } \\
(\mathrm{Ci})\end{array}$ & $\mathrm{TRF}^{\mathrm{a}}$ & $\begin{array}{c}\text { Source } \\
\text { Term (Ci) }\end{array}$ & $\begin{array}{c}\text { Frequency } \\
\text { (/yr) }\end{array}$ & $\begin{array}{l}\text { Frequency } \\
\text { Category }^{b}\end{array}$ \\
\hline \multicolumn{8}{|c|}{ Case 8 (Regionalized 3) } \\
\hline Hanford & Explosion in the rotary kiln & $1.9 \mathrm{E}-01$ & $7.4 \mathrm{E}+01$ & $8.4 \mathrm{E}-06$ & $6.2 \mathrm{E}-04$ & $1.5 \mathrm{E}-02$ & $\mathrm{I}$ \\
\hline Hanford & Fire in the baghouse area & $1.9 \mathrm{E}-01$ & $7.4 \mathrm{E}+01$ & $1.8 \mathrm{E}-06$ & $1.3 \mathrm{E}-04$ & $1.0 \mathrm{E}-03$ & II \\
\hline Hanford & Earthquake with fireball blasting HEPA filter & $1.9 \mathrm{E}-01$ & $7.4 \mathrm{E}+01$ & $4.6 \mathrm{E}-04$ & $3.4 \mathrm{E}-02$ & $1.2 \mathrm{E}-05$ & ill \\
\hline INEL & Explosion in the rotary kiln & $1.7 \mathrm{E}+00$ & $4.7 \mathrm{E}+02$ & $8.4 \mathrm{E}-06$ & $4.0 \mathrm{E}-03$ & $1.5 \mathrm{E}-02$ & 1 \\
\hline INEL & Fire in the baghouse area & $1.7 \mathrm{E}+00$ & 4.7E+02 & $1.8 \mathrm{E}-06$ & $8.5 \mathrm{E}-04$ & $1.0 \mathrm{E}-03$ & II \\
\hline INEL & Earthquake with fireball blasting HEPA filter & $1.7 \mathrm{E}+00$ & $4.7 \mathrm{E}+02$ & $4.6 \mathrm{E}-04$ & $2.2 \mathrm{E}-01$ & $1.2 \mathrm{E}-05$ & III \\
\hline SRS & Explosion in the rotary kiln & $1.6 \mathrm{E}-02$ & $1.1 \mathrm{E}+00$ & $8.4 \mathrm{E}-06$ & $9.2 \mathrm{E}-06$ & $1.5 \mathrm{E}-02$ & $\mathbf{I}$ \\
\hline SRS & Fire in the baghouse area & $1.6 \mathrm{E}-02$ & $1.1 \mathrm{E}+00$ & $1.8 \mathrm{E}-06$ & $2.0 \mathrm{E}-06$ & $1.0 \mathrm{E}-03$ & II \\
\hline SRS & Earthquake with fireball blasting HEPA filter & $1.6 \mathrm{E}-02$ & $1.1 \mathrm{E}+00$ & $4.6 \mathrm{E}-04$ & $5.0 \mathrm{E}-04$ & $1.2 \mathrm{E}-05$ & III \\
\hline
\end{tabular}

\section{Case 9 (Centralized)}

\begin{tabular}{|c|c|c|c|c|c|c|c|}
\hline WIPP & Explosion in the rotary kiln & $1.9 \mathrm{E}+00$ & $5.5 \mathrm{E}+02$ & $8.4 \mathrm{E}-06$ & $4.6 \mathrm{E}-03$ & $1.5 \mathrm{E}-02$ & I \\
\hline WIPP & Fire in the baghouse area & $1.9 \mathrm{E}+00$ & $5.5 \mathrm{E}+02$ & $1.8 \mathrm{E}-06$ & $9.9 \mathrm{E}-04$ & $1.0 \mathrm{E}-03$ & II \\
\hline WIPP & Earthquake with fireball blasting HEPA filter & $1.9 \mathrm{E}+00$ & $5.5 \mathrm{E}+02$ & 4.6E-04 & $2.5 \mathrm{E}-01$ & $1.2 \mathrm{E}-05$ & III \\
\hline
\end{tabular}

Case 15 (Remote-handled)

\begin{tabular}{|c|c|c|c|c|c|c|c|}
\hline Hanford & Explosion in the rotary kiln & $4.6 \mathrm{E}-03$ & $1.7 \mathrm{E}+00$ & $8.4 \mathrm{E}-06$ & $1.5 \mathrm{E}-05$ & $1.5 \mathrm{E}-02$ & I \\
\hline Hanford & Fire in the baghouse area & $4.6 \mathrm{E}-03$ & $1.7 \mathrm{E}+00$ & $1.8 \mathrm{E}-06$ & $3.1 \mathrm{E}-06$ & $1.0 \mathrm{E}-03$ & II \\
\hline Hanford & Earthquake with fireball blasting HEPA filter & $4.6 \mathrm{E}-03$ & $1.7 \mathrm{E}+00$ & $4.6 \mathrm{E}-04$ & $8.0 \mathrm{E}-04$ & $1.2 \mathrm{E}-05$ & III \\
\hline ORNL & Fire in the baghouse area & $4.2 \mathrm{E}-02$ & $3.4 \mathrm{E}+01$ & $1.8 \mathrm{E}-06$ & $6.0 \mathrm{E}-05$ & $1.0 \mathrm{E}-03$ & II \\
\hline ORNL & Earthquake with fireball blasting HEPA filter & $4.2 \mathrm{E}-02$ & $3.4 \mathrm{E}+01$ & $4.6 \mathrm{E}-04$ & $1.5 \mathrm{E}-02$ & $1.2 \mathrm{E}-05$ & III \\
\hline
\end{tabular}

a $T R F=$ total release fraction.

b Frequency categories are defined as follows: $\mathrm{I}=$ likely $(>1.0 \mathrm{E}-02 / \mathrm{yr}) ; \mathrm{II}=$ unlikely (between $1.0 \mathrm{E}-02 / \mathrm{yr}$ and $1.0 \mathrm{E}-04 / \mathrm{yr}) ; \mathrm{III}=$ extremely unlikely (between 1.0E-04/yr and 1.0E-06/yr); and IV $=$ not credible $(<1.0 \mathrm{E}-06 / \mathrm{yr}$ ). 


\section{ACCIDENT ANALYSIS FOR LOW-LEVEL WASTE}

\subsection{OVERVIEW OF LOW-LEVEL WASTE MANAGEMENT}

LLW includes all radioactive waste not classified as HLW, TRUW, SNF, or most of the by-product material defined in Section 11(e) 2 of the Atomic Energy Act of 1954. When chemically hazardous components regulated under RCRA are present, the waste is referred to as LLMW. A specific category of LLW considered separately for risk impact analysis is referred to as Greater-than-Class-C (GTCC). This category, which has concentrations of radionuclides exceeding thresholds specified in 10 CFR 61.55, is discussed in Section 7 of this report.

LLW results from a variety of DOE activities, including defense-related activities and the processing of special nuclear materials and energy research and development activities. It ranges from low-activity waste that can be disposed of without treatment by engineered, shallow land disposal techniques, to higher-activity waste requiring the use of treatment and disposal techniques that provide greater confinement. Operations waste includes contaminated equipment (components and maintenance waste), contaminated dry solids, and solidified sludges from processing (e.g., evaporator bottoms).

LLW is also generated during environmental restoration (ER) activities from the treatment of contaminated environmental media such as soil, groundwater, surface water, and underlying sediments. LLW generated during D\&D of surplus facilities includes (1) neutron-activated wastes such as a nuclear reactor vessel and its internal components; (2) surface-contaminated wastes, including radioactively contaminated concrete walls and process piping; and (3) miscellaneous wastes such as spent ion-exchange resins, cartridge filters, and discarded contaminated items such as tools and contaminated clothing.

LLW is generated at more than 30 sites. The major waste generators are SRS, Oak Ridge Reservation (ORR), LANL, Hanford, and Portsmouth Gaseous Diffusion Plant (PORTS) (by volume for 1991 generation data). Site-specific WAC affect the type and quantity of disposed materials. All DOE sites must minimize the quantities of generated waste, with commercial and on-site volume reduction emphasized to minimize the use of disposal land areas. LLW from ER activities is generated during the cleanup of sites contaminated by radioactive waste and from contaminated facilities. Generally, these ER sites and facilities were initially associated with the production of materials for national defense. LLW from previous ER activities has either been shipped to one of the six disposal sites or retained on-site under controls commensurate with a site-specific plan. As ER activities continue, the number of sites with ER-derived LLW will increase. However, ER LLW is excluded from consideration in the WM PEIS.

Table 5.1 summarizes the waste management alternatives and specific cases currently under evaluation in the WM PEIS. Each case results in distinct inventories for potential TSD at each DOE site. The table provides an abbreviated case description and treatment (T) and disposal (D) codes 


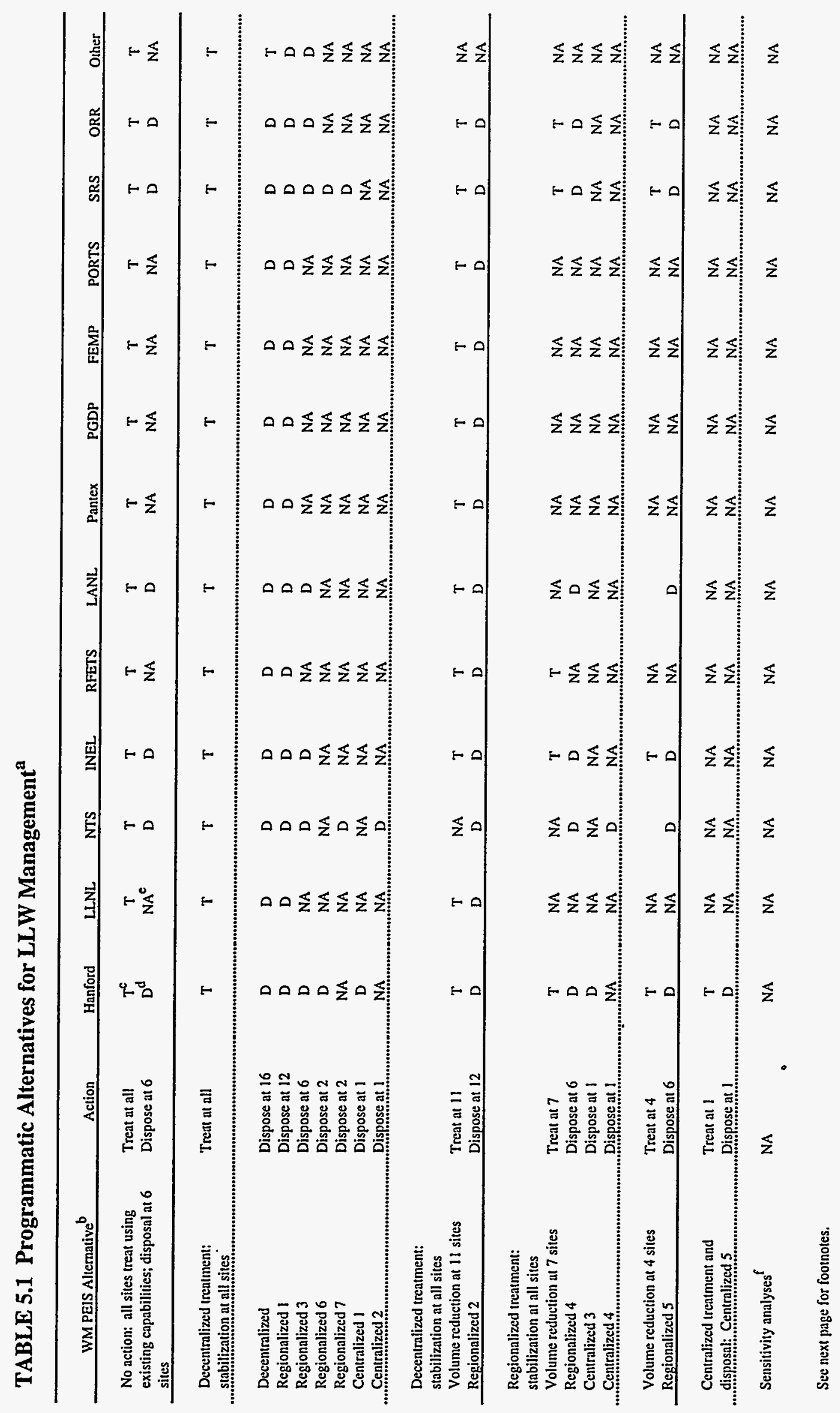




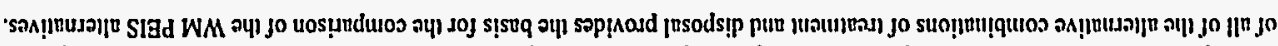

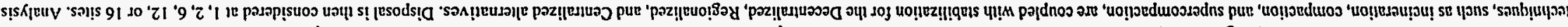

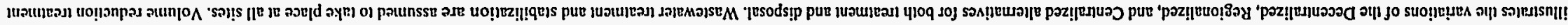

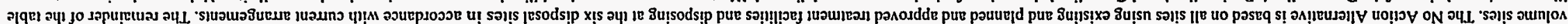
is

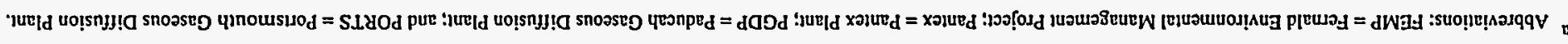


for each of the 16 highest-volume sites. The No Action Alternative is based upon all sites using existing and planned and approved treatment facilities and disposing at the six disposal sites in accordance with current arrangements. The remainder of the table illustrates the variations of the decentralized, regionalized, and centralized alternatives for both treatment and disposal. Wastewater treatment and stabilization is assumed to take place at all sites. Volume reduction treatment techniques such as incineration, compaction, and supercompaction are coupled with stabilization for decentralized, regionalized and centralized alternatives. Disposal is then considered at $1,2,6,12$, or 16 sites. Analysis of all the alternative combinations of treatment and disposal provides the basis for the comparison of the WM PEIS alternatives.

The treatment technologies employed are dependent on the physical characteristics of the waste and the final waste form as defined by the site-specific WAC. LLW is treated primarily for volume reduction or for rendering the waste more suitable for disposal. Ten representative treatment technologies with associated process options for the TSD of LLW are considered in the WM PEIS. Detailed descriptions of treatment processes can be found in Goyette and Dolak (1996). Process options encompass (1) incineration, (2) solidification, (3) vitrification, (4) compaction and supercompaction, (5) size reduction (e.g., shredding, metal cutting, and shearing), (6) evaporation, (7) general aqueous treatment, and (8) various waste packaging alternatives. Disposal alternatives include shallow land burial, above-ground vault/tumulus, below-ground vault, or enhanced confinement structures. Figure 5.1 identifies the representative physical waste types or treatability categories, possible waste management technologies, and the potential flow paths of the waste during treatment.

\subsection{RISK-DOMINANT ACCIDENTS.AND MODELING ASSUMPTIONS}

Accident selection has been based on potential risk dominance, with the general modeling assumptions and related source term parameters described in Section 2. The RARFs are a function of the physical form of the material rendered airborne, which varies by treatability category for each waste type. A matrix has been developed for each waste type to map the treatability categories into the physical forms for which airborne release data (Appendix D) were developed. The LLW mapping, shown in Table 5.2, is based on the WM PEIS waste and process descriptions (Feizollahi and Shropshire 1992; Goyette and Dolak 1996).

\subsubsection{Handling Accidents}

Storage or staging operations and related handling accidents were investigated because they are expected to dominate the exposure risk to workers due to their frequency and to the proximity of the workers to waste in hands-on operations. Representative handling accidents involve a single 


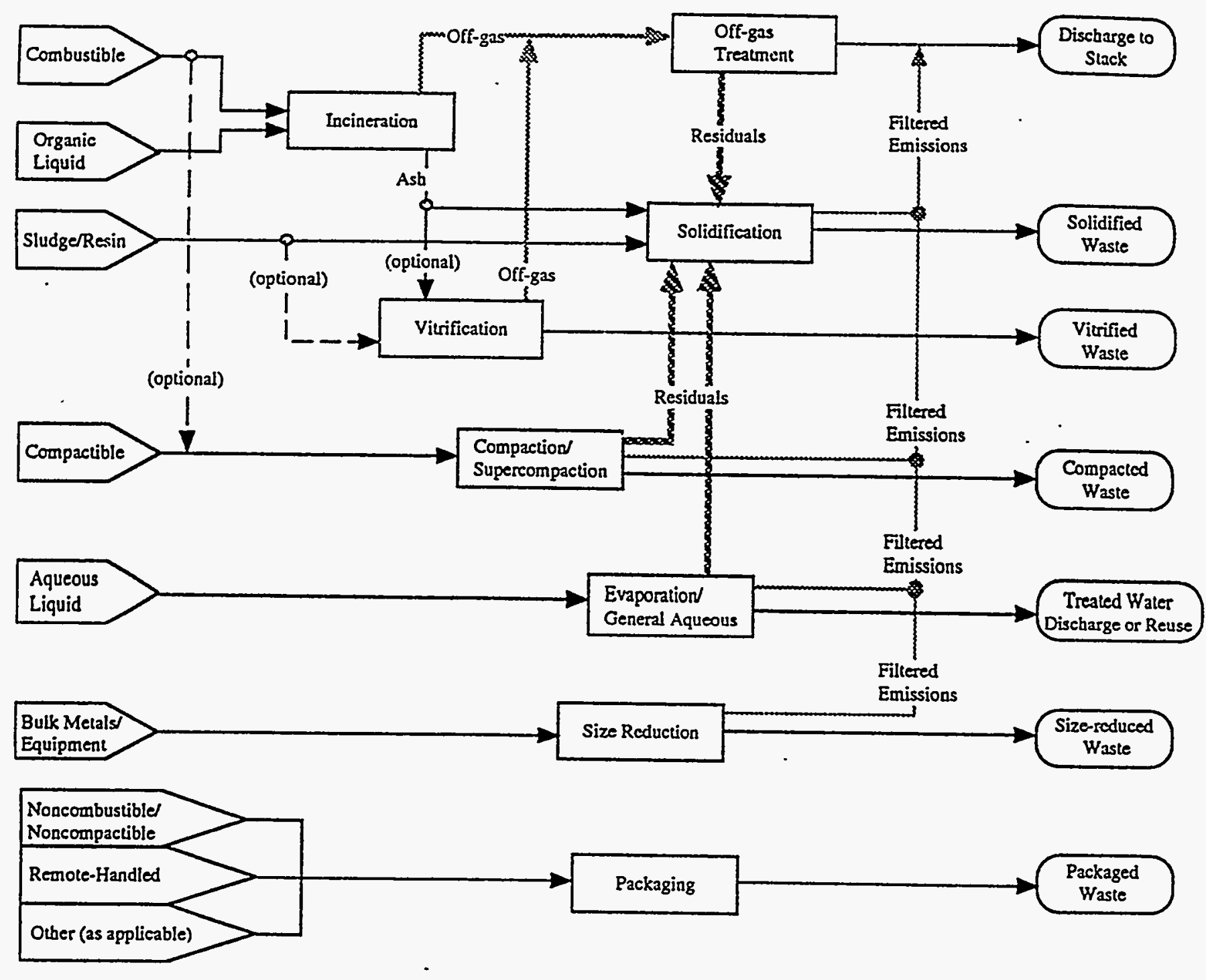

FIGURE 5.1 LLW Management Technologies and Flow Paths

drum and assume that $25 \%$ of the drum inventory is affected and subject to stresses capable of rendering the contents airborne.

The inventories, physical forms, and radiological compositions of waste stored at each site were characterized in the WM PEIS and stored in a database. However, compilation of detailed information for individual operations and facilities on each site was beyond the scope of the WM PEIS. Accordingly, handling accidents assume a single, site-dependent radiological and physical composition derived by volume-weighting the inventories of the treatability categories within each waste type. This composition is based on waste generation and inventory data at each 
TABLE 5.2 Mapping of LLW Treatability Categories with Accident Analysis Physical Forms

\begin{tabular}{|c|c|c|c|c|}
\hline LLW Treatability Category & Technology & Fonn $^{2}$ & $\begin{array}{l}\text { Accident Physical } \\
\text { Form } \\
\end{array}$ & CoInments/Assumptions \\
\hline \multirow[t]{2}{*}{ Aqueous liquids } & $\begin{array}{l}\text { General aqueous } \\
\text { treatment }^{\mathrm{b}}\end{array}$ & Product & Aqueous solution & Output waste form is a dilute aqueous LLW solution. \\
\hline & & Solid residual & Aqueous slurry & Solid residual is an aqueous slurry to be sent for solidification. \\
\hline Aqueous liquids & Current storage & Input & Aqueous solution & Input waste form is a dilute aqueous LLW solution. \\
\hline \multirow[t]{2}{*}{ Aqueous liquids } & Evaporation & Product & $\begin{array}{l}\text { Superheated } \\
\text { aqueous solution }\end{array}$ & $\begin{array}{l}\text { Assumes dominant accident sequences involve release of evaporator contents } \\
\text { (at high temperature and pressure) and radionuclide composition of product } \\
\text { stream similar to evaporator contents. }\end{array}$ \\
\hline & & Solid residual & Aqueous slurry & $\begin{array}{l}\text { Evaporator bottoms are an aqueous slurry with a high solids concentration to } \\
\text { be sent for solidification. }\end{array}$ \\
\hline Aqueous liquids & Solidification & Product & $\begin{array}{l}\text { Noncombustible } \\
\text { aggregated solid }\end{array}$ & Noncombustible aggregated solids surrogate for grout monolithic product. \\
\hline Combustible solids & Current storage & Input & Dry active solid & Based on waste form description given in Goyette and Dolak (1996). \\
\hline \multirow[t]{2}{*}{ Combustible solids } & Incineration & Product & $\begin{array}{l}\text { Noncombustible } \\
\text { powder }\end{array}$ & \\
\hline & & Liquid residual & Aqueous solution & $\begin{array}{l}\text { Slurry blowdown from off-gas treatment is an aqueous solution (Goyette and } \\
\text { Dolak 1996). }\end{array}$ \\
\hline Combustible solids & Packaging & Product & Dry active solid & Assumes packaging does not affect physical form. \\
\hline Combustible solids & Solidification & Product & $\begin{array}{l}\text { Noncombustible } \\
\text { aggregated solid }\end{array}$ & Noncombustible aggregated solids surrogate for grout monolithic product. \\
\hline \multirow[t]{2}{*}{ Combustible solids } & $\alpha$-Incineration ${ }^{\mathrm{c}}$ & Product & $\begin{array}{l}\text { Noncombustible } \\
\text { powder }\end{array}$ & \\
\hline & & Liquid residual & Aqueous solution & \\
\hline Combustible solids & $\alpha$-Solidification & Product & $\begin{array}{l}\text { Noncombustible } \\
\text { aggregated solid }\end{array}$ & Noncombustible aggregated solids surrogate for grout monolithic product. \\
\hline Activated metals & Current storage & Input & Inert metal & Based on waste form description given in Goyette and Dolak (1996). \\
\hline Activated metals & Packaging & Product & Inert metal & Assumes packaging does not affect physical forn. \\
\hline
\end{tabular}


TABLE 5.2 (Cont.)

\begin{tabular}{|c|c|c|c|c|}
\hline LLW Treatability Category & Technology & Form ${ }^{a}$ & $\begin{array}{l}\text { Accident Physical } \\
\text { Form }\end{array}$ & Comments/Assumptions \\
\hline Activated metals & Size reduction & Product & Inert metal & $\begin{array}{l}\text { Assumes production of noncombustible powder during size reduction is } \\
\text { negligible, on the basis of release fraction information for nonnal operations } \\
\text { (Goyette and Dolak 1996). }\end{array}$ \\
\hline Surface-contaminated metals & Current storage & Input & $\begin{array}{l}\text { Noncombustible } \\
\text { powder }\end{array}$ & Noncombustible powder assumed to contaminate outer surfaces of waste. \\
\hline \multirow[t]{2}{*}{ Surface-contaminated metals } & Decontamination & Product & Inert metal & $\begin{array}{l}\text { Assumes decontamination removes surface contamination resulting in a } \\
\text { potentially activated metal. }\end{array}$ \\
\hline & & Liquid residual & Aqueous slurry & Based on waste form description given in Goyette and Dolak (1996). \\
\hline \multirow[t]{2}{*}{ Surface-contaminated metals } & Metal melting & Product & $\begin{array}{l}\text { Viscous (molten) } \\
\text { liquid }\end{array}$ & $\begin{array}{l}\text { Assumes dominant accident sequence involves process upset during melting } \\
\text { stage and radionuclide composition of product streasn similar to molten } \\
\text { material. }\end{array}$ \\
\hline & & Liquid residual & Aqueous slurry & Based on waste form description given in Goyette and Dolak (1996). \\
\hline Surface-contaminated metals & Packaging & Product & Inert metal & Assumes packaging does not affect physical form. \\
\hline Surface-contaninated metals & Size reduction & Product & Inert metal & Based on waste form description given in Goyette and Dolak (1996). \\
\hline Surface-contaminated metals & $\alpha-$ Size reduction & Product & Inert metal & Based on waste form description given in Goyette and Dolak (1996). \\
\hline $\begin{array}{l}\text { Noncombustible-noncompactible } \\
\text { solids }\end{array}$ & Current storage & Input & Inert metal & Based on waste form description given in Goyette and Dolak (1996). \\
\hline $\begin{array}{l}\text { Noncombustible-noncompactible } \\
\text { solids }\end{array}$ & Packaging & Product & Inert metal & Assumes packaging does not affect physical form. \\
\hline $\begin{array}{l}\text { Noncombustible-noncompactible } \\
\text { solids }\end{array}$ & Solidification & Product & $\begin{array}{l}\text { Noncombustible } \\
\text { aggregated solid }\end{array}$ & Noncombustible aggregated solids surrogate for grout monolithic product. \\
\hline $\begin{array}{l}\text { Noncombustible-noncompactible } \\
\text { solids }\end{array}$ & $\alpha$-Solidification & Product & $\begin{array}{l}\text { Noncombustible } \\
\text { aggregated solid }\end{array}$ & Noncombustible aggregated solids surrogate for grout monolithic product. \\
\hline \multirow{2}{*}{$\begin{array}{l}\text { Noncombustible-noncompactible } \\
\text { solids }\end{array}$} & Supercompaction & Product & Inert metal & Assumes supercompaction does not affect initial physical form. \\
\hline & & Liquid residual & Aqueous solution & $\begin{array}{l}\text { Fugitive liquids from supercompaction stated to be an aqueous solution } \\
\text { (Feizollahi and Shropshire 1992). }\end{array}$ \\
\hline
\end{tabular}


TABLE 5.2 (Cont.)

\begin{tabular}{|c|c|c|c|c|}
\hline LLW Treatability Category & Technology & Form ${ }^{\mathrm{a}}$ & $\begin{array}{l}\text { Accident Physical } \\
\text { Form }\end{array}$ & Comments/Assumptions \\
\hline \multirow{2}{*}{$\begin{array}{l}\text { Noncombustible-noncompactible } \\
\text { solids }\end{array}$} & $\alpha$-Supercompaction & Product & Inert metal & Assumes $\alpha$-supercompaction does not affect initial physical fom. \\
\hline & & Liquid residual & Aqueous solution & $\begin{array}{l}\text { Fugitive liquids from } \alpha \text {-supercompaction stated to be an aqueous solution } \\
\text { (Feizollahi and Shropshire 1992). }\end{array}$ \\
\hline Organic liquids & Current storage & Input & $\begin{array}{l}\text { Organic combustible } \\
\text { liquid }\end{array}$ & Based on waste form description given in Goyette and Dolak (1996). \\
\hline \multirow[t]{2}{*}{ Organic liquids } & Incineration & Product & $\begin{array}{l}\text { Noncombustible } \\
\text { powder }\end{array}$ & $\begin{array}{l}\text { Assumes organic liquids contain both suspended and dissolved solids, so that } \\
\text { incinerator ash is a noncombustible powder. }\end{array}$ \\
\hline & & Liquid residual & Aqueous solution & Assumes slurry blowdown from off-gas treatment is an aqueous solution. \\
\hline \multirow[t]{2}{*}{ Organic liquids } & $\alpha$-Incineration & Product & $\begin{array}{l}\text { Noncombustible } \\
\text { powder }\end{array}$ & $\begin{array}{l}\text { Assumes organic liquids contain both suspended and dissolved solids, so that } \\
\text { incinerator ash is a noncombustible powder. }\end{array}$ \\
\hline & & Liquid residual & Aqueous solution & $\begin{array}{l}\text { Slurry blowdown from off-gas treatment is an aqueous solution (Goyette and } \\
\text { Dolak 1996). }\end{array}$ \\
\hline Organic liquids & Solidification & Product & $\begin{array}{l}\text { Noncombustible } \\
\text { aggregated solid }\end{array}$ & $\begin{array}{l}\text { Assumes product from solidification process is a nonflammable monolithic } \\
\text { solid. }\end{array}$ \\
\hline Organic liquids & $\alpha$-Solidification & Product & $\begin{array}{l}\text { Noncombustible } \\
\text { aggregated solid }\end{array}$ & $\begin{array}{l}\text { Assumes product from } \alpha \text {-solidificution process is a nonflammable monolithic } \\
\text { solid. }\end{array}$ \\
\hline Organic liquids & Packaging & Product & $\begin{array}{l}\text { Organic combustible } \\
\text { liquid }\end{array}$ & $\begin{array}{l}\text { Assumes packaging does not affect physical form although packaging of liquid } \\
\text { generally involves addition of absorbent to remove excess free liquids prior to } \\
\text { shipment. }\end{array}$ \\
\hline Olher/special case & Current storage & Input & Inert metal & $\begin{array}{l}\text { Accident analysis assumption due to lack of information about this waste } \\
\text { form. }\end{array}$ \\
\hline Other/special case & Packaging & Product & Inert metal & Assumes packaging does not affect physical form. \\
\hline Remote-handled & Current storage & Input & Inert metal & Typically activated metal waste. \\
\hline Remote-handled & Packaging & Product & Inert metal & Assumes packaging does not affect physical form. \\
\hline
\end{tabular}


TABLE 5.2 (Cont.)

\begin{tabular}{|c|c|c|c|c|}
\hline LLW Treatability Category & Technology & Form ${ }^{2}$ & $\begin{array}{l}\text { Accident Physical } \\
\text { Form } \\
\end{array}$ & Comments/Assumptions \\
\hline Sludge/resin & Current storage & Input & Aqueous slurry & Sludge/resin form stated to be wet solid (Goyette and Dolak 1996). \\
\hline Sludge/resin & Solidification & Product & $\begin{array}{l}\text { Noncombustible } \\
\text { aggregated solid }\end{array}$ & Noncombustible aggregated solids surrogate for grout monolithic product. \\
\hline Sludge/resin & $\alpha$-Solidification & Product & $\begin{array}{l}\text { Noncombustible } \\
\text { aggregated solid }\end{array}$ & Noncombustible aggregated solids surrogate for grout monolithic product. \\
\hline \multirow[t]{2}{*}{ Sludge/resin } & Vitrification & Product & Brittle solid (glass) & \\
\hline & & Liquid residual & Aqueous slurry & $\begin{array}{l}\text { Slurry blowdown from off-gas treatment is an aqueous solution (Goyette and } \\
\text { Dolak 1996). }\end{array}$ \\
\hline \multirow[t]{2}{*}{ Sludge/resin } & $\alpha$-Vitrification & Product & Brittle solid (glass) & \\
\hline & & Liquid residual & Aqueous slurry & $\begin{array}{l}\text { Slurry blowdown from off-gas treatment is an aqueous solution (Goyelte and } \\
\text { Dolak 1996). }\end{array}$ \\
\hline
\end{tabular}

a Waste form divided into input, product, liquid residual, and solid residual waste forms. Dolak 1996)

b General aqueous treatment typically involves removal of suspended and dissolved solids.

c $\alpha$ refers to treatment of waste categorized as alpha-emitting. 
site. Since each site is assumed to store only its own waste, the source terms associated with these handling accidents will not change from one alternative to another.

\subsubsection{Storage Facility Accidents}

Accidents and source terms for current storage were not analyzed explicitly. Unlike treatment that will predominantly use new facilities that will have common characteristics, current (pretreatment) storage will consist predominantly of preexisting facilities (storage buildings or enclosures) that vary greatly in the amounts and types of wastes that they can store, the configurations in which they can store wastes, and their containment and confinement characteristics.

Recent DOE safety reports and NEPA information are cited in Section 6 to provide guidance on the potential risk impacts applicable to LLMW storage facility accidents. This same information can be used to evaluate the anticipated risks of LLW storage facility accidents. On the basis of available information, this risk for LLW storage accidents should be very low.

It should be noted that explicitly analyzing risks from storage would not help to discriminate among alternatives because of the assumption used in the WM PEIS for estimating the treatment throughputs, which dictate the inventories to be stored prior to treatment. This assumption is that all sites will accumulate or at least not reduce these inventories for roughly 10 years, at which time complexwide treatment will begin. Thus, all sites will achieve their maximum inventories (leading to maximum potential releases during a storage facility accident) independent of alternative.

\subsubsection{Treatment Facility and Inventory Modeling Assumptions}

Evaluations have shown that incineration is the thermal treatment technology most likely to dominate risk to facility and site staff, as well as to the surrounding general populations. Radiological accidents investigated here focus on sequences involving fire and explosions capable of producing large airborne releases of the highly dispersible ash present in the various components of incinerators.

A generic treatment facility, consisting of a series of linked process modules, each providing a specific treatment process, was defined to assess the releases from treatment accidents (see Section 2). A DOE Hazard Category of 2 and concomitant structural performance requirements on its systems were assumed. Double HEPA filtration systems were assumed to be in place. The inventory was based on the facility throughput at each site. Volumetric inventories and physical and radiological compositions for each waste treatability category were considered at each site for each alternative. 
Accidents investigated included operation-induced facility fires and external-event-induced fires and explosions. Treatment facility accident sequences analyzed include:

- A fire in the baghouse area of the incineration facility causing a complete failure of the filtration systems ( $L P F=1$ ) with a damage fraction of 3.0E-02 of the total amount of ash existing in the facility at the time of the accident $(\mathrm{DF}=3.0 \mathrm{E}-02)$;

- A rotary kiln explosion caused by combustible gas buildup that affects the ash existing in the rotary kiln (a damage fraction of $1.2 \mathrm{E}-01$ of the total in the facility at the time of the accident; $\mathrm{DF}=1.2 \mathrm{E}-01$ ) and partially degrades the filtration system of the facility ( $L P F=1.0 \mathrm{E}-03)$; and

- External events leading to a fire. All external-event source term parameters vary according to the particular sequence.

All accidents are assumed to be ground releases without filtration with the exception of the rotary kiln explosion accident where a stack emission and partial HEPA filtration is assumed, with a remaining efficiency of $99.9 \%(\mathrm{LPF}=1.0 \mathrm{E}-03$ ); therefore, the intrafacility source term used to determine worker risk is 1,000 times the atmospheric source term.

\subsubsection{Disposal Facility Accidents}

Disposal accidents were not evaluated because of the lack of details of ultimate disposal. However, except for dedicated centralized repositories such as Yucca Mountain or WIPP, disposal sites would generally lack a concentrated volume of MAR being stored in a configuration susceptible to phenomena such as fires and explosions capable of causing significant releases. These repositories have accident analyses performed as part of their site-specific EISs. Although seismic events could breach in-ground containers, leading to airborne releases, such events would be bounded by accidents breaching the concentrated volumes of waste being held in a treatment or storage facility. The available safety literature does not indicate any credible accident sequence in which the risk from airborne releases in a LLW disposal facility would be significant enough to eliminate a site from consideration and thereby serve as a discriminator among disposal alternatives.

\subsection{RESULTS}

Preliminary results of the accident sequences described above for various site consolidation cases within each WM PEIS alternative were reviewed for risk dominance using the frequencyweighted dose to the MEI. The results were then grouped into four annual frequency categories: 
likely (>1.0E-02), unlikely (between 1.0E-02 and 1.0E-04), extremely unlikely (between 1.0E-04 and 1.0E-06), and not credible ( $<1.0 \mathrm{E}-06)$. Representative source terms for the important sequences were then selected as the bases for health effects calculations. Of the thermal treatment technologies, only source terms for incineration facility accidents are provided because they were found to bound other treatment accidents, including potential vitrification facilities. Accident sequences for vitrification facilities result in atmospheric releases much lower than analogous incineration accidents.

The WM LLW accidents analyzed here are listed in Table 5.3. Fourteen cases are considered for WM LLW alternatives, including Cases 1-9, 12, 14, 14a, 19, and 21. Only cases that included incineration for treatment were analyzed; therefore, no treatment process or facility was analyzed for Cases 2-8 in which all sites perform minimum treatment. Cases 12 (Regionalized 5), 14 (Centralized 3), and 14a (Centralized 4) involve treatment at seven sites with various disposal sites. These cases are equivalent with respect to the risk-dominant treatment technologies and amount of waste throughput at each site; therefore, only Case 12 was analyzed. The WM PEIS cases analyzed are described as follows:

- Case I (No Action). All sites treat LLW by using existing, planned, and approved treatment facilities and dispose of LLW at the six current disposal sites in accordance with current arrangements. Two sites (INEL and SRS) incinerate.

- Case 9 (Regionalized 2). Eleven sites (Hanford, INEL, LANL, ORR, SRS, PORTS, Paducah Gaseous Diffusion Plant [PGDP], Fernald Environmental Management Project [FEMP], LLNL, Pantex Plant [Pantex], and RFETS) incinerate, supercompact, reduce the size of, and grout volume-reducible waste; all sites minimally treat other waste; disposal is at 12 sites (Hanford, INEL, NTS, LANL, ORR, SRS, PORTS, PGDP, FEMP, LLNL, Pantex, and RFETS).

- Case 12 (Regionalized 4). Seven sites (Hanford, INEL, LANL, ORR, PORTS, RFETS, and SRS) incinerate, supercompact, reduce the size of, and grout volume-reducible waste; all sites minimally treat other waste; disposal is at six sites (Hanford, INEL, NTS, LANL, ORR, and SRS).

- Case 19 (Regionalized 5). Four sites (Hanford, INEL, ORR, and SRS) incinerate, supercompact, reduce the size of, and grout volume-reducible waste; all sites minimally treat other waste; disposal is at six sites (Hanford, INEL, NTS, LANL, ORR, and SRS). 
TABLE 5.3 Summary of WM LLW Accidents Analyzed ${ }^{\mathrm{a}}$

\begin{tabular}{|c|c|c|c|c|c|c|c|c|}
\hline \multirow[b]{2}{*}{ Function } & \multirow{2}{*}{$\begin{array}{l}\text { WM PEIS }^{b} \\
\text { Alternative } \\
\text { Case } \\
\end{array}$} & \multirow[b]{2}{*}{ Site $^{c}$} & \multicolumn{3}{|c|}{ Operational Events } & \multicolumn{3}{|c|}{ External Events } \\
\hline & & & $\begin{array}{l}\text { Handling } \\
\text { Breaches } \\
\end{array}$ & $\begin{array}{c}\text { Facility } \\
\text { Fire }\end{array}$ & $\begin{array}{c}\text { Facility } \\
\text { Explosion } \\
\end{array}$ & Seismic & $\begin{array}{c}\text { Large } \\
\text { Aircraft } \\
\end{array}$ & $\begin{array}{c}\text { Small } \\
\text { Aircraft }\end{array}$ \\
\hline \multirow[t]{10}{*}{ Drum handling ${ }^{d}$} & All & Hanford & $\mathrm{x}$ & $\mathrm{NA}^{\mathrm{e}}$ & NA & NA & NA & NA \\
\hline & All & INEL & $x$ & $\mathrm{NA}$ & NA & NA & NA & NA \\
\hline & All & LANL & $x$ & $\mathrm{NA}$ & NA & NA & NA & $\mathrm{NA}$ \\
\hline & All & LLNL & $x$ & NA & NA & NA & $\mathrm{NA}$ & NA \\
\hline & All & ORR. & $\mathrm{x}$ & NA & NA & NA & NA & NA \\
\hline & All & PGDP & $\mathrm{x}$ & NA & NA & $\mathrm{NA}$ & $\mathrm{NA}$ & NA \\
\hline & All & Pantex & $\mathrm{x}$ & NA & NA & NA & NA & NA \\
\hline & All & PORTS & $\mathrm{x}$ & NA & NA & NA & NA & NA \\
\hline & All & RFETS & $\mathrm{x}$ & NA & NA & $\mathrm{NA}$ & NA & NA \\
\hline & All & SRS & $\mathrm{x}$ & NA & $\mathrm{NA}$ & NA & NA & NA \\
\hline \multirow{12}{*}{ Incineration } & 1 & INEL & NA & $x$ & $\mathrm{x}$ & $\mathrm{x}$ & $x$ & NA \\
\hline & 1 & SRS & NA & $x$ & $\mathrm{x}$ & $x$ & $x$ & NA \\
\hline & 9 & FEMP & NA & $\mathrm{x}$ & $\mathrm{x}$ & $\mathrm{x}$ & NA & NA \\
\hline & 9 & Hanford & NA & $\mathrm{x}$ & $x$ & $x$ & $\mathrm{x}$ & NA \\
\hline & 9 & INEL & NA & $\mathrm{x}$ & $\mathrm{x}$ & $x$ & $x$ & NA \\
\hline & 9 & LANL & NA & $\mathrm{x}$ & $x$ & $\mathrm{x}$ & NA & NA \\
\hline & 9 & LLNL & NA & $\mathrm{x}$ & $x$ & $\mathrm{x}$ & NA & NA \\
\hline & 9 & ORR & NA & $\mathrm{x}$ & $\mathrm{x}$ & $x$ & NA & NA \\
\hline & 9 & Pantex & NA & NA & NA & NA & NA & NA \\
\hline & 9 & PORTS & NA & $x$ & $\mathrm{x}$ & $\mathrm{x}$ & $\mathrm{NA}$ & NA \\
\hline & 9 & PGDP & NA & $\mathrm{x}$ & $x$ & $\mathrm{x}$ & NA & $\mathrm{x}$ \\
\hline & 9 & SRS & NA & $x$ & $x$ & $x$ & $\mathrm{x}$ & NA \\
\hline$\alpha$-Incineration ${ }^{f}$ & 9 & RFETS & NA & $\mathrm{x}$ & $x$ & $\mathrm{x}$ & NA & $\mathrm{x}$ \\
\hline \multirow[t]{7}{*}{ Incineration } & 12 & Hanford & NA & $\mathrm{x}$ & $\mathrm{x}$ & $\mathrm{x}$ & $\mathrm{x}$ & $\mathrm{NA}$ \\
\hline & 12 & INEL & NA & $X$ & $x$ & $\mathrm{x}$ & $\mathrm{x}$ & NA \\
\hline & 12 & LANL & NA & $x$ & $x$ & $\mathrm{x}$ & NA & NA \\
\hline & 12 & ORR & NA & $x$ & $\mathrm{x}$ & $\mathrm{x}$ & NA & NA \\
\hline & 12 & PORTS & NA & $x$ & $x$ & $\mathrm{X}$ & NA & $\mathrm{x}$ \\
\hline & 12 & RFETS & NA & $x$ & $\mathrm{x}$ & $\mathrm{x}$ & NA & $x$ \\
\hline & 12 & SRS & NA & $x$ & $\mathrm{x}$ & $\mathrm{X}$ & $\mathrm{x}$ & NA \\
\hline$\alpha$-Incineration ${ }^{f}$ & 12 & RFETS & NA & $\mathrm{x}$ & $\mathrm{x}$ & $\mathrm{x}$ & NA & $\mathrm{x}$ \\
\hline \multirow[t]{4}{*}{ Incineration } & 19 & Hanford & NA & $x$ & $\mathrm{x}$ & $x$ & $\mathrm{x}$ & NA \\
\hline & 19 & INEL & NA & $x$ & $x$ & $x$ & $\mathrm{x}$ & NA \\
\hline & 19 & ORR & NA & $\mathrm{X}$ & $x$ & $\mathrm{x}$ & NA & NA \\
\hline & 19 & SRS & NA & $x$ & $x$ & $x$ & $\mathrm{x}$ & NA \\
\hline$\alpha$-Incineration ${ }^{\mathrm{f}}$ & 19 & INEL & NA & $\mathbf{x}$ & $x$ & $\mathrm{x}$ & $x$ & NA \\
\hline Incineration $f$ & 21 & Hanford & NA & $\mathbf{x}$ & $\mathrm{x}$ & $\mathrm{x}$ & $\mathrm{x}$ & NA \\
\hline$\alpha$-Incineration ${ }^{\mathrm{f}}$ & 21 & Hanford & NA & $\mathbf{x}$ & $\mathrm{x}$ & $x$ & $\mathrm{x}$ & NA \\
\hline
\end{tabular}

a Only one source term, generally corresponding to the risk-dominant sequence for each accident initiator, was considered.

b The WM PEIS cases analyzed are described as follows:

- Case 1 (No Action). All sites treat LLW by using existing, planned. and approved treatment facilities and dispose of LLW at the six current disposal sites in accordance with current arrangements. Two sites (INEL and SRS) incinerate.

- Case 9 (Regionalized 2). Eleven sites (Hanford, INEL, LANL, ORR, SRS, PORTS, PGDP, FEMP, LLNL, Pantex, and RFETS) incinerate, supercompact, reduce the size of, and grout volume-reducible waste; all sites minimally treat other waste; disposal is at 12 sites (Hanford, INEL, NTS, LANL, ORR, SRS, PORTS, PGDP, FEMP, LLNL, Pantex, and RFETS).

- Case 12 (Regionalized 4). Seven sites (Hanford, INEL, LANL, ORR, PORTS, RFETS, and SRS) incinerate, supercompact, reduce the size of, and grout volume-reducible waste; all sites minimally treat other waste; disposal is at six sites (Hanford, INEL, NTS, LANL. ORR, and SRS).

- Case 19 (Regionalized 5). Four sites (Hanford, INEL, ORR, and SRS) incinerate, supercompact, reduce the size of, and grout volumereducible waste; all sites minimally treat other waste; disposal is at six sites (Hanford, INEL, NTS, LANL, ORR, and SRS).

- Case 21 (Centralized 5). One site (Hanford) incinerates, supercompacts, reduces the size of, and grouts volume-reducible waste; all sites minimally treat other waste; disposal is at one site (Hanford).

c Abbreviations: PGDP = Paducah Gaseous Diffusion Plant; Pantex = Pantex Plant

d The 10 major storage sites were selected for handling accidents; FEMP is not included here because it is an ER site.

e $\mathrm{NA}=$ not applicable.

f $\alpha$-Incineration refers to incineration of waste categorized as alpha-emitting. 
- Case 21 (Centralized 5). One site (Hanford) incinerates, supercompacts, reduces the size of, and grouts volume-reducible waste; all sites minimally treat other waste; disposal is at one site (Hanford).

Table 5.4 summarizes the radiological source term parameters and frequency groups for drum handling accidents at LLW facilities. Table 5.5 summarizes the radiological source term parameters and frequency groups for incineration facility accidents. Separate incineration facilities were assumed for treating alpha- and nonalpha-contaminated waste. Detailed radionuclide releases are provided in Appendix B. 
TABLE 5.4 Frequencies and Source Term Parameters for WM LLW Drum Handling Accidents

\begin{tabular}{|c|c|c|c|c|c|c|c|c|c|}
\hline \multirow[b]{2}{*}{$\begin{array}{l}\text { WM PEIS } \\
\text { Alternative }\end{array}$} & \multirow[b]{2}{*}{ Site } & \multicolumn{4}{|c|}{ Frequency Bin (/yr) } & \multicolumn{3}{|c|}{ Source Term Parameters } & \multirow{2}{*}{$\begin{array}{c}\text { Total } \\
\text { Release }^{a} \\
\text { (Ci) }\end{array}$} \\
\hline & & $>1 E-02$ & $\begin{array}{c}1 \mathrm{E}-04 \text { to } \\
1 \mathrm{E}-02\end{array}$ & $\begin{array}{c}1 \mathrm{E}-06 \text { to } \\
1 \mathrm{E}-04\end{array}$ & $<1 \mathrm{E}-06$ & $\begin{array}{c}\text { VMAR } \\
\left(\mathrm{m}^{3}\right) \\
\end{array}$ & $\begin{array}{c}\text { MAR } \\
(\mathrm{Ci}) \\
\end{array}$ & DF & \\
\hline All & Hantord & $\mathrm{X}$ & $N A^{b}$ & NA & NA & $2.0 \mathrm{E}-01$ & $3.0 \mathrm{E}-01$ & 0.25 & $4.3 E-04$ \\
\hline All & INEL & $\mathrm{X}$ & NA & NA & NA & $2.0 \mathrm{E}-01$ & $2.1 \mathrm{E}-01$ & 0.25 & $5.3 \mathrm{E}-05$ \\
\hline All & ORR & $X$ & NA & NA & NA & $2.0 \mathrm{E}-01$ & $7.1 \mathrm{E}-01$ & 0.25 & $1.9 \mathrm{E}-03 *$ \\
\hline All & PGDP & $\mathrm{X}$ & NA & NA & NA & $2.0 \mathrm{E}-01$ & $6.0 \mathrm{E}-05$ & 0.25 & $1.8 \mathrm{E}-08$ \\
\hline All & Pantex & $\mathrm{X}$ & NA & NA & NA & $2.0 \mathrm{E}-01$ & $7.1 \mathrm{E}-05$ & 0.25 & $1.7 \mathrm{E}-05^{*}$ \\
\hline All & PORTS & $\mathrm{X}$ & NA & NA & NA & $2.0 \mathrm{E}-01$ & $2.8 \mathrm{E}-06$ & 0.25 & $6.4 \mathrm{E}-09$ \\
\hline All & RFP & $X$ & NA & NA & NA & $2.0 \mathrm{E}-01$ & $1.1 \mathrm{E}-03$ & 0.25 & $1.2 \mathrm{E}-06$ \\
\hline
\end{tabular}

a $*$ = mainly $\mathrm{H}-3$ released.

b $N A=$ not applicable. 
TABLE 5.5 Frequencies and Source Term Parameters for WM LLW Incineration Facility Accidents

\begin{tabular}{|c|c|c|c|c|c|c|c|c|c|c|c|c|}
\hline \multirow[b]{2}{*}{$\begin{array}{l}\text { WM PEIS } \\
\text { Alternatived }\end{array}$} & \multirow[b]{2}{*}{ Sile } & \multirow[b]{2}{*}{ Accident } & \multicolumn{4}{|c|}{ Freyuency Bin $(/ y r)$} & \multicolumn{5}{|c|}{ Source Term Parameters } & \multirow{2}{*}{$\begin{array}{l}\text { Total } \\
\text { Release } \\
\text { (Ci) }\end{array}$} \\
\hline & & & $>1.0 \mathrm{EE}-0.2$ & $\begin{array}{c}1.0 E-01010 \\
1.0 E-112 \\
\end{array}$ & $\begin{array}{c}1.0 \mathrm{E}-06 \text { to } \\
1.0 \mathrm{E}-1 \mathrm{1} 4\end{array}$ & $<t .0 E-\alpha K$ & $\begin{array}{c}\text { VMAR } \\
\left(\mathrm{ml}^{3}\right)\end{array}$ & $\begin{array}{c}\text { MAR } \\
(\mathrm{Ci})\end{array}$ & $\mathrm{DF}$ & RARF & L.PF & \\
\hline 1 & INEL & Explosion in the rotary kiln & $\mathrm{x}$ & $N A^{c}$ & NA & NA & $4.3 \mathrm{E}-1) 1$ & $1.5 \mathrm{E}-01$ & $1.2 \mathrm{E}-01$ & 1.010E-0) & $1.018-\{133$ & $1.8 \mathrm{E}-(1) 6$ \\
\hline 1 & INEL & Fire in the bashouse area & NA & $\mathrm{x}$ & NA & NA & $4.3 \mathrm{E}-1) 1$ & $1.5 \mathrm{E}-01$ & $3.0 \mathrm{E}-1.22$ & I.OE- -1$) 2$ & 1.0EE-(X) & 4.6E- -105 \\
\hline 1 & INEL. & Earhyuauke followed by fire and cxplosion & NA & NA & $\mathrm{x}$ & NA & $4.3 E-111$ & $1.5 E-(1) 1$ & $2.0 E-(1) 1$ & I.(UE-1)I & $1.010-(10)$ & $3.1 E-103$ \\
\hline 1 & INELL. & Large aireralt Inpact with fire and explosion & NA & NA & NA & $\mathrm{x}$ & $4.3 E-111$ & $(.5 E-1) !$ & $3.08-(1)\}$ & (.) $(1)-101$ & $(.0) E-(x)$ & 4.6E- -103 \\
\hline$i$ & SRS & Explosion in the rotary kiln & $\mathrm{x}$ & NA & $\mathrm{NA}$ & NA & 3.6E-(1) & $1.1 E+(x)$ & $1.2 \mathrm{E}-01$ & $1.0 \mathrm{E}-(1) 1$ & $1.08-103$ & $1.3 E-05$ \\
\hline$i$ & SRS & Fire in the baghousc arca & NA & $\mathrm{x}$ & NA & NA & $3.6 \mathrm{E}-(1) 1$ & l. $.1 E+(1)$ & $3.10 E-102$ & 1.0.10-(1) & $1.08-(x)$ & $3.3 \mathrm{E}-(24$ \\
\hline 1 & SRS & Earhhyuake followed by firc and cxplosion & NA & NA & $\mathrm{x}$ & NA & $3.6 \mathrm{E}-1) 1$ & $1.1 E+(x)$ & $2.0 \mathrm{E}-(0)$ & (.)(OE-1)1 & 1.0EE-(x) & $2.2 E-(12$ \\
\hline 1 & SRS & Large aircraft impact with fire and explosion & NA & NA & NA & $\mathrm{x}$ & 3.6E-(1) & 1.IE+(x) & $3.0 \mathrm{E}-101$ & $1 .(0 E-01$ & $1.0 E-(X)$ & $3.3 \mathrm{E}-(12$ \\
\hline 9 & FEMP & Exploston in the rutary kiln & $\mathrm{x}$ & NA & NA & NA & $1.9 \mathrm{E}-11)$ & $2.8 E-105$ & $1.2 E-(1)]$ & $1.00-111$ & $1.08-113$ & $3.3 \mathrm{E}-10$ \\
\hline 9 & FEMP & Fire in the baghouse arca & NA & $\mathrm{x}$ & NA & NA & $1.9 \mathrm{E}-0.11$ & $2.8 E-015$ & $3.0 \mathrm{E}-02$ & $1.0 E-112$ & $1.0 E-(X)$ & $8.3 E-(x)$ \\
\hline 9 & FEMP & Earthyuake followed by fire and explosion & $\mathrm{NA}$ & $\mathrm{NA}$ & $\mathrm{x}$ & NA & $1.9 E-(0)$ & $2.8 E-05$ & $2.0 \mathrm{E}-01$ & 1.(1)E-(1)1 & $1.010--(x)$ & $5.6 E-(1) 7$ \\
\hline 9 & Hanford & Explosion in the rutary kiln & $\mathrm{x}$ & NA & NA & NA & $9.7 \mathrm{E}-0.4$ & 5.3E--112 & $1.2 \mathrm{E}-0 !$ & 1.0E-(0) & $1.08-013$ & $6.3 \mathrm{E}-107$ \\
\hline y & Hanford & Fire in the baghouse area & $\mathrm{NA}$ & $\mathrm{x}$ & NA & NA & $9.7 E-(04$ & $5.3 E-(122$ & 3.10E-02 & $1.0 \mathrm{E}-1.2$ & $1.010-(x)$ & $1.6 \mathrm{E}-05$ \\
\hline y & Hanford & Earhyuake followed by fire and explasion & $\mathrm{NA}$ & NA & $x$ & NA & $9.7 E-1) 4$ & $5.3 E-(1) 2$ & $2.0 \mathrm{E}-01$ & $1.0 \mathrm{E}-01$ & $1.0 E-(x)$ & $1.1 E-0.03$ \\
\hline 9 & Hanford & Large aircraft impact with fire and explosion & $\mathrm{NA}$ & NA & $\mathrm{NA}$ & $\mathrm{x}$ & $9.7 \mathrm{E}-0.4$ & $5.3 E-(122$ & 3.0E-01 & $1.0 \mathrm{E}-01$ & $1.00-(x)$ & $1.6 \mathrm{E}-03$ \\
\hline g & INEL & Explosion in the rotary kiln & $\mathrm{x}$ & NA & $\mathrm{NA}$ & NA & $4,3 E-111$ & $1.5 \mathrm{E}-(1) 1$ & $1.2 E-1) 1$ & $1,0 E-(1)$ & $1.06-103$ & $1.8 E-06$ \\
\hline y & INEL & Fire in the baghouse area & $\mathrm{NA}$ & $\mathrm{x}$ & NA & NA & $4.3 \mathrm{E}-(1) 1$ & $1.5 \mathrm{E}-01$ & 3.0E- 02 & $1.0 \mathrm{E}-102$ & 1. $.0 E-(x)$ & $4.6 E-015$ \\
\hline 9 & INEL & Earthyuakc followed by fire and explosion & NA & NA & $\mathrm{x}$ & NA & $4.3 \mathrm{E}-0.1$ & $1.5 E-(0)$ & $2.0 E-011$ & $1.0 \mathrm{E}-01$ & 1.0E-(X) & $3.1 E-03$ \\
\hline 9) & INEL & Large aircraft impact with fire and explosion & NA & NA & NA & $\mathrm{x}$ & $4.3 E-(1) 1$ & $1.5 E-111$ & 3.10E-(1)\} & $(.0 E-1) 1$ & $1.0 E-(10)$ & +. $6 E-(1) 5$ \\
\hline y & LANL & Explusion in the rotary kiln & $\mathrm{x}$ & NA & NA & NA & $1.4 E+(10)$ & $9.6 \mathrm{E}+(0 \mathrm{X})$ & $1.2 \mathrm{E}-01$ & $1.0 \mathrm{E}-0.01$ & 1.(0)-103 & $1.2 \mathrm{E}-(24$ \\
\hline 9 & LANL. & Fire in the baghouse area & $\mathrm{NA}$ & $\mathrm{x}$ & NA & NA & $1.4 E+(x)$ & $9.6 \mathrm{E}+(1)$ & 3.11E-012 & $1.0 \mathrm{E}-102$ & $1.08-(X)$ & $2.9 \mathrm{E}-(1) 3$ \\
\hline g) & LANL. & Earthyuake followed by fire and explosion & NA & $\mathrm{NA}$ & $\mathrm{x}$ & NA & $1.4 \mathrm{E}+(\mathrm{K})$ & $9.6 \mathrm{E}+(\mathrm{X})$ & $2.0 E-101$ & $1.0 E-101$ & $1.0 E-(0)$ & $1.9 \mathrm{E}-01$ \\
\hline y & LLNL & Explosion in the rotary kiln & $\mathrm{x}$ & NA & NA & NA & $6.9 \mathrm{E}-113$ & $9.8 \mathrm{E}-(0) 1$ & $1.2 \mathrm{E}-(1) 1$ & I.0E-101 & $1.08-03$ & $1.2 \mathrm{E}-105$ \\
\hline y & LLNL & Fire in the baghouse area & NA & $\mathrm{x}$ & NA & NA & $6.9 E-113$ & $9.8 \mathrm{E}-01$ & $3.10 E-122$ & $1.00-112$ & $(1.0)-(1)$ & $2.9 E-124$ \\
\hline y) & LLNL & Earthyuake followed by fire and explosion & $\mathrm{NA}$ & $\mathrm{NA}$ & $x$ & NA & $6.9 \mathrm{E}-113$ & $9.8 E-01$ & $2 .(1)-1) 1$ & $1,\left(01 E_{-10 !}\right.$ & $1.0 E-(x)$ & $2,0 E-(1) 2$ \\
\hline y & ORR & Explosion in the rotary kiln & $\mathrm{x}$ & NA & NA & NA & $1.5 \mathrm{E}+(\mathrm{X})$ & $1 . \mid E-(01$ & $1.2 \mathrm{E}-011$ & $7.0 E-112$ & $1.018-(13)$ & $9.4 E-(17)$ \\
\hline 9 & ORR & Fire in the baghouse areu & $\mathrm{NA}$ & $\mathrm{x}$ & NA & NA & $1.5 E+(10)$ & $(.1 E-(1) \mid$ & $3.0 E-102$ & $6.01-115$ & 1.01)E-(x) & $2.0)-(17)$ \\
\hline y & ORR & Earthyuake followed by fire and explosion & $\mathrm{NA}$ & NA & $x$ & NA & $1.5 \mathrm{E}+(\mathrm{K})$ & $1.1 E-(01$ & $2.0[E-01$ & $7.0 \mathrm{E}-12$ & (.). E- $-(X)$ & $1.6 \mathrm{E}-(1) 3$ \\
\hline y & PORTS & Explosion in the rotary kiln & $\mathrm{x}$ & NA & NA & NA & $3.5 E-111$ & $1.8 \mathrm{E}-104$ & $1.2 \mathrm{E}-101$ & 1.0E-(0) & $1.0 \mathrm{E}-113$ & $2.1 \mathrm{E}-(\infty)$ \\
\hline 9 & PORTS & Fitre in the baghouse arca & $\mathrm{NA}$ & $\mathrm{x}$ & NA & NA & $3.5 \mathrm{E}-0) 1$ & $1.8 \mathrm{E}-1 \mathrm{H}$ & $3.0 \mathrm{~B}-(1) 2$ & $1.00-102$ & $1.0 \mathrm{E}-(x)$ & $5.3 \mathrm{E}-08$ \\
\hline 9 & PORTS & Earthyuake followed by fire and explosion & $\mathrm{NA}$ & $\mathrm{NA}$ & $x$ & $\mathrm{NA}$ & $3.5 E-(1) !$ & $1.8 \mathrm{E}-1.44$ & $2.0 E-01$ & $1 .(0 E-0)$ & $1.0 E-(x)$ & $3.5 E-06$ \\
\hline y & PGDP & Explosion in the rotary kiln & $\mathrm{x}$ & NA & NA & NA & $1.3 E-(0)$ & 1.5E-013 & $1.2 \mathrm{E}-01$ & $1.0 E-011$ & $1.0 E-(1) 3$ & $1.8 \mathrm{E}-08$ \\
\hline 9 & PGDP & Firc in the baghousc area & NA & $\mathrm{x}$ & NA & $\mathrm{NA}$ & $1.3 E-111$ & $1.5 \mathrm{E}-03$ & 3. $01-02$ & $1,0 E-112$ & 1.0E-(x) & $4.6 E-177$ \\
\hline 9 & PGDP & Earthuuake followed by fire and explosion & nA & NA & $\mathrm{x}$ & NA & $1.3 \mathrm{E}-131$ & $1.5 E-103$ & $2.0 \mathrm{E}-0)$ & $1.0 E-01$ & I. (OE- $(0)$ & $3.0 E-05$ \\
\hline 9 & PGDP & Small aircraft impatit with firc and explosion & $\mathrm{NA}$ & NA & NA & $\mathrm{x}$ & 1.3E- -01 & $1.5 E-(1) 3$ & $5.10 \mathrm{E}-102$ & 1..10E-(0) & 1.(1)- $1(x)$ & 7.6E- -196 \\
\hline $9 \alpha^{d}$ & RFETS & Explusion in the rotury kiln & $\mathrm{x}$ & $\mathrm{NA}$ & NA & NA & $7.0 \mathrm{E}-01$ & $1.5 E_{-101}$ & $|.2 \mathrm{E}-(0)|$ & I.,OE-10! & {$[,(1) E-1) 3$} & $1.8 E-96$ \\
\hline $9 \alpha^{4}$ & RFETS & Fire in the baghouse area & $\mathrm{NA}$ & $\mathrm{x}$ & NA & NA & 7.0E-01 & $1.5 \mathrm{E}-01$ & 3.10E-102 & 1.01E-102 & 1.(0)- $-(x)$ & $4.6 \mathrm{E}-0.5$ \\
\hline $9 \alpha^{d}$ & RFETS & Earthquake followed by fire and explosion & NA & $\mathrm{NA}$ & $x$ & NA & 7.(1E- -11 & $1.5 \mathrm{E}-0.1$ & $2.0 E-01$ & $1.0 \mathrm{E}-01$ & $1.0 E-(x)$ & $3.1 E-03$ \\
\hline$y \alpha^{d}$ & RFETS & Small aircraft timpact with lite und explosion & $\mathrm{NA}$ & NA & NA & $\mathrm{x}$ & 7.IEE-111 & $1.5 E-01$ & $5.10 E-112$ & 1.0Eg-01 & 1. (1):-1(x) & $7.7 E-124$ \\
\hline 9 & SRS & Explosion in the rotary kiln & $\mathrm{x}$ & NA & NA & NA & $3.6 \mathrm{E}-111$ & $1.18+(x)$ & $1.2 \mathrm{E}-01$ & $1.0 E-01$ & I. IEE-113 & $1.3 \mathrm{E}-0.05$ \\
\hline 9 & SRS & Fire in the baghouse arca & $\mathrm{NA}$ & $\mathrm{x}$ & NA & NA & $3.6 \mathrm{E}-011$ & i. $1 E+(x)$ & 3.1.E-112 & $1.0 E-112$ & 1..(IE- $-(x)$ & $3.3 E-04$ \\
\hline 9 & SRS & Earthyuuuke followed by fire and cxplosion & NA & NA & $\mathrm{x}$ & NA & $3.6 \mathrm{E}-111$ & $1.1 E+(K)$ & $2.0 E-101$ & (..OE-10! & I.(IE- $-(x)$ & $22 E-(12$ \\
\hline y) & SRS & Large aircrafl Impact with fire and explosion & NA & $\mathrm{NA}$ & NA & $\mathrm{x}$ & 3.6E--1)1 & I.IE+(N) & 3.0E-01 & $1.0 \mathrm{E}-011$ & $1.0 E-(x)$ & $3.3 \mathrm{E}-02$ \\
\hline 12 & Hanford & Explaston in the rotury kiln & $\mathrm{x}$ & NA & $\mathrm{NA}$ & NA & $7.8 \mathrm{E}-113$ & $1.00+(X)$ & $1.28-101$ & $1.0 \mathrm{E}-\mathrm{0}) \mathrm{H}$ & $1.08-113$ & $1.2 \mathrm{E}-105$ \\
\hline 12 & Hanford & Fire in the baghouse areu & $\mathrm{NA}$ & $\mathrm{x}$ & NA & NA & $7.8 E-113$ & $1.018+(x)$ & 3.01E-102 & $1.01 \mathrm{E}_{-112}$ & 1. (ULEE+(X) & $3.115-124$ \\
\hline 12 & Hanford & Earhyuake followed by fire and explosion & $\mathrm{NA}$ & NA & $x$ & NA & 7.8E-103 & $1.0 \mathrm{E}+(0)$ & $2.0 E-0 !$ & $1.0 \mathrm{E}-01$ & $1,(0 E+(x)$ & $2.1 E-02$ \\
\hline 12 & Hanford & Large ulrcraft inpract with firc and explosion & $\mathrm{NA}$ & NA & NA & $x$ & $7.8 E-133$ & 1.0. $+(x)$ & $3.0 E-101$ & 1.(.)E-(1)1 & 1.(1) $(1)+(x)$ & $3.1 E-(12$ \\
\hline 12 & INEL & Explustion in the rotary $\mathrm{ktln}$ & $\mathrm{x}$ & NA & NA & $\mathrm{NA}$ & $4.3 \mathrm{E}-1) 1$ & $|.5 E-(1)|$ & $1.2 \mathrm{E}-101$ & I. (OEE-1)1 & $1.0 \mathrm{EE}-(1) 3$ & $1.8 E-116$ \\
\hline 12 & INEL. & Fire in the baghouse area & $\mathrm{NA}$ & $\mathrm{x}$ & NA & NA & $4.3 \mathrm{E}-(1)$ & $1.5 \mathrm{E}-01$ & $3.0 \mathrm{E}-102$ & $1.0 \mathrm{~N}-102$ & $1.08+(0)$ & $4.6 \mathrm{E}-05$ \\
\hline 12 & INEL & Earthyuake followed by fire and explosion & NA & $\mathrm{NA}$ & $x$ & NA & $4,3 \mathrm{E}-1) 1$ & $1.5 E-01$ & $2.0 \mathrm{E}-01$ & 1.OE- $(0)$ & 1.0EE+(X) & $3.1 E-03$ \\
\hline 12 & INEL & Large uirerant impact with fire und explosion & $\mathrm{NA}$ & NA & NA & $x$ & $4.38--01$ & $\mid .5 E=-1) 1$ & $3.010-(0)$ & I.(OE-A1) & $1.018++(x)$ & $4.6 E-(1) 3$ \\
\hline
\end{tabular}


TABLE 5.5 (Cont.)

\begin{tabular}{|c|c|c|c|c|c|c|c|c|c|c|c|c|}
\hline \multirow[b]{2}{*}{$\begin{array}{l}\text { WM PEIS } \\
\text { Allernative }\end{array}$} & \multirow[b]{2}{*}{ Sitc } & \multirow[b]{2}{*}{ Accidenl } & \multicolumn{4}{|c|}{ Frequency Bin (/yr) } & \multicolumn{5}{|c|}{ Source Term Paramelers } & \multirow{2}{*}{$\begin{array}{l}\text { Tolat } \\
\text { Release } \\
\text { (Ci) }\end{array}$} \\
\hline & & & $>1.0 E-02$ & $\begin{array}{c}1.0 E-(1) 4 \text { to } \\
1.0 E-122 \\
\end{array}$ & $\begin{array}{c}1.0 E-10610 \\
1.0 E-104 \\
\end{array}$ & $<1.0 E-06$ & $\begin{array}{c}\text { VMAR } \\
\left(\mathrm{m}^{3}\right)\end{array}$ & $\begin{array}{c}\text { MAR } \\
(\mathrm{Ci}) \\
\end{array}$ & DF & RARF & LPF" & \\
\hline 12 & LANL & Explosion in the rotary kiln & $\mathrm{x}$ & NA & $\mathrm{NA}$ & NA & $1.4 E+(10)$ & $9.6 E+(x)$ & $1.2 E-01$ & $1.0 \mathrm{E}-01$ & $1.0 \mathrm{E}-113$ & $1.2 \mathrm{E}-1 \mathrm{H}$ \\
\hline 12 & LANL & Fire in the baghouse area & $\mathrm{NA}$ & $\mathrm{x}$ & $\mathrm{NA}$ & NA & $1.4 E+(X)$ & $9.6 \mathrm{E}+(X)$ & $3.0 E-112$ & $1.0 \mathrm{E}-102$ & 1.0E+(X) & $2.9 E-113$ \\
\hline 12 & LANL & Earthyuake followed by fire and explositon & NA & NA & $\mathbf{x}$ & NA & $1.4 E+(X)$ & $9.6 \mathrm{E}+(\mathrm{K})$ & $2.010 \mathrm{E}-(1) 1$ & $1.01 \mathrm{E}-11)$ & 1.01EE+(X) & $1.9 E-111$ \\
\hline 12 & ORR & Lixplusion in the rutary killn & $\mathrm{x}$ & $\mathrm{NA}$ & NA & NA & 1.SE $+(X)$ & $1.1 E-(1)$ & $1.2 \mathrm{E}-111$ & 7.(1):-102 & $1.010 \mathrm{~B}-103.3$ & 9. $.4 \mathrm{~L}-177$ \\
\hline 12 & ORR & Fire in the baghouse area & NA & $\mathrm{x}$ & NA & NA & $1.5 \mathrm{E}+(\mathrm{X})$ & $1.1 E-01$ & $3.0 \mathrm{E}-112$ & $6.118-115$ & $1.08 \mathrm{E}+(0)$ & $2.0 \mathrm{E}-107$ \\
\hline 12 & ORR & Earthyuake followed by fire and explosion & NA & NA & $\mathbf{x}$ & NA & 1.SE+(1) & $\mid .1 E-(1)$ & $2.0 \mathrm{E}-111$ & $7.11 \mathrm{E}-102$ & $1.010++(x)$ & $1.6[-(1) 3$ \\
\hline 12 & PORTS & Explusion in the rulary kiln & $x$ & NA & $\mathrm{NA}$ & NA & 2.3E-0)! & $3.2 E-115$ & $1.2 \mathrm{E}-(1)$ & $1.0 E-1) 1$ & $1.018-113$ & $3.95-10$ \\
\hline 12 & PORTS & Fire in the baghouse area & NA & $\mathrm{x}$ & NA & NA & $2.3 E-01$ & $3.2 \mathrm{E}-115$ & $3.00-112$ & $1.0 \mathrm{E}-02$ & $1.0 E+(X)$ & $9.6 \mathrm{E}-(1)$ \\
\hline 12 & PORTS & Earthquake fullowed by fire and expiosion & NA & $\mathrm{NA}$ & $x$ & $\mathrm{NA}$ & $2.3 E-(1) 1$ & $3.2 \mathrm{E}-105$ & $2.00 E-101$ & $1.0 \mathrm{E}-01)$ & $1.0 \mathrm{E}+(\mathrm{K})$ & 6.4E- -177 \\
\hline 12 & PORTS & Small aircraf inipact with firc and explosion & NA & $\mathrm{NA}$ & NA & $x$ & $2.3 E-01$ & $3.2 E-115$ & $5.10 E-(1) 2$ & $1.0 E-(01$ & $1.01+(X)$ & $1.6 E-177$ \\
\hline 12 & RFETS & Explusion in the rotary kiln & $\mathrm{x}$ & - & NA & NA & $1.0 \mathrm{E}-103$ & $2.2 \mathrm{E}-144$ & $1.2 \mathrm{E}-01$ & $1.0 \mathrm{E}-(1) 1$ & $1.0 \mathrm{E}-03$ & 2.6E-(k) \\
\hline 12 & RFETS & Fire in the baghouse area & $\mathrm{NA}$ & $x$ & NA & NA & $1.0 \mathrm{E}-03$ & $2.2 E-14$ & $3.0 \mathrm{E}-102$ & $1.0 \mathrm{E}-02$ & $1.08+(x)$ & $6.6 E-1) 8$ \\
\hline 12 & RFETS & Earthyuake followed by fire and explosion & $\mathrm{NA}$ & $\mathrm{NA}$ & $x$ & NA & $1.0 \mathrm{E}-03$ & $2.2 E-144$ & $2.0 \mathrm{E}-0 !$ & (.0EE-01) & $1.010 E+(x)$ & $4.4 E-16$ \\
\hline 12 & RFETS & Small aircraft inpact with fire and explosion & NA & NA & NA & $\mathrm{x}$ & $1.08-133$ & $2.2 E-14$ & $5.110-102$ & (..1E-A) & $1.10 E+(x)$ & $1.1 \mathrm{E}-06$ \\
\hline 12 & SRS & Explusion in the rotary kiln & $\mathrm{x}$ & $\mathrm{NA}$ & NA & NA & $3.6 \mathrm{E}-01$ & $1.1 \mathrm{E}+(\mathrm{X})$ & $1.2 E-01$ & $1.0 E-0 !$ & $1.01-013$ & $1.3 E-115$ \\
\hline 12 & SRS & Fire in the baghouse area & NA & $\mathrm{x}$ & NA & NA & $3.6 \mathrm{E}-01 \mathrm{I}$ & $1.1 \mathrm{E}+(0)$ & 3.0E- -122 & $1.0 \mathrm{E}-1.2$ & 1. $(0 \mathrm{E}+(X)$ & 3.3E-144 \\
\hline 12 & SRS & Earthquake followed by fine and explosion & NA & $\mathrm{NA}$ & $\mathrm{x}$ & NA & $3.6 \mathrm{E}-(1) 1$ & $1.1 E+(X)$ & $2.0 E-01$ & $1.0 \mathrm{E}-01$ & $1.0 \mathrm{E}+(x)$ & $2.2 \mathrm{E}-112$ \\
\hline 12 & SRS & Large airctaft impact with fire and explosion & NA & $\mathrm{NA}$ & NA & $\mathrm{x}$ & 3.6E-0! & $1.1 E+(x)$ & $3.0 \mathrm{E}-01$ & $1.0 \mathrm{E}-(01$ & $1.0 \mathrm{E}+(x)$ & $3.3 E-1.2$ \\
\hline $12 \alpha^{\prime \prime}$ & RFETS & Explusion in the rotary kiln & $\mathrm{x}$ & NA & NA & NA & $7.118-111$ & $1.5 E-811$ & $1.2 E-101$ & $1.0 \mathrm{E}-(1)\}$ & $1.018-113$ & $1.8 E-16$ \\
\hline $12 a^{4}$ & RFETS & Firc in the baghouse ureal & NA & $x$ & NA & NA & $7.08-(2)$ & $1.5 E-(1)$ & $3.01-012$ & 1.01E-1)2 & $1.018-(x)$ & 4.6E--115 \\
\hline $12 \alpha^{4}$ & RFETS & Eurthquake followed by firc and explosion & NA & NA & $\mathrm{x}$ & NA & 7.0E-011 & $1.5 E-(0)$ & $2.0 \mathrm{E}-01$ & $1,0 E-1) 1$ & 1.01E-(x) & $3.1 \mathrm{E}-113$ \\
\hline $12 \alpha^{\mathrm{d}}$ & RFETS & Small aireraft impact with fine and explosion & NA & NA & NA & $x$ & 7.0E-(0)! & 1.5E-01) & $5.0 E-(1) 2$ & I. (.)E-01 & $1.08 t+(x)$ & $7.7 \mathrm{E}-(1) 4$ \\
\hline 19 & Hanford & Explusion in the rotary kiln & $\mathrm{x}$ & $\mathrm{NA}$ & NA & NA & 7.8E-113 & $1.0 \mathrm{E}+(x)$ & $1.2 \mathrm{E}-01$ & $1.0 \mathrm{E}-(01$ & $1.01 \mathrm{E}-113$ & $1.2 \mathrm{E}-1.15$ \\
\hline 19 & Hanford & Fire in the baghouse area & NA & $x$ & NA & NA & $7.8 \mathrm{E}-1,133$ & $1.0 E+(1)$ & $3.0 \mathrm{E}-102$ & 1.t)E-1122 & $1.0 E-(x)$ & $3.1 E-14$ \\
\hline 19 & Hanford & Earthquake followed by fire and explosion & $\mathrm{NA}$ & NA & $\mathrm{x}$ & NA & $7.8 E-133$ & $1.0 E+(X)$ & $2.0 E-01$ & 1.(0E-(0) & $1.0 E-(x)$ & 2.IE-1)2 \\
\hline 19 & Hanrord & Large airerault inpuact with fire and explosion & $\mathrm{NA}$ & $\mathrm{NA}$ & NA & $x$ & $7.8 E-133$ & $1.0 E+(X)$ & $3 .(1 \mathrm{E}-10 !$ & $1.0 \mathrm{E}-01)$ & $1,0 E-(X)$ & $3.11 E-(1) 2$ \\
\hline $19 \alpha^{4}$ & INEL & Explusion in the rolary kiln & $\mathrm{x}$ & $\mathrm{NA}$ & NA & NA & $1.8 E+(x)$ & $9,8 E+(x)$ & $|.2 E-0|$ & $1.0 E-(01$ & $1.08 \mathrm{e}-03$ & $1.2 E-14$ \\
\hline $19 \alpha^{\|}$ & INEL & Fire in the baghuusc area & NA & $\mathrm{x}$ & NA & NA & $1.8 \mathrm{E}+(1)$ & $y .8 E+(x)$ & $3.0 \mathrm{E}-122$ & $1.0 \mathrm{E}-1.2$ & 1.01:-(x) & $2.9 \mathrm{E}-(1)$ \\
\hline $1 \omega \alpha^{山}$ & INEL & Earthyuake followed by tire and explosion & $\mathrm{NA}$ & NA & $\mathbf{x}$ & NA & $1.8 \mathrm{E}+(x)$ & $9.8 E+(x)$ & $2.0 E-(0)$ & $1 .(1) E-(1)]$ & $(.018-(x)$ & $2.0 E-111$ \\
\hline $12 \alpha^{4}$ & INEL. & Large aircratt impact with fire and exploston & NA & NA & NA & $\mathrm{x}$ & $1.8 \mathrm{E}+(x)$ & $9.8 E+(x)$ & 3.0E-01) & $1.0 \mathrm{E}-0)$ & 1.0)E-(x) & $2.9 E-(1)$ \\
\hline 1) & INEL & Explosiun in the rotary kiln & $\mathrm{x}$ & NA & NA & NA & $7.01 \mathrm{E}-011$ & $1.5 E-(0)$ & $1.2 \mathrm{E}-01$ & 1.0E-(0) & $1.0 E-113$ & $1.8 E-166$ \\
\hline 19) & INEL & Fire in the baghouse area & $\mathrm{NA}$ & $x$ & NA & $\mathrm{NA}$ & $7.0 E-01$ & $1.5 E-01 !$ & $3.0 E-102$ & $1.0 E-112$ & 1.UEE-(X) & $4,6 E-05$ \\
\hline 19) & INEL & Earthquake followed by fic and explosion & NA & $\mathrm{NA}$ & $\mathbf{x}$ & NA & $7.0 E-01$ & $1.5 \mathrm{E}-011$ & 2.0E-01 & $1.0 E-(0)$ & 1.0E-(x) & 3. IE- -13 \\
\hline 19) & INEL & Large aircraft impact with fire and explosion & $\mathrm{NA}$ & NA & NA & $x$ & $7 .(10 E-101$ & $1.5 \mathrm{E}-111$ & $3,(0 \mathrm{E}-1) 1$ & $1.010-(1)]$ & $1.0 E-100$ & $4.6 \mathrm{E}-05$ \\
\hline 19 & ORR & Explusion in the rotary kiln & $\mathrm{x}$ & NA & NA & NA & $1.7 \mathrm{E}+(1)$ & $4.9 E-(1) !$ & $|.2 E-(1)|$ & $7.0 \mathrm{E}-102$ & $10 E-113$ & $4.1 E-166$ \\
\hline 1) & ORR & Fire in the baghouse area & NA & $x$ & NA & $\mathrm{NA}$ & $1.7 \mathrm{E}+(\mathrm{x})$ & $4.9 \mathrm{E}-(1)$ & 3.10E-122 & $6.0 \mathrm{E}-105$ & $1.018-(x)$ & $8.8 E-177$ \\
\hline 19) & ORR & Earthquake rollowed by fire and explosion & $\mathrm{NA}$ & $\mathrm{NA}$ & $x$ & $\mathrm{NA}$ & $1.7 \mathrm{E}+(\mathrm{x})$ & $4.9 E-01$ & $2.0 E-0 !$ & $7,0 E-112$ & 1.0EE-(x) & $6.9 E-03$ \\
\hline 19) & SRS & Explositon in the rotary kiln & $x$ & NA & NA & NA & $3.6 \mathrm{E}-0 \mathrm{t}$ & $1.1 E+(X)$ & $1.2 \mathrm{E}-01$ & I.(1E-01) & $1.01-03$ & $1.3 \mathrm{E}-05$ \\
\hline 19) & SRS & Fire in the baghuuse area & NA & $\mathrm{x}$ & NA & $\mathrm{NA}$ & $3.6 \mathrm{E}-111$ & $1.1 E+(x)$ & $3.12 E-122$ & 1.11E-112 & $1.0 E-(x)$ & $3.3 \mathrm{E}-104$ \\
\hline 19 & SRS & Earthquake followed by fire and explosion & NA & NA & $\mathrm{x}$ & NA & $3.6 \mathrm{E}-01$ & $1.1 \mathrm{E}+(\mathrm{X})$ & $2.0 E-(1)$ & $1.0 E-(0)$ & $1.08-(1)$ & $2.2 \mathrm{E}-112$ \\
\hline 19) & SRS & Large uircraft impact with fire and explosion & NA & $\mathrm{NA}$ & NA & $x$ & $3.6 E-(1) 1$ & $1.1 E+(x)$ & $3.0 E-01$ & $1.0 E-(0)$ & (.). $(1 E-1)$ & $3.3 E-02$ \\
\hline
\end{tabular}


TABLE 5.5 (Cont.)

\begin{tabular}{|c|c|c|c|c|c|c|c|c|c|c|c|c|}
\hline \multirow[b]{2}{*}{$\begin{array}{l}\text { WM PEIS } \\
\text { Allernative }\end{array}$} & \multirow[b]{2}{*}{ Sitc } & \multirow[b]{2}{*}{ Accident } & \multicolumn{4}{|c|}{ Frequency Bin $(y y r)$} & \multicolumn{5}{|c|}{ Suuree Term Parameters } & \multirow{2}{*}{$\begin{array}{l}\text { Tolal } \\
\text { Rele:ase } \\
\left(C_{1}\right)\end{array}$} \\
\hline & & & $>1.0 \mathrm{EE}-1.2$ & $\begin{array}{l}1.0 \mathrm{E}-14410 \\
1.0 \mathrm{E}-102 \\
\end{array}$ & $\begin{array}{c}1.0 \mathrm{E}-116 \text { to } \\
1.0 \mathrm{0E}-124 \\
\end{array}$ & $<1.0 E-116$ & $\begin{array}{c}\text { VMAR } \\
\left(\mathrm{m}^{3}\right) \\
\end{array}$ & $\begin{array}{l}\text { MAR } \\
\text { (Ci) }\end{array}$ & $\mathrm{DF}$ & RARF & LPFF" & \\
\hline 21 & Hanford & Fire in the baghouse area & NA & $\mathrm{x}$ & NA & NA & $2,9 \mathrm{E}+(10)$ & $1.2 \mathrm{E}+(01$ & $3.0 \mathrm{E}-02$ & $1,0 E-(02$ & $1 .(0 E-1 X)$ & $3.6 \mathrm{E}-(1.3$ \\
\hline 21 & Hanford & Earhyuake fullowed by fire and explusion & $\mathrm{NA}$ & $\mathrm{NA}$ & $\mathrm{x}$ & $\mathrm{NA}$ & 2.9E $+(\mathrm{X})$ & $1.2 \mathrm{E}+111$ & $2.0 \mathrm{E}-01$ & $1.0 \mathrm{E}-01$ & 1.(1)E- $-(x)$ & 2.4E-(1) \\
\hline 21 & Hanford & Large aircran impact with fire and explusion & NA & $\mathrm{NA}$ & $\mathrm{NA}$ & $x$ & $2.9 \mathrm{E}+100$ & $1.2 \mathrm{E}+10 !$ & $3.0 \mathrm{E}-81$. & $1.0 \mathrm{E}-(1) 1$ & $1 .(1 E-(x)$ & $3.6 \mathrm{E}-(1) 1$ \\
\hline $21 a^{d}$ & Hanford & Explosion in the rolary kiln & $x$ & NA & $\mathrm{NA}$ & NA & 7.(1)E--01 & $1.5 \mathrm{E}-(0)$ & $1.2 E-(1) 1$ & $1.00-0101$ & 1.(10E-113 & $1.8 E-166$ \\
\hline $21 \alpha^{d}$ & Hanford & Firc in the baghousc arca & NA & $\mathrm{x}$ & $\mathrm{NA}$ & NA & $7.00-01$ & $1.5 E-01$ & $3.01--12$ & $1.0 E-112$ & 1.(1)E-(x) & $4.6 E-115$ \\
\hline $21 a^{d}$ & Hanfurd & Earthquake followed by fire and explosion & NA & $\mathrm{NA}$ & $\mathrm{x}$ & NA & 7.0E-(1) & $1.5 \mathrm{E}-0)$ & $2.0 E-01$ & $1.0 E-(1) 1$ & $1 .(10 E-(X)$ & $3.1 \mathrm{E}-(13)$ \\
\hline $21 a^{\mathrm{d}}$ & Hanford & Large aircraft impact with fire and explosion & $\mathrm{NA}$ & $\mathrm{NA}$ & $\mathrm{NA}$ & $\mathrm{x}$ & $7.0 \mathrm{E}-(1) 1$ & $\mid .5 E-(0)$ & $3.0 \mathrm{E}-01$ & $1.0 E-(1)]$ & $1.0 \mathrm{E}-(\mathbf{x )}$ & $4.6 \mathrm{E}-133$ \\
\hline
\end{tabular}

a The WM PEIS cases analyied are described as follows:

- Case I (No Action). All sitcs Ireal LLW by using existing, planned, and approved treatment facilities and dispose of LLW at the 6 currenl dispusal siles in accordance with current arrangements. Two sites (INEL, and SRS) incinerate.

- Case 9 (Regionalized 2). Eleven siles (Hanfurd, INEL, LANL, ORR, SRS, PORTS, PGDP, FEMP, LLNL, Pantex, and RFETS) incinerate, supercompact, reduce the size of, and grout volume-reducible waste; all siles minimally treal uther Wastc; Usppusul Is al 12 sitcs (Hanfurd, INEL, NTS, LANL, ORR, SRS, PORTS, PGDP, FEMP, LLNL, Pantex, and RFETS).

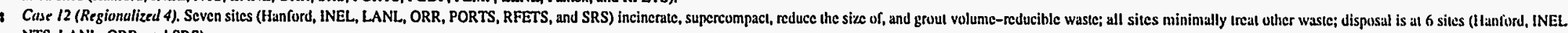
NTS, LANL, ORR, and SRS).

- Case /S (Regionalized S). Four sitcs (Hanford, INEL, ORR, and SRS) incinerate, supercompact, reduce the size of, and groul volume-reducible waste; all sites minimally treal other wastc; disposal is at 6 sitcs (Hanfiord, INEL, NTS, LANL, ORR, and SRS).

- Case 21 (Centralized S). One site (Hanford) incinerates, supercompacts, neduces the sile of, and grouls volume-reducible waste; all sites ninimally treat other waste; dispusal is at 1 site (Hanford).

"Values shown are for particulate (nonvolatile) solids such as U-235 or Pu-238; see Appendix D.

- NA = nul applicable.

a a ruters to treatment of waste categurized as alpha-emilting. 


\section{ACCIDENT ANALYSIS FOR LOW-LEVEL MIXED WASTE}

\subsection{OVERVIEW OF LOW-LEVEL MIXED WASTE MANAGEMENT}

LLMW contains both low-level radioactive and hazardous components and generally results from the same processes that generate LLW. The radioactive component, which can range from low to high activity, is regulated under the Atomic Energy Act as amended, while the hazardous component is regulated under RCRA. Some hazardous components are subject to LDRs under RCRA, which imposes treatment standards. Storage subject to LDRs is restricted by EPA regulations. All disposal of hazardous components must also be in compliance with RCRA standards. The current program, pursuant to the Federal Facility Compliance Act of 1992, will provide either DOE or commercial treatment capacity subject to LDRs for newly generated and stored LLMW. Under the program, treated LLMW at DOE facilities permitted under RCRA will be disposed of. DOE currently has neither RCRA-permitted disposal facilities nor adequate treatment capacity for restricted LLMW.

The inventory and future generation rate data used in the WM PEIS for LLMW were compiled by the Mixed Waste Treatment Project (MWTP) from data published in May 1994 as the Mixed Waste Inventory Report (MWIR) (DOE 1994). This report lists about $415,000 \mathrm{~m}^{3}$ $\left(548,000 \mathrm{yd}^{3}\right)$ of LLMW either currently stored or projected for generation over the next 20 years at 43 DOE sites. More than $99 \%$ of this waste has been or will be generated at 12 sites (Hanford, INEL, ORR, RFETS, SRS, LANL, FEMP, PORTS, PGDP, LLNL, ANL-E, and Middlesex Sampling Plant [Middlesex]). The largest generating sites are Hanford $\left(148,000 \mathrm{~m}^{3}\left[195,000 \mathrm{yd}^{3}\right]\right)$, ORR $\left(73,500 \mathrm{~m}^{3}\left[97,000 \mathrm{yd}^{3}\right]\right)$, RFETS $\left(69,400 \mathrm{~m}^{3}\left[91,600 \mathrm{yd}^{3}\right]\right)$, and INEL $\left(35,000 \mathrm{~m}^{3}\right.$ $\left.\left[46,200 \mathrm{yd}^{3}\right]\right)$. Various waste streams are not considered in the LLMW analysis for the WM PEIS (see Wilkins et al. 1996 for specific details on the exclusion of particular waste streams).

The WM PEIS alternatives being considered for TSD of LLMW are the following.

\section{No Action (Existing and Approved)}

- Continue to store untreated LLMW in existing and approved storage facilities at current generator/storage locations pending availability of treatment capacity.

- Utilize existing and approved DOE and commercial treatment facilities to meet RCRA LDRs. 


\section{Decentralization}

- Establish treatment facilities (including the capacity for mobile treatment technologies), storage facilities, and possibly disposal facilities for treated LLMW at all sites where LLMW is to be generated or is currently stored.

- The WM PEIS will consider both (1) treatment to meet LDRs at all sites and (2) minimal treatment at all sites with treatment to meet LDRs at large sites (i.e., those with greater than $99 \%$ of the wastes).

\section{Regionalization}

- Same as decentralization, except consolidate some treatment capabilities at the 11 DOE sites with greater than $99 \%$ of wastes. All sites will treat their own aqueous wastes.

\section{Centralization}

- Same as regionalization, except further consolidate some treatment capabilities and possibly dispose of at only one DOE site. All sites will treat their own aqueous wastes.

The Decentralized Alternative considers establishing treatment and storage facilities at all current storage or future generation sites with disposal at as many as 13 sites. Regionalization and centralization alternatives consider consolidation of selected treatment capabilities with some level of treatment at every site. LLMW alternatives are summarized in Table 6.1.

LLMW is classified as $\mathrm{CH}$ or $\mathrm{RH}$ and alpha- (having transuranic alpha-emitting radionuclides) or non-alpha-contaminated. Each of these classifications ( $\mathrm{CH}$-alpha, $\mathrm{CH}$-non-alpha, $\mathrm{RH}$-alpha, and RH-non-alpha), is further subdivided into 32 waste types, depending on the physical and chemical characteristics, which in turn dictate the possible treatment technologies used in the treatment of LLMW.

The WM PEIS treatment technologies were compressed into the nine generic treatment capabilities described in Table 6.2, combinations of which define the treatment train for each of the different waste streams. Figure 6.1 is a flow sheet of the entire LLMW treatment complex showing the LLMW streams taken from current storage to final form. A detailed description of treatment processes can be found in Wilkins et al. (1996). 


\section{TABLE 6.1 Specification of LLMW Alternatives ${ }^{\mathrm{a}}$}

\begin{tabular}{|c|c|c|c|c|c|c|c|c|c|c|c|c|c|c|c|c|}
\hline WM PEIS Alternative ${ }^{\mathrm{b}}$ & Action & $\begin{array}{r}\text { 롱 } \\
\text { 总 } \\
\end{array}$ & $\underset{\mathrm{Z}}{\stackrel{1}{\mathrm{I}}}$ & 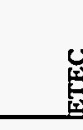 & $\stackrel{\varphi}{z}$ & 岦 & 点 & $\stackrel{\vec{z}}{\underline{\Sigma}}$ & 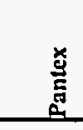 & 它 & 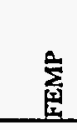 & 里 & 总 & 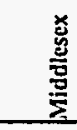 & $\frac{y}{3}$ & 点 \\
\hline $\begin{array}{l}\text { No action: L.DR ireatment at } 3 \text { sites. } \\
\text { All sites store }\end{array}$ & $\begin{array}{l}\text { Treat al all } \\
\text { Slore at all }\end{array}$ & $\begin{array}{l}\text { NA } \\
s^{d}\end{array}$ & $\begin{array}{c}\text { NA } \\
S\end{array}$ & $\begin{array}{c}\text { NA } \\
S\end{array}$ & $\begin{array}{c}\text { NA } \\
S\end{array}$ & $\begin{array}{l}T^{c} \\
S \\
\end{array}$ & $\begin{array}{c}\text { NA } \\
S\end{array}$ & $\begin{array}{c}\text { NA } \\
S\end{array}$ & $\begin{array}{c}\text { NA } \\
S\end{array}$ & $\begin{array}{c}\text { NA } \\
S\end{array}$ & $\begin{array}{c}\text { NA } \\
S\end{array}$ & $\begin{array}{c}\mathrm{S} A \\
\end{array}$ & $\begin{array}{l}\mathrm{T} \\
\mathrm{s} \\
\end{array}$ & $\begin{array}{c}\text { NA } \\
S\end{array}$ & $\begin{array}{l}\mathrm{T} \\
\mathrm{S}\end{array}$ & $\begin{array}{c}\text { NA } \\
S\end{array}$ \\
\hline $\begin{array}{l}\text { Decentralized: LDR treatment at } \\
49 \text { sites } \\
\text { Disposal at } 16 \text { sites }\end{array}$ & $\begin{array}{l}\text { Treat at all } \\
\text { Dispose at } 16\end{array}$ & $\begin{array}{l}T \\
D^{c}\end{array}$ & D & $\begin{array}{c}T \\
N A^{f}\end{array}$ & $\begin{array}{l}\mathrm{T} \\
\mathrm{D}\end{array}$ & D & D & D & D & $\mathrm{T}$ & $\mathrm{D}$ & D & D & D & $\mathrm{D}$ & $\begin{array}{c}\mathrm{T} \\
\mathrm{NA}\end{array}$ \\
\hline $\begin{array}{l}\text { Regionalized } 1: \text { LDR treatment at } \\
11 \text { sites } \\
\text { Disposal at } 12 \text { sites }\end{array}$ & $\begin{array}{l}\text { Treat at } 11+2 \\
\text { Dispose at } 12\end{array}$ & $D$ & $\mathrm{D}$ & NA & NA & D & D & $\mathrm{D}$ & $\mathrm{D}$ & $D$ & $\mathrm{D}$ & $\mathrm{D}$ & $\mathrm{T}$ & $T^{*}$ & $\mathrm{~T}$ & $\begin{array}{l}\text { NA } \\
\text { NA }\end{array}$ \\
\hline $\begin{array}{l}\text { Regionalized 2: LDR } \\
\text { treatment at } 7 \text { sites } \\
\text { Disposal at } 6 \text { sites }\end{array}$ & $\begin{array}{l}\text { Treat at } 7 \\
\text { Dispose at } 6\end{array}$ & D & $\mathrm{D}$ & NA & NA & T & $\mathrm{TA}$ & $\mathrm{T}$ & NA & NA & NA & $\begin{array}{l}\mathrm{T} \\
\mathrm{NA}\end{array}$ & T & $\begin{array}{l}\mathrm{NA} \\
\mathrm{NA}\end{array}$ & $\mathrm{T}$ & $\begin{array}{l}\text { NA } \\
\text { NA }\end{array}$ \\
\hline $\begin{array}{l}\text { Regionalized 3: LDR } \\
\text { trutment at } 7 \text { sites } \\
\text { Disposal at 1 }\end{array}$ & $\begin{array}{l}\text { Treat at } 7 \\
\text { Dispose at } 1\end{array}$ & TA & NA & NA & NA & NA & $\mathrm{T}$ & T & $\begin{array}{l}\mathrm{NA} \\
\mathrm{NA}\end{array}$ & $\begin{array}{l}\text { NA } \\
\text { NA }\end{array}$ & $\begin{array}{l}\text { NA } \\
\text { NA }\end{array}$ & $\begin{array}{l}\mathrm{T} \\
\mathrm{NA}\end{array}$ & $\begin{array}{l}T \\
\text { NA }\end{array}$ & NA & $\begin{array}{l}\mathrm{T} \\
\mathrm{NA}\end{array}$ & $\mathrm{NA}$ \\
\hline $\begin{array}{l}\text { Regionalized 4: LDR treatment at } \\
4 \text { sites } \\
\text { Disposal at } 6 \text { sites }\end{array}$ & $\begin{array}{l}\text { Treat at } 4 \\
\text { Dispose at } 6\end{array}$ & $\mathbf{T}$ & $\begin{array}{l}\text { NA } \\
\text { NA }\end{array}$ & $\begin{array}{l}\text { NA } \\
\text { NA }\end{array}$ & NA & $T$ & $\begin{array}{l}\text { NA } \\
\text { NA }\end{array}$ & $\begin{array}{l}\text { NA } \\
\text { D }\end{array}$ & $\mathrm{NA}$ & NA & $\mathrm{NA}$ & $\mathrm{NA}$ & $\mathrm{T}$ & NA & $\mathbf{T}$ & NA \\
\hline $\begin{array}{l}\text { Centralized: LDR treatment at } \\
\text { I site } \\
\text { Disposal at 1 site }\end{array}$ & $\begin{array}{l}\text { Treat at I } \\
\text { Dispose at } 1\end{array}$ & $\mathrm{~T}$ & NA & $\mathrm{NA}$ & NA & NA & NA & $\mathrm{NA}$ & $\mathrm{NA}$ & NA & $\mathrm{NA}$ & $\mathrm{NA}$ & $\mathrm{NA}$ & $\mathrm{NA}$ & NA & $\begin{array}{l}\text { NA } \\
\text { NA }\end{array}$ \\
\hline Sensitivity analyses ${ }^{\mathrm{h}}$ & NA & NA & NA & NA & NA & NA & $\mathrm{NA}$ & NA & NA & NA & NA & $\mathrm{NA}$ & NA & NA & $\mathrm{NA}$ & NA \\
\hline
\end{tabular}

a $\quad$ ETEC $=$ Energy Technology Engineering Center; Middlesex $=$ Middlesex Sampling Plant.

"Ilie WM PEIS considers four alcernatives: No Action, Decentralized, Regionalized, and Centralized. This table provides an abbreviated case description and treatment (I) and disposal (D) codes for each of the 14 hightest volume sites. The No Action Alternative is based on all sites using existing treatment facilities and placing the treated waste in monitored, aboveground storage facilities at all DOE sites. The Decentrulized 'Treatment Alternative analyzes LDR treatment at 49 sites with disposal at 16 sites. Several regionalized treatment alternatives are considered, which include LDR treatment at 11 , 7, or 4 sites, and disposal at either 12,6 , or I site(s). The Centralized Alternative analyzes treatment and disposal at only 1 site. The Remote-Handled Alternative involves treatment and disposal at 4 sites.

c $T$ = treatment.

$4 S=$ storage.

- $\mathrm{D}=$ disposal.

I $\mathrm{NA}=$ not applicable.

\& $T^{*}=$ specialized treatment

" Sensitivity analyses include examination of vitrification and nonthermal treatment options, engineered disposal options, the use of alternative characterization methods, and the consolidation of special waste streams. 


\section{TABLE 6.2 Generic Treatment Categories and Descriptions}

\begin{tabular}{|c|c|c|}
\hline Treatment Capability & Abbreviation & Description \\
\hline Organic destruction & ORDST & $\begin{array}{l}\text { Destruction of organic liquids and solids using a broad spectrum of thermal and nonthermal organic destruction } \\
\text { technologies. Examples include incineration; other thermal technologies such as vitrification, plasma hearth, and } \\
\text { molten metal; and nonthermal technologies such as chemical oxidation, electron beam, and silent discharge } \\
\text { plasma. Some of these technologies are also applicable for the STABL and METRC capabilities. }\end{array}$ \\
\hline $\begin{array}{l}\text { Aqueous liquids } \\
\text { (wastewater treatment for } \\
\text { organics) }\end{array}$ & WWTOR & $\begin{array}{l}\text { Treatment technologies for oxidation of organics contained in a predominantly aqueous medium. Examples } \\
\text { include wet oxidation, catalyzed wet oxidation, supercritical water oxidation, and related technology variations }\end{array}$ \\
\hline Metal removal & METRM & $\begin{array}{l}\text { Metal ion and particulate removal from liquids. Examples include settling, filtration, precipitation, ion } \\
\text { exchange, and carbon adsorption. }\end{array}$ \\
\hline Stabilization & STABL & $\begin{array}{l}\text { All immobilization and microencapsulation technologies. Examples include cementation, vitrification, and } \\
\text { polymer encapsulation. }\end{array}$ \\
\hline Metal recovery & METRC & $\begin{array}{l}\text { Methods for separation/collection of metals from waste streams for reuse or recycle. Examples include sorting, } \\
\text { melting, and decontamination. }\end{array}$ \\
\hline Mercury separation & HGSEP & $\begin{array}{l}\text { All mercury separation, collection, and immobilization methods. Examples include gravitational, thermal, and } \\
\text { chemical techniques to separate mercury for recycle or for immobilization by amalgamation. }\end{array}$ \\
\hline Decontamination & DECON & $\begin{array}{l}\text { Extractive, mechanical, hydraulic, thermal, and electrochemical techniques used to remove contamination from } \\
\text { substrate materials. }\end{array}$ \\
\hline Neutralization & NEUTR & Acid or base additions to neutralize waste streams. \\
\hline Deactivation & DEACT & $\begin{array}{l}\text { Appropriate technologies to deactivate reactives such as a sodium or uranium metal or cyanides prior to } \\
\text { disposal. }\end{array}$ \\
\hline
\end{tabular}




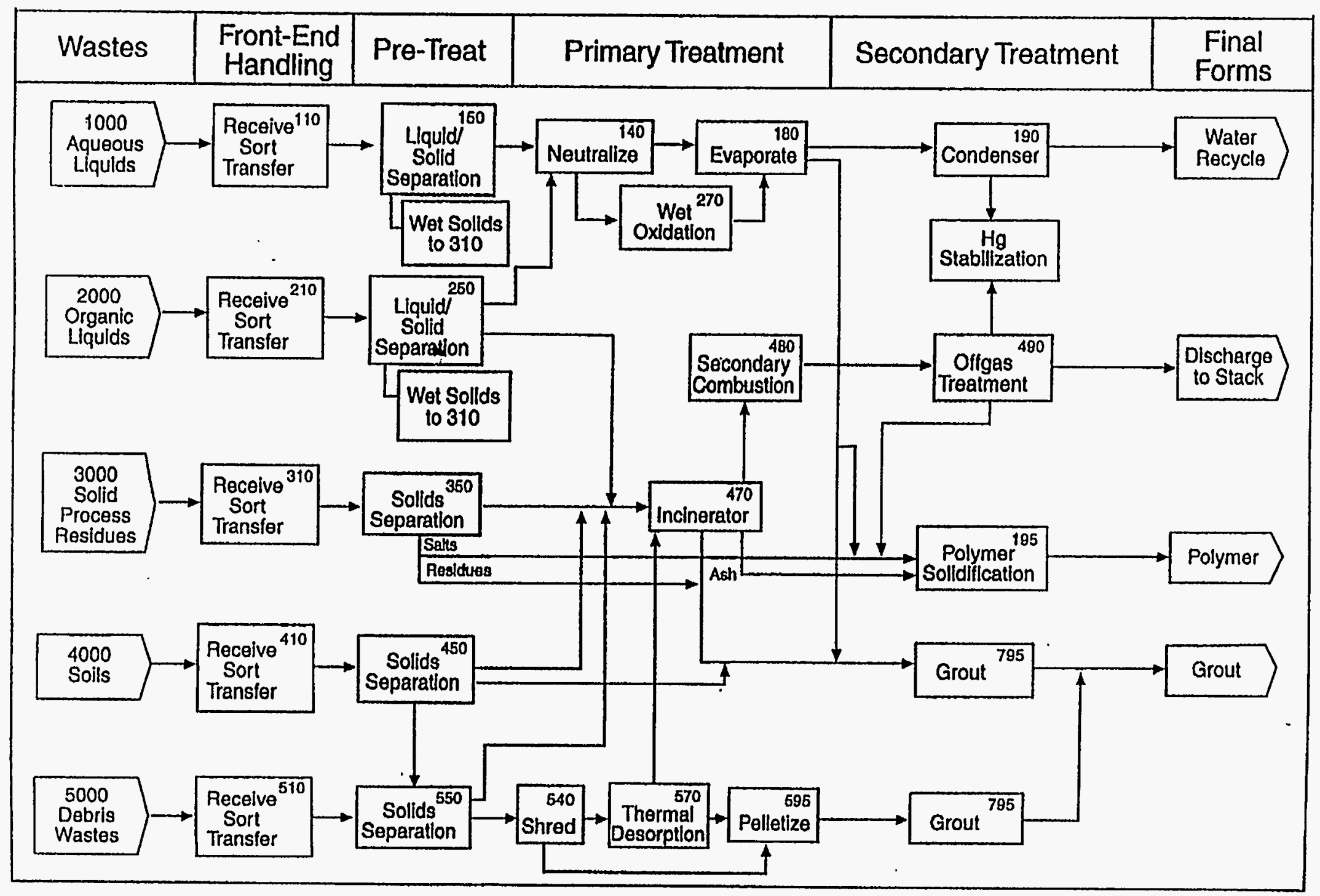


The WM PEIS approximated site-dependent radiological profiles based on the radiological profile of LLW generated at a site, independent of the waste types, with the radionuclides allowed to decay over an average elapsed time according to the site's process history. The WM PEIS approximated waste-stream-dependent chemical profiles for each of the 32 different waste types, independent of the site of origin, by averaging over the concentrations of chemical contaminants in MWIR.

\subsection{RISK-DOMINANT ACCIDENTS AND MODELING ASSUMPTIONS}

The selection of accidents considers importance to risk of both radiological and chemical hazards. The general modeling assumptions and related parameters for radiological MAR, DF, and LPF are detailed in Section 2. The RARFs are a function of the physical form of the material rendered airborne, which varies by treatability category for each waste type. A matrix has been developed for each waste type to map the treatability categories into the physical forms for which airborne release data (Appendix D) were developed. The LLMW mapping shown in Table 6.3 is based on the WM PEIS waste and process descriptions (Wilkins et al. 1996).

Review of the hazardous contents of the wastes and their concentrations suggests that spills of organic liquids (Treatability Categories [TCs] 3-6) followed by evaporation and/or combustion reactions are the events most likely to lead to the airborne release of chemically hazardous substances. The possibility of fires is strongest in the waste streams containing a large fraction of combustible organic substances. These include TC 6 (58\% organic solvents), TC 12 (organic particulates, oily sludges), TC 13-14 (solid organic materials), TC 19 (combustible debris), TC 20 (heterogeneous debris, including paper), TC 21 (organic lab packs), and TC 23 (solid lab packs). The inorganic contaminants are present in small concentrations and are unlikely to become involved, except in a catalytic role, in any chemistry leading to the release of toxic materials. It is assumed that the listed elements are present either in elemental form or in common oxidation states such as arsenic (As[II]), barium (Ba[m]), cadmium (Cd[II]), chromium ( $\mathrm{Cr}[\mathrm{III}]$ and $\mathrm{Cr}[\mathrm{VT}]$ ), lead $(\mathrm{Pb}[\mathrm{II})$ ), selenium (Se[II] and $\mathrm{Se}[\mathrm{VT}]$ ), mercury $\mathrm{Hg}(\mathrm{I})$ and $\mathrm{Hg}(\mathrm{II})$, and silver ( $\mathrm{Ag}[\mathrm{I}])$. Table 6.4 summarizes the chemical release characteristics developed for the accidents.

\subsubsection{Handling Accidents}

Handling accidents during the staging and storage of $\mathrm{CH}$ waste are expected to dominate the risk of exposure for workers because of their high frequency and the proximity of the workers during hands-on operations. The frequencies of accidents at a given site would be a strong function of waste throughput at that site. The assumption (taken independently for both chemical and radiological accidents) is that two severe breaches of containment occur per year for each inventory 
TABLE 6.3 Mapping of LLMW Treatability Categories with Accident Analysis Physical Forms

\begin{tabular}{|c|c|c|}
\hline LLMW Treatability Category & Accident Physical Form & Comments/Assumptions \\
\hline $\begin{array}{l}\text { Aqueous liquid } \\
\text { (TC 1-2) }\end{array}$ & Aqueous solution & Input waste form is a dilute aqueous LLMW solution. \\
\hline $\begin{array}{l}\text { Organic liquid } \\
\text { (TC } 3-6 \text { ) }\end{array}$ & $\begin{array}{l}\text { Organic combustible } \\
\text { solution }\end{array}$ & $\begin{array}{l}\text { Input waste form consists of flammable components } \\
\text { (i.e, petroleum distillates, solvents) with low amounts } \\
\text { of suspended solids. }\end{array}$ \\
\hline $\begin{array}{l}\text { Inorganic sludges/particulates } \\
\text { (TC 7-8) }\end{array}$ & Aqueous slurry & $\begin{array}{l}\text { Based on logic of previous treatability category. When } \\
\text { the particulates are not in intimate contact with the } \\
\text { solution so that they can be considered easily } \\
\text { dispersible, then the accident category of } \\
\text { "Noncombustible Powder" may be more appropriate. } \\
\text { This waste stream does not include significant } \\
\text { organics or halogenated compounds. }\end{array}$ \\
\hline $\begin{array}{l}\text { Salt waste } \\
\text { (TC 9) }\end{array}$ & Noncombustible powder & \\
\hline $\begin{array}{l}\text { Cemented solids } \\
\text { (TC 10) }\end{array}$ & $\begin{array}{l}\text { Noncombustible aggregated } \\
\text { solid }\end{array}$ & $\begin{array}{l}\text { Noncombustible aggregated solids surrogate for } \\
\text { cemented solids; would expect minimal risk from any } \\
\text { potential current storage accidents, unless the } \\
\text { cohesiveness of the cement has been degraded. }\end{array}$ \\
\hline $\begin{array}{l}\text { Organic sludges/particulates } \\
\text { (TC 11-12) }\end{array}$ & Organic combustible slurry & $\begin{array}{l}\text { Assumes a homogeneous mixture of solid particulates } \\
\text { and an organic solution, with the particulate surfaces } \\
\text { "wetted" by the solution. If, however, the particulates } \\
\text { are not in intimate contact with the solution so that } \\
\text { they can be considered easily dispersible, then the } \\
\text { accident category of "Combustible Powder" may be } \\
\text { more appropriate. }\end{array}$ \\
\hline $\begin{array}{l}\text { Solid organic materials } \\
\text { (TC 13-14) }\end{array}$ & Combustible solid plastic & \\
\hline $\begin{array}{l}\text { Soils without debris } \\
\text { (TC 15) }\end{array}$ & Noncombustible powder & $\begin{array}{l}\text { Based on Mishima's original accident categories taken } \\
\text { from the WRAP II safety documentation (WHC } \\
\text { 1991b). }\end{array}$ \\
\hline $\begin{array}{l}\text { Soils with }<50 \% \text { debris } \\
\text { (TC 16) }\end{array}$ & Noncombustible powder & As above. \\
\hline $\begin{array}{l}\text { Inorganic } \\
\text { debris (TC 17-18) }\end{array}$ & Inert metal & $\begin{array}{l}\text { Waste includes construction materials, equipment, and } \\
\text { structures. }\end{array}$ \\
\hline
\end{tabular}


TABLE 6.3 (Cont.)

\begin{tabular}{|c|c|c|}
\hline LLMW Treatability Category & Accident Physical Form & Comments/Assumptions \\
\hline $\begin{array}{l}\text { Organic debris } \\
\text { (TC 19) }\end{array}$ & Dry active waste & Based on waste form description (ORNL 1994). \\
\hline $\begin{array}{l}\text { Heterogeneous debris } \\
\text { (TC 20) }\end{array}$ & Inert metal & $\begin{array}{l}\text { Logic used for "Inorganic Debris" also applied to this } \\
\text { treatability category. }\end{array}$ \\
\hline $\begin{array}{l}\text { Lab packs with organic liquids } \\
\text { (TC 21) }\end{array}$ & $\begin{array}{l}\text { Organic combustible } \\
\text { solution }\end{array}$ & $\begin{array}{l}\text { RARFs for dry active waste were developed from } \\
\text { available data for combustible trash and lab packs; } \\
\text { assume that the presence of RCRA toxic metals will } \\
\text { not significantly affect the release characteristics of } \\
\text { this treatability category. }\end{array}$ \\
\hline $\begin{array}{l}\text { Lab packs without organic liquids } \\
\text { (TC 22) }\end{array}$ & Aqueous solution & $\begin{array}{l}\text { Assumes the aqueous liquids in the lab packs are not } \\
\text { absorbed. }\end{array}$ \\
\hline $\begin{array}{l}\text { Solid lab packs } \\
\text { (TC 23) }\end{array}$ & Dry active waste & \\
\hline $\begin{array}{l}\text { Reactive metals } \\
\text { (TC 24) }\end{array}$ & Reactive metal & By definition. \\
\hline $\begin{array}{l}\text { Explosives } \\
\text { (TC 25) }\end{array}$ & $\begin{array}{l}\text { Not considered in accident } \\
\text { analysis }\end{array}$ & $\begin{array}{l}\text { When the accident physical forms were initially } \\
\text { developed, the WM PEIS treatability categories for } \\
\text { LLMW did not include this treatability category. } \\
\text { Further information on the nature of contamination is } \\
\text { required; it may, however, be expected that the } \\
\text { explosive material has a fine layer of surface } \\
\text { contamination. In this case, the "Combustible Powder" } \\
\text { accident physical form may be applicable. For } \\
\text { assessment of shock-induced explosions, the } \\
\text { trinitrotoluene (TNT) equivalence of various } \\
\text { explosives given in Table } 3.4 \text { of NUREG-1320 (Ayer } \\
\text { et al. 1988) may be used. However, it should be noted } \\
\text { that the release of energy may be great enough to } \\
\text { cause failure of containment boundaries and lead to } \\
\text { opening of alternative flow paths during an accident, } \\
\text { affecting the LPF. }\end{array}$ \\
\hline $\begin{array}{l}\text { Compressed gases } \\
\text { (TC 26) }\end{array}$ & $\begin{array}{l}\text { Not considered in accident } \\
\text { analysis }\end{array}$ & $\begin{array}{l}\text { The release category is dependent on the compressed } \\
\text { gas(es); if the gas is a noncondensible or a noble gas, } \\
\text { then the "Noble Gas" category should be applied. A } \\
\text { similar situation applies for halogens and condensible } \\
\text { vapors. }\end{array}$ \\
\hline
\end{tabular}


TABLE 6.3 (Cont.)

\begin{tabular}{|c|c|c|}
\hline LLMW Treatability Category & Accident Physical Form & Comments/Assumptions \\
\hline Liquid $\mathrm{Hg}$ & Waste-form dependent & $\begin{array}{l}\text { When the accident physical forms were initially } \\
\text { developed, the WM PEIS treatability categories for } \\
\text { LLMW did not include this treatability category. It is } \\
\text { assumed that the solution and not the mercury itself is } \\
\text { radioactively contaminated. One significant mercury- } \\
\text { containing solution is the LLMW stream generated at } \\
\text { Savannah River during reprocessing and other waste } \\
\text { processing steps. The SRS stream is an organic liquid } \\
\text { containing small amounts of mercury; in this case, the } \\
\text { "Organic Combustible Solution" accident physical } \\
\text { form may be applicable. Aqueous solutions containing } \\
\text { mercury are also present; in this case, the appropriate } \\
\text { accident physical form would be "Aqueous Liquids, } \\
\text { Solutions." }\end{array}$ \\
\hline $\begin{array}{l}\text { Elemental Pb } \\
\text { (TC 28) }\end{array}$ & Waste-form dependent & $\begin{array}{l}\text { When the accident physical forms were initially } \\
\text { developed, the WM PEIS treatability categories for } \\
\text { LLMW did not include this treatability category. This } \\
\text { treatability category may in general contain both } \\
\text { surface contamination and induced activity in the lead. } \\
\text { In the case of surface contamination (of radionuclides } \\
\text { other than lead), then the "Noncombustible Powder" } \\
\text { accident physical form may be applied. If, however, } \\
\text { this stream contains significant amounts of induced } \\
\text { activity, then the "Inert Metal" physical form may be } \\
\text { more appropriate for accident stresses that do not } \\
\text { involve high temperatures (e.g., mechanical releases). }\end{array}$ \\
\hline $\begin{array}{l}\text { Be dust } \\
\text { (TC 29) }\end{array}$ & Waste-form dependent & See above. \\
\hline $\begin{array}{l}\text { Batteries, Pb-acid, Cd } \\
\text { (TC 30) }\end{array}$ & Noncombustible powder & $\begin{array}{l}\text { Assumes that neither the } \mathrm{Pb} \text { nor } \mathrm{Cd} \text { are radioactive, } \\
\text { and that the majority of the radioactivity is associated } \\
\text { with surface contamination. }\end{array}$ \\
\hline
\end{tabular}


TABLE 6.4 Chemical Releases Analyzed for LLMW

\begin{tabular}{|c|c|c|c|}
\hline Accident Sequence & Toxic Gases Released & Mass of Waste & Release Rate \\
\hline $\begin{array}{l}\text { Spill of aqueous nonhalogenated } \\
\text { organic liquids (TC } 4 \text { ) }\end{array}$ & Acetone, butanone, methanol & $73 \mathrm{~kg} / \mathrm{drum}$ & $907-1,361 \mathrm{~g} / \mathrm{min}^{b}$ \\
\hline $\begin{array}{l}\text { Spill of aqueous halogenated organic } \\
\text { liquids (TC } 3 \text { ) }\end{array}$ & $\begin{array}{l}\text { Trichloroethanes, other } \\
\text { chlorohydrocarbons }\end{array}$ & $3 \mathrm{~kg} / \mathrm{drum}$ & $45 \mathrm{~g} / \mathrm{min}$ \\
\hline $\begin{array}{l}\text { Spill of "pure" organic liquids } \\
\text { halogenated by (TC 5) }\end{array}$ & $\begin{array}{l}\text { Trichloroethanes } \\
\text { Tetrachloroethanes }\end{array}$ & $\begin{array}{l}23 \mathrm{~kg} / \mathrm{drum} \\
5 \mathrm{~kg} / \mathrm{drum}\end{array}$ & $\begin{array}{l}227 \mathrm{~g} / \mathrm{min} \\
45 \mathrm{~g} / \mathrm{min}\end{array}$ \\
\hline $\begin{array}{l}\text { Spill of "pure" nonhalogenated organic } \\
\text { liquids (TC 6) }\end{array}$ & $\begin{array}{l}\text { Acetone, butanone, methanol } \\
\text { BTX }\end{array}$ & $\begin{array}{l}27 \mathrm{~kg} / \mathrm{drum} \\
91 \mathrm{~kg} / \mathrm{drum}\end{array}$ & $\begin{array}{l}454 \mathrm{~g} / \mathrm{min}^{\mathrm{a}} \\
907 \mathrm{~g} / \mathrm{min}^{\mathrm{a}}\end{array}$ \\
\hline $\begin{array}{l}\text { Spill of "pure" nonhalogenated organic } \\
\text { liquids (TC 6) followed by fire }\end{array}$ & $\begin{array}{l}\text { BTX } \\
\text { CO } \\
\text { Cd fumes } \\
\text { Cr compounds } \\
\text { Soot }\end{array}$ & $\begin{array}{l}5 \mathrm{~kg} / \mathrm{drum} \\
91 \mathrm{~kg} / \mathrm{drum} \\
0.2 \mathrm{~kg} / \mathrm{drum} \\
0.2-0.5 \mathrm{~kg} / \mathrm{drum} \\
36 \mathrm{~kg} / \mathrm{drum}\end{array}$ & $\begin{array}{l}136 \mathrm{~g} / \mathrm{min} \\
3,175 \mathrm{~g} / \mathrm{min} \\
9 \mathrm{~g} / \mathrm{min} \\
9 \mathrm{~g} / \mathrm{min} \\
1,225 \mathrm{~g} / \mathrm{min}\end{array}$ \\
\hline \multirow[t]{5}{*}{$\begin{array}{l}\text { Incinerator staging area fire; } \\
\text { involvement of TC } 12 \text { (organic } \\
\text { sludges), TC } 19 \text { (combustible debris), } \\
\text { organic liquid (intermediate), and } \\
\text { organic particulates (intermediate) }\end{array}$} & $\begin{array}{l}\mathrm{CO} \\
\mathrm{HCl}\end{array}$ & $\begin{array}{l}40-50 \% \text { of mass of drum } \\
60 \% \text { of mass of } \\
\text { Cl-containing compounds } \\
\text { in the stream }\end{array}$ & $\begin{array}{l}3,175 \mathrm{~g} / \mathrm{min} / \mathrm{drum} \\
907 \mathrm{~g} / \mathrm{min} / \mathrm{drum}\end{array}$ \\
\hline & BTX fumes & $\begin{array}{l}5 \% \text { of mass of BTX } \\
\text { present }\end{array}$ & $136 \mathrm{~g} / \mathrm{min} / \mathrm{drum}$ \\
\hline & Soot & $\begin{array}{l}40 \% \text { of mass of BTX plus } \\
10 \% \text { of total mass }\end{array}$ & $136 \mathrm{~g} / \mathrm{min} / \mathrm{drum}$ \\
\hline & $\begin{array}{l}\text { Cd fumes (condensing to very small } \\
\text { particles) }\end{array}$ & $\begin{array}{l}100 \% \text { of mass of } \mathrm{Cd} \\
\text { present }\end{array}$ & $9 \mathrm{~g} / \mathrm{min} / \mathrm{drum}$ \\
\hline & Cr compounds & $\begin{array}{l}250 \% \text { of mass of } \mathrm{Cr} \\
\text { present }\end{array}$ & $9 \mathrm{~g} / \mathrm{min} / \mathrm{drum}$ \\
\hline
\end{tabular}

a $\mathrm{BTX}=$ benzene, toluene, and xylene; $\mathrm{Cd}=$ cadmium; $\mathrm{CO}=$ carbon monoxide; $\mathrm{Cr}=$ chromium; and $\mathrm{HCl}=$ hydrogen chloride.

b An approximation of this release rate can be estimated from Salazar and Lane (1992) :

$$
Q R=\frac{0.106 \mu^{0.78}(M W)^{0.667}(A)(V P)}{R(t+273)}
$$

where $\quad Q R=$ release rate $(g / \mathrm{min})$,

$$
\begin{aligned}
M W & =\text { molecular weight }(\mathrm{g} / \mathrm{mol}), \\
A & =\text { surface area }\left(\mathrm{m}^{2}\right), \\
V P & =\text { effective vapor pressure }(\mathrm{mm} \mathrm{Hg}), \\
R & =82.05 \text { atm } \mathrm{cm}^{3} / \mathrm{mol} \mathrm{K}, \\
t & =\text { temperature }\left({ }^{\circ} \mathrm{C}\right), \text { and } \\
\mu & =\text { wind speed }(\mathrm{m} / \mathrm{s}) .
\end{aligned}
$$

It is assumed that $t=30^{\circ} \mathrm{C}, A=20 \mathrm{~m}^{2}$, and wind speed $=2 \mathrm{~m} / \mathrm{s}$. For acetone in TC $4, M W=58$, and $V P=0.36 \times 285 \mathrm{~mm}$ Hg. For acetone in TC 6, VP $=0.14 \times 285 \mathrm{~mm} \mathrm{Hg}$. For benzene in TC $6, M W=78$, and $V P=0.44 \times 120 \mathrm{~mm} \mathrm{Hg}$. 
of 10,000 drums handled. It is assumed for the results herein that handling breaches fall in the $>0.001 / y r$ frequency category.

Representative radiological accident scenarios involve a single drum and assume that $25 \%$ of its inventory is subjected to stresses capable of rendering the contents airborne (DF $=2.5 \mathrm{E}-01$ ). The composition of the representative drum is taken as a volume-weighted average of the treatability category compositions (excluding aqueous streams) at each site. The treatability category compositions are based on waste generation and inventory data at each site.

Representative chemical releases assume a single drum with $100 \%(\mathrm{DF}=1)$ of its contents spilled. The release characteristics for the spills are as follows.

Spill of TC 4 Waste. This aqueous nonhalogenated organic liquid waste is approximately $50 \%$ water, which makes a fire unlikely. A 208-L (55-gal) drum contains about $75 \mathrm{~kg}$ (160 lb) of acetone, butanone, and methanol. In a spill, the evaporation of moderately toxic acetone, butanone (or "MEK," methyl ethyl ketone), and methanol would take place at a rate of $907-1,361 \mathrm{~g} / \mathrm{min}$ $(2-3 \mathrm{lb} / \mathrm{min})$ and last $60-90 \mathrm{~min}$.

Spill of TC 3 Waste. This aqueous halogenated organic liquid waste contains approximately $50 \%$ water. A 208-L drum contains about $3 \mathrm{~kg}(6 \mathrm{lb})$ (about 1.5\%) trichloroethanes and other chlorohydrocarbons. In a spill, the trichloroethanes would evaporate at a low rate ( $>45 \mathrm{~g} / \mathrm{min}$ $[0.1 \mathrm{lb} / \mathrm{min}])$ and last at least $60 \mathrm{~min}$. Some gaseous hydrogen chloride would also escape, but the amount would be negligible.

The organic compounds in TC 3 are known to decompose when exposed to moisture, light, air, heat, and metal surfaces. The decomposition routes are hydrolysis, oxidation, and dehydrochlorination. All three routes give corrosive $\mathrm{HCl}$ as a product. An example is the hydrolysis of 1,1,1-trichloroethane:

or

$$
\mathrm{H}_{2} \mathrm{O}+\mathrm{Cl}_{3} \mathrm{C}-\mathrm{CH}_{3} \quad \cdots \quad \mathrm{CH}_{3} \mathrm{COCl} \text { (acetyl chloride) }+2 \mathrm{HCl} \text {, }
$$

$$
2 \mathrm{H}_{2} \mathrm{O}+\mathrm{Cl}_{3} \mathrm{C}-\mathrm{CH}_{3} \rightarrow \mathrm{CH}_{3} \mathrm{COOH} \text { (acetic acid) }+3 \mathrm{HCl}
$$

These reactions are normally slow, but are catalyzed by metal chlorides, including (but not limited to) barium chloride $\left(\mathrm{BaCl}_{2}\right)$, cadmium chloride $\left(\mathrm{CdCl}_{2}\right)$, chromium chloride $\left(\mathrm{CrCl}_{3}\right)$, and lead chloride $\left(\mathrm{PbCl}_{2}\right)$.

The dehydrochlorination of 1,1,2-trichloroethane $\left(\mathrm{Cl}_{2} \mathrm{HC}-\mathrm{CH}_{2} \mathrm{Cl}\right)$ yields $\mathrm{HCl}$ plus the isomeric dichloroethylenes $\left(\mathrm{Cl}_{2} \mathrm{C}-\mathrm{CH}_{2}\right)$ :

$$
\mathrm{Cl}_{2} \mathrm{HC}-\mathrm{CH}_{2} \mathrm{Cl} \quad-->\mathrm{Cl}_{2} \mathrm{C}-\mathrm{CH}_{2}+\mathrm{HCl}
$$


1,1,1-Trichloroethane experiences a similar reaction. Under strongly basic conditions (and at higher temperature), the $\mathrm{Cl}_{2} \mathrm{C}-\mathrm{CH}_{2}$ can lose another molecule of $\mathrm{HCl}$ to give the spontaneously flammable gas chloroacetylene:

$$
\mathrm{H}_{2} \mathrm{C}-\mathrm{CCl}_{2} \quad-->\mathrm{H}-\mathrm{CC}-\mathrm{Cl}+\mathrm{HCl} \text {. }
$$

This last reaction is unlikely under the conditions of storage of the wastes: the system would be acidic from $\mathrm{HCl}$ produced previously.

Finally, the reaction of 1,1,1-trichloroethane with aluminum is vigorous at or near ordinary conditions:

$$
2 \mathrm{Al}+6 \mathrm{Cl}_{3} \mathrm{C}-\mathrm{CH}_{3} \quad--->2 \mathrm{AlCl}_{3}+3 \mathrm{H}_{3} \mathrm{C}-\mathrm{CCl}_{2}-\mathrm{CCl}_{2}-\mathrm{CH}_{3} \text {. }
$$

The analogous reaction with iron is much slower but, like the reaction with $\mathrm{Al}$, is favored by acidic conditions. Such reactions precluded the use of these solvents in cleaning and degreasing operations (especially for aluminum) until stabilizers were discovered to prevent (vastly slow) them. Metalcleaning and vapor-degreasing grades of 1,1,1-trichloroethane and 1,1,2-trichloroethane may contain up to $7 \%$ by mass of a wide variety of stabilizers.

In chlorohydrocarbon-containing wastes, storage might allow time for the slow decomposition of chlorohydrocarbons to generate enough $\mathrm{HCl}$ to corrode and breach the walls of the container. It is also possible that unanticipated reactions in the waste might destroy or sequester the stabilizer, allowing more rapid generation of $\mathrm{HCl}$.

Spill of TC 5 Waste. This waste contains $5 \%$ water and "pure halogenated organic liquids," with a 208-L drum containing approximately $30 \mathrm{~kg}(60 \mathrm{lb})$ of chlorohydrocarbons. In a spill, unreacted trichloroethanes $(12.1 \%)$ and tetrachloroethanes $(2.7 \%)$ would evaporate at $<0.2 \mathrm{~kg} / \mathrm{min}$ $(<0.5 \mathrm{lb} / \mathrm{min})$ and last at least 2 hours. The escape of gaseous hydrogen chloride would be slight.

Spill of TC 6 Waste. A 208-L drum of this "pure" nonhalogenated organic liquid waste contains about $30 \mathrm{~kg}$ of acetone, butanone, and methanol and about $90 \mathrm{~kg}(200 \mathrm{lb})$ of BTX (benzene, toluene, and xylene). Evaporation of moderately toxic acetone and butanone and methanol would take place at a rate of $0.5 \mathrm{~kg} / \mathrm{min}(1 \mathrm{lb} / \mathrm{min})$ and last 40 to $60 \mathrm{~min}$. The evaporation of the less volatile but more prevalent BTX fraction would take place at a rate approximating $1 \mathrm{~kg} / \mathrm{min}$ ( $2 \mathrm{lb} / \mathrm{min}$ ) and last 90 to 100 minutes.

Spill of TC 6 Waste Followed by Fire. Waste stream TC 6 contains at least $58 \%$ flammable organic materials and $<5 \%$ water, too low a proportion to prevent combustion of the organic substances in air. Even if the unspecified $27 \%$ of the waste stream is nonflammable, a fire is 
possible. Acetone $\left(\mathrm{C}_{3} \mathrm{H}_{6} \mathrm{O}[1]\right)$ and butanone $\left(\mathrm{C}_{4} \mathrm{H}_{8} \mathrm{O}[1]\right)$ are volatile and exceedingly flammable, giving mainly carbon dioxide and water in a fire:

and

$$
\mathrm{C}_{3} \mathrm{H}_{6} \mathrm{O}(\mathrm{l})+4 \mathrm{O}_{2}(\mathrm{~g}) \rightarrow-\cdots 3 \mathrm{CO}_{2}(\mathrm{~g})+3 \mathrm{H}_{2} \mathrm{O}(\mathrm{g}) \quad \Delta \mathrm{H}^{\mathrm{o}}=-1,658 \mathrm{~kJ},
$$

$$
\left.2 \mathrm{C}_{4} \mathrm{H}_{8} \mathrm{O}(\mathrm{l})+11 \mathrm{O}_{2}(\mathrm{~g})\right] \quad-->8 \mathrm{CO}_{2}(\mathrm{~g})+8 \mathrm{H}_{2} \mathrm{O}(\mathrm{g}) \quad \Delta \mathrm{H}^{\mathrm{o}}=-4,844 \mathrm{~kJ},
$$

where "s" is solid, "g" is gas, and "l" is liquid. The complete combustion of benzene (which, together with xylene and toluene constitutes $44 \%$ of TC 6) would generate similarly innocuous products. For example, the complete combustion of benzene $\left(\mathrm{C}_{6} \mathrm{H}_{6}[\mathrm{l}]\right)$ proceeds as follows:

$$
2 \mathrm{C}_{6} \mathrm{H}_{6}(\mathrm{l})+15 \mathrm{O}_{2}(\mathrm{~g}) \quad \rightarrow 12 \mathrm{CO}_{2}(\mathrm{~g})+6 \mathrm{H}_{2} \mathrm{O}(\mathrm{g}) \quad \Delta \mathrm{H}^{\circ}=-6,271 \mathrm{~kJ}
$$

The combustion of BTX in a pool in the open air is, however, quite incomplete and yields CO and soot. Soot is a mixture of carbon and many compounds, including polycyclic aromatic hydrocarbons (PAHs) such as benzo[a]pyrene $\left(\mathrm{C}_{20} \mathrm{H}_{12}\right)$. Thus, a range of oxidation reactions takes place:

and

$$
\begin{aligned}
& 10 \mathrm{C}_{6} \mathrm{H}_{6}(\mathrm{l})+6 \mathrm{O}_{2}(\mathrm{~g}) \rightarrow 3 \mathrm{C}_{20} \mathrm{H}_{12}(\mathrm{~s})+12 \mathrm{H}_{2} \mathrm{O}(\mathrm{g}), \\
& 2 \mathrm{C}_{6} \mathrm{H}_{6}(\mathrm{l})+3 \mathrm{O}_{2}(\mathrm{~g}) \rightarrow 12 \mathrm{C}(\mathrm{s})+6 \mathrm{H}_{2} \mathrm{O}(\mathrm{g}),
\end{aligned}
$$

$$
2 \mathrm{C}_{6} \mathrm{H}_{6}(\mathrm{l})+9 \mathrm{O}_{2}(\mathrm{~g}) \quad-->12 \mathrm{CO}(\mathrm{g})+6 \mathrm{H}_{2} \mathrm{O}(\mathrm{g})
$$

The ratio of oxygen to benzene increases from 0.6 to 4.5 in this series.

The heat of combustion of the first portions of the hydrocarbons would evaporate other portions. A fire in $210 \mathrm{~kg}$ ( $460 \mathrm{lb}$ ) of waste (a single 208-L drum full of TC 6 waste having a density of $1 \mathrm{~kg} / \mathrm{L})$ would involve about $90 \mathrm{~kg}(200 \mathrm{lb})$ of BTX. It would evaporate perhaps $5 \mathrm{~kg}(10 \mathrm{lb})$ of unreacted BTX, an inhalation hazard, and generate on the order of $40 \mathrm{~kg}(80 \mathrm{lb})$ of soot and $90 \mathrm{~kg}$ (1981b) of CO. The combustion of the acetone, butanone, and methanol, which contain oxygen in their molecules, would give mainly $\mathrm{CO}_{2}$ (and water), although some $\mathrm{CO}$ would always form; substantial quantities of $\mathrm{CO}$ could form if the fire smoldered because of a lack of air. Such a fire would last perhaps $30 \mathrm{~min}$ (depending on the area of the spill). The proportions of the products would depend on the area of the spill as well as other circumstances of the fire.

TC 6 waste contains $1,100 \mathrm{mg} / \mathrm{kg}$ of Cd, for a total of about $225 \mathrm{~g}(0.5 \mathrm{lb})$ in a 208-L drum. Elemental $\mathrm{Cd}$ and its common compounds $\left(\mathrm{CdCl}_{2}\right.$, cadmium oxide [CdO], and cadmium nitrate [Cd $\left.\left(\mathrm{NO}_{3}\right)_{2}\right]$ ) emit toxic fumes of $\mathrm{Cd}(\mathrm{g})$ when strongly heated. These $\mathrm{Cd}$ fumes would present an

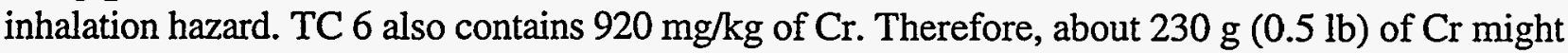
also be released, probably in the form of a somewhat larger mass (about $450 \mathrm{~g}$ [1 lb]) of compounds 
of $\mathrm{Cr}$ such as $\mathrm{CrCl}_{3}$ and chromium oxide $\left[\mathrm{CrO}_{3}\right]$. This assumes the original presence of the $\mathrm{Cr}$ as $\mathrm{CrCl}_{3}$ or $\mathrm{CrO}_{3}$, or the conversion of other $\mathrm{Cr}$-containing substances to these compounds in the fire.

\subsubsection{Storage Facility Accidents}

Accidents and source terms for current storage were not analyzed explicitly. Unlike treatment that will predominantly use new facilities that will have common characteristics, current (pretreatment) storage will consist predominantly of preexisting facilities (storage buildings or enclosures) that vary greatly in the amounts and types of wastes that they can store, the configurations in which they can store wastes, and their containment and confinement characteristics. However, because recent DOE safety or NEPA information on storage facility accidents provides guidance on the potential risk impacts applicable to storage, this information is discussed herewith.

Current SARs predict consequences for a range of selected waste storage accidents of varying frequency. Sometimes these accidents involve facilities that primarily store LLMW. A brief summary of some of these accidents involving LLMW, assumptions used by the sites in preparing the analyses, and release or health effect results are provided in Table 6.5.

The INEL SAR for the Radioactive Waste Management Complex (RWMC) identifies three bounding accidents involving LLMW (EG\&G, 1993b). All of these accidents occur at or involve in some manner the Air Support Building II (ASB-I), the facility that stores most of the LLMW at INEL. An accident with fire was identified as occurring at ASB-II. The cause is a propane leak in the fuel line supplying the heat and inflation unit within the facility. This accident would involve only the waste stored at ASB-II and results in an exposure of $2.0 \mathrm{E}-02 \mathrm{rem}$ (MEI). A second accident was initiated by an earthquake, sufficiently severe to damage all of the buildings (ASB-II included) at the RWMC. The radiological release and consequences listed in Table 6.5 for this accident (i.e., $0.041 \mathrm{Ci}$ and $0.75 \mathrm{rem}$ ) are due primarily to wastes stored in buildings other than ASB-II. The third accident, a fuel-air explosion originating in ASB-II has the potential to release hazardous materials due primarily to the explosion and subsequent fire. However, a similar fuel-air explosion originating in the Certified and Segregated (C\&S) Facility with the subsequent fire impacting all TSA facilities at the RWMC will bound the consequences of the fuel-air explosion originating at ASB-II. Because of this bounding condition, the consequence analysis for the ASB-II accident was not performed. Table 6.5 lists the parameters and results for the similar C\&S bounding accident.

The RFETS SAR for the Central Waste Storage Facility (Building 906) identifies three accidents associated with LLMW (RFETS 1994). Each of these accidents assumes 8,300 drums of waste as the material at risk with each drum filled with waste to $50 \%$ of total volume. The void

space is assumed to contain dust (at $100 \mathrm{mg} / \mathrm{m}^{3}$ ) that is vented to the air upon breaching of the drum. Other variables of each accident type are given in Table F.6-5. 
TABLE 6.5 Representative Accidents and Source Term Parameters from Recent DOE Safety Analysis Documents Relevant to LLMW

\begin{tabular}{|c|c|c|c|c|c|}
\hline Safety Document & Scenario & $\mathrm{DF}^{3}$ & ARF or RARF ${ }^{b}$ & Release (Ci) & $\begin{array}{l}\text { Consequence } \\
\text { (MEI-rem) }^{\mathrm{c}}\end{array}$ \\
\hline \multirow[t]{3}{*}{$\begin{array}{l}\text { RWMC SAR } \\
\text { (EG\&G 1993b) }\end{array}$} & $\begin{array}{l}\text { 1. Propane line leak at } \\
\text { ASB II, medium fire }\end{array}$ & $1.0 \mathrm{E}-02$ & $\begin{array}{l}5.0 \mathrm{E}-04 \\
\text { (combustible) } \\
1.0 \mathrm{E}-02 \\
\text { (noncombustible) }\end{array}$ & $2.0 \mathrm{E}-02$ & $2.0 \mathrm{E}-02$ \\
\hline & $\begin{array}{l}\text { 2. Earthquake initiating } \\
\text { breach in CH LLW Pit } \\
\text { and involving ASB II }\end{array}$ & $1.0 \mathrm{E}-03$ & $1.0 \mathrm{E}-03$ & $4.1 E-02$ & $7.5 \mathrm{E}-01$ \\
\hline & $\begin{array}{l}\text { 3. Fuel air explosion in } \\
\text { ASB II, bounded by } \\
\text { same type event in } \\
C \& S^{d} \text { Facility }\end{array}$ & $2.0 \mathrm{E}-01$ & $\begin{array}{l}1.0 \mathrm{E}-03 \\
\text { (numbers for } \\
\text { a C\&S event) }\end{array}$ & $1.3 \mathrm{E}+01$ & 3.2 \\
\hline \multirow[t]{3}{*}{$\begin{array}{l}\text { Building } 906 \text { SAR } \\
\text { Central Waste } \\
\text { Storage Facility } \\
\text { (RFETS 1994) }\end{array}$} & $\begin{array}{l}\text { 1. Earthquake and spill } \\
\text { (collapsed building), } \\
\text { void space volume of } \\
8,300 \text { drums (MAR) } \\
\text { (assume drum } 1 / 2 \text { full) }\end{array}$ & 1.0 & 1.0 & $\begin{array}{l}3.37 \mathrm{E}-05 \mathrm{~g} \\
\text { Pu-239 }\end{array}$ & $2.0 \mathrm{E}-06$ \\
\hline & $\begin{array}{l}\text { 2. Spill from impacts, } \\
100 \% \text { void space vented } \\
(8,300 \text { drums })\end{array}$ & 1.0 & 1.0 & $\begin{array}{l}100 \mathrm{mg} / \mathrm{m}^{3} \\
\text { particulate } \\
\text { loading in void } \\
\text { space }\end{array}$ & $-e$ \\
\hline & $\begin{array}{l}\text { 3. Fire ruptures all exposed } \\
\text { containers }\end{array}$ & $\begin{array}{l}100 \% \text { burn of } \\
\text { combustibles } \\
18 \% \text { ablation of } \\
\text { noncombustibles }\end{array}$ & $\begin{array}{l}5.0 \mathrm{E}-4 \text { particulate } \\
1.0 \mathrm{E}-5 \text { metals } \\
1.0 \text { liquids }\end{array}$ & $\begin{array}{l}\text { Varies with } \\
\text { assumptions } \\
\text { about fire }\end{array}$ & - \\
\hline $\begin{array}{l}\text { Hazard Classifi- } \\
\text { cation and } \\
\text { Preliminary Safety } \\
\text { Evaluation (PSE) for } \\
\text { WRAP Module 2 } \\
\text { (WHC 1991a) }\end{array}$ & $\begin{array}{l}\text { 1. Earthquake and spill of } \\
\text { dry waste and fire }\end{array}$ & 1.0 & $5.3 \mathrm{E}-04$ & $4.1 \mathrm{E}-02$ & $3.9 \mathrm{E}-05$ \\
\hline
\end{tabular}

a $\mathrm{DF}=$ damage fraction.

b $A R F=$ aiborne release fraction; $R A R F=$ respirable airbome release fraction.

c $\mathrm{MEI}=$ Maximally exposed individual off-site.

d $\mathbf{C} \& \mathrm{~S}=$ Certified and Segregated Facility.

c $-=$ not available. 
A PSE conducted for WRAP (Module 2) at Hanford identifies an earthquake as a bounding accident scenario causing waste spills and fire (WHC 199la). This accident leads to a release of $0.041 \mathrm{Ci}$ with a consequence of 3.9E-05 rem (MEI) and an accident frequency of $1.0 \mathrm{E}-03 / \mathrm{yr}$ (see Table 6.5).

The International Technology Corporation (IT) has calculated the risks associated with the TSD of many types of LLMW. IT Corporation has looked at many kinds of accidents related to the treatment, storage, and handling of these wastes. An example of a storage accident scenario is a fire within a container in the storage facility that might cause waste particulates to resuspend and be inhaled by workers. Members of the public might also be exposed to airborne effluents if building ventilation fails. IT Corporation has used a system analysis methodology to accumulate risk across different management options rather than breaking out the consequences and contaminant releases associated with a particular accident as the SARs usually do. This different approach to the problem has made comparison difficult with the more conventional approach of calculating the consequences of each separate accident. In general, IT Corporation has tended to look at sets of accidents of relatively high frequency with low consequences rather than the more standard approach of surveying accidents of very low frequency but with very high consequences (EG\&G 1993a).

In reviewing the cited analyses, it was observed that there is considerable variation in the assumptions used by the various DOE sites to develop accidents and estimate associated source term parameters. However, it appears from the analyses that overall, the risks to the public health resulting from storage facility accidents would be small.

It should be noted that explicitly analyzing risks from storage would not help to discriminate among alternatives because of the assumption used in the WM PEIS for estimating the treatment throughputs, which dictate the inventories to be stored prior to treatment. This assumption is that all sites will accumulate or at least not reduce these inventories for roughly 10 years, at which time complexwide treatment will begin. Thus, all sites will achieve their maximum inventories (leading to maximum potential releases during a storage facility accident) independent of alternative.

\subsubsection{Treatment Facility and Inventory Modeling Assumptions}

Evaluations have shown that incineration is the thermal treatment technology most likely to be important to risk to facility workers and the public. Radiological accident sequences analyzed here focus on severe fires and explosions that produce large airborne releases of the ash present in the incinerator area or in the filtration systems. A generic treatment facility, consisting of a series of linked treatment process modules, is described in Section 2. A DOE Hazard Category of 2, concomitant system performance requirements, and double HEPA filtration systems were assumed. For each alternative, each waste treatability category at each site has a unique volumetric inventory 
and physical, chemical, and radiological composition. Each incineration facility was assumed to have $1 \%$ of its annual incinerable LLMW throughput at the time of the accident.

Accidents investigated included operation-induced facility fires and explosions and external-event-induced fires and explosions. Treatment facility accident sequences analyzed included the following:

- A fire in the baghouse area of the incineration facility that disperses the dry ash in the filters, with a damage fraction of $3 \%$ of the facility inventory $(\mathrm{DF}=3.0 \mathrm{E}-02)$ and failing the filtration systems completely $(\mathrm{LPF}=1)$;

- An incinerator explosion resulting from combustible gas buildup that disperses the ash in the rotary kiln, with a damage fraction of $12 \%$ of facility inventory $(\mathrm{DF}=1.2 \mathrm{E}-01)$ and partially degrades the filtration system $(\mathrm{LPF}=1.0 \mathrm{E}-03)$; and

- External events leading to a fire. External-event source term parameters vary according to the particular sequence.

All accidents are assumed to be ground releases without filtration, with the exception of the incinerator explosion where partial HEPA filtration and a stack emission are assumed. The LPF of $1.0 \mathrm{E}-03$ results in the intrafacility source term used to determine worker risk equaling 1,000 times the atmospheric source term for this accident.

Wet-air oxidation was also analyzed because of the high treatment volumes at some of the sites. A rupture with a subsequent violent pressurized and unfiltered release to the atmosphere of the entire vessel contents was postulated as the only plausible sequence capable of producing any measurable consequences to site staff or the public. An earthquake that simultaneously breached the containment building was defined as the most likely initiator. Calculations were specifically performed for a limited set of alternatives, and the resulting risk was found to be significantly lower than that for the incineration accidents. As a result, source terms for wet-air oxidation accidents were not used for health effects calculations.

Frequencies of accidents are consistent with those for the LLW analysis. The frequency of $1.5 \mathrm{E}-02 / \mathrm{yr}$ for explosions in the rotary kiln assembly and the secondary combustion chamber, respectively, provide the basis for the internal fire frequencies. The frequencies of aircraft-initiated accidents depend on the site. The annual frequency of a seismic event exceeding the design basis for a Hazard Category 2 facility is $1.0 \mathrm{E}-03 / \mathrm{yr}$ with the conditional probability of rupturing containment and initiating a fire estimated to equal 5.0E-02. Screening calculations of airplane accidents for the LLMW treatment facilities were performed, and the risks were found to be much lower than the risk 
of an earthquake, or negligible. As a result, source terms for airplane accidents were not provided for health effects calculations.

The limiting chemical accident is assumed to be an operational fire in the feedstock staging area and includes waste in processing and lag storage. The MAR was assumed to be $1 \%$ of annual throughput of the incineration facility as established by the WM PEIS alternative. A DF of 1.0E-01 was assumed to account for the presence of noncombustible material and the distribution of the combustible materials in areas other than the feedstock area. Because of the high frequency of internal fires compared with those caused by external events, only the internal, operational fire was analyzed.

\subsubsection{Disposal Facility Accidents}

Disposal accidents were not evaluated because of the lack of details of ultimate disposal. However, except for dedicated centralized repositories such as Yucca Mountain or WIPP, disposal sites would generally lack a concentrated volume of MAR being stored in a configuration susceptible to phenomena such as fires and explosions capable of causing significant releases. These repositories have accident analyses performed as part of their site-specific EISs. Although seismic events could breach in-ground containers, leading to airborne releases, such events would be bounded by accidents breaching the concentrated volumes of waste being held in a treatment or storage facility. It is hard to imagine any plausible accident sequence in which the risk from airborne releases in a LLMW disposal facility would be significant enough to rule out a site from consideration and thereby serve as a discriminator among disposal alternatives.

\subsection{RESULTS}

Preliminary results of the radiological accident sequences described above for various site consolidation cases within each WM PEIS alternative were reviewed for risk dominance using the frequency-weighted dose to the MEI, and then grouped into four annual frequency categories: likely $(>1.0 \mathrm{E}-02$ ), unlikely (between 1.0E-02 and 1.0E-04), extremely unlikely (between 1.0E-04 and $1.0 \mathrm{E}-06$ ), and not credible ( $<1.0 \mathrm{E}-06)$. Representative source terms for the risk-dominant sequences were then selected as the bases for health effects calculations. Of the treatment technologies, only source terms for incineration facility accidents are provided because they were found to bound other treatment accidents, including wet-air oxidation, which resulted in atmospheric releases much lower than analogous incineration accidents. Chemical accident releases were also calculated.

No radiological source terms were estimated for the representative treatment facility chemical accident because they were determined to be unimportant to overall risk compared with radiological source terms for the reference radiological accident. Specifically, the radionuclide 
concentrations and dispersibility of the ash in the filter fire are much greater than for the feedstock fire and precludes the need for radiological source term calculations for the latter.

Similarly, no chemical source terms have been produced for the reference radiological accident because of their insignificance compared with the reference chemical accidents. Specifically, the concentrations of toxic chemicals released in the incinerator feedstock fire are much higher than in the ash dispersed in the reference radiological accidents, precluding the need to calculate chemical source terms for the latter accident.

The waste management LLMW facility accidents analyzed here are summarized in Table 6.6. Eight cases are considered for the WM LLMW alternatives: Cases 1, 2, 4, 7, 10, 15, 17, and 26. Cases 7 (Regionalized 2: seven sites treat, six sites dispose) and 10 (Regionalized 3: seven sites treat, one site disposes) are equivalent with respect to the risk-dominant treatment technologies and the amount of waste throughput at each site; therefore, only Case 7 was analyzed. Eight cases are considered for WM LLMW alternatives, including Cases 1, 2, 4, 7, 10, 15, 17 and 26. Cases 7 (Regionalized 2: 7 sites treat, 6 sites dispose) and 10 (Regionalized 3: 7 sites treat, 1 site disposes) are equivalent with respect to the risk-dominant treatment technologies and the amount of waste at each site; therefore, only Case 7 was analyzed. The WM PEIS cases analyzed are described as follows:

- Case 1 (No Action). Three sites (INEL, ORR, and SRS) treat and store, all remaining sites store.

- Case 2 (Decentralized). Forty-nine sites treat, and 16 sites dispose.

- Case 4 (Regionalized 1). Eleven sites (Hanford, INEL, LANL, ORR, SRS, PORTS, PGDP, FEMP, LLNL, Pantex, and RFETS) treat, and 12 sites dispose.

- Case 7 (Regionalized 2). Seven sites (Hanford, INEL, LANL, ORR, SRS, PORTS, and RFETS) treat, and six sites dispose.

- Case 15 (Regionalized 4). Four sites (Hanford, INEL, ORR, and SRS) treat, and six sites dispose.

- Case 17(Centralized). One site treats (Hanford), and one site disposes.

- Case 26 (Remote-handled). Four sites (Hanford, INEL, ORR, and SRS) treat and dispose (RH). 
Tables 6.7 through 6.9 summarize the radiological source term parameters and frequency groups for the accidents. Separate incineration facilities were assumed for treating alpha and nonalpha contaminated waste. Detailed radionuclide releases are provided in Appendix B. Chemical source terms for accidents are provided in Appendix A. 
TABLE 6.6 Summary of WM LLMW Radiological Accidents Analyzed ${ }^{2}$

\begin{tabular}{|c|c|c|c|c|c|c|c|c|}
\hline \multirow[b]{2}{*}{ Function } & \multirow[b]{2}{*}{$\begin{array}{l}\text { WM PEIS } \\
\text { Alternative }^{\mathrm{b}}\end{array}$} & \multirow[b]{2}{*}{ Site ${ }^{c}$} & \multicolumn{3}{|c|}{ Operntional Events } & \multicolumn{3}{|c|}{ External Events } \\
\hline & & & $\begin{array}{l}\text { Handling } \\
\text { Breaches }\end{array}$ & $\begin{array}{c}\text { Facility } \\
\text { Fire }\end{array}$ & $\begin{array}{l}\text { Facility } \\
\text { Explosion }\end{array}$ & Seismic & $\begin{array}{c}\text { Large } \\
\text { Aircraft }\end{array}$ & $\begin{array}{c}\text { Small } \\
\text { Aircraft }\end{array}$ \\
\hline \multirow[t]{41}{*}{ Drum handling } & All & Ames & $x$ & $N A^{d}$ & NA & NA & NA & NA \\
\hline & All & ANL-W & $x$ & NA & $\mathrm{NA}$ & NA & NA & NA \\
\hline & Al! & Bettis & $x$ & NA & NA & NA & NA & NA \\
\hline & All & $\mathrm{BCL}$ & $x$ & NA & NA & NA & NA & NA \\
\hline & All & BNL & $x$ & NA & NA & NA & NA & NA \\
\hline & All & Charleston & $x$ & NA & NA & NA & NA & NA \\
\hline & All & Colonie & $x$ & NA & NA & NA & NA & NA \\
\hline & All & ETEC & $x$ & NA & $\mathrm{NA}$ & NA & NA & NA \\
\hline & All & FEMP & $x$ & NA & NA & NA & NA & NA \\
\hline & All & $\mathrm{GA}$ & $x$ & NA & NA & NA & NA & $\mathrm{NA}$ \\
\hline & All & GJPO & $x$ & NA & NA & NA & NA & NA \\
\hline & All & Hanford & $x$ & NA & NA & NA & NA & NA \\
\hline & All & INEL & $x$ & NA & NA & NA & NA & NA \\
\hline & All & ITRI & $x$ & NA & NA & NA & NA & NA \\
\hline & All & KAPL-S & $x$ & NA & NA & NA & NA & NA \\
\hline & All & $\mathrm{KCP}$ & $x$ & NA & NA & NA & NA & NA \\
\hline & All & KAPL-K & $x$ & NA & NA & NA & NA & NA \\
\hline & All & KAPL-W & $x$ & NA & NA & NA & NA & $\mathbf{N A}$ \\
\hline & All & LANL & $x$ & NA & NA & NA & NA & NA \\
\hline & All & LBL & $x$ & NA & NA & NA & NA & NA \\
\hline & All & LEHR & $x$ & NA & NA & NA & NA & NA \\
\hline & All & LLNL & $x$ & NA & NA & NA & NA & NA \\
\hline & All & Mare Is & $x$ & NA & NA & NA & NA & NA \\
\hline & All & Mound & $x$ & NA & NA & NA & NA & NA \\
\hline & All & Norfolk & $x$ & NA & NA & NA & NA & NA \\
\hline & All & NTS & $x$ & NA & NA & NA & NA & NA \\
\hline & All & ORR & $x$ & NA & NA & NA & $\mathbf{N A}$ & NA \\
\hline & All & PGDP & $x$ & NA & NA & NA & NA & NA \\
\hline & All & Pantex & $x$ & NA & NA & NA & NA & NA \\
\hline & All & Pearl H & $x$ & $\mathbf{N A}$ & NA & NA & NA & NA \\
\hline & All & Ports Nav & $x$ & NA & NA & NA & NA & NA \\
\hline & All & PORTS & $x$ & NA & NA & $\mathbf{N A}$ & NA & NA \\
\hline & All & PPPL & $x$ & NA & NA & NA & NA & NA \\
\hline & All & Puget So & $x$ & NA & NA & NA & NA & NA \\
\hline & All & RFETS & $x$ & NA & NA & NA & NA & NA \\
\hline & All & RMI & $x$ & NA & NA & NA & NA & NA \\
\hline & All & SNL-NM & $x$ & NA & NA & NA & NA & NA \\
\hline & All & SNL-CA & $x$ & NA & NA & NA & NA & NA \\
\hline & All & SRS & $x$ & NA & NA & NA & NA & NA \\
\hline & All & UofMo & $x$ & NA & NA & NA & NA & NA \\
\hline & All & WVDP & $x$ & NA & NA & NA & NA & NA \\
\hline \multirow[t]{22}{*}{ Incineration } & 1 & INEL & NA & $x$ & $x$ & $x$ & NA & NA \\
\hline & 1 & ORR & NA & $x$ & $x$ & $x$ & NA & NA \\
\hline & 1 & SRS & NA & $x$ & $x$ & $x$ & $N A$ & NA \\
\hline & 2 & Ames & NA & $x$ & $x$ & $x$ & NA & NA \\
\hline & 2 & ANL-E & NA & $x$ & $x$ & $x$ & NA & NA \\
\hline & 2 & Bettis & NA & $x$ & $x$ & $x$ & NA & NA \\
\hline & 2 & $\mathrm{BCL}$ & NA & $x$ & $x$ & $x$ & NA & NA \\
\hline & 2 & BNL & NA & $x$ & $x$ & $x$ & NA & $\mathbf{N A}$ \\
\hline & 2 & Charleston & NA & $x$ & $x$ & $x$ & NA & NA \\
\hline & 2 & Colonie & NA & $x$ & $x$ & $x$ & NA & $N A$ \\
\hline & 2 & ETEC & NA & $x$ & $x$ & $x$ & NA & NA \\
\hline & 2 & FEMP & NA & $x$ & $x$ & $x$ & NA & NA \\
\hline & 2 & GA & NA & $x$ & $x$ & $x$ & $\mathbf{N A}$ & NA \\
\hline & 2 & GJPO & NA & $x$ & $x$ & $x$ & NA & NA \\
\hline & 2 & Hanford & NA & $x$ & $x$ & $x$ & NA & NA \\
\hline & 2 & INEL & $\mathbf{N A}$ & $x$ & $x$ & $x$ & NA & NA \\
\hline & 2 & ITRI & NA & $x$ & $x$ & $x$ & NA & NA \\
\hline & 2 & KAPL-S & NA & $x$ & $x$ & $x$ & NA & NA \\
\hline & 2 & $\mathrm{KCP}$ & $\mathbf{N A}$ & $x$ & $x$ & $x$ & NA & NA \\
\hline & 2 & KAPL-K & NA & $x$ & $x$ & $x$ & NA & NA \\
\hline & 2 & KAPL-W & NA & $x$ & $x$ & $x$ & NA & NA \\
\hline & 2 & LANL & NA & $x$ & $x$ & $x$ & NA & NA \\
\hline
\end{tabular}


TABLE 6.6 (Cont.)

\begin{tabular}{|c|c|c|c|c|c|c|c|c|}
\hline \multirow[b]{2}{*}{ Function } & \multirow[b]{2}{*}{$\begin{array}{l}\text { WM PEIS } \\
\text { Alternative }^{\mathrm{b}}\end{array}$} & \multirow[b]{2}{*}{ Site $^{c}$} & \multicolumn{3}{|c|}{ Operational Events } & \multicolumn{3}{|c|}{ Extemal Events } \\
\hline & & & $\begin{array}{l}\text { Handling } \\
\text { Breaches }\end{array}$ & $\begin{array}{c}\text { Facility } \\
\text { Fire }\end{array}$ & $\begin{array}{c}\text { Facility } \\
\text { Explosion }\end{array}$ & Seismic & $\begin{array}{c}\text { Large } \\
\text { Aircraft }\end{array}$ & $\begin{array}{c}\text { Small } \\
\text { Aircraft }\end{array}$ \\
\hline & 2 & LBL & $\mathrm{NA}$ & $x$ & $x$ & $x$ & NA & $\mathrm{NA}$ \\
\hline & 2 & LEHR & NA & $x$ & $x$ & $x$ & NA & NA \\
\hline & 2 & LLNL & NA & $x$ & $x$ & $x$ & NA & NA \\
\hline & 2 & Mare Is & NA & $x$ & $x$ & $x$ & NA & NA \\
\hline & 2 & Norfolk & NA & $x$ & $x$ & $x$ & NA & NA \\
\hline & 2 & NTS & NA & $x$ & $x$ & $x$ & NA & NA \\
\hline & 2 & ORR & NA & $x$ & $x$ & $x$ & NA & NA \\
\hline & 2 & PGDP & NA & $x$ & $x$ & $x$ & NA & NA \\
\hline & 2 & Pantex & NA & $x$ & $x$ & $x$ & NA & NA \\
\hline & 2 & Pearl H & NA & $x$ & $x$ & $x$ & $\mathrm{NA}$ & NA \\
\hline & 2 & Ports Nav & NA & $x$ & $x$ & $x$ & NA & NA \\
\hline & 2 & PORTS & NA & $x$ & $x$ & $x$ & NA & NA \\
\hline & 2 & PPPL & NA & $x$ & $x$ & $x$ & NA & NA \\
\hline & 2 & Puget So & NA & $x$ & $x$ & $x$ & NA & NA \\
\hline & 2 & RMI & $\mathrm{NA}$ & $x$ & $x$ & $x$ & NA & $\mathrm{NA}$ \\
\hline & 2 & SNL-NM & NA & $x$ & $x$ & $x$ & $\mathrm{NA}$ & $\mathrm{NA}$ \\
\hline & 2 & SRS & NA & $x$ & $x$ & $x$ & NA & NA \\
\hline & 4 & ETEC & NA & $x$ & $x$ & $x$ & NA & NA \\
\hline & 4 & FEMP & NA & $x$ & $x$ & $x$ & NA & NA \\
\hline & 4 & Hanford & $\mathrm{NA}$ & $x$ & $x$ & $x$ & $\mathrm{NA}$ & NA \\
\hline & 4 & INEL & NA & $x$ & $x$ & $x$ & NA & NA \\
\hline & 4 & LANL & NA & $x$ & $x$ & $x$ & NA & NA \\
\hline & 4 & LLNL & NA & $x$ & $x$ & $x$ & NA & NA \\
\hline & 4 & ORNL & NA & $x$ & $x$ & $x$ & NA & NA \\
\hline & 4 & PGDP & NA & $x$ & $x$ & $x$ & NA & NA \\
\hline & 4 & Pantex & NA & $x$ & $x$ & $x$ & NA & NA \\
\hline & 4 & PORTS & $\mathrm{NA}$ & $x$ & $x$ & $x$ & NA & NA \\
\hline & 4 & RFETS & NA & $x$ & $x$ & $x$ & NA & NA \\
\hline & 4 & SRS & NA & $x$ & $x$ & $x$ & NA & NA \\
\hline & 7 & Hanford & NA & $x$ & $x$ & $x$ & NA & NA \\
\hline & 7 & INEL & NA & $x$ & $x$ & $x$ & NA & NA \\
\hline & 7 & LANL & NA & $x$ & $x$ & $x$ & NA & NA \\
\hline & 7 & ORNL & NA & $x$ & $x$ & $x$ & NA & NA \\
\hline & 7 & PORTS & NA & $x$ & $x$ & $x$ & NA & NA \\
\hline & 7 & RFETS & NA & $x$ & $x$ & $x$ & NA & NA \\
\hline & 7 & SRS & NA & $x$ & $x$ & $x$ & NA & NA \\
\hline & 15 & Hanford & NA & $x$ & $x$ & $x$ & NA & NA \\
\hline & 15 & INEL & NA & $x$ & $x$ & $x$ & NA & NA \\
\hline & 15 & ORR & NA & $x$ & $x$ & $x$ & NA & NA \\
\hline & 15 & SRS & $\mathrm{NA}$ & $x$ & $x$ & $x$ & $\mathrm{NA}$ & NA \\
\hline & 17 & Hanford & $\mathrm{NA}$ & $x$ & $x$ & $x$ & NA & NA \\
\hline & 26 & Hanford & NA & $x$ & $x$ & $x$ & NA & NA \\
\hline & 26 & INEL & NA & $x$ & $x$ & $x$ & NA & NA \\
\hline & 26 & ORR & NA & $x$ & $x$ & $x$ & NA & NA \\
\hline & 26 & SRS & $\mathrm{NA}$ & $x$ & $x$ & $x$ & NA & NA \\
\hline \multirow{18}{*}{$\alpha$-Incineration ${ }^{e}$} & 2 & INEL & NA & $x$ & $x$ & $x$ & NA & NA \\
\hline & 2 & LANL & $\mathrm{NA}$ & $x$ & $x$ & $x$ & NA & NA \\
\hline & 2 & LINL & NA & $x$ & $x$ & $x$ & NA & NA \\
\hline & 2 & RFETS & NA & $x$ & $x$ & $x$ & NA & NA \\
\hline & 2 & SRS & NA & $x$ & $x$ & $x$ & NA & NA \\
\hline & 4 & INEL & $\mathrm{NA}$ & $x$ & $x$ & $x$ & NA & $\mathrm{NA}$ \\
\hline & 4 & LANL & NA & $x$ & $x$ & $x$ & NA & NA \\
\hline & 4 & LLNL & NA & $x$ & $x$ & $x$ & $\mathrm{NA}$ & $\mathrm{NA}$ \\
\hline & 4 & RFETS & NA & $x$ & $x$ & $x$ & $\mathrm{NA}$ & NA \\
\hline & 4 & SRS & NA & $x$ & $x$ & $x$ & NA & NA \\
\hline & 7 & INEL & NA & $x$ & $x$ & $x$ & NA & NA \\
\hline & 7 & LANL & NA & $x$ & $x$ & $x$ & NA & NA \\
\hline & 7 & RFETS & NA & $x$ & $x$ & $x$ & $\mathrm{NA}$ & NA \\
\hline & 7 & SRS & NA & $x$ & $x$ & $x$ & NA & NA \\
\hline & 15 & INEL & NA & $x$ & $x$ & $x$ & $\mathrm{NA}$ & $\mathrm{NA}$ \\
\hline & 15 & SRS & $\mathrm{NA}$ & $x$ & $x$ & $x$ & NA & NA \\
\hline & 17 & Hanford & NA & $x$ & $x$ & $x$ & NA & NA \\
\hline & 26 & INEL & NA & $x$ & $x$ & $x$ & NA & NA \\
\hline
\end{tabular}

See next page for footnotes. 


\section{TABLE 6.6 (Cont.)}

a Only one source term, generally corresponding to the risk-dominant sequence for each accident initiator, was selected for transmittal to ORR.

b The WM PEIS cases analyzed are described as follows:

- Case I (No Action). Three sites (INEL, ORR, and SRS) treat and store; all remaining sites store.

- Case 2 (Decentralized). Forny-nine sites treat, and 16 sites dispose.

- Case 4 (Regionalized 1). Eleven sites (Hanford, INEL, LANL, ORR, SRS, PORTS, PGDP, FEMP, LLNL, Pantex, and RFETS) treat, and 12 sites dispose.

- Case 7 (Regionalized 2). Seven sites (Hanford, INEL, LANL, ORR, SRS, PORTS, and RFETS) treat, and six sites dispose.

- Case 15 (Regionalized 4). Four sites (Hanford, INEL, ORR, and SRS) treat, and six sites dispose.

- Case 17 (Centralized). One site treats (Hanford), and one site disposes.

- Case 26 (Remtote-handled). Four sites (Hanford, INEL, ORR, and SRS) treat and dispose (RH).

c Abbreviations: Ames = Ames Laboratory; Bettis $=$ Bettis Atomic Power Plant; $\mathrm{BCL}=$ Battelle Columbus Laboratories; BNL = Brookhaven National Laboratory; Charleston $=$ Charleston Naval Shipyard; GA = General Atomics; GJPO = Grand Junctions Project Office; ITRI = Inhalations Toxicology Research Institute; KAPL-K = Knolls Atomic Power Laboratory (Kesselring); KAPL-S = Knolls Atomic Power Laboratory (Schenectady); KAPL$\mathrm{W}=$ Knolls Atomic Power Laboratory (Windsor); KCP = Kansas City Plant; LBL = Lawrence Berkeley National Laboratory: LEHR = Laboratory for Energy-Related Health Research; Mare Is = Mare Island Naval Shipyard: Mound = Mound Plant; Norfolk = Norfolk Naval Shipyard: Pearl H = Pearl Harbor Naval Shipyard; Ports Nav = Portsmouth Naval Shipyard; PPPL = Princeton Plasma Physics Laboratory: Puget So = Puget Sound Naval Shipyard; RMI = Reactive Metals, Inc.; SNL-NM = Sandia National Laboratories (New Mexico); SNL-CA = Sandia National Laboratories (California); and UofMo = University of Missouri.

d NA = not applicable.

e $\alpha$-Incineration refers to incineration of waste categorized as alpha-emitting. 
TABLE 6.7 Frequencies and Radiological Source Term Parameters for WM LLMW Drum Handling Accidents

\begin{tabular}{|c|c|c|c|c|c|c|c|c|c|}
\hline \multirow[b]{2}{*}{$\begin{array}{l}\text { WM PEIS } \\
\text { Alternative }\end{array}$} & \multirow[b]{2}{*}{ Site } & \multicolumn{4}{|c|}{ Frequency Bin (/yr) } & \multicolumn{3}{|c|}{ Source Term Parameters } & \multirow{2}{*}{$\begin{array}{l}\text { Total } \\
\text { Release } \\
(\mathrm{Ci})\end{array}$} \\
\hline & & $>1 \mathrm{E}-02$ & $\begin{array}{c}1 \mathrm{E}-04 \text { to } \\
1 \mathrm{E}-02\end{array}$ & $\begin{array}{c}1 \mathrm{E}-06 \text { to } \\
1 \mathrm{E}-04\end{array}$ & $<1 \mathrm{E}-06$ & $\begin{array}{c}\text { VMAR } \\
\left(\mathrm{m}^{3}\right) \\
\end{array}$ & $\begin{array}{c}\text { MAR } \\
(\mathrm{Ci})\end{array}$ & DF & \\
\hline All & Ames & $\mathrm{X}$ & $N A^{a}$ & NA & NA & $2.0 \mathrm{E}-01$ & $1.1 \mathrm{E}-03$ & 0.25 & 2.4E-07 \\
\hline All & ANL-W & $\mathrm{x}$ & $\mathrm{NA}$ & NA & NA & $2.0 \mathrm{E}-01$ & $7.3 \mathrm{E}+00$ & 0.25 & $1.6 \mathrm{E}-01$ \\
\hline All & Bettis & $\mathrm{X}$ & NA & NA & NA & $2.0 \mathrm{E}-01$ & $6.1 \mathrm{E}-01$ & 0.25 & $3.5 \mathrm{E}-03$ \\
\hline All & $\mathrm{BCL}$ & $\mathrm{X}$ & NA & NA & NA & $2.0 \mathrm{E}-01$ & $1.1 \mathrm{E}-03$ & 0.25 & $5.4 \mathrm{E}-08$ \\
\hline All & BNL & $\mathrm{X}$ & NA & NA & NA & $2.0 \mathrm{E}-01$ & $1.5 \mathrm{E}-01$ & 0.25 & $2.8 \mathrm{E}-04$ \\
\hline All & Charleston & $\mathrm{X}$ & NA & NA & NA & $2.0 \mathrm{E}-01$ & $7.3 \mathrm{E}+00$ & 0.25 & $1.5 \mathrm{E}-01$ \\
\hline All & Colonie & $\mathrm{x}$ & NA & NA & NA & $2.0 \mathrm{E}-01$ & $1.1 \mathrm{E}-03$ & 0.25 & $5.0 \mathrm{E}-08$ \\
\hline All & ETEC & $\mathrm{X}$ & NA & NA & $\mathrm{NA}$ & $2.0 \mathrm{E}-01$ & $1.5 \mathrm{E}-01$ & 0.25 & $3.7 \mathrm{E}-04$ \\
\hline All & FEMP & $\mathrm{X}$ & NA & $\mathrm{NA}$ & NA & $2.0 \mathrm{E}-01$ & $1.1 \mathrm{E}-03$ & 0.25 & $4.5 \mathrm{E}-07$ \\
\hline All & GA & $\mathrm{X}$ & NA & NA & $\mathrm{NA}$ & $2.0 \mathrm{E}-01$ & $1.1 \mathrm{E}-03$ & 0.25 & $2.6 \mathrm{E}-07$ \\
\hline All & GJPO & $\mathrm{X}$ & NA & NA & $\mathrm{NA}$ & $2.0 \mathrm{E}-01$ & $1.1 \mathrm{E}-03$ & 0.25 & $1.8 \mathrm{E}-06$ \\
\hline All & Hanford & $x$ & NA & NA & NA & $2.0 \mathrm{E}-01$ & $6.1 \mathrm{E}-01$ & 0.25 & $3.1 \mathrm{E}-03$ \\
\hline All & INEL & $\mathrm{X}$ & $\mathrm{NA}$ & $\mathrm{NA}$ & NA & $2.0 \mathrm{E}-01$ & $3.5 \mathrm{E}+00$ & 0.25 & $2.9 \mathrm{E}-02$ \\
\hline All & ITRI & $X$ & NA & NA & NA & $2.0 \mathrm{E}-01$ & $5.5 \mathrm{E}-01$ & 0.25 & $1.3 \mathrm{E}-01$ \\
\hline All & KAPL-S & $X$ & NA & NA & NA & $2.0 \mathrm{E}-01$ & $7.0 \mathrm{E}+00$ & 0.25 & $8.2 \mathrm{E}-02$ \\
\hline All & $\mathrm{KCP}$ & $\mathrm{X}$ & $\mathrm{NA}$ & NA & NA & $2.0 \mathrm{E}-01$ & $7.3 \mathrm{E}+00$ & 0.25 & $1.6 \mathrm{E}-01$ \\
\hline All & KAPL-K & $\mathrm{X}$ & NA & NA & NA & $2.0 \mathrm{E}-01$ & $7.0 \mathrm{E}+00$ & 0.25 & $7.3 E-02$ \\
\hline All & KAPL-W & $\mathrm{X}$ & $\mathrm{NA}$ & NA & NA & $2.0 \mathrm{E}-01$ & $7.1 \mathrm{E}+00$ & 0.25 & $1.1 \mathrm{E}-01$ \\
\hline All & LANL & $\mathrm{X}$ & NA & NA & NA & $2.0 \mathrm{E}-01$ & $5.4 \mathrm{E}-01$ & 0.25 & $1.3 \mathrm{E}-01$ \\
\hline All & LBL & $\mathrm{X}$ & NA & $\mathrm{NA}$ & NA & $2.0 \mathrm{E}-01$ & $1.3 \mathrm{E}+01$ & 0.25 & $3.1 \mathrm{E}+00$ \\
\hline All & LEHR & $\mathrm{X}$ & NA & NA & NA & $2.0 \mathrm{E}-01$ & $1.5 \mathrm{E}-01$ & 0.25 & $3.2 \mathrm{E}-04$ \\
\hline All & LLNL & $\mathrm{X}$ & $\mathrm{NA}$ & NA & NA & $2.0 \mathrm{E}-01$ & $1.2 \mathrm{E}+01$ & 0.25 & $3.1 E+00$ \\
\hline All & Mare Is & $\mathrm{X}$ & NA & NA & NA & $2.0 \mathrm{E}-01$ & $7.1 \mathrm{E}+00$ & 0.25 & $9.4 \mathrm{E}-02$ \\
\hline All & Mound & $\mathrm{X}$ & NA & NA & NA & $2.0 \mathrm{E}-01$ & $1.3 \mathrm{E}+01$ & 0.25 & $3.1 \mathrm{E}+00$ \\
\hline All & Norfolk & $\mathrm{X}$ & NA & $\mathrm{NA}$ & NA & $2.0 \mathrm{E}-01$ & $7.3 \mathrm{E}+00$ & 0.25 & $1.6 \mathrm{E}-01$ \\
\hline
\end{tabular}


TABLE 6.7 (Cont.)

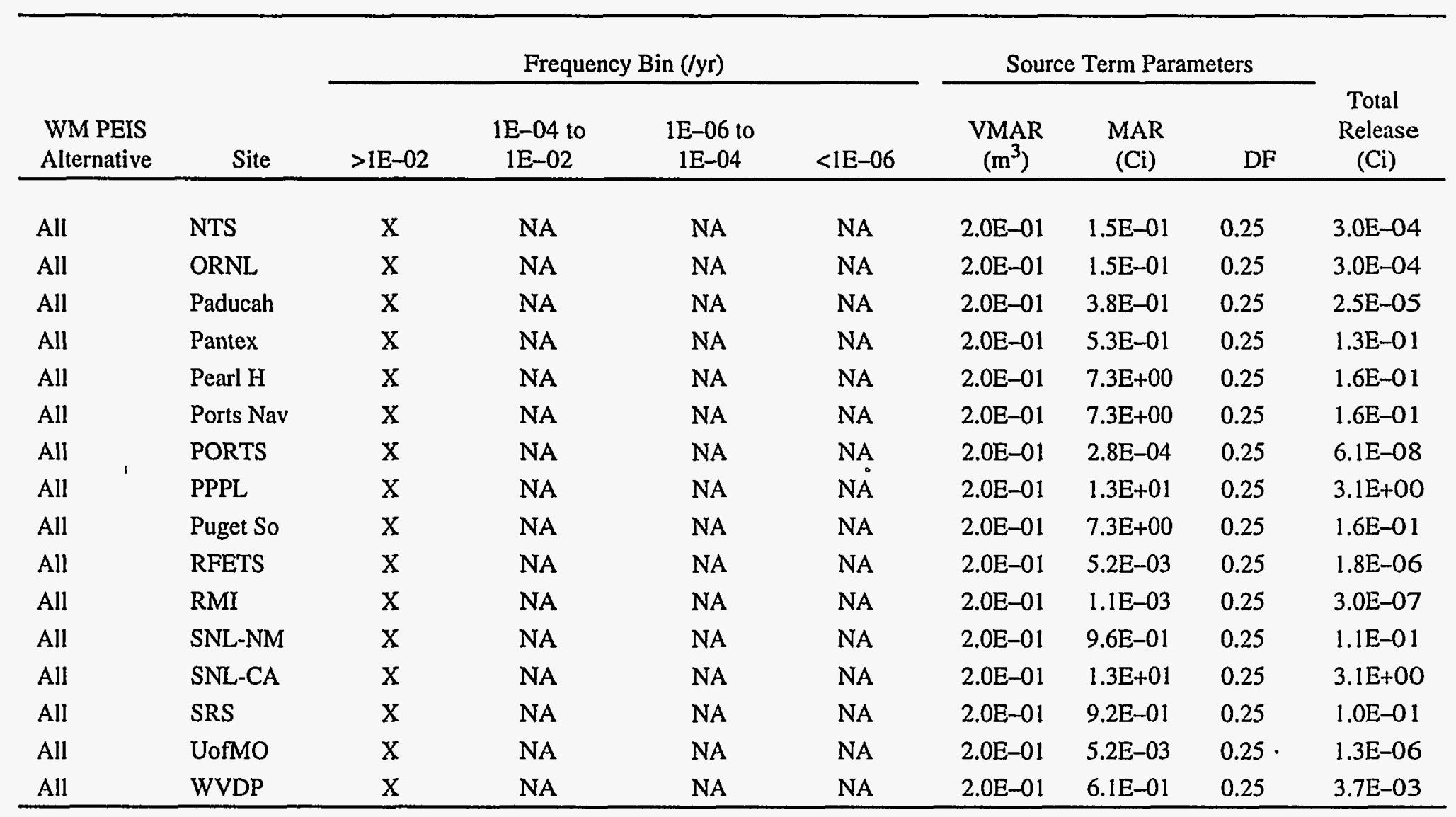

${ }^{\mathrm{a}} \mathrm{NA}=$ not applicable. 
TABLE 6.8 Frequencies and Radiological Source Term Parameters for WM LLMW Non-Alpha Incineration Facility Accidents

\begin{tabular}{|c|c|c|c|c|c|c|c|c|c|c|c|c|}
\hline \multirow[b]{2}{*}{$\begin{array}{l}\text { WM PEIS } \\
\text { Allermative } \\
\end{array}$} & \multirow[b]{2}{*}{ Sile } & \multirow[b]{2}{*}{ Accident } & \multicolumn{4}{|c|}{ Frequency Bin (/yr) } & \multicolumn{5}{|c|}{ Source Term Parameters } & \multirow[b]{2}{*}{$\begin{array}{c}\text { Total Release } \\
\text { (Ci) } \\
\end{array}$} \\
\hline & & & $>1.0 \mathrm{E}-02$ & $\begin{array}{c}1.0 \mathrm{E}-04 \text { to } \\
1.0 \mathrm{E}-(12) \\
\end{array}$ & $\begin{array}{c}1.0 \mathrm{E}-06106 \\
1.0 \mathrm{E}-0.4 \\
\end{array}$ & $<1.0 E-106$ & $\begin{array}{c}\text { VMAR } \\
\left(\mathrm{m}^{3}\right) \\
\end{array}$ & $\begin{array}{r}\text { MAR } \\
\left(C^{i}\right) \\
\end{array}$ & $\mathrm{DF}$ & RARF & $L \mathrm{PF}^{\mathrm{b}}$ & \\
\hline 1 & INEL & Explosion in the rotary kiln & $\mathbf{x}$ & $N A^{c}$ & NA & $\mathrm{NA}$ & $6.0 \mathrm{E}-02$ & $2.1 \mathrm{E}+(10)$ & $1.2 \mathrm{E}-(0) !$ & $1.0 E-(1)$ & $1.0 E-103$ & 2.6E-ASS \\
\hline 1 & INEL & Fire in the haghouse area & NA & $\mathrm{x}$ & NA & NA & 6.(1)- 112 & $2.1 E+(0)$ & $3.010-612$ & 1.01E-(12 & $1.01++(x)$ & $6.51:-(24)$ \\
\hline 1 & INEL & Earthyuake followed by fire and explosion & NA & $\mathrm{NA}$ & $x$ & NA & $6.01 .1-112$ & $2.1 E+(X)$ & 2.0E-011 & $1.0 E-01$ & $1.0 \mathrm{E}+(x)$ & $+.3 \mathrm{E}-(1) 2$ \\
\hline 1 & ORR & Explosion in the rotary kiln & $\mathrm{x}$ & NA & $\mathrm{NA}$ & $\mathrm{NA}$ & $1.1 E+(0)$ & $2.2 \mathrm{E}+(0)$ & $1.2 \mathrm{E}-01$ & $1.0 \mathrm{E}-01$ & $1.0 E-103$ & $2.6 \mathrm{E}-115$ \\
\hline 1 & ORR & Firc in the baghouse arca & NA & $\mathrm{x}$ & NA & NA & $1.12+(x)$ & $2.2 \mathrm{E}+(\mathrm{XO})$ & 3.0E- -12 & $1.0 \mathrm{E}-(1) 2$ & $1.0 \mathrm{E}+(\mathrm{x})$ & 6.5E:-124 \\
\hline 1 & ORR & Earthyuake followed by fire and explosion & NA & NA & $\mathrm{x}$ & NA & $1.1 E+(K)$ & $2.2 \mathrm{E}+(\mathrm{K})$ & $2.0 \mathrm{E}-01$ & $1.0 \mathrm{E}-0)$ & $1.0 \mathrm{E}+(0)$ & $4.3 E-112$ \\
\hline 1 & SRS & Explosion in the rolary kiln & $x$ & $\mathrm{NA}$ & NA & $\mathrm{NA}$ & $1.3 \mathrm{E}-01)$ & $3.0 \mathrm{E}+(0)$ & $1.2 \mathrm{E}-01$ & $1.0 \mathrm{E}-1) 1$ & $1.0 \mathrm{E}-(1) 3$ & 3.6E-015 \\
\hline 1 & SRS & Fire in the baghouse area & NA & $\mathrm{x}$ & $\mathrm{NA}$ & NA & $1.3 \mathrm{E}-01$ & $3.0 E+(0)$ & $3.0 E-112$ & $1.0 E-112$ & $1.0 E+(x)$ & $9.0 E-(2)-4$ \\
\hline 1 & SRS & Earhquake followed by fire and explosion & NA & $\mathrm{NA}$ & $x$ & NA & $1.3 \mathrm{E}-01$ & $3.0 \mathrm{E}+(10)$ & 2.0E-O1) & $1.0 E-(1) 1$ & $1.0 E+(0)$ & $6.0 \mathrm{E}-(1) 2$ \\
\hline 2 & Ames & Explosion in the rotary kiln & $x$ & $\mathrm{NA}$ & NA & NA & $3.3 \mathrm{E}-05$ & $3.5 E-177$ & $1.2 \mathrm{E}-01$ & $1.0 E_{-01}$ & $1.0 E-133$ & $4.2 \mathrm{E}-12$ \\
\hline 2 & Ames & Fire in the baghouse area & $\mathrm{NA}$ & $\mathrm{x}$ & NA & NA & 3.3E- -05 & 3.5E-47 & $3.0 \mathrm{E}-(1) 2$ & $1.0 \mathrm{E}-02$ & $1.0 \mathrm{E}+(x)$ & $1.0 \mathrm{E}-10$ \\
\hline 2 & Amcs & Earthquake followed by fire and explosion & NA & $\mathrm{NA}$ & $\mathrm{x}$ & NA & $3.3 \mathrm{E}-0 \mathrm{~S}$ & $3.5 E-07$ & $2.0 \mathrm{E}-01$ & $1.0 \mathrm{E}-01$ & $1.0 \mathrm{E}+(x)$ & $7.0 E-(1) 9$ \\
\hline 2 & ANL.E & Explosion in the rotary kiln & $x$ & NA & $\mathrm{NA}$ & $\mathrm{NA}$ & $1.1 E-02$ & $1.4 E-102$ & $1.2 E-01$ & $7.0 \mathrm{E}-12$ & $1.0 \mathrm{E}-103$ & $1.1 \mathrm{E}-07$ \\
\hline 2 & ANLE & Fire in the baghouse area & NA & $x$ & $\mathrm{NA}$ & NA & $1.1 E-02$ & $1.4 E-02$ & $3 .(1)-(12$ & $6.0 \mathrm{E}-115$ & $1.0 \mathrm{E}+(x)$ & $2.4 E-108$ \\
\hline 2 & ANL-E & Earthquake followed by fire and explosion & NA & NA & $\mathrm{x}$ & NA & $1.1 \mathrm{E}-02$ & $1.4 E-1.2$ & 2.(1) -01$)$ & $7.0 \mathrm{E}-102$ & $1.0 \mathrm{E}+(x)$ & $1.9 \mathrm{E}-0.4$ \\
\hline 2 & Bellis & Explosion in the rotary kiln & $\mathbf{x}$ & NA & $\mathrm{NA}$ & $\mathrm{NA}$ & 2.5E-104 & $7.5 E-03$ & $1.2 \mathrm{E}-0) 1$ & $1.0 \mathrm{E}-01$ & $1.0 \mathrm{E}-013$ & $8.9 \mathrm{E}-08$ \\
\hline 2 & Bettis & Fire in the baghouse area & $\mathrm{NA}$ & $\mathrm{x}$ & NA & $\mathrm{NA}$ & $2.5 E-04$ & $7.5 E-03$ & $3 .(1)-02$ & $1.0 E-112$ & $1.0 E+(x)$ & $2.2 \mathrm{E}-06$ \\
\hline 2 & Betlis & Earthquake followed by fire and explosion & NA & NA & $x$ & $\mathrm{NA}$ & $2.5 E-144$ & 7.5E-03 & 2.(1)E-O)I & $1.0 \mathrm{E}-01$ & $1.0 \mathrm{E}+(0)$ & $1.5 \mathrm{E}-(1) 4$ \\
\hline 2 & BCL & Explosion in the rotary kiln & $x$ & NA & NA & NA & $6.3 \mathrm{E}-16$ & $6.4 E-188$ & $1.2 \mathrm{E}-1) 1$ & $1.0 \mathrm{E}-1) 1$ & 1.0E-103 & $7.7 \mathrm{E}-13$ \\
\hline 2 & BCL & Fire in the baghouse area & $\mathrm{NA}$ & $\mathrm{x}$ & $\mathrm{NA}$ & $\mathrm{NA}$ & $6.3 E-166$ & $6.4 E-08$ & $3.0 E-112$ & $1.0 E-02$ & $1.0 E+(0)$ & $1.9 \mathrm{E}-11$ \\
\hline 2 & BCL & Earthyuake followed by fire and explosion & $\mathrm{NA}$ & NA & $\mathrm{x}$ & NA & $6.3 E-166$ & $6.4 E-08$ & $2.0 E-(0) 1$ & I.UE-N1) & $1.0 \mathrm{E}+(00)$ & $1.3 E-(x)$ \\
\hline 2 & BNL & Explusion in the rotary kiln & $x$ & NA & $\mathrm{NA}$ & NA & $1.7 \mathrm{E}-(1) 2$ & $3.3 E-102$ & $1.2 \mathrm{E}-011$ & $1.0 E-011$ & $1.0 \mathrm{EE-103}$ & 3.9E- -177 \\
\hline 2 & BNL & Fire in the baghouse area & $\mathrm{NA}$ & $x$ & NA & NA & $1.7 E-12$ & 3.3E-02 & $3.0 E-112$ & $1.0 \mathrm{E}-02$ & $1.0 \mathrm{E}+(00)$ & प.7E-106 \\
\hline 2 & BNL & Earthquake followed by fire and explosion & $\mathrm{NA}$ & $\mathrm{NA}$ & $\mathrm{x}$ & NA & $1.7 \mathrm{E}-(12$ & 3.3E- 02 & $2.0 E-1) !$ & $1.0 \mathrm{E}-01$ & $1.0 E+(1)$ & $6.5 \mathrm{E}-(1) 4$ \\
\hline 2 & Charlesion & Explosion in the rotary kiln & $\mathrm{x}$ & NA & $\mathrm{NA}$ & $\mathrm{NA}$ & 2.IE-(1)4 & $6.8 \mathrm{E}-02$ & $1.2 \mathrm{E}-01$ & $1.0 E-01$ & $1.0 E-(13)$ & $8.2 \mathrm{E}-107$ \\
\hline 2 & Charleston & Fire in the baghouse arca & NA & $x$ & NA & NA & 2.IE-(4) & $6.8 \mathrm{E}-1) 2$ & $3 .(1)-112$ & $1.0 E-102$ & $1.0 E+(x)$ & $2.00-(1) 5$ \\
\hline 2 & Charleston & Earthyuake followed by fire and explosion & NA & NA & $x$ & NA & 2.1E-04 & $6.8 \mathrm{E}-102$ & 2.0E-101 & $1.0 E-(01)$ & $1.0 E+(K)$ & $1.4 E-(1) 3$ \\
\hline 2 & Colonic & Explosion in the rolary kiln & $\mathrm{x}$ & NA & $\mathrm{NA}$ & $\mathrm{NA}$ & $2.4 E-04$ & $1.5 E-05$ & $1.2 \mathrm{E}-0.1$ & $1.0 \mathrm{E}-01$ & $1.0 \mathrm{E}-113$ & $1.7 E-10$ \\
\hline 2 & Colonic & Fire in the baghouse arca & NA & $x$ & NA & NA & $2.4 \mathrm{E}-04$ & $1.5 \mathrm{E}-0.05$ & $3.0 \mathrm{E}-02$ & $1.0 E-102$ & $1.0 E+(X)$ & $4.4 E-(1) y$ \\
\hline 2 & Colonic & Earhyuake followed by fire and explosion & NA & NA & $x$ & NA & $2.4 E-144$ & $1.5 \mathrm{E}-0 \mathrm{~S}$ & 2.0E-01 & $1.0 \mathrm{E}-01)$ & $1.0 \mathrm{E}+(x)$ & 2.9E- -07 \\
\hline 2 & ETEC & Explosion in the rotary kiln & $\mathrm{x}$ & $\mathrm{NA}$ & $\mathrm{NA}$ & NA & $1.6 \mathrm{E}-01$ & $1.2 \mathrm{E}-1) \mathrm{I}$ & $1.2 \mathrm{E}-01$ & $1.0 \mathrm{E}-01$ & t.0E-013 & $1.5 \mathrm{E}-06$ \\
\hline 2 & ETEC & Fire in the baghouse area & NA & $x$ & $\mathrm{NA}$ & NA & $1.6 \mathrm{E}-01$ & $1.2 \mathrm{E}-01$ & $3.0 E-02$ & $1.0 \mathrm{E}-02$ & $1.0 \mathrm{E}+(0)$ & $3.6 E-05$ \\
\hline 2 & ETEC & Earthquake followed by fire and explosion & NA & $\mathrm{NA}$ & $\mathrm{x}$ & $\mathrm{NA}$ & $1.6 \mathrm{E}-1) 1$ & $1.2 E-11$ & $2.0 \mathrm{E}-01$ & $1.0 \mathrm{E}-01$ & $1.0 \mathrm{E}+(0)$ & $2.4 E-1) 3$ \\
\hline 2 & FEMP & Explosion in the rotary kiln & $x$ & $\mathrm{NA}$ & $\mathrm{NA}$ & NA & $1.6 \mathrm{E}-01$ & $8.5 \mathrm{E}-0.4$ & $1.2 \mathrm{E}-01$ & $1.05-0 !$ & $1.0 \mathrm{E}-0.03$ & $1.0 \mathrm{E}-10 \mathrm{~K}$ \\
\hline 2 & FEMP & Fire in the baghouse area & NA & $x$ & NA & $\mathrm{NA}$ & $1.6 \mathrm{E}-111$ & $8.5 E_{-}-04$ & $3.0 E-112$ & $1.0 \mathrm{E}-102$ & $1.0 \mathrm{E}+(x)$ & $2.6 E-107$ \\
\hline 2 & FEMP & Earthquake followed by fire and explosion & $\mathrm{NA}$ & NA & $x$ & NA & $1.6 E-(1) \mid$ & $8.5 E-144$ & $2.0 E-01$ & $1.0 \mathrm{E}-01$ & $1.0 \mathrm{E}+(0)$ & $1.7 \mathrm{E}-115$ \\
\hline 2 & GA & Explestion in the rotary kiln & $\mathrm{x}$ & NA & $\mathrm{N} \Lambda$ & NA & $1.0 \mathrm{E}-103$ & $5.7 \mathrm{E}-06$ & $1.2 \mathrm{E}-0.01$ & $1.0 E-01$ & $1.08-103$ & $6.8 \mathrm{E}-11$ \\
\hline 2 & GA & Fire in the baghouse area & NA & $\mathbf{x}$ & NA & NA & $1.0 E-03$ & $5.7 \mathrm{E}-06$ & $3.0 \mathrm{E}-122$ & $1.0 \mathrm{E}-02$ & 1. $.() E+(x)$ & $1.76-1(x)$ \\
\hline 2 & GA & Earthquake followed by fire and explosion & $\mathrm{NA}$ & $\mathrm{NA}$ & $x$ & $\mathrm{NA}$ & $1.0 E-133$ & $5.7 \mathrm{E}-116$ & $2,0 E-(0)$ & $1.0 E-0 !$ & $1.0 \mathrm{E}+(x)$ & $1.1 E-117$ \\
\hline 2 & GJPO & Explosion in the rotary kiln & $\mathrm{x}$ & NA & NA & $\mathrm{NA}$ & $6.8 \mathrm{E}-05$ & $3.3 E-177$ & $1.2 E-01$ & $1.0 E-01$ & $1.0 \mathrm{E}-013$ & $4.015-12$ \\
\hline 2 & GJPO & Fire in the baghouse area & NA & $\mathrm{x}$ & $\mathrm{NA}$ & NA & $6.8 \mathrm{E}-0.15$ & $3.3 E-177$ & 3.OE- $(12$ & $1.0 E-02$ & $1.0 E+(1)$ & $1.0 \mathrm{E}-10$ \\
\hline 2 & GJPO & Earthquake followed by fire and explosion & $\mathrm{NA}$ & NA & $x$ & $\mathrm{NA}$ & $6.8 \mathrm{E}-0 \mathrm{~S}$ & $3.3 E-177$ & $2.0 \mathrm{E}-01$ & $1.0 \mathrm{E}-01$ & 1.0E+(8) & $6.7 E-(x)$ \\
\hline 2 & Hanford & Explosion in the rotary kiln & $x$ & NA & NA & NA & 1. $6 \mathrm{E}+(x)$ & $4.3 \mathrm{E}+(\mathrm{K})$ & $1.2 \mathrm{E}-01$ & 1.0E-(1) & $1.0 \mathrm{E}-113$ & $5.2 \mathrm{E}-115$ \\
\hline 2 & Hanford & Fire in the baghouse arca & $\mathrm{NA}$ & $x$ & NA & $\mathrm{NA}$ & $1.6 \mathrm{E}+(x)$ & $4.3 \mathrm{E}+100$ & $3.0 \mathrm{E}-1) 2$ & $1.0 \mathrm{E}-02$ & $1.0 E+(0)$ & $1.3 E-133$ \\
\hline 2 & Ilanford & Earthyuake followed by fire and explosion & $\mathrm{NA}$ & NA & $\mathrm{x}$ & NA & $1.6 E+(x)$ & $4.3 \mathrm{E}+(10)$ & $2.0 E-(1) 1$ & $1.0 E-01$ & $1.0 \mathrm{E}+(\mathrm{x})$ & $8.6 \mathrm{E}-112$ \\
\hline 2 & INEL & Explosion in the rotary kiln & $x$ & NA & NA & NA & $1.3 E-01$ & $4.3 E+(x)$ & $1.2 E-1) 1$ & $1.00-101$ & $1.0 E-133$ & 5.1E-115 \\
\hline 2 & INEL & Fire in the baghouse area & $\mathrm{NA}$ & $\mathrm{x}$ & $\mathrm{NA}$ & NA & $1.3 E-01$ & 4.3E+(X) & $3.0 \mathrm{E}-112$ & $1.0 E-102$ & $1.0 \mathrm{E}+(0)$ & $1.3 E-113$ \\
\hline 2 & INEL & Earthquake followed by fire and explosion & $\mathrm{NA}$ & $\mathrm{NA}$ & $x$ & $\mathrm{NA}$ & $1.3 E-011$ & $4.3 E+(x)$ & 2.0E-10! & $1.0 \mathrm{E}-01$ & 1. $.0 \mathrm{E}+(0)$ & $8.6 \mathrm{E}-112$ \\
\hline
\end{tabular}


TABLE 6.8 (Cont.)

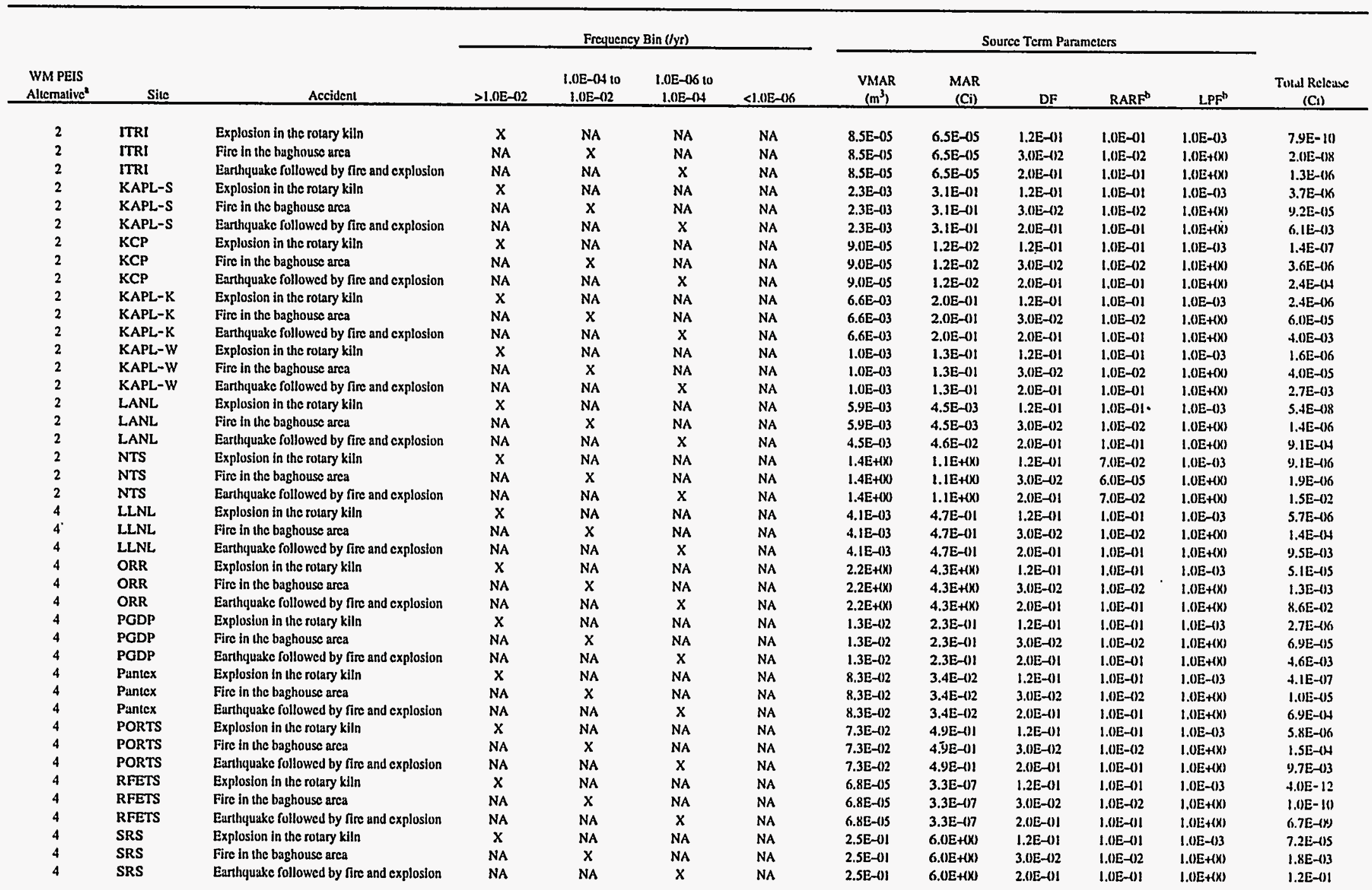


TABLE 6.8 (Cont.)

\begin{tabular}{|c|c|c|c|c|c|c|c|c|c|c|c|c|}
\hline \multirow[b]{2}{*}{$\begin{array}{l}\text { WM PEIS } \\
\text { Allernative" }\end{array}$} & \multirow[b]{2}{*}{ Site } & \multirow[b]{2}{*}{ Accident } & \multicolumn{4}{|c|}{ Frequency Bin $(y y)$} & \multicolumn{5}{|c|}{ Source Term Paramelers } & \multirow[b]{2}{*}{$\begin{array}{c}\text { Total Release } \\
\text { (Ci) }\end{array}$} \\
\hline & & & $>1.0 \mathrm{E}-112$ & $\begin{array}{c}1.0 \mathrm{E}-0.04 \text { to } \\
1.0 \mathrm{E}-02 \\
\end{array}$ & $\begin{array}{l}1.0 \mathrm{E}-106 \text { to } \\
1.0 \mathrm{E}-04 \\
\end{array}$ & $<1.0 E-1) 6$ & $\begin{array}{c}\text { VMAR } \\
\left(\mathrm{m}^{3}\right) \\
\end{array}$ & $\begin{array}{r}\text { MAR } \\
\text { (Ci) } \\
\end{array}$ & DF & RARF $^{b}$ & $\mathrm{LPF}^{b}$ & \\
\hline 7 & Hanford & Explosion in the rotary kiln & $x$ & $\mathrm{NA}$ & $\mathrm{NA}$ & NA & $1.6 \mathrm{E}+(1) 0$ & $4.3 \mathrm{E}+(x)$ & $(.2 \mathrm{E}-(1) 1$ & $1,0 E-01$ & $1.0 \mathrm{E}-1.33$ & $5.2 E-105$ \\
\hline 7 & Hanfurd & Fire in the baghouse area & $\mathrm{NA}$ & $x$ & NA & NA & $1.6 E+(x)$ & $4.3 E+(X)$ & 3.1.E-112 & $1.01--12$ & $1.0 E+(x)$ & $1.3 E-13$ \\
\hline 7 & Ilanford & Earthyuake followed by fire and explosion & NA & NA & $\mathbf{x}$ & NA & 1. $6 \mathrm{E}+(x)$ & $4.3 E+(x)$ & $2.08-111$ & (.0E--0! & 1. $.0 \mathrm{E}+(\mathrm{K})$ & $8.6 \mathrm{E}-112$ \\
\hline 7 & INEL & Explosion in the rutary kiln & $\mathrm{x}$ & NA & NA & $\mathrm{NA}$ & $1.3 \mathrm{E}-01$ & 4.3E+(X) & $1.2 \mathrm{E}-(1) 1$ & I.0E-0! & $1.0 E-113$ & $5.1 E-115$ \\
\hline 7 & INEL & Fire in the baghouse area & NA & $\mathrm{x}$ & NA & $\mathrm{NA}$ & $1.3 \mathrm{E}-011$ & $4.3 \mathrm{E}+(10)$ & $3.0 E-112$ & $1.0 \mathrm{E}-02$ & $1.0 \mathrm{E}+(x)$ & $1.3 \mathrm{E}-113$ \\
\hline 7 & INEL. & Earhyuake followed by fire and explosion & NA & NA & $\mathrm{x}$ & NA & $1.3 \mathrm{E}-01$ & 4.3E+(0) & 2.0E- 011 & $1.0 \mathrm{E}-01$ & 1. $.0 E+(0)$ & $8.6 \mathrm{E}-122$ \\
\hline 7 & LANL & Explosion in the rotary kiln & $\mathrm{x}$ & $\mathrm{NA}$ & NA & $\mathrm{NA}$ & $8.7 \mathrm{E}-02$ & $8.0 \mathrm{E}-(12$ & $1.2 \mathrm{E}-01$ & $1.0 \mathrm{E}-01$ & $1.0 E-1.3$ & $9.6 E-077$ \\
\hline 7 & LANL & Earhiquake followed by fire and explosion & NA & $\mathrm{NA}$ & $\mathrm{x}$ & NA & $8.7 \mathrm{E}-(12)$ & $8.0 \mathrm{E}-02$ & $2.0 \mathrm{E}-101$ & $1.0 \mathrm{E}-0 !$ & $1,(0 E+(x)$ & $1.6 E-113$ \\
\hline 7 & ORR & Explosion in ule rotary kiln & $\mathrm{x}$ & NA & NA & $\mathrm{NA}$ & $3.4 \mathrm{E}-01$ & $2.5 \mathrm{E}+(0)$ & $1.2 E-(1) 1$ & $1.0 \mathrm{E}-01$ & $1.0 E-103$ & 3.10E-115 \\
\hline 7 & ORR & Fire in the baghouse arca & $\mathrm{NA}$ & $x$ & NA & NA & $3.4 \mathrm{E}-01$ & $2.5 E+\infty 0$ & $3.0 \mathrm{E}-02$ & $1.0 \mathrm{E}-02$ & $1.0 E+(x)$ & $7.4 E-144$ \\
\hline 7 & ORR & Earthquake followed by fire and explosion & $\mathrm{NA}$ & $\mathrm{NA}$ & $\mathrm{x}$ & NA & $3.4 \mathrm{E}-101$ & $2.5 E+(X)$ & 2.0E-101 & $1.0 \mathrm{E}-0101$ & $1.0 \mathrm{E}+((x)$ & $4.9 \mathrm{E}-(1) 2$ \\
\hline 7 & PORTS & Explosion in the rotary kiln & $\mathrm{x}$ & NA & NA & $\mathrm{NA}$ & $8.2 \mathrm{E}-01$ & $8.6 \mathrm{E}-01$ & $1.2 \mathrm{E}-01 \mathrm{I}$ & $1.0 \mathrm{E}-01$ & 1.0E-103 & $1.0 \mathrm{E}-105$ \\
\hline 7 & PORTS & Fire in the baghouse area & NA & $x$ & NA & NA & $8.2 \mathrm{E}-0) 1$ & $8.6 \mathrm{E}-01$ & $3.0 \mathrm{E}-102$ & $1.0 E-(02)$ & $1.0 \mathrm{E}+(\mathrm{X})$ & $2.6 \mathrm{E}-104$ \\
\hline 7 & PORTS & Earthquake followed by fire and explosion & $\mathrm{NA}$ & NA & $\mathrm{x}$ & $\mathrm{NA}$ & $8.2 \mathrm{E}-101$ & $8.6 \mathrm{E}-01$ & $2.0 \mathrm{E}-01$ & $1.0 \mathrm{E}-01$ & $1.0 \mathrm{E}+(x)$ & $1.7 E-112$ \\
\hline 7 & RFETS & Explosion in the rotary kiln & $\mathrm{x}$ & NA & $\mathrm{NA}$ & NA & $9.0 E-05$ & $1.2 \mathrm{E}-02$ & $1.2 \mathrm{E}-01$ & $1.0 \mathrm{E}-01$ & $1.0 E-1) 3$ & $1.4 E-177$ \\
\hline 7 & RFETS & Fire in the baghouse arca & $\mathrm{NA}$ & $\mathrm{x}$ & $\mathrm{NA}$ & $\mathrm{NA}$ & $9.0 E-105$ & $1.2 \mathrm{E}-02$ & $3 .(1)-112$ & $1.0 \mathrm{E}-02$ & $1.0 \mathrm{E}+(k)$ & $3.6 E-166$ \\
\hline 7 & RFETS & Earhyuake followed by fire and explosion & $\mathrm{NA}$ & $\mathrm{NA}$ & $\mathrm{x}$ & $\mathrm{NA}$ & $9.0 \mathrm{E}-105$ & $1.2 \mathrm{E}-02$ & $2.0 \mathrm{E}-011$ & $1.0 \mathrm{E}-01$ & 1.0E+(K) & 2.4E-14.4 \\
\hline 7 & SRS & Explosion in the rotary kiln & $\mathrm{x}$ & NA & NA & NA & $2.5 \mathrm{E}-0) 1$ & $6.0 \mathrm{E}+(x)$ & $1.2 \mathrm{E}-011$ & 1.0E--10! & 1.0E--03 & $7.2 \mathrm{E}-105$ \\
\hline 7 & SRS & Firse in the baghousc urea & NA & $x$ & $\mathrm{NA}$ & NA & 2.5E-(0)! & $6.02 E+(x)$ & $3.0 E-112$ & 1.01E-102 & 1. $(1) E+(x)$ & $1.86-133$ \\
\hline 7 & SRS & Earthyuake followed by fire and explosion & NA & NA & $\mathrm{x}$ & $\mathrm{NA}$ & $2.5 E-(1)]$ & $6.0 \mathrm{E}+(\mathrm{K})$ & $2.0 \mathrm{E}-1) 1$ & $1.0 \mathrm{E}-01$ & $1,0 \mathrm{E}+(x)$ & $1.2 \mathrm{E}-011$ \\
\hline 15 & Ilanford & Explusion in the rotary kiln & $\mathrm{x}$ & NA & NA & $\mathrm{NA}$ & $1.6 \mathrm{E}+(\mathbf{x )}$ & 4.3E+(x) & $1.2 \mathrm{E}-01)$ & $1.0 \mathrm{E}-01$ & $1.06-133$ & $5.2 \mathrm{E}-105$ \\
\hline 15 & Hanford & Fire in the baghouse area & NA & $x$ & NA & NA & $1.6 \mathrm{E}+100$ & 4.3E+(X) & $3.0 \mathrm{E}-112$ & $1.0 \mathrm{E}-122$ & $1.0 E+(x)$ & $1.3 \mathrm{E}-133$ \\
\hline 15 & Hanford & Eurthyuake followed by fire and explosion & $\mathrm{NA}$ & NA & $\mathrm{x}$ & NA & $1.6 \mathrm{E}+100$ & $4.3 \mathrm{E}+(\mathbf{x )}$ & $2.0 \mathrm{E}-01$ & $1.0 \mathrm{E}-01$ & 1.0E+(K) & $8.6 E-(1) 2$ \\
\hline 15 & INEL & Explosion in the rutary kiln & $x$ & NA & NA & NA & $1.4 \mathrm{E}-011$ & 4.3E+(x) & $|.2 E-(0)|$ & [.0E-0! & 1.0E-133 & 5. IE-115 \\
\hline 15 & INEL & Fire in the baghouse area & NA & $\mathrm{x}$ & $\mathrm{NA}$ & NA & $1.4 \mathrm{E}-(01$ & $4.3 E+(x)$ & $3.010-122$ & 1.0E- -122 & 1. $.0 \mathrm{E}+(\mathrm{K})$ & $(2 E-1) 3$ \\
\hline 15 & INEL & Earthyuake followed by fire and explosion & $\mathrm{NA}$ & NA & $\mathrm{x}$ & NA & $1,4 E-01$ & $4.3 E+(x)$ & $2.11 E-111$ & $1.0 \mathrm{E}-101$ & $1,0 E+(x)$ & $8.6 E-112$ \\
\hline 15 & ORR & Explosion in the rotary kiln & $\mathrm{x}$ & NA & NA & NA & $2.7 \mathrm{E}+(X)$ & $4.7 E+(x)$ & $(.2 \mathrm{E}-(1) \mid$ & $1.0 \mathrm{E}-01$ & 1.(0E-10.3 & $5.7 \mathrm{E}-115$ \\
\hline 15 & ORR & Fire in the baghouse arca & $\mathrm{NA}$ & $\mathrm{x}$ & NA & NA & $2.7 \mathrm{E}+(x)$ & 4.7E+(X) & $3.0 \mathrm{E}-1.12$ & $1.0 \mathrm{E}-02$ & $1.0 \mathrm{E}+(1)$ & 1. $.4 E-103$ \\
\hline 15 & ORR & Eardiquake followed by fire and explosion & NA & $\mathrm{NA}$ & $x$ & $\mathrm{NA}$ & $2.7 \mathrm{E}+(\mathrm{K})$ & 4.7E+(x) & $2.0 E-111$ & $1.0 E-01$ & $1.0 \mathrm{E}+(x)$ & $9.5 E-112$ \\
\hline 15 & SRS & Explosion in the rotary kiln & $\mathrm{x}$ & NA & NA & $\mathrm{NA}$ & $2.5 \mathrm{E}-01$ & $6.0 \mathrm{E}+(00)$ & $1.2 \mathrm{E}-(1) 1$ & $1.0 \mathrm{E}-0 !$ & $1.0 \mathrm{E}-133$ & $7.2 \mathrm{E}-115$ \\
\hline 15 & SRS & Fire in the baghouse area & NA & $\mathrm{x}$ & $\mathrm{NA}$ & NA & $2.5 \mathrm{E}-011$ & $6.0 \mathrm{E}+(0)$ & $3.0 \mathrm{E}-102$ & $1.0 \mathrm{E}-02$ & $1.0 \mathrm{E}+(\mathrm{k})$ & $1.8 \mathrm{E}-(1) 3$ \\
\hline 15 & SRS & Earthquake followed by fire and explosion & NA & $\mathrm{NA}$ & $\mathrm{x}$ & NA & $2.5 E-01$ & $6.0 \mathrm{E}+100$ & 2.UE-OII & $1.0 E-01$ & $(1,0 E+(K)$ & $1.2 E-11 !$ \\
\hline 17 & Hanford & Explusion in the rotary kiln & $x$ & NA & $\mathrm{NA}$ & $\mathrm{NA}$ & $3.5 E+(x)$ & $1.0 \mathrm{E}+01$ & $1.2 \mathrm{E}-(1) 1$ & $1.0 \mathrm{E}-01$ & 1.0E-103 & $1.2 \mathrm{E}-1) 4$ \\
\hline 17 & Hanford & Fire in the baghouse area & NA & $\mathrm{x}$ & $\mathrm{NA}$ & $\mathrm{NA}$ & $3.5 \mathrm{E}+(10)$ & $1.0 \mathrm{E}+01$ & $3.0 E-112$ & $1.0 \mathrm{E}-02$ & $1.0 \mathrm{E}+(\mathrm{k})$ & $3.1 E-103$ \\
\hline 17 & Hanford & Earthyuake followed by fire and explosion & $\mathrm{NA}$ & $\mathrm{NA}$ & $\mathrm{x}$ & $\mathrm{NA}$ & $3.5 \mathrm{E}+(X)$ & $1.0 \mathrm{E}+01$ & $2.0 \mathrm{E}-(1) 1$ & 1.0E- -01 & 1.0E+(o) & 2.JE-(01 \\
\hline 26 & Hanford & Explusion in the rotary kiln & $\mathrm{x}$ & NA & $\mathrm{NA}$ & NA & $6.5 \mathrm{E}-05$ & $9.9 \mathrm{E}-13$ & $1.2 \mathrm{E}-01$ & $1.0 \mathrm{E}-(01$ & $1.0 \mathrm{E}-103$ & $1.2 \mathrm{E}-107$ \\
\hline 26 & Hanford & Fire in the baghouse area & $\mathrm{NA}$ & $x$ & $\mathrm{NA}$ & $\mathrm{NA}$ & $6.5 \mathrm{E}-195$ & $9.9 \mathrm{E}-03$ & $3.0 E-112$ & $1.0 \mathrm{E}-02$ & $1.0 \mathrm{E}+(x)$ & $3.018-166$ \\
\hline 26 & Hanford & Earthyuake followed by fire and explosion & NA & $\mathrm{NA}$ & $\mathrm{x}$ & NA & $6.5 E-115$ & $9.9 \mathrm{E}-113$ & $2.0 \mathrm{E}-011$ & $1,0 E-0 !$ & 1.0IE+(x) & $2,0 E-14$ \\
\hline 26 & INEL & Explusion in the rotary kiln & $\mathrm{x}$ & NA & $\mathrm{NA}$ & NA & $1.9 \mathrm{E}-01$ & $1.8 \mathrm{E}+01$ & $1.2 \mathrm{E}-011$ & $1.0 E-01$ & 1.0E-113 & $2.2 \mathrm{E}-144$ \\
\hline 26 & INEL & Fire in the baghouse area & NA & $x$ & $\mathrm{NA}$ & $\mathrm{NA}$ & $1.9 \mathrm{E}-0) 1$ & $1.8 \mathrm{E}+01$ & $3.0 \mathrm{E}-02$ & $1.0 E-112$ & $1.0 \mathrm{E}+(1)$ & $5.5 \mathrm{E}-103$ \\
\hline 26 & INEL & Earthyuake followed by fire and explosion & NA & NA & $\mathrm{x}$ & NA & $1.9 \mathrm{E}-01$ & $1.8 \mathrm{E}+0 !$ & 2.0E-01 & $1.0 \mathrm{E}-01$ & $1.0 E+(x)$ & $3.7 \mathrm{E}-(1) !$ \\
\hline 26 & ORR & Explosion in the rotary kiln & $\mathrm{x}$ & NA & $\mathrm{NA}$ & $\mathrm{NA}$ & I.IE-1) & $3.0 \mathrm{E}+00$ & $1.2 \mathrm{E}-01$ & $1.0 \mathrm{E}-0 !$ & $1.0 E-1 / 3$ & $3.6 \mathrm{E}-115$ \\
\hline 26 & ORR & Fire in the baghouse area & $\mathrm{NA}$ & $\mathrm{x}$ & $\mathrm{NA}$ & $\mathrm{NA}$ & $1.1 \mathrm{E}-1.12$ & 3.0E $+(0)$ & 3.0E- -122 & $1.00-12$ & $1.0 \mathrm{E}+(0)$ & $9.18-14$ \\
\hline 26 & ORR & Earthquake followed by fire and explosion & NA & NA & $\mathrm{x}$ & NA & L.1E-0.12 & $3.0 \mathrm{E}+00$ & $2.0 E-011$ & $1.00-01$ & 1. $.(1)+(x)$ & $6.1 E-112$ \\
\hline
\end{tabular}


TABLE 6.8 (Cont.)

\begin{tabular}{|c|c|c|c|c|c|c|c|c|c|c|c|c|}
\hline \multirow[b]{2}{*}{$\begin{array}{l}\text { WM PEIS } \\
\text { Altemative" }\end{array}$} & \multirow[b]{2}{*}{ Sitc } & \multirow[b]{2}{*}{ Accident } & \multicolumn{4}{|c|}{ Frequency Bin (lyr) } & \multicolumn{5}{|c|}{ Source Term Paramelers } & \multirow[b]{2}{*}{$\begin{array}{c}\text { Tutal Release } \\
\text { (Ci) }\end{array}$} \\
\hline & & & $>1.0 \mathrm{E}-02$ & $\begin{array}{c}1.0 E-04 \text { to } \\
1.0 E-02 \\
\end{array}$ & $\begin{array}{c}1.0 E-06 \text { to } \\
1.0 E-04 \\
\end{array}$ & $<1.0 E-96$ & $\begin{array}{c}\text { VMAR } \\
\left(\mathrm{m}^{3}\right)\end{array}$ & $\begin{array}{r}\text { MAR } \\
\text { (Ci) }\end{array}$ & $\mathrm{DF}$ & RARF & LPF & \\
\hline 26 & SRS & Explosion in the rotary kiln & $\mathbf{x}$ & NA & NA & $\mathrm{NA}$ & $7.8 \mathrm{E}-1-14$ & $8.3 E-112$ & $1.2 E-(1 !$ & 1.0E-O)! & $3.0 \mathrm{E}-13$ & 1.0E-165 \\
\hline 26 & SRS & Fire in the haghuuse area & NA & $x$ & NA & $\mathrm{NA}$ & $7.8 E-144$ & $8.3 E-112$ & $3.11 \mathrm{E}-1.2$ & $1,(1)-112$ & $1.0 E+(0)$ & 2.5E 115 \\
\hline 26 & SRS & Earthuuake followed by fine and explosion & NA & $\mathrm{NA}$ & $x$ & $\mathrm{NA}$ & 7.8E-14 & 8.3E-112 & $2.0 \mathrm{E}-01$ & 1.0E-01 & $1.0 E+(x)$ & $1.7 \mathrm{E}-113$ \\
\hline
\end{tabular}

- The WM PEIS cases analyzed are deceribed as follows:

- Case $l$ (No Action). Three sites (INEL, ORR, and SRS) treat and store; all remaining sites store.

- Case 2 (Decentralized). Furty-nine sites treat, and 16 sites dispose.

Case 4 (Regionalized l). Eleven siles (Hanford, INEL, LANL, ORR, SRS, PORTS, PGDP. FEMP, LLNL, Pantex, and RFETS) treal, and 12 siles dispuse.

- Case 7 (Regionalized 2). Seven sites (Hanford, INEL, LANL, ORR, SRS, PORTS, and RFETS) treat, and six sites dispose.

Case 15 (Regionalized 4). Four sites (Hanford, INEL, ORR, and SRS) treat, and six sites dispose.

Case 17 (Centralized). One site treats (tanford), and one sile disposes.

Case 26 (Remore-handled). Four sites (Hanford, INEL, ORR, and SRS) treat and dispose (RH).

- Values shown are for (nonvolatile) solids such as U-235 or Pu-238; sec Appendix D.

c $N A=$ not applicable. 
TABLE 6.9 Frequencies and Radiological Source Term Parameters for WM LLMW Alpha-Incineration Facility Accidents

\begin{tabular}{|c|c|c|c|c|c|c|c|c|c|c|c|c|}
\hline \multirow[b]{2}{*}{$\begin{array}{l}\text { WM PEIS } \\
\text { Allermative" }\end{array}$} & \multirow[b]{2}{*}{ Sile } & \multirow[b]{2}{*}{ Accident Sequence } & \multicolumn{4}{|c|}{ Frequency Bin (/yr) } & \multicolumn{5}{|c|}{ Source Term Paramelers } & \multirow[b]{2}{*}{$\begin{array}{c}\text { Total Reledset } \\
\text { (Ci) }\end{array}$} \\
\hline & & & $>1.0 \mathrm{E}-02$ & $\begin{array}{c}1.0 \mathrm{E}-104 \text { to } \\
1.0 \mathrm{E}-102\end{array}$ & $\begin{array}{c}1.0 E-06 \text { to } \\
1.0 E-04\end{array}$ & $<1.0 E-016$ & $\begin{array}{c}\text { VMAR } \\
\left(\mathrm{m}^{3}\right)\end{array}$ & $\begin{array}{c}\text { MAR } \\
\text { (Ci) }\end{array}$ & $\mathrm{DF}$ & RARF & LPF & \\
\hline 2 & INEL. & Explosion in the rotary kiln & $\mathbf{x}$ & $N A^{c}$ & NA & $\mathrm{NA}$ & $1.5 \mathrm{E}-\Omega) 1$ & $9.3 E+(X)$ & $1.2 \mathrm{E}-1)$ & $1.0 E-01$ & 1.0E-113 & $1.1 E-1 / 4$ \\
\hline 2 & INEI. & Fire in the baghwuse area & NA & $x$ & NA & NA & $1.55:-0 !$ & $0,3 \mathrm{E}+(\mathbf{0})$ & $3.018-(1) 2$ & $1.018-(122$ & (.) $(0):+(x)$ & $2.81:-1.3$ \\
\hline 2 & INEL & Earthyuake followed by fine and explosion & NA & $\mathrm{NA}$ & $\mathrm{x}$ & NA & 1.SE-H1) & $9.3 \mathrm{E}+(\mathrm{K})$ & $2.01-(1) 1$ & $3.018-011$ & (.)1)E+(x) & $(1.9 \mathrm{E}-1) 1$ \\
\hline 2 & LANL & Explosion in the rotary kiln & $\mathrm{x}$ & $\mathrm{NA}$ & NA & NA & $2.9 \mathrm{E}-0.12$ & $4.0 \mathrm{E}-102$ & $1.2 \mathrm{E}-(1) 1$ & $(.0 E-0 !$ & $1.0 \mathrm{E}-113$ & $4.8 \mathrm{E}-177$ \\
\hline 2 & LANL & Fire in the baghouse arca & NA & $\mathrm{x}$ & NA & $\mathrm{NA}$ & $2,9 \mathrm{E}-112$ & $4.0 \mathrm{E}-02$ & $3.0 E-02$ & 1.0E-102 & $1.0 \mathrm{E}+(\mathrm{K})$ & $1.2 E-105$ \\
\hline 2 & LANL & Eanthyuake collowed by fire and explosion & $\mathrm{NA}$ & $\mathrm{NA}$ & $\mathrm{x}$ & NA & $2.9 E-112$ & $4.0 E-102$ & $2.0 \mathrm{E}-111$ & $1.0 \mathrm{E}-101$ & $1.0 \mathrm{E}+(0)$ & $8.1 E-144$ \\
\hline 2 & LLNL & Explosion in the rotary kiln & $\mathrm{x}$ & NA & NA & NA & $2.0 \mathrm{E}-02$ & $1.7 \mathrm{E}-02$ & $1.2 \mathrm{E}-01$ & $1.0 E-011$ & $1.0 \mathrm{E}-03$ & $2.0 \mathrm{E}-107$ \\
\hline 2 & LLNL. & Firc in the baghousc arca & NA & $\mathrm{x}$ & $\mathrm{NA}$ & NA & $2.0 \mathrm{E}-12$ & $1.7 \mathrm{E}-1.2$ & 3.1.E-112 & 1.0E- 112 & $1.0 \mathrm{E}+(\mathbf{x )}$ & $5.10 \mathrm{E}-116$ \\
\hline 2 & LLNL & Earhquake followed by fire and explosion & NA & $\ddot{N A}$ & $\mathrm{x}$ & $\mathrm{NA}$ & $2.0 E-12$ & $1.7 \mathrm{E}-1.2$ & $2.0 E-1) !$ & $1.0 E-01$ & $1.0 \mathrm{E}+(0)$ & $3.4 E-(1)-4$ \\
\hline 2 & RFETS & Explosion in the rotary kiln & $\mathrm{x}$ & NA & NA & NA & $1.6 \mathrm{E}-(01$ & $1.4 \mathrm{E}-02$ & $(.2 \mathrm{E}-01$ & $1.0 \mathrm{E}-0 \mathrm{I}$ & $1.0 \mathrm{E}-03$ & $1.7 \mathrm{E}-07$ \\
\hline 2 & RFETS & Fire in the baghouse area & NA & $\mathrm{x}$ & NA & $\mathrm{NA}$ & $1.6 \mathrm{E}-01$ & $1.4 \mathrm{E}-02$ & $3.0 E-112$ & $1.0 E-102$ & $1.0 \mathrm{E}+(0)$ & $4.2 E-1) 6$ \\
\hline 2 & RFETS & Earthyuake followed by fire and explosion & NA & $\hat{N A}$ & $\mathrm{x}$ & $\mathrm{NA}$ & $1.6 \mathrm{E}-01$ & $1.4 \mathrm{E}-102$ & 2,0E-101 & $1.0 \mathrm{E}-01$ & $1.0 E+(0)$ & $2.8 E-1) 4$ \\
\hline 2 & SRS & Explosion in the rotary kiln & $\mathrm{x}$ & $\mathrm{NA}$ & NA & NA & 2.1E-01 & $4.8 \mathrm{E}-01$ & $1.2 \mathrm{E}-01$ & I. $.1 E-01$ & $1.0 \mathrm{E}-013$ & $5.7 E-06$ \\
\hline 2 & SRS & Firc in the baghouse arca & NA & $\mathrm{x}$ & $\mathrm{NA}$ & $\mathrm{NA}$ & 2. IE- 01 & $4.8 \mathrm{E}-01$ & $3.0 \mathrm{E}-112$ & $1.0 \mathrm{EE-102}$ & $1.0 \mathrm{E}+(1)$ & $1.4 E-(1)-4$ \\
\hline 2 & SRS & Earthyuake followed by fire and explosion & NA & $\mathrm{NA}$ & $\mathrm{x}$ & NA & $2.1 \mathrm{E}-01$ & $4.8 \mathrm{E}-01$ & 2.0E-01) & I.OE- $0 \mathrm{t}$ & $1.0 E+(0)$ & $9.5 E-133$ \\
\hline 4 & INEL & Explosion in the rotary kiln & $\mathrm{x}$ & NA & NA & NA & $1.5 \mathrm{E}-01$ & $9.3 E+00$ & $(.2 \mathrm{E}-1) 1$ & (.0E-101 & $1.0 \mathrm{E}-103$ & $1.1 E-(1) 4$ \\
\hline 4 & INEL & Firc in the baghouse area & $\mathrm{NA}$ & $\mathrm{x}$ & NA & $\mathrm{NA}$ & $1.5 \mathrm{E}-01$ & $9.3 \mathrm{E}+00$ & $3.0 E-102$ & $1.0 E-102$ & $1,0 E+(x)$ & $2.8 \mathrm{E}-103$ \\
\hline 4 & INEL & Earthyuake followed by fire and explosion & $\mathrm{NA}$ & NA & $\mathrm{x}$ & NA & $1.5 \mathrm{E}-01$ & $9.3 \mathrm{E}+(0)$ & $2,0 E-1) !$ & (.0E-0)! & $1.0 \mathrm{E}+(x)$ & $(.9 E-01)$ \\
\hline 4 & LANL & Explosion in the rotary kiln & $\mathrm{x}$ & NA & NA & NA & $2.9 \mathrm{E}-112$ & 4.11E- 112 & $1.2 \mathrm{E}-01$ & $1.0 \mathrm{E}-01$ & $1.0 \mathrm{E}-03$ & $4.8 \mathrm{E}-07$ \\
\hline 4 & LANL & Fire in the baghouse area & NA & $\mathrm{x}$ & NA & NA & $2.9 \mathrm{E}-112$ & $4.0 \mathrm{E}-02$ & 3.10E-112 & $1.0 \mathrm{E}-122$ & $1.0 \mathrm{E}+(x)$ & $1.2 \mathrm{E}-105$ \\
\hline 4 & LANL & Earthquake followed by fire and explosion & NA & $\mathrm{NA}$ & $\mathrm{x}$ & NA & $2.9 E-122$ & $4.0 \mathrm{E}-102$ & $2.0 E-1) 1$ & $1.0 \mathrm{E}-1) 1$ & $1.0 E+(10)$ & $8.1 E-0.4$ \\
\hline 4 & LLNL & Explosion in the rotary kiln & $\mathrm{x}$ & NA & NA & NA & $2.0 \mathrm{E}-12$ & $1.7 \mathrm{E}-12$ & $1.2 E-(1) 1$ & $1.08-01$ & $1.0 \mathrm{E}-03$ & $2.0 \mathrm{E}-107$ \\
\hline 4 & LLNL & Fire in the baghouse area & NA & $\mathrm{x}$ & NA & NA & $2.0 E-12$ & $1.7 E-02$ & $3 .(1)-112$ & $1.0 \mathrm{E}-02$ & 1. $.0 E+(x)$ & $5.10 E-06$ \\
\hline 4 & LLNL & Earthquake followed by fire and explosion & NA & NA & $x$ & NA & $2.0 \mathrm{E}-112$ & $1.7 \mathrm{E}-112$ & $2.0 \mathrm{E}-1) 1$ & $1.0 \mathrm{E}-101$ & $1.0 E+(0)$ & $3.4 \mathrm{E}-0.4$ \\
\hline 4 & RFETS & Explosion in the rotary kiln & $\mathrm{x}$ & $\mathrm{NA}$ & $\mathrm{NA}$ & NA & $1.6 \mathrm{E}-(0)]$ & $1.4 \mathrm{E}-122$ & $1.2 \mathrm{E}-011$ & I.OEE-011 & $1.0 \mathrm{E}-113$ & $1.7 \mathrm{E}-07$ \\
\hline 4 & RFETS & Firc in the baghouse area & NA & $\mathrm{x}$ & NA & NA & $1.6 \mathrm{E}-01$ & $1.4 \mathrm{E}-1.2$ & $3.0 E-112$ & $1.0 \mathrm{E}-1.2$ & $1.0 E+(1)$ & $4.2 \mathrm{E}-106$ \\
\hline 4 & RFETS & Earthyuake followed by fire and explosion & NA & $\mathrm{NA}$ & $\mathrm{x}$ & NA & $1.6 \mathrm{E}-01$ & $1.4 \mathrm{E}-02$ & $2.0 E-(1) 1$ & 1.0E-1)! & $1.0 E+(0)$ & $2.8 E-(1) 4$ \\
\hline 4 & SRS & Incineration ash explosion & $\mathrm{x}$ & NA & $\mathrm{NA}$ & NA & $2.1 E-(1) 1$ & $4.8 \mathrm{E}-01$ & $1.2 \mathrm{E}-111$ & 1.0E-011 & $1.0 \mathrm{E}-03$ & $5.7 E-116$ \\
\hline 4 & SRS & Fire in the baghouse area & NA & $\mathrm{x}$ & $\mathrm{NA}$ & NA & $2.1 E-11$ & $4,8 E-01$ & $3,0 E-102$ & 1.0E-0.12 & $1.0 \mathrm{E}+(\mathrm{X})$ & $1.4 E-S H$ \\
\hline 4 & SRS & Earthyuake followed by fire and explosion & NA & $\mathrm{NA}$ & $\mathrm{x}$ & NA & 2.IE-(0) & $4.8 \mathrm{E}-0 \mathrm{I}$ & $2,0 \mathrm{E}-1) 1$ & (.OEE- 01 & $1.0 E+(x)$ & $9.5 E-013$ \\
\hline 7 & INEL, & Explosion in the rotary kiln & $x$ & NA & NA & NA & $1.5 E-011$ & $9.3 \mathrm{E}+(10)$ & $1.2 E-101$ & $1.0 \mathrm{E}-01$ & $1.0 E-03$ & $1.18-(1) 4$ \\
\hline 7 & INEL & Fire in the baghouse area & NA & $\mathrm{x}$ & $\mathrm{NA}$ & NA & $1.5 \mathrm{E}-(1) 1$ & $9.3 \mathrm{E}+(1)$ & 3.1. $E-102$ & 1.0E-102 & 1. $(0 E+(0)$ & $2.8 \mathrm{E}-103$ \\
\hline 7 & INEL & Earthyuake followed by fire and explosion & NA & $\mathrm{NA}$ & $\mathrm{x}$ & NA & $1.5 E-(0)$ & $\left.9.3 \mathrm{E}+()_{1}\right)$ & $2,0 E-(1) 1$ & $1.0 \mathrm{E}-01$ & $1.018+(x)$ & $1.9 \mathrm{E}-01$ \\
\hline 7 & LANL & Explosion in the cotary kiln & $\mathrm{x}$ & $\mathrm{NA}$ & NA & NA & $2.9 E-112$ & $4.010-12$ & $1.2 \mathrm{E}-10 \mathrm{t}$ & $1.0 \mathrm{E}-01$ & $1.00-103$ & $4.8 \mathrm{E}-107$ \\
\hline 7 & LANL & Firc in the baghouse area & NA & $\mathrm{x}$ & NA & NA & $2.9 \mathrm{E}-112$ & $4.0 \mathrm{E}-102$ & $3.10 \mathrm{E}-1.12$ & $1.0 \mathrm{E}-1,12$ & $1.0 E+(K)$ & $1.2 E-115$ \\
\hline 7 & LANL & Earthyuake followed by fire and explosion & NA & NA & $x$ & NA & $2,9 E-112$ & 4.0E- -12 & $2.18-(1) 1$ & I.OEE-01 & 1.0E+(0) & $8.118-(1) 4$ \\
\hline 7 & RFETS & Explosion in the rotary Kiln & $\mathrm{x}$ & NA & NA & NA & $1.6 \mathrm{E}-(1)$ & $1.4 E-122$ & $1.2 \mathrm{E}-(0)$ & $1.0 \mathrm{E}-0)$ & $1.0 E-103$ & $1.7 E-107$ \\
\hline 7 & RFETS & Fire in the baghouse area & $\mathrm{NA}$ & $x$ & NA & NA & $1.6 \mathrm{E}-01$ & $1.4 \mathrm{E}-1.12$ & 3.0E- -02 & $1.0 \mathrm{E}-02$ & $1.0 \mathrm{E}+(0)$ & $4.2 E-116$ \\
\hline 7 & RFETS & Earthyuake followed by fire and explosion & NA & $\mathrm{NA}$ & $\mathrm{x}$ & NA & $1.6 \mathrm{E}-01$ & $1.4 \mathrm{E}-(122$ & $2.08-(3)$ & $1.0 \mathrm{E}-01$ & $1.0 \mathrm{E}+(x)$ & $2.8 E-144$ \\
\hline 7 & SRS & Explosion in the rotary kiln & $\mathrm{x}$ & NA & NA & NA & $2.1 E-011$ & $4.8 \mathrm{E}-01$ & $1.2 \mathrm{E}-01$ & $1.0 \mathrm{E}-01$ & $1.0 E-03$ & $5.7 \mathrm{E}-06$ \\
\hline 7 & SRS & Fire in the baghouse arca & NA & $\mathrm{x}$ & NA & NA & 2.1E-01 & $4.8 \mathrm{E}-01$ & 3.1.EE-0. & $1.0 E-02$ & $1.0 \mathrm{E}+(1)$ & $1.4 E-(04$ \\
\hline 7 & SRS & Earrhyuake followed by fire and explosion & NA & NA & $\mathrm{x}$ & NA & $2.1 E-(1) 1$ & $4.8 \mathrm{E}-1) 1$ & $2.0 \mathrm{E}-01$ & $1.0 \mathrm{E}-01$ & $1.0 E+(x)$ & $9.5 E-113$ \\
\hline is & INEL & Explosion in the rotary kils & $x$ & NA & $\hat{\mathrm{NA}}$ & NA & $1.5 \mathrm{E}-01$ & $9.3 \mathrm{E}+(00)$ & $1.2 \mathrm{E}-0 \mathrm{I}$ & $1.0 \mathrm{E}-01$ & $1.0 \mathrm{E}-013$ & I.IE-14 \\
\hline 15 & INEL. & Fire in the baghouse area & NA & $\mathrm{x}$ & NA & $\mathrm{NA}$ & $1.5 \mathrm{E}-0 \mid$ & $9.3 \mathrm{E}+(10)$ & 3.10E-102 & $1.0 \mathrm{E}-02$ & $1.0 E+(x)$ & $2.8 \mathrm{E}-1,33$ \\
\hline 15 & INEL & Earthyuake followed by fire and explosion & NA & NA & $\mathrm{x}$ & NA & $1.5 \mathrm{E}-(0)$ & $9.3 \mathrm{E}+(0)$ & $2.0 E-011$ & $1.0 \mathrm{E}-01$ & 1. $0 E+(x)$ & $1.9 \mathrm{E}-01$ \\
\hline 15 & SRS & Explosion in Uhe rotary kiln & $\mathrm{x}$ & $\mathrm{NA}$ & NA & NA & $2.1 E-(1) 1$ & $4.8 \mathrm{E}-1)$ & $1.2 \mathrm{E}-0 \mathrm{t}$ & $1.0 \mathrm{E}-(1) 1$ & I.0.0E-03 & $5.7 \mathrm{E}-0.06$ \\
\hline 15 & SRS & Fire in the baghouse areu & NA & $\mathrm{x}$ & NA & NA & $2.1 E-111$ & $\left.4.8 E^{2}-1\right) 1$ & 3.01E-102 & $1.01-112$ & $1.08 E+(x)$ & $1.4 E-(04$ \\
\hline 15 & SRS & Earthyuake followed hy fire and explosion & NA & $\hat{\mathrm{NA}}$ & $\mathrm{x}$ & NA & $2.1 \mathrm{E}-01$ & $4.8 \mathrm{E}-111$ & 2.0E-AI & $1,0 E-0 !$ & $1.0 \mathrm{E}+(x)$ & $9.5 E-103$ \\
\hline
\end{tabular}




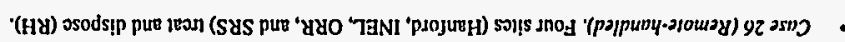

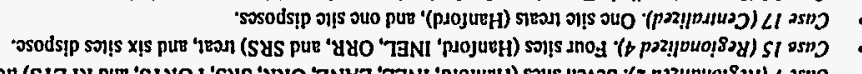

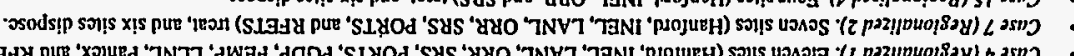

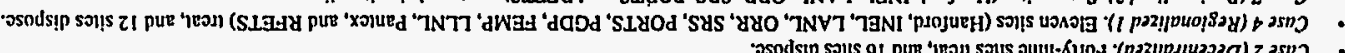

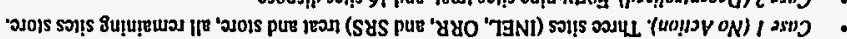

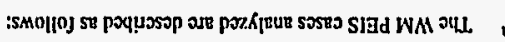

\begin{tabular}{|c|c|c|c|c|c|c|c|c|c|c|c|c|}
\hline 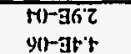 & $\begin{array}{l}(x)+300) \\
(00+301)\end{array}$ & 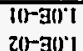 & 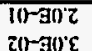 & 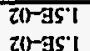 & 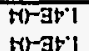 & $\begin{array}{l}V \\
Y N\end{array}$ & $\begin{array}{c}x \\
y\end{array}$ & $\begin{array}{c}\forall N \\
X \\
x\end{array}$ & $\overline{V N}$ & 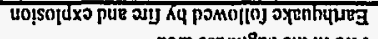 & TISI & $\overline{9 \pi}$ \\
\hline$(1)-38.1$ & $\varepsilon(0-3)$ & $(10-30) 1$ & $10-3 z \div$ & $20-351$ & $m-3 \div$ & VN & YN & YN & $\mathrm{x}$ & 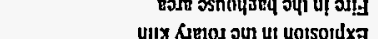 & TENI & $9 i$ \\
\hline (4)-3xi & $(0)+30) 1$ & 10-301 & $10-3102$ & $201-a+1$ & $(1)-39.1$ & $\forall N$ & $\mathrm{x}$ & VN & VN & 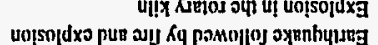 & 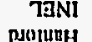 & $9 \tau$ \\
\hline 9(I-ZEE & $(x)+30) 1$ & $201-301$ & $z(1)-30)^{\prime} \varepsilon$ & $20-\exists=1$ & $10-391$ & VN & VN & $\mathrm{x}$ & VN & 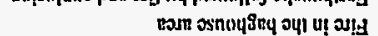 & กномин: & 4 \\
\hline$\angle(1-3 \ell)$ & $\varepsilon(1-30) t$ & $10-301$ & $11-3 z i$ & $20-3+1$ & $10-991$ & VN & VN & YN & $\mathrm{x}$ & 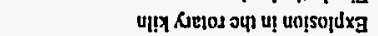 & рнојuен & $\angle 1$ \\
\hline 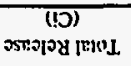 & क्षाd7 & 4878 & पव & $\begin{array}{l}\text { (5) } \\
\text { uVW }\end{array}$ & $\begin{array}{l}\text { (qui) } \\
\text { dVW }\end{array}$ & $91-3011>$ & $\begin{array}{l}50-30^{\circ} \mathrm{t} \\
\text { ot } 90-0^{\circ} \mathrm{t}\end{array}$ & $\begin{array}{c}60-30^{\circ} 1 \\
01+0-901\end{array}$ & $20-30 \%$ & 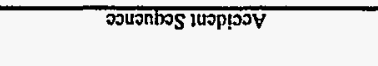 & ग1!S & 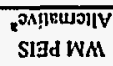 \\
\hline
\end{tabular}

('740D) 6.9 G79VL 


\section{ACCIDENT ANALYSIS FOR GREATER-THAN-CLASS-C LOW-LEVEL WASTE}

\subsection{OVERVIEW OF GREATER-THAN-CLASS-C LOW-LEVEL WASTE MANAGEMENT}

GTCC is LLW generated by licensees of the NRC or Agreement States with concentrations of certain radionuclides exceeding thresholds as specified in 10 CFR 61.55. DOE has responsibility for the disposal of commercial GTCC under the Low-Level Radioactive Waste Policy Amendments Act of 1985. Disposal requires a NRC-licensed geologic repository or an NRC-approved alternative facility that provides isolation of the waste. At the request of NRC and the Agreement States, DOE currently provides interim storage for limited amounts of GTCC LLW, primarily small, sealed radioactive sources (e.g., cesium [Cs] and strontium [Sr] for medical therapy research and Am for well logging). A much larger future potential source includes nuclear utility waste, mainly activated metals from SNF assemblies and reactor core components. Uncertainties include the effect of concentration averaging and a clear delineation between SNF and GTCC, the resolution of which could substantially alter projected volumes.

The DOE program consists of three phases: (1) continuation of limited interim storage of (primarily) sealed sources, (2) providing a centralized dedicated storage facility until an NRC-licensed facility is available, and (3) disposal in either an HLW repository or a separate NRC-licensed facility. Because DOE has not yet initiated efforts on an NRC-licensed facility, the current program assumes disposal in the HLW repository. Nuclear utility volumes will be needed to define Phase 2 centralized storage requirements, potential packaging and treatment requirements, and fee specifications. The dedicated and interim storage phases could be merged, depending on commercial reactor decommissioning decisions. The WM PEIS only considers alternatives for current interim storage of sealed sources. These alternatives are:

\section{No Action (Existing and Approved)}

- Continue to store limited quantities of commercial GTCC at Hanford, FEMP, INEL, LANL, ORR, and SRS in existing and approved storage facilities.

\section{Decentralization}

- Continue no action and either expand existing or establish new interim storage facilities at DOE sites as may be required for additional limited commercial quantities (for example, in response to an emergency request by the NRC). 


\section{Regionalization}

- Same as decentralization except ship and store at a limited number of DOE sites (probably between two and five) until an appropriate disposal facility is available.

\section{Centralization}

- Same as decentralization except ship and store at one DOE site until an appropriate disposal facility is available.

\subsection{ACCIDENT CONSIDERATIONS AND CONCLUSIONS RELATING TO SOURCE TERMS}

Current projected volumes of sealed sources (on the order of a few cubic meters) are uncertain with regard to the mix of compositions that will be received and are expected to be a minimal fraction of the total volume provided by utility waste. Independent of the mix of sealed sources received, the facility accident potential associated with these sources will be small for the following reasons:

- Most of these sources are double-encapsulated in stainless steel,

- The source material form is physically and chemically stable,

- Quantities are relatively small, and

- The sources will probably be stored in their shipping packages. Since these packages will meet U.S. Department of Transportation (DOT) and NRC requirements, they will already be designed to withstand transportation accidents that are likely to be more severe than those postulated for a storage facility.

Thus, the utility waste inventories will undoubtedly dictate future facility accident impacts. Moreover, given the overall programmatic uncertainties, the results of analyses of facility accidents for current DOE interim storage of sealed sources would have no bearing on the DOE guidelines. For these reasons, no source terms have been developed. 


\section{ACCIDENT ANALYSIS FOR HAZARDOUS WASTE}

\subsection{OVERVIEW OF HAZARDOUS WASTE MANAGEMENT}

Hazardous waste is waste regulated under RCRA, the Toxic Substances Control Act, or by the States. DOE sources of HW include defense, nuclear energy, and energy research programs. Examples of HW include laboratory solutions, acids, caustics, degreasing agents, and materials contaminated with hazardous cleaning compounds. Wastewater, which represents $97 \%$ of the DOE complex's total volume of HW, is generally treated on-site at the largest facilities. The WM PEIS alternatives do not address wastewater because on-site treatment remains part of each alternative. DOE's strategy is to first minimize the generation of hazardous waste. For the HW generated, the next step is to properly classify, treat, and dispose of that waste.

Between 1984 and 1991, DOE shipped 13 million kg/yr (14,330 tons/yr) of HW to off-site commercial waste management facilities. Each site implements its own waste management program, with the use of commercial facilities generally exceeding use of DOE facilities. A DOE moratorium now prohibits shipping certain wastes to commercial facilities unless the wastes can be proven to be solely in the hazardous classification (i.e., it has been demonstrated that there is "no added" radioactivity from DOE operations, and the surface radioactivity satisfies limits established in DOE orders).

The WM PEIS alternatives being considered for TSD of HW are the following.

\section{No Action/Decentralization}

- Minimize generation to the extent possible.

- Maintain and operate existing approved DOE storage facilities and limited treatment facilities at DOE sites in accordance with applicable permit requirements.

- Manifest, package, and ship HW to commercial permitted TSD facilities.

\section{Regionalization}

- Manage approximately $50 \%$ of the HW with DOE-owned and -operated facilities to be permitted under RCRA. 


\section{Centralization}

- Manage all HW in a very limited number of either DOE-owned and -operated or commercial facilities. Approximately $90 \%$ of the waste in this alternative is to be treated at DOE-owned and -operated facilities.

The alternatives and specific cases considered in the WM PEIS are shown in Table 8.1. They address the extent and manner of continued reliance on commercial TSD facilities. A selected number of these commercial facilities were chosen to represent the spectrum of commercial facilities DOE has been using and that are available for DOE use. In addition, instead of considering all 35 or so DOE facilities, the focus has been on the 10 facilities that produce more than $90 \%$ of the hazardous waste. The alternatives cover the mix of treatment alternatives from minimal to considerable use of outside commercial facilities. The treatment technologies and the HW categories are summarized in Table 6.2. Detailed descriptions of HW treatment processes can be found in Lazaro et al. (1996).

The assessment here considers only the quantities of $H W$ arising from ongoing DOE facility waste management activities (WM HW). Wastes generated by the environmental restoration program (ER HW wastes) were excluded from consideration in the WM PEIS.

Accidents involving the on-site treatment of WM waste were expected to lead to low consequences and risk (except possibly for incineration, because of the high dispersibility of the resulting ash and the potential for enhanced propagation due to the elevated temperature and pressure). For incineration, an accident involving a facility fire and explosion was postulated to occur.

\subsection{RISK-DOMINANT ACCIDENTS AND FACILITY MODELING ASSUMPTIONS}

The analysis herein develops distinct risk-dominant accident sequences and associated source terms for handling accidents, storage facility accidents, and treatment facility accidents.

Accident scenarios involving chemical wastes representative of (1) potentially lifethreatening health effects and (2) the potential for any adverse health effects were selected. The potential for any adverse effects excluded carcinogenesis. Developing a category for carcinogenic effects alone would lead to accidents of negligible consequences, considering the specific chemicals present in the storage facilities. Consequently, only two categories of accidents were determined. The HW constituents of concern were chosen from the DOT list of poison inhalation hazards and from toxicological analyses (Hartmann et al. 1994). Eleven installations that accept more than $90 \%$ of the HW from the DOE complex were selected as representative of the DOE sites. Inventory data for the selected installations were taken from 1992 DOE HW shipment records. Because 


\section{TABLE 8.1 Specification of HW Alternatives ${ }^{\mathrm{a}}$}

\begin{tabular}{|c|c|c|c|c|c|c|c|c|c|c|c|c|c|}
\hline WM PEIS Altemative ${ }^{\mathrm{b}}$ & Action & $\begin{array}{l}\text { 몀 } \\
\text { 营 } \\
\end{array}$ & 岂 & $\overrightarrow{3}$ & 崖 & $\begin{array}{l}\sum_{j} \\
\substack{3 \\
m} \\
\end{array}$ & 递 & பे & 岁 & 宦 & 农 & $\begin{array}{l}\tilde{z} \\
\tilde{n} \\
\tilde{n}\end{array}$ & 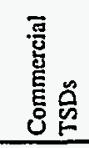 \\
\hline No Action/Decentralized: ${ }^{c}$ & $\begin{array}{l}\text { Treat at } 2 \\
\text { Dispose }\end{array}$ & $\begin{array}{l}\text { NA } \\
\text { NA }\end{array}$ & $\begin{array}{l}\text { NA } \\
\text { NA }\end{array}$ & $\begin{array}{l}\text { NA } \\
\text { NA }\end{array}$ & $\begin{array}{l}\text { NA } \\
\text { NA }\end{array}$ & $\begin{array}{l}\text { NA } \\
\text { NA }\end{array}$ & $\begin{array}{l}\text { NA } \\
\text { NA }\end{array}$ & $\begin{array}{l}N A \\
N A\end{array}$ & $\begin{array}{l}\text { NA } \\
\text { NA }\end{array}$ & $\begin{array}{l}\text { NA } \\
\text { NA }\end{array}$ & $\begin{array}{c}T \\
N A\end{array}$ & $\begin{array}{c}T \\
N \\
N\end{array}$ & $\begin{array}{l}T \\
D\end{array}$ \\
\hline $\begin{array}{l}\text { Regionalized I: } \\
50 \% \text { treated/disposed on-site at } 5 \text { sites } \\
50 \% \text { treated/disposed commercially }\end{array}$ & $\begin{array}{l}\text { Treat at } 5 \\
\text { Dispose }\end{array}$ & $\begin{array}{c}\mathrm{T} \\
\mathrm{NA}\end{array}$ & $\begin{array}{c}\mathrm{T} \\
\mathrm{NA}\end{array}$ & $\begin{array}{l}\text { NA } \\
\text { NA }\end{array}$ & $\begin{array}{c}\mathrm{T} \\
\mathrm{NA}\end{array}$ & $\begin{array}{l}\text { NA } \\
\text { NA }\end{array}$ & $\begin{array}{l}\text { NA } \\
\text { NA }\end{array}$ & $\begin{array}{l}\text { NA } \\
\text { NA }\end{array}$ & $\begin{array}{l}\text { NA } \\
\text { NA }\end{array}$ & $\begin{array}{l}\text { NA } \\
\text { NA }\end{array}$ & $\begin{array}{c}T \\
\text { NA }\end{array}$ & $\begin{array}{c}T \\
\text { NA }\end{array}$ & $\begin{array}{l}\mathrm{T} \\
\mathrm{D}\end{array}$ \\
\hline $\begin{array}{l}\text { Regionalized 2: } \\
90 \% \text { treated/disposed on-site at } 2 \text { sites } \\
10 \% \text { treated/disposed commercially }\end{array}$ & $\begin{array}{l}\text { Treat at } 2 \\
\text { Dispose }\end{array}$ & $\begin{array}{l}\text { NA } \\
\text { NA }\end{array}$ & $\begin{array}{l}\text { T } \\
\mathbf{D}\end{array}$ & $\begin{array}{l}\text { NA } \\
\text { NA }\end{array}$ & $\begin{array}{l}\text { NA } \\
\text { NA }\end{array}$ & $\begin{array}{l}\text { NA } \\
\text { NA }\end{array}$ & $\begin{array}{l}\text { NA } \\
\text { NA }\end{array}$ & $\begin{array}{l}\text { NA } \\
\text { NA }\end{array}$ & $\begin{array}{l}\text { NA } \\
\text { NA }\end{array}$ & $\begin{array}{l}\text { NA } \\
\text { NA }\end{array}$ & $\begin{array}{l}\mathrm{T} \\
\mathrm{D}\end{array}$ & $\begin{array}{l}\mathrm{NA} \\
\mathrm{NA}\end{array}$ & $\begin{array}{l}T \\
D\end{array}$ \\
\hline
\end{tabular}

2 $T=$ treatment by on-site organic destruction; $D=$ disposal; $N A=$ not applicable.

b The WM PEIS considers the potential consequences of increased use of on-site facilities for treatment and disposal versus reliance on commercial facilities. The existing program (No Action Alternative) relies heavily on commercial vendors for treatment and disposal of wastes with organic constituents. This table presents a breakdown of activities at 11 sites for these three alternatives. The WM PEIS focuses on waste with organics; the sites denoted by a single "T" in the table conduct organic destruction. It is assumed, however, that these sites also conduct any additional treatment necessary to meet LDRs. In addition,

although organic destruction is assumed to be a part of the existing program at only three locations (LANL, ORR, SRS), most sites perform some very limited degree of treatment on-site using one or more of the

following treatment technologies: fuel blending, fuel burning, solvent recycling, stabilization, deactivation, metal removal and recovery, mercury removal and recovery, aqueous treatment, and/or recycling.

- Most sites conduct on-site treatment and/or neutralization or deactivation of selected waste streams. 
information on chemical concentrations is usually not given in HW inventory data, concentrations in industrial-grade products were assumed when modeling the source term of a release.

Accident scenarios were divided into the following three general categories, each having subcategories and including potentially life-threatening and any adverse effects endpoints.

1. Spills resulting in partial vaporization of the waste ("spill only"),

2. Spills followed by ignition of the waste ("spill plus fire"), and .

3. "Other event combinations:"

- Spills followed by ignition of the waste and an induced explosion in a waste container ("spill plus fire plus explosion"),

- Facility fires resulting in a waste container breach ("fire only"),

- Mechanical failure of a compressed-gas container resulting in an explosion ("spill and explosion"), and

- Explosion from exposure of reactive material to air followed by fire ("fire and explosion").

Table 8.2 lists the representative accidents chosen to serve as surrogates for all risk-dominant sequences. Thirteen accidents involve the release of potentially life-threatening toxic gases. Five accidents (1e through $1 \mathrm{~g}$ and $2 \mathrm{e}$ through $2 \mathrm{f}$ in Table 8.2) involve the release of materials not 


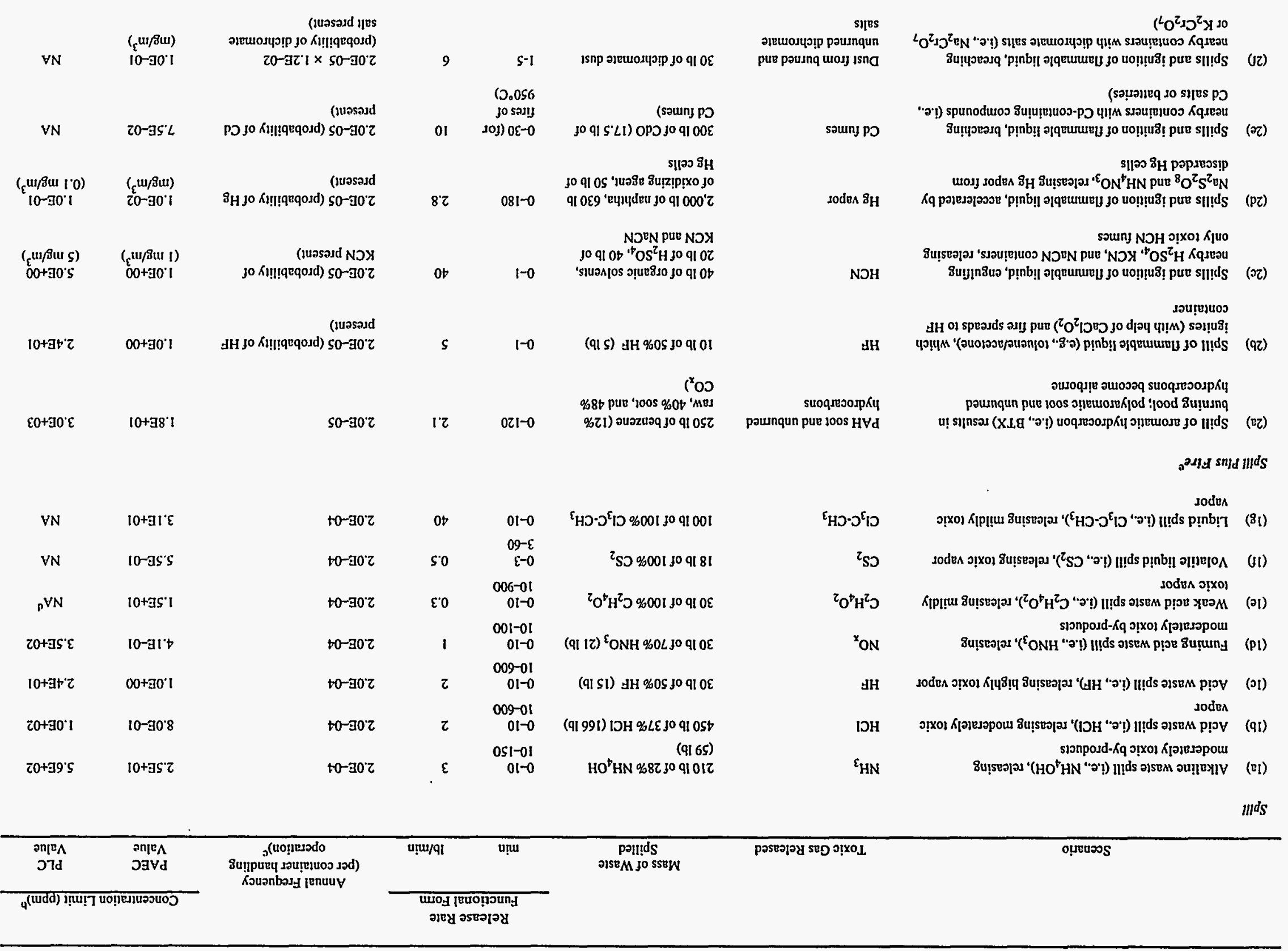

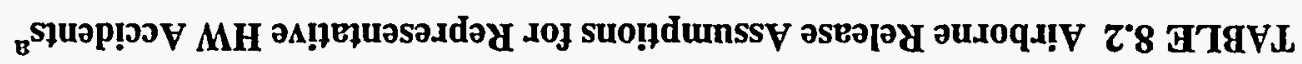


TABLE 8.2 (Cont.)

\begin{tabular}{|c|c|c|c|c|c|c|c|c|}
\hline & \multirow[b]{2}{*}{ Scenario } & \multirow[b]{2}{*}{ Toxic Gas Released } & \multirow[b]{2}{*}{$\begin{array}{l}\text { Mass of Waste } \\
\text { Spilled }\end{array}$} & \multicolumn{2}{|c|}{$\begin{array}{c}\text { Release Rate } \\
\text { Functional Form }\end{array}$} & \multirow{2}{*}{$\begin{array}{l}\text { Annual Frequency } \\
\text { (per container handling } \\
\text { operation) }\end{array}$} & \multicolumn{2}{|c|}{ Concentration Linuis $(\mathrm{ppm})^{t}$} \\
\hline & & & & $\min$ & $\mathrm{lb} / \mathrm{min}$ & & $\begin{array}{l}\text { PAEC } \\
\text { Value }\end{array}$ & $\begin{array}{l}\text { PLC } \\
\text { Value }\end{array}$ \\
\hline \multicolumn{9}{|c|}{ other } \\
\hline (3a) & $\begin{array}{l}\text { Spills and ignition of flammable liquids; heat from fire } \\
\text { causes explosion in compressed gas cylinder, venting } \\
\mathrm{NH}_{3}\end{array}$ & $\mathrm{NH}_{3}$ & $\begin{array}{l}\text { Flammable liquid } 30.5 \mathrm{lb} \text {; } \\
\text { compressed } \mathrm{NH}_{3}\end{array}$ & $0-5$ & 12 & $\begin{array}{l}2.0 \mathrm{E}-05 \times 1.0 \mathrm{E}-02 \\
\text { (probability of } \mathrm{NH}_{3} \text { present) }\end{array}$ & $2.5 \mathrm{E}+01$ & $5.6 \mathrm{E}+02$ \\
\hline (3b) & $\begin{array}{l}\text { Accidental confinement of oxidizing and reducing } \\
\text { agents; reaction generates heat and ignites packaging, } \\
\text { breaching nearby container }\end{array}$ & $\begin{array}{l}\mathrm{NH}_{3} \text { or contents of any } \\
\text { other nearby gas } \\
\text { cylinder }\end{array}$ & $\mathrm{NH}_{3}(60 \mathrm{lb})$ & $0-5$ & 12 & $\begin{array}{l}3.0 \mathrm{E}-03 \text { (probability of both } \\
\text { agents present) }\end{array}$ & $2.5 E+01$ & $5 . \dot{6} \mathrm{E}+02$ \\
\hline (3c) & $\begin{array}{l}\text { Accidental confinement of water with alkali-metal bases } \\
\left.\text { or alkali-earth oxides (i.e., } \mathrm{Na}_{2} \mathrm{O}, \mathrm{K}_{2} \mathrm{O}, \mathrm{CaO}\right) \text {; reaction } \\
\text { generates heat, igniting packaging, breaching nearby } \\
\text { containers }\end{array}$ & $\begin{array}{l}\mathrm{NH}_{3} \text { or any other nearby } \\
\text { gas cylinder }\end{array}$ & $\mathrm{NH}_{3}(60 \mathrm{lb})$ & $0-5$ & 12 & $\begin{array}{l}3.0 \mathrm{E}-03 \text { (probability of } \\
\text { both agents present) }\end{array}$ & $2.5 \mathrm{E}+01$ & $5.6 \mathrm{E}+02$ \\
\hline (3d) & $\begin{array}{l}\text { Accidental rupture of compressed gas cylinder }\left(\mathrm{NO}_{\mathrm{x}^{\prime}}\right. \\
\text { flammable) due to valve failure, releasing toxic gas }\end{array}$ & $\mathrm{NH}_{3}$ & $\begin{array}{l}\text { Compressed gas } 100 \mathrm{lb} / \\
\text { container }\end{array}$ & $0-5$ & 100 & $2.0 \mathrm{E}-05^{8}$ & $2.5 \mathrm{E}+01$ & $5.6 \mathrm{E}+02$ \\
\hline (3e) & $\begin{array}{l}\text { Accidental explosion (without previous spill) of diethyl } \\
\text { cther peroxides formed by exposure to air; remaining } \\
\text { diethyl ether ignites, spreading to nearby container }\end{array}$ & $\begin{array}{l}\mathrm{NH}_{3} \text { or contents of any } \\
\text { other nearby gas } \\
\text { cylinder }\end{array}$ & $\begin{array}{l}\text { Diethyl ether } 2 \mathrm{lb} ; 210 \mathrm{lb} \\
\text { of } \mathrm{NH}_{4} \mathrm{OH}(60 \mathrm{lb})\end{array}$ & $0-5$ & 12 & $3.0 \mathrm{E}-03^{h}$ & $2.5 E+01$ & $5.6 \mathrm{E}+02$ \\
\hline
\end{tabular}

a See notation list for compounds referred to in this table.

b Limits apply for a 15-min exposure and are in parts per million (ppm) unless otherwise specified.

c Number of containers at each site varies.

¿ NA $=$ not applicable.

- It is assumed that 1 in 10 spills will be ignited by a nearby spark (a conservative value) for an outdoor storage facility. When an accident sequence requires a number of initiating steps involving more than one type of waste, the probability that all of the necessary constituents be present at the same time must be included.

t The frequency of improper mixing of stored $\mathrm{HW}$ containers is approximately 3.0E-03 (according to Sasser 1992).

s The value for the probability of compressed gas container breach is 1 per 10,000 handling operations; the value for breaching secondary containment is 1 in 10 .

"The frequency of improperly loading a container containing diethyl ether (allowing air to enter the container) is 3.0E-03 (according to Sasser 1992). 
considered potentially life-threatening but are analyzed for any adverse effects. The development of these accidents took into account the following:

- The location proximity of classes of chemicals to each other in the storage facilities;

- The typical designs of the storage facilities and the required separation of such groups of chemicals as flammable liquids, acids, caustics, combustibles, and oxidizers; and

- The 90-day residence limit for RCRA HW in a storage facility.

The accident scenarios include a range of high-probability, low-consequence accidents to high-consequence, low-probability accidents. In general, they involve a chemical or physical change in stored materials after an initial incident. Equations were written to represent the changes anticipated to occur during the accidents. Toxic gaseous products were identified, and their masses generated during an event were estimated from the mass of the reactants and the stoichiometry of the reactions. The annual frequency of accidents includes both the spill frequency and, where appropriate, the probability that all the agents are present at the same time. Rates of releases were estimated based on engineering judgment and the recognition that such rates often decay exponentially with time. Obviously, the exact course of an accident is shaped by a multitude of factors, including (but not limited to) temperature, humidity, pooling versus spreading of spills, the exact composition/concentration of reactive materials (often unknown), and the proximity and nature of nearby reactive materials (including packaging, shelving, and flooring). Appendix $\mathrm{H}$ provides details of the selection of the accident sequences, the chemistry involved in their progress, and the estimation of toxic gas release rates.

The probability of an accident depends on the throughput of the waste type(s) involved. The progression of some accident sequences requires certain additional waste types to be near the initiating container. For instance, accident subcategory $2 \mathrm{~d}$ in Table 8.2 is dependent upon the probability that flammable liquids, accelerants, and $\mathrm{Hg}$ cells are being stored near one another.

A release is defined as some form of airborne emission (e.g., vapor, gas, aerosol, or particulates) from the original chemical or a reaction product. Recall that all hazardous chemical releases were placed into one of 18 subcategories depending on (1) the category of accident (e.g., spill, spill plus fire), (2) the range of accidents within the category, and (3) the particular health end point. (Note also that many chemicals in the inventory of each site pose no risk if released and therefore do not need to be considered further.) The HW inventories for FY 1992 for 12 DOE sites (the 11 referred to earlier and NTS) were analyzed to determine the most representative set. Detailed chemical knowledge and engineering judgment were used to assign chemicals to categories. Accident risk during storage is dependent on the number of drums and average masses of the 
chemicals placed in each category. Once each accident category was defined, the mass of a released chemical, the elapsed time for release, and the release rates were determined using mass balance equations with consideration of vapor pressure and heat of vaporization at room temperature (see Appendix H).

\subsubsection{Packaged Waste Storage and Handling Operations}

Hazardous wastes are first accumulated in drums or lab packs at the source (laboratory or shop), then shipped to a centralized storage facility. Handling accidents during storage or staging operations are expected to dominate the risk of chemical releases to workers because of the frequency of handling and the proximity of the workers. Ignition or explosion of containers due to chemical reactions originating from container loading errors have also been considered in handling accidents for HW.

\subsubsection{Material at Risk and Damage Fractions}

Since storage packages are typically plastic-lined, carbon steel, 208-L (55-gal) drums, the MAR for handling accident scenarios is assumed to be one drum. Double containment is typical of packaged, chemically hazardous liquids with an intervening packing of absorbent material; however, consistent with previous analyses, the assumption is made that the liquid is completely spilled (i.e., $\mathrm{DF}=1$ ) upon breach of the waste package (Salazar and Lane 1992; ORNL 1993).

\subsubsection{Spill Scenario Frequencies}

The frequency of container breaches is on the order of 1.0E-04 per handling operation (see Section 2). Because HW storage facilities are allowed to hold materials for a maximum of 90 days, it was assumed that all the containers that arrive at a facility are shipped out within 90 days. Two handling operations per container of waste stored at the facility, one loading and one unloading, were assumed. Consistent with the discussion in Section 2, the annual frequency for a spill from a container breach for chemical $x$ due to a handling accident can then be given by

$$
f_{s x}=2 \times 10^{-4} n_{x},
$$

where $n_{x}$ is the number of waste containers of chemical $x$ received annually at the facility. 


\subsubsection{Spill Plus Fire Scenario Frequencies}

The frequency of occurrence for subcategory $3 \mathrm{a}$ in Table 8.2 - the spill, ignition, and atmospheric release of chemical $x$ - is given by

$$
f_{s f x}=f_{s x} P_{f}
$$

where $P_{f}$ is the conditional probability of ignition (1.0E-01 for outdoor storage pads and $2.0 \mathrm{E}-01$ for enclosed facilities; see Section 2). The frequency of occurrence in accident subcategories $2 b-f$ (the spill and ignition of a flammable chemical, followed by fire propagation and release of chemical $y$ depends on the concurrent presence of the flammable initiator and the container with the toxic chemical contents:

$$
f_{s f y}=\left(2 \times 10^{-4} n_{f} P_{f} P_{f y}\right)+\left(2 \times 10^{-4} n_{y} P_{f}\right),
$$

where $n_{f}$ is the number of flammable chemical containers, and $P_{f y}$ is the conditional probability that fires involving the flammable chemicals propagate to and ignite the contents of drums containing chemical $y . P_{f y}$ is approximated by the ratio of the number of chemical $y$ drums to the total number of containers. The second term in the expression is added only when chemical $y$ is also flammable.

\subsubsection{Frequencies of Other Event Combinations}

Accident subcategory $3 \mathrm{a}$ involves a spill and subsequent fire, which then induces an explosion. EG\&G (1990) lists a value of 2.0E-02 for the annual probability of a fire-induced explosion sufficient to rupture the end-walls of a facility. The reference scenario herein assumes the explosion of a compressed gas cylinder engulfed in fire. The frequency is given by

$$
f_{s f y}=2 \times 10^{-4} n_{f} P_{f} P_{f y} P_{e} \text {, }
$$

where the probability $P_{f y}$ of a drum or cylinders being engulfed is estimated as the approximate fraction of drums containing compressed-gas cylinders and $P_{e}$, the conditional probability that the engulfed gas canister will explode, conservatively assumed to be 1 .

Fire-only scenarios ( $3 b$ and $c$ ) involve the inadvertent mixing of incompatible wastes. Human error probabilities between 1.0E-03 and 3.0E-03 are reported (Trusty et al. 1989; Sasser 
1992) for loading or sorting a chemical in the wrong place. Subsequent chemical reactions then generate enough heat to ignite the packaging material with a frequency estimated by

$$
f_{f r c}=3 \times 10^{-3} n_{r c},
$$

where $n_{r c}$ is the number of containers containing potentially reactive chemical $r c$ (or its equivalent) that are received annually at the facility. The surrogate toxic gas assumed to be released during the accident is $\mathrm{NH}_{3}$.

The fire may then spread to other containers and result in a release of toxic chemicals. However, the probability that a reaction among incompatible wastes will generate enough heat to ignite nearby combustible material is expected to be relatively small. The combustible material closest to the containers is usually a cardboard pallet, which requires temperatures higher than $232^{\circ} \mathrm{C}$ $\left(450^{\circ} \mathrm{F}\right)$ to ignite. Furthermore, the frequency with which containers of toxic waste are stored in proximity to the potential fire needs to be considered. Given the combination of events required for releases of other toxic gases, only the $\mathrm{NH}_{3}$ release is treated herein.

Accident subcategory $3 \mathrm{~d}$ involves a mechanical breach and subsequent explosion of cylinders of compressed gases. Such cylinders are expected to be stored inside drums, providing double-walled storage of the compressed gas. The annual frequency of double-walled container breach per unit handling operation is estimated at $1.0 \mathrm{E}-05$, implying an order of magnitude credit for the second containment. This estimate is probably conservative, given that conditional breach probabilities after a drop are estimated at $1.0 \mathrm{E}-02$. Thus, the frequency of a handling accident resulting in an explosion of compressed gas cylinder $x$ is conservatively estimated as

$$
f_{\text {secg }}=2 \times 10^{-5} n_{c g} \text {, }
$$

where $n_{c g}$ is the number of drums with compressed-gas containers received annually at the facility.

The spontaneous fire and explosion scenario (3e) corresponds to a waste fire and explosion induced by an error in the loading of the waste containers. Some chemicals react violently on contact and must be segregated. The gases produced by such reactions may produce enough pressure inside containers to cause explosions with resulting container failure. The frequency of this scenario is

$$
f_{\text {ferx }}=3 \times 10^{-3} n_{r x} \text {, }
$$

where $n_{r x}$ is the number of containers containing potentially reactive chemical $r x$ (or its equivalent) that are received annually at the facility. It should be noted that the spontaneous formation of 
peroxides upon exposure of ether to air, and the later ignition of those peroxides, is considered here to be an error in loading. Ether should never be stored for extended periods because of this potential accidence sequence.

\subsubsection{Storage Facility Accidents}

HW is generally packaged in 208-L (55-gal) drums and stored in RCRA-compliant staging areas or weather-protection sheds prior to off-site shipment for commercial treatment and disposal. An HWSF typically houses more than 100 different chemicals, which may include chlorinated solvents, acids, bases, photographic chemicals, ignitable solids and liquids, compressed gases, metal salts, polychlorinated biphenyls, asbestos, and other regulated wastes. Because explosives are generally prohibited, the important hazard characteristics include volatility, flammability, dispersibility, and toxicity. The HW is characterized and segregated on the basis of toxicity, corrosivity, reactivity, and ignitability. Most HWSFs have containment berm areas and individual storage cells that permit waste segregation per RCRA/EPA criteria, some have fire detection and suppression capability, and some have forced ventilation. Because of the great diversity of storage facility designs among the DOE sites, a generic facility with segregated storage (Figure 2.5 ) was assumed for the analyses.

A facilitywide fire has been chosen as the representative internal accident. This is the type of accident scenario considered as the maximum reasonably foreseeable accident in the INEL HWSF SAR (EG\&G 1990). It would engulf a large fraction of the facility, would involve secondary explosions and fire propagation from one area to another, and would consume numerous chemicals that vent hazardous substances upon combustion or heating.

External events have also been evaluated. The relevant chemicals identified in the operational accidents are assumed to be involved in the facility accident, with the amount of each chemical in facility sequences assumed proportional to the average number of drums at the facility. A facility fire is the dominant sequence for aircraft impacts; a large spill resulting from numerous breached containers is the dominant sequence for earthquakes.

Evaluation of Source Term Parameters and Frequencies. The chemicals in the facility fire source term are those identified as particularly hazardous in spills with fire (Table 8.2). The sum of the amounts of these particularly hazardous chemicals defines the MAR, the release rate and duration for each chemical are the same as that for the individual drum fires. The DF is assumed to be 1 , because the accident scenario assumes no mitigation. In the representative seismic event, it is assumed that $1 \%$ of the containers fall and break (DF of 1.0E-02), leading to a large spill of varied chemicals. The externally induced fires (large and small aircraft impacts) result in a combined MAR that includes the hazardous releases in a facilitywide fire plus the hazardous releases due to 
explosions caused by fires or impacts. The representative chemicals in these accidents are shown on Table 8.2. As in the case of facility fires, the DF for aircraft-induced accidents is taken as 1 because of the 90-day limit on storage of RCRA waste.

Conditional probabilities for ignition and fire attendant upon violent breach of flammable liquid packages are estimated to lie between 1.0E-01 and 1 (ORNL 1993). An initiating event frequency of $1.0 \mathrm{E}-02 / \mathrm{yr}$ for a fire involving local propagation is assumed here. A frequency of $1.0 \mathrm{E}-02$ for failure of the segregation design, the fire suppression systems, or manual procedures is assumed, yielding a resulting facilitywide fire frequency of $1.0 \mathrm{E}-04 / \mathrm{yr}$.

The frequencies of the external initiators are site-dependent as discussed in Section 2. A conditional probability of container breach of 1 has been used for large airplane impacts and of 9.0E-01 for small airplane impacts, consistent with the LLW storage facility analysis (LLW and HW are both generally packaged in DOT 208-L drums). For earthquakes, the best estimate (Coats and Murray 1984) of the annual frequency of events with a peak ground acceleration exceeding $0.15 \mathrm{~g}$ at the different sites is taken as the frequency of seismic initiation. A ground acceleration of $0.15 \mathrm{~g}$ is assumed to be the minimum acceleration required to topple drums in the upper rows of a storage array. A conditional probability of $2.0 \mathrm{E}-01$ for subsequent drum breach and spill, consistent with the LLW event tree analysis, has been used.

\subsubsection{Treatment Facility Accidents}

Evaluations have shown that incineration is the most risk-dominant thermal treatment technology for HW. Because SARs for both radioactive waste incinerators and commercial HW incinerators assign a high frequency to kiln explosions, the representative accident is taken to be an explosion that initiates a fire in the waste in the feedstock area. Three externally initiated events (large and small aircraft impacts and seismic events) igniting a feedstock fire are also analyzed. A generic treatment facility, consisting of a series of linked treatment process modules, was described in Section 2. A DOE Hazard Category of 2, concomitant performance of its systems, and doubleHEPA filtration systems were assumed.

Evaluation of Source Term Parameters and Frequencies. The representative source term chemicals are those that were identified as particularly hazardous in case of a fire. The MAR is a fraction of the annual throughput of the incineration facility as established by the WM PEIS alternative. Information from commercial facilities indicates that only a few containers (a few hours worth of throughput) are kept in the feedstock area. Therefore, 1\% of the annual throughput was assumed to be in the staging area. This fraction represents the amount of waste in processing and lag storage. The DF depends upon the magnitude of the initiator and is assumed to be $1.0 \mathrm{E}-01$ for an internal explosion, 2.0E-01 for seismic events and small plane crashes, and 3.0E-01 for large airplane impacts. These values were assumed because of the scattered physical locations of the waste 
in the treatment facility and the fact that only some of the chemicals in the feedstock area were identified as airborne release hazards in Table 8.2.

Estimates discussed in Section 2 of an annual frequency of 1.5E-02/yr for explosions in the rotary kiln assembly and the secondary combustion chamber, respectively, agree with the experience of commercial incineration operation and provide the basis for the internal fire frequencies used herein. The frequencies of aircraft-initiated accidents are site dependent. They were obtained in the same manner as for the storage facilities. The conditional probabilities of containment and confinement rupture and fire initiation are consistent with those in the LLW accident analysis: $4.5 \mathrm{E}-01$ and $1.0 \mathrm{E}-02$ for large and small airplane crashes, respectively. The annual frequency of a seismic event exceeding the design basis for a category 2 facility is $1.0 \mathrm{E}-03 / \mathrm{yr}$. As in the LLW facility accident analysis, the conditional probability of rupturing containment and initiating a fire is estimated at 5.0E-02.

\subsection{RESULTS}

The airborne release parameters for all accident types were shown in Table 8.2. Table 8.3 summarizes the estimated frequencies for the different handling accidents in the No Action Decentralized, Regionalized, and Centralized alternatives for each DOE site based on the appropriate surrogate chemical inventories. Single drum inventories are assumed for the handling accidents.

Tables 8.4 and 8.5 summarize the results for the storage and treatment facility accidents by site and alternative. The column labeled "Total Number Containers" represents the MAR, that is, the total number of containers with the relevant chemicals for each accident that are estimated to be involved in accidents at the facility. The "Number of Containers Breached" is the product of the containers at risk and the DF. The remaining columns in the tables provide the breakdown of the total number of containers involved in the accident for each of the various relevant surrogate chemicals. 
TABLE 8.3 Site-Dependent Annual Frequencies of Representative HW Handling Accidents

\begin{tabular}{|c|c|c|c|c|c|c|c|}
\hline \multirow{2}{*}{$\frac{\text { Site/Event }}{\text { Spill }^{a}}$} & \multicolumn{7}{|c|}{ Decentralized Alternative } \\
\hline & (1a) & (1b) & (lc) & (Id) & (le) & (lf) & $(\lg )$ \\
\hline ANL-E & $1.00 \mathrm{E}-03$ & $3.00 \mathrm{E}-03$ & $8.00 \mathrm{E}-04$ & $6.80 \mathrm{E}-03$ & $4.00 \mathrm{E}-04$ & $2.00 \mathrm{E}-04$ & $1.20 \mathrm{E}-03$ \\
\hline Fermi & $0.00 \mathrm{E}+00$ & $0.00 E+00$ & $0.00 \mathrm{E}+00$ & $8.00 \mathrm{E}-04$ & $0.00 \mathrm{E}+00$ & $0.00 \mathrm{E}+\infty$ & $2.00 \mathrm{E}-04$ \\
\hline Hanford & $1.80 \mathrm{E}-03$ & $1.00 \mathrm{E}-03$ & $4.00 \mathrm{E}-04$ & $7.20 \mathrm{E}-03$ & $4.00 \mathrm{E}-04$ & $0.00 \mathrm{E}+00$ & $3.20 \mathrm{E}-03$ \\
\hline INEL & $2.60 \mathrm{E}-03$ & $5.40 \mathrm{E}-03$ & $6.00 \mathrm{E}-04$ & $6.00 \mathrm{E}-03$ & $0.00 \mathrm{E}+00$ & $0.00 \mathrm{E}+00$ & $3.60 \mathrm{E}-03$ \\
\hline KCP & $1.60 \mathrm{E}-03$ & $0.00 \mathrm{E}+00$ & $0.00 \mathrm{E}+00$ & $2.00 \mathrm{E}-04$ & $0.00 \mathrm{E}+00$ & $0.00 \mathrm{E}+00$ & $0.00 \mathrm{E}+00$ \\
\hline LLNL & $6.40 \mathrm{E}-03$ & $3.08 \mathrm{E}-02$ & $4.40 \mathrm{E}-03$ & $5.84 \mathrm{E}-02$ & $7.60 \mathrm{E}-03$ & $.4 .00 \mathrm{E}-04$ & $2.26 \mathrm{E}-02$ \\
\hline LANL & $3.60 \mathrm{E}-03$ & $6.20 \mathrm{E}-03$ & $3.60 \mathrm{E}-03$ & $4.22 \mathrm{E}-02$ & $3.60 \mathrm{E}-03$ & $0.00 \mathrm{E}+00$ & $7.60 \mathrm{E}-03$ \\
\hline ORR & $0.00 \mathrm{E}+00$ & $0.00 E+00$ & $0.00 \mathrm{E}+00$ & $0.00 \mathrm{E}+00$ & $0.00 E+00$ & $0.00 \mathrm{E}+00$ & $1.00 \mathrm{E}-03$ \\
\hline Pantex & $0.00 \mathrm{E}+00$ & $2.20 \mathrm{E}-03$ & $4.00 \mathrm{E}-04$ & $1.22 \mathrm{E}-02$ & $2.00 \mathrm{E}-04$ & $0.00 \mathrm{E}+00$ & $0.00 \mathrm{E}+00$ \\
\hline SNL-NM & $4.20 \mathrm{E}-03$ & $0.00 \mathrm{E}+00$ & $8.20 \mathrm{E}-03$ & $2.96 \mathrm{E}-02$ & $8.00 \mathrm{E}-04$ & $0.00 \mathrm{E}+00$ & $6.40 \mathrm{E}-03$ \\
\hline SRS & $2.00 \mathrm{E}-04$ & $0.00 \mathrm{E}+00$ & $0.00 \mathrm{E}+00$ & $1.50 \mathrm{E}-02$ & $1.56 \mathrm{E}-02$ & $0.00 \mathrm{E}+00$ & $4.00 \mathrm{E}-04$ \\
\hline Spill Plus Fire ${ }^{a}$ & (2a) & (2b) & $(2 c)$ & (2d) & (2e) & $(2 f)$ & \\
\hline ANL-E & $8.00 \mathrm{E}-05$ & $7.29 \mathrm{E}-04$ & $3.19 \mathrm{E}-04$ & $1.00 \mathrm{E}-03$ & $1.82 \mathrm{E}-04$ & $1.37 \mathrm{E}-04$ & \\
\hline Fermi & $0.00 \mathrm{E}+00$ & $6.67 \mathrm{E}-05$ & $6.67 E-05$ & $1.78 \mathrm{E}-04$ & $0.00 E+00$ & $0.00 \mathrm{E}+\infty 0$ & \\
\hline Hanford & $4.00 \mathrm{E}-05$ & $7.58 \mathrm{E}-04$ & $9.48 \mathrm{E}-05$ & $2.13 \mathrm{E}-04$ & $1.90 \mathrm{E}-04$ & $7.11 \mathrm{E}-05$ & \\
\hline INEL & $6.00 \mathrm{E}-05$ & $1.34 \mathrm{E}-03$ & $7.17 \mathrm{E}-05$ & $2.15 \mathrm{E}-04$ & $7.89 \mathrm{E}-04$ & $2.63 E-04$ & \\
\hline $\mathrm{KCP}$ & $0.00 \mathrm{E}+00$ & $1.80 \mathrm{E}-03$ & $2.95 E-05$ & $5.60 \mathrm{E}-04$ & $1.18 \mathrm{E}-04$ & $0.00 \mathrm{E}+00$ & \\
\hline LLNL & 4.40E-04 & $8.09 \mathrm{E}-03$ & $5.04 \mathrm{E}-04$ & $1.20 \mathrm{E}-03$ & $8.16 \mathrm{E}-04$ & $3.12 \mathrm{E}-04$ & \\
\hline LANL & $3.60 \mathrm{E}-04$ & $3.20 \mathrm{E}-03$ & $3.45 \mathrm{E}-04$ & $0.00 \mathrm{E}+00$ & $5.98 \mathrm{E}-04$ & $4.37 \mathrm{E}-04$ & \\
\hline ORR & $0.00 \mathrm{E}+00$ & $2.51 \mathrm{E}-03$ & $0.00 \mathrm{E}+00$ & $3.81 E-05$ & $3.81 \mathrm{E}-05$ & $0.00 \mathrm{E}+00$ & \\
\hline Pantex & $4.00 \mathrm{E}-05$ & $2.48 \mathrm{E}-03$ & $5.52 \mathrm{E}-05$ & $5.52 \mathrm{E}-04$ & $3.31 \mathrm{E}-04$ & $0.00 \mathrm{E}+\infty$ & \\
\hline SNL-NM & $8.20 \mathrm{E}-04$ & $2.74 \mathrm{E}-03$ & $3.62 \mathrm{E}-04$ & $3.28 \mathrm{E}-03$ & $2.31 \mathrm{E}-03$ & $3.85 \mathrm{E}-04$ & \\
\hline SRS & $0.00 \mathrm{E}+\infty$ & $7.24 \mathrm{E}-03$ & $2.78 \mathrm{E}-05$ & $2.31 \mathrm{E}-03$ & $2.37 \mathrm{E}-03$ & $0.00 \mathrm{E}+00$ & \\
\hline Other ${ }^{a}$ & (3a) & (3b) & (3c) & (3d) & (3e) & & \\
\hline ANL-E & $1.39 \mathrm{E}-05$ & $3.00 \mathrm{E}-03$ & $9.30 \mathrm{E}-02$ & $2.80 \mathrm{E}-04$ & $1.20 \mathrm{E}-02$ & & \\
\hline Fermi & $0.00 \mathrm{E}+00$ & $0.00 \mathrm{E}+00$ & $3.00 \mathrm{E}-03$ & $1.40 \mathrm{E}-04$ & $0.00 \mathrm{E}+00$ & & \\
\hline Hanford & $3.33 \mathrm{E}-05$ & $3.00 \mathrm{E}-03$ & $6.60 \mathrm{E}-02$ & $1.40 \mathrm{E}-04$ & $1.20 \mathrm{E}-02$ & & \\
\hline INEL & $5.09 \mathrm{E}-05$ & $3.00 \mathrm{E}-03$ & $1.47 \mathrm{E}-01$ & $1.60 \mathrm{E}-04$ & $2.70 \mathrm{E}-02$ & & \\
\hline $\mathrm{KCP}$ & $7.57 \mathrm{E}-05$ & $3.00 \mathrm{E}-03$ & $9.00 \mathrm{E}-03$ & $4.40 \mathrm{E}-04$ & $3.00 \mathrm{E}-03$ & & \\
\hline LLNL & $1.28 \mathrm{E}-04$ & $1.20 \mathrm{E}-02$ & $5.04 \mathrm{E}-01$ & $6.40 \mathrm{E}-03$ & $1.02 \mathrm{E}-01$ & & \\
\hline LANL & $5.39 \mathrm{E}-05$ & $1.80 \mathrm{E}-02$ & $8.16 \mathrm{E}-01$ & $1.48 \mathrm{E}-03$ & $2.40 \mathrm{E}-02$ & & \\
\hline ORR & $0.00 \mathrm{E}+00$ & $0.00 \mathrm{E}+00$ & $0.00 \mathrm{E}+00$ & $0.00 \mathrm{E}+00$ & $0.00 \mathrm{E}+00$ & & \\
\hline Pantex & $0.00 \mathrm{E}+00$ & $3.00 \mathrm{E}-03$ & $1.02 \mathrm{E}-01$ & $0.00 \mathrm{E}+00$ & $3.00 \mathrm{E}-03$ & & \\
\hline SNL-NM & $5.57 \mathrm{E}-05$ & $8.40 \mathrm{E}-02$ & $2.67 \mathrm{E}-01$ & $1.26 \mathrm{E}-03$ & $6.90 \mathrm{E}-02$ & & \\
\hline SRS & $7.84 \mathrm{E}-06$ & $0.00 \mathrm{E}+00$ & $2.10 \mathrm{E}-01$ & $0.00 \mathrm{E}+00$ & $2.10 \mathrm{E}-02$ & & \\
\hline
\end{tabular}




\section{TABLE 8.3 (Cont.)}

\begin{tabular}{|c|c|c|c|c|c|c|c|}
\hline \multirow{2}{*}{$\frac{\text { Site/Event }}{\text { Spill }^{a}}$} & \multicolumn{7}{|c|}{ Regionalized Alternative } \\
\hline & (la) & (1b) & (lc) & (ld) & (le) & (1f) & $(\mathrm{lg})$ \\
\hline Hanford & $8.20 \mathrm{E}-03$ & $3.22 \mathrm{E}-02$ & $4.80 \mathrm{E}-03$ & $6.56 \mathrm{E}-02$ & $8.00 \mathrm{E}-03$ & $4.00 \mathrm{E}-04$ & $2.58 \mathrm{E}-02$ \\
\hline INEL & $2.60 \mathrm{E}-03$ & $5.40 \mathrm{E}-03$ & $6.00 \mathrm{E}-04$ & $6.00 \mathrm{E}-03$ & $0.00 \mathrm{E}+00$ & $0.00 \mathrm{E}+00$ & $3.60 \mathrm{E}-03$ \\
\hline LANL & $7.80 \mathrm{E}-03$ & $8.40 \mathrm{E}-03$ & $1.22 \mathrm{E}-02$ & $8.40 \mathrm{E}-02$ & $4.60 \mathrm{E}-03$ & $0.00 \mathrm{E}+00$ & $1.40 \mathrm{E}-02$ \\
\hline ORR & $2.60 \mathrm{E}-03$ & $3.00 \mathrm{E}-03$ & $8.00 \mathrm{E}-04$ & $7.80 \mathrm{E}-03$ & $4.00 \mathrm{E}-04$ & $2.00 \mathrm{E}-04$ & $2.40 \mathrm{E}-03$ \\
\hline SRS & $2.00 \mathrm{E}-04$ & $0.00 \mathrm{E}+00$ & $0.00 \mathrm{E}+00$ & $1.50 \mathrm{E}-02$ & $1.56 \mathrm{E}-02$ & $0.00 E+00$ & $4.00 \mathrm{E}-04$ \\
\hline Spill Plus Fire ${ }^{a}$ & (2a) & (2b) & (2c) & (2d) & (2e) & $(2 f)$ & \\
\hline Hanford & $4.80 \mathrm{E}-04$ & $7.38 \mathrm{E}-03$ & $5.00 \mathrm{E}-04$ & $1.18 \mathrm{E}-03$ & $8.40 \mathrm{E}-04$ & $3.20 \mathrm{E}-04$ & \\
\hline INEL & $6.00 \mathrm{E}-05$ & $1.12 E-03$ & $6.00 \mathrm{E}-05$ & $1.80 \mathrm{E}-04$ & $6.60 \mathrm{E}-04$ & $2.20 \mathrm{E}-04$ & \\
\hline LANL & $1.22 \mathrm{E}-03$ & $7.00 \mathrm{E}-03$ & $6.60 \mathrm{E}-04$ & $3.30 \mathrm{E}-03$ & $2.80 \mathrm{E}-03$ & $7.20 \mathrm{E}-04$ & \\
\hline ORR & $8.00 \mathrm{E}-05$ & $3.24 \mathrm{E}-03$ & $3.60 \mathrm{E}-04$ & $1.44 \mathrm{E}-03$ & $2.60 \mathrm{E}-04$ & $1.20 \mathrm{E}-04$ & \\
\hline SRS & $0.00 \mathrm{E}+\infty$ & $5.20 \mathrm{E}-03$ & $2.00 \mathrm{E}-05$ & $1.66 \mathrm{E}-03$ & $1.70 \mathrm{E}-03$ & $0.00 \mathrm{E}+00$ & \\
\hline Other ${ }^{a}$ & (3a) & (3b) & (3c) & (3d) & (3e) & & \\
\hline Hanford & $7.85 \mathrm{E}-09$ & $1.50 \mathrm{E}-02$ & $5.70 \mathrm{E}-01$ & $6.54 \mathrm{E}-03$ & $1.14 \mathrm{E}-01$ & & \\
\hline INEL & $0.00 \mathrm{E}+00$ & $3.00 \mathrm{E}-03$ & $1.47 \mathrm{E}-01$ & $1.60 \mathrm{E}-04$ & $2.70 \mathrm{E}-02$ & & \\
\hline LANL & $0.00 \mathrm{E}+00$ & $1.05 \mathrm{E}-01$ & $1.19 \mathrm{E}+00$ & $2.74 \mathrm{E}-03$ & $9.60 \mathrm{E}-02$ & & \\
\hline ORR & $7.28 \mathrm{E}-09$ & $6.00 \mathrm{E}-03$ & $1.05 \mathrm{E}-01$ & $8.60 \mathrm{E}-04$ & $1.50 \mathrm{E}-02$ & & \\
\hline SRS & $0.00 \mathrm{E}+00$ & $0.00 \mathrm{E}+00$ & $2.10 \mathrm{E}-01$ & $0.00 \mathrm{E}+00$ & $2.10 \mathrm{E}-02$ & & \\
\hline Site/Event & \multicolumn{7}{|c|}{ Centralized Alternative } \\
\hline Spill $^{a}$ & (1a) & (1b) & (1c) & (1d) & (le) & (1f) & (lg) \\
\hline East & $2.80 \mathrm{E}-03$ & $3.00 \mathrm{E}-03$ & $8.00 \mathrm{E}-04$ & $2.28 \mathrm{E}-02$ & $1.60 \mathrm{E}-02$ & $2.00 \mathrm{E}-04$ & $2.80 \mathrm{E}-03$ \\
\hline West & $1.86 \mathrm{E}-02$ & 4.60E-02 & $1.76 \mathrm{E}-02$ & $1.56 \mathrm{E}-01$ & $1.26 \mathrm{E}-02$ & $4.00 \mathrm{E}-04$ & $4.34 \mathrm{E}-02$ \\
\hline Spill Plus Fire ${ }^{a}$ & (2a) & (2b) & $(2 c)$ & (2d) & (2e) & $(2 f)$ & \\
\hline East & $8.00 \mathrm{E}-05$ & 8.44E-03 & $3.80 \mathrm{E}-04$ & $3.10 \mathrm{E}-03$ & $1.96 \mathrm{E}-03$ & $1.20 \mathrm{E}-04$ & \\
\hline West & $1.76 \mathrm{E}-03$ & $1.55 \mathrm{E}-02$ & $1.22 \mathrm{E}-03$ & $4.66 \mathrm{E}-03$ & $4.31 \mathrm{E}-03$ & $1.26 \mathrm{E}-03$ & \\
\hline \multicolumn{8}{|l|}{ Other } \\
\hline & (3a) & (3b) & $(3 c)$ & (3d) & (3e) & & \\
\hline East & $7.41 \mathrm{E}-09$ & $6.00 \mathrm{E}-03$ & $3.15 \mathrm{E}-01$ & $8.60 \mathrm{E}-04$ & $3.60 \mathrm{E}-02$ & & \\
\hline West & $3.76 \mathrm{E}-09$ & $1.23 \mathrm{E}-01$ & $1.90 \mathrm{E}+00$ & $9.44 \mathrm{E}-03$ & $2.37 \mathrm{E}-01$ & & \\
\hline
\end{tabular}

a Refer to Table 8.2 for definitions of accidents and released chemicals. 
TABLE 8.4 Frequencies and Source Term Parameters for WM HW Storage Facility Accidents

\begin{tabular}{|c|c|c|c|c|c|c|c|c|c|c|c|c|}
\hline \multirow{2}{*}{$\begin{array}{c}\text { WM PEIS } \\
\text { Alternative }^{\mathfrak{a}} \\
\text { Representative }\end{array}$} & \multirow[t]{2}{*}{ Site } & \multirow[t]{2}{*}{$\begin{array}{c}\text { Accident } \\
\text { Frequency } \\
(/ y r) \\
\end{array}$} & \multirow[t]{2}{*}{$\begin{array}{c}\text { Total } \\
\text { Number of } \\
\text { Containers } \\
\end{array}$} & \multirow[t]{2}{*}{$\begin{array}{l}\text { Damage } \\
\text { Fraction } \\
\end{array}$} & \multirow[t]{2}{*}{$\begin{array}{c}\text { Number of } \\
\text { Containers } \\
\text { Breached } \\
\end{array}$} & \multicolumn{6}{|c|}{$\begin{array}{l}\text { Representative Subcategory Chemical } \\
\text { Containers Involved }\end{array}$} & \\
\hline & & & & & & (2a) & (2b) & (2c) & (2d) & (2e) & (2f) & \\
\hline \multirow[t]{11}{*}{1} & INEL & $1.0 \mathrm{E}-04$ & 29 & $1.0 \mathrm{E}+00$ & 29 & 14 & 1 & 1 & 2 & 8 & 3 & \\
\hline & $\mathrm{KCP}$ & $1.0 \mathrm{E}-04$ & 21 & $1.0 \mathrm{E}+00$ & 21 & 15 & 0 & 0 & 5 & 1 & 0 & \\
\hline & LLNL & $1.0 \mathrm{E}-04$ & 119 & $1.0 \mathrm{E}+00$ & 119 & 84 & 6 & 5 & 13 & 8 & 3 & \\
\hline & LANL & $1.0 \mathrm{E}-04$ & 56 & $1.0 \mathrm{E}+00$ & 56 & 35 & 5 & 4 & 0 & 7 & 5 & \\
\hline & ORR & $1.0 \mathrm{E}-04$ & 17 & $1.0 \mathrm{E}+00$ & 17 & 17 & 0 & 0 & 0 & 0 & 0 & \\
\hline & Pantex & $1.0 \mathrm{E}-04$ & 33 & $1.0 \mathrm{E}+00$ & 33 & 23 & 1 & 1 & 5 & 3 & 0 & \\
\hline & Hanford & $1.0 \mathrm{E}-04$ & 15 & $1.0 \mathrm{E}+00$ & 15 & 8 & 1 & 1 & 2 & 2 & 1 & \\
\hline & SNL-NM & $1.0 \mathrm{E}-04$ & 109 & $1.0 \mathrm{E}+00$ & 109 & 30 & 10 & 4 & 36 & 25 & 4 & \\
\hline & SRS & $1.0 \mathrm{E}-04$ & 107 & $1.0 \mathrm{E}+00$ & 107 & 65 & 0 & 0 & 21 & 21 & 0 & \\
\hline & ANL-E & $1.0 \mathrm{E}-04$ & 28 & $1.0 \mathrm{E}+00$ & 28 & 8 & 1 & 4 & 11 & 2 & 2 & \\
\hline & Fermi & $1.0 \mathrm{E}-04$ & 4 & $1.0 \mathrm{E}+00$ & 4 & 1 & 0 & 1 & 2 & 0 & 0 & \\
\hline \multirow[t]{5}{*}{2} & INEL & $1.0 \mathrm{E}-04$ & 29 & $1.0 \mathrm{E}+00$ & 29 & 14 & 1 & 1 & 2 & 8 & 3 & \\
\hline & Hanford & $1.0 \mathrm{E}-04$ & 94 & $1.0 \mathrm{E}+00$ & 94 & 64 & 5 & 4 & 11 & 7 & 3 & \\
\hline & LANL & $1.0 \mathrm{E}-04$ & 151 & $1.0 \mathrm{E}+00$ & 151 & 69 & 12 & 7 & 27 & 26 & 8 & \\
\hline & ORR & $1.0 \mathrm{E}-04$ & 52 & $1.0 \mathrm{E}+00$ & 52 & 33 & 1 & 3 & 12 & 2 & 1 & \\
\hline & SRS & $1.0 \mathrm{E}-04$ & 107 & $1.0 \mathrm{E}+00$ & 107 & 65 & 0 & 0 & 21 & 21 & 0 & \\
\hline \multirow[t]{2}{*}{3} & INEL & $1.0 \mathrm{E}-04$ & 361 & $1.0 \mathrm{E}+00$ & 361 & 194 & 24 & 16 & 58 & 53 & 16 & \\
\hline & ORR & $1.0 \mathrm{E}-04$ & 177 & $1.0 \mathrm{E}+00$ & 177 & 106 & 1 & 5 & 39 & 24 & 2 & \\
\hline Seismic Events & & & & & & (1a) & (lb) & (Ic) & (1d) & (le) & (1f) & (1g) \\
\hline \multirow[t]{11}{*}{1} & INEL & $1.8 \mathrm{E}-04$ & 24 & $1.0 \mathrm{E}-02$ & 0 & 0 & 0 & 0 & 0 & 0 & 0 & 0 \\
\hline & $\mathrm{KCP}$ & $6.0 \mathrm{E}-05$ & 2 & $1.0 \mathrm{E}-02$ & 0 & 0 & 0 & 0 & 0 & 0 & 0 & 0 \\
\hline & LLNL & $1.0 \mathrm{E}-03$ & 165 & $1.0 \mathrm{E}-02$ & 2 & 0 & 1 & 0 & 1 & 0 & 0 & 0 \\
\hline & LANL & $6.0 \mathrm{E}-04$ & 86 & $1.0 \mathrm{E}-02$ & 1 & 0 & 0 & 0 & 1 & 0 & 0 & 0 \\
\hline & ORR & $4.0 \mathrm{E}-04$ & 1 & $1.0 \mathrm{E}-02$ & 0 & 0 & 0 & 0 & 0 & 0 & 0 & 0 \\
\hline & Pantex & $6.0 \mathrm{E}-05$ & 19 & $1.0 \mathrm{E}-02$ & 0 & 0 & 0 & 0 & 0 & 0 & 0 & 0 \\
\hline & Hanford & $6.0 \mathrm{E}-05$ & 19 & $1.0 \mathrm{E}-02$ & 0 & 0 & 0 & 0 & 0 & 0 & 0 & 0 \\
\hline & SNL-NM & $6.0 \mathrm{E}-04$ & 61 & $1.0 \mathrm{E}-02$ & 1 & 0 & 0 & 0 & 1 & 0 & 0 & 0 \\
\hline & SRS & $8.0 \mathrm{E}-05$ & 40 & $1.0 \mathrm{E}-02$ & 0 & 0 & 0 & 0 & 0 & 0 & 0 & 0 \\
\hline & ANL-E & $1.0 \mathrm{E}-04$ & 17 & $1.0 \mathrm{E}-02$ & 0 & 0 & 0 & 0 & 0 & 0 & 0 & 0 \\
\hline & Fermi & $1.0 \mathrm{E}-04$ & 1 & $1.0 \mathrm{E}-02$ & 0 & 0 & 0 & 0 & 0 & 0 & 0 & 0 \\
\hline
\end{tabular}


TABLE 8.4 (Cont.)

\begin{tabular}{|c|c|c|c|c|c|c|c|c|c|c|c|c|c|}
\hline \multirow{2}{*}{$\begin{array}{c}\text { WM PEIS } \\
\text { Alternative }^{\mathrm{a}} \\
2\end{array}$} & \multirow{2}{*}{$\frac{\text { Site }}{\text { INEL }}$} & \multirow{2}{*}{$\begin{array}{c}\begin{array}{c}\text { Accident } \\
\text { Frequency } \\
(/ \mathrm{yr})\end{array} \\
1.8 \mathrm{E}-04\end{array}$} & \multirow{2}{*}{$\begin{array}{c}\text { Total } \\
\text { Number of } \\
\text { Containers }\end{array}$} & \multirow{2}{*}{$\begin{array}{c}\text { Damage } \\
\text { Fraction } \\
1.0 \mathrm{E}-02\end{array}$} & \multirow{2}{*}{$\begin{array}{c}\text { Number of } \\
\text { Containers } \\
\text { Breached } \\
0\end{array}$} & \multicolumn{8}{|c|}{$\begin{array}{c}\text { Representative Subcategory Chemical } \\
\text { Containers Involved }\end{array}$} \\
\hline & & & & & & $\mathbf{0}$ & 0 & 0 & 0 & 0 & 0 & 0 & \\
\hline & Hanford & $6.0 \mathrm{E}-05$ & 129 & $1.0 \mathrm{E}-02$ & 1 & $\mathbf{0}$ & 0 & 0 & 1 & 0 & 0 & 0 & \\
\hline & LANL & $6.0 \mathrm{E}-04$ & 139 & $1.0 \mathrm{E}-02$ & 1 & 0 & 0 & 0 & 1 & 0 & 0 & 0 & \\
\hline & ORR & $4.0 \mathrm{E}-04$ & 14 & $1.0 \mathrm{E}-02$ & 0 & 0 & 0 & 0 & 0 & 0 & 0 & 0 & \\
\hline & SRS & $8.0 \mathrm{E}-05$ & 40 & $1.0 \mathrm{E}-02$ & 0 & 0 & 0 & 0 & 0 & 0 & 0 & 0 & \\
\hline 3 & INEL & $1.8 \mathrm{E}-04$ & 374 & $1.0 \mathrm{E}-02$ & 4 & $\mathbf{0}$ & 1 & 0 & 2 & 0 & 0 & 1 & \\
\hline & ORR & $4.0 \mathrm{E}-04$ & 61 & $1.0 \mathrm{E}-02$ & 1 & 0 & 0 & 0 & 1 & 0 & 0 & 0 & \\
\hline \multicolumn{2}{|c|}{ Large Aircraft Impacts } & & & & & $(2 a)$ & (2b) & (2c) & (2d) & (2e) & $(2 f)$ & (3a) & (3d) \\
\hline 1 & INEL & $2.0 \mathrm{E}-09$ & 34 & $1.0 \mathrm{E}+00$ & 34 & 14 & 1 & 1 & 2 & 8 & 3 & 3 & 2 \\
\hline & KCP & $N A^{c}$ & 29 & NA & $\mathrm{NA}$ & NA & NA & NA & NA & NA & NA & NA & NA \\
\hline & LLNL & NA & 207 & NA & $\mathrm{NA}$ & NA & NA & NA & $\mathrm{NA}$ & NA & NA & $\mathrm{NA}$ & NA \\
\hline & LANL & NA & 80 & NA & $\mathrm{NA}$ & NA & $\mathrm{NA}$ & NA & NA & NA & NA & $\mathrm{NA}$ & NA \\
\hline & ORR & NA & 17 & NA & $\mathrm{NA}$ & $\mathrm{NA}$ & $\mathrm{NA}$ & NA & NA & NA & $\mathrm{NA}$ & $\mathrm{NA}$ & NA \\
\hline & Pantex & $2.3 \mathrm{E}-07$ & 33 & $1.0 \mathrm{E}+00$ & 33 & 23 & 1 & 1 & 5 & 3 & 0 & 0 & 0 \\
\hline & Hanford & $8.5 \mathrm{E}-09$ & 19 & $1.0 \mathrm{E}+00$ & 19 & 8 & 1 & 1 & 2 & 2 & 1 & 2 & 2 \\
\hline & SNL-NM & $2.1 \mathrm{E}-05$ & 130 & $1.0 \mathrm{E}+00$ & 130 & 30 & 10 & 4 & 36 & 25 & 4 & 5 & 16 \\
\hline & SRS & $8.2 \mathrm{E}-09$ & 107 & $1.0 \mathrm{E}+00$ & 107 & 65 & 0 & 0 & 21 & 21 & 0 & 0 & 0 \\
\hline & ANL-E & NA & 33 & NA & $\mathrm{NA}$ & NA & NA & NA & $\mathrm{NA}$ & NA & NA & $\mathrm{NA}$ & NA \\
\hline & Fermi & NA & 6 & NA & NA & NA & NA & NA & NA & NA & NA & NA & NA \\
\hline \multirow[t]{5}{*}{2} & INEL & $2.0 \mathrm{E}-09$ & 34 & $1.0 \mathrm{E}+00$ & 34 & 14 & 1 & 1 & 2 & 8 & 3 & 3 & 2 \\
\hline & Hanford & 8.5E-09 & 157 & $1.0 \mathrm{E}+00$ & 157 & 64 & 5 & 4 & 11 & 7 & 3 & 7 & 3 \\
\hline & LANL & NA & 189 & NA & NA & NA & NA & NA & NA & NA & NA & NA & NA \\
\hline & ORR & NA & 62 & NA & NA & NA & NA & NA & NA & $\mathrm{NA}$ & NA & NA & NA \\
\hline & SRS & $8.2 \mathrm{E}-09$ & 107 & $1.0 \mathrm{E}+00$ & 107 & 65 & 0 & 0 & 21 & 21 & 0 & 0 & 0 \\
\hline \multirow[t]{2}{*}{3} & INEL & $2.0 \mathrm{E}-09$ & 503 & $1.0 \mathrm{E}+00$ & 503 & 194 & 24 & 16 & 58 & 53 & 16 & 23 & 119 \\
\hline & ORR & NA & 192 & NA & $\mathrm{NA}$ & NA & NA & NA & NA & NA & NA & NA & NA \\
\hline \multicolumn{14}{|c|}{ Small Aircraft Impacts } \\
\hline \multirow[t]{7}{*}{1} & INEL & NA & 34 & NA & NA & NA & NA & NA & NA & NA & NA & $\mathrm{NA}$ & NA \\
\hline & KCP & $2.7 \mathrm{E}-07$ & 29 & $1.0 \mathrm{E}+00$ & 29 & 15 & 0 & 0 & 5 & 1 & 0 & 2 & 6 \\
\hline & LLNL & 2.7E-07 & 207 & $1.0 \mathrm{E}+00$ & 207 & 84 & 6 & 5 & 13 & 8 & 3 & 8 & 80 \\
\hline & LANL & $2.7 \mathrm{E}-07$ & 80 & $1.0 \mathrm{E}+00$ & 80 & 35 & 5 & 4 & 0 & 7 & 5 & 5 & 19 \\
\hline & ORR' & $2.7 \mathrm{E}-07$ & 17 & $1.0 \mathrm{E}+00$ & 17 & 17 & 0 & 0 & 0 & 0 & 0 & 0 & 0 \\
\hline & Pantex & NA & 33 & NA & NA & NA & NA & NA & $\mathrm{NA}$ & NA & NA & NA & NA \\
\hline & Hanford & NA & 19 & NA & NA & NA & $\mathrm{NA}$ & NA & $\mathrm{NA}$ & $\mathrm{NA}$ & $\mathrm{NA}$ & NA & $\mathrm{NA}$ \\
\hline
\end{tabular}


TABLE 8.4 (Cont.)

\begin{tabular}{|c|c|c|c|c|c|c|c|c|c|c|c|c|c|}
\hline \multirow[t]{2}{*}{$\begin{array}{l}\text { WM PEIS } \\
\text { Alternative }^{\mathrm{a}}\end{array}$} & \multirow{2}{*}{$\frac{\text { Site }}{\text { SNL-NM }}$} & \multirow{2}{*}{$\begin{array}{c}\begin{array}{c}\text { Accident } \\
\text { Frequency } \\
(/ \mathrm{yr})\end{array} \\
\frac{\mathrm{NA}}{}\end{array}$} & \multirow{2}{*}{$\begin{array}{c}\begin{array}{c}\text { Total } \\
\text { Number of } \\
\text { Containers }\end{array} \\
130\end{array}$} & \multirow{2}{*}{$\begin{array}{c}\begin{array}{c}\text { Damage } \\
\text { Fraction }\end{array} \\
\text { NA }\end{array}$} & \multirow{2}{*}{$\begin{array}{c}\begin{array}{c}\text { Number of } \\
\text { Containers } \\
\text { Breached }\end{array} \\
\text { NA }\end{array}$} & \multicolumn{8}{|c|}{$\begin{array}{l}\text { Representative Subcategory Chemical } \\
\text { Containers Involved }\end{array}$} \\
\hline & & & & & & NA & NA & NA & NA & NA & NA & NA & NA \\
\hline \multirow{8}{*}{2} & SRS & NA & 107 & NA & NA & $\mathrm{NA}$ & NA & NA & NA & NA & $\mathrm{NA}$ & NA & NA \\
\hline & ANL-E & 2.7E-07 & 33 & $1.0 \mathrm{E}+00$ & 33 & 8 & 1 & 4 & 11 & 2 & 2 & 1 & 4 \\
\hline & Fermi & 2.7E-07 & 6 & $1.0 \mathrm{E}+00$ & 6 & 1 & 0 & 1 & 2 & 0 & 0 & 0 & 2 \\
\hline & INEL & NA & 34 & NA & NA & NA & NA & NA & $\mathrm{NA}$ & $\mathrm{NA}$ & NA & NA & NA \\
\hline & Hanford & $\mathrm{NA}$ & 157 & NA & $\mathrm{NA}$ & $\mathrm{NA}$ & $\mathrm{NA}$ & NA & NA & NA & NA & NA & NA \\
\hline & LANL & $2.7 \mathrm{E}-07$ & 189 & $1.0 \mathrm{E}+00$ & 189 & 71 & 12 & 7 & 27 & 26 & 8 & 8 & 30 \\
\hline & ORR & $2.7 \mathrm{E}-07$ & 62 & $1.0 \mathrm{E}+00$ & 62 & 33 & 1 & 3 & 12 & 2 & $i$ & 2 & 8 \\
\hline & SRS & NA & 107 & $\mathrm{NA}$ & NA & $\mathrm{NA}$ & NA & NA & NA & NA & NA & NA & NA \\
\hline \multirow[t]{2}{*}{3} & INEL & $\mathrm{NA}$ & 503 & NA & $\mathrm{NA}$ & $\mathrm{NA}$ & $\mathrm{NA}$ & $\mathrm{NA}$ & NA & NA & NA & NA & NA \\
\hline & ORR & $2.7 \mathrm{E}-07$ & 192 & $1.0 \mathrm{E}+00$ & 192 & 106 & 1 & 5 & 39 & 24 & 2 & 3 & 12 \\
\hline
\end{tabular}

a Case 1 is the No Action/Decentralized Altemative with two treatment sites, Case 2 is the Regionalized 1 Alternative with five treatment sites, and Case 3 is the Regionalized 2 Alternative with two treatment sites.

b Refer to Table 8.2 for definitions of released chemicals.

c $\mathrm{NA}=$ not applicable. 
TABLE 8.5 Frequencies and Source Term Parameters for WM HW Incineration Facility Accidents

\begin{tabular}{|c|c|c|c|c|c|c|c|c|c|c|c|}
\hline \multirow{2}{*}{$\begin{array}{l}\text { WM PEIS } \\
\text { Alternative }^{3}\end{array}$} & \multirow[b]{2}{*}{ Site } & \multirow{2}{*}{$\begin{array}{c}\text { Accident } \\
\text { Frequency } \\
(/ \mathrm{yr})\end{array}$} & \multirow{2}{*}{$\begin{array}{c}\text { Total } \\
\text { Number of } \\
\text { Containers }\end{array}$} & \multirow{2}{*}{$\begin{array}{l}\text { Damage } \\
\text { Fraction } \\
\end{array}$} & \multirow{2}{*}{$\begin{array}{c}\text { Number of } \\
\text { Containers } \\
\text { Breached }\end{array}$} & \multicolumn{6}{|c|}{$\begin{array}{c}\text { Representative Subcategory Chemital } \\
\text { Containers Involved }{ }^{\mathbf{b}}\end{array}$} \\
\hline & & & & & & (2a) & $(2 b)$ & (2c) & (2d) & (2e) & $(2 \mathrm{f})$ \\
\hline \multicolumn{12}{|c|}{ Representative Fire } \\
\hline \multirow[t]{5}{*}{2} & INEL & $1.5 E-02$ & 20 & $1.0 \mathrm{E}-01$ & 2 & 1 & 0 & 0 & 0 & 1 & 0 \\
\hline & LANL & $1.5 \mathrm{E}-02$ & 50 & $1.0 \mathrm{E}-01$ & 5 & 3 & 0 & 0 & 1 & 1 & 0 \\
\hline & ORR & $1.5 \mathrm{E}-02$ & 50 & $1.0 \mathrm{E}-01$ & 5 & 2 & 1 & 0 & 1 & 1 & 0 \\
\hline & Hanford & $1.5 \mathrm{E}-02$ & 30 & $1.0 \mathrm{E}-01$ & 3 & 2 & 0 & 0 & 1 & 0 & 0 \\
\hline & SRS & $1.5 \mathrm{E}-02$ & 20 & $1.0 \mathrm{E}-01$ & 2 & 1 & 0 & 0 & 1 & 0 & 0 \\
\hline \multirow[t]{2}{*}{3} & INEL & $1.5 \mathrm{E}-02$ & 80 & $1.0 \mathrm{E}-01$ & 8 & 5 & 1 & 0 & 1 & 1 & 0 \\
\hline & ORR & $1.5 \mathrm{E}-02$ & 80 & $1.0 \mathrm{E}-01$ & 8 & 5 & 0 & 0 & 2 & 1 & 0 \\
\hline \multicolumn{12}{|l|}{ Seismic Events } \\
\hline \multirow[t]{5}{*}{2} & INEL & $5.0 \mathrm{E}-05$ & 20 & $2.0 \mathrm{E}-01$ & 4 & 2 & 0 & 0 & 0 & 1 & 1 \\
\hline & LANL & $5.0 \mathrm{E}-05$ & 50 & $2.0 E-01$ & 10 & 7 & 1 & 0 & 1 & 1 & 0 \\
\hline & ORR & $5.0 \mathrm{E}-05$ & 50 & $2.0 \mathrm{E}-01$ & 10 & 5 & 1 & 0 & 2 & 2 & 0 \\
\hline & Hanford & $5.0 \mathrm{E}-05$ & 30 & $2.0 \mathrm{E}-0 \mathrm{I}$ & 6 & 4 & 0 & 1 & 1 & 0 & 0 \\
\hline & SRS & $5.0 \mathrm{E}-05$ & 20 & $2.0 \mathrm{E}-0 \mathrm{I}$ & 4 & 2 & 0 & 0 & 1 & 1 & 0 \\
\hline \multirow[t]{2}{*}{3} & INEL & $5.0 \mathrm{E}-05$ & 80 & $2.0 \mathrm{E}-01$ & 16 & 9 & 1 & 1 & 3 & 2 & 0 \\
\hline & ORR & $5.0 \mathrm{E}-05$ & 80 & $2.0 E-01$ & 16 & 10 & 0 & 1 & 3 & 2 & 0 \\
\hline \multicolumn{12}{|c|}{ Large Aircraft Impacts } \\
\hline \multirow[t]{5}{*}{2} & INEL & $1.2 \mathrm{E}-09$ & 20 & $3.0 \mathrm{E}-01$ & 6 & 3 & 0 & 0 & 0 & 2 & 1 \\
\hline & LANL & $N A^{c}$ & NA & NA & NA & NA & NA & NA & NA & NA & NA \\
\hline & ORR & NA & NA & NA & $\mathbf{N A}$ & NA & NA & NA & NA & NA & NA \\
\hline & Hanford & $5.4 \mathrm{E}-09$ & 30 & $3.0 \mathrm{E}-01$ & 9 & 6 & 0 & I & 2 & 0 & 0 \\
\hline & SRS & $5.0 \mathrm{E}-09$ & 20 & $3.0 \mathrm{E}-01$ & 6 & 4 & 0 & 0 & 1 & 1 & 0 \\
\hline \multirow[t]{2}{*}{3} & INEL & $2.7 \mathrm{E}-09$ & 80 & $3.0 \mathrm{E}-01$ & 24 & 12 & 2 & 1 & 4 & 4 & 1 \\
\hline & ORR & NA & NA & NA & $\mathrm{NA}$ & NA & NA & NA & NA & NA & NA \\
\hline \multicolumn{12}{|c|}{ Small Aircraft Impacts } \\
\hline \multirow[t]{5}{*}{2} & INEL & NA & NA & NA & $N A$ & NA & NA & NA & $\mathbf{N A}$ & NA & NA \\
\hline & LANL & $7.0 \mathrm{E}-09$ & 50 & $2.0 \mathrm{E}-01$ & 10 & 6 & 1 & 1 & 1 & 1 & 0 \\
\hline & ORR & $7.0 \mathrm{E}-09$ & 50 & $2.0 \mathrm{E}-01$ & 10 & 5 & 1 & 0 & 2 & 2 & 0 \\
\hline & Hanford & NA & NA & NA & NA & NA & NA & NA & NA & NA & NA \\
\hline & SRS & NA & NA & NA & NA & NA & NA & NA & NA & $\mathbf{N A}$ & NA \\
\hline \multirow[t]{2}{*}{3} & INEL & NA & NA & NA & NA & $\mathrm{NA}$ & NA & NA & NA & NA & NA \\
\hline & ORR & $7.0 \mathrm{E}-09$ & 80 & $2.0 \mathrm{E}-01$ & 16 & 10 & 0 & 1 & 3 & 2 & 0 \\
\hline
\end{tabular}

a Case $I$ is the No Action/Decentralized Alternative with two treatment sites, Case 2 is the Regionalized 1 Alternative with five trearnent sites, and Case 3 is the Regionalized 2 Alternative with two treatment sites.

b Refer to Table 8.2 for definitions of released chemicals.

c NA $=$ not applicable. 


\section{REFERENCES}

Ayer, J.E., et al., 1988, Nuclear Fuel Cycle Facility Accident Analysis Handbook, NUREG-1320, U.S. Nuclear Regulatory Commission, Washington, D.C., May.

Barnes, S.M., et al., 1988, "Three Year's Progress of the West Valley Demonstration Project Vitrification System," in Proceedings of Waste Management '88, R. Post and M. Walks (editors), Laser Options, Inc., Tucson, Ariz., pp. 195-202.

Benchmark Environmental Corporation, 1994, Preliminary Safety Analysis Report for the Retrieval of Transuranic Waste from Pads 1, 2, and 4 at TA-54, Area 6, CST7G-REPORT-001, R.O., prepared for Los Alamos National Laboratory.

Boomer, K.D., 1992, Tank Waste Systems Engineering Study, WHC-EP-0405, rev. 0, prepared by Westinghouse Hanford Co., Richland, Wash., for U.S. Department of Energy, Office of Environmental Restoration and Waste Management, Oct.

Braun, D.J., et al., 1993, "Hanford Waste Vitrification Building Limited Scope Risk Assessment," in Proceedings of the International Topical Meeting on Probabilistic Safety Assessment, PSA '93, vol.1, American Nuclear Society, La Grange, Ill., pp. 458-464.

Choi, A.S., and J.R. Fowler, 1990, Material Balance Tables for the DWPF Basic Data Report, Revision 138: Appendix G, Table 19-1, WSRC-TR-90-93, Westinghouse Savannah River Co., Aiken, S.C., Feb.

Coats, D.W., and R.C. Murray, 1984, Natural Phenomena Hazards Modeling Project: Seismic Hazard Models for Department of Energy Sites, UCRL-53582, Lawrence Livermore Laboratory, Nov.

Davis, M.L., and D.G. Satterwhite, 1989, Fire Hazards Analysis of the Radioactive Waste Management Complex Air Support Buildings, EGG-WM-8703, EG\&G Idaho, Inc., Idaho Falls, Idaho, Sept.

DOE: See U.S. Department of Energy.

DuPont: See E.I. DuPont de Nemours \& Co.

EG\&G, 1990, Safety Analysis Report for the Hazardous Waste Storage Facility, EG\&G-WM-PD-88-014, rev. 1, EG\&G Idaho, Inc., Idaho Falls, Idaho, Nov.

EG\&G, 1992a, Final Safety Analysis Report and Technical Safety Requirements for Building 910, EG\&G Rocky Flats, Inc., Golden, Colo., March. 
EG\&G, 1992b, Preliminary Safety Analysis Report for Building 374: Addendum, EG\&G Rocky Flats, Inc., Golden, Colo., Dec.

EG\&G, 1992c, Draft Environmental Assessment: Idaho National Laboratory Low-Level and Mixed Waste Processing, EG\&G Idaho, Inc., Idaho Falls, Idaho, Dec.

EG\&G, 1993a, Mixed Low-Level Waste Systems Analysis Methodology and Applications Report, vols. I and II, draft, EG\&G Idaho, Inc., Idaho Falls, Idaho, Sept.

EG\&G, 1993b, Radioactive Waste Management Complex Safety Analysis Report, draft, EGG-WM-10881, EG\&G Idaho, Inc., Idaho Falls, Idaho, Sept.

EG\&G, 1994a, DOE Programmatic Spent Nuclear Fuel and Waste Management Environmental Impact Statement, in "Accident Analysis," Appendix J, EG\&G Idaho, Inc., Idaho Falls, Idaho, June.

EG\&G, 1994b, Safety Analysis Report for the Waste Storage Facility, EGG-WM-10774, rev. 2, EG\&G Idaho, Inc., Idaho Falls, Idaho, May.

E.I. DuPont de Nemours \& Co., 1987, Safety Assessment Document: Consolidated Incineration Facility, approved draft, DPSTAD-200-6, Savannah River Laboratory, Aiken, S.C., Oct.

E.I. DuPont de Nemours \& Co., 1989, CIF Fire Analysis, Aiken, S.C.

Electric Power Research Institute, 1979, Status Report on the EPRI Fuel Cycle Accident Risk Assessment, EPRI NP-1128, research project 767-1, Palo Alto, Calif., July.

EPA: See U.S. Environmental Protection Agency.

EPRI: See Electric Power Research Institute.

Feizollahi, F., and D. Shropshire, 1992, Waste Management Facilities Cost Information Report, EGG-WTD-10443, EG\&G Idaho, Inc., Idaho Falls, Idaho, Oct.

Folga, S.M., et al., 1996a, High-Level Waste Inventory, Characteristics, Generation, and Facility Assessment for Treatment, Storage, and Disposal Alternatives Considered in the U.S. Department of Energy Waste Management Programmatic Environmental Impact Statement, ANL/EAD/TM-17, Argonne National Laboratory, Argonne, $\mathrm{Il}$.

Folga, S.M., et al., 1996b, Supplemental Analysis of Accident Sequences and Source Terms for Waste Treatment and Storage Operations and Related Facilities for the U.S. Department of Energy Waste Management Programmatic Environmental Impact Statement, ANL/EAD/TM-53, Argonne National Laboratory, Argonne, $\mathrm{Il}$.

GAO: See U.S. General Accounting Office. 
Goyette, M.L., and D.A. Dolak, 1996, Low-Level Waste Inventory, Characteristics, Generation, and Facility Assessment for Treatment, Storage, and Disposal Alternatives Considered in the U.S. Department of Energy Waste Management Programmatic Environmental Impact Statement, ANL/EAD/TM-20, Argonne National Laboratory, Argonne, Ill.

Hartmann, H.M., et al., 1994, "Hazardous Waste Transportation Risk Assessment for the U.S. Department of Energy Environmental Restoration and Waste Management Programmatic Environmental Impact Statement: Human Health Endpoints," in vol. 2, WM '94: Working Towards a Cleaner Environment: Waste Processing, Transportation, Storage and Disposal, Technical Programs and Public Education: Technology and Programs for Radioactive Waste Management and Environmental Restoration, Laser Options, Inc., Tucson, Ariz.

Herborn, D.I., and D.A. Smith, 1990, Hanford Waste Vitrification Plant Preliminary Safety Analysis Report, WHC-EP-0250, rev. B (Draft), Westinghouse Hanford Company, Richland, Wash., July.

Hong, K.J., 1996, Transuranic Waste Inventory, Characteristics, Generation, and Facility Assessment for Treatment, Storage, and Disposal Alternatives Considered in the U.S. Department of Energy Waste Management Programmatic Environmental Impact Statement, ANL/EAD/TM-22, Argonne National Laboratory, Argonne, Ill.

Kennedy, R.P., and S.A. Short, 1990, Design and Evaluation Guidelines for Department of Energy Facilities Subject to Natural Phenomena, UCRL-15910, Lawrence Livermore National Laboratory, Livermore, Calif., June.

Kotek, T.J., et al., 1996, WASTE_MGMT: A Computer Model for Calculation of Waste Loads, Profiles, and Emissions, ANL/EAD/TM-30, Argonne National Laboratory, Argonne, Ill.

Lazaro, M.A., et al., 1996, Hazardous Waste Inventory, Characteristics, Generation, and Facility Assessment for Treatment, Storage, and Disposal Alternatives Considered in the U.S. Department of Energy Waste Management Programmatic Environmental Impact Statement, ANL/EAD/TM-25, Argonne National Laboratory, Argonne, $\mathrm{Ill}$.

Machida, N., et al., 1989. "Conceptual Design of a High-Level Vitrified Waste Storage Facility," in Proceedings of the 1989 Joint International Waste Management Conference, High Level Radioactive Waste and Spent Fuel Management, F. Feizollahi (editor), American Society of Mechanical Engineers, New York, N.Y., pp. 291-296.

McDonell, W.R., and C.M. Jantzen, 1986, "Effects of Waste Content of Glass Waste Forms on Savannah River High-Level Waste Disposal Costs," in High-Level Nuclear Waste Disposal, Proceedings from the American Nuclear Society International Topical Meeting of High-Level Nuclear Waste Disposal-Technology and Engineering, American Nuclear Society, La Grange, Ill. 
Mishima, J., et al., 1986, Potential Radiological Impacts of Upper-Bound Operational Accidents during Proposed Disposal Alternatives for Hanford Defense Waste, PNL-5356, Pacific Northwest Laboratory, Richland, Wash.

Nabelssi, B.K., et al., 1996, WASTE_ACC: A Computer Model for Analysis of Waste Management Accidents, ANL/EAD/TM-52, Argonne National Laboratory, Argonne, Ill.

NRC: See U.S. Nuclear Regulatory Commission.

Oak Ridge National Laboratory, 1992, Integrated Data BBase for 1992: U.S. Spent Fuel and Radioactive Waste Inventories, Projections, and Characteristics, DOE/RW-0006, rev. 8, Oak Ridge, Tenn., Oct.

Oak Ridge National Laboratory, 1993, ORRSF Preliminary Safety Analysis Report, Y/ENG/PSAR-73, Draft, Martin Marrietta Energy Systems, Inc., Oak Ridge, Tenn., July.

Oak Ridge National Laboratory, 1994, Integrated Data Base for 1993: U.S. Spent Fuel and Radioactive Waste Inventories, Projections, and Characteristics, DOE/RW-006, rev. 9, Oak Ridge, Tenn., March.

ORNL: See Oak Ridge National Laboratory.

RFETS: See Rocky Flats Environmental Technology Site.

Rocky Flats Environmental Technology Site, 1994, Final Safety Analysis Report: Building 906, Centralized Waste Storage Facility, rev. 0, RFETS, Golden, Colo., Aug.

Salazar, R.J., and S. Lane, 1992, Final Safety Analysis Document for Building 693 Chemical Waste Storage Building at Lawrence Livermore National Laboratory, UCRL-ID-109144, Lawrence Livermore National Laboratory, Livermore, Calif., Feb.

Sasser, M.K., 1992, Probabilistic Safety Analysis for TA-63, Hazardous Waste Treatment Facility, interoffice memorandum from Sasser to G. Lussiez (Los Alamos National Laboratory, Los Alamos, N.M.), Sept.

Trusty, A.D., et al., 1989, Hazardous Assessment of the Hazardous Waste Storage Facility, EGG-PRA-4032, Idaho National Engineering Laboratory, Idaho Falls, Idaho, March.

U.S. Congress, 1983, Nuclear Waste Policy Act of 1982, Public Law 97-425.

U.S. Department of Energy, 1982a, Environmental Evaluation of Alternatives for Long-Term Management of Defense High-Level Radioactive Wastes at the Idaho Chemical Processing Plant, IDO-10105, Idaho Operations Office, Idaho Falls, Idaho, Sept. 
U.S. Department of Energy, 1982b, Final Environmental Impact Statement - Defense Waste Processing Facility, Savannah River Plant, Aiken, S.C., DOE/EIS-0082, UC70, Washington, D.C., Feb.

U.S. Department of Energy, 1987a, "Safety Analysis and Review System," DOE Order 5481.1B.

U.S. Department of Energy, 1987b, "Fire Protection," DOE Order 5480.7A.

U.S. Department of Energy, 1988, "Radioactive Waste Management," DOE Order 5820.2A.

U.S. Department of Energy, 1989, "General Design Criteria," DOE Order 6430.1A.

U.S. Department of Energy, 1990a, Final Supplement Environmental Impact Statement: Waste Isolation Pilot Plant, DOE/EIS-0026 FS, Washington, D.C., Jan.

U.S. Department of Energy, 1990b, Waste Isolation Pilot Plant Final Safety Analysis Report, rev. 0, WP-02-9, Washington, D.C., May.

U.S. Department of Energy, 1991a, Waste Isolation Pilot Plant Fire Hazards and Risk Analysis, DOE/WIPP91-031, Washington, D.C.

U.S. Department of Energy, 1991b, Draft Analysis of the Environmental Effects of the Waste Receiving and Processing Facility Module, WRAP-1, predecisional draft, Washington, D.C., March.

U.S. Department of Energy, 1991c, Analysis of the Environmental Effects of the Waste Receiving and Processing Facility Module 2, Hanford Site, Richland, Washington, WRAP-2, predecisional draft, Washington, D.C., Sept.

U.S. Department of Energy, 1991d, Draft Environmental Impact Statement for the Siting, Construction, and Operation of New Production Reactor Capacity, DOE/EIS-0144D, Office of New Production Reactors, Washington, D.C., April.

U.S. Department of Energy, 1992a, Environmental Assessment Retrieval and Re-Storage of Transuranic Storage Area Waste at the Idaho National Engineering Laboratory, DOE/EA-0499, Washington, D.C., Feb.

U.S. Department of Energy, 1992b, Hazard Categorization and Accident Analysis Techniques for Compliance with DOE Order 5480.23, Nuclear Safety Analysis Reports, DOE-STD-1027-92, Washington, D.C., Dec.

U.S. Department of Energy, 1993a, Recommendations for the Preparation of Environmental Assessments and Impacts Statements, Office of National Environmental Policy Oversight, Washington, D.C., May. 
U.S. Department of Energy, 1993b, Performance Categorization Criteria for Structures, Systems, and Components Subjected to Natural Phenomena Hazards, DOE-STD-1021-93, Washington, D.C., July.

U.S. Department of Energy, 1993c, "Natural Phenomena Hazards Mitigation," DOE Order 5480.28.

U.S. Department of Energy, 1993d, Natural Phenomena Hazards Design and Evaluation Criteria, DOE-STD-1020-92, Washington, D.C., Feb.

U.S. Department of Energy, 1993e, "Nuclear Safety Analysis Reports," DOE Order 5480.23.

U.S. Department of Energy, 1993f, Defense Programs Safety Survey Report, DOE/DP/70056-H1, Washington, D.C., Nov.

U.S. Department of Energy, 1993g, 1992 Idaho National Engineering Laboratory (INEL) National Emission Standards for Hazardous Air Pollutants (NESHAPs) Annual Report, DOE/ID-10342(92), Idaho Operations Office, Idaho Falls, Idaho.

U.S. Department of Energy, 1994, Airborne Release Fractions/Rates and Respirable Fractions at DOE Nonreactor Facilities, DOE-HDBK-3010-94, Office of Scientific and Technical Information, Oak Ridge, Tenn.

U.S. Department of Energy, 1995, Savannah River Site Waste Management Draft Environmental Impact Statement Volume II, DOE/EIS-0217D, Washington, D.C., Jan.

U.S. Department of Energy, 1996, Waste Management Programmatic Environmental Impact Statement for Managing Treatment, Storage, and Disposal of Radioactive and Hazardous Waste, DOE/EIS-0200-PF, Office of Environmental Management, Washington, D.C.

U.S. Environmental Protection Agency, 1993, Environmental Reaction Protection Standards for the Management and Disposal of Spent Nuclear Fuel, High-Level and Transuranic Radioactive Wastes, 58 FR 66398, Dec 20.

U.S. General Accounting Office, 1993, Hanford Tank Waste Program Needs-Cost, Schedule, and Management Changes, GAO/RCED-93-99, Washington, D.C., March.

U.S. Nuclear Regulatory Commission, 1988, Nuclear Fuel Cycle Facility Accident Analysis Handbook, NUREG-1320, Washington, D.C., May.

U.S. Nuclear Regulatory Commission, 1994, Disposal of High-Level Radioactive Wastes in Geologic Repositories, 10 CFR Part 60, Washington, D.C., Jan. 1. 
Westinghouse Hanford Company, 1991a, Hazard Classification and Preliminary Safety Evaluation for Waste Receiving and Processing Facility, Module 1 Project W026, rev. 0 , WHD-SD-W026-PSE-001, Richland, Wash.

Westinghouse Hanford Company, 1991b, Hazard Classification and Preliminary Safety Evaluation for Waste Receiving and Processing Facility (WRAP): Module 2 Project W100, Draft, Richland, Wash., June.

Westinghouse Savannah River Company, 1990, Safety Analysis-200-S Area Savannah River Site Defense Waste Processing Facility Operations (U), DPSTSA-200-10-rev. 1 SUP-20, Aiken, S.C., Feb.

Westinghouse Savannah River Company, 1994a, "Analysis of Operations," chap. 9 in Defense Waste Processing Facility Safety Analysis Report, rev. 9, suppl. 20, DPSTSA-200-10, Aiken, S.C., Jan.

Westinghouse Savannah River Company, 1994b, Savannah River Site Human Error Data Base Development for Nonreactor Nuclear Facilities (U), WSRC-TR-93-581, Aiken, S.C., Feb.

West Valley Nuclear Services Co., Inc., 1994, Safety Analysis Report for Vitrification System Operations and High-Level Waste Interim Storage, rev. 2, WVNS-SAR-003, draft C, West Valley, N.Y., March 28.

WHC: See Westinghouse Hanford Company.

Wilkins, B.D., et al., 1996, Low-Level Mixed Waste Inventory, Characteristics, Generation, and Facility Assessment for Treatment, Storage, and Disposal Alternatives Considered in the U.S. Department of Energy Waste Management Programmatic Environmental Impact Statement, ANL/EAD/TM-32, Argonne National Laboratory, Argonne, $\mathrm{Ill}$.

WSRC: See Westinghouse Savannah River Company.

WVNS: See West Valley Nuclear Services Co., Inc. 


\section{Analysis of Accident Sequences and Source Terms at Treatment and Storage Facilities for Waste Generated by U.S. Department of Energy Waste Management Operations}

Volume 2: Appendixes A and B

by C. Mueller, B. Nabelssi, J. Roglans-Ribas, S. Folga, A. Policastro, W. Freeman,"

R. Jackson, ${ }^{\star}$ J. Mishima, ${ }^{*}$ and S. Turner ${ }^{\star}$

Environmental Assessment Division,

Argonne National Laboratory, 9700 South Cass Avenue, Argonne, Illinois 60439

December 1996

Work sponsored by United States Department of Energy,

Assistant Secretary for Environmental Management

- Freeman is affiliated with the University of Illinois at Chicago; Jackson and Tumer with Science Applications International Corporation, Golden, Colorado; and Mishima with Science Applications International Corporation, Richland, Washington. 
APPENDIX A:

CHEMICAL SOURCE TERMS FOR LOW-LEVEL MIXED WASTE ACCIDENTS 
A-2 


\section{CONTENTS}

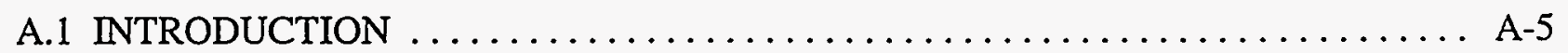

\section{TABLES}

A.1 Frequencies and Chemical Source Terms for WM-LEMW

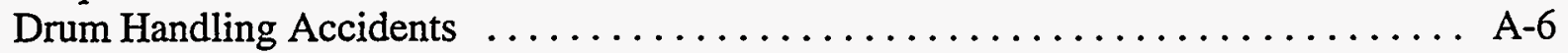

A.2 Frequencies and Chemical Source Terms for WM-LLMW

Non-Alpha Incineration Facility Accidents $\ldots \ldots \ldots \ldots \ldots \ldots \ldots \ldots \ldots \ldots \ldots \ldots$

A.3 Frequencies and Chemical Source Terms for WM-LLMW

Alpha Incineration Facility Accidents $\ldots \ldots \ldots \ldots \ldots \ldots \ldots \ldots \ldots \ldots \ldots \ldots \ldots \ldots \ldots \ldots$ 
A-4 


\section{APPENDIX A:}

\section{CHEMICAL SOURCE TERMS FOR LOW-LEVEL MIXED WASTE ACCIDENTS}

\section{A.1 INTRODUCTION}

The following tables provide the chemical source terms for low-level mixed waste accidents. The accident identifications used in the tables are as follows: IFF = incineration facility fire (in the feedstock staging area) and SHA = single drum handling accident. 
TABLE A.1 Frequencies and Chemical Source Terms for WM-LLMW Drum Handling Accidents

\begin{tabular}{|c|c|c|c|c|c|c|c|c|}
\hline $\begin{array}{l}\text { WM PEIS } \\
\text { Alternative } \\
\end{array}$ & Site $^{\mathrm{a}}$ & $\begin{array}{c}\text { Initial } \\
\text { Accident }^{b} \\
\end{array}$ & $\begin{array}{c}\text { Accident } \\
\text { Frequency }(1 / y r) \\
\end{array}$ & $\begin{array}{c}\text { Release } \\
\text { Amount (g) }\end{array}$ & Chemical $^{\mathrm{C}}$ ID & Contaminant & Toxic Gas ${ }^{\mathrm{d}}$ & $\begin{array}{l}\text { Release Time } \\
\text { (min) }\end{array}$ \\
\hline All & Bettis & SHA & $2.4 \mathrm{E}-04$ & $2.7 \mathrm{E}+04$ & $\mathrm{Cl}-3-\mathrm{x}$ & Tri/tetrachloroethanes & $1,1,1-\mathrm{C}_{2} \mathrm{H}_{3} \mathrm{Cl}_{3}$ & 120 \\
\hline All & Bettis & SHA & $2.4 \mathrm{E}-04$ & $5.4 \mathrm{E}+03$ & $\mathrm{Cl}-4-\mathrm{x}$ & Tri/tetrachloroethanes & $\mathrm{CCl}_{4}$ & 120 \\
\hline All & Bettis & SHA & $8.5 \mathrm{E}-02$ & $9.1 E+04$ & HC-insoluble & Benzene/toluene/xylene & $\mathrm{C}_{6} \mathrm{H}_{6}$ & 100 \\
\hline All & Bettis & SHA & $8.5 \mathrm{E}-02$ & $2.7 E+04$ & HC-soluble & Acetone/butanone/methanol & $\mathrm{CH}_{3} \mathrm{COCH}_{3}$ & 60 \\
\hline All & BNL & SHA & $8.1 \mathrm{E}-02$ & $2.7 \mathrm{E}+03$ & $\mathrm{Cl}-3-\mathrm{x}$ & Trichloroethanes & $1,1,1-\mathrm{C}_{2} \mathrm{H}_{3} \mathrm{Cl}_{3}$ & 60 \\
\hline All & BNL & SHA & $6.4 \mathrm{E}-02$ & $2.7 \mathrm{E}+04$ & Cl-3-x & Tri/tetrachloroethanes & $1,1,1 \cdot \mathrm{C}_{2} \mathrm{H}_{3} \mathrm{Cl}_{3}$ & 120 \\
\hline All & BNL & SHA & $6.4 \mathrm{E}-02$ & $5.4 \mathrm{E}+03$ & Cl-4-x & Tri/tetrachloroethanes & $\mathrm{CCl}_{4}$ & 120 \\
\hline All & BNL & SHA & $6.0 \mathrm{E}-02$ & $9.1 E+04$ & HC-insoluble & Benzene/toluene/xylene & $\mathrm{C}_{6} \mathrm{H}_{6}$ & 100 \\
\hline All & BNL & SHA & $9.0 \mathrm{E}-02$ & $7.4 \mathrm{E}+04$ & HC-soluble & Acetone/butanone/methanol & $\mathrm{CH}_{3} \mathrm{COCH}_{3}$ & 60 \\
\hline All & BNL & SHA & $6.0 \mathrm{E}-02$ & $2.7 \mathrm{E}+04$ & HC-soluble & Acetone/butanone/methanol & $\mathrm{CH}_{3} \mathrm{COCH}_{3}$ & 60 \\
\hline All & Charleston & SHA & $3.8 \mathrm{E}-01$ & $2.7 \mathrm{E}+03$ & CI-3-x & Trichloroethanes & $1,1,1-\mathrm{C}_{2} \mathrm{H}_{3} \mathrm{Cl}_{3}$ & 60 \\
\hline All & Charleston & SHA & $4.0 \mathrm{E}-01$ & $2.7 E+04$ & $\mathrm{Cl}-3-\mathrm{x}$ & Tri/tetrachloroethanes & $1,1,1-\mathrm{C}_{2} \mathrm{H}_{3} \mathrm{Cl}_{3}$ & 120 \\
\hline All & Charleston & SHA & $4.0 \mathrm{E}-01$ & $5.4 \mathrm{E}+03$ & $\mathrm{Cl}-4-\mathrm{x}$ & Tri/tetrachloroethanes & $\mathrm{CCl}_{4}$ & 120 \\
\hline All & Charleston & SHA & $3.7 \mathrm{E}-01$ & $9.1 E+04$ & HC-insoluble & Benzene/toluene/xylene & $\mathrm{C}_{6} \mathrm{H}_{6}$ & 100 \\
\hline All & Charleston & SHA & $5.5 \mathrm{E}-01$ & $7.4 \mathrm{E}+04$ & HC-soluble & Acetone/butanone/methanol & $\mathrm{CH}_{3} \mathrm{COCH}_{3}$ & 60 \\
\hline All & Charleston & SHA & $3.7 \mathrm{E}-01$ & $2.7 \mathrm{E}+04$ & HC-soluble & Acetone/butanone/methanol & $\mathrm{CH}_{3} \mathrm{COCH}_{3}$ & 60 \\
\hline All & ETEC & SHA & $8.7 \mathrm{E}-05$ & $2.7 \mathrm{E}+03$ & $\mathrm{Cl}-3-\mathrm{x}$ & Trichloroethanes & $1,1,1-\mathrm{C}_{2} \mathrm{H}_{3} \mathrm{Cl}_{3}$ & 60 \\
\hline All & ETEC & SHA & $9.6 \mathrm{E}-05$ & $7.4 \mathrm{E}+04$ & HC-soluble & Acetone/butanone/methanol & $\mathrm{CH}_{3} \mathrm{COCH}_{3}$ & 60 \\
\hline All & FEMP & SHA & $1.7 \mathrm{E}-03$ & $2.7 \mathrm{E}+03$ & $\mathrm{Cl}-3-\mathrm{x}$ & Trichloroethanes & $1,1,1-\mathrm{C}_{2} \mathrm{H}_{3} \mathrm{Cl}_{3}$ & 60 \\
\hline All & FEMP & SHA & $1.0 \mathrm{E}-01$ & $2.7 \mathrm{E}+04$ & $\mathrm{Cl}-3-\mathrm{x}$ & Tri/tetrachloroethanes & $1,1,1-\mathrm{C}_{2} \mathrm{H}_{3} \mathrm{Cl}_{3}$ & 120 \\
\hline All & FEMP & SHA & $1.0 \mathrm{E}-01$ & $5.4 \mathrm{E}+03$ & $\mathrm{Cl}-4-x$ & Tri/tetrachloroethanes & $\mathrm{CCl}_{4}$ & 120 \\
\hline All & FEMP & SHA & $1.1 \mathrm{E}-01$ & $9.1 \mathrm{E}+04$ & HC-insoluble & Benzene/toluene/xylene & $\mathrm{C}_{6} \mathrm{H}_{6}^{4}$ & 100 \\
\hline All & FEMP & SHA & $3.3 \mathrm{E}-02$ & $7.4 \mathrm{E}+04$ & HC-soluble & Acetone/butanone/methanol & $\mathrm{CH}_{3} \mathrm{COCH}_{3}$ & 60 \\
\hline All & FEMP & SHA & $1.1 \mathrm{E}-01$ & $2.7 E+04$ & HC-soluble & Acetone/butanone/methanol & $\mathrm{CH}_{3} \mathrm{COCH}_{3}$ & 60 \\
\hline All & GJPO & SHA & $5.8 \mathrm{E}-02$ & $2.7 E+03$ & $\mathrm{Cl}-3-\mathrm{x}$ & Trichloroethanes & $1,1,1-\mathrm{C}_{2} \mathrm{H}_{3} \mathrm{Cl}_{3}$ & 60 \\
\hline All & GJPO & SHA & $6.1 E-02$ & 2.7E+04 & Cl-3-x & Tri/tetrachloroethanes & $1,1,1-\mathrm{C}_{2} \mathrm{H}_{3} \mathrm{Cl}_{3}$ & 120 \\
\hline All & GJPO & SHA & $6.1 \mathrm{E}-02$ & $5.4 \mathrm{E}+03$ & Cl-4-x & Tri/tetrachloroethanes & $\mathrm{CCl}_{4}$ & 120 \\
\hline All & GJPO & SHA & $5.7 \mathrm{E}-02$ & $9.1 \mathrm{E}+04$ & $\mathrm{HC}$-insoluble & Benzene/toluene/xylene & $\mathrm{C}_{6} \mathrm{H}_{6}$ & 100 \\
\hline All & GJPO & SHA & $6.5 \mathrm{E}-02$ & $7.4 \mathrm{E}+04$ & HC-soluble & Acetone/butanone/methanol & $\mathrm{CH}_{3} \mathrm{COCH}_{3}$ & 60 \\
\hline All & GJPO & SHA & $5.7 \mathrm{E}-02$ & $2.7 \mathrm{E}+04$ & HC-soluble & Acetone/butanone/methanol & $\mathrm{CH}_{3} \mathrm{COCH}_{3}$ & 60 \\
\hline All & ITRI & SHA & $2.0 \mathrm{E}+00$ & $7.4 \mathrm{E}+04$ & HC-soluble & Acetone/butanone/methanol & $\mathrm{CH}_{3} \mathrm{COCH}_{3}$ & 60 \\
\hline All & KAPL-N & SHA & $7.1 \mathrm{E}-02$ & $2.7 \mathrm{E}+03$ & $\mathrm{Cl}-3-\mathrm{x}$ & Trichloroethanes & $1,1,1-\mathrm{C}_{2} \mathrm{H}_{3} \mathrm{Cl}_{3}$ & 60 \\
\hline All & KAPL-N & SHA & $7.5 \mathrm{E}-02$ & $2.7 E+04$ & $\mathrm{Cl}-3-\mathrm{x}$ & Tri/tetrachloroethanes & $1,1,1 \cdot \mathrm{C}_{2} \mathrm{H}_{3} \mathrm{Cl}_{3}$ & 120 \\
\hline All & KAPL-N & SHA & $7.5 \mathrm{E}-02$ & $5.4 \mathrm{E}+03$ & $\mathrm{Cl}-4-\mathrm{x}$ & Tri/tetrachloroethanes & $\mathrm{CCl}_{4}$ & 120 \\
\hline All & KAPL-N & SHA & $7.0 \mathrm{E}-02$ & $9.1 \mathrm{E}+04$ & HC-insoluble & Benzene/toluene/xylene & $\mathrm{C}_{6} \mathrm{H}_{6}$ & 100 \\
\hline All & KAPL-N & SHA & $7.9 \mathrm{E}-02$ & $7.4 \mathrm{E}+04$ & HC-soluble & Acetone/butanone/methanol & $\mathrm{CH}_{3} \mathrm{COCH}_{3}$ & 60 \\
\hline All & KAPL-N & SHA & $7.0 \mathrm{E}-02$ & $2.7 \mathrm{E}+04$ & HC-soluble & Acetone/butanone/methanol & $\mathrm{CH}_{3} \mathrm{COCH}_{3}$ & 60 \\
\hline All & KAPL-K & SHA & $5.2 \mathrm{E}-02$ & 2.7E+03 & $\mathrm{Cl}-3-\mathrm{x}$ & Trichloroethanes & $1,1,1-\mathrm{C}_{2} \mathrm{H}_{3} \mathrm{Cl}_{3}$ & 60 \\
\hline All & KAPL-K & SHA & $5.4 \mathrm{E}-02$ & 2.7E+04 & $\mathrm{Cl}-3-\mathrm{x}$ & Tri/tetrachloroethanes & $1,1,1-\mathrm{C}_{2} \mathrm{H}_{3} \mathrm{Cl}_{3}$ & 120 \\
\hline All & KAPL-K & SHA & $5.4 \mathrm{E}-02$ & $5.4 \mathrm{E}+03$ & $\mathrm{Cl}-4-\mathrm{x}$ & Tri/tetrachloroethanes & $\mathrm{CCl}_{4}$ & 120 \\
\hline
\end{tabular}


TABLE A.1 (Cont.)

\begin{tabular}{|c|c|c|c|c|c|c|c|c|}
\hline $\begin{array}{l}\text { WM PEIS } \\
\text { Alternative }\end{array}$ & Site $^{\mathfrak{a}}$ & $\begin{array}{c}\text { Initial } \\
\text { Accident }^{b}\end{array}$ & $\begin{array}{c}\text { Accident } \\
\text { Frequency (1/yr) }\end{array}$ & $\begin{array}{c}\text { Release } \\
\text { Amount (g) }\end{array}$ & Chemical $^{c}$ ID & Contaminant & Toxic Gas ${ }^{d}$ & $\begin{array}{c}\text { Release Time } \\
\text { (min) }\end{array}$ \\
\hline All & KAPL-K & SHA & $5.1 \mathrm{E}-02$ & $9.1 E+04$ & HC-insoluble & Benzene/toluene/xylene & $\mathrm{C}_{6} \mathrm{H}_{6}$ & 100 \\
\hline All & KAPL-K & SHA & $5.8 \mathrm{E}-02$ & $7.4 \mathrm{E}+04$ & HC-soluble & Acetone/butanone/methanol & $\mathrm{CH}_{3} \mathrm{COCH}_{3}$ & 60 \\
\hline All & KAPL-K & SHA & $5.1 \mathrm{E}-02$ & $2.7 \mathrm{E}+04$ & HC-soluble & Acetone/butanone/muthanol & $\mathrm{CH}_{3} \mathrm{COCH}_{3}$ & 60 \\
\hline All & KAPL-W & SHA & $2.4 \mathrm{E}-02$ & $2.7 E+03$ & Cl-3-x & Trichloroethanes & $1,1,1-\mathrm{C}_{2} \mathrm{H}_{3} \mathrm{Cl}_{3}$ & 60 \\
\hline All & KAPL-W & SHA & $2.5 \mathrm{E}-02$ & $2.7 \mathrm{E}+04$ & Cl-3-x & Tri/tetrachloroethanes & $1,1,1-\mathrm{C}_{2} \mathrm{H}_{3} \mathrm{Cl}_{3}$ & 120 \\
\hline All & KAPL-W & SHA & $2.5 \mathrm{E}-02$ & $5.4 \mathrm{E}+03$ & Cl-4-x & Tri/tetrachloroethanes & $\mathrm{CCl}_{4}$ & 120 \\
\hline All & KAPL-W & SHA & $2.3 \mathrm{E}-02$ & $9.1 E+04$ & HC-insoluble & Benzene/toluene/xylene & $\mathrm{C}_{6} \mathrm{H}_{6}$ & 100 \\
\hline All & KAPL-W & SHA & $2.6 \mathrm{E}-02$ & $7.4 \mathrm{E}+04$ & HC-soluble & Acetone/butanone/methanol & $\mathrm{CH}_{3} \mathrm{COCH}_{3}$ & 60 \\
\hline All & KAPL-W & SHA & $2.3 \mathrm{E}-02$ & $2.7 \mathrm{E}+04$ & HC-soluble & Acetone/butanone/methanol & $\mathrm{CH}_{3} \mathrm{COCH}_{3}$ & 60 \\
\hline All & LANL & SHA & $6.1 E-01$ & $2.7 E+03$ & $\mathrm{Cl}-3-\mathrm{x}$ & Trichloroethanes & $1,1,1-\mathrm{C}_{2} \mathrm{H}_{3} \mathrm{Cl}_{3}$ & 60 \\
\hline All & LANL & SHA & $5.8 \mathrm{E}-01$ & $7.4 \mathrm{E}+04$ & HC-soluble & Acetone/butanone/methanol & $\mathrm{CH}_{3} \mathrm{COCH}_{3}$ & 60 \\
\hline All & LBL & SHA & $1.9 \mathrm{E}-01$ & $9.1 E+04$ & HC-insoluble & Benzene/toluene/xylene & $\mathrm{C}_{6} \mathrm{H}_{6}$ & 100 \\
\hline All & LBL & SHA & $1.9 \mathrm{E}-01$ & $2.7 \mathrm{E}+04$ & HC-soluble & Acetone/butanone/methanol & $\mathrm{CH}_{3} \mathrm{COCH}_{3}$ & 60 \\
\hline All & LLNL & SHA & $4.9 \mathrm{E}-01$ & $2.7 E+03$ & Cl-3-x & Trichloroethanes & $1,1,1-\mathrm{C}_{2} \mathrm{H}_{3} \mathrm{Cl}_{3}$ & 60 \\
\hline All & LLNL & SHA & $5.0 \mathrm{E}-02$ & $2.7 \mathrm{E}+04$ & Cl-3-x & Tri/tetrachloroethanes & $1,1,1-\mathrm{C}_{2} \mathrm{H}_{3} \mathrm{Cl}_{3}$ & 120 \\
\hline All & LLNL & SHA & $5.0 \mathrm{E}-02$ & $5.4 \mathrm{E}+03$ & Cl-4-x & Tri/tetrachloroethanes & $\mathrm{CCl}_{4}$ & 120 \\
\hline All & LLNL & SHA & $4.7 \mathrm{E}-02$ & $9.1 \mathrm{E}+04$ & HC-insoluble & Benzene/toluene/xylene & $\mathrm{C}_{6} \mathrm{H}_{6}$ & 100 \\
\hline All & LLNL & SHA & $5.5 \mathrm{E}-01$ & $7.4 \mathrm{E}+04$ & HC-soluble & Acetone/butanone/methanol & $\mathrm{CH}_{3} \mathrm{COCH}_{3}$ & 60 \\
\hline All & LLNL & SHA & $4.7 \mathrm{E}-02$ & $2.7 \mathrm{E}+04$ & HC-soluble & Acetone/butanone/methanol & $\mathrm{CH}_{3} \mathrm{COCH}_{3}$ & 60 \\
\hline All & Pantex & SHA & $6.0 \mathrm{E}-02$ & $2.7 \mathrm{E}+04$ & Cl-3-x & Tri/tetrachloroethanes & $1,1,1-\mathrm{C}_{2} \mathrm{H}_{3} \mathrm{Cl}_{3}$ & 120 \\
\hline All & Pantex & SHA & $6.0 \mathrm{E}-02$ & $5.4 \mathrm{E}+03$ & Cl-4-x & Tri/tetrachloroethanes & $\mathrm{CCl}_{4}$ & 120 \\
\hline All & Pantex & SHA & $6.9 \mathrm{E}-03$ & $9.1 E+04$ & HC-insoluble & Benzene/toluene/xylene & $\mathrm{C}_{6} \mathrm{H}_{6}$ & 100 \\
\hline All & Pantex & SHA & $6.9 \mathrm{E}-03$ & $2.7 E+04$ & HC-soluble & Acetone/butanone/methanol & $\mathrm{CH}_{3} \mathrm{COCH}_{3}$ & 60 \\
\hline All & Pearl H & SHA & $1.2 \mathrm{E}-02$ & $2.7 \mathrm{E}+03$ & $\mathrm{Cl}-3-\mathrm{x}$ & Trichloroethanes & $1,1,1-\mathrm{C}_{2} \mathrm{H}_{3} \mathrm{Cl}_{3}$ & 60 \\
\hline All & Ports Nav & SHA & $1.2 \mathrm{E}-02$ & 2.7E+04 & $\mathrm{Cl}-3-\mathrm{x}$ & Tri/tetrachloroethanes & $1,1,1-\mathrm{C}_{2} \mathrm{H}_{3} \mathrm{Cl}_{3}$ & 120 \\
\hline All & Ports Nav & SHA & $1.2 \mathrm{E}-02$ & $5.4 \mathrm{E}+03$ & $\mathrm{Cl}-4-\mathrm{x}$ & Tri/tetrachloroethanes & $\mathrm{CCl}_{4}$ & 120 \\
\hline All & RFETS & SHA & $6.8 \mathrm{E}-04$ & $2.7 \mathrm{E}+03$ & $\mathrm{Cl}-3-\mathrm{x}$ & Trichloroethanes & $1,1,1-\mathrm{C}_{2} \mathrm{H}_{3} \mathrm{Cl}_{3}$ & 60 \\
\hline All & RFETS & SHA & $1.2 \mathrm{E}-03$ & $2.7 \mathrm{E}+04$ & $\mathrm{Cl}-3-\mathrm{x}$ & Tri/tetrachloroethanes & $1,1,1-\mathrm{C}_{2} \mathrm{H}_{3} \mathrm{Cl}_{3}$ & 120 \\
\hline All & RFETS & SHA & $1.2 \mathrm{E}-03$ & $5.4 \mathrm{E}+03$ & $\mathrm{Cl}-4-\mathrm{x}$ & Tri/tetrachloroethanes & $\mathrm{CCl}_{4}$ & 120 \\
\hline All & RFETS & SHA & $1.1 \mathrm{E}-03$ & $9.1 E+04$ & HC-insoluble & Benzene/toluene/xylene & $\mathrm{C}_{6} \mathrm{H}_{6}^{4}$ & 100 \\
\hline All & RFETS & SHA & $7.5 \mathrm{E}-04$ & $7.4 \mathrm{E}+04$ & HC-soluble & Acetone/butanone/methanol & $\mathrm{CH}_{3} \mathrm{COCH}_{3}$ & 60 \\
\hline All & RFETS & SHA & $1.1 \mathrm{E}-03$ & $2.7 \mathrm{E}+04$ & HC-soluble & Acetone/butanone/methanol & $\mathrm{CH}_{3} \mathrm{COCH}_{3}$ & 60 \\
\hline All & RMI & SHA & $5.5 \mathrm{E}-01$ & 2.7E+04 & $\mathrm{Cl}-3-\mathrm{x}$ & Tri/tetrachloroethanes & $1,1,1-\mathrm{C}_{2} \mathrm{H}_{3} \mathrm{Cl}_{3}$ & 120 \\
\hline All & RMI & SHA & $5.5 \mathrm{E}-01$ & $5.4 \mathrm{E}+03$ & $\mathrm{Cl}-4-\mathrm{x}$ & Tri/tetrachloroethanes & $\mathrm{CCl}_{4}$ & 120 \\
\hline All & RMI & SHA & $4.6 \mathrm{E}-02$ & $9.1 \mathrm{E}+04$ & HC-insoluble & Benzene/toluene/xylene & $\mathrm{C}_{6} \mathrm{H}_{6}$ & 100 \\
\hline All & RMI & SHA & $4.6 \mathrm{E}-02$ & 2.7E+04 & HC-soluble & Acetone/butanone/methanol & $\mathrm{CH}_{3} \mathrm{COCH}_{3}$ & 60 \\
\hline All & SNL-NM & SHA & $1.8 \mathrm{E}-04$ & $2.7 \mathrm{E}+\mathrm{O} 3$ & $\mathrm{Cl}-3-\mathrm{x}$ & Trichloroethanes & $1,1,1-\mathrm{C}_{2} \mathrm{H}_{3} \mathrm{Cl}$ & 60 \\
\hline All & SNL-NM & SHA & $2.0 \mathrm{E}-04$ & $7.4 \mathrm{E}+04$ & HC-soluble & Acetone/butanone/methanol & $\mathrm{CH}_{3} \mathrm{COCH}_{3}$ & 60 \\
\hline All & SNL-CA & SHA & $1.8 \mathrm{E}+00$ & $9.1 \mathrm{E}+04$ & HC-insoluble & Benzene/toluene/xylene & $\mathrm{C}_{6} \mathrm{H}_{6}$ & 100 \\
\hline All & SNL-CA & SHA & $1.8 \mathrm{E}+00$ & $2.7 \mathrm{E}+04$ & HC-soluble & Acetone/butanone/methanol & $\mathrm{CH}_{3} \mathrm{COCH}_{3}$ & 60 \\
\hline
\end{tabular}


TABLE A.1 (Cont.)

\begin{tabular}{|c|c|c|c|c|c|c|c|c|}
\hline $\begin{array}{l}\text { WM PEIS } \\
\text { Alternative }\end{array}$ & Site $^{\mathrm{a}}$ & $\begin{array}{c}\text { Initial } \\
\text { Accident }^{\mathrm{b}}\end{array}$ & $\begin{array}{c}\text { Accident } \\
\text { Frequency }(1 / \mathrm{yr})\end{array}$ & $\begin{array}{c}\text { Release } \\
\text { Amount (g) }\end{array}$ & Chemical $^{\mathrm{c}}$ ID & Contaminant & Toxic Gas & $\begin{array}{c}\text { Release Time } \\
\text { (min) }\end{array}$ \\
\hline All & SRS & SHA & $3.2 E-02$ & 2.7E+03 & $\mathrm{Cl}-3-\mathrm{x}$ & Trichloroethanes & $1,1,1-\mathrm{C}_{2} \mathrm{H}_{3} \mathrm{Cl}_{3}$ & 60 \\
\hline All & SRS & SHA & $3.6 \mathrm{E}-02$ & $7.4 \mathrm{E}+04$ & HC-soluble & Acetone/butanone/methanol & $\mathrm{CH}_{3} \mathrm{COCH}_{3}$ & 60 \\
\hline All & WVDP & SHA & $5.8 \mathrm{E}-01$ & $2.7 \mathrm{E}+03$ & $\mathrm{Cl}-3-\mathrm{x}$ & Trichloroethanes & $1,1,1-\mathrm{C}_{2} \mathrm{H}_{3} \mathrm{Cl}_{3}$ & 60 \\
\hline All & WVDP & SHA & $4.7 \mathrm{E}-02$ & $2.7 \mathrm{E}+04$ & $\mathrm{Cl}-3-\mathrm{x}$ & Tri/tetrachloroethanes & $1,1,1-C_{2} H_{3} \mathrm{Cl}_{3}$ & 120 \\
\hline All & WVDP & SHA & $4.7 \mathrm{E}-02$ & $5.4 \mathrm{E}+03$ & $\mathrm{Cl}-4-\mathrm{x}$ & Tri/tetrachloroethanes & $\mathrm{CCl}_{4}$ & 120 \\
\hline All & WVDP & SHA & $9.9 \mathrm{E}-03$ & $9.1 \mathrm{E}+04$ & HC-insoluble & Benzene/toluene/xylene & $\mathrm{C}_{6} \mathrm{H}_{6}$ & 100 \\
\hline All & WVDP & SHA & $6.6 \mathrm{E}-01$ & $7.4 \mathrm{E}+04$ & HC-soluble & Acetone/butanone/methanol & $\mathrm{CH}_{3} \mathrm{COCH}_{3}$ & 60 \\
\hline All & WVDP & SHA & $9.9 E-03$ & $2.7 \mathrm{E}+04$ & HC-soluble & Acetone/butanone/methanol & $\mathrm{CH}_{3} \mathrm{COCH}_{3}$ & 60 \\
\hline
\end{tabular}

a Abbreviations: Bettis = Bettis Atomic Power Laboratory; BNL = Brookhaven National Laboratory; Charleston $=$ Charleston Naval Shipyard; ETEC $=$ Energy Technology Engineering Center; FEMP $=$ Fernald Environmental Management Project; GJPO = Grand Junction Projects Office; Hanford = Hanford Site; INEL = Idaho National Engineering Laboratory; ITRI = Inhalation Toxicology Research Institute; KAPL-N = Knolls Atomic Power Laboratory (Niskayuna); KAPL-K = Knolls Atomic Power Laboratory (Kesselring); KAPL-W = Knolls Atomic Power Laboratory (Windsor); LANL = Los Alamos National Laboratory; LBL = Lawrence Berkeley National Laboratory; ORR = Oak Ridge National Laboratory; Pearl H = Pearl Harbor; PPPL = Princeton Plasma Physics Laboratory; Ports Nav = Portsmouth Naval Shipyard; RFETS = Rocky Flats Environmental Technology Site; RMI = Reactive Metals; Inc.; SNL-NM = Sandia National Laboratories (New Mexico); SNL-CA = Sandia National Laboratories (California); SRS = Savanah River Site; and WVDP = West Valley Demonstration Project.

b $\mathrm{SHA}=$ single drum handling accident.

c Cl-3-x = tri-chloro-hydrocarbons; Cl-4-x = tetra-chloro-hydrocarbons; HC-soluble = hazardous chemical-water soluble organics; HC-insoluble = hazardous chemical-water insoluble organics.

d $\mathrm{CH}_{3} \mathrm{COCH}_{3}=$ acetone; 1,1,1- $\mathrm{C}_{2} \mathrm{H}_{3} \mathrm{Cl}_{3}=1,1$,1-trichloroethane; $\mathrm{CCl}_{4}=$ carbon tetrachloride; $\mathrm{C}_{6} \mathrm{H}_{6}=$ benzene; $\mathrm{PAH}$ soot = polyaromatic hydrocarbon soot; $\mathrm{CO}=$ carbon monoxide; $\mathrm{HCl}=$ hydrogen chloride; $\mathrm{Cd}$ fumes = cadmium fumes; and $\mathrm{Cr}$ fumes = chromium fumes. 
TABLE A.2 Frequencies and Chemical Source Terms for WM-LLMW Non-Alpha Incineration Facility Accidents

\begin{tabular}{|c|c|c|c|c|c|c|c|c|}
\hline $\begin{array}{l}\text { WM PEIS } \\
\text { Alternative }^{\mathrm{a}} \\
\end{array}$ & Site $^{b}$ & $\begin{array}{c}\text { Initial } \\
\text { Accident }^{c} \\
\end{array}$ & $\begin{array}{l}\text { Accident Frequency } \\
(1 / y r)\end{array}$ & $\begin{array}{c}\text { Release } \\
\text { Amount (g) }\end{array}$ & Chemical ID & Contaminant & Toxic Gas ${ }^{\mathfrak{c}}$ & $\begin{array}{l}\text { Release Time } \\
\text { (min) }\end{array}$ \\
\hline 1 & INEL & IFF & $1.5 \mathrm{E}-02$ & $1.7 \mathrm{E}+03$ & HC-insoluble & Benzene/toluene/xylene & $\mathrm{CO}$ & 30 \\
\hline 1 & INEL & IFF & $1.5 \mathrm{E}-02$ & $4.8 \mathrm{E}+02$ & $\mathrm{Cl}-4-\mathrm{x}$ & Benzene/toluene/xylene & $\mathrm{HCl}$ & 30 \\
\hline 1 & INEL & IFF & $1.5 \mathrm{E}-02$ & $7.2 \mathrm{E}+01$ & HC-insoluble & Benzene/toluene/xylene & $\mathrm{C}_{6} \mathrm{H}_{6}$ & 30 \\
\hline 1 & INEL & IFF & $1.5 \mathrm{E}-02$ & $7.2 \mathrm{E}+02$ & HC-insoluble & Benzene/toluene/xylene & PÄH soot & 30 \\
\hline 1 & INEL & IFF & $1.5 \mathrm{E}-02$ & $4.8 \mathrm{E}+00$ & HC-insoluble & Benzene/toluene/xylene & Cd fumes & 30 \\
\hline 1 & INEL & IFF & $1.5 \mathrm{E}-02$ & $4.8 \mathrm{E}+00$ & HC-insoluble & Benzene/toluene/xylene & $\mathrm{Cr}$ fumes & 30 \\
\hline 1 & ORR & IFF & $1.5 \mathrm{E}-02$ & $5.2 \mathrm{E}+05$ & HC-insoluble & Benzene/toluene/xylene & $\mathrm{CO}$ & 30 \\
\hline 1 & ORR & IFF & $1.5 \mathrm{E}-02$ & $1.5 \mathrm{E}+05$ & $\mathrm{Cl}-4-\mathrm{x}$ & Benzene/toluene/xylene & $\mathrm{HCl}$ & 30 \\
\hline 1 & ORR & IFF & $1.5 \mathrm{E}-02$ & $2.2 \mathrm{E}+04$ & HC-insoluble & Benzene/toluene/xylene & $\mathrm{C}_{6} \mathrm{H}_{6}$ & 30 \\
\hline 1 & ORR & IFF & $1.5 \mathrm{E}-02$ & $2.2 E+05$ & HC-insoluble & Benzene/toluene/xylene & PAH soot & 30 \\
\hline 1 & ORR & IFF & $1.5 \mathrm{E}-02$ & $1.5 \mathrm{E}+03$ & HC-insoluble & Benzene/toluene/xylene & $\mathrm{Cd}$ fumes & 30 \\
\hline 1 & ORR & IFF & $1.5 \mathrm{E}-02$ & $1.5 \mathrm{E}+03$ & HC-insoluble & Benzene/toluene/xylene & $\mathrm{Cr}$ fumes & 30 \\
\hline 1 & SRS & IFF & $1.5 \mathrm{E}-02$ & $2.2 E+05$ & HC-insoluble & Benzene/toluene/xylene & $\mathrm{CO}$ & 30 \\
\hline 1 & SRS & IFF & $1.5 \mathrm{E}-02$ & $6.4 \mathrm{E}+04$ & Cl-4-x & Benzene/toluene/xylene & $\mathrm{HCl}$ & 30 \\
\hline 1 & SRS & IFF & $1.5 \mathrm{E}-02$ & $9.6 \mathrm{E}+03$ & HC-insoluble & Benzene/toluene/xylene & $\mathrm{C}_{6} \mathrm{H}_{6}$ & 30 \\
\hline 1 & SRS & IFF & $1.5 \mathrm{E}-02$ & $9.6 \mathrm{E}+04$ & HC-insoluble & Benzene/toluene/xylene & PAH soot & 30 \\
\hline 1 & SRS & IFF & $1.5 \mathrm{E}-02$ & $6.4 E+02$ & HC-insoluble & Benzene/toluene/xylene & Cd fumes & 30 \\
\hline 1 & SRS & IFF & $1.5 \mathrm{E}-02$ & $6.4 \mathrm{E}+02$ & HC-insoluble & Benzene/toluene/xylene & $\mathrm{Cr}$ fumes & 30 \\
\hline 2 & Ames & IFF & $1.5 \mathrm{E}-02$ & $1.6 \mathrm{E}+00$ & HC-insoluble & Benzene/toluene/xylene & $\mathrm{CO}$ & 30 \\
\hline 2 & Ames & IFF & $1.5 \mathrm{E}-02$ & $4.5 \mathrm{E}-01$ & $\mathrm{Cl}-4-\mathrm{x}$ & Benzene/toluene/xylene & $\mathrm{HCl}$ & 30 \\
\hline 2 & Ames & IFF & $1.5 \mathrm{E}-02$ & $6.8 \mathrm{E}-02$ & HC-insoluble & Benzene/toluene/xylene & $\mathrm{C}_{6} \mathrm{H}_{6}$ & 30 \\
\hline 2 & Ames & IFF & $1.5 \mathrm{E}-02$ & $6.8 \mathrm{E}-01$ & HC-insoluble & Benzene/toluene/xylene & PAHH soot & 30 \\
\hline 2 & Ames & IFF & $1.5 \mathrm{E}-02$ & $4.5 \mathrm{E}-03$ & HC-insoluble & Benzene/toluene/xylene & Cd fumes & 30 \\
\hline 2 & Ames & IFF & $1.5 \mathrm{E}-02$ & $4.5 \mathrm{E}-03$ & HC-insoluble & Benzene/toluene/xylene & $\mathrm{Cr}$ fumes & 30 \\
\hline 2 & ANL-E & IFF & $1.5 \mathrm{E}-02$ & $1.6 \mathrm{E}+03$ & HC-insoluble & Benzene/toluene/xylene & $\mathrm{CO}$ & 30 \\
\hline 2 & ANL-E & IFF & $1.5 \mathrm{E}-02$ & $4.5 E+02$ & Cl-4-x & Benzene/toluene/xylene & $\mathrm{HCl}$ & 30 \\
\hline 2 & ANL-E & IFF & $1.5 \mathrm{E}-02$ & $6.7 \mathrm{E}+01$ & HC-insoluble & Benzene/toluene/xylene & $\mathrm{C}_{6} \mathrm{H}_{6}$ & 30 \\
\hline 2 & ANL-E & IFF & $1.5 \mathrm{E}-02$ & $6.7 \mathrm{E}+02$ & HC-insoluble & Benzene/toluene/xylene & PAH soot & 30 \\
\hline 2 & ANL-E & IFF & $1.5 \mathrm{E}-02$ & $4.5 \mathrm{E}+00$ & HC-insoluble & Benzene/toluene/xylene & $\mathrm{Cd}$ fumes & 30 \\
\hline 2 & ANL-E & IFF & $1.5 \mathrm{E}-02$ & $4.5 E+00$ & HC-insoluble & Benzene/toluene/xylene & Cr fumes & 30 \\
\hline 2 & Beltis & IFF & $1.5 \mathrm{E}-02$ & $2.4 \mathrm{E}+02$ & HC-insoluble & Benzene/toluene/xylene & $\mathrm{CO}$ & 30 \\
\hline 2 & Bettis & IFF & $1.5 \mathrm{E}-02$ & $7.0 \mathrm{E}+01$ & $\mathrm{Cl}-4-\mathrm{x}$ & Benzene/toluene/xylene & $\mathrm{HCl}$ & 30 \\
\hline 2 & Bettis & IFF & $1.5 \mathrm{E}-02$ & $1.0 \mathrm{E}+01$ & HC-insoluble & Benzene/toluene/xylene & $\mathrm{C}_{6} \mathrm{H}_{6}$ & 30 \\
\hline 2 & Bettis & IFF & $1.5 \mathrm{E}-02$ & $1.0 \mathrm{E}+02$ & HC-insoluble & Benzene/toluene/xylene & PÄH soot & 30 \\
\hline 2 & Bettis & IFF & $1.5 \mathrm{E}-02$ & $7.0 \mathrm{E}-01$ & HC-insoluble & Benzene/toluene/xylene & Cd fumes & 30 \\
\hline 2 & Bettis & IFF & $1.5 \mathrm{E}-02$ & $7.0 \mathrm{E}-01$ & HC-insoluble & Benzene/toluene/xylene & Cr fumes & 30 \\
\hline 2 & Bettis & IFF & $1.5 \mathrm{E}-02$ & $2.8 \mathrm{E}-0 \mathrm{I}$ & HC-insoluble & Benzene/toluene/xylene & $\mathrm{CO}$ & 30 \\
\hline 2 & Bettis & IFF & $1.5 \mathrm{E}-02$ & $8.1 \mathrm{E}-02$ & Cl-4-x & Benzene/toluene/xylene & $\mathrm{HCl}$ & 30 \\
\hline 2 & Bettis & IFF & $1.5 \mathrm{E}-02$ & $1.2 \mathrm{E}-02$ & HC-insoluble & Benzene/toluene/xylene & $\mathrm{C}_{6} \mathrm{H}_{6}$ & 30 \\
\hline 2 & Bettis & IFF & $1.5 \mathrm{E}-02$ & $1.2 \mathrm{E}-01$ & HC-insoluble & Benzene/toluene/xylene & PÁH soot & 30 \\
\hline
\end{tabular}


TABLE A.2 (Cont.)

\begin{tabular}{|c|c|c|c|c|c|c|c|c|}
\hline $\begin{array}{l}\text { WM PEIS } \\
\text { Alternative }^{\mathrm{a}}\end{array}$ & Site & $\begin{array}{c}\text { Initial } \\
\text { Accident }^{c} \\
\end{array}$ & $\begin{array}{c}\text { Accident Frequency } \\
(1 / y r)\end{array}$ & $\begin{array}{c}\text { Release } \\
\text { Amount (g) }\end{array}$ & Chemical ID & Contaminant & Toxic Gas ${ }^{\mathfrak{c}}$ & $\begin{array}{c}\text { Release Time } \\
(\min )\end{array}$ \\
\hline 2 & Bettis & IFF & $1.5 \mathrm{E}-02$ & 8.1E-04 & HC-insoluble & Benzene/toluene/xylene & Cd fumes & 30 \\
\hline 2 & Bettis & IFF & $1.5 \mathrm{E}-02$ & $8.1 \mathrm{E}-04$ & HC-insoluble & Benzene/toluene/xylene & Cr fumes & 30 \\
\hline 2 & BNL & IFF & $1.5 \mathrm{E}-02$ & $7.7 E+02$ & HC-insoluble & Benzene/toluene/xylene & $\mathrm{CO}$ & 30 \\
\hline 2 & BNL & IFF & $1.5 \mathrm{E}-02$ & $2.2 \mathrm{E}+02$ & $\mathrm{Cl}-4-\mathrm{x}$ & Benzene/toluene/xylene & $\mathrm{HCl}$ & 30 \\
\hline 2 & BNL & IFF & $1.5 \mathrm{E}-02$ & $3.3 E+01$ & HC-insoluble & Benzene/toluene/xylene & $\mathrm{C}_{6} \mathrm{H}_{6}$ & 30 \\
\hline 2 & BNL & IFF & $1.5 \mathrm{E}-02$ & $3.3 \mathrm{E}+02$ & HC-insoluble & Benzene/toluene/xylene & PÁH soot & 30 \\
\hline 2 & BNL & IFF & $1.5 \mathrm{E}-02$ & $2.2 \mathrm{E}+00$ & HC-insoluble & Benzene/toluene/xylene & Cd fumes & 30 \\
\hline 2 & BNL & IFF & $1.5 \mathrm{E}-02$ & $2.2 \mathrm{E}+00$ & HC-insoluble & Benzene/toluene/xylene & Cr fumes & 30 \\
\hline 2 & Charleston & IFF & $1.5 \mathrm{E}-02$ & $4.5 \mathrm{E}+02$ & HC-insoluble & Benzene/toluene/xylene & $\mathrm{CO}$ & 30 \\
\hline 2 & Charleston & IFF & $1.5 \mathrm{E}-02$ & $1.3 \mathrm{E}+02$ & Cl-4-x & Benzene/toluene/xylene & $\mathrm{HCl}$ & 30 \\
\hline 2 & Charleston & IFF & $1.5 \mathrm{E}-02$ & $1.9 \mathrm{E}+01$ & HC-insoluble & Benzene/toluene/xylene & $\mathrm{C}_{6} \mathrm{H}_{6}$ & 30 \\
\hline 2 & Charleston & IFF & $1.5 \mathrm{E}-02$ & $1.9 \mathrm{E}+02$ & HC-insoluble & Benzene/toluene/xylene & PAH soot & 30 \\
\hline 2 & Charleston & IFF & $1.5 \mathrm{E}-02$ & $1.3 \mathrm{E}+00$ & HC-insoluble & Benzene/toluene/xylene & Cd fumes & 30 \\
\hline 2 & Charleston & IFF & $1.5 \mathrm{E}-02$ & $1.3 \mathrm{E}+00$ & HC-insoluble & Benzene/toluene/xylene & Cr fumes & 30 \\
\hline 2 & Colonie & IFF & $1.5 \mathrm{E}-02$ & $4.2 \mathrm{E}+02$ & HC-insoluble & Benzene/toluene/xylene & $\mathrm{CO}$ & 30 \\
\hline 2 & Colonie & IFF & $1.5 \mathrm{E}-02$ & $1.2 \mathrm{E}+02$ & Cl-4-x & Benzene/toluene/xylene & $\mathrm{HCl}$ & 30 \\
\hline 2 & Colonie & IFF & $1.5 \mathrm{E}-02$ & $1.8 \mathrm{E}+01$ & HC-insoluble & Benzene/toluene/xylene & $\mathrm{C}_{6} \mathrm{H}_{6}$ & 30 \\
\hline 2 & Colonie & IFF & $1.5 \mathrm{E}-02$ & $1.8 \mathrm{E}+02$ & HC-insoluble & Benzene/toluene/xylene & PAH soot & 30 \\
\hline 2 & Colonie & IFF & $1.5 \mathrm{E}-02$ & $1.2 \mathrm{E}+00$ & HC-insoluble & Benzene/toluene/xylene & Cd fumes & 30 \\
\hline 2 & Colonie & IFF & $1.5 \mathrm{E}-02$ & $1.2 \mathrm{E}+00$ & HC-insoluble & Benzene/toluene/xylene & $\mathrm{Cr}$ fumes & 30 \\
\hline 2 & ETEC & IFF & $1.5 \mathrm{E}-02$ & $7.6 \mathrm{E}+01$ & HC-insoluble & Benzene/toluene/xylene & $\mathrm{CO}$ & 30 \\
\hline 2 & ETEC & IFF & $1.5 \mathrm{E}-02$ & $2.2 \mathrm{E}+01$ & Cl-4-x & Benzene/toluene/xylene & $\mathrm{HCl}$ & 30 \\
\hline 2 & ETEC & IFF & $1.5 \mathrm{E}-02$ & $3.3 \mathrm{E}+00$ & HC-insoluble & Benzene/toluene/xylene & $\mathrm{C}_{6} \mathrm{H}_{6}$ & 30 \\
\hline 2 & ETEC & IFF & $1.5 \mathrm{E}-02$ & $3.3 E+01$ & HC-insoluble & Benzene/toluene/xylene & PAH soot & 30 \\
\hline 2 & ETEC & IFF & $1.5 \mathrm{E}-02$ & $2.2 \mathrm{E}-01$ & HC-insoluble & Benzene/toluene/xylene & $\mathrm{Cd}$ fumes & 30 \\
\hline 2 & ETEC & IFF & $1.5 \mathrm{E}-02$ & $2.2 \mathrm{E}-01$ & HC-insoluble & Benzene/toluene/xylene & $\mathrm{Cr}$ fumes & 30 \\
\hline 2 & FEMP & IFF & $1.5 \mathrm{E}-02$ & $1.6 \mathrm{E}+04$ & HC-insoluble & Benzene/toluene/xylene & $\mathrm{CO}$ & 30 \\
\hline 2 & FEMP & IFF & $1.5 \mathrm{E}-02$ & $4.6 \mathrm{E}+03$ & Cl-4-x & Benzene/toluene/xylene & $\mathrm{HCl}$ & 30 \\
\hline 2 & FEMP & IFF & $1.5 \mathrm{E}-02$ & $6.9 \mathrm{E}+02$ & HC-insoluble & Benzene/toluene/xylene & $\mathrm{C}_{6} \mathrm{H}_{6}$ & 30 \\
\hline 2 & FEMP & IFF & $1.5 \mathrm{E}-02$ & $6.9 \mathrm{E}+03$ & HC-insoluble & Benzene/toluene/xylene & PAH soot & 30 \\
\hline 2 & FEMP & IFF & $1.5 E-02$ & $4.6 \mathrm{E}+01$ & HC-insoluble & Benzene/toluene/xylene & $\mathrm{Cd}$ fumes & 30 \\
\hline 2 & FEMP & IFF & $1.5 \mathrm{E}-02$ & $4.6 \mathrm{E}+01$ & HC-insoluble & Benzene/toluene/xylene & $\mathrm{Cr}$ fumes & 30 \\
\hline 2 & $\mathrm{GA}$ & IFF & $1.5 \mathrm{E}-02$ & $8.0 \mathrm{E}+0 !$ & HC-insoluble & Benzene/toluene/xylene & $\mathrm{CO}$ & 30 \\
\hline 2 & $\mathrm{GA}$ & IFF & $1.5 \mathrm{E}-02$ & $2.3 \mathrm{E}+01$ & Cl-4-x & Benzene/toluene/xylene & $\mathrm{HCl}$ & 30 \\
\hline 2 & GA & IFF & $1.5 \mathrm{E}-02$ & $3.4 \mathrm{E}+00$ & HC-insoluble & Benzene/toluene/xylene & $\mathrm{C}_{6} \mathrm{H}_{6}$ & 30 \\
\hline 2 & GA & IFF & $1.5 \mathrm{E}-02$ & $3.4 \mathrm{E}+01$ & HC-insoluble & Benzene/toluene/xylene & PAH soot & 30 \\
\hline 2 & GA & IFF & $1.5 E-02$ & $2.3 E-01$ & HC-insoluble & Benzene/toluene/xylene & Cd fumes & 30 \\
\hline 2 & $\mathrm{GA}$ & IFF & $1.5 \mathrm{E}-02$ & $2.3 E-01$ & HC-insoluble & Benzene/toluene/xylene & Cr fumes & 30 \\
\hline 2 & GJPO & IFF & $1.5 \mathrm{E}-02$ & $6.1 \mathrm{E}+00$ & HC-insoluble & Benzene/toluene/xylene & $\mathrm{CO}$ & 30 \\
\hline 2 & GJPO & IFF & $1.5 \mathrm{E}-02$ & $1.7 \mathrm{E}+00$ & $\mathrm{Cl}-4-\mathrm{x}$ & Benzene/toluene/xylene & $\mathrm{HCl}$ & 30 \\
\hline
\end{tabular}


TABLE A.2 (Cont.)

\begin{tabular}{|c|c|c|c|c|c|c|c|c|}
\hline $\begin{array}{l}\text { WM PEIS } \\
\text { Alternative }^{\mathrm{a}}\end{array}$ & Site $^{b}$ & $\begin{array}{c}\text { Initial } \\
\text { Accident }^{\mathbf{c}} \\
\end{array}$ & $\begin{array}{c}\text { Accident Frequency } \\
(1 / y r)\end{array}$ & $\begin{array}{c}\text { Release } \\
\text { Amount (g) } \\
\end{array}$ & Chemical ID & Contaminant & Toxic Gas & $\begin{array}{c}\text { Release Time } \\
\text { (min) }\end{array}$ \\
\hline 2 & GJPO & IFF & $1.5 \mathrm{E}-02$ & $2.6 \mathrm{E}-01$ & HC-insoluble & Benzene/toluene/xylene & $\mathrm{C}_{6} \mathrm{H}_{6}$ & 30 \\
\hline 2 & GJPO & IFF & $1.5 \mathrm{E}-02$ & $2.6 \mathrm{E}+00$ & HC-insoluble & Benzene/toluene/xylene & PAH soot & 30 \\
\hline 2 & GJPO & IFF & $1.5 E-02$ & $1.7 E-02$ & HC-insoluble & Benzene/toluene/xylene & $\mathrm{Cd}$ fumes & 30 \\
\hline 2 & GJPO & IFF & $1.5 \mathrm{E}-02$ & $1.7 \mathrm{E}-02$ & HC-insoluble & Benzene/toluene/xylene & $\mathrm{Cr}$ fumes & 30 \\
\hline 2 & Hanford & IFF & $1.5 \mathrm{E}-02$ & $7.7 \mathrm{E}+04$ & HC-insoluble & Benzene/toluene/xylene & $\mathrm{CO}$ & 30 \\
\hline 2 & Hanford & IFF & $1.5 \mathrm{E}-02$ & $2.2 E+04$ & $\mathrm{Cl}-4-x$ & Benzene/toluene/xylene & $\mathrm{HCl}$ & 30 \\
\hline 2 & Hanford & IFF & $1.5 \mathrm{E}-02$ & $3.3 E+03$ & HC-insoluble & Benzene/toluene/xylene & $\mathrm{C}_{6} \mathrm{H}_{6}$ & 30 \\
\hline 2 & Hanford & IFF & $1.5 \mathrm{E}-02$ & $3.3 \mathrm{E}+04$ & HC-insoluble & Benzene/toluene/xylene & PAH soot & 30 \\
\hline 2 & Hanford & IFF & $1.5 \mathrm{E}-02$ & $2.2 \mathrm{E}+02$ & HC-insoluble & Benzene/toluene/xylene & Cd fumes & 30 \\
\hline 2 & Hanford & IFF & $1.5 \mathrm{E}-02$ & $2.2 \mathrm{E}+02$ & HC-insoluble & Benzene/toluene/xylene & $\mathrm{Cr}$ fumes & 30 \\
\hline 2 & INEL & IFF & $1.5 \mathrm{E}-02$ & $5.4 \mathrm{E}+03$ & HC-insoluble & Benzene/toluene/xylene & $\mathrm{CO}$ & 30 \\
\hline 2 & INEL & IFF & $1.5 \mathrm{E}-02$ & $1.5 \mathrm{E}+03$ & $\mathrm{Cl}-4-\mathrm{x}$ & Benzene/toluene/xylene & $\mathrm{HCl}$ & 30 \\
\hline 2 & INEL & IFF & $1.5 \mathrm{E}-02$ & $2.3 E+02$ & HC-insoluble & Benzene/toluene/xylene & $\mathrm{C}_{6} \mathrm{H}_{6}$ & 30 \\
\hline 2 & INEL & IFF & $1.5 \mathrm{E}-02$ & $2.3 E+03$ & HC-insoluble & Benzene/toluene/xylene & PAH soot & 30 \\
\hline 2 & INEL & IFF & $1.5 \mathrm{E}-02$ & $1.5 \mathrm{E}+01$ & HC-insoluble & Benzene/toluene/xylene & Ca fumes & 30 \\
\hline 2 & INEL & IFF & $1.5 \mathrm{E}-02$ & $1.5 \mathrm{E}+01$ & HC-insoluble & Benzene/toluene/xylene & $\mathrm{Cr}$ fumes & 30 \\
\hline 2 & ITRI & IFF & $1.5 \mathrm{E}-02$ & $4.7 E+01$ & HC-insoluble & Benzene/toluene/xylene & $\mathrm{CO}$ & 30 \\
\hline 2 & ITRI & IFF & $1.5 \mathrm{E}-02$ & $1.3 \mathrm{E}+01$ & Cl-4-x & Benzene/toluene/xylene & $\mathrm{HCl}$ & 30 \\
\hline 2 & ITRI & IFF & $1.5 E-02$ & $2.0 \mathrm{E}+00$ & HC-insoluble & Benzene/toluene/xylene & $\mathrm{C}_{6} \mathrm{H}_{6}$ & 30 \\
\hline 2 & ITRI & IFF & $1.5 \mathrm{E}-02$ & $2.0 \mathrm{E}+01$ & HC-insoluble & Benzene/toluene/xylene & PAH soot & 30 \\
\hline 2 & ITRI & IFF & $1.5 \mathrm{E}-02$ & $1.3 \mathrm{E}-01$ & HC-insoluble & Benzene/toluene/xylene & $\mathrm{Cd}$ fumes & 30 \\
\hline 2 & ITRI & IFF & $1.5 \mathrm{E}-02$ & $1.3 \mathrm{E}-01$ & HC-insoluble & Benzene/toluene/xylene & $\mathrm{Cr}$ fumes & 30 \\
\hline 2 & KAPL-N & IFF & $1.5 \mathrm{E}-02$ & $7.9 \mathrm{E}+02$ & HC-insoluble & Benzene/toluene/xylene & $\mathrm{CO}$ & 30 \\
\hline 2 & KAPL-N & IFF & $1.5 \mathrm{E}-02$ & $2.3 \mathrm{E}+02$ & $\mathrm{Cl}-4-\mathrm{x}$ & Benzene/toluene/xylene & $\mathrm{HCl}$ & 30 \\
\hline 2 & KAPL-N & IFF & $1.5 \mathrm{E}-02$ & $3.4 \mathrm{E}+01$ & HC-insoluble & Benzene/toluene/xylene & $\mathrm{C}_{6} \mathrm{H}_{6}$ & 30 \\
\hline 2 & KAPL-N & IFF & $1.5 \mathrm{E}-02$ & $3.4 \mathrm{E}+02$ & HC-insoluble & Benzene/toluene/xylene & PAH soot & 30 \\
\hline 2 & KAPL-N & IFF & $1.5 \mathrm{E}-02$ & $2.3 \mathrm{E}+00$ & HC-insoluble & Benzene/toluene/xylene & Cd fumes & 30 \\
\hline 2 & KAPL-N & IFF & $1.5 \mathrm{E}-02$ & $2.3 \mathrm{E}+00$ & HC-insoluble & Benzene/toluene/xylene & $\mathrm{Cr}$ fumes & 30 \\
\hline 2 & $\mathrm{KCP}$ & IFF & $1.5 \mathrm{E}-02$ & $1.7 \mathrm{E}+01$ & HC-insoluble & Benzene/toluene/xylene & $\mathrm{CO}$ & 30 \\
\hline 2 & KCP & IFF & $1.5 \mathrm{E}-02$ & $4.9 \mathrm{E}+00$ & $\mathrm{Cl}-4-\mathrm{x}$ & Benzene/toluene/xylene & $\mathrm{HCl}$ & 30 \\
\hline 2 & $\mathrm{KCP}$ & IFF & $1.5 \mathrm{E}-02$ & $7.4 \mathrm{E}-01$ & HC-insoluble & Benzene/toluene/xylene & $\mathrm{C}_{6} \mathrm{H}_{6}$ & 30 \\
\hline 2 & $\mathrm{KCP}$ & IFF & $1.5 \mathrm{E}-02$ & $7.4 \mathrm{E}+00$ & HC-insoluble & Benzene/toluene/xylene & PAH soot & 30 \\
\hline 2 & KCP & IFF & $1.5 \mathrm{E}-02$ & $4.9 \mathrm{E}-02$ & HC-insoluble & Benzene/toluene/xylene & Cd fumes & 30 \\
\hline 2 & $\mathrm{KCP}$ & IFF & $1.5 \mathrm{E}-02$ & $4.9 \mathrm{E}-02$ & HC-insoluble & Benzene/toluene/xylene & Cr fumes & 30 \\
\hline 2 & KAPL-K & IFF & $1.5 \mathrm{E}-02$ & $5.9 \mathrm{E}+02$ & HC-insoluble & Benzene/toluene/xylene & $\mathrm{CO}$ & 30 \\
\hline 2 & KAPL-K & IFF & $1.5 \mathrm{E}-02$ & $1.7 \mathrm{E}+02$ & Cl-4-x & Benzene/toluene/xylene & $\mathrm{HCl}$ & 30 \\
\hline 2 & KAPL-K & IFF & $1.5 \mathrm{E}-02$ & $2.5 E+01$ & HC-insoluble & Benzene/toluene/xylene & $\mathrm{C}_{6} \mathrm{H}_{6}$ & 30 \\
\hline 2 & KAPL-K & IFF & $1.5 \mathrm{E}-02$ & $2.5 E+02$ & HC-insoluble & Benzene/toluene/xylene & PAH soot & 30 \\
\hline 2 & KAPL-K & IFF & $1.5 \mathrm{E}-02$ & $1.7 \mathrm{E}+00$ & HC-insoluble & Benzene/toluene/xylene & Cd fumes & 30 \\
\hline 2 & KAPL-K & IFF & $1.5 \mathrm{E}-02$ & $1.7 \mathrm{E}+00$ & HC-insoluble & Benzene/toluene/xylene & Cr fumes & 30 \\
\hline
\end{tabular}


TABLE A.2 (Cont.)

\begin{tabular}{|c|c|c|c|c|c|c|c|c|}
\hline $\begin{array}{l}\text { WM PEIS } \\
\text { Altemative }^{\mathfrak{a}}\end{array}$ & Site $^{b}$ & $\begin{array}{c}\text { Initial } \\
\text { Accident }^{\mathrm{c}}\end{array}$ & $\begin{array}{c}\text { Accident Frequency } \\
(1 / y r)\end{array}$ & $\begin{array}{c}\text { Release } \\
\text { Amount (g) }\end{array}$ & Chemical ID & Contaminant & Toxic Gas ${ }^{\mathfrak{e}}$ & $\begin{array}{l}\text { Release Time } \\
\text { (min) }\end{array}$ \\
\hline 2 & KAPL-K & IFF & $1.5 \mathrm{E}-02$ & $3.3 \mathrm{E}+02$ & HC-insoluble & Benzene/toluene/xylene & $\mathrm{CO}$ & 30 \\
\hline 2 & KAPL-K & IFF & $1.5 \mathrm{E}-02$ & $9.3 \mathrm{E}+01$ & $\mathrm{Cl}-4-\mathrm{x}$ & Benzene/toluene/xylene & $\mathrm{HCl}$ & 30 \\
\hline 2 & KAPL-K & IFF & $1.5 \mathrm{E}-02$ & $1.4 \mathrm{E}+01$ & HC-insoluble & Benzene/toluene/xylene & $\mathrm{C}_{6} \mathrm{H}_{6}$ & 30 \\
\hline 2 & KAPL-K & IFF & $1.5 \mathrm{E}-02$ & $1.4 \mathrm{E}+02$ & $\mathrm{HC}$-insoluble & Benzene/toluene/xylene & PAH soot & 30 \\
\hline 2 & KAPL-K & IFF & $1.5 \mathrm{E}-02$ & $9.3 \mathrm{E}-01$ & HC-insoluble & Benzene/toluene/xylene & Cd fumes & 30 \\
\hline 2 & KAPL-K & IFF & $1.5 \mathrm{E}-02$ & $9.3 \mathrm{E}-01$ & HC-insoluble & Benzene/toluene/xylene & $\mathrm{Cr}$ fumes & 30 \\
\hline 2 & LANL & IFF & $1.5 \mathrm{E}-02$ & $3.3 E+03$ & HC-insoluble & Benzene/toluene/xylene & $\mathrm{CO}$ & 30 \\
\hline 2 & LANL & IFF & $1.5 \mathrm{E}-02$ & $9.5 \mathrm{E}+02$ & $\mathrm{Cl}-4-\mathrm{x}$ & Benzene/toluene/xylene & $\mathrm{HCl}$ & 30 \\
\hline 2 & LANL & IFF & $1.5 \mathrm{E}-02$ & $1.4 \mathrm{E}+02$ & HC-insoluble & Benzene/toluene/xylene & $\mathrm{C}_{6} \mathrm{H}_{6}$ & 30 \\
\hline 2 & LANL & IFF & $1.5 \mathrm{E}-02$ & $1.4 \mathrm{E}+03$ & HC-insoluble & Benzene/toluene/xylene & PAH soot & 30 \\
\hline 2 & LANL & IFF & $1.5 \mathrm{E}-02$ & $9.5 \mathrm{E}+00$ & HC-insoluble & Benzene/toluene/xylene & Cd fumes & 30 \\
\hline 2 & LANL & IFF & $1.5 \mathrm{E}-02$ & $9.5 \mathrm{E}+00$ & HC-insoluble & Benzene/toluene/xylene & $\mathrm{Cr}$ fumes & 30 \\
\hline 2 & LBL & IFF & $1.5 \mathrm{E}-02$ & $6.2 \mathrm{E}+02$ & HC-insoluble & Benzene/toluene/xylene & $\mathrm{CO}$ & 30 \\
\hline 2 & LBL & IFF & $1.5 \mathrm{E}-02$ & $1.8 \mathrm{E}+02$ & $\mathrm{Cl}-4-\mathrm{x}$ & Benzene/toluene/xylene & $\mathrm{HCl}$ & 30 \\
\hline 2 & LBL & IFF & $1.5 \mathrm{E}-02$ & $2.7 \mathrm{E}+01$ & HC-insoluble & Benzene/toluene/xylene & $\mathrm{C}_{6} \mathrm{H}_{6}$ & 30 \\
\hline 2 & LBL & IFF & $1.5 \mathrm{E}-02$ & $2.7 E+02$ & HC-insoluble & Benzene/toluene/xylene & PÁH soot & 30 \\
\hline 2 & LBL & IFF & $1.5 \mathrm{E}-02$ & $1.8 \mathrm{E}+00$ & HC-insoluble & Benzene/toluene/xylene & Cd fumes & 30 \\
\hline 2 & LBL & IFF & $1.5 \mathrm{E}-02$ & $1.8 \mathrm{E}+00$ & HC-insoluble & Benzene/toluene/xylene & $\mathrm{Cr}$ fumes & 30 \\
\hline 2 & LEHR & IFF & $1.5 \mathrm{E}-02$ & $1.6 \mathrm{E}+02$ & HC-insoluble & Benzene/toluene/xylene & $\mathrm{CO}$ & 30 \\
\hline 2 & LEHR & IFF & $1.5 \mathrm{E}-02$ & $4.6 \mathrm{E}+01$ & $\mathrm{Cl}-4-\mathrm{x}$ & Benzene/toluene/xylene & $\mathrm{HCl}$ & 30 \\
\hline 2 & LEHR & IFF & $1.5 \mathrm{E}-02$ & $7.0 \mathrm{E}+00$ & HC-insoluble & Benzene/toluene/xylene & $\mathrm{C}_{6} \mathrm{H}_{6}$ & 30 \\
\hline 2 & LEHR & IFF & $1.5 \mathrm{E}-02$ & $7.0 \mathrm{E}+01$ & HC-insoluble & Benzene/toluene/xylene & PAH soot & 30 \\
\hline 2 & LEHR & IFF & $1.5 \mathrm{E}-02$ & $4.6 \mathrm{E}-01$ & HC-insoluble & Benzene/toluene/xylene & Cd fumes & 30 \\
\hline 2 & LEHR & IFF & $1.5 \mathrm{E}-02$ & $4.6 \mathrm{E}-01$ & HC-insoluble & Benzene/toluene/xylene & Cr fumes & 30 \\
\hline 2 & LLNL & IFF & $1.5 \mathrm{E}-02$ & $3.9 \mathrm{E}+04$ & HC-insoluble & Benzene/toluene/xylene & $\mathrm{CO}$ & 30 \\
\hline 2 & LLNL & IFF & $1.5 \mathrm{E}-02$ & $1.1 \mathrm{E}+04$ & $\mathrm{Cl}-4-\mathrm{x}$ & Benzene/toluene/xylene & $\mathrm{HCl}$ & 30 \\
\hline 2 & LLNL & IFF & $1.5 \mathrm{E}-02$ & $1.7 \mathrm{E}+03$ & HC-insoluble & Benzene/toluene/xylene & $\mathrm{C}_{6} \mathrm{H}_{6}$ & 30 \\
\hline 2 & LLNL & IFF & $1.5 \mathrm{E}-02$ & $1.7 \mathrm{E}+04$ & HC-insoluble & Benzene/toluene/xylene & PÄH soot & 30 \\
\hline 2 & LLNL & IFF & $1.5 \mathrm{E}-02$ & $1.1 \mathrm{E}+02$ & HC-insoluble & Benzene/toluene/xylene & Cd fumes & 30 \\
\hline 2 & LLNL & IFF & $1.5 \mathrm{E}-02$ & $1.1 \mathrm{E}+02$ & HC-insoluble & Benzene/toluene/xylene & $\mathrm{Cr}$ fumes & 30 \\
\hline 2 & Mare Is & IFF & $1.5 \mathrm{E}-02$ & $6.8 \mathrm{E}+02$ & HC-insoluble & Benzene/toluene/xylene & $\mathrm{CO}$ & 30 \\
\hline 2 & Mare Is & IFF & $1.5 \mathrm{E}-02$ & $1.9 \mathrm{E}+02$ & Cl-4-x & Benzene/toluene/xylene & $\mathrm{HCl}$ & 30 \\
\hline 2 & Mare Is & IFF & $1.5 \mathrm{E}-02$ & $2.9 \mathrm{E}+01$ & HC-insoluble & Benzene/toluene/xylene & $\mathrm{C}_{6} \mathrm{H}_{6}$ & 30 \\
\hline 2 & Mare Is & IFF & $1.5 \mathrm{E}-02$ & $2.9 \mathrm{E}+02$ & HC-insoluble & Benzene/toluene/xylene & PAH soot & 30 \\
\hline 2 & Mare Is & IFF & $1.5 \mathrm{E}-02$ & $1.9 \mathrm{E}+00$ & HC-insoluble & Benzene/toluene/xylene & Cd fumes & 30 \\
\hline 2 & Mare Is & IFF & $1.5 \mathrm{E}-02$ & $1.9 \mathrm{E}+00$ & HC-insoluble & Benzene/toluene/xylene & Cr fumes & 30 \\
\hline 2 & Norfolk & IFF & $1.5 \mathrm{E}-02$ & $7.3 \mathrm{E}+01$ & HC-insoluble & Benzene/toluene/xylene & $\mathrm{CO}$ & 30 \\
\hline 2 & Norfolk & IFF & $1.5 \mathrm{E}-02$ & $2.1 E+01$ & Cl-4-x & Benzene/toluene/xylene & $\mathrm{HCl}$ & 30 \\
\hline 2 & Norfolk & IFF & $1.5 \mathrm{E}-02$ & $3.1 E+00$ & HC-insoluble & Benzene/toluene/xylene & $\mathrm{C}_{6} \mathrm{H}_{6}$ & 30 \\
\hline 2 & Norfolk & IFF & $1.5 \mathrm{E}-02$ & $2.1 \mathrm{E}-01$ & HC-insoluble & Benzene/toluene/xylene & Cd fumes & 30 \\
\hline
\end{tabular}


TABLE A.2 (Cont.)

\begin{tabular}{|c|c|c|c|c|c|c|c|c|}
\hline $\begin{array}{l}\text { WM PEIS } \\
\text { Alternative }^{a}\end{array}$ & Site $^{b}$ & $\begin{array}{c}\text { Initial } \\
\text { Accident }^{\mathbf{c}}\end{array}$ & $\begin{array}{c}\text { Accident Frequency } \\
(1 / y r)\end{array}$ & $\begin{array}{c}\text { Release } \\
\text { Amount (g) }\end{array}$ & Chemical ID & Contaminant & Toxic Gas & $\begin{array}{c}\text { Release Time } \\
\text { (min) }\end{array}$ \\
\hline 2 & Norfolk & IFF & $1.5 \mathrm{E}-02$ & $2.1 \mathrm{E}-01$ & HC-insoluble & Benzene/toluene/xylene & Cr fumes & 30 \\
\hline 2 & ORR & IFF & $1.5 E-02$ & $6.2 \mathrm{E}+05$ & HC-insoluble & Benzene/toluene/xylene & $\mathrm{CO}$ & 30 \\
\hline 2 & ORR & IFF & $1.5 \mathrm{E}-02$ & $1.8 \mathrm{E}+05$ & $\mathrm{Cl}-4-\mathrm{x}$ & Benzene/toluene/xylene & $\mathrm{HCl}$ & 30 \\
\hline 2 & ORR & IFF & $1.5 \mathrm{E}-02$ & $2.6 \mathrm{E}+04$ & HC-insoluble & Benzene/toluene/xylene & $\mathrm{C}_{6} \mathrm{H}_{6}$ & 30 \\
\hline 2 & ORR & IFF & $1.5 \mathrm{E}-02$ & $2.6 \mathrm{E}+05$ & HC-insoluble & Benzene/toluene/xylene & PAH soot & 30 \\
\hline 2 & ORR & IFF & $1.5 \mathrm{E}-02$ & $1.8 \mathrm{E}+03$ & HC-insoluble & Benzene/toluene/xylene & Cd fumes & 30 \\
\hline 2 & ORR & IFF & $1.5 \mathrm{E}-02$ & $1.8 E+03$ & HC-insoluble & Benzene/toluene/xylene & Cr fumes & 30 \\
\hline 2 & PGDP & IFF & $1.5 \mathrm{E}-02$ & $1.5 E+04$ & HC-insoluble & Benzene/toluene/xylene & $\mathrm{CO}$ & 30 \\
\hline 2 & PGDP & IFF & $1.5 \mathrm{E}-02$ & $4.2 E+03$ & $\mathrm{Cl}-4-\mathrm{x}$ & Benzene/toluene/xylene & $\mathrm{HCl}$ & 30 \\
\hline 2 & PGDP & IFF & $1.5 \mathrm{E}-02$ & $6.3 \mathrm{E}+02$ & HC-insoluble & Benzene/toluene/xylene & $\mathrm{C}_{6} \mathrm{H}_{6}$ & 30 \\
\hline 2 & PGDP & IFF & $1.5 \mathrm{E}-02$ & $6.3 E+03$ & HC-insoluble & Benzene/toluene/xylene & PAH soot & 30 \\
\hline 2 & PGDP & IFF & $1.5 \mathrm{E}-02$ & $4.2 \mathrm{E}+01$ & HC-insoluble & Benzene/toluene/xylene & Cd fumes & 30 \\
\hline 2 & PGDP & IFF & $1.5 \mathrm{E}-02$ & $4.2 E+01$ & HC-insoluble & Benzene/toluene/xylene & Cr fumes & 30 \\
\hline 2 & Pantex & IFF & $1.5 E-02$ & $1.7 \mathrm{E}+04$ & HC-insoluble & Benzene/toluene/xylene & $\mathrm{CO}$ & 30 \\
\hline 2 & Pantex & IFF & $1.5 \mathrm{E}-02$ & $4.8 E+03$ & Cl-4-x & Benzene/toluene/xylene & $\mathrm{HCl}$ & 30 \\
\hline 2 & Pantex & IFF & $1.5 \mathrm{E}-02$ & $7.2 \mathrm{E}+02$ & HC-insoluble & Benzene/toluene/xylene & $\mathrm{C}_{6} \mathrm{H}_{6}$ & 30 \\
\hline 2 & Pantex & IFF & $1.5 \mathrm{E}-02$ & $7.2 E+03$ & HC-insoluble & Benzene/toluene/xylene & PAH soot & 30 \\
\hline 2 & Pantex & IFF & $1.5 \mathrm{E}-02$ & $4.8 \mathrm{E}+01$ & HC-insoluble & Benzene/toluene/xylene & Cd fumes & 30 \\
\hline 2 & Pantex & IFF & $1.5 \mathrm{E}-02$ & $4.8 \mathrm{E}+01$ & HC-insoluble & Benzene/toluene/xylene & Cr fumes & 30 \\
\hline 2 & Pearl $\mathrm{H}$ & IFF & $1.5 \mathrm{E}-02$ & $4.1 E+01$ & HC-insoluble & Benzene/toluene/xylene & $\mathrm{CO}$ & 30 \\
\hline 2 & Pearl $\mathrm{H}$ & IFF & $1.5 \mathrm{E}-02$ & $1.2 \mathrm{E}+01$ & $\mathrm{Cl}-4-\mathrm{x}$ & Benzene/toluene/xylene & $\mathrm{HCl}$ & 30 \\
\hline 2 & Pearl H & IFF & $1.5 \mathrm{E}-02$ & $1.8 \mathrm{E}+00$ & HC-insoluble & Benzene/toluene/xylene & $\mathrm{C}_{6} \mathrm{H}_{6}$ & 30 \\
\hline 2 & Pearl H & IFF & $1.5 \mathrm{E}-02$ & $1.8 \mathrm{E}+01$ & HC-insoluble & Benzene/toluene/xylene & PAH soot & 30 \\
\hline 2 & Pearl $\mathrm{H}$ & IFF & $1.5 \mathrm{E}-02$ & $1.2 \mathrm{E}-01$ & HC-insoluble & Benzene/toluene/xylene & Cd fumes & 30 \\
\hline 2 & Pearl H & IFF & $1.5 \mathrm{E}-02$ & $1.2 \mathrm{E}-01$ & HC-insoluble & Benzene/toluene/xylene & Cr fumes & 30 \\
\hline 2 & PORTS & IFF & $1.5 \mathrm{E}-02$ & $1.5 \mathrm{E}+05$ & HC-insoluble & Benzene/toluene/xylene & $\mathrm{CO}$ & 30 \\
\hline 2 & PORTS & IFF & $1.5 E-02$ & $4.4 \mathrm{E}+04$ & $\mathrm{Cl}-4-\mathrm{x}$ & Benzene/toluene/xylene & $\mathrm{HCl}$ & 30 \\
\hline 2 & PORTS & IFF & $1.5 \mathrm{E}-02$ & $6.5 E+03$ & HC-insoluble & Benzene/toluene/xylene & $\mathrm{C}_{6} \mathrm{H}_{6}$ & 30 \\
\hline 2 & PORTS & IFF & $1.5 \mathrm{E}-02$ & $6.5 E+04$ & HC-insoluble & Benzene/toluene/xylene & PAH soot & 30 \\
\hline 2 & PORTS & IFF & $1.5 \mathrm{E}-02$ & $4.4 \mathrm{E}+02$ & HC-insoluble & Benzene/toluene/xylene & Cd fumes & 30 \\
\hline 2 & PORTS & IFF & $1.5 \mathrm{E}-02$ & $4.4 \mathrm{E}+02$ & HC-insoluble & Benzene/toluene/xylene & Cr fumes & 30 \\
\hline 2 & PPPL & IFF & $1.5 \mathrm{E}-02$ & $1.0 \mathrm{E}-01$ & HC-insoluble & Benzene/toluene/xylene & $\mathrm{CO}$ & 30 \\
\hline 2 & PPPL & IFF & $1.5 \mathrm{E}-02$ & $3.0 \mathrm{E}-02$ & Cl-4-x & Benzene/toluene/xylene & $\mathrm{HCl}$ & 30 \\
\hline 2 & PPPL & IFF & $1.5 \mathrm{E}-02$ & $4.4 \mathrm{E}-03$ & HC-insoluble & Benzene/toluene/xylene & $\mathrm{C}_{6} \mathrm{H}_{6}$ & 30 \\
\hline 2 & PPPL & IFF & $1.5 \mathrm{E}-02$ & $4.4 \mathrm{E}-02$ & HC-insoluble & Benzene/toluene/xylene & PAH soot & 30 \\
\hline 2 & PPPL & IFF & $1.5 \mathrm{E}-02$ & $3.0 \mathrm{E}-04$ & HC-insoluble & Benzene/toluene/xylene & Cd fumes & 30 \\
\hline 2 & PPPL & IFF & $1.5 \mathrm{E}-02$ & $3.0 \mathrm{E}-04$ & HC-insoluble & Benzene/toluene/xylene & Cr fumes & 30 \\
\hline 2 & Puget So & IFF & $1.5 \mathrm{E}-02$ & $1.3 E+03$ & HC-insoluble & Benzene/toluene/xylene & $\mathrm{CO}$ & 30 \\
\hline 2 & Puget So & IFF & $1.5 \mathrm{E}-02$ & $3.7 \mathrm{E}+02$ & $\mathrm{Cl}-4-\mathrm{x}$ & Benzene/toluene/xylene & $\mathrm{HCl}$ & 30 \\
\hline 2 & Puget So & IFF & $1.5 \mathrm{E}-02$ & $5.5 \mathrm{E}+01$ & HC-insoluble & Benzene/toluene/xylene & $\mathrm{C}_{6} \mathrm{H}_{6}$ & 30 \\
\hline
\end{tabular}


TABLE A.2 (Cont.)

\begin{tabular}{|c|c|c|c|c|c|c|c|c|}
\hline $\begin{array}{l}\text { WM PEIS } \\
\text { Alternative }^{\mathrm{a}}\end{array}$ & Site $^{\mathrm{b}}$ & $\begin{array}{c}\text { Initial } \\
\text { Accident }^{c} \\
\end{array}$ & $\begin{array}{c}\text { Accident Frequency } \\
\text { (1/yr) }\end{array}$ & $\begin{array}{c}\text { Release } \\
\text { Amount (g) } \\
\end{array}$ & Chemical ID ${ }^{d}$ & Contaminant & Toxic Gas ${ }^{\mathrm{c}}$ & $\begin{array}{c}\begin{array}{c}\text { Release Time } \\
\text { (min) }\end{array} \\
\end{array}$ \\
\hline 2 & Puget So & IFF & $1.5 \mathrm{E}-02$ & $5.5 \mathrm{E}+02$ & HC-insoluble & Benzene/toluene/xylene & PAH soot & 30 \\
\hline 2 & Puget So & IFF & $1.5 \mathrm{E}-02$ & $3.7 E+00$ & HC-insoluble & Benzene/toluene/xylene & Cd fumes & 30 \\
\hline 2 & Puget So & IFF & $1.5 \mathrm{E}-02$ & 3.7E+00 & HC-insoluble & Benzene/toluene/xylene & $\mathrm{Cr}$ fumes & 30 \\
\hline 2 & RMI & IFF & $1.5 \mathrm{E}-02$ & $6.9 \mathrm{E}+02$ & HC-insoluble & Benzene/toluene/xylene & $\mathrm{CO}$ & 30 \\
\hline 2 & RMI & IFF & $1.5 \mathrm{E}-02$ & $2.0 \mathrm{E}+02$ & $\mathrm{Cl}-4-\mathrm{x}$ & Benzene/toluene/xylene & $\mathrm{HCl}$ & 30 \\
\hline 2 & RMI & IFF & $1.5 \mathrm{E}-02$ & $3.0 \mathrm{E}+01$ & HC-insoluble & Benzene/toluene/xylene & $\mathrm{C}_{6} \mathrm{H}_{6}$ & 30 \\
\hline 2 & RMI & IFF & $1.5 \mathrm{E}-02$ & $3.0 \mathrm{E}+02$ & HC-insoluble & Benzene/toluene/xylene & PAH soot & 30 \\
\hline 2 & RMI & IFF & $1.5 \mathrm{E}-02$ & $2.0 \mathrm{E}+00$ & HC-insoluble & Benzene/toluene/xylene & Cd fumes & 30 \\
\hline 2 & RMI & IFF & $1.5 \mathrm{E}-02$ & $2.0 \mathrm{E}+00$ & HC-insoluble & Benzene/toluene/xylene & Cr fumes & 30 \\
\hline 2 & SNL-NM & IFF & $1.5 \mathrm{E}-02$ & $1.0 \mathrm{E}+03$ & HC-insoluble & Benzene/toluene/xylène & $\mathrm{CO}$ & 30 \\
\hline 2 & SNL-NM & IFF & $1.5 \mathrm{E}-02$ & $3.0 \mathrm{E}+02$ & Cl-4-x & Benzene/toluene/xylene & $\mathrm{HCl}$ & 30 \\
\hline 2 & SNL-NM & IFF & $1.5 \mathrm{E}-02$ & $4.5 \mathrm{E}+01$ & HC-insoluble & Benzene/toluene/xylene & $\mathrm{C}_{6} \mathrm{H}_{6}$ & 30 \\
\hline 2 & SNL-NM & IFF & $1.5 \mathrm{E}-02$ & $4.5 \mathrm{E}+02$ & HC-insoluble & Benzene/toluene/xylene & PAH soot & 30 \\
\hline 2 & SNL-NM & IFF & $1.5 \mathrm{E}-02$ & $3.0 \mathrm{E}+00$ & HC-insoluble & Benzene/toluene/xylene & Cd fumes & 30 \\
\hline 2 & SNL-NM & IFF & $1.5 \mathrm{E}-02$ & $3.0 \mathrm{E}+00$ & HC-insoluble & Benzene/toluene/xylene & Cr fumes & 30 \\
\hline 2 & SRS & IFF & $1.5 \mathrm{E}-02$ & $2.4 \mathrm{E}+05$ & HC-insoluble & Benzene/toluene/xylene & $\mathrm{CO}$ & 30 \\
\hline 2 & SRS & IFF & $1.5 \mathrm{E}-02$ & $6.8 \mathrm{E}+04$ & $\mathrm{Cl}-4-\mathrm{x}$ & Benzene/toluene/xylene & $\mathrm{HCl}$ & 30 \\
\hline 2 & SRS & IFF & $1.5 \mathrm{E}-02$ & $1.0 \mathrm{E}+04$ & HC-insoluble & Benzene/toluene/xylene & $\mathrm{C}_{6} \mathrm{H}_{6}$ & 30 \\
\hline 2 & SRS & IFF & $1.5 \mathrm{E}-02$ & $1.0 \mathrm{E}+05$ & HC-insoluble & Benzene/toluene/xylene & PAH soot & 30 \\
\hline 2 & SRS & IFF & $1.5 \mathrm{E}-02$ & $6.8 \mathrm{E}+02$ & HC-insoluble & Benzene/toluene/xylene & Cd fumes & 30 \\
\hline 2 & SRS & IFF & $1.5 \mathrm{E}-02$ & $6.8 \mathrm{E}+02$ & HC-insoluble & Benzene/toluene/xylene & $\mathrm{Cr}$ fumes & 30 \\
\hline 4 & ETEC & IFF & $1.5 \mathrm{E}-02$ & $7.6 \mathrm{E}+01$ & HC-insoluble & Benzene/toluene/xylene & $\mathrm{CO}$ & 30 \\
\hline 4 & ETEC & IFF & $1.5 \mathrm{E}-02$ & $2.2 \mathrm{E}+0 \mathrm{I}$ & $\mathrm{Cl}-4-\mathrm{x}$ & Benzene/toluene/xylene & $\mathrm{HCl}$ & 30 \\
\hline 4 & ETEC & IFF & $1.5 \mathrm{E}-02$ & $3.3 \mathrm{E}+00$ & HC-insoluble & Benzene/toluene/xylene & $\mathrm{C}_{6} \mathrm{H}_{6}$ & 30 \\
\hline 4 & ETEC & IFF & $1.5 \mathrm{E}-02$ & 3.3E+01 & $\mathrm{HC}$-insoluble & Benzene/toluene/xylene & PAH soot & 30 \\
\hline 4 & ETEC & IFF & $1.5 \mathrm{E}-02$ & $2.2 \mathrm{E}-01$ & HC-insoluble & Benzene/toluene/xylene & $\mathrm{Cd}$ fumes & 30 \\
\hline 4 & ETEC & IFF & $1.5 \mathrm{E}-02$ & $2.2 \mathrm{E}-01$ & HC-insoluble & Benzene/toluene/xylene & Cr fumes & 30 \\
\hline 4 & FEMP & IFF & $1.5 \mathrm{E}-02$ & $1.8 \mathrm{E}+04$ & HC-insoluble & Benzene/toluene/xylene & $\mathrm{CO}$ & 30 \\
\hline 4 & FEMP & IFF & $1.5 \mathrm{E}-02$ & $5.0 \mathrm{E}+03$ & Cl-4-x & Benzene/toluene/xylene & $\mathrm{HCl}$ & 30 \\
\hline 4 & FEMP & IFF & $1.5 \mathrm{E}-02$ & $7.6 \mathrm{E}+02$ & HC-insoluble & Benzene/toluene/xylene & $\mathrm{C}_{6} \mathrm{H}_{6}$ & 30 \\
\hline 4 & FEMP & IFF & $1.5 \mathrm{E}-02$ & $7.6 \mathrm{E}+03$ & HC-insoluble & Benzene/toluene/xylene & PAH soot & 30 \\
\hline 4 & FEMP & IFF & $1.5 \mathrm{E}-02$ & $5.0 \mathrm{E}+01$ & HC-insoluble & Benzene/toluene/xylene & $\mathrm{Cd}$ fumes & 30 \\
\hline 4 & FEMP & IFF & $1.5 \mathrm{E}-02$ & $5.0 \mathrm{E}+01$ & HC-insoluble & Benzene/toluene/xylene & Cr fumes & 30 \\
\hline 4 & Hanford & IFF & $1.5 \mathrm{E}-02$ & $7.9 \mathrm{E}+04$ & HC-insoluble & Benzene/toluene/xylene & $\mathrm{CO}$ & 30 \\
\hline 4 & Hanford & IFF & $1.5 \mathrm{E}-02$ & $2.2 \mathrm{E}+04$ & $\mathrm{Cl}-4-\mathrm{x}$ & Benzene/toluene/xylene & $\mathrm{HCl}$ & 30 \\
\hline 4 & Hanford & IFF & $1.5 \mathrm{E}-02$ & $3.4 \mathrm{E}+03$ & HC-insoluble & Benzene/toluene/xylene & $\mathrm{C}_{6} \mathrm{H}_{6}$ & 30 \\
\hline 4 & Hanford & IFF & $1.5 \mathrm{E}-02$ & $3.4 \mathrm{E}+04$ & HC-insoluble & Benzene/toluene/xylene & PAH soot & 30 \\
\hline 4 & Hanford & IFF & $1.5 E-02$ & $2.2 \mathrm{E}+02$ & HC-insoluble & Benzene/toluene/xylene & Cu fumes & 30 \\
\hline 4 & Hanford & IFF & $1.5 \mathrm{E}-02$ & $2.2 \mathrm{E}+02$ & HC-insoluble & Benzene/toluene/xylene & Cr fumes & 30 \\
\hline 4 & INEL & IFF & $1.5 \mathrm{E}-02$ & $5.4 \mathrm{E}+03$ & HC-insoluble & Benzene/toluene/xylene & $\mathrm{CO}$ & 30 \\
\hline
\end{tabular}


TABLE A.2 (Cont.)

\begin{tabular}{|c|c|c|c|c|c|c|c|c|}
\hline $\begin{array}{l}\text { WM PEIS } \\
\text { Altemative }^{\mathrm{a}}\end{array}$ & Site $^{b}$ & $\begin{array}{c}\text { Initial } \\
\text { Accident }\end{array}$ & $\begin{array}{l}\text { Accident Frequency } \\
(1 / \mathrm{yr})\end{array}$ & $\begin{array}{c}\text { Release } \\
\text { Amount (g) }\end{array}$ & Chemical ID & Contaminant & Toxic Gas & $\begin{array}{c}\text { Release Time } \\
\text { (min) }\end{array}$ \\
\hline 4 & INEL & IFF & $1.5 \mathrm{E}-02$ & $1.5 \mathrm{E}+03$ & $\mathrm{Cl}-4-\mathrm{x}$ & Benzene/toluene/xylene & $\mathrm{HCl}$ & 30 \\
\hline 4 & INEL & IFF & $1.5 \mathrm{E}-02$ & $2.3 \mathrm{E}+02$ & HC-insoluble & Benzene/toluene/xylene & $\mathrm{C}_{6} \mathrm{H}_{6}$ & 30 \\
\hline 4 & INEL & IFF & $1.5 \mathrm{E}-02$ & $2.3 E+03$ & HC-insoluble & Benzene/toluene/xylene & PÄH soot & 30 \\
\hline 4 & INEL & IFF & $1.5 \mathrm{E}-02$ & $1.5 \mathrm{E}+01$ & HC-insoluble & Benzene/toluene/xylene & Cd fumes & 30 \\
\hline 4 & INEL & IFF & $1.5 \mathrm{E}-02$ & $1.5 \mathrm{E}+01$ & HC-insoluble & Benzene/toluene/xylene & Cr furnes & 30 \\
\hline 4 & LANL & IFF & $1.5 \mathrm{E}-02$ & $4.4 E+03$ & HC-insoluble & Benzene/toluene/xylene & $\mathrm{CO}$ & 30 \\
\hline 4 & LANL & IFF & $1.5 \mathrm{E}-02$ & $1.3 E+03$ & $\mathrm{Cl}-4-\mathrm{x}$ & Benzene/toluene/xylene & $\mathrm{HCl}$ & 30 \\
\hline 4 & LANL & IFF & $1.5 \mathrm{E}-02$ & $1.9 \mathrm{E}+02$ & HC-insoluble & Benzene/toluene/xylene & $\mathrm{C}_{6} \mathrm{H}_{6}$ & 30 \\
\hline 4 & LANL & IFF & $1.5 \mathrm{E}-02$ & $1.9 \mathrm{E}+03$ & HC-insoluble & Benzene/toluene/xylene & PAH soot & 30 \\
\hline 4 & LANL & IFF & $1.5 \mathrm{E}-02$ & $1.3 \mathrm{E}+01$ & HC-insoluble & Benzene/toluene/xylene & Cd fumes & 30 \\
\hline 4 & LANL & IFF & $1.5 \mathrm{E}-02$ & $1.3 \mathrm{E}+01$ & HC-insoluble & Benzene/toluene/xylene & Cr fumes & 30 \\
\hline 4 & LLNL & IFF & $1.5 \mathrm{E}-02$ & 4.1E+04 & HC-insoluble & Benzene/toluene/xylene & $\mathrm{CO}$ & 30 \\
\hline 4 & LLNL & IFF & $1.5 \mathrm{E}-02$ & $1.2 \mathrm{E}+04$ & $\mathrm{Cl}-4-\mathrm{x}$ & Benzene/toluene/xylene & $\mathrm{HCl}$ & 30 \\
\hline 4 & LLNL & IFF & $1.5 \mathrm{E}-02$ & $1.8 \mathrm{E}+03$ & HC-insoluble & Benzene/toluene/xylene & $\mathrm{C}_{6} \mathrm{H}_{6}$ & 30 \\
\hline 4 & LLNL & IFF & $1.5 \mathrm{E}-02$ & $1.8 \mathrm{E}+04$ & HC-insoluble & Benzene/toluene/xylene & PAH soot & 30 \\
\hline 4 & LLNL & IFF & $1.5 \mathrm{E}-02$ & $1.2 \mathrm{E}+02$ & HC-insoluble & Benzene/toluene/xylene & Cd fumes & 30 \\
\hline 4 & LLNL & IFF & $1.5 \mathrm{E}-02$ & $1.2 \mathrm{E}+02$ & HC-insoluble & Benzene/toluene/xylene & $\mathrm{Cr}$ fumes & 30 \\
\hline 4 & ORR & IFF & $1.5 \mathrm{E}-02$ & $6.2 E+05$ & HC-insoluble & Benzene/toluene/xylene & $\mathrm{CO}$ & 30 \\
\hline 4 & ORR & IFF & $1.5 \mathrm{E}-02$ & $1.8 \mathrm{E}+05$ & $\mathrm{Cl}-4-\mathrm{x}$ & Benzene/toluene/xylene & $\mathrm{HCl}$ & 30 \\
\hline 4 & ORR & IFF & $1.5 \mathrm{E}-02$ & 2.7E+04 & HC-insoluble & Benzene/toluene/xylene & $\mathrm{C}_{6} \mathrm{H}_{6}$ & 30 \\
\hline 4 & ORR & IFF & $1.5 \mathrm{E}-02$ & $2.7 \mathrm{E}+05$ & HC-insoluble & Benzene/toluene/xylene & PÁH soot & 30 \\
\hline 4 & ORR & IFF & $1.5 \mathrm{E}-02$ & $1.8 \mathrm{E}+03$ & HC-insoluble & Benzene/toluene/xylene & $\mathrm{Cd}$ fumes & 30 \\
\hline 4 & ORR & IFF & $1.5 \mathrm{E}-02$ & $1.8 \mathrm{E}+03$ & HC-insoluble & Benzene/toluene/xylene & $\mathrm{Cr}$ fumes & 30 \\
\hline 4 & PGDP & IFF & $1.5 \mathrm{E}-02$ & $1.5 E+04$ & HC-insoluble & Benzene/toluene/xylene & $\mathrm{CO}$ & 30 \\
\hline 4 & PGDP & IFF & $1.5 \mathrm{E}-02$ & $4.2 \mathrm{E}+03$ & $\mathrm{Cl}-4-\mathrm{x}$ & Benzene/toluene/xylene & $\mathrm{HCl}$ & 30 \\
\hline 4 & PGDP & IFF & $1.5 \mathrm{E}-02$ & $6.3 E+02$ & HC-insoluble & Benzene/toluene/xylene & $\mathrm{C}_{6} \mathrm{H}_{6}$ & 30 \\
\hline 4 & PGDP & IFF & $1.5 \mathrm{E}-02$ & $6.3 E+03$ & HC-insoluble & Benzene/toluene/xylene & PAH soot & 30 \\
\hline 4 & PGDP & IFF & $1.5 \mathrm{E}-02$ & $4.2 \mathrm{E}+01$ & HC-insoluble & Benzene/toluene/xylene & $\mathrm{Cd}$ fumes & 30 \\
\hline 4 & PGDP & IFF & $1.5 \mathrm{E}-02$ & $4.2 \mathrm{E}+01$ & HC-insoluble & Benzene/toluene/xylene & $\mathrm{Cr}$ fumes & 30 \\
\hline 4 & Pantex & IFF & $1.5 \mathrm{E}-02$ & $1.7 \mathrm{E}+0.4$ & HC-insoluble & Benzene/toluene/xylene & $\mathrm{CO}$ & 30 \\
\hline 4 & Pantex & IFF & $1.5 \mathrm{E}-02$ & $4.8 \mathrm{E}+03$ & Cl-4-x & Benzene/toluene/xylene & $\mathrm{HCl}$ & 30 \\
\hline 4 & Pantex & IFF & $1.5 \mathrm{E}-02$ & $7.2 \mathrm{E}+02$ & HC-insoluble & Benzene/toluene/xylene & $\mathrm{C}_{6} \mathrm{H}_{6}$ & 30 \\
\hline 4 & Pantex & IFF & $1.5 \mathrm{E}-02$ & $7.2 \mathrm{E}+03$ & HC-insoluble & Benzene/toluene/xylene & PÄH soot & 30 \\
\hline 4 & Pantex & IFF & $1.5 \mathrm{E}-02$ & $4.8 \mathrm{E}+01$ & HC-insoluble & Benzene/toluene/xylene & Cd fumes & 30 \\
\hline 4 & Pantex & IFF & $1.5 E-02$ & $4.8 \mathrm{E}+01$ & HC-insoluble & Benzene/toluene/xylene & $\mathrm{Cr}$ fumes & 30 \\
\hline 4 & PORTS & IFF & $1.5 \mathrm{E}-02$ & $1.6 \mathrm{E}+05$ & HC-insoluble & Benzene/toluene/xylene & $\mathrm{CO}$ & 30 \\
\hline 4 & PORTS & IFF & $1.5 E-02$ & $4.5 \mathrm{E}+04$ & $\mathrm{Cl}-4-\mathrm{x}$ & Benzene/toluene/xylene & $\mathrm{HCl}$ & 30 \\
\hline 4 & PORTS & IFF & $1.5 E-02$ & $6.7 \mathrm{E}+03$ & HC-insoluble & Benzene/toluene/xylene & $\mathrm{C}_{6} \mathrm{H}_{6}$ & 30 \\
\hline 4 & PORTS & IFF & $1.5 \mathrm{E}-02$ & $6.7 \mathrm{E}+04$ & HC-insoluble & Benzene/toluene/xylene & PAH soot & 30 \\
\hline 4 & PORTS & IFF & $1.5 \mathrm{E}-02$ & $4.5 \mathrm{E}+02$ & $\mathrm{HC}$-insoluble & Benzene/toluene/xylene & Cd fumes & 30 \\
\hline
\end{tabular}


TABLE A.2 (Cont.)

\begin{tabular}{|c|c|c|c|c|c|c|c|c|}
\hline $\begin{array}{l}\text { WM PEIS } \\
\text { Alternative }^{a}\end{array}$ & Site $^{b}$ & $\begin{array}{c}\text { Initial } \\
\text { Accident }^{\mathbf{c}} \\
\end{array}$ & $\begin{array}{c}\text { Accident Frequency } \\
(1 / \mathrm{yr})\end{array}$ & $\begin{array}{c}\text { Release } \\
\text { Amount (g) }\end{array}$ & Chemical ID & Contaminant & Toxic Gas $^{c}$ & $\begin{array}{c}\text { Release Time } \\
\text { (min) }\end{array}$ \\
\hline 4 & PORTS & IFF & $1.5 \mathrm{E}-02$ & $4.5 E+02$ & HC-insoluble & Benzene/toluene/xylene & $\mathrm{Cr}$ fumes & 30 \\
\hline 4 & RFETS & IFF & $1.5 \mathrm{E}-02$ & $6.1 E+00$ & HC-insoluble & Benzene/toluene/xylene & $\mathrm{CO}$ & 30 \\
\hline 4 & RFETS & IFF & $1.5 \mathrm{E}-02$ & $1.7 \mathrm{E}+00$ & $\mathrm{Cl}-4-\mathrm{x}$ & Benzene/toluene/xylene & $\mathrm{HCl}$ & 30 \\
\hline 4 & RFETS & IFF & $1.5 \mathrm{E}-02$ & $2.6 \mathrm{E}-01$ & HC-insoluble & Benzene/toluene/xylene & $\mathrm{C}_{6} \mathrm{H}_{6}$ & 30 \\
\hline 4 & RFETS & IFF & $1.5 \mathrm{E}-02$ & $2.6 \mathrm{E}+00$ & HC-insoluble & Benzene/toluene/xylene & PAH soot & 30 \\
\hline 4 & RFETS & IFF & $1.5 \mathrm{E}-02$ & $1.7 \mathrm{E}-02$ & HC-insoluble & Benzene/toluene/xylene & Cd fumes & 30 \\
\hline 4 & RFETS & IFF & $1.5 \mathrm{E}-02$ & $1.7 \mathrm{E}-02$ & HC-insoluble & Benzene/toluene/xylene & $\mathrm{Cr}$ fumes & 30 \\
\hline 4 & SRS & IFF & $1.5 \mathrm{E}-02$ & $2.4 \mathrm{E}+05$ & HC-insoluble & Benzene/toluene/xylene & $\mathrm{CO}$ & 30 \\
\hline 4 & SRS & IFF & $1.5 \mathrm{E}-02$ & $6.8 \mathrm{E}+04$ & $\mathrm{Cl}-4-\mathrm{x}$ & Benzene/toluene/xylene & $\mathrm{HCl}$ & 30 \\
\hline 4 & SRS & IFF & $1.5 \mathrm{E}-02$ & $1.0 \mathrm{E}+04$ & HC-insoluble & Benzene/toluene/xylene & $\mathrm{C}_{6} \mathrm{H}_{6}$ & 30 \\
\hline 4 & SRS & IFF & $1.5 \mathrm{E}-02$ & $1.0 \mathrm{E}+05$ & HC-insoluble & Benzene/toluene/xylene & PAH soot & 30 \\
\hline 4 & SRS & IFF & $1.5 \mathrm{E}-02$ & $6.8 \mathrm{E}+02$ & HC-insoluble & Benzene/toluene/xylene & Cd fumes & 30 \\
\hline 4 & SRS & IFF & $1.5 \mathrm{E}-02$ & $6.8 \mathrm{E}+02$ & HC-insoluble & Benzene/toluene/xylene & $\mathrm{Cr}$ fumes & 30 \\
\hline 7 & Hanford & IFF & $1.5 \mathrm{E}-02$ & $1.2 \mathrm{E}+05$ & HC-insoluble & Benzene/toluene/xylene & $\mathrm{CO}$ & 30 \\
\hline 7 & Hanford & IFF & $1.5 \mathrm{E}-02$ & $3.4 \mathrm{E}+04$ & Cl-4-x & Benzene/toluene/xylene & $\mathrm{HCl}$ & 30 \\
\hline 7 & Hanford & IFF & $1.5 \mathrm{E}-02$ & $5.1 \mathrm{E}+03$ & HC-insoluble & Benzene/toluene/xylene & $\mathrm{C}_{6} \mathrm{H}_{6}$ & 30 \\
\hline 7 & Hanford & IFF & $1.5 \mathrm{E}-02$ & $5.1 \mathrm{E}+04$ & HC-insoluble & Benzene/toluene/xylene & PAH soot & 30 \\
\hline 7 & Hanford & IFF & $1.5 \mathrm{E}-02$ & $3.4 \mathrm{E}+02$ & HC-insoluble & Benzene/toluene/xylene & Cd fumes & 30 \\
\hline 7 & Hanford & IFF & $1.5 \mathrm{E}-02$ & $3.4 \mathrm{E}+02$ & HC-insoluble & Benzene/toluene/xylene & $\mathrm{Cr}$ fumes & 30 \\
\hline 7 & INEL & IFF & $1.5 \mathrm{E}-02$ & $5.5 E+03$ & HC-insoluble & Benzene/toluene/xylene & $\mathrm{CO}$ & 30 \\
\hline 7 & INEL & IFF & $1.5 \mathrm{E}-02$ & $1.6 \mathrm{E}+03$ & $\mathrm{Cl}-4-\mathrm{x}$ & Benzene/toluene/xylene & $\mathrm{HCl}$ & 30 \\
\hline 7 & INEL & IFF & $1.5 E-02$ & $2.4 \mathrm{E}+02$ & HC-insoluble & Benzene/toluene/xylene & $\mathrm{C}_{6} \mathrm{H}_{6}$ & 30 \\
\hline 7 & INEL & IFF & $1.5 \mathrm{E}-02$ & $2.4 E+03$ & HC-insoluble & Benzene/toluene/xylene & PAH soot & 30 \\
\hline 7 & INEL & IFF & $1.5 E-02$ & $1.6 \mathrm{E}+01$ & HC-insoluble & Benzene/toluene/xylene & $\mathrm{Cd}$ fumes & 30 \\
\hline 7 & INEL & IFF & $1.5 E-02$ & $1.6 \mathrm{E}+01$ & HC-insoluble & Benzene/toluene/xylene & Cr fumes & 30 \\
\hline 7 & LANL & IFF & $1.5 \mathrm{E}-02$ & $2.1 E+04$ & HC-insoluble & Benzene/toluene/xylene & $\mathrm{CO}$ & 30 \\
\hline 7 & LANL & IFF & $1.5 \mathrm{E}-02$ & $6.0 \mathrm{E}+03$ & $\mathrm{Cl}-4-\mathrm{x}$ & Benzene/toluene/xylene & $\mathrm{HCl}$ & 30 \\
\hline 7 & LANL & IFF & $1.5 \mathrm{E}-02$ & $9.1 E+02$ & HC-insoluble & Benzene/toluene/xylene & $\mathrm{C}_{6} \mathrm{H}_{6}$ & 30 \\
\hline 7 & LANL & IFF & $1.5 \mathrm{E}-02$ & $9.1 \mathrm{E}+03$ & HC-insoluble & Benzene/toluene/xylene & PAH soot & 30 \\
\hline 7 & LANL & IFF & $1.5 \mathrm{E}-02$ & $6.0 \mathrm{E}+01$ & HC-insoluble & Benzene/toluene/xylene & Cd fumes & 30 \\
\hline 7 & LANL & IFF & $1.5 \mathrm{E}-02$ & $6.0 \mathrm{E}+01$ & HC-insoluble & Benzene/toluene/xylene & $\mathrm{Cr}$ fumes & 30 \\
\hline 7 & ORR & IFF & $1.5 \mathrm{E}-02$ & $6.3 E+05$ & HC-insoluble & Benzene/toluene/xylene & $\mathrm{CO}$ & 30 \\
\hline 7 & ORR & IFF & 1.5E-02 & $1.8 \mathrm{E}+05$ & $\mathrm{Cl}-4-\mathrm{x}$ & Benzene/toluene/xylene & $\mathrm{HCl}$ & 30 \\
\hline 7 & ORR & IFF & $1.5 E-02$ & $2.7 \mathrm{E}+04$ & HC-insoluble & Benzene/toluene/xylene & $\mathrm{C}_{6} \mathrm{H}_{6}$ & 30 \\
\hline 7 & ORR & IFF & $1.5 \mathrm{E}-02$ & $2.7 \mathrm{E}+05$ & HC-insoluble & Benzene/toluene/xylene & PAH soot & 30 \\
\hline 7 & ORR & IFF & $1.5 \mathrm{E}-02$ & $1.8 \mathrm{E}+03$ & HC-insoluble & Benzene/toluene/xylene & Cd fumes & 30 \\
\hline 7 & ORR & IFF & $1.5 \mathrm{E}-02$ & $1.8 \mathrm{E}+03$ & HC-insoluble & Benzene/toluene/xylene & Cr fumes & 30 \\
\hline 7 & PORTS & IFF & $1.5 \mathrm{E}-02$ & $1.7 \mathrm{E}+05$ & HC-insoluble & Benzene/toluene/xylene & $\mathrm{CO}$ & 30 \\
\hline 7 & PORTS & IFF & $1.5 \mathrm{E}-02$ & $5.0 \mathrm{E}+04$ & $\mathrm{Cl}-4-\mathrm{x}$ & Benzene/toluene/xylene & $\mathrm{HCl}$ & 30 \\
\hline 7 & PORTS & IFF & $1.5 \mathrm{E}-02$ & $7.5 \mathrm{E}+03$ & HC-insoluble & Benzene/toluene/xylene & $\mathrm{C}_{6} \mathrm{H}_{6}$ & 30 \\
\hline
\end{tabular}


TABLE A.2 (Cont.)

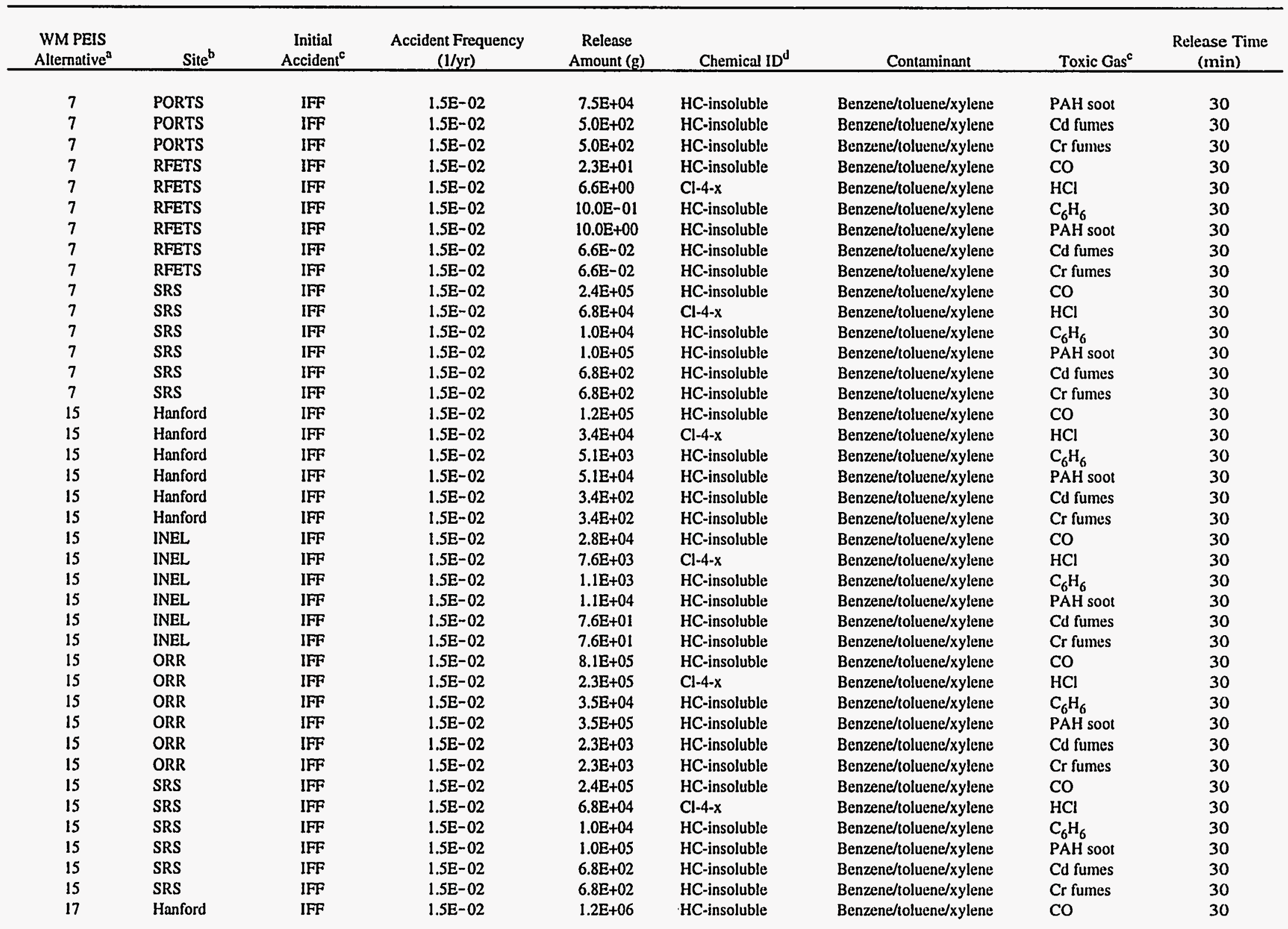


TABLE A.2 (Cont.)

\begin{tabular}{|c|c|c|c|c|c|c|c|c|}
\hline $\begin{array}{l}\text { WM PEIS } \\
\text { Alternative }^{a}\end{array}$ & Site $^{\mathrm{b}}$ & $\begin{array}{c}\text { Initial } \\
\text { Accident }^{c} \\
\end{array}$ & $\begin{array}{l}\text { Accident Frequency } \\
(1 / y r)\end{array}$ & $\begin{array}{c}\text { Release } \\
\text { Amount (g) }\end{array}$ & Chemical ID & Contaminant & Toxic Gas ${ }^{\mathfrak{c}}$ & $\begin{array}{c}\text { Release Time } \\
\text { (min) }\end{array}$ \\
\hline 17 & Hanford & IFF & $1.5 \mathrm{E}-02$ & $3.4 E+05$ & $\mathrm{Cl}-4-\mathrm{x}$ & Benzene/toluene/xylene & $\mathrm{HCl}$ & 30 \\
\hline 17 & Hanford & IFF & $1.5 \mathrm{E}-02$ & $5.1 E+04$ & HC-insoluble & Benzene/toluene/xylene & $\mathrm{C}_{6} \mathrm{H}_{6}$ & 30 \\
\hline 17 & Hanford & IFF & $1.5 \mathrm{E}-02$ & $5.1 E+05$ & HC-insoluble & Benzene/toluene/xylene & PAH soot & 30 \\
\hline 17 & Hanford & IFF & $1.5 \mathrm{E}-02$ & $3.4 \mathrm{E}+03$ & HC-insoluble & Benzene/toluene/xylene & Cd fumes & 30 \\
\hline 17 & Hanford & IFF & $1.5 \mathrm{E}-02$ & $3.4 \mathrm{E}+03$ & HC-insoluble & Benzene/toluene/xylene & $\mathrm{Cr}$ fumes & 30 \\
\hline 26 & SRS & IFF & $1.50 \mathrm{E}-02$ & $7.64 \mathrm{E}+01$ & HC-insoluble & Benzene/toluene/xylene & $\mathrm{CO}$ & 30 \\
\hline 26 & SRS & IFF & $1.50 \mathrm{E}-02$ & $2.18 E+01$ & $\mathrm{Cl}-4-\mathrm{x}$ & Benzene/toluene/xylene & $\mathrm{HCl}$ & 30 \\
\hline 26 & SRS & IFF & $1.50 \mathrm{E}-02$ & $3.28 \mathrm{E}+00$ & HC-insoluble & Benzene/toluene/xylene & $\mathrm{C}_{6} \mathrm{H}_{6}$ & 30 \\
\hline 26 & SRS & IFF & $1.50 \mathrm{E}-02$ & $3.28 \mathrm{E}+01$ & HC-insoluble & Benzene/toluene/xylene & PAH soot & 30 \\
\hline 26 & SRS & IFF & $1.50 \mathrm{E}-02$ & $2.18 \mathrm{E}-01$ & HC-insoluble & Benzene/toluene/xylene & Cd fumes & 30 \\
\hline 26 & SRS & IFF & $1.50 \mathrm{E}-02$ & $2.18 \mathrm{E}-01$ & HC-insoluble & Benzene/toluene/xylene & $\mathrm{Cr}$ fumes & 30 \\
\hline
\end{tabular}

a The WM PEIS cases analyzed are described as follows:

- Case I (No Action). Three sites (INEL, ORR, and SRS) treat and store, all remaining sites store.

- Case 2 (Decentralized). Forty-nine sites treat, and 16 sites dispose.

- Case 4 (Regionalized 1). Eleven sites (Hanford, INEL, LANL, ORR, SRS PORTS, PGDP, FEMP, LLNL, Pantex, and RFETS) treat, and 12 sites dispose.

- Case 7 (Regionalized 2). Seven sites (Hanford, INEL, LANL, ORR, SRS, PORTS, and RFETS) treat, and 6 sites dispose.

- Case 15 (Regionalized 4). Four sites (Hanford, INEL, ORR, and SRS) treat, and 6 sites dispose.

- $\quad$ Case 17 (Centralized). One site treats (Hanford) and 1 site disposes.
$\quad$ Case (Rmote-handled). Four sites (Hanford, INEL, ORR, and SRS) treat and dispose (RH) and dispose.

b Abbreviations: Ames = Ames Laboratory; ANL-E = Argonne National Laboratory-East; GA = General Atomics; KCP = Kansas City Plant; LEHR = Laboratory for Energy-Related Health Research; Mare Is $=$ Mare Island; Norfolk = Norfolk Naval Shipyard; PGDP = Paducah Gaseous Diffusion Plant; PORTS = Portsmouth Gaseous Diffusion Plant; and Puget So = Puget Sound.

- IFF = incineration facility fire in the feedstock staging area.

¿ Cl-4-x = tetra-chloro-hydrocarbons; and HC-insoluble = hazardous chemical-water insoluble organics.

- $\mathrm{C}_{6} \mathrm{H}_{6}=$ benzene; $\mathrm{PAH}$ soot = polyaromatic hydrocarbon soot $\mathrm{CO}=$ carbon monoxide; $\mathrm{HCl}=$ hydrogen chloride; $\mathrm{Cd}$ fumes = cadmium fumes; and $\mathrm{Cr}$ fumes = chromium fumes. 
TABLE A.3 Frequencies and Chemical Source Terms for WM-LLMW Alpha Incineration Facility Accidents

\begin{tabular}{|c|c|c|c|c|c|c|c|c|}
\hline $\begin{array}{c}\text { WM PEIS } \\
\text { Alternative }^{a}\end{array}$ & Site & $\begin{array}{c}\text { Initial } \\
\text { Accident }^{b}\end{array}$ & $\begin{array}{l}\text { Accident } \\
\text { Frequency }\end{array}$ & $\begin{array}{c}\text { Release } \\
\text { Amount (g) } \\
\end{array}$ & Chemical ID & Contaminant & Toxic Gas ${ }^{d}$ & $\begin{array}{c}\text { Release Time } \\
\text { (min) }\end{array}$ \\
\hline 2 & INEL & IFF & $1.5 \mathrm{E}-02$ & $6.5 E+04$ & HC-insoluble & Benzene/toluene/xylene & $\mathrm{CO}$ & 30 \\
\hline 2 & INEL & IFF & $1.5 E-02$ & $1.9 \mathrm{E}+04$ & $\mathrm{Cl}-4-\mathrm{x}$ & Benzene/toluene/xylene & $\mathrm{HCl}$ & 30 \\
\hline 2 & INEL & IFF & $1.5 \mathrm{E}-02$ & $2.8 E+03$ & HC-insoluble & Benzene/toluene/xylene & $\mathrm{C}_{6} \mathrm{H}_{6}$ & 30 \\
\hline 2 & INEL & IFF & $1.5 \mathrm{E}-02$ & $2.8 E+04$ & HC-insoluble & Benzene/toluene/xylene & PAH soot & 30 \\
\hline 2 & INEL & IFF & $1.5 \mathrm{E}-02$ & $1.9 \mathrm{E}+02$ & HC-insoluble & Benzene/toluene/xylene & Cd fumes & 30 \\
\hline 2 & INEL & IFF & $1.5 \mathrm{E}-02$ & $1.9 \mathrm{E}+02$ & HC-insoluble & Benzene/toluene/xylene & $\mathrm{Cr}$ fumes & 30 \\
\hline 2 & LANL & IFF & $1.5 E-02$ & $2.9 E+04$ & HC-insoluble & Benzene/toluene/xylene & $\mathrm{CO}$ & 30 \\
\hline 2 & LANL & IFF & $1.5 \mathrm{E}-02$ & $8.2 \mathrm{E}+03$ & $\mathrm{Cl}-4-\mathrm{x}$ & Benzene/toluene/xylene & $\mathrm{HCl}$ & 30 \\
\hline 2 & LANL & IFF & $1.5 \mathrm{E}-02$ & $1.2 \mathrm{E}+03$ & HC-insoluble & Benzene/toluene/xylene & $\mathrm{C}_{6} \mathrm{H}_{6}$ & 30 \\
\hline 2 & LANL & IFF & $1.5 \mathrm{E}-02$ & $1.2 E+04$ & HC-insoluble & Benzene/toluene/xylene & PAH soot & 30 \\
\hline 2 & LANL & IFF & $1.5 \mathrm{E}-02$ & $8.2 \mathrm{E}+01$ & HC-insoluble & Benzene/toluene/xylene & $\mathrm{Cd}$ fumes & 30 \\
\hline 2 & LANL & IFF & $1.5 E-02$ & $8.2 E+01$ & HC-insoluble & Benzene/toluene/xylene & $\mathrm{Cr}$ fumes & 30 \\
\hline 2 & LLNL & IFF & $1.5 \mathrm{E}-02$ & $2.9 E+04$ & HC-insoluble & Benzene/toluene/xylene & $\mathrm{CO}$ & 30 \\
\hline 2 & LLNL & IFF & $1.5 \mathrm{E}-02$ & $8.3 E+03$ & $\mathrm{Cl}-4-\mathrm{x}$ & Benzene/toluene/xylene & $\mathrm{HCl}$ & 30 \\
\hline 2 & LLNL & IFF & $1.5 \mathrm{E}-02$ & $1.2 \mathrm{E}+03$ & HC-insoluble & Benzene/toluene/xylene & $\mathrm{C}_{6} \mathrm{H}_{6}$ & 30 \\
\hline 2 & LLNL & IFF & $1.5 \mathrm{E}-02$ & $1.2 \mathrm{E}+04$ & HC-insoluble & Benzene/toluene/xylene & PAH soot & 30 \\
\hline 2 & LLNL & IFF & $1.5 \mathrm{E}-02$ & $8.3 E+01$ & HC-insoluble & Benzene/toluene/xylene & $\mathrm{Cd}$ fumes & 30 \\
\hline 2 & LLNL & IFF & $1.5 \mathrm{E}-02$ & $8.3 E+01$ & HC-insoluble & Benzene/toluene/xylene & $\mathrm{Cr}$ fumes & 30 \\
\hline 2 & RFETS & IFF & $1.5 \mathrm{E}-02$ & $1.4 \mathrm{E}+04$ & HC-insoluble & Benzene/toluene/xylene & $\mathrm{CO}$ & 30 \\
\hline 2 & RFETS & IFF & $1.5 \mathrm{E}-02$ & $3.9 E+03$ & $\mathrm{Cl}-4-\mathrm{x}$ & Benzene/toluene/xylene & $\mathrm{HCl}$ & 30 \\
\hline 2 & RFETS & IFF & $1.5 \mathrm{E}-02$ & $5.9 \mathrm{E}+02$ & HC-insoluble & Benzene/toluene/xylene & $\mathrm{C}_{6} \mathrm{H}_{6}$ & 30 \\
\hline 2 & RFETS & IFF & $1.5 \mathrm{E}-02$ & $5.9 \mathrm{E}+03$ & HC-insoluble & Benzene/toluene/xylene & PAH soot & 30 \\
\hline 2 & RFETS & IFF & $1.5 \mathrm{E}-02$ & $3.9 \mathrm{E}+01$ & HC-insoluble & Benzene/toluene/xylene & Cd fumes & 30 \\
\hline 2 & RFETS & IFF & $1.5 \mathrm{E}-02$ & $3.9 E+0 I$ & HC-insoluble & Benzene/toluene/xylene & Cr fumes & 30 \\
\hline 2 & SRS & IFF & $1.5 \mathrm{E}-02$ & $2.1 E+04$ & HC-insoluble & Benzene/toluene/xylene & $\mathrm{CO}$ & 30 \\
\hline 2 & SRS & IFF & $1.5 \mathrm{E}-02$ & $6.0 \mathrm{E}+03$ & $\mathrm{Cl}-4-\mathrm{x}$ & Benzene/toluene/xylene & $\mathrm{HCl}$ & 30 \\
\hline 2 & SRS & IFF & $1.5 \mathrm{E}-02$ & $9.1 \mathrm{E}+02$ & HC-insoluble & Benzene/toluene/xylene & $\mathrm{C}_{6} \mathrm{H}_{6}$ & 30 \\
\hline 2 & SRS & IFF & $1.5 \mathrm{E}-02$ & $9.1 E+03$ & HC-insoluble & Benzene/toluene/xylene & PÄH soot & 30 \\
\hline 2 & SRS & IFF & $1.5 \mathrm{E}-02$ & $6.0 \mathrm{E}+01$ & HC-insoluble & Benzene/toluene/xylene & Cd fumes & 30 \\
\hline 2 & SRS & IFF & $1.5 \mathrm{E}-02$ & $6.0 \mathrm{E}+01$ & HC-insoluble & Benzene/toluene/xylene & $\mathrm{Cr}$ fumes & 30 \\
\hline 4 & INEL & IFF & $1.5 E-02$ & $6.5 \mathrm{E}+04$ & HC-insoluble & Benzene/toluene/xylene & $\mathrm{CO}$ & 30 \\
\hline 4 & INEL & IFF & $1.5 \mathrm{E}-02$ & $1.9 \mathrm{E}+04$ & $\mathrm{Cl}-4-\mathrm{x}$ & Benzene/toluene/xylene & $\mathrm{HCl}$ & 30 \\
\hline 4 & INEL & IFF & $1.5 \mathrm{E}-02$ & $2.8 \mathrm{E}+03$ & HC-insoluble & Benzene/toluene/xylene & $\mathrm{C}_{6} \mathrm{H}_{6}$ & 30 \\
\hline 4 & INEL & $\mathrm{IFF}$ & $1.5 \mathrm{E}-02$ & $2.8 \mathrm{E}+04$ & HC-insoluble & Benzene/toluene/xylene & PAH soot & 30 \\
\hline 4 & INEL & IFF & $1.5 \mathrm{E}-02$ & $1.9 \mathrm{E}+02$ & HC-insoluble & Benzene/toluene/xylene & $\mathrm{Cd}$ fumes & 30 \\
\hline 4 & INEL & IFF & $1.5 \mathrm{E}-02$ & $1.9 \mathrm{E}+02$ & HC-insoluble & Benzene/toluene/xylene & $\mathrm{Cr}$ fumes & 30 \\
\hline
\end{tabular}


TABLE A.3 (Cont.)

\begin{tabular}{|c|c|c|c|c|c|c|c|c|}
\hline $\begin{array}{l}\text { WM PEIS } \\
\text { Alternative }^{\mathrm{a}}\end{array}$ & Site & $\begin{array}{c}\text { Initial } \\
\text { Accident }^{b} \\
\end{array}$ & $\begin{array}{l}\text { Accident } \\
\text { Frequency }\end{array}$ & $\begin{array}{c}\text { Release } \\
\text { Amount (g) } \\
\end{array}$ & Chemical ID & Contaminant & Toxic Gas ${ }^{\mathrm{d}}$ & $\begin{array}{c}\text { Release Time } \\
\text { (min) }\end{array}$ \\
\hline 4 & LANL & IFF & $1.5 \mathrm{E}-02$ & $2.9 \mathrm{E}+04$ & HC-insoluble & Benzene/toluene/xylene & $\mathrm{CO}$ & 30 \\
\hline 4 & LANL & IFF & $1.5 \mathrm{E}-02$ & $8.2 \mathrm{E}+03$ & $\mathrm{Cl}-4-\mathrm{x}$ & Benzene/toluene/xylene & $\mathrm{HCl}$ & 30 \\
\hline 4 & LANL & IFF & $1.5 \mathrm{E}-02$ & $1.2 \mathrm{E}+03$ & HC-insoluble & Benzene/toluene/xylene & $\mathrm{C}_{6} \mathrm{H}_{6}$ & 30 \\
\hline 4 & LANL & IFF & $1.5 \mathrm{E}-02$ & $1.2 \mathrm{E}+04$ & HC-insoluble & Benzene/toluene/xylene & PAH soot & 30 \\
\hline 4 & LANL & IFF & $1.5 \mathrm{E}-02$ & $8.2 E+01$ & HC-insoluble & Benzene/toluene/xylene & Cd fumes & 30 \\
\hline 4 & LANL & IFF & $1.5 \mathrm{E}-02$ & $8.2 E+01$ & HC-insoluble & Benzene/toluene/xylene & $\mathrm{Cr}$ fumes & 30 \\
\hline 4 & LLNL. & IFF & $1.5 E-02$ & $2.9 E+04$ & HC-insoluble & Benzene/toluene/xylene & $\mathrm{CO}$ & 30 \\
\hline 4 & LLNL & IFF & $1.5 \mathrm{E}-02$ & $8.3 E+03$ & Cl-4-x & Benzene/toluene/xylene & $\mathrm{HCl}$ & 30 \\
\hline 4 & LLNL & IFF & $1.5 \mathrm{E}-02$ & $1.2 E+03$ & HC-insoluble & Benzene/toluene/xylene & $\mathrm{C}_{6} \mathrm{H}_{6}$ & 30 \\
\hline 4 & LLNL & IFF & $1.5 \mathrm{E}-02$ & $1.2 \mathrm{E}+04$ & HC-insoluble & Benzene/toluene/xylene & PAH soot & 30 \\
\hline 4 & LLNL & IFF & $1.5 \mathrm{E}-02$ & $8.3 \mathrm{E}+01$ & HC-insoluble & Benzene/toluene/xylene & $\mathrm{Cd}$ fumes & 30 \\
\hline 4 & LLNL & IFF & $1.5 \mathrm{E}-02$ & $8.3 \mathrm{E}+01$ & HC-insoluble & Benzene/toluene/xylene & $\mathrm{Cr}$ fumes & 30 \\
\hline 4 & RFETS & IFF & $1.5 \mathrm{E}-02$ & $1.4 \mathrm{E}+04$ & HC-insoluble & Benzene/toluene/xylene & $\mathrm{CO}$ & 30 \\
\hline 4 & RFETS & IFF & $1.5 \mathrm{E}-02$ & $3.9 E+03$ & Cl-4-x & Benzene/toluene/xylene & $\mathrm{HCl}$ & 30 \\
\hline 4 & RFETS & IFF & $1.5 \mathrm{E}-02$ & $5.9 \mathrm{E}+02$ & HC-insoluble & Benzene/toluene/xylene & $\mathrm{C}_{6} \mathrm{H}_{6}$ & 30 \\
\hline 4 & RFETS & IFF & $1.5 \mathrm{E}-02$ & $5.9 E+03$ & HC-insoluble & Benzene/toluene/xylene & PÄH soot & 30 \\
\hline 4 & RFETS & IFF & $1.5 \mathrm{E}-02$ & $3.9 \mathrm{E}+01$ & HC-insoluble & Benzene/toluene/xylene & Cd fumes & 30 \\
\hline 4 & RFETS & IFF & $1.5 \mathrm{E}-02$ & $3.9 \mathrm{E}+01$ & HC-insoluble & Benzene/toluene/xylene & $\mathrm{Cr}$ fumes & 30 \\
\hline 4 & SRS & IFF & $1.5 \mathrm{E}-02$ & $2.1 E+04$ & HC-insoluble & Benzene/toluene/xylene & $\mathrm{CO}$ & 30 \\
\hline 4 & SRS & IFF & $1.5 \mathrm{E}-02$ & $6.0 \mathrm{E}+03$ & Cl-4-x & Benzene/toluene/xylene & $\mathrm{HCl}$ & 30 \\
\hline 4 & SRS & IFF & $1.5 \mathrm{E}-02$ & $9.1 \mathrm{E}+02$ & HC-insoluble & Benzene/toluene/xylene & $\mathrm{C}_{6} \mathrm{H}_{6}$ & 30 \\
\hline 4 & SRS & IFF & $1.5 \mathrm{E}-02$ & $9.1 \mathrm{E}+03$ & HC-insoluble & Benzene/toluene/xylene & PAH soot & 30 \\
\hline 4 & SRS & IFF & $1.5 \mathrm{E}-02$ & $6.0 \mathrm{E}+01$ & HC-insoluble & Benzene/toluene/xylene & Cd fumes & 30 \\
\hline 4 & SRS & IFF & $1.5 \mathrm{E}-02$ & $6.0 \mathrm{E}+01$ & HC-insoluble & Benzene/toluenc/xylene & Cr fumes & 30 \\
\hline 7 & INEL & IFF & $1.5 \mathrm{E}-02$ & $9.4 \mathrm{E}+04$ & HC-insoluble & Benzene/toluene/xylene & $\mathrm{CO}$ & 30 \\
\hline 7 & INEL & IFF & $1.5 \mathrm{E}-02$ & $2.7 \mathrm{E}+04$ & $\mathrm{Cl}-4-\mathrm{x}$ & Benzene/toluene/xylene & $\mathrm{HCl}$ & 30 \\
\hline 7 & INEL & IFF & $1.5 \mathrm{E}-02$ & $4.0 \mathrm{E}+03$ & HC-insoluble & Benzene/toluene/xylene & $\mathrm{C}_{6} \mathrm{H}_{6}$ & 30 \\
\hline 7 & INEL & IFF & $1.5 \mathrm{E}-02$ & $4.0 \mathrm{E}+04$ & HC-insoluble & Benzene/toluene/xylene & PAH soot & 30 \\
\hline 7 & INEL & IFF & $1.5 \mathrm{E}-02$ & $2.7 \mathrm{E}+02$ & HC-insoluble & Benzene/toluene/xylene & Cd fumes & 30 \\
\hline 7 & INEL & IFF & $1.5 \mathrm{E}-02$ & $2.7 \mathrm{E}+02$ & HC-insoluble & Benzene/toluene/xylene & $\mathrm{Cr}$ fumes & 30 \\
\hline 7 & LANL & IFF & $1.5 \mathrm{E}-02$ & $2.9 \mathrm{E}+04$ & HC-insoluble & Benzene/toluene/xylene & $\mathrm{CO}$ & 30 \\
\hline 7 & LANL & IFF & $1.5 \mathrm{E}-02$ & $8.2 E+03$ & $\mathrm{Cl}-4-\mathrm{x}$ & Benzene/toluene/xylene & $\mathrm{HCl}$ & 30 \\
\hline 7 & LANL & IFF & $1.5 \mathrm{E}-02$ & $1.2 \mathrm{E}+03$ & HC-insoluble & Benzene/toluene/xylene & $\mathrm{C}_{6} \mathrm{H}_{6}$ & 30 \\
\hline 7 & LANL & IFF & $1.5 \mathrm{E}-02$ & $1.2 \mathrm{E}+04$ & HC-insoluble & Benzene/toluene/xylene & PAH soot & 30 \\
\hline 7 & LANL & IFF & $1.5 \mathrm{E}-02$ & $8.2 \mathrm{E}+01$ & HC-insoluble & Benzene/toluene/xylene & Cd fumes & 30 \\
\hline 7 & LANL & IFF & $1.5 \mathrm{E}-02$ & $8.2 \mathrm{E}+01$ & HC-insoluble & Benzene/toluene/xylene & $\mathrm{Cr}$ furnes & 30 \\
\hline
\end{tabular}


TABLE A.3 (Cont.)

\begin{tabular}{|c|c|c|c|c|c|c|c|c|}
\hline $\begin{array}{l}\text { WM PEIS } \\
\text { Alternative }^{\mathrm{a}}\end{array}$ & Site & $\begin{array}{c}\text { Initial } \\
\text { Accident }^{\mathrm{b}} \\
\end{array}$ & $\begin{array}{c}\text { Accident } \\
\text { Frequency }\end{array}$ & $\begin{array}{c}\text { Release } \\
\text { Amount (g) }\end{array}$ & Chemical ID & Contaminant & Toxic Gas & $\begin{array}{l}\text { Release Time } \\
\quad \text { (min) }\end{array}$ \\
\hline 7 & RFETS & $\mathrm{IFF}$ & $1.5 \mathrm{E}-02$ & $1.4 \mathrm{E}+04$ & HC-insoluble & Benzene/toluene/xylene & $\mathrm{CO}$ & 30 \\
\hline 7 & RFETS & IFF & $1.5 \mathrm{E}-02$ & $3.9 \mathrm{E}+03$ & $\mathrm{Cl}-4-\mathrm{x}$ & Benzene/toluene/xylene & $\mathrm{HCl}$ & 30 \\
\hline 7 & RFETS & IFF & $1.5 \mathrm{E}-02$ & $5.9 \mathrm{E}+02$ & HC-insoluble & Benzene/loluene/xylene & $\mathrm{C}_{6} \mathrm{H}_{6}$ & 30 \\
\hline 7 & RFETS & IFF & $1.5 \mathrm{E}-02$ & $5.9 \mathrm{E}+03$ & HC-insoluble & Benzene/toluene/xylene & PAH soot & 30 \\
\hline 7 & RFETS & IFF & $1.5 \mathrm{E}-02$ & $3.9 \mathrm{E}+01$ & HC-insoluble & Benzene/toluene/xylene & $\mathrm{Cd}$ fumes & 30 \\
\hline 7 & RFETS & IFF & $1.5 \mathrm{E}-02$ & $3.9 E+01$ & HC-insoluble & Benzene/toluene/xylene & Cr fumes & 30 \\
\hline 7 & SRS & IFF & $1.5 \mathrm{E}-02$ & $2.1 \mathrm{E}+04$ & HC-insoluble & Benzene/toluene/xylene & $\mathrm{CO}$ & 30 \\
\hline 7 & SRS & IFF & $1.5 \mathrm{E}-02$ & $6.0 \mathrm{E}+03$ & $\mathrm{Cl}-4-\mathrm{x}$ & Benzene/toluene/xylene & $\mathrm{HCl}$ & 30 \\
\hline 7 & SRS & IFF & $1.5 \mathrm{E}-02$ & $9.1 \mathrm{E}+02$ & HC-insoluble & Benzene/toluene/xylene & $\mathrm{C}_{6} \mathrm{H}_{6}$ & 30 \\
\hline 7 & SRS & IFF & $1.5 \mathrm{E}-02$ & $9.1 E+03$ & HC-insoluble & Benzene/toluene/xylene & PÁH soot & 30 \\
\hline 7 & SRS & IFF & $1.5 \mathrm{E}-02$ & $6.0 \mathrm{E}+01$. & HC-insoluble & Benzene/toluene/xylene & Cd fumes & 30 \\
\hline 7 & SRS & IFF & $1.5 \mathrm{E}-02$ & $6.0 \mathrm{E}+01$ & HC-insoluble & Benzene/toluene/xylene & $\mathrm{Cr}$ fumes & 30 \\
\hline 15 & INEL & IFF & $1.5 \mathrm{E}-02$ & $1.4 \mathrm{E}+05$ & HC-insoluble & Benzene/toluene/xylene & $\mathrm{CO}$ & 30 \\
\hline 15 & INEL & IFF & $1.5 \mathrm{E}-02$ & $3.9 \mathrm{E}+04$ & $\mathrm{Cl}-4-\mathrm{x}$ & Benzene/toluene/xylene & $\mathrm{HCl}$ & 30 \\
\hline 15 & - INEL & IFF & $1.5 E-02$ & $5.9 E+03$ & HC-insoluble & Benzene/toluene/xylene & $\mathrm{C}_{6} \mathrm{H}_{6}$ & 30 \\
\hline 15 & INEL & IFF & $1.5 \mathrm{E}-02$ & $5.9 E+04$ & HC-insoluble & Benzene/toluene/xylene & PÄH soot & 30 \\
\hline 15 & INEL & IFF & $1.5 \mathrm{E}-02$ & $3.9 \mathrm{E}+02$ & HC-insoluble & Benzene/toluene/xylene & Cd fumes & 30 \\
\hline 15 & INEL & IFF & $1.5 \mathrm{E}-02$ & $3.9 \mathrm{E}+02$ & HC-insoluble & Benzene/toluene/xylene & $\mathrm{Cr}$ fumes & 30 \\
\hline 15 & SRS & IFF & $1.5 \mathrm{E}-02$ & 2.1E+04 & HC-insoluble & Benzene/toluene/xylene & $\mathrm{CO}$ & 30 \\
\hline 15 & SRS & IFF & $1.5 E-02$ & $6.0 \mathrm{E}+03$ & $\mathrm{Cl}-4-\mathrm{x}$ & Benzene/toluene/xylene & $\mathrm{HCl}$ & 30 \\
\hline 15 & SRS & IFF & $1.5 \mathrm{E}-02$ & $9.1 \mathrm{E}+02$ & HC-insoluble & Benzene/toluene/xylene & $\mathrm{C}_{6} \mathrm{H}_{6}$ & 30 \\
\hline 15 & SRS & IFF & $1.5 \mathrm{E}-02$ & $9.1 \mathrm{E}+03$ & HC-insoluble & Benzene/toluene/xylene & PAH soot & 30 \\
\hline 15 & SRS & IFF & $1.5 \mathrm{E}-02$ & $6.0 \mathrm{E}+01$ & HC-insoluble & Benzene/toluene/xylene & $\mathrm{Cd}$ fumes & 30 \\
\hline 15 & SRS & IFF & $1.5 E-02$ & $6.0 \mathrm{E}+01$ & HC-insoluble & Benzene/toluene/xylene & $\mathrm{Cr}$ fumes & 30 \\
\hline 17 & Hanford & IFF & $1.5 E-02$ & $1.6 \mathrm{E}+05$ & HC-insoluble & Benzene/toluene/xylene & $\mathrm{CO}$ & 30 \\
\hline 17 & Hanford & IFF & $1.5 \mathrm{E}-02$ & $4.5 \mathrm{E}+04$ & Cl-4-x & Benzene/toluene/xylene & $\mathrm{HCl}$ & 30 \\
\hline 17 & Hanford & IFF & $1.5 \mathrm{E}-02$ & $6.8 \mathrm{E}+03$ & HC-insoluble & Benzene/toluene/xylene & $\mathrm{C}_{6} \mathrm{H}_{6}$ & 30 \\
\hline 17 & Hanford & IFF & $1.5 \mathrm{E}-02$ & $6.8 \mathrm{E}+04$ & HC-insoluble & Benzene/toluene/xylene & PÄH soot & 30 \\
\hline 17 & Hanford & IFF & $1.5 \mathrm{E}-02$ & $4.5 E+02$ & HC-insoluble & Benzene/toluene/xylene & $\mathrm{Cd}$ fumes & 30 \\
\hline 17 & Hanford & IFF & $1.5 E-02$ & $4.5 \mathrm{E}+02$ & HC-insoluble & Benzene/toluene/xylene & $\mathrm{Cr}$ fumes & 30 \\
\hline 26 & INEL & IFF & $1.5 \mathrm{E}-02$ & $3.8 \mathrm{E}+04$ & HC-insoluble & Benzene/toluene/xylene & $\mathrm{CO}$ & 30 \\
\hline 26 & INEL & IFF & $1.5 \mathrm{E}-02$ & $1.1 \mathrm{E}+04$ & $C L-4-x$ & Benzene/toluene/xylene & $\mathrm{HCl}$ & 30 \\
\hline 26 & INEL & IFF & $1.5 \mathrm{E}-02$ & $1.6 \mathrm{E}+03$ & HC-insoluble & Benzene/toluene/xylene & $\mathrm{C}_{6} \mathrm{H}_{6}$ & 30 \\
\hline 26 & INEL & IFF & $1.5 \mathrm{E}-02$ & $1.6 \mathrm{E}+04$ & HC-insoluble & Benzene/toluene/xylene & PÄH soot & 30 \\
\hline 26 & INEL & IFF & $1.5 \mathrm{E}-02$ & $1.1 E+02$ & HC-insoluble & Benzene/toluene/xylene & $\mathrm{Cd}$ fumes & 30 \\
\hline 26 & INEL & IFF & $1.5 \mathrm{E}-02$ & $1.1 \mathrm{E}+02$ & HC-insoluble & Benzene/toluene/xylene & $\mathrm{Cr}$ fumes & \\
\hline
\end{tabular}




\section{TABLE A.3 (Cont.)}

a The WM PEIS cases analyzed are described as follows:

- Case 1 (No Action). Three sites (INEL, ORR, and SRS) treat and store, all remaining sites store.

Case 2 (Decentralized). Forty-nine sites treat, and 16 sites dispose.

Case 4 (Regionalized I). Eleven sites (Hanford, INEL, LANL, ORR, SRS PORTS, PGDP, FEMP, LLNL, Pantex, and RFETS) treat, and 12 sites dispose.

Case 7 (Regionalized 2). Seven sites (Hanford, INEL, LANL, ORR, SRS, PORTS, and RFETS) treat, and 6 sites dispose.

- Case IS (Regionalized 4). Four sites (Hanford, INEL, ORR, and SRS) treat, and 6 sites dispose.

- Case 17 (Centralized). One site treats (Hanford) and 1 site disposes.

- Case 26 (Rmote-handled). Four sites (Hanford, INEL, ORR, and SRS) treat and dispose (RH) and dispose.

b IFF $=$ incineration facility fire in the feedstock staging area.

c $\quad$ l-4- $\mathrm{x}=$ tetra-chloro-hydrocarbons; and HC-insoluble $=$ hazardous chemical-water insoluble organics.

d $\mathrm{C}_{6} \mathrm{H}_{6}=$ benzene; $\mathrm{PAH}$ soot = polyaromatic hydrocarbon soot; $\mathrm{CO}=$ carbon monoxide; $\mathrm{HCl}=$ hydrogen chloride; $\mathrm{Cd}$ fumes = cadmium fumes; and $\mathrm{Cr}$ fumes $=$ chromium fumes. 
$B-1$

APPENDIX B:

RADIONUCLIDE RELEASES FROM ACCIDENTS (RADIOLOGICAL SOURCE TERMS) 
B-2 
CONTENTS

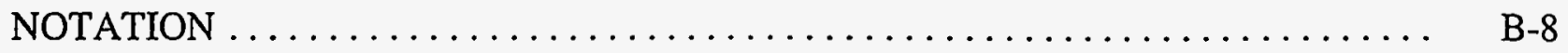

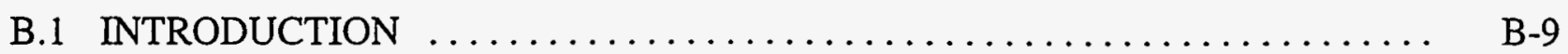

B.2 RADIONUCLIDE RELEASES FROM HLW ACCIDENTS $\ldots \ldots \ldots \ldots \ldots$ B-11

B.3 RADIONUCLIDE RELEASES FROM TRUW ACCIDENTS ............ B-15

B.4 RADIONUCLIDE RELEASES FROM LLW ACCIDENTS $\ldots \ldots \ldots \ldots \ldots \ldots$ B-29

B.5 RADIONUCLIDE RELEASES FROM ALPHA-LLMW

TREATMENT ACCDENTS $\ldots \ldots \ldots \ldots \ldots \ldots \ldots \ldots \ldots \ldots \ldots \ldots \ldots \ldots \ldots . \ldots \ldots$

B.6 RADIONUCLDE RELEASES FROM NON-ALPHA LLMW

TREATMENT ACCIDENTS $\ldots \ldots \ldots \ldots \ldots \ldots \ldots \ldots \ldots \ldots \ldots \ldots \ldots$

B-79

B.7 RADIONUCLIDE RELEASES FROM LLMW DRUM

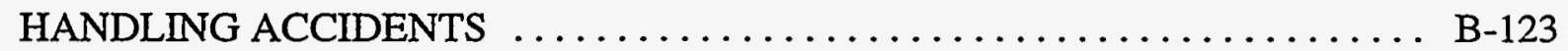

TABLES

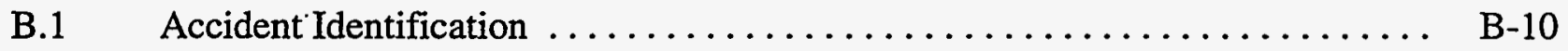

B.2.1 High-Level Waste, All Cases: Hanford $\ldots \ldots \ldots \ldots \ldots \ldots \ldots \ldots \ldots$ B-11

B.2.2 High-Level Waste, All Cases: Savannah River Site $\ldots \ldots \ldots \ldots \ldots \ldots \ldots$ B-12

B.2.3 High-Level Waste, All Cases: West Valley Demonstration Project ......... B-13

B.3.1 Transuranic Waste, Case 6: Hanford $\ldots \ldots \ldots \ldots \ldots \ldots \ldots \ldots \ldots \ldots \ldots$ B-15

B.3.2 Transuranic Waste, Case 6: Idaho National Engineering Laboratory ......... B-16

B.3.3 Transuranic Waste, Case 6: Los Alamos National Laboratory ............. . B-17

B.3.4 Transuranic Waste, Case 6: Rocky Flats Plant ................. B-18

B.3.5 Transuranic Waste, Case 6: Savannah River Site .................. B-19

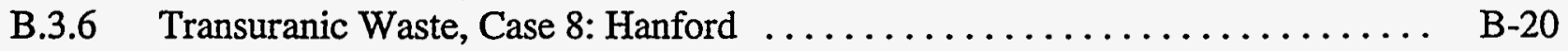

B.3.7 Transuranic Waste, Case 8: Idaho National Engineering Laboratory ......... B-21

B.3.8 Transuranic Waste, Case 8: Savannah River Site ................. B-22

B.3.9 Transuranic Waste, Case 9: Waste Isolation Pilot Plant ............. B-23

B.3.10 Transuranic Waste, Case 15: Hanford $\ldots \ldots \ldots \ldots \ldots \ldots \ldots \ldots \ldots \ldots$ B-24

B.3.11 Transuranic Waste, Case 15: Oak Ridge National Laboratory ........... B-25

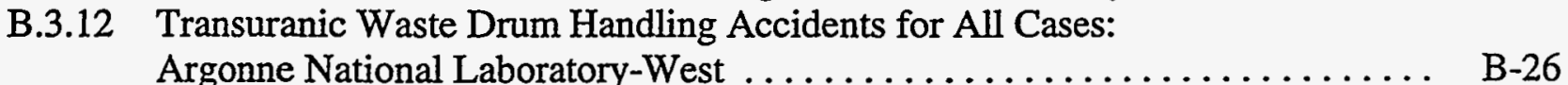

B.3.13 Transuranic Waste Drum Handling Accidents for All Cases: Hanford . . . . . . B-26

B.3.14 Transuranic Waste Drum Handling Accidents for All Cases:
Los Alamos National Laboratory $\ldots \ldots \ldots \ldots \ldots \ldots \ldots \ldots \ldots \ldots \ldots \ldots . . \ldots \ldots$ 
B.3.15 Transuranic Waste Drum Handling Accidents for All Cases:

Lawrence Livermore National Laboratory $\ldots \ldots \ldots \ldots \ldots \ldots \ldots \ldots \ldots$ B-27

B.3.16 Transuranic Waste Drum Handling Accidents for All Cases:

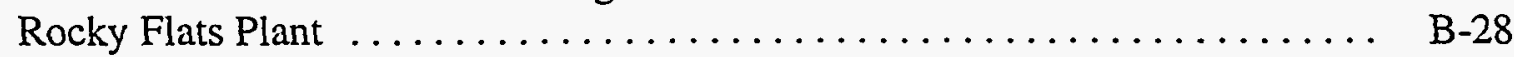

B.3.17 Transuranic Waste Drum Handling Accidents for All Cases:

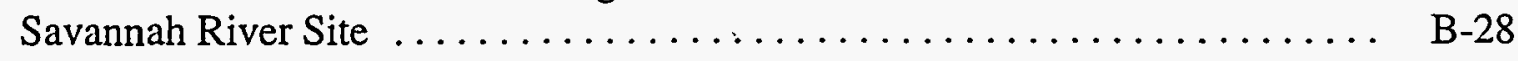

B.4.1 Low-Level Waste, Case 1: Idaho National Engineering Laboratory ......... B-29

B.4.2 Low-Level Waste, Case 1: Savannah River Site .................. B-30

B.4.3 Low-Level Waste, Case 9: Fernald Environmental Management Project ...... B-31

B.4.4 Low-Level Waste, Case 9: Hanford ....................... B-32

B.4.5 Low-Level Waste, Case 9: Idaho National Engineering Laboratory ......... B-33

B.4.6 Low-Level Waste, Case 9: Lawrence Livermore National Laboratory ........ B-34

B.4.7 Low-Level Waste, Case 9: Los Alamos National Laboratory ........... B-35

B.4.8 Low-Level Waste, Case 9: Oak Ridge National Laboratory . . . . . . . . . . . B B

B.4.9 Low-Level Waste, Case 9: Paducah Gaseous Diffusion Plant $\ldots \ldots \ldots \ldots$ B-37

B.4.10 Low-Level Waste, Case 9: Portsmouth Gaseous Diffusion Plant ......... B-38

B.4.11 Low-Level Waste, Case 9: Rocky Flats Environmental Technology Site ..... B B-39

B.4.12 Low-Level Waste, Case 9: Savannah River Site . . . . . . . . . . . . . . B-40

B.4.13 Low-Level Waste, Case 12: Hanford ..................... B-41

B.4.14 Low-Level Waste, Case 12: Idaho National Engineering Laboratory ......... B-42

B.4.15 Low-Level Waste, Case 12: Los Alamos National Laboratory ............ B-43

B.4.16 Low-Level Waste, Case 12: Oak Ridge National Laboratory ............ B-44

B.4.17 Low-Level Waste, Case 12: Portsmouth Gaseous Diffusion Plant ......... B-45

B.4.18 Low-Level Waste, Case 12: Rocky Flats Environmental Technology Site .... . B-46

B.4.19 Low-Level Waste, Case 12: Rocky Flats Environmental Technology Site ..... B-47

B.4.20 Low-Level Waste, Case 12: Savannah River Site ................ B-48

B.4.21 Low-Level Waste, Case 19: Hanford ...................... B-49

B.4.22 Low-Level Waste, Case 19: Idaho National Engineering Laboratory . ........ B-50

B.4.23 Low-Level Waste, Case 19: Idaho National Engineering Laboratory ........ B-51

B.4.24 Low-Level Waste, Case 19: Oak Ridge National Laboratory . . . . . . . . . . B B

B.4.25 Low-Level Waste, Case 19: Savannah River Site . . . . . . . . . . . . . B-53

B.4.26 Low-Level Waste, Case 21: Hanford ...................... B-54

B.4.27 Low-Level Waste, Case 21: Hanford ...................... B-55

B.4.28 Low-Level Waste, All Cases: Hanford ..................... B-56

B.4.29 Low-Level Waste, All Cases: Idaho National Engineering Laboratory . . . . . . B B-57

B.4.30 Low-Level Waste, All Cases: Los Alamos National Laboratory . . . . . . . . . . B-58

B.4.31 Low-Level Waste, All Cases: Lawrence Livermore National Laboratory . . . . $\quad$ B-59

B.4.32 Low-Level Waste, All Cases: Oak Ridge National Laboratory ............ B-60

B.4.33 Low-Level Waste, All Cases: Paducah Gaseous Diffusion Plant .......... B-61

B.4.34 Low-Level Waste, All Cases: Pantex Plant ...................... B-61

B.4.35 Low-Level Waste, All Cases: Portsmouth Gaseous Diffusion Plant ......... B B-62

B.4.36 Low-Level Waste, All Cases: Rocky Flats Plant ................. B-62

B.4.37 Low-Level Waste, All Cases: Savannah River Site . . . . . . . . . . . . . . B-63

B.5.1 Low-Level Mixed Waste, Case 2: Idaho National Engineering Laboratory .... B-64

B.5.2 Low-Level Mixed Waste, Case 2: Los Alamos National Laboratory ........ B-65 
B.5.3 Low-Level Mixed Waste, Case 2: Lawrence Livermore National Laboratory . . B-66

B.5.4 Low-Level Mixed Waste, Case 2: Rocky Flats Environmental

Technology Site . . . . . . . . . . . . . . . .

B.5.5 Low-Level Mixed Waste, Case 2: Savannah River Site . . . . . . . . . . . B-67

B.5.6 Low-Level Mixed Waste, Case 4: Idaho National Engineering Laboratory .... B-68

B.5.7 Low-Level Mixed Waste, Case 4: Lawrence Livermore

National Laboratory . . . . . . . . . . . . . . . . . . . . . . B-69

B.5.8 Low-Level Mixed Waste, Case 4: Los Alamos National Laboratory ........ B-69

B.5.9 Low-Level Mixed Waste, Case 4: Rocky Flats Environmental

Technology Site . . . . . . . . . . . . . . .

B.5.10 Low-Level Mixed Waste, Case 4: Savannah River Site . . . . . . . . . . . B-71

B.5.11 Low-Level Mixed Waste, Case 7: Idaho National Engineering Laboratory . . . . B-72

B.5.12 Low-Level Mixed Waste, Case 7: Los Alamos National Laboratory . . . . . . . B B-73

B.5.13 Low-Level Mixed Waste, Case 7: Rocky Flats Environmental

Technology Site ............................... B-74

B.5.14 Low-Level Mixed Waste, Case 7: Savannah River Site . . . . . . . . . . . B-74

B.5.15 Low-Level Mixed Waste, Case 15: Idaho National

Engineering Laboratory.$\ldots \ldots \ldots \ldots \ldots \ldots \ldots \ldots \ldots \ldots \ldots \ldots \ldots$

B.5.16 Low-Level Mixed Waste, Case 15: Savannah River Site . . . . . . . . . . . . B-76

B.5.17 Low-Level Mixed Waste, Case 17: Hanford . . . . . . . . . . . . . . . B-77

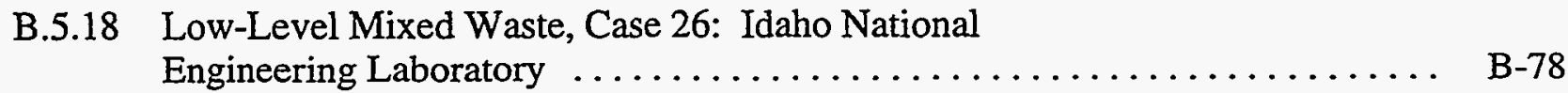

B.6.1 Low-Level Mixed Waste, Case 1: Idaho National Engineering Laboratory . ... B-79

B.6.2 Low-Level Mixed Waste, Case 1: Oak Ridge National Laboratory . . . . . . . . B-80

B.6.3 Low-Level Mixed Waste, Case 1: Savannah River Site . . . . . . . . . . . . . B-81

B.6.4 Low-Level Mixed Waste, Case 2: Argonne National Laboratory-East . . . . . . . B-82

B.6.5 Low-Level Mixed Waste, Case 2: Brookhaven National Laboratory . . . . . . . B B-83

B.6.6 Low-Level Mixed Waste, Case 2: Energy Technology Engineering Center .... B-84

B.6.7 Low-Level Mixed Waste, Case 2: Fernald Environmental

Management Project ............................. B 85

B.6.8 Low-Level Mixed Waste, Case 2: Hanford ................... B-86

B.6.9 Low-Level Mixed Waste, Case 2: Idaho National Engineering Laboratory .... B-87

B.6.10 Low-Level Mixed Waste, Case 2: Knolls Atomic Power

Laboratory, Schenectady .......................... B-88

B.6.11 Low-Level Mixed Waste, Case 2: Nevada Test Site . . . . . . . . . . . . . B B-89

B.6.12 Low-Level Mixed Waste, Case 2: Oak Ridge National Laboratory . . . . . . . . B-90

B.6.13 Low-Level Mixed Waste, Case 2: Paducah Gaseous Diffusion Plant ......... B-91

B.6.14 Low-Level Mixed Waste, Case 2: Pantex Plant ................. B-92

B.6.15 Low-Level Mixed Waste, Case 2: Portsmouth Gaseous Diffusion Plant ...... B-92

B.6.16 Low-Level Mixed Waste, Case 2: Sandia National Laboratories-

New Mexico ................................. B -93

B.6.17 Low-Level Mixed Waste, Case 2: Savannah River Site . . . . . . . . . . . . B B-94

B.6.18 Low-Level Mixed Waste, Case 4: Energy Technology Engineering Center .... B-95 
B.6.19 Low-Level Mixed Waste, Case 4: Fernald Environmental

Management Project ............................. B-96

B.6.20 Low-Level Mixed Waste, Case 4: Hanford .................. B-97

B.6.21 Low-Level Mixed Waste, Case 4: Idaho National Engineering Laboratory . . . . B B-98

B.6.22 Low-Level Mixed Waste, Case 4: Lawrence Livermore National Laboratory $\ldots \ldots \ldots \ldots \ldots \ldots \ldots \ldots \ldots \ldots \ldots \ldots \ldots \ldots \ldots$

B.6.23 Low-Level Mixed Waste, Case 4: Los Alamos National Laboratory . . . . . . . . B-100

B.6.24 Low-Level Mixed Waste, Case 4: Oak Ridge National Laboratory ........ B B-101

B.6.25 Low-Level Mixed Waste, Case 4: Paducah Gaseous Diffusion Plant . . . . . . . . B-102

B.6.26 Low-Level Mixed Waste, Case 4: Pantex Plant .................. B-103

B.6.27 Low-Level Mixed Waste, Case 4: Portsmouth Gaseous Diffusion Plant ... . . B B-104

B.6.28 Low-Level Mixed Waste, Case 4: Rocky Flats Environmental

Technology Site .................................. B-105

B.6.29 Low-Level Mixed Waste, Case 4: Savannah River Site .............. B-106

B.6.30 Low-Level Mixed Waste, Case 7: Hanford ................... B-107

B.6.31 Low-Level Mixed Waste, Case 7: Idaho National Engineering Laboratory .... B-108

B.6.32 Low-Level Mixed Waste, Case 7: Los Alamos National Laboratory ........ . B-109

B.6.33 Low-Level Mixed Waste, Case 7: Oak Ridge National Laboratory . . . . . . . . B-110

B.6.34 Low-Level Mixed Waste, Case 7: Portsmouth Gaseous Diffusion Plant ..... . B-111

B.6.35 Low-Level Mixed Waste, Case 7: Rocky Flats Environmental

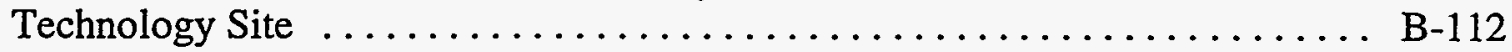

B.6.36 Low-Level Mixed Waste, Case 7: Savannah River Site .............. B-113

B.6.37 Low-Level Mixed Waste, Case 15: Hanford ................... B-114

B.6.38 Low-Level Mixed Waste, Case 15: Idaho National

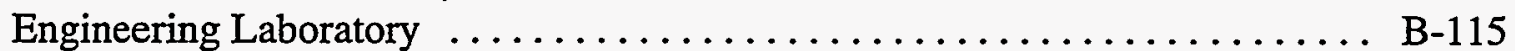

B.6.39 Low-Level Mixed Waste, Case 15: Oak Ridge National Laboratory . . . . . . . . B-116

B.6.40 Low-Level Mixed Waste, Case 15: Savannah River Site .............. B-117

B.6.41 Low-Level Mixed Waste, Case 17: Hanford ................... B-118

B.6.42 Low-Level Mixed Waste, Case 26: Hanford ................... B-119

B.6.43 Low-Level Mixed Waste, Case 26: Idaho National

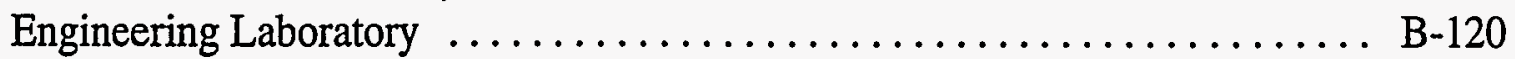

B.6.44 Low-Level Mixed Waste, Case 26: Oak Ridge National Laboratory . . . . . . . . B-121

B.6.45 Low-Level Mixed Waste, Case 26: Savannah River Site . . . . . . . . . . . . B-122

B.7.1 Low-Level Mixed Waste, All Cases: Ames Laboratory . . . . . . . . . . . . . . B-123

B.7.2 Low-Level Mixed Waste, All Cases: Argonne National Laboratory-East . . . . . B-123

B.7.3 Low-Level Mixed Waste, All Cases: Argonne National Laboratory-West . . . . . B-124

B.7.4 Low-Level Mixed Waste, All Cases: Bettis Atomic Power Laboratory . . . . . . . B-124

B.7.5 Low-Level Mixed Waste, All Cases: Battelle Columbus Laboratory . . . . . . . . B-125

B.7.6 Low-Level Mixed Waste, All Cases: Brookhaven National Laboratory . . . . . . . B-125

B.7.7 Low-Level Mixed Waste, All Cases: Charleston Naval Shipyard . . . . . . . . . . B-126

B.7.8 Low-Level Mixed Waste, All Cases: Colonie Interim Storage . . . . . . . . . . B-126

B.7.9 Low-Level Mixed Waste, All Cases: Energy Technology

Engineering Center ................................... B-127

B.7.10 Low-Level Mixed Waste, All Cases: Fernald Environmental

Management Project .......................... B-127

B.7.11 Low-Level Mixed Waste, All Cases: General Atomics . . . . . . . . . . . . . . B-128 
B.7.12 Low-Level Mixed Waste, All Cases: Grand Junction Project Office . . . . . . B B-128

B.7.13 Low-Level Mixed Waste, All Cases: Hanford . . . . . . . . . . . . . . . . . . B-129

B.7.14 Low-Level Mixed Waste, All Cases: Idaho National

Engineering Laboratory . . . . . . . . . . . . . . . . . . . B-129

B.7.15 Low-Level Mixed Waste, All Cases: Inhalation Toxicology

Research Institute . . . . . . . . . . . . . . . . . . . . B-130

B.7.16 Low-Level Mixed Waste, All Cases: Knolls Atomic Power Laboratory . . . . . B-130

B.7.17 Low-Level Mixed Waste, All Cases: Kansas City Plant . . . . . . . . . . . . . . B-131

B.7.18 Low-Level Mixed Waste, All Cases: Knolls-Kesselring Site . . . . . . . . . . . B-131

B.7.19 Low-Level Mixed Waste, All Cases: Knolls-Windsor Site . . . . . . . . . . . . . B-132

B.7.20 Low-Level Mixed Waste, All Cases: Los Alamos National Laboratory . . . . . . B-132

B.7.21 Low-Level Mixed Waste, All Cases: Lawrence Berkeley Laboratory . . . . . . . B-133

B.7.22 Low-Level Mixed Waste, All Cases: Laboratory for Energy-Related

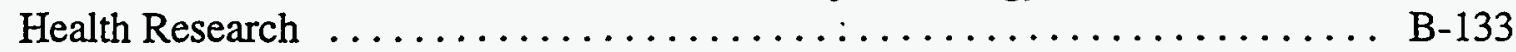

B.7.23 Low-Level Mixed Waste, All Cases: Lawrence Livermore

National Laboratory . . . . . . . . . . . . . . . . . . . . B-134

B.7.24 Low-Level Mixed Waste, All Cases: Mare Island Naval Shipyard . . . . . . . . . B-134

B.7.25 Low-Level Mixed Waste, All Cases: Mound Plant . . . . . . . . . . . . . . . B-135

B.7.26 Low-Level Mixed Waste, All Cases: Norfolk Naval Shipyard . . . . . . . . . . . B-135

B.7.27 Low-Level Mixed Waste, All Cases: Nevada Test Site . . . . . . . . . . . . . . . B-136

B.7.28 Low-Level Mixed Waste, All Cases: Oak Ridge National Laboratory . . . . . . . B-136

B.7.29 Low-Level Mixed Waste, All Cases: Paducah Gaseous Diffusion Plant .... . . B-137

B.7.30 Low-Level Mixed Waste, All Cases: Pantex Plant . . . . . . . . . . . . . . . B-137

B.7.31 Low-Level Mixed Waste, All Cases: Pearl Harbor Naval Shipyard . . . . . . . . . B-138

B.7.32 Low-Level Mixed Waste, All Cases: Portsmouth Naval Shipyard . . . . . . . . . B-138

B.7.33 Low-Level Mixed Waste, All Cases: Portsmouth Gaseous Diffusion Plant . . . B B-139

B.7.34 Low-Level Mixed Waste, All Cases: Princeton Plasma

Physics Laboratory . . . . . . . . . . . . . . . . . . . . . B -139

B.7.35 Low-Level Mixed Waste, All Cases: Puget Sound Naval Shipyard . . . . . . . . B-140

B.7.36 Low-Level Mixed Waste, All Cases: Rocky Flats Plant . . . . . . . . . . . . . . . B-140

B.7.37 Low-Level Mixed Waste, All Cases: Reactive Materials, Inc. . . . . . . . . . . . B-141

B.7.38 Low-Level Mixed Waste, All Cases: Sandia National

Laboratories-New Mexico ......................... B-141

B.7.39 Low-Level Mixed Waste, All Cases: Sandia National

B.7.40 Low-Level Mixed Waste, All Cases: Savannah River Site . . . . . . . . . . . . B-142

B.7.41 Low-Level Mixed Waste, All Cases: University of Missouri, Columbia . . . . . B-143

B.7.42 Low-Level Mixed Waste, All Cases: West Valley Demonstration Project . . . . B B-143 


\section{NOTATION}

The following is a list of the acronyms, initialisms, and abbreviations (including units of measure) used in this appendix.

\section{ACRONYMS, INITIALISMS, AND ABBREVIATIONS}

$\begin{array}{ll}\text { DOE } & \text { U.S. Department of Energy } \\ \text { HLW } & \text { high-level waste } \\ \text { LLMW } & \text { low-level mixed waste } \\ \text { LLW } & \text { low-level waste } \\ \text { PEIS } & \text { Programmatic Environmental Impact Statement } \\ \text { TRUW } & \text { transuranic waste } \\ \text { WM } & \text { Waste Management }\end{array}$

\section{UNITS OF MEASURE}

$\mathrm{Ci} \quad$ curie(s) 


\section{APPENDIX B:}

\section{RADIONUCLIDE RELEASES FROM ACCIDENTS (RADIOLOGICAL SOURCE TERMS)}

\section{B.1 INTRODUCTION}

This appendix contains the radiological source terms for the accidents analyzed for the waste types considered in the U.S. Department of Energy (DOE) Waste Management (WM) Programmatic Environmental Impact Statement (PEIS). The source terms contain the radionuclide amounts (in curies [ $\mathrm{Ci}]$ ) released in each accident considered. Only the radionuclide distributions for the risk-dominant accidents are included in the following sections.

For inclusion in this appendix, the source terms have been organized by waste type. Section B.2 presents the source terms for high-level waste (HLW) accidents, Section B.3 for transuranic waste (TRUW) accidents, Section B.4 for low-level waste (LLW), and Sections B.5, B.6, and B.7 for low-level mixed waste (LLMW) (drum handling, alpha-waste treatment, and non-alpha waste treatment have been addressed separately).

Within each section, the radionuclide release listings are organized by WM PEIS alternative (referred to as CASE in the printouts), DOE site, and waste management function (i.e., handling, incineration, etc.), and the particular, if any, waste affected (e.g., combustible waste only, all waste, etc.). For a given WM PEIS alternative, DOE site and function, all the accident releases have been included in the same table, although they were generated separately. The column headings indicate the particular accident sequence to which the radionuclide release corresponds.

The WM PEIS alternatives covered in the source terms are the result of the WM PEIS alternative definitions and screenings that have been performed. The details are summarized in the results section for each individual waste type. The radionuclide listing, which varies from site to site and waste stream to waste stream, reflects the waste characterization determined in the WM PEIS waste management database. The DOE sites and functions appearing in the source terms are the result of the alternative definitions and the screenings performed to eliminate sites and functions with small waste volumes or low impacts.

Finally, the nomenclature for identifying the accidents sequence is as follows: $\mathrm{XXX}$ or $X X n$. Three letters $(X X X)$ are used for single-sequence accident identification, and two letters and a single digit $(\mathrm{XXn})$ are used to identify the accident initiator and the sequence number in the event tree developed for the initiator. Table B.1 summarizes the accident identification used in the source term tables. 


\section{TABLE B.1 Accident Identification}

\begin{tabular}{|c|c|c|c|}
\hline Function & Identifier & Description & Applicable Waste \\
\hline \multirow[t]{2}{*}{ Glass storage } & $\mathrm{GCl}$ & Glass canister crush, fully filtered release & HLW \\
\hline & GC3 & Glass canister crush, unfiltered release & HLW \\
\hline Drum handling & SHA & Single drum handling breach accident & $\begin{array}{l}\text { TRUW, LLW, } \\
\text { LLMW }\end{array}$ \\
\hline \multirow[t]{6}{*}{ Incineration $^{\mathrm{a}}$} & IFF & Fire in the baghouse area & $\begin{array}{l}\text { TRUW, LLW, } \\
\text { LLMW }\end{array}$ \\
\hline & IEX & Explosion in the rotary kiln & $\begin{array}{l}\text { TRUW, LLW, } \\
\text { LLMW }\end{array}$ \\
\hline & EQ7 & Earthquake followed by fire and explosion & LLW, LLMW \\
\hline & EQ5 & Earthquake with fireball blasting HEPA filters & TRUW \\
\hline & AS5 & Small aircraft impact with fire and explosion & LLW \\
\hline & AL7 & Large aircraft impact with fire and explosion & LLW \\
\hline
\end{tabular}

a Incineration here includes the following functions:

- Incineration of non-alpha waste (incineration),

- Incineration of non-alpha-remote-handled waste (q-incineration),

- Incineration of alpha waste ( $\alpha$-incineration), and

- Incineration of alpha-remote-handled waste (r-incineration). 


\section{B.2 RADIONUCLIDE RELEASES FROM HLW ACCIDENTS}

TABLE B.2.1 High-Level Waste, All Cases: Hanford

\begin{tabular}{|c|c|c|c|c|c|}
\hline \multicolumn{6}{|c|}{$\begin{array}{l}\text { Function: Glass Storage } \\
\text { Waste Stream: All }\end{array}$} \\
\hline \multirow[b]{2}{*}{ Nuclide } & \multicolumn{2}{|c|}{ Release (Ci) } & \multirow[b]{2}{*}{ Nuclide } & \multicolumn{2}{|c|}{ Release (Ci) } \\
\hline & GC3 & $\mathrm{GC1}$ & & GC3 & $\mathrm{GCl}$ \\
\hline Ag-110m & $1.11 \mathrm{E}-09$ & $0.00 \mathrm{E}+00$ & $\mathrm{Pu}-240$ & $1.97 \mathrm{E}-07$ & $3.93 \mathrm{E}-13$ \\
\hline Am-241 & $1.42 \mathrm{E}-04$ & $2.84 \mathrm{E}-10$ & Pu-241 & $6.30 \mathrm{E}-08$ & $1.26 \mathrm{E}-13$ \\
\hline Am-242 & $1.10 \mathrm{E}-07$ & $2.21 \mathrm{E}-13$ & Pu-242 & $3.81 \mathrm{E}-11$ & $0.00 \mathrm{E}+00$ \\
\hline Am-243 & $1.89 \mathrm{E}-08$ & $3.80 \mathrm{E}-14$ & $\mathrm{Rh}-103 \mathrm{~m}$ & $0.00 \mathrm{E}+00$ & $0.00 \mathrm{E}+00$ \\
\hline C-14 & $0.00 \mathrm{E}+00$ & $0.00 \mathrm{E}+00$ & $R u-103$ & $0.00 \mathrm{E}+00$ & $0.00 \mathrm{E}+00$ \\
\hline Cd-113m & $4.26 \mathrm{E}-06$ & $8.53 \mathrm{E}-12$ & Ru-106 & $2.09 \mathrm{E}-05$ & $4.18 \mathrm{E}-11$ \\
\hline $\mathrm{Cd}-115 \mathrm{~m}$ & $0.00 \mathrm{E}+00$ & $0.00 \mathrm{E}+00$ & $\mathrm{Sb}-124$ & $0.00 \mathrm{E}+00$ & $0.00 \mathrm{E}+00$ \\
\hline $\mathrm{Ce}-141$ & $0.00 E+00$ & $0.00 \mathrm{E}+00$ & $\mathrm{Sb}-125$ & $1.27 \mathrm{E}-04$ & $2.54 \mathrm{E}-10$ \\
\hline Ce-144 & $4.00 \mathrm{E}-05$ & $8.00 \mathrm{E}-11$ & $\mathrm{Sb}-126$ & $2.55 \mathrm{E}-08$ & $5.10 \mathrm{E}-14$ \\
\hline $\mathrm{Cm}-242$ & $9.10 \mathrm{E}-08$ & $1.82 \mathrm{E}-13$ & $\mathrm{Sb}-126 \mathrm{~m}$ & $1.82 \mathrm{E}-07$ & $3.65 \mathrm{E}-13$ \\
\hline $\mathrm{Cm}-244$ & 2.52E-06 & $5.03 \mathrm{E}-12$ & Se-79 & 1.57 E-09 & $0.00 \mathrm{E}+00$ \\
\hline Co-60 & $7.50 \mathrm{E}-07$ & $1.50 \mathrm{E}-12$ & Sm-151 & $3.49 \mathrm{E}-04$ & $6.98 \mathrm{E}-10$ \\
\hline Cs-134 & $4.66 \mathrm{E}-05$ & $9.31 \mathrm{E}-11$ & Sn-113 & $5.10 \mathrm{E}-14$ & $0.00 \mathrm{E}+\infty 0$ \\
\hline Cs-135 & $1.01 \mathrm{E}-07$ & $2.02 \mathrm{E}-13$ & Sn-119m & 3.40E-09 & $0.00 \mathrm{E}+00$ \\
\hline Cs-137 & $1.81 \mathrm{E}-02$ & 3.61E-08 & $\mathrm{Sn}-121 \mathrm{~m}$ & 3.88E-08 & $7.80 \mathrm{E}-14$ \\
\hline $\mathrm{Eu}-152$ & $7.00 \mathrm{E}-07$ & $1.40 \mathrm{E}-12$ & Sn-123 & $1.82 \mathrm{E}-11$ & $0.00 \mathrm{E}+00$ \\
\hline Eu-154 & $7.25 \mathrm{E}-05$ & $1.45 \mathrm{E}-10$ & Sn-126 & $1.82 \mathrm{E}-07$ & $3.65 \mathrm{E}-13$ \\
\hline Eu-155 & $6.85 \mathrm{E}-05$ & 1.37E-10 & Sr-89 & $0.00 \mathrm{E}+00$ & $0.00 \mathrm{E}+00$ \\
\hline $\mathrm{Fe}-55$ & $9.00 \mathrm{E}-06$ & $1.80 \mathrm{E}-11$ & Sr-90 & $1.49 \mathrm{E}-02$ & $2.98 \mathrm{E}-08$ \\
\hline Gd-153 & $6.75 \mathrm{E}-12$ & $0.00 \mathrm{E}+00$ & $\mathrm{~Tb}-160$ & $0.00 \mathrm{E}+00$ & $0.00 \mathrm{E}+00$ \\
\hline $\mathrm{H}-3$ & $0.00 \mathrm{E}+00$ & $0.00 \mathrm{E}+00$ & Тc-99 & $3.75 \mathrm{E}-06$ & $7.51 \mathrm{E}-12$ \\
\hline I-129 & $1.29 \mathrm{E}-05$ & $1.29 \mathrm{E}-05$ & $\mathrm{Te}-125 \mathrm{~m}$ & $3.10 \mathrm{E}-05$ & $6.20 \mathrm{E}-11$ \\
\hline In-113m & $5.10 \mathrm{E}-14$ & $0.00 E+00$ & $\mathrm{Te}-127$ & 3.27E-12 & $0.00 \mathrm{E}+00$ \\
\hline $\mathrm{Nb}-93 \mathrm{~m}$ & $3.08 \mathrm{E}-07$ & $6.16 \mathrm{E}-13$ & $\mathrm{Te}-127 \mathrm{~m}$ & $3.33 \mathrm{E}-12$ & $0.00 \mathrm{E}+00$ \\
\hline Nb-95 & $0.00 \mathrm{E}+00$ & $0.00 \mathrm{E}+00$ & Te-129 & $0.00 \mathrm{E}+00$ & $0.00 \mathrm{E}+00$ \\
\hline $\mathrm{Ni}-59$ & $5.45 \mathrm{E}-08$ & $1.09 \mathrm{E}-13$ & Te-129m & $0.00 \mathrm{E}+00$ & $0.00 \mathrm{E}+00$ \\
\hline $\mathrm{Ni}-63$ & $6.05 \mathrm{E}-06$ & $1.21 \mathrm{E}-11$ & U-234 & $2.29 \mathrm{E}-09$ & $0.00 \mathrm{E}+00$ \\
\hline Np-237 & $7.80 \mathrm{E}-08$ & $1.56 \mathrm{E}-13$ & U-235 & $9.55 \mathrm{E}-11$ & $0.00 \mathrm{E}+00$ \\
\hline Pd-107 & $1.51 \mathrm{E}-08$ & $3.00 \mathrm{E}-14$ & U-236 & $2.10 \mathrm{E}-10$ & $0.00 \mathrm{E}+00$ \\
\hline$P m-147$ & $2.61 \mathrm{E}-03$ & $5.21 \mathrm{E}-09$ & U-238 & $1.76 \mathrm{E}-09$ & $0.00 \mathrm{E}+00$ \\
\hline Pm-148m & $0.00 \mathrm{E}+00$ & $0.00 \mathrm{E}+00$ & $Y-90$ & $1.49 \mathrm{E}-02$ & $2.98 E-08$ \\
\hline Pr-144 & $4.00 \mathrm{E}-05$ & $8.00 \mathrm{E}-11$ & $Y-91$ & $0.00 \mathrm{E}+00$ & $0.00 \mathrm{E}+00$ \\
\hline $\operatorname{Pr}-144 m$ & $4.80 \mathrm{E}-07$ & $9.60 \mathrm{E}-13$ & $\mathrm{Zr}-93$ & $5.25 \mathrm{E}-07$ & $1.05 \mathrm{E}-12$ \\
\hline $\mathrm{Pu}-238$ & $2.21 \mathrm{E}-07$ & $4.43 \mathrm{E}-13$ & Zr-95 & $0.00 \mathrm{E}+00$ & $0.00 \mathrm{E}+00$ \\
\hline Pu-239 & 5.85E-07 & $1.17 \mathrm{E}-12$ & Total & $5.14 \mathrm{E}-02$ & $1.30 \mathrm{E}-05$ \\
\hline
\end{tabular}


TABLE B.2.2 High-Level Waste, All Cases: Savannah River Site

Function: Glass Storage

Waste Stream: All

\begin{tabular}{|c|c|c|c|c|c|}
\hline \multirow[b]{2}{*}{ Nuclide } & \multicolumn{2}{|c|}{ Release (Ci) } & \multirow[b]{2}{*}{ Nuclide } & \multicolumn{2}{|c|}{ Release (Ci) } \\
\hline & GC3 & $\mathrm{GCl}$ & & GC3 & $\mathrm{GCl}$ \\
\hline Am-241 & 5.51E-06 & $1.10 \mathrm{E}-11$ & $\mathrm{Pu}-238$ & 7.42E-04 & $1.48 \mathrm{E}-09$ \\
\hline Am-242 & $7.18 \mathrm{E}-09$ & $1.40 \mathrm{E}-14$ & $\mathrm{Pu}-239$ & $6.46 \mathrm{E}-06$ & $1.29 \mathrm{E}-11$ \\
\hline Am-242m & 7.24E-09 & $1.40 \mathrm{E}-14$ & $\mathrm{Pu}-240$ & 4.34E-06 & $8.68 \mathrm{E}-12$ \\
\hline Am-243 & $2.89 \mathrm{E}-09$ & $0.00 \mathrm{E}+00$ & $\mathrm{Pu}-241$ & 8.35E-04 & 1.67E-09 \\
\hline C-14 & $0.00 \mathrm{E}+00$ & $0.00 \mathrm{E}+00$ & $\mathrm{Pu}-242$ & 6.12E-09 & $1.20 \mathrm{E}-14$ \\
\hline Ce-144 & 4.93E-03 & 9.87E-09 & $\mathrm{Rb}-87$ & $4.36 \mathrm{E}-13$ & $0.00 \mathrm{E}+00$ \\
\hline $\mathrm{Cm}-242$ & $1.75 \mathrm{E}-08$ & $3.50 \mathrm{E}-14$ & $\mathrm{Ru}-106$ & $1.13 \mathrm{E}-03$ & $2.25 \mathrm{E}-09$ \\
\hline $\mathrm{Cm}-243$ & $2.78 \mathrm{E}-09$ & $0.00 \mathrm{E}+00$ & $\mathrm{Sb}-125$ & 4.25E-04 & $8.50 \mathrm{E}-10$ \\
\hline $\mathrm{Cm}-244$ & 5.38E-05 & $1.08 \mathrm{E}-10$ & $S b-126$ & $3.08 \mathrm{E}-08$ & $6.20 \mathrm{E}-14$ \\
\hline Co-60 & 8.50E-05 & $1.70 \mathrm{E}-10$ & $\mathrm{Sb}-126 \mathrm{~m}$ & 2.21E-07 & $4.42 \mathrm{E}-13$ \\
\hline Cs-134 & $1.69 \mathrm{E}-04$ & 3.37E-10 & Se-79 & $8.50 \mathrm{E}-08$ & $1.70 \mathrm{E}-13$ \\
\hline Cs-135 & $4.97 \mathrm{E}-08$ & $9.90 \mathrm{E}-14$ & Sm-151 & $1.24 \mathrm{E}-04$ & $2.48 \mathrm{E}-10$ \\
\hline Cs-137 & 2.17E-02 & 4.34E-08 & $\mathrm{Sn}-121 \mathrm{~m}$ & 3.95E-08 & $7.90 \mathrm{E}-14$ \\
\hline Eu-152 & $1.84 \mathrm{E}-06$ & $3.69 \mathrm{E}-12$ & Sn-126 & 2.21E-07 & $4.42 \mathrm{E}-13$ \\
\hline Eu-154 & $3.10 \mathrm{E}-04$ & $6.20 \mathrm{E}-10$ & Sr-90 & 2.34E-02 & 4.67E-08 \\
\hline Eu-155 & 2.37E-04 & $4.75 \mathrm{E}-10$ & Tc-99 & $1.54 \mathrm{E}-06$ & $3.08 \mathrm{E}-12$ \\
\hline $\mathrm{H}-3$ & $0.00 \mathrm{E}+00$ & $0.00 \mathrm{E}+00$ & $\mathrm{Te}-125 \mathrm{~m}$ & $1.38 \mathrm{E}-04$ & $2.76 \mathrm{E}-10$ \\
\hline $\mathrm{I}-129$ & $0.00 \mathrm{E}+00$ & $0.00 \mathrm{E}+00$ & $\mathrm{U}-232$ & $6.70 \mathrm{E}-09$ & $1.30 \mathrm{E}-14$ \\
\hline $\mathrm{Nb}-95$ & $1.06 \mathrm{E}-08$ & $2.10 \mathrm{E}-14$ & U-233 & $7.92 \mathrm{E}-13$ & $0.00 \mathrm{E}+00$ \\
\hline $\mathrm{Ni}-59$ & $1.20 \mathrm{E}-08$ & $2.40 \mathrm{E}-14$ & $\mathrm{U}-234$ & $1.71 \mathrm{E}-08$ & $3.40 \mathrm{E}-14$ \\
\hline $\mathrm{Ni}-63$ & 1.49E-06 & $2.97 \mathrm{E}-12$ & U-235 & $7.86 \mathrm{E}-11$ & $0.00 \mathrm{E}+00$ \\
\hline Np-237 & 4.45E-09 & $9.00 \mathrm{E}-15$ & U-236 & $5.64 \mathrm{E}-10$ & $0.00 \mathrm{E}+00$ \\
\hline Pd-107 & 7.37E-09 & $1.50 \mathrm{E}-14$ & U-238 & $5.25 \mathrm{E}-09$ & $1.00 \mathrm{E}-14$ \\
\hline Pm-147 & $1.21 \mathrm{E}-02$ & $2.42 \mathrm{E}-08$ & $Y-90$ & 2.34E-02 & 4.67E-08 \\
\hline Pr-144 & 4.93E-03 & 9.87E-09 & $\mathrm{Zr}-93$ & 5.59E-07 & $1.12 \mathrm{E}-12$ \\
\hline Pr-144m & 5.94E-05 & $1.19 E-10$ & $\mathrm{Zr}-95$ & 5.03E-09 & $1.00 \mathrm{E}-14$ \\
\hline $\mathrm{Pu}-236$ & $6.11 \mathrm{E}-08$ & $1.22 \mathrm{E}-13$ & Total & $9.47 \mathrm{E}-02$ & $1.89 \mathrm{E}-07$ \\
\hline
\end{tabular}


TABLE B.2.3 High-Level Waste, All Cases: West Valley Demonstration Project

Function: Glass Storage

Waste Stream: All

\begin{tabular}{|c|c|c|c|c|c|}
\hline \multirow[b]{2}{*}{ Nuclide } & \multicolumn{2}{|c|}{ Release $(\mathrm{Ci})$} & \multirow[b]{2}{*}{ Nuclide } & \multicolumn{2}{|c|}{ Release (Ci) } \\
\hline & GC3 & $\mathrm{GC} 1$ & & GC3 & $\mathrm{GC} 1$ \\
\hline Ac-225 & 4.13E-10 & $0.00 \mathrm{E}+00$ & Pu-236 & 1.65E-09 & $0.00 E+00$ \\
\hline Ac- 227 & $1.61 \mathrm{E}-10$ & $0.00 \mathrm{E}+00$ & $\mathrm{Pu}-238$ & $1.63 \mathrm{E}-05$ & $3.26 \mathrm{E}-11$ \\
\hline Ac-228 & $2.99 \mathrm{E}-09$ & $0.00 \mathrm{E}+00$ & Pu-239 & $3.20 \mathrm{E}-06$ & $6.39 \mathrm{E}-12$ \\
\hline Am-241 & $1.05 \mathrm{E}-04$ & $2.10 \mathrm{E}-10$ & $\mathrm{Pu}-240$ & 2.34E-06 & $4.68 \mathrm{E}-12$ \\
\hline Am-242 & $5.80 \mathrm{E}-07$ & $1.16 \mathrm{E}-12$ & Pu-241 & 1.59E-04 & 3.17E-10 \\
\hline$A m-242 m$ & 5.85E-07 & $1.17 \mathrm{E}-12$ & $\mathrm{Pu}-242$ & 3.19E-09 & $0.00 E+00$ \\
\hline Am-243 & $6.80 \mathrm{E}-07$ & $1.36 \mathrm{E}-12$ & $\mathrm{Ra}-223$ & $1.62 \mathrm{E}-08$ & $3.20 \mathrm{E}-14$ \\
\hline $\mathrm{Bi}-212$ & 1.77E-08 & $3.50 \mathrm{E}-14$ & $\mathrm{Ra}-224$ & 1.77E-08 & $3.50 \mathrm{E}-14$ \\
\hline C-14 & $0.00 \mathrm{E}+00$ & $0.00 \mathrm{E}+00$ & $\mathrm{Ra}-225$ & $4.13 E-10$ & $0.00 \mathrm{E}+00$ \\
\hline Cd-113m & 4.17E-06 & $8.34 \mathrm{E}-12$ & $\mathrm{Ra}-228$ & $2.99 \mathrm{E}-09$ & $0.00 E+00$ \\
\hline Ce-144 & $1.28 \mathrm{E}-09$ & $0.00 \mathrm{E}+00$ & Ru-106 & 2.77E-08 & $5.50 \mathrm{E}-14$ \\
\hline $\mathrm{Cm}-242$ & $4.82 \mathrm{E}-07$ & $9.63 \mathrm{E}-13$ & Sb-125 & $1.43 E-05$ & $2.86 \mathrm{E}-11$ \\
\hline $\mathrm{Cm}-243$ & $2.64 \mathrm{E}-07$ & $5.27 \mathrm{E}-13$ & $\mathrm{Sb}-126$ & $2.87 E-08$ & $5.70 \mathrm{E}-14$ \\
\hline $\mathrm{Cm}-244$ & $1.50 \mathrm{E}-05$ & $3.00 \mathrm{E}-11$ & $\mathrm{Sb}-126 \mathrm{~m}$ & 2.05E-07 & $4.09 \mathrm{E}-13$ \\
\hline $\mathrm{Cm}-245$ & $1.73 \mathrm{E}-09$ & $0.00 \mathrm{E}+00$ & $\mathrm{Se}-79$ & $6.90 \mathrm{E}-09$ & $1.40 \mathrm{E}-14$ \\
\hline $\mathrm{Cm}-246$ & $1.96 \mathrm{E}-10$ & $0.00 \mathrm{E}+00$ & Sm-151 & $1.66 \mathrm{E}-04$ & $3.31 \mathrm{E}-10$ \\
\hline Co-60 & 1.52E-06 & 3.03E-12 & Sn-121m & 3.43E-08 & $6.90 \mathrm{E}-14$ \\
\hline Cs-134 & 1.02E-05 & $2.03 \mathrm{E}-11$ & Sn-126 & 2.05E-07 & $4.09 \mathrm{E}-13$ \\
\hline Cs-135 & 3.17E-07 & $6.34 \mathrm{E}-13$ & Sr-90 & $1.32 \mathrm{E}-02$ & $2.63 \mathrm{E}-08$ \\
\hline Cs-137 & $1.42 \mathrm{E}-02$ & $2.83 \mathrm{E}-08$ & Tc-99 & 2.14E-07 & $4.28 \mathrm{E}-13$ \\
\hline Eu-152 & $7.15 \mathrm{E}-07$ & $1.43 \mathrm{E}-12$ & $\mathrm{Te}-125 \mathrm{~m}$ & $3.50 \mathrm{E}-06$ & $7.00 \mathrm{E}-12$ \\
\hline Eu-154 & $1.88 \mathrm{E}-04$ & 3.75E-10 & Th-227 & $1.59 \mathrm{E}-08$ & $3.20 \mathrm{E}-14$ \\
\hline Eu-155 & 4.69E-05 & $9.37 \mathrm{E}-11$ & Th-228 & 1.77E-08 & $3.50 \mathrm{E}-14$ \\
\hline $\mathrm{Fe}-55$ & $1.38 \mathrm{E}-06$ & $2.76 \mathrm{E}-12$ & Th-229 & $4.13 \mathrm{E}-10$ & $0.00 \mathrm{E}+00$ \\
\hline Fr-223 & $2.16 \mathrm{E}-10$ & $0.00 E+00$ & Th-230 & $1.18 \mathrm{E}-10$ & $0.00 \mathrm{E}+00$ \\
\hline $\mathrm{H}-3$ & $0.00 E+00$ & $0.00 \mathrm{E}+00$ & Th-231 & $1.77 \mathrm{E}-10$ & $0.00 \mathrm{E}+00$ \\
\hline I-129 & $0.00 \mathrm{E}+00$ & $0.00 \mathrm{E}+00$ & Th-232 & 3.23E-09 & $0.00 \mathrm{E}+00$ \\
\hline $\mathrm{Nb}-93 \mathrm{~m}$ & 3.58E-07 & $7.15 \mathrm{E}-13$ & Th-234 & $1.57 \mathrm{E}-09$ & $0.00 E+00$ \\
\hline Ni-59 & $2.08 \mathrm{E}-07$ & $4.16 \mathrm{E}-13$ & U-232 & $1.36 \mathrm{E}-08$ & $2.70 \mathrm{E}-14$ \\
\hline $\mathrm{Ni}-63$ & $1.51 E-05$ & $3.02 \mathrm{E}-11$ & $\mathrm{U}-233$ & $1.78 \mathrm{E}-08$ & $3.50 \mathrm{E}-14$ \\
\hline $\mathrm{Np}-237$ & $4.59 \mathrm{E}-08$ & $9.20 \mathrm{E}-14$ & U-234 & 8.25E-09 & $1.70 \mathrm{E}-14$ \\
\hline
\end{tabular}


TABLE B.2.3 (Cont.)

Function: Glass Storage

Waste Stream: All

\begin{tabular}{lllllll}
\hline & \multicolumn{2}{c}{ Release (Ci) } & & & \multicolumn{2}{c}{ Release (Ci) } \\
\cline { 2 - 3 } Nuclide & GC3 & GC1 & & Nuclide & GC3 & GC1 \\
\cline { 2 - 3 } Np-239 & $6.80 \mathrm{E}-07$ & $1.36 \mathrm{E}-12$ & $\mathrm{U}-235$ & & $1.77 \mathrm{E}-10$ & $0.00 \mathrm{E}+00$ \\
$\mathrm{~Pa}-231$ & $2.99 \mathrm{E}-08$ & $6.00 \mathrm{E}-14$ & $\mathrm{U}-236$ & & $5.50 \mathrm{E}-10$ & $0.00 \mathrm{E}+00$ \\
$\mathrm{~Pa}-233$ & $4.59 \mathrm{E}-08$ & $9.20 \mathrm{E}-14$ & $\mathrm{U}-238$ & & $1.57 \mathrm{E}-09$ & $0.00 \mathrm{E}+00$ \\
$\mathrm{~Pb}-212$ & $1.77 \mathrm{E}-08$ & $3.50 \mathrm{E}-14$ & $\mathrm{Y}-90$ & & $1.32 \mathrm{E}-02$ & $2.63 \mathrm{E}-08$ \\
$\mathrm{Pd}-107$ & $2.17 \mathrm{E}-08$ & $4.30 \mathrm{E}-14$ & $\mathrm{Zr}-93$ & & $5.35 \mathrm{E}-07$ & $1.07 \mathrm{E}-12$ \\
$\mathrm{Pm}-147$ & $1.73 \mathrm{E}-04$ & $3.45 \mathrm{E}-10$ & Total & & $4.14 \mathrm{E}-02$ & $8.28 \mathrm{E}-08$ \\
$\mathrm{Pr}-144$ & $1.28 \mathrm{E}-09$ & $0.00 \mathrm{E}+00$ & & & & \\
\hline
\end{tabular}




\section{B.3 RADIONUCLIDE RELEASES FROM TRUW ACCIDENTS}

TABLE B.3.1 Transuranic Waste, Case 6: Hanford

\begin{tabular}{|c|c|c|c|}
\hline \multicolumn{4}{|c|}{ Function: $\alpha$-Incineration } \\
\hline \multirow[b]{2}{*}{ Nuclide } & \multicolumn{3}{|c|}{ Release (Ci) } \\
\hline & EQ5 & IEX1 & IFF1 \\
\hline Am-241 & $1.17 \mathrm{E}-03$ & $2.14 \mathrm{E}-05$ & $4.58 \mathrm{E}-06$ \\
\hline Am-243 & $4.37 \mathrm{E}-08$ & $8.02 E-10$ & $1.72 \mathrm{E}-10$ \\
\hline Cf-252 & $6.78 \mathrm{E}-06$ & $1.24 \mathrm{E}-07$ & $2.66 \mathrm{E}-08$ \\
\hline $\mathrm{Cm}-244$ & $1.30 \mathrm{E}-04$ & $2.38 \mathrm{E}-06$ & $5.09 \mathrm{E}-07$ \\
\hline $\mathrm{Cm}-245$ & $3.23 \mathrm{E}-06$ & $5.92 \mathrm{E}-08$ & $1.27 \mathrm{E}-08$ \\
\hline Cs-137 & $1.31 \mathrm{E}-04$ & $2.41 \mathrm{E}-06$ & $5.16 \mathrm{E}-07$ \\
\hline Np-237 & $0.00 \mathrm{E}+00$ & $0.00 \mathrm{E}+00$ & $0.00 \mathrm{E}+00$ \\
\hline $\mathrm{Pb}-210$ & $0.00 \mathrm{E}+00$ & $0.00 \mathrm{E}+00$ & $0.00 \mathrm{E}+00$ \\
\hline Pm-147 & $9.19 \mathrm{E}-09$ & $1.68 \mathrm{E}-10$ & $3.61 \mathrm{E}-11$ \\
\hline Pu-238 & $1.56 \mathrm{E}-02$ & $2.86 \mathrm{E}-04$ & $6.14 \mathrm{E}-05$ \\
\hline Pu-239 & $5.35 \mathrm{E}-03$ & $9.80 \mathrm{E}-05$ & $2.10 \mathrm{E}-05$ \\
\hline Pu-240 & $1.30 \mathrm{E}-03$ & $2.38 \mathrm{E}-05$ & $5.09 \mathrm{E}-06$ \\
\hline Pu-241 & $1.02 \mathrm{E}-02$ & $1.86 \mathrm{E}-04$ & $4.00 \mathrm{E}-05$ \\
\hline $\mathrm{Pu}-242$ & $0.00 \mathrm{E}+00$ & $0.00 \mathrm{E}+00$ & $0.00 \mathrm{E}+00$ \\
\hline $\mathrm{Ra}-228$ & $1.08 \mathrm{E}-08$ & $1.97 \mathrm{E}-10$ & $4.23 \mathrm{E}-11$ \\
\hline Sr-90 & $1.33 E-04$ & $2.44 \mathrm{E}-06$ & $5.23 \mathrm{E}-07$ \\
\hline Th-229 & $2.51 \mathrm{E}-08$ & $4.61 \mathrm{E}-10$ & $9.87 \mathrm{E}-11$ \\
\hline Th-232 & $1.29 \mathrm{E}-08$ & $2.37 E-10$ & $5.07 \mathrm{E}-11$ \\
\hline U-233 & $1.54 \mathrm{E}-05$ & $2.82 \mathrm{E}-07$ & $6.04 \mathrm{E}-08$ \\
\hline U-234 & $1.03 E-05$ & $1.90 \mathrm{E}-07$ & $4.06 \mathrm{E}-08$ \\
\hline U-235 & $3.30 \mathrm{E}-07$ & $6.05 \mathrm{E}-09$ & $1.30 \mathrm{E}-09$ \\
\hline U-236 & $1.36 \mathrm{E}-11$ & $2.49 \mathrm{E}-13$ & $5.30 \mathrm{E}-14$ \\
\hline $\mathrm{U}-238$ & $1.18 \mathrm{E}-06$ & $2.16 \mathrm{E}-08$ & 4.64E-09 \\
\hline Total & $3.40 \mathrm{E}-02$ & $6.24 \mathrm{E}-04$ & $1.34 \mathrm{E}-04$ \\
\hline
\end{tabular}


TABLE B.3.2 Transuranic Waste, Case 6: Idaho National Engineering Laboratory

\begin{tabular}{lccc}
\hline & & \\
Function: $\alpha$-Incineration & \\
& \multicolumn{4}{c}{ Release (Ci) } \\
\cline { 2 - 4 } Nuclide & EQ5 & IEX1 & IFF1 \\
\hline & & & \\
Ac-227 & $1.07 \mathrm{E}-08$ & $1.96 \mathrm{E}-10$ & $4.20 \mathrm{E}-11$ \\
Am-241 & $2.50 \mathrm{E}-02$ & $4.58 \mathrm{E}-04$ & $9.81 \mathrm{E}-05$ \\
Cm-244 & $1.37 \mathrm{E}-04$ & $2.50 \mathrm{E}-06$ & $5.36 \mathrm{E}-07$ \\
Co-60 & $1.73 \mathrm{E}-05$ & $3.17 \mathrm{E}-07$ & $6.80 \mathrm{E}-08$ \\
Cs-137 & $1.67 \mathrm{E}-05$ & $3.07 \mathrm{E}-07$ & $6.57 \mathrm{E}-08$ \\
Eu-152 & $4.50 \mathrm{E}-08$ & $8.25 \mathrm{E}-10$ & $1.77 \mathrm{E}-10$ \\
Eu-154 & $1.78 \mathrm{E}-07$ & $3.27 \mathrm{E}-09$ & $7.01 \mathrm{E}-10$ \\
Eu-155 & $1.06 \mathrm{E}-07$ & $1.95 \mathrm{E}-09$ & $4.17 \mathrm{E}-10$ \\
Pb-210 & $7.48 \mathrm{E}-09$ & $1.37 \mathrm{E}-10$ & $2.94 \mathrm{E}-11$ \\
Pm-147 & $7.28 \mathrm{E}-07$ & $1.33 \mathrm{E}-08$ & $2.86 \mathrm{E}-09$ \\
Pu-238 & $1.66 \mathrm{E}-02$. & $3.04 \mathrm{E}-04$ & $6.51 \mathrm{E}-05$ \\
Pu-239 & $1.11 \mathrm{E}-02$ & $2.04 \mathrm{E}-04$ & $4.37 \mathrm{E}-05$ \\
Pu-240 & $2.73 \mathrm{E}-03$ & $5.00 \mathrm{E}-05$ & $1.07 \mathrm{E}-05$ \\
Pu-241 & $4.16 \mathrm{E}-02$ & $7.62 \mathrm{E}-04$ & $1.63 \mathrm{E}-04$ \\
Ra-228 & $8.53 \mathrm{E}-08$ & $1.56 \mathrm{E}-09$ & $3.35 \mathrm{E}-10$ \\
Sm-151 & $6.62 \mathrm{E}-09$ & $1.21 \mathrm{E}-10$ & $2.60 \mathrm{E}-11$ \\
Sr-90 & $5.44 \mathrm{E}-07$ & $9.97 \mathrm{E}-09$ & $2.14 \mathrm{E}-09$ \\
Th-229 & $4.21 \mathrm{E}-07$ & $7.72 \mathrm{E}-09$ & $1.65 \mathrm{E}-09$ \\
Th-230 & $5.77 \mathrm{E}-09$ & $1.06 \mathrm{E}-10$ & $2.27 \mathrm{E}-11$ \\
Th-232 & $9.16 \mathrm{E}-08$ & $1.68 \mathrm{E}-09$ & $3.60 \mathrm{E}-10$ \\
U-232 & $7.02 \mathrm{E}-06$ & $1.29 \mathrm{E}-07$ & $2.76 \mathrm{E}-08$ \\
U-233 & $2.49 \mathrm{E}-04$ & $4.57 \mathrm{E}-06$ & $9.79 \mathrm{E}-07$ \\
U-234 & $1.71 \mathrm{E}-06$ & $3.14 \mathrm{E}-08$ & $6.73 \mathrm{E}-09$ \\
U-235 & $1.71 \mathrm{E}-08$ & $3.14 \mathrm{E}-10$ & $6.73 \mathrm{E}-11$ \\
U-238 & $3.21 \mathrm{E}-08$ & $5.88 \mathrm{E}-10$ & $1.26 \mathrm{E}-10$ \\
Total & $9.74 \mathrm{E}-02$ & $1.79 \mathrm{E}-03$ & $3.83 \mathrm{E}-04$ \\
\hline & & & \\
& &
\end{tabular}


TABLE B.3.3 Transuranic Waste, Case 6: Los Alamos National Laboratory

\begin{tabular}{lccc}
\hline & & & \\
Function: $\alpha$-Incineration & \\
& \multicolumn{3}{c}{ Release (Ci) } \\
Nuclide & EQ5 & IEX1 & IFF1 \\
\cline { 2 - 4 } Ac-227 & $1.06 \mathrm{E}-07$ & $1.94 \mathrm{E}-09$ & $4.16 \mathrm{E}-10$ \\
Am-241 & $5.34 \mathrm{E}-03$ & $9.78 \mathrm{E}-05$ & $2.10 \mathrm{E}-05$ \\
Am-243 & $1.75 \mathrm{E}-06$ & $3.21 \mathrm{E}-08$ & $6.87 \mathrm{E}-09$ \\
Cm-244 & $7.15 \mathrm{E}-05$ & $1.31 \mathrm{E}-06$ & $2.81 \mathrm{E}-07$ \\
Cs-134 & $1.94 \mathrm{E}-09$ & $3.55 \mathrm{E}-11$ & $7.61 \mathrm{E}-12$ \\
Cs-137 & $2.20 \mathrm{E}-05$ & $4.03 \mathrm{E}-07$ & $8.64 \mathrm{E}-08$ \\
Eu-154 & $1.12 \mathrm{E}-08$ & $2.05 \mathrm{E}-10$ & $4.40 \mathrm{E}-11$ \\
Eu-155 & $1.10 \mathrm{E}-07$ & $2.02 \mathrm{E}-09$ & $4.33 \mathrm{E}-10$ \\
Pb-210 & $1.28 \mathrm{E}-07$ & $2.35 \mathrm{E}-09$ & $5.03 \mathrm{E}-10$ \\
Pm-147 & $9.17 \mathrm{E}-07$ & $1.68 \mathrm{E}-08$ & $3.60 \mathrm{E}-09$ \\
Pu-238 & $5.24 \mathrm{E}-02$ & $9.61 \mathrm{E}-04$ & $2.06 \mathrm{E}-04$ \\
Pu-239 & $3.62 \mathrm{E}-02$ & $6.63 \mathrm{E}-04$ & $1.42 \mathrm{E}-04$ \\
Pu-240 & $4.63 \mathrm{E}-05$ & $8.49 \mathrm{E}-07$ & $1.82 \mathrm{E}-07$ \\
Pu-241 & $7.43 \mathrm{E}-04$ & $1.36 \mathrm{E}-05$ & $2.92 \mathrm{E}-06$ \\
Pu-242 & $2.22 \mathrm{E}-04$ & $4.07 \mathrm{E}-06$ & $8.71 \mathrm{E}-07$ \\
Sb-125 & $2.13 \mathrm{E}-08$ & $3.91 \mathrm{E}-10$ & $8.38 \mathrm{E}-11$ \\
Sm-151 & $2.75 \mathrm{E}-07$ & $5.05 \mathrm{E}-09$ & $1.08 \mathrm{E}-09$ \\
Sn-121m & $4.98 \mathrm{E}-09$ & $9.12 \mathrm{E}-11$ & $1.95 \mathrm{E}-11$ \\
Sr-90 & $2.03 \mathrm{E}-05$ & $3.72 \mathrm{E}-07$ & $7.98 \mathrm{E}-08$ \\
Tc-99 & $4.68 \mathrm{E}-09$ & $8.57 \mathrm{E}-11$ & $1.84 \mathrm{E}-11$ \\
Th-229 & $3.69 \mathrm{E}-08$ & $6.76 \mathrm{E}-10$ & $1.45 \mathrm{E}-10$ \\
U-233 & $2.04 \mathrm{E}-05$ & $3.74 \mathrm{E}-07$ & $8.01 \mathrm{E}-08$ \\
U-234 & $2.77 \mathrm{E}-06$ & $5.08 \mathrm{E}-08$ & $1.09 \mathrm{E}-08$ \\
U-235 & $2.41 \mathrm{E}-07$ & $4.41 \mathrm{E}-09$ & $9.46 \mathrm{E}-10$ \\
U-238 & $1.08 \mathrm{E}-08$ & $1.98 \mathrm{E}-10$ & $4.24 \mathrm{E}-11$ \\
Total & $9.51 \mathrm{E}-02$ & $1.74 \mathrm{E}-03$ & $3.73 \mathrm{E}-04$ \\
\hline & & & \\
& &
\end{tabular}


TABLE B.3.4 Transuranic Waste, Case 6:

Rocky Flats Plant

\begin{tabular}{lccc}
\hline & & \\
Function: $\alpha$-Incineration \\
& \multicolumn{3}{c}{ Release (Ci) } \\
\cline { 2 - 4 } Nuclide & EQ5 & IEX1 & IFF1 \\
\hline & & & \\
Am-241 & $3.35 E-03$ & $6.14 \mathrm{E}-05$ & $1.32 \mathrm{E}-05$ \\
Pu-238 & $1.11 \mathrm{E}-04$ & $2.03 \mathrm{E}-06$ & $4.35 \mathrm{E}-07$ \\
Pu-239 & $3.03 \mathrm{E}-03$ & $5.55 \mathrm{E}-05$ & $1.19 \mathrm{E}-05$ \\
Pu-240 & $2.29 \mathrm{E}-03$ & $4.20 \mathrm{E}-05$ & $9.00 \mathrm{E}-06$ \\
Pu-241 & $1.54 \mathrm{E}-02$ & $2.83 \mathrm{E}-04$ & $6.06 \mathrm{E}-05$ \\
U-233 & $4.14 \mathrm{E}-06$ & $7.59 \mathrm{E}-08$ & $1.63 \mathrm{E}-08$ \\
$\mathrm{U}-234$ & $1.54 \mathrm{E}-09$ & $2.82 \mathrm{E}-11$ & $6.04 \mathrm{E}-12$ \\
$\mathrm{U}-236$ & $2.93 \mathrm{E}-10$ & $5.37 \mathrm{E}-12$ & $1.15 \mathrm{E}-12$ \\
Total & $2.42 \mathrm{E}-02$ & $4.44 \mathrm{E}-04$ & $9.51 \mathrm{E}-05$ \\
\hline
\end{tabular}


TABLE B.3.5 Transuranic Waste, Case 6: Savannah River Site

\begin{tabular}{|c|c|c|c|}
\hline \multicolumn{4}{|c|}{ Function: $\alpha$-Incineration } \\
\hline \multirow[b]{2}{*}{ Nuclide } & \multicolumn{3}{|c|}{ Release (Ci) } \\
\hline & EQ5 & IEX1 & IFF1 \\
\hline Am-241 & $1.63 \mathrm{E}-05$ & $2.99 \mathrm{E}-07$ & $6.40 \mathrm{E}-08$ \\
\hline Am-243 & $2.13 \mathrm{E}-07$ & $3.90 \mathrm{E}-09$ & $8.36 \mathrm{E}-10$ \\
\hline Cf-252 & $9.81 E-09$ & $1.80 \mathrm{E}-10$ & $3.85 \mathrm{E}-11$ \\
\hline $\mathrm{Cm}-244$ & $3.79 \mathrm{E}-06$ & $6.94 \mathrm{E}-08$ & $1.49 \mathrm{E}-08$ \\
\hline $\mathrm{Cm}-245$ & 4.67E-09 & $8.56 \mathrm{E}-11$ & $1.83 \mathrm{E}-11$ \\
\hline Co-60 & $1.18 \mathrm{E}-11$ & $2.17 \mathrm{E}-13$ & $4.60 \mathrm{E}-14$ \\
\hline Cs-137 & $8.40 \mathrm{E}-06$ & $1.54 \mathrm{E}-07$ & $3.30 \mathrm{E}-08$ \\
\hline Eu-155 & $1.76 \mathrm{E}-09$ & $3.22 \mathrm{E}-11$ & $6.90 \mathrm{E}-12$ \\
\hline $\mathrm{Ni}-59$ & $4.00 \mathrm{E}-14$ & $0.00 E+00$ & $0.00 \mathrm{E}+00$ \\
\hline $\mathrm{Ni}-63$ & $5.07 \mathrm{E}-12$ & $9.30 \mathrm{E}-14$ & $2.00 \mathrm{E}-14$ \\
\hline Np-237 & $8.93 \mathrm{E}-06$ & $1.64 \mathrm{E}-07$ & $3.51 \mathrm{E}-08$ \\
\hline $\mathrm{Pa}-231$ & $1.11 \mathrm{E}-09$ & $2.03 E-11$ & $4.36 E-12$ \\
\hline $\mathrm{Pb}-210$ & $4.47 \mathrm{E}-09$ & $8.18 \mathrm{E}-11$ & $1.75 \mathrm{E}-11$ \\
\hline Pm-147 & $1.33 \mathrm{E}-11$ & $2.44 \mathrm{E}-13$ & $5.20 \mathrm{E}-14$ \\
\hline $\mathrm{Pu}-238$ & $2.36 E-04$ & $4.33 \mathrm{E}-06$ & $9.27 \mathrm{E}-07$ \\
\hline Pu-239 & $3.36 \mathrm{E}-05$ & $6.16 \mathrm{E}-07$ & $1.32 \mathrm{E}-07$ \\
\hline Pu-240 & $5.13 \mathrm{E}-06$ & $9.41 \mathrm{E}-08$ & $2.02 \mathrm{E}-08$ \\
\hline Pu-241 & $1.84 E-04$ & $3.38 \mathrm{E}-06$ & $7.24 \mathrm{E}-07$ \\
\hline $\mathrm{Pu}-242$ & $2.20 \mathrm{E}-12$ & $4.00 \mathrm{E}-14$ & $9.00 E-15$ \\
\hline $\mathrm{Ra}-228$ & $1.59 \mathrm{E}-11$ & $2.92 \mathrm{E}-13$ & $6.20 \mathrm{E}-14$ \\
\hline Sr-90 & $5.41 \mathrm{E}-06$ & $9.91 E-08$ & $2.12 \mathrm{E}-08$ \\
\hline Tc-99 & $6.29 \mathrm{E}-08$ & $1.15 \mathrm{E}-09$ & $2.47 \mathrm{E}-10$ \\
\hline Th-229 & $7.67 \mathrm{E}-10$ & $1.41 \mathrm{E}-11$ & $3.01 E-12$ \\
\hline Th-230 & $7.72 E-13$ & $1.40 \mathrm{E}-14$ & $0.00 \mathrm{E}+00$ \\
\hline Th-232 & $1.94 \mathrm{E}-11$ & $3.55 \mathrm{E}-13$ & $7.60 \mathrm{E}-14$ \\
\hline $\mathrm{U}-232$ & $1.03 \mathrm{E}-09$ & $1.88 \mathrm{E}-11$ & $4.04 \mathrm{E}-12$ \\
\hline$U-233$ & $6.47 \mathrm{E}-07$ & $1.19 \mathrm{E}-08$ & $2.54 \mathrm{E}-09$ \\
\hline U-234 & $8.03 E-08$ & $1.47 \mathrm{E}-09$ & $3.15 \mathrm{E}-10$ \\
\hline U-235 & $5.84 \mathrm{E}-10$ & $1.07 \mathrm{E}-11$ & $2.29 \mathrm{E}-12$ \\
\hline U-236 & $1.64 \mathrm{E}-12$ & $3.00 \mathrm{E}-14$ & $0.00 \mathrm{E}+00$ \\
\hline $\begin{array}{l}\text { U-238 } \\
\text { Total }\end{array}$ & $\begin{array}{l}1.73 E-09 \\
5.03 E-04\end{array}$ & $\begin{array}{l}3.17 \mathrm{E}-11 \\
9.22 \mathrm{E}-06\end{array}$ & $\begin{array}{l}6.78 \mathrm{E}-12 \\
1.98 \mathrm{E}-06\end{array}$ \\
\hline
\end{tabular}


TABLE B.3.6 Transuranic Waste, Case 8: Hanford

\begin{tabular}{|c|c|c|c|}
\hline \multicolumn{4}{|c|}{ Function: $\alpha$-Incineration } \\
\hline \multirow[b]{2}{*}{ Nuclide } & \multicolumn{3}{|c|}{ Release $(\mathrm{C} \mathbf{i})$} \\
\hline & EQ5 & IEX1 & IFF1 \\
\hline Am-241 & $1.17 \mathrm{E}-03$ & $2.14 \mathrm{E}-05$ & $4.58 \mathrm{E}-06$ \\
\hline Am-243 & 4.37E-08 & $8.02 \mathrm{E}-10$ & $1.72 \mathrm{E}-10$ \\
\hline Cf-252 & $6.78 \mathrm{E}-06$ & $1.24 \mathrm{E}-07$ & $2.66 E-08$ \\
\hline $\mathrm{Cm}-244$ & $1.30 \mathrm{E}-04$ & $2.38 \mathrm{E}-06$ & $5.09 \mathrm{E}-07$ \\
\hline $\mathrm{Cm}-245$ & $3.23 \mathrm{E}-06$ & $5.92 \mathrm{E}-08$ & $1.27 \mathrm{E}-08$ \\
\hline Cs-137 & $1.31 \mathrm{E}-04$ & $2.41 \mathrm{E}-06$ & $5.16 \mathrm{E}-07$ \\
\hline Np-237 & $0.00 \mathrm{E}+00$ & $0.00 \mathrm{E}+00$ & $0.00 \mathrm{E}+00$ \\
\hline $\mathrm{Pb}-210$ & $0.00 \mathrm{E}+00$ & $0.00 \mathrm{E}+00$ & $0.00 \mathrm{E}+00$ \\
\hline Pm-147 & $9.19 \mathrm{E}-09$ & $1.68 \mathrm{E}-10$ & $3.61 E-11$ \\
\hline $\mathrm{Pu}-238$ & $1.56 \mathrm{E}-02$ & $2.86 \mathrm{E}-04$ & $6.14 \mathrm{E}-05$ \\
\hline $\mathrm{Pu}-239$ & $5.35 \mathrm{E}-03$ & $9.80 \mathrm{E}-05$ & $2.10 \mathrm{E}-05$ \\
\hline $\mathrm{Pu}-240$ & $1.30 \mathrm{E}-03$ & $2.38 \mathrm{E}-05$ & $5.09 \mathrm{E}-06$ \\
\hline Pu-241 & $1.02 \mathrm{E}-02$ & $1.86 \mathrm{E}-04$ & $4.00 \mathrm{E}-05$ \\
\hline $\mathrm{Pu}-242$ & $0.00 \mathrm{E}+00$ & $0.00 \mathrm{E}+00$ & $0.00 \mathrm{E}+00$ \\
\hline $\mathrm{Ra}-228$ & $1.08 \mathrm{E}-08$ & $1.97 \mathrm{E}-10$ & $4.23 \mathrm{E}-11$ \\
\hline Sr-90 & $1.33 \mathrm{E}-04$ & $2.44 \mathrm{E}-06$ & $5.23 \mathrm{E}-07$ \\
\hline Th-229 & $2.51 \mathrm{E}-08$ & $4.61 \mathrm{E}-10$ & $9.87 \mathrm{E}-11$ \\
\hline Th-232 & $1.29 \mathrm{E}-08$ & $2.37 \mathrm{E}-10$ & $5.07 \mathrm{E}-11$ \\
\hline U-233 & $1.54 \mathrm{E}-05$ & $2.82 \mathrm{E}-07$ & $6.04 \mathrm{E}-08$ \\
\hline U-234 & $1.03 \mathrm{E}-05$ & $1.90 \mathrm{E}-07$ & $4.06 \mathrm{E}-08$ \\
\hline U-235 & $3.30 \mathrm{E}-07$ & $6.05 E-09$ & $1.30 \mathrm{E}-09$ \\
\hline U-236 & $1.36 \mathrm{E}-11$ & $2.49 \mathrm{E}-13$ & $5.30 \mathrm{E}-14$ \\
\hline U-238 & $1.18 \mathrm{E}-06$ & $2.16 \mathrm{E}-08$ & $4.64 \mathrm{E}-09$ \\
\hline Total & $3.40 \mathrm{E}-02$ & $6.24 \mathrm{E}-04$ & $1.34 \mathrm{E}-04$ \\
\hline
\end{tabular}


TABLE B.3.7 Transuranic Waste, Case 8: Idaho National Engineering Laboratory

\begin{tabular}{lccc}
\hline & & & \\
Function: $\alpha$-Incineration & \\
\hline & \multicolumn{3}{c}{ Release (Ci) } \\
\cline { 2 - 4 } Nuclide & EQ5 & IEX1 & IFE1 \\
\hline & & & \\
Ac-227 & $1.17 \mathrm{E}-07$ & $2.14 \mathrm{E}-09$ & $4.58 \mathrm{E}-10$ \\
Am-241 & $3.37 \mathrm{E}-02$ & $6.17 \mathrm{E}-04$ & $1.32 \mathrm{E}-04$ \\
Am-243 & $1.75 \mathrm{E}-06$ & $3.21 \mathrm{E}-08$ & $6.87 \mathrm{E}-09$ \\
Cm-244 & $2.08 \mathrm{E}-04$ & $3.81 \mathrm{E}-06$ & $8.17 \mathrm{E}-07$ \\
Co-60 & $1.73 \mathrm{E}-05$ & $3.17 \mathrm{E}-07$ & $6.80 \mathrm{E}-08$ \\
Cs-134 & $1.94 \mathrm{E}-09$ & $3.55 \mathrm{E}-11$ & $7.61 \mathrm{E}-12$ \\
Cs-137 & $3.87 \mathrm{E}-05$ & $7.10 \mathrm{E}-07$ & $1.52 \mathrm{E}-07$ \\
Eu-152 & $4.50 \mathrm{E}-08$ & $8.25 \mathrm{E}-10$ & $1.77 \mathrm{E}-10$ \\
Eu-154 & $1.90 \mathrm{E}-07$ & $3.48 \mathrm{E}-09$ & $7.45 \mathrm{E}-10$ \\
Eu-155 & $2.16 \mathrm{E}-07$ & $3.97 \mathrm{E}-09$ & $8.50 \mathrm{E}-10$ \\
Pb-210 & $1.36 \mathrm{E}-07$ & $2.49 \mathrm{E}-09$ & $5.33 \mathrm{E}-10$ \\
Pm-147 & $1.64 \mathrm{E}-06$ & $3.01 \mathrm{E}-08$ & $6.46 \mathrm{E}-09$ \\
Pu-238 & $6.91 \mathrm{E}-02$ & $1.27 \mathrm{E}-03$ & $2.71 \mathrm{E}-04$ \\
Pu-239 & $5.03 \mathrm{E}-02$ & $9.22 \mathrm{E}-04$ & $1.98 \mathrm{E}-04$ \\
Pu-240 & $5.07 \mathrm{E}-03$ & $9.29 \mathrm{E}-05$ & $1.99 \mathrm{E}-05$ \\
Pu-241 & $5.77 \mathrm{E}-02$ & $1.06 \mathrm{E}-03$ & $2.27 \mathrm{E}-04$ \\
Pu-242 & $2.22 \mathrm{E}-04$ & $4.07 \mathrm{E}-06$ & $8.71 \mathrm{E}-07$ \\
Ra-228 & $8.53 \mathrm{E}-08$ & $1.56 \mathrm{E}-09$ & $3.35 \mathrm{E}-10$ \\
Sb-125 & $2.13 \mathrm{E}-08$ & $3.91 \mathrm{E}-10$ & $8.38 \mathrm{E}-11$ \\
Sm-151 & $2.82 \mathrm{E}-07$ & $5.17 \mathrm{E}-09$ & $1.11 \mathrm{E}-09$ \\
Sn-121m & $4.98 \mathrm{E}-09$ & $9.12 \mathrm{E}-11$ & $1.95 \mathrm{E}-11$ \\
Sr-90 & $2.09 \mathrm{E}-05$ & $3.82 \mathrm{E}-07$ & $8.19 \mathrm{E}-08$ \\
Tc-99 & $4.68 \mathrm{E}-09$ & $8.57 \mathrm{E}-11$ & $1.84 \mathrm{E}-11$ \\
Th-229 & $4.58 \mathrm{E}-07$ & $8.39 \mathrm{E}-09$ & $1.80 \mathrm{E}-09$ \\
Th-230 & $5.77 \mathrm{E}-09$ & $1.06 \mathrm{E}-10$ & $2.27 \mathrm{E}-11$ \\
Th-232 & $9.16 \mathrm{E}-08$ & $1.68 \mathrm{E}-09$ & $3.60 \mathrm{E}-10$ \\
U-232 & $7.02 \mathrm{E}-06$ & $1.29 \mathrm{E}-07$ & $2.76 \mathrm{E}-08$ \\
U-233 & $2.74 \mathrm{E}-04$ & $5.02 \mathrm{E}-06$ & $1.08 \mathrm{E}-06$ \\
U-234 & $4.49 \mathrm{E}-06$ & $8.22 \mathrm{E}-08$ & $1.76 \mathrm{E}-08$ \\
U-235 & $2.58 \mathrm{E}-07$ & $4.73 \mathrm{E}-09$ & $1.01 \mathrm{E}-09$ \\
U-236 & $2.93 \mathrm{E}-10$ & $5.37 \mathrm{E}-12$ & $1.15 \mathrm{E}-12$ \\
U-238 & $4.29 \mathrm{E}-08$ & $7.86 \mathrm{E}-10$ & $1.68 \mathrm{E}-10$ \\
& $2.17 \mathrm{E}-01$ & $3.97 \mathrm{E}-03$ & $8.51 \mathrm{E}-04$ \\
\hline & & & \\
& &
\end{tabular}


TABLE B.3.8 Transuranic Waste, Case 8: Savannah River Site

\begin{tabular}{|c|c|c|c|}
\hline \multicolumn{4}{|c|}{ Function: $\alpha$-Incineration } \\
\hline \multirow[b]{2}{*}{ Nuclide } & \multicolumn{3}{|c|}{ Release (Ci) } \\
\hline & EQ5 & IEX1 & IFF1 \\
\hline Am-241 & $1.63 E-05$ & 2.99E-07 & $6.40 \mathrm{E}-08$ \\
\hline Am-243 & $2.13 E-07$ & $3.90 \mathrm{E}-09$ & $8.36 \mathrm{E}-10$ \\
\hline Cf-252 & $9.81 \mathrm{E}-09$ & $1.80 \mathrm{E}-10$ & $3.85 \mathrm{E}-11$ \\
\hline $\mathrm{Cm}-244$ & $3.79 \mathrm{E}-06$ & $6.94 \mathrm{E}-08$ & $1.49 \mathrm{E}-08$ \\
\hline $\mathrm{Cm}-245$ & 4.67E-09 & $8.56 \mathrm{E}-11$ & $1.83 \mathrm{E}-11$ \\
\hline $\mathrm{Co}-60$ & $1.18 \mathrm{E}-11$ & $2.17 \mathrm{E}-13$ & $4.60 \mathrm{E}-14$ \\
\hline Cs- 137 & $8.40 E-06$ & $1.54 \mathrm{E}-07$ & $3.30 E-08$ \\
\hline Eu-155 & $1.76 \mathrm{E}-09$ & $3.22 \mathrm{E}-11$ & $6.90 \mathrm{E}-12$ \\
\hline $\mathrm{Ni}-59$ & $4.00 \mathrm{E}-14$ & $0.00 \mathrm{E}+00$ & $0.00 \mathrm{E}+00$ \\
\hline $\mathrm{Ni}-63$ & $5.07 \mathrm{E}-12$ & $9.30 \mathrm{E}-14$ & $2.00 \mathrm{E}-14$ \\
\hline Np-237 & $8.93 E-06$ & $1.64 \mathrm{E}-07$ & $3.51 \mathrm{E}-08$ \\
\hline $\mathrm{Pa}-231$ & $1.11 \mathrm{E}-09$ & $2.03 \mathrm{E}-11$ & $4.36 \mathrm{E}-12$ \\
\hline $\mathrm{Pb}-210$ & 4.47E-09 & $8.18 \mathrm{E}-11$ & $1.75 \mathrm{E}-11$ \\
\hline Pm-147 & $1.33 \mathrm{E}-11$ & $2.44 E-13$ & $5.20 \mathrm{E}-14$ \\
\hline Pu-238 & $2.36 \mathrm{E}-04$ & $4.33 \mathrm{E}-06$ & $9.27 \mathrm{E}-07$ \\
\hline Pu-239 & $3.36 \mathrm{E}-05$ & $6.16 \mathrm{E}-07$ & $1.32 \mathrm{E}-07$ \\
\hline Pu-240 & $5.13 E-06$ & $9.41 \mathrm{E}-08$ & $2.02 E-08$ \\
\hline Pu-241 & $1.84 \mathrm{E}-04$ & $3.38 \mathrm{E}-06$ & $7.24 \mathrm{E}-07$ \\
\hline Pu-242 & $2.20 \mathrm{E}-12$ & $4.00 \mathrm{E}-14$ & $9.00 \mathrm{E}-15$ \\
\hline Ra-228 & $1.59 \mathrm{E}-11$ & $2.92 E-13$ & $6.20 \mathrm{E}-14$ \\
\hline Sr-90 & $5.41 \mathrm{E}-06$ & $9.91 \mathrm{E}-08$ & $2.12 \mathrm{E}-08$ \\
\hline Tc-99 & $6.29 \mathrm{E}-08$ & $1.15 \mathrm{E}-09$ & $2.47 \mathrm{E}-10$ \\
\hline Th-229 & $7.67 \mathrm{E}-10$ & $1.41 \mathrm{E}-11$ & $3.01 E-12$ \\
\hline Th-230 & $7.72 \mathrm{E}-13$ & $1.40 \mathrm{E}-14$ & $0.00 \mathrm{E}+00$ \\
\hline Th-232 & $1.94 \mathrm{E}-11$ & $3.55 E-13$ & $7.60 \mathrm{E}-14$ \\
\hline U-232 & $1.03 \mathrm{E}-09$ & $1.88 \mathrm{E}-11$ & $4.04 \mathrm{E}-12$ \\
\hline U-233 & $6.47 \mathrm{E}-07$ & $1.19 \mathrm{E}-08$ & $2.54 \mathrm{E}-09$ \\
\hline U-234 & $8.03 \mathrm{E}-08$ & $1.47 \mathrm{E}-09$ & $3.15 \mathrm{E}-10$ \\
\hline U-235 & $5.84 \mathrm{E}-10$ & $1.07 \mathrm{E}-11$ & $2.29 \mathrm{E}-12$ \\
\hline$U-236$ & $1.64 \mathrm{E}-12$ & $3.00 \mathrm{E}-14$ & $0.00 \mathrm{E}+00$ \\
\hline $\begin{array}{l}\text { U-238 } \\
\text { Total }\end{array}$ & $\begin{array}{l}1.73 E-09 \\
5.03 E-04\end{array}$ & $\begin{array}{l}3.17 \mathrm{E}-11 \\
9.22 \mathrm{E}-06\end{array}$ & $\begin{array}{l}6.78 \mathrm{E}-12 \\
1.98 \mathrm{E}-06\end{array}$ \\
\hline
\end{tabular}


TABLE B.3.9 Transuranic Waste, Case 9: Waste Isolation Pilot Plant

\begin{tabular}{|c|c|c|c|}
\hline \multicolumn{4}{|c|}{ Function: $\alpha$-Incineration } \\
\hline \multirow[b]{2}{*}{ Nuclide } & \multicolumn{3}{|c|}{ Release $(\mathrm{Ci})$} \\
\hline & EQ5 & IEX1 & IFFI \\
\hline Ac-227 & $1.17 \mathrm{E}-07$ & $2.14 \mathrm{E}-09$ & $4.58 \mathrm{E}-10$ \\
\hline Am-241 & $3.48 \mathrm{E}-02$ & $6.39 \mathrm{E}-04$ & $1.37 \mathrm{E}-04$ \\
\hline Am-243 & $2.01 \mathrm{E}-06$ & $3.68 \mathrm{E}-08$ & $7.88 \mathrm{E}-09$ \\
\hline Cf-252 & $6.79 E-06$ & $1.24 \mathrm{E}-07$ & $2.67 \mathrm{E}-08$ \\
\hline $\mathrm{Cm}-244$ & $3.42 \mathrm{E}-04$ & $6.26 \mathrm{E}-06$ & $1.34 \mathrm{E}-06$ \\
\hline $\mathrm{Cm}-245$ & $3.23 \mathrm{E}-06$ & $5.93 \mathrm{E}-08$ & $1.27 \mathrm{E}-08$ \\
\hline Co-60 & $1.73 \mathrm{E}-05$ & $3.17 \mathrm{E}-07$ & $6.80 \mathrm{E}-08$ \\
\hline Cs-134 & $1.94 \mathrm{E}-09$ & $3.55 \mathrm{E}-11$ & $7.61 \mathrm{E}-12$ \\
\hline Cs-137 & $1.79 \mathrm{E}-04$ & $3.27 \mathrm{E}-06$ & $7.01 \mathrm{E}-07$ \\
\hline Eu-152 & $4.50 \mathrm{E}-08$ & $8.25 \mathrm{E}-10$ & $1.77 \mathrm{E}-10$ \\
\hline Eu-154 & $1.90 \mathrm{E}-07$ & $3.48 \mathrm{E}-09$ & $7.45 \mathrm{E}-10$ \\
\hline Eu-155 & $2.18 \mathrm{E}-07$ & $4.00 \mathrm{E}-09$ & $8.57 \mathrm{E}-10$ \\
\hline $\mathrm{Ni}-59$ & $4.00 \mathrm{E}-14$ & $0.00 \mathrm{E}+00$ & $0.00 \mathrm{E}+00$ \\
\hline $\mathrm{Ni}-63$ & $5.07 \mathrm{E}-12$ & $9.30 \mathrm{E}-14$ & $2.00 \mathrm{E}-14$ \\
\hline Np-237 & $8.93 \mathrm{E}-06$ & $1.64 \mathrm{E}-07$ & $3.51 \mathrm{E}-08$ \\
\hline $\mathrm{Pa}-231$ & $1.11 \mathrm{E}-09$ & $2.03 E-11$ & $4.36 \mathrm{E}-12$ \\
\hline $\mathrm{Pb}-210$ & $1.40 \mathrm{E}-07$ & $2.57 \mathrm{E}-09$ & $5.50 \mathrm{E}-10$ \\
\hline Pm-147 & $1.65 \mathrm{E}-06$ & $3.03 \mathrm{E}-08$ & $6.49 \mathrm{E}-09$ \\
\hline Pu-238 & $8.50 \mathrm{E}-02$ & $1.56 \mathrm{E}-03$ & $3.34 \mathrm{E}-04$ \\
\hline Pu-239 & $5.57 \mathrm{E}-02$ & $1.02 \mathrm{E}-03$ & $2.19 \mathrm{E}-04$ \\
\hline $\mathrm{Pu}-240$ & $6.37 \mathrm{E}-03$ & $1.17 \mathrm{E}-04$ & $2.50 \mathrm{E}-05$ \\
\hline $\mathrm{Pu}-241$ & $6.81 \mathrm{E}-02$ & $1.25 \mathrm{E}-03$ & $2.67 \mathrm{E}-04$ \\
\hline $\mathrm{Pu}-242$ & $2.22 \mathrm{E}-04$ & $4.07 \mathrm{E}-06$ & $8.71 \mathrm{E}-07$ \\
\hline Ra-228 & $9.61 \mathrm{E}-08$ & $1.76 \mathrm{E}-09$ & 3.77E-10 \\
\hline Sb-125 & 2.13E-08 & $3.91 \mathrm{E}-10$ & $8.38 \mathrm{E}-11$ \\
\hline Sm-151 & $2.82 \mathrm{E}-07$ & $5.17 \mathrm{E}-09$ & $1.11 \mathrm{E}-09$ \\
\hline $\mathrm{Sn}-121 \mathrm{~m}$ & 4.98E-09 & $9.12 \mathrm{E}-11$ & $1.95 \mathrm{E}-11$ \\
\hline Sr-90 & $1.59 \mathrm{E}-04$ & $2.92 \mathrm{E}-06$ & $6.26 \mathrm{E}-07$ \\
\hline Tc-99 & $6.76 \mathrm{E}-0.08$ & $1.24 \mathrm{E}-09$ & $2.65 \mathrm{E}-10$ \\
\hline Th-229 & $4.84 \mathrm{E}-07$ & 8.87E-09 & $1.90 \mathrm{E}-09$ \\
\hline Th-230 & $5.77 \mathrm{E}-09$ & $1.06 \mathrm{E}-10$ & $2.27 \mathrm{E}-11$ \\
\hline Th-232 & $1.05 \mathrm{E}-07$ & $1.92 \mathrm{E}-09$ & $4.10 \mathrm{E}-10$ \\
\hline U-232 & $7.02 \mathrm{E}-06$ & $1.29 \mathrm{E}-07$ & $2.76 \mathrm{E}-08$ \\
\hline U-233 & $2.90 \mathrm{E}-04$ & $5.31 \mathrm{E}-06$ & $1.14 \mathrm{E}-06$ \\
\hline U-234 & $1.49 \mathrm{E}-05$ & $2.73 \mathrm{E}-07$ & $5.86 \mathrm{E}-08$ \\
\hline U-235 & $5.89 \mathrm{E}-07$ & $1.08 \mathrm{E}-08$ & $2.31 \mathrm{E}-09$ \\
\hline U-236 & $3.08 \mathrm{E}-10$ & $5.65 \mathrm{E}-12$ & $1.21 \mathrm{E}-12$ \\
\hline U-238 & $1.23 \mathrm{E}-06$ & $2.25 \mathrm{E}-08$ & $4.81 E-09$ \\
\hline Total & $2.51 \mathrm{E}-01$ & $4.60 \mathrm{E}-03$ & $9.87 \mathrm{E}-04$ \\
\hline
\end{tabular}


TABLE B.3.10 Transuranic Waste, Case 15:

Hanford

\begin{tabular}{|c|c|c|c|}
\hline \multicolumn{4}{|c|}{ Function: $r$-Incineration ${ }^{\mathfrak{a}}$} \\
\hline \multirow[b]{2}{*}{ Nuclide } & \multicolumn{3}{|c|}{ Release $(\mathrm{Ci})$} \\
\hline & EQ5 & IEXI & IFF1 \\
\hline Am-241 & $6.85 \mathrm{E}-06$ & $1.25 \mathrm{E}-07$ & $2.69 E-08$ \\
\hline $\mathrm{Cm}-243$ & $2.12 \mathrm{E}-09$ & $3.89 \mathrm{E}-11$ & $8.33 \mathrm{E}-12$ \\
\hline $\mathrm{Cm}-244$ & $1.41 \mathrm{E}-08$ & $2.58 \mathrm{E}-10$ & $5.52 E-11$ \\
\hline Co-60 & $4.95 E-06$ & $9.08 \mathrm{E}-08$ & $1.94 \mathrm{E}-08$ \\
\hline Cs-134 & $7.87 \mathrm{E}-06$ & $1.44 \mathrm{E}-07$ & $3.09 \mathrm{E}-08$ \\
\hline Cs-137 & $3.60 \mathrm{E}-04$ & $6.60 \mathrm{E}-06$ & $1.41 \mathrm{E}-06$ \\
\hline Eu-152 & $1.66 \mathrm{E}-08$ & $3.04 \mathrm{E}-10$ & $6.52 \mathrm{E}-11$ \\
\hline Eu-154 & $1.37 \mathrm{E}-07$ & $2.50 \mathrm{E}-09$ & $5.37 \mathrm{E}-10$ \\
\hline Eu-155 & $1.13 \mathrm{E}-06$ & $2.07 \mathrm{E}-08$ & $4.43 \mathrm{E}-09$ \\
\hline FE-55 & 8.71E-08 & $1.60 \mathrm{E}-09$ & $3.42 \mathrm{E}-10$ \\
\hline $\mathrm{Ni}-63$ & $5.12 \mathrm{E}-07$ & $9.37 \mathrm{E}-09$ & $2.01 \mathrm{E}-09$ \\
\hline Pm-147 & $9.04 \mathrm{E}-06$ & $1.66 \mathrm{E}-07$ & $3.55 \mathrm{E}-08$ \\
\hline Pu-238 & $1.13 \mathrm{E}-05$ & $2.07 \mathrm{E}-07$ & $4.43 \mathrm{E}-08$ \\
\hline Pu-239 & $6.08 \mathrm{E}-05$ & $1.11 \mathrm{E}-06$ & $2.39 \mathrm{E}-07$ \\
\hline $\mathrm{Pu}-240$ & $3.62 \mathrm{E}-06$ & $6.63 \mathrm{E}-08$ & $1.42 \mathrm{E}-08$ \\
\hline $\mathrm{Pu}-241$ & $7.03 \mathrm{E}-06$ & $1.29 \mathrm{E}-07$ & $2.76 \mathrm{E}-08$ \\
\hline Sb-125 & $1.84 \mathrm{E}-06$ & $3.37 \mathrm{E}-08$ & $7.22 \mathrm{E}-09$ \\
\hline Sm-151 & $3.65 \mathrm{E}-07$ & $6.69 \mathrm{E}-09$ & $1.43 \mathrm{E}-09$ \\
\hline $\mathrm{Sn}-121 \mathrm{~m}$ & $6.64 \mathrm{E}-09$ & $1.22 \mathrm{E}-10$ & $2.61 E-11$ \\
\hline Sr-90 & $3.24 \mathrm{E}-04$ & $5.93 E-06$ & $1.27 \mathrm{E}-06$ \\
\hline Tc-99 & $5.80 \mathrm{E}-09$ & $1.06 \mathrm{E}-10$ & $2.28 E-11$ \\
\hline U-233 & $5.71 \mathrm{E}-08$ & $1.05 \mathrm{E}-09$ & $2.24 \mathrm{E}-10$ \\
\hline U-234 & $2.20 \mathrm{E}-08$ & $4.04 \mathrm{E}-10$ & $8.65 \mathrm{E}-11$ \\
\hline U-235 & $5.34 \mathrm{E}-09$ & $9.78 \mathrm{E}-11$ & $2.10 \mathrm{E}-11$ \\
\hline Total & $7.99 \mathrm{E}-04$ & $1.46 \mathrm{E}-05$ & $3.14 \mathrm{E}-06$ \\
\hline
\end{tabular}

${ }^{a}$ Incineration of $\mathrm{RH}$ waste. 
TABLE B.3.11 Transuranic Waste, Case 15:

Oak Ridge National Laboratory

\begin{tabular}{|c|c|c|c|}
\hline \multicolumn{4}{|c|}{ Function: $r$-Incineration ${ }^{\mathrm{a}}$} \\
\hline \multirow[b]{2}{*}{ Nuclide } & \multicolumn{3}{|c|}{ Release $(\mathrm{Ci})$} \\
\hline & EQ5 & IEX1 & IFF1 \\
\hline Am-241 & $6.91 \mathrm{E}-05$ & $1.27 \mathrm{E}-06$ & $2.71 \mathrm{E}-07$ \\
\hline Cf- 252 & $1.10 \mathrm{E}-06$ & $2.01 \mathrm{E}-08$ & $4.31 \mathrm{E}-09$ \\
\hline $\mathrm{Cm}-243$ & $4.22 \mathrm{E}-05$ & 7.73E-07 & $1.66 \mathrm{E}-07$ \\
\hline $\mathrm{Cm}-244$ & $2.88 \mathrm{E}-04$ & $5.27 \mathrm{E}-06$ & $1.13 E-06$ \\
\hline Co-60 & $1.75 \mathrm{E}-04$ & $3.21 \mathrm{E}-06$ & $6.87 \mathrm{E}-07$ \\
\hline Cs-134 & $8.05 E-06$ & $1.48 \mathrm{E}-07$ & $3.16 \mathrm{E}-08$ \\
\hline Cs-137 & $2.87 \mathrm{E}-03$ & $5.26 \mathrm{E}-05$ & $1.13 \mathrm{E}-05$ \\
\hline Eu-152 & $1.04 \mathrm{E}-03$ & $1.91 \mathrm{E}-05$ & $4.09 \mathrm{E}-06$ \\
\hline Eu-154 & $5.06 \mathrm{E}-04$ & $9.27 \mathrm{E}-06$ & $1.99 \mathrm{E}-06$ \\
\hline Eu-155 & $1.00 \mathrm{E}-04$ & $1.83 \mathrm{E}-06$ & $3.93 \mathrm{E}-07$ \\
\hline Pm-147 & $1.03 \mathrm{E}-05$ & $1.89 \mathrm{E}-07$ & $4.05 \mathrm{E}-08$ \\
\hline Pu-238 & $4.49 \mathrm{E}-05$ & $8.22 \mathrm{E}-07$ & $1.76 \mathrm{E}-07$ \\
\hline $\mathrm{Pu}-239$ & $2.81 \mathrm{E}-05$ & $5.14 \mathrm{E}-07$ & $1.10 \mathrm{E}-07$ \\
\hline $\mathrm{Pu}-240$ & $3.10 \mathrm{E}-07$ & $5.68 \mathrm{E}-09$ & $1.22 \mathrm{E}-09$ \\
\hline Pu-241 & $8.75 \mathrm{E}-07$ & $1.60 \mathrm{E}-08$ & $3.43 \mathrm{E}-09$ \\
\hline Sb-125 & $6.00 \mathrm{E}-07$ & $1.10 \mathrm{E}-08$ & $2.36 \mathrm{E}-09$ \\
\hline Sr-90 & $1.01 \mathrm{E}-02$ & $1.85 \mathrm{E}-04$ & $3.97 \mathrm{E}-05$ \\
\hline U-232 & $5.02 \mathrm{E}-07$ & $9.19 \mathrm{E}-09$ & $1.97 \mathrm{E}-09$ \\
\hline U-233 & $1.63 \mathrm{E}-05$ & $2.99 \mathrm{E}-07$ & $6.40 \mathrm{E}-08$ \\
\hline U-235 & $5.28 \mathrm{E}-05$ & $9.68 \mathrm{E}-07$ & $2.07 \mathrm{E}-07$ \\
\hline U-238 & $9.58 \mathrm{E}-07$ & $1.76 \mathrm{E}-08$ & $3.76 \mathrm{E}-09$ \\
\hline Total & $1.54 \mathrm{E}-02$ & $2.82 \mathrm{E}-04$ & $6.04 \mathrm{E}-05$ \\
\hline
\end{tabular}

${ }^{a}$ Incineration of RH waste. 
TABLE B.3.12 Transuranic Waste Drum Handling Accidents for All Cases: Argonne National Laboratory-West

\begin{tabular}{lc}
\hline & Release (Ci) \\
\cline { 2 - 2 } Nuclide & SHA1 \\
\hline & \\
Ac-227 & $2.21 \mathrm{E}-11$ \\
Am-241 & $5.16 \mathrm{E}-05$ \\
C-14 & $1.47 \mathrm{E}-07$ \\
Cm-244 & $2.82 \mathrm{E}-07$ \\
Co-60 & $3.58 \mathrm{E}-08$ \\
Cs-137 & $3.46 \mathrm{E}-08$ \\
Eu-152 & $9.31 \mathrm{E}-11$ \\
Eu-154 & $3.69 \mathrm{E}-10$ \\
Eu-155 & $2.20 \mathrm{E}-10$ \\
H-3 & $7.09 \mathrm{E}-07$ \\
Pb-210 & $1.55 \mathrm{E}-11$ \\
Pm-147 & $1.50 \mathrm{E}-09$ \\
Pu-238 & $3.42 \mathrm{E}-05$ \\
Pu-239 & $2.30 \mathrm{E}-05$ \\
Pu-240 & $5.64 \mathrm{E}-06$ \\
Pu-241 & $8.59 \mathrm{E}-05$ \\
Ra-228 & $1.76 \mathrm{E}-10$ \\
Sm-151 & $1.37 \mathrm{E}-11$ \\
Sr-90 & $1.12 \mathrm{E}-09$ \\
Th-229 & $8.70 \mathrm{E}-10$ \\
Th-230 & $1.19 \mathrm{E}-11$ \\
Th-232 & $1.89 \mathrm{E}-10$ \\
$\mathrm{U}-232$ & $1.45 \mathrm{E}-08$ \\
$\mathrm{U}-233$ & $5.15 \mathrm{E}-07$ \\
$\mathrm{U}-234$ & $3.54 \mathrm{E}-09$ \\
$\mathrm{U}-235$ & $3.54 \mathrm{E}-11$ \\
$\mathrm{U}-238$ & $6.63 \mathrm{E}-11$ \\
Total & $2.02 \mathrm{E}-04$ \\
\hline &
\end{tabular}

TABLE B.3.13 Transuranic Waste Drum Handling Accidents for All Cases: Hanford

\begin{tabular}{lc}
\hline & Release (Ci) \\
\cline { 2 - 2 } Nuclide & SHA1 \\
\hline & \\
Am-241 & $1.25 \mathrm{E}-05$ \\
C-14 & $7.72 \mathrm{E}-06$ \\
Cf-252 & $9.30 \mathrm{E}-08$ \\
Cm-244 & $1.80 \mathrm{E}-07$ \\
Cm-245 & $4.43 \mathrm{E}-08$ \\
Cs-137 & $1.80 \mathrm{E}-06$ \\
Pm-147 & $1.26 \mathrm{E}-10$ \\
Pu-238 & $2.13 \mathrm{E}-04$ \\
Pu-239 & $6.94 \mathrm{E}-05$ \\
Pu-240 & $1.62 \mathrm{E}-05$ \\
Pu-241 & $9.97 \mathrm{E}-05$ \\
Ra-228 & $1.48 \mathrm{E}-10$ \\
Sr-90 & $1.83 \mathrm{E}-06$ \\
Th-229 & $3.45 \mathrm{E}-10$ \\
Th-232 & $1.77 \mathrm{E}-10$ \\
U-233 & $2.11 \mathrm{E}-07$ \\
U-234 & $1.42 \mathrm{E}-07$ \\
U-235 & $4.51 \mathrm{E}-09$ \\
U-238 & $1.55 \mathrm{E}-08$ \\
Total & $4.22 \mathrm{E}-04$ \\
\hline &
\end{tabular}


TABLE B.3.14 Transuranic Waste Drum Handling Accidents for All Cases: Los Alamos National Laboratory

\begin{tabular}{|c|c|}
\hline & Release (Ci) \\
\hline Nuclide & SHAl \\
\hline Ac-227 & 8.77E-10 \\
\hline Am-241 & $4.42 \mathrm{E}-05$ \\
\hline Am-243 & $1.45 \mathrm{E}-08$ \\
\hline $\mathrm{Cm}-244$ & $5.93 \mathrm{E}-07$ \\
\hline Cs-134 & $1.61 \mathrm{E}-11$ \\
\hline Cs-137 & $1.82 \mathrm{E}-07$ \\
\hline Eu-154 & $9.29 \mathrm{E}-11$ \\
\hline Eu-155 & $9.13 \mathrm{E}-10$ \\
\hline $\mathrm{Pb}-210$ & $1.06 \mathrm{E}-09$ \\
\hline Pm-147 & $7.60 \mathrm{E}-09$ \\
\hline Pu-238 & $4.34 \mathrm{E}-04$ \\
\hline Pu-239 & $3.00 \mathrm{E}-04$ \\
\hline Pu-240 & $3.84 \mathrm{E}-07$ \\
\hline Pu-241 & $6.15 E-06$ \\
\hline $\mathrm{Pu}-242$ & $1.84 \mathrm{E}-06$ \\
\hline Sb-125 & $1.77 \mathrm{E}-10$ \\
\hline Sm-151 & $2.28 \mathrm{E}-09$ \\
\hline Sn-121m & $4.12 E-11$ \\
\hline $\mathrm{Sr}-90$ & $1.68 \mathrm{E}-07$ \\
\hline Tc-99 & $3.87 \mathrm{E}-11$ \\
\hline Th-229 & $3.06 \mathrm{E}-10$ \\
\hline U-233 & $1.69 \mathrm{E}-07$ \\
\hline U-234 & $2.30 \mathrm{E}-08$ \\
\hline U-235 & $2.00 \mathrm{E}-09$ \\
\hline U-238 & $8.95 \mathrm{E}-11$ \\
\hline Total & $7.88 \mathrm{E}-04$ \\
\hline
\end{tabular}

TABLE B.3.15 Transuranic Waste Drum Handling Accidents for All Cases: Lawrence Livermore National Laboratory

\begin{tabular}{lc}
\hline & Release (Ci) \\
\cline { 2 - 2 } Nuclide & SHA1 \\
\hline & \\
Am-241 & $6.79 \mathrm{E}-05$ \\
Am-243 & $1.16 \mathrm{E}-08$ \\
Cm-244 & $3.09 \mathrm{E}-05$ \\
Pu-238 & $3.61 \mathrm{E}-05$ \\
Pu-239 & $7.76 \mathrm{E}-05$ \\
Pu-240 & $3.04 \mathrm{E}-05$ \\
Pu-241 & $7.70 \mathrm{E}-04$ \\
U-234 & $1.55 \mathrm{E}-09$ \\
U-235 & $2.80 \mathrm{E}-10$ \\
U-236 & $3.60 \mathrm{E}-12$ \\
U-238 & $1.43 \mathrm{E}-08$ \\
Total & $1.01 \mathrm{E}-03$ \\
\hline
\end{tabular}


TABLE B.3.16 Transuranic Waste Drum Handling Accidents for All Cases: Rocky Flats Plant

\begin{tabular}{lc}
\hline & Release (Ci) \\
\cline { 2 - 2 } Nuclide & SHAl \\
\hline & \\
Am-241 & $1.93 \mathrm{E}-04$ \\
Pu-238 & $6.36 \mathrm{E}-06$ \\
Pu-239 & $1.74 \mathrm{E}-04$ \\
Pu-240 & $1.32 \mathrm{E}-04$ \\
Pu-241 & $8.87 \mathrm{E}-04$ \\
$\mathrm{U}-233$ & $2.38 \mathrm{E}-07$ \\
$\mathrm{U}-234$ & $8.84 \mathrm{E}-11$ \\
$\mathrm{U}-236$ & $1.68 \mathrm{E}-11$ \\
Total & $1.39 \mathrm{E}-03$ \\
\hline
\end{tabular}

TABLE B.3.17 Transuranic Waste Drum Handling Accidents for All Cases: Savannah River Site

\begin{tabular}{|c|c|}
\hline & Release (Ci) \\
\hline Nuclide & SHAl \\
\hline Am-241 & $1.83 \mathrm{E}-05$ \\
\hline $\mathrm{Cm}-244$ & $3.63 \mathrm{E}-06$ \\
\hline Co-60 & $1.73 E-09$ \\
\hline Cs-137 & $3.65 \mathrm{E}-08$ \\
\hline Eu-155 & $2.57 \mathrm{E}-07$ \\
\hline $\mathrm{Ni}-59$ & $6.08 \mathrm{E}-12$ \\
\hline $\mathrm{Ni}-63$ & $7.41 \mathrm{E}-10$ \\
\hline Np-237 & $4.18 \mathrm{E}-08$ \\
\hline Pu-238 & $2.37 \mathrm{E}-03$ \\
\hline Pu-239 & $4.52 \mathrm{E}-05$ \\
\hline Pu-240 & $1.12 \mathrm{E}-05$ \\
\hline $\mathrm{Pu}-241$ & $3.01 \mathrm{E}-04$ \\
\hline $\mathrm{Ra}-228$ & $4.92 \mathrm{E}-11$ \\
\hline Sr-90 & $3.40 \mathrm{E}-08$ \\
\hline Th-230 & $1.14 \mathrm{E}-11$ \\
\hline Th-232 & $1.04 E-10$ \\
\hline U-232 & $4.35 \mathrm{E}-10$ \\
\hline U-233 & $1.83 \mathrm{E}-08$ \\
\hline U-234 & $1.24 \mathrm{E}-07$ \\
\hline U-235 & $2.84 \mathrm{E}-11$ \\
\hline U-236 & $2.33 E-10$ \\
\hline U-238 & $2.78 \mathrm{E}-11$ \\
\hline Total & $2.75 \mathrm{E}-03$ \\
\hline
\end{tabular}




\title{
B.4 RADIONUCLIDE RELEASES FROM LLW ACCIDENTS
}

\author{
TABLE B.4.1 Low-Level Waste, Case 1: Idaho National \\ Engineering Laboratory
}

Function: Incineration

Waste Stream: Combustible

\begin{tabular}{lcccc}
\hline & \multicolumn{5}{c}{ Release (Ci) } \\
\cline { 2 - 5 } Nuclide & AL7 & IFF & IEX & EQ7 \\
\hline & & & \\
Am-241 & $1.77 \mathrm{E}-08$ & $1.77 \mathrm{E}-10$ & $7.09 \mathrm{E}-12$ & $1.18 \mathrm{E}-08$ \\
Ce-144 & $1.62 \mathrm{E}-05$ & $1.62 \mathrm{E}-07$ & $6.49 \mathrm{E}-09$ & $1.08 \mathrm{E}-05$ \\
Co-58 & $2.43 \mathrm{E}-04$ & $2.43 \mathrm{E}-06$ & $9.73 \mathrm{E}-08$ & $1.62 \mathrm{E}-04$ \\
Co-60 & $1.91 \mathrm{E}-03$ & $1.91 \mathrm{E}-05$ & $7.63 \mathrm{E}-07$ & $1.27 \mathrm{E}-03$ \\
Cr-51 & $9.52 \mathrm{E}-05$ & $9.52 \mathrm{E}-07$ & $3.81 \mathrm{E}-08$ & $6.35 \mathrm{E}-05$ \\
Cs-134 & $5.63 \mathrm{E}-06$ & $5.63 \mathrm{E}-08$ & $2.25 \mathrm{E}-09$ & $3.76 \mathrm{E}-06$ \\
Cs-137 & $5.20 \mathrm{E}-05$ & $5.20 \mathrm{E}-07$ & $2.08 \mathrm{E}-08$ & $3.47 \mathrm{E}-05$ \\
Eu-152 & $5.91 \mathrm{E}-09$ & $5.91 \mathrm{E}-11$ & $2.36 \mathrm{E}-12$ & $3.94 \mathrm{E}-09$ \\
Eu-154 & $1.01 \mathrm{E}-06$ & $1.01 \mathrm{E}-08$ & $4.05 \mathrm{E}-10$ & $6.76 \mathrm{E}-07$ \\
Eu-155 & $8.04 \mathrm{E}-07$ & $8.04 \mathrm{E}-09$ & $3.21 \mathrm{E}-10$ & $5.36 \mathrm{E}-07$ \\
Fe-55 & $6.77 \mathrm{E}-04$ & $6.77 \mathrm{E}-06$ & $2.71 \mathrm{E}-07$ & $4.51 \mathrm{E}-04$ \\
Fe-59 & $6.12 \mathrm{E}-06$ & $6.12 \mathrm{E}-08$ & $2.45 \mathrm{E}-09$ & $4.08 \mathrm{E}-06$ \\
Mn-54 & $1.81 \mathrm{E}-04$ & $1.81 \mathrm{E}-06$ & $7.25 \mathrm{E}-08$ & $1.21 \mathrm{E}-04$ \\
Ni-59 & $8.74 \mathrm{E}-06$ & $8.74 \mathrm{E}-08$ & $3.50 \mathrm{E}-09$ & $5.83 \mathrm{E}-06$ \\
Ni-63 & $1.24 \mathrm{E}-03$ & $1.24 \mathrm{E}-05$ & $4.97 \mathrm{E}-07$ & $8.28 \mathrm{E}-04$ \\
Pm-147 & $3.96 \mathrm{E}-05$ & $3.96 \mathrm{E}-07$ & $1.58 \mathrm{E}-08$ & $2.64 \mathrm{E}-05$ \\
Pr-144 & $1.62 \mathrm{E}-05$ & $1.62 \mathrm{E}-07$ & $6.49 \mathrm{E}-09$ & $1.08 \mathrm{E}-05$ \\
Pr-144m & $1.95 \mathrm{E}-07$ & $1.95 \mathrm{E}-09$ & $7.80 \mathrm{E}-11$ & $1.30 \mathrm{E}-07$ \\
Pu-238 & $1.22 \mathrm{E}-06$ & $1.22 \mathrm{E}-08$ & $4.88 \mathrm{E}-10$ & $8.13 \mathrm{E}-07$ \\
Pu-239 & $1.18 \mathrm{E}-08$ & $1.18 \mathrm{E}-10$ & $4.73 \mathrm{E}-12$ & $7.88 \mathrm{E}-09$ \\
Pu-240 & $5.91 \mathrm{E}-09$ & $5.91 \mathrm{E}-11$ & $2.36 \mathrm{E}-12$ & $3.94 \mathrm{E}-09$ \\
Pu-241 & $1.36 \mathrm{E}-06$ & $1.36 \mathrm{E}-08$ & $5.46 \mathrm{E}-10$ & $9.10 \mathrm{E}-07$ \\
Ru-106 & $4.84 \mathrm{E}-06$ & $4.84 \mathrm{E}-08$ & $1.94 \mathrm{E}-09$ & $3.23 \mathrm{E}-06$ \\
Sb-125 & $1.39 \mathrm{E}-06$ & $1.39 \mathrm{E}-08$ & $5.57 \mathrm{E}-10$ & $9.28 \mathrm{E}-07$ \\
Sm-151 & $3.87 \mathrm{E}-07$ & $3.87 \mathrm{E}-09$ & $1.55 \mathrm{E}-10$ & $2.58 \mathrm{E}-07$ \\
Sr-90 & $4.96 \mathrm{E}-05$ & $4.96 \mathrm{E}-07$ & $1.99 \mathrm{E}-08$ & $3.31 \mathrm{E}-05$ \\
Tc-99 & $8.86 \mathrm{E}-09$ & $8.86 \mathrm{E}-11$ & $3.55 \mathrm{E}-12$ & $5.91 \mathrm{E}-09$ \\
Te-125m & $3.40 \mathrm{E}-07$ & $3.40 \mathrm{E}-09$ & $1.36 \mathrm{E}-10$ & $2.26 \mathrm{E}-07$ \\
Y-90 & $4.96 \mathrm{E}-05$ & $4.96 \mathrm{E}-07$ & $1.99 \mathrm{E}-08$ & $3.31 \mathrm{E}-05$ \\
$\mathrm{Zr}-95$ & $7.43 \mathrm{E}-06$ & $7.43 \mathrm{E}-08$ & $2.97 \mathrm{E}-09$ & $4.95 \mathrm{E}-06$ \\
\hline & $4.61 \mathrm{E}-03$ & $4.61 \mathrm{E}-05$ & $1.84 \mathrm{E}-06$ & $3.07 \mathrm{E}-03$ \\
\hline
\end{tabular}


TABLE B.4.2 Low-Level Waste, Case 1: Savannah River Site

\begin{tabular}{|c|c|c|c|c|}
\hline \multicolumn{5}{|c|}{$\begin{array}{l}\text { Function: Incineration } \\
\text { Waste Stream: Combustible }\end{array}$} \\
\hline \multirow[b]{2}{*}{ Nuclide } & \multicolumn{4}{|c|}{ Release (Ci) } \\
\hline & IFF & IEX & EQ7 & AL7 \\
\hline Ac-228 & $3.10 \mathrm{E}-08$ & $1.24 \mathrm{E}-09$ & 2.07E-06 & $3.10 \mathrm{E}-06$ \\
\hline Am-241 & 8.24E-09 & $3.29 \mathrm{E}-10$ & $5.49 \mathrm{E}-07$ & $8.24 \mathrm{E}-07$ \\
\hline $\mathrm{Bi}-212$ & $5.18 \mathrm{E}-09$ & $2.07 \mathrm{E}-10$ & $3.45 \mathrm{E}-07$ & $5.18 \mathrm{E}-07$ \\
\hline Ce-144 & $7.54 \mathrm{E}-06$ & $3.01 \mathrm{E}-07$ & 5.02E-04 & $7.54 \mathrm{E}-04$ \\
\hline Co-58 & 7.65E-06 & $3.06 \mathrm{E}-07$ & $5.10 \mathrm{E}-04$ & $7.65 \mathrm{E}-04$ \\
\hline Co- 60 & $6.01 \mathrm{E}-05$ & $2.40 \mathrm{E}-06$ & $4.01 E-03$ & 6.01E-03 \\
\hline $\mathrm{Cr}_{\mathrm{r}-51}$ & 2.99E-06 & $1.20 \mathrm{E}-07$ & $2.00 \mathrm{E}-04$ & $2.99 \mathrm{E}-04$ \\
\hline Cs-134 & 2.62E-06 & $1.05 \mathrm{E}-07$ & $1.75 \mathrm{E}-04$ & 2.62E-04 \\
\hline Cs- 137 & $2.42 \mathrm{E}-05$ & $9.66 \mathrm{E}-07$ & $1.61 \mathrm{E}-03$ & $2.42 \mathrm{E}-03$ \\
\hline Eu-152 & 2.75E-09 & $1.10 \mathrm{E}-10$ & 1.83E-07 & 2.75E-07 \\
\hline Eu-154 & 4.71E-07 & $1.88 \mathrm{E}-08$ & $3.14 \mathrm{E}-05$ & $4.71 \mathrm{E}-05$ \\
\hline Eu-155 & 3.73E-07 & $1.49 \mathrm{E}-08$ & $2.49 \mathrm{E}-05$ & $3.73 \mathrm{E}-05$ \\
\hline Fe-55 & $2.13 \mathrm{E}-05$ & 8.51E-07 & $1.42 \mathrm{E}-03$ & $2.13 \mathrm{E}-03$ \\
\hline $\mathrm{Fe}-59$ & $1.92 \mathrm{E}-07$ & $7.69 \mathrm{E}-09$ & $1.28 \mathrm{E}-05$ & $1.92 \mathrm{E}-05$ \\
\hline$M n-54$ & $5.70 \mathrm{E}-06$ & $2.28 \mathrm{E}-07$ & $3.80 \mathrm{E}-04$ & $5.70 \mathrm{E}-04$ \\
\hline $\mathrm{Ni}-59$ & 2.75E-07 & $1.10 \mathrm{E}-08$ & $1.83 \mathrm{E}-05$ & 2.75E-05 \\
\hline $\mathrm{Ni}-63$ & 3.93E-05 & $1.57 \mathrm{E}-06$ & $2.62 \mathrm{E}-03$ & 3.93E-03 \\
\hline $\mathrm{Pb}-212$ & $5.18 \mathrm{E}-09$ & 2.07E-10 & 3.45E-07 & $5.18 \mathrm{E}-07$ \\
\hline Pm-147 & $1.84 \mathrm{E}-05$ & $7.36 \mathrm{E}-07$ & $1.23 \mathrm{E}-03$ & $1.84 \mathrm{E}-03$ \\
\hline Pr-144 & $7.54 \mathrm{E}-06$ & 3.01E-07 & 5.02E-04 & $7.54 \mathrm{E}-04$ \\
\hline Pr-144m & $9.06 \mathrm{E}-08$ & 3.62E-09 & $6.04 \mathrm{E}-06$ & $9.06 \mathrm{E}-06$ \\
\hline $\mathrm{Pu}-238$ & 5.67E-07 & $2.27 \mathrm{E}-08$ & $3.78 \mathrm{E}-05$ & $5.67 \mathrm{E}-05$ \\
\hline $\mathrm{Pu}-239$ & 5.49E-09 & $2.20 \mathrm{E}-10$ & $3.66 \mathrm{E}-07$ & $5.49 \mathrm{E}-07$ \\
\hline Pu-240 & 2.75E-09 & $1.10 \mathrm{E}-10$ & $1.83 \mathrm{E}-07$ & $2.75 \mathrm{E}-07$ \\
\hline Pu-241 & $6.34 \mathrm{E}-07$ & $2.54 \mathrm{E}-08$ & 4.23E-05 & $6.34 \mathrm{E}-05$ \\
\hline $\mathrm{Ra}-224$ & $5.18 \mathrm{E}-09$ & $2.07 \mathrm{E}-10$ & 3.45E-07 & $5.18 \mathrm{E}-07$ \\
\hline $\mathrm{Ra}-228$ & $3.10 \mathrm{E}-08$ & $1.24 \mathrm{E}-09$ & 2.07E-06 & 3.10E-06 \\
\hline $\mathrm{Ru}-106$ & $2.25 \mathrm{E}-06$ & $9.00 \mathrm{E}-08$ & $1.50 \mathrm{E}-04$ & $2.25 \mathrm{E}-04$ \\
\hline Sb-125 & $6.47 \mathrm{E}-07$ & $2.59 \mathrm{E}-08$ & 4.31E-05 & $6.47 \mathrm{E}-05$ \\
\hline Sm-151 & $1.80 \mathrm{E}-07$ & 7.19E-09 & $1.20 \mathrm{E}-05$ & $1.80 \mathrm{E}-05$ \\
\hline Sr-90 & $2.31 \mathrm{E}-05$ & $9.22 \mathrm{E}-07$ & $1.54 \mathrm{E}-03$ & $2.31 E-03$ \\
\hline Tc-99 & 4.12E-09 & $1.65 \mathrm{E}-10$ & 2.75E-07 & 4.12E-07 \\
\hline $\mathrm{Te}-125 \mathrm{~m}$ & $1.58 \mathrm{E}-07$ & $6.31 \mathrm{E}-09$ & $1.05 \mathrm{E}-05$ & $1.58 \mathrm{E}-05$ \\
\hline Th-228 & $5.18 \mathrm{E}-09$ & $2.07 \mathrm{E}-10$ & 3.45E-07 & $5.18 \mathrm{E}-07$ \\
\hline Th-231 & $2.98 \mathrm{E}-08$ & 1.19E-09 & $1.99 \mathrm{E}-06$ & $2.98 \mathrm{E}-06$ \\
\hline Th-232 & $3.14 \mathrm{E}-07$ & $1.26 \mathrm{E}-08$ & $2.10 \mathrm{E}-05$ & $3.14 \mathrm{E}-05$ \\
\hline Th-234 & 3.82E-05 & 1.53E-06 & $2.55 \mathrm{E}-03$ & $3.82 \mathrm{E}-03$ \\
\hline U-235 & 2.97E-08 & $1.19 \mathrm{E}-09$ & $1.98 \mathrm{E}-06$ & 2.97E-06 \\
\hline U-238 & 3.82E-05 & $1.53 \mathrm{E}-06$ & $2.55 \mathrm{E}-03$ & $3.82 \mathrm{E}-03$ \\
\hline$Y-90$ & $2.31 \mathrm{E}-05$ & $9.22 \mathrm{E}-07$ & $1.54 \mathrm{E}-03$ & $2.31 \mathrm{E}-03$ \\
\hline Zr-95 & 2.33E-07 & 9.34E-09 & $1.56 \mathrm{E}-05$ & 2.33E-05 \\
\hline Total & $3.26 \mathrm{E}-04$ & $1.31 \mathrm{E}-05$ & $2.18 \mathrm{E}-02$ & $3.26 \mathrm{E}-02$ \\
\hline
\end{tabular}


TABLE B.4.3 Low-Level Waste, Case 9: Fernald Environmental Management Project

\begin{tabular}{|c|c|c|c|}
\hline \multicolumn{4}{|c|}{$\begin{array}{l}\text { Function: Incineration } \\
\text { Waste Stream: Combustible }\end{array}$} \\
\hline \multirow[b]{2}{*}{ Nuclide } & \multicolumn{3}{|c|}{ Release (Ci) } \\
\hline & EQ7 & IFF & IEX \\
\hline Ac-228 & $9.00 \mathrm{E}-11$ & $1.35 \mathrm{E}-12$ & $5.40 \mathrm{E}-14$ \\
\hline Am-241 & $1.40 \mathrm{E}-11$ & $2.10 \mathrm{E}-13$ & $8.00 \mathrm{E}-15$ \\
\hline $\mathrm{Bi}-212$ & $1.4 \dot{0} \mathrm{E}-11$ & $2.10 \mathrm{E}-13$ & $8.00 \mathrm{E}-15$ \\
\hline $\mathrm{Cm}-242$ & $1.86 \mathrm{E}-10$ & $2.79 \mathrm{E}-12$ & $1.12 \mathrm{E}-13$ \\
\hline $\mathrm{Cm}-244$ & $6.60 \mathrm{E}-11$ & $9.90 \mathrm{E}-13$ & $4.00 \mathrm{E}-14$ \\
\hline $\mathrm{Pb}-212$ & $1.40 \mathrm{E}-11$ & $2.10 \mathrm{E}-13$ & $8.00 \mathrm{E}-15$ \\
\hline Pu-238 & 8.72E-09 & $1.31 \mathrm{E}-10$ & $5.23 \mathrm{E}-12$ \\
\hline Pu-239 & $6.66 \mathrm{E}-10$ & $9.99 \mathrm{E}-12$ & $4.00 \mathrm{E}-13$ \\
\hline Pu-240 & $2.33 \mathrm{E}-09$ & $3.49 \mathrm{E}-11$ & $1.40 \mathrm{E}-12$ \\
\hline $\mathrm{Pu}-241$ & $3.21 \mathrm{E}-07$ & 4.82E-09 & $1.93 \mathrm{E}-10$ \\
\hline Ra-224 & $1.40 \mathrm{E}-11$ & $2.10 \mathrm{E}-13$ & $8.00 \mathrm{E}-15$ \\
\hline Ra-228 & $9.00 \mathrm{E}-11$ & $1.35 \mathrm{E}-12$ & $5.40 \mathrm{E}-14$ \\
\hline Th-228 & $1.40 \mathrm{E}-11$ & $2.10 \mathrm{E}-13$ & $8.00 \mathrm{E}-15$ \\
\hline Th-231 & $8.60 \mathrm{E}-11$ & $1.29 \mathrm{E}-12$ & $5.20 \mathrm{E}-14$ \\
\hline Th-232 & $9.10 \mathrm{E}-10$ & $1.36 \mathrm{E}-11$ & $5.46 \mathrm{E}-13$ \\
\hline Th-234 & 1.11E-07 & $1.66 \mathrm{E}-09$ & $6.63 \mathrm{E}-11$ \\
\hline U-235 & $8.60 \mathrm{E}-11$ & $1.29 \mathrm{E}-12$ & $5.20 \mathrm{E}-14$ \\
\hline U-238 & 1.11E-07 & $1.66 \mathrm{E}-09$ & $6.63 \mathrm{E}-11$ \\
\hline Total & $5.55 \mathrm{E}-07$ & 8.33E-09 & 3.33E-10 \\
\hline
\end{tabular}


TABLE B.4.4 Low-Level Waste, Case 9: Hanford

\begin{tabular}{|c|c|c|c|c|}
\hline \multicolumn{5}{|c|}{$\begin{array}{l}\text { Function: Incineration } \\
\text { Waste Stream: Combustible }\end{array}$} \\
\hline \multirow[b]{2}{*}{ Nuclide } & \multicolumn{4}{|c|}{ Release $(\mathrm{Ci})$} \\
\hline & IFF & IEX & AL7 & EQ7 \\
\hline Ac- 228 & $5.67 \mathrm{E}-12$ & $2.27 \mathrm{E}-13$ & $5.67 \mathrm{E}-10$ & $3.78 \mathrm{E}-10$ \\
\hline Am-241 & $9.12 \mathrm{E}-10$ & $3.65 \mathrm{E}-11$ & $9.12 \mathrm{E}-08$ & $6.08 \mathrm{E}-08$ \\
\hline $\mathrm{Bi}-212$ & $9.60 \mathrm{E}-13$ & $3.80 \mathrm{E}-14$ & $9.60 \mathrm{E}-11$ & $6.40 \mathrm{E}-11$ \\
\hline Ce-144 & 8.35E-07 & 3.34E-08 & 8.35E-05 & $5.56 \mathrm{E}-05$ \\
\hline Co-58 & $1.91 \mathrm{E}-07$ & $7.65 \mathrm{E}-09$ & $1.91 \mathrm{E}-05$ & $1.28 \mathrm{E}-05$ \\
\hline $\mathrm{Co}-60$ & $1.51 \mathrm{E}-06$ & $6.06 \mathrm{E}-08$ & $1.51 \mathrm{E}-04$ & $1.01 \mathrm{E}-04$ \\
\hline Cr-51 & $7.49 \mathrm{E}-08$ & $3.00 \mathrm{E}-09$ & $7.49 \mathrm{E}-06$ & $4.99 \mathrm{E}-06$ \\
\hline Cs-134 & $2.90 \mathrm{E}-07$ & $1.16 \mathrm{E}-08$ & $2.90 \mathrm{E}-05$ & $1.93 \mathrm{E}-05$ \\
\hline Cs-137 & $2.68 \mathrm{E}-06$ & $1.07 \mathrm{E}-07$ & $2.68 \mathrm{E}-04$ & $1.78 \mathrm{E}-04$ \\
\hline Eu-152 & 3.04E-10 & $1.22 \mathrm{E}-11$ & $3.04 \mathrm{E}-08$ & $2.03 \mathrm{E}-08$ \\
\hline Eu-154 & 5.21E-08 & $2.09 \mathrm{E}-09$ & $5.21 \mathrm{E}-06$ & $3.48 \mathrm{E}-06$ \\
\hline Eu-155 & 4.13E-08 & $1.65 \mathrm{E}-09$ & 4.13E-06 & $2.76 \mathrm{E}-06$ \\
\hline $\mathrm{Fe}-55$ & $5.32 E-07$ & $2.13 \mathrm{E}-08$ & 5.32E-05 & 3.55E-05 \\
\hline $\mathrm{Fe}-59$ & 4.81E-09 & $1.92 \mathrm{E}-10$ & $4.81 \mathrm{E}-07$ & $3.21 \mathrm{E}-07$ \\
\hline Mn-54 & $1.43 \mathrm{E}-07$ & $5.70 \mathrm{E}-09$ & $1.43 \mathrm{E}-05$ & $9.50 \mathrm{E}-06$ \\
\hline $\mathrm{Ni}-59$ & $6.87 \mathrm{E}-09$ & $2.75 \mathrm{E}-10$ & 6.87E-07 & 4.58E-07 \\
\hline $\mathrm{Ni}-63$ & $1.01 \mathrm{E}-06$ & $4.02 \mathrm{E}-08$ & $1.01 \mathrm{E}-04$ & $6.70 \mathrm{E}-05$ \\
\hline $\mathrm{Pb}-212$ & $9.60 \mathrm{E}-13$ & $3.80 \mathrm{E}-14$ & $9.60 \mathrm{E}-11$ & $6.40 \mathrm{E}-11$ \\
\hline Pm-147 & $2.04 \mathrm{E}-06$ & 8.15E-08 & $2.04 \mathrm{E}-04$ & $1.36 \mathrm{E}-04$ \\
\hline Pr-144 & 8.35E-07 & 3.34E-08 & 8.35E-05 & $5.56 \mathrm{E}-05$ \\
\hline Pr-144m & $1.00 \mathrm{E}-08$ & $4.01 \mathrm{E}-10$ & $1.00 \mathrm{E}-06$ & $6.69 \mathrm{E}-07$ \\
\hline Pu-238 & $6.28 \mathrm{E}-08$ & $2.51 \mathrm{E}-09$ & $6.28 \mathrm{E}-06$ & 4.19E-06 \\
\hline Pu-239 & $6.08 \mathrm{E}-10$ & $2.43 \mathrm{E}-11$ & $6.08 \mathrm{E}-08$ & 4.05E-08 \\
\hline $\mathrm{Pu}-240$ & 3.04E-10 & $1.22 \mathrm{E}-11$ & $3.04 \mathrm{E}-08$ & 2.03E-08 \\
\hline $\mathrm{Pu}-241$ & $7.02 \mathrm{E}-08$ & 2.81E-09 & $7.02 \mathrm{E}-06$ & 4.68E-06 \\
\hline Ra-224 & $9.60 \mathrm{E}-13$ & $3.80 \mathrm{E}-14$ & $9.60 \mathrm{E}-11$ & $6.40 E-11$ \\
\hline $\mathrm{Ra}-228$ & $5.67 \mathrm{E}-12$ & $2.27 \mathrm{E}-13$ & $5.67 \mathrm{E}-10$ & $3.78 \mathrm{E}-10$ \\
\hline Ru-106 & $2.49 \mathrm{E}-07$ & $9.97 \mathrm{E}-09$ & $2.49 \mathrm{E}-05$ & $1.66 \mathrm{E}-05$ \\
\hline $\mathrm{Sb}-125$ & $7.16 \mathrm{E}-08$ & $2.86 \mathrm{E}-09$ & $7.16 \mathrm{E}-06$ & 4.77E-06 \\
\hline Sm-151 & $1.99 \mathrm{E}-08$ & $7.97 \mathrm{E}-10$ & $1.99 \mathrm{E}-06$ & $1.33 \mathrm{E}-06$ \\
\hline Sr-90 & 2.55E-06 & $1.02 \mathrm{E}-07$ & $2.55 \mathrm{E}-04$ & $1.70 \mathrm{E}-04$ \\
\hline Tc-99 & $4.56 \mathrm{E}-10$ & $1.82 \mathrm{E}-11$ & $4.56 \mathrm{E}-08$ & $3.04 \mathrm{E}-08$ \\
\hline $\mathrm{Te}-125 \mathrm{~m}$ & $1.75 \mathrm{E}-08$ & $6.99 \mathrm{E}-10$ & $1.75 \mathrm{E}-06$ & $1.17 \mathrm{E}-06$ \\
\hline Th-228 & $9.60 \mathrm{E}-13$ & $3.80 \mathrm{E}-14$ & $9.60 \mathrm{E}-11$ & $6.40 \mathrm{E}-11$ \\
\hline Th-231 & $5.46 \mathrm{E}-12$ & $2.18 \mathrm{E}-13$ & $5.46 \mathrm{E}-10$ & $3.64 \mathrm{E}-10$ \\
\hline Th-232 & $5.75 \mathrm{E}-11$ & $2.30 \mathrm{E}-12$ & 5.75E-09 & $3.83 \mathrm{E}-09$ \\
\hline Th-234 & 6.99E-09 & $2.80 \mathrm{E}-10$ & $6.99 \mathrm{E}-07$ & $4.66 \mathrm{E}-07$ \\
\hline U-235 & $5.43 \mathrm{E}-12$ & $2.17 \mathrm{E}-13$ & 5.43E-10 & $3.62 \mathrm{E}-10$ \\
\hline U-238 & $6.99 \mathrm{E}-09$ & $2.80 \mathrm{E}-10$ & $6.99 \mathrm{E}-07$ & $4.66 \mathrm{E}-07$ \\
\hline Y-90 & $2.55 \mathrm{E}-06$ & $1.02 \mathrm{E}-07$ & $2.55 \mathrm{E}-04$ & $1.70 \mathrm{E}-04$ \\
\hline Zr-95 & 5.84E-09 & $2.34 \mathrm{E}-10$ & 5.84E-07 & $3.89 \mathrm{E}-07$ \\
\hline Total & $1.59 \mathrm{E}-05$ & $6.35 \mathrm{E}-07$ & $1.59 \mathrm{E}-03$ & $1.06 \mathrm{E}-03$ \\
\hline
\end{tabular}


TABLE B.4.5 Low-Level Waste, Case 9: Idaho National Engineering Laboratory

. Function: Incineration

Waste Stream: Combustible

Release (Ci)

\begin{tabular}{lllll} 
& & & & \\
\cline { 2 - 5 } Nuclide & AL7 & EQ7 & IFE & IEX \\
\hline Am-241 & $1.77 \mathrm{E}-08$ & $1.18 \mathrm{E}-08$ & $1.77 \mathrm{E}-10$ & $7.09 \mathrm{E}-12$ \\
Ce-144 & $1.62 \mathrm{E}-05$ & $1.08 \mathrm{E}-05$ & $1.62 \mathrm{E}-07$ & $6.49 \mathrm{E}-09$ \\
Co-58 & $2.43 \mathrm{E}-04$ & $1.62 \mathrm{E}-04$ & $2.43 \mathrm{E}-06$ & $9.73 \mathrm{E}-08$ \\
Co-60 & $1.91 \mathrm{E}-03$ & $1.27 \mathrm{E}-03$ & $1.91 \mathrm{E}-05$ & $7.63 \mathrm{E}-07$ \\
Cr-51 & $9.52 \mathrm{E}-05$ & $6.35 \mathrm{E}-05$ & $9.52 \mathrm{E}-07$ & $3.81 \mathrm{E}-08$ \\
Cs-134 & $5.63 \mathrm{E}-06$ & $3.76 \mathrm{E}-06$ & $5.63 \mathrm{E}-08$ & $2.25 \mathrm{E}-09$ \\
Cs-137 & $5.20 \mathrm{E}-05$ & $3.47 \mathrm{E}-05$ & $5.20 \mathrm{E}-07$ & $2.08 \mathrm{E}-08$ \\
Eu-152 & $5.91 \mathrm{E}-09$ & $3.94 \mathrm{E}-09$ & $5.91 \mathrm{E}-11$ & $2.36 \mathrm{E}-12$ \\
Eu-154 & $1.01 \mathrm{E}-06$ & $6.76 \mathrm{E}-07$ & $1.01 \mathrm{E}-08$ & $4.05 \mathrm{E}-10$ \\
Eu-155 & $8.04 \mathrm{E}-07$ & $5.36 \mathrm{E}-07$ & $8.04 \mathrm{E}-09$ & $3.21 \mathrm{E}-10$ \\
Fe-55 & $6.77 \mathrm{E}-04$ & $4.51 \mathrm{E}-04$ & $6.77 \mathrm{E}-06$ & $2.71 \mathrm{E}-07$ \\
Fe-59 & $6.12 \mathrm{E}-06$ & $4.08 \mathrm{E}-06$ & $6.12 \mathrm{E}-08$ & $2.45 \mathrm{E}-09$ \\
Mn-54 & $1.81 \mathrm{E}-04$ & $1.21 \mathrm{E}-04$ & $1.81 \mathrm{E}-06$ & $7.25 \mathrm{E}-08$ \\
Ni-59 & $8.74 \mathrm{E}-06$ & $5.83 \mathrm{E}-06$ & $8.74 \mathrm{E}-08$ & $3.50 \mathrm{E}-09$ \\
Ni-63 & $1.24 \mathrm{E}-03$ & $8.28 \mathrm{E}-04$ & $1.24 \mathrm{E}-05$ & $4.97 \mathrm{E}-07$ \\
Pm-147 & $3.96 \mathrm{E}-05$ & $2.64 \mathrm{E}-05$ & $3.96 \mathrm{E}-07$ & $1.58 \mathrm{E}-08$ \\
Pr-144 & $1.62 \mathrm{E}-05$ & $1.08 \mathrm{E}-05$ & $1.62 \mathrm{E}-07$ & $6.49 \mathrm{E}-09$ \\
Pr-144m & $1.95 \mathrm{E}-07$ & $1.30 \mathrm{E}-07$ & $1.95 \mathrm{E}-09$ & $7.80 \mathrm{E}-11$ \\
Pu-238 & $1.22 \mathrm{E}-06$ & $8.13 \mathrm{E}-07$ & $1.22 \mathrm{E}-08$ & $4.88 \mathrm{E}-10$ \\
Pu-239 & $1.18 \mathrm{E}-08$ & $7.88 \mathrm{E}-09$ & $1.18 \mathrm{E}-10$ & $4.73 \mathrm{E}-12$ \\
Pu-240 & $5.91 \mathrm{E}-09$ & $3.94 \mathrm{E}-09$ & $5.91 \mathrm{E}-11$ & $2.36 \mathrm{E}-12$ \\
Pu-241 & $1.36 \mathrm{E}-06$ & $9.10 \mathrm{E}-07$ & $1.36 \mathrm{E}-08$ & $5.46 \mathrm{E}-10$ \\
Ru-106 & $4.84 \mathrm{E}-06$ & $3.23 \mathrm{E}-06$ & $4.84 \mathrm{E}-08$ & $1.94 \mathrm{E}-09$ \\
Sb-125 & $1.39 \mathrm{E}-06$ & $9.28 \mathrm{E}-07$ & $1.39 \mathrm{E}-08$ & $5.57 \mathrm{E}-10$ \\
Sm-151 & $3.87 \mathrm{E}-07$ & $2.58 \mathrm{E}-07$ & $3.87 \mathrm{E}-09$ & $1.55 \mathrm{E}-10$ \\
Sr-90 & $4.96 \mathrm{E}-05$ & $3.31 \mathrm{E}-05$ & $4.96 \mathrm{E}-07$ & $1.99 \mathrm{E}-08$ \\
Tc-99 & $8.86 \mathrm{E}-09$ & $5.91 \mathrm{E}-09$ & $8.86 \mathrm{E}-11$ & $3.55 \mathrm{E}-12$ \\
Te-125m & $3.40 \mathrm{E}-07$ & $2.26 \mathrm{E}-07$ & $3.40 \mathrm{E}-09$ & $1.36 \mathrm{E}-10$ \\
Y-90 & $4.96 \mathrm{E}-05$ & $3.31 \mathrm{E}-05$ & $4.96 \mathrm{E}-07$ & $1.99 \mathrm{E}-08$ \\
$\mathrm{Zr}-95$ & $7.43 \mathrm{E}-06$ & $4.95 \mathrm{E}-06$ & $7.43 \mathrm{E}-08$ & $2.97 \mathrm{E}-09$ \\
\hline & $4.61 \mathrm{E}-03$ & $3.07 \mathrm{E}-03$ & $4.61 \mathrm{E}-05$ & $1.84 \mathrm{E}-06$ \\
\hline & & & & \\
Total & & & &
\end{tabular}


TABLE B.4.6 Low-Level Waste, Case 9:

Lawrence Livermore National Laboratory

Function: Incineration

Waste Stream: Combustible

\begin{tabular}{|c|c|c|c|}
\hline \multirow[b]{2}{*}{ Nuclide } & \multicolumn{3}{|c|}{ Release (Ci) } \\
\hline & EQ7 & IFF & IEX \\
\hline Ac-228 & $1.69 \mathrm{E}-08$ & $2.54 \mathrm{E}-10$ & $1.02 \mathrm{E}-11$ \\
\hline Am-241 & $1.00 \mathrm{E}-09$ & $1.50 \mathrm{E}-11$ & $6.00 \mathrm{E}-13$ \\
\hline $\mathrm{Bi}-212$ & $2.83 \mathrm{E}-09$ & $4.25 \mathrm{E}-11$ & $1.70 \mathrm{E}-12$ \\
\hline $\mathrm{Ce}-144$ & $5.49 \mathrm{E}-07$ & 8.23E-09 & 3.29E-10 \\
\hline $\mathrm{Cm}-242$ & $5.60 \mathrm{E}-09$ & $8.40 \mathrm{E}-11$ & $3.36 \mathrm{E}-12$ \\
\hline $\mathrm{Cm}-244$ & $2.00 \mathrm{E}-09$ & $3.00 \mathrm{E}-11$ & $1.20 \mathrm{E}-12$ \\
\hline Co-60 & $2.52 \mathrm{E}-03$ & $3.78 \mathrm{E}-05$ & $1.51 \mathrm{E}-06$ \\
\hline Cs-134 & $1.91 \mathrm{E}-07$ & $2.86 \mathrm{E}-09$ & $1.14 \mathrm{E}-10$ \\
\hline Cs-137 & $4.38 \mathrm{E}-03$ & $6.56 \mathrm{E}-05$ & 2.63E-06 \\
\hline Eu-152 & $2.00 \mathrm{E}-10$ & $3.00 \mathrm{E}-12$ & $1.20 \mathrm{E}-13$ \\
\hline Eu-154 & 3.43E-08 & $5.14 \mathrm{E}-10$ & $2.06 \mathrm{E}-11$ \\
\hline Eu-155 & 2.72E-08 & $4.08 \mathrm{E}-10$ & $1.63 \mathrm{E}-11$ \\
\hline $\mathrm{Fe}-55$ & $6.29 \mathrm{E}-05$ & $9.44 \mathrm{E}-07$ & 3.78E-08 \\
\hline $\mathrm{Ni}-63$ & $1.89 \mathrm{E}-08$ & $2.83 E-10$ & $1.13 \mathrm{E}-11$ \\
\hline P-32 & $5.25 \mathrm{E}-03$ & 7.87E-05 & 3.15E-06 \\
\hline $\mathrm{Pb}-212$ & $2.83 \mathrm{E}-09$ & $4.25 \mathrm{E}-11$ & $1.70 \mathrm{E}-12$ \\
\hline Pm-147 & $1.34 \mathrm{E}-06$ & $2.01 \mathrm{E}-08$ & $8.04 \mathrm{E}-10$ \\
\hline Pr-144 & 5.49E-07 & 8.23E-09 & $3.29 \mathrm{E}-10$ \\
\hline $\operatorname{Pr}-144 m$ & $6.60 \mathrm{E}-09$ & $9.90 \mathrm{E}-11$ & $3.96 \mathrm{E}-12$ \\
\hline Pu-238 & $3.03 \mathrm{E}-07$ & 4.55E-09 & $1.82 \mathrm{E}-10$ \\
\hline Pu-239 & 2.04E-08 & $3.06 \mathrm{E}-10$ & $1.22 \mathrm{E}-11$ \\
\hline Pu-240 & $7.02 \mathrm{E}-08$ & $1.05 \mathrm{E}-09$ & $4.21 \mathrm{E}-11$ \\
\hline Pu-241 & $9.69 \mathrm{E}-06$ & $1.45 \mathrm{E}-07$ & $5.81 \mathrm{E}-09$ \\
\hline Ra-224 & $2.83 \mathrm{E}-09$ & $4.25 \mathrm{E}-11$ & $1.70 \mathrm{E}-12$ \\
\hline $\mathrm{Ra}-228$ & $1.69 \mathrm{E}-08$ & $2.54 \mathrm{E}-10$ & $1.02 \mathrm{E}-11$ \\
\hline Ru-106 & $1.64 \mathrm{E}-07$ & $2.46 \mathrm{E}-09$ & $9.84 \mathrm{E}-11$ \\
\hline S-35 & 4.51E-03 & 6.77E-05 & $2.71 \mathrm{E}-06$ \\
\hline Sb-125 & 4.71E-08 & $7.06 \mathrm{E}-10$ & $2.83 \mathrm{E}-11$ \\
\hline Sm-151 & $1.31 \mathrm{E}-08$ & $1.96 \mathrm{E}-10$ & $7.86 \mathrm{E}-12$ \\
\hline St-90 & $1.68 \mathrm{E}-06$ & $2.52 \mathrm{E}-08$ & $1.01 \mathrm{E}-09$ \\
\hline Tc-99 & $3.00 \mathrm{E}-10$ & $4.50 \mathrm{E}-12$ & $1.80 \mathrm{E}-13$ \\
\hline $\mathrm{Te}-125 \mathrm{~m}$ & $1.15 \mathrm{E}-08$ & $1.72 \mathrm{E}-10$ & $6.90 \mathrm{E}-12$ \\
\hline Th-228 & $2.83 \mathrm{E}-09$ & $4.25 \mathrm{E}-11$ & $1.70 \mathrm{E}-12$ \\
\hline Th-231 & $1.63 \mathrm{E}-08$ & $2.44 \mathrm{E}-10$ & $9.78 \mathrm{E}-12$ \\
\hline Th-232 & $1.20 \mathrm{E}-03$ & $1.80 \mathrm{E}-05$ & $7.19 \mathrm{E}-07$ \\
\hline Th-234 & $2.09 \mathrm{E}-05$ & 3.13E-07 & $1.25 \mathrm{E}-08$ \\
\hline U-235 & $1.62 \mathrm{E}-08$ & $2.44 \mathrm{E}-10$ & $9.74 \mathrm{E}-12$ \\
\hline U-238 & $1.64 \mathrm{E}-03$ & $2.46 \mathrm{E}-05$ & $9.83 \mathrm{E}-07$ \\
\hline Y-90 & $1.68 \mathrm{E}-06$ & $2.52 \mathrm{E}-08$ & $1.01 \mathrm{E}-09$ \\
\hline Total & $1.96 \mathrm{E}-02$ & 2.94E-04 & $1.18 \mathrm{E}-05$ \\
\hline
\end{tabular}


TABLE B.4.7 Low-Level Waste, Case 9: Los Alamos National Laboratory

\begin{tabular}{|c|c|c|c|}
\hline \multicolumn{4}{|c|}{$\begin{array}{l}\text { Function: Incineration } \\
\text { Waste Stream: Combustible }\end{array}$} \\
\hline \multirow[b]{2}{*}{ Nuclide } & \multicolumn{3}{|c|}{ Release (Ci) } \\
\hline & EQ7 & IEX & IFF \\
\hline Ac- 228 & $5.28 \mathrm{E}-05$ & 3.17E-08 & 7.92E-07 \\
\hline Am-241 & $3.40 \mathrm{E}-06$ & 2.04E-09 & $5.11 \mathrm{E}-08$ \\
\hline $\mathrm{Bi}-212$ & 8.83E-06 & 5.30E-09 & $1.32 E-07$ \\
\hline $\mathrm{Ce}-144$ & $1.87 \mathrm{E}-03$ & 1.12E-06 & $2.80 \mathrm{E}-05$ \\
\hline $\mathrm{Cm}-242$ & $1.91 \mathrm{E}-05$ & $1.14 \mathrm{E}-08$ & $2.86 \mathrm{E}-07$ \\
\hline $\mathrm{Cm}-244$ & $6.81 \mathrm{E}-06$ & $4.09 \mathrm{E}-09$ & $1.02 \mathrm{E}-07$ \\
\hline Co-58 & $2.37 \mathrm{E}-06$ & $1.42 \mathrm{E}-09$ & $3.56 \mathrm{E}-08$ \\
\hline Co-60 & $5.09 \mathrm{E}-05$ & $3.05 \mathrm{E}-08$ & 7.63E-07 \\
\hline Cr-51 & $9.28 \mathrm{E}-07$ & $5.57 \mathrm{E}-10$ & $1.39 \mathrm{E}-08$ \\
\hline Cs-134 & $6.49 \mathrm{E}-04$ & $3.89 \mathrm{E}-07$ & 9.73E-06 \\
\hline Cs-137 & $5.99 \mathrm{E}-03$ & $3.59 \mathrm{E}-06$ & $8.98 \mathrm{E}-05$ \\
\hline Eu-152 & $6.80 \mathrm{E}-07$ & $4.08 \mathrm{E}-10$ & $1.02 \mathrm{E}-08$ \\
\hline Eu-154 & $1.17 \mathrm{E}-04$ & $7.00 \mathrm{E}-08$ & $1.75 \mathrm{E}-06$ \\
\hline Eu-155 & $9.25 \mathrm{E}-05$ & $5.55 \mathrm{E}-08$ & 1.39E-06 \\
\hline $\mathrm{Fe}-55$ & $6.59 \mathrm{E}-06$ & $3.96 \mathrm{E}-09$ & $9.89 E-08$ \\
\hline $\mathrm{Fe}-59$ & $5.96 \mathrm{E}-08$ & $3.57 \mathrm{E}-11$ & $8.94 \mathrm{E}-10$ \\
\hline Mn-54 & $1.77 \mathrm{E}-06$ & $1.06 \mathrm{E}-09$ & $2.65 \mathrm{E}-08$ \\
\hline $\mathrm{Ni}-59$ & 8.51E-08 & $5.11 \mathrm{E}-11$ & $1.28 \mathrm{E}-09$ \\
\hline $\mathrm{Ni}-63$ & $7.64 \mathrm{E}-05$ & $4.58 \mathrm{E}-08$ & $1.15 \mathrm{E}-06$ \\
\hline $\mathrm{Pb}-212$ & $8.83 \mathrm{E}-06$ & 5.30E-09 & $1.32 \mathrm{E}-07$ \\
\hline$P m-147$ & $4.56 \mathrm{E}-03$ & 2.73E-06 & $6.84 \mathrm{E}-05$ \\
\hline Pr-144 & $1.87 \mathrm{E}-03$ & $1.12 \mathrm{E}-06$ & $2.80 \mathrm{E}-05$ \\
\hline Pr-144m & $2.24 \mathrm{E}-05$ & 1.35E-08 & 3.37E-07 \\
\hline Pu-238 & $1.03 \mathrm{E}-03$ & $6.20 \mathrm{E}-07$ & $1.55 \mathrm{E}-05$ \\
\hline Pu-239 & $6.95 \mathrm{E}-05$ & 4.17E-08 & $1.04 \mathrm{E}-06$ \\
\hline Pu-240 & $2.39 \mathrm{E}-04$ & 1.43E-07 & $3.59 \mathrm{E}-06$ \\
\hline Pu-241 & $3.30 \mathrm{E}-02$ & $1.98 \mathrm{E}-05$ & $4.95 \mathrm{E}-0.4$ \\
\hline $\mathrm{Ra}-224$ & $8.83 \mathrm{E}-06$ & 5.30E-09 & $1.32 \mathrm{E}-07$ \\
\hline $\mathrm{Ra}-228$ & $5.28 \mathrm{E}-05$ & 3.17E-08 & 7.92E-07 \\
\hline Ru-106 & $5.58 \mathrm{E}-04$ & 3.35E-07 & 8.37E-06 \\
\hline Sb-125 & $1.60 \mathrm{E}-04$ & 9.61E-08 & $2.40 \mathrm{E}-06$ \\
\hline Sm-151 & $4.46 \mathrm{E}-05$ & $2.67 \mathrm{E}-08$ & $6.68 \mathrm{E}-07$ \\
\hline Sr-90 & $5.71 \mathrm{E}-03$ & 3.43E-06 & 8.57E-05 \\
\hline Tc-99 & $1.02 \mathrm{E}-06$ & $6.12 \mathrm{E}-10$ & $1.53 \mathrm{E}-08$ \\
\hline $\mathrm{Te}-125 \mathrm{~m}$ & $3.91 \mathrm{E}-05$ & 2.35E-08 & $5.87 \mathrm{E}-07$ \\
\hline Th-228 & $8.83 \mathrm{E}-06$ & $5.30 \mathrm{E}-09$ & $1.32 \mathrm{E}-07$ \\
\hline Th-231 & $5.08 \mathrm{E}-05$ & $3.05 \mathrm{E}-08$ & $7.62 \mathrm{E}-07$ \\
\hline Th-232 & $5.36 \mathrm{E}-04$ & 3.21E-07 & 8.03E-06 \\
\hline Th-234 & $6.51 \mathrm{E}-02$ & $3.91 \mathrm{E}-05$ & 9.77E-04 \\
\hline U-235 & $5.06 \mathrm{E}-05$ & $3.04 \mathrm{E}-08$ & $7.59 \mathrm{E}-07$ \\
\hline $\mathrm{U}-238$ & $6.51 \mathrm{E}-02$ & $3.91 \mathrm{E}-05$ & $9.77 \mathrm{E}-04$ \\
\hline$Y-90$ & 5.71E-03 & 3.43E-06 & 8.57E-05 \\
\hline Zr-95 & $7.23 \mathrm{E}-08$ & 4.34E-11 & $1.09 \mathrm{E}-09$ \\
\hline Total & 1.93E-01 & $1.16 \mathrm{E}-04$ & $2.89 \mathrm{E}-03$ \\
\hline
\end{tabular}


TABLE B.4.8 Low-Level Waste, Case 9: Oak Ridge National Laboratory

Function: Incineration

Waste Stream: Combustible

Release (Ci)

\begin{tabular}{llll} 
& & & \\
\cline { 2 - 4 } Nuclide & EQ7 & IEX & IFF \\
\hline Ac-228 & $1.69 \mathrm{E}-07$ & $1.01 \mathrm{E}-10$ & $2.17 \mathrm{E}-11$ \\
Bi-212 & $2.82 \mathrm{E}-08$ & $1.69 \mathrm{E}-11$ & $3.63 \mathrm{E}-12$ \\
Co-58 & $8.86 \mathrm{E}-05$ & $5.32 \mathrm{E}-08$ & $1.14 \mathrm{E}-08$ \\
Co-60 & $2.56 \mathrm{E}-04$ & $1.54 \mathrm{E}-07$ & $3.29 \mathrm{E}-08$ \\
Cs-134 & $1.98 \mathrm{E}-04$ & $1.19 \mathrm{E}-07$ & $2.55 \mathrm{E}-08$ \\
Cs-137 & $2.62 \mathrm{E}-04$ & $1.57 \mathrm{E}-07$ & $3.37 \mathrm{E}-08$ \\
$\mathrm{Mn}-54$ & $9.60 \mathrm{E}-05$ & $5.76 \mathrm{E}-08$ & $1.23 \mathrm{E}-08$ \\
Pb-212 & $2.82 \mathrm{E}-08$ & $1.69 \mathrm{E}-11$ & $3.63 \mathrm{E}-12$ \\
Ra-224 & $2.82 \mathrm{E}-08$ & $1.69 \mathrm{E}-11$ & $3.63 \mathrm{E}-12$ \\
Ra-228 & $1.69 \mathrm{E}-07$ & $1.01 \mathrm{E}-10$ & $2.17 \mathrm{E}-11$ \\
Sr-90 & $1.20 \mathrm{E}-04$ & $7.22 \mathrm{E}-08$ & $1.55 \mathrm{E}-08$ \\
Tc-99 & $1.70 \mathrm{E}-06$ & $1.02 \mathrm{E}-09$ & $2.19 \mathrm{E}-10$ \\
Th-228 & $2.82 \mathrm{E}-08$ & $1.69 \mathrm{E}-11$ & $3.63 \mathrm{E}-12$ \\
Th-231 & $1.62 \mathrm{E}-07$ & $9.74 \mathrm{E}-11$ & $2.09 \mathrm{E}-11$ \\
Th-232 & $1.71 \mathrm{E}-06$ & $1.03 \mathrm{E}-09$ & $2.20 \mathrm{E}-10$ \\
Th-234 & $2.08 \mathrm{E}-04$ & $1.25 \mathrm{E}-07$ & $2.68 \mathrm{E}-08$ \\
U-235 & $1.62 \mathrm{E}-07$ & $9.71 \mathrm{E}-11$ & $2.08 \mathrm{E}-11$ \\
U-238 & $2.19 \mathrm{E}-04$ & $1.31 \mathrm{E}-07$ & $2.81 \mathrm{E}-08$ \\
Y-90 & $1.20 \mathrm{E}-04$ & $7.22 \mathrm{E}-08$ & $1.55 \mathrm{E}-08$ \\
Total & $1.57 \mathrm{E}-03$ & $9.44 \mathrm{E}-07$ & $2.02 \mathrm{E}-07$ \\
\hline & & &
\end{tabular}


TABLE B.4.9 Low-Level Waste, Case 9: Paducah Gaseous Diffusion Plant

\begin{tabular}{|c|c|c|c|c|}
\hline \multicolumn{5}{|c|}{$\begin{array}{l}\text { Function: Incineration } \\
\text { Waste Stream: Combustible }\end{array}$} \\
\hline \multirow[b]{2}{*}{ Nuclide } & \multicolumn{4}{|c|}{ Release (Ci) } \\
\hline & AS5 & EQ7 & IEX & IFF \\
\hline Ac-228 & 3.02E-09 & $1.21 \mathrm{E}-08$ & $7.24 \mathrm{E}-12$ & $1.81 \mathrm{E}-10$ \\
\hline $\mathrm{Bi}-212$ & $5.04 E-10$ & $2.02 \mathrm{E}-09$ & $1.21 \mathrm{E}-12$ & $3.03 E-11$ \\
\hline Np-237 & $3.40 \mathrm{E}-08$ & $1.36 \mathrm{E}-07$ & $8.16 \mathrm{E}-11$ & $2.04 \mathrm{E}-09$ \\
\hline $\mathrm{Pb}-212$ & $5.04 \mathrm{E}-10$ & 2.02E-09 & $1.21 \mathrm{E}-12$ & $3.03 \mathrm{E}-11$ \\
\hline Pu-239 & $3.40 \mathrm{E}-08$ & $1.36 \mathrm{E}-07$ & $8.16 \mathrm{E}-11$ & 2.04E-09 \\
\hline $\mathrm{Ra}-224$ & $5.04 \mathrm{E}-10$ & 2.02E-09 & $1.21 \mathrm{E}-12$ & $3.03 \mathrm{E}-11$ \\
\hline $\mathrm{Ra}-228$ & 3.02E-09 & $1.21 \mathrm{E}-08$ & $7.24 \mathrm{E}-12$ & $1.81 \mathrm{E}-10$ \\
\hline Tc-99 & $4.53 \mathrm{E}-08$ & $1.81 \mathrm{E}-07$ & $1.09 \mathrm{E}-10$ & $2.72 \mathrm{E}-09$ \\
\hline Th-228 & $5.04 \mathrm{E}-10$ & 2.02E-09 & $1.21 E-12$ & $3.03 \mathrm{E}-11$ \\
\hline Th-231 & 2.90E-09 & $1.16 \mathrm{E}-08$ & $6.97 \mathrm{E}-12$ & $1.74 \mathrm{E}-10$ \\
\hline Th-232 & $3.06 \mathrm{E}-08$ & $1.22 \mathrm{E}-07$ & $7.35 \mathrm{E}-11$ & $1.84 \mathrm{E}-09$ \\
\hline Th-234 & 3.72E-06 & $1.49 \mathrm{E}-05$ & 8.93E-09 & $2.23 \mathrm{E}-07$ \\
\hline U-235 & 2.89E-09 & $1.16 \mathrm{E}-08$ & $6.94 \mathrm{E}-12$ & $1.74 \mathrm{E}-10$ \\
\hline U-238 & 3.72E-06 & $1.49 \mathrm{E}-05$ & 8.93E-09 & $2.23 \mathrm{E}-07$ \\
\hline Total & 7.60E-06 & $3.04 \mathrm{E}-05$ & $1.82 \mathrm{E}-08$ & $4.56 \mathrm{E}-07$ \\
\hline
\end{tabular}


TABLE B.4.10 Low-Level Waste, Case 9:

Portsmouth Gaseous Diffusion Plant

\begin{tabular}{|c|c|c|c|}
\hline \multicolumn{4}{|c|}{$\begin{array}{l}\text { Function: Incineration } \\
\text { Waste Stream: Combustible }\end{array}$} \\
\hline \multirow[b]{2}{*}{ Nuclide } & \multicolumn{3}{|c|}{ Release (Ci) } \\
\hline & EQ7 & IFF & IEX \\
\hline Ac-228 & 1.42E-09 & $2.13 \mathrm{E}-11$ & $8.52 \mathrm{E}-13$ \\
\hline $\mathrm{Bi}-212$ & $2.38 \mathrm{E}-10$ & 3.57E-12 & $1.43 \mathrm{E}-13$ \\
\hline $\mathrm{Pb}-212$ & $2.38 \mathrm{E}-10$ & $3.57 \mathrm{E}-12$ & $1.43 \mathrm{E}-13$ \\
\hline $\mathrm{Ra}-224$ & $2.38 \mathrm{E}-10$ & 3.57E-12 & $1.43 \mathrm{E}-13$ \\
\hline $\mathrm{Ra}-228$ & $1.42 \mathrm{E}-09$ & $2.13 \mathrm{E}-11$ & $8.52 \mathrm{E}-13$ \\
\hline Th-228 & $2.38 \mathrm{E}-10$ & 3.57E-12 & $1.43 \mathrm{E}-13$ \\
\hline Th-231 & 1.37E-09 & $2.05 \mathrm{E}-11$ & $8.21 \mathrm{E}-13$ \\
\hline Th-232 & $1.44 \mathrm{E}-08$ & $2.16 \mathrm{E}-10$ & $8.65 \mathrm{E}-12$ \\
\hline Th-234 & $1.75 \mathrm{E}-06$ & $2.63 \mathrm{E}-08$ & $1.05 \mathrm{E}-09$ \\
\hline U-235 & $1.36 \mathrm{E}-09$ & $2.04 \mathrm{E}-11$ & 8.17E-13 \\
\hline$U-238$ & $1.75 \mathrm{E}-06$ & 2.63E-08 & $1.05 \mathrm{E}-09$ \\
\hline Total & 3.53E-06 & 5.29E-08 & 2.12E-09 \\
\hline
\end{tabular}


TABLE B.4.11 Low-Level Waste, Case 9: Rocky Flats Environmental Technology Site

Function: $\alpha$-Incineration

Waste Stream: Combustible

\begin{tabular}{lcccc}
\hline & \multicolumn{5}{c}{ Release (Ci) } \\
\cline { 2 - 5 } Nuclide & AS5 & EQ7 & IFF & IEX \\
\hline & & & \\
Ac-228 & $1.94 \mathrm{E}-08$ & $7.77 \mathrm{E}-08$ & $1.17 \mathrm{E}-09$ & $4.66 \mathrm{E}-11$ \\
Am-241 & $2.89 \mathrm{E}-08$ & $1.15 \mathrm{E}-07$ & $1.73 \mathrm{E}-09$ & $6.93 \mathrm{E}-11$ \\
Bi-212 & $3.25 \mathrm{E}-09$ & $1.30 \mathrm{E}-08$ & $1.95 \mathrm{E}-10$ & $7.80 \mathrm{E}-12$ \\
Cm-242 & $4.04 \mathrm{E}-07$ & $1.62 \mathrm{E}-06$ & $2.43 \mathrm{E}-08$ & $9.70 \mathrm{E}-10$ \\
Cm-244 & $1.44 \mathrm{E}-07$ & $5.77 \mathrm{E}-07$ & $8.66 \mathrm{E}-09$ & $3.46 \mathrm{E}-10$ \\
Pb-212 & $3.25 \mathrm{E}-09$ & $1.30 \mathrm{E}-08$ & $1.95 \mathrm{E}-10$ & $7.80 \mathrm{E}-12$ \\
Pu-238 & $1.89 \mathrm{E}-05$ & $7.56 \mathrm{E}-05$ & $1.13 \mathrm{E}-06$ & $4.54 \mathrm{E}-08$ \\
Pu-239 & $1.44 \mathrm{E}-06$ & $5.77 \mathrm{E}-06$ & $8.66 \mathrm{E}-08$ & $3.46 \mathrm{E}-09$ \\
Pu-240 & $5.05 \mathrm{E}-06$ & $2.02 \mathrm{E}-05$ & $3.03 \mathrm{E}-07$ & $1.21 \mathrm{E}-08$ \\
Pu-241 & $6.96 \mathrm{E}-04$ & $2.78 \mathrm{E}-03$ & $4.18 \mathrm{E}-05$ & $1.67 \mathrm{E}-06$ \\
Ra-224 & $3.25 \mathrm{E}-09$ & $1.30 \mathrm{E}-08$ & $1.95 \mathrm{E}-10$ & $7.80 \mathrm{E}-12$ \\
Ra-228 & $1.94 \mathrm{E}-08$ & $7.77 \mathrm{E}-08$ & $1.17 \mathrm{E}-09$ & $4.66 \mathrm{E}-11$ \\
Th-228 & $3.25 \mathrm{E}-09$ & $1.30 \mathrm{E}-08$ & $1.95 \mathrm{E}-10$ & $7.80 \mathrm{E}-12$ \\
Th-231 & $1.87 \mathrm{E}-08$ & $7.48 \mathrm{E}-08$ & $1.12 \mathrm{E}-09$ & $4.49 \mathrm{E}-11$ \\
Th-232 & $1.97 \mathrm{E}-07$ & $7.88 \mathrm{E}-07$ & $1.18 \mathrm{E}-08$ & $4.73 \mathrm{E}-10$ \\
Th-234 & $2.40 \mathrm{E}-05$ & $9.59 \mathrm{E}-05$ & $1.44 \mathrm{E}-06$ & $5.75 \mathrm{E}-08$ \\
U-235 & $1.86 \mathrm{E}-08$ & $7.45 \mathrm{E}-08$ & $1.12 \mathrm{E}-09$ & $4.47 \mathrm{E}-11$ \\
U-238 & $2.40 \mathrm{E}-05$ & $9.59 \mathrm{E}-05$ & $1.44 \mathrm{E}-06$ & $5.75 \mathrm{E}-08$ \\
Total & $7.70 \mathrm{E}-04$ & $3.08 \mathrm{E}-03$ & $4.62 \mathrm{E}-05$ & $1.85 \mathrm{E}-06$ \\
\hline
\end{tabular}


TABLE B.4.12 Low-Level Waste, Case 9: Savannah River Site

Function: Incineration

Waste Stream: Combustible

\begin{tabular}{|c|c|c|c|c|}
\hline \multirow[b]{2}{*}{ Nuclide } & \multicolumn{4}{|c|}{ Release (Ci) } \\
\hline & AL7 & EQ7 & IFF & IEX \\
\hline Ac-228 & $3.10 \mathrm{E}-06$ & 2.07E-06 & $3.10 \mathrm{E}-08$ & $1.24 \mathrm{E}-09$ \\
\hline Am-241 & 8.24E-07 & 5.49E-07 & $8.24 \mathrm{E}-09$ & $3.29 \mathrm{E}-10$ \\
\hline $\mathrm{Bi}-212$ & $5.18 \mathrm{E}-07$ & $3.45 \mathrm{E}-07$ & $5.18 \mathrm{E}-09$ & $2.07 \mathrm{E}-10$ \\
\hline $\mathrm{Ce}-144$ & 7.54E-04 & $5.02 \mathrm{E}-04$ & 7.54E-06 & $3.01 \mathrm{E}-07$ \\
\hline Co-58 & 7.65E-04 & $5.10 \mathrm{E}-04$ & 7.65E-06 & $3.06 \mathrm{E}-07$ \\
\hline Co-60 & $6.01 \mathrm{E}-03$ & 4.01E-03 & $6.01 E-05$ & $2.40 \mathrm{E}-06$ \\
\hline Cr-51 & 2.99E-04 & 2.00E-04 & $2.99 \mathrm{E}-06$ & $1.20 \mathrm{E}-07$ \\
\hline Cs-134 & 2.62E-04 & $1.75 \mathrm{E}-04$ & 2.62E-06 & $1.05 \mathrm{E}-07$ \\
\hline Cs-137 & 2.42E-03 & $1.61 \mathrm{E}-03$ & 2.42E-05 & $9.66 \mathrm{E}-07$ \\
\hline Eu-152 & 2.75E-07 & $1.83 \mathrm{E}-07$ & $2.75 \mathrm{E}-09$ & $1.10 \mathrm{E}-10$ \\
\hline Eu-154 & 4.71E-05 & $3.14 \mathrm{E}-05$ & 4.71E-07 & $1.88 \mathrm{E}-08$ \\
\hline Eu-155 & 3.73E-05 & 2.49E-05 & 3.73E-07 & $1.49 \mathrm{E}-08$ \\
\hline Fe-55 & $2.13 \mathrm{E}-03$ & $1.42 \mathrm{E}-03$ & 2.13E-05 & $8.51 \mathrm{E}-07$ \\
\hline Fe-59 & $1.92 \mathrm{E}-05$ & $1.28 \mathrm{E}-05$ & 1.92E-07 & 7.69E-09 \\
\hline $\mathrm{Mn}-54$ & $5.70 \mathrm{E}-04$ & $3.80 \mathrm{E}-04$ & $5.70 \mathrm{E}-06$ & 2.28E-07 \\
\hline $\mathrm{Ni}-59$ & $2.75 \mathrm{E}-05$ & $1.83 \mathrm{E}-05$ & 2.75E-07 & $1.10 \mathrm{E}-08$ \\
\hline $\mathrm{Ni}-63$ & $3.93 \mathrm{E}-03$ & 2.62E-03 & 3.93E-05 & $1.57 \mathrm{E}-06$ \\
\hline $\mathrm{Pb}-212$ & $5.18 \mathrm{E}-07$ & 3.45E-07 & $5.18 \mathrm{E}-09$ & 2.07E-10 \\
\hline Pm-147 & $1.84 \mathrm{E}-03$ & $1.23 \mathrm{E}-03$ & $1.84 \mathrm{E}-05$ & $7.36 \mathrm{E}-07$ \\
\hline Pr-144 & $7.54 \mathrm{E}-04$ & $5.02 \mathrm{E}-04$ & 7.54E-06 & $3.01 \mathrm{E}-07$ \\
\hline $\mathrm{Pr}-144 \mathrm{~m}$ & $9.06 \mathrm{E}-06$ & $6.04 \mathrm{E}-06$ & $9.06 \mathrm{E}-08$ & 3.62E-09 \\
\hline Pu-238 & 5.67E-05 & $3.78 \mathrm{E}-05$ & $5.67 \mathrm{E}-07$ & $2.27 \mathrm{E}-08$ \\
\hline Pu-239 & $5.49 \mathrm{E}-07$ & 3.66E-07 & $5.49 \mathrm{E}-09$ & $2.20 \mathrm{E}-10$ \\
\hline $\mathrm{Pu}-240$ & 2.75E-07 & $1.83 \mathrm{E}-07$ & 2.75E-09 & $1.10 \mathrm{E}-10$ \\
\hline $\mathrm{Pu}-241$ & $6.34 \mathrm{E}-05$ & 4.23E-05 & $6.34 \mathrm{E}-07$ & $2.54 \mathrm{E}-08$ \\
\hline Ra-224 & 5.18E-07 & 3.45E-07 & $5.18 \mathrm{E}-09$ & 2.07E-10 \\
\hline Ra-228 & $3.10 \mathrm{E}-06$ & 2.07E-06 & $3.10 \mathrm{E}-08$ & $1.24 \mathrm{E}-09$ \\
\hline Ru-106 & $2.25 \mathrm{E}-04$ & $1.50 \mathrm{E}-04$ & $2.25 \mathrm{E}-06$ & $9.00 \mathrm{E}-08$ \\
\hline Sb-125 & $6.47 \mathrm{E}-05$ & 4.31E-05 & 6.47E-07 & $2.59 \mathrm{E}-08$ \\
\hline Sm-151 & $1.80 \mathrm{E}-05$ & $1.20 \mathrm{E}-05$ & $1.80 \mathrm{E}-07$ & $7.19 \mathrm{E}-09$ \\
\hline St-90 & $2.31 \mathrm{E}-03$ & $1.54 \mathrm{E}-03$ & 2.31E-05 & 9.22E-07 \\
\hline Tc-99 & 4.12E-07 & 2.75E-07 & 4.12E-09 & $1.65 \mathrm{E}-10$ \\
\hline $\mathrm{Te}-125 \mathrm{~m}$ & $1.58 \mathrm{E}-05$ & 1.05E-05 & $1.58 \mathrm{E}-07$ & $6.31 \mathrm{E}-09$ \\
\hline Th-228 & 5.18E-07 & 3.45E-07 & $5.18 \mathrm{E}-09$ & $2.07 \mathrm{E}-10$ \\
\hline Th-231 & $2.98 \mathrm{E}-06$ & $1.99 \mathrm{E}-06$ & $2.98 \mathrm{E}-08$ & $1.19 \mathrm{E}-09$ \\
\hline Th-232 & $3.14 \mathrm{E}-05$ & 2.10E-05 & $3.14 \mathrm{E}-07$ & $1.26 \mathrm{E}-08$ \\
\hline Th-234 & $3.82 \mathrm{E}-03$ & $2.55 \mathrm{E}-03$ & 3.82E-05 & $1.53 \mathrm{E}-06$ \\
\hline U-235 & 2.97E-06 & $1.98 \mathrm{E}-06$ & $2.97 \mathrm{E}-08$ & $1.19 \mathrm{E}-09$ \\
\hline U-238 & $3.82 \mathrm{E}-03$ & $2.55 \mathrm{E}-03$ & 3.82E-05 & $1.53 \mathrm{E}-06$ \\
\hline Y-90 & $2.31 \mathrm{E}-03$ & $1.54 \mathrm{E}-03$ & $2.31 \mathrm{E}-05$ & $9.22 \mathrm{E}-07$ \\
\hline Zr-95 & $2.33 \mathrm{E}-05$ & $1.56 \mathrm{E}-05$ & 2.33E-07 & $9.34 \mathrm{E}-09$ \\
\hline Total & $3.26 \mathrm{E}-02$ & $2.18 \mathrm{E}-02$ & $3.26 \mathrm{E}-04$ & $1.31 \mathrm{E}-05$ \\
\hline
\end{tabular}


TABLE B.4.13 Low-Level Waste, Case 12: Hanford

Function: Incineration

Waste Stream: Combustible

\begin{tabular}{|c|c|c|c|c|}
\hline \multirow[b]{2}{*}{ Nuclide } & \multicolumn{4}{|c|}{ Release $(\mathrm{Ci})$} \\
\hline & AL7 & $\mathrm{EQ7}$ & IEX & IFF \\
\hline Ac- 228 & $2.60 \mathrm{E}-08$ & $1.73 E-08$ & $1.04 \mathrm{E}-11$ & $2.60 \mathrm{E}-10$ \\
\hline Am-241 & 9.27E-08 & $6.18 \mathrm{E}-08$ & $3.71 E-11$ & $9.27 \mathrm{E}-10$ \\
\hline $\mathrm{Bi}-212$ & 4.34E-09 & $2.90 \mathrm{E}-09$ & $1.74 \mathrm{E}-12$ & $4.34 \mathrm{E}-11$ \\
\hline Ce-144 & 8.43E-05 & $5.62 \mathrm{E}-05$ & 3.37E-08 & $8.43 \mathrm{E}-07$ \\
\hline $\mathrm{Cm}-242$ & 8.40E-09 & $5.60 \mathrm{E}-09$ & $3.36 \mathrm{E}-12$ & $8.40 \mathrm{E}-11$ \\
\hline $\mathrm{Cm}-244$ & $3.00 \mathrm{E}-09$ & $2.00 \mathrm{E}-09$ & $1.20 \mathrm{E}-12$ & $3.00 \mathrm{E}-11$ \\
\hline $\mathrm{Co}-58$ & $1.91 \mathrm{E}-05$ & $1.28 \mathrm{E}-05$ & 7.65E-09 & $1.91 \mathrm{E}-07$ \\
\hline Co-60 & 3.93E-03 & $2.62 \mathrm{E}-03$ & $1.57 \mathrm{E}-06$ & $3.93 \mathrm{E}-05$ \\
\hline $\mathrm{Cr}-51$ & 7.49E-06 & 4.99E-06 & $3.00 \mathrm{E}-09$ & $7.49 \mathrm{E}-08$ \\
\hline Cs-134 & 2.93E-05 & $1.95 \mathrm{E}-05$ & 1.17E-08 & $2.93 \mathrm{E}-07$ \\
\hline Cs-137 & $6.83 \mathrm{E}-03$ & $4.55 \mathrm{E}-03$ & 2.73E-06 & $6.83 \mathrm{E}-05$ \\
\hline Eu-152 & 3.07E-08 & $2.05 \mathrm{E}-08$ & $1.23 \mathrm{E}-11$ & 3.07E-10 \\
\hline Eu-154 & $5.27 \mathrm{E}-06$ & $3.51 \mathrm{E}-06$ & $2.11 \mathrm{E}-09$ & $5.27 \mathrm{E}-08$ \\
\hline Eu-155 & $4.18 \mathrm{E}-06$ & 2.78E-06 & $1.67 \mathrm{E}-09$ & $4.18 \mathrm{E}-08$ \\
\hline $\mathrm{Fe}-55$ & $1.48 \mathrm{E}-04$ & 9.84E-05 , & $5.90 \mathrm{E}-08$ & $1.48 \mathrm{E}-06$ \\
\hline Fe-59 & $4.81 \mathrm{E}-07$ & $3.21 \mathrm{E}-07$ & $1.92 \mathrm{E}-10$ & $4.81 \mathrm{E}-09$ \\
\hline$M n-54$ & $1.43 \mathrm{E}-05$ & $9.50 \mathrm{E}-06$ & 5.70E-09 & $1.43 \mathrm{E}-07$ \\
\hline $\mathrm{Ni}-59$ & $6.87 \mathrm{E}-07$ & $4.58 \mathrm{E}-07$ & 2.75E-10 & $6.87 \mathrm{E}-09$ \\
\hline $\mathrm{Ni}-63$ & 1.01E-04 & $6.70 \mathrm{E}-05$ & $4.02 \mathrm{E}-08$ & $1.01 \mathrm{E}-06$ \\
\hline P-32 & 7.87E-03 & $5.25 \mathrm{E}-03$ & 3.15E-06 & $7.87 \mathrm{E}-05$ \\
\hline $\mathrm{Pb}-212$ & 4.34E-09 & 2.90E-09 & $1.74 \mathrm{E}-12$ & $4.34 \mathrm{E}-11$ \\
\hline Pm-147 & $2.06 \mathrm{E}-04$ & $1.37 \mathrm{E}-04$ & 8.23E-08 & $2.06 \mathrm{E}-06$ \\
\hline Pr-144 & 8.43E-05 & 5.62E-05 & 3.37E-08 & $8.43 \mathrm{E}-07$ \\
\hline Pr-144m & $1.01 \mathrm{E}-06$ & $6.75 \mathrm{E}-07$ & $4.05 \mathrm{E}-10$ & $1.01 \mathrm{E}-08$ \\
\hline Pu-238 & 6.73E-06 & 4.49E-06 & 2.69E-09 & $6.73 \mathrm{E}-08$ \\
\hline Pu-239 & $9.14 \mathrm{E}-08$ & $6.09 \mathrm{E}-08$ & $3.66 \mathrm{E}-11$ & $9.14 \mathrm{E}-10$ \\
\hline Pu-240 & $1.36 \mathrm{E}-07$ & $9.05 \mathrm{E}-08$ & 5.43E-11 & $1.36 \mathrm{E}-09$ \\
\hline Pu-241 & $2.16 \mathrm{E}-05$ & $1.44 \mathrm{E}-05$ & 8.62E-09 & $2.16 \mathrm{E}-07$ \\
\hline $\mathrm{Ra}-224$ & 4.34E-09 & 2.90E-09 & $1.74 \mathrm{E}-12$ & $4.34 \mathrm{E}-11$ \\
\hline $\mathrm{Ra}-228$ & $2.60 \mathrm{E}-08$ & $1.73 \mathrm{E}-08$ & $1.04 \mathrm{E}-11$ & $2.60 \mathrm{E}-10$ \\
\hline Ru-106 & $2.52 \mathrm{E}-05$ & $1.68 \mathrm{E}-05$ & $1.01 \mathrm{E}-08$ & $2.52 \mathrm{E}-07$ \\
\hline S-35 & $6.77 \mathrm{E}-03$ & $4.51 \mathrm{E}-03$ & 2.71E-06 & $6.77 \mathrm{E}-05$ \\
\hline$S b-125$ & $7.23 \mathrm{E}-06$ & $4.82 \mathrm{E}-06$ & $2.89 \mathrm{E}-09$ & $7.23 \mathrm{E}-08$ \\
\hline Sm-151 & $2.01 E-06$ & $1.34 \mathrm{E}-06$ & $8.04 \mathrm{E}-10$ & 2.01E-08 \\
\hline Sr-90 & 2.58E-04 & $1.72 E-04$ & $1.03 \mathrm{E}-07$ & $2.58 \mathrm{E}-06$ \\
\hline Tc-99 & 4.61E-08 & $3.07 \mathrm{E}-08$ & $1.84 \mathrm{E}-11$ & $4.61 \mathrm{E}-10$ \\
\hline $\mathrm{Te}-125 \mathrm{~m}$ & 1.77E-06 & $1.18 \mathrm{E}-06$ & $7.06 \mathrm{E}-10$ & $1.77 \mathrm{E}-08$ \\
\hline Th-228 & 4.34E-09 & $2.90 \mathrm{E}-09$ & $1.74 \mathrm{E}-12$ & $4.34 \mathrm{E}-11$ \\
\hline Th-231 & $2.50 \mathrm{E}-08$ & $1.67 \mathrm{E}-08$ & $1.00 \mathrm{E}-11$ & $2.50 \mathrm{E}-10$ \\
\hline Th-232 & $1.80 \mathrm{E}-03$ & $1.20 \mathrm{E}-03$ & 7.19E-07 & $1.80 \mathrm{E}-05$ \\
\hline Th-234 & $3.20 \mathrm{E}-05$ & $2.14 E-05$ & $1.28 \mathrm{E}-08$ & $3.20 \mathrm{E}-07$ \\
\hline U-235 & $2.49 \mathrm{E}-08$ & $1.66 \mathrm{E}-08$ & $9.96 \mathrm{E}-12$ & $2.49 \mathrm{E}-10$ \\
\hline U-238 & $2.46 \mathrm{E}-03$ & $1.64 \mathrm{E}-03$ & $9.84 \mathrm{E}-07$ & $2.46 \mathrm{E}-05$ \\
\hline$Y-90$ & $2.58 \mathrm{E}-04$ & $1.72 \mathrm{E}-04$ & $1.03 \mathrm{E}-07$ & $2.58 \mathrm{E}-06$ \\
\hline $\mathrm{Zr}-95$ & 5.84E-07 & $3.89 E-07$ & $2.34 \mathrm{E}-10$ & $5.84 \mathrm{E}-09$ \\
\hline Total & $3.10 \mathrm{E}-02$ & 2.07E-02 & $1.24 \mathrm{E}-05$ & $3.10 \mathrm{E}-04$ \\
\hline
\end{tabular}


TABLE B.4.14 Low-Level Waste, Case 12: Idaho National Engineering Laboratory

Function: Incineration

Waste Stream: Combustible

\begin{tabular}{|c|c|c|c|c|}
\hline \multirow[b]{2}{*}{ Nuclide } & \multicolumn{4}{|c|}{ Release $(\mathrm{Ci})$} \\
\hline & AL7 & IEX & IFF & EQ7 \\
\hline Am-241 & $1.77 \mathrm{E}-08$ & $7.09 \mathrm{E}-12$ & $1.77 \mathrm{E}-10$ & $1.18 \mathrm{E}-08$ \\
\hline Ce-144 & $1.62 \mathrm{E}-05$ & $6.49 \mathrm{E}-09$ & $1.62 \mathrm{E}-07$ & $1.08 \mathrm{E}-05$ \\
\hline Co-58 & $2.43 \mathrm{E}-04$ & $9.73 \mathrm{E}-08$ & $2.43 E-06$ & $1.62 \mathrm{E}-04$ \\
\hline Co-60 & $1.91 \mathrm{E}-03$ & $7.63 \mathrm{E}-07$ & $1.91 E-05$ & $1.27 \mathrm{E}-03$ \\
\hline $\mathrm{Cr}-51$ & 9.52E-05 & $3.81 \mathrm{E}-08$ & 9.52E-07 & $6.35 \mathrm{E}-05$ \\
\hline Cs- 134 & 5.63E-06 & 2.25E-09 & $5.63 \mathrm{E}-08$ & $3.76 \mathrm{E}-06$ \\
\hline Cs-137 & 5.20E-05 & $2.08 \mathrm{E}-08$ & $5.20 \mathrm{E}-07$ & $3.47 \mathrm{E}-05$ \\
\hline Eu-152 & 5.91E-09 & $2.36 \mathrm{E}-12$ & $5.91 \mathrm{E}-11$ & $3.94 \mathrm{E}-09$ \\
\hline Eu-154 & $1.01 \mathrm{E}-06$ & $4.05 \mathrm{E}-10$ & $1.01 E-08$ & $6.76 \mathrm{E}-07$ \\
\hline Eu-155 & 8.04E-07 & $3.21 \mathrm{E}-10$ & 8.04E-09 & $5.36 \mathrm{E}-07$ \\
\hline $\mathrm{Fe}-55$ & $6.77 \mathrm{E}-04$ & 2.71E-07 & $6.77 \mathrm{E}-06$ & $4.51 \mathrm{E}-04$ \\
\hline $\mathrm{Fe}-59$ & $6.12 \mathrm{E}-06$ & 2.45E-09 & $6.12 \mathrm{E}-08$ & $4.08 \mathrm{E}-06$ \\
\hline $\mathrm{Mn}-54$ & $1.81 \mathrm{E}-04$ & 7.25E-08 & $1.81 \mathrm{E}-06$ & $1.21 \mathrm{E}-04$ \\
\hline $\mathrm{Ni}-59$ & 8.74E-06 & $3.50 \mathrm{E}-09$ & $8.74 \mathrm{E}-08$ & 5.83E-06 \\
\hline $\mathrm{Ni}-63$ & $1.24 \mathrm{E}-03$ & 4.97E-07 & $1.24 \mathrm{E}-05$ & 8.28E-04 \\
\hline Pm-147 & $3.96 \mathrm{E}-05$ & $1.58 \mathrm{E}-08$ & $3.96 \mathrm{E}-07$ & $2.64 \mathrm{E}-05$ \\
\hline Pr-144 & $1.62 \mathrm{E}-05$ & $6.49 \mathrm{E}-09$ & $1.62 \mathrm{E}-07$ & $1.08 \mathrm{E}-05$ \\
\hline Pr-144m & $1.95 \mathrm{E}-07$ & $7.80 \mathrm{E}-11$ & $1.95 \mathrm{E}-09$ & $1.30 \mathrm{E}-07$ \\
\hline $\mathrm{Pu}-238$ & $1.22 \mathrm{E}-06$ & $4.88 \mathrm{E}-10$ & 1.22E-08 & 8.13E-07 \\
\hline Pu-239 & $1.18 \mathrm{E}-08$ & 4.73E-12 & $1.18 \mathrm{E}-10$ & $7.88 \mathrm{E}-09$ \\
\hline Pu-240 & 5.91E-09 & $2.36 \mathrm{E}-12$ & $5.91 \mathrm{E}-11$ & $3.94 \mathrm{E}-09$ \\
\hline $\mathrm{Pu}-241$ & $1.36 \mathrm{E}-06$ & $5.46 \mathrm{E}-10$ & $1.36 \mathrm{E}-08$ & $9.10 \mathrm{E}-07$ \\
\hline Ru-106 & 4.84E-06 & $1.94 \mathrm{E}-09$ & 4.84E-08 & $3.23 \mathrm{E}-06$ \\
\hline Sb-125 & $1.39 \mathrm{E}-06$ & $5.57 \mathrm{E}-10$ & $1.39 \mathrm{E}-08$ & $9.28 \mathrm{E}-07$ \\
\hline Sm-151 & 3.87E-07 & $1.55 \mathrm{E}-10$ & 3.87E-09 & $2.58 \mathrm{E}-07$ \\
\hline Sr-90 & $4.96 \mathrm{E}-05$ & $1.99 \mathrm{E}-08$ & $4.96 \mathrm{E}-07$ & 3.31E-05 \\
\hline Tc-99 & $8.86 \mathrm{E}-09$ & $3.55 \mathrm{E}-12$ & $8.86 \mathrm{E}-11$ & $5.91 \mathrm{E}-09$ \\
\hline $\mathrm{Te}-125 \mathrm{~m}$ & 3.40E-07 & $1.36 \mathrm{E}-10$ & $3.40 \mathrm{E}-09$ & $2.26 \mathrm{E}-07$ \\
\hline $\mathrm{Y}-90$ & $4.96 \mathrm{E}-05$ & $1.99 \mathrm{E}-08$ & $4.96 \mathrm{E}-07$ & 3.31E-05 \\
\hline $\mathrm{Zr}-95$ & 7.43E-06 & 2.97E-09 & 7.43E-08 & 4.95E-06 \\
\hline Total & 4.61E-03 & $1.84 \mathrm{E}-06$ & 4.61E-05 & $3.07 \mathrm{E}-03$ \\
\hline
\end{tabular}


TABLE B.4.15 Low-Level Waste, Case 12:

Los Alamos National Laboratory

\begin{tabular}{|c|c|c|c|}
\hline \multicolumn{4}{|c|}{$\begin{array}{l}\text { Function: Incineration } \\
\text { Waste Stream: Combustible }\end{array}$} \\
\hline \multirow[b]{2}{*}{ Nuclide } & \multicolumn{3}{|c|}{ Release (Ci) } \\
\hline & IFF & IEX & EQ7 \\
\hline Ac-228 & 7.92E-07 & 3.17E-08 & $5.28 \mathrm{E}-05$ \\
\hline Am-24l & $5.11 \mathrm{E}-08$ & $2.04 \mathrm{E}-09$ & $3.40 \mathrm{E}-06$ \\
\hline $\mathrm{Bi}-212$ & 1.32E-07 & 5.30E-09 & $8.83 \mathrm{E}-06$ \\
\hline Ce-144 & $2.80 \mathrm{E}-05$ & 1.12E-06 & $1.87 E-03$ \\
\hline $\mathrm{Cm}-242$ & $2.86 \mathrm{E}-07$ & 1.14E-08 & $1.91 \mathrm{E}-05$ \\
\hline $\mathrm{Cm}-244$ & $1.02 \mathrm{E}-07$ & $4.09 \mathrm{E}-09$ & $6.81 \mathrm{E}-06$ \\
\hline Co-58 & $3.56 \mathrm{E}-08$ & 1.42E-09 & 2.37E-06 \\
\hline Co-60 & 7.63E-07 & 3.05E-08 & $5.09 \mathrm{E}-05$ \\
\hline Cr-51 & $1.39 \mathrm{E}-08$ & 5.57E-10 & $9.28 \mathrm{E}-07$ \\
\hline Cs-134 & 9.73E-06 & 3.89E-07 & $6.49 \mathrm{E}-04$ \\
\hline Cs-137 & 8.98E-05 & $3.59 \mathrm{E}-06$ & $5.99 \mathrm{E}-03$ \\
\hline Eu-152 & $1.02 \mathrm{E}-08$ & $4.08 \mathrm{E}-10$ & $6.80 \mathrm{E}-07$ \\
\hline Eu-154 & $1.75 \mathrm{E}-06$ & $7.00 \mathrm{E}-08$ & $1.17 \mathrm{E}-04$ \\
\hline Eu-155 & $1.39 \mathrm{E}-06$ & 5.55E-08 & $9.25 \mathrm{E}-05$ \\
\hline $\mathrm{Fe}-55$ & $9.89 \mathrm{E}-08$ & $3.96 \mathrm{E}-09$ & $6.59 \mathrm{E}-06$ \\
\hline Fe-59 & $8.94 \mathrm{E}-10$ & 3.57E-11 & $5.96 \mathrm{E}-08$ \\
\hline Mn-54 & 2.65E-08 & $1.06 \mathrm{E}-09$ & $1.77 \mathrm{E}-06$ \\
\hline $\mathrm{Ni}-59$ & $1.28 \mathrm{E}-09$ & $5.11 \mathrm{E}-11$ & 8.51E-08 \\
\hline $\mathrm{Ni}-63$ & $1.15 \mathrm{E}-06$ & 4.58E-08 & $7.64 \mathrm{E}-05$ \\
\hline $\mathrm{Pb}-212$ & $1.32 \mathrm{E}-07$ & $5.30 \mathrm{E}-09$ & 8.83E-06 \\
\hline Pm-147 & $6.84 \mathrm{E}-05$ & 2.73E-06 & $4.56 \mathrm{E}-03$ \\
\hline Pr-144 & $2.80 \mathrm{E}-05$ & $1.12 \mathrm{E}-06$ & $1.87 \mathrm{E}-03$ \\
\hline Pr-144m & $3.37 \mathrm{E}-07$ & $1.35 \mathrm{E}-08$ & $2.24 \mathrm{E}-05$ \\
\hline Pu-238 & $1.55 \mathrm{E}-05$ & $6.20 \mathrm{E}-07$ & $1.03 E-03$ \\
\hline Pu-239 & $1.04 \mathrm{E}-06$ & $4.17 \mathrm{E}-08$ & $6.95 \mathrm{E}-05$ \\
\hline Pu-240 & $3.59 \mathrm{E}-06$ & $1.43 \mathrm{E}-07$ & $2.39 \mathrm{E}-04$ \\
\hline Pu-241 & 4.95E-04 & $1.98 \mathrm{E}-05$ & $3.30 \mathrm{E}-02$ \\
\hline Ra-224 & 1.32E-07 & $5.30 \mathrm{E}-09$ & $8.83 \mathrm{E}-06$ \\
\hline $\mathrm{Ra}-228$ & 7.92E-07 & 3.17E-08 & $5.28 \mathrm{E}-05$ \\
\hline Ru-106 & 8.37E-06 & 3.35E-07 & $5.58 \mathrm{E}-04$ \\
\hline Sb-125 & $2.40 \mathrm{E}-06$ & 9.61E-08 & $1.60 \mathrm{E}-04$ \\
\hline Sm-151 & 6.68E-07 & $2.67 \mathrm{E}-08$ & $4.46 \mathrm{E}-05$ \\
\hline Sr-90 & 8.57E-05 & $3.43 \mathrm{E}-06$ & $5.71 \mathrm{E}-03$ \\
\hline Tc-99 & $1.53 \mathrm{E}-08$ & $6.12 \mathrm{E}-10$ & $1.02 \mathrm{E}-06$ \\
\hline $\mathrm{Te}-125 \mathrm{~m}$ & $5.87 \mathrm{E}-07$ & 2.35E-08 & 3.91E-05 \\
\hline Th-228 & $1.32 \mathrm{E}-07$ & 5.30E-09 & 8.83E-06 \\
\hline Th-231 & 7.62E-07 & $3.05 \mathrm{E}-08$ & $5.08 \mathrm{E}-05$ \\
\hline Th-232 & 8.03E-06 & $3.21 \mathrm{E}-07$ & $5.36 \mathrm{E}-04$ \\
\hline Th-234 & 9.77E-04 & $3.91 \mathrm{E}-05$ & $6.51 E-02$ \\
\hline U-235 & $7.59 \mathrm{E}-07$ & $3.04 \mathrm{E}-08$ & $5.06 \mathrm{E}-05$ \\
\hline U-238 & $9.77 \mathrm{E}-04$ & $3.91 \mathrm{E}-05$ & $6.51 \mathrm{E}-02$ \\
\hline Y-90 & 8.57E-05 & 3.43E-06 & $5.71 \mathrm{E}-03$ \\
\hline Zr-95 & $1.09 \mathrm{E}-09$ & $4.34 \mathrm{E}-11$ & 7.23E-08 \\
\hline Total & $2.89 \mathrm{E}-03$ & 1.16E-04 & $1.93 \mathrm{E}-01$ \\
\hline
\end{tabular}


TABLE B.4.16 Low-Level Waste, Case 12:

Oak Ridge National Laboratory

Function: Incineration

Waste Stream: Combustible

\begin{tabular}{lccc}
\hline & \multicolumn{3}{c}{ Release (Ci) } \\
\cline { 2 - 4 } Nuclide & EQ7 & IEX1 & IFF1 \\
\hline & & & \\
Ac-228 & $1.69 \mathrm{E}-07$ & $1.01 \mathrm{E}-10$ & $2.17 \mathrm{E}-11$ \\
Bi-212 & $2.82 \mathrm{E}-08$ & $1.69 \mathrm{E}-11$ & $3.63 \mathrm{E}-12$ \\
Co-58 & $8.86 \mathrm{E}-05$ & $5.32 \mathrm{E}-08$ & $1.14 \mathrm{E}-08$ \\
Co-60 & $2.56 \mathrm{E}-04$ & $1.54 \mathrm{E}-07$ & $3.29 \mathrm{E}-08$ \\
Cs-134 & $1.98 \mathrm{E}-04$ & $1.19 \mathrm{E}-07$ & $2.55 \mathrm{E}-08$ \\
Cs-137 & $2.62 \mathrm{E}-04$ & $1.57 \mathrm{E}-07$ & $3.37 \mathrm{E}-08$ \\
Mn-54 & $9.60 \mathrm{E}-05$ & $5.76 \mathrm{E}-08$ & $1.23 \mathrm{E}-08$ \\
Pb-212 & $2.82 \mathrm{E}-08$ & $1.69 \mathrm{E}-11$ & $3.63 \mathrm{E}-12$ \\
Ra-224 & $2.82 \mathrm{E}-08$ & $1.69 \mathrm{E}-11$ & $3.63 \mathrm{E}-12$ \\
Ra-228 & $1.69 \mathrm{E}-07$ & $1.01 \mathrm{E}-10$ & $2.17 \mathrm{E}-11$ \\
Sr-90 & $1.20 \mathrm{E}-04$ & $7.22 \mathrm{E}-08$ & $1.55 \mathrm{E}-08$ \\
Tc-99 & $1.70 \mathrm{E}-06$ & $1.02 \mathrm{E}-09$ & $2.19 \mathrm{E}-10$ \\
Th-228 & $2.82 \mathrm{E}-08$ & $1.69 \mathrm{E}-11$ & $3.63 \mathrm{E}-12$ \\
Th-231 & $1.62 \mathrm{E}-07$ & $9.74 \mathrm{E}-11$ & $2.09 \mathrm{E}-11$ \\
Th-232 & $1.71 \mathrm{E}-06$ & $1.03 \mathrm{E}-09$ & $2.20 \mathrm{E}-10$ \\
Th-234 & $2.08 \mathrm{E}-04$ & $1.25 \mathrm{E}-07$ & $2.68 \mathrm{E}-08$ \\
U-235 & $1.62 \mathrm{E}-07$ & $9.71 \mathrm{E}-11$ & $2.08 \mathrm{E}-11$ \\
U-238 & $2.19 \mathrm{E}-04$ & $1.31 \mathrm{E}-07$ & $2.81 \mathrm{E}-08$ \\
Y-90 & $1.20 \mathrm{E}-04$ & $7.22 \mathrm{E}-08$ & $1.55 \mathrm{E}-08$ \\
Total & $1.57 \mathrm{E}-03$ & $9.44 \mathrm{E}-07$ & $2.02 \mathrm{E}-07$ \\
\hline & & &
\end{tabular}


TABLE B.4.17 Low-Level Waste, Case 12: Portsmouth Gaseous Diffusion Plant

Function: Incineration

Waste Stream: Combustible

\begin{tabular}{lllll}
\hline & \multicolumn{5}{c}{ Release (Ci) } \\
\cline { 2 - 5 } Nuclide & AS5 & IEX & IFF & EQ7 \\
\cline { 2 - 5 } Ac-228 & $3.15 \mathrm{E}-11$ & $7.60 \mathrm{E}-14$ & $1.89 \mathrm{E}-12$ & $1.26 \mathrm{E}-10$ \\
Am-241 & $3.50 \mathrm{E}-12$ & $8.00 \mathrm{E}-15$ & $2.10 \mathrm{E}-13$ & $1.40 \mathrm{E}-11$ \\
Bi-212 & $5.00 \mathrm{E}-12$ & $1.20 \mathrm{E}-14$ & $3.00 \mathrm{E}-13$ & $2.00 \mathrm{E}-11$ \\
Cm-242 & $4.65 \mathrm{E}-11$ & $1.12 \mathrm{E}-13$ & $2.79 \mathrm{E}-12$ & $1.86 \mathrm{E}-10$ \\
Cm-244 & $1.65 \mathrm{E}-11$ & $4.00 \mathrm{E}-14$ & $9.90 \mathrm{E}-13$ & $6.60 \mathrm{E}-11$ \\
Pb-212 & $5.00 \mathrm{E}-12$ & $1.20 \mathrm{E}-14$ & $3.00 \mathrm{E}-13$ & $2.00 \mathrm{E}-11$ \\
Pu-238 & $2.18 \mathrm{E}-09$ & $5.23 \mathrm{E}-12$ & $1.31 \mathrm{E}-10$ & $8.72 \mathrm{E}-09$ \\
Pu-239 & $1.66 \mathrm{E}-10$ & $4.00 \mathrm{E}-13$ & $9.99 \mathrm{E}-12$ & $6.66 \mathrm{E}-10$ \\
Pu-240 & $5.82 \mathrm{E}-10$ & $1.40 \mathrm{E}-12$ & $3.49 \mathrm{E}-11$ & $2.33 \mathrm{E}-09$ \\
Pu-241 & $8.03 \mathrm{E}-08$ & $1.93 \mathrm{E}-10$ & $4.82 \mathrm{E}-09$ & $3.21 \mathrm{E}-07$ \\
Ra-224 & $5.00 \mathrm{E}-12$ & $1.20 \mathrm{E}-14$ & $3.00 \mathrm{E}-13$ & $2.00 \mathrm{E}-11$ \\
Ra-228 & $3.15 \mathrm{E}-11$ & $7.60 \mathrm{E}-14$ & $1.89 \mathrm{E}-12$ & $1.26 \mathrm{E}-10$ \\
Th-228 & $5.00 \mathrm{E}-12$ & $1.20 \mathrm{E}-14$ & $3.00 \mathrm{E}-13$ & $2.00 \mathrm{E}-11$ \\
Th-231 & $3.00 \mathrm{E}-11$ & $7.20 \mathrm{E}-14$ & $1.80 \mathrm{E}-12$ & $1.20 \mathrm{E}-10$ \\
Th-232 & $3.16 \mathrm{E}-10$ & $7.60 \mathrm{E}-13$ & $1.90 \mathrm{E}-11$ & $1.27 \mathrm{E}-09$ \\
Th-234 & $3.85 \mathrm{E}-08$ & $9.23 \mathrm{E}-11$ & $2.31 \mathrm{E}-09$ & $1.54 \mathrm{E}-07$ \\
U-235 & $3.00 \mathrm{E}-11$ & $7.20 \mathrm{E}-14$ & $1.80 \mathrm{E}-12$ & $1.20 \mathrm{E}-10$ \\
U-238 & $3.85 \mathrm{E}-08$ & $9.23 \mathrm{E}-11$ & $2.31 \mathrm{E}-09$ & $1.54 \mathrm{E}-07$ \\
Total & $1.61 \mathrm{E}-07$ & $3.85 \mathrm{E}-10$ & $9.64 \mathrm{E}-09$ & $6.42 \mathrm{E}-07$ \\
\hline & & & &
\end{tabular}


TABLE B.4.18 Low-Level Waste, Case 12: Rocky Flats Environmental Technology Site

Function: $\alpha$-Incineration

Waste Stream: Combustible

\begin{tabular}{lllll}
\hline & \multicolumn{5}{c}{ Release (Ci) } \\
\cline { 2 - 5 } Nuclide & AS5 & IEX & IFF & EQ7 \\
\hline & & & \\
Ac-228 & $1.94 \mathrm{E}-08$ & $4.66 \mathrm{E}-11$ & $1.17 \mathrm{E}-09$ & $7.77 \mathrm{E}-08$ \\
Am-241 & $2.89 \mathrm{E}-08$ & $6.93 \mathrm{E}-11$ & $1.73 \mathrm{E}-09$ & $1.15 \mathrm{E}-07$ \\
$\mathrm{Bi}-212$ & $3.25 \mathrm{E}-09$ & $7.80 \mathrm{E}-12$ & $1.95 \mathrm{E}-10$ & $1.30 \mathrm{E}-08$ \\
$\mathrm{Cm}-242$ & $4.04 \mathrm{E}-07$ & $9.70 \mathrm{E}-10$ & $2.43 \mathrm{E}-08$ & $1.62 \mathrm{E}-06$ \\
$\mathrm{Cm}-244$ & $1.44 \mathrm{E}-07$ & $3.46 \mathrm{E}-10$ & $8.66 \mathrm{E}-09$ & $5.77 \mathrm{E}-07$ \\
$\mathrm{~Pb}-212$ & $3.25 \mathrm{E}-09$ & $7.80 \mathrm{E}-12$ & $1.95 \mathrm{E}-10$ & $1.30 \mathrm{E}-08$ \\
$\mathrm{Pu}-238$ & $1.89 \mathrm{E}-05$ & $4.54 \mathrm{E}-08$ & $1.13 \mathrm{E}-06$ & $7.56 \mathrm{E}-05$ \\
$\mathrm{Pu}-239$ & $1.44 \mathrm{E}-06$ & $3.46 \mathrm{E}-09$ & $8.66 \mathrm{E}-08$ & $5.77 \mathrm{E}-06$ \\
$\mathrm{Pu}-240$ & $5.05 \mathrm{E}-06$ & $1.21 \mathrm{E}-08$ & $3.03 \mathrm{E}-07$ & $2.02 \mathrm{E}-05$ \\
$\mathrm{Pu}-241$ & $6.96 \mathrm{E}-04$ & $1.67 \mathrm{E}-06$ & $4.18 \mathrm{E}-05$ & $2.78 \mathrm{E}-03$ \\
$\mathrm{Ra}-224$ & $3.25 \mathrm{E}-09$ & $7.80 \mathrm{E}-12$ & $1.95 \mathrm{E}-10$ & $1.30 \mathrm{E}-08$ \\
$\mathrm{Ra}-228$ & $1.94 \mathrm{E}-08$ & $4.66 \mathrm{E}-11$ & $1.17 \mathrm{E}-09$ & $7.77 \mathrm{E}-08$ \\
Th-228 & $3.25 \mathrm{E}-09$ & $7.80 \mathrm{E}-12$ & $1.95 \mathrm{E}-10$ & $1.30 \mathrm{E}-08$ \\
Th-231 & $1.87 \mathrm{E}-08$ & $4.49 \mathrm{E}-11$ & $1.12 \mathrm{E}-09$ & $7.48 \mathrm{E}-08$ \\
Th-232 & $1.97 \mathrm{E}-07$ & $4.73 \mathrm{E}-10$ & $1.18 \mathrm{E}-08$ & $7.88 \mathrm{E}-07$ \\
Th-234 & $2.40 \mathrm{E}-05$ & $5.75 \mathrm{E}-08$ & $1.44 \mathrm{E}-06$ & $9.59 \mathrm{E}-05$ \\
U-235 & $1.86 \mathrm{E}-08$ & $4.47 \mathrm{E}-11$ & $1.12 \mathrm{E}-09$ & $7.45 \mathrm{E}-08$ \\
U-238 & $2.40 \mathrm{E}-05$ & $5.75 \mathrm{E}-08$ & $1.44 \mathrm{E}-06$ & $9.59 \mathrm{E}-05$ \\
Total & $7.70 \mathrm{E}-04$ & $1.85 \mathrm{E}-06$ & $4.62 \mathrm{E}-05$ & $3.08 \mathrm{E}-03$ \\
\hline & & & &
\end{tabular}


TABLE B.4.19 Low-Level Waste, Case 12: Rocky Flats Environmental Technology Site

\begin{tabular}{|c|c|c|c|c|}
\hline \multicolumn{5}{|c|}{$\begin{array}{l}\text { Function: Incineration } \\
\text { Waste Stream: Organic }\end{array}$} \\
\hline \multirow[b]{2}{*}{ Nuclide } & \multicolumn{4}{|c|}{ Release (Ci) } \\
\hline & AS5 & IEX & IFF & EQ7 \\
\hline Ac-228 & $2.80 \mathrm{E}-11$ & $6.70 \mathrm{E}-14$ & $1.68 \mathrm{E}-12$ & $1.12 \mathrm{E}-10$ \\
\hline $\mathrm{Am}-241$ & $4.15 \mathrm{E}-11$ & $1.00 \mathrm{E}-13$ & $2.49 \mathrm{E}-12$ & $1.66 \mathrm{E}-10$ \\
\hline $\mathrm{Bi}-212$ & $4.50 \mathrm{E}-12$ & $1.10 \mathrm{E}-14$ & $2.70 \mathrm{E}-13$ & $1.80 \mathrm{E}-11$ \\
\hline $\mathrm{Cm}-242$ & 5.77E-10 & 1.39E-12 & $3.46 \mathrm{E}-11$ & 2.31E-09 \\
\hline $\mathrm{Cm}-244$ & $2.06 \mathrm{E}-10$ & $4.96 \mathrm{E}-13$ & $1.24 \mathrm{E}-11$ & $8.26 \mathrm{E}-10$ \\
\hline $\mathrm{Pb}-212$ & $4.50 \mathrm{E}-12$ & $1.10 \mathrm{E}-14$ & $2.70 \mathrm{E}-13$ & $1.80 \mathrm{E}-11$ \\
\hline Pu-238 & $2.70 \mathrm{E}-08$ & $6.49 \mathrm{E}-11$ & 1.62E-09 & $1.08 \mathrm{E}-07$ \\
\hline Pu-239 & $2.06 \mathrm{E}-09$ & $4.95 \mathrm{E}-12$ & $1.24 \mathrm{E}-10$ & 8.25E-09 \\
\hline Pu-240 & 7.22E-09 & $1.73 \mathrm{E}-11$ & $4.33 \mathrm{E}-10$ & $2.89 \mathrm{E}-08$ \\
\hline $\mathrm{Pu}-241$ & 9.94E-07 & $2.39 \mathrm{E}-09$ & 5.97E-08 & $3.98 \mathrm{E}-06$ \\
\hline $\mathrm{Ra}-224$ & $4.50 \mathrm{E}-12$ & $1.10 \mathrm{E}-14$ & $2.70 \mathrm{E}-13$ & $1.80 \mathrm{E}-11$ \\
\hline $\mathrm{Ra}-228$ & $2.80 E-11$ & $6.70 \mathrm{E}-14$ & $1.68 \mathrm{E}-12$ & $1.12 \mathrm{E}-10$ \\
\hline Th-228 & $4.50 \mathrm{E}-12$ & $1.10 \mathrm{E}-14$ & $2.70 \mathrm{E}-13$ & $1.80 \mathrm{E}-11$ \\
\hline Th-231 & $2.65 \mathrm{E}-11$ & $6.40 \mathrm{E}-14$ & $1.59 \mathrm{E}-12$ & $1.06 \mathrm{E}-10$ \\
\hline Th-232 & $2.81 E-10$ & $6.76 \mathrm{E}-13$ & $1.69 \mathrm{E}-11$ & 1.13E-09 \\
\hline Th-234 & 3.42E-08 & 8.22E-11 & $2.05 \mathrm{E}-09$ & $1.37 \mathrm{E}-07$ \\
\hline U-235 & $2.65 \mathrm{E}-11$ & $6.40 \mathrm{E}-14$ & $1.59 \mathrm{E}-12$ & $1.06 \mathrm{E}-10$ \\
\hline U-238 & $3.42 \mathrm{E}-08$ & $8.22 \mathrm{E}-11$ & 2.05E-09 & $1.37 \mathrm{E}-07$ \\
\hline Total & $1.10 \mathrm{E}-06$ & 2.64E-09 & $6.60 \mathrm{E}-08$ & $4.40 \mathrm{E}-06$ \\
\hline
\end{tabular}


TABLE B.4.20 Low-Level Waste, Case 12: Savannah River Site

\begin{tabular}{|c|c|c|c|c|}
\hline \multicolumn{5}{|c|}{$\begin{array}{l}\text { Function: Incineration } \\
\text { Waste Stream: Combustible }\end{array}$} \\
\hline \multirow[b]{2}{*}{ Nuclide } & \multicolumn{4}{|c|}{ Release $(\mathrm{Ci})$} \\
\hline & AL7 & $\mathrm{EQ} 7$ & IFF & IEX \\
\hline Ac- 228 & $3.10 \mathrm{E}-06$ & 2.07E-06 & $3.10 \mathrm{E}-08$ & $1.24 \mathrm{E}-09$ \\
\hline Am-241 & 8.24E-07 & 5.49E-07 & 8.24E-09 & $3.29 \mathrm{E}-10$ \\
\hline $\mathrm{Bi}-212$ & 5.18E-07 & 3.45E-07 & $5.18 \mathrm{E}-09$ & $2.07 \mathrm{E}-10$ \\
\hline Ce-144 & 7.54E-04 & $5.02 \mathrm{E}-04$ & $7.54 \mathrm{E}-06$ & $3.01 \mathrm{E}-07$ \\
\hline Co-58 & 7.65E-04 & $5.10 \mathrm{E}-04$ & $7.65 \mathrm{E}-06$ & $3.06 \mathrm{E}-07$ \\
\hline Co-60 & $6.01 E-03$ & $4.01 \mathrm{E}-03$ & $6.01 \mathrm{E}-05$ & $2.40 \mathrm{E}-06$ \\
\hline Cr-51 & 2.99E-04 & $2.00 \mathrm{E}-04$ & 2.99E-06 & $1.20 \mathrm{E}-07$ \\
\hline Cs-134 & $2.62 \mathrm{E}-04$ & $1.75 \mathrm{E}-04$ & 2.62E-06 & $1.05 \mathrm{E}-07$ \\
\hline Cs-137 & $2.42 \mathrm{E}-03$ & $1.61 \mathrm{E}-03$ & $2.42 \mathrm{E}-05$ & $9.66 \mathrm{E}-07$ \\
\hline Eu-152 & 2.75E-07 & $1.83 \mathrm{E}-07$ & 2.75E-09 & $1.10 \mathrm{E}-10$ \\
\hline Eu-154 & $4.71 \mathrm{E}-05$ & 3.14E-05 & $4.71 \mathrm{E}-07$ & $1.88 \mathrm{E}-08$ \\
\hline Eu-155 & $3.73 E-05$ & 2.49E-05 & 3.73E-07 & $1.49 \mathrm{E}-08$ \\
\hline $\mathrm{Fe}-55$ & 2.13E-03 & $1.42 \mathrm{E}-03$ & 2.13E-05 & 8.51E-07 \\
\hline Fe-59 & $1.92 \mathrm{E}-05$ & $1.28 \mathrm{E}-05$ & 1.92E-07 & $7.69 \mathrm{E}-09$ \\
\hline $\mathrm{Mn}-54$ & $5.70 \mathrm{E}-04$ & $3.80 \mathrm{E}-04$ & 5.70E-06 & 2.28E-07 \\
\hline $\mathrm{Ni}-59$ & $2.75 \mathrm{E}-05$ & $1.83 \mathrm{E}-05$ & 2.75E-07 & $1.10 \mathrm{E}-08$ \\
\hline $\mathrm{Ni}-63$ & $3.93 \mathrm{E}-03$ & 2.62E-03 & $3.93 \mathrm{E}-05$ & $1.57 \mathrm{E}-06$ \\
\hline $\mathrm{Pb}-212$ & $5.18 \mathrm{E}-07$ & $3.45 \mathrm{E}-07$ & $5.18 \mathrm{E}-09$ & $2.07 \mathrm{E}-10$ \\
\hline Pm-147 & $1.84 \mathrm{E}-03$ & $1.23 \mathrm{E}-03$ & $1.84 \mathrm{E}-05$ & $7.36 \mathrm{E}-07$ \\
\hline Pr-144 & 7.54E-04 & 5.02E-04 & $7.54 \mathrm{E}-06$ & 3.01E-07 \\
\hline Pr-144m & $9.06 \mathrm{E}-06$ & $6.04 \mathrm{E}-06$ & $9.06 \mathrm{E}-08$ & $3.62 \mathrm{E}-09$ \\
\hline $\mathrm{Pu}-238$ & $5.67 \mathrm{E}-05$ & $3.78 \mathrm{E}-05$ & 5.67E-07 & $2.27 \mathrm{E}-08$ \\
\hline Pu-239 & $5.49 \mathrm{E}-07$ & $3.66 \mathrm{E}-07$ & 5.49E-09 & $2.20 \mathrm{E}-10$ \\
\hline $\mathrm{Pu}-240$ & 2.75E-07 & $1.83 \mathrm{E}-07$ & 2.75E-09 & $1.10 \mathrm{E}-10$ \\
\hline Pu-241 & $6.34 \mathrm{E}-05$ & $4.23 \mathrm{E}-05$ & $6.34 \mathrm{E}-07$ & $2.54 \mathrm{E}-08$ \\
\hline $\mathrm{Ra}-224$ & $5.18 \mathrm{E}-07$ & 3.45E-07 & $5.18 \mathrm{E}-09$ & $2.07 \mathrm{E}-10$ \\
\hline $\mathrm{Ra}-228$ & $3.10 \mathrm{E}-06$ & 2.07E-06 & 3.10E-08 & $1.24 \mathrm{E}-09$ \\
\hline Ru-106 & 2.25E-04 & $1.50 \mathrm{E}-04$ & $2.25 \mathrm{E}-06$ & $9.00 \mathrm{E}-08$ \\
\hline Sb-125 & 6.47E-05 & 4.31E-05 & 6.47E-07 & $2.59 \mathrm{E}-08$ \\
\hline Sm-151 & $1.80 \mathrm{E}-05$ & $1.20 \mathrm{E}-05$ & $1.80 \mathrm{E}-07$ & $7.19 \mathrm{E}-09$ \\
\hline Sr-90 & $2.31 \mathrm{E}-03$ & $1.54 \mathrm{E}-03$ & 2.31E-05 & $9.22 \mathrm{E}-07$ \\
\hline Tc-99 & 4.12E-07 & $2.75 \mathrm{E}-07$ & 4.12E-09 & $1.65 E-10$ \\
\hline $\mathrm{Te}-125 \mathrm{~m}$ & $1.58 \mathrm{E}-05$ & $1.05 \mathrm{E}-05$ & $1.58 \mathrm{E}-07$ & $6.31 \mathrm{E}-09$ \\
\hline Th-228 & $5.18 \mathrm{E}-07$ & $3.45 \mathrm{E}-07$ & $5.18 \mathrm{E}-09$ & $2.07 \mathrm{E}-10$ \\
\hline Th-231 & 2.98E-06 & $1.99 \mathrm{E}-06$ & $2.98 \mathrm{E}-08$ & 1.19E-09 \\
\hline Th-232 & 3.14E-05 & $2.10 \mathrm{E}-05$ & $3.14 \mathrm{E}-07$ & $1.26 \mathrm{E}-08$ \\
\hline Th-234 & $3.82 \mathrm{E}-03$ & $2.55 \mathrm{E}-03$ & $3.82 \mathrm{E}-05$ & $1.53 \mathrm{E}-06$ \\
\hline $\mathrm{U}-235$ & 2.97E-06 & $1.98 \mathrm{E}-06$ & 2.97E-08 & $1.19 \mathrm{E}-09$ \\
\hline U-238 & $3.82 \mathrm{E}-03$ & $2.55 \mathrm{E}-03$ & 3.82E-05 & $1.53 \mathrm{E}-06$ \\
\hline$Y-90$ & $2.31 \mathrm{E}-03$ & $1.54 \mathrm{E}-03$ & 2.31E-05 & 9.22E-07 \\
\hline $\mathrm{Zr}-95$ & 2.33E-05 & $1.56 \mathrm{E}-05$ & $2.33 \mathrm{E}-07$ & $9.34 \mathrm{E}-09$ \\
\hline Total & $3.26 \mathrm{E}-02$ & $2.18 \mathrm{E}-02$ & $3.26 \mathrm{E}-04$ & $1.31 \mathrm{E}-05$ \\
\hline
\end{tabular}


TABLE B.4.21 Low-Level Waste, Case 19: Hanford

\begin{tabular}{|c|c|c|c|c|}
\hline \multicolumn{5}{|c|}{$\begin{array}{l}\text { Function: Incineration } \\
\text { Waste Stream: Combustible }\end{array}$} \\
\hline \multirow[b]{2}{*}{ Nuclide } & \multicolumn{4}{|c|}{ Release (Ci) } \\
\hline & AL7 & IEX & IFF & EQ7 \\
\hline Ac- 228 & $2.60 \mathrm{E}-08$ & $1.04 \mathrm{E}-11$ & $2.60 \mathrm{E}-10$ & $1.73 E-08$ \\
\hline Am-241 & 9.27E-08 & $3.71 E-11$ & $9.27 \mathrm{E}-10$ & $6.18 E-08$ \\
\hline $\mathrm{Bi}-212$ & 4.34E-09 & $1.74 \mathrm{E}-12$ & $4.34 E-11$ & $2.90 \mathrm{E}-09$ \\
\hline $\mathrm{Ce}-144$ & $8.43 E-05$ & 3.37E-08 & 8.43E-07 & $5.62 \mathrm{E}-05$ \\
\hline $\mathrm{Cm}-242$ & 8.40E-09 & $3.36 \mathrm{E}-12$ & $8.40 \mathrm{E}-11$ & $5.60 \mathrm{E}-09$ \\
\hline $\mathrm{Cm}-244$ & $3.00 \mathrm{E}-09$ & $1.20 \mathrm{E}-12$ & $3.00 \mathrm{E}-11$ & $2.00 \mathrm{E}-09$ \\
\hline $\mathrm{Co}-58$ & 1.91E-05 & $7.65 \mathrm{E}-09$ & $1.91 \mathrm{E}-07$ & $1.28 \mathrm{E}-05$ \\
\hline $\mathrm{Co}-60$ & $3.93 \mathrm{E}-03$ & $1.57 \mathrm{E}-06$ & $3.93 E-05$ & 2.62E-03 \\
\hline Cr-51 & 7.49E-06 & $3.00 \mathrm{E}-09$ & $7.49 \mathrm{E}-08$ & $4.99 \mathrm{E}-06$ \\
\hline Cs-134 & 2.93E-05 & $1.17 \mathrm{E}-08$ & $2.93 \mathrm{E}-07$ & $1.95 \mathrm{E}-05$ \\
\hline Cs-137 & $6.83 \mathrm{E}-03$ & $2.73 \mathrm{E}-06$ & $6.83 \mathrm{E}-05$ & 4.55E-03 \\
\hline Eu-152 & 3.07E-08 & $1.23 \mathrm{E}-11$ & 3.07E-10 & 2.05E-08 \\
\hline Eu-154 & $5.27 \mathrm{E}-06$ & 2.11E-09 & $5.27 \mathrm{E}-08$ & $3.51 \mathrm{E}-06$ \\
\hline Eu-155 & 4.18E-06 & 1.67E-09 & $4.18 \mathrm{E}-08$ & $2.78 \mathrm{E}-06$ \\
\hline $\mathrm{Fe}-55$ & $1.48 \mathrm{E}-04$ & $5.90 \mathrm{E}-08$ & $1.48 \mathrm{E}-06$ & $9.84 \mathrm{E}-05$ \\
\hline Fe-59 & $4.81 \mathrm{E}-07$ & $1.92 \mathrm{E}-10$ & 4.81E-09 & 3.21E-07 \\
\hline $\mathrm{Mn}-54$ & $1.43 E-05$ & 5.70E-09 & $1.43 \mathrm{E}-07$ & $9.50 \mathrm{E}-06$ \\
\hline $\mathrm{Ni}-59$ & $6.87 \mathrm{E}-07$ & $2.75 \mathrm{E}-10$ & $6.87 \mathrm{E}-09$ & 4.58E-07 \\
\hline $\mathrm{Ni}-63$ & 1.01E-04 & $4.02 E-08$ & $1.01 \mathrm{E}-06$ & $6.70 \mathrm{E}-05$ \\
\hline P-32 & $7.87 \mathrm{E}-03$ & $3.15 \mathrm{E}-06$ & $7.87 \mathrm{E}-05$ & $5.25 \mathrm{E}-03$ \\
\hline $\mathrm{Pb}-212$ & 4.34E-09 & $1.74 \mathrm{E}-12$ & $4.34 \mathrm{E}-11$ & $2.90 \mathrm{E}-09$ \\
\hline Pm-147 & $2.06 \mathrm{E}-04$ & 8.23E-08 & $2.06 \mathrm{E}-06$ & 1.37E-04 \\
\hline Pr-144 & 8.43E-05 & 3.37E-08 & 8.43E-07 & 5.62E-05 \\
\hline Pr-144m & 1.01E-06 & $4.05 \mathrm{E}-10$ & $1.01 E-08$ & $6.75 \mathrm{E}-07$ \\
\hline Pu-238 & $6.73 E-06$ & $2.69 \mathrm{E}-09$ & $6.73 E-08$ & 4.49E-06 \\
\hline Pu-239 & $9.14 \mathrm{E}-08$ & $3.66 \mathrm{E}-11$ & $9.14 \mathrm{E}-10$ & $6.09 \mathrm{E}-08$ \\
\hline Pu-240 & $1.36 \mathrm{E}-07$ & $5.43 \mathrm{E}-11$ & $1.36 \mathrm{E}-09$ & $9.05 \mathrm{E}-08$ \\
\hline Pu-241 & $2.16 \mathrm{E}-05$ & 8.62E-09 & $2.16 \mathrm{E}-07$ & $1.44 \mathrm{E}-05$ \\
\hline $\mathrm{Ra}-224$ & 4.34E-09 & $1.74 \mathrm{E}-12$ & $4.34 \mathrm{E}-11$ & $2.90 \mathrm{E}-09$ \\
\hline $\mathrm{Ra}-228$ & $2.60 \mathrm{E}-08$ & $1.04 \mathrm{E}-11$ & $2.60 \mathrm{E}-10$ & $1.73 \mathrm{E}-08$ \\
\hline Ru-106 & $2.52 \mathrm{E}-05$ & $1.01 \mathrm{E}-08$ & $2.52 \mathrm{E}-07$ & $1.68 \mathrm{E}-05$ \\
\hline S-35 & $6.77 \mathrm{E}-03$ & 2.71E-06 & $6.77 \mathrm{E}-05$ & $4.51 \mathrm{E}-03$ \\
\hline $\mathrm{Sb}-125$ & $7.23 \mathrm{E}-06$ & $2.89 \mathrm{E}-09$ & $7.23 \mathrm{E}-08$ & $4.82 \mathrm{E}-06$ \\
\hline Sm-151 & 2.01E-06 & $8.04 \mathrm{E}-10$ & $2.01 \mathrm{E}-08$ & $1.34 \mathrm{E}-06$ \\
\hline Sr-90 & 2.58E-04 & $1.03 \mathrm{E}-07$ & $2.58 \mathrm{E}-06$ & $1.72 \mathrm{E}-04$ \\
\hline Tc-99 & $4.61 \mathrm{E}-08$ & $1.84 \mathrm{E}-11$ & $4.61 \mathrm{E}-10$ & $3.07 \mathrm{E}-08$ \\
\hline $\mathrm{Te}-125 \mathrm{~m}$ & $1.77 \mathrm{E}-06$ & $7.06 \mathrm{E}-10$ & $1.77 \mathrm{E}-08$ & $1.18 \mathrm{E}-06$ \\
\hline Th-228 & 4.34E-09 & $1.74 \mathrm{E}-12$ & $4.34 \mathrm{E}-11$ & $2.90 \mathrm{E}-09$ \\
\hline$T h-231$ & $2.50 \mathrm{E}-08$ & $1.00 \mathrm{E}-11$ & $2.50 \mathrm{E}-10$ & 1.67E-08 \\
\hline Th-232 & $1.80 \mathrm{E}-03$ & $7.19 \mathrm{E}-07$ & $1.80 \mathrm{E}-05$ & $1.20 \mathrm{E}-03$ \\
\hline Th-234 & $3.20 \mathrm{E}-05$ & $1.28 \mathrm{E}-08$ & $3.20 \mathrm{E}-07$ & 2.14E-05 \\
\hline U-235 & $2.49 \mathrm{E}-08$ & $9.96 \mathrm{E}-12$ & $2.49 \mathrm{E}-10$ & $1.66 \mathrm{E}-08$ \\
\hline U-238 & $2.46 \mathrm{E}-03$ & 9.84E-07 & $2.46 \mathrm{E}-05$ & $1.64 \mathrm{E}-03$ \\
\hline Y-90 & $2.58 \mathrm{E}-04$ & $1.03 \mathrm{E}-07$ & $2.58 \mathrm{E}-06$ & $1.72 E-04$ \\
\hline $\mathrm{Zr}-95$ & 5.84E-07 & $2.34 \mathrm{E}-10$ & $5.84 \mathrm{E}-09$ & $3.89 \mathrm{E}-07$ \\
\hline Total & $3.10 \mathrm{E}-02$ & $1.24 \mathrm{E}-05$ & $3.10 \mathrm{E}-04$ & $2.07 \mathrm{E}-02$ \\
\hline
\end{tabular}


TABLE B.4.22 Low-Level Waste, Case 19: Idaho National Engineering Laboratory

Function: $\alpha$-Incineration

Waste Stream: Combustible

Release (Ci)

\begin{tabular}{lllll} 
& & & & \\
\cline { 2 - 5 } Nuclide & AL7 & EQ7 & IEX & IFF \\
\hline Ac-228 & $1.17 \mathrm{E}-07$ & $7.77 \mathrm{E}-08$ & $4.66 \mathrm{E}-11$ & $1.17 \mathrm{E}-09$ \\
Am-241 & $1.73 \mathrm{E}-07$ & $1.15 \mathrm{E}-07$ & $6.93 \mathrm{E}-11$ & $1.73 \mathrm{E}-09$ \\
Bi-212 & $1.95 \mathrm{E}-08$ & $1.30 \mathrm{E}-08$ & $7.80 \mathrm{E}-12$ & $1.95 \mathrm{E}-10$ \\
$\mathrm{Cm}-242$ & $2.43 \mathrm{E}-06$ & $1.62 \mathrm{E}-06$ & $9.70 \mathrm{E}-10$ & $2.43 \mathrm{E}-08$ \\
$\mathrm{Cm}-244$ & $8.66 \mathrm{E}-07$ & $5.77 \mathrm{E}-07$ & $3.46 \mathrm{E}-10$ & $8.66 \mathrm{E}-09$ \\
Pb-212 & $1.95 \mathrm{E}-08$ & $1.30 \mathrm{E}-08$ & $7.80 \mathrm{E}-12$ & $1.95 \mathrm{E}-10$ \\
Pu-238 & $1.13 \mathrm{E}-04$ & $7.56 \mathrm{E}-05$ & $4.54 \mathrm{E}-08$ & $1.13 \mathrm{E}-06$ \\
Pu-239 & $8.66 \mathrm{E}-06$ & $5.77 \mathrm{E}-06$ & $3.46 \mathrm{E}-09$ & $8.66 \mathrm{E}-08$ \\
Pu-240 & $3.03 \mathrm{E}-05$ & $2.02 \mathrm{E}-05$ & $1.21 \mathrm{E}-08$ & $3.03 \mathrm{E}-07$ \\
Pu-241 & $4.18 \mathrm{E}-03$ & $2.78 \mathrm{E}-03$ & $1.67 \mathrm{E}-06$ & $4.18 \mathrm{E}-05$ \\
Ra-224 & $1.95 \mathrm{E}-08$ & $1.30 \mathrm{E}-08$ & $7.80 \mathrm{E}-12$ & $1.95 \mathrm{E}-10$ \\
Ra-228 & $1.17 \mathrm{E}-07$ & $7.77 \mathrm{E}-08$ & $4.66 \mathrm{E}-11$ & $1.17 \mathrm{E}-09$ \\
Th-228 & $1.95 \mathrm{E}-08$ & $1.30 \mathrm{E}-08$ & $7.80 \mathrm{E}-12$ & $1.95 \mathrm{E}-10$ \\
Th-231 & $1.12 \mathrm{E}-07$ & $7.48 \mathrm{E}-08$ & $4.49 \mathrm{E}-11$ & $1.12 \mathrm{E}-09$ \\
Th-232 & $1.18 \mathrm{E}-06$ & $7.88 \mathrm{E}-07$ & $4.73 \mathrm{E}-10$ & $1.18 \mathrm{E}-08$ \\
Th-234 & $1.44 \mathrm{E}-04$ & $9.59 \mathrm{E}-05$ & $5.75 \mathrm{E}-08$ & $1.44 \mathrm{E}-06$ \\
U-235 & $1.12 \mathrm{E}-07$ & $7.45 \mathrm{E}-08$ & $4.47 \mathrm{E}-11$ & $1.12 \mathrm{E}-09$ \\
U-238 & $1.44 \mathrm{E}-04$ & $9.59 \mathrm{E}-05$ & $5.75 \mathrm{E}-08$ & $1.44 \mathrm{E}-06$ \\
Total & $4.62 \mathrm{E}-03$ & $3.08 \mathrm{E}-03$ & $1.85 \mathrm{E}-06$ & $4.62 \mathrm{E}-05$ \\
\hline & & & &
\end{tabular}


TABLE B.4.23 Low-Level Waste, Case 19: Idaho National Engineering Laboratory

Function: Incineration

Waste Stream: Combustible

Release (Ci)

\begin{tabular}{|c|c|c|c|c|}
\hline Nuclide & $\mathrm{AL7}$ & $\mathrm{EQ7}$ & IEX & IFF \\
\hline Ac-228 & 7.92E-05 & $5.28 \mathrm{E}-05$ & 3.17E-08 & 7.92E-07 \\
\hline Am-241 & 5.12E-06 & 3.42E-06 & 2.05E-09 & $5.12 \mathrm{E}-08$ \\
\hline $\mathrm{Bi}-212$ & 1.32E-05 & 8.83E-06 & $5.30 \mathrm{E}-09$ & $1.32 \mathrm{E}-07$ \\
\hline Ce-144 & 2.82E-03 & $1.88 \mathrm{E}-03$ & $1.13 E-06$ & 2.82E-05 \\
\hline $\mathrm{Cm}-242$ & $2.86 \mathrm{E}-05$ & $1.91 \mathrm{E}-05$ & $1.14 \mathrm{E}-08$ & $2.86 \mathrm{E}-07$ \\
\hline $\mathrm{Cm}-244$ & $1.02 \mathrm{E}-05$ & $6.81 \mathrm{E}-06$ & $4.09 \mathrm{E}-09$ & $1.02 \mathrm{E}-07$ \\
\hline Co-58 & 2.47E-04 & $1.65 \mathrm{E}-04$ & $9.88 \mathrm{E}-08$ & 2.47E-06 \\
\hline Co- 60 & $1.98 \mathrm{E}-03$ & $1.32 \mathrm{E}-03$ & 7.94E-07 & $1.98 \mathrm{E}-05$ \\
\hline Cr-51 & $9.66 \mathrm{E}-05$ & $6.44 \mathrm{E}-05$ & 3.87E-08 & $9.66 \mathrm{E}-07$ \\
\hline Cs-134 & 9.79E-04 & 6.52E-04 & $3.91 \mathrm{E}-07$ & 9.79E-06 \\
\hline Cs-137 & $9.03 \mathrm{E}-03$ & $6.02 \mathrm{E}-03$ & 3.61E-06 & 9.03E-05 \\
\hline Eu-152 & $1.03 \mathrm{E}-06$ & $6.84 \mathrm{E}-07$ & $4.11 \mathrm{E}-10$ & $1.03 \mathrm{E}-08$ \\
\hline Eu-154 & $1.76 \mathrm{E}-04$ & 1.17E-04 & 7.04E-08 & $1.76 \mathrm{E}-06$ \\
\hline Eu-155 & $1.40 \mathrm{E}-04$ & $9.31 \mathrm{E}-05$ & $5.58 \mathrm{E}-08$ & $1.40 \mathrm{E}-06$ \\
\hline $\mathrm{Fe}-55$ & 6.87E-04 & $4.58 \mathrm{E}-04$ & 2.75E-07 & $6.87 \mathrm{E}-06$ \\
\hline $\mathrm{Fe}-59$ & $6.21 \mathrm{E}-06$ & 4.14E-06 & $2.48 \mathrm{E}-09$ & $6.21 \mathrm{E}-08$ \\
\hline $\mathrm{Mn}-54$ & $1.84 \mathrm{E}-04$ & $1.23 \mathrm{E}-04$ & $7.36 \mathrm{E}-08$ & $1.84 \mathrm{E}-06$ \\
\hline $\mathrm{Ni}-59$ & 8.87E-06 & 5.91E-06 & $3.55 \mathrm{E}-09$ & $8.87 \mathrm{E}-08$ \\
\hline $\mathrm{Ni}-63$ & $1.36 \mathrm{E}-03$ & $9.05 \mathrm{E}-04$ & 5.43E-07 & $1.36 \mathrm{E}-05$ \\
\hline $\mathrm{Pb}-212$ & 1.32E-05 & 8.83E-06 & $5.30 \mathrm{E}-09$ & $1.32 \mathrm{E}-07$ \\
\hline $\mathrm{Pm}-147$ & $6.88 \mathrm{E}-03$ & $4.58 \mathrm{E}-03$ & $2.75 \mathrm{E}-06$ & $6.88 \mathrm{E}-05$ \\
\hline Pr-144 & $2.82 \mathrm{E}-03$ & $1.88 \mathrm{E}-03$ & $1.13 \mathrm{E}-06$ & 2.82E-05 \\
\hline Pr-144m & 3.39E-05 & $2.26 \mathrm{E}-05$ & 1.35E-08 & $3.39 \mathrm{E}-07$ \\
\hline $\mathrm{Pu}-238$ & $1.55 \mathrm{E}-03$ & $1.03 \mathrm{E}-03$ & $6.20 \mathrm{E}-07$ & $1.55 \mathrm{E}-05$ \\
\hline Pu-239 & $1.04 \mathrm{E}-04$ & $6.95 \mathrm{E}-05$ & 4.17E-08 & $1.04 \mathrm{E}-06$ \\
\hline Pu-240 & 3.59E-04 & 2.39E-04 & $1.44 \mathrm{E}-07$ & $3.59 \mathrm{E}-06$ \\
\hline Pu-241 & 4.95E-02 & $3.30 \mathrm{E}-02$ & $1.98 \mathrm{E}-05$ & 4.95E-04 \\
\hline $\mathrm{Ra}-224$ & $1.32 \mathrm{E}-05$ & 8.83E-06 & $5.30 \mathrm{E}-09$ & $1.32 \mathrm{E}-07$ \\
\hline $\mathrm{Ra}-228$ & 7.92E-05 & $5.28 \mathrm{E}-05$ & 3.17E-08 & $7.92 \mathrm{E}-07$ \\
\hline Ru-106 & 8.42E-04 & 5.61E-04 & 3.37E-07 & 8.42E-06 \\
\hline $\mathrm{Sb}-125$ & 2.42E-04 & $1.61 \mathrm{E}-04$ & $9.67 \mathrm{E}-08$ & 2.42E-06 \\
\hline Sm-151 & $6.72 \mathrm{E}-05$ & $4.48 \mathrm{E}-05$ & $2.69 \mathrm{E}-08$ & $6.72 \mathrm{E}-07$ \\
\hline$S_{r}-90$ & 8.62E-03 & $5.75 \mathrm{E}-03$ & $3.45 \mathrm{E}-06$ & $8.62 \mathrm{E}-05$ \\
\hline Tc-99 & $1.54 \mathrm{E}-06$ & $1.03 \mathrm{E}-06$ & $6.16 \mathrm{E}-10$ & $1.54 \mathrm{E}-08$ \\
\hline $\mathrm{Te}-125 \mathrm{~m}$ & $5.90 \mathrm{E}-05$ & 3.93E-05 & $2.36 \mathrm{E}-08$ & $5.90 \mathrm{E}-07$ \\
\hline Th-228 & $1.32 \mathrm{E}-05$ & 8.83E-06 & $5.30 \mathrm{E}-09$ & $1.32 \mathrm{E}-07$ \\
\hline Th-231 & 7.62E-05 & 5.08E-05 & 3.05E-08 & 7.62E-07 \\
\hline Th-232 & 8.03E-04 & $5.36 \mathrm{E}-04$ & 3.21E-07 & 8.03E-06 \\
\hline Th-234 & $9.77 \mathrm{E}-02$ & $6.51 \mathrm{E}-02$ & $3.91 \mathrm{E}-05$ & 9.77E-04 \\
\hline U-235 & $7.59 \mathrm{E}-05$ & $5.06 \mathrm{E}-05$ & $3.04 \mathrm{E}-08$ & $7.59 \mathrm{E}-07$ \\
\hline U-238 & $9.77 \mathrm{E}-02$ & $6.51 \mathrm{E}-02$ & $3.91 \mathrm{E}-05$ & 9.77E-04 \\
\hline$Y-90$ & $8.62 \mathrm{E}-03$ & $5.75 \mathrm{E}-03$ & 3.45E-06 & $8.62 \mathrm{E}-05$ \\
\hline $\mathrm{Zr}-95$ & $7.54 \mathrm{E}-06$ & 5.02E-06 & 3.01E-09 & $7.54 \mathrm{E}-08$ \\
\hline Total & $2.94 \mathrm{E}-01$ & $1.96 \mathrm{E}-01$ & $1.18 \mathrm{E}-04$ & $2.94 \mathrm{E}-03$ \\
\hline
\end{tabular}


TABLE B.4.24 Low-Level Waste, Case 19: Oak Ridge National Laboratory

Function: Incineration

Waste Stream: Combustible

\begin{tabular}{|c|c|c|c|}
\hline \multirow[b]{2}{*}{ Nuclide } & \multicolumn{3}{|c|}{ Release (Ci) } \\
\hline & EQ7 & IEX & IFF \\
\hline Ac-228 & $1.69 \mathrm{E}-07$ & $1.01 \mathrm{E}-10$ & $2.17 \mathrm{E}-11$ \\
\hline Am-241 & $3.86 \mathrm{E}-07$ & $2.31 \mathrm{E}-10$ & $4.96 \mathrm{E}-11$ \\
\hline $\mathrm{Bi}-212$ & $2.82 \mathrm{E}-08$ & $1.69 \mathrm{E}-11$ & $3.63 E-12$ \\
\hline $\mathrm{Ce}-144$ & $3.53 \mathrm{E}-04$ & $2.12 \mathrm{E}-07$ & $4.54 \mathrm{E}-08$ \\
\hline Co-58 & $9.02 \mathrm{E}-05$ & $5.41 \mathrm{E}-08$ & $1.16 \mathrm{E}-08$ \\
\hline Co- 60 & $2.74 \mathrm{E}-04$ & $1.64 \mathrm{E}-07$ & $3.52 \mathrm{E}-08$ \\
\hline $\mathrm{Cr}-51$ & $5.36 \mathrm{E}-07$ & $3.22 \mathrm{E}-10$ & $6.89 \mathrm{E}-11$ \\
\hline Cs-134 & $3.22 \mathrm{E}-04$ & $1.93 \mathrm{E}-07$ & $4.14 \mathrm{E}-08$ \\
\hline Cs-137 & $1.39 \mathrm{E}-03$ & 8.37E-07 & $1.79 \mathrm{E}-07$ \\
\hline Eu-152 & $1.29 \mathrm{E}-07$ & $7.72 \mathrm{E}-11$ & $1.65 \mathrm{E}-11$ \\
\hline Eu-154 & $2.21 \mathrm{E}-05$ & $1.32 \mathrm{E}-08$ & $2.84 \mathrm{E}-09$ \\
\hline Eu-155 & $1.75 \mathrm{E}-05$ & $1.05 \mathrm{E}-08$ & $2.25 \mathrm{E}-09$ \\
\hline $\mathrm{Fe}-55$ & $3.81 \mathrm{E}-06$ & $2.29 \mathrm{E}-09$ & $4.90 \mathrm{E}-10$ \\
\hline $\mathrm{Fe}-59$ & $3.44 \mathrm{E}-08$ & $2.07 \mathrm{E}-11$ & $4.43 \mathrm{E}-12$ \\
\hline $\mathrm{Mn}-54$ & $9.73 E-05$ & $5.84 \mathrm{E}-08$ & $1.25 \mathrm{E}-08$ \\
\hline $\mathrm{Ni}-59$ & $4.92 E-08$ & $2.95 E-11$ & $6.32 \mathrm{E}-12$ \\
\hline $\mathrm{Ni}-63$ & $1.91 \mathrm{E}-05$ & $1.15 \mathrm{E}-08$ & $2.46 \mathrm{E}-09$ \\
\hline $\mathrm{Pb}-212$ & $2.82 E-08$ & $1.69 \mathrm{E}-11$ & $3.63 E-12$ \\
\hline Pm-147 & 8.62E-04 & $5.17 \mathrm{E}-07$ & $1.11 \mathrm{E}-07$ \\
\hline $\operatorname{Pr}-144$ & $3.53 \mathrm{E}-04$ & $2.12 E-07$ & $4.54 \mathrm{E}-08$ \\
\hline Pr-144m & $4.24 \mathrm{E}-06$ & $2.55 \mathrm{E}-09$ & $5.46 \mathrm{E}-10$ \\
\hline Pu-238 & $2.66 \mathrm{E}-05$ & $1.59 \mathrm{E}-08$ & $3.41 \mathrm{E}-09$ \\
\hline Pu-239 & $2.57 \mathrm{E}-07$ & $1.54 \mathrm{E}-10$ & $3.31 \mathrm{E}-11$ \\
\hline Pu-240 & $1.29 \mathrm{E}-07$ & $7.72 \mathrm{E}-11$ & $1.65 \mathrm{E}-11$ \\
\hline Pu-241 & $2.97 \mathrm{E}-05$ & $1.78 \mathrm{E}-08$ & $3.82 \mathrm{E}-09$ \\
\hline $\mathrm{Ra}-224$ & $2.82 \mathrm{E}-08$ & $1.69 \mathrm{E}-11$ & $3.63 \mathrm{E}-12$ \\
\hline $\mathrm{Ra}-228$ & $1.69 \mathrm{E}-07$ & $1.01 \mathrm{E}-10$ & $2.17 \mathrm{E}-11$ \\
\hline Ru-106 & $1.05 E-04$ & $6.33 \mathrm{E}-08$ & $1.36 \mathrm{E}-08$ \\
\hline Sb-125 & $3.03 \mathrm{E}-05$ & $1.82 \mathrm{E}-08$ & $3.89 \mathrm{E}-09$ \\
\hline Sm-151 & $8.42 \mathrm{E}-06$ & $5.05 \mathrm{E}-09$ & $1.08 \mathrm{E}-09$ \\
\hline Sr-90 & $1.20 \mathrm{E}-03$ & $7.21 \mathrm{E}-07$ & $1.54 \mathrm{E}-07$ \\
\hline Tc-99 & $1.90 \mathrm{E}-06$ & $1.14 \mathrm{E}-09$ & $2.45 \mathrm{E}-10$ \\
\hline $\mathrm{Te}-125 \mathrm{~m}$ & $7.39 \mathrm{E}-06$ & $4.44 \mathrm{E}-09$ & $9.51 E-10$ \\
\hline Th-228 & $2.82 \mathrm{E}-08$ & $1.69 \mathrm{E}-11$ & $3.63 \mathrm{E}-12$ \\
\hline Th-231 & $1.63 \mathrm{E}-07$ & $9.75 \mathrm{E}-11$ & $2.09 E-11$ \\
\hline Th-232 & $1.71 \mathrm{E}-06$ & $1.03 E-09$ & $2.20 \mathrm{E}-10$ \\
\hline Th-234 & $2.08 \mathrm{E}-04$ & $1.25 \mathrm{E}-07$ & $2.68 \mathrm{E}-08$ \\
\hline U-235 & $1.62 \mathrm{E}-07$ & $9.72 E-11$ & $2.08 \mathrm{E}-11$ \\
\hline U-238 & $2.19 \mathrm{E}-04$ & $1.31 \mathrm{E}-07$ & $2.81 \mathrm{E}-08$ \\
\hline$Y-90$ & $1.20 \mathrm{E}-03$ & $7.21 \mathrm{E}-07$ & $1.54 \mathrm{E}-07$ \\
\hline $\mathrm{Zr}-95$ & $4.18 \mathrm{E}-08$ & $2.51 \mathrm{E}-11$ & $5.38 \mathrm{E}-12$ \\
\hline Total & $6.85 \mathrm{E}-03$ & $4.11 \mathrm{E}-06$ & $8.81 E-07$ \\
\hline
\end{tabular}


TABLE B.4.25 Low-Level Waste, Case 19: Savannah River Site

Function: Incineration

Waste Stream: Combustible

\begin{tabular}{|c|c|c|c|c|}
\hline \multirow[b]{2}{*}{ Nuclide } & \multicolumn{4}{|c|}{ Release $(\mathrm{Ci})$} \\
\hline & AL7 & IEX & IFF & EQ7 \\
\hline Ac-228 & $3.10 \mathrm{E}-06$ & $1.24 \mathrm{E}-09$ & $3.10 \mathrm{E}-08$ & $2.07 \mathrm{E}-06$ \\
\hline Am-241 & $8.24 \mathrm{E}-07$ & $3.29 \mathrm{E}-10$ & 8.24E-09 & $5.49 \mathrm{E}-07$ \\
\hline $\mathrm{Bi}-212$ & $5.18 \mathrm{E}-07$ & $2.07 \mathrm{E}-10$ & $5.18 \mathrm{E}-09$ & $3.45 \mathrm{E}-07$ \\
\hline Ce-144 & 7.54E-04 & $3.01 \mathrm{E}-07$ & $7.54 \mathrm{E}-06$ & $5.02 \mathrm{E}-04$ \\
\hline Co-58 & 7.65E-04 & $3.06 \mathrm{E}-07$ & 7.65E-06 & $5.10 \mathrm{E}-04$ \\
\hline Co-60 & $6.01 \mathrm{E}-03$ & $2.40 \mathrm{E}-06$ & $6.01 \mathrm{E}-05$ & $4.01 \mathrm{E}-03$ \\
\hline $\mathrm{Cr}-51$ & 2.99E-04 & $1.20 \mathrm{E}-07$ & $2.99 \mathrm{E}-06$ & $2.00 \mathrm{E}-04$ \\
\hline Cs-134 & 2.62E-04 & $1.05 \mathrm{E}-07$ & 2.62E-06 & $1.75 \mathrm{E}-04$ \\
\hline Cs-137 & $2.42 \mathrm{E}-03$ & $9.66 \mathrm{E}-07$ & 2.42E-05 & $1.61 \mathrm{E}-03$ \\
\hline Eu-152 & 2.75E-07 & $1.10 \mathrm{E}-10$ & 2.75E-09 & $1.83 \mathrm{E}-07$ \\
\hline Eu-154 & 4.71E-05 & $1.88 \mathrm{E}-08$ & 4.71E-07 & $3.14 \mathrm{E}-05$ \\
\hline Eu-155 & 3.73E-05 & $1.49 \mathrm{E}-08$ & 3.73E-07 & $2.49 \mathrm{E}-05$ \\
\hline $\mathrm{Fe}-55$ & 2.13E-03 & $8.51 \mathrm{E}-07$ & 2.13E-05 & $1.42 \mathrm{E}-03$ \\
\hline $\mathrm{Fe}-59$ & $1.92 \mathrm{E}-05$ & 7.69E-09 & 1.92E-07 & $1.28 \mathrm{E}-05$ \\
\hline Mn-54 & $5.70 \mathrm{E}-04$ & $2.28 \mathrm{E}-07$ & $5.70 \mathrm{E}-06$ & 3.80E-04 \\
\hline $\mathrm{Ni}-59$ & $2.75 \mathrm{E}-05$ & $1.10 \mathrm{E}-08$ & 2.75E-07 & $1.83 \mathrm{E}-05$ \\
\hline $\mathrm{Ni}-63$ & 3.93E-03 & $1.57 \mathrm{E}-06$ & 3.93E-05 & 2.62E-03 \\
\hline $\mathrm{Pb}-212$ & 5.18E-07 & $2.07 \mathrm{E}-10$ & $5.18 \mathrm{E}-09$ & 3.45E-07 \\
\hline $\mathrm{Pm}-147$ & $1.84 \mathrm{E}-03$ & 7.36E-07 & $1.84 \mathrm{E}-05$ & $1.23 \mathrm{E}-03$ \\
\hline Pr-144 & 7.54E-04 & $3.01 \mathrm{E}-07$ & $7.54 \mathrm{E}-06$ & $5.02 \mathrm{E}-04$ \\
\hline $\operatorname{Pr}-144 m$ & $9.06 \mathrm{E}-06$ & $3.62 \mathrm{E}-09$ & $9.06 \mathrm{E}-08$ & $6.04 \mathrm{E}-06$ \\
\hline Pu-238 & $5.67 \mathrm{E}-05$ & $2.27 \mathrm{E}-08$ & 5.67E-07 & $3.78 \mathrm{E}-05$ \\
\hline Pu-239 & 5.49E-07 & $2.20 \mathrm{E}-10$ & $5.49 \mathrm{E}-09$ & 3.66E-07 \\
\hline $\mathrm{Pu}-240$ & 2.75E-07 & $1.10 \mathrm{E}-10$ & 2.75E-09 & $1.83 \mathrm{E}-07$ \\
\hline $\mathrm{Pu}-241$ & $6.34 \mathrm{E}-05$ & $2.54 \mathrm{E}-08$ & $6.34 \mathrm{E}-07$ & 4.23E-05 \\
\hline $\mathrm{Ra}-224$ & $5.18 \mathrm{E}-07$ & 2.07E-10 & $5.18 \mathrm{E}-09$ & 3.45E-07 \\
\hline Ra-228 & $3.10 \mathrm{E}-06$ & $1.24 \mathrm{E}-09$ & $3.10 \mathrm{E}-08$ & 2.07E-06 \\
\hline $\mathrm{Ru}-106$ & $2.25 \mathrm{E}-04$ & $9.00 \mathrm{E}-08$ & 2.25E-06 & $1.50 \mathrm{E}-04$ \\
\hline Sb-125 & $6.47 \mathrm{E}-05$ & $2.59 \mathrm{E}-08$ & $6.47 \mathrm{E}-07$ & 4.31E-05 \\
\hline Sm-151 & $1.80 \mathrm{E}-05$ & $7.19 \mathrm{E}-09$ & $1.80 \mathrm{E}-07$ & $1.20 \mathrm{E}-05$ \\
\hline Sr -90 & $2.31 \mathrm{E}-03$ & $9.22 \mathrm{E}-07$ & $2.31 \mathrm{E}-05$ & $1.54 \mathrm{E}-03$ \\
\hline Tc-99 & 4.12E-07 & $1.65 \mathrm{E}-10$ & $4.12 \mathrm{E}-09$ & 2.75E-07 \\
\hline $\mathrm{Te}-125 \mathrm{~m}$ & $1.58 \mathrm{E}-05$ & $6.31 \mathrm{E}-09$ & $1.58 \mathrm{E}-07$ & $1.05 \mathrm{E}-05$ \\
\hline Th-228 & $5.18 \mathrm{E}-07$ & $2.07 \mathrm{E}-10$ & $5.18 \mathrm{E}-09$ & 3.45E-07 \\
\hline Th-231 & $2.98 \mathrm{E}-06$ & $1.19 \mathrm{E}-09$ & $2.98 \mathrm{E}-08$ & $1.99 \mathrm{E}-06$ \\
\hline Th-232 & $3.14 \mathrm{E}-05$ & $1.26 \mathrm{E}-08$ & $3.14 \mathrm{E}-07$ & $2.10 \mathrm{E}-05$ \\
\hline Th-234 & $3.82 \mathrm{E}-03$ & $1.53 \mathrm{E}-06$ & 3.82E-05 & $2.55 \mathrm{E}-03$ \\
\hline U-235 & 2.97E-06 & $1.19 \mathrm{E}-09$ & $2.97 \mathrm{E}-08$ & $1.98 \mathrm{E}-06$ \\
\hline U-238 & $3.82 \mathrm{E}-03$ & $1.53 \mathrm{E}-06$ & $3.82 \mathrm{E}-05$ & $2.55 \mathrm{E}-03$ \\
\hline$Y-90$ & $2.31 \mathrm{E}-03$ & $9.22 \mathrm{E}-07$ & $2.31 \mathrm{E}-05$ & $1.54 \mathrm{E}-03$ \\
\hline Zr-95 & 2.33E-05 & $9.34 \mathrm{E}-09$ & 2.33E-07 & $1.56 \mathrm{E}-05$ \\
\hline Total & $3.26 \mathrm{E}-02$ & $1.31 \mathrm{E}-05$ & $3.26 \mathrm{E}-04$ & $2.18 \mathrm{E}-02$ \\
\hline
\end{tabular}


TABLE B.4.26 Low-Level Waste, Case 21: Hanford

Function: $\alpha$-Incineration

Waste Stream: Combustible

\begin{tabular}{lllll}
\hline & \multicolumn{5}{c}{ Release (Ci) } \\
\cline { 2 - 5 } Nuclide & AL7 & IEX & IFF & EQ7 \\
\hline & & & \\
Ac-228 & $1.17 \mathrm{E}-07$ & $4.66 \mathrm{E}-11$ & $1.17 \mathrm{E}-09$ & $7.77 \mathrm{E}-08$ \\
Am-241 & $1.73 \mathrm{E}-07$ & $6.93 \mathrm{E}-11$ & $1.73 \mathrm{E}-09$ & $1.15 \mathrm{E}-07$ \\
$\mathrm{Bi}-212$ & $1.95 \mathrm{E}-08$ & $7.80 \mathrm{E}-12$ & $1.95 \mathrm{E}-10$ & $1.30 \mathrm{E}-08$ \\
$\mathrm{Cm}-242$ & $2.43 \mathrm{E}-06$ & $9.70 \mathrm{E}-10$ & $2.43 \mathrm{E}-08$ & $1.62 \mathrm{E}-06$ \\
$\mathrm{Cm}-244$ & $8.66 \mathrm{E}-07$ & $3.46 \mathrm{E}-10$ & $8.66 \mathrm{E}-09$ & $5.77 \mathrm{E}-07$ \\
$\mathrm{~Pb}-212$ & $1.95 \mathrm{E}-08$ & $7.80 \mathrm{E}-12$ & $1.95 \mathrm{E}-10$ & $1.30 \mathrm{E}-08$ \\
$\mathrm{Pu}-238$ & $1.13 \mathrm{E}-04$ & $4.54 \mathrm{E}-08$ & $1.13 \mathrm{E}-06$ & $7.56 \mathrm{E}-05$ \\
$\mathrm{Pu}-239$ & $8.66 \mathrm{E}-06$ & $3.46 \mathrm{E}-09$ & $8.66 \mathrm{E}-08$ & $5.77 \mathrm{E}-06$ \\
$\mathrm{Pu}-240$ & $3.03 \mathrm{E}-05$ & $1.21 \mathrm{E}-08$ & $3.03 \mathrm{E}-07$ & $2.02 \mathrm{E}-05$ \\
Pu-241 & $4.18 \mathrm{E}-03$ & $1.67 \mathrm{E}-06$ & $4.18 \mathrm{E}-05$ & $2.78 \mathrm{E}-03$ \\
Ra-224 & $1.95 \mathrm{E}-08$ & $7.80 \mathrm{E}-12$ & $1.95 \mathrm{E}-10$ & $1.30 \mathrm{E}-08$ \\
Ra-228 & $1.17 \mathrm{E}-07$ & $4.66 \mathrm{E}-11$ & $1.17 \mathrm{E}-09$ & $7.77 \mathrm{E}-08$ \\
Th-228 & $1.95 \mathrm{E}-08$ & $7.80 \mathrm{E}-12$ & $1.95 \mathrm{E}-10$ & $1.30 \mathrm{E}-08$ \\
Th-231 & $1.12 \mathrm{E}-07$ & $4.49 \mathrm{E}-11$ & $1.12 \mathrm{E}-09$ & $7.48 \mathrm{E}-08$ \\
Th-232 & $1.18 \mathrm{E}-06$ & $4.73 \mathrm{E}-10$ & $1.18 \mathrm{E}-08$ & $7.88 \mathrm{E}-07$ \\
Th-234 & $1.44 \mathrm{E}-04$ & $5.75 \mathrm{E}-08$ & $1.44 \mathrm{E}-06$ & $9.59 \mathrm{E}-05$ \\
U-235 & $1.12 \mathrm{E}-07$ & $4.47 \mathrm{E}-11$ & $1.12 \mathrm{E}-09$ & $7.45 \mathrm{E}-08$ \\
U-238 & $1.44 \mathrm{E}-04$ & $5.75 \mathrm{E}-08$ & $1.44 \mathrm{E}-06$ & $9.59 \mathrm{E}-05$ \\
Total & $4.62 \mathrm{E}-03$ & $1.85 \mathrm{E}-06$ & $4.62 \mathrm{E}-05$ & $3.08 \mathrm{E}-03$ \\
\hline & & & &
\end{tabular}


TABLE B.4.27 Low-Level Waste, Case 21: Hanford

Function: Incineration

Waste Stream: Combustible

Release (Ci)

\begin{tabular}{|c|c|c|c|c|}
\hline Nuclide & AL7 & IEX & IFF & EQ7 \\
\hline AC-228 & 8.23E-05 & $3.29 \mathrm{E}-08$ & 8.23E-07 & 5.49E-05 \\
\hline Am-241 & $6.04 \mathrm{E}-06$ & 2.42E-09 & $6.04 \mathrm{E}-08$ & 4.03E-06 \\
\hline $\mathrm{Bi}-212$ & $1.38 \mathrm{E}-05$ & 5.51E-09 & $1.38 \mathrm{E}-07$ & $9.18 \mathrm{E}-06$ \\
\hline Ce-144 & $3.66 \mathrm{E}-03$ & $1.46 \mathrm{E}-06$ & $3.66 \mathrm{E}-05$ & $2.44 \mathrm{E}-03$ \\
\hline $\mathrm{Cm}-242$ & $2.86 \mathrm{E}-05$ & $1.15 \mathrm{E}-08$ & $2.86 \mathrm{E}-07$ & $1.91 \mathrm{E}-05$ \\
\hline $\mathrm{Cm}-244$ & $1.02 \mathrm{E}-05$ & 4.09E-09 & $1.02 \mathrm{E}-07$ & $6.82 \mathrm{E}-06$ \\
\hline Co-58 & 1.03E-03 & 4.12E-07 & $1.03 \mathrm{E}-05$ & $6.87 \mathrm{E}-04$ \\
\hline Co- 60 & $1.20 \mathrm{E}-02$ & $4.80 \mathrm{E}-06$ & $1.20 \mathrm{E}-04$ & $7.99 \mathrm{E}-03$ \\
\hline $\mathrm{Cr}-51$ & $4.03 \mathrm{E}-04$ & $1.61 \mathrm{E}-07$ & 4.03E-06 & $2.69 \mathrm{E}-04$ \\
\hline Cs-134 & $1.27 \mathrm{E}-03$ & $5.08 \mathrm{E}-07$ & $1.27 \mathrm{E}-05$ & $8.46 \mathrm{E}-04$ \\
\hline Cs-137 & $1.84 \mathrm{E}-02$ & 7.36E-06 & $1.84 \mathrm{E}-04$ & $1.23 \mathrm{E}-02$ \\
\hline Eu-152 & $1.33 \mathrm{E}-06$ & 5.33E-10 & $1.33 \mathrm{E}-08$ & 8.88E-07 \\
\hline Eu-154 & $2.28 \mathrm{E}-04$ & $9.13 \mathrm{E}-08$ & $2.28 \mathrm{E}-06$ & 1.52E-04 \\
\hline Eu-155 & 1.81E-04 & $7.24 \mathrm{E}-08$ & $1.81 \mathrm{E}-06$ & 1.21E-04 \\
\hline $\mathrm{Fe}-55$ & $2.96 \mathrm{E}-03$ & $1.18 \mathrm{E}-06$ & $2.96 \mathrm{E}-05$ & $1.97 \mathrm{E}-03$ \\
\hline $\mathrm{Fe}-59$ & $2.59 \mathrm{E}-05$ & $1.04 \mathrm{E}-08$ & 2.59E-07 & $1.73 \mathrm{E}-05$ \\
\hline$M n-54$ & $7.68 \mathrm{E}-04$ & 3.07E-07 & $7.68 \mathrm{E}-06$ & 5.12E-04 \\
\hline $\mathrm{Ni}-59$ & $3.70 \mathrm{E}-05$ & $1.48 \mathrm{E}-08$ & 3.70E-07 & $2.47 \mathrm{E}-05$ \\
\hline $\mathrm{Ni}-63$ & $5.39 \mathrm{E}-03$ & $2.15 E-06$ & 5.39E-05 & $3.59 \mathrm{E}-03$ \\
\hline $\mathrm{Np}-237$ & $2.04 \mathrm{E}-07$ & $8.16 \mathrm{E}-11$ & 2.04E-09 & $1.36 \mathrm{E}-07$ \\
\hline P-32 & 8.01E-03 & $3.20 \mathrm{E}-06$ & 8.01E-05 & $5.34 \mathrm{E}-03$ \\
\hline $\mathrm{Pb}-212$ & $1.38 \mathrm{E}-05$ & 5.51E-09 & $1.38 \mathrm{E}-07$ & $9.18 \mathrm{E}-06$ \\
\hline Pm-147 & $8.92 \mathrm{E}-03$ & 3.57E-06 & $8.92 \mathrm{E}-05$ & $5.95 \mathrm{E}-03$ \\
\hline Pr-144 & $3.66 \mathrm{E}-03$ & $1.46 \mathrm{E}-06$ & $3.66 \mathrm{E}-05$ & $2.44 \mathrm{E}-03$ \\
\hline Pr-144m & 4.39E-05 & $1.76 \mathrm{E}-08$ & 4.39E-07 & 2.93E-05 \\
\hline$P u-238$ & $1.61 \mathrm{E}-03$ & $6.46 \mathrm{E}-07$ & $1.61 \mathrm{E}-05$ & $1.08 \mathrm{E}-03$ \\
\hline Pu-239 & $1.05 \mathrm{E}-04$ & $4.20 \mathrm{E}-08$ & $1.05 \mathrm{E}-06$ & 7.01E-05 \\
\hline Pu-240 & 3.59E-04 & $1.44 \mathrm{E}-07$ & $3.59 \mathrm{E}-06$ & $2.39 \mathrm{E}-04$ \\
\hline Pu-241 & $4.96 \mathrm{E}-02$ & $1.98 \mathrm{E}-05$ & $4.96 \mathrm{E}-04$ & 3.31E-02 \\
\hline $\mathrm{Ra}-224$ & $1.38 \mathrm{E}-05$ & $5.51 \mathrm{E}-09$ & 1.38E-07 & $9.18 \mathrm{E}-06$ \\
\hline Ra-228 & 8.23E-05 & $3.29 \mathrm{E}-08$ & 8.23E-07 & $5.49 \mathrm{E}-05$ \\
\hline Ru-106 & $1.09 \mathrm{E}-03$ & 4.37E-07 & $1.09 \mathrm{E}-05$ & $7.28 \mathrm{E}-04$ \\
\hline S-35 & $6.88 \mathrm{E}-03$ & $2.75 \mathrm{E}-06$ & $6.88 \mathrm{E}-05$ & $4.59 \mathrm{E}-03$ \\
\hline $\mathrm{Sb}-125$ & $3.14 \mathrm{E}-04$ & $1.25 \mathrm{E}-07$ & $3.14 E-06$ & 2.09E-04 \\
\hline Sm-151 & 8.72E-05 & $3.49 \mathrm{E}-08$ & 8.72E-07 & 5.81E-05 \\
\hline Sr-90 & 1.12E-02 & 4.49E-06 & 1.12E-04 & $7.49 \mathrm{E}-03$ \\
\hline Tc-99 & 2.27E-06 & $9.08 \mathrm{E}-10$ & $2.27 \mathrm{E}-08$ & $1.51 \mathrm{E}-06$ \\
\hline $\mathrm{Te}-125 \mathrm{~m}$ & $7.66 \mathrm{E}-05$ & $3.06 \mathrm{E}-08$ & $7.66 \mathrm{E}-07$ & $5.10 \mathrm{E}-05$ \\
\hline Th-228 & 1.38E-05 & 5.51E-09 & $1.38 \mathrm{E}-07$ & $9.18 \mathrm{E}-06$ \\
\hline Th-231 & $7.93 \mathrm{E}-05$ & 3.17E-08 & $7.93 \mathrm{E}-07$ & $5.28 \mathrm{E}-05$ \\
\hline Th-232 & $2.66 \mathrm{E}-03$ & $1.07 \mathrm{E}-06$ & $2.66 \mathrm{E}-05$ & $1.78 \mathrm{E}-03$ \\
\hline Th-234 & $1.02 \mathrm{E}-01$ & $4.06 \mathrm{E}-05$ & $1.02 \mathrm{E}-03$ & $6.77 \mathrm{E}-02$ \\
\hline $\mathrm{U}-235$ & 7.89E-05 & $3.16 \mathrm{E}-08$ & 7.89E-07 & $5.26 \mathrm{E}-05$ \\
\hline U-238 & $1.04 E-01$ & $4.16 \mathrm{E}-05$ & $1.04 \mathrm{E}-03$ & $6.94 \mathrm{E}-02$ \\
\hline$Y-90$ & $1.12 \mathrm{E}-02$ & $4.49 E-06$ & $1.12 \mathrm{E}-04$ & $7.49 \mathrm{E}-03$ \\
\hline $\mathrm{Zr}-95$ & $3.15 \mathrm{E}-05$ & $1.26 \mathrm{E}-08$ & $3.15 E-07$ & $2.10 \mathrm{E}-05$ \\
\hline Total & $3.58 \mathrm{E}-01$ & $1.43 \mathrm{E}-04$ & $3.58 \mathrm{E}-03$ & 2.39E-01 \\
\hline
\end{tabular}


TABLE B.4.28 Low-Level Waste, All Cases: Hanford

\begin{tabular}{|c|c|c|c|}
\hline \multicolumn{4}{|c|}{$\begin{array}{l}\text { Function: Handling } \\
\text { Waste Stream: All }\end{array}$} \\
\hline Nuclide & $\begin{array}{c}\text { Release (Ci), } \\
\text { SHA }\end{array}$ & Nuclide & $\begin{array}{c}\text { Release }(\mathrm{Ci}) \\
\text { SHA }\end{array}$ \\
\hline Ac-228 & $1.06 \mathrm{E}-10$ & Pu-238 & 1.17E-06 \\
\hline Am-241 & $1.70 \mathrm{E}-08$ & Pu-239 & $1.14 \mathrm{E}-08$ \\
\hline Bi-212 & $1.77 \mathrm{E}-11$ & $\mathrm{Pu}-240$ & $5.68 \mathrm{E}-09$ \\
\hline Ce-144 & $1.56 \mathrm{E}-05$ & $\mathrm{Pu}-241$ & $1.31 \mathrm{E}-06$ \\
\hline Co-58 & $4.00 \mathrm{E}-06$ & Ra-224 & $1.77 \mathrm{E}-11$ \\
\hline Co-60 & 3.17E-05 & $\mathrm{Ra}-228$ & $1.06 \mathrm{E}-10$ \\
\hline $\mathrm{Cr}-51$ & $1.57 \mathrm{E}-06$ & $\mathrm{Ru}-106$ & $4.66 \mathrm{E}-06$ \\
\hline Cs-134 & $5.41 \mathrm{E}-06$ & $\mathrm{Sb}-125$ & $1.34 \mathrm{E}-06$ \\
\hline Cs-137 & $5.00 \mathrm{E}-05$ & Sm-151 & $3.72 \mathrm{E}-07$ \\
\hline Eu-152 & $5.68 \mathrm{E}-09$ & Sr-90 & 4.77E-05 \\
\hline Eu-154 & 9.74E-07 & Tc-99 & 8.52E-09 \\
\hline $\mathrm{Eu}-155$ & 7.72E-07 & $\mathrm{Te}-125 \mathrm{~m}$ & 3.27E-07 \\
\hline $\mathrm{Fe}-55$ & $1.11 \mathrm{E}-05$ & Th-228 & $1.77 \mathrm{E}-11$ \\
\hline $\mathrm{Fe}-59$ & $1.01 \mathrm{E}-07$ & Th-231 & $1.02 \mathrm{E}-10$ \\
\hline H-3 & $1.25 \mathrm{E}-04$ & Th-232 & 1.07E-09 \\
\hline $\mathrm{Mn}-54$ & $2.98 \mathrm{E}-06$ & Th-234 & $1.31 \mathrm{E}-07$ \\
\hline $\mathrm{Ni}-59$ & 1.44E-07 & U-235 & $1.01 \mathrm{E}-10$ \\
\hline $\mathrm{Ni}-63$ & $2.10 \mathrm{E}-05$ & U-238 & $1.31 \mathrm{E}-07$ \\
\hline $\mathrm{Pb}-212$ & $1.77 \mathrm{E}-11$ & $Y-90$ & 4.77E-05 \\
\hline $\mathrm{Pm}-147$ & $3.80 \mathrm{E}-05$ & Zr-95 & $1.22 \mathrm{E}-07$ \\
\hline $\operatorname{Pr}-144$ & $1.56 \mathrm{E}-05$ & Total & $4.29 \mathrm{E}-04$ \\
\hline Pr-144m & $1.87 \mathrm{E}-07$ & & \\
\hline
\end{tabular}


TABLE B.4.29 Low-Level Waste, All Cases: Idaho National Engineering Laboratory

\begin{tabular}{|c|c|c|c|}
\hline \multicolumn{4}{|c|}{$\begin{array}{l}\text { Function: Handling } \\
\text { Waste Stream: All }\end{array}$} \\
\hline Nuclide & $\begin{array}{l}\text { Release (Ci), } \\
\text { SHA }\end{array}$ & Nuclide & $\begin{array}{c}\text { Release (Ci), } \\
\text { SHA }\end{array}$ \\
\hline Am-241 & $1.91 \mathrm{E}-10$ & Pm-147 & 4.28E-07 \\
\hline Ce-144 & $1.75 \mathrm{E}-07$ & Pr-144 & $1.75 \mathrm{E}-07$ \\
\hline Co-58 & $2.79 \mathrm{E}-06$ & $\operatorname{Pr}-144 \mathrm{~m}$ & 2.11E-09 \\
\hline Co-60 & $2.18 \mathrm{E}-05$ & $\mathrm{Pu}-238$ & $1.32 \mathrm{E}-08$ \\
\hline $\mathrm{Cr}-51$ & $1.09 \mathrm{E}-06$ & Pu-239 & $1.28 \mathrm{E}-10$ \\
\hline Cs-134 & $6.09 \mathrm{E}-08$ & Pu-240 & $6.38 \mathrm{E}-11$ \\
\hline Cs-137 & 5.62E-07 & $\mathrm{Pu}-241$ & $1.47 \mathrm{E}-08$ \\
\hline Eu-152 & $6.38 \mathrm{E}-11$ & Ru-106 & 5.23E-08 \\
\hline Eu-154 & $1.09 \mathrm{E}-08$ & $\mathrm{Sb}-125$ & $1.50 \mathrm{E}-08$ \\
\hline Eu-155 & 8.68E-09 & Sm-151 & 4.18E-09 \\
\hline $\mathrm{Fe}-55$ & 7.75E-06 & Sr-90 & $5.36 \mathrm{E}-07$ \\
\hline $\mathrm{Fe}-59$ & 7.00E-08 & Tc-99 & 9.57E-11 \\
\hline $\mathrm{H}-3$ & 6.37E-07 & $\mathrm{Te}-125 \mathrm{~m}$ & 3.67E-09 \\
\hline $\mathrm{Mn}-54$ & $2.08 \mathrm{E}-06$ & $Y-90$ & $5.36 \mathrm{E}-07$ \\
\hline Ni-59 & $1.00 \mathrm{E}-07$ & $\mathrm{Zr}-95$ & $8.50 \mathrm{E}-08$ \\
\hline $\mathrm{Ni}-63$ & 1.42E-05 & Total & 5.33E-05 \\
\hline
\end{tabular}


TABLE B.4.30 Low-Level Waste, All Cases:

Los Alamos National Laboratory

\begin{tabular}{|c|c|c|c|}
\hline \multicolumn{4}{|c|}{$\begin{array}{l}\text { Function: Handling } \\
\text { Waste Stream: All }\end{array}$} \\
\hline Nuclide & $\begin{array}{c}\text { Release }(\mathrm{Ci}), \\
\text { SHA }\end{array}$ & Nuclide & $\begin{array}{c}\text { Release (Ci), } \\
\text { SHA }\end{array}$ \\
\hline Ac-228 & $3.01 \mathrm{E}-10$ & $\operatorname{Pr}-144 m$ & 1.37E-06 \\
\hline Am-241 & $1.25 \mathrm{E}-07$ & $\mathrm{Pu}-238$ & $8.61 \mathrm{E}-06$ \\
\hline $\mathrm{Bi}-212$ & $5.03 E-11$ & $\mathrm{Pu}-239$ & 8.37E-08 \\
\hline Ce-144 & $1.14 \mathrm{E}-04$ & $\mathrm{Pu}-240$ & $4.32 \mathrm{E}-08$ \\
\hline $\mathrm{Cm}-242$ & $1.25 \mathrm{E}-10$ & $\mathrm{Pu}-241$ & $9.84 \mathrm{E}-06$ \\
\hline $\mathrm{Cm}-244$ & $4.45 \mathrm{E}-11$ & Ra-224 & $5.03 \mathrm{E}-11$ \\
\hline Co-58 & $7.70 \mathrm{E}-08$ & Ra-228 & $3.01 E-10$ \\
\hline Co-60 & $2.58 \mathrm{E}-06$ & Ru-106 & $3.42 \mathrm{E}-05$ \\
\hline $\mathrm{Cr}-51$ & $3.01 \mathrm{E}-08$ & $\mathrm{Sb}-125$ & $9.81 \mathrm{E}-06$ \\
\hline Cs-134 & 3.97E-05 & Sm-151 & 2.73E-06 \\
\hline Cs-137 & $3.67 \mathrm{E}-04$ & Sr-90 & $3.50 \mathrm{E}-04$ \\
\hline Eu-152 & 4.17E-08 & Tc-99 & $6.25 \mathrm{E}-08$ \\
\hline Eu-154 & 7.14E-06 & $\mathrm{Te}-125 \mathrm{~m}$ & $2.40 \mathrm{E}-06$ \\
\hline Eu-155 & $5.66 \mathrm{E}-06$ & Th-228 & $5.03 \mathrm{E}-11$ \\
\hline $\mathrm{Fe}-55$ & $2.14 \mathrm{E}-07$ & Th-231 & $2.89 \mathrm{E}-10$ \\
\hline $\mathrm{Fe}-59$ & $1.94 \mathrm{E}-09$ & Th-232 & $3.05 \mathrm{E}-09$ \\
\hline $\mathrm{H}-3$ & $2.08 \mathrm{E}+00$ & Th-234 & $3.71 \mathrm{E}-07$ \\
\hline $\mathrm{Mn}-54$ & 5.74E-08 & U-235 & $2.88 \mathrm{E}-10$ \\
\hline $\mathrm{Ni}-59$ & 2.77E-09 & $\mathrm{U}-238$ & 3.71E-07 \\
\hline $\mathrm{Ni}-63$ & 4.33E-06 & $Y-90$ & $3.50 \mathrm{E}-04$ \\
\hline $\mathrm{Pb}-212$ & $5.03 \mathrm{E}-11$ & $\mathrm{Zr}-95$ & 2.35E-09 \\
\hline Pm-147 & $2.79 \mathrm{E}-04$ & Total & $2.08 \mathrm{E}+00$ \\
\hline Pr-144 & $1.14 \mathrm{E}-04$ & & \\
\hline
\end{tabular}


TABLE B.4.31 Low-Level Waste, All Cases:

Lawrence Livermore National Laboratory

Function: Handling

Waste Stream: All

\begin{tabular}{lcll}
\hline Nuclide & $\begin{array}{c}\text { Release (Ci), } \\
\text { SHA }\end{array}$ & Nuclide & $\begin{array}{c}\text { Release (Ci), } \\
\text { SHA }\end{array}$ \\
\hline Am-241 & $1.92 \mathrm{E}-09$ & Pr-144m & $1.27 \mathrm{E}-08$ \\
C-14 & $1.84 \mathrm{E}-05$ & Pu-238 & $5.84 \mathrm{E}-07$ \\
Ce-144 & $1.06 \mathrm{E}-06$ & Pu-239 & $3.93 \mathrm{E}-08$ \\
Cm-242 & $1.08 \mathrm{E}-08$ & Pu-240 & $1.35 \mathrm{E}-07$ \\
Cm-244 & $3.85 \mathrm{E}-09$ & Pu-241 & $1.86 \mathrm{E}-05$ \\
Co-60 & $5.59 \mathrm{E}-07$ & Ru-106 & $3.16 \mathrm{E}-07$ \\
Cs-134 & $3.67 \mathrm{E}-07$ & S-35 & $9.93 \mathrm{E}-07$ \\
Cs-137 & $4.35 \mathrm{E}-06$ & Sb-125 & $9.07 \mathrm{E}-08$ \\
Eu-152 & $3.85 \mathrm{E}-10$ & Sm-151 & $2.52 \mathrm{E}-08$ \\
Eu-154 & $6.60 \mathrm{E}-08$ & Sr-90 & $3.23 \mathrm{E}-06$ \\
Eu-155 & $5.24 \mathrm{E}-08$ & Tc-99 & $5.77 \mathrm{E}-10$ \\
H-3 & $5.25 \mathrm{E}+00$ & Te-125m & $2.21 \mathrm{E}-08$ \\
Ni-63 & $3.64 \mathrm{E}-08$ & Th-232 & $2.64 \mathrm{E}-07$ \\
P-32 & $1.16 \mathrm{E}-06$ & U-238 & $3.56 \mathrm{E}-07$ \\
Pm-147 & $2.58 \mathrm{E}-06$ & Y-90 & $3.23 \mathrm{E}-06$ \\
Pr-144 & $1.06 \mathrm{E}-06$ & Total & $5.25 \mathrm{E}+00$ \\
\hline
\end{tabular}


TABLE B.4.32 Low-Level Waste, All Cases:

Oak Ridge National Laboratory

\begin{tabular}{|c|c|c|c|}
\hline \multicolumn{4}{|c|}{$\begin{array}{l}\text { Function: Handling } \\
\text { Waste Stream: All }\end{array}$} \\
\hline Nuclide & $\begin{array}{l}\text { Release (Ci), } \\
\text { SHA }\end{array}$ & Nuclide & $\begin{array}{c}\text { Release (Ci), } \\
\text { SHA }\end{array}$ \\
\hline Ac- 228 & $4.48 \mathrm{E}-11$ & $\operatorname{Pr}-144$ & 1.72E-06 \\
\hline Am-241 & $1.89 \mathrm{E}-09$ & $\operatorname{Pr}-144 \mathrm{~m}$ & $2.07 \mathrm{E}-08$ \\
\hline $\mathrm{Bi}-212$ & $7.46 \mathrm{E}-12$ & Pu-238 & 1.34E-07 \\
\hline C-14 & $1.52 \mathrm{E}-06$ & Pu-239 & $1.59 \mathrm{E}-09$ \\
\hline Ce-144 & $1.72 \mathrm{E}-06$ & Pu-240 & $1.80 \mathrm{E}-09$ \\
\hline $\mathrm{Cm}-242$ & $9.39 \mathrm{E}-11$ & $\mathrm{Pu}-241$ & 3.06E-07 \\
\hline $\mathrm{Cm}-244$ & $3.36 \mathrm{E}-11$ & $\mathrm{Ra}-224$ & $7.46 \mathrm{E}-12$ \\
\hline Co-58 & $4.50 \mathrm{E}-07$ & $\mathrm{Ra}-228$ & $4.48 \mathrm{E}-11$ \\
\hline Co-60 & $3.56 \mathrm{E}-06$ & Ru-106 & 5.14E-07 \\
\hline $\mathrm{Cr}-51$ & $1.76 \mathrm{E}-07$ & S-35 & $1.72 \mathrm{E}-09$ \\
\hline Cs-134 & 5.97E-07 & $\mathrm{Sb}-125$ & $1.48 \mathrm{E}-07$ \\
\hline Cs-137 & 5.52E-06 & Sm-151 & 4.10E-08 \\
\hline Eu-152 & $6.27 \mathrm{E}-10$ & Sr-90 & $6.85 \mathrm{E}-06$ \\
\hline Eu-154 & $1.07 \mathrm{E}-07$ & Tc-99 & $9.40 \mathrm{E}-10$ \\
\hline Eu-155 & 8.52E-08 & $\mathrm{Te}-125 \mathrm{~m}$ & 3.60E-08 \\
\hline $\mathrm{Fe}-55$ & $1.25 \mathrm{E}-06$ & Th-228 & $7.46 \mathrm{E}-12$ \\
\hline $\mathrm{Fe}-59$ & $1.13 E-08$ & Th-231 & 4.35E-11 \\
\hline $\mathrm{H}-3$ & 2.79E-05 & Th-232 & $9.14 \mathrm{E}-10$ \\
\hline $\mathrm{Mn}-54$ & 3.35E-07 & Th-234 & 5.55E-08 \\
\hline $\mathrm{Ni}-59$ & $1.62 \mathrm{E}-08$ & U-235 & $4.29 \mathrm{E}-11$ \\
\hline $\mathrm{Ni}-63$ & $2.36 \mathrm{E}-06$ & U-238 & 5.62E-08 \\
\hline P-32 & 2.01E-09 & $Y-90$ & $6.85 \mathrm{E}-06$ \\
\hline $\mathrm{Pb}-212$ & $7.46 \mathrm{E}-12$ & $\mathrm{Zr}-95$ & $1.37 \mathrm{E}-08$ \\
\hline Pm-147 & $4.20 \mathrm{E}-06$ & Total & $6.66 \mathrm{E}-05$ \\
\hline
\end{tabular}


TABLE B.4.33 Low-

Level Waste, All Cases:

Paducah Gaseous

Diffusion Plant

\begin{tabular}{ll}
\hline $\begin{array}{l}\text { Function: Handling } \\
\text { Waste Stream: All }\end{array}$ \\
\hline & $\begin{array}{c}\text { Release (Ci), } \\
\text { SHA }\end{array}$ \\
\hline Nuclide & \multicolumn{1}{c}{. } \\
\hline Ac-228 & $7.07 \mathrm{E}-12$ \\
Bi-212 & $1.19 \mathrm{E}-12$ \\
Np-237 & $7.98 \mathrm{E}-11$ \\
Pb-212 & $1.19 \mathrm{E}-12$ \\
Pu-239 & $7.98 \mathrm{E}-11$ \\
Ra-224 & $1.19 \mathrm{E}-12$ \\
Ra-228 & $7.07 \mathrm{E}-12$ \\
Tc-99 & $1.06 \mathrm{E}-10$ \\
Th-228 & $1.19 \mathrm{E}-12$ \\
Th-231 & $6.80 \mathrm{E}-12$ \\
Th-232 & $7.19 \mathrm{E}-11$ \\
Th-234 & $8.74 \mathrm{E}-09$ \\
U-235 & $6.80 \mathrm{E}-12$ \\
U-238 & $8.74 \mathrm{E}-09$ \\
Total & $1.79 \mathrm{E}-08$ \\
\hline
\end{tabular}

TABLE B.4.34 Low-

Level Waste, All Cases:

Pantex Plant

\begin{tabular}{|c|c|}
\hline Nuclide & $\begin{array}{c}\text { Release (Ci), } \\
\text { SHA }\end{array}$ \\
\hline Ac-228 & $6.36 \mathrm{E}-11$ \\
\hline $\mathrm{Bi}-212$ & $1.06 \mathrm{E}-11$ \\
\hline $\mathrm{H}-3$ & $2.96 \mathrm{E}-03$ \\
\hline $\mathrm{Pb}-212$ & $1.06 \mathrm{E}-11$ \\
\hline $\mathrm{Ra}-224$ & $1.06 \mathrm{E}-11$ \\
\hline $\mathrm{Ra}-228$ & $6.36 \mathrm{E}-11$ \\
\hline Th-228 & $1.06 \mathrm{E}-11$ \\
\hline Th-231 & $6.12 E-11$ \\
\hline Th-232 & $6.45 \mathrm{E}-10$ \\
\hline Th-234 & 7.84E-08 \\
\hline U-235 & $6.09 \mathrm{E}-11$ \\
\hline U-238 & $7.84 \mathrm{E}-08$ \\
\hline Total & $2.96 \mathrm{E}-03$ \\
\hline
\end{tabular}


TABLE B.4.35 Low-

Level Waste, All Cases: Portsmouth Gaseous Diffusion Plant

\begin{tabular}{lc}
\hline \multicolumn{2}{l}{$\begin{array}{l}\text { Function: Handling } \\
\text { Waste Stream: All }\end{array}$} \\
\hline & Release (Ci), \\
& SHA \\
Nuclide & \\
& \\
Ac-228 & $2.51 \mathrm{E}-12$ \\
Bi-212 & $4.51 \mathrm{E}-13$ \\
$\mathrm{~Pb}-212$ & $4.51 \mathrm{E}-13$ \\
Ra-224 & $4.51 \mathrm{E}-13$ \\
Ra-228 & $2.51 \mathrm{E}-12$ \\
Th-228 & $4.51 \mathrm{E}-13$ \\
Th-231 & $2.51 \mathrm{E}-12$ \\
Th-232 & $2.60 \mathrm{E}-11$ \\
Th-234 & $3.17 \mathrm{E}-09$ \\
U-235 & $2.51 \mathrm{E}-12$ \\
U-238 & $3.17 \mathrm{E}-09$ \\
Total & $6.37 \mathrm{E}-09$ \\
\hline
\end{tabular}

TABLE B.4.36 LowLevel Waste, All Cases: Rocky Flats Plant

Function: Handling

Waste Stream: All

\begin{tabular}{ll}
\hline Nuclide & $\begin{array}{c}\text { Release (Ci), } \\
\text { SHA }\end{array}$ \\
\hline & \\
Ac-228 & $3.00 \mathrm{E}-11$ \\
$\mathrm{Am}-241$ & $4.47 \mathrm{E}-11$ \\
$\mathrm{Bi}-212$ & $5.08 \mathrm{E}-12$ \\
$\mathrm{Cm}-242$ & $6.26 \mathrm{E}-10$ \\
$\mathrm{Cm}-244$ & $2.24 \mathrm{E}-10$ \\
$\mathrm{~Pb}-212$ & $5.08 \mathrm{E}-12$ \\
$\mathrm{Pu}-238$ & $2.93 \mathrm{E}-08$ \\
$\mathrm{Pu}-239$ & $2.24 \mathrm{E}-09$ \\
$\mathrm{Pu}-240$ & $7.82 \mathrm{E}-09$ \\
$\mathrm{Pu}-241$ & $1.08 \mathrm{E}-06$ \\
$\mathrm{Ra}-224$ & $5.08 \mathrm{E}-12$ \\
$\mathrm{Ra}-228$ & $3.00 \mathrm{E}-11$ \\
Th-228 & $5.08 \mathrm{E}-12$ \\
Th-231 & $2.90 \mathrm{E}-11$ \\
Th-232 & $3.05 \mathrm{E}-10$ \\
Th-234 & $3.71 \mathrm{E}-08$ \\
$\mathrm{U}-235$ & $2.89 \mathrm{E}-11$ \\
$\mathrm{U}-238$ & $3.71 \mathrm{E}-08$ \\
Total & $1.19 \mathrm{E}-06$ \\
\hline
\end{tabular}


TABLE B.4.37 Low-Level Waste, All Cases: Savannah River Site

\begin{tabular}{|c|c|c|c|}
\hline \multicolumn{4}{|c|}{$\begin{array}{l}\text { Function: Handling } \\
\text { Waste Stream: All }\end{array}$} \\
\hline Nuclide & $\begin{array}{c}\text { Release (Ci), } \\
\text { SHA } \\
\end{array}$ & Nuclide & $\begin{array}{c}\text { Release (Ci), } \\
\text { SHA }\end{array}$ \\
\hline Ac-228 & $2.78 \mathrm{E}-11$ & $\operatorname{Pr}-144$ & $1.09 \mathrm{E}-06$ \\
\hline Am-241 & $1.20 \mathrm{E}-09$ & $\operatorname{Pr}-144 m$ & $1.31 \mathrm{E}-08$ \\
\hline $\mathrm{Bi}-212$ & $4.65 E-12$ & Pu-238 & 8.55E-08 \\
\hline C-14 & $9.44 \mathrm{E}-05$ & $\mathrm{Pu}-239$ & $1.06 \mathrm{E}-09$ \\
\hline Ce-144 & $1.09 \mathrm{E}-06$ & $\mathrm{Pu}-240$ & $1.31 \mathrm{E}-09$ \\
\hline $\mathrm{Cm}-242$ & 7.31E-11 & $\mathrm{Pu}-241$ & $2.18 \mathrm{E}-07$ \\
\hline $\mathrm{Cm}-244$ & $2.61 \mathrm{E}-11$ & $\mathrm{Ra}-224$ & 4.65E-12 \\
\hline Co-58 & $4.88 \mathrm{E}-06$ & $\mathrm{Ra}-228$ & 2.78E-11 \\
\hline Co-60 & 3.83E-05 & $\mathrm{Ru}-106$ & $3.26 \mathrm{E}-07$ \\
\hline $\mathrm{Cr}-51$ & $1.91 \mathrm{E}-06$ & S-35 & $1.07 \mathrm{E}-07$ \\
\hline Cs-134 & 3.79E-07 & Sb-125. & $9.36 \mathrm{E}-08$ \\
\hline Cs- 137 & $3.60 \mathrm{E}-06$ & Sm-151 & $2.60 \mathrm{E}-08$ \\
\hline Eu-152 & $3.97 \mathrm{E}-10$ & Sr-90 & 3.34E-06 \\
\hline Eu-154 & $6.81 \mathrm{E}-08$ & Tc-99 & $1.23 \mathrm{E}-06$ \\
\hline Eu-155 & $5.40 \mathrm{E}-08$ & $\mathrm{Te}-125 \mathrm{~m}$ & $2.28 \mathrm{E}-08$ \\
\hline $\mathrm{Fe}-55$ & $1.36 \mathrm{E}-05$ & Th-228 & $4.65 \mathrm{E}-12$ \\
\hline $\mathrm{Fe}-59$ & $1.23 \mathrm{E}-07$ & Th-231 & $2.68 \mathrm{E}-11$ \\
\hline $\mathrm{H}-3$ & $4.80 \mathrm{E}-02$ & Th-232 & $2.86 \mathrm{E}-08$ \\
\hline $\mathrm{Mn}-54$ & $3.63 \mathrm{E}-06$ & Th-234 & 3.43E-08 \\
\hline $\mathrm{Ni}-59$ & $1.75 \mathrm{E}-07$ & U-235 & $2.67 \mathrm{E}-11$ \\
\hline $\mathrm{Ni}-63$ & $2.49 \mathrm{E}-05$ & U-238 & $7.26 \mathrm{E}-08$ \\
\hline P-32 & 1.24E-07 & $Y-90$ & $3.34 \mathrm{E}-06$ \\
\hline $\mathrm{Pb}-212$ & $4.65 \mathrm{E}-12$ & $\mathrm{Zr}-95$ & 1.49E-07 \\
\hline Pm-147 & $2.66 \mathrm{E}-06$ & Total & $4.82 \mathrm{E}-02$ \\
\hline
\end{tabular}




\section{B.5 RADIONUCLIDE RELEASES FROM ALPHA-LLMW TREATMENT ACCIDENTS}

TABLE B.5.1 Low-Level Mixed Waste, Case 2: Idaho National Engineering Laboratory

\begin{tabular}{|c|c|c|c|}
\hline \multicolumn{4}{|c|}{ Function: $\alpha$-Incineration } \\
\hline \multirow[b]{2}{*}{ Nuclide } & \multicolumn{3}{|c|}{ Release $(\mathrm{Ci})$} \\
\hline & EQ7 & IEX & IFF \\
\hline Am-241 & 3.87E-06 & 2.32E-09 & $5.81 \mathrm{E}-08$ \\
\hline Co-60 & $1.22 \mathrm{E}-03$ & $7.30 \mathrm{E}-07$ & $1.82 \mathrm{E}-05$ \\
\hline Cs-137 & $3.60 \mathrm{E}-03$ & $2.16 \mathrm{E}-06$ & $5.40 \mathrm{E}-05$ \\
\hline Eu-154 & $5.81 \mathrm{E}-06$ & $3.49 \mathrm{E}-09$ & $8.72 E-08$ \\
\hline $\mathrm{Nb}-94$ & 8.13E-05 & 4.88E-08 & $1.22 \mathrm{E}-06$ \\
\hline $\mathrm{Ni}-59$ & $1.86 \mathrm{E}-03$ & 1.12E-06 & 2.79E-05 \\
\hline $\mathrm{Ni}-63$ & $1.71 E-01$ & $1.02 \mathrm{E}-04$ & $2.56 \mathrm{E}-03$ \\
\hline $\mathrm{Pu}-238$ & $1.80 \mathrm{E}-04$ & $1.08 \mathrm{E}-07$ & $2.70 \mathrm{E}-06$ \\
\hline $\mathrm{Pu}-240$ & 5.81E-06 & $3.49 \mathrm{E}-09$ & 8.72E-08 \\
\hline Pu-241 & $1.55 \mathrm{E}-04$ & $9.30 \mathrm{E}-08$ & $2.32 \mathrm{E}-06$ \\
\hline Sm-151 & 5.23E-05 & $3.14 \mathrm{E}-08$ & $7.84 \mathrm{E}-07$ \\
\hline $\mathrm{Sr}-90$ & $3.25 \mathrm{E}-03$ & $1.95 \mathrm{E}-06$ & $4.88 \mathrm{E}-05$ \\
\hline Th-234 & $3.08 \mathrm{E}-04$ & $1.85 \mathrm{E}-07$ & $4.62 E-06$ \\
\hline U-238 & 3.08E-04 & $1.85 \mathrm{E}-07$ & 4.62E-06 \\
\hline$Y-90$ & 3.25E-03 & $1.95 \mathrm{E}-06$ & $4.88 \mathrm{E}-05$ \\
\hline Total & $1.85 \mathrm{E}-01$ & $1.11 \mathrm{E}-04$ & $2.78 \mathrm{E}-03$ \\
\hline
\end{tabular}


TABLE B.5.2 Low-Level Mixed Waste, Case 2: Los Alamos National Laboratory

\begin{tabular}{lccc}
\hline & & \\
Function: $\alpha$-Incineration & \multicolumn{3}{c}{ Release (Ci) } \\
& \multicolumn{3}{c}{ IEX } \\
\cline { 2 - 4 } Nuclide & EQ7 & IFF \\
\hline & & & \\
Co-60 & $1.25 \mathrm{E}-04$ & $7.51 \mathrm{E}-08$ & $1.88 \mathrm{E}-06$ \\
Cs-137 & $4.75 \mathrm{E}-06$ & $2.85 \mathrm{E}-09$ & $7.12 \mathrm{E}-08$ \\
Eu-154 & $1.04 \mathrm{E}-06$ & $6.25 \mathrm{E}-10$ & $1.56 \mathrm{E}-08$ \\
Fe-55 & $1.57 \mathrm{E}-05$ & $9.44 \mathrm{E}-09$ & $2.36 \mathrm{E}-07$ \\
Ni-59 & $2.08 \mathrm{E}-06$ & $1.25 \mathrm{E}-09$ & $3.13 \mathrm{E}-08$ \\
Ni-63 & $2.77 \mathrm{E}-04$ & $1.66 \mathrm{E}-07$ & $4.15 \mathrm{E}-06$ \\
Pm-147 & $8.72 \mathrm{E}-06$ & $5.23 \mathrm{E}-09$ & $1.31 \mathrm{E}-07$ \\
Pu-238 & $1.90 \mathrm{E}-05$ & $1.14 \mathrm{E}-08$ & $2.84 \mathrm{E}-07$ \\
Pu-239 & $1.52 \mathrm{E}-06$ & $9.15 \mathrm{E}-10$ & $2.29 \mathrm{E}-08$ \\
Pu-240 & $5.11 \mathrm{E}-06$ & $3.07 \mathrm{E}-09$ & $7.67 \mathrm{E}-08$ \\
Pu-241 & $3.37 \mathrm{E}-04$ & $2.02 \mathrm{E}-07$ & $5.06 \mathrm{E}-06$ \\
Sm-151 & $8.30 \mathrm{E}-07$ & $4.98 \mathrm{E}-10$ & $1.24 \mathrm{E}-08$ \\
Sr-90 & $4.46 \mathrm{E}-06$ & $2.68 \mathrm{E}-09$ & $6.70 \mathrm{E}-08$ \\
Y-90 & $4.46 \mathrm{E}-06$ & $2.68 \mathrm{E}-09$ & $6.70 \mathrm{E}-08$ \\
Total & $8.07 \mathrm{E}-04$ & $4.84 \mathrm{E}-07$ & $1.21 \mathrm{E}-05$ \\
\hline & & &
\end{tabular}


TABLE B.5.3 Low-Level Mixed Waste, Case 2: Lawrence Livermore National Laboratory

\begin{tabular}{lccc}
\hline & & \\
\multicolumn{4}{c}{ Function: $\alpha$-Incineration } \\
& \multicolumn{3}{c}{ Release (Ci) } \\
\cline { 2 - 4 } Nuclide & EQ7 & IEX & IFF \\
\hline & & & \\
Cs-137 & $3.13 \mathrm{E}-06$ & $1.88 \mathrm{E}-09$ & $4.69 \mathrm{E}-08$ \\
Pu-238 & $1.42 \mathrm{E}-05$ & $8.51 \mathrm{E}-09$ & $2.13 \mathrm{E}-07$ \\
Pu-241 & $2.84 \mathrm{E}-04$ & $1.70 \mathrm{E}-07$ & $4.26 \mathrm{E}-06$ \\
Sr-90 & $2.99 \mathrm{E}-06$ & $1.79 \mathrm{E}-09$ & $4.48 \mathrm{E}-08$ \\
Th-234 & $1.45 \mathrm{E}-05$ & $8.68 \mathrm{E}-09$ & $2.17 \mathrm{E}-07$ \\
$\mathrm{U}-238$. & $1.45 \mathrm{E}-05$ & $8.68 \mathrm{E}-09$ & $2.17 \mathrm{E}-07$ \\
Y-90 & $2.99 \mathrm{E}-06$ & $1.79 \mathrm{E}-09$ & $4.48 \mathrm{E}-08$ \\
Total & $3.36 \mathrm{E}-04$ & $2.02 \mathrm{E}-07$ & $5.04 \mathrm{E}-06$ \\
\hline
\end{tabular}

TABLE B.5.4 Low-Level Mixed Waste, Case 2: Rocky Flats Environmental Technology Site

\begin{tabular}{lccc}
\hline & & \\
Function: $\alpha$-Incineration \\
& \multicolumn{3}{c}{ Release (Ci) } \\
\cline { 2 - 4 } Nuclide & EQ7 & IEX & IFF \\
\hline & & & \\
Am-241 & $4.81 \mathrm{E}-08$ & $2.89 \mathrm{E}-11$ & $7.22 \mathrm{E}-10$ \\
$\mathrm{Cm}-244$ & $6.51 \mathrm{E}-08$ & $3.91 \mathrm{E}-11$ & $9.77 \mathrm{E}-10$ \\
$\mathrm{Pu}-238$ & $2.51 \mathrm{E}-05$ & $1.51 \mathrm{E}-08$ & $3.77 \mathrm{E}-07$ \\
$\mathrm{Pu}-239$ & $2.58 \mathrm{E}-06$ & $1.55 \mathrm{E}-09$ & $3.86 \mathrm{E}-08$ \\
$\mathrm{Pu}-240$ & $9.00 \mathrm{E}-06$ & $5.40 \mathrm{E}-09$ & $1.35 \mathrm{E}-07$ \\
$\mathrm{Pu}-241$ & $2.46 \mathrm{E}-04$ & $1.47 \mathrm{E}-07$ & $3.68 \mathrm{E}-06$ \\
Th-234 & $2.35 \mathrm{E}-07$ & $1.41 \mathrm{E}-10$ & $3.52 \mathrm{E}-09$ \\
$\mathrm{U}-238$ & $2.35 \mathrm{E}-07$ & $1.41 \mathrm{E}-10$ & $3.52 \mathrm{E}-09$ \\
Total & $2.83 \mathrm{E}-04$ & $1.70 \mathrm{E}-07$ & $4.24 \mathrm{E}-06$ \\
\hline
\end{tabular}


TABLE B.5.5 Low-Level Mixed Waste, Case 2: Savannah River Site

\begin{tabular}{|c|c|c|c|}
\hline \multicolumn{4}{|c|}{ Function: $\alpha$-Incineration } \\
\hline \multirow[b]{2}{*}{ Nuclide } & \multicolumn{3}{|c|}{ Release (Ci) } \\
\hline & EQ7 & IEX & IFF \\
\hline Am-241 & $1.03 E-07$ & $6.17 \mathrm{E}-11$ & $1.54 \mathrm{E}-09$ \\
\hline Co-60 & $4.26 \mathrm{E}-04$ & $2.56 \mathrm{E}-07$ & $6.39 \mathrm{E}-06$ \\
\hline Cs-137 & $5.40 \mathrm{E}-04$ & 3.24E-07 & $8.10 \mathrm{E}-06$ \\
\hline Eu-154 & $1.92 \mathrm{E}-06$ & $1.15 \mathrm{E}-09$ & $2.88 \mathrm{E}-08$ \\
\hline Eu-155 & 3.17E-07 & $1.90 \mathrm{E}-10$ & 4.75E-09 \\
\hline $\mathrm{Fe}-55$ & 8.08E-06 & 4.85E-09 & $1.21 \mathrm{E}-07$ \\
\hline $\mathrm{Nb}-94$ & $3.18 \mathrm{E}-06$ & 1.91E-09 & 4.77E-08 \\
\hline $\mathrm{Ni}-59$ & $6.79 \mathrm{E}-05$ & 4.07E-08 & $1.02 \mathrm{E}-06$ \\
\hline $\mathrm{Ni}-63$ & $7.36 \mathrm{E}-03$ & $4.42 E-06$ & 1.10E-04 \\
\hline $\mathrm{Pu}-238$ & 2.79E-05 & $1.67 \mathrm{E}-08$ & 4.19E-07 \\
\hline $\mathrm{Pu}-239$ & $7.26 \mathrm{E}-07$ & $4.36 \mathrm{E}-10$ & $1.09 E-08$ \\
\hline Pu-240 & 2.42E-06 & $1.45 \mathrm{E}-09$ & 3.63E-08 \\
\hline Pu-241 & 9.33E-05 & $5.60 \mathrm{E}-08$ & $1.40 \mathrm{E}-06$ \\
\hline Sm-151 & $6.63 \mathrm{E}-06$ & 3.98E-09 & 9.94E-08 \\
\hline Sr-90 & 4.93E-04 & 2.96E-07 & $7.40 \mathrm{E}-06$ \\
\hline Tc-99 & 5.33E-08 & $3.20 \mathrm{E}-11$ & $8.00 \mathrm{E}-10$ \\
\hline Th-234 & $2.28 \mathrm{E}-06$ & 1.37E-09 & 3.43E-08 \\
\hline U-238 & $2.28 \mathrm{E}-06$ & 1.37E-09 & $3.43 \mathrm{E}-08$ \\
\hline Y-90 & 4.93E-04 & 2.96E-07 & $7.40 \mathrm{E}-06$ \\
\hline Total & $9.53 \mathrm{E}-03$ & 5.72E-06 & $1.43 \mathrm{E}-04$ \\
\hline
\end{tabular}


TABLE B.5.6 Low-Level Mixed Waste, Case 4: Idaho National Engineering Laboratory

\begin{tabular}{lccc}
\hline & & \\
Function: $\alpha$-Incineration \\
& \multicolumn{3}{c}{ Release (Ci) } \\
\cline { 2 - 4 } Nuclide & EQ7 & IEX & IFF \\
\hline & & \\
Am-241 & $3.87 \mathrm{E}-06$ & $2.32 \mathrm{E}-09$ & $5.81 \mathrm{E}-08$ \\
Co-60 & $1.22 \mathrm{E}-03$ & $7.30 \mathrm{E}-07$ & $1.82 \mathrm{E}-05$ \\
Cs-137 & $3.60 \mathrm{E}-03$ & $2.16 \mathrm{E}-06$ & $5.40 \mathrm{E}-05$ \\
Eu-154 & $5.81 \mathrm{E}-06$ & $3.49 \mathrm{E}-09$ & $8.72 \mathrm{E}-08$ \\
Nb-94 & $8.13 \mathrm{E}-05$ & $4.88 \mathrm{E}-08$ & $1.22 \mathrm{E}-06$ \\
Ni-59 & $1.86 \mathrm{E}-03$ & $1.12 \mathrm{E}-06$ & $2.79 \mathrm{E}-05$ \\
Ni-63 & $1.71 \mathrm{E}-01$ & $1.02 \mathrm{E}-04$ & $2.56 \mathrm{E}-03$ \\
Pu-238 & $1.80 \mathrm{E}-04$ & $1.08 \mathrm{E}-07$ & $2.70 \mathrm{E}-06$ \\
Pu-240 & $5.81 \mathrm{E}-06$ & $3.49 \mathrm{E}-09$ & $8.72 \mathrm{E}-08$ \\
Pu-241 & $1.55 \mathrm{E}-04$ & $9.30 \mathrm{E}-08$ & $2.32 \mathrm{E}-06$ \\
Sm-151 & $5.23 \mathrm{E}-05$ & $3.14 \mathrm{E}-08$ & $7.84 \mathrm{E}-07$ \\
Sr-90 & $3.25 \mathrm{E}-03$ & $1.95 \mathrm{E}-06$ & $4.88 \mathrm{E}-05$ \\
Th-234 & $3.08 \mathrm{E}-04$ & $1.85 \mathrm{E}-07$ & $4.62 \mathrm{E}-06$ \\
U-238 & $3.08 \mathrm{E}-04$ & $1.85 \mathrm{E}-07$ & $4.62 \mathrm{E}-06$ \\
Y-90 & $3.25 \mathrm{E}-03$ & $1.95 \mathrm{E}-06$ & $4.88 \mathrm{E}-05$ \\
Total & $1.85 \mathrm{E}-01$ & $1.11 \mathrm{E}-04$ & $2.78 \mathrm{E}-03$ \\
\hline & & &
\end{tabular}


TABLE B.5.7 Low-Level Mixed Waste, Case 4: Lawrence Livermore National Laboratory

\begin{tabular}{lccc}
\hline & & & \\
Function: $\alpha$-Incineration \\
& \multicolumn{3}{c}{ Release (Ci) } \\
\cline { 2 - 4 } Nuclide & EQ7 & IEX & IFF \\
\hline & & & \\
Cs-137 & $3.13 \mathrm{E}-06$ & $1.88 \mathrm{E}-09$ & $4.69 \mathrm{E}-08$ \\
Pu-238 & $1.42 \mathrm{E}-05$ & $8.51 \mathrm{E}-09$ & $2.13 \mathrm{E}-07$ \\
Pu-241 & $2.84 \mathrm{E}-04$ & $1.70 \mathrm{E}-07$ & $4.26 \mathrm{E}-06$ \\
Sr-90 & $2.99 \mathrm{E}-06$ & $1.79 \mathrm{E}-09$ & $4.48 \mathrm{E}-08$ \\
Th-234 & $1.45 \mathrm{E}-05$ & $8.68 \mathrm{E}-09$ & $2.17 \mathrm{E}-07$ \\
$\mathrm{U}-238$ & $1.45 \mathrm{E}-05$ & $8.68 \mathrm{E}-09$ & $2.17 \mathrm{E}-07$ \\
Y-90 & $2.99 \mathrm{E}-06$ & $1.79 \mathrm{E}-09$ & $4.48 \mathrm{E}-08$ \\
Total & $3.36 \mathrm{E}-04$ & $2.02 \mathrm{E}-07$ & $5.04 \mathrm{E}-06$ \\
\hline
\end{tabular}

TABLE B.5.8 Low-Level Mixed Waste, Case 4: Los Alamos National Laboratory

\begin{tabular}{llll}
\hline & & \\
Function: $\alpha$-Incineration \\
& \multicolumn{3}{c}{ Release (Ci) } \\
\cline { 2 - 4 } Nuclide & EQ7 & IEX & IFF \\
\hline & & & \\
Co-60 & $1.25 \mathrm{E}-04$ & $7.51 \mathrm{E}-08$ & $1.88 \mathrm{E}-06$ \\
$\mathrm{Cs}-137$ & $4.75 \mathrm{E}-06$ & $2.85 \mathrm{E}-09$ & $7.12 \mathrm{E}-08$ \\
Eu-154 & $1.04 \mathrm{E}-06$ & $6.25 \mathrm{E}-10$ & $1.56 \mathrm{E}-08$ \\
Fe-55 & $1.57 \mathrm{E}-05$ & $9.44 \mathrm{E}-09$ & $2.36 \mathrm{E}-07$ \\
Ni-59 & $2.08 \mathrm{E}-06$ & $1.25 \mathrm{E}-09$ & $3.13 \mathrm{E}-08$ \\
$\mathrm{Ni}-63$ & $2.77 \mathrm{E}-04$ & $1.66 \mathrm{E}-07$ & $4.15 \mathrm{E}-06$ \\
$\mathrm{Pm}-147$ & $8.72 \mathrm{E}-06$ & $5.23 \mathrm{E}-09$ & $1.31 \mathrm{E}-07$ \\
$\mathrm{Pu}-238$ & $1.90 \mathrm{E}-05$ & $1.14 \mathrm{E}-08$ & $2.84 \mathrm{E}-07$ \\
$\mathrm{Pu}-239$ & $1.52 \mathrm{E}-06$ & $9.15 \mathrm{E}-10$ & $2.29 \mathrm{E}-08$ \\
$\mathrm{Pu}-240$ & $5.11 \mathrm{E}-06$ & $3.07 \mathrm{E}-09$ & $7.67 \mathrm{E}-08$ \\
$\mathrm{Pu}-241$ & $3.37 \mathrm{E}-04$ & $2.02 \mathrm{E}-07$ & $5.06 \mathrm{E}-06$ \\
$\mathrm{Sm}-151$ & $8.30 \mathrm{E}-07$ & $4.98 \mathrm{E}-10$ & $1.24 \mathrm{E}-08$ \\
Sr-90 & $4.46 \mathrm{E}-06$ & $2.68 \mathrm{E}-09$ & $6.70 \mathrm{E}-08$ \\
Y-90 & $4.46 \mathrm{E}-06$ & $2.68 \mathrm{E}-09$ & $6.70 \mathrm{E}-08$ \\
Total & $8.07 \mathrm{E}-04$ & $4.84 \mathrm{E}-07$ & $1.21 \mathrm{E}-05$ \\
\hline & & &
\end{tabular}


TABLE B.5.9 Low-Level Mixed Waste, Case 4: Rocky Flats Environmental Technology Site

\begin{tabular}{lccc}
\hline & & & \\
Function: $\alpha$-Incineration \\
& \multicolumn{3}{c}{ Release (Ci) } \\
\cline { 2 - 4 } Nuclide & EQ7 & IEX & IFF \\
\hline & & & \\
Am-241 & $4.81 \mathrm{E}-08$ & $2.89 \mathrm{E}-11$ & $7.22 \mathrm{E}-10$ \\
$\mathrm{Cm}-244$ & $6.51 \mathrm{E}-08$ & $3.91 \mathrm{E}-11$ & $9.77 \mathrm{E}-10$ \\
$\mathrm{Pu}-238$ & $2.51 \mathrm{E}-05$ & $1.51 \mathrm{E}-08$ & $3.77 \mathrm{E}-07$ \\
$\mathrm{Pu}-239$ & $2.58 \mathrm{E}-06$ & $1.55 \mathrm{E}-09$ & $3.86 \mathrm{E}-08$ \\
$\mathrm{Pu}-240$ & $9.00 \mathrm{E}-06$ & $5.40 \mathrm{E}-09$ & $1.35 \mathrm{E}-07$ \\
$\mathrm{Pu}-241$ & $2.46 \mathrm{E}-04$ & $1.47 \mathrm{E}-07$ & $3.68 \mathrm{E}-06$ \\
Th-234 & $2.35 \mathrm{E}-07$ & $1.41 \mathrm{E}-10$ & $3.52 \mathrm{E}-09$ \\
$\mathrm{U}-238$ & $2.35 \mathrm{E}-07$ & $1.41 \mathrm{E}-10$ & $3.52 \mathrm{E}-09$ \\
Total & $2.83 \mathrm{E}-04$ & $1.70 \mathrm{E}-07$ & $4.24 \mathrm{E}-06$ \\
\hline
\end{tabular}


TABLE B.5.10 Low-Level Mixed Waste, Case 4: Savannah River Site

\begin{tabular}{|c|c|c|c|}
\hline \multicolumn{4}{|c|}{ Function: $\alpha$-Incineration } \\
\hline \multirow[b]{2}{*}{ Nuclide } & \multicolumn{3}{|c|}{ Release (Ci) } \\
\hline & EQ7 & IEX & IFF \\
\hline Am-241 & $1.03 \mathrm{E}-07$ & $6.17 \mathrm{E}-11$ & $1.54 \mathrm{E}-09$ \\
\hline Co-60 & $4.26 \mathrm{E}-04$ & $2.56 \mathrm{E}-07$ & $6.39 \mathrm{E}-06$ \\
\hline Cs-137 & $5.40 \mathrm{E}-04$ & $3.24 E-07$ & $8.10 \mathrm{E}-06$ \\
\hline Eu-154 & $1.92 \mathrm{E}-06$ & $1.15 E-09$ & $2.88 \mathrm{E}-08$ \\
\hline Eu-155 & 3.17E-07 & $1.90 \mathrm{E}-10$ & 4.75E-09 \\
\hline $\mathrm{Fe}-55$ & $8.08 \mathrm{E}-06$ & 4.85E-09 & $1.21 \mathrm{E}-07$ \\
\hline $\mathrm{Nb}-94$ & $3.18 \mathrm{E}-06$ & 1.91E-09 & 4.77E-08 \\
\hline $\mathrm{Ni}-59$ & $6.79 \mathrm{E}-05$ & 4.07E-08 & $1.02 \mathrm{E}-06$ \\
\hline $\mathrm{Ni}-63$ & $7.36 \mathrm{E}-03$ & 4.42E-06 & $1.10 \mathrm{E}-04$ \\
\hline $\mathrm{Pu}-238$ & 2.79E-05 & $1.67 \mathrm{E}-08$ & 4.19E-07 \\
\hline $\mathrm{Pu}-239$ & $7.26 \mathrm{E}-07$ & $4.36 \mathrm{E}-10$ & $1.09 \mathrm{E}-08$ \\
\hline Pu-240 & 2.42E-06 & $1.45 \mathrm{E}-09$ & 3.63E-08 \\
\hline $\mathrm{Pu}-241$ & 9.33E-05 & $5.60 \mathrm{E}-08$ & $1.40 \mathrm{E}-06$ \\
\hline Sm-151 & $6.63 \mathrm{E}-06$ & $3.98 \mathrm{E}-09$ & 9.94E-08 \\
\hline Sr-90 & 4.93E-04 & $2.96 \mathrm{E}-07$ & $7.40 \mathrm{E}-06$ \\
\hline Tc-99 & 5.33E-08 & $3.20 \mathrm{E}-11$ & $8.00 \mathrm{E}-10$ \\
\hline Th-234 & $2.28 \mathrm{E}-06$ & 1.37E-09 & 3.43E-08 \\
\hline $\mathrm{U}-238$ & $2.28 \mathrm{E}-06$ & 1.37E-09 & $3.43 E-08$ \\
\hline$Y-90$ & 4.93E-04 & 2.96E-07 & $7.40 \mathrm{E}-06$ \\
\hline Total & 9.53E-03 & 5.72E-06 & $1.43 \mathrm{E}-04$ \\
\hline
\end{tabular}


TABLE B.5.11 Low-Level Mixed Waste, Case 7: Idaho National Engineering Laboratory

\begin{tabular}{lccc}
\hline & & \\
Function: $\alpha$-Incineration \\
& \multicolumn{3}{c}{ Release (Ci) } \\
\cline { 2 - 4 } \multicolumn{1}{c}{ Nuclide } & EQ7 & IEX & IFF \\
\hline & & & \\
Am-241 & $3.87 \mathrm{E}-06$ & $2.32 \mathrm{E}-09$ & $5.81 \mathrm{E}-08$ \\
Co-60 & $1.22 \mathrm{E}-03$ & $7.30 \mathrm{E}-07$ & $1.82 \mathrm{E}-05$ \\
Cs-137 & $3.60 \mathrm{E}-03$ & $2.16 \mathrm{E}-06$ & $5.41 \mathrm{E}-05$ \\
Eu-154 & $5.81 \mathrm{E}-06$ & $3.49 \mathrm{E}-09$ & $8.72 \mathrm{E}-08$ \\
Nb-94 & $8.13 \mathrm{E}-05$ & $4.88 \mathrm{E}-08$ & $1.22 \mathrm{E}-06$ \\
Ni-59 & $1.86 \mathrm{E}-03$ & $1.12 \mathrm{E}-06$ & $2.79 \mathrm{E}-05$ \\
Ni-63 & $1.71 \mathrm{E}-01$ & $1.02 \mathrm{E}-04$ & $2.56 \mathrm{E}-03$ \\
Pu-238 & $1.80 \mathrm{E}-04$ & $1.08 \mathrm{E}-07$ & $2.71 \mathrm{E}-06$ \\
Pu-240 & $5.81 \mathrm{E}-06$ & $3.49 \mathrm{E}-09$ & $8.72 \mathrm{E}-08$ \\
Pu-241 & $1.62 \mathrm{E}-04$ & $9.74 \mathrm{E}-08$ & $2.44 \mathrm{E}-06$ \\
Sm-151 & $5.23 \mathrm{E}-05$ & $3.14 \mathrm{E}-08$ & $7.84 \mathrm{E}-07$ \\
Sr-90 & $3.26 \mathrm{E}-03$ & $1.95 \mathrm{E}-06$ & $4.88 \mathrm{E}-05$ \\
Th-234 & $3.08 \mathrm{E}-04$ & $1.85 \mathrm{E}-07$ & $4.62 \mathrm{E}-06$ \\
U-238 & $3.08 \mathrm{E}-04$ & $1.85 \mathrm{E}-07$ & $4.62 \mathrm{E}-06$ \\
Y-90 & $3.26 \mathrm{E}-03$ & $1.95 \mathrm{E}-06$ & $4.88 \mathrm{E}-05$ \\
Total & $1.85 \mathrm{E}-01$ & $1.11 \mathrm{E}-04$ & $2.78 \mathrm{E}-03$ \\
\hline & & & \\
& & &
\end{tabular}


TABLE B.5.12 Low-Level Mixed Waste, Case 7: Los Alamos National Laboratory

\begin{tabular}{|c|c|c|c|}
\hline \multicolumn{4}{|c|}{ Function: $\alpha$-Incineration } \\
\hline \multirow[b]{2}{*}{ Nuclide } & \multicolumn{3}{|c|}{ Release (Ci) } \\
\hline & EQ7 & IEX & IFF \\
\hline Co-60 & $1.25 \mathrm{E}-04$ & $7.51 \mathrm{E}-08$ & $1.88 \mathrm{E}-06$ \\
\hline Cs-137 & 4.75E-06 & 2.85E-09 & $7.12 \mathrm{E}-08$ \\
\hline Eu-154 & $1.04 \mathrm{E}-06$ & $6.25 \mathrm{E}-10$ & $1.56 \mathrm{E}-08$ \\
\hline $\mathrm{Fe}-55$ & $1.57 \mathrm{E}-05$ & $9.44 \mathrm{E}-09$ & $2.36 \mathrm{E}-07$ \\
\hline $\mathrm{Ni}-59$ & $2.08 \mathrm{E}-06$ & $1.25 \mathrm{E}-09$ & 3.13E-08 \\
\hline $\mathrm{Ni}-63$ & 2.77E-04 & $1.66 \mathrm{E}-07$ & 4.15E-06 \\
\hline Pm-147 & 8.72E-06 & 5.23E-09 & $1.31 \mathrm{E}-07$ \\
\hline Pu-238 & $1.90 \mathrm{E}-05$ & $1.14 \mathrm{E}-08$ & $2.84 \mathrm{E}-07$ \\
\hline Pu-239 & $1.52 \mathrm{E}-06$ & $9.15 \mathrm{E}-10$ & $2.29 \mathrm{E}-08$ \\
\hline Pu-240 & 5.11E-06 & 3.07E-09 & 7.67E-08 \\
\hline $\mathrm{Pu}-241$ & 3.37E-04 & 2.02E-07 & $5.06 \mathrm{E}-06$ \\
\hline Sm-151 & 8.30E-07 & $4.98 \mathrm{E}-10$ & $1.24 \mathrm{E}-08$ \\
\hline Sr-90 & $4.46 \mathrm{E}-06$ & 2.68E-09 & $6.70 \mathrm{E}-08$ \\
\hline Y-90 & $4.46 \mathrm{E}-06$ & $2.68 \mathrm{E}-09$ & $6.70 \mathrm{E}-08$ \\
\hline Total & 8.07E-04 & $4.84 \mathrm{E}-07$ & $1.21 \mathrm{E}-05$ \\
\hline
\end{tabular}


TABLE B.5.13 Low-Level Mixed Waste, Case 7: Rocky Flats Environmental Technology Site

\begin{tabular}{lccc}
\hline & & & \\
Function: $\alpha$-Incineration & \multicolumn{3}{c}{ Release (Ci) } \\
\cline { 2 - 4 } Nuclide & EQ7 & IEX & IFF \\
\cline { 2 - 4 } Am-241 & $4.81 \mathrm{E}-08$ & $2.89 \mathrm{E}-11$ & $7.22 \mathrm{E}-10$ \\
Cm-244 & $6.51 \mathrm{E}-08$ & $3.91 \mathrm{E}-11$ & $9.77 \mathrm{E}-10$ \\
Pu-238 & $2.51 \mathrm{E}-05$ & $1.51 \mathrm{E}-08$ & $3.77 \mathrm{E}-07$ \\
Pu-239 & $2.58 \mathrm{E}-06$ & $1.55 \mathrm{E}-09$ & $3.86 \mathrm{E}-08$ \\
Pu-240 & $9.00 \mathrm{E}-06$ & $5.40 \mathrm{E}-09$ & $1.35 \mathrm{E}-07$ \\
Pu-241 & $2.46 \mathrm{E}-04$ & $1.47 \mathrm{E}-07$ & $3.68 \mathrm{E}-06$ \\
Th-234 & $2.35 \mathrm{E}-07$ & $1.41 \mathrm{E}-10$ & $3.52 \mathrm{E}-09$ \\
$\mathrm{U}-238$ & $2.35 \mathrm{E}-07$ & $1.41 \mathrm{E}-10$ & $3.52 \mathrm{E}-09$ \\
Total & $2.83 \mathrm{E}-04$ & $1.70 \mathrm{E}-07$ & $4.24 \mathrm{E}-06$ \\
\hline
\end{tabular}

TABLE B.5.14 Low-Level Mixed Waste, Case 7: Savannah River Site

Function: $\alpha$-Incineration

\begin{tabular}{llll} 
& \multicolumn{3}{c}{ Release (Ci) } \\
\cline { 2 - 4 } Nuclide & EQ7 & IEX & IFF \\
\hline & & & \\
Am-241 & $1.03 E-07$ & $6.17 \mathrm{E}-11$ & $1.54 \mathrm{E}-09$ \\
Co-60 & $4.26 \mathrm{E}-04$ & $2.56 \mathrm{E}-07$ & $6.39 \mathrm{E}-06$ \\
Cs-137 & $5.40 \mathrm{E}-04$ & $3.24 \mathrm{E}-07$ & $8.10 \mathrm{E}-06$ \\
Eu-154 & $1.92 \mathrm{E}-06$ & $1.15 \mathrm{E}-09$ & $2.88 \mathrm{E}-08$ \\
Eu-155 & $3.17 \mathrm{E}-07$ & $1.90 \mathrm{E}-10$ & $4.75 \mathrm{E}-09$ \\
Fe-55 & $8.08 \mathrm{E}-06$ & $4.85 \mathrm{E}-09$ & $1.21 \mathrm{E}-07$ \\
Nb-94 & $3.18 \mathrm{E}-06$ & $1.91 \mathrm{E}-09$ & $4.77 \mathrm{E}-08$ \\
Ni-59 & $6.79 \mathrm{E}-05$ & $4.07 \mathrm{E}-08$ & $1.02 \mathrm{E}-06$ \\
Ni-63 & $7.36 \mathrm{E}-03$ & $4.42 \mathrm{E}-06$ & $1.10 \mathrm{E}-04$ \\
Pu-238 & $2.79 \mathrm{E}-05$ & $1.67 \mathrm{E}-08$ & $4.19 \mathrm{E}-07$ \\
Pu-239 & $7.26 \mathrm{E}-07$ & $4.36 \mathrm{E}-10$ & $1.09 \mathrm{E}-08$ \\
Pu-240 & $2.42 \mathrm{E}-06$ & $1.45 \mathrm{E}-09$ & $3.63 \mathrm{E}-08$ \\
Pu-241 & $9.33 \mathrm{E}-05$ & $5.60 \mathrm{E}-08$ & $1.40 \mathrm{E}-06$ \\
Sm-151 & $6.63 \mathrm{E}-06$ & $3.98 \mathrm{E}-09$ & $9.94 \mathrm{E}-08$ \\
Sr-90 & $4.93 \mathrm{E}-04$ & $2.96 \mathrm{E}-07$ & $7.40 \mathrm{E}-06$ \\
Tc-99 & $5.33 \mathrm{E}-08$ & $3.20 \mathrm{E}-11$ & $8.00 \mathrm{E}-10$ \\
Th-234 & $2.28 \mathrm{E}-06$ & $1.37 \mathrm{E}-09$ & $3.43 \mathrm{E}-08$ \\
U-238 & $2.28 \mathrm{E}-06$ & $1.37 \mathrm{E}-09$ & $3.43 \mathrm{E}-08$ \\
Y-90 & $4.93 \mathrm{E}-04$ & $2.96 \mathrm{E}-07$ & $7.40 \mathrm{E}-06$ \\
Total & $9.53 \mathrm{E}-03$ & $5.72 \mathrm{E}-06$ & $1.43 \mathrm{E}-04$ \\
\hline & & & \\
& & &
\end{tabular}


TABLE B.5.15 Low-Level Mixed Waste, Case 15: Idaho National Engineering Laboratory

\begin{tabular}{|c|c|c|c|}
\hline \multirow[b]{2}{*}{ Nuclide } & \multicolumn{3}{|c|}{ Release (Ci) } \\
\hline & EQ7 & IEX & IFF \\
\hline Am-241 & $3.87 \mathrm{E}-06$ & 2.32E-09 & $5.81 \mathrm{E}-08$ \\
\hline $\mathrm{Cm}-244$ & $1.28 \mathrm{E}-09$ & $7.66 \mathrm{E}-13$ & $1.91 \mathrm{E}-11$ \\
\hline $\mathrm{Co}-60$ & $1.22 \mathrm{E}-03$ & 7.30E-07 & $1.82 \mathrm{E}-05$ \\
\hline Cs-137 & $3.60 \mathrm{E}-03$ & $2.16 \mathrm{E}-06$ & 5.41E-05 \\
\hline Eu-154 & 5.81E-06 & 3.49E-09 & $8.72 \mathrm{E}-08$ \\
\hline $\mathrm{Nb}-94$ & 8.13E-05 & $4.88 \mathrm{E}-08$ & $1.22 \mathrm{E}-06$ \\
\hline $\mathrm{Ni}-59$ & $1.86 \mathrm{E}-03$ & 1.12E-06 & $2.79 \mathrm{E}-05$ \\
\hline $\mathrm{Ni}-63$ & 1.71E-01 & $1.02 \mathrm{E}-04$ & $2.56 \mathrm{E}-03$ \\
\hline Pu-238 & $1.81 \mathrm{E}-04$ & 1.09E-07 & 2.71E-06 \\
\hline $\mathrm{Pu}-239$ & $5.05 \mathrm{E}-08$ & $3.03 \mathrm{E}-11$ & $7.58 \mathrm{E}-10$ \\
\hline Pu-240 & 5.99E-06 & $3.59 \mathrm{E}-09$ & 8.98E-08 \\
\hline Pu-241 & $1.67 \mathrm{E}-04$ & $1.00 \mathrm{E}-07$ & $2.51 \mathrm{E}-06$ \\
\hline Sm-151 & 5.23E-05 & $3.14 \mathrm{E}-08$ & 7.84E-07 \\
\hline Sr-90 & $3.26 \mathrm{E}-03$ & $1.95 \mathrm{E}-06$ & $4.88 \mathrm{E}-05$ \\
\hline Th-234 & 3.08E-04 & $1.85 \mathrm{E}-07$ & 4.62E-06 \\
\hline $\mathrm{U}-238$ & $3.08 \mathrm{E}-04$ & 1.85E-07 & 4.62E-06 \\
\hline$Y-90$ & $3.26 \mathrm{E}-03$ & $1.95 \mathrm{E}-06$ & $4.88 \mathrm{E}-05$ \\
\hline Total & $1.85 \mathrm{E}-01$ & 1.11E-04 & $2.78 \mathrm{E}-03$ \\
\hline
\end{tabular}


TABLE B.5.16 Low-Level Mixed Waste, Case 15: Savannah River Site

\begin{tabular}{|c|c|c|c|}
\hline \multicolumn{4}{|c|}{ Function: $\alpha$-Incineration } \\
\hline \multirow[b]{2}{*}{ Nuclide } & \multicolumn{3}{|c|}{ Release (Ci) } \\
\hline & EQ7 & IEX & IFF \\
\hline Am-241 & $1.03 \mathrm{E}-07$ & $6.17 \mathrm{E}-11$ & $1.54 \mathrm{E}-09$ \\
\hline Co-60 & $4.26 \mathrm{E}-04$ & $2.56 \mathrm{E}-07$ & $6.39 \mathrm{E}-06$ \\
\hline Cs-137 & $5.40 \mathrm{E}-04$ & $3.24 \mathrm{E}-07$ & $8.10 \mathrm{E}-06$ \\
\hline Eu-154 & $1.92 \mathrm{E}-06$ & 1.15E-09 & $2.88 \mathrm{E}-08$ \\
\hline Eu-155 & 3.17E-07 & $1.90 \mathrm{E}-10$ & $4.75 \mathrm{E}-09$ \\
\hline Fe-55 & $8.08 \mathrm{E}-06$ & 4.85E-09 & $1.21 \mathrm{E}-07$ \\
\hline $\mathrm{Nb}-94$ & $3.18 \mathrm{E}-06$ & $1.91 \mathrm{E}-09$ & 4.77E-08 \\
\hline $\mathrm{Ni}-59$ & $6.79 \mathrm{E}-05$ & 4.07E-08 & $1.02 \mathrm{E}-06$ \\
\hline $\mathrm{Ni}-63$ & $7.36 \mathrm{E}-03$ & 4.42E-06 & $1.10 \mathrm{E}-04$ \\
\hline $\mathrm{Pu}-238$ & $2.79 \mathrm{E}-05$ & $1.67 \mathrm{E}-08$ & $4.19 \mathrm{E}-07$ \\
\hline Pu-239 & $7.26 \mathrm{E}-07$ & $4.36 \mathrm{E}-10$ & $1.09 \mathrm{E}-08$ \\
\hline Pu-240 & $2.42 \mathrm{E}-06$ & $1.45 \mathrm{E}-09$ & $3.63 \mathrm{E}-08$ \\
\hline $\mathrm{Pu}-241$ & 9.33E-05 & $5.60 \mathrm{E}-08$ & $1.40 \mathrm{E}-06$ \\
\hline $\mathrm{Sm}-151$ & 6.63E-06 & $3.98 \mathrm{E}-09$ & $9.94 \mathrm{E}-08$ \\
\hline Sr-90 & 4.93E-04 & 2.96E-07 & $7.40 \mathrm{E}-06$ \\
\hline Tc-99 & 5.33E-08 & $3.20 \mathrm{E}-11$ & $8.00 \mathrm{E}-10$ \\
\hline Th-234 & $2.28 \mathrm{E}-06$ & 1.37E-09 & $3.43 E-08$ \\
\hline U-238 & $2.28 \mathrm{E}-06$ & $1.37 \mathrm{E}-09$ & $3.43 E-08$ \\
\hline$Y-90$ & 4.93E-04 & $2.96 \mathrm{E}-07$ & $7.40 \mathrm{E}-06$ \\
\hline Total & 9.53E-03 & $5.72 \mathrm{E}-06$ & $1.43 \mathrm{E}-04$ \\
\hline
\end{tabular}


TABLE B.5.17 Low-Level Mixed Waste, Case 17: Hanford

\begin{tabular}{|c|c|c|c|}
\hline Function: & ineration & & \\
\hline \multirow[b]{2}{*}{ Nuclide } & \multicolumn{3}{|c|}{ Release (Ci) } \\
\hline & EQ7 & IEX & IFF \\
\hline Am-241 & 4.83E-08 & $2.90 \mathrm{E}-11$ & $7.24 \mathrm{E}-10$ \\
\hline $\mathrm{Cm}-244$ & $6.51 \mathrm{E}-08$ & $3.91 \mathrm{E}-11$ & $9.77 \mathrm{E}-10$ \\
\hline Co-60 & 8.08E-08 & $4.85 \mathrm{E}-11$ & $1.21 \mathrm{E}-09$ \\
\hline Cs-137 & $1.16 \mathrm{E}-07$ & $6.94 \mathrm{E}-11$ & $1.74 \mathrm{E}-09$ \\
\hline Eu-154 & $9.26 \mathrm{E}-10$ & $5.55 \mathrm{E}-13$ & $1.39 \mathrm{E}-11$ \\
\hline $\mathrm{Fe}-55$ & $1.01 \mathrm{E}-08$ & $6.08 \mathrm{E}-12$ & $1.52 \mathrm{E}-10$ \\
\hline Nb-94 & $1.46 \mathrm{E}-11$ & $9.00 \mathrm{E}-15$ & $2.19 \mathrm{E}-13$ \\
\hline $\mathrm{Ni}-59$ & $1.67 \mathrm{E}-09$ & $1.00 \mathrm{E}-12$ & $2.50 \mathrm{E}-11$ \\
\hline $\mathrm{Ni}-63$ & 2.12E-07 & $1.27 \mathrm{E}-10$ & $3.18 \mathrm{E}-09$ \\
\hline Pm-147 & $5.62 \mathrm{E}-09$ & $3.37 \mathrm{E}-12$ & $8.43 \mathrm{E}-11$ \\
\hline Pu-238 & $2.52 \mathrm{E}-05$ & $1.51 \mathrm{E}-08$ & 3.77E-07 \\
\hline Pu-239 & $2.58 \mathrm{E}-06$ & $1.55 \mathrm{E}-09$ & $3.87 \mathrm{E}-08$ \\
\hline $\mathrm{Pu}-240$ & $9.01 \mathrm{E}-06$ & $5.40 \mathrm{E}-09$ & $1.35 \mathrm{E}-07$ \\
\hline Pu-241 & $2.46 \mathrm{E}-04$ & 1.47E-07 & $3.69 \mathrm{E}-06$ \\
\hline Sm-151 & 2.97E-09 & $1.78 \mathrm{E}-12$ & $4.46 E-11$ \\
\hline Sr-90 & $1.04 \mathrm{E}-07$ & $6.27 \mathrm{E}-11$ & 1.57E-09 \\
\hline Tc-99 & 3.78E-11 & $2.30 \mathrm{E}-14$ & 5.67E-13 \\
\hline Th-234 & 2.35E-07 & $1.41 \mathrm{E}-10$ & 3.53E-09 \\
\hline U-238 & 2.35E-07 & $1.41 \mathrm{E}-10$ & 3.53E-09 \\
\hline Y-90 & $1.04 \mathrm{E}-07$ & $6.27 \mathrm{E}-11$ & $1.57 \mathrm{E}-09$ \\
\hline Total & 2.84E-04 & $1.70 \mathrm{E}-07$ & $4.26 \mathrm{E}-06$ \\
\hline
\end{tabular}


TABLE B.5.18 Low-Level Mixed Waste, Case 26: Idaho National Engineering Laboratory

\begin{tabular}{|c|c|c|c|}
\hline \multicolumn{4}{|c|}{ Function: $r$-Incineration ${ }^{\mathrm{a}}$} \\
\hline \multirow[b]{2}{*}{ Nuclide } & \multicolumn{3}{|c|}{ Release $(\mathrm{Ci})$} \\
\hline & EQ7 & IEX & IFF \\
\hline Am-241 & $6.14 \mathrm{E}-09$ & $3.68 \mathrm{E}-12$ & $9.21 \mathrm{E}-11$ \\
\hline Co-60 & $1.93 \mathrm{E}-06$ & $1.16 \mathrm{E}-09$ & $2.89 \mathrm{E}-08$ \\
\hline Cs-137 & $5.71 \mathrm{E}-06$ & 3.43E-09 & 8.57E-08 \\
\hline Eu-154 & $9.21 \mathrm{E}-09$ & $5.53 \mathrm{E}-12$ & $1.38 \mathrm{E}-10$ \\
\hline $\mathrm{Nb}-94$ & $1.29 \mathrm{E}-07$ & $7.74 \mathrm{E}-11$ & $1.93 \mathrm{E}-09$ \\
\hline $\mathrm{Ni}-59$ & $2.95 \mathrm{E}-06$ & 1.77E-09 & 4.42E-08 \\
\hline $\mathrm{Ni}-63$ & 2.71E-04 & 1.62E-07 & $4.06 \mathrm{E}-06$ \\
\hline Pu-238 & $2.86 \mathrm{E}-07$ & $1.71 \mathrm{E}-10$ & $4.28 \mathrm{E}-09$ \\
\hline Pu-240 & $9.21 \mathrm{E}-09$ & $5.53 \mathrm{E}-12$ & $1.38 \mathrm{E}-10$ \\
\hline Pu-241 & $2.46 \mathrm{E}-07$ & $1.47 \mathrm{E}-10$ & $3.68 \mathrm{E}-09$ \\
\hline Sm-151 & $8.29 \mathrm{E}-08$ & $4.97 \mathrm{E}-11$ & $1.24 \mathrm{E}-09$ \\
\hline Sr-90 & $5.16 \mathrm{E}-06$ & 3.09E-09 & 7.74E-08 \\
\hline Th-234 & $4.88 \mathrm{E}-07$ & 2.93E-10 & 7.32E-09 \\
\hline U-238 & 4.88E-07 & 2.93E-10 & 7.32E-09 \\
\hline$Y-90$ & $5.16 \mathrm{E}-06$ & 3.09E-09 & $7.74 \mathrm{E}-08$ \\
\hline Total & 2.93E-04 & $1.76 \mathrm{E}-07$ & $4.40 \mathrm{E}-06$ \\
\hline
\end{tabular}

a Incineration of RH waste. 


\section{B.6 RADIONUCLIDE RELEASES FROM NON-ALPHA LLMW TREATMENT ACCIDENTS}

TABLE B.6.1 Low-Level Mixed Waste, Case 1: Idaho National Engineering Laboratory

\begin{tabular}{|c|c|c|c|}
\hline \multicolumn{4}{|c|}{ Function: Incineration } \\
\hline \multirow[b]{2}{*}{ Nuclide } & \multicolumn{3}{|c|}{ Release (Ci) } \\
\hline & EQ7 & IEX & IFF \\
\hline Co-60 & 2.72E-02 & $1.63 \mathrm{E}-05$ & $4.08 \mathrm{E}-04$ \\
\hline Cs-134 & $1.60 \mathrm{E}-05$ & $9.60 \mathrm{E}-09$ & $2.40 \mathrm{E}-07$ \\
\hline Cs-137 & $1.78 \mathrm{E}-03$ & $1.07 \mathrm{E}-06$ & 2.67E-05 \\
\hline $\mathrm{Eu}-154$ & $2.16 \mathrm{E}-05$ & $1.30 \mathrm{E}-08$ & $3.25 \mathrm{E}-07$ \\
\hline Eu-155 & $1.03 E-05$ & $6.21 \mathrm{E}-09$ & $1.55 \mathrm{E}-07$ \\
\hline $\mathrm{Fe}-55$ & $3.56 \mathrm{E}-03$ & 2.13E-06 & $5.33 \mathrm{E}-05$ \\
\hline $\mathrm{Mn}-54$ & 1.13E-05 & $6.77 \mathrm{E}-09$ & $1.69 \mathrm{E}-07$ \\
\hline $\mathrm{Nb}-94$ & $1.69 \mathrm{E}-05$ & $1.02 \mathrm{E}-08$ & $2.54 \mathrm{E}-07$ \\
\hline $\mathrm{Ni}-59$ & $3.56 \mathrm{E}-04$ & 2.13E-07 & $5.33 \mathrm{E}-06$ \\
\hline $\mathrm{Ni}-63$ & 4.78E-02 & 2.87E-05 & 7.17E-04 \\
\hline $\mathrm{Pm}-147$ & $1.94 \mathrm{E}-04$ & $1.16 \mathrm{E}-07$ & $2.91 \mathrm{E}-06$ \\
\hline $\mathrm{Pu}-238$ & $5.55 \mathrm{E}-05$ & 3.33E-08 & 8.33E-07 \\
\hline $\mathrm{Pu}-241$ & 4.52E-05 & 2.71E-08 & $6.77 \mathrm{E}-07$ \\
\hline Sb-125 & 7.53E-06 & 4.52E-09 & $1.13 \mathrm{E}-07$ \\
\hline Sm-151 & $1.51 \mathrm{E}-05$ & $9.03 \mathrm{E}-09$ & $2.26 \mathrm{E}-07$ \\
\hline Sr-90 & $1.67 \mathrm{E}-03$ & $1.00 \mathrm{E}-06$ & $2.51 \mathrm{E}-05$ \\
\hline $\mathrm{Te}-125 \mathrm{~m}$ & $1.88 \mathrm{E}-06$ & 1.13E-09 & $2.82 \mathrm{E}-08$ \\
\hline Th-234 & $6.68 \mathrm{E}-05$ & 4.01E-08 & $1.00 \mathrm{E}-06$ \\
\hline $\mathrm{U}-238$ & $6.68 \mathrm{E}-05$ & 4.01E-08 & $1.00 \mathrm{E}-06$ \\
\hline$Y-90$ & $1.67 \mathrm{E}-03$ & $1.00 \mathrm{E}-06$ & $2.51 \mathrm{E}-05$ \\
\hline Total & $8.46 E-02$ & $5.08 \mathrm{E}-05$ & 1.27E-03 \\
\hline
\end{tabular}


TABLE B.6.2 Low-Level Mixed Waste, Case 1: Oak Ridge National Laboratory

\begin{tabular}{|c|c|c|c|}
\hline \multicolumn{4}{|c|}{ Function: Incineration } \\
\hline \multirow[b]{2}{*}{ Nuclide } & \multicolumn{3}{|c|}{ Release (Ci) } \\
\hline & IEX & IFF & EQ7 \\
\hline Am-241 & $3.46 \mathrm{E}-09$ & 8.64E-08 & $5.76 \mathrm{E}-06$ \\
\hline Co-60 & $1.89 \mathrm{E}-06$ & 4.73E-05 & $3.15 \mathrm{E}-03$ \\
\hline Cs-137 & 5.44E-06 & $1.36 \mathrm{E}-04$ & $9.06 \mathrm{E}-03$ \\
\hline Eu-154 & 2.02E-08 & $5.04 \mathrm{E}-07$ & $3.36 \mathrm{E}-05$ \\
\hline Eu-155 & $6.91 \mathrm{E}-09$ & $1.73 \mathrm{E}-07$ & $1.15 \mathrm{E}-05$ \\
\hline $\mathrm{Nb}-94$ & $1.44 \mathrm{E}-08$ & $3.60 \mathrm{E}-07$ & $2.40 \mathrm{E}-05$ \\
\hline $\mathrm{Ni}-59$ & 3.05E-07 & 7.64E-06 & $5.09 \mathrm{E}-04$ \\
\hline $\mathrm{Ni}-63$ & $3.21 \mathrm{E}-05$ & 8.04E-04 & $5.36 \mathrm{E}-02$ \\
\hline Pu-238 & $2.14 \mathrm{E}-07$ & 5.35E-06 & $3.57 \mathrm{E}-04$ \\
\hline Pu-239 & $3.46 \mathrm{E}-09$ & 8.64E-08 & $5.76 \mathrm{E}-06$ \\
\hline $\mathrm{Pu}-240$ & 5.18E-09 & $1.30 \mathrm{E}-07$ & $8.64 \mathrm{E}-06$ \\
\hline Pu-241 & $2.27 \mathrm{E}-07$ & 5.67E-06 & $3.78 \mathrm{E}-04$ \\
\hline Sm-151 & $6.56 \mathrm{E}-08$ & $1.64 \mathrm{E}-06$ & $1.09 \mathrm{E}-04$ \\
\hline Sr-90 & $4.81 \mathrm{E}-06$ & $1.20 \mathrm{E}-04$ & 8.02E-03 \\
\hline Tc-99 & 5.75E-08 & $1.44 \mathrm{E}-06$ & $9.59 \mathrm{E}-05$ \\
\hline Th-232 & $5.76 \mathrm{E}-09$ & 1.44E-07 & $9.60 \mathrm{E}-06$ \\
\hline Th-234 & $6.96 \mathrm{E}-07$ & $1.74 \mathrm{E}-05$ & $1.16 \mathrm{E}-03$ \\
\hline $\mathrm{U}-238$ & $6.96 \mathrm{E}-07$ & $1.74 \mathrm{E}-05$ & $1.16 \mathrm{E}-03$ \\
\hline Y-90 & 4.81E-06 & $1.20 \mathrm{E}-04$ & $8.02 \mathrm{E}-03$ \\
\hline Total & $5.14 \mathrm{E}-05$ & $1.29 \mathrm{E}-03$ & 8.57E-02 \\
\hline
\end{tabular}


TABLE B.6.3 Low-Level Mixed Waste, Case 1: Savannah River Site

\begin{tabular}{llll}
\multicolumn{3}{l}{ Function: Incineration } \\
& \multicolumn{3}{c}{ Release (Ci) } \\
\cline { 2 - 4 } Nuclide & EQ7 & IEX & IFF \\
\hline & & & \\
Co-60 & $8.07 E-03$ & $4.84 \mathrm{E}-06$ & $1.21 \mathrm{E}-04$ \\
Cs-137 & $5.87 \mathrm{E}-03$ & $3.52 \mathrm{E}-06$ & $8.80 \mathrm{E}-05$ \\
Eu-154 & $2.95 \mathrm{E}-05$ & $1.77 \mathrm{E}-08$ & $4.42 \mathrm{E}-07$ \\
Eu-155 & $6.80 \mathrm{E}-06$ & $4.08 \mathrm{E}-09$ & $1.02 \mathrm{E}-07$ \\
Fe-55 & $1.61 \mathrm{E}-04$ & $9.65 \mathrm{E}-08$ & $2.41 \mathrm{E}-06$ \\
Nb-94 & $3.85 \mathrm{E}-05$ & $2.31 \mathrm{E}-08$ & $5.78 \mathrm{E}-07$ \\
Ni-59 & $7.61 \mathrm{E}-04$ & $4.57 \mathrm{E}-07$ & $1.14 \mathrm{E}-05$ \\
Ni-63 & $9.21 \mathrm{E}-02$ & $5.52 \mathrm{E}-05$ & $1.38 \mathrm{E}-03$ \\
Pu-238 & $1.99 \mathrm{E}-04$ & $1.20 \mathrm{E}-07$ & $2.99 \mathrm{E}-06$ \\
Pu-240 & $1.59 \mathrm{E}-04$ & $9.52 \mathrm{E}-08$ & $2.38 \mathrm{E}-06$ \\
Pu-241 & $1.59 \mathrm{E}-04$ & $9.52 \mathrm{E}-08$ & $2.38 \mathrm{E}-06$ \\
Sm-151 & $6.34 \mathrm{E}-05$ & $3.81 \mathrm{E}-08$ & $9.52 \mathrm{E}-07$ \\
Sr-90 & $5.46 \mathrm{E}-03$ & $3.28 \mathrm{E}-06$ & $8.19 \mathrm{E}-05$ \\
Tc-99 & $2.27 \mathrm{E}-06$ & $1.36 \mathrm{E}-09$ & $3.40 \mathrm{E}-08$ \\
Th-234 & $2.72 \mathrm{E}-05$ & $1.63 \mathrm{E}-08$ & $4.08 \mathrm{E}-07$ \\
U-238 & $2.72 \mathrm{E}-05$ & $1.63 \mathrm{E}-08$ & $4.08 \mathrm{E}-07$ \\
Y-90 & $5.46 \mathrm{E}-03$ & $3.28 \mathrm{E}-06$ & $8.19 \mathrm{E}-05$ \\
Total & $1.19 \mathrm{E}-01$ & $7.11 \mathrm{E}-05$ & $1.78 \mathrm{E}-03$ \\
\hline & & &
\end{tabular}


TABLE B.6.4 Low-Level Mixed Waste, Case 2: Argonne National Laboratory-East

\begin{tabular}{lccc}
\hline & & \\
& & \\
& \multicolumn{3}{c}{ Runction: Incineration $(\mathrm{Ci})$} \\
\cline { 2 - 4 } Nuclide & EQ7 & IEX1 & IFF1 \\
\cline { 2 - 4 } Am-241 & $1.28 \mathrm{E}-08$ & $7.69 \mathrm{E}-12$ & $1.65 \mathrm{E}-12$ \\
Co-60 & $7.02 \mathrm{E}-06$ & $4.21 \mathrm{E}-09$ & $9.03 \mathrm{E}-10$ \\
Cs-137 & $2.00 \mathrm{E}-05$ & $1.20 \mathrm{E}-08$ & $2.57 \mathrm{E}-09$ \\
Eu-154 & $7.48 \mathrm{E}-08$ & $4.49 \mathrm{E}-11$ & $9.62 \mathrm{E}-12$ \\
Eu-155 & $2.56 \mathrm{E}-08$ & $1.54 \mathrm{E}-11$ & $3.30 \mathrm{E}-12$ \\
Nb-94 & $5.34 \mathrm{E}-08$ & $3.21 \mathrm{E}-11$ & $6.87 \mathrm{E}-12$ \\
Ni-59 & $1.13 \mathrm{E}-06$ & $6.80 \mathrm{E}-10$ & $1.46 \mathrm{E}-10$ \\
Ni-63 & $1.19 \mathrm{E}-04$ & $7.16 \mathrm{E}-08$ & $1.53 \mathrm{E}-08$ \\
Pu-238 & $7.94 \mathrm{E}-07$ & $4.76 \mathrm{E}-10$ & $1.02 \mathrm{E}-10$ \\
Pu-239 & $1.28 \mathrm{E}-08$ & $7.69 \mathrm{E}-12$ & $1.65 \mathrm{E}-12$ \\
Pu-240 & $1.92 \mathrm{E}-08$ & $1.15 \mathrm{E}-11$ & $2.47 \mathrm{E}-12$ \\
Pu-241 & $8.41 \mathrm{E}-07$ & $5.05 \mathrm{E}-10$ & $1.08 \mathrm{E}-10$ \\
Sm-151 & $2.43 \mathrm{E}-07$ & $1.46 \mathrm{E}-10$ & $3.13 \mathrm{E}-11$ \\
Sr-90 & $1.77 \mathrm{E}-05$ & $1.06 \mathrm{E}-08$ & $2.28 \mathrm{E}-09$ \\
Tc-99 & $2.12 \mathrm{E}-07$ & $1.27 \mathrm{E}-10$ & $2.72 \mathrm{E}-11$ \\
Th-232 & $2.14 \mathrm{E}-08$ & $1.28 \mathrm{E}-11$ & $2.75 \mathrm{E}-12$ \\
Th-234 & $2.58 \mathrm{E}-06$ & $1.55 \mathrm{E}-09$ & $3.32 \mathrm{E}-10$ \\
U-238 & $2.58 \mathrm{E}-06$ & $1.55 \mathrm{E}-09$ & $3.32 \mathrm{E}-10$ \\
Y-90 & $1.77 \mathrm{E}-05$ & $1.06 \mathrm{E}-08$ & $2.28 \mathrm{E}-09$ \\
Total & $1.90 \mathrm{E}-04$ & $1.14 \mathrm{E}-07$ & $2.45 \mathrm{E}-08$ \\
\hline & & &
\end{tabular}


TABLE B.6.5 Low-Level Mixed Waste, Case 2: Brookhaven National Laboratory

\begin{tabular}{lccc}
\hline & & \\
Function: Incineration \\
& \multicolumn{3}{c}{ Release (Ci) } \\
\cline { 2 - 4 } Nuclide & EQ7 & IEX & IFF \\
\hline & & \\
Am-241 & $4.36 \mathrm{E}-08$ & $2.62 \mathrm{E}-11$ & $6.54 \mathrm{E}-10$ \\
Co-60 & $2.39 \mathrm{E}-05$ & $1.43 \mathrm{E}-08$ & $3.58 \mathrm{E}-07$ \\
Cs-137 & $6.87 \mathrm{E}-05$ & $4.12 \mathrm{E}-08$ & $1.03 \mathrm{E}-06$ \\
Eu-154 & $2.54 \mathrm{E}-07$ & $1.53 \mathrm{E}-10$ & $3.82 \mathrm{E}-09$ \\
Eu-155 & $8.72 \mathrm{E}-08$ & $5.23 \mathrm{E}-11$ & $1.31 \mathrm{E}-09$ \\
Nb-94 & $1.82 \mathrm{E}-07$ & $1.09 \mathrm{E}-10$ & $2.73 \mathrm{E}-09$ \\
Ni-59 & $3.86 \mathrm{E}-06$ & $2.31 \mathrm{E}-09$ & $5.78 \mathrm{E}-08$ \\
Ni-63 & $4.06 \mathrm{E}-04$ & $2.43 \mathrm{E}-07$ & $6.09 \mathrm{E}-06$ \\
Pu-238 & $2.70 \mathrm{E}-06$ & $1.62 \mathrm{E}-09$ & $4.05 \mathrm{E}-08$ \\
Pu-239 & $4.36 \mathrm{E}-08$ & $2.62 \mathrm{E}-11$ & $6.54 \mathrm{E}-10$ \\
Pu-240 & $6.54 \mathrm{E}-08$ & $3.93 \mathrm{E}-11$ & $9.81 \mathrm{E}-10$ \\
Pu-241 & $2.86 \mathrm{E}-06$ & $1.72 \mathrm{E}-09$ & $4.29 \mathrm{E}-08$ \\
Sm-151. & $8.28 \mathrm{E}-07$ & $4.97 \mathrm{E}-10$ & $1.24 \mathrm{E}-08$ \\
Sr-90 & $6.07 \mathrm{E}-05$ & $3.64 \mathrm{E}-08$ & $9.11 \mathrm{E}-07$ \\
Tc-99 & $7.26 \mathrm{E}-07$ & $4.36 \mathrm{E}-10$ & $1.09 \mathrm{E}-08$ \\
Th-232 & $7.27 \mathrm{E}-08$ & $4.36 \mathrm{E}-11$ & $1.09 \mathrm{E}-09$ \\
Th-234 & $8.79 \mathrm{E}-06$ & $5.27 \mathrm{E}-09$ & $1.32 \mathrm{E}-07$ \\
U-238 & $8.79 \mathrm{E}-06$ & $5.27 \mathrm{E}-09$ & $1.32 \mathrm{E}-07$ \\
Y-90 & $6.07 \mathrm{E}-05$ & $3.64 \mathrm{E}-08$ & $9.11 \mathrm{E}-07$ \\
Total & $6.49 \mathrm{E}-04$ & $3.89 \mathrm{E}-07$ & $9.74 \mathrm{E}-06$ \\
\hline & & &
\end{tabular}




\section{B-84}

TABLE B.6.6 Low-Level Mixed Waste, Case 2: Energy Technology Engineering Center

\begin{tabular}{lccc}
\hline & & \\
Function: Incineration \\
& \multicolumn{3}{c}{ Release (Ci) } \\
\cline { 2 - 4 } Nuclide & EQ7 & IEX & IFF \\
\hline & & & \\
Am-241 & $1.63 \mathrm{E}-07$ & $9.77 \mathrm{E}-11$ & $2.44 \mathrm{E}-09$ \\
Co-60 & $8.92 \mathrm{E}-05$ & $5.35 \mathrm{E}-08$ & $1.34 \mathrm{E}-06$ \\
Cs-137 & $2.56 \mathrm{E}-04$ & $1.54 \mathrm{E}-07$ & $3.84 \mathrm{E}-06$ \\
Eu-154 & $9.49 \mathrm{E}-07$ & $5.70 \mathrm{E}-10$ & $1.42 \mathrm{E}-08$ \\
Eu-155 & $3.26 \mathrm{E}-07$ & $1.95 \mathrm{E}-10$ & $4.88 \mathrm{E}-09$ \\
Nb-94 & $6.78 \mathrm{E}-07$ & $4.07 \mathrm{E}-10$ & $1.02 \mathrm{E}-08$ \\
Ni-59 & $1.44 \mathrm{E}-05$ & $8.63 \mathrm{E}-09$ & $2.16 \mathrm{E}-07$ \\
Ni-63 & $1.51 \mathrm{E}-03$ & $9.08 \mathrm{E}-07$ & $2.27 \mathrm{E}-05$ \\
Pu-238 & $1.01 \mathrm{E}-05$ & $6.05 \mathrm{E}-09$ & $1.51 \mathrm{E}-07$ \\
Pu-239 & $1.63 \mathrm{E}-07$ & $9.77 \mathrm{E}-11$ & $2.44 \mathrm{E}-09$ \\
Pu-240 & $2.44 \mathrm{E}-07$ & $1.46 \mathrm{E}-10$ & $3.66 \mathrm{E}-09$ \\
Pu-241 & $1.07 \mathrm{E}-05$ & $6.41 \mathrm{E}-09$ & $1.60 \mathrm{E}-07$ \\
Sm-151 & $3.09 \mathrm{E}-06$ & $1.85 \mathrm{E}-09$ & $4.63 \mathrm{E}-08$ \\
Sr-90 & $2.27 \mathrm{E}-04$ & $1.36 \mathrm{E}-07$ & $3.40 \mathrm{E}-06$ \\
Tc-99 & $2.71 \mathrm{E}-06$ & $1.63 \mathrm{E}-09$ & $4.06 \mathrm{E}-08$ \\
Th-232 & $2.71 \mathrm{E}-07$ & $1.63 \mathrm{E}-10$ & $4.07 \mathrm{E}-09$ \\
Th-234 & $3.28 \mathrm{E}-05$ & $1.97 \mathrm{E}-08$ & $4.92 \mathrm{E}-07$ \\
U-238 & $3.28 \mathrm{E}-05$ & $1.97 \mathrm{E}-08$ & $4.92 \mathrm{E}-07$ \\
Y-90 & $2.27 \mathrm{E}-04$ & $1.36 \mathrm{E}-07$ & $3.40 \mathrm{E}-06$ \\
Total & $2.42 \mathrm{E}-03$ & $1.45 \mathrm{E}-06$ & $3.63 \mathrm{E}-05$ \\
\hline & & &
\end{tabular}


TABLE B.6.7 Low-Level Mixed Waste, Case 2:

Fernald Environmental Management Project

\begin{tabular}{|c|c|c|c|}
\hline \multicolumn{4}{|c|}{ Function: Incineration } \\
\hline \multirow[b]{2}{*}{ Nuclide } & \multicolumn{3}{|c|}{ Release (Ci) } \\
\hline & EQ7 & IEX & IFF \\
\hline Ac-228 & $3.19 \mathrm{E}-11$ & $1.90 \mathrm{E}-14$ & $4.78 \mathrm{E}-13$ \\
\hline $\mathrm{Bi}-212$ & $5.36 \mathrm{E}-12$ & $0.00 \mathrm{E}+00$ & $8.00 \mathrm{E}-14$ \\
\hline $\mathrm{Pb}-212$ & $5.36 \mathrm{E}-12$ & $0.00 \mathrm{E}+00$ & $8.00 \mathrm{E}-14$ \\
\hline $\mathrm{Ra}-224$ & $5.36 \mathrm{E}-12$ & $0.00 \mathrm{E}+00$ & 8.00E-14 \\
\hline Ra-228 & $3.19 \mathrm{E}-11$ & $1.90 \mathrm{E}-14$ & $4.78 \mathrm{E}-13$ \\
\hline Tc-99 & $5.92 \mathrm{E}-10$ & $3.55 E-13$ & $8.89 \mathrm{E}-12$ \\
\hline Th-228 & $5.36 \mathrm{E}-12$ & $0.00 E+00$ & $8.00 \mathrm{E}-14$ \\
\hline Th-231 & 3.07E-11 & $1.80 \mathrm{E}-14$ & $4.61 \mathrm{E}-13$ \\
\hline Th-232 & $3.23 \mathrm{E}-10$ & $1.94 \mathrm{E}-13$ & $4.85 \mathrm{E}-12$ \\
\hline Th-234 & $3.93 \mathrm{E}-08$ & $2.36 \mathrm{E}-11$ & $5.90 \mathrm{E}-10$ \\
\hline U-235 & $3.06 \mathrm{E}-11$ & $1.80 \mathrm{E}-14$ & $4.59 \mathrm{E}-13$ \\
\hline $\mathrm{U}-238$ & 3.93E-08 & $2.36 \mathrm{E}-11$ & $5.90 \mathrm{E}-10$ \\
\hline Total & 7.97E-08 & $4.78 \mathrm{E}-11$ & $1.20 \mathrm{E}-09$ \\
\hline
\end{tabular}


TABLE B.6.8 Low-Level Mixed Waste, Case 2: Hanford

\begin{tabular}{|c|c|c|c|}
\hline \multicolumn{4}{|c|}{ Function: Incineration } \\
\hline \multirow[b]{2}{*}{ Nuclide } & \multicolumn{3}{|c|}{ Release (Ci) } \\
\hline & EQ7 & IEX & IFF \\
\hline Am-241 & $2.39 \mathrm{E}-05$ & $1.43 \mathrm{E}-08$ & $3.58 \mathrm{E}-07$ \\
\hline Co-60 & $3.54 \mathrm{E}-05$ & 2.12E-08 & 5.31E-07 \\
\hline Cs-137 & $2.81 \mathrm{E}-02$ & $1.68 \mathrm{E}-05$ & $4.21 \mathrm{E}-04$ \\
\hline Eu-154 & $4.22 \mathrm{E}-05$ & 2.53E-08 & $6.33 \mathrm{E}-07$ \\
\hline $\mathrm{Nb}-94$ & $2.40 \mathrm{E}-06$ & $1.44 \mathrm{E}-09$ & $3.59 \mathrm{E}-08$ \\
\hline $\mathrm{Ni}-59$ & 5.41E-05 & 3.25E-08 & $8.11 \mathrm{E}-07$ \\
\hline $\mathrm{Ni}-63$ & $5.56 \mathrm{E}-03$ & 3.33E-06 & $8.34 \mathrm{E}-05$ \\
\hline $\mathrm{Pu}-238$ & $1.26 \mathrm{E}-03$ & 7.53E-07 & $1.88 \mathrm{E}-05$ \\
\hline Pu-239 & $1.70 \mathrm{E}-05$ & $1.02 \mathrm{E}-08$ & $2.55 \mathrm{E}-07$ \\
\hline $\mathrm{Pu}-240$ & $9.70 \mathrm{E}-06$ & $5.82 \mathrm{E}-09$ & $1.46 \mathrm{E}-07$ \\
\hline Pu-241 & $2.78 \mathrm{E}-04$ & 1.67E-07 & 4.18E-06 \\
\hline Sm-151 & 4.04E-04 & $2.42 \mathrm{E}-07$ & $6.06 \mathrm{E}-06$ \\
\hline Sr-90 & $2.50 \mathrm{E}-02$ & $1.50 \mathrm{E}-05$ & $3.75 \mathrm{E}-04$ \\
\hline Tc-99 & $1.26 \mathrm{E}-05$ & 7.53E-09 & $1.88 \mathrm{E}-07$ \\
\hline Th-234 & $1.55 \mathrm{E}-05$ & 9.31E-09 & 2.33E-07 \\
\hline $\mathrm{U}-238$ & $1.55 \mathrm{E}-05$ & $9.31 \mathrm{E}-09$ & 2.33E-07 \\
\hline$Y-90$ & $2.50 \mathrm{E}-02$ & $1.50 \mathrm{E}-05$ & 3.75E-04 \\
\hline Total & $8.58 \mathrm{E}-02$ & 5.15E-05 & 1.29E-03 \\
\hline
\end{tabular}


TABLE B.6.9 Low-Level Mixed Waste, Case 2: Idaho National Engineering Laboratory

\begin{tabular}{lccc}
\hline & & \\
Function: Incineration & \multicolumn{3}{c}{ Release (Ci) } \\
\multicolumn{5}{c}{ Nuclide } & EQ7 & IEX & IFF \\
\cline { 2 - 4 } Co-60 & $2.75 \mathrm{E}-02$ & $1.65 \mathrm{E}-05$ & $4.13 \mathrm{E}-04$ \\
Cs-134 & $1.62 \mathrm{E}-05$ & $9.71 \mathrm{E}-09$ & $2.43 \mathrm{E}-07$ \\
Cs-137 & $1.80 \mathrm{E}-03$ & $1.08 \mathrm{E}-06$ & $2.70 \mathrm{E}-05$ \\
Eu-154 & $2.19 \mathrm{E}-05$ & $1.31 \mathrm{E}-08$ & $3.28 \mathrm{E}-07$ \\
Eu-155 & $1.05 \mathrm{E}-05$ & $6.28 \mathrm{E}-09$ & $1.57 \mathrm{E}-07$ \\
Fe-55 & $3.60 \mathrm{E}-03$ & $2.16 \mathrm{E}-06$ & $5.40 \mathrm{E}-05$ \\
Mn-54 & $1.14 \mathrm{E}-05$ & $6.85 \mathrm{E}-09$ & $1.71 \mathrm{E}-07$ \\
Nb-94 & $1.71 \mathrm{E}-05$ & $1.03 \mathrm{E}-08$ & $2.57 \mathrm{E}-07$ \\
Ni-59 & $3.60 \mathrm{E}-04$ & $2.16 \mathrm{E}-07$ & $5.40 \mathrm{E}-06$ \\
Ni-63 & $4.84 \mathrm{E}-02$ & $2.90 \mathrm{E}-05$ & $7.26 \mathrm{E}-04$ \\
Pm-147 & $1.96 \mathrm{E}-04$ & $1.18 \mathrm{E}-07$ & $2.94 \mathrm{E}-06$ \\
Pu-238 & $5.62 \mathrm{E}-05$ & $3.37 \mathrm{E}-08$ & $8.43 \mathrm{E}-07$ \\
Pu-241 & $4.57 \mathrm{E}-05$ & $2.74 \mathrm{E}-08$ & $6.85 \mathrm{E}-07$ \\
Sb-125 & $7.62 \mathrm{E}-06$ & $4.57 \mathrm{E}-09$ & $1.14 \mathrm{E}-07$ \\
Sm-151 & $1.52 \mathrm{E}-05$ & $9.14 \mathrm{E}-09$ & $2.28 \mathrm{E}-07$ \\
Sr-90 & $1.69 \mathrm{E}-03$ & $1.02 \mathrm{E}-06$ & $2.54 \mathrm{E}-05$ \\
Te-125m & $1.90 \mathrm{E}-06$ & $1.14 \mathrm{E}-09$ & $2.86 \mathrm{E}-08$ \\
Th-234 & $6.76 \mathrm{E}-05$ & $4.06 \mathrm{E}-08$ & $1.01 \mathrm{E}-06$ \\
U-238 & $6.76 \mathrm{E}-05$ & $4.06 \mathrm{E}-08$ & $1.01 \mathrm{E}-06$ \\
Y-90 & $1.69 \mathrm{E}-03$ & $1.02 \mathrm{E}-06$ & $2.54 \mathrm{E}-05$ \\
Total & $8.56 \mathrm{E}-02$ & $5.14 \mathrm{E}-05$ & $1.28 \mathrm{E}-03$ \\
\hline & & &
\end{tabular}


TABLE B.6.10 Low-Level Mixed Waste, Case 2: Knolls Atomic Power Laboratory, Schenectady

Function: Incineration

\begin{tabular}{llcl}
\hline & \multicolumn{3}{c}{ Release (Ci) } \\
\cline { 2 - 4 } Nuclide & EQ7 & IEX & IFF \\
\hline & & & \\
Co-60 & $1.09 \mathrm{E}-03$ & $6.53 \mathrm{E}-07$ & $1.63 \mathrm{E}-05$ \\
Cs-134 & $6.40 \mathrm{E}-07$ & $3.84 \mathrm{E}-10$ & $9.59 \mathrm{E}-09$ \\
Cs-137 & $7.11 \mathrm{E}-05$ & $4.27 \mathrm{E}-08$ & $1.07 \mathrm{E}-06$ \\
Eu-154 & $8.65 \mathrm{E}-07$ & $5.19 \mathrm{E}-10$ & $1.30 \mathrm{E}-08$ \\
Eu-155 & $4.14 \mathrm{E}-07$ & $2.48 \mathrm{E}-10$ & $6.21 \mathrm{E}-09$ \\
Fe-55 & $1.42 \mathrm{E}-04$ & $8.53 \mathrm{E}-08$ & $2.13 \mathrm{E}-06$ \\
Mn-54 & $4.51 \mathrm{E}-07$ & $2.71 \mathrm{E}-10$ & $6.77 \mathrm{E}-09$ \\
Nb-94 & $6.77 \mathrm{E}-07$ & $4.06 \mathrm{E}-10$ & $1.02 \mathrm{E}-08$ \\
Ni-59 & $1.42 \mathrm{E}-05$ & $8.53 \mathrm{E}-09$ & $2.13 \mathrm{E}-07$ \\
Ni-63 & $1.91 \mathrm{E}-03$ & $1.15 \mathrm{E}-06$ & $2.87 \mathrm{E}-05$ \\
Pm-147 & $7.75 \mathrm{E}-06$ & $4.65 \mathrm{E}-09$ & $1.16 \mathrm{E}-07$ \\
Pu-238 & $2.22 \mathrm{E}-06$ & $1.33 \mathrm{E}-09$ & $3.33 \mathrm{E}-08$ \\
Pu-241 & $1.81 \mathrm{E}-06$ & $1.08 \mathrm{E}-09$ & $2.71 \mathrm{E}-08$ \\
Sb-125 & $3.01 \mathrm{E}-07$ & $1.81 \mathrm{E}-10$ & $4.51 \mathrm{E}-09$ \\
Sm-151 & $6.02 \mathrm{E}-07$ & $3.61 \mathrm{E}-10$ & $9.03 \mathrm{E}-09$ \\
Sr-90 & $6.70 \mathrm{E}-05$ & $4.02 \mathrm{E}-08$ & $1.00 \mathrm{E}-06$ \\
Te-125m & $7.52 \mathrm{E}-08$ & $4.51 \mathrm{E}-11$ & $1.13 \mathrm{E}-09$ \\
Th-234 & $2.67 \mathrm{E}-06$ & $1.60 \mathrm{E}-09$ & $4.01 \mathrm{E}-08$ \\
U-238 & $2.67 \mathrm{E}-06$ & $1.60 \mathrm{E}-09$ & $4.01 \mathrm{E}-08$ \\
Y-90 & $6.70 \mathrm{E}-05$ & $4.02 \mathrm{E}-08$ & $1.00 \mathrm{E}-06$ \\
Total & $3.38 \mathrm{E}-03$ & $2.03 \mathrm{E}-06$ & $5.07 \mathrm{E}-05$ \\
\hline & & &
\end{tabular}


TABLE B.6.11 Low-Level Mixed Waste, Case 2: Nevada Test Site

\begin{tabular}{lccc}
\hline & & \\
Function: Incineration \\
& \multicolumn{3}{c}{ Release (Ci) } \\
\cline { 2 - 4 } Nuclide & EQ7 & IEX1 & IFF1 \\
\hline & & & \\
Am-241 & $1.02 \mathrm{E}-06$ & $6.10 \mathrm{E}-10$ & $1.31 \mathrm{E}-10$ \\
Co-60 & $5.57 \mathrm{E}-04$ & $3.34 \mathrm{E}-07$ & $7.16 \mathrm{E}-08$ \\
Cs-137 & $1.60 \mathrm{E}-03$ & $9.57 \mathrm{E}-07$ & $2.05 \mathrm{E}-07$ \\
Eu-154 & $5.93 \mathrm{E}-06$ & $3.56 \mathrm{E}-09$ & $7.62 \mathrm{E}-10$ \\
Eu-155 & $2.03 \mathrm{E}-06$ & $1.22 \mathrm{E}-09$ & $2.61 \mathrm{E}-10$ \\
Nb-94 & $4.24 \mathrm{E}-06$ & $2.54 \mathrm{E}-09$ & $5.45 \mathrm{E}-10$ \\
Ni-59 & $8.99 \mathrm{E}-05$ & $5.39 \mathrm{E}-08$ & $1.16 \mathrm{E}-08$ \\
Ni-63 & $9.46 \mathrm{E}-03$ & $5.67 \mathrm{E}-06$ & $1.22 \mathrm{E}-06$ \\
Pu-238 & $6.30 \mathrm{E}-05$ & $3.78 \mathrm{E}-08$ & $8.09 \mathrm{E}-09$ \\
Pu-239 & $1.02 \mathrm{E}-06$ & $6.10 \mathrm{E}-10$ & $1.31 \mathrm{E}-10$ \\
Pu-240 & $1.52 \mathrm{E}-06$ & $9.15 \mathrm{E}-10$ & $1.96 \mathrm{E}-10$ \\
Pu-241 & $6.67 \mathrm{E}-05$ & $4.00 \mathrm{E}-08$ & $8.57 \mathrm{E}-09$ \\
Sm-151 & $1.93 \mathrm{E}-05$ & $1.16 \mathrm{E}-08$ & $2.48 \mathrm{E}-09$ \\
Sr-90 & $1.41 \mathrm{E}-03$ & $8.47 \mathrm{E}-07$ & $1.81 \mathrm{E}-07$ \\
Tc-99 & $1.69 \mathrm{E}-05$ & $1.01 \mathrm{E}-08$ & $2.17 \mathrm{E}-09$ \\
Th-232 & $1.69 \mathrm{E}-06$ & $1.02 \mathrm{E}-09$ & $2.18 \mathrm{E}-10$ \\
Th-234 & $2.05 \mathrm{E}-04$ & $1.23 \mathrm{E}-07$ & $2.63 \mathrm{E}-08$ \\
U-238 & $2.05 \mathrm{E}-04$ & $1.23 \mathrm{E}-07$ & $2.63 \mathrm{E}-08$ \\
Y-90 & $1.41 \mathrm{E}-03$ & $8.47 \mathrm{E}-07$ & $1.81 \mathrm{E}-07$ \\
Total & $1.51 \mathrm{E}-02$ & $9.07 \mathrm{E}-06$ & $1.94 \mathrm{E}-06$ \\
\hline & & &
\end{tabular}


TABLE B.6.12 Low-Level Mixed Waste,

Case 2: Oak Ridge National Laboratory

\begin{tabular}{|c|c|c|c|}
\hline \multicolumn{4}{|c|}{ Function: Incineration } \\
\hline \multirow[b]{2}{*}{ Nuclide } & \multicolumn{3}{|c|}{ Release (Ci) } \\
\hline & $\mathrm{EQ7}$ & IEX & IFF \\
\hline Am-241 & $5.76 \mathrm{E}-06$ & $3.46 \mathrm{E}-09$ & $8.64 \mathrm{E}-08$ \\
\hline Co-60 & $3.15 \mathrm{E}-03$ & $1.89 \mathrm{E}-06$ & 4.73E-05 \\
\hline Cs-137 & $9.06 \mathrm{E}-03$ & $5.44 \mathrm{E}-06$ & $1.36 \mathrm{E}-04$ \\
\hline Eu-154 & $3.36 \mathrm{E}-05$ & $2.02 \mathrm{E}-08$ & 5.04E-07 \\
\hline Eu-155 & 1.15E-05 & $6.91 \mathrm{E}-09$ & $1.73 \mathrm{E}-07$ \\
\hline $\mathrm{Nb}-94$ & $2.40 \mathrm{E}-05$ & $1.44 \mathrm{E}-08$ & $3.60 \mathrm{E}-07$ \\
\hline $\mathrm{Ni}-59$ & $5.09 \mathrm{E}-04$ & $3.05 \mathrm{E}-07$ & $7.64 \mathrm{E}-06$ \\
\hline $\mathrm{Ni}-63$ & $5.36 \mathrm{E}-02$ & $3.21 \mathrm{E}-05$ & $8.04 \mathrm{E}-04$ \\
\hline Pu-238 & 3.57E-04 & $2.14 \mathrm{E}-07$ & $5.35 \mathrm{E}-06$ \\
\hline Pu-239 & $5.76 \mathrm{E}-06$ & $3.46 \mathrm{E}-09$ & $8.64 \mathrm{E}-08$ \\
\hline Pu-240 & 8.64E-06 & $5.18 \mathrm{E}-09$ & $1.30 \mathrm{E}-07$ \\
\hline Pu-241 & $3.78 \mathrm{E}-04$ & 2.27E-07 & 5.67E-06 \\
\hline Sm-151 & $1.09 \mathrm{E}-04$ & $6.56 \mathrm{E}-08$ & $1.64 \mathrm{E}-06$ \\
\hline Sr-90 & 8.02E-03 & 4.81E-06 & $1.20 \mathrm{E}-04$ \\
\hline Tc-99 & $9.59 \mathrm{E}-05$ & 5.75E-08 & $1.44 \mathrm{E}-06$ \\
\hline Th-232 & $9.60 \mathrm{E}-06$ & $5.76 \mathrm{E}-09$ & $1.44 \mathrm{E}-07$ \\
\hline Th-234 & $1.16 \mathrm{E}-03$ & $6.96 \mathrm{E}-07$ & $1.74 \mathrm{E}-05$ \\
\hline $\mathrm{U}-238$ & $1.16 \mathrm{E}-03$ & $6.96 \mathrm{E}-07$ & $1.74 \mathrm{E}-05$ \\
\hline$Y-90$ & 8.02E-03 & $4.81 \mathrm{E}-06$ & $1.20 \mathrm{E}-04$ \\
\hline Total & 8.57E-02 & $5.14 \mathrm{E}-05$ & $1.29 \mathrm{E}-03$ \\
\hline
\end{tabular}


TABLE B.6.13 Low-Level Mixed Waste, Case 2: Paducah Gaseous Diffusion Plant

\begin{tabular}{llll}
\hline & & & \\
Function: Incineration & \multicolumn{3}{c}{ Release (Ci) } \\
\cline { 2 - 4 } Nuclide & EQ7 & IEX & IFF \\
\cline { 2 - 4 } Ac-228 & $1.46 \mathrm{E}-06$ & $8.79 \mathrm{E}-10$ & $2.20 \mathrm{E}-08$ \\
$\mathrm{Bi}-212$ & $2.42 \mathrm{E}-07$ & $1.45 \mathrm{E}-10$ & $3.63 \mathrm{E}-09$ \\
$\mathrm{~Pb}-212$ & $2.42 \mathrm{E}-07$ & $1.45 \mathrm{E}-10$ & $3.63 \mathrm{E}-09$ \\
$\mathrm{Ra}-224$ & $2.42 \mathrm{E}-07$ & $1.45 \mathrm{E}-10$ & $3.63 \mathrm{E}-09$ \\
$\mathrm{Ra}-228$ & $1.46 \mathrm{E}-06$ & $8.79 \mathrm{E}-10$ & $2.20 \mathrm{E}-08$ \\
$\mathrm{Tc}-99$ & $5.94 \mathrm{E}-04$ & $3.57 \mathrm{E}-07$ & $8.91 \mathrm{E}-06$ \\
Th-228 & $2.42 \mathrm{E}-07$ & $1.45 \mathrm{E}-10$ & $3.63 \mathrm{E}-09$ \\
Th-231 & $1.54 \mathrm{E}-06$ & $9.26 \mathrm{E}-10$ & $2.31 \mathrm{E}-08$ \\
Th-232 & $1.62 \mathrm{E}-05$ & $9.73 \mathrm{E}-09$ & $2.43 \mathrm{E}-07$ \\
Th-234 & $1.97 \mathrm{E}-03$ & $1.18 \mathrm{E}-06$ & $2.96 \mathrm{E}-05$ \\
U-235 & $1.53 \mathrm{E}-06$ & $9.18 \mathrm{E}-10$ & $2.29 \mathrm{E}-08$ \\
U-238 & $1.97 \mathrm{E}-03$ & $1.18 \mathrm{E}-06$ & $2.96 \mathrm{E}-05$ \\
Total & $4.56 \mathrm{E}-03$ & $2.74 \mathrm{E}-06$ & $6.85 \mathrm{E}-05$ \\
\hline
\end{tabular}


TABLE B.6.14 Low-Level Mixed Waste, Case 2: Pantex Plant

\begin{tabular}{lccc}
\hline & & \\
& & \\
& & \\
& & \\
Nunction: Incineration \\
\cline { 2 - 4 } Nuclide & EQ7 & IEX & IFF \\
\hline & & & \\
Co-60 & $1.19 \mathrm{E}-04$ & $7.13 \mathrm{E}-08$ & $1.78 \mathrm{E}-06$ \\
Cs-137 & $9.00 \mathrm{E}-05$ & $5.40 \mathrm{E}-08$ & $1.35 \mathrm{E}-06$ \\
Eu-154 & $9.90 \mathrm{E}-07$ & $5.94 \mathrm{E}-10$ & $1.49 \mathrm{E}-08$ \\
Fe-55 & $1.49 \mathrm{E}-05$ & $8.97 \mathrm{E}-09$ & $2.24 \mathrm{E}-07$ \\
Ni-59 & $1.98 \mathrm{E}-06$ & $1.19 \mathrm{E}-09$ & $2.97 \mathrm{E}-08$ \\
Ni-63 & $2.63 \mathrm{E}-04$ & $1.58 \mathrm{E}-07$ & $3.94 \mathrm{E}-06$ \\
Pm-147 & $8.28 \mathrm{E}-06$ & $4.97 \mathrm{E}-09$ & $1.24 \mathrm{E}-07$ \\
Pu-238 & $3.42 \mathrm{E}-06$ & $2.05 \mathrm{E}-09$ & $5.13 \mathrm{E}-08$ \\
Pu-241 & $1.73 \mathrm{E}-05$ & $1.04 \mathrm{E}-08$ & $2.59 \mathrm{E}-07$ \\
Sm-151 & $7.92 \mathrm{E}-07$ & $4.75 \mathrm{E}-10$ & $1.19 \mathrm{E}-08$ \\
Sr-90 & $8.46 \mathrm{E}-05$ & $5.08 \mathrm{E}-08$ & $1.27 \mathrm{E}-06$ \\
Y-90 & $8.46 \mathrm{E}-05$ & $5.08 \mathrm{E}-08$ & $1.27 \mathrm{E}-06$ \\
Total & $6.89 \mathrm{E}-04$ & $4.13 \mathrm{E}-07$ & $1.03 \mathrm{E}-05$ \\
\hline
\end{tabular}

TABLE B.6.15 Low-Level Mixed Waste, Case 2: Portsmouth Gaseous Diffusion Plant

Function: Incineration

Release (Ci)

\begin{tabular}{llll} 
& \multicolumn{3}{c}{ Release (Ci) } \\
\cline { 2 - 4 } Nuclide & EQ7 & IEX & IFE \\
\hline & & & \\
Ac-228 & $2.39 \mathrm{E}-09$ & $1.43 \mathrm{E}-12$ & $3.58 \mathrm{E}-11$ \\
$\mathrm{Bi}-212$ & $3.99 \mathrm{E}-10$ & $2.40 \mathrm{E}-13$ & $5.99 \mathrm{E}-12$ \\
$\mathrm{~Pb}-212$ & $3.99 \mathrm{E}-10$ & $2.40 \mathrm{E}-13$ & $5.99 \mathrm{E}-12$ \\
$\mathrm{Ra}-224$ & $3.99 \mathrm{E}-10$ & $2.40 \mathrm{E}-13$ & $5.99 \mathrm{E}-12$ \\
$\mathrm{Ra}-228$ & $2.39 \mathrm{E}-09$ & $1.43 \mathrm{E}-12$ & $3.58 \mathrm{E}-11$ \\
Tc-99 & $9.55 \mathrm{E}-07$ & $5.73 \mathrm{E}-10$ & $1.43 \mathrm{E}-08$ \\
Th-228 & $3.99 \mathrm{E}-10$ & $2.40 \mathrm{E}-13$ & $5.99 \mathrm{E}-12$ \\
Th-231 & $2.48 \mathrm{E}-09$ & $1.49 \mathrm{E}-12$ & $3.72 \mathrm{E}-11$ \\
Th-232 & $2.61 \mathrm{E}-08$ & $1.56 \mathrm{E}-11$ & $3.91 \mathrm{E}-10$ \\
Th-234 & $3.17 \mathrm{E}-06$ & $1.90 \mathrm{E}-09$ & $4.76 \mathrm{E}-08$ \\
$\mathrm{U}-235$ & $2.46 \mathrm{E}-09$ & $1.47 \mathrm{E}-12$ & $3.69 \mathrm{E}-11$ \\
$\mathrm{U}-238$ & $3.17 \mathrm{E}-06$ & $1.90 \mathrm{E}-09$ & $4.76 \mathrm{E}-08$ \\
Total & $7.34 \mathrm{E}-06$ & $4.40 \mathrm{E}-09$ & $1.10 \mathrm{E}-07$ \\
\hline
\end{tabular}


TABLE B.6.16 Low-Level Mixed Waste, Case 2: Sandia National Laboratories-New Mexico

Function: Incineration

\begin{tabular}{llll}
\hline & \multicolumn{3}{c}{ Release (Ci) } \\
\cline { 2 - 4 } Nuclide & IEX & IFF & EQ7 \\
\hline & & & \\
Co-60 & $3.73 E-08$ & $9.33 \mathrm{E}-07$ & $6.22 \mathrm{E}-05$ \\
Cs-137 & $2.71 \mathrm{E}-08$ & $6.79 \mathrm{E}-07$ & $4.52 \mathrm{E}-05$ \\
Eu-154 & $1.36 \mathrm{E}-10$ & $3.41 \mathrm{E}-09$ & $2.27 \mathrm{E}-07$ \\
Eu-155 & $3.14 \mathrm{E}-11$ & $7.86 \mathrm{E}-10$ & $5.24 \mathrm{E}-08$ \\
Fe-55 & $7.44 \mathrm{E}-10$ & $1.86 \mathrm{E}-08$ & $1.24 \mathrm{E}-06$ \\
Nb-94 & $1.78 \mathrm{E}-10$ & $4.45 \mathrm{E}-09$ & $2.97 \mathrm{E}-07$ \\
Ni-59 & $3.52 \mathrm{E}-09$ & $8.80 \mathrm{E}-08$ & $5.87 \mathrm{E}-06$ \\
Ni-63 & $4.26 \mathrm{E}-07$ & $1.06 \mathrm{E}-05$ & $7.10 \mathrm{E}-04$ \\
Pu-238 & $9.22 \mathrm{E}-10$ & $2.31 \mathrm{E}-08$ & $1.54 \mathrm{E}-06$ \\
Pu-240 & $7.34 \mathrm{E}-10$ & $1.83 \mathrm{E}-08$ & $1.22 \mathrm{E}-06$ \\
Pu-241 & $7.34 \mathrm{E}-10$ & $1.83 \mathrm{E}-08$ & $1.22 \mathrm{E}-06$ \\
Sm-151 & $2.93 \mathrm{E}-10$ & $7.34 \mathrm{E}-09$ & $4.89 \mathrm{E}-07$ \\
Sr-90 & $2.53 \mathrm{E}-08$ & $6.31 \mathrm{E}-07$ & $4.21 \mathrm{E}-05$ \\
Tc-99 & $1.05 \mathrm{E}-11$ & $2.62 \mathrm{E}-10$ & $1.75 \mathrm{E}-08$ \\
Th-234 & $1.26 \mathrm{E}-10$ & $3.14 \mathrm{E}-09$ & $2.10 \mathrm{E}-07$ \\
U-238 & $1.26 \mathrm{E}-10$ & $3.14 \mathrm{E}-09$ & $2.10 \mathrm{E}-07$ \\
Y-90 & $2.53 \mathrm{E}-08$ & $6.31 \mathrm{E}-07$ & $4.21 \mathrm{E}-05$ \\
Total & $5.48 \mathrm{E}-07$ & $1.37 \mathrm{E}-05$ & $9.14 \mathrm{E}-04$ \\
\hline & & & \\
\hline
\end{tabular}


TABLE B.6.17 Low-Level Mixed Waste, Case 2: Savannah River Site

\begin{tabular}{lccc}
\hline & & \\
\multicolumn{4}{c}{ Function: Incineration } \\
\multicolumn{4}{c}{ Release (Ci) } \\
\cline { 2 - 4 } Nuclide & EQ7 & IEX & IFF \\
\hline & & & \\
Co-60 & $8.07 \mathrm{E}-03$ & $4.84 \mathrm{E}-06$ & $1.21 \mathrm{E}-04$ \\
Cs-137 & $5.87 \mathrm{E}-03$ & $3.52 \mathrm{E}-06$ & $8.80 \mathrm{E}-05$ \\
Eu-154 & $2.95 \mathrm{E}-05$ & $1.77 \mathrm{E}-08$ & $4.42 \mathrm{E}-07$ \\
Eu-155 & $6.80 \mathrm{E}-06$ & $4.08 \mathrm{E}-09$ & $1.02 \mathrm{E}-07$ \\
Fe-55 & $1.61 \mathrm{E}-04$ & $9.65 \mathrm{E}-08$ & $2.41 \mathrm{E}-06$ \\
Nb-94 & $3.85 \mathrm{E}-05$ & $2.31 \mathrm{E}-08$ & $5.78 \mathrm{E}-07$ \\
Ni-59 & $7.61 \mathrm{E}-04$ & $4.57 \mathrm{E}-07$ & $1.14 \mathrm{E}-05$ \\
Ni-63 & $9.21 \mathrm{E}-02$ & $5.52 \mathrm{E}-05$ & $1.38 \mathrm{E}-03$ \\
Pu-238 & $1.99 \mathrm{E}-04$ & $1.20 \mathrm{E}-07$ & $2.99 \mathrm{E}-06$ \\
Pu-240 & $1.59 \mathrm{E}-04$ & $9.52 \mathrm{E}-08$ & $2.38 \mathrm{E}-06$ \\
Pu-241 & $1.59 \mathrm{E}-04$ & $9.52 \mathrm{E}-08$ & $2.38 \mathrm{E}-06$ \\
Sm-151 & $6.34 \mathrm{E}-05$ & $3.81 \mathrm{E}-08$ & $9.52 \mathrm{E}-07$ \\
Sr-90 & $5.46 \mathrm{E}-03$ & $3.28 \mathrm{E}-06$ & $8.19 \mathrm{E}-05$ \\
Tc-99 & $2.27 \mathrm{E}-06$ & $1.36 \mathrm{E}-09$ & $3.40 \mathrm{E}-08$ \\
Th-234 & $2.72 \mathrm{E}-05$ & $1.63 \mathrm{E}-08$ & $4.08 \mathrm{E}-07$ \\
U-238 & $2.72 \mathrm{E}-05$ & $1.63 \mathrm{E}-08$ & $4.08 \mathrm{E}-07$ \\
Y-90 & $5.46 \mathrm{E}-03$ & $3.28 \mathrm{E}-06$ & $8.19 \mathrm{E}-05$ \\
Total & $1.19 \mathrm{E}-01$ & $7.11 \mathrm{E}-05$ & $1.78 \mathrm{E}-03$ \\
\hline & & &
\end{tabular}


TABLE B.6.18 Low-Level Mixed Waste, Case 4:

Energy Technology Engineering Center

\begin{tabular}{|c|c|c|c|}
\hline \multicolumn{4}{|c|}{ Function: Incineration } \\
\hline \multirow[b]{2}{*}{ Nuclide } & \multicolumn{3}{|c|}{ Release (Ci) } \\
\hline & EQ7 & IEX & IFF \\
\hline Am-241 & 1.63E-07 & $9.77 \mathrm{E}-11$ & 2.44E-09 \\
\hline Co-60 & 8.92E-05 & 5.35E-08 & $1.34 \mathrm{E}-06$ \\
\hline Cs-137 & $2.56 \mathrm{E}-04$ & $1.54 \mathrm{E}-07$ & $3.84 \mathrm{E}-06$ \\
\hline Eu-154 & $9.49 \mathrm{E}-07$ & $5.70 \mathrm{E}-10$ & $1.42 \mathrm{E}-08$ \\
\hline Eu-155 & $3.26 \mathrm{E}-07$ & $1.95 \mathrm{E}-10$ & $4.88 \mathrm{E}-09$ \\
\hline $\mathrm{Nb}-94$ & $6.78 \mathrm{E}-07$ & 4.07E-10 & $1.02 \mathrm{E}-08$ \\
\hline $\mathrm{Ni}-59$ & 1.44E-05 & 8.63E-09 & $2.16 \mathrm{E}-07$ \\
\hline $\mathrm{Ni}-63$ & $1.51 \mathrm{E}-03$ & $9.08 \mathrm{E}-07$ & 2.27E-05 \\
\hline $\mathrm{Pu}-238$ & $1.01 \mathrm{E}-05$ & $6.05 E-09$ & $1.51 \mathrm{E}-07$ \\
\hline $\mathrm{Pu}-239$ & $1.63 \mathrm{E}-07$ & $9.77 \mathrm{E}-11$ & $2.44 \mathrm{E}-09$ \\
\hline $\mathrm{Pu}-240$ & 2.44E-07 & $1.46 \mathrm{E}-10$ & $3.66 \mathrm{E}-09$ \\
\hline Pu-241 & 1.07E-05 & $6.41 \mathrm{E}-09$ & $1.60 \mathrm{E}-07$ \\
\hline Sm-151 & 3.09E-06 & $1.85 E-09$ & 4.63E-08 \\
\hline Sr-90 & 2.27E-04 & $1.36 \mathrm{E}-07$ & $3.40 \mathrm{E}-06$ \\
\hline Tc-99 & 2.71E-06 & $1.63 \mathrm{E}-09$ & $4.06 \mathrm{E}-08$ \\
\hline Th-232 & 2.71E-07 & $1.63 \mathrm{E}-10$ & 4.07E-09 \\
\hline Th-234 & $3.28 \mathrm{E}-05$ & $1.97 \mathrm{E}-08$ & $4.92 \mathrm{E}-07$ \\
\hline U-238 & $3.28 \mathrm{E}-05$ & $1.97 \mathrm{E}-08$ & 4.92E-07 \\
\hline$Y-90$ & 2.27E-04 & 1.36E-07 & $3.40 \mathrm{E}-06$ \\
\hline Total & $2.42 \mathrm{E}-03$ & $1.45 \mathrm{E}-06$ & 3.63E-05 \\
\hline
\end{tabular}


TABLE B.6.19 Low-Level Mixed Waste, Case 4: Fernald Environmental Management Project

\begin{tabular}{|c|c|c|c|}
\hline \multicolumn{4}{|c|}{ Function: Incineration } \\
\hline \multirow[b]{2}{*}{ Nuclide } & \multicolumn{3}{|c|}{ Release $(\mathrm{Ci})$} \\
\hline & EQ7 & IEX & IFF \\
\hline Ac-228 & $3.19 \mathrm{E}-11$ & $1.90 \mathrm{E}-14$ & $4.78 \mathrm{E}-13$ \\
\hline Am-241 & 8.27E-07 & 4.96E-10 & $1.24 \mathrm{E}-08$ \\
\hline $\mathrm{Bi}-212$ & $5.36 \mathrm{E}-12$ & $0.00 \mathrm{E}+00$ & $8.00 \mathrm{E}-14$ \\
\hline Co-60 & 4.53E-04 & 2.72E-07 & $6.80 \mathrm{E}-06$ \\
\hline Cs-137 & $1.30 \mathrm{E}-03$ & $7.81 \mathrm{E}-07$ & $1.95 \mathrm{E}-05$ \\
\hline Eu-154 & 4.82E-06 & 2.89E-09 & 7.24E-08 \\
\hline Eu-155 & $1.65 \mathrm{E}-06$ & $9.92 \mathrm{E}-10$ & $2.48 \mathrm{E}-08$ \\
\hline $\mathrm{Nb}-94$ & 3.45E-06 & 2.07E-09 & $5.17 \mathrm{E}-08$ \\
\hline $\mathrm{Ni}-59$ & $7.31 \mathrm{E}-05$ & $4.39 \mathrm{E}-08$ & $1.10 \mathrm{E}-06$ \\
\hline $\mathrm{Ni}-63$ & $7.69 \mathrm{E}-03$ & 4.62E-06 & $1.15 \mathrm{E}-04$ \\
\hline $\mathrm{Pb}-212$ & $5.36 \mathrm{E}-12$ & $0.00 \mathrm{E}+00$ & 8.00E-14 \\
\hline Pu-238 & 5.12E-05 & 3.07E-08 & $7.68 \mathrm{E}-07$ \\
\hline Pu-239 & 8.27E-07 & $4.96 \mathrm{E}-10$ & $1.24 \mathrm{E}-08$ \\
\hline Pu-240 & $1.24 \mathrm{E}-06$ & $7.44 \mathrm{E}-10$ & $1.86 \mathrm{E}-08$ \\
\hline Pu-241 & 5.43E-05 & $3.26 \mathrm{E}-08$ & 8.14E-07 \\
\hline $\mathrm{Ra}-224$ & $5.36 \mathrm{E}-12$ & $0.00 \mathrm{E}+00$ & $8.00 \mathrm{E}-14$ \\
\hline Ra-228 & $3.19 \mathrm{E}-11$ & $1.90 \mathrm{E}-14$ & $4.78 \mathrm{E}-13$ \\
\hline Sm-151 & $1.57 \mathrm{E}-05$ & 9.42E-09 & $2.35 \mathrm{E}-07$ \\
\hline Sr-90 & $1.15 \mathrm{E}-03$ & $6.91 \mathrm{E}-07$ & $1.73 \mathrm{E}-05$ \\
\hline Тc-99 & $1.38 \mathrm{E}-05$ & 8.26E-09 & 2.07E-07 \\
\hline Th-228 & $5.36 \mathrm{E}-12$ & $0.00 \mathrm{E}+00$ & $8.00 \mathrm{E}-14$ \\
\hline Th-231 & 3.07E-11 & $1.80 \mathrm{E}-14$ & $4.61 \mathrm{E}-13$ \\
\hline Th-232 & $1.38 \mathrm{E}-06^{\circ}$ & 8.27E-10 & $2.07 E-08$ \\
\hline Th-234 & $1.67 \mathrm{E}-04$ & $1.00 \mathrm{E}-07$ & $2.50 \mathrm{E}-06$ \\
\hline U-235 & $3.06 \mathrm{E}-11$ & $1.80 \mathrm{E}-14$ & $4.59 \mathrm{E}-13$ \\
\hline U-238 & $1.67 \mathrm{E}-04$ & $1.00 \mathrm{E}-07$ & $2.50 \mathrm{E}-06$ \\
\hline Y-90 & $1.15 \mathrm{E}-03$ & $6.91 \mathrm{E}-07$ & $1.73 \mathrm{E}-05$ \\
\hline Total & $1.23 \mathrm{E}-02$ & 7.38E-06 & $1.85 \mathrm{E}-04$ \\
\hline
\end{tabular}


TABLE B.6.20 Low-Level Mixed Waste, Case 4: Hanford

Function: Incineration

\begin{tabular}{llll}
\hline & \multicolumn{3}{c}{ Release (Ci) } \\
\cline { 2 - 4 } Nuclide & EQ7 & IEX & IFF \\
\hline & & & \\
Am-241 & $2.39 \mathrm{E}-05$ & $1.43 \mathrm{E}-08$ & $3.58 \mathrm{E}-07$ \\
Co-60 & $3.54 \mathrm{E}-05$ & $2.12 \mathrm{E}-08$ & $5.31 \mathrm{E}-07$ \\
Cs-137 & $2.81 \mathrm{E}-02$ & $1.68 \mathrm{E}-05$ & $4.21 \mathrm{E}-04$ \\
Eu-154 & $4.22 \mathrm{E}-05$ & $2.53 \mathrm{E}-08$ & $6.33 \mathrm{E}-07$ \\
Nb-94 & $2.40 \mathrm{E}-06$ & $1.44 \mathrm{E}-09$ & $3.59 \mathrm{E}-08$ \\
Ni-59 & $5.41 \mathrm{E}-05$ & $3.25 \mathrm{E}-08$ & $8.11 \mathrm{E}-07$ \\
Ni-63 & $5.56 \mathrm{E}-03$ & $3.33 \mathrm{E}-06$ & $8.34 \mathrm{E}-05$ \\
Pu-238 & $1.26 \mathrm{E}-03$ & $7.53 \mathrm{E}-07$ & $1.88 \mathrm{E}-05$ \\
Pu-239 & $1.70 \mathrm{E}-05$ & $1.02 \mathrm{E}-08$ & $2.55 \mathrm{E}-07$ \\
Pu-240 & $9.70 \mathrm{E}-06$ & $5.82 \mathrm{E}-09$ & $1.46 \mathrm{E}-07$ \\
Pu-241 & $2.78 \mathrm{E}-04$ & $1.67 \mathrm{E}-07$ & $4.18 \mathrm{E}-06$ \\
Sm-151 & $4.04 \mathrm{E}-04$ & $2.42 \mathrm{E}-07$ & $6.06 \mathrm{E}-06$ \\
Sr-90 & $2.50 \mathrm{E}-02$ & $1.50 \mathrm{E}-05$ & $3.75 \mathrm{E}-04$ \\
Tc-99 & $1.26 \mathrm{E}-05$ & $7.53 \mathrm{E}-09$ & $1.88 \mathrm{E}-07$ \\
Th-234 & $1.55 \mathrm{E}-05$ & $9.31 \mathrm{E}-09$ & $2.33 \mathrm{E}-07$ \\
U-238 & $1.55 \mathrm{E}-05$ & $9.31 \mathrm{E}-09$ & $2.33 \mathrm{E}-07$ \\
Y-90 & $2.50 \mathrm{E}-02$ & $1.50 \mathrm{E}-05$ & $3.75 \mathrm{E}-04$ \\
Total & $8.58 \mathrm{E}-02$ & $5.15 \mathrm{E}-05$ & $1.29 \mathrm{E}-03$ \\
\hline & & & \\
& & &
\end{tabular}


TABLE B.6.21 Low-Level Mixed Waste, Case 4: Idaho National Engineering Laboratory

\begin{tabular}{|c|c|c|c|}
\hline \multicolumn{4}{|c|}{ Function: Incineration } \\
\hline \multirow[b]{2}{*}{ Nuclide } & \multicolumn{3}{|c|}{ Release (Ci) } \\
\hline & EQ7 & IEX & IFF \\
\hline Co-60 & 2.75E-02 & $1.65 \mathrm{E}-05$ & 4.13E-04 \\
\hline Cs-134 & $1.62 \mathrm{E}-05$ & 9.71E-09 & $2.43 \mathrm{E}-07$ \\
\hline Cs-137 & $1.80 \mathrm{E}-03$ & $1.08 \mathrm{E}-06$ & 2.70E-05 \\
\hline Eu-154 & 2.19E-05 & $1.31 \mathrm{E}-08$ & $3.28 \mathrm{E}-07$ \\
\hline Eu-155 & $1.05 \mathrm{E}-05$ & $6.28 \mathrm{E}-09$ & $1.57 \mathrm{E}-07$ \\
\hline Fe-55 & $3.60 \mathrm{E}-03$ & $2.16 \mathrm{E}-06$ & $5.40 \mathrm{E}-05$ \\
\hline$M n-54$ & $1.14 \mathrm{E}-05$ & $6.85 \mathrm{E}-09$ & $1.71 \mathrm{E}-07$ \\
\hline $\mathrm{Nb}-94$ & $1.71 \mathrm{E}-05$ & $1.03 \mathrm{E}-08$ & 2.57E-07 \\
\hline $\mathrm{Ni}-59$ & 3.60E-04 & $2.16 \mathrm{E}-07$ & $5.40 \mathrm{E}-06$ \\
\hline $\mathrm{Ni}-63$ & $4.84 \mathrm{E}-02$ & $2.90 \mathrm{E}-05$ & $7.26 \mathrm{E}-04$ \\
\hline $\mathrm{Pm}-147$ & $1.96 \mathrm{E}-04$ & $1.18 \mathrm{E}-07$ & $2.94 \mathrm{E}-06$ \\
\hline Pu-238 & $5.62 \mathrm{E}-05$ & 3.37E-08 & 8.43E-07 \\
\hline Pu-241 & 4.57E-05 & 2.74E-08 & $6.85 \mathrm{E}-07$ \\
\hline $\mathrm{Sb}-125$ & $7.62 \mathrm{E}-06$ & 4.57E-09 & $1.14 \mathrm{E}-07$ \\
\hline Sm-151 & $1.52 \mathrm{E}-05$ & 9.14E-09 & $2.28 \mathrm{E}-07$ \\
\hline Sr-90 & $1.69 \mathrm{E}-03$ & 1.02E-06 & $2.54 \mathrm{E}-05$ \\
\hline $\mathrm{Te}-125 \mathrm{~m}$ & $1.90 \mathrm{E}-06$ & 1.14E-09 & $2.86 \mathrm{E}-08$ \\
\hline Th-234 & $6.76 \mathrm{E}-05$ & $4.06 \mathrm{E}-08$ & $1.01 \mathrm{E}-06$ \\
\hline $\mathrm{U}-238$ & $6.76 \mathrm{E}-05$ & $4.06 \mathrm{E}-08$ & $1.01 \mathrm{E}-06$ \\
\hline Y-90 & $1.69 \mathrm{E}-03$ & 1.02E-06 & $2.54 \mathrm{E}-05$ \\
\hline Total & $8.56 \mathrm{E}-02$ & 5.14E-05 & $1.28 \mathrm{E}-03$ \\
\hline
\end{tabular}


TABLE B.6.22 Low-Level Mixed Waste, Case 4: Lawrence Livermore National Laboratory

Function: Incineration

\begin{tabular}{|c|c|c|c|}
\hline \multirow[b]{2}{*}{ Nuclide } & \multicolumn{3}{|c|}{ Release (Ci) } \\
\hline & EQ7 & IEX & IFF \\
\hline Am-241 & $2.23 \mathrm{E}-09$ & $1.34 \mathrm{E}-12$ & $3.34 \mathrm{E}-11$ \\
\hline Co-60 & 3.03E-03 & 1.82E-06 & $4.55 \mathrm{E}-05$ \\
\hline Cs-134 & $1.78 \mathrm{E}-06$ & $1.07 \mathrm{E}-09$ & $2.68 \mathrm{E}-08$ \\
\hline Cs-137 & 2.02E-04 & $1.21 \mathrm{E}-07$ & 3.03E-06 \\
\hline Eu-154 & $2.43 \mathrm{E}-06$ & $1.46 \mathrm{E}-09$ & 3.64E-08 \\
\hline Eu-155 & $1.16 \mathrm{E}-06$ & $6.95 \mathrm{E}-10$ & $1.74 \mathrm{E}-08$ \\
\hline $\mathrm{Fe}-55$ & 3.97E-04 & 2.38E-07 & $5.95 \mathrm{E}-06$ \\
\hline $\mathrm{Mn}-54$ & $1.26 \mathrm{E}-06$ & $7.55 \mathrm{E}-10$ & $1.89 \mathrm{E}-08$ \\
\hline $\mathrm{Nb}-94$ & $1.90 \mathrm{E}-06$ & $1.14 \mathrm{E}-09$ & 2.85E-08 \\
\hline $\mathrm{Ni}-59$ & $3.98 \mathrm{E}-05$ & $2.39 \mathrm{E}-08$ & $5.98 \mathrm{E}-07$ \\
\hline $\mathrm{Ni}-63$ & $5.35 \mathrm{E}-03$ & $3.21 \mathrm{E}-06$ & 8.03E-05 \\
\hline Pm-147 & $2.16 \mathrm{E}-05$ & $1.30 \mathrm{E}-08$ & 3.24E-07 \\
\hline Pu-238 & $6.33 \mathrm{E}-06$ & $3.80 \mathrm{E}-09$ & $9.49 E-08$ \\
\hline Pu-239 & 2.23E-09 & $1.34 \mathrm{E}-12$ & 3.34E-11 \\
\hline Pu-240 & 3.34E-09 & $2.00 \mathrm{E}-12$ & $5.01 \mathrm{E}-11$ \\
\hline Pu-241 & 5.18E-06 & $3.11 E-09$ & 7.77E-08 \\
\hline Sb-125 & 8.39E-07 & $5.04 \mathrm{E}-10$ & $1.26 \mathrm{E}-08$ \\
\hline Sm-151 & $1.72 \mathrm{E}-06$ & $1.03 \mathrm{E}-09$ & $2.58 \mathrm{E}-08$ \\
\hline Sr-90 & $1.90 \mathrm{E}-04$ & $1.14 \mathrm{E}-07$ & $2.85 \mathrm{E}-06$ \\
\hline Tc-99 & 3.71E-08 & $2.23 \mathrm{E}-11$ & $5.56 \mathrm{E}-10$ \\
\hline $\mathrm{Te}-125 \mathrm{~m}$ & $2.10 \mathrm{E}-07$ & $1.26 \mathrm{E}-10$ & $3.15 \mathrm{E}-09$ \\
\hline Th-232 & $3.71 E-09$ & $2.23 \mathrm{E}-12$ & 5.57E-11 \\
\hline Th-234 & $7.90 \mathrm{E}-06$ & 4.74E-09 & $1.18 \mathrm{E}-07$ \\
\hline U-238 & 7.90E-06 & 4.74E-09 & $1.18 \mathrm{E}-07$ \\
\hline$Y-90$ & $1.90 \mathrm{E}-04$ & 1.14E-07 & $2.85 \mathrm{E}-06$ \\
\hline Total & $9.46 \mathrm{E}-03$ & $5.68 \mathrm{E}-06$ & $1.42 \mathrm{E}-04$ \\
\hline
\end{tabular}


TABLE B.6.23 Low-Level Mixed Waste, Case 4: Los Alamos National Laboratory

\begin{tabular}{lccc}
\hline & & \\
\multicolumn{3}{l}{ Function: Incineration } \\
& \multicolumn{3}{c}{ Release (Ci) } \\
\cline { 2 - 4 } Nuclide & EQ7 & IEX & IFF \\
\hline & & & \\
Co-60 & $6.22 \mathrm{E}-05$ & $3.73 \mathrm{E}-08$ & $9.33 \mathrm{E}-07$ \\
Cs-137 & $4.52 \mathrm{E}-05$ & $2.71 \mathrm{E}-08$ & $6.79 \mathrm{E}-07$ \\
Eu-154 & $2.27 \mathrm{E}-07$ & $1.36 \mathrm{E}-10$ & $3.41 \mathrm{E}-09$ \\
Eu-155 & $5.24 \mathrm{E}-08$ & $3.14 \mathrm{E}-11$ & $7.86 \mathrm{E}-10$ \\
Fe-55 & $1.24 \mathrm{E}-06$ & $7.44 \mathrm{E}-10$ & $1.86 \mathrm{E}-08$ \\
Nb-94 & $2.97 \mathrm{E}-07$ & $1.78 \mathrm{E}-10$ & $4.45 \mathrm{E}-09$ \\
Ni-59 & $5.87 \mathrm{E}-06$ & $3.52 \mathrm{E}-09$ & $8.80 \mathrm{E}-08$ \\
Ni-63 & $7.10 \mathrm{E}-04$ & $4.26 \mathrm{E}-07$ & $1.06 \mathrm{E}-05$ \\
Pu-238 & $1.54 \mathrm{E}-06$ & $9.22 \mathrm{E}-10$ & $2.31 \mathrm{E}-08$ \\
Pu-240 & $1.22 \mathrm{E}-06$ & $7.34 \mathrm{E}-10$ & $1.83 \mathrm{E}-08$ \\
Pu-241 & $1.22 \mathrm{E}-06$ & $7.34 \mathrm{E}-10$ & $1.83 \mathrm{E}-08$ \\
Sm-151 & $4.89 \mathrm{E}-07$ & $2.93 \mathrm{E}-10$ & $7.34 \mathrm{E}-09$ \\
Sr-90 & $4.21 \mathrm{E}-05$ & $2.53 \mathrm{E}-08$ & $6.31 \mathrm{E}-07$ \\
Tc-99 & $1.75 \mathrm{E}-08$ & $1.05 \mathrm{E}-11$ & $2.62 \mathrm{E}-10$ \\
Th-234 & $2.10 \mathrm{E}-07$ & $1.26 \mathrm{E}-10$ & $3.14 \mathrm{E}-09$ \\
U-238 & $2.10 \mathrm{E}-07$ & $1.26 \mathrm{E}-10$ & $3.14 \mathrm{E}-09$ \\
Y-90 & $4.21 \mathrm{E}-05$ & $2.53 \mathrm{E}-08$ & $6.31 \mathrm{E}-07$ \\
Total & $9.14 \mathrm{E}-04$ & $5.48 \mathrm{E}-07$ & $1.37 \mathrm{E}-05$ \\
\hline & & &
\end{tabular}


TABLE B.6.24 Low-Level Mixed Waste, Case 4: Oak Ridge National Laboratory

\begin{tabular}{|c|c|c|c|}
\hline \multicolumn{4}{|c|}{ Function: Incineration } \\
\hline \multirow[b]{2}{*}{ Nuclide } & \multicolumn{3}{|c|}{ Release $(\mathrm{Ci})$} \\
\hline & EQ7 & IEX & IFF \\
\hline Am-241 & $5.76 \mathrm{E}-06$ & $3.46 \mathrm{E}-09$ & 8.64E-08 \\
\hline Co- 60 & $3.15 \mathrm{E}-03$ & $1.89 \mathrm{E}-06$ & 4.73E-05 \\
\hline Cs-137 & $9.06 \mathrm{E}-03$ & $5.44 \mathrm{E}-06$ & $1.36 \mathrm{E}-04$ \\
\hline Eu-154 & $3.36 \mathrm{E}-05$ & $2.02 \mathrm{E}-08$ & 5.04E-07 \\
\hline Eu-155 & $1.15 \mathrm{E}-05$ & $6.91 E-09$ & 1.73E-07 \\
\hline $\mathrm{Nb}-94$ & 2.40E-05 & $1.44 \mathrm{E}-08$ & $3.60 E-07$ \\
\hline $\mathrm{Ni}-59$ & $5.09 \mathrm{E}-04$ & $3.05 E-07$ & $7.64 \mathrm{E}-06$ \\
\hline $\mathrm{Ni}-63$ & 5.36E-02 & $3.21 \mathrm{E}-05$ & 8.04E-04 \\
\hline Pu-238 & 3.57E-04 & 2.14E-07 & $5.35 \mathrm{E}-06$ \\
\hline Pu-239 & 5.76E-06 & $3.46 \mathrm{E}-09$ & 8.64E-08 \\
\hline $\mathrm{Pu}-240$ & 8.64E-06 & $5.18 \mathrm{E}-09$ & $1.30 \mathrm{E}-07$ \\
\hline Pu-241 & $3.78 \mathrm{E}-04$ & 2.27E-07 & $5.67 \mathrm{E}-06$ \\
\hline Sm-151 & $1.09 \mathrm{E}-04$ & $6.56 \mathrm{E}-08$ & $1.64 \mathrm{E}-06$ \\
\hline Sr-90 & 8.02E-03 & $4.81 \mathrm{E}-06$ & $1.20 \mathrm{E}-04$ \\
\hline Tc-99 & 9.59E-05 & 5.75E-08 & $1.44 \mathrm{E}-06$ \\
\hline Th-232 & $9.60 \mathrm{E}-06$ & $5.76 \mathrm{E}-09$ & $1.44 \mathrm{E}-07$ \\
\hline Th-234 & $1.16 \mathrm{E}-03$ & $6.96 \mathrm{E}-07$ & 1.74E-05 \\
\hline $\mathrm{U}-238$ & $1.16 \mathrm{E}-03$ & $6.96 \mathrm{E}-07$ & 1.74E-05 \\
\hline$Y-90$ & 8.02E-03 & $4.81 \mathrm{E}-06$ & 1.20E-04 \\
\hline Total & 8.57E-02 & 5.14E-05 & $1.29 \mathrm{E}-03$ \\
\hline
\end{tabular}


TABLE B.6.25 Low-Level Mixed Waste, Case 4: Paducah Gaseous Diffusion Plant

Function: Incineration

\begin{tabular}{llll}
\hline & \multicolumn{3}{c}{ Release (Ci) } \\
\cline { 2 - 4 } Nuclide & EQ7 & IEX & IFF \\
\hline & & & \\
Ac-228 & $1.46 \mathrm{E}-06$ & $8.79 \mathrm{E}-10$ & $2.20 \mathrm{E}-08$ \\
Bi-212 & $2.42 \mathrm{E}-07$ & $1.45 \mathrm{E}-10$ & $3.63 \mathrm{E}-09$ \\
$\mathrm{~Pb}-212$ & $2.42 \mathrm{E}-07$ & $1.45 \mathrm{E}-10$ & $3.63 \mathrm{E}-09$ \\
Ra-224 & $2.42 \mathrm{E}-07$ & $1.45 \mathrm{E}-10$ & $3.63 \mathrm{E}-09$ \\
Ra-228 & $1.46 \mathrm{E}-06$ & $8.79 \mathrm{E}-10$ & $2.20 \mathrm{E}-08$ \\
Tc-99 & $5.94 \mathrm{E}-04$ & $3.57 \mathrm{E}-07$ & $8.91 \mathrm{E}-06$ \\
Th-228 & $2.42 \mathrm{E}-07$ & $1.45 \mathrm{E}-10$ & $3.63 \mathrm{E}-09$ \\
Th-231 & $1.54 \mathrm{E}-06$ & $9.26 \mathrm{E}-10$ & $2.31 \mathrm{E}-08$ \\
Th-232 & $1.62 \mathrm{E}-05$ & $9.73 \mathrm{E}-09$ & $2.43 \mathrm{E}-07$ \\
Th-234 & $1.97 \mathrm{E}-03$ & $1.18 \mathrm{E}-06$ & $2.96 \mathrm{E}-05$ \\
U-235 & $1.53 \mathrm{E}-06$ & $9.18 \mathrm{E}-10$ & $2.29 \mathrm{E}-08$ \\
U-238 & $1.97 \mathrm{E}-03$ & $1.18 \mathrm{E}-06$ & $2.96 \mathrm{E}-05$ \\
Total & $4.56 \mathrm{E}-03$ & $2.74 \mathrm{E}-06$ & $6.85 \mathrm{E}-05$ \\
\hline
\end{tabular}


TABLE B.6.26 Low-Level Mixed Waste, Case 4: Pantex Plant

\begin{tabular}{lccc}
\hline & & \\
& & \\
& \multicolumn{3}{c}{ Runction: Incineration (Ci) } \\
\cline { 2 - 4 } Nuclide & EQ7 & IEX & IFF \\
\hline & & & \\
Co-60 & $1.19 \mathrm{E}-04$ & $7.13 \mathrm{E}-08$ & $1.78 \mathrm{E}-06$ \\
Cs-137 & $9.00 \mathrm{E}-05$ & $5.40 \mathrm{E}-08$ & $1.35 \mathrm{E}-06$ \\
Eu-154 & $9.90 \mathrm{E}-07$ & $5.94 \mathrm{E}-10$ & $1.49 \mathrm{E}-08$ \\
Fe-55 & $1.49 \mathrm{E}-05$ & $8.97 \mathrm{E}-09$ & $2.24 \mathrm{E}-07$ \\
Ni-59 & $1.98 \mathrm{E}-06$ & $1.19 \mathrm{E}-09$ & $2.97 \mathrm{E}-08$ \\
Ni-63 & $2.63 \mathrm{E}-04$ & $1.58 \mathrm{E}-07$ & $3.94 \mathrm{E}-06$ \\
Pm-147 & $8.28 \mathrm{E}-06$ & $4.97 \mathrm{E}-09$ & $1.24 \mathrm{E}-07$ \\
Pu-238 & $3.42 \mathrm{E}-06$ & $2.05 \mathrm{E}-09$ & $5.13 \mathrm{E}-08$ \\
Pu-241 & $1.73 \mathrm{E}-05$ & $1.04 \mathrm{E}-08$ & $2.59 \mathrm{E}-07$ \\
Sm-151 & $7.92 \mathrm{E}-07$ & $4.75 \mathrm{E}-10$ & $1.19 \mathrm{E}-08$ \\
Sr-90 & $8.46 \mathrm{E}-05$ & $5.08 \mathrm{E}-08$ & $1.27 \mathrm{E}-06$ \\
Y-90 & $8.46 \mathrm{E}-05$ & $5.08 \mathrm{E}-08$ & $1.27 \mathrm{E}-06$ \\
Total & $6.89 \mathrm{E}-04$ & $4.13 \mathrm{E}-07$ & $1.03 \mathrm{E}-05$ \\
\hline
\end{tabular}


TABLE B.6.27 Low-Level Mixed Waste, Case 4: Portsmouth Gaseous Diffusion Plant

\begin{tabular}{|c|c|c|c|}
\hline \multicolumn{4}{|c|}{ Function: Incineration } \\
\hline \multirow[b]{2}{*}{ Nuclide } & \multicolumn{3}{|c|}{ Release (Ci) } \\
\hline & EQ7 & IEX & IFF \\
\hline Ac-228 & 2.72E-09 & $1.63 E-12$ & $4.08 \mathrm{E}-11$ \\
\hline Am-241 & $3.14 \mathrm{E}-08$ & $1.88 \mathrm{E}-11$ & $4.71 \mathrm{E}-10$ \\
\hline $\mathrm{Bi}-212$ & $4.55 \mathrm{E}-10$ & $2.73 E-13$ & $6.83 \mathrm{E}-12$ \\
\hline Co-60 & $3.09 \mathrm{E}-03$ & $1.86 \mathrm{E}-06$ & 4.64E-05 \\
\hline Cs- 134 & $1.82 \mathrm{E}-06$ & $1.09 \mathrm{E}-09$ & $2.73 \mathrm{E}-08$ \\
\hline Cs-137 & $2.39 \mathrm{E}-04$ & $1.43 E-07$ & $3.59 \mathrm{E}-06$ \\
\hline Eu-154 & $2.52 \mathrm{E}-06$ & $1.51 \mathrm{E}-09$ & 3.77E-08 \\
\hline Eu-155 & $1.18 \mathrm{E}-06$ & $7.06 \mathrm{E}-10$ & $1.77 \mathrm{E}-08$ \\
\hline $\mathrm{Fe}-55$ & 4.04E-04 & 2.43E-07 & $6.07 \mathrm{E}-06$ \\
\hline $\mathrm{Mn}-54$ & $1.28 \mathrm{E}-06$ & $7.70 \mathrm{E}-10$ & $1.93 \mathrm{E}-08$ \\
\hline $\mathrm{Nb}-94$ & $1.93 \mathrm{E}-06$ & $1.16 \mathrm{E}-09$ & $2.89 \mathrm{E}-08$ \\
\hline $\mathrm{Ni}-59$ & $4.05 \mathrm{E}-05$ & $2.43 E-08$ & $6.08 \mathrm{E}-07$ \\
\hline $\mathrm{Ni}-63$ & $5.44 \mathrm{E}-03$ & 3.27E-06 & 8.17E-05 \\
\hline $\mathrm{Pb}-212$ & 4.55E-10 & 2.73E-13 & $6.83 \mathrm{E}-12$ \\
\hline Pm-147 & $2.20 \mathrm{E}-05$ & 1.32E-08 & $3.31 \mathrm{E}-07$ \\
\hline Pu-238 & $7.96 \mathrm{E}-06$ & 4.78E-09 & $1.19 \mathrm{E}-07$ \\
\hline Pu-239 & $2.24 \mathrm{E}-08$ & $1.34 \mathrm{E}-11$ & $3.36 \mathrm{E}-10$ \\
\hline Pu-240 & $1.28 \mathrm{E}-08$ & $7.66 \mathrm{E}-12$ & $1.92 \mathrm{E}-10$ \\
\hline $\mathrm{Pu}-241$ & $5.50 \mathrm{E}-06$ & $3.30 \mathrm{E}-09$ & $8.25 \mathrm{E}-08$ \\
\hline $\mathrm{Ra}-224$ & $4.55 \mathrm{E}-10$ & $2.73 E-13$ & $6.83 \mathrm{E}-12$ \\
\hline $\mathrm{Ra}-228$ & 2.72E-09 & $1.63 \mathrm{E}-12$ & $4.08 \mathrm{E}-11$ \\
\hline $\mathrm{Sb}-125$ & $8.56 \mathrm{E}-07$ & $5.14 \mathrm{E}-10$ & $1.28 \mathrm{E}-08$ \\
\hline Sm-151 & $2.24 \mathrm{E}-06$ & $1.35 \mathrm{E}-09$ & 3.37E-08 \\
\hline Sr-90 & 2.23E-04 & $1.34 \mathrm{E}-07$ & $3.35 \mathrm{E}-06$ \\
\hline Tc-99 & $9.78 \mathrm{E}-07$ & $5.87 \mathrm{E}-10$ & $1.47 \mathrm{E}-08$ \\
\hline $\mathrm{Te}-125 \mathrm{~m}$ & 2.14E-07 & $1.28 \mathrm{E}-10$ & $3.21 \mathrm{E}-09$ \\
\hline Th-228 & $4.55 \mathrm{E}-10$ & $2.73 \mathrm{E}-13$ & $6.83 \mathrm{E}-12$ \\
\hline Th-231 & $2.80 \mathrm{E}-09$ & $1.68 \mathrm{E}-12$ & $4.20 \mathrm{E}-11$ \\
\hline Th-232 & 2.95E-08 & $1.77 \mathrm{E}-11$ & $4.42 E-10$ \\
\hline Th-234 & $1.12 \mathrm{E}-05$ & $6.72 \mathrm{E}-09$ & $1.68 \mathrm{E}-07$ \\
\hline U-235 & $2.78 \mathrm{E}-09$ & $1.67 \mathrm{E}-12$ & 4.17E-11 \\
\hline U-238 & 1.12E-05 & $6.72 \mathrm{E}-09$ & $1.68 \mathrm{E}-07$ \\
\hline$Y-90$ & $2.23 \mathrm{E}-04$ & $1.34 \mathrm{E}-07$ & $3.35 \mathrm{E}-06$ \\
\hline Total & $9.74 \mathrm{E}-03$ & $5.84 \mathrm{E}-06$ & $1.46 \mathrm{E}-04$ \\
\hline
\end{tabular}


TABLE B.6.28 Low-Level Mixed Waste, Case 4: Rocky Flats Environmental Technology Site

\begin{tabular}{lccc}
\hline & & \\
& & \\
& \multicolumn{3}{c}{ Runction: Incineration } \\
& \multicolumn{3}{c}{ (Ci) } \\
\cline { 2 - 4 } Nuclide & EQ7 & IEX & IFF \\
\hline & & & \\
Ac-228 & $2.66 \mathrm{E}-12$ & $0.00 \mathrm{E}+00$ & $4.00 \mathrm{E}-14$ \\
Bi-212 & $4.48 \mathrm{E}-13$ & $0.00 \mathrm{E}+00$ & $0.00 \mathrm{E}+00$ \\
Pb-212 & $4.48 \mathrm{E}-13$ & $0.00 \mathrm{E}+00$ & $0.00 \mathrm{E}+00$ \\
Ra-224 & $4.48 \mathrm{E}-13$ & $0.00 \mathrm{E}+00$ & $0.00 \mathrm{E}+00$ \\
Ra-228 & $2.66 \mathrm{E}-12$ & $0.00 \mathrm{E}+00$ & $4.00 \mathrm{E}-14$ \\
Tc-99 & $4.95 \mathrm{E}-11$ & $3.00 \mathrm{E}-14$ & $7.43 \mathrm{E}-13$ \\
Th-228 & $4.48 \mathrm{E}-13$ & $0.00 \mathrm{E}+00$ & $0.00 \mathrm{E}+00$ \\
Th-231 & $2.57 \mathrm{E}-12$ & $0.00 \mathrm{E}+00$ & $3.90 \mathrm{E}-14$ \\
Th-232 & $2.70 \mathrm{E}-11$ & $1.60 \mathrm{E}-14$ & $4.05 \mathrm{E}-13$ \\
Th-234 & $3.29 \mathrm{E}-09$ & $1.97 \mathrm{E}-12$ & $4.93 \mathrm{E}-11$ \\
U-235 & $2.56 \mathrm{E}-12$ & $0.00 \mathrm{E}+00$ & $3.80 \mathrm{E}-14$ \\
U-238 & $3.29 \mathrm{E}-09$ & $1.97 \mathrm{E}-12$ & $4.93 \mathrm{E}-11$ \\
Total & $6.66 \mathrm{E}-09$ & $3.99 \mathrm{E}-12$ & $9.99 \mathrm{E}-11$ \\
\hline
\end{tabular}


TABLE B.6.29 Low-Level Mixed Waste, Case 4: Savannah River Site

\begin{tabular}{|c|c|c|c|}
\hline \multicolumn{4}{|c|}{ Function: Incineration } \\
\hline \multirow[b]{2}{*}{ Nuclide } & \multicolumn{3}{|c|}{ Release (Ci) } \\
\hline & IEX & IFF & EQ7 \\
\hline Co-60 & $5.10 \mathrm{E}-06$ & $1.28 \mathrm{E}-04$ & 8.50E-03 \\
\hline Cs-134 & $1.54 \mathrm{E}-10$ & $3.85 \mathrm{E}-09$ & 2.57E-07 \\
\hline Cs-137 & $3.54 \mathrm{E}-06$ & $8.85 \mathrm{E}-05$ & $5.90 \mathrm{E}-03$ \\
\hline Eu-154 & $1.79 \mathrm{E}-08$ & 4.47E-07 & $2.98 \mathrm{E}-05$ \\
\hline Eu-155 & 4.18E-09 & $1.04 \mathrm{E}-07$ & $6.96 \mathrm{E}-06$ \\
\hline $\mathrm{Fe}-55$ & $1.31 \mathrm{E}-07$ & 3.27E-06 & $2.18 E-04$ \\
\hline $\mathrm{Mn}-54$ & $1.09 \mathrm{E}-10$ & 2.72E-09 & 1.81E-07 \\
\hline $\mathrm{Nb}-94$ & 2.33E-08 & 5.82E-07 & $3.88 \mathrm{E}-05$ \\
\hline $\mathrm{Ni}-59$ & 4.60E-07 & $1.15 \mathrm{E}-05$ & 7.67E-04 \\
\hline $\mathrm{Ni}-63$ & 5.57E-05 & $1.39 \mathrm{E}-03$ & $9.28 \mathrm{E}-02$ \\
\hline Pm-147 & $1.87 \mathrm{E}-09$ & 4.67E-08 & $3.11 E-06$ \\
\hline $\mathrm{Pu}-238$ & $1.20 \mathrm{E}-07$ & $3.00 \mathrm{E}-06$ & $2.00 \mathrm{E}-04$ \\
\hline $\mathrm{Pu}-240$ & $9.52 \mathrm{E}-08$ & $2.38 \mathrm{E}-06$ & $1.59 \mathrm{E}-04$ \\
\hline Pu-241 & $9.56 \mathrm{E}-08$ & $2.39 \mathrm{E}-06$ & $1.59 \mathrm{E}-04$ \\
\hline $\mathrm{Sb}-125$ & $7.26 \mathrm{E}-11$ & $1.81 \mathrm{E}-09$ & 1.21E-07 \\
\hline Sm-151 & $3.82 \mathrm{E}-08$ & 9.55E-07 & $6.37 \mathrm{E}-05$ \\
\hline Sr-90 & $3.29 \mathrm{E}-06$ & 8.23E-05 & $5.49 \mathrm{E}-03$ \\
\hline Tc-99 & $1.36 \mathrm{E}-09$ & $3.40 \mathrm{E}-08$ & 2.27E-06 \\
\hline $\mathrm{Te}-125 \mathrm{~m}$ & $1.81 \mathrm{E}-11$ & $4.53 \mathrm{E}-10$ & $3.02 \mathrm{E}-08$ \\
\hline Th-234 & $1.70 \mathrm{E}-08$ & $4.24 \mathrm{E}-07$ & 2.83E-05 \\
\hline U-238 & $1.70 \mathrm{E}-08$ & 4.24E-07 & 2.83E-05 \\
\hline $\mathrm{Y}-90$ & $3.29 \mathrm{E}-06$ & 8.23E-05 & $5.49 \mathrm{E}-03$ \\
\hline Total & $7.19 \mathrm{E}-05$ & $1.80 \mathrm{E}-03$ & $1.20 \mathrm{E}-01$ \\
\hline
\end{tabular}


TABLE B.6.30 Low-Level Mixed Waste, Case 7: Hanford

Function: Incineration

\begin{tabular}{llll}
\hline & \multicolumn{3}{c}{ Release (Ci) } \\
\cline { 2 - 4 } Nuclide & EQ7 & IEX & IFF \\
\hline & & & \\
Am-241 & $2.39 \mathrm{E}-05$ & $1.43 \mathrm{E}-08$ & $3.58 \mathrm{E}-07$ \\
Co-60 & $3.54 \mathrm{E}-05$ & $2.12 \mathrm{E}-08$ & $5.31 \mathrm{E}-07$ \\
Cs-137 & $2.81 \mathrm{E}-02$ & $1.68 \mathrm{E}-05$ & $4.21 \mathrm{E}-04$ \\
Eu-154 & $4.22 \mathrm{E}-05$ & $2.53 \mathrm{E}-08$ & $6.33 \mathrm{E}-07$ \\
Nb-94 & $2.40 \mathrm{E}-06$ & $1.44 \mathrm{E}-09$ & $3.59 \mathrm{E}-08$ \\
Ni-59 & $5.41 \mathrm{E}-05$ & $3.25 \mathrm{E}-08$ & $8.11 \mathrm{E}-07$ \\
Ni-63 & $5.56 \mathrm{E}-03$ & $3.33 \mathrm{E}-06$ & $8.34 \mathrm{E}-05$ \\
Pu-238 & $1.26 \mathrm{E}-03$ & $7.53 \mathrm{E}-07$ & $1.88 \mathrm{E}-05$ \\
Pu-239 & $1.70 \mathrm{E}-05$ & $1.02 \mathrm{E}-08$ & $2.55 \mathrm{E}-07$ \\
Pu-240 & $9.70 \mathrm{E}-06$ & $5.82 \mathrm{E}-09$ & $1.46 \mathrm{E}-07$ \\
Pu-241 & $2.78 \mathrm{E}-04$ & $1.67 \mathrm{E}-07$ & $4.18 \mathrm{E}-06$ \\
Sm-151 & $4.04 \mathrm{E}-04$ & $2.42 \mathrm{E}-07$ & $6.06 \mathrm{E}-06$ \\
Sr-90 & $2.50 \mathrm{E}-02$ & $1.50 \mathrm{E}-05$ & $3.75 \mathrm{E}-04$ \\
Tc-99 & $1.26 \mathrm{E}-05$ & $7.53 \mathrm{E}-09$ & $1.88 \mathrm{E}-07$ \\
Th-234 & $1.55 \mathrm{E}-05$ & $9.31 \mathrm{E}-09$ & $2.33 \mathrm{E}-07$ \\
U-238 & $1.55 \mathrm{E}-05$ & $9.31 \mathrm{E}-09$ & $2.33 \mathrm{E}-07$ \\
Y-90 & $2.50 \mathrm{E}-02$ & $1.50 \mathrm{E}-05$ & $3.75 \mathrm{E}-04$ \\
Total & $8.58 \mathrm{E}-02$ & $5.15 \mathrm{E}-05$ & $1.29 \mathrm{E}-03$ \\
\hline & & & \\
\hline
\end{tabular}


TABLE B.6.31 Low-Level Mixed Waste, Case 7: Idaho National Engineering Laboratory

\begin{tabular}{|c|c|c|c|}
\hline \multicolumn{4}{|c|}{ Function: Incineration } \\
\hline \multirow[b]{2}{*}{ Nuclide } & \multicolumn{3}{|c|}{ Release $(\mathrm{Ci})$} \\
\hline & EQ7 & IEX & IFF \\
\hline Ac-228 & $4.54 \mathrm{E}-11$ & $2.70 \mathrm{E}-14$ & $6.81 E-13$ \\
\hline Am-241 & $1.72 \mathrm{E}-09$ & $1.03 \mathrm{E}-12$ & $2.59 \mathrm{E}-11$ \\
\hline $\mathrm{Bi}-212$ & $7.64 \mathrm{E}-12$ & $0.00 \mathrm{E}+00$ & $1.15 \mathrm{E}-13$ \\
\hline Co-60 & $2.75 \mathrm{E}-02$ & $1.65 E-05$ & 4.13E-04 \\
\hline Cs-134 & $1.62 \mathrm{E}-05$ & $9.71 \mathrm{E}-09$ & 2.43E-07 \\
\hline Cs-137 & $1.80 \mathrm{E}-03$ & $1.08 \mathrm{E}-06$ & 2.70E-05 \\
\hline Eu-154 & $2.19 \mathrm{E}-05$ & $1.31 \mathrm{E}-08$ & $3.29 \mathrm{E}-07$ \\
\hline Eu-155 & $1.05 \mathrm{E}-05$ & $6.29 \mathrm{E}-09$ & 1.57E-07 \\
\hline $\mathrm{Fe}-55$ & $3.60 \mathrm{E}-03$ & $2.16 \mathrm{E}-06$ & $5.40 \mathrm{E}-05$ \\
\hline $\mathrm{Mn}-54$ & $1.14 \mathrm{E}-05$ & $6.85 \mathrm{E}-09$ & 1.71E-07 \\
\hline $\mathrm{Nb}-94$ & $1.71 \mathrm{E}-05$ & $1.03 \mathrm{E}-08$ & 2.57E-07 \\
\hline $\mathrm{Ni}-59$ & 3.60E-04 & $2.16 \mathrm{E}^{2} 07$ & $5.40 \mathrm{E}-06$ \\
\hline Ni-63 & 4.84E-02 & $2.90 \mathrm{E}-05$ & $7.26 \mathrm{E}-04$ \\
\hline $\mathrm{Pb}-212$ & $7.64 \mathrm{E}-12$ & $0.00 \mathrm{E}+00$ & $1.15 \mathrm{E}-13$ \\
\hline Pm-147 & $1.96 \mathrm{E}-04$ & $1.18 \mathrm{E}-07$ & $2.94 \mathrm{E}-06$ \\
\hline Pu-238 & $5.63 \mathrm{E}-05$ & $3.38 \mathrm{E}-08$ & 8.44E-07 \\
\hline $\mathrm{Pu}-239$ & 1.72E-09 & $1.03 \mathrm{E}-12$ & $2.59 E-11$ \\
\hline Pu-240 & $2.59 \mathrm{E}-09$ & $1.55 \mathrm{E}-12$ & $3.88 \mathrm{E}-11$ \\
\hline Pu-241 & $4.58 \mathrm{E}-05$ & 2.75E-08 & 6.87E-07 \\
\hline $\mathrm{Ra}-224$ & $7.64 \mathrm{E}-12$ & $0.00 \mathrm{E}+00$ & $1.15 \mathrm{E}-13$ \\
\hline $\mathrm{Ra}-228$ & $4.54 \mathrm{E}-11$ & $2.70 \mathrm{E}-14$ & $6.81 E-13$ \\
\hline Sb-125 & 7.62E-06 & 4.57E-09 & $1.14 \mathrm{E}-07$ \\
\hline Sm-151 & $1.53 \mathrm{E}-05$ & $9.16 \mathrm{E}-09$ & $2.29 \mathrm{E}-07$ \\
\hline Sr-90 & $1.70 \mathrm{E}-03$ & $1.02 E-06$ & 2.55E-05 \\
\hline Tc-99 & $2.96 \mathrm{E}-08$ & $1.77 \mathrm{E}-11$ & 4. $43 \mathrm{E}-10$ \\
\hline $\mathrm{Te}-125 \mathrm{~m}$ & $1.90 \mathrm{E}-06$ & 1.14E-09 & $2.86 \mathrm{E}-08$ \\
\hline Th-228 & $7.64 \mathrm{E}-12$ & $0.00 \mathrm{E}+00$ & $1.15 \mathrm{E}-13$ \\
\hline Th-231 & $4.38 \mathrm{E}-11$ & $2.60 \mathrm{E}-14$ & $6.57 \mathrm{E}-13$ \\
\hline Th-232 & 3.33E-09 & $2.00 \mathrm{E}-12$ & $5.00 \mathrm{E}-11$ \\
\hline Th-234 & $6.80 \mathrm{E}-05$ & $4.08 \mathrm{E}-08$ & $1.02 \mathrm{E}-06$ \\
\hline U-235 & $4.36 \mathrm{E}-11$ & $2.60 \mathrm{E}-14$ & $6.54 \mathrm{E}-13$ \\
\hline U-238 & $6.80 \mathrm{E}-05$ & $4.08 \mathrm{E}-08$ & $1.02 E-06$ \\
\hline Y-90 & $1.70 \mathrm{E}-03$ & $1.02 \mathrm{E}-06$ & $2.55 \mathrm{E}-05$ \\
\hline Total & $8.56 \mathrm{E}-02$ & $5.14 \mathrm{E}-05$ & $1.28 \mathrm{E}-03$ \\
\hline
\end{tabular}


TABLE B.6.32 Low-Level Mixed Waste, Case 7: Los Alamos National Laboratory

\begin{tabular}{lccc}
\hline & & \\
Function: Incineration \\
& \multicolumn{3}{c}{ Release (Ci) } \\
\cline { 2 - 4 } Nuclide & EQ7 & IEX & IFF \\
\hline & & & \\
Co-60 & $1.81 \mathrm{E}-04$ & $1.09 \mathrm{E}-07$ & $2.72 \mathrm{E}-06$ \\
Cs-137 & $1.35 \mathrm{E}-04$ & $8.12 \mathrm{E}-08$ & $2.03 \mathrm{E}-06$ \\
Eu-154 & $1.22 \mathrm{E}-06$ & $7.30 \mathrm{E}-10$ & $1.83 \mathrm{E}-08$ \\
Eu-155 & $5.24 \mathrm{E}-08$ & $3.14 \mathrm{E}-11$ & $7.86 \mathrm{E}-10$ \\
Fe-55 & $1.62 \mathrm{E}-05$ & $9.71 \mathrm{E}-09$ & $2.43 \mathrm{E}-07$ \\
Nb-94 & $2.97 \mathrm{E}-07$ & $1.78 \mathrm{E}-10$ & $4.45 \mathrm{E}-09$ \\
Ni-59 & $7.85 \mathrm{E}-06$ & $4.71 \mathrm{E}-09$ & $1.18 \mathrm{E}-07$ \\
Ni-63 & $9.72 \mathrm{E}-04$ & $5.83 \mathrm{E}-07$ & $1.46 \mathrm{E}-05$ \\
Pm-147 & $8.28 \mathrm{E}-06$ & $4.97 \mathrm{E}-09$ & $1.24 \mathrm{E}-07$ \\
Pu-238 & $4.96 \mathrm{E}-06$ & $2.98 \mathrm{E}-09$ & $7.44 \mathrm{E}-08$ \\
Pu-240 & $1.22 \mathrm{E}-06$ & $7.34 \mathrm{E}-10$ & $1.83 \mathrm{E}-08$ \\
Pu-241 & $1.85 \mathrm{E}-05$ & $1.11 \mathrm{E}-08$ & $2.78 \mathrm{E}-07$ \\
Sm-151 & $1.28 \mathrm{E}-06$ & $7.69 \mathrm{E}-10$ & $1.92 \mathrm{E}-08$ \\
Sr-90 & $1.27 \mathrm{E}-04$ & $7.60 \mathrm{E}-08$ & $1.90 \mathrm{E}-06$ \\
Tc-99 & $1.75 \mathrm{E}-08$ & $1.05 \mathrm{E}-11$ & $2.62 \mathrm{E}-10$ \\
Th-234 & $2.10 \mathrm{E}-07$ & $1.26 \mathrm{E}-10$ & $3.14 \mathrm{E}-09$ \\
U-238 & $2.10 \mathrm{E}-07$ & $1.26 \mathrm{E}-10$ & $3.14 \mathrm{E}-09$ \\
Y-90 & $1.27 \mathrm{E}-04$ & $7.60 \mathrm{E}-08$ & $1.90 \mathrm{E}-06$ \\
Total & $1.60 \mathrm{E}-03$ & $9.62 \mathrm{E}-07$ & $2.40 \mathrm{E}-05$ \\
\hline & & & \\
\hline
\end{tabular}


TABLE B.6.33 Low-Level Mixed Waste, Case 7: Oak Ridge National Laboratory

Function: Incineration

\begin{tabular}{|c|c|c|c|}
\hline \multirow[b]{2}{*}{ Nuclide } & \multicolumn{3}{|c|}{ Release (Ci) } \\
\hline & EQ7 & IEX & IFF \\
\hline Ac- 228 & $1.46 \mathrm{E}-06$ & $8.79 \mathrm{E}-10$ & $2.20 \mathrm{E}-08$ \\
\hline Am-241 & $3.00 \mathrm{E}-06$ & $1.80 \mathrm{E}-09$ & $4.49 \mathrm{E}-08$ \\
\hline $\mathrm{Bi}-212$ & 2.42E-07 & $1.45 \mathrm{E}-10$ & 3.63E-09 \\
\hline Co-60 & $1.64 \mathrm{E}-03$ & $9.85 \mathrm{E}-07$ & $2.46 \mathrm{E}-05$ \\
\hline Cs-137 & $4.72 \mathrm{E}-03$ & $2.83 \mathrm{E}-06$ & 7.07E-05 \\
\hline Eu-154 & $1.75 \mathrm{E}-05$ & $1.05 \mathrm{E}-08$ & 2.62E-07 \\
\hline Eu-155 & $5.99 \mathrm{E}-06$ & 3.59E-09 & $8.99 \mathrm{E}-08$ \\
\hline $\mathrm{Nb}-94$ & $1.25 \mathrm{E}-05$ & 7.49E-09 & $1.87 \mathrm{E}-07$ \\
\hline $\mathrm{Ni}-59$ & $2.65 \mathrm{E}-04$ & $1.59 \mathrm{E}-07$ & 3.97E-06 \\
\hline $\mathrm{Ni}-63$ & $2.79 \mathrm{E}-02$ & $1.67 \mathrm{E}-05$ & $4.18 \mathrm{E}-04$ \\
\hline $\mathrm{Pb}-212$ & $2.42 \mathrm{E}-07$ & $1.45 \mathrm{E}-10$ & 3.63E-09 \\
\hline Pu-238 & $1.86 \mathrm{E}-04$ & $1.11 \mathrm{E}-07$ & $2.78 \mathrm{E}-06$ \\
\hline Pu-239 & $3.00 \mathrm{E}-06$ & $1.80 \mathrm{E}-09$ & $4.49 \mathrm{E}-08$ \\
\hline Pu-240 & 4.49E-06 & 2.70E-09 & $6.74 \mathrm{E}-08$ \\
\hline Pu-241 & $1.97 \mathrm{E}-04$ & $1.18 \mathrm{E}-07$ & $2.95 \mathrm{E}-06$ \\
\hline $\mathrm{Ra}-224$ & 2.42E-07 & $1.45 \mathrm{E}-10$ & 3.63E-09 \\
\hline $\mathrm{Ra}-228$ & $1.46 \mathrm{E}-06$ & $8.79 \mathrm{E}-10$ & $2.20 \mathrm{E}-08$ \\
\hline Sm-151 & $5.69 \mathrm{E}-05$ & $3.41 \mathrm{E}-08$ & 8.53E-07 \\
\hline Sr-90 & 4.17E-03 & $2.50 \mathrm{E}-06$ & $6.25 \mathrm{E}-05$ \\
\hline Tc-99 & $6.44 \mathrm{E}-04$ & $3.86 \mathrm{E}-07$ & $9.66 \mathrm{E}-06$ \\
\hline Th-228 & $2.42 \mathrm{E}-07$ & $1.45 \mathrm{E}-10$ & 3.63E-09 \\
\hline Th-231 & $1.54 \mathrm{E}-06$ & $9.26 \mathrm{E}-10$ & $2.31 \mathrm{E}-08$ \\
\hline Th-232 & 2.12E-05 & $1.27 \mathrm{E}-08$ & $3.18 \mathrm{E}-07$ \\
\hline Th-234 & $2.58 \mathrm{E}-03$ & $1.55 \mathrm{E}-06$ & $3.86 \mathrm{E}-05$ \\
\hline $\mathrm{U}-235$ & 1.53E-06 & $9.18 \mathrm{E}-10$ & $2.29 \mathrm{E}-08$ \\
\hline U-238 & $2.58 \mathrm{E}-03$ & $1.55 \mathrm{E}-06$ & $3.86 \mathrm{E}-05$ \\
\hline$Y-90$ & 4.17E-03 & $2.50 \mathrm{E}-06$ & $6.25 \mathrm{E}-05$ \\
\hline Total & 4.91E-02 & 2.95E-05 & 7.37E-04 \\
\hline
\end{tabular}


TABLE B.6.34 Low-Level Mixed Waste, Case 7: Portsmouth Gaseous Diffusion Plant

\begin{tabular}{|c|c|c|c|}
\hline \multicolumn{4}{|c|}{ Function: Incineration } \\
\hline \multirow[b]{2}{*}{ Nuclide } & \multicolumn{3}{|c|}{ Release $(\mathrm{Ci})$} \\
\hline & EQ7 & IEX & IFF \\
\hline Ac-228 & $4.18 \mathrm{E}-11$ & $2.50 \mathrm{E}-14$ & $6.26 \mathrm{E}-13$ \\
\hline Am-241 & 8.32E-07 & $4.99 \mathrm{E}-10$ & $1.25 \mathrm{E}-08$ \\
\hline $\mathrm{Bi}-212$ & $7.02 \mathrm{E}-12$ & $0.00 \mathrm{E}+00$ & $1.05 \mathrm{E}-13$ \\
\hline Co-60 & $2.04 E-03$ & $1.22 \mathrm{E}-06$ & $3.06 \mathrm{E}-05$ \\
\hline Cs-134 & 9.32E-07 & $5.59 \mathrm{E}-10$ & $1.40 \mathrm{E}-08$ \\
\hline Cs-137 & $1.41 \mathrm{E}-03$ & 8.47E-07 & $2.12 \mathrm{E}-05$ \\
\hline Eu-154 & $6.10 \mathrm{E}-06$ & $3.66 \mathrm{E}-09$ & $9.14 \mathrm{E}-08$ \\
\hline Eu-155 & $2.26 \mathrm{E}-06$ & $1.35 \mathrm{E}-09$ & $3.39 \mathrm{E}-08$ \\
\hline $\mathrm{Fe}-55$ & 2.07E-04 & $1.24 \mathrm{E}-07$ & $3.11 \mathrm{E}-06$ \\
\hline $\mathrm{Mn}-54$ & $6.58 \mathrm{E}-07$ & $3.95 \mathrm{E}-10$ & $9.87 \mathrm{E}-09$ \\
\hline $\mathrm{Nb}-94$ & 4.43E-06 & $2.66 \mathrm{E}-09$ & $6.65 \mathrm{E}-08$ \\
\hline $\mathrm{Ni}-59$ & $9.39 E-05$ & $5.63 E-08$ & $1.41 \mathrm{E}-06$ \\
\hline $\mathrm{Ni}-63$ & $1.05 \mathrm{E}-02$ & $6.29 \mathrm{E}-06$ & $1.57 \mathrm{E}-04$ \\
\hline $\mathrm{Pb}-212$ & 7.02E-12 & $0.00 \mathrm{E}+00$ & $1.05 \mathrm{E}-13$ \\
\hline Pm-147 & $1.13 \mathrm{E}-05$ & $6.78 \mathrm{E}-09$ & $1.69 \mathrm{E}-07$ \\
\hline Pu-238 & $5.47 \mathrm{E}-05$ & $3.28 \mathrm{E}-08$ & $8.21 \mathrm{E}-07$ \\
\hline Pu-239 & 8.31E-07 & $4.99 \mathrm{E}-10$ & $1.25 \mathrm{E}-08$ \\
\hline Pu-240 & $1.24 \mathrm{E}-06$ & $7.46 \mathrm{E}-10$ & $1.86 \mathrm{E}-08$ \\
\hline Pu-241 & $5.69 \mathrm{E}-05$ & $3.42 \mathrm{E}-08$ & $8.54 \mathrm{E}-07$ \\
\hline $\mathrm{Ra}-224$ & $7.02 \mathrm{E}-12$ & $0.00 \mathrm{E}+00$ & $1.05 \mathrm{E}-13$ \\
\hline $\mathrm{Ra}-228$ & $4.18 \mathrm{E}-11$ & $2.50 \mathrm{E}-14$ & $6.26 \mathrm{E}-13$ \\
\hline Sb-125 & 4.39E-07 & $2.63 \mathrm{E}-10$ & $6.58 \mathrm{E}-09$ \\
\hline Sm-151 & 1.67E-05 & $1.00 \mathrm{E}-08$ & $2.50 \mathrm{E}-07$ \\
\hline Sr-90 & $1.25 \mathrm{E}-03$ & 7.53E-07 & $1.88 \mathrm{E}-05$ \\
\hline Tc-99 & $1.38 \mathrm{E}-05$ & 8.27E-09 & 2.07E-07 \\
\hline $\mathrm{Te}-125 \mathrm{~m}$ & $1.10 \mathrm{E}-07$ & $6.58 \mathrm{E}-11$ & $1.65 \mathrm{E}-09$ \\
\hline Th-228 & 7.02E-12 & $0.00 \mathrm{E}+00$ & $1.05 \mathrm{E}-13$ \\
\hline Th-231 & $4.10 \mathrm{E}-11$ & $2.50 \mathrm{E}-14$ & $6.15 \mathrm{E}-13$ \\
\hline Th-232 & $1.38 \mathrm{E}-06$ & 8.27E-10 & $2.07 \mathrm{E}-08$ \\
\hline Th-234 & $1.71 \mathrm{E}-04$ & $1.02 \mathrm{E}-07$ & $2.56 \mathrm{E}-06$ \\
\hline U-235 & $4.08 \mathrm{E}-11$ & $2.40 \mathrm{E}-14$ & $6.12 \mathrm{E}-13$ \\
\hline $\mathrm{U}-238$ & 1.71E-04 & $1.02 \mathrm{E}-07$ & $2.56 \mathrm{E}-06$ \\
\hline$Y-90$ & $1.25 \mathrm{E}-03$ & 7.53E-07 & $1.88 \mathrm{E}-05$ \\
\hline Total & 1.73E-02 & $1.04 \mathrm{E}-05$ & $2.59 \mathrm{E}-04$ \\
\hline
\end{tabular}


TABLE B.6.35 Low-Level Mixed Waste, Case 7: Rocky Flats Environmental

Technology Site

\begin{tabular}{|c|c|c|c|}
\hline \multicolumn{4}{|c|}{ Function: Incineration } \\
\hline \multirow[b]{2}{*}{ Nuclide } & \multicolumn{3}{|c|}{ Release (Ci) } \\
\hline & IEX & IFF & EQ7 \\
\hline Co- 60 & $4.60 \mathrm{E}-08$ & $1.15 \mathrm{E}-06$ & 7.67E-05 \\
\hline Cs-134 & $2.71 E-11$ & $6.77 \mathrm{E}-10$ & $4.51 \mathrm{E}-08$ \\
\hline Cs-137 & 3.01E-09 & $7.52 \mathrm{E}-08$ & $5.02 \mathrm{E}-06$ \\
\hline Eu-154 & $3.66 \mathrm{E}-11$ & $9.15 \mathrm{E}-10$ & $6.10 \mathrm{E}-08$ \\
\hline Eu-155 & $1.75 \mathrm{E}-11$ & $4.38 \mathrm{E}-10$ & 2.92E-08 \\
\hline $\mathrm{Fe}-55$ & $6.02 E-09$ & $1.50 \mathrm{E}-07$ & $1.00 \mathrm{E}-05$ \\
\hline $\mathrm{Mn}-54$ & $1.91 \mathrm{E}-11$ & $4.78 \mathrm{E}-10$ & 3.18E-08 \\
\hline $\mathrm{Nb}-94$ & $2.87 E-11$ & $7.16 \mathrm{E}-10$ & 4.78E-08 \\
\hline $\mathrm{Ni}-59$ & $6.02 \mathrm{E}-10$ & $1.50 \mathrm{E}-08$ & $1.00 \mathrm{E}-06$ \\
\hline $\mathrm{Ni}-63$ & 8.09E-08 & $2.02 \mathrm{E}-06$ & $1.35 \mathrm{E}-04$ \\
\hline Pm-147 & $3.28 \mathrm{E}-10$ & $8.20 \mathrm{E}-09$ & 5.47E-07 \\
\hline $\mathrm{Pu}-238$ & $9.39 \mathrm{E}-11$ & 2.35E-09 & $1.57 \mathrm{E}-07$ \\
\hline Pu-241 & 7.64E-11 & $1.91 \mathrm{E}-09$ & 1.27E-07 \\
\hline $\mathrm{Sb}-125$ & $1.27 \mathrm{E}-11$ & $3.18 \mathrm{E}-10$ & $2.12 \mathrm{E}-08$ \\
\hline Sm-151 & $2.55 \mathrm{E}-11$ & $6.37 \mathrm{E}-10$ & $4.25 \mathrm{E}-08$ \\
\hline Sr-90 & 2.83E-09 & 7.09E-08 & 4.72E-06 \\
\hline $\mathrm{Te}-125 \mathrm{~m}$ & $3.18 \mathrm{E}-12$ & $7.96 \mathrm{E}-11$ & 5.31E-09 \\
\hline Th-234 & $1.13 \mathrm{E}-10$ & 2.83E-09 & $1.88 \mathrm{E}-07$ \\
\hline U-238 & 1.13E-10 & 2.83E-09 & $1.88 \mathrm{E}-07$ \\
\hline Y-90 & 2.83E-09 & $7.09 \mathrm{E}-08$ & 4.72E-06 \\
\hline Total & $1.43 \mathrm{E}-07$ & $3.58 \mathrm{E}-06$ & 2.39E-04 \\
\hline
\end{tabular}


TABLE B.6.36 Low-Level Mixed Waste, Case 7: Savannah River Site

\begin{tabular}{|c|c|c|c|}
\hline \multicolumn{4}{|c|}{ Function: Incineration } \\
\hline \multirow[b]{2}{*}{ Nuclide } & \multicolumn{3}{|c|}{ Release (Ci) } \\
\hline & EQ7 & IEX & IFF \\
\hline Co-60 & $8.50 \mathrm{E}-03$ & $5.10 \mathrm{E}-06$ & $1.28 \mathrm{E}-04$ \\
\hline Cs-134 & 2.57E-07 & $1.54 \mathrm{E}-10$ & 3.85E-09 \\
\hline Cs-137 & $5.90 \mathrm{E}-03$ & $3.54 \mathrm{E}-06$ & $8.85 \mathrm{E}-05$ \\
\hline Eu-154. & $2.98 \mathrm{E}-05$ & 1.79E-08 & 4.47E-07 \\
\hline Eu-155 & $6.96 \mathrm{E}-06$ & 4.18E-09 & $1.04 \mathrm{E}-07$ \\
\hline $\mathrm{Fe}-55$ & $2.18 \mathrm{E}-04$ & $1.31 \mathrm{E}-07$ & 3.27E-06 \\
\hline $\mathrm{Mn}-54$ & $1.81 \mathrm{E}-07$ & $1.09 \mathrm{E}-10$ & $2.72 \mathrm{E}-09$ \\
\hline $\mathrm{Nb}-94$ & $3.88 \mathrm{E}-05$ & $2.33 \mathrm{E}-08$ & $5.82 \mathrm{E}-07$ \\
\hline $\mathrm{Ni}-59$ & 7.67E-04 & $4.60 \mathrm{E}-07$ & $1.15 \mathrm{E}-05$ \\
\hline $\mathrm{Ni}-63$ & $9.28 \mathrm{E}-02$ & $5.57 \mathrm{E}-05$ & $1.39 \mathrm{E}-03$ \\
\hline $\mathrm{Pm}-147$ & $3.11 \mathrm{E}-06$ & $1.87 \mathrm{E}-09$ & 4.67E-08 \\
\hline Pu-238 & $2.00 \mathrm{E}-04$ & $1.20 \mathrm{E}-07$ & $3.00 \mathrm{E}-06$ \\
\hline Pu-240 & $1.59 \mathrm{E}-04$ & $9.52 \mathrm{E}-08$ & 2.38E-06 \\
\hline $\mathrm{Pu}-241$ & $1.59 \mathrm{E}-04$ & $9.56 \mathrm{E}-08$ & $2.39 \mathrm{E}-06$ \\
\hline $\mathrm{Sb}-125$ & $1.21 \mathrm{E}-07$ & $7.26 \mathrm{E}-11$ & 1.81E-09 \\
\hline Sm-151 & $6.37 \mathrm{E}-05$ & $3.82 \mathrm{E}-08$ & 9.55E-07 \\
\hline $\mathrm{Sr}-90$ & $5.49 \mathrm{E}-03$ & $3.29 \mathrm{E}-06$ & 8.23E-05 \\
\hline Tc-99 & 2.27E-06 & $1.36 \mathrm{E}-09$ & 3.40E-08 \\
\hline $\mathrm{Te}-125 \mathrm{~m}$ & $3.02 \mathrm{E}-08$ & $1.81 \mathrm{E}-11$ & $4.53 \mathrm{E}-10$ \\
\hline Th-234 & $2.83 \mathrm{E}-05$ & $1.70 \mathrm{E}-08$ & 4.24E-07 \\
\hline U-238 & $2.83 \mathrm{E}-05$ & $1.70 \mathrm{E}-08$ & 4.24E-07 \\
\hline$Y-90$ & $5.49 \mathrm{E}-03$ & 3.29E-06 & 8.23E-05 \\
\hline Total & $1.20 \mathrm{E}-01$ & 7.19E-05 & $1.80 \mathrm{E}-03$ \\
\hline
\end{tabular}


TABLE B.6.37 Low-Level Mixed Waste, Case 15: Hanford

\begin{tabular}{|c|c|c|c|}
\hline \multirow[b]{3}{*}{ Nuclide } & eration & & \\
\hline & \multicolumn{3}{|c|}{ Release $(\mathrm{Ci})$} \\
\hline & EQ7 & IEX & $\mathrm{IFF}$ \\
\hline Am-241 & 2.39E-05 & $1.43 \mathrm{E}-08$ & $3.58 \mathrm{E}-07$ \\
\hline Co-60 & $3.54 \mathrm{E}-05$ & $2.12 \mathrm{E}-08$ & $5.31 \mathrm{E}-07$ \\
\hline Cs-137 & $2.81 \mathrm{E}-02$ & $1.68 \mathrm{E}-05$ & $4.21 \mathrm{E}-04$ \\
\hline Eu-154 & $4.22 \mathrm{E}-05$ & $2.53 \mathrm{E}-08$ & $6.33 \mathrm{E}-07$ \\
\hline $\mathrm{Nb}-94$ & $2.40 \mathrm{E}-06$ & 1.44E-09 & $3.59 \mathrm{E}-08$ \\
\hline $\mathrm{Ni}-59$ & 5.41E-05 & $3.25 \mathrm{E}-08$ & $8.11 \mathrm{E}-07$ \\
\hline $\mathrm{Ni}-63$ & $5.56 \mathrm{E}-03$ & $3.33 \mathrm{E}-06$ & 8.34E-05 \\
\hline $\mathrm{Pu}-238$ & $1.26 \mathrm{E}-03$ & 7.53E-07 & $1.88 \mathrm{E}-05$ \\
\hline $\mathrm{Pu}-239$ & $1.70 \mathrm{E}-05$ & $1.02 \mathrm{E}-08$ & $2.55 \mathrm{E}-07$ \\
\hline $\mathrm{Pu}-240$ & 9.70E-06 & 5.82E-09 & $1.46 \mathrm{E}-07$ \\
\hline Pu-241 & $2.78 \mathrm{E}-04$ & 1.67E-07 & $4.18 \mathrm{E}-06$ \\
\hline Sm-151 & 4.04E-04 & 2.42E-07 & $6.06 \mathrm{E}-06$ \\
\hline Sr-90 & $2.50 \mathrm{E}-02$ & $1.50 \mathrm{E}-05$ & 3.75E-04 \\
\hline Tc-99 & $1.26 \mathrm{E}-05$ & 7.53E-09 & $1.88 \mathrm{E}-07$ \\
\hline Th-234 & $1.55 \mathrm{E}-05$ & 9.31E-09 & 2.33E-07 \\
\hline U-238 & $1.55 \mathrm{E}-05$ & 9.31E-09 & 2.33E-07 \\
\hline Y-90 & $2.50 \mathrm{E}-02$ & $1.50 \mathrm{E}-05$ & 3.75E-04 \\
\hline Total & 8.58E-02 & $5.15 \mathrm{E}-05$ & $1.29 \mathrm{E}-03$ \\
\hline
\end{tabular}


TABLE B.6.38 Low-Level Mixed Waste, Case 15: Idaho National Engineering

Laboratory

Function: Incineration

\begin{tabular}{lccc}
\hline & \multicolumn{3}{c}{ Release (Ci) } \\
\cline { 2 - 4 } Nuclide & EQ7 & IEX & IFF \\
\hline & & & \\
Ac-228 & $4.57 \mathrm{E}-11$ & $2.70 \mathrm{E}-14$ & $6.86 \mathrm{E}-13$ \\
Am-241 & $1.72 \mathrm{E}-09$ & $1.03 \mathrm{E}-12$ & $2.59 \mathrm{E}-11$ \\
Bi-212 & $7.69 \mathrm{E}-12$ & $0.00 \mathrm{E}+00$ & $1.15 \mathrm{E}-13$ \\
Co-60 & $2.75 \mathrm{E}-02$ & $1.65 \mathrm{E}-05$ & $4.13 \mathrm{E}-04$ \\
Cs-134 & $1.62 \mathrm{E}-05$ & $9.71 \mathrm{E}-09$ & $2.43 \mathrm{E}-07$ \\
Cs-137 & $1.80 \mathrm{E}-03$ & $1.08 \mathrm{E}-06$ & $2.71 \mathrm{E}-05$ \\
Eu-154 & $2.19 \mathrm{E}-05$ & $1.32 \mathrm{E}-08$ & $3.29 \mathrm{E}-07$ \\
Eu-155 & $1.05 \mathrm{E}-05$ & $6.29 \mathrm{E}-09$ & $1.57 \mathrm{E}-07$ \\
Fe-55 & $3.60 \mathrm{E}-03$ & $2.16 \mathrm{E}-06$ & $5.40 \mathrm{E}-05$ \\
Mn-54 & $1.14 \mathrm{E}-05$ & $6.85 \mathrm{E}-09$ & $1.71 \mathrm{E}-07$ \\
Nb-94 & $1.71 \mathrm{E}-05$ & $1.03 \mathrm{E}-08$ & $2.57 \mathrm{E}-07$ \\
Ni-59 & $3.60 \mathrm{E}-04$ & $2.16 \mathrm{E}-07$ & $5.40 \mathrm{E}-06$ \\
Ni-63 & $4.84 \mathrm{E}-02$ & $2.90 \mathrm{E}-05$ & $7.26 \mathrm{E}-04$ \\
Pb-212 & $7.69 \mathrm{E}-12$ & $0.00 \mathrm{E}+00$ & $1.15 \mathrm{E}-13$ \\
Pm-147 & $1.96 \mathrm{E}-04$ & $1.18 \mathrm{E}-07$ & $2.95 \mathrm{E}-06$ \\
Pu-238 & $5.64 \mathrm{E}-05$ & $3.38 \mathrm{E}-08$ & $8.46 \mathrm{E}-07$ \\
Pu-239 & $1.72 \mathrm{E}-09$ & $1.03 \mathrm{E}-12$ & $2.59 \mathrm{E}-11$ \\
Pu-240 & $2.59 \mathrm{E}-09$ & $1.55 \mathrm{E}-12$ & $3.88 \mathrm{E}-11$ \\
Pu-241 & $4.64 \mathrm{E}-05$ & $2.78 \mathrm{E}-08$ & $6.95 \mathrm{E}-07$ \\
Ra-224 & $7.69 \mathrm{E}-12$ & $0.00 \mathrm{E}+00$ & $1.15 \mathrm{E}-13$ \\
Ra-228 & $4.57 \mathrm{E}-11$ & $2.70 \mathrm{E}-14$ & $6.86 \mathrm{E}-13$ \\
Sb-125 & $7.62 \mathrm{E}-06$ & $4.57 \mathrm{E}-09$ & $1.14 \mathrm{E}-07$ \\
Sm-151 & $1.53 \mathrm{E}-05$ & $9.17 \mathrm{E}-09$ & $2.29 \mathrm{E}-07$ \\
Sr-90 & $1.70 \mathrm{E}-03$ & $1.02 \mathrm{E}-06$ & $2.55 \mathrm{E}-05$ \\
Tc-99 & $2.96 \mathrm{E}-08$ & $1.77 \mathrm{E}-11$ & $4.43 \mathrm{E}-10$ \\
Te-125m & $1.90 \mathrm{E}-06$ & $1.14 \mathrm{E}-09$ & $2.86 \mathrm{E}-08$ \\
Th-228 & $7.69 \mathrm{E}-12$ & $0.00 \mathrm{E}+00$ & $1.15 \mathrm{E}-13$ \\
Th-231 & $4.41 \mathrm{E}-11$ & $2.70 \mathrm{E}-14$ & $6.62 \mathrm{E}-13$ \\
Th-232 & $3.34 \mathrm{E}-09$ & $2.00 \mathrm{E}-12$ & $5.01 \mathrm{E}-11$ \\
Th-234 & $6.80 \mathrm{E}-05$ & $4.08 \mathrm{E}-08$ & $1.02 \mathrm{E}-06$ \\
U-235 & $4.39 \mathrm{E}-11$ & $2.60 \mathrm{E}-14$ & $6.59 \mathrm{E}-13$ \\
U-238 & $6.80 \mathrm{E}-05$ & $4.08 \mathrm{E}-08$ & $1.02 \mathrm{E}-06$ \\
Y-90 & $1.70 \mathrm{E}-03$ & $1.02 \mathrm{E}-06$ & $2.55 \mathrm{E}-05$ \\
Total & $8.56 \mathrm{E}-02$ & $5.14 \mathrm{E}-05$ & $1.28 \mathrm{E}-03$ \\
\hline & & & \\
& & &
\end{tabular}


TABLE B.6.39 Low-Level Mixed Waste, Case 15: Oak Ridge National Laboratory

\begin{tabular}{|c|c|c|c|}
\hline \multicolumn{4}{|c|}{ Function: Incineration } \\
\hline \multirow[b]{2}{*}{ Nuclide } & \multicolumn{3}{|c|}{ Release (Ci) } \\
\hline & EQ7 & IEX & IFF \\
\hline Ac- 228 & 8.61E-08 & $5.16 \mathrm{E}-11$ & $1.29 \mathrm{E}-09$ \\
\hline Am-241 & $6.34 \mathrm{E}-06$ & $3.81 \mathrm{E}-09$ & $9.51 \mathrm{E}-08$ \\
\hline $\mathrm{Bi}-212$ & $1.42 \mathrm{E}-08$ & $8.55 \mathrm{E}-12$ & $2.14 \mathrm{E}-10$ \\
\hline $\mathrm{Co}-60$ & $3.53 \mathrm{E}-03$ & $2.12 \mathrm{E}-06$ & $5.29 \mathrm{E}-05$ \\
\hline Cs-134 & $3.00 \mathrm{E}-08$ & $1.80 \mathrm{E}-11$ & $4.50 \mathrm{E}-10$ \\
\hline Cs- 137 & $9.99 \mathrm{E}-03$ & $5.99 \mathrm{E}-06$ & $1.50 \mathrm{E}-04$ \\
\hline Eu-154 & 3.70E-05 & $2.22 \mathrm{E}-08$ & $5.56 \mathrm{E}-07$ \\
\hline Eu-155 & $1.27 \mathrm{E}-05$ & 7.62E-09 & $1.91 \mathrm{E}-07$ \\
\hline $\mathrm{Fe}-55$ & $6.66 \mathrm{E}-06$ & 4.00E-09 & $1.00 \mathrm{E}-07$ \\
\hline$M n-54$ & $2.12 E-08$ & $1.27 \mathrm{E}-11$ & 3.17E-10 \\
\hline $\mathrm{Nb}-94$ & $2.65 \mathrm{E}-05$ & $1.59 \mathrm{E}-08$ & $3.97 \mathrm{E}-07$ \\
\hline $\mathrm{Ni}-59$ & 5.61E-04 & 3.37E-07 & 8.42E-06 \\
\hline $\mathrm{Ni}-63$ & 5.91E-02 & 3.55E-05 & $8.86 \mathrm{E}-04$ \\
\hline $\mathrm{Pb}-212$ & $1.42 \mathrm{E}-08$ & $8.55 \mathrm{E}-12$ & $2.14 \mathrm{E}-10$ \\
\hline Pm-147 & $3.63 \mathrm{E}-07$ & $2.18 \mathrm{E}-10$ & $5.45 \mathrm{E}-09$ \\
\hline $\mathrm{Pu}-238$ & 3.93E-04 & $2.36 \mathrm{E}-07$ & $5.89 \mathrm{E}-06$ \\
\hline Pu-239 & $6.34 \mathrm{E}-06$ & $3.81 \mathrm{E}-09$ & $9.51 \mathrm{E}-08$ \\
\hline Pu-240 & $9.51 \mathrm{E}-06$ & 5.71E-09 & $1.43 \mathrm{E}-07$ \\
\hline $\mathrm{Pu}-241$ & 4.16E-04 & $2.50 \mathrm{E}-07$ & $6.24 \mathrm{E}-06$ \\
\hline $\mathrm{Ra}-224$ & $1.42 \mathrm{E}-08$ & $8.55 E-12$ & $2.14 \mathrm{E}-10$ \\
\hline $\mathrm{Ra}-228$ & 8.61E-08 & $5.16 \mathrm{E}-11$ & $1.29 \mathrm{E}-09$ \\
\hline Sb-125 & $1.41 \mathrm{E}-08$ & $8.46 \mathrm{E}-12$ & $2.12 \mathrm{E}-10$ \\
\hline Sm-151 & $1.20 \mathrm{E}-04$ & 7.23E-08 & $1.81 \mathrm{E}-06$ \\
\hline Sr-90 & 8.83E-03 & 5.30E-06 & 1.32E-04 \\
\hline Tc-99 & $1.38 \mathrm{E}-04$ & $8.28 \mathrm{E}-08$ & $2.07 \mathrm{E}-06$ \\
\hline $\mathrm{Te}-125 \mathrm{~m}$ & 3.53E-09 & $2.12 \mathrm{E}-12$ & $5.29 \mathrm{E}-11$ \\
\hline Th-228 & 1.42E-08 & $8.55 \mathrm{E}-12$ & $2.14 \mathrm{E}-10$ \\
\hline Th-231 & $9.01 \mathrm{E}-08$ & $5.40 \mathrm{E}-11$ & $1.35 \mathrm{E}-09$ \\
\hline Th-232 & 1.15E-05 & $6.91 \mathrm{E}-09$ & $1.73 \mathrm{E}-07$ \\
\hline Th-234 & $1.39 \mathrm{E}-03$ & 8.36E-07 & $2.09 \mathrm{E}-05$ \\
\hline U-235 & $8.93 E-08$ & $5.36 \mathrm{E}-11$ & $1.34 \mathrm{E}-09$ \\
\hline U-238 & $1.39 \mathrm{E}-03$ & 8.36E-07 & $2.09 E-05$ \\
\hline Y-90 & 8.83E-03 & $5.30 \mathrm{E}-06$ & $1.32 \mathrm{E}-04$ \\
\hline Total & $9.48 \mathrm{E}-02$ & $5.69 \mathrm{E}-05$ & $1.42 \mathrm{E}-03$ \\
\hline
\end{tabular}


TABLE B.6.40 Low-Level Mixed Waste, Case 15: Savannah River Site

\begin{tabular}{|c|c|c|c|}
\hline \multirow[b]{2}{*}{ Nuclide } & \multicolumn{3}{|c|}{ Release $(\mathrm{Ci})$} \\
\hline & EQ7 & IEX & IFF \\
\hline Co-60 & 8.50E-03 & $5.10 \mathrm{E}-06$ & $1.28 \mathrm{E}-04$ \\
\hline Cs-134 & $2.57 \mathrm{E}-07$ & $1.54 \mathrm{E}-10$ & 3.85E-09 \\
\hline Cs-137 & $5.90 \mathrm{E}-03$ & $3.54 \mathrm{E}-06$ & $8.85 \mathrm{E}-05$ \\
\hline Eu-154 & 2.98E-05 & 1.79E-08 & 4.47E-07 \\
\hline Eu-155 & $6.96 \mathrm{E}-06$ & 4.18E-09 & $1.04 \mathrm{E}-07$ \\
\hline $\mathrm{Fe}-55$ & $2.18 \mathrm{E}-04$ & 1.31E-07 & $3.27 \mathrm{E}-06$ \\
\hline$M n-54$ & $1.81 \mathrm{E}-07$ & $1.09 \mathrm{E}-10$ & 2.72E-09 \\
\hline $\mathrm{Nb}-94$ & 3.88E-05 & 2.33E-08 & $5.82 \mathrm{E}-07$ \\
\hline $\mathrm{Ni}-59$ & 7.67E-04 & 4.60E-07 & $1.15 \mathrm{E}-05$ \\
\hline $\mathrm{Ni}-63$ & $9.28 \mathrm{E}-02$ & 5.57E-05 & $1.39 \mathrm{E}-03$ \\
\hline Pm-147 & $3.11 \mathrm{E}-06$ & 1.87E-09 & 4.67E-08 \\
\hline $\mathrm{Pu}-238$ & $2.00 \mathrm{E}-04$ & 1.20E-07 & $3.00 \mathrm{E}-06$ \\
\hline $\mathrm{Pu}-240$ & $1.59 \mathrm{E}-04$ & 9.52E-08 & $2.38 \mathrm{E}-06$ \\
\hline $\mathrm{Pu}-241$ & $1.59 \mathrm{E}-04$ & $9.56 \mathrm{E}-08$ & $2.39 \mathrm{E}-06$ \\
\hline $\mathrm{Sb}-125$ & $1.21 \mathrm{E}-07$ & $7.26 \mathrm{E}-11$ & $1.81 \mathrm{E}-09$ \\
\hline Sm-151 & 6.37E-05 & 3.82E-08 & $9.55 \mathrm{E}-07$ \\
\hline Sr-90 & $5.49 \mathrm{E}-03$ & $3.29 \mathrm{E}-06$ & 8.23E-05 \\
\hline Tc-99 & 2.27E-06 & $1.36 \mathrm{E}-09$ & $3.40 \mathrm{E}-08$ \\
\hline $\mathrm{Te}-125 \mathrm{~m}$ & 3.02E-08 & $1.81 \mathrm{E}-11$ & 4.53E-10 \\
\hline Th-234 & $2.83 \mathrm{E}-05$ & $1.70 \mathrm{E}-08$ & $4.24 \mathrm{E}-07$ \\
\hline U-238 & 2.83E-05 & $1.70 \mathrm{E}-08$ & 4.24E-07 \\
\hline Y-90 & $5.49 \mathrm{E}-03$ & 3.29E-06 & 8.23E-05 \\
\hline Total & $1.20 \mathrm{E}-01$ & 7.19E-05 & $1.80 \mathrm{E}-03$ \\
\hline
\end{tabular}


TABLE B.6.41 Low-Level Mixed Waste, Case 17: Hanford

Function: Incineration

\begin{tabular}{|c|c|c|c|}
\hline \multirow[b]{2}{*}{ Nuclide } & \multicolumn{3}{|c|}{ Release (Ci) } \\
\hline & EQ7 & IEX & IFF \\
\hline Ac- 228 & 8.61E-08 & $5.17 \mathrm{E}-11$ & $1.29 \mathrm{E}-09$ \\
\hline Am-241 & 2.72E-05 & 1.63E-08 & 4.09E-07 \\
\hline $\mathrm{Bi}-212$ & 1.42E-08 & 8.55E-12 & 2.14E-10 \\
\hline Co-60 & $6.81 \mathrm{E}-03$ & 4.09E-06 & $1.02 \mathrm{E}-04$ \\
\hline Cs-134 & 5.70E-07 & $3.42 \mathrm{E}-10$ & 8.55E-09 \\
\hline Cs-137 & $3.64 \mathrm{E}-02$ & $2.18 \mathrm{E}-05$ & $5.46 \mathrm{E}-04$ \\
\hline Eu-154 & 8.33E-05 & $5.00 \mathrm{E}-08$ & $1.25 \mathrm{E}-06$ \\
\hline Eu-155 & $1.50 \mathrm{E}-05$ & $9.01 \mathrm{E}-09$ & 2.25E-07 \\
\hline $\mathrm{Fe}-55$ & $1.73 \mathrm{E}-04$ & 1.04E-07 & 2.60E-06 \\
\hline $\mathrm{Mn}-54$ & 4.02E-07 & $2.41 E-10$ & $6.04 \mathrm{E}-09$ \\
\hline $\mathrm{Nb}-94$ & 4.03E-05 & $2.42 \mathrm{E}-08$ & $6.04 \mathrm{E}-07$ \\
\hline $\mathrm{Ni}-59$ & 8.41E-04 & 5.05E-07 & $1.26 \mathrm{E}-05$ \\
\hline $\mathrm{Ni}-63$ & $9.22 \mathrm{E}-02$ & 5.53E-05 & $1.38 \mathrm{E}-03$ \\
\hline $\mathrm{Pb}-212$ & $1.42 \mathrm{E}-08$ & $8.55 \mathrm{E}-12$ & 2.14E-10 \\
\hline Pm-147 & $6.91 \mathrm{E}-06$ & 4.15E-09 & $1.04 \mathrm{E}-07$ \\
\hline Pu-238 & $1.55 \mathrm{E}-03$ & $9.31 \mathrm{E}-07$ & 2.33E-05 \\
\hline Pu-239 & 2.12E-05 & 1.27E-08 & $3.19 \mathrm{E}-07$ \\
\hline Pu-240 & $6.39 \mathrm{E}-05$ & $3.83 \mathrm{E}-08$ & $9.59 \mathrm{E}-07$ \\
\hline $\mathrm{Pu}-241$ & $7.21 \mathrm{E}-04$ & $4.33 \mathrm{E}-07$ & $1.08 \mathrm{E}-05$ \\
\hline $\mathrm{Ra}-224$ & $1.42 \mathrm{E}-08$ & 8.55E-12 & $2.14 \mathrm{E}-10$ \\
\hline $\mathrm{Ra}-228$ & 8.61E-08 & 5.17E-11 & $1.29 \mathrm{E}-09$ \\
\hline $\mathrm{Sb}-125$ & $2.68 \mathrm{E}-07$ & $1.61 \mathrm{E}-10$ & $4.02 \mathrm{E}-09$ \\
\hline Sm-151 & 4.93E-04 & $2.96 \mathrm{E}-07$ & 7.40E-06 \\
\hline Sr-90 & $3.24 \mathrm{E}-02$ & $1.95 \mathrm{E}-05$ & $4.86 \mathrm{E}-04$ \\
\hline Tc-99 & $1.50 \mathrm{E}-04$ & 8.98E-08 & 2.25E-06 \\
\hline $\mathrm{Te}-125 \mathrm{~m}$ & $6.71 \mathrm{E}-08$ & $4.02 \mathrm{E}-11$ & $1.01 \mathrm{E}-09$ \\
\hline Th-228 & $1.42 \mathrm{E}-08$ & $8.55 \mathrm{E}-12$ & $2.14 \mathrm{E}-10$ \\
\hline Th-231 & 9.01E-08 & $5.41 E-11$ & $1.35 \mathrm{E}-09$ \\
\hline Th-232 & $1.15 \mathrm{E}-05$ & $6.91 \mathrm{E}-09$ & $1.73 E-07$ \\
\hline Th-234 & $1.43 \mathrm{E}-03$ & 8.58E-07 & 2.15E-05 \\
\hline U-235 & 8.94E-08 & $5.36 \mathrm{E}-11$ & $1.34 \mathrm{E}-09$ \\
\hline U-238 & $1.43 \mathrm{E}-03$ & 8.58E-07 & 2.15E-05 \\
\hline$Y-90$ & $3.24 \mathrm{E}-02$ & $1.95 \mathrm{E}-05$ & $4.86 \mathrm{E}-04$ \\
\hline Total & 2.07E-01 & $1.24 \mathrm{E}-04$ & $3.11 \mathrm{E}-03$ \\
\hline
\end{tabular}


TABLE B.6.42 Low-Level Mixed Waste, Case 26: Hanford

\begin{tabular}{|c|c|c|c|}
\hline \multicolumn{4}{|c|}{ Function: q-Incineration } \\
\hline \multirow[b]{2}{*}{ Nuclide } & \multicolumn{3}{|c|}{ Release $(\mathrm{Ci})$} \\
\hline & EQ7 & IEX & IFF \\
\hline $\mathrm{Am}-241$ & $5.53 \mathrm{E}-08$ & 3.32E-11 & $8.30 \mathrm{E}-10$ \\
\hline Co-60 & $8.21 \mathrm{E}-08$ & 4.29E-11 & $1.23 \mathrm{E}-09$ \\
\hline Cs-137 & $6.51 E-08$ & $3.91 \mathrm{E}-08$ & $9.76 \mathrm{E}-07$ \\
\hline Eu-154 & $9.80 \mathrm{E}-08$ & $5.88 \mathrm{E}-11$ & $1.47 \mathrm{E}-09$ \\
\hline $\mathrm{Nb}-94$ & $5.56 \mathrm{E}-09$ & $3.34 \mathrm{E}-12$ & $8.34 \mathrm{E}-11$ \\
\hline $\mathrm{Ni}-59$ & $1.26 \mathrm{E}-07$ & $7.53 \mathrm{E}-11$ & $1.88 \mathrm{E}-09$ \\
\hline $\mathrm{Ni}-63$ & $1.29 \mathrm{E}-05$ & 7.74E-09 & $1.93 \mathrm{E}-07$ \\
\hline $\mathrm{Pu}-238$ & $2.91 \mathrm{E}-06$ & $1.75 \mathrm{E}-09$ & 4.37E-08 \\
\hline Pu-239 & 3.95E-08 & $2.37 \mathrm{E}-11$ & $5.92 \mathrm{E}-10$ \\
\hline $\mathrm{Pu}-240$ & 2.25E-08 & $1.35 \mathrm{E}-11$ & $3.38 \mathrm{E}-10$ \\
\hline $\mathrm{Pu}-241$ & $6.46 \mathrm{E}-07$ & $3.88 \mathrm{E}-10$ & $9.69 \mathrm{E}-09$ \\
\hline Sm-151 & 9.37E-07 & $5.62 \mathrm{E}-10$ & $1.41 \mathrm{E}-08$ \\
\hline Sr-90 & $5.80 \mathrm{E}-05$ & $3.48 \mathrm{E}-08$ & $8.70 \mathrm{E}-07$ \\
\hline Tc-99 & $2.91 E-08$ & $1.75 \mathrm{E}-11$ & $4.37 \mathrm{E}-10$ \\
\hline Th-234 & 3.60E-08 & $2.16 \mathrm{E}-11$ & $5.40 \mathrm{E}-10$ \\
\hline U-238 & $3.60 \mathrm{E}-08$ & $2.16 \mathrm{E}-11$ & $5.40 \mathrm{E}-10$ \\
\hline$Y-90$ & $5.80 \mathrm{E}-05$ & $3.48 \mathrm{E}-08$ & $8.70 \mathrm{E}-07$ \\
\hline Total & $1.99 \mathrm{E}-04$ & 1.19E-07 & $2.98 \mathrm{E}-06$ \\
\hline
\end{tabular}


TABLE B.6.43 Low-Level Mixed Waste, Case 26: Idaho National Engineering Laboratory

Function: q-Incineration

\begin{tabular}{llcl}
\hline & \multicolumn{3}{c}{ Release (Ci) } \\
\cline { 2 - 4 } Nuclide & EQ7 & IEX & IFF \\
\hline & & & \\
Co-60 & $1.19 \mathrm{E}-01$ & $7.14 \mathrm{E}-05$ & $1.78 \mathrm{E}-03$ \\
Cs-134 & $6.99 \mathrm{E}-05$ & $4.20 \mathrm{E}-08$ & $1.05 \mathrm{E}-06$ \\
Cs-137 & $7.78 \mathrm{E}-03$ & $4.67 \mathrm{E}-06$ & $1.17 \mathrm{E}-04$ \\
Eu-154 & $9.46 \mathrm{E}-05$ & $5.68 \mathrm{E}-08$ & $1.42 \mathrm{E}-06$ \\
Eu-155 & $4.53 \mathrm{E}-05$ & $2.72 \mathrm{E}-08$ & $6.79 \mathrm{E}-07$ \\
Fe-55 & $1.56 \mathrm{E}-02$ & $9.33 \mathrm{E}-06$ & $2.33 \mathrm{E}-04$ \\
Mn-54 & $4.94 \mathrm{E}-05$ & $2.96 \mathrm{E}-08$ & $7.41 \mathrm{E}-07$ \\
Nb-94 & $7.41 \mathrm{E}-05$ & $4.44 \mathrm{E}-08$ & $1.11 \mathrm{E}-06$ \\
Ni-59 & $1.56 \mathrm{E}-03$ & $9.33 \mathrm{E}-07$ & $2.33 \mathrm{E}-05$ \\
Ni-63 & $2.09 \mathrm{E}-01$ & $1.25 \mathrm{E}-04$ & $3.14 \mathrm{E}-03$ \\
Pm-147 & $8.48 \mathrm{E}-04$ & $5.09 \mathrm{E}-07$ & $1.27 \mathrm{E}-05$ \\
Pu-238 & $2.43 \mathrm{E}-04$ & $1.46 \mathrm{E}-07$ & $3.64 \mathrm{E}-06$ \\
Pu-241 & $1.97 \mathrm{E}-04$ & $1.18 \mathrm{E}-07$ & $2.96 \mathrm{E}-06$ \\
Sb-125 & $3.29 \mathrm{E}-05$ & $1.97 \mathrm{E}-08$ & $4.94 \mathrm{E}-07$ \\
Sm-151 & $6.58 \mathrm{E}-05$ & $3.95 \mathrm{E}-08$ & $9.87 \mathrm{E}-07$ \\
Sr-90 & $7.32 \mathrm{E}-03$ & $4.39 \mathrm{E}-06$ & $1.10 \mathrm{E}-04$ \\
Te-125m & $8.23 \mathrm{E}-06$ & $4.94 \mathrm{E}-09$ & $1.23 \mathrm{E}-07$ \\
Th-234 & $2.92 \mathrm{E}-04$ & $1.75 \mathrm{E}-07$ & $4.38 \mathrm{E}-06$ \\
U-238 & $2.92 \mathrm{E}-04$ & $1.75 \mathrm{E}-07$ & $4.38 \mathrm{E}-06$ \\
Y-90 & $7.32 \mathrm{E}-03$ & $4.39 \mathrm{E}-06$ & $1.10 \mathrm{E}-04$ \\
Total & $3.70 \mathrm{E}-01$ & $2.22 \mathrm{E}-04$ & $5.55 \mathrm{E}-03$ \\
\hline & & & \\
\hline
\end{tabular}


TABLE B.6.44 Low-Level Mixed Waste, Case 26: Oak Ridge National Laboratory

\begin{tabular}{|c|c|c|c|}
\hline \multicolumn{4}{|c|}{ Function: q-Incineration } \\
\hline \multirow[b]{2}{*}{ Nuclide } & \multicolumn{3}{|c|}{ Release (Ci) } \\
\hline & EQ7 & IEX & IFF \\
\hline Am-241 & $4.79 \mathrm{E}-06$ & 2.88E-09 & 7.19E-08 \\
\hline Co-60 & 2.63E-03 & $1.58 \mathrm{E}-06$ & $3.94 \mathrm{E}-05$ \\
\hline Cs-137 & 3.77E-03 & $2.26 \mathrm{E}-06$ & $5.66 \mathrm{E}-05$ \\
\hline Eu-154 & $2.80 \mathrm{E}-05$ & $1.68 \mathrm{E}-08$ & 4.19E-07 \\
\hline Eu-155 & $9.58 \mathrm{E}-06$ & 5.75E-09 & $1.44 \mathrm{E}-07$ \\
\hline $\mathrm{Nb}-94$ & $2.00 \mathrm{E}-05$ & $1.20 \mathrm{E}-08$ & 2.99E-07 \\
\hline $\mathrm{Ni}-59$ & $4.24 \mathrm{E}-04$ & $2.54 \mathrm{E}-07$ & $6.36 \mathrm{E}-06$ \\
\hline $\mathrm{Ni}-63$ & 4.46E-02 & 2.67E-05 & 6.69E-04 \\
\hline Pu-238 & 2.97E-04 & $1.78 \mathrm{E}-07$ & 4.45E-06 \\
\hline Pu-239 & $4.79 \mathrm{E}-06$ & $2.88 \mathrm{E}-09$ & 7.19E-08 \\
\hline $\mathrm{Pu}-240$ & 7.19E-06 & 4.31E-09 & $1.08 \mathrm{E}-07$ \\
\hline Pu-241 & 3.14E-04 & $1.89 \mathrm{E}-07$ & 4.72E-06 \\
\hline Sm-151 & $9.10 \mathrm{E}-05$ & $5.46 \mathrm{E}-08$ & $1.36 \mathrm{E}-06$ \\
\hline Sr-90 & $3.34 \mathrm{E}-03$ & $2.00 \mathrm{E}-06$ & $5.00 \mathrm{E}-05$ \\
\hline Тc-99 & $3.99 \mathrm{E}-05$ & $2.39 \mathrm{E}-08$ & 5.98E-07 \\
\hline Th-232 & 7.99E-06 & 4.79E-09 & $1.20 \mathrm{E}-07$ \\
\hline Th-234 & $9.65 \mathrm{E}-04$ & 5.79E-07 & $1.45 \mathrm{E}-05$ \\
\hline $\mathrm{U}-238$ & $9.65 \mathrm{E}-04$ & 5.79E-07 & $1.45 \mathrm{E}-05$ \\
\hline$Y-90$ & $3.34 \mathrm{E}-03$ & $2.00 \mathrm{E}-06$ & $5.00 \mathrm{E}-05$ \\
\hline Total & $6.08 \mathrm{E}-02$ & 3.65E-05 & 9.12E-04 \\
\hline
\end{tabular}


TABLE B.6.45 Low-Level Mixed Waste, Case 26: Savannah River Site

\begin{tabular}{lccc}
\hline & & \\
Function: q-Incineration \\
& \multicolumn{3}{c}{ Release (Ci) } \\
\cline { 2 - 4 } Nuclide & EQ7 & IEX & IFF \\
\hline & & & \\
Co-60 & $1.13 \mathrm{E}-04$ & $6.79 \mathrm{E}-08$ & $1.70 \mathrm{E}-06$ \\
Cs-137 & $8.23 \mathrm{E}-05$ & $4.94 \mathrm{E}-08$ & $1.23 \mathrm{E}-06$ \\
Eu-154 & $4.13 \mathrm{E}-07$ & $2.48 \mathrm{E}-10$ & $6.20 \mathrm{E}-09$ \\
Eu-155 & $9.53 \mathrm{E}-08$ & $5.72 \mathrm{E}-11$ & $1.43 \mathrm{E}-09$ \\
Fe-55 & $2.26 \mathrm{E}-06$ & $1.35 \mathrm{E}-09$ & $3.38 \mathrm{E}-08$ \\
Nb-94 & $5.40 \mathrm{E}-07$ & $3.24 \mathrm{E}-10$ & $8.10 \mathrm{E}-09$ \\
Ni-59 & $1.07 \mathrm{E}-05$ & $6.41 \mathrm{E}-09$ & $1.60 \mathrm{E}-07$ \\
Ni-63 & $1.29 \mathrm{E}-03$ & $7.75 \mathrm{E}-07$ & $1.94 \mathrm{E}-05$ \\
Pu-238 & $2.80 \mathrm{E}-06$ & $1.68 \mathrm{E}-09$ & $4.19 \mathrm{E}-08$ \\
Pu-240 & $2.22 \mathrm{E}-06$ & $1.33 \mathrm{E}-09$ & $3.34 \mathrm{E}-08$ \\
Pu-241 & $2.22 \mathrm{E}-06$ & $1.33 \mathrm{E}-09$ & $3.34 \mathrm{E}-08$ \\
Sm-151 & $8.90 \mathrm{E}-07$ & $5.34 \mathrm{E}-10$ & $1.33 \mathrm{E}-08$ \\
Sr-90 & $7.66 \mathrm{E}-05$ & $4.59 \mathrm{E}-08$ & $1.15 \mathrm{E}-06$ \\
Tc-99 & $3.18 \mathrm{E}-08$ & $1.91 \mathrm{E}-11$ & $4.77 \mathrm{E}-10$ \\
Th-234 & $3.81 \mathrm{E}-07$ & $2.29 \mathrm{E}-10$ & $5.72 \mathrm{E}-09$ \\
U-238 & $3.81 \mathrm{E}-07$ & $2.29 \mathrm{E}-10$ & $5.72 \mathrm{E}-09$ \\
Y-90 & $7.66 \mathrm{E}-05$ & $4.59 \mathrm{E}-08$ & $1.15 \mathrm{E}-06$ \\
Total & $1.66 \mathrm{E}-03$ & $9.97 \mathrm{E}-07$ & $2.49 \mathrm{E}-05$ \\
\hline & & &
\end{tabular}




\section{B.7 RADIONUCLIDE.RELEASES FROM LLMW DRUM HANDLING ACCIDENTS}

TABLE B.7.1 LowLevel Mixed Waste, All Cases: Ames Laboratory

Function: Handling

Waste Stream: All

\begin{tabular}{ll}
\hline Nuclide & $\begin{array}{c}\text { Release (Ci), } \\
\text { SHA }\end{array}$ \\
\hline Ac-228 & $9.64 \mathrm{E}-11$ \\
$\mathrm{Bi}-212$ & $1.62 \mathrm{E}-11$ \\
$\mathrm{~Pb}-212$ & $1.62 \mathrm{E}-11$ \\
$\mathrm{Ra}-224$ & $1.62 \mathrm{E}-11$ \\
Ra-228 & $9.64 \mathrm{E}-11$ \\
Tc-99 & $1.79 \mathrm{E}-09$ \\
Th-228 & $1.62 \mathrm{E}-11$ \\
Th-231 & $9.29 \mathrm{E}-11$ \\
Th-232 & $9.78 \mathrm{E}-10$ \\
Th-234 & $1.19 \mathrm{E}-07$ \\
U-235 & $9.26 \mathrm{E}-11$ \\
U-238 & $1.19 \mathrm{E}-07$ \\
Total & $2.41 \mathrm{E}-07$ \\
\hline
\end{tabular}

TABLE B.7.2 Low-Level Mixed Waste, All Cases: Argonne National Laboratory-East

\begin{tabular}{lc}
$\begin{array}{l}\text { Function: Handling } \\
\text { Waste Stream: }\end{array}$ \\
\hline & $\begin{array}{c}\text { Release (Ci), } \\
\text { NHAclide }\end{array}$ \\
\hline Am-241 & $1.90 \mathrm{E}-08$ \\
Co-60 & $1.04 \mathrm{E}-05$ \\
Cs-137 & $2.99 \mathrm{E}-05$ \\
Eu-154 & $1.11 \mathrm{E}-07$ \\
Eu-155 & $3.80 \mathrm{E}-08$ \\
H-3 & $6.41 \mathrm{E}-05$ \\
Nb-94 & $7.92 \mathrm{E}-08$ \\
Ni-59 & $1.68 \mathrm{E}-06$ \\
Ni-63 & $1.77 \mathrm{E}-04$ \\
Pu-238 & $1.18 \mathrm{E}-06$ \\
Pu-239 & $1.90 \mathrm{E}-08$ \\
Pu-240 & $2.85 \mathrm{E}-08$ \\
Pu-241 & $1.25 \mathrm{E}-06$ \\
Sm-151 & $3.61 \mathrm{E}-07$ \\
Sr-90 & $2.65 \mathrm{E}-05$ \\
Tc-99 & $3.17 \mathrm{E}-07$ \\
Th-232 & $3.17 \mathrm{E}-08$ \\
Th-234 & $3.83 \mathrm{E}-06$ \\
U-238 & $3.83 \mathrm{E}-06$ \\
Y-90 & $2.65 \mathrm{E}-05$ \\
Total & $3.47 \mathrm{E}-04$ \\
\hline &
\end{tabular}


TABLE B.7.3 Low-

Level Mixed Waste, All

Cases: Argonne

National Laboratory-

West

\begin{tabular}{lc}
$\begin{array}{l}\text { Function: Handling } \\
\text { Waste Stream: All }\end{array}$ \\
\hline & $\begin{array}{c}\text { Release (Ci), } \\
\text { SHA }\end{array}$ \\
\hline Nuclide & \\
Co-60 & $5.41 \mathrm{E}-04$ \\
Cs-134 & $3.18 \mathrm{E}-07$ \\
Cs-137 & $3.53 \mathrm{E}-05$ \\
Eu-154 & $4.30 \mathrm{E}-07$ \\
Eu-155 & $2.06 \mathrm{E}-07$ \\
Fe-55 & $7.07 \mathrm{E}-05$ \\
H-3 & $1.54 \mathrm{E}-01$ \\
Mn-54 & $2.24 \mathrm{E}-07$ \\
Nb-94 & $3.37 \mathrm{E}-07$ \\
Ni-59 & $7.07 \mathrm{E}-06$ \\
Ni-63 & $9.50 \mathrm{E}-04$ \\
Pm-147 & $3.85 \mathrm{E}-06$ \\
Pu-238 & $1.10 \mathrm{E}-06$ \\
Pu-241 & $8.98 \mathrm{E}-07$ \\
Sb-125 & $1.50 \mathrm{E}-07$ \\
Sm-151 & $2.99 \mathrm{E}-07$ \\
Sr-90 & $3.33 \mathrm{E}-05$ \\
Te-125m & $3.74 \mathrm{E}-08$ \\
Th-234 & $1.33 \mathrm{E}-06$ \\
U-238 & $1.33 \mathrm{E}-06$ \\
Y-90 & $3.33 \mathrm{E}-05$ \\
Total & $1.56 \mathrm{E}-01$ \\
\hline
\end{tabular}

TABLE B.7.4 LowLevel Mixed Waste, All Cases: Bettis Atomic Power Laboratory

Function: Handling

Waste Stream: All

\begin{tabular}{|c|c|}
\hline Nuclide & $\begin{array}{c}\text { Release }(\mathrm{Ci}) \text {, } \\
\text { SHA }\end{array}$ \\
\hline Am-241 & 7.01E-08 \\
\hline Co-60 & $1.04 \mathrm{E}-07$ \\
\hline Cs-137 & $8.23 \mathrm{E}-05$ \\
\hline Eu-154 & $1.24 \mathrm{E}-07$ \\
\hline $\mathrm{H}-3$ & $3.28 \mathrm{E}-03$ \\
\hline $\mathrm{Nb}-94$ & 7.04E-09 \\
\hline $\mathrm{Ni}-59$ & $1.58 \mathrm{E}-07$ \\
\hline $\mathrm{Ni}-63$ & $1.63 \mathrm{E}-05$ \\
\hline $\mathrm{Pu}-238$ & 3.73E-06 \\
\hline Pu-239 & 5.43E-08 \\
\hline Pu-240 & $2.84 \mathrm{E}-08$ \\
\hline Pu-241 & $1.09 \mathrm{E}-06$ \\
\hline Sm-151 & $1.18 \mathrm{E}-06$ \\
\hline Sr-90 & 7.33E-05 \\
\hline Tc-99 & 3.67E-08 \\
\hline Th-234 & $4.55 \mathrm{E}-08$ \\
\hline U-238 & 4.55E-08 \\
\hline$Y-90$ & 7.33E-05 \\
\hline Total & 3.54E-03 \\
\hline
\end{tabular}


TABLE B.7.5 LowLevel Mixed Waste, All Cases: Battelle Columbus Laboratory

Function: Handling

Waste Stream: All

\begin{tabular}{ll}
\hline Nuclide & $\begin{array}{c}\text { Release (Ci), } \\
\text { SHA }\end{array}$ \\
\hline Ac-228 & $2.14 \mathrm{E}-11$ \\
Bi-212 & $3.60 \mathrm{E}-12$ \\
$\mathrm{~Pb}-212$ & $3.60 \mathrm{E}-12$ \\
Ra-224 & $3.60 \mathrm{E}-12$ \\
Ra-228 & $2.14 \mathrm{E}-11$ \\
Tc-99 & $3.98 \mathrm{E}-10$ \\
Th-228 & $3.60 \mathrm{E}-12$ \\
Th-231 & $2.06 \mathrm{E}-11$ \\
Th-232 & $2.17 \mathrm{E}-10$ \\
Th-234 & $2.64 \mathrm{E}-08$ \\
U-235 & $2.06 \mathrm{E}-11$ \\
U-238 & $2.64 \mathrm{E}-08$ \\
Total & $5.36 \mathrm{E}-08$ \\
\hline
\end{tabular}

TABLE B.7.6 LowLevel Mixed Waste, All Cases: Brookhaven National Laboratory

Function: Handling Waste Stream: All

\begin{tabular}{ll}
\hline Nuclide & $\begin{array}{c}\text { Release (Ci), } \\
\text { SHA }\end{array}$ \\
\hline Am-241 & $3.01 \mathrm{E}-10$ \\
Co-60 & $1.65 \mathrm{E}-07$ \\
Cs-137 & $4.74 \mathrm{E}-07$ \\
Eu-154 & $1.76 \mathrm{E}-09$ \\
Eu-155 & $6.02 \mathrm{E}-10$ \\
H-3 & $2.79 \mathrm{E}-04$ \\
Nb-94 & $1.25 \mathrm{E}-09$ \\
Ni-59 & $2.66 \mathrm{E}-08$ \\
Ni-63 & $2.80 \mathrm{E}-06$ \\
Pu-238 & $1.87 \mathrm{E}-08$ \\
Pu-239 & $3.01 \mathrm{E}-10$ \\
Pu-240 & $4.52 \mathrm{E}-10$ \\
Pu-241 & $1.98 \mathrm{E}-08$ \\
Sm-151 & $5.72 \mathrm{E}-09$ \\
Sr-90 & $4.19 \mathrm{E}-07$ \\
Tc-99 & $5.01 \mathrm{E}-09$ \\
Th-232 & $5.02 \mathrm{E}-10$ \\
Th-234 & $6.07 \mathrm{E}-08$ \\
U-238 & $6.07 \mathrm{E}-08$ \\
Y-90 & $4.19 \mathrm{E}-07$ \\
Total & $2.83 \mathrm{E}-04$ \\
\hline &
\end{tabular}


TABLE B.7.7 Low-

Level Mixed Waste, All

Cases: Charleston Naval

Shipyard

Function: Handling

Waste Stream: All

\begin{tabular}{lc} 
Nuclide & $\begin{array}{c}\text { Release (Ci), } \\
\text { SHA }\end{array}$ \\
\hline Co-60 & $1.38 \mathrm{E}-04$ \\
Cs-134 & $8.13 \mathrm{E}-08$ \\
Cs-137 & $9.04 \mathrm{E}-06$ \\
Eu-154 & $1.10 \mathrm{E}-07$ \\
Eu-155 & $5.26 \mathrm{E}-08$ \\
Fe-55 & $1.81 \mathrm{E}-05$ \\
H-3 & $1.54 \mathrm{E}-01$ \\
$\mathrm{Mn}-54$ & $5.74 \mathrm{E}-08$ \\
Nb-94 & $8.61 \mathrm{E}-08$ \\
Ni-59 & $1.81 \mathrm{E}-06$ \\
Ni-63 & $2.43 \mathrm{E}-04$ \\
Pm-147 & $9.85 \mathrm{E}-07$ \\
Pu-238 & $2.82 \mathrm{E}-07$ \\
Pu-241 & $2.29 \mathrm{E}-07$ \\
Sb-125 & $3.82 \mathrm{E}-08$ \\
Sm-151 & $7.65 \mathrm{E}-08$ \\
Sr-90 & $8.51 \mathrm{E}-06$ \\
Te-125m & $9.56 \mathrm{E}-09$ \\
Th-234 & $3.39 \mathrm{E}-07$ \\
U-238 & $3.39 \mathrm{E}-07$ \\
Y-90 & $8.51 \mathrm{E}-06$ \\
Total & $1.54 \mathrm{E}-01$ \\
\hline
\end{tabular}

TABLE B.7.8 LowLevel Mixed Waste, All Cases: Colonie Interim Storage

Function: Handling

Waste Stream: All

\begin{tabular}{ll}
\hline Nuclide & $\begin{array}{c}\text { Release (Ci), } \\
\text { SHA }\end{array}$ \\
\hline Ac-228 & $2.00 \mathrm{E}-11$ \\
$\mathrm{Bi}-212$ & $3.36 \mathrm{E}-12$ \\
$\mathrm{~Pb}-212$ & $3.36 \mathrm{E}-12$ \\
$\mathrm{Ra}-224$ & $3.36 \mathrm{E}-12$ \\
$\mathrm{Ra}-228$ & $2.00 \mathrm{E}-11$ \\
$\mathrm{Tc}-99$ & $3.71 \mathrm{E}-10$ \\
Th-228 & $3.36 \mathrm{E}-12$ \\
Th-231 & $1.93 \mathrm{E}-11$ \\
Th-232 & $2.03 \mathrm{E}-10$ \\
Th-234 & $2.47 \mathrm{E}-08$ \\
U-235 & $1.92 \mathrm{E}-11$ \\
U-238 & $2.47 \mathrm{E}-08$ \\
Total & $5.00 \mathrm{E}-08$ \\
\hline
\end{tabular}


TABLE B.7.9 Low-

Level Mixed Waste, All

Cases: Energy

Technology Engineering

Center

Function: Handling

Waste Stream: All

\begin{tabular}{ll}
\hline Nuclide & $\begin{array}{c}\text { Release (Ci), } \\
\text { SHA }\end{array}$ \\
\hline Am-241 & $2.45 \mathrm{E}-08$ \\
Co-60 & $1.34 \mathrm{E}-05$ \\
Cs-137 & $3.85 \mathrm{E}-05$ \\
Eu-154 & $1.43 \mathrm{E}-07$ \\
Eu-155 & $4.89 \mathrm{E}-08$ \\
H-3 & $1.87 \mathrm{E}-06$ \\
Nb-94 & $1.02 \mathrm{E}-07$ \\
Ni-59 & $2.16 \mathrm{E}-06$ \\
Ni-63 & $2.28 \mathrm{E}-04$ \\
Pu-238 & $1.51 \mathrm{E}-06$ \\
Pu-239 & $2.45 \mathrm{E}-08$ \\
Pu-240 & $3.67 \mathrm{E}-08$ \\
Pu-241 & $1.60 \mathrm{E}-06$ \\
Sm-151 & $4.64 \mathrm{E}-07$ \\
Sr-90 & $3.40 \mathrm{E}-05$ \\
Tc-99 & $4.07 \mathrm{E}-07$ \\
Th-232 & $4.08 \mathrm{E}-08$ \\
Th-234 & $4.93 \mathrm{E}-06$ \\
U-238 & $4.93 \mathrm{E}-06$ \\
Y-90 & $3.40 \mathrm{E}-05$ \\
Total & $3.66 \mathrm{E}-04$ \\
\hline
\end{tabular}

TABLE B.7.10 LowLevel Mixed Waste, All

Cases: Fernald

Environmental

Management Project

Function: Handling

Waste Stream: All

\begin{tabular}{ll}
\hline Nuclide & $\begin{array}{c}\text { Release (Ci), } \\
\text { SHA }\end{array}$ \\
\hline Ac-228 & $1.81 \mathrm{E}-10$ \\
Bi-212 & $3.05 \mathrm{E}-11$ \\
$\mathrm{~Pb}-212$ & $3.05 \mathrm{E}-11$ \\
$\mathrm{Ra}-224$ & $3.05 \mathrm{E}-11$ \\
$\mathrm{Ra}-228$ & $1.81 \mathrm{E}-10$ \\
Tc-99 & $3.37 \mathrm{E}-09$ \\
Th-228 & $3.05 \mathrm{E}-11$ \\
Th-231 & $1.75 \mathrm{E}-10$ \\
Th-232 & $1.84 \mathrm{E}-09$ \\
Th-234 & $2.24 \mathrm{E}-07$ \\
U-235 & $1.74 \mathrm{E}-10$ \\
U-238 & $2.24 \mathrm{E}-07$ \\
Total & $4.54 \mathrm{E}-07$ \\
\hline
\end{tabular}


TABLE B.7.11 LowLevel Mixed Waste, All

Cases: General Atomics

Function: Handling

Waste Stream: All

\begin{tabular}{ll}
\hline Nuclide & $\begin{array}{c}\text { Release (Ci), } \\
\text { SHA }\end{array}$ \\
\hline Ac-228 & $1.03 \mathrm{E}-10$ \\
$\mathrm{Bi}-212$ & $1.72 \mathrm{E}-11$ \\
$\mathrm{~Pb}-212$ & $1.72 \mathrm{E}-11$ \\
$\mathrm{Ra}-224$ & $1.72 \mathrm{E}-11$ \\
$\mathrm{Ra}-228$ & $1.03 \mathrm{E}-10$ \\
Tc-99 & $1.91 \mathrm{E}-09$ \\
Th-228 & $1.72 \mathrm{E}-11$ \\
Th-231 & $9.89 \mathrm{E}-11$ \\
Th-232 & $1.04 \mathrm{E}-09$ \\
Th-234 & $1.27 \mathrm{E}-07$ \\
U-235 & $9.85 \mathrm{E}-11$ \\
U-238 & $1.27 \mathrm{E}-07$ \\
Total & $2.57 \mathrm{E}-07$ \\
\hline
\end{tabular}

TABLE B.7.12 LowLevel Mixed Waste, All Cases: Grand Junction Project Office

Function: Handling

Waste Stream: All

\begin{tabular}{ll}
\hline Nuclide & $\begin{array}{c}\text { Release (Ci), } \\
\text { SHA }\end{array}$ \\
\hline Ac-228 & $7.05 \mathrm{E}-10$ \\
Bi-212 & $1.19 \mathrm{E}-10$ \\
Pb-212 & $1.19 \mathrm{E}-10$ \\
Ra-224 & $1.19 \mathrm{E}-10$ \\
Ra-228 & $7.05 \mathrm{E}-10$ \\
Tc-99 & $1.31 \mathrm{E}-08$ \\
Th-228 & $1.19 \mathrm{E}-10$ \\
Th-231 & $6.80 \mathrm{E}-10$ \\
Th-232 & $7.16 \mathrm{E}-09$ \\
Th-234 & $8.70 \mathrm{E}-07$ \\
U-235 & $6.77 \mathrm{E}-10$ \\
U-238 & $8.70 \mathrm{E}-07$ \\
Total & $1.76 \mathrm{E}-06$ \\
\hline
\end{tabular}


TABLE B.7.13 LowLevel Mixed Waste, All Cases: Hanford

\begin{tabular}{ll}
\hline \multicolumn{2}{l}{$\begin{array}{l}\text { Function: Handling } \\
\text { Waste Stream: All }\end{array}$} \\
\hline & $\begin{array}{c}\text { Release (Ci), } \\
\text { SHA }\end{array}$ \\
\multicolumn{1}{c}{ Nuclide } & \\
\hline & \\
Am-241 & $1.42 \mathrm{E}-07$ \\
Co-60 & $2.10 \mathrm{E}-07$ \\
Cs-137 & $1.67 \mathrm{E}-04$ \\
Eu-154 & $2.51 \mathrm{E}-07$ \\
H-3 & $2.62 \mathrm{E}-03$ \\
Nb-94 & $1.42 \mathrm{E}-08$ \\
Ni-59 & $3.21 \mathrm{E}-07$ \\
Ni-63 & $3.30 \mathrm{E}-05$ \\
Pu-238 & $7.46 \mathrm{E}-06$ \\
Pu-239 & $1.01 \mathrm{E}-07$ \\
Pu-240 & $5.76 \mathrm{E}-08$ \\
Pu-241 & $1.65 \mathrm{E}-06$ \\
Sm-151 & $2.40 \mathrm{E}-06$ \\
Sr-90 & $1.48 \mathrm{E}-04$ \\
Tc-99 & $7.46 \mathrm{E}-08$ \\
Th-234 & $9.22 \mathrm{E}-08$ \\
U-238 & $9.22 \mathrm{E}-08$ \\
Y-90 & $1.48 \mathrm{E}-04$ \\
Total & $3.13 \mathrm{E}-03$ \\
\hline
\end{tabular}

TABLE B.7.14 LowLevel Mixed Waste, All Cases: Idaho National Engineering Laboratory

Function: Handling Waste Stream: All

\begin{tabular}{ll}
\hline Nuclide & $\begin{array}{c}\text { Release (Ci), } \\
\text { SHA }\end{array}$ \\
\hline & \\
Am-241 & $2.44 \mathrm{E}-08$ \\
Co-60 & $6.51 \mathrm{E}-05$ \\
Cs-134 & $3.38 \mathrm{E}-08$ \\
Cs-137 & $2.65 \mathrm{E}-05$ \\
Eu-154 & $8.23 \mathrm{E}-08$ \\
Eu-155 & $2.18 \mathrm{E}-08$ \\
Fe-55 & $7.51 \mathrm{E}-06$ \\
H-3 & $2.79 \mathrm{E}-02$ \\
Mn-54 & $2.38 \mathrm{E}-08$ \\
Nb-94 & $5.49 \mathrm{E}-07$ \\
Ni-59 & $1.25 \mathrm{E}-05$ \\
Ni-63 & $1.18 \mathrm{E}-03$ \\
Pm-147 & $4.09 \mathrm{E}-07$ \\
Pu-238 & $1.25 \mathrm{E}-06$ \\
Pu-240 & $3.66 \mathrm{E}-08$ \\
Pu-241 & $1.07 \mathrm{E}-06$ \\
Sb-125 & $1.59 \mathrm{E}-08$ \\
Sm-151 & $3.62 \mathrm{E}-07$ \\
Sr-90 & $2.41 \mathrm{E}-05$ \\
Te-125m & $3.97 \mathrm{E}-09$ \\
Th-234 & $2.08 \mathrm{E}-06$ \\
U-238 & $2.08 \mathrm{E}-06$ \\
Y-90 & $2.41 \mathrm{E}-05$ \\
Total & $2.92 \mathrm{E}-02$ \\
\hline &
\end{tabular}


TABLE B.7.15 LowLevel Mixed Waste, All Cases: Inhalation Toxicology Research Institute

Function: Handling

Waste Stream: All

\begin{tabular}{ll}
\hline Nuclide & $\begin{array}{c}\text { Release (Ci), } \\
\text { SHA }\end{array}$ \\
\hline Co-60 & $1.83 \mathrm{E}-07$ \\
Cs-137 & $1.38 \mathrm{E}-07$ \\
Eu-154 & $1.52 \mathrm{E}-09$ \\
Fe-55 & $2.30 \mathrm{E}-08$ \\
$\mathrm{H}-3$ & $1.33 \mathrm{E}-01$ \\
Ni-59 & $3.05 \mathrm{E}-09$ \\
Ni-63 & $4.04 \mathrm{E}-07$ \\
Pm-147 & $1.27 \mathrm{E}-08$ \\
Pu-238 & $5.26 \mathrm{E}-09$ \\
Pu-241 & $2.66 \mathrm{E}-08$ \\
Sm-151 & $1.22 \mathrm{E}-09$ \\
Sr-90 & $1.30 \mathrm{E}-07$ \\
Y-90 & $1.30 \mathrm{E}-07$ \\
Total & $1.33 \mathrm{E}-01$ \\
\hline
\end{tabular}

TABLE B.7.16 LowLevel Mixed Waste, All Cases: Knolls Atomic Power Laboratory

Function: Handling

Waste Stream: All

\begin{tabular}{lc}
\hline Nuclide & $\begin{array}{c}\text { Release (Ci), } \\
\text { SHA }\end{array}$ \\
\hline Co-60 & $3.03 \mathrm{E}-03$ \\
Cs-134 & $1.78 \mathrm{E}-06$ \\
Cs-137 & $1.98 \mathrm{E}-04$ \\
Eu-154 & $2.41 \mathrm{E}-06$ \\
Eu-155 & $1.15 \mathrm{E}-06$ \\
Fe-55 & $3.96 \mathrm{E}-04$ \\
H-3 & $7.26 \mathrm{E}-02$ \\
Mn-54 & $1.26 \mathrm{E}-06$ \\
Nb-94 & $1.89 \mathrm{E}-06$ \\
Ni-59 & $3.96 \mathrm{E}-05$ \\
Ni-63 & $5.33 \mathrm{E}-03$ \\
Pm-147 & $2.16 \mathrm{E}-05$ \\
Pu-238 & $6.19 \mathrm{E}-06$ \\
Pu-241 & $5.03 \mathrm{E}-06$ \\
Sb-125 & $8.39 \mathrm{E}-07$ \\
Sm-151 & $1.68 \mathrm{E}-06$ \\
Sr-90 & $1.87 \mathrm{E}-04$ \\
Te-125m & $2.10 \mathrm{E}-07$ \\
Th-234 & $7.44 \mathrm{E}-06$ \\
U-238 & $7.44 \mathrm{E}-06$ \\
Y-90 & $1.87 \mathrm{E}-04$ \\
Total & $8.20 \mathrm{E}-02$ \\
\hline &
\end{tabular}


TABLE B.7.17 Low-

Level Mixed Waste, All

Cases: Kansas City

Plant

Function: Handling

Waste Stream: All

\begin{tabular}{ll}
\hline Nuclide & $\begin{array}{c}\text { Release (Ci), } \\
\text { SHA }\end{array}$ \\
\hline Co-60 & 5.41E-04 \\
Cs-134 & $3.18 \mathrm{E}-07$ \\
Cs-137 & $3.53 \mathrm{E}-05$ \\
Eu-154 & $4.30 \mathrm{E}-07$ \\
Eu-155 & $2.06 \mathrm{E}-07$ \\
Fe-55 & $7.07 \mathrm{E}-05$ \\
H-3 & $1.54 \mathrm{E}-01$ \\
Mn-54 & $2.24 \mathrm{E}-07$ \\
Nb-94 & $3.37 \mathrm{E}-07$ \\
Ni-59 & $7.07 \mathrm{E}-06$ \\
Ni-63 & $9.50 \mathrm{E}-04$ \\
Pm-147 & $3.85 \mathrm{E}-06$ \\
Pu-238 & $1.10 \mathrm{E}-06$ \\
Pu-241 & $8.98 \mathrm{E}-07$ \\
Sb-125 & $1.50 \mathrm{E}-07$ \\
Sm-151 & $2.99 \mathrm{E}-07$ \\
Sr-90 & $3.33 \mathrm{E}-05$ \\
Te-125m & $3.74 \mathrm{E}-08$ \\
Th-234 & $1.33 \mathrm{E}-06$ \\
U-238 & $1.33 \mathrm{E}-06$ \\
Y-90 & $3.33 \mathrm{E}-05$ \\
Total & $1.56 \mathrm{E}-01$ \\
\hline
\end{tabular}

TABLE B.7.18 LowLevel Mixed Waste, All Cases: Knolls-

Kesselring Site

Function: Handling

Waste Stream: All

\begin{tabular}{ll}
\hline Nuclide & $\begin{array}{c}\text { Release (Ci), } \\
\text { SHA }\end{array}$ \\
\hline Co-60 & $3.37 \mathrm{E}-03$ \\
Cs-134 & $1.98 \mathrm{E}-06$ \\
Cs-137 & $2.20 \mathrm{E}-04$ \\
Eu-154 & $2.68 \mathrm{E}-06$ \\
Eu-155 & $1.28 \mathrm{E}-06$ \\
Fe-55 & $4.40 \mathrm{E}-04$ \\
H-3 & $6.26 \mathrm{E}-02$ \\
Mn-54 & $1.40 \mathrm{E}-06$ \\
Nb-94 & $2.10 \mathrm{E}-06$ \\
Ni-59 & $4.40 \mathrm{E}-05$ \\
Ni-63 & $5.92 \mathrm{E}-03$ \\
Pm-147 & $2.40 \mathrm{E}-05$ \\
Pu-238 & $6.87 \mathrm{E}-06$ \\
Pu-241 & $5.59 \mathrm{E}-06$ \\
Sb-125 & $9.32 \mathrm{E}-07$ \\
Sm-151 & $1.86 \mathrm{E}-06$ \\
Sr-90 & $2.07 \mathrm{E}-04$ \\
Te-125m & $2.33 \mathrm{E}-07$ \\
Th-234 & $8.27 \mathrm{E}-06$ \\
U-238 & $8.27 \mathrm{E}-06$ \\
Y-90 & $2.07 \mathrm{E}-04$ \\
Total & $7.31 \mathrm{E}-02$ \\
\hline
\end{tabular}


TABLE B.7.19 LowLevel Mixed Waste, All Cases: Knolls-Windsor Site

Function: Handling

Waste Stream: All

\begin{tabular}{ll}
\hline Nuclide & $\begin{array}{c}\text { Release (Ci), } \\
\text { SHA }\end{array}$ \\
\hline Co-60 & $2.03 \mathrm{E}-03$ \\
Cs-134 & $1.20 \mathrm{E}-06$ \\
Cs-137 & $1.33 \mathrm{E}-04$ \\
Eu-154 & $1.62 \mathrm{E}-06$ \\
Eu-155 & $7.74 \mathrm{E}-07$ \\
Fe-55 & $2.66 \mathrm{E}-04$ \\
H-3 & $1.06 \mathrm{E}-01$ \\
Mn-54 & $8.44 \mathrm{E}-07$ \\
Nb-94 & $1.27 \mathrm{E}-06$ \\
Ni-59 & $2.66 \mathrm{E}-05$ \\
Ni-63 & $3.57 \mathrm{E}-03$ \\
Pm-147 & $1.45 \mathrm{E}-05$ \\
Pu-238 & $4.15 \mathrm{E}-06$ \\
Pu-241 & $3.38 \mathrm{E}-06$ \\
Sb-125 & $5.63 \mathrm{E}-07$ \\
Sm-151 & $1.13 \mathrm{E}-06$ \\
Sr-90 & $1.25 \mathrm{E}-04$ \\
Te-125m & $1.41 \mathrm{E}-07$ \\
Th-234 & $4.99 \mathrm{E}-06$ \\
U-238 & $4.99 \mathrm{E}-06$ \\
Y-90 & $1.25 \mathrm{E}-04$ \\
Total & $1.12 \mathrm{E}-01$ \\
\hline &
\end{tabular}

TABLE B.7.20 LowLevel Mixed Waste, All Cases: Los Alamos National Laboratory

Function: Handling

Waste Stream: All

\begin{tabular}{ll}
\hline Nuclide & $\begin{array}{c}\text { Release (Ci), } \\
\text { SHA }\end{array}$ \\
\hline Co-60 & $1.26 \mathrm{E}-06$ \\
Cs-137 & $9.56 \mathrm{E}-07$ \\
Eu-154 & $1.05 \mathrm{E}-08$ \\
Fe-55 & $1.59 \mathrm{E}-07$ \\
$\mathrm{H}-3$ & $1.26 \mathrm{E}-01$ \\
Ni-59 & $2.10 \mathrm{E}-08$ \\
Ni-63 & $2.79 \mathrm{E}-06$ \\
Pm-147 & $8.80 \mathrm{E}-08$ \\
Pu-238 & $7.73 \mathrm{E}-08$ \\
Pu-239 & $4.07 \mathrm{E}-09$ \\
Pu-240 & $1.37 \mathrm{E}-08$ \\
Pu-241 & $1.04 \mathrm{E}-06$ \\
Sm-151 & $8.40 \mathrm{E}-09$ \\
Sr-90 & $8.99 \mathrm{E}-07$ \\
Y-90 & $8.99 \mathrm{E}-07$ \\
Total & $1.26 \mathrm{E}-01$ \\
\hline
\end{tabular}


TABLE B.7.21 Low-

Level Mixed Waste, All

Cases: Lawrence

Berkeley Laboratory

Function: Handling

Waste Stream: All

\begin{tabular}{ll}
\hline Nuclide & $\begin{array}{c}\text { Release (Ci), } \\
\text { SHA }\end{array}$ \\
\hline Cs-137 & $5.05 \mathrm{E}-07$ \\
$\mathrm{H}-3$ & $3.15 \mathrm{E}+00$ \\
Pu-241 & $1.15 \mathrm{E}-07$ \\
Sr-90 & $4.82 \mathrm{E}-07$ \\
Th-234 & $1.17 \mathrm{E}-07$ \\
U-238 & $1.17 \mathrm{E}-07$ \\
Y-90 & $4.82 \mathrm{E}-07$ \\
Total & $3.15 \mathrm{E}+00$ \\
\hline
\end{tabular}

TABLE B.7.22 LowLevel Mixed Waste, All Cases: Laboratory for Energy-Related Health Research

Function: Handling

Waste Stream: All

\begin{tabular}{ll}
\hline Nuclide & $\begin{array}{c}\text { Release (Ci), } \\
\text { SHA }\end{array}$ \\
\hline Am-2421 & $2.78 \mathrm{E}-09$ \\
Co-60 & $1.52 \mathrm{E}-06$ \\
Cs-137 & $4.37 \mathrm{E}-06$ \\
Eu-154 & $1.62 \mathrm{E}-08$ \\
Eu-155 & $5.55 \mathrm{E}-09$ \\
H-3 & $2.79 \mathrm{E}-04$ \\
Nb-94 & $1.16 \mathrm{E}-08$ \\
Ni-59 & $2.46 \mathrm{E}-07$ \\
Ni-63 & $2.58 \mathrm{E}-05$ \\
Pu-238 & $1.72 \mathrm{E}-07$ \\
Pu-239 & $2.78 \mathrm{E}-09$ \\
Pu-240 & $4.17 \mathrm{E}-09$ \\
Pu-241 & $1.82 \mathrm{E}-07$ \\
Sm-151 & $5.27 \mathrm{E}-08$ \\
Sr-90 & $3.87 \mathrm{E}-06$ \\
Tc-99 & $4.62 \mathrm{E}-08$ \\
Th-232 & $4.63 \mathrm{E}-09$ \\
Th-234 & $5.59 \mathrm{E}-07$ \\
U-238 & $5.59 \mathrm{E}-07$ \\
Y-90 & $3.87 \mathrm{E}-06$ \\
Total & $3.20 \mathrm{E}-04$ \\
\hline
\end{tabular}




\section{TABLE B.7.23 Low- \\ Level Mixed Waste, All \\ Cases: Lawrence \\ Livermore National \\ Laboratory}

\begin{tabular}{lc}
\hline $\begin{array}{l}\text { Function: Handling } \\
\text { Waste Stream: All }\end{array}$ \\
\hline & $\begin{array}{c}\text { Release (Ci), } \\
\text { SHA }\end{array}$ \\
Nuclide & 3.94E-07 \\
\hline Cs-137 & $3.08 \mathrm{E}+00$ \\
H-3 & $4.12 \mathrm{E}-08$ \\
Pu-238 & $8.72 \mathrm{E}-07$ \\
Pu-241 & $3.76 \mathrm{E}-07$ \\
Sr-90 & $9.14 \mathrm{E}-08$ \\
Th-234 & $9.14 \mathrm{E}-08$ \\
U-238 & $3.76 \mathrm{E}-07$ \\
Y-90 & $3.08 \mathrm{E}+00$ \\
Total &
\end{tabular}

\section{TABLE B.7.24 Low- \\ Level Mixed Waste, All \\ Cases: Mare Island \\ Naval Shipyard}

\begin{tabular}{lc}
$\begin{array}{l}\text { Function: Handling } \\
\text { Waste Stream: }\end{array}$ \\
\hline & Rell \\
\hline & Suse (Ci), \\
Nuclide & SHA \\
\hline Co-60 & $2.80 \mathrm{E}-03$ \\
Cs-134 & $1.65 \mathrm{E}-06$ \\
Cs-137 & $1.83 \mathrm{E}-04$ \\
Eu-154 & $2.23 \mathrm{E}-06$ \\
Eu-155 & $1.07 \mathrm{E}-06$ \\
Fe-55 & $3.67 \mathrm{E}-04$ \\
H-3 & $8.48 \mathrm{E}-02$ \\
Mn-54 & $1.16 \mathrm{E}-06$ \\
Nb-94 & $1.75 \mathrm{E}-06$ \\
Ni-59 & $3.67 \mathrm{E}-05$ \\
Ni-63 & $4.93 \mathrm{E}-03$ \\
Pm-147 & $2.00 \mathrm{E}-05$ \\
Pu-238 & $5.72 \mathrm{E}-06$ \\
Pu-241 & $4.66 \mathrm{E}-06$ \\
Sb-125 & $7.76 \mathrm{E}-07$ \\
Sm-151 & $1.55 \mathrm{E}-06$ \\
Sr-90 & $1.73 \mathrm{E}-04$ \\
Te-125m & $1.94 \mathrm{E}-07$ \\
Th-234 & $6.89 \mathrm{E}-06$ \\
U-238 & $6.89 \mathrm{E}-06$ \\
Y-90 & $1.73 \mathrm{E}-04$ \\
Total & $9.36 \mathrm{E}-02$ \\
\hline &
\end{tabular}


TABLE B.7.25 LowLevel Mixed Waste, All Cases: Mound Plant

Function: Handling

Waste Stream: All

\begin{tabular}{ll}
\hline Nuclide & $\begin{array}{c}\text { Release (Ci), } \\
\text { SHA }\end{array}$ \\
\hline Cs-137 & $1.40 \mathrm{E}-07$ \\
$\mathrm{H}-3$ & $3.14 \mathrm{E}+00$ \\
$\mathrm{Pu}-238$ & $3.18 \mathrm{E}-08$ \\
$\mathrm{Pu}-241$ & $6.36 \mathrm{E}-07$ \\
$\mathrm{Sr}-90$ & $1.34 \mathrm{E}-07$ \\
Th-234 & $3.24 \mathrm{E}-08$ \\
U-238 & $3.24 \mathrm{E}-08$ \\
Y-90 & $1.34 \mathrm{E}-07$ \\
Total & $3.14 \mathrm{E}+00$ \\
\hline
\end{tabular}

TABLE B.7.26 LowLevel Mixed Waste, All Cases: Norfolk Naval Shipyard

Function: Handling

Waste Stream: All

\begin{tabular}{ll}
\hline Nuclide & $\begin{array}{c}\text { Release (Ci), } \\
\text { SHA }\end{array}$ \\
\hline Co-60 & $8.49 \mathrm{E}-04$ \\
Cs-134 & $4.99 \mathrm{E}-07$ \\
Cs-137 & $5.55 \mathrm{E}-05$ \\
Eu-154 & $6.75 \mathrm{E}-07$ \\
Eu-155 & $3.23 \mathrm{E}-07$ \\
Fe-55 & $1.11 \mathrm{E}-04$ \\
H-3 & $1.54 \mathrm{E}-01$ \\
$\mathrm{Mn}-54$ & $3.52 \mathrm{E}-07$ \\
Nb-94 & $5.28 \mathrm{E}-07$ \\
Ni-59 & $1.11 \mathrm{E}-05$ \\
Ni-63 & $1.49 \mathrm{E}-03$ \\
Pm-147 & $6.05 \mathrm{E}-06$ \\
Pu-238 & $1.73 \mathrm{E}-06$ \\
Pu-241 & $1.41 \mathrm{E}-06$ \\
Sb-125 & $2.35 \mathrm{E}-07$ \\
Sm-151 & $4.70 \mathrm{E}-07$ \\
Sr-90 & $5.22 \mathrm{E}-05$ \\
Te-125m & $5.87 \mathrm{E}-08$ \\
Th-234 & $2.08 \mathrm{E}-06$ \\
U-238 & $2.08 \mathrm{E}-06$ \\
Y-90 & $5.22 \mathrm{E}-05$ \\
Total & $1.57 \mathrm{E}-01$ \\
\hline
\end{tabular}


TABLE B.7.27 LowLevel Mixed Waste, All

Cases: Nevada Test Site

Function: Handling

Waste Stream: All

\begin{tabular}{ll}
\hline Nuclide & $\begin{array}{c}\text { Release (Ci), } \\
\text { SHA }\end{array}$ \\
\hline Cs-137 & $1.39 \mathrm{E}-06$ \\
$\mathrm{H}-3$ & $3.15 \mathrm{E}+00$ \\
$\mathrm{Pu}-241$ & $3.15 \mathrm{E}-07$ \\
Sr-90 & $1.32 \mathrm{E}-06$ \\
Th-234 & $3.21 \mathrm{E}-07$ \\
$\mathrm{U}-238$ & $3.21 \mathrm{E}-07$ \\
Y-90 & $1.32 \mathrm{E}-06$ \\
Total & $3.15 \mathrm{E}+00$ \\
\hline
\end{tabular}

TABLE B.7.28 LowLevel Mixed Waste, All

Cases: Oak Ridge

National Laboratory

Function: Handling

Waste Stream: All

\begin{tabular}{ll}
\hline Nuclide & $\begin{array}{c}\text { Release (Ci), } \\
\text { SHA }\end{array}$ \\
\hline Am-241 & $3.03 \mathrm{E}-09$ \\
Co-60 & $1.66 \mathrm{E}-06$ \\
Cs-134 & $4.78 \mathrm{E}-06$ \\
Eu-154 & $1.77 \mathrm{E}-08$ \\
Eu-155 & $6.07 \mathrm{E}-09$ \\
H-3 & $2.50 \mathrm{E}-04$ \\
Nb-94 & $1.26 \mathrm{E}-08$ \\
Ni-59 & $2.68 \mathrm{E}-07$ \\
Ni-63 & $2.82 \mathrm{E}-05$ \\
Pu-238 & $1.88 \mathrm{E}-07$ \\
Pu-239 & $3.03 \mathrm{E}-09$ \\
Pu-240 & $4.55 \mathrm{E}-09$ \\
Pu-241 & $1.99 \mathrm{E}-07$ \\
Sm-151 & $5.76 \mathrm{E}-08$ \\
Sr-90 & $4.22 \mathrm{E}-06$ \\
Tc-99 & $5.05 \mathrm{E}-08$ \\
Th-232 & $5.06 \mathrm{E}-09$ \\
Th-234 & $6.11 \mathrm{E}-07$ \\
U-238 & $6.11 \mathrm{E}-07$ \\
Y-90 & $4.22 \mathrm{E}-06$ \\
Total & $2.95 \mathrm{E}-04$ \\
\hline &
\end{tabular}


TABLE B.7.29 Low-

Level Mixed Waste, All

Cases: Paducah

Gaseous Diffusion Plant

Function: Handling

Waste Stream: All

\begin{tabular}{ll}
\hline Nuclide & $\begin{array}{c}\text { Release (Ci), } \\
\text { SHA }\end{array}$ \\
\hline Ac-228 & $8.18 \mathrm{E}-09$ \\
$\mathrm{Bi}-212$ & $1.35 \mathrm{E}-09$ \\
$\mathrm{~Pb}-212$ & $1.35 \mathrm{E}-09$ \\
$\mathrm{Ra}-224$ & $1.35 \mathrm{E}-09$ \\
$\mathrm{Ra}-228$ & $8.18 \mathrm{E}-09$ \\
$\mathrm{Tc}-99$ & $3.32 \mathrm{E}-06$ \\
Th-228 & $1.35 \mathrm{E}-09$ \\
Th-231 & $8.61 \mathrm{E}-09$ \\
Th-232 & $9.06 \mathrm{E}-08$ \\
Th-234 & $1.10 \mathrm{E}-05$ \\
U-235 & $8.54 \mathrm{E}-09$ \\
U-238 & $1.10 \mathrm{E}-05$ \\
Total & $2.55 \mathrm{E}-05$ \\
\hline
\end{tabular}

TABLE B.7.30 LowLevel Mixed Waste, All Cases: Pantex Plant

Function: Handling

Waste Stream: All

\begin{tabular}{ll}
\hline Nuclide & $\begin{array}{c}\text { Release (Ci), } \\
\text { SHA }\end{array}$ \\
\hline Co-60 & $1.12 \mathrm{E}-06$ \\
Cs-137 & $8.52 \mathrm{E}-07$ \\
Eu-154 & $9.37 \mathrm{E}-09$ \\
Fe-55 & $1.41 \mathrm{E}-07$ \\
H-3 & $1.28 \mathrm{E}-01$ \\
Ni-59 & $1.87 \mathrm{E}-08$ \\
Ni-63 & $2.49 \mathrm{E}-06$ \\
Pm-147 & $7.84 \mathrm{E}-08$ \\
Pu-238 & $3.24 \mathrm{E}-08$ \\
Pu-241 & $1.64 \mathrm{E}-07$ \\
Sm-151 & $7.50 \mathrm{E}-09$ \\
Sr-90 & $8.01 \mathrm{E}-07$ \\
Y-90 & $8.01 \mathrm{E}-07$ \\
Total & $1.28 \mathrm{E}-01$ \\
\hline
\end{tabular}


TABLE B.7.31 LowLevel Mixed Waste, All Cases: Pearl Harbor Naval Shipyard

Function: Handling

Waste Stream: All

\begin{tabular}{|c|c|}
\hline Nuclide & $\begin{array}{c}\text { Release (Ci), } \\
\text { SHA }\end{array}$ \\
\hline Co-60 & $7.22 \mathrm{E}-04$ \\
\hline Cs- 134 & $4.25 \mathrm{E}-07$ \\
\hline Cs- 137 & $4.72 \mathrm{E}-05$ \\
\hline Eu-154 & 5.74E-07 \\
\hline Eu-155 & $2.75 \mathrm{E}-07$ \\
\hline $\mathrm{Fe}-55$ & $9.44 \mathrm{E}-05$ \\
\hline $\mathrm{H}-3$ & $1.54 \mathrm{E}-01$ \\
\hline Mn-54 & $3.00 \mathrm{E}-07$ \\
\hline $\mathrm{Nb}-94$ & 4.50E-07 \\
\hline $\mathrm{Ni}-59$ & $9.44 \mathrm{E}-06$ \\
\hline $\mathrm{Ni}-63$ & $1.27 \mathrm{E}-03$ \\
\hline Pm-147 & 5.14E-06 \\
\hline $\mathrm{Pu}-238$ & $1.47 \mathrm{E}-06$ \\
\hline $\mathrm{Pu}-241$ & $1.20 \mathrm{E}-06$ \\
\hline Sb-125 & $2.00 \mathrm{E}-07$ \\
\hline Sm-151 & $4.00 \mathrm{E}-07$ \\
\hline Sr-90 & $4.45 E-05$ \\
\hline $\mathrm{Te}-125 \mathrm{~m}$ & $5.00 \mathrm{E}-08$ \\
\hline Th-234 & $1.77 \mathrm{E}-06$ \\
\hline U-238 & $1.77 \mathrm{E}-06$ \\
\hline$Y-90$ & $4.45 \mathrm{E}-05$ \\
\hline Total & $1.56 \mathrm{E}-01$ \\
\hline
\end{tabular}

TABLE B.7.32 LowLevel Mixed Waste, All Cases: Portsmouth Naval Shipyard

Function: Handling

Waste Stream: All

\begin{tabular}{ll}
\hline Nuclide & $\begin{array}{c}\text { Release (Ci), } \\
\text { SHA }\end{array}$ \\
\hline Co-60 & $9.62 \mathrm{E}-04$ \\
Cs-134 & $5.66 \mathrm{E}-07$ \\
Cs-137 & $6.29 \mathrm{E}-05$ \\
Eu-154 & $7.66 \mathrm{E}-07$ \\
Eu-155 & $3.66 \mathrm{E}-07$ \\
Fe-55 & $1.26 \mathrm{E}-04$ \\
H-3 & $1.54 \mathrm{E}-01$ \\
Mn-54 & $3.99 \mathrm{E}-07$ \\
Nb-94 & $5.99 \mathrm{E}-07$ \\
Ni-59 & $1.26 \mathrm{E}-05$ \\
Ni-63 & $1.69 \mathrm{E}-03$ \\
Pm-147 & $6.86 \mathrm{E}-06$ \\
Pu-238 & $1.96 \mathrm{E}-06$ \\
Pu-241 & $1.60 \mathrm{E}-06$ \\
Sb-125 & $2.66 \mathrm{E}-07$ \\
Sm-151 & $5.33 \mathrm{E}-07$ \\
Sr-90 & $5.92 \mathrm{E}-05$ \\
Te-125m & $6.66 \mathrm{E}-08$ \\
Th-234 & $2.36 \mathrm{E}-06$ \\
U-238 & $2.36 \mathrm{E}-06$ \\
Y-90 & $5.92 \mathrm{E}-05$ \\
Total & $1.57 \mathrm{E}-01$ \\
\hline
\end{tabular}


TABLE B.7.33 LowLevel Mixed Waste, All Cases: Portsmouth Gaseous Diffusion Plant

Function: Handling

Waste Stream: All

\begin{tabular}{ll}
\hline Nuclide & $\begin{array}{c}\text { Release (Ci), } \\
\text { SHA }\end{array}$ \\
\hline Ac-228 & $1.98 \mathrm{E}-11$ \\
$\mathrm{Bi}-212$ & $3.30 \mathrm{E}-12$ \\
$\mathrm{~Pb}-212$ & $3.30 \mathrm{E}-12$ \\
$\mathrm{Ra}-224$ & $3.30 \mathrm{E}-12$ \\
$\mathrm{Ra}-228$ & $1.98 \mathrm{E}-11$ \\
$\mathrm{Tc}-99$ & $7.94 \mathrm{E}-09$ \\
Th-228 & $3.30 \mathrm{E}-12$ \\
Th-231 & $2.06 \mathrm{E}-11$ \\
Th-232 & $2.17 \mathrm{E}-10$ \\
Th-234 & $2.64 \mathrm{E}-08$ \\
U-235 & $2.04 \mathrm{E}-11$ \\
U-238 & $2.64 \mathrm{E}-08$ \\
Total & $6.10 \mathrm{E}-08$ \\
\hline
\end{tabular}

TABLE B.7.34 LowLevel Mixed Waste, All Cases: Princeton Plasma Physics Laboratory

Function: Handling

Waste Stream: All

\begin{tabular}{ll}
\hline Nuclide & $\begin{array}{c}\text { Release (Ci), } \\
\text { SHA }\end{array}$ \\
\hline Cs-137 & $1.39 \mathrm{E}-07$ \\
$\mathrm{H}-3$ & $3.15 \mathrm{E}+00$ \\
Pu-241 & $3.15 \mathrm{E}-08$ \\
Sr-90 & $1.32 \mathrm{E}-07$ \\
Th-234 & $3.21 \mathrm{E}-08$ \\
U-238 & $3.21 \mathrm{E}-08$ \\
Y-90 & $1.32 \mathrm{E}-07$ \\
Total & $3.15 \mathrm{E}+00$ \\
\hline
\end{tabular}


TABLE B.7.35 Low-

Level Mixed Waste, All

Cases: Puget Sound

Naval Shipyard

Function: Handling

Waste Stream: All

\begin{tabular}{ll}
\hline Nuclide & $\begin{array}{c}\text { Release (Ci), } \\
\text { SHA }\end{array}$ \\
\hline Co-60 & 5.38E-04 \\
Cs-134 & $3.16 \mathrm{E}-07$ \\
Cs-137 & $3.52 \mathrm{E}-05$ \\
Eu-154 & $4.28 \mathrm{E}-07$ \\
Eu-155 & $2.05 \mathrm{E}-07$ \\
Fe-55 & $7.03 \mathrm{E}-05$ \\
H-3 & $1.54 \mathrm{E}-01$ \\
Mn-54 & $2.23 \mathrm{E}-07$ \\
Nb-94 & $3.35 \mathrm{E}-07$ \\
Ni-59 & $7.03 \mathrm{E}-06$ \\
Ni-63 & $9.46 \mathrm{E}-04$ \\
Pm-147 & $3.83 \mathrm{E}-06$ \\
Pu-238 & $1.10 \mathrm{E}-06$ \\
Pu-241 & $8.93 \mathrm{E}-07$ \\
Sb-125 & $1.49 \mathrm{E}-07$ \\
Sm-151 & $2.98 \mathrm{E}-07$ \\
Sr-90 & $3.31 \mathrm{E}-05$ \\
Te-125m & $3.72 \mathrm{E}-08$ \\
Th-234 & $1.32 \mathrm{E}-06$ \\
U-238 & $1.32 \mathrm{E}-06$ \\
Y-90 & $3.31 \mathrm{E}-05$ \\
Total & $1.56 \mathrm{E}-01$ \\
\hline &
\end{tabular}

TABLE B.7.36 LowLevel Mixed Waste, All Cases: Rocky Flats Plant

Function: Handling

Waste Stream: All

\begin{tabular}{ll}
\hline Nuclide & $\begin{array}{c}\text { Release (Ci), } \\
\text { SHA }\end{array}$ \\
\hline Am-241 & $2.99 \mathrm{E}-10$ \\
$\mathrm{Cm}-244$ & $4.04 \mathrm{E}-10$ \\
$\mathrm{Pu}-238$ & $1.56 \mathrm{E}-07$ \\
$\mathrm{Pu}-239$ & $1.60 \mathrm{E}-08$ \\
$\mathrm{Pu}-240$ & $5.59 \mathrm{E}-08$ \\
$\mathrm{Pu}-241$ & $1.52 \mathrm{E}-06$ \\
Th-234 & $1.46 \mathrm{E}-09$ \\
$\mathrm{U}-238$ & $1.46 \mathrm{E}-09$ \\
Total & $1.76 \mathrm{E}-06$ \\
\hline
\end{tabular}


TABLE B.7.37 LowLevel Mixed Waste, All Cases: Reactive Materials, Inc.

Function: Handling

Waste Stream: All

\begin{tabular}{ll}
\hline Nuclide & $\begin{array}{c}\text { Release (Ci), } \\
\text { SHA }\end{array}$ \\
\hline Ac-228 & $1.20 \mathrm{E}-10$ \\
$\mathrm{Bi}-212$ & $2.02 \mathrm{E}-11$ \\
$\mathrm{~Pb}-212$ & $2.02 \mathrm{E}-11$ \\
$\mathrm{Ra}-224$ & $2.02 \mathrm{E}-11$ \\
$\mathrm{Ra}-228$ & $1.20 \mathrm{E}-10$ \\
Tc-99 & $2.24 \mathrm{E}-09$ \\
Th-228 & $2.02 \mathrm{E}-11$ \\
Th-231 & $1.16 \mathrm{E}-10$ \\
Th-232 & $1.22 \mathrm{E}-09$ \\
Th-234 & $1.49 \mathrm{E}-07$ \\
U-235 & $1.16 \mathrm{E}-10$ \\
U-238 & $1.49 \mathrm{E}-07$ \\
Total & $3.01 \mathrm{E}-07$ \\
\hline
\end{tabular}

TABLE B.7.38 LowLevel Mixed Waste, All Cases: Sandia National Laboratories-New Mexico

Function: Handling

Waste Stream: All

\begin{tabular}{ll}
\hline Nuclide & $\begin{array}{c}\text { Release (Ci), } \\
\text { SHA }\end{array}$ \\
\hline Co-60 & $\begin{array}{l}8.77 \mathrm{E}-06 \\
\text { Cs-137 }\end{array}$ \\
Eu-154 & $6.38 \mathrm{E}-06$ \\
Eu-155 & $3.20 \mathrm{E}-08$ \\
Fe-55 & $7.39 \mathrm{E}-09$ \\
H-3 & $1.75 \mathrm{E}-07$ \\
Nb-94 & $1.11 \mathrm{E}-01$ \\
Ni-59 & $4.19 \mathrm{E}-08$ \\
Ni-63 & $8.28 \mathrm{E}-07$ \\
Pu-238 & $1.00 \mathrm{E}-04$ \\
Pu-240 & $2.17 \mathrm{E}-07$ \\
Pu-241 & $1.72 \mathrm{E}-07$ \\
Sm-151 & $1.72 \mathrm{E}-07$ \\
Sr-90 & $6.90 \mathrm{E}-08$ \\
Tc-99 & $5.94 \mathrm{E}-06$ \\
Th-234 & $2.46 \mathrm{E}-09$ \\
U-238 & $2.96 \mathrm{E}-08$ \\
Y-90 & $2.96 \mathrm{E}-08$ \\
Total & $5.94 \mathrm{E}-06$ \\
\hline & $1.12 \mathrm{E}-01$ \\
\hline
\end{tabular}


TABLE B.7.39 Low-

Level Mixed Waste, All

Cases: Sandia National

Laboratories-California

Function: Handling

Waste Stream: All

\begin{tabular}{ll}
\hline \multicolumn{1}{c}{ Nuclide } & $\begin{array}{c}\text { Release (Ci), } \\
\text { SHA }\end{array}$ \\
\hline Cs-137 & $2.17 \mathrm{E}-07$ \\
H-3 & $3.14 \mathrm{E}+00$ \\
Pu-241 & $4.93 \mathrm{E}-08$ \\
Sr-90 & $2.07 \mathrm{E}-07$ \\
Th-234 & $5.03 \mathrm{E}-08$ \\
U-238 & $5.03 \mathrm{E}-08$ \\
Y-90 & $2.07 \mathrm{E}-07$ \\
Total & $3.14 \mathrm{E}+00$ \\
\hline
\end{tabular}

TABLE B.7.40 Low-

Level Mixed Waste, All

Cases: Savannah

River Site

Function: Handling

Waste Stream: All

\begin{tabular}{lc}
\hline Nuclide & $\begin{array}{c}\text { Release (Ci), } \\
\text { SHA }\end{array}$ \\
\hline Co-60 & 5.04E-06 \\
Cs-137 & $3.93 \mathrm{E}-06$ \\
Eu-154 & $1.89 \mathrm{E}-08$ \\
Eu-155 & $4.15 \mathrm{E}-09$ \\
Fe-55 & $9.96 \mathrm{E}-08$ \\
H-3 & $1.03 \mathrm{E}-01$ \\
Nb-94 & $2.68 \mathrm{E}-08$ \\
Ni-59 & $5.42 \mathrm{E}-07$ \\
Ni-63 & $6.35 \mathrm{E}-05$ \\
Pu-238 & $1.53 \mathrm{E}-07$ \\
Pu-239 & $1.52 \mathrm{E}-09$ \\
Pu-240 & $8.48 \mathrm{E}-08$ \\
Pu-241 & $2.97 \mathrm{E}-07$ \\
Sm-151 & $4.34 \mathrm{E}-08$ \\
Sr-90 & $3.65 \mathrm{E}-06$ \\
Tc-99 & $1.13 \mathrm{E}-09$ \\
Th-234 & $1.89 \mathrm{E}-08$ \\
U-238 & $1.89 \mathrm{E}-08$ \\
Y-90 & $3.65 \mathrm{E}-06$ \\
Total & $1.03 \mathrm{E}-01$ \\
\hline
\end{tabular}


TABLE B.7.41 Low-

Level Mixed Waste, All

Cases: University of

Missouri, Columbia

Function: Handling

Waste Stream: All

\begin{tabular}{ll}
\hline Nuclide & $\begin{array}{c}\text { Release (Ci), } \\
\text { SHA }\end{array}$ \\
\hline Am-241 & $2.21 \mathrm{E}-10$ \\
Cm-244 & $2.99 \mathrm{E}-10$ \\
Pu-238 & $1.15 \mathrm{E}-07$ \\
Pu-239 & $1.18 \mathrm{E}-08$ \\
Pu-240 & $4.13 \mathrm{E}-08$ \\
Pu-241 & $1.13 \mathrm{E}-06$ \\
Th-234 & $1.08 \mathrm{E}-09$ \\
U-238 & $1.08 \mathrm{E}-09$ \\
Total & $1.30 \mathrm{E}-06$ \\
\hline
\end{tabular}

TABLE B.7.42 Low-

Level Mixed Waste, All

Cases: West Valley

Demonstration Project

Function: Handling

Waste Stream: All

\begin{tabular}{|c|c|}
\hline Nuclide & $\begin{array}{c}\text { Release (Ci), } \\
\text { SHA }\end{array}$ \\
\hline Am-241 & 3.13E-08 \\
\hline Co-60 & 4.57E-08 \\
\hline Cs-137 & $3.65 \mathrm{E}-05$ \\
\hline Eu-154 & $5.45 \mathrm{E}-08$ \\
\hline $\mathrm{H}-3$ & 3.62E-03 \\
\hline $\mathrm{Nb}-94$ & 3.13E-09 \\
\hline $\mathrm{Ni}-59$ & $7.00 \mathrm{E}-08$ \\
\hline $\mathrm{Ni}-63$ & $7.20 \mathrm{E}-06$ \\
\hline Pu-238 & $1.70 \mathrm{E}-06$ \\
\hline Pu-239 & $2.82 \mathrm{E}-08$ \\
\hline Pu-240 & $1.25 \mathrm{E}-08$ \\
\hline $\mathrm{Pu}-241$ & 7.31E-07 \\
\hline Sm-151 & 5.23E-07 \\
\hline Sr-90 & $3.25 \mathrm{E}-05$ \\
\hline Tc-99 & $1.62 E-08$ \\
\hline Th-234 & 2.01E-08 \\
\hline U-238 & 2.01E-08 \\
\hline$Y-90$ & 3.25E-05 \\
\hline Total & 3.73E-03 \\
\hline
\end{tabular}


B- 144 


\section{Analysis of Accident Sequences and Source Terms at Treatment and Storage Facilities for Waste Generated by U.S. Department of Energy Waste Management Operations}

Volume 3: Appendixes C-H

by C. Mueller, B. Nabelssi, J. Roglans-Ribas, S. Folga, A. Policastro, W. Freeman,"

R. Jackson, ${ }^{\star}$ J. Mishima, ${ }^{\star}$ and S. Turner*

Environmental Assessment Division,

Argonne National Laboratory, 9700 South Cass Avenue, Argonne, Illinois 60439

December 1996

Work sponsored by United States Department of Energy, Assistant Secretary for Environmental Management

* Freeman is affiliated with the University of Illinois at Chicago; Jackson and Turner with Science Applications International Corporation, Golden, Colorado; and Mishima with Science Applications International Corporation, Richland, Washington. 
APPENDIX C:

REFERENCE DATA ON FIRES, EXPLOSIONS, AND CRITICALITIES IN NUCLEAR AND CHEMICAL PROCESSING AND WASTE MANAGEMENT FACILITIES 


$$
c-2
$$




\section{CONTENTS}

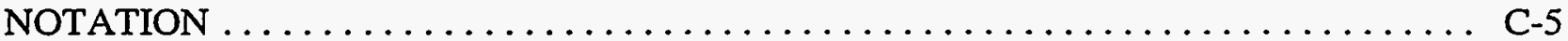

C. $1 \quad$ INTRODUCTION AND SUMMARY $\ldots \ldots \ldots \ldots \ldots \ldots \ldots \ldots \ldots \ldots \ldots \ldots \ldots \ldots$

C.2 RECENT EXPLOSIONS OR FIRES AT HAZARDOUS WASTE

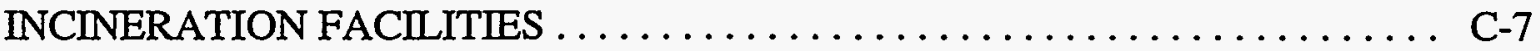

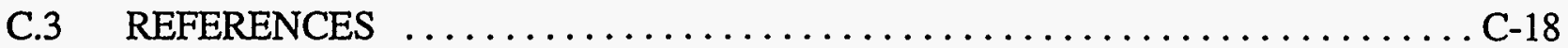

\section{TABLES}

C.1 Postulated Fires and Explosions in Treatment, Storage, and Disposal Facilities . . . C-8

C.2 Summary of Fire and Explosion Sources $\ldots \ldots \ldots \ldots \ldots \ldots \ldots \ldots \ldots \ldots \ldots \ldots$

C.3 Postulated Criticalities in Treatment, Storage, and Disposal Facilities . . . . . . . . C-14

C.4 Summary of Criticality Accident Fission Yields $\ldots \ldots \ldots \ldots \ldots \ldots \ldots \ldots$ C-15

C.5 Summary of Fires, Explosions, and Incidents of Drum Overpressurization . . . . C C-16 
C. 4 


\section{NOTATION}

The following is a list of acronyms, initialisms, and abbreviations (including units of measure) used in this appendix.

\section{ACRONYMS, INITIALISMS, AND ABBREVIATIONS}

$\begin{array}{ll}\mathrm{GPC} & \text { general purpose concentrator } \\ \mathrm{H}_{2} & \text { hydrogen } \\ \mathrm{H}_{2} \mathrm{O} & \text { water } \\ \mathrm{HEPA} & \text { high-efficiency particulate air (filter) } \\ \mathrm{HLLW} & \text { high-level liquid waste } \\ \mathrm{ILW} & \text { intermediate-level waste } \\ \mathrm{NA} & \text { sodium } \\ \mathrm{NO}_{x} & \text { nitrogen oxides } \\ \mathrm{O}_{2} & \text { oxygen } \\ \mathrm{Pu} & \text { plutonium } \\ \mathrm{Ru} & \text { ruthenium } \\ \mathrm{U} & \text { uranium } \\ \text { VOG } & \text { vessel off-gas }\end{array}$

\section{UNITS OF MEASURE}

$\begin{array}{ll}{ }^{\circ} \mathrm{C} & \text { degree(s) Celsius } \\ { }^{\circ} \mathrm{F} & \text { degree(s) Fahrenheit } \\ \mathrm{ft} & \text { foot (feet) } \\ \mathrm{J} & \text { joule(s) } \\ \mathrm{m} & \text { meter(s) }\end{array}$




\section{APPENDIX C:}

\section{REFERENCE DATA ON FIRES, EXPLOSIONS, AND CRITICALITIES IN NUCLEAR AND CHEMICAL PROCESSING AND WASTE MANAGEMENT FACILITIES}

\section{C.1 INTRODUCTION AND SUMMARY}

This appendix summarizes existing information that has been used to estimate the potential for and radiological consequences of fires, explosions, and nuclear criticalities that could occur in treatment, storage, and disposal facilities. Because almost all scenarios with radiological consequences that have measurable public health effects involve these mechanisms, this information, much of which is based on materials in Elder et al. (1986) and Ayer et al. (1988), is provided to complement the related discussions in the main text of this report.

Table C.1 lists plausible accidents involving fires and explosions in nuclear and chemical processing and waste management facilities, identifies conditions that could lead to their occurrence, and describes their potential consequences. Table C. 2 identifies the categorization of fires, explosions, and their sources provided in Elder et al. (1986).

Table C.3 lists plausible criticality accidents, identifies conditions that could lead to their occurrence, and qualitatively describes their potential consequences. Table C.4 summarizes fission yields predicted from selected configurations that potentially could occur in U.S. Department of Energy facilities. Table C.5 summarizes fires, explosions, and incidents of drum overpressurization.

\section{C.2 RECENT EXPLOSIONS OR FIRES AT HAZARDOUS WASTE INCINERATION FACILITIES}

Hazardous waste incinerators that have experienced explosions are discussed in subsequent paragraphs; no explosion required community evacuation. Further, most explosions occurred in boilers or ducts downstream of the incinerators and thus did not involve the release of hazardous constituents. The summaries were compiled in April of 1994 by the U.S. Environmental Protection Agency (Hlustick 1994).

Rollins Deer Park, Deer Park, Texas. This fire occurred in November 1991 in the furnace duct, not the incinerator. The plant shut down as many vents as possible and allowed the facility a few days to cool down. A new duct was installed, and the plant was back up and running in about five days. 


\section{TABLE C.1 Postulated Fires and Explosions in Treatment, Storage, and Disposal Facilities}

Accident

Conditions Leading to Occurrence

Poor housekeeping/administrative control; quantity of fuel at location; strong ignition source.

\section{General cell fire}

\section{Fires involving}

- Stored combustible waste

- Combustible fluids

- Flammable gas or liquid

- Organics/lint in exhaust ducts

- Ion-exchange resin
Accumulation of combustible materials in cell (e.g., plastics, dust, solvent leak, some cloth, grease, organic film) and ignition; cell window breaks and oil ignites.

Strong ignition source (in combustibles); pathway from drum to drum; violation of procedures (leaving drum uncovered).

Undetected leak; very strong ignition source or elevated temperature of fluid and ignition source.

Unauthorized use (violation of administrative control); careless use (excess vapor generation); leak; ignition source.

Exhaust ducts not routinely cleaned; ignition source.

Nitration of resin; ignition source.
Potential Consequences and Considerations

Loss of glove box integrity (loss of gloves, glass or plastic viewing windows); potential loss of airflow via filter clogging; failure of piping and equipment from thermal effects of pressurization of contents.

Cell filters clogged; all plastics in cell lose integrity; cell pressurizes and radioactive material disperses to operating and service areas; material transported to cell filters.

Combustion of contaminated combustibles; generation of heat and combustion products.

Loss of glove box integrity (loss of gloves, glass or plastic viewing windows); potential loss of airflow via filter clogging; failure of piping and equipment from thermal effects of pressurization of contents.

Loss of glove box integrity (loss of gloves, plastic or glass viewing windows); heat/flame intrusion on equipment in box; potential loss of glove box filter (and ignition of organics/lint in exhaust ducts); potential clogging of filter and diffusion from glove box back into room.

Loss of final HEPA filters; loss of combustible exhaust ducts; potential ignition source for fires in other areas.

Catastrophic loss of glove box integrity; (loss of gloves, windows, inlet and outlet filters); damage to adjacent glove boxes and equipment; damage to structure; damage to exhaust ducts or filters in glove box. 


\section{TABLE C.1 (Cont.)}

\begin{tabular}{lll}
\hline & \multicolumn{1}{c}{ Conditions Leading to Occurrence } & \multicolumn{1}{c}{ Potential Consequences and Considerations } \\
\hline - Solvents & $\begin{array}{l}\text { High organic stream temperature; solvent } \\
\text { leak and vaporization or spray on hot } \\
\text { equipment (e.g., stream line, evaporator } \\
\text { reboiled); steam jet leak in solvent recovery; } \\
\text { solvent cooler failure; solvent spills from } \\
\text { skimmer, overflow, flooded decanter, or } \\
\text { makeup tank overflow; cell atmosphere } \\
\text { oxygen concentration above limit; ignition } \\
\text { source. }\end{array}$ & $\begin{array}{l}\text { Airborne activity in process cell; possible overheating and } \\
\text { plugging of cell ventilation filters; air reversal; loss of } \\
\text { process control; equipment damage. Energy release by } \\
\text { solvent burning somewhat limited by amount in process } \\
\text { cells. }\end{array}$ \\
\hline $\begin{array}{ll}\text { Sodium leak and loss of control of cell } \\
\text { atmosphere. }\end{array}$ & $\begin{array}{l}\text { Sodium smoke released to cell ventilation system with } \\
\text { possible pressurization of cell, ventilation filter failure; local } \\
\text { temperature to 1,250 }{ }^{\circ} \mathrm{C} ; \text { any overheated fuel elements could } \\
\text { release noble gases, iodine, and volatiles. }\end{array}$ \\
& & Sodium (in handling)
\end{tabular}

Explosions involving

- Solvent in glove box

Unauthorized use (violation of administrative control); careless use (excess vapor generation); leak; accumulation of substantial quantity of flammable mixture.

- Hydrogen

Accumulation of quantity of flammable mixture prior to contact with ignition source (failure of several protection devices); ignition source.

- Flammable gas

Undetected leak in cylinder; accumulation of quantity of flammable mixture prior to contact with ignition source; ignition source.
Catastrophic loss of glove box integrity; (loss of gloves, windows, inlet and outlet filters); damage to adjacent glove boxes and equipment; damage to structure; damage to exhaust ducts or filters in glove box.

Catastrophic loss of glove box integrity; (loss of gloves, windows, inlet and outlet filters); damage to adjacent glove boxes and equipment; damage to structure; damage to exhaust ducts or filters in glove box; damage dependent upon quantity of gas involved and location of explosion.

Catastrophic to minor damage to enclosures, equipment and structure; ignition of combustibles in area; damage dependent upon quantity of gas involved and location of explosion. 
TABLE C.1 (Cont.)

\begin{tabular}{|c|c|}
\hline Accident & Conditions Leading to Occurrence \\
\hline $\begin{array}{l}\text { - Red oil in concentrator from } \\
\text { solvent extraction system }\end{array}$ & $\begin{array}{l}\text { Undetected long-range accumulation of } \\
\text { solvent in concentrator; nitration of solvent; } \\
\text { temperature exceeding } 135^{\circ} \mathrm{C} \text { after } \\
\text { nitration. }\end{array}$ \\
\hline - Ammonia & $\begin{array}{l}\text { Undetected leak in cylinder; accumulation } \\
\text { of quantity of flammable mixture prior to } \\
\text { contact with ignition source; ignition } \\
\text { source. }\end{array}$ \\
\hline $\begin{array}{l}\text { Fire or explosion associated with } \\
\text { ion-exchange resin }\end{array}$ & $\begin{array}{l}\text { Self-heating of resin due to abnormal } \\
\text { conditions in column such as high nitric } \\
\text { acid concentration, column overloading, dry } \\
\text { resin in column, or high column } \\
\text { temperature; self heating of spent resin in } \\
\text { waste; spontaneous combustion of spilled } \\
\text { resins. }\end{array}$ \\
\hline
\end{tabular}

Evaporator explosion

Uncontrolled reaction in evaporator; solvent in feed and loss of temperature control; overpressurization of plutonium evaporator, hydrogen accumulation, and ignition source.

Hydrazoic acid explosion

Uncontrolled reaction of hydrazide products used in solvent recovery.

Explosion in uranium cvaporator-denitrator system or in concentrate evaporator

Uncontrolled reaction caused by excessive organic material in feed or loss of temperature control in evaporators; oil leak in denitrator; organic material in feed to concentrate evaporators.

Potential Consequences and Considerations

Loss of concentrator; loss of nearby equipment, and piping; ignition of flammables and combustibles in area; potential loss of structural components from blast and pressure effects.

Catastrophic loss of glove box integrity; (loss of gloves, windows, inlet and outlet filters); damage to adjacent glove boxes and equipment; damage to structure; damage to exhaust ducts or filters in glove box.

Column pressurization and column rupture; eruption; airborne activity in process cell; release of fission products to ventilation system; waste fires; cell pressurization; damage to equipment and to ventilation system; possible plugging or overheating of VOG filters.

Severe damage to equipment and VOG; possible missiles in process cell; airborne activity released to process cell; substantial amounts of aerosol generated; cell pressurization.

Damage to VOG system; fire in solvent recovery; airborne activity in process cell; cell pressurization.

Damage to equipment, $\mathrm{NO}_{\mathrm{x}}$ absorber, and VOG system; release of process material to cell and cell air; cell pressurization. 
TABLE C.1 (Cont.)

\begin{tabular}{lll}
\hline Accident & Conditions Leading to Occurrence & Potential Consequences and Considerations \\
\hline
\end{tabular}

Hydrogen or red oil explosions in

- Product storage tank

- General tank or vessel vent system

- Process cell

- Fuel cleaning cells

- General purpose concentrator (GPC)
Hydrogen produced by radiolysis of product solutions; loss of purge; ignition source.

Concentration of feed solution; hydrogen produced by radiolysis of feed solution; loss of purge to feed tank; oxygen and/or ignition source.

Ignition source and/or excessive oxygen present in cell atmosphere; hydrogen release to cell from $\mathrm{H}_{2}$ generator (e.g., leaks) or purifier catalyst poisoned causing excess oxygen in cell; emergency hydrogen supply system leak into cell.

Uncontrolled sodium reaction in fuel cleaning vessel; overloaded catalytic oxidizer; ignition of $\mathrm{H}_{2}$ in off-gas; loss of inert cell atmosphere (humidity control) during unloading of $\mathrm{Na}$-cooled fuel, uncontrolled $\mathrm{Na}-\mathrm{H}_{2} \mathrm{O}$ reaction in cell, or ignition of $\mathrm{H}_{2}$ in cell.

Simultaneous occurrence of all of the following: insufficient caustic added to GPC feed (acidic feed); excessive bottoms temperature $\left(>130^{\circ} \mathrm{C}\right)$; heavy metal present (e.g., uranium from analytical laboratory); solvent in feed.
Damage to off-gas system and release of off-gas; other equipment damage; release of fissiles to cell floor; cell pressurization.

Severe damage to equipment; potential damage to off-gas system; release of radioactive material to process cell.

Damage to shielding cell, cell ventilation, and VOG systems; release of radioactive material from process cells to occupied areas; possible missiles; possible severe damage to equipment items in cell; initiation and development of additional major accident sequences (fires, etc.).

Damage to cell equipment and/or off-gas system; possible rupture of fuel element being cleaned with release of airborne activity to process cell ventilation system.

Release of ILW to cell floor; airborne ILW in process cell and cell exhaust; possible missiles; fire in cell; damage to VOG system; cell pressurization; release to occupied areas. 
TABLE C.1 (Cont.)

\begin{tabular}{|c|c|c|}
\hline Accident & Conditions Leading to Occurrence & Potential Consequences and Considerations \\
\hline \multirow[t]{3}{*}{ - High-level concentrator } & $\begin{array}{l}\text { Uncontrolled red oil reaction from all of the } \\
\text { following: solvent in feed, temperatures } \\
\text { above } 130^{\circ} \mathrm{C} \text {, heavy metal }(\mathrm{U}, \mathrm{Pu}) \text { present. }\end{array}$ & $\begin{array}{l}\text { Rupture of concentrator would cause possibly violent } \\
\text { ejection of liquid, with formation of aerosol; subsequent boil- } \\
\text { off of residual liquid with release of volatile species and } \\
\text { additional aerosol may occur. }\end{array}$ \\
\hline & $\begin{array}{l}\text { Hydrogen explosion from all of the } \\
\text { following: } \mathrm{H}_{2} \text { accumulation, } \mathrm{O}_{2} \\
\text { concentration above limit, and ignition } \\
\text { source. }\end{array}$ & $\begin{array}{l}\text { Damage to VOG treatment system; release to process stack; } \\
\text { cell pressurization and possible rupture producing missiles; } \\
\text { release to occupied areas. }\end{array}$ \\
\hline & $\begin{array}{l}\text { Pressure buildup from all of the following: } \\
\text { VOG vent plugging, loss of temperature } \\
\text { control, pressurization. }\end{array}$ & \\
\hline Rupture of a HLLW storage tank & $\begin{array}{l}\text { Corrosion/erosion; mechanical stress from } \\
\text { overpressurization or loss of cooling; } \\
\text { simultaneous failure of the VOG system } \\
\text { (e.g., by a } \mathrm{H}_{2} \text { explosion from loss of air } \\
\text { sparge). }\end{array}$ & $\begin{array}{l}\text { Release of HLLW to cell floor; airborne HLLW in process } \\
\text { cells; potential for large release to process stack if safety } \\
\text { features fail. } \\
\text { Self-heating liquid, if undrained, could boil away water and } \\
\text { acid; self-heating of resulting solids could melt and damage } \\
\text { containment in addition to producing fumes and aerosols; } \\
\text { decay energy content of } 75,000 \text {-L tank could be } 2.5 \mathrm{E}+6 \mathrm{~W} \text {. }\end{array}$ \\
\hline
\end{tabular}

a Abbreviations: $\mathrm{GPC}=$ general purpose concentrator, $\mathrm{H}_{2}=$ hydrogen, $\mathrm{H}_{2} \mathrm{O}=$ water, $\mathrm{HEPA}=$ high efficiency particulate air, $\mathrm{HLLW}=$ high-level liquid waste, $\mathrm{ILW}=$ intermediate-level waste, $\mathrm{Na}=$ sodium, $\mathrm{NO}_{\mathrm{x}}=$ nitrogen oxides, $\mathrm{O}_{2}=$ oxygen, $\mathrm{Pu}=$ plutonium, $\mathrm{Ru}=$ ruthenium, $\mathrm{U}=$ uranium, and VOG $=$ vessel off-gas.

Source: Adapted from Ayer et al. (1988). 
TABLE C.2 Summary of Fire and Explosion Sources

Potential Fire Sources

\begin{tabular}{|c|c|}
\hline Fire Category & Source \\
\hline General & Vehicle fuel, welding, poor housekeeping. \\
\hline Organic solvent & $\begin{array}{l}\text { Solvent separation columns, solvent recovery tanks, } \\
\text { piping leaks. }\end{array}$ \\
\hline Hydrogen & Radiolysis of process solution. \\
\hline Electrical & Source of fire spread, loss of services. \\
\hline Sodium & Liquid sodium spills. \\
\hline Pyrophoric metal & $\begin{array}{l}\mathrm{U}, \mathrm{Pu} \text { metal production, scrap recovery, loss of inert } \\
\text { atmosphere. }\end{array}$ \\
\hline Cellulose & $\begin{array}{l}\text { Spontaneous combustion of cellulose wipes and nitric } \\
\text { acid. }\end{array}$ \\
\hline \multicolumn{2}{|c|}{ Potential Chemical Processing Explosion Sources } \\
\hline Explosion Category & Source \\
\hline $\mathrm{H}_{2}$ explosion & $\begin{array}{l}\text { Radiolysis, } \mathrm{Na}-\mathrm{H}_{2} \mathrm{O} \text { reaction, fluoride-zirconium reaction } \\
\text { in dissolver or in a reducing furnace. }\end{array}$ \\
\hline Solvent or red oil explosion & Organics in evaporators, concentrators, denitrators. \\
\hline Ion-exchange resin & Fire followed by explosion. \\
\hline Unstable compounds & $\begin{array}{l}\text { Silver-nitrogen-halogen compounds, ammonium nitrate, } \\
\text { mercury compounds. }\end{array}$ \\
\hline \multicolumn{2}{|c|}{ Generic Materials with Explosion Potential } \\
\hline Powdered metals & Picric acid \\
\hline Hydrogen & Explosive gas mixtures \\
\hline Acetylene & Fuels, natural gas \\
\hline Volatile organic liquids & Ozone \\
\hline
\end{tabular}

Source: Adapted from Elder et al. (1986). 


\section{TABLE C.3 Postulated Criticalities in Treatment, Storage, and Disposal Facilities ${ }^{\mathrm{a}}$}

Accident

Criticality in fuel storage facility associated with reprocessing plant

Inadequate poison in dissolvent

Criticality in mechanical processing and feed preparation operations

Criticality in solvent extraction operations

Criticality in productconversion operations
Distortion of fuel storage array; improper storage; fuel assembly dropped into fuel storage array; fissile material on pool water filter.

Chemical makeup error due to incorrect chemical analysis, addition of wrong chemical, or weak poison concentration; failure to add poison at correct volume ratio because of plugging, pump failure, operator error, valving error, or metering malfunction.

Inadequate poison in dissolvent; overconcentration of solution in digester or feed adjustment, followed by precipitation; accumulation of fissile residue in digester or in solids recycle tank; voloxidizer flooding with water; caustic addition to feed; dissolver blockage in addition to loss of poison; accumulation of chopped fuel on undetected stuck-shut voloxidizer and dissolver.

Excessive fissiles in HAW centrifuge bowl; fissile material in unintended location; damage to equipment; plutonium reflux in first, second, or plutonium purification cycle; plutonium precipitation; fissile uranium reflux; fissile material in solvent tank.

Transfer errors in solvent extraction or in product storage systems; overbatched peroxide precipitator; fissile material in $\mathrm{UO}_{3}$ conversion systems; no denaturant U-235 in feed to mixed-oxide system.
Potential Consequences and Considerations
Damaged elements could release shortlived noble gases and iodine; radiation high locally but largely shielded by pool water.

Criticality potential in dissolver (in conjunction with undetected plugging of liquid or solids); digestor (in conjunction with undetected accumulations of solids or with over-concentrated solution); and feed adjustment, accountability, surge, and co-decontamination feed tanks.

Criticality potential in cited tanks; probable release of airborne activity, including noble gases and iodine to cell atmosphere and off-gas system; possible severe equipment damage; high radiation levels in cells; mass and energy probably contained in cell; energy release $11.0 \mathrm{E}+18$ fissions $(3.2 \mathrm{E}+4 \mathrm{~J})$.

High local radiation and releases of gaseous fission products to cell or to VOG.

High local radiation and release of gaseous fission products to cell or VOG system; damage to equipment.

a Abbreviations: $\mathrm{HAW}=$ high-level aqueous waste and $\mathrm{UO}_{3}=$ uranium trioxide.

Source: Adapted from Ayer et al. (1988). 
C- 15

TABLE C.4 Summary of Criticality Accident Fission Yields

\begin{tabular}{lcc}
\hline \multicolumn{1}{c}{ System } & $\begin{array}{c}\text { Initial Burst Yield } \\
\text { (fissions) }\end{array}$ & $\begin{array}{c}\text { Total Yield } \\
\text { (fissions) }\end{array}$ \\
\hline $\begin{array}{l}\text { Solutions under } 100 \mathrm{gal} \\
\text { Solutions over } 100 \mathrm{gal}\end{array}$ & $\begin{array}{c}1.0 \mathrm{E}+17 \\
1.0 \mathrm{E}+18\end{array}$ & $\begin{array}{c}3.0 \mathrm{E}+18 \\
3.0 \mathrm{E}+19\end{array}$ \\
$\begin{array}{l}\text { Liquid powder } \\
\text { a }\end{array}$ & $3.0 \mathrm{E}+20$ & $3.0 \mathrm{E}+20$ \\
Liquid/metal pieces & $3.0 \mathrm{E}+18$ & $1.0 \mathrm{E}+19$ \\
Solid uranium & $3.0 \mathrm{E}+19$ & $3.0 \mathrm{E}+19$ \\
$\begin{array}{l}\text { Solid plutonium } \\
\text { Large storage arrays }\end{array}$ & $1.0 \mathrm{E}+18$ & $1.0 \mathrm{E}+18$ \\
(below prompt critical) & None & $1.0 \mathrm{E}+19$ \\
$\begin{array}{l}\text { Large storage arrays } \\
\text { (above prompt critical) }\end{array}$ & $3.0 \mathrm{E}+22$ & $3.0 \mathrm{E}+22$ \\
\hline
\end{tabular}

a A system where agitation of a powder layer could result in progressively higher reactivity insertion.

b A system of small pieces of fissile metal.

c Large storage arrays in which many pieces of fissile material are present and could conceivably come together.

Source: Adapted from Elder et al. (1986). 
TABLE C.5 Summary of Fires, Explosions, and Incidents of Drum Overpressurization ${ }^{\text {a }}$

\begin{tabular}{|c|c|c|c|c|}
\hline Date & Site $^{\mathrm{b}}$ & Event & Probable Cause & Current Regulation $^{c}$ \\
\hline $6 / 1 / 70$ & INEL & $\begin{array}{l}\text { Burial ground fire in } \\
55 \text {-gal drum }\end{array}$ & Pyrophorics & Restriction on pyrophorics \\
\hline $12 / 3 / 76$ & ANL-E & $\begin{array}{l}\text { Explosion of 55-gal } \\
\text { drum }\end{array}$ & Flammable VOCs & $\begin{array}{l}\text { Vents, restriction on flammable } \\
\text { VOCs }\end{array}$ \\
\hline $8 / 17 / 78$ & Hanford & $\begin{array}{l}\text { Distortion of 55-gal } \\
\text { drums }\end{array}$ & $\begin{array}{l}\text { Reaction between } \\
\text { nitric acid and } \\
\text { organic compounds }\end{array}$ & $\begin{array}{l}\text { Vents, restriction on free liquids } \\
\text { and incompatible chemicals }\end{array}$ \\
\hline $3 / 13 / 82$ & Hanford & $\begin{array}{l}\text { Uranium-concrete } \\
\text { billet fire }\end{array}$ & Pyrophorics & Restrictions on pyrophorics \\
\hline $6 / 30 / 83$ & LLNL & $\begin{array}{l}\text { Fire in bags of dry } \\
\text { waste }\end{array}$ & $\begin{array}{l}\text { Pyrophorics, } \\
\text { flammable VOCs }\end{array}$ & $\begin{array}{l}\text { Restrictions on pyrophorics, } \\
\text { flammable VOCs }\end{array}$ \\
\hline $4 / 20 / 84$ & INEL & $\begin{array}{l}\text { Fire in a radioactive } \\
\text { waste container }\end{array}$ & $\begin{array}{l}\text { Spontaneous } \\
\text { combustion of nitric } \\
\text { acid }\end{array}$ & $\begin{array}{l}\text { Restrictions on corrosives, } \\
\text { chemical incompatibility }\end{array}$ \\
\hline $7 / 20 / 85$ & $\begin{array}{l}\text { ORNL at } \\
\mathrm{Y}-12\end{array}$ & $\begin{array}{l}\text { Fire involving } \\
\text { thorium in a scrapped } \\
\text { glove box }\end{array}$ & Pyrophorics & Restrictions on pyrophorics \\
\hline 9/19/85 & RFETS & $\begin{array}{l}\text { Pressurization of } \\
\text { containers and release } \\
\text { of plutonium }\end{array}$ & $\begin{array}{l}\text { Plutonium fines, } \\
\text { calcium, moisture }\end{array}$ & $\begin{array}{l}\text { Restriction on chemical } \\
\text { incompatibility, vents }\end{array}$ \\
\hline
\end{tabular}

a Source: adapted from M. Silva (1992).

b Abbreviations: ANL-E = Argonne National Laboratory-East, INEL = Idaho National Engineering Laboratory, LLNL = Lawrence Livermore National Laboratory, ORNL = Oak Ridge National Laboratory, RFETS = Rocky Flats Environmental Technology Site, and VOC = volatile organic compound.

c Source: DOE (1991). 
Ensco, El Dorado, Arkansas. This explosion occurred around September 1991 in the waste heat recovery boiler, not the incinerator. This unit was fairly old; excessive pressure had built up because of structure failure. As a result, the unit exploded. No extensive damage was done to the incinerator itself, and no injuries or releases resulted. The particular unit was shut down, and the rest of the plant was back up and operating under normal conditions within one week.

CWM Chemical Systems Inc., Chicago Incinerator (previously SCA) Chicago, Illinois. This explosion occurred in February 1991 in a drum inserted in the rotary kiln incinerator. The drum contained a lab pack that the company failed to identify, but which was found to be an explosive in its pure form called tetra-zole. The explosion caused a bulge in the kiln, and one of the plates on the back of the kiln popped off as a result of the pressure buildup. No one was hurt as a result of the explosion; however, a site worker complained about slight dizziness. There was no indication of any toxic releases into the neighboring areas. The regional EPA required the plant to replace several parts of the unit before restarting operations. Additional fire prevention and safety equipment were also required.

Thermalkem, Roebuck, South Carolina. This explosion occurred in July 1987 as a result of a $10 \%$ nitroglycerine/ $90 \%$ lactose material that had been incorrectly identified by the generator and was found to be an explosive. This material triggered two explosions within the incinerator and one partially outside the incinerator. No environmental releases were reported from the fires, although two employees complained of ringing of the ears. Following the incident, a more rigorous waste approval procedure was instituted.

Another explosion occurred in March 1991 in the tubes of the boiler operating on natural gas/fuel oil. The tubes in the boiler failed to operate, and steam was introduced into the flame. This moved the package boiler about $15 \mathrm{~m}(50 \mathrm{ft})$, resulting in extensive damage to the boiler and the boiler house and severance of the steam and fuel oil lines. The natural gas lines were immediately shut off, and no hazardous waste was involved in the incident. No one was hurt as a result, and a new boiler was in operation in three days.

U.S. Department of Energy, Oak Ridge, Tennessee. In June 1989, the induced draft fan for the incinerator failed. The failure breached the fan housing, and debris was found as far away as $113 \mathrm{~m}$ ( $370 \mathrm{ft}$ ). Flying debris damaged the stack. There were no injuries and no detectable off-site release of toxic material as a result of the incident.

DOW Chemical Company, Midland, Michigan. In January 1992, a natural gas explosion resulted from blockage of a feed line to the incinerator. In the process of trying to clear the line, a drill bit broke off in the nozzle. The nozzle was removed improperly, and as a result, natural gas leaked out causing an explosion. This incident occurred during normal operations in a room at the front of the incinerator. One worker sustained first and second degree burns to the face and hands, while another worker complained of ringing in the ears. There is no evidence that any hazardous 
waste was released, and there was no natural resource damage. Following the incident, improvements were made in the gas sensing equipment, and steps to ensure adherence to proper procedures for unplugging feed lines were ensured.

TWI, Sauget, Illinois. Several explosions occurred at this facility. The first occurred when a large volume of ash accumulated and fell into the unit's quench tank, causing a steam explosion in the incinerator. No date was given for this incident.

The second explosion occurred in January 1991 when sodium azide, the explosive found in automobile air bags, was incinerated. The ash from this waste was placed in a dumpster; a few hours later, the ash exploded. No injuries or environmental impacts from these two incidents were reported.

A third explosion occurred in February 1991 as a result of a worker using a pole to dislodge molten slag that partly blocked the exit from an incinerator during operation. The slag fell into standing water below and caused a steam explosion that severely burned the worker. Vaporized hazardous waste was released.

Monsanto Company, Muscatine, Iowa. In July, 1992, the incinerator at the Monsanto facility was shut down while the facility's process unit was being repaired. When the incinerator was brought back on line, there was a loss of quench water flow that caused the temperature in the scrubber to rise to $108^{\circ} \mathrm{C}\left(2,000^{\circ} \mathrm{F}\right)$. Consequently, the unit's scrubber caught fire. However, only natural gas was present in the incinerator at the time of the incident; no hazardous waste was in the incinerator. As a result, there were no releases of hazardous waste to the environment and no injuries were reported. Since then, the facility has updated its controls to better identify losses of water pressure.

Aptus, Coffeyville, Kansas. This incident occurred in the fall of 1990 during normal operations. Waste with an exceedingly high British thermal unit (Btu) level was introduced to the incinerator. Gas accumulated in the electrostatic precipitator and was set off by a spark. The explosion was completely contained within the unit. The unit's air pollution control devices were damaged internally, and the unit was out of operation for about one week. No injuries or natural resources damage was reported. Since this incident, tighter controls of the waste stream have been instituted.

\section{C.3 REFERENCES}

Ayer, J.E., et al., 1988, Nuclear Fuel Cycle Accident Analysis Handbook, NUREG-1320, U.S. Nuclear Regulatory Commission, Washington, D.C., May. 
Elder, J., et al., 1986, A Guide to Radiological Accident Considerations for Siting and Design of DOE Nonreactor Nuclear Facilities, LA-10294-MS/UC-41, Los Alamos National Laboratory, Los Alamos, N.M.

Hlustick, D., 1994, personal communication from Hlustick (U.S. Environmental Protection Agency, Washington, D.C.) to C. Herzenberg (Argonne National Laboratory, Argonne, Ill.), April 14.

Silva, M., 1992, "An Assessment of the Flammability and Explosion Potential of Defense Transuranic Waste," Nuclear Safety 33(2).

U.S. Department of Energy, 1991, Position Paper on Flammability Concerns Associated with TRU Waste Destined for WIPP, DOE/WIPP-91-018, Washington, D.C. 
C. 20 
APPENDIX D:

REFERENCE DATA ON RESPIRABLE AIRBORNE RELEASE FRACTIONS AND LEAK PATH FACTORS 
D-2 


\section{CONTENTS}

NOTATION

D. 1 RESPIRABLE AIRBORNE RELEASE FRACTION $\ldots \ldots \ldots \ldots \ldots \ldots \ldots \ldots$ D-9

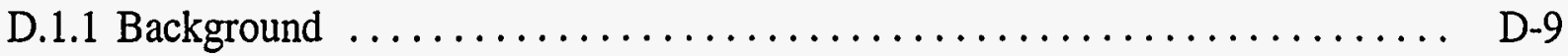

D.1.2 Airborne Release Fractions, Respirable Fractions, and Respirable Airborne Release Fractions . . . . . . . . . . . . D -10

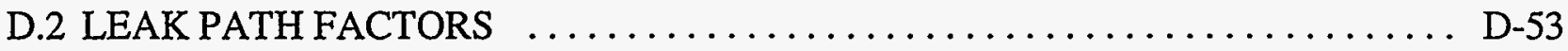

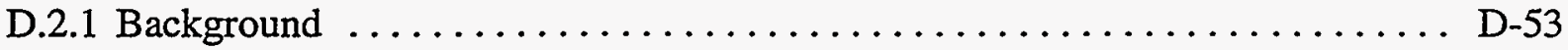

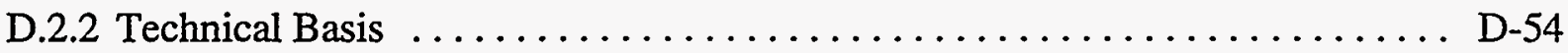

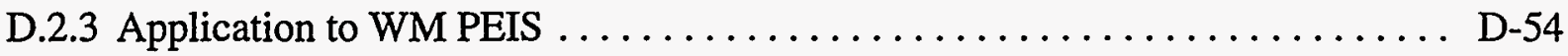

D.3 MAPPING OF WM PEIS TREATABILITY CATEGORIES WITH

PHYSICAL FORM CATEGORIES FOR ACCIDENT ANALYSIS $\ldots \ldots \ldots \ldots \ldots$ D-55

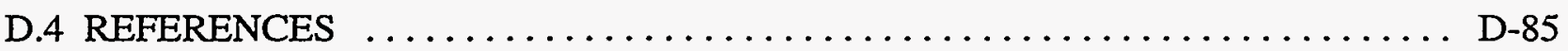

\section{TABLES}

D.1 Summary of Release Fraction Parameters Abstracted from

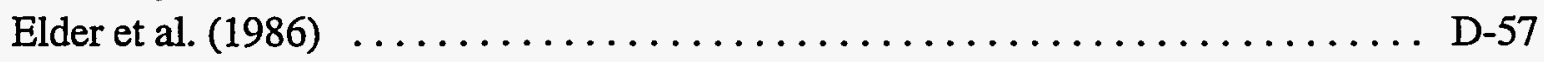

D.2 WM PEIS Waste RARFs: Physical Type or Subcategory versus Stress ........ D-58

D.3 WM PEIS Waste RARFs for LLW, LLMW, and TRUW Storage and Handling $\ldots \ldots \ldots \ldots \ldots \ldots \ldots \ldots \ldots \ldots \ldots \ldots \ldots \ldots$

D.4 WM PEIS Waste RARFs for LLW Processing by Incineration $\ldots \ldots \ldots \ldots \ldots$ D-63

D.5 WM PEIS Waste RARFs for HLW Processing and Storage $\ldots \ldots \ldots \ldots \ldots$ D-68

D.6 Threshold Values of Differential Pressure Required to Structurally

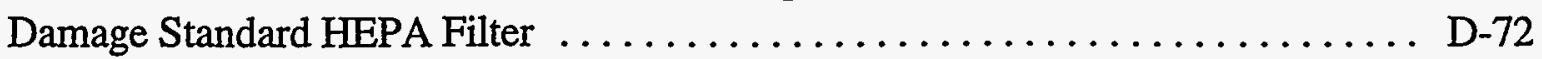

D.7 Effects of Environmental Filter Parameters on Aerosol Penetration

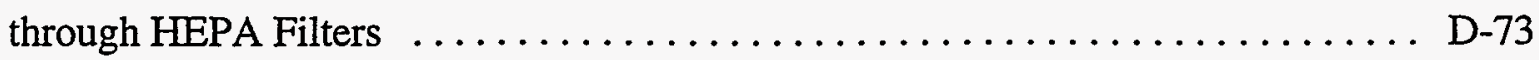




\section{TABLES (Cont.)}

D.8 Summary of Reduction and Removal Factors Abstracted from

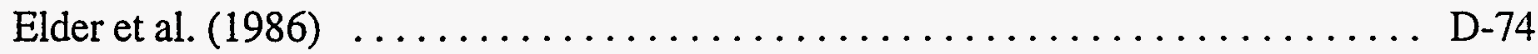

D.9 Mapping of WM PEIS Treatability Categories for LLW with Accident Analysis Physical Forms . ........................... D-75

D.10 Mapping of WM PEIS Treatability Categories for TRUW with Accident

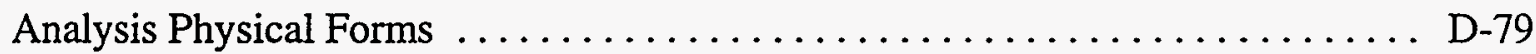

D.11 Mapping of WM PEIS Treatability Categories for HLW with Accident

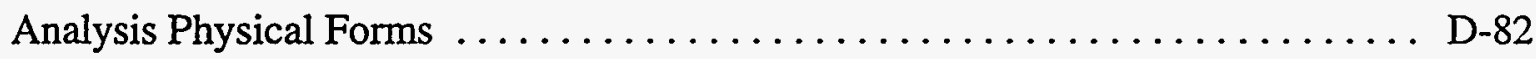




\section{NOTATION}

The following is a list of the acronyms, initialisms, and abbreviations (including elements and compounds and units of measure) that appear in this appendix.

\section{ACRONYMS, INITIALISMS, AND ABBREVIATIONS}

AED aerodynamic equivalent diameter

ARF airborne release fraction

DAW dry active waste

DOE U.S. Department of Energy

EM Environmental Management

HEPA high-efficiency particulate air (filter)

HLW high-level waste

LLMW low-level mixed waste

LLW low-level waste

LPF leak path factor

NRC U.S. Nuclear Regulatory Commission

PEIS Programmatic Environmental Impact Statement

RARF respirable airborne release fraction

RF respirable fraction

SAIC Science Applications International Corp.

SNF spent nuclear fuel

SpG specific gravity

SRS Savannah River Site

TRUW transuranic waste

WM Waste Management

\section{ELEMENTS AND COMPOUNDS}

$\begin{array}{ll}\mathrm{Ag} & \text { silver } \\ \mathrm{CaO} & \text { calcium oxide } \\ \mathrm{CH}_{3} \mathrm{I} & \text { methyl iodide } \\ \mathrm{CO}_{2} & \text { carbon dioxide } \\ \mathrm{Cs} & \text { cesium } \\ \mathrm{CsI} & \text { cesium iodide } \\ { }^{3} \mathrm{H} & \text { tritium } \\ \mathrm{HF} & \text { hydrogen fluoride }\end{array}$




$\begin{array}{ll}{ }^{3} \mathrm{H}_{2} \mathrm{O} & \text { tritiated water } \\ \mathrm{HNO}_{3} & \text { nitric acid } \\ \mathrm{I}_{2} & \text { elemental iodine } \\ \mathrm{Kr} & \text { krypton } \\ \mathrm{Pu} & \text { plutonium } \\ \mathrm{PuF}_{4} & \text { plutonium fluoride } \\ \mathrm{Rb} & \text { rubidium } \\ \mathrm{Ru} & \text { ruthenium } \\ \mathrm{RuO}_{4} & \text { ruthenium tetroxide } \\ \mathrm{Se} & \text { selenium } \\ \mathrm{Tc} & \text { technetium } \\ \mathrm{Te} & \text { tellurium } \\ \mathrm{TiO}_{2} & \text { titanium dioxide } \\ \mathrm{TNT}^{-} & \text {trinitrotoluene } \\ \mathrm{U} & \text { uranium } \\ \mathrm{UO}_{2} & \text { uranium dioxide }\end{array}$

UNITS OF MEASURE

$\begin{array}{ll}{ }^{\circ} \mathrm{C} & \text { degree(s) Celsius } \\ \mathrm{cm} & \text { centimeter(s) } \\ \mathrm{cm}^{2} & \text { square centimeter(s) } \\ \mathrm{cm}^{3} & \text { cubic centimeter(s) } \\ \mathrm{cp} & \text { centipoise } \\ \mathrm{dp} & \text { differential pressure } \\ { }^{\circ} \mathrm{F} & \text { degree(s) Fahrenheit } \\ \mathrm{ft} & \text { foot (feet) } \\ \mathrm{ft}^{2} & \text { square foot (feet) } \\ \mathrm{g} & \text { gram(s) } \\ \mathrm{gal} & \text { gallon(s) } \\ \mathrm{h} & \text { hour(s); fall height (cm) } \\ \text { in. } & \text { inch(es) } \\ \mathrm{J} & \text { joule(s) } \\ \mathrm{kg} & \text { kilogram(s) } \\ \mathrm{L} & \text { liter(s) } \\ \mathrm{lb} & \text { pound(s) } \\ \mathrm{lb}_{\mathrm{m}} & \text { pound(s) mass } \\ \mathrm{m} & \text { meter(s) } \\ \mathrm{m}^{2} & \text { square meter(s) } \\ \mathrm{m}^{3} & \text { cubic meter(s) }\end{array}$




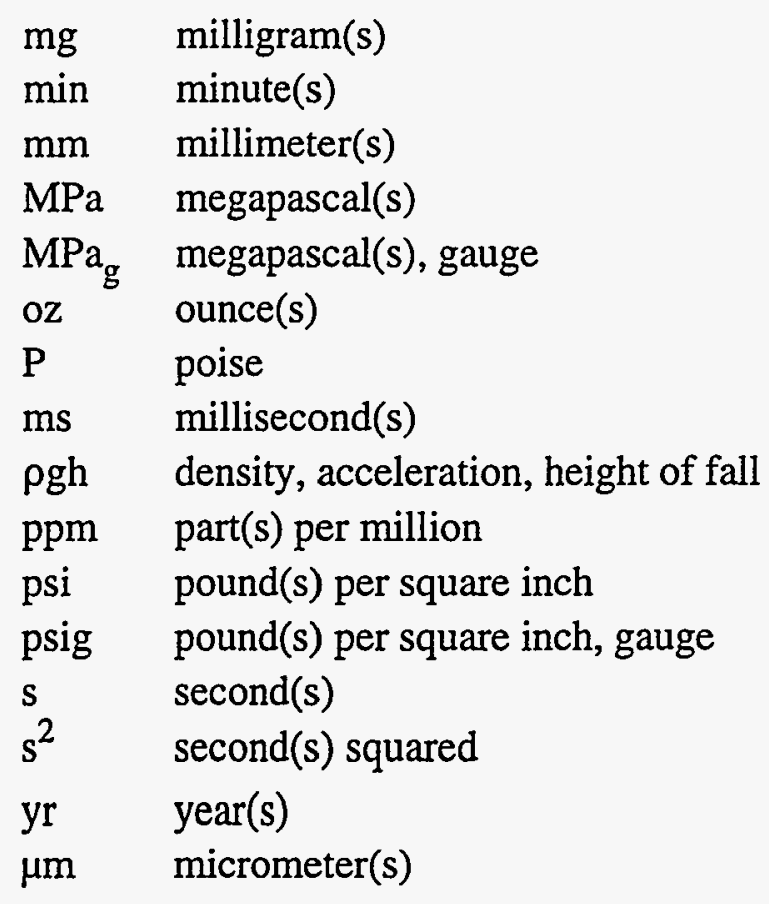


D-8

, 


\section{APPENDIX D:}

\section{REFERENCE DATA ON RESPIRABLE AIRBORNE RELEASE FRACTIONS AND LEAK PATH FACTORS}

Respirable airborne release fractions (RARFs) and leak path factors (LPFs) are two of the four components used to estimate the source term from inadvertent events during handling, storage, and processing of waste. The RARF and LPF represent the fraction of the materials of concern (in this analysis, radionuclides) that enters the ambient environment from that event. The other components (material at risk and damage ratios) are covered in Section 2.4 of this report. The RARF is a combination of the airborne release fraction (ARF - the fraction of the material of concern made airborne at the point of origin) and the respirable fraction ( $R F$ - the fraction of the ARF that is in the respirable size range ${ }^{1}$ ). The LPF is the fraction of the released material that will travel from the point of origin to the equipment-atmosphere interface for the facility or enclosure or container and be released to the ambient environment; the LPF includes the reduction of the airborne materials by functional air-treatment attenuation devices (e.g., filters) and by other factors (i.e., deposition within the ventilation ducts) for the physical or chemical form. This appendix presents the technical basis for the RARFs and LPFs used in these analyses.

\section{D.1 RESPIRABLE AIRBORNE RELEASE FRACTION}

\section{D.1.1 Background}

In prior years, compilations of release fractions (Elder et al. 1986; Walker 1987) have been documented for varying purposes. Walker's compilation (1987) presents the release fractions derived from experimental studies for both fuel-cycle and reactor accident evaluations available at that time. Elder et al. (1986) presented very conservative estimates of release fractions for evaluating events of unknown magnitude that could involve the entire inventory of the facility; these estimates were used for evaluating the proposed facility's conformance to siting criteria. The release fractions derived from Elder et al. (1986) are shown in Table D.1. (To aid the reader, all tables are presented after the text of this appendix.)

1 The respirable size range is commonly assumed to be that fraction of particulate material that has an aerodynamic equivalent diameter (AED) of $10 \mu \mathrm{m}$ or less. The AED is the size of a sphere of material with a density of $1 \mathrm{~g} / \mathrm{cm}^{3}$ that shows the same aerodynamic behavior (terminal velocity of the sphere) as the particle. All materials in the gaseous phase are assumed to be transportable and respirable; $a \mathrm{RF}$ of 1.0 is assumed for the purposes of these analyses. Some materials in the gaseous phase (i.e., vapors) may condense when they encounter varying physical and chemical conditions. 
More recently, large numbers of experiments have been performed to ascertain the release fractions from both industrial and reactor accident stresses. The most recent experimental data on ARFs and RFs for accident stress for nuclear materials can be found in a U.S. Department of Energy (DOE) report (DOE [1994]). These data were used as the primary basis for the RARFs used in these analyses. Other recent data and estimations of reactor or spent nuclear fuel (SNF) accident release fractions (Restrepo 1992; Teleyarkhan 1992; Soffer 1993) can also be found in DOE (1994).

The values presented in this appendix should be applied cautiously. The characteristics of the materials made airborne are the result of interactions between two complex physicochemical processes: the initiating event and the responses of the materials involved. Both the stress and the level of stress for the specific scenario must be ascertained to ensure that the appropriate RARF is selected. The experimental bases only cover a range of parameters and may not cover the level of the specific stress estimated for the postulated release. For generic systems, the bounding event for the generic process or facility situation is chosen by using limiting factors. To generate a reasonable bounding source term, factors describing the various parameters are chosen that reflect the lack of definition for these attributes; the less precise the definition, the greater the conservatism.

\section{D.1.2 Airborne Release Fractions, Respirable Fractions, and Respirable Airborne Release Fractions}

Most radioactive materials are separated from the ambient environment by a barrier (e.g., a structure; enclosures such as glove boxes or hot cells; equipment such as tanks or piping; containers ranging from large casks to sheet-metal cans, including 208-L [55-gal] sheet-metal drums). Often the materials released are confined by many barriers, such as a building or gaseouseffluent treatment system, including filtration devices for specific materials (e.g., high-efficiency particulate air [HEPA] filters; fibrous filters of various materials, such as bag or cartridge-type filters; impregnated activated charcoal or silver-substituted zeolite for iodine). Most of the materials are at rest or, if in process, are controlled to prevent release.

The data and assumptions for the response of the various waste form subcategories to the stresses postulated are shown in Table D.2 and discussed in the following sections.

\section{D.1.2.1 Technical Basis}

D.1.2.1.1 Noncondensable Gases. No direct data were found on the airborne release of noncondensable gases on loss of containment. On the basis of the established physical behavior of the material, the assumption is that all noncondensable gases and all materials in the gaseous state are made airborne on loss of containment. Noncondensable gases produced by nuclear fissions in 
a nonporous matrix (SNF and production targets) are covered under the appropriate matrices. The RARF is derived on the assumption that all radionuclides in the form of noncondensable gases are released on loss of containment.

D.1.2.1.2 Vapors. On generation, vapors in the gaseous state are assumed to behave as a gas and become airborne. Materials volatilized by elevated temperatures (e.g., water vapor or metal fume) may condense into particulate materials on cooling. The particle size of the condensed phase is a function of the cooling conditions, among other factors (local concentration, air velocity, etc.). Furthermore, chemically active vapors (e.g., iodine) may react with other materials encountered (in the air or surfaces) or attach to preexisting airborne particles.

The RARF was derived on the basis of the following assumptions:

- For all tritiated water $\left({ }^{3} \mathrm{H}_{2} \mathrm{O}\right)$ or tritiated hydrides, all material converted to the vapor form is considered released on loss of containment. Fires and deflagrations constitute the primary concern because these situations may possess the requisite conditions to breach containment (pressure) and to convert the water or hydride to vapor (heat).

- All iodine present is converted to the vapor form in the presence of oxidizing, acid conditions. The primary concern is with fires that involve iodine in nitric acid solutions that may pressurize containment and convert the iodine $(I)$ in solution to molecular iodine or gaseous forms of iodine compounds.

- For ruthenium (Ru), strong oxidizing conditions are required, and not all of the $\mathrm{Ru}$ converts to ruthenium tetroxide $\left(\mathrm{RuO}_{4}\right)$, which is the volatile compound. Under fire conditions (fires involving Ru compounds in a strong nitric acid solution), some fraction may be converted. Conservative estimates of $1 \mathrm{E}-02$ for a small fire and 1E-01 for a large fire are assumed.

D.1.2.1.3 Liquids. Three types of liquids are commonly encountered in the storage, handling, and processing of Environmental Management (EM) waste. The three materials are (1) aqueous solutions and slurries, (2) organic liquids and slurries, and (3) viscous liquids such as molten high-level waste ( $\mathrm{HLW}$ ). The responses of the first two categories to the various postulated stresses are discussed subsequently. Two subcategories are described for organic combustible liquids (organic combustible solutions and slurries), and three subcategories are covered for aqueous liquids (aqueous solutions, aqueous slurries, and superheated solutions). Viscous liquids will be covered later, along with vitrified HLW: 
Organic, Combustible Liquids Organic, Combustible Solutions. Only data on the airborne release of radionuclides during the combustion of organic combustible liquids were found. Other RARF values were inferred from the behavior of aqueous liquid in response to the following stresses:

- Free-Fall Spill. On the basis of the configuration of equipment in most facilities involving waste in solution form, the assumption was that a free-fall of $3 \mathrm{~m}(10 \mathrm{ft})$ is bounding. The bounding value for the $A R F$ was $2 \mathrm{E}-04$, with a $R F$ of 0.7 , resulting in a RARF of $1 E-04$. The value was rounded upward to $2 \mathrm{E}-04$ for conservatism.

- Crush-Impact. No direct experimental data exist on the fragmentation and suspension of an organic combustible solution due to the impact of debris or foreign objects. The assumption was that the RARF will be bounded by the RARF for the free-fall spill discussed previously; a RARF of $2 \mathrm{E}-04$ was assumed.

- Overpressurization or Breach by Mechanical Action. This subcategory represents the breach of a container by mechanical action; only minor pressurization incidental to the breaching process was assumed. The breach was assumed to occur at a point low on the sidewall to allow most of the liquid to be sprayed from the breach by the pressure of the water column above the liquid. Data for the size distribution of spray generated by commercial spray nozzles designed to generate a fine spray with an orifice of $3.25 \mathrm{~mm}(0.128$-in.) at a pressure of $1.38 \mathrm{MPa}(200 \mathrm{psig})$ resulted in a RF of $1 \mathrm{E}-04$. The value certainly bounds most punctures and breaches due to mechanical action. Very long, narrow (on the order of a $0.1-\mathrm{mm}$ span) punctures at high pressure may generate a larger fraction of particles in the respirable size range.

- Small Fire. The assumption was that a small isolated pool of organic combustible solution is ignited and burns to a small residual puddle of viscous liquid that would not allow the combustion process to go to completion. The combustion does not generate high turbulence over the burning liquid. All ${ }^{3} \mathrm{H}_{2} \mathrm{O}$ dissolved in the liquid and the hydride compounds are released during burning. The ARF for nonvolatile solutes during quiescent burning was $1 E-02$, with no measured RF. A conservative value of 1.0 was assumed for the RF. The resultant RARF was $1 E-02$.

- Large Fire. The assumption was that a large pool of organic combustible solution is ignited and burns. Because of the physical configuration and the 
presence of metal (a heat-conducting material), the fire is vigorous, and surface turbulence is high. The liquid is all consumed (burns to dryness). All of the tritiated materials are released, as stated previously. The ARF for nonvolatile solutes for a vigorous fire that burns to dryness was $1 \mathrm{E}-01$, with no measured RF. A conservative RF of 1.0 was assumed. The resultant RARF was $1 \mathrm{E}-01$.

- Explosive Release: Blast Effects. The assumption was that a volume of flammable gas mixture deflagrates above the organic, combustible liquid and both disturbs the surface and ignites the liquid. The RARF determined for a large fire (1E-01) was selected for this subcategory.

- Explosive Release: Shock Effects. The assumption was that a detonation (commonly the only source of significant shock effects) occurs in or on the surface of the organic combustible solution. The Steindler and Seefeldt correlation given in DOE (1994) is $1 \mathrm{~g}$ of liquid mass per gram of trinitrotoluene (TNT) equivalence calculated for the detonation. Detonation occurs in microseconds to milliseconds and, because of the rapidity of the reaction, is not assumed to ignite the liquid. The mass of airborne liquid is not the mass of the material of concern released. To determine the mass of the material of concern made airborne, the mass of liquid airborne must be multiplied by the concentration of the material of concern in the liquid (with the assumption that no material of concern is converted into a volatile form).

- Venting of the Free Volume over the Liquid at Pressures Ranging from Less Than $0.345 \mathrm{MPa}_{\mathrm{g}}(50 \mathrm{psig})$ to $3.45 \mathrm{MPa}_{\mathrm{g}}(500 \mathrm{psig}$ ). The assumption was that the products of some conditions (e.g., a leak of high-pressure gas into the container or increased vapor pressure due to the heating of the liquid to less than the temperature needed to form a "flashing spray") in a closed vessel holding the organic combustible solutions breach the vessel at a point above the liquid level. The rapid depressurization causes the rapid release of the gas dissolved in the liquid, resulting in a condition similar to boiling of the liquid (bubbles breaking at the surface). The ARF for the depressurization of liquid was $2 \mathrm{E}-03$, with a RF of 0.3 , resulting in a RARF of $6 \mathrm{E}-04$. This RARF does not cover the churn-turbulent or chaotic regimes of bubbling.

Organic-Combustible Slurries. This subcategory of waste is assumed to be composed of insoluble nonreactive particles in an organic combustible liquid. No experimental data on the airborne release for the impact of the various stresses covered here were found. The response of the organic combustible slurries is assumed to be similar to that of aqueous slurries under accident 
stress, and the data for that subcategory were applied. The assumptions for the stresses were as follows:

- Free-Fall Spill. On the basis of the configuration of equipment in most facilities involving waste in this form, the assumption was that a free-fall of $3 \mathrm{~m}(10 \mathrm{ft})$ or less is bounding. The measured ARF for the free-fall spill of aqueous slurries of $3 \mathrm{~m}$ ( $10 \mathrm{ft}$ ) or less was $5 \mathrm{E}-05$, with a $R F$ of 0.8 , resulting in a RARF of $4 \mathrm{E}-05$.

- Crush-Impact. The impact of a foreign object is bounded by the free-fall of the slurry; the same RARF of 4E-05 was applied.

- Overpressurization/Breach by Mechanical Action. The assumption was that organic combustible slurries behave like the organic combustible solutions described previously when vented from a breach under the liquid level at a point near the bottom of the sidewall of the container. The RARF of $1 E-04$ was applied.

- Small Fires. The maximum ARF for nonreactive particles during the burning of a cellulosic substrate was $1 \mathrm{E}-02$, with no measured $R F$. A lesser value was measured during the heating of a nonreactive powder $(6 \mathrm{E}-05)$ and reactive powders (1E-05 for plutonium oxalate and $1 \mathrm{E}-06$ for plutonium fluoride $\left.\left[\mathrm{PuF}_{4}\right]\right)$. Because of the lack of knowledge of the specific compounds comprising the insoluble particles that could be found in the slurry, a bounding RARF of $1 \mathrm{E}-02$ was assigned.

- Large Fire. The size of the fire may have an impact on the burning rate and characteristics of the fires, but the behavior of the insoluble particles that tend to collect at the bottom of the liquid would not be seriously different from that proposed previously. Because of the conservative nature of the assumptions for the small fire, the same RARF (1E-02) was assigned for a large fire.

- Explosive Release: Blast Effects. Deflagration generates surface turbulence, entrains a small amount of liquid (<7E-05), and ignites the airborne material, resulting in conditions similar to those encountered in a large fire that burns to dryness. The RARF selected for the large fire (1E-01) was assigned for this subcategory.

- Explosive Reaction: Shock Effects. A detonation in or on the surface of the slurry would result in the same response as described previously for the organic combustible solution. The RARF assigned was $1 \mathrm{~g}$ of slurry airborne 
per gram of TNT equivalence calculated for the detonation. To determine the mass of the insoluble particles made airborne, multiply the mass of the slurry by the concentration of the insoluble particles in the slurry. The assumption was that the reaction is too rapid to ignite the organic combustible liquid.

- Venting of the Free Volume over the Liquid at Pressures Ranging from Less Than $0.345 \mathrm{MPa}_{\mathrm{g}}\left(50 \mathrm{psig}\right.$ ) to $3.45 \mathrm{MPa}_{\mathrm{g}}(500 \mathrm{psig}$ ). Insoluble particles are uniformly mixed in the organic slurry by the generation of bubbles in the liquid. The slurry also behaves like the organic combustible liquid described previously for this stress. A RARF of $6 \mathrm{E}-04$ was assigned.

Aqueous Liquids, Aqueous Solutions. This subcategory encompasses solutes soluble in water. For RARFs that represent a fraction of the material aerosolized, the fraction of the material of concern aerosolized would be the same, assuming a uniform concentration. Experimental data for most stresses were available and were applied. The assumptions for the stresses were as follows:

- Free-Fall Spill. On the basis of (1) the configuration of equipment in most facilities involving this form of waste, (2) the fact that the liquid must be released from the bottom or from the bottom of the sidewall of a vessel for essentially all of the liquid to leak from a container, and (3) the angle that the container must assume to pour the liquid from the top of a tilted vessel, the

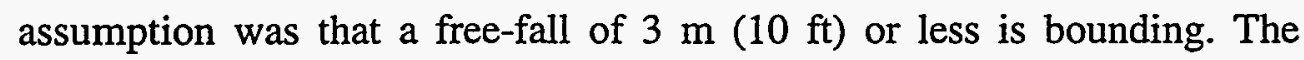
measured ARF for the free-fall spill of an aqueous solution was $2 \mathrm{E}-04$, with a $R F$ of 0.7 , resulting in a RARF of $1 E-04$. The value was rounded upward for conservatism, and a RARF of $2 \mathrm{E}-04$ was assigned.

- Crush-Impact. As with the previous subcategories, the assumption was that the impact or crushing by a foreign body results in behavior similar to but bounded by the free-fall of the aqueous solution. A RARF of $2 \mathrm{E}-04$ was assigned.

- Overpressurization/Breach by Mechanical Action. This scenario involves low container pressures because the venting is by mechanical actions such as puncture. As with the organic combustible liquids, spray formation was presumed to be the mechanism for aerosolization of the liquid. The RARF assigned was $1 \mathrm{E}-04$.

- Small Fire. A small fire heats the aqueous solution, resulting in boiling of the liquid (simply heating the liquid with no bubble breakup at the surface results in much less aerosolization: ARF of 3E-05). The measured ARF for boiling 
was $2 \mathrm{E}-03$, with no measured RF. A conservative RF of 1.0 was assumed, with a resultant RARF of $2 \mathrm{E}-03$. This value is not applicable to the churnturbulent or chaotic regimes of liquid boiling that may result in a greater fraction breaking away from the liquid surface (and possibly eructation - the violent ejection of liquid from a container) but does not necessarily form a greater RF.

- Large Fire. A large fire results in a greater release rate but does not result in a larger RARF. A RARF of $2 E-03$ was assigned.

- Explosive Release: Blast Effects. Aerosolization is by the impact of shear stress upon the surface (accelerated airflow across the liquid surface resulting in surface turbulence and droplet formation). The maximum measured airborne release rate of $9 \mathrm{E}-05 / \mathrm{h}$ was rounded to $1 \mathrm{E}-04$, although assuming that the passage of the pressure impulse resulting from a deflagration (completed in milliseconds to seconds) over the surface of the aqueous solution requires one hour is highly conservative.

- Explosive Release: Shock Effects. The conservative interpretation of the correlation for detonation in or on the surface of liquids and metals was assigned ( $1 \mathrm{~g}$ of droplets in the respirable size range for each gram of TNT equivalence calculated). The fraction of the solute aerosolized depends on its concentration in the liquid.

- Venting of the Free Volume above the Liquid at Pressures Ranging from Less Than $0.345 \mathrm{MPa}_{\mathrm{g}}(50 \mathrm{psig})$ to $3.45 \mathrm{MPa}_{\mathrm{g}}(500 \mathrm{psig}$ ). The process described previously for this stress for organic combustible solutions is also postulated here. The bounding measured ARF was $2 \mathrm{E}-03$, with a RF of 0.3. The RARF was $6 \mathrm{E}-04$.

Aqueous Slurries. The only experimental data for this subcategory were for free-fall spill. All other ressponses were assumed to be the same as for aqueous solutions. For a release value given as a fraction of the mass, the mass of the material of concern was determined by multiplying the mass released by the stress times the concentration of the material of concern in the water. This procedure assumes a uniform concentration of insoluble particles in the water. This assumption can be questionable for slurries under many situations where the release occurs primarily from the upper surface of a volume. Nonetheless, for these analyses, where precise definitions were not possible, 
assuming uniform concentration is conservative inasmuch as the particles tend to settle to the lower levels of the slurry in most cases. The assumptions for the stresses were as follows:

- Free-Fall Spills. The bounding ARF was 5E-05, with a RF of 0.8, resulting in a RARF of $4 \mathrm{E}-05$.

- Crush-Impact. The impact of or crushing by a foreign body was bounded by the free-fall aerosolization, and a RARF of $4 \mathrm{E}-5$ was assigned.

- Overpressurization/Breach by Mechanical Action. The same assumptions applied to aqueous solutions apply here, and the RARF of $1 E-04$ for sprays was assigned.

- Small Fire. Although some bases exist for applying the nonboiling aerosolization RARF (3E-05) in these situations, the temperature or boiling of the aqueous liquid depends on many factors, such as the relative size of the fire, the volume of liquid, the distance from the flame to the liquid, and the heat transfer through the vessel wall. On these bases, the assumption was that the boiling RARF of $2 \mathrm{E}-03$ was applicable.

- Large Fire. The RARF of 2E-03 for boiling aqueous liquids was assigned for the stress.

- Explosive Release: Blast Effects. As for other liquids, the aerosolization due to the shear stress induced on the liquid surface by the accelerated air velocity generated by the deflagration was assumed to apply here. The RARF for the stress (1E-04) was assigned to this stress.

- Explosive Release: Shock Effects. As for other liquids, the very conservative RARF of $1 \mathrm{~g}$ of respirable droplets for each gram of TNT equivalence calculated for the detonation was applied. The mass of the solute must be calculated.

- Venting of the Free Volume over the Liquid at Pressures Ranging from Less than $0.345 \mathrm{MPa}_{\mathrm{g}}$ (50 psig) to $3.45 \mathrm{MPa} \mathrm{a}_{\mathrm{g}}(500 \mathrm{psig}$ ). The RARF (6E-04) for aqueous solutions was assigned for this stress. 
Superheated Liquids. For these analyses, it was assumed that any aqueous liquid heated to a superheat ${ }^{1}$ temperature of $50^{\circ} \mathrm{C}\left(122^{\circ} \mathrm{F}\right)$ and greater will form a flashing spray (the bulk formation of vapor internally in the liquid results in a high degree of fragmentation and is dependent on the superheat temperature). For aqueous liquids with a superheat of $50-100^{\circ} \mathrm{C}\left(122-212^{\circ} \mathrm{F}\right)$, the maximum measured $A R F$ was $9 \mathrm{E}-02$, with a RF of 0.7 , resulting in a RARF of $7 \mathrm{E}-02$. Because of the level of uncertainty in the amount of size reduction of the droplets that may result from the evaporation of water (the temperature of the water is near $100^{\circ} \mathrm{C}\left[212^{\circ} \mathrm{F}\right]$ ), subsequent to formation, a bounding RARF of $1 \mathrm{E}-01$ was assigned for this phenomenon. For aqueous liquids with a superheat greater than $100^{\circ} \mathrm{C}\left(212^{\circ} \mathrm{F}\right)$, the $\mathrm{ARF}$ can be estimated by

$$
A R F=0.33\left(M F_{v}\right)^{0.91},
$$

where $M F_{v}$ is the mole fraction of vapor formed by the depressurization.

The aerodynamic mass median diameter of the droplets is $21 \mu \mathrm{m}$, with a geometric standard deviation of 3.0 corrected for evaporation and settling, resulting in a RF of 0.3 for the conditions stated. To approximate the AED and to determine the RF, the density of the droplet is required. The final density would depend on the final solute concentration, which depends on the initial concentration and the amount of water vaporized. It was assumed that the ARF is equal to the RARF, even though this assumption may represent a gross conservatism.

D.1.2.1.4 Solids: Powders. Two subcategories of powders were considered: combustible and noncombustible. Combustible powders are defined as insoluble nonreactive particles in an organic combustible liquid - the same as the subcategory of organic, combustible slurries.

Combustible Powders. Because the definition of this subcategory is the same as that for organic combustible slurries, the RARF for that material in response to the various stresses was applied here.

Noncombustible Powders. This subcategory represents powders that are normally found in waste facilities - powders that do not burn. The powders are dry, and many are ceramic metallic oxides. The experimental data are generally based on dry uranium dioxide $\left(\mathrm{UO}_{2}\right)$ or titanium dioxide

1 Superheat is the temperature $\left({ }^{\circ} \mathrm{C}\right)$ of the liquid greater than the boiling point of the solvent in the same temperature scale. 
$\left(\mathrm{TiO}_{2}\right)$ but also include data from experiments involving soil or other powders. The following assumptions were used for the stresses:

- Free-Fall Spill. As described previously, the bounding distance was assumed to be $3 \mathrm{~m}$ ( $10 \mathrm{ft}$ ). The measured data for powder from this distance were assigned a bounding ARF of $2 \mathrm{E}-03$, with a RF of 0.3 . The RARF was $6 \mathrm{E}-04$.

- Crush-Impact. No data are available for the suspension of a noncombustible powder due to the impact of a hard unyielding object on the powder or the crush from such an object. It was assumed that such a phenomenon would have an impact no greater than the impact of the powder falling the same distance $(3 \mathrm{~m}[10 \mathrm{ft}])$ onto a hard unyielding surface or a RARF of $6 \mathrm{E}-04$.

- Mechanical Overpressurization (Puncture or Loss of Lid). The suspension of a noncombustible powder due to mechanical action (e.g., puncture, loss of a lid) would be equivalent to the experimentally measured value during the venting of such powders at pressures equal to or less than $0.17 \mathrm{MPa}_{\mathrm{g}}(25$ psig). The measured values for $A R F$ and $R F$ were $5 E-03$ and 0.3 , respectively, resulting in a RARF of $2 E-03$.

- Small Fire. The greater RARF experimentally measured for chemically reactive powders was applied (RARF of $1 \mathrm{E}-02$ ). The experimentally measured value for chemically inert powders (e.g., ceramic oxides) was $6 \mathrm{E}-05$.

- Large Fire. The same factor was applied for a large fire because the presence of heat over a given duration results in the altered chemical state of the material. Therefore, small fires over a long duration may have the same relative effect for this material.

- Explosive Release: Blast Effects. The RARF derived for the suspension of an enclosed powder during the rapid burning of a volume of a flammable mixture of gases filling less than $25 \%$ of the free volume of the enclosure was $1 \mathrm{E}-01$. The RARF was limited to the RF of the source powder if that fraction was less than 1E-01 (assuming complete deagglomeration of a powder at rest by the action of accelerated gas flow is very conservative). The value is very close to the experimentally measured value for the suspension of powder during the venting of powders pressurized to $3.45 \mathrm{MPa}_{\mathrm{g}}$ (500 psig). If the gas fills the entire free volume of the enclosure, the ARF could be as high as 1.0 (all of the powder), but the RARF was limited to the RF in the source powder. If the powder is not enclosed and is a distance from the burning gases, where the 
accelerated flow is parallel to the surface on which the powder rests, the RARF would be $2 \mathrm{E}-04$.

- Explosive Release: Shock Effects. An ARF of 8E-01 and a RF of 0.25 are the experimentally measured values for the suspension of soil for explosions of TNT equivalence up to $100 \mathrm{~kg}(220 \mathrm{lb})$. The RARF is for a mass equal to 2E-01 TNT mass equivalence for the explosion. The powder in this case is relatively tightly packed as opposed to the loose, dry ceramic material found in some cases. This value was chosen because it is more representative of the overall conditions that are anticipated (e.g., salt that may be partly fused, damp powders, or powders that have absorbed some moisture). The RARF is a mass of powder $2 \mathrm{E}-01$ of the calculated TNT mass equivalence for the shock-generating portion of the explosion. This value was limited by the mass of powder in the respirable size range of the mass of material (0.8 TNT equivalence) affected by the explosion.

- Venting of Pressurized Powder. The experimentally measured bounding values for the ARF and RF for the powder pressurized up to $3.45 \mathrm{MPa}_{\mathrm{g}}$ (500 psig) were $1 \mathrm{E}-01$ and 0.5 , respectively. The RARF was 5E-02.

D.1.2.1.5 Solids: Contaminated Combustible Material. Four subcategories were considered for this type of material: (1) dry active waste (DAW - a mixture of combustible wastes [mostly cellulosic materials, but also plastics] in plastic wrapping); (2) unenclosed plastic (polymethyl methacrylate [Lucite], rubber, and elastomer); (3) cellulosic materials (paper, rags, and wood scrap); and (4) polyethylene.

$D A W$. The following assumptions were used for the stresses:

- Free-Fall Spill. The suspension of sparse surface contamination (particles covering less than $10 \%$ of the surface area to a depth of less than $2 \mathrm{dp}$ ) would not be anticipated to result in substantial entrainment. The material itself is relatively light and would not result in a large impact force. The material is encased in plastic wrap and would not release materials suspended unless the plastic wrap loses its integrity. The experimentally measured value (ARF of $1 \mathrm{E}-03$ ) for the suspension of loose dry powder from a hard flexible surface (plywood) was applied, and a very conservative RF of 1.0 was assumed because of the lack of characterization of the potential source materials. 
- Crush-Impact. As with other materials, the same factor applied for a free-fall spill was used for the suspension due to crushing or impact (RARF of 1E-3).

- Mechanical Overpressurization (Puncture or Loss of Lid). In the absence of any known experimentally measured values for suspension, the RARF for free-fall spill or vibration (1E-03) was applied.

- Small Fire. For wrapped, contaminated combustible materials, the experimentally measured ARF of 5E-04 for the release of the contaminant during the combustion of contaminated combustible material in cardboard boxes was applied. In the absence of any measured RF values, a conservative value of 1.0 was assumed. The RARF was $5 \mathrm{E}-04$.

- Large Fire. Because of the uncertainty of the fire conditions that may exist, the very conservative ARF (4E-01) experimentally measured for the suspension of a fine, dry powder contaminant during its combustion on a grate with air flowing through the burning mass (similar in effect to a forced-draft furnace) was applied. In the absence of any measured RF, a conservative value of 1.0 was assumed. The RARF was $4 \mathrm{E}-01$. Extreme caution should be used in applying this value; the fire conditions should generate conditions similar to a forced-draft furnace before this value is applicable.

- Explosive Release: Blast Effects. Because of its low mass, the entire package would probably be displaced, and the most significant suspension would result from the ignition of the material due to the flame front. The RARF of 5E-04 for a small fire was applied.

- Explosive Release: Shock Effects. The RARF was based on the assumption that the shock effect will fragment a mass of total material equal to the TNT equivalence calculated for the shock-generating mass of the explosive materials. The RARF applied was that fraction of the containment associated with the fragmented mass.

- Venting High Pressure. In the absence of any known experimentally measured values, the very conservative assumption was made that the RARF for this material under these conditions would be simulated by the behavior of a loose dry powder. The RARF applied was 5E-02.

Plastics. The values represented here are for the uncovered materials designated (the contaminated surfaces are directly exposed to air). The experimental values were derived for small 
samples of materials and are very conservative (as the pile of material becomes deeper, the particles and vapors formed by the destruction of the plastic must pass through increasingly deeper beds of ash and residues that may act as a filter or occur on the surface of a sticky high-viscosity mass of melted plastic). As such, the conditions represented here are very uncommon (all waste but that currently in process is contained to some level). These conditions represent extreme values for the situations normally encountered in waste facilities that handle and process radioactive waste. The following assumptions were used for the stresses:

- Free-Fall Spill. The experimentally applied factor measured for the suspension of loose powder from a hard flexible surface from the impact of large (up to $5 \mathrm{lb}_{\mathrm{m}}$ ) debris (i.e., vibration) was applied. Because of the uncertainty of the characteristics of the surface contamination, the measured $\mathrm{RF}$ of 0.7 was not applied, and a conservative value of 1.0 was assumed. The recommended RARF is $1 \mathrm{E}-03$.

- Crush-Impact. The experimentally measured value described in the free-fall spill (RARF of 1E-03) was applied.

- Mechanical Overpressurization (Puncture or Loss of Lid). Values for the $\mathrm{ARF}$ and $\mathrm{RF}$ of $5 \mathrm{E}-03$ and 0.3 , respectively, were experimentally measured for the venting of dry ceramic oxide powder at pressures less than $0.17 \mathrm{MPa}_{\mathrm{g}}$ (25 psig). The value of $1 \mathrm{E}-03$ was measured for the suspension of loose ceramic oxide powder from the impact of debris. The ARFs for these two situations that appear to bound the conditions described resulted in RARFs of $1 \mathrm{E}-03$ and $7 \mathrm{E}-04$. A value of $1 \mathrm{E}-03$ was selected to represent this phenomenon on the basis that the value is an average of the two RARFs for - the situations and that not all of the surface contamination is available for suspension (it must be loose contamination, and some of the surface contamination is incorporated within the matrix of the material).

- Small Fire. The experimentally measured value for plastics (ARF of 1E-02 with an assumed RF of 1.0) was applied. Measured size distributions for airborne material for some plastics indicated that almost all of the materials were in the respirable size range. The value was not as great as measured for the combustion of loose, dry ceramic oxide powder on polymethyl methacrylate, but the experimental configurations represented (piles of loose powder on polymethyl methacrylate granules) were not considered (the residues of surface contamination after treatment for removal [e.g., wiping or more rigorous methods] from sheets of polymethyl methacrylate with surface contamination). 
- Large Fire. The same values as those applied for small fires were applied for large fires because the formation-and-suspension phenomena (destruction of the substrate and lofting of the particles formed by the vapors generated by the destruction) are the same. A RARF of 1E-02 was applied.

- Explosive Release: Blast Effects. The combustible substrate is ignited by the flame front associated with rapid burning (although the flame front may not be of sufficient duration to ignite some materials), and the value for fires was applied. A RARF of 1E-02 was applied.

- Explosive Release: Shock Effect. If the conservative interpretation of the Steindler and Seefeldt correlation (DOE 1994) is applied to other solid materials, the mass airborne in the respirable size range is equal to the mass TNT equivalence calculated for the explosion (mass $=$ TNT equivalence). The mass concentration of the material of concern on the substrate must be used to determine the mass of the material of concern suspended.

- Venting of High Pressure: The venting of the gases results in violent motion of loose pieces of the substrate, and the surface contamination is suspended by the vibratory action. A RARF of $1 \mathrm{E}-03$ was applied.

Cellulosics. The values presented here are for the designated uncovered materials (i.e., the contaminated surfaces are directly exposed to air). Experimental values were derived for small samples of materials and are very conservative. (As the pile of material becomes deeper, the particles and vapors formed by the destruction of the cellulose must pass through increasingly deeper beds of ash and residues that may act as a filter.) As such, the conditions represented here are very uncommon (all waste but that currently in process is contained to some level) and represent extreme values for the situations normally encountered in waste facilities handling and processing radioactive waste. The following assumptions were used for the stresses:

- Free-Fall Spill. As with all materials in this category, the aerosolization of surface contamination was assumed to result from the vibratory motion from the impact of the substrate upon a hard unyielding surface or by the oscillatory motion of the substrate during the fall. The RARF of $1 E-03$ was applied.

- Crush-Impact. As with all materials in this category, the RARF for suspension of the surface contamination was assumed to be equivalent to that for a freefall spill (1E-03). 
- Mechanical Overpressurization (Puncture or Loss of Lid). The RARF for suspension of surface contamination from cellulosics (in most cases, a thin flexible form) is due to vibratory action; the RARF applied was $1 E-03$.

- Small Fire. The experimental bounding ARF of $1 E-02$, with an assumed RF of 1.0, was applied for the suspension of surface contamination from small exposed pieces of cellulosic materials. In the absence of measured RFs for these experiments, a conservative value of 1.0 was assumed. The resultant RARF was $1 E-02$.

- Large Fire. The mechanism of suspension for surface contamination from cellulosic materials is the same for small and large fires. Large fires may include more cellulosic materials, subjecting larger inventories of radionuclides to combustion; however, it is very unlikely that large quantities of contaminated combustible material would be available. Large volumes of cellulosics would mean larger piles of burning cellulose, which would decrease the availability of particles generated within the pile to the surface.

- Explosive Release: Blast Effects. The accelerated flow from the rapid burning uncovers the contaminated cellulosics and ignites the material. The RARF for the burning of exposed contaminated cellulosics (1.0E-02) was applied.

- Explosive Release: Shock Effects. The cellulosic substrate is fragmented by the shock like any solid material (particles on the surface of a thin flexible substrate may simply be dislodged and entrained with the resultant flow), and the fraction of contaminant of the substrate would be made airborne with the base material. The mass fraction of the substrate suspended as particles in the respirable size range is equal to the mass of TNT equivalence calculated for the explosion. The mass of the contaminant is determined by multiplying the mass concentration of the contaminant on the substrate by the mass fraction of substrate aerosolized.

- Venting of High Pressure. Venting of high-pressure gas from the free volume above the contaminated material would result in suspension of the surface contamination by vibratory action of the substrate. A RARF (described in previous subsections) of $1 \mathrm{E}-03$ was applied.

Polyethylene. No direct experimental data exist on the behavior of polyethylene under the stresses covered. Data for other plastics and plasticlike materials (e.g., polymethyl methacrylate, 
polystyrene, polychloroprene) show that they exhibit very similar behavior. On that basis, the RARFs applied for plastics were applied.

D.1.2.1.6 Solids: Brittle Solids. Materials that shatter, rather than deform, on impact are considered brittle solids. Both vitrified HLW and aggregate HLW (covered subsequently) fall into this class of materials. Vitrified $\mathrm{HLW}$ was considered. Vitrified HLW is normally encased in a substantial stainless steel canister that must be compromised before any fragments of the material generated can be made airborne. The behavior described subsequently assumes that the stress either is or is not capable of compromising the canister. The potential airborne release of the contained material assessed is as follows:

- Free-Fall Spill. Canisters must qualify to sustain greater than a 9-m (30-ft) drop to qualify for transport; any vitrified HLW produced is normally poured into such canisters. No compromise of the canister was assumed for these situations.

- Crush-Impact. An empirical correlation of the RF of the fragments generated by crush-impact experiments (using small specimens that were completely covered by the impacting object) yielded the following:

$$
R A R F=(A)(D)(g)(h),
$$

where

$$
\begin{aligned}
& A=\text { empirical correlation coefficient }(2 \mathrm{E}-11), \\
& D=\text { material density }\left(\mathrm{g} / \mathrm{cm}^{3}\right), \\
& g=\text { acceleration due to gravity }\left(980 \mathrm{~cm} / \mathrm{s}^{2}\right), \text { and } \\
& h=\text { height of fall }(\mathrm{cm}) .
\end{aligned}
$$

While this equation is applicable to small specimens of vitrified HLW, applicability to large monoliths, such as HLW poured into a canister, is not known.

- Mechanical Overpressurization (Puncture or Loss of Lid). Although the venting of a $\mathrm{HLW}$ canister at a pressure of less than $0.17 \mathrm{MPa}_{\mathrm{g}}(25 \mathrm{psig})$ is doubtful, on the basis of the value reported for vitrified fragments in the respirable size range found on the waste surface in the upper plenum of a cooled canister (3E-04) and the ARF of 2E-03, a RARF of 7E-07 can be applied to this situation, provided some reason for the venting at such pressures is determined. 
- Small Fire. The vitrified HLW is subjected to higher temperatures during formation than those anticipated for any typical industrial fire, and such temperatures are not expected to defeat the stainless steel canister. Consequently, no significant airborne release of material was postulated for this situation.

- Large Fire. No significant airborne release was postulated for the impact of a large fire on a vitrified HLW canister, as described previously.

- Explosive Release: Blast Effects. The RARF was based on the assumptions that the blast occurs in the upper plenum of the canister and that $1 \mathrm{E}-01$ of the vitrified HLW fragment (4E-04) found in the upper plenum is suspended. A RARF of 4E-05 was applied.

- Explosive Release: Shock Effects. The mass of vitrified HLW airborne in the respirable size range was assumed to be, as for all other solids, equal in mass to the TNT equivalence calculated for the explosion, but no less than the RARF for blast effects (4E-05).

- Venting of High Pressure. It was assumed that 0.1 of the $4 \mathrm{E}-04$ of the inventory found as fragments of vitrified $\mathrm{HLW}$ in the respirable size range after cooling in the upper plenum is suspended; a RARF of $4 \mathrm{E}-05$ was applied.

D.1.2.1.7 Solids: Viscous Liquids. The viscous liquid covered here is molten vitrified waste. No direct experimental evidence exists on the behavior of molten vitrified HLW subjected to the stresses considered. Values were inferred from the effect of viscosity on the release of aqueous liquids. Values for only three stresses (free-fall spill, crush-impact, and shock effect) are recommended at this time. The following assumptions were used for the stresses:

- Free-Fall Spill. On the basis of (1) a model for the fragmentation of liquids on impact following a free-fall and (2) the ratio of the liquids involved $(<100 \mathrm{cp}$ for an aqueous solution and $>20 \mathrm{P}$ for molten vitrified $\mathrm{HLW}$ ), the calculated RARF for a 3-m (10-ft) distance is $6.5 \mathrm{E}-09$ or about $7 \mathrm{E}-09$.

- Crush-Impact. The impact and crushing by a hard unyielding object on molten vitrified $H L W$ is equivalent to the free-fall spill and impact of the material.

- Mechanical Overpressurization (Puncture or Loss of Lid). No significant airborne release was postulated for the exposure of molten vitrified HLW to 
the ambient environment. If the release results in a spill of the material, application of the RARF for a free-fall spill is appropriate.

- Small Fire. Because molten vitrified HLW is produced by using equal or higher temperatures than those anticipated for industrial fires, no significant airborne release was postulated for this stress.

- Large Fire. As discussed previously, no significant airborne release was postulated for this stress.

- Blast Effects. No significant airborne release is expected from the impact of accelerated gas flow on the surface or over the surface of molten vitrified HLW because of the high viscosity of the material.

- Shock Effect. Molten vitrified $\mathrm{HLW}$ was postulated to behave like the metal or liquids covered in the Steindler and Seefeldt (1980) correlation (DOE 1994). The mass of material fragmented and suspended in the respirable size range was postulated to be equal to the mass calculated for the TNT equivalence of the explosion.

- Venting of High Pressure. Venting of high-pressure gases contained over molten vitrified HLW is not expected to suspend any significant fraction of material from the surface.

D.1.2.1.8 Solids: Metals. Two subcategories of metals were considered: inert and reactive. The reactive metals covered are those that may attain self-sustaining oxidation at an elevated temperature (i.e., uranium [ $\mathrm{U}]$ and plutonium [Pu]). Other reactive metals such as sodium, are principally hazardous materials, and their behavior should be covered in the consideration of hazardous materials.

Inert Metals. Inert metals (e.g., iron, stainless steel, and aluminum) are not highly chemically active at the normal processing temperature. Except for shock effects and the effects of heat on reactive metal, all of the values for the RARF stated here apply only to the loose corrosion products and contamination on the surface of the metal. If the material suspended is a corrosion product or fragments of the substrate, the amount of the material of concern associated with the inert 
material must be calculated by multiplying the mass released by the mass concentration of the material of concern. The following assumptions were used for the stresses:

- Free-Fall Spill. The RARF was based on the suspension of powder from the impact of falling debris. The rationale was that the impact of the metal after free-fall would generate an equal amount of stress. The experimentally measured ARF for this phenomenon was $1 E-03$, with a RF of 0.7. Because of the uncertainty of the powder characteristics covered here compared with the experiment powder, a conservative $R F$ of 1.0 was assumed, yielding a RARF of 1E-03 for the loose particulate materials on the surface of the metal.

- Crush-Impact. The same RARF (1E-03) assumed previously for a free-fall spill was applied here.

- Mechanical Overpressurization (Puncture or Loss of Lid by Impact). The experimentally measured suspension during the venting of powder at a pressure of $0.17 \mathrm{MPa}_{\mathrm{g}}$ (25 psig) was applied (RARF of $2 \mathrm{E}-03$ ).

- Small Fire. The experimentally measured suspension during the heating of nonreactive powders to a temperature up to $1,000^{\circ} \mathrm{C}\left(1,832^{\circ} \mathrm{F}\right)$ in an airflow up to $100 \mathrm{~cm} / \mathrm{s}(39 \mathrm{in} . / \mathrm{s})$ was applied. The measured ARF was $6 \mathrm{E}-05$. No RF was measured during these experiments; a conservative value of 1.0 was assumed. The RARF was $6 \mathrm{E}-05$ of the loose particulate material on the surface of the metal.

- Large Fire. The same factor as applied for a small fire (6E-05) is applicable here.

- Explosive Release: Blast Effects. The ARF assumed for the rapid burning of a limited volume ( $<25 \%$ of the free volume of the container holding the powder) could be applied here for the loose particulate material on the surface of the metal. In most cases, nonreactive metals would be found in large containers, such as enclosures, rooms, or, in some cases, specially built waste containers. The RARF of $1 \mathrm{E}-01$ was limited by the total mass of the particles in that size range in the source powder.

- Explosive Release: Shock Effects. The RARF for shock effects would be the amount of the material of concern associated with the mass of the metal suspended equal to the mass calculated for the TNT equivalence for the explosion. The amount of material suspended should never be less than the amount of material suspended by the blast effects; if the value calculated for 
the shock effect is less, the amount of material suspended defaults to the blasteffect value.

- Venting of High Pressure. The experimentally measured RARF of 5E-02 during the venting of dry ceramic oxide powder pressurized to $3.45 \mathrm{MPa}_{\mathrm{g}}$ (500 psig) was applied to the loose particulate materials (corrosion products or surface contamination) on the surface of the metal.

Reactive Metals. A reactive metal is a metal that can attain self-sustaining oxidation at elevated temperatures. Except for the impacts of fires and shock, the RARFs stated here apply to the loose corrosion products on the surface of the reactive metal. In some cases, some small differences were found in the response of the two metals considered ( $\mathrm{U}$ and $\mathrm{Pu}$ ); the higher values were selected. The following assumptions were used for the stresses:

- Free-Fall Spill. The RARF recommended for the suspension of loose powder (i.e., corrosion products or oxides) on the exposed surfaces of solid materials $(1 \mathrm{E}-03)$ was applied for this situation.

- Crush-Impact. The stress imposed by the impact of, or the crushing by, a hard unyielding object on the exposed surface of a coherent piece of reactive metal is bounded by the assumptions for the free-fall spill and the impact of the metal on a hard, unyielding surface. The RARF for a free-fall spill (1E-03) for loose powder (corrosion product or oxide) on the surface is recommended.

- Mechanical Overpressurization (Puncture or Loss of Lid by Impact/Crush). The RARF for the venting of a dry ceramic oxide powder pressurized to $0.17 \mathrm{MPa}_{\mathrm{g}}$ (25 psig) (2E-03) of the loose powder (ceramic oxide or corrosion product) on the surface is recommended to bound the releases from this event.

- Small Fire. The fire is postulated to heat the reactive metal but not have sufficient temperature or duration of burn to achieve self-sustained oxidation. Twice the experimentally measured RARF (ARF of $3 E-05$ and an assumed $R F$ of 1.0 in the absence of a measured $R F$ ) for the suspension from a reactive metal $(\mathrm{Pu})$ during oxidation at elevated temperatures less than that needed to achieve self-sustained oxidation (RARF of $6 \mathrm{E}-05$ ) is recommended to bound the release for this situation.

- Large Fire. The fire was postulated to be of sufficient intensity and duration to achieve a state of self-sustained oxidation for the reactive metal. Self-sustained oxidation generates molten metal in an oxide coating; the metal 
becomes elevated in temperature during self-sustained oxidation, and the molten metal in the coat flows and falls. The experimentally measured RARF for the suspension of oxide during the free-fall of small $(100-\mu \mathrm{m}$ diameter $)$ drops of molten $\mathrm{Pu}$ was $1 \mathrm{E}-02$. The value is sufficiently conservative to bound this situation.

- Venting of High Pressure. The experimentally measured RARF of 5E-02 during the venting of a dry ceramic oxide powder at pressures up to $3.45 \mathrm{MPa}_{\mathrm{g}}$ (500 psig) is recommended to bound the suspension of loose powder on the surface of reactive metals.

D.1.2.1.9 Solids: Noncombustible Aggregate. The most commonly found aggregate in this category is cement or grout. For noncombustible aggregates, the radionuclides can be lying on the surface, incorporated into the surface matrix, or incorporated within the body of the aggregate by design. The following assumptions were used for the stresses:

- Free-Fall Spill. Because of the use of aggregate as building material (often as the floor) and as material poured into trenches for entombment, free-fall of the material is not a strong possibility. If pieces of aggregate removed from their initial location are placed in a container for handling and shipping, the crushimpact value, which is discussed subsequently, may be applied, if appropriate.

- Crush-Impact. The empirical correlation applied to the fragmentation of vitrified HLW is also appropriate for this class of materials. (See Equation D2.)

- Mechanical Overpressurization (Puncture or Loss of Lid). Because of the nature of the use of the material, it is often found uncontained. Therefore, a RARF cannot be defined. If fragments or debris are in a container, a RARF of $2 \mathrm{E}-03$ of the aggregate in powder form and the radionuclides associated with that fraction may be suspended. The characteristics of such powder are difficult to define and depend on many unspecified factors, such as the method of fragmentation, the condition of the aggregate fragmented, the original composition of the aggregate, the condition after fragmentation, and the conditions of containerization and handling. The RARF is limited by the mass of the particles in the respirable size range in the source powder.

- Small Fire. Aggregate is composed of an appreciable fraction of water, and any bound ${ }^{3} \mathrm{H}_{2} \mathrm{O}$ incorporated into the aggregate would be lost if the temperature of the aggregate reaches $200^{\circ} \mathrm{C}\left(392^{\circ} \mathrm{F}\right)$ or greater. 
- Large Fire. If the aggregate reaches a temperature of greater than $600^{\circ} \mathrm{C}$ $\left(1,112^{\circ} \mathrm{F}\right)$ for a sufficient duration, the aggregate decomposes, and $6 \mathrm{E}-03$ of the powder formed plus all of the tritium $\left({ }^{3} \mathrm{H}\right)$ could be released. The conditions do not result in the fragmentation of the powder (calcium oxide [Ca0]) produced, and the RF in the source powder may limit the release of particles in the respirable size range.

- Explosive Release: Blast Effects. Many of the exposed surfaces of contaminated aggregate materials are in occupied areas and, therefore, are stabilized by treatment of the surface.

- Venting of High Pressure. As postulated for blast effects, the contamination of aggregate surfaces in occupied areas is assumed to be stabilized and not subject to resuspension by aerodynamic forces. If loose powder or contamination is on the exposed surfaces of the aggregate, venting of highpressure gases over the exposed surfaces would be bounded by the RARF applied to powders under this stress.

\section{D.1.2.2 Application to Waste Management (WM) Programmatic Environmental Impact Statement (PEIS)}

The RARFs developed in Section D.1.2.1 were applied to the various waste categories and activities. The specific applications are covered subsequently.

\section{D.1.2.2.1 WM PEIS Waste RARFs for LLW, LLMW, and TRUW Storage and} Handling. The RARFs for the activities and accident stresses anticipated during the storage and handling of low-level waste (LLW), low-level mixed waste (LLMW), and transuranic waste (TRUW) are listed in Table D.3; the following assumptions were used for the activities and waste forms for LLW:

1. Noncondensable Gases. The RARF is not applicable. The presence of noncondensable gases in LLW is not anticipated. Radionuclides as noncondensable gases are found in SNF, and in special collection components for SNF reprocessing and are generated by inadvertent nuclear criticalities. The SNF and SNF reprocessing equipment are not classified as LLW. Inadvertent nuclear criticalities are not a credible event for LLW storage or processing. 
2. Volatiles. Volatile radionuclides (e.g., $\mathrm{I}_{2}, \mathrm{Ru},{ }^{3} \mathrm{H}$ as ${ }^{3} \mathrm{H}_{2} \mathrm{O}$ or as ${ }^{3} \mathrm{H}$ hydrides) are assumed to exist in LLW as material dissolved in a liquid or as solid compounds and require special physicochemical conditions to be converted to a vapor. Only ${ }^{3} \mathrm{H}$ in the form of ${ }^{3} \mathrm{H}_{2} \mathrm{O}$ or of ${ }^{3} \mathrm{H}$ hydrides is vaporized by heat alone; other radionuclides require additional conditions such as an acidic environment or an oxidant.

\section{Organic Combustible Liquids}

a. Solutions

(1) Spills. Assume free-fall of solution $3 \mathrm{~m}$ (10 ft) or less and impact with hard unyielding surface.

(2) Crush-Impact. Crush without restraint of the liquid is not considered an efficient airborne droplet-generation mechanism, and suspension from the impact of an object on the liquid surface appears to be the more dominant droplet-generation mechanism. Assume that the suspension of droplets in the respirable size range from the impact of an object over a portion of the surface of the liquid is bounded by the suspension of droplets in the respirable size range by the impact of the solution onto a hard unyielding surface.

(3) Pressurized Release. Pressurized release assumes the rapid ( $<1 \mathrm{~min}$; does not allow the absorption of the gases into the liquid) pressurization to $1.38 \mathrm{MPa}_{\mathrm{g}}$ (200 psig) or less of the free volume above the liquid and the venting of the pressurized liquid through an opening equivalent to an orifice with a diameter of $1 \mathrm{~mm}(0.04 \mathrm{in}$.) or more at the bottom of the sidewall of the vessel or container.

(4) Small Fire (less than the entire inventory is involved, and the structural containment is not impaired). The RARF for any iodine dissolved in the liquid is 1.0. The RARF for all other radionuclides is based on the maximum measured experimental value for suspension of particles in the respirable size range during the burning of an organic combustible liquid with a residue (liquid or moist sludge) (1E-02).

(5) Large Fire (almost the entire inventory is involved, and the structural containment is damaged). The RARF for any iodine dissolved in the liquid is 1.0E. The RARF for all other radionuclides 
is the maximum experimental value measured for the suspension of particles in the respirable size range during the burning of a contaminated, organic combustible liquid to complete dryness (1E-01).

(6) Deflagration (Blast Effects). Droplets can be generated by the passage of gas at an accelerated velocity over the surface of the liquid (shear stress) and by the ignition of the organic combustible liquid by the passage of the flame front over the liquid. The RARF for shear stress is $4 \mathrm{E}-03 / \mathrm{h}$ for the duration of the passage of the pressure impulse (assume $1 \mathrm{~min}$ ), resulting in a value of 7E-05. This RARF is greatly exceeded by the RARF for a large fire (1E-01).

(7) Detonation (shock effects). The RARF applied is the sum of the releases from fragmentation and suspension from the liquid due to shock effects and the RARF for the passage of the pressure impulse without ignition of the liquid (detonations normally occur within a microsecond to millisecond, and the flame front is not present for a sufficient period of time to result in the ignition of the liquid). The RARF for the shock effect is a conservative interpretation of the Steindler and Seefeldt (1980) correlation for the fragmentation and suspension of drops in the respirable size range by detonation on or in liquids and solids; the mass of material airborne in the respirable size range is equal to the mass of the TNT equivalence calculated for the explosion.

(8) Pressurized Releases. Suspension occurs during the venting of a slow ( $>1$ min pressurization period that allows the pressurizing gases to be absorbed into the liquid) pressurization of the free volume above the liquid to a pressure of $3.45 \mathrm{MPa}_{\mathrm{g}}$ (500 psig) through an opening near the surface of the liquid or at the bottom of the sidewall of the vessel or container.

b. Slurries

(1) Spills. The RARF is based on the suspension of particles in the respirable size range from the free-fall from a distance of $3 \mathrm{~m}(10 \mathrm{ft})$ or less and the impact of aqueous slurries on a hard unyielding surface. If the radionuclides are involved with only the particulate materials present, the airborne release may be limited by the amount 
of particles in the respirable size fraction present in the source material.

(2) Crush-Impact. (See point 3.a.2.) A slurry has two components: the liquid and the particles. If the radionuclides are associated with the particle fraction, the airborne release may be limited by the fraction of particles in the respirable size range found in the particle component.

(3) Pressurized Release. (See points 3.a.3 and 3.b.2.)'

(4) Small Fire (less than the entire inventory is involved, and structural containment is not impaired). (See point 3.a.4.) If the radionuclides are dissolved in the organic combustible liquid, the applicable RARF would be the suspension during the burning of the liquid (1E-02). If the radionuclides are involved only with the nonreactive particle component, the applicable RARF is for the suspension of particles in the respirable size range during the heating of a nonreactive powder (6E-05).

(5) Large Fire (almost the entire inventory is involved, and structural containment is damaged). (See points 3.a.5 and 3.b.4.)

(6) Deflagration (Blast Effects). (See point 3.a.6.) If the radionuclides are dissolved in the organic combustible liquid and the combustible solvent is ignited, the RARF for the burning of the combustible liquid (1E-01) would dominate the releases. If the radionuclides are associated only with the nonreactive particle fraction, the applicable RARF is for the suspension of particles in the respirable fraction by the result of heating of the nonreactive powder $(6 \mathrm{E}-05)$.

(7) Detonation (Shock Effects). (See point 3.a.7.) If the radionuclides are associated with the particle fraction, suspension by shear stress (aerodynamic entrainment) is possible, although the presence of the liquid increases the force necessary to suspend the particles. The most applicable RARF is a conservative interpretation of the Steindler and Seefeldt (1980) correlation for the fragmentation and suspension of particles in the respirable size range due to detonations on or in solids and liquids: the mass of particles in the airborne respirable size range is equal to the mass of the TNT equivalence of the explosion. 
(8) Pressurized Release. (See point 3.a.8.) If the radionuclides are associated with only the particle fraction, the airborne release of particles in the respirable size range may be limited by the amount of material in that range in the source material.

\section{Aqueous Liquids}

a. Solutions

(1) Spills. (See point 3.a.1.)

(2) Crush-Impact. (See point 3.a.2.)

(3) Pressurized Release. (See point 3.a.3.)

(4) Small Fires (less than the entire inventory is involved, and structural containment is not impaired). The RARF is based on the maximum value measured for the suspension of droplets in the respirable size range during the heating and boiling of aqueous solutions (2E-03). The RARF is not applicable to the churn-turbulent or chaotic boiling regimes.

(5) Large Fires (almost the entire inventory is involved, and structural containment is damaged). (See point 4.a.4.)

(6) Deflagration (Blast Effects). The RARF is based on the suspension of drops in the respirable size range by the passage of air at an accelerated velocity over the surface of an aqueous solution (shear stress). The $A R F$ is $4 E-03 / h$ from a hard unyielding surface for velocities in excess of $32 \mathrm{~km} / \mathrm{h}(20 \mathrm{mi} / \mathrm{h})$. A conservative estimate of $1 \mathrm{~min}$ is applied for the time of passage of the pressure impulse over the surface of the liquid, resulting in a RARF of 7E-05.

(7) Detonation (Shock Effect). (See point 3.a.7.)

(8) Pressurized Release. (See point 3.a.8.)

b. Slurries

(1) Spills. (See point 3.b.1.) 
(2) Crush-Impact. (See point 3.a.2.)

(3) Pressurized Release. (See points 3.a.3 and 3.b.2.)

(4) Small Fire (less than the entire inventory present is involved, and structural containment is not impaired). (See point 4.a.4.) If the inventory is involved with the nonreactive particulate fraction of the slurry, the RARF is based on the maximum values measured for the suspension of particles in the respirable size range during the heating of nonreactive powders on a hard unyielding surface.

(5) Large Fire (almost the entire inventory of radionuclides is involved, and the structural containment is damaged). (See points $4 . a .4$ and 4.b.4.)

(6) Deflagration (Blast Effects). Droplets in the respirable size range can be generated by the passage of accelerated gas velocities over the surface of the aqueous solution. If the inventory is dissolved in the aqueous phase or uniformly distributed in the aqueous phase, the RARF for this mechanism is based on the aerodynamic entrainment (shear stress) rate of $4 \mathrm{E}-03 / \mathrm{h}$ for an assumed duration of $1 \mathrm{~min}$ for the passage of the pressure impulse, resulting in a RARF of 7E-05. If the inventory is involved with the particulate phase and that phase is not exposed to the surface of the liquid, a RARF of less than $1 \mathrm{E}-05$ can be postulated for this phenomenon.

(7) Detonation (Shock Effects). The RARF for radionuclides dissolved in the aqueous phase or in particulates uniformly distributed in the aqueous phase is based on a conservative interpretation of the Steindler and Seefeldt (1980) correlation. This correlation predicts the fragmentation and suspension of particles in the respirable size range from detonations on or in the material; the mass of particles airborne in the respirable size range is equal to the mass of the TNT equivalence estimated for the explosion.

(8) Pressurized Release. (See points 3.a.8 and 3.b.8.)

c. Superheated Aqueous Liquids

(1) Spills. The spill of the container defeats the vessel or container and the superheated liquid is released to the atmosphere. The RARF is 
based on the maximum measured value for the suspension of droplets in the respirable size range from the venting of aqueous liquids superheated to $50-100^{\circ} \mathrm{C}\left(122-212^{\circ} \mathrm{F}\right)$ above the boiling point of the solvent (water); the liquid forms a flashing spray with a RARF of 7E-02.

(2) Crush-Impact. The event defeats the vessel or container holding the superheated aqueous liquid and the release results in a flashing spray of the aqueous liquid, as in point 4.c.2.

(3) Pressurized Release. The pressure generated by the heated liquid defeats the structural containment, allowing the release of the liquid and the formation of a flashing spray. The RARF is $7 \mathrm{E}-02$.

(4) Small Fire (less than the entire inventory of radionuclides is involved, and the structural containment is not impaired). The assumption is that the event defeats the vessel or container holding the superheated liquid, which forms a flashing spray. The RARF is $7 \mathrm{E}-02$.

(5) Large Fire (almost the entire inventory of radionuclides is involved, and the structural containment is damaged). The event defeats the vessel or container holding the superheated liquid, which forms a flashing spray. The RARF is 7E-02.

(6) Deflagration (Blast Effects). The event defeats the vessel or container and releases the superheated liquid, which flashes. The RARF is $7 \mathrm{E}-02$.

(7) Detonation (Shock Effect). The event defeats the vessel or container and releases the superheated liquid, which flashes. The RARF is the sum of the RARF in point 4.c.1 and the conservative interpretation of the predicted airborne release of solids and liquids from detonations on or in materials. The mass of the drops in the respirable size range is equal to the mass of the TNT equivalence estimated for the explosion.

\section{Powders}

a. Combustible Powders (Nonreactive Powder Mixed with an Organic Combustible Liquid; a Powder Slurry) 
(1) Spill (Free-Fall Spill of Powder $3 \mathrm{~m}$ [10 ft] or Less). Although the presence of the organic combustible liquid undoubtedly increases the forces required to separate the particles, the RARF is based on the maximum experimental value measured for the suspension of particles in the respirable size range from the free-fall spill of a dry ceramic powder $3 \mathrm{~m}(10 \mathrm{ft})$ or less and the impact against a hard unyielding surface. If the radionuclides are associated with the liquid, the RARF in point 3.b.1 is applicable.

(2) Crush-Impact (Crush or Impact of Slurry by Objects). No experimental data exist on the effect of crush-impact forces on the subdivision and suspension of organic sludges or slurries. The suspension is assumed to be conservatively bounded by the RARF measured for the deagglomeration and suspension of uncontained dry ceramic powders from a stiff, flexible nonporous surface by the impact of objects (1E-02).

(3) Pressurized Release (Venting of Volume Pressurized to $3.45 \mathrm{MPa}_{\mathrm{g}}$ [500 psig] or Less Containing the Powder). The RARF is based on the maximum experimental value measured for the deagglomeration and suspension of a dry ceramic powder pressurized to $3.45 \mathrm{MPa}_{\mathrm{g}}$ (500 psig) or less during venting. The RARF can be limited by the amount of particles in the respirable size range present in the source powder slurry.

(4) Small Fire (less than the entire inventory of radionuclides is involved, and the containment of the facility is not impaired). (See point 3.b.4.) If the inventory of radionuclides is associated with the nonreactive particle phase of the slurry, the RARF for the maximum experimental value measured for the suspension of particles during the heating of a dry, ceramic nonreactive powder $(6 \mathrm{E}-05)$ is applicable.

(5) Large Fire (almost the entire inventory of radionuclides is involved, and the containment of the facility is damaged). (See points 3.b.6 and 5.a.4.)

(6) Deflagration (Fast Burning of a Flammable Mixture of Gases: Blast Effects). The RARF is based on the suspension of nonvolatile radionuclides dissolved in an organic combustible liquid during burning (after ignition of the organic combustible liquid by the 
passage of the flame front) to complete dryness (no wet or moist residue). If the inventory of radionuclides is associated with the particle component of the slurry, the RARF is that for the suspension due to blast effects from deflagrations of a mixture of flammable gases that fills less than $25 \%$ of the volume directly over the powder. The RARF for the suspension of powder may be limited by the amount of particles in the respirable size range found in the source powder slurry.

(7) Detonation (Reaction Completed in Microseconds to Milliseconds). The RARF is based on a conservative interpretation of the Steindler and Seefeldt (1980) correlation that predicts the fragmentation and suspension of particles in the respirable size range from detonations on or in solids and liquids. The RARF for this shock effect is the mass of particles airborne in the respirable size range equal to the mass of the TNT equivalence estimated for the explosion. The blast effects for the event are additive, but ignition of the organic combustible liquid cannot be postulated because of the speed of the reaction. If the inventory is associated with the powder fraction of the powder slurry, the blast effect shown in point 5.a.5 would probably dominate the RARF. If the blast effect dominates, the RARF may be limited by the amount of particles in the respirable size range present in the powder slurry.

(8) Pressurized Release (Venting of Volumes Pressurized to $3.45 \mathrm{MPa}_{\mathrm{g}}$ [500 psig] Containing the Slurry). (See point 5.a.3.)

b. Noncombustible Powders

(1) Spills (Free-Fall Spills of Powder $3 \mathrm{~m}[10 \mathrm{ft}]$ or Less). (See point 5.a.1.)

(2) Crush-Impact (Crush or Impact of Object on Powder). (See point 5.a.2.)

(3) Pressurized Release (Venting of Volume Containing the Powder That Has Slowly Been Pressurized up to $3.45 \mathrm{MPa}_{\mathrm{g}}$ [500 psig] before Release). (See point 5.a.3.)

(4) Small Fire (less than the entire inventory of radionuclides is involved, and the containment of the facility is not impaired). The 
RARF is based on the maximum value measured for the suspension during the heating of a reactive powder in an upflow of air with a velocity of $100 \mathrm{~cm} / \mathrm{s}$ (39 in./s) (1E-02).

(5) Large Fire (almost the entire inventory of radionuclides is involved, and the containment of the facility is damaged). (See point 5.b.2.)

(6) Deflagration (Blast Effect; Rapid Burning of a Flammable Gas Mixture). The RARF is that selected for deflagration of a flammable gas mixture that fills less than $25 \%$ of the free volume directly over the powder.

(7) Detonation (Shock Effect; Reactions Completed in Microseconds to Milliseconds). The applicable RARF is the sum of the RARFs for the shock and blast effects. The RARF for the shock effect is based on a conservative interpretation of the Steindler and Seefeldt (1980) correlation that predicts the fragmentation of solids and liquids from detonations on or in the materials: the mass of particles in the respirable size range suspended is equal to the mass of the TNT equivalence estimated for the explosion. The blast-effect RARF is given in point 5.b.6, (1E-01) and probably dominates the shockeffect RARF. Because it cannot be postulated that the blast will further subdivide the powder, the RARF may be limited by the amount of particles in the respirable size range present in the source powder (the source powder must have a fraction of particles in the respirable size range greater than $10 \%$ ).

(8) Pressurized Release (Venting of the Volume Holding the Powder That Has Slowly Been Pressurized to $3.45 \mathrm{MPa}_{\mathrm{g}}[500 \mathrm{psig}$ ] before the Release). (See point 5.a.3.)

\section{Contaminated Combustible Solids}

a. DAW (Dry Active Waste; Contaminated Combustibles Wrapped in an Uncontaminated Wrapper)

(1) Spill. The free-fall and impact of DAW on a hard, unyielding surface can be postulated to result in the loss of the wrapping and the suspension of particulate contamination by shock or vibration. No direct data exist for the suspension of particles in the respirable size range from light flexible materials such as paper, rags, or 
plastic wrapping. It was assumed, however, that the RARF is bounded by the maximum value measured for the suspension of powder in this size range due to the impact of objects on uncontained, dry ceramic powder on a stiff, flexible nonporous surfaçe (1E-03).

(2) Crush-Impact. Crush or impact by objects can be postulated to result in the loss of containment of the wrapping and the suspension of particulate contamination from the surface by shock or vibration forces. (See point 5.a.1.)

(3) Pressurized Release. Rapid pressurization of the volume containing the DAW to a pressure of $1.38 \mathrm{MPa}_{\mathrm{g}}$ (200 psig) or less can be postulated to defeat the vessel containment and to eject the DAW. Impact of the DAW with a hard unyielding surface or other object can be postulated to defeat the wrapping and suspend the particulate surface contamination by shock or vibration. (See point 5.a.1.)

(4) Small Fire (less than the entire inventory of radionuclides is involved, and the containment of the facility is not impaired). The $\mathrm{RARF}$ is based on the maximum experimental value measured for the suspension of particles during the burning of a mixture of contaminated combustible waste packaged in plastic and cardboard (5E-04).

(5) Large Fire (almost the entire inventory of radionuclides is involved, and the containment of the facility is damaged). The RARF is based on the assumption that the force of the impact of aircraft parts on the waste packages is sufficient to free the contaminated combustible materials from their wrapping and to disperse them into the air, where the combustible materials ignite due to the burning of the aircraft fuel and burn before falling to the ground. The scenario requires extreme force to be brought to bear on the packages. The RARF is based on the maximum experimental value measured during the burning of tissue paper contaminated with a very fine, dry ceramic powder while suspended in flowing air (4E-01). The RARF may be limited by the amount of particles in the respirable size fraction present in the source powder contaminant.

(6) Deflagration (Rapid Burning of a Flammable Gas Mixture: Blast Effect). The RARF is based on the assumptions that the pressure 
impulse from the deflagration disperses the entire wrapped material and that the wrapping is ignited by the passage of the flame front (5E-04).

(7) Detonation (Reaction Completed in Microseconds to Milliseconds: Shock Effect). The RARF is the sum of the RARFs for both shock and blast effects. The RARF for the shock effect is a conservative interpretation of the Steindler and Seefeldt (1980) correlation that predicts the fragmentation of solids and liquids from detonation on or in the material. The mass of particles in the respirable size range suspended is equal to the mass of the TNT equivalence estimated for the explosion. The contaminated combustible materials cannot be postulated to ignite because of the speed of the reaction. The RARF for the blast effect is based on the suspension of contamination from surfaces by shock or vibration (1E-03).

(8) Pressurized Release (Venting of the Volume Holding the Material That Has Been Pressurized before Release to $3.43 \mathrm{MPa}_{\mathrm{g}}[500 \mathrm{psig}]$ ). The event cannot be postulated to eject the contaminated combustible waste without altering its state; however, the wrapping is defeated by the impact of the material with a hard, unyielding surface, and the particulate contamination is suspended by the shock or vibration. The RARF of $1 \mathrm{E}-03$ can be applied.

b. Plastics (All Solid Combustible Plastics and Elastomers except Polystyrene)

(1) Spill (Free-Fall of the Plastic Contaminated with a Solid Material). No direct experimental data exist for the suspension of particulate contamination from the surface of plastics as a result of the free-fall and impact of the plastic on a hard unyielding surface. It was assumed that the release is bounded by the maximum experimental value measured for the suspension of particles in the respirable size range by the impact of falling objects onto uncontained dry powder resting on a stiff, flexible nonporous surface (1E-03).

(2) Crush-Impact (Impact of a Moving Object on the Material). No direct experimental data are available for the suspension of particles from the surface of contaminated plastics. (See point 6.a.1.) 
(3) Pressurized Release (Venting of a Volume Holding the Material That Has Been Rapidly Pressurized to $3.45 \mathrm{MPa}_{\mathrm{g}}[500 \mathrm{psig}]$ and Less before Release). No direct experimental measurements exist for the suspension of particulate contamination from the surface of plastic by the pressurized release of the material. (See point 6.a.3.)

(4) Small Fire (less than the entire inventory of the radionuclides is involved, and the containment of the facility is not impaired). The RARF (1E-02) is based on the maximum experimental value measured for the suspension of particles in the respirable size range during the burning of plastics and elastomers contaminated with powders and aqueous solutions in flowing air (up to $100 \mathrm{~cm} / \mathrm{s}$ [39 in./s]).

(5) Large Fire (almost the entire inventory of radionuclides is involved, and the containment of the facility is not impaired). Because of the weight of the material, plastics cannot be postulated to remain airborne while burning, and the RARF for suspension of contaminant during simple burning is applicable. (See point 6.b.4.)

(6) Deflagration (Rapid Burning of a Flammable Gas Mixture: Blast Effects). The RARF is based on the assumption that the contaminated combustible material is ignited by the passage of the flame front; the RARF for the burning of contaminated plastics applies (1E-02).

(7) Detonation (Reaction Completed in Microseconds to Milliseconds: Shock Effects). The RARF is the sum of the RARFs for the shock and blast effects. The RARF for the shock effect is based on a conservative interpretation of the Steindler and Seefeldt (1980) correlation that predicts the fragmentation of solid and liquids from detonation on or in the material. The mass of the particles in the respirable size fraction suspended is equal to the mass of the TNT equivalence estimated for the explosion. The mass suspended is that of the contaminated plastic, and the amount of radionuclide suspended depends on the concentration of radionuclide present. The RARF for the suspension due to blast effect without ignition of the combustible materials is difficult to ascertain because the material itself would be displaced by the accelerated airflow. The RARF selected is that for the suspension due to shock or vibration (1E-03). 
(8) Pressurized Release (Venting of the Volume Holding the Material That Has Been Slowly Pressurized [>1 min] up to $3.45 \mathrm{MPa}_{\mathrm{g}}$ [500 psig] before the Release). (See point 6.b.3.)

c. Cellulosics (All Cellulose Materials Such as Paper, Rags, Wood, Cardboard, etc.). The contaminated surface of the material was assumed to be exposed to the atmosphere.

(1) Spill (Free-Fall of the Material and Impact with a Hard, Unyielding Surface). No direct experimental data exist on the suspension of solid contaminants from the surface of cellulosic material as a result of the free-fall and impact of the material on a hard unyielding surface. (See point 6.a.1.)

(2) Crush-Impact (Crush-Impact of Material by a Moving Object). No direct experimental data exist on the suspension of particulate contamination from the surface of cellulosic materials by crushimpact forces. (See point 6.a.1.)

(3) Pressurized Release (Venting of Volume Holding Material That Has Been Rapidly Pressurized to $3.45 \mathrm{MPa}_{\mathrm{g}}$ [500 psig] before Release). No direct experimental data exist for the suspension of particulate contamination from the surface of cellulosic material by the airborne transport of the material and impact with a hard unyielding surface. (See point 6.a.1.)

(4) Small Fire (less than the entire inventory of radionuclides is involved, and the containment of the facility is not impaired). The RARF is based on the maximum experimental value measured for suspension of particles in the respirable size range during the burning of the uncontained contaminated material in flowing air $(1 \mathrm{E}-02)$.

(5) Large Fire (almost all of the inventory of radionuclides is involved, and the containment of the facility is damaged). For the purpose of this scenario, the extremely conservative assumption was made that the event would defeat the package containment, make the material airborne, and ignite and burn the contaminated material while it is airborne. For materials with a large surface-to-volume ratio and a low mass, keeping the material airborne while it burns may be possible. The likelihood that a substantial fraction of the inventory 
will show this behavior is much less probable. Nonetheless, the RARF is based on the maximum experimental value measured for the suspension of particles from the burning of tissue paper contaminated with a dry ceramic powder while it is suspended in a flow of air greater than $100 \mathrm{~cm} / \mathrm{s}$ (39 in./s) (4E-01).

(6) Deflagration (Rapid Burning of a Flammable Mixture of Gas: Blast Effect). This scenario assumes that the contaminated combustible material is ignited by the passage of the flame front; the RARF is based on the suspension of material during burning of the material. (See point 6.c.4.)

(7) Detonation (Reactions Completed in Microseconds to Milliseconds: Shock Effects). The RARF is a sum of the RARFs for shock and blast (without ignition of the contaminated combustible material) effects. The RARF for the shock effect is a conservative interpretation of the Steindler and Seefeldt (1980) correlation that predicts the fragmentation of solids and liquids due to a detonation on or in the material. The mass of particles in the respirable size range is equal to the mass of the TNT equivalence estimated for the explosion. The mass of material fragmented is the contaminated combustible material; the amount of radionuclides made airborne with this mass depends on the concentration of the radionuclides on the combustible material. The RARF for the blast effect is the suspension of the powder from the surface of the cellulosic material due to the accelerated gas velocity resulting from the detonation. The estimation of the suspension under this circumstance is complicated by the movement of the light cellulosic that may have a high surface-to-mass ratio. The RARF for this condition can be postulated to be bounded by the RARF assumed for the suspension of surface contamination due to shock or vibration (1E-03).

(8) Pressurized Release (Venting of the Volume Holding the Contaminated Combustible Material That Was Slowly [ $>1 \mathrm{~min}]$ Pressurized to $3.45 \mathrm{MPa}_{\mathrm{g}}[500 \mathrm{psig}]$ or Less). (See point 6.c.3.)

d. Polystyrene (Polystyrene Beads Such as Ion-Exchange Resin)

(1) Spill (Free-Fall and Impact on a Hard, Unyielding Surface of the Polystyrene). No direct experimental data exist on the suspension of particulate surface contamination from the free-fall and impact 
of small pieces of polystyrene. The RARF is based on the assumption that the RARF will be bounded by the maximum experimental value measured for the suspension of an unrestrained, dry ceramic powder from a stiff, flexible nonporous surface by the impact of moving objects (1E-03).

(2) Crush-Impact (Crush or Impact of Moving Object on Contaminated Polystyrene). No direct data exist on the suspension of particulate surface contamination from polystyrene pieces as a result of the impact of moving objects. The RARF is based on the assumption that the RARF will be bounded by the suspension of an unrestrained, dry ceramic powder by the impact of falling objects (1E-03).

(3) Pressurized Release (Venting of the Volume Containing the Contaminated Polystyrene Rapidly Pressurized up to $3.45 \mathrm{MPa}_{\mathrm{g}}$ [500 psig]). No direct experimental data exist on the suspension of solid particulate contamination from the surface of polystyrene pieces during the airborne transport of the material. The RARF is based on the maximum experimental value measured for the suspension of an unrestrained, dry ceramic powder due to the impact of falling objects (1E-03).

(4) Small Fire (less than the entire inventory of radionuclides is involved, and the confinement of the facility is unimpaired). The RARF is based on the maximum experimental value for the suspension of particles in the respirable size range during the burning in flowing air of polystyrene contaminated with liquid (1E-02).

(5) Large Fire (almost the entire inventory of radionuclides is involved, and the confinement of the facility is damaged). (See point 6.d.4.)

(6) Deflagration (Rapid Burning of a Flammable Mixture of Gas; Reaction Completed in Milliseconds to Seconds; Blast Effects). No direct experimental value was found for the suspension of surface contamination from the surface of polystyrene under accelerated gas flow. The scenario assumed here is the deflagration of a flammable mixture that fills up to $25 \%$ of the free volume directly over the powder, leading to a RARF of $1 E-01$ of the powder on the surface of the polystyrene. 
(7) Detonation (Reaction Completed in Microseconds to Milliseconds; Shock Effects). The RARF is the sum of the shock and blast effects from a detonation. The RARF for the shock effect is based on a conservative interpretation of the Steindler and Seefeldt (1980) correlation that predicts the fragmentation of solids and liquids as a result of a detonation on or in the material. The mass of particles in the respirable size range airborne is equal to the mass of the TNT equivalence estimated for the explosion. The RARF is for the blast effects outlined in point 6.d.6.

(8) Pressurized Release (Venting of the Volume Containing the Contaminated Polystyrene That Has Been Slowly [ $>1 \mathrm{~min}]$ Pressurized to $3.45 \mathrm{MPa}_{\mathrm{g}}[500 \mathrm{psig}]$ ). (See point 6.d.3.)

7. Brittle Solids. (Solids That May Undergo Brittle Fracture under Crush-Impact Stress). For the purposes of these analyses, the brittle materials under consideration are vitrified HLW, and, therefore, RARFs are not applicable. Other physical forms that may undergo brittle fracture under crush-impact stresses (aggregates such as concrete) are covered in point 10 under noncombustible aggregate solids.

8. Viscous Liquids. Viscous liquids have many forms, such as sludges and nonNewtonian fluids. The form of primary concern to these analyses is the molten vitrified HLW not found in LLW. The RARFs for this physical form are not applicable here.

9. Metals.

a. Inert (Nonreactive under Normal Atmospheric Conditions)

(1) Spills (Free-Fall of Metal and Impact with a Hard, Unyielding Surface). No direct experimental data exist for the suspension of loose, particulate contamination from the surface of metal during free-fall or impact with a hard unyielding surface. The RARF is based on the assumption that the RARF will be bounded by the maximum experimental value measured for the suspension of particles in the respirable size range by the impact of a falling object from unrestrained, dry ceramic powder on a stiff, flexible nonporous surface $(1 \mathrm{E}-03)$. The materials at risk in this case are the radionuclides contained in the loose, particulate surface contamination. Radionuclides that have been absorbed into the 
metal matrix by prior conditions or treatment may be vulnerable if the surface of the inert metal has been subject to corrosion during the long storage period.

(2) Crush-Impact (Crush or Impact by a Moving Object). No direct experimental data exist for the suspension of loose particulate contamination from the surface of metals by crush or impact stresses. The RARF is based on the assumption that the RARF will be bounded by the maximum experimental value for the suspension of particles in the respirable size range by the impact of falling objects on unrestrained, dry ceramic powder on a stiff, flexible nonporous surface (1E-03). (See point 9.a.1 for materials at risk.)

(3) Pressurized Release (Venting of Volume Rapidly Pressurized to a Pressure up to $3.45 \mathrm{MPa}_{\mathrm{g}}$ [500 psig] Holding the Contaminated Metal). No direct experimental data exist for the suspension of loose particulate contamination from the surface of metal pieces during transport through the air or on impact. The RARF is based on the assumption that the RARF will be bounded by the maximum experimental value for the suspension of a dry ceramic powder during venting (5E-02). (See point 9.a.1 for materials at risk.)

(4) Small Fires (less than the entire inventory of radionuclides is involved, and the confinement capability of the facility is not impaired). The RARF is based on the maximum experimental value measured during the heating of a nonreactive, dry ceramic powder on a hard unyielding surface in flowing air (6E-05). (See point covered in 9.a.1 for materials at risk.)

(5) Large Fire (almost the entire inventory of radionuclides is involved, and the confinement capability of the facility is damaged). (See point 9.a.4.)

(6) Deflagration (Rapid Burning [Reaction Completed in Milliseconds to Seconds] of a Flammable Mixture of Gas: Blast Effects). No direct experimental data exist on the suspension of particles in the respirable size range as the result of a deflagration near or over an unrestrained, dry ceramic powder. The RARF is based on the value assumed for the suspension of particles from an unrestrained, dry ceramic powder on a hard unyielding surface as the result of the deflagration of a flammable mixture of gas filling less than $25 \%$ of 
the free volume available directly over the powder (1E-01). (See point 9.a.1 for materials at risk.) The RARF may be limited by the amount of particles in the respirable size range present in the loose, particulate surface contamination.

(7) Detonation (Reaction Completed in Microseconds to Milliseconds: Shock Effects). The RARF is the sum of the shock and blast effects from the explosion. The RARF for the shock effects is based on a conservative interpretation of the Steindler and Seefeldt (1980) correlation that predicts the fragmentation of metals and liquids by detonation on or in the material. In this case, the RARF is applied to the total metal mass, and the radionuclides suspended are the radionuclides associated with the fraction of metal made airborne. The RARF for the blast effects is given in point 9.a.6 (1E-01).

(8) Pressurized Release (Venting of the Volume Holding the Metal That Has Been Slowly Pressurized to $3.45 \mathrm{MPa}_{\mathrm{g}}$ [500 psig] before Release). (See point 9.a.3.)

b. Reactive Metals (Uranium; Plutonium)

(1) Spill (Free-Fall and Impact onto a Hard, Unyielding Surface of the Reactive Metal). Reactive metal has a greater potential for corrosion under storage conditions (varying temperature, oxygen availability, presence of moisture). However, because corrosion is a function of the surface area and LLW does not normally contain large pieces of reactive metal, the effect of corrosion is limited. Very small pieces of reactive metal stored for long periods of time may well be present as pockets of oxide powder. No direct experimental data exist for the suspension of particles in the respirable size range from corroded surfaces of reactive metal during free-fall and impact with hard unyielding surfaces. The RARF is based on the assumption stated in point 9.a.1 and is $1 E-03$. The materials at risk for this event are outlined in point 9.a.1.

(2) Crush-Impact (Crush or Impact of Moving Object onto Reactive Metal). (See point 9.b.1.)

(3) Pressurized Release (Venting of the Volume Holding the Reactive Metal That Has Been Rapidly [ $<1 \mathrm{~min}$ ] Pressurized up to $3.45 \mathrm{MPa}_{\mathrm{g}}$ [500 psig]). No direct experimental data exist for the suspension of 
loose particulate material from the surface of reactive metal by the accelerated velocities present during the venting or, if the metal pieces are ejected from the volume by the venting, during transport through the air and impact with a hard unyielding surface. The RARF is based on the assumption that the suspension of any loose, particulate surface material will be bounded by the maximum experimental value measured for the suspension of particles in the respirable size range during the venting of a dry ceramic powder slowly pressurized to $3.45 \mathrm{MPa}_{\mathrm{g}}$ (500 psig) (5E-02).

(4) Small Fire (less than the entire inventory of radionuclides is involved, and the confinement capability of the facility is not impaired). Reactive metals oxidize as a function of temperature and oxygen availability. At a temperature that is a function of the surface-to-mass ratio, the metal may achieve a state of self-sustained oxidation. For bulk pieces (surface-to-mass ratio $<10 \mathrm{~cm}^{2} / \mathrm{g}$ ), the suspension of particles from the oxidizing surface in flowing air has a maximum experimental value of $6 \mathrm{E}-04$, which was selected for this event. If the reactive metal is postulated to have completely oxidized in storage before the event, the RARF shown in point 9.b.3 (5E-02) is applicable if the severity of impact of aircraft parts is postulated to make the LLW airborne.

(5) Large Fire (almost the entire inventory of radionuclides is involved, and the confinement capability of the facility is damaged). (See point 9.a.4.) If the reactive metal is postulated to exist in very fine pieces $\left(0.1 \mathrm{~cm}^{2} / \mathrm{g}\right)$ and to be made airborne by the severity of the impact of aircraft parts, the metal would probably achieve selfsustained oxidation; a RARF would be applicable for ignited reactive metal in free-fall (1E-02). If the reactive metal is postulated to have completely oxidized during storage before the event, the RARF shown in point 9.b.3 (5E-02), is applicable.

(6) Deflagration (Rapid Burning of Flammable Mixture of Gas, with Reaction Completed in Milliseconds to Seconds: Blast Effects). The RARF is based on the value assumed for the suspension of powder from a hard unyielding surface due to the deflagration of a flammable gas mixture that fills less than $25 \%$ of the free volume directly over the unrestrained powder. The RARF may be limited by the fraction of the metal (or oxide powder if so postulated) that is present as particles in the respirable size range. The fraction of 
metal as particles in the respirable size range may be very small because metal in this form is very reactive because of the high surface-to-mass ratio. If finely divided metal (surface-to-mass ratio of $100 \mathrm{~cm}^{2} / \mathrm{g}$ ) were made airborne in the elevated-temperature atmosphere resulting from a deflagration, the fine particles would probably achieve self-sustained oxidation; the RARF for suspension from ignited drops of molten metal in free-fall (1E-02) would be applicable to pieces of reactive metal in this size range.

(7) Detonation (Reaction Completed in Microseconds to Milliseconds: Shock Effects). The RARF is the sum of the RARFs for shock and blast effects. The RARF for the shock effects is based on a conservative interpretation of the Steindler and Seefeldt (1980) correlation that predicts the fragmentation of solids and liquids as a result of detonations on or in the material. The RARF is the mass of particles in the respirable size range suspended equal to the mass of the TNT equivalence predicted for the experiment. The RARF for the blast effects is given in point 9.a.6.

(8) Pressurized Release (Venting of the Volume Holding the Reactive Metal That Has Been Slowly [ $>1 \mathrm{~min}$ ] Pressurized to $3.45 \mathrm{MPa}_{\mathrm{g}}$ [500 psig] or less). (See point 9.b.3.)

\section{Noncombustible Aggregated Solids}

a. Spills (Free-Fall and Impact on a Hard, Unyielding Surface). Based on experiments where crush-impact forces were imposed on brittle materials (e.g., glass, sintered compacted ceramic oxide, cement, sandstone), an empirical model was formulated that predicts the particles in the respirable size range generated. (See Equation D.2.)

b. Crush-Impact (Crush or Impact from Contact with a Moving Object). The RARF is given in point 10.a.

c. Pressurized Release (Venting of the Volume Holding the Noncombustible Aggregated Solid That Has Been Rapidly [ $<1 \mathrm{~min}]$ Pressurized to $3.45 \mathrm{MPa}_{\mathrm{g}}$ [500 psig] or Less). No direct experimental data exist for the suspension of particles in the respirable size range from noncombustible aggregated solids. Large pieces would not be suspended by the accelerated gas velocities induced by the pressure release. Only the fine, powdery corrosion product (if any) on the surface of the solid 
would be subject to suspension, and this fraction may contain an appreciable fraction of the radionuclide inventory that usually exists as surface contamination. The most applicable RARF would be that postulated for the venting of dry ceramic powder under these conditions $(5 \mathrm{E}-02)$. The material at risk, however, would be the fraction of the radionuclide inventory associated with the loose, powdery corrosion product on the surfaces of the noncombustible aggregated solid.

d. Small Fires (less than the entire inventory of radionuclides is involved, and the confinement capability of the facility is not impaired). Noncombustible aggregated solids such as concrete (grout) react under high temperature and oxidize with time to a loose powder (calcium oxide [CaO]) that would increase the material at risk. Substantial oxidation is not anticipated for small fires. The RARF is based on the maximum experimental value for suspension of a dry ceramic powder heated on a hard unyielding surface in flowing air (6E-05).

e. Large Fires (almost the entire inventory of radionuclides is involved, and the confinement capability of the facility is damaged). Depending on the surface-to-volume ratio, a substantial fraction of the noncombustible aggregated solid and the radionuclides associated with the solid may oxidize during fires of long duration $(>1 \mathrm{~h}$ ), thereby increasing the material at risk. The RARF is given in point 10.d.

f. Deflagration (Rapid Burning of Flammable Mixtures of Gas, with Reaction Completed in Milliseconds to Seconds: Blast Effects). The accelerated velocities induced by a deflagration would not suspend substantial pieces ( $>100 \mathrm{~g}$ [3.5 oz]) of noncombustible aggregated solids. Only the loose powdery material present on the surface of the solid exposed to the accelerated gas velocities would be affected. The RARF is based on the assumption that $1.0 \mathrm{E}-01$ of the powder is suspended by a deflagration of a flammable mixture of gas that fills less than $25 \%$ of the free volume directly over the unrestrained powder.

g. Detonation (Reaction Completed in Microseconds to Milliseconds: Shock Effects). The RARF is the sum of the shock and blast effects. The RARF for the shock effects is based on a conservative interpretation of the Steindler and Seefeldt (1980) correlation that predicts the fragmentation of solids or liquid from a detonation on or in the material. The RARF is the mass of material suspended as particles in the 
respirable size range equal to the mass of the TNT equivalence estimated for the explosion. The RARF for the blast effects is given in point 10.f.

h. Pressurized Release (Venting of the Volume Holding the Noncombustible Aggregated Solids That Have Been Slowly Pressurized to $3.45 \mathrm{MPa}_{\mathrm{g}}$ [500 psig] or Less). (See point 10.c.)

D.1.2.2.2 WM PEIS Waste RARFs for LLW Processing by Incineration. The RARFs for the waste categories and accident stresses anticipated during the incineration of LLW are tabulated in Table D.4 with the accompanying explanations.

D.1.2.2.3 WM PEIS Waste RARFs for HLW Processing and Storage. The RARFs for this waste category and the accident stresses during storage and processing of HLW (recovery and vitrification) are tabulated in Table D.5 with some additional clarification of the assumptions on which the values are based.

\section{D.2 LEAK PATH FACTORS}

\section{D.2.1 Background}

The LPF is defined as the fraction of material generated by the accident stress at the point of origin (RARF) that challenges the interface to the next volume. If the initial volume is the free volume of a container, the next volume could be an enclosure such as a glove box or hot cell. For these analyses, the next volume is the ambient environment; the initial volume is the exhaust system or operating area around the material. The implicit assumptions are that the waste form is contained or confined and that the initiating event breaches the initial barrier, thus releasing the airborne material suspended to the initial volume.

Facilities of various categories have varying degrees of air control systems ranging from none, to systems that direct the flow from areas of lesser contamination to areas of greater contamination by the use of negative pressure. The latter systems have single or multiple stages of filtration devices to attenuate the release of specific materials (e.g., particulate material, iodine). The directional flow systems may also filter both the enclosure or process exhaust and the operationalarea or room exhaust. For the airborne materials of concern (nonvolatile particulate materials) in this study, the only filtration devices that are considered are HEPA filters. 


\section{D.2.2 Technical Basis}

The filtration medium for a HEPA filter is a glass-fiber mat that collects particles challenging the medium through direct impaction (large-diameter particles that cross stream lines), interception (medium-diameter particles that deviate from the stream lines), and diffusion (submicron-sized particles that follow the stream lines but are collected in the pockets formed by the intersecting fibers). Particle collection depends on the aerodynamic size of the particle, the flow velocity, the fiber diameter, and leakage. The filter depends on multiple layers of packed fibers to provide the collection efficiency of the filter.

High-efficiency particulate air filters have approximately $18.6 \mathrm{~m}^{2}\left(200 \mathrm{ft}^{2}\right)$ of filter mat for a collection area. This expanse of filter medium is packed into a package $61-\mathrm{cm} \times 61-\mathrm{cm} \times \sim 30.5-\mathrm{cm}$ (2-ft $\times 2-\mathrm{ft} \times \sim 1-\mathrm{ft}$ ) deep by pleating the filter and separating the pleat using rigid separators at three locations across the filter folds. Air that enters the filter has momentum, and most of the filtration occurs at the face of the back folds, migrating back toward the face as the filter pores become filled or blocked by collected material. Thus, filters fail when the back fold is torn by impact from shock fronts exceeding the strength of the medium. Other accident environments may result in loss of function for the HEPA filters ranging from failure due to the temperature duration exceeding the strength of the mat, the chemical environment (e.g., hydrogen fluoride [HF]), static pressure, and blinding from the deposition of combustion products (i.e., soot and moisture) and (Bergman 1993). Conservative values for the potential failure pressure of HEPA filters due to various accident and environmental parameters taken from the report by Bergman (1993) are shown in Table D.6.

Normal environmental factors also have a deleterious effect. The filter medium is relatively (but not completely) free of organic binder and loses strength with age (Bergman 1993). Other factors, such as radiation, elevated temperature, chemical environment, and moisture may also result in loss of collection efficiency (Bergman 1993). Conservative values for the loss of collection efficiency due to various environmental conditions taken from the report by Bergman (1993) are tabulated in Table D.7. Recommended filter efficiencies for various types of systems extracted from Elder et al. (1986) are shown in Table D.8.

\section{D.2.3 Application to WM PEIS}

Because of the diversity of situations, conditions, equipment, and materials that may be present in waste handling, storage, and processing facilities, the LPFs that may be applicable are just as diverse. For the purpose of these analyses, the simplifying assumption was made that a functional exhaust system in a structurally sound structure will function as designed; air is drawn into the system and exhausted via the designed outlet. If the system is equipped with HEPA filters, the filters are assumed to be structurally sound, unless demonstrated by engineering calculations to be deteriorated by age or environmental conditions. A particle collection efficiency of $99.9 \%$ 
(transmission factor of $1 \mathrm{E}-03$ ) was assumed for the first bank, and a particle collection efficiency of $99.8 \%$ (transmission factor of 2E-03) was assumed for each subsequent bank. Bergman (1993) suggests that the particle collection efficiency of $99.9 \%$ (transmission factor of $1 \mathrm{E}-03$ ) be applied to each bank; but the standard is still in the review process, and the more conservative values are recommended. The damage thresholds listed in Table D.6 can be used to evaluate the failure of HEPA filters under accident conditions.

Simplistic calculations have been performed to ascertain the failure of HEPA filters due to explosive events within facilities. The very conservative assumption was made that a HEPA filter of standard size $(61-\mathrm{cm} \times 61-\mathrm{cm} \times 30.5-\mathrm{cm}$ deep $[2-\mathrm{ft} \times 2-\mathrm{ft} \times 1-\mathrm{ft}$ deep] $)$ was at the system inlet from a room measuring $20 \mathrm{~m}(65.6 \mathrm{ft})$ long $\times 10 \mathrm{~m}(32.8 \mathrm{ft})$ wide $\times 5 \mathrm{~m}(16.4 \mathrm{ft})$ high with a functional exhaust system. A failure pressure of $1.5 \mathrm{psig}\left(0.00103 \mathrm{MPa}_{\mathrm{g}}\right)$ was assumed for the HEPA filter failure. The explosion was assumed to occur in the center of the room, and the minimum TNT equivalence necessary to result in the estimated HEPA-filter-failure pressure at the exhaust inlet was calculated. Under these very conservative assumptions, filter failure would not occur unless the TNT equivalence for a deflagration exceeded $7.7 \mathrm{~kg}\left(16.9 \mathrm{lb}_{\mathrm{m}}\right)$ and a detonation exceeded $5.8 \mathrm{~kg}$ $\left(12.7 \mathrm{lb}_{\mathrm{m}}\right)$. These values may be used as a screening level when explosive events are considered for this study.

\section{D.3 MAPPING OF WM PEIS TREATABILITY CATEGORIES WITH PHYSICAL FORM CATEGORIES FOR ACCIDENT ANALYSIS}

The WM PEIS (DOE 1996) accident analysis assumes the application of a single accident physical form to approximate the actual physicochemical characteristics of the various treatability categories. A major assumption is that the release mechanism is assumed to be similar for all radionuclides within a given release class. This approach ignores the fact that the release fraction may, in general, be dependent on many variables, including the possible conversion into a less reactive form (as in the case of elemental iodine $\left[\mathrm{I}_{2}\right]$ reacting with cesium [Cs] to form cesium iodide [CsI, a much less volatile and more water-soluble form than iodine), the nature of the substrate, the form of contamination, and the characteristics of the container. This oversimplification is, however, necessary, given the lack of information concerning the physical and chemical characteristics of the various WM PEIS treatability categories.

The generic accident physical forms were developed on the basis of interaction with Science Applications International Corporation and review of the available information. Elder et al. (1986) divided the various radionuclides under a fire or explosive stress into four categories: (1) noble gases (e.g., krypton 85 [Kr-85]); (2) halogens; (3) volatile solids (Cs, rubidium [Rb], Ru, tellurium [Te], technetium [Tc], and selenium [Se]); and (4) nonvolatile solids (including actinides and other fission products). Elder et al. (1986) stated that the release fractions for the various 
semivolatile radionuclides are to be reviewed on a case-by-case basis as a function of accident stress and conditions. Identical release fractions were applied to both volatile and nonvolatile solids by Elder et al. (1986). On the basis of this and other references (DOE-STD-3010-94, 1994), the categories of volatile solids and nonvolatile solids were combined into a single release class. In all cases, the assumption was that, on application of a given accident stress, all of the noble gases and halogens (including noncondensable gases) would be completely released (release fraction of unity). The mapping shown here applies only for the semivolatile and nonvolatile radionuclides.

Consideration of physical and chemical properties were used to match appropriate accident physical forms to the treatability categories. A matrix displaying waste characteristics was developed for the various WM PEIS waste types on the basis of available safety documentation and inventory characteristics. The mapping of the LLW treatability categories with the accident analysis physical forms shown in Table D.9 is, in general, based on the waste and process descriptions given by Feizollahi and Shropshire (1992) and by Goyette and Dolak (1996). As shown in Table D.9, both the waste treatability category and the accident analysis physical form are assumed to be independent of site. Similar information for current storage of TRUW is presented in Table D.10.

More detailed information on process and waste characterization is available for HLW management, and therefore site- and process-specific physical forms were generated (Table D.11). Available safety documentation was used to ensure that the physicochemical characteristics for the dominant accident scenarios were considered. 
TABLE D.1 Summary of Release Fraction Parameters Abstracted from Elder et al. (1986)

\begin{tabular}{|c|c|c|c|}
\hline $\begin{array}{l}\text { Release Mechanism and } \\
\text { Safety Analysis Parameter }\end{array}$ & $\begin{array}{l}\text { Range of } \\
\text { Observation }\end{array}$ & Current Practice & $\begin{array}{l}\text { Recommended } \\
\text { Value }\end{array}$ \\
\hline Failed fuel-gap release ${ }^{a}$ & $0.015-0.34$ & $0.818-0.10$ & 0.10 \\
\hline Noble gas & $-b$ & 0.30 & 0.30 \\
\hline $\mathrm{K}-85$ & $0.025-0.49$ & $0.0032-0.10$ & 0.10 \\
\hline Halogens & - & 0.30 & 0.30 \\
\hline$I-129$ & $<4.0 \mathrm{E}-06-0.80$ & - & 0.01 \\
\hline \multicolumn{4}{|l|}{ Volatile solids (Cs, $\mathrm{Rb}, \mathrm{Ru})$} \\
\hline Nonvolatile solids & $\begin{array}{l}<2.0 \mathrm{E}-06- \\
8.0 \mathrm{E}-04\end{array}$ & $<10.0 \mathrm{E}-6-0.05$ & 0.01 \\
\hline Fire release ${ }^{a}$ & - & $0.90-1.00$ & 1.00 \\
\hline Noble gas & $0.65-0.84$ & 1.00 & 1.00 \\
\hline Halogens & $3.0 \mathrm{E}-06-0.01$ & $0.01-0.90$ & 0.01 \\
\hline Volatile solids & $4.0 \mathrm{E}-06-0.38$ & $0.01-0.60$ & 0.01 \\
\hline Nonvolatile solids & $5.0 \mathrm{E}-04-0.20$ & $0.01-0.05$ & 0.01 \\
\hline Fly ash & $<0.1-10$ & $<5$ & $<5$ \\
\hline \multicolumn{4}{|l|}{ Airborne particle size $(\mu \mathrm{m})$} \\
\hline Explosion $^{2}$ & - & 1.00 & 1.00 \\
\hline Noble gas & - & 1.00 & 1.00 \\
\hline Halogens & - & 0.001 & 0.01 \\
\hline Volatile solids & $9.0 \mathrm{E}-05-0.14$ & 0.01 & 0.01 \\
\hline Nonvolatile solids & $1.0-71 \mathrm{mg} / \mathrm{m}^{3}$ & $10-100 \mathrm{mg} / \mathrm{m}^{3}$ & $100 \mathrm{mg} / \mathrm{m}^{3} \mathrm{c}$ \\
\hline Airborne material & - & $<10-30$ & $<10$ \\
\hline \multicolumn{4}{|l|}{ Airbome particle size $(\mu \mathrm{m})$} \\
\hline Criticality & 1.0E $15-4.7 \mathrm{E} 18$ & 1.0E18-3.7E18 & $1.0 \times 10^{18}$ \\
\hline Initial pulse: fissions & No estimate & $0.4 \mathrm{E} 17-5.0 \mathrm{E} 17$ & $1.9 \times 10^{17}$ \\
\hline $\begin{array}{l}\text { Secondary pulse: fissions } \\
\text { Pulse interval }\end{array}$ & No estimate & $10 \mathrm{~min}$ & $10 \min$ \\
\hline Total fissions & $3.0 \mathrm{E} 15-1.2 \mathrm{E} 20$ & $1.0 \mathrm{E} 18-1.0 \mathrm{E} 20$ & $1.0 \mathrm{E} 19$ \\
\hline Total time & No estimate & $7 \mathrm{~min}-24 \mathrm{~h}$ & $8 \mathrm{~h}$ \\
\hline Gas release fraction & No estimate & 1.00 & 1.00 \\
\hline Halogen release fraction & No estimate & $0.25-1.00$ & $0.25^{\mathrm{d}}$ \\
\hline Solid release fraction & No estimate & $0.001-0.20$ & $\mathrm{e}$ \\
\hline
\end{tabular}

a Fraction released, except as noted.

b A hyphen indicates data not available.

c Applicable to particulate material only.

d Includes release and plate-out.

e Use values from regulatory guides 3.33, 3.34, and 3.35 from the U.S. Nuclear Regulatory Commission (NRC 1977a, c, b). 
TABLE D.2 WM PEIS Waste RARFs: Physical Type or Subcategory versus Stress

\begin{tabular}{|c|c|c|c|c|c|c|c|c|c|}
\hline \multirow{3}{*}{\multicolumn{2}{|c|}{$\begin{array}{c}\text { Physical Form of Waste: } \\
\text { Waste Categories and Subcategory }\end{array}$}} & \multicolumn{8}{|c|}{ Stress } \\
\hline & & \multicolumn{3}{|c|}{ Mechanical Release } & \multicolumn{2}{|c|}{ Fire } & \multicolumn{3}{|c|}{ Explosive Release } \\
\hline & & $\begin{array}{c}\text { Free-Fall } \\
\text { Spill }\end{array}$ & Crush-Impact & $\begin{array}{c}\text { Over- } \\
\text { pressurization }\end{array}$ & Sinall & Large & Blast & Shock & $\begin{array}{l}\text { Venting High } \\
\text { Pressure }\end{array}$ \\
\hline I. & Noncondensable gases ${ }^{a}$ & $N A^{b}$ & NA & NA & NA & $\mathrm{NA}$ & NA & NA & NA \\
\hline \multirow[t]{4}{*}{2.} & Volatiles & & & & & & & & \\
\hline & a. ${ }^{3} \mathrm{H}_{2} \mathrm{O} /{ }^{3} \mathrm{H}$ hydride ${ }^{c}$ & NA & NA & NA & NA & NA & NA & NA & NA \\
\hline & b. Iodine $e^{d}$ & NA & NA & $\mathrm{NA}$ & NA & NA & NA & $\mathrm{NA}$ & $\mathrm{NA}$ \\
\hline & c. Ruthenium & NA & NA & NA & $1 E-02$ & $1 \mathrm{E}-01$ & $\mathrm{NA}$ & NA & $\mathrm{NA}$ \\
\hline \multicolumn{10}{|c|}{ 3. Organic combustible liquids } \\
\hline & a. Solutions & $2 \mathrm{E}-04$ & $2 \mathrm{E}-04$ & $1 \mathrm{E}-04$ & $1 E+\infty\left({ }^{3} \mathrm{H}\right)$ & $1 \mathrm{E}+00\left({ }^{3} \mathrm{H}\right)$ & $|\mathrm{E}-0|$ & mass $=\mathrm{TNT} \mathrm{Eq}^{\mathrm{c}}$ & $6 E-0.4$ \\
\hline & & & & & IE-02 & $|E-0|$ & & & \\
\hline & b. Slurries & $4 \mathrm{E}-05$ & $4 \mathrm{E}-05$ & IE-04 & $1 \mathrm{E}-02$ & $\mid E-01$ & $|\mathrm{E}-0|$ & mass $=$ TNT Eq & $4 \mathrm{E}-04$ \\
\hline \multicolumn{10}{|c|}{ 4. Aqueous liquids } \\
\hline & a. Solutions & $2 \mathrm{E}-04$ & $2 \mathrm{E}-04$ & IE-04 & $2 \mathrm{E}-03$ & $2 \mathrm{E}-03$ & $1 E-04$ & mass $=\mathrm{TNT} E q$ & $6 \mathrm{E}-04$ \\
\hline & b. Slurrics & $4 \mathrm{E}-05$ & $4 E-05$ & IE-04 & $2 E-03$ & $2 E-03$ & $1 E-04$ & mass $=$ TNT Eq & $6 \mathrm{E}-04$ \\
\hline & c. Superheated solutions ${ }^{r}$ & $\mathrm{NA}$ & NA & $\mathrm{NA}$ & NA & NA & NA & NA & $\mathrm{NA}$ \\
\hline \multicolumn{10}{|c|}{ 5. Powders } \\
\hline & a. Combustible & $4 E-05$ & $4 \mathrm{E}-05$ & IE-04 & $1 \mathrm{E}-02$ & $\mid \mathrm{E}-01$ & $1 E-01$ & mass $=0.2 \mathrm{TNT} \mathrm{E}_{\mathrm{q}}$ & $4 \mathrm{E}-04$ \\
\hline & b. Noncombustible & $6 \mathrm{E}-04$ & $3 E-03$ & $2 \mathrm{E}-03$ & $1 \mathrm{E}-02$ & $1 \mathrm{E}-02$ & $7 \mathrm{E}-02$ & Inass $=0.2 \mathrm{TNT}$ Eq & $7 \mathrm{E}-02$ \\
\hline \multirow[t]{5}{*}{6.} & Combustible solids & & & & & & & & \\
\hline & a. $D A W^{\text {h }}$ & $1 \mathrm{E}-03$ & $1 \mathrm{E}-03$ & IE-03 & $5 \mathrm{E}-04$ & $4 \mathrm{E}-03$ & $5 \mathrm{E}-04$ & mass $=\mathrm{TNT} E \mathrm{E}$ & IE-03 \\
\hline & $\begin{array}{l}\text { b. Plastic (including } \\
\text { elastomers) }\end{array}$ & IE-03 & IE-03 & $1 E-03$ & IE-02 & $5 E-02$ & $1 \mathrm{E}-02$ & mass $=\mathrm{TNT} E \mathrm{q}$ & $1 \mathrm{E}-03$ \\
\hline & c. Cellulosics & $1 \mathrm{E}-03$ & $1 \mathrm{E}-03$ & $1 \mathrm{E}-03$ & IE-02 & $1 \mathrm{E}-02$ & $1 \mathrm{E}-02$ & mass $=$ TNT Eq & IE-03 \\
\hline & d. Polyethylene & IE-03 & IE-03 & $1 \mathrm{E}-03$ & $1 E-02$ & $1 \mathrm{E}-02$ & $1 \mathrm{E}-02$ & mass $=$ TNT Eq & $1 E-03$ \\
\hline
\end{tabular}




\section{TABLE D.2 (Cont.)}

\begin{tabular}{|c|c|c|c|c|c|c|c|c|}
\hline \multirow[b]{3}{*}{$\begin{array}{l}\text { Physical Form of Waste: } \\
\text { Waste Categories and Subcategory }\end{array}$} & \multicolumn{8}{|c|}{ Stress } \\
\hline & \multicolumn{3}{|c|}{ Mechanical Release } & \multicolumn{2}{|c|}{ Fire } & \multicolumn{3}{|c|}{ Explosive Release } \\
\hline & $\begin{array}{l}\text { Free-Fall } \\
\text { Spill }\end{array}$ & Crush-Impact & $\begin{array}{c}\text { Over- } \\
\text { pressurization }\end{array}$ & Stmall & Large & Blast & Shock & $\begin{array}{l}\text { Veming High } \\
\text { Pressure }\end{array}$ \\
\hline 7. Brittle solids (excluding SNF) & NA & $2 \mathrm{E}-11 \mathrm{pgh}$ & $6 \mathrm{E}-07$ & NA & NA & $4 \mathrm{E}-05$ & mass $=\mathrm{TNT} \mathrm{Eq}$ & $4 E-0.5$ \\
\hline 8. Viscous liquids (vitrified HLW) ${ }^{k}$ & $7 \mathrm{E}-09$ & 7E-09 & NA & NA & NA & NA & mass $=\mathrm{TNT} \mathrm{Eq}$ & NA \\
\hline \multicolumn{9}{|l|}{ 9. Metals } \\
\hline a. Inert & $1 \mathrm{E}-03$ & $1 \mathrm{E}-03$ & $2 \mathrm{E}-03$ & $6 \mathrm{E}-05$ & $6 \mathrm{E}-05$ & $7 \mathrm{E}-02$ & mass $=\mathrm{TNT} E q$ & SE-02 \\
\hline b. Reactive & $1 E-03$ & $1 \mathrm{E}-03$ & $2 E-03$ & $6 \mathrm{E}-04$ & $1 \mathrm{E}-02$ & $7 \mathrm{E}-02$ & mass $=\mathrm{TNT} E q$ & $5 \mathrm{E}-02$ \\
\hline 10. Noncombustible aggregate & $2 E-11 p g h^{j}$ & $2 E-11 \rho g h^{j}$ & $2 \mathrm{E}-03$ & $\begin{array}{l}6 \mathrm{E}-05 \\
1 \mathrm{E}+00\left(^{3} \mathrm{H}\right) \\
\left(200^{\circ} \mathrm{C}\right)\end{array}$ & $\begin{array}{l}7 \mathrm{E}-02 \\
6 \mathrm{E}-03\left({ }^{3} \mathrm{H}\right) \\
\left(>600^{\circ} \mathrm{C}\right)\end{array}$ & $\mathrm{NA}$ & mass = TNT Eq & $7 \mathrm{E}-02$ \\
\hline
\end{tabular}

a Assume that all noncondensable gases are released if containment is lost.

b $\mathrm{NA}=$ not applicable.

c Assume that all ${ }^{3} \mathrm{H}_{2} \mathrm{O}$ or ${ }^{3} \mathrm{H}$ hydrides generated by local conditions are lost if containment is lost.

A Assume that a fraction of the iodine generated by local conditions is released if containnent is lost.

c Mass $=$ trinitrotoluene (TNT) equivalence (Eq)

r For $50-100^{\circ} \mathrm{C}\left(122-212^{\circ} \mathrm{F}\right)$ superheating; $A R F=1.0 \mathrm{E}-001 / R F 0.7$. For $>100^{\circ} \mathrm{C}\left(>212^{\circ} \mathrm{F}\right), A R F=0.33[\mathrm{MF}]^{0.91}$.

I Use same RARF as for organic combustible liquid slurries.

" DAW $=$ dry active waste.

$i$ A hyphen indicates data not available.

J $p g h=$ density, gravitational acceleration $\left(980^{\circ} \mathrm{cm} / \mathrm{s}^{2}\right)$, and height of drop.

k HLW = high-level waste. 


\section{TABLE D.3 WM PEIS Waste RARFs for LLW, LLMW, and TRUW Storage and Handling}

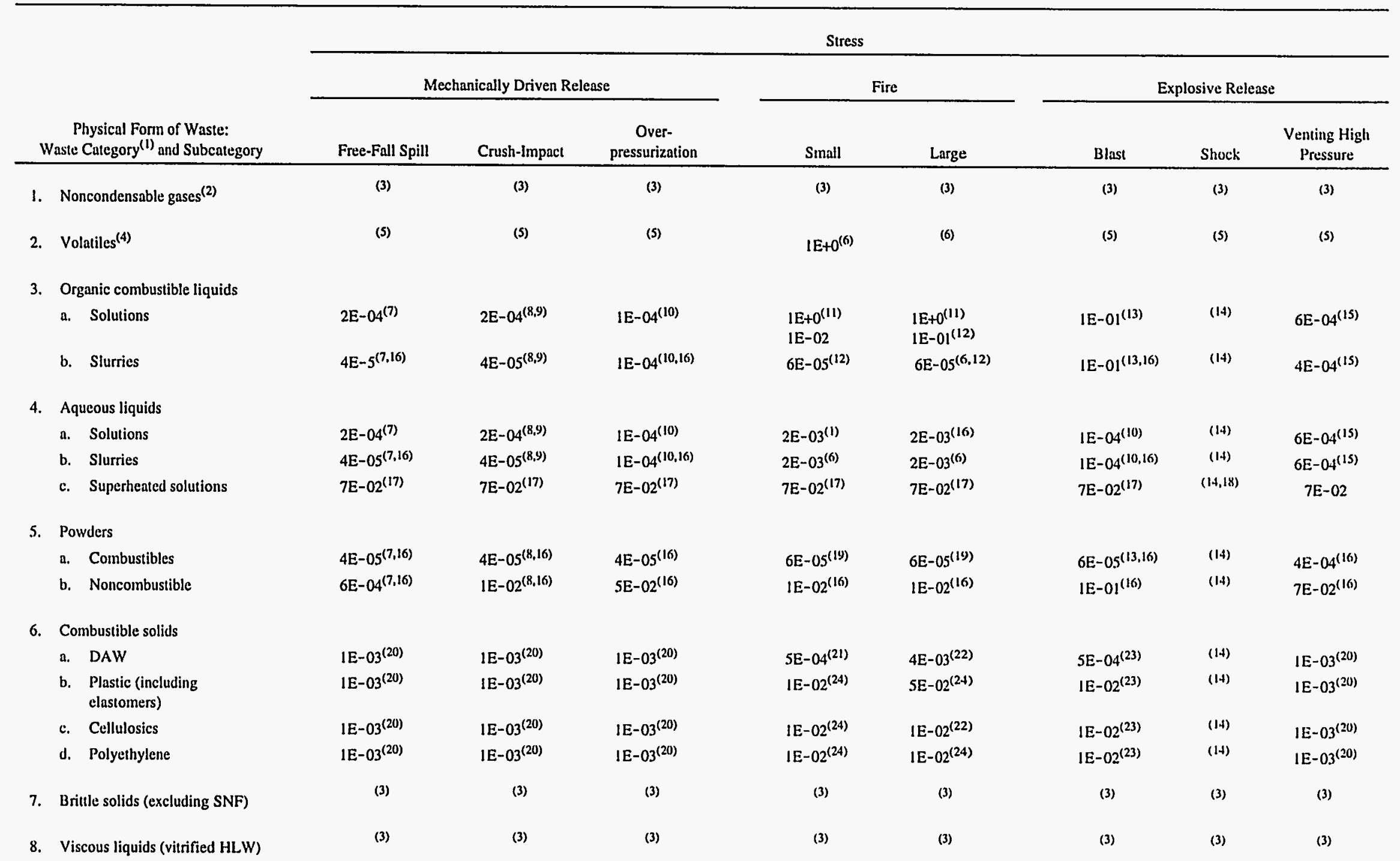




\section{TABLE D.3 (Cont.)}

Stress

\begin{tabular}{|c|c|c|c|c|c|c|c|c|}
\hline \multirow[b]{3}{*}{$\begin{array}{l}\text { Physical Form of Waste: } \\
\text { Waste Category }(1) \text { and Subcategory }\end{array}$} & \multicolumn{8}{|c|}{ Stress } \\
\hline & \multicolumn{3}{|c|}{ Mechanically Driven Release } & \multicolumn{2}{|c|}{ Fire } & \multicolumn{3}{|c|}{ Explosive Release } \\
\hline & Free-Fall Spill & Crush-Impact & $\begin{array}{c}\text { Over- } \\
\text { pressurization }\end{array}$ & Small & Large & Blast & Shock & $\begin{array}{l}\text { Venting High } \\
\text { Pressure }\end{array}$ \\
\hline \multicolumn{9}{|l|}{ 9. Metals } \\
\hline a. Inert & $1 E-03^{(20,25)}$ & $1 \mathrm{E}-03^{(20,25)}$ & $2 E-03^{(25)}$ & $6 \mathrm{E}-05^{(25,26)}$ & $6 \mathrm{E}-05^{(25.26)}$ & $7 \mathrm{E}-02^{(25)}$ & (14) & $5 E-02^{(25)}$ \\
\hline b. Reactive & $1 \mathrm{E}-03^{(20,25)}$ & $1 \mathrm{E}-03^{(20,25)}$ & $2 \mathrm{E}-03^{(25)}$ & $3 E-04^{(27)}$ & $1 E-02^{(27)}$ & $7 E-02^{(25)}$ & (14) & $5 \mathrm{E}-02^{(25)}$ \\
\hline 10. Noncombustible aggregate & $2 E-11 \rho g^{(28)}$ & $2 \mathrm{E}-11 \rho \mathrm{gh}^{(28)}$ & $2 \mathrm{E}-03^{(16,25)}$ & $6 \mathrm{E}-05^{(16,25)}$ & $6 \mathrm{E}-05^{(16,25)}$ & $7 \mathrm{E}-02^{(16,25)}$ & (14) & $7 \mathrm{E}-02^{(29)}$ \\
\hline
\end{tabular}

(1) Physical forms are as defined in Section 5 with the exceptions and additions noted in the following footnotes.

(2) For noncondensable gases, the RARF is not applicable. Noncondensable gases are not anticipated for LLW. Radionuclides as noncondensable gases are found in SNFs, accumulated in special off-gas components from the processing of SNF, or generated during inadvertent nuclear criticalities. The SNFs are not LLW, nor is the equipment associated with the processing of SNF. Inadvertent nuclear criticalities are not a credible event for LLW.

(3) Not anticipated.

(4) Volatile radionuclides (such as ${ }^{3} \mathrm{H}$, iodine, or $\mathrm{Ru}$ ) are assumed to be dissolved in a liquid or occur as a solid compound and require special physicochemical conditions to be generated as a vapor. Only ${ }^{3} \mathrm{H}$ in the form of ${ }^{3} \mathrm{H}_{2} \mathrm{O}$ or of ${ }^{3} \mathrm{H}$ hydrides is assumed to be volatilized by heat alone and is assigned a RARF of IE under thermal stress. All other volatiles (such as iodine or Ru require additional chemical environments (acidic solutions and oxidants) and behave as nonvolatiles. The RARF for the dissolved iodine during the burning of an organic combustible liquid is assumed to be 1.0 .

(5) Use the RARF for the appropriate physical form.

(6) Tritium as ${ }^{3} \mathrm{H}_{2} \mathrm{O}$ or ${ }^{3} \mathrm{H}$ hydrides.

(7) Free-fall distances up $103 \mathrm{~m}(10 \mathrm{ft})$.

(8) The RARF is based on a conservative interpretation of the experimental data for the suspension of uncontained loose powder from a stiff, flexible nonporous surface by the impact of hard objects after freefall.

(9) The RARF is based on the suspension of particles in the respirable size range by the impact of a foreign object on uncontained loose powder on a stiff, flexible nonporous surface.

(10) The RARF for the venting of rapidly ( $<1 \mathrm{~min}$ ) pressurized volumes (gas does not have time to absorb into a liquid) to a pressure of $1.38 \mathrm{MPa}_{\mathrm{g}}$ (200 psig) through an opening equivalent in size to an orifice with a diameter of $1 \mathrm{~mm}(0.04 \mathrm{in}$.) or greater near the bottom of the sidewall of the container. The RARF is not applicable to very fine ( $<0.1-\mathrm{mm}$ [<0.04-in.] width) slot-1ype openings.

(II) Iodine.

(12) Assumes the organic combustible liquid is burned to complete dryness (no liquid or moist residue).

(13) Deflagrations are assumed to generate drops of liquid both by shear stress (RARF of $4 \mathrm{E}-03 / \mathrm{h}$ for 1 min [duration of passage of pressure impulse] $=7 \mathrm{E}-05$ ) and during the burning of the organic combustible liquid ignited by the passage of the flame front. The RARF for the event is dominated by the RARF for the buming of the organic combustible liquid to complete dryness (IE-0I).

Footnotes continue on next page. 


\section{TABLE D.3 (Cont.)}

(14) Detonation must occur on or in the material of concern. The RARF is based on a conservative interpretation of the Steindler and Seefeldt (1980) correlation (fragmentation and suspension due to shock effect) and the suspension due to passage of the gases generated by the detonation (blast effect, shear stress) without ignition of the organic combustible liquid. The RARF for shock effect is the mass of the particles in the respirable size range airborne equal to the mass of TNT equivalence estimated for the explosion.

(15) The RARF is for the venting of a slowly (>1 min) pressurized volume (pressurizing gas can be absorbed into the liquid; initial pressure up to (3.45 $\mathrm{MPa}_{\mathrm{g}}$ [500 psig]) through an opening near the surface of the liquid or at the bottom of the sidewall of the vessel or container.

(16) The amount of particles suspended may be limited by the amount of particles in the respirable size range present in the source.

(17) Aqueous liquids superheated to $50-100^{\circ} \mathrm{C}\left(122-212^{\circ} \mathrm{F}\right)$ above the boiling point of the solvent (water).

(18) The RARF for this event is the grenter of the RARF for shock effect (mass of particles in the respirable size range airborne equal to the mass of TNT equivalence estimated for the explosion) or the RARF for pressurized release (7E-02).

(19) See organic combustible liquid slurries.

(20) Solid contamination jarred from the surface of the material by impact with a hard unyielding surface. The RARF for this stress is assumed to be bounded by the RARF for the impact of objects on uncontained powder lying on a stiff, flexible nonporous surface after free-fall.

(21) The DAWs are defined as contaminated combustible solids in an uncontaminated combustible wrapping (usually plastic). The RARF applies to the suspension of particles in the respirable size range during the burning of the packages of wrapped waste.

(22) The RARF is based on the assumption that the contaminated combustible material burns while suspended in air due to the force of impact of aircraft components with the package.

(23) The RARF is for suspension of particles in the respirable size range during the burning of the contaminated combustible materials ignited by the passage of the flame front resulting from the deflagration that dominates the RARF for the suspension of particles in the respirable size range by vibration (1E-03).

(24) The RARF applies to the suspension of particles in the respirable size range during the burning of uncontained, contaminated, combustible solids (the contaninated surface is exposed to the atmosphere before burning).

(25) The material at risk is the loose, powdery corrosion product present in the package or on the surface of the object.

(26) Based on the RARF for the heating of a nonreactive powder on a hard unyiclding surface.

(27) The RARF is based on the suspension of particles in the respirable size range during the complete oxidation of large pieces of uranium metal.

(2K) The RARF is the mass of particles in the respirable size range formed and suspended by the impact of the physical form with a hard unyielding surface after free-fall or by the impact of a foreign body on the physical form after free-fall and is estimated by the following:

$R A R F=(A)(D)(g)(h)$, where $A=$ empirical correlation factor $(2 \mathrm{E}-11), D=$ density $\left(\mathrm{g} / \mathrm{cm}^{3}\right), g=$ gravitational acceleration $\left(980 \mathrm{~cm} / \mathrm{s}^{2}\left[32 \mathrm{ft} / \mathrm{s}^{2}\right]\right)$, and $h=h$ eight of fall $(\mathrm{cm})$. If the RARF is applied to foreign objects impacting the physical form, the damage ratio is the fraction of the total surface area impacted by the object.

(29) The RARF for frogmentation of briule solids due to free-fall or for the impact of foreign objects on the surface of brittle solids after free-fall is as follows: $R A R F=[A][D][g][h]$, where $A=$ eillpitical correlation coefficient (2E-1 ),$D=$ density of the falling material $\left(\mathrm{g} / \mathrm{cm}^{3}\right), g=$ acceleration due to gravity $\left(980 \mathrm{~cm} / \mathrm{s}^{2}\left[32 \mathrm{f} / \mathrm{s}^{2}\right]\right.$ ) and $h=$ distance of fall (cm). If the correlation is applied to the impact of a foreign object on brittle solids, the damage ratio should be adjusted to correspond to the fraction of the impact area to the total surface area available. 
TABLE D.4 WM PEIS Waste RARFs for LLW Processing by Incineration

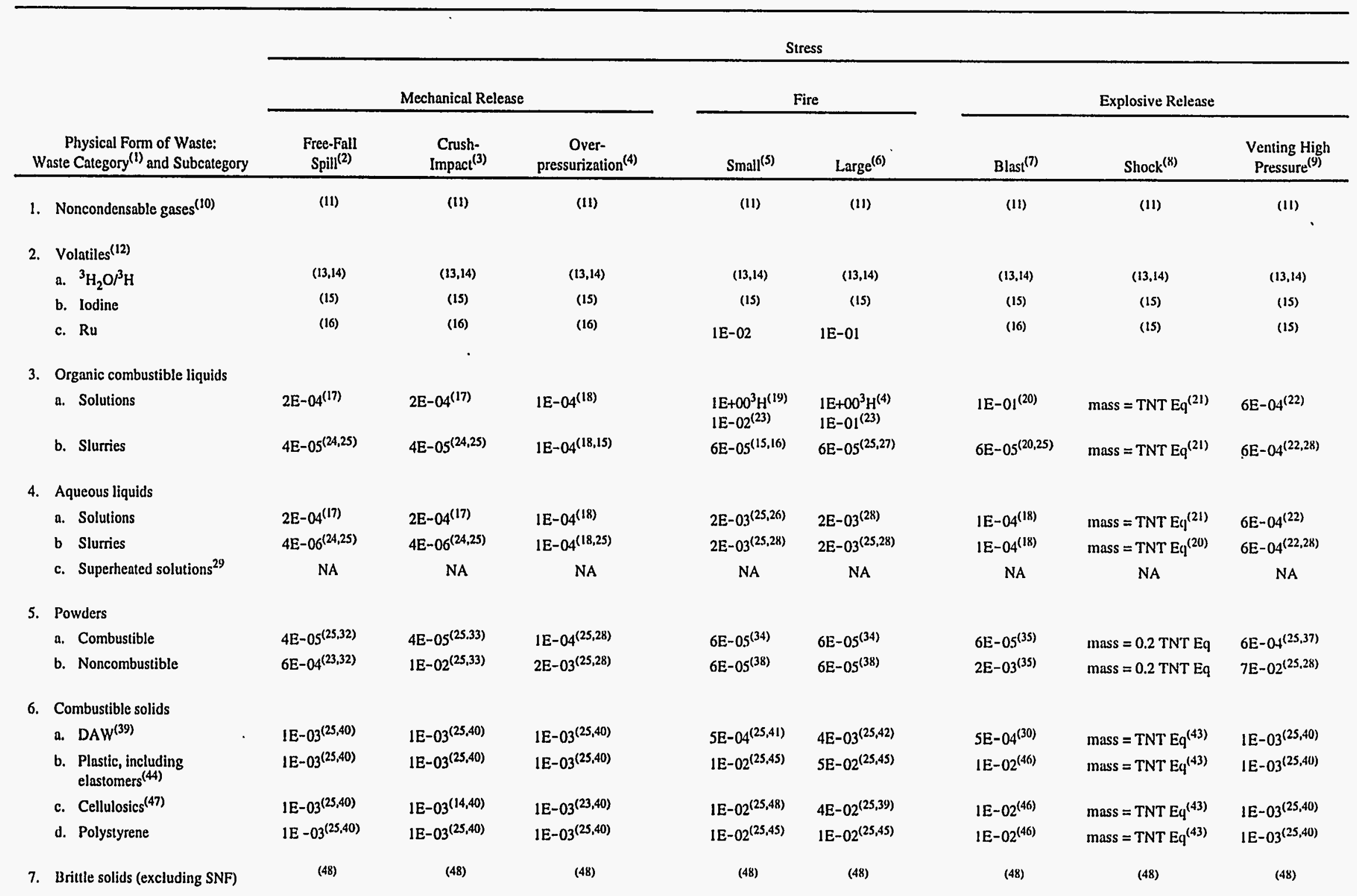




\section{TABLE D.4 (Cont.)}

\begin{tabular}{|c|c|c|c|c|c|c|c|c|}
\hline \multirow[b]{3}{*}{$\begin{array}{l}\text { Pliysical Form of Waste: } \\
\text { Waste Category (1) and Subcategory }\end{array}$} & \multicolumn{8}{|c|}{ Stress } \\
\hline & \multicolumn{3}{|c|}{ Mechanical Release } & \multicolumn{2}{|c|}{ Fire } & \multicolumn{3}{|c|}{ Explosive Release } \\
\hline & $\begin{array}{l}\text { Free-Fall } \\
\text { Spill! (2) }\end{array}$ & $\begin{array}{l}\text { Crush- } \\
\text { Impact }^{(3)}\end{array}$ & $\begin{array}{l}\text { Over- } \\
\text { pressurization } \\
\end{array}$ & Small ${ }^{(5)}$ & $\operatorname{Large} e^{(6)}$ & Blast $^{(7)}$ & Shock $^{(8)}$ & $\begin{array}{l}\text { Venting High } \\
\text { Pressure( }(9)\end{array}$ \\
\hline 8. Viscous liquids (vitrified HLW) & (48) & (48) & (48) & (4K) & (48) & $(4 x)$ & $(48)$ & $(48)$ \\
\hline \multicolumn{9}{|l|}{ 9. Metals } \\
\hline a. Inert & $1 E-03^{(40,49)}$ & $1 \mathrm{E}-03^{(40,49)}$ & $2 \mathrm{E}-03^{(37,49)}$ & $6 \mathrm{E}-05^{(38,49)}$ & $6 \mathrm{E}-05^{(38,49)}$ & $2 \mathrm{E}-03^{(35,49)}$ & mass $=\mathrm{TNT}_{\mathrm{T}} \mathrm{q}^{(21)}$ & $7 \mathrm{E}-02^{(37,4 y)}$ \\
\hline b. Reactive & $5 \mathrm{E}-04^{(40,49)}$ & $5 E-04^{(40,49)}$ & $2 \mathrm{E}-03^{(37,49)}$ & $3 E-04^{(50)}$ & $1 E-02^{(48)}$ & $1.0^{(40,49)}$ & mass $=T_{N T ~ E q}^{(2 l)}$ & $5 \mathrm{E}-02^{(37,49)}$ \\
\hline 10. Noncombustible aggregate & $2 E-11 \rho g h^{(50)}$ & $2 E-11 \rho g h^{(50)}$ & $5 E-02^{(37,49)}$ & $6 \mathrm{E}-05^{(38,49)}$ & $6 \mathrm{E}-05^{(38,49)}$ & $1.0^{(35,49)}$ & mass $=\mathrm{TNT} \mathrm{Eq}^{(21)}$ & $7 \mathrm{E}-02^{(51)}$ \\
\hline 11. HEPA filters ${ }^{(52)}$ & $5 E-04$ & 5E-04 & (54) & $1 E-04^{(55)}$ & $1 E-04^{(55)}$ & IE- $02^{(56)}$ & $2 \mathrm{E}-06^{(57)}$ & (s+1) \\
\hline
\end{tabular}

(1) The physical forms are as defined in Mueller's (1994) fax to Mishima, with the exceptions and additions as noted in the following footnotes.

(2) The stress postulated is for the free-fall spill of the physical form a distance of $3 \mathrm{~m}$ ( $10 \mathrm{ft}$ ) or less and for the impact on a hard unyielding surface.

(3) Crush-impact assumes that the RARF for crushing of the physical form is bounded by the RARF for impact of the physical form by an object.

(4) The venting of a rapidly (<1 min) pressurized volume (up to a pressure of $1.38 \mathrm{MPa}_{\mathrm{g}}$ [200 psig]) containing the physical form is postulated. The RARF does not assume that the pressurizing gases are absorbed into a liquid and can effervesce on depressurization.

(5) For a small fire, assume that less than the entire inventory of material is involved in the fire and that the structural containment is not compromised.

(6) For a large fire, assume that close to the entire inventory of radionuclides is involved and that the structural containment is damaged. An example of a large fire is the fire resulting from the impact of an aircraft on the structure containing the LLW.

(7) Deflagration (blast effect). Deflagrations are the rapid (within minutes) burning of a flammable gas mixture (air and fuel) that fills most (greater than $25 \%$ ) of the volume of an equipment component or package. It is assumed that the pressure generated is adequate to defeat containment and that other components of an off-gas system may be impacted, depending on the gas pressures generated, the design of the component, and the distance of the component from the deflagration.

(8) For detonation (shock effect), the RARF is based on a conservative interpretation of the Steindler and Secfeldt (1980) correlation for the fragnentation by condensed-phase explosion in or on metals or aqueous solutions: the mass of particles in the respirable size range suspended by detonations on or in metal and aqueous solution is equal to the mass of TNT equivalency (Eq) estimated for (the explosion.

(9) For pressurized release, the RARF is for the venting of a slowly (>l min) pressurized volume (at a pressure to $3.45 \mathrm{MPa}_{\mathrm{g}}$ [500 psig]) containing the physical forn.

(10) The presence of noncondensable gases is not anticipated in LLW, and, therefore, RARFs for the physical form are not applicable. Noncondensable gases imust be contained or generated. Noncondensable gases are found in SNF (not a LLW form), collected in special off-gas equipment, or generated in inadvertent nuclear criticalities that are not a credible scenario for LLW.

(II) Assume all noncondensable gases are released if containment is lost.

(12) Use the RARF designated for the appropriate physical form under this stress.

Footnotes continue on next page. 


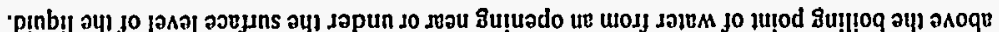

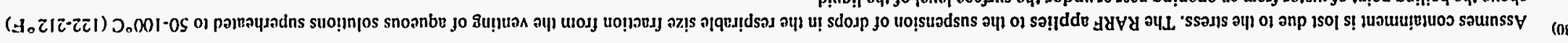

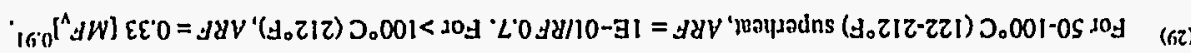

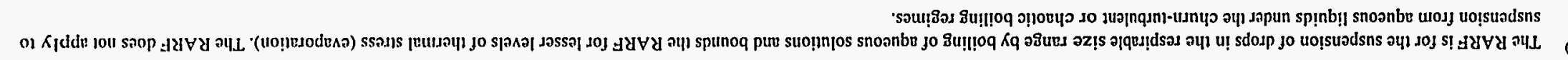

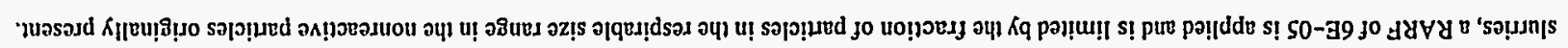

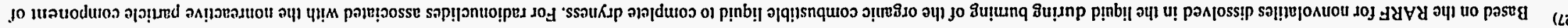

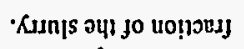

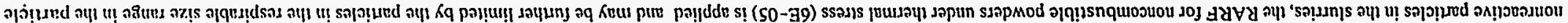

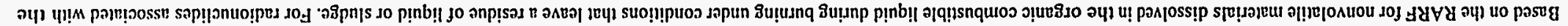

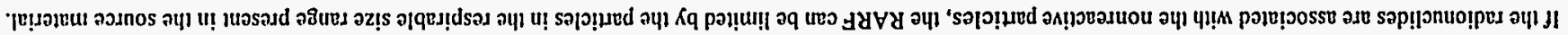

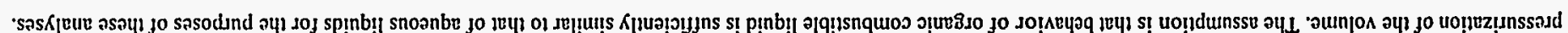

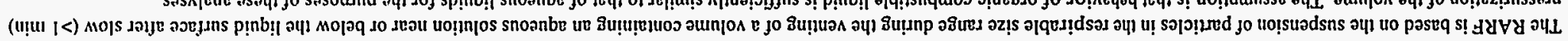

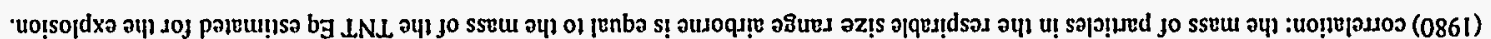

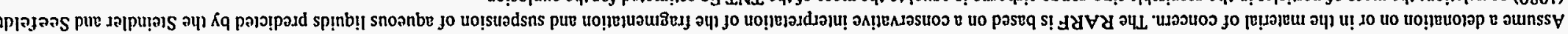

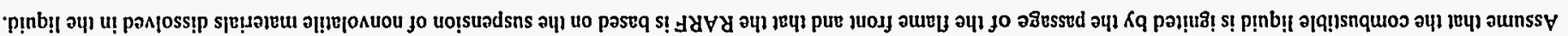

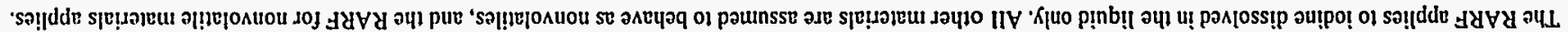

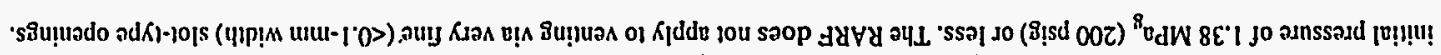

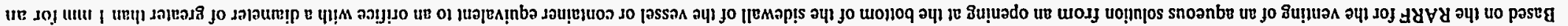

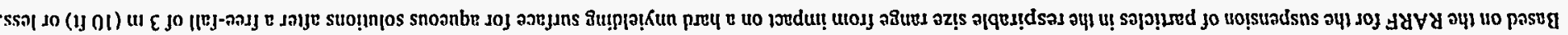




\section{TABLE D.4 (Cont.)}

(31) Assumes a detonation on or in the superheated aqueous solution, resulting in the loss of containment. The RARF is the sum of the RARFs for the shock (mass of particles in the respirable size range equal to the mass of TNT Eq of the explosion) and for the venting of the superheated aqueous solution (IE-01).

(32) The RARF is for the suspension of a dry ceramic powder on impact with a hard unyielding surface after a fail of $3 \mathrm{~m}$ (10 $\mathrm{ft}$ ) or less.

(33) The RARF is based on the RARF for suspension of particles in the respirable size range by the impact of large objects on uncontained powders on a stiff nonporous surface.

(34) If the radionuclides are dissolved in the organic combustible phase, the RARF listed for organic combustible liquids under thernal stress, above, is applied. If the radionuclides are associaled with the nonreactive powder component of the slurry, the RARF for the powders, noncombustible, below, apply.

(35) Assumes a deflagration of a flammable gas mixture that fills greater than $25 \%$ of the volume of the vessel or equipment or package directly over the exposed powder and causes failure of the containment.

(36) Detonation in or on the exposed powder of a severity sufficient to cause the containment to fail. The RARF is a sum of the RARFs for shock (mass of particles in the respirable size range airborne equal to the mass of the TNT Eq of the explosion) and blast (1.0E). Because the RARF for the blast is 1.0E, the RARF for this stress cannot exceed 1.0E

(37) Based on the suspension of a dry ceramic powder during venting of a volume pressurized to $3.45 \mathrm{MPa}_{\mathrm{g}}(500 \mathrm{psig})$ and less.

(38) The RARF is for the suspension of respirable particles in the respirable size range from a dry, ceramic nonreactive powder under thermal stress.

(39) DAW = dry active waste (contaminated combustible trash wrapped in uncontaminated thin combustible wrapping).

(40) The RARF for surface contamination suspended by vibration or impact of objects on the surface of the physical form without fragmentation of the substrate. For impact of foreign objects, the damage ratio may be adjusted to compensate for the fraction of the surface area affected by the object (assume twice the impact area of the object).

(41) The RARF for the suspension of particles in the respirable size range during the burning of contained (wrapped), contaminated combustible materials.

(42) The RARF for the suspension of particles in the respirable size range by air passing through the mass during the burning of uncontained, contaminated, combustible cellulosic material. This scenario assumes that the DAW is unwrapped by the severity of the impact of aircraft parts on the container and that the cellulosic material is suspended in air during the burning.

(43) The RARF for this scenario is the sum of the RARFs for shock (mass of particles in the respirable size range made airbome is equal to the mass of the TNT Eq estimated for the explosion) and blast (suspension of particles in the respirable size range by vibration [IE-03]) effects.

(44) Plastic $=$ all uncontained, contaninated, combustible plastic and elastomer materials except polystyrene.

(45) The RARF is the value for the suspension of particles in the respirable size range from the burning of the uncontained, contaminated physical form.

(46) Scenario assumes that the deflagration disperses and ignites the DAW. The RARF is based on the burning of contained, contaminated combustible material.

(47) Cellulosics $=$ all cellulose-based trash (e.g., wood, paper, rags, cardboard).

(48) Not anticipated.

(4)) The RARF applies to the loose, powder corrosion product present in the package and on the surface of the physical form. The contamination is assumed to be uniformly distributed over the entire surface of the physical form.

Footnotes continue on next page. 


\section{TABLE D.4 (Cont.)}

(50) The RARF is based on the suspension of particles in the respirable size range suspended during the oxidation of bulk pieces of uranium metal and bounds the release anticipated during the self-sustained oxidation of large pieces of Pu metal.

(51) The RARF is the mass of particles in the respirable size range formed and suspended by the impact of the physical form with a hard unyielding surface after free-fall or by the impact of a foreign body on the physical form after free-fall and is estimated by the following:

$R A R F=(A)(D)(g)(h)$, where: $A=$ empirical correlation factor $(2.11 \mathrm{E}-04), D=$ density $\left(g / \mathrm{cm}^{3}\right), g=$ gravitational acceleration $\left(980 \mathrm{~cm} / \mathrm{s}^{2}\left[32 \mathrm{f} / \mathrm{s}^{2}\right]\right)$, and $h=$ height of fall $(\mathrm{cm})$.

If the RARF is applied to foreign objects impacting the physical form, the damage ratio is 2 times the fraction of the total surface area impacted by the object.

(52) A $61-\mathrm{cm} \times 61-\mathrm{cm} \times 30.5-\mathrm{cm}$ deep (2-ft $\times 2-\mathrm{ft} \times 1-\mathrm{ft}$ deep), pleated, glass-fiber HEPA filter. Filters of other configurations and designs may exhibit substantially different behavior under the stated stresses, and the values listed for the RARF may not apply.

(53) The RARF is applied to the suspension of particles in the respirable size range accumulated in a $61-\mathrm{cm} \times 61-\mathrm{cm} \times 30.5-\mathrm{cm}$ deep (2-ft $\times 2-\mathrm{ft} \times 1-\mathrm{ft}$ deep) HEPA filter on impact with a hard unyielding surface after free-fall through an appreciable distance $(\leq 3 \mathrm{~m}[\leq 10 \mathrm{ft}])$. The HEPA filter is not contained in a package or housing. The RARF for the same situation for HEPA filters contained in a package or housing is $5 \mathrm{E}-04$.

(54) No significant release of the inventory accumulated in a HEPA filter is postulated for the passage of gas at an accelerated velocity through the filter. The filters are designed for gas passage through the filter and would not release their accumulated inventory by the simple passage of gas through the filter. If any material is released by reverse flow through the filter, the material is released into the contained volume.

(55) The RARF is for the suspension of particles in the respirable size range by the passage of gas heated to a temperature below the failure temperature of the glass-fiber collection medium. Failure of the medium is by melting and is not postulated to release the accumulated inventory.

(56) The RARF is for the release of particles in the respirable size range from the accumulated inventory due to the failure of the filter collection medium by static or slow buildup of pressure.

(57) The RARF is for the release of particles in the respirable size range from the accumulated inventory due to the failure of the HEPA filter medium from a shock front. 


\section{TABLE D.5 WM PEIS Waste RARFs for HLW Processing and Storage}

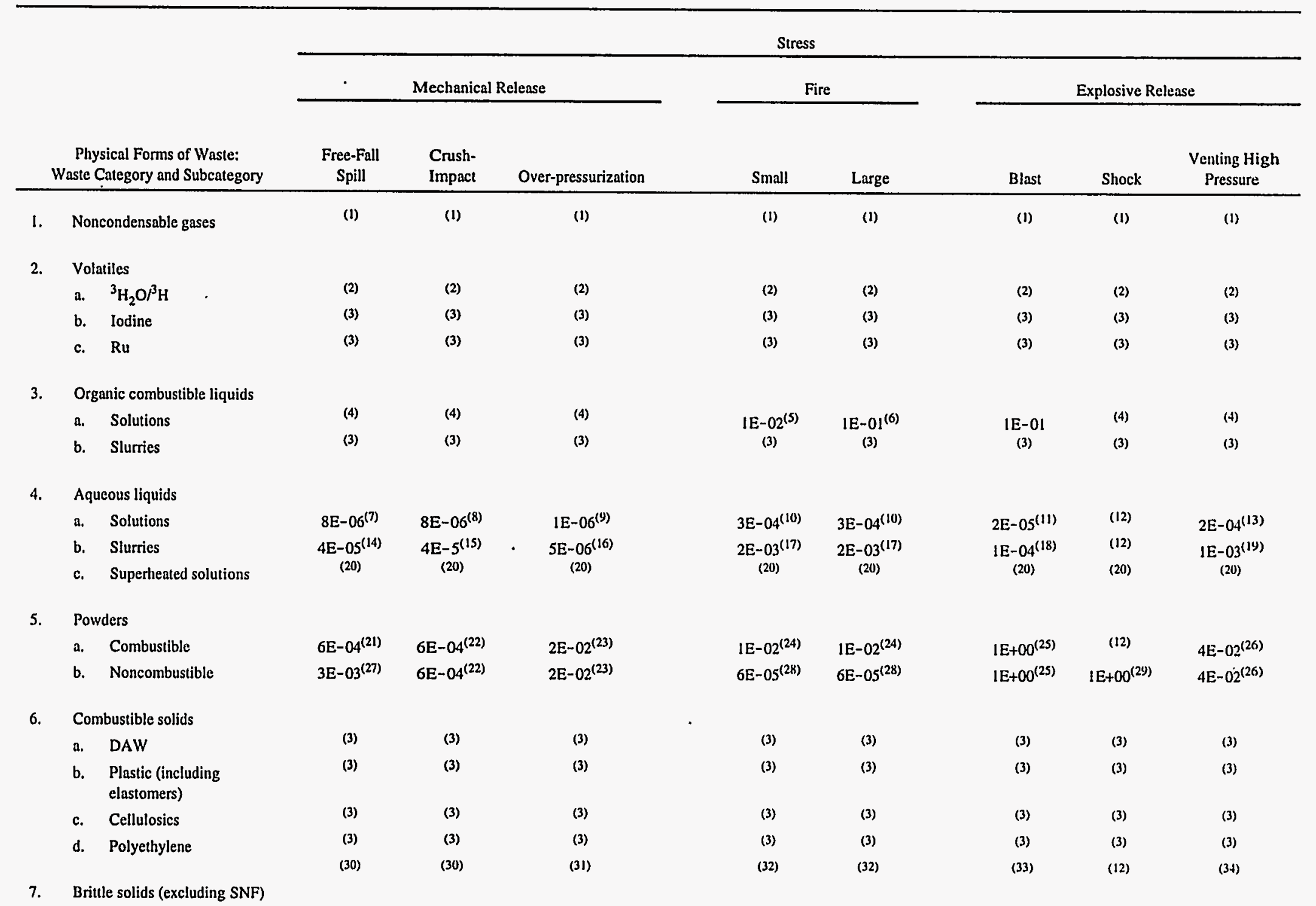


TABLE D.5 (Cont.)

\begin{tabular}{|c|c|c|c|c|c|c|c|c|c|}
\hline \multirow{3}{*}{\multicolumn{2}{|c|}{$\begin{array}{l}\text { Physical Forms of Waste: } \\
\text { Waste Category and Subcategory }\end{array}$}} & \multicolumn{8}{|c|}{ Stress } \\
\hline & & \multicolumn{3}{|c|}{ Mechanical Release } & \multicolumn{2}{|c|}{ Fire } & \multicolumn{3}{|c|}{ Explosive Release } \\
\hline & & $\begin{array}{l}\text { Free-Fall } \\
\text { Spill }\end{array}$ & $\begin{array}{l}\text { Crush- } \\
\text { Impact }\end{array}$ & Over-pressurization & Small & Large & Blast & Shock & $\begin{array}{l}\text { Venting High } \\
\text { Pressure }\end{array}$ \\
\hline 8. & Viscous liquids (vitrified HLW) & $7 \mathrm{E}-09^{(35)}$ & $7 \mathrm{E}-09^{(36)}$ & (37) & (38) & (38) & (39) & (40) & (37) \\
\hline \multirow[t]{2}{*}{9.} & Metals & & & & & & & & \\
\hline & a. Inert & (3) & (3) & (3) & (3) & (3) & (3) & (3) & (3) \\
\hline 9. & b. Reactive & (3) & (3) & (3) & (3) & (3) & (3) & (3) & (3) \\
\hline 10. & Noncombustible aggregate & (4I) & (41) & (42) & $6 \mathrm{E}-05^{(43)}$ & $6 \mathrm{E}-05^{(43)}$ & $1 E+00^{(44)}$ & (45) & (42) \\
\hline 11. & HEPA filters & (3) & (3) & (3) & (3) & (3) & (3) & (3) & (3) \\
\hline
\end{tabular}

(1) Assume that all noncondensable gases are released if containment is lost.

(2) Assume that all ${ }^{3} \mathrm{H}_{2} \mathrm{O}$ and ${ }^{3} \mathrm{H}$ hydrides generated by local conditions are released if containment is lost.

(3) Not anticipated.

(4) Use value for aqueous liquids, solutions (subcategory 4.a), for this stress.

(5) Assume that the organic combustible liquids burn, but the intensity of a small fire is not adequate to bum all of the liquid to complete dryness.

(6) Assume that all of the organic combustible liquid is burned to complete dryness.

(7) For free-fall spill of aqueous liquids solution. Assume that the vessel containing the liquid is elevated above a hard unyielding floor and fails near the bottom of the sidewall so that almost adl of the liquid falls to the floor. Experimental results reported by Ballinger and Hodgson (1986) show that the ARF decreases with increasing viscosity or specific gravity (SpG). In the range of viscosity of $1-50 \mathrm{cp}$, the relationship appears linear. The SpGs of the viscous liquids used in the experiments was in the range of 1.102-1.277, on the lower end of the range of SpGs of liquid HLW. The maximum measured RARF for this range was $8 \mathrm{E}-06$ and appears to be very conservative for this material.

(8) Assume that the impact of an object with liquid HLW is equivalent to the impact on a hard unyielding surface of liquid HLW after free-fall and that the RARF for free-fall applies.

(9) Assume that the impact of an object into the liquid is as efficient at suspension of droplets in the respirable size range as the impact of the liquid on a hard unyielding surface after a free-fall of $3 \mathrm{~m}(10 \mathrm{ft})$.

(10) Assume that the reduction in RARF during the boiling of an aqueous viscous solution is proportional to the reduction of RARF between free-fall of an aqueous solution and free-fall of an aqueous viscous solution $(0.144)(2 \mathrm{E}-03 \times 0.144=2.9 \mathrm{E}-04$ or $-3 \mathrm{E}-04)$

Footnotes continue on next page. 
(11) It is assumed that the viscous aqueous solution is vented via a crack or opening at or near the bottom of the sidewall of the vessel holding the liquid (the RARF for underground liquid HLW storage tanks is discussed subsequently); a comparable reduction in the RARF shown in free-fall spills (0.144) also applies. The RARF for this case is $1 E-04 \times 0.144=1.44 E-0.5$ or conservatively rounded upward to $2 \mathrm{E}-05$. Venting of the pressure resulting from a deflagration via an opening well above the liquid level (as is the case for the failure of an underground liquid storage tank) would depend on the energy generated (affects the pressure and failure of the vessel), the size and location of the opening (affects the velocity, turbulence, and direction of flow in the free volume of the vessel), and the characteristics of the material (high viscosity decreases the formation of drops). No data are known on the RARF for this type of material. The RARF is certainly less than that for the venting of a pressurized liquid when the gas is absorbed in the liquid (2E-03). Calculations that use very conservative parameters in the SPRAYMASS model (Roblyer and Owczarski 1992), which were modified for the higher viscosity of alkaline liquid HLW, indicate a value of $6 E-05$.

(12) The mass of particles in the respirable size range made airbome by a detonation is equal to the mass of the TNT equivalence (Eq) of the explosion.

(13) Assumes the reduction in RARF for the venting of an aqueous viscous solution is in the same ratio as the reduction in RARF as a result of the free-fall of $3 \mathrm{~m}$ (10 $\mathrm{ft}$ ) between an aqueous solution and an aqueous visçous solution.

(14) Maximum RARF measured for the 3-m (10-ft) free-fall spill of slurries of Ballinger and Hodgson (1986).

(15) Assumes the impact of an object on the slurry has the same or less effect on suspension of the slurry as the impact of the slurry on a hard unyielding surface after a free-fall of $3 \mathrm{~m}$ (10 $\mathrm{ft}$ ).

(16) Assume that the reduction in RARF for the venting of a slurry pressurized to $50 \mathrm{psig}\left(0.34 \mathrm{MPa}_{\mathrm{g}}\right)$ is proportional to the reduction in RARF between an aqueous solution and an aqueous viscous solution.

(17) Assunes that the RARF for the slurry is controlled by the behavior of the solvent (water).

(18) The RARF is for the venting of a slurry via an opening at or near the bottom of the sidewall of the vessel; the slurry is conservatively assumed to behave as water although, many of the insoluble particles may be above the respirable size range.

(19) Assumes that the reduction in RARF for venting of a slurry pressurized to $50-500 \mathrm{psig}\left(0.34-3.45 \mathrm{MPa}_{\mathrm{g}}\right)$ is proportional to the reduction in RARF between an aqueous solution and an aqueous viscous solution.

(20) For $50-100^{\circ} \mathrm{C}\left(122-212^{\circ} \mathrm{F}\right)$ superheating, $A R F=1 \mathrm{E}-0 \mathrm{l} / R F$ 0.7. For $>100^{\circ} \mathrm{C}\left(212^{\circ} \mathrm{F}\right), A R F=0.33\left[M F_{\mathrm{v}}\right]^{0.91}$.

(21) The RARF is for a fine dry powder after a free-fall of $3 \mathrm{~m} \mathrm{(10} \mathrm{ft)} \mathrm{and} \mathrm{impact} \mathrm{against} \mathrm{a} \mathrm{hard} \mathrm{unyielding} \mathrm{surface} \mathrm{and} \mathrm{is} \mathrm{considered} \mathrm{very} \mathrm{conservative} \mathrm{for} \mathrm{salts} \mathrm{or} \mathrm{damp} \mathrm{salts} \mathrm{that} \mathrm{may} \mathrm{be} \mathrm{found} \mathrm{in}$ a residue in some HLW storage tanks.

(22) Assumes that the impact of an object onto the surface of salt or damp salt suspends as much material as a 3-m (10-ft) free-fall and impact onto a hard unyielding surface of a fine dry powder.

(23) Maximum RARF measured during the venting of a fine, dry powder pressurized to $50 \mathrm{psig}\left(0.34 \mathrm{MPa}_{\mathrm{g}}\right)$ (Sutter 1983).

(24) Maximum RARF measured during the heating of a reactive powder in flowing air (Mishima et al. 1968).

(25) Assumes a deflagration of a flammable gas mixture that fills from 10 to $100 \%$ of the free volume above a shallow pile of fine dry powder on a hard unyielding surface. The RARF is reduced by smaller quantities of flammable gas mixture, powder with a tendency to clump (e.g.. presence of moisture), or very deep beds of powders that tend to expose lesser fractions of the material at risk to the turbulemt entraining flow generated.

(20) Maximum RARF measured during the venting of a fine dry powder pressurized to $50-500 \mathrm{psig}$ (0.34-3.45 MPa s $_{\mathrm{g}}$ (Sutter 1983).

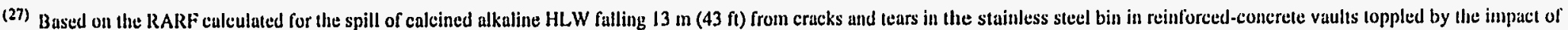
a large commercial aircraft (reported in INEL EIS) modified for the release of the powder in discrete packets, rather than a single slug $(5.2 \mathrm{E}-02 \times 0.05=2.75 \mathrm{E}-03$ or $-3 \mathrm{E}-03)$.

(28) Maximum RARF measured during the heating of a fine dry powder on an inert Pu compound (Mishima et al. 1968).

(2y) Assume that the blast effects during a detonation are equal to the deflagration considered. The shock effect suspends a mass of powder in the respirable size fraction that is equal to the mass of the TNT Eq estimated for the explosion.

Footnotes continue on next puge. 


\section{TABLE D.5 (Cont.)}

(30) Assume that the spilled canister of solidified vitrified HLW impacts the surface with sufficient force to breech the canister. The RARF is calculated on the basis of the impact energy density imposed on the vitrified waste by the following: $R A R F=A / J(d)(g)(h)$, where $A=$ empirical correlation coefficient $\left(2 \mathrm{E}-11 \mathrm{~cm}{ }^{3} / \mathrm{J}\right), d=$ density of the material, $g=$ gravitational acceleration $\left(980 \mathrm{~cm} / \mathrm{s}^{2}\left[32 \mathrm{fu} / \mathrm{s}^{2}\right]\right), h=$ distance of fall $(\mathrm{cm})$, and $J=$ joule $\left(\mathrm{kg} / \mathrm{m}^{2} \mathrm{~s}^{-1}\right)$. If all of the impact energy is absorbed in a limited volume (e.g., only a corner of the canister is initially impacted), the total energy (in joules) from the fall of the canister and vittified HLW is assumed to be absorbed in a volume equal to a hemisphere 1.5 times the diameter of the impact area. The canister is assumed to be breached by the impact.

(31) No airborne release is postulated. Assume that internal pressures of $0.34 \mathrm{MPa}_{\mathrm{g}}(50 \mathrm{psig}$ ) and less are inadequate to breach the canister.

(32) No airborne release is postulated. Assume that fires of any size cannot breach the stainless steel canister.

(33) No airborne release is postulated. Assume that external deflagration will not breach the canister.

(34) Maximum RARF measured during the venting of a fine dry powder pressurized to $0.34 \mathrm{MPa}_{\mathrm{g}}$ ( 50 psig). The materials at risk are the loose particles in the respirable size range exposed on the surface of the vitrified HLW in the canister. The Westinghouse Hanford Company (1993) has reported that $73.1 \mathrm{~g}(2.58 \mathrm{oz})$ of such particles was found in the upper compartment of a canister and represents $3.5 \mathrm{E}-04$ of the $465 \mathrm{~kg}(1,025 \mathrm{lb})$ of vitrified HLW.

(35) The assumption is that the behavior of the molten HLW-glass former mixture is similar to lava (molten rock). On the basis of the "best estimates" available, the viscosity of the molten mixture at the proposed operating temperature $\left(1,150^{\circ} \mathrm{C}\left[2,102^{\circ} \mathrm{F}\right]\right)$ ranges from 20 to $74 \mathrm{P}$. On the basis of on an extrapolation of the empirical correlation for free-fall spills of liquids published by Ayer et al. (1988), $\left.F=\left(d_{\mathrm{a}}{ }^{2}\right)(H)\right](g) / m u_{1}$, where $F=A R F, d_{\mathrm{a}}=$ density of air $\left(0.746 \mathrm{~kg} / \mathrm{m}^{3}\right)\left(200^{\circ} \mathrm{C}\left[392^{\circ} \mathrm{F}\right]\right.$ for event), $H=$ height of fall $(\mathrm{m}), g=$ gravitational acceleration $(9.8$ $\mathrm{m} / \mathrm{s}^{2}\left[32 \mathrm{ft} / \mathrm{s}^{2}\right]$ ), and $m u_{1}=$ liquid viscosity (assume $20 \mathrm{P}$ for conservatism). The RARF for a 3-m (10-ft) free-fall is $6.5 \mathrm{E}-09$ to $\sim 7 \mathrm{E}-05$. The release locations considered were the bottom of the pour spout for the melter or the edge of the melter lip when the molten mix begins to spill if the melter is tipped.

(36) Assumes that the impact of an object on the molten mix is equivalent to a $3-\mathrm{m}(10-\mathrm{ft})$ free-fall and impact with a hard unyielding surface.

(37) No significant airborne release is postulated for this situation. Venting of the free space above the molten mix in the melter with a functional air-treatment system does not appear to have the potential to release any significant fraction of the off-gas.

(38) Fires of any size do not appear to generate any additional mechanisms for the airborne release of materials: the molten mixture is normally at a temperature, $\left(1,150^{\circ} \mathrm{C}\left[2,102^{\circ} \mathrm{F}\right]\right)$ that is greater than would be anticipated for most accidental fires. The fire may initiate events that would result in airborne release, such as loss of the melter-effluent treatment system or release from collection equipment (e.g., liquid absorbers, HEPA filters) in the effluent-treatment system.

(3)) No significant airborne release of the molten mixture is postulated. Deflagrations above the molten surface do not appear to generate conditions that would lead to the subdivision and entrainment of the molten material. Deflagrations may result in the loss of containment and the effluent-treatment system. Loss of contaimnent would result in the release of all radionuclides (volatile and nonvolatile particulates) airborne in the containment at the time of the deflagration.

(40) The RARF for a detonation in or on the molten mix is a mass of droplets of molten material in the respirable size range equal to the mass of the TNT Eq estimated for the explosion. The detonation may also initiate other events, such as loss of containment and the off-gas treatment system.

(41) Apply the RARF in footnote 30 for the impact of an aggregate material on a hard unyielding surface after free-fall or the impact of an object on the surface of aggregate material.

(42) Venting of the pressurized atmosphere confined above an aggregate material may entrain any loose fragments or particles on the exposed surfaces. The RARFs for venting of atunosphere pressurized to various levels are as follows: for the venting of atmosphere pressurized to $50 \mathrm{psig}\left(0.34 \mathrm{MPa}_{\mathrm{g}}\right)$ and less, $2 \mathrm{E}-02$; for venting of atmosphere pressurized to $3.45 \mathrm{MPa}$ ( $500 \mathrm{psig}$ ), $4 \mathrm{E}-02$

(43) With time, heat and dry air will result in the deterioration of some aggregate materials, such as concrete. Even a relatively thin (<2.54-con [<1-in.]-1hick) panel will prevem the propagation of a fire between adjacent spaces for greater than one hour. A RARF of $6 \mathrm{E}-05$ of the loose particles on the exposed surfaces of aggregates during a fire is recommended. If the surface is postulated to deteriorate as a consequence of the fire, the amount of loose particles increases.

(44) Blast effects do not directly result in the fragmentation of large pieces of aggregate. The pressure, flame, and accelerated gas velocities resulting from a deflagration may initiate events leading to the fragmentation of aggregate materials (e.g. failure of structural members such as wall pants, fire, the fragmentation of small pieces of aggregate entrained by the gas tlow on impact with a hard unyielding surface). The RARF for a deflagration of a volume of flammable gas mixture that fills from 10 to $100 \%$ of the free volume above the exposed aggregate surface is $1.0 \mathrm{E}$ of the loose respirable particles exposed on the surface. The RARF for a deflagration of a flammable gas mixture that fills $10 \%$ or less of the free volume is estimated to bo IE-0I of the loose respirable particles exposed on the surface.

(45) The RARF for a detonation on or in aggregate materials is a mass equal to the mass of TNT Eq estimated for the explosion. 
TABLE D.6 Threshold Values of Differential Pressure Required to Structurally Damage Standard HEPA Filter

\begin{tabular}{|c|c|}
\hline Parameter & $\begin{array}{c}\Delta \mathrm{P} \text { Threshold }{ }^{\mathrm{a}} \\
{\text { (in. } \mathrm{wg}^{\mathrm{b}} \text { ) }}^{\text {a }}\end{array}$ \\
\hline Baseline (new filter, normal conditions) & 37 \\
\hline Age (greater than $14 \mathrm{yr}$ ) & 13 \\
\hline Radiation (5E-07 Rad) & 18 \\
\hline Chemical $\left(\mathrm{HNO}_{3}, \mathrm{HF}\right)$ & $N A^{c}$ \\
\hline \multicolumn{2}{|l|}{ Temperature } \\
\hline Less than $200^{\circ} \mathrm{C}$ & 37 \\
\hline $200-300^{\circ} \mathrm{C}, 1 \mathrm{~h}$ & 26 \\
\hline $300-400^{\circ} \mathrm{C}, 1 \mathrm{~h}$ & 15 \\
\hline $400-500^{\circ} \mathrm{C}, 1 \mathrm{~h}$ & 8 \\
\hline Moisture (greater than $95 \%$ relative humidity) & 10 \\
\hline
\end{tabular}

a These values were determined from an analysis of experimental studies reviewed in Bergman (1993).

b $w g=$ water gauge.

c $\mathrm{NA}=$ not applicable. 
.TABLE D.7 Effects of Environmental Filter Parameters on Aerosol Penetration through HEPA Filters

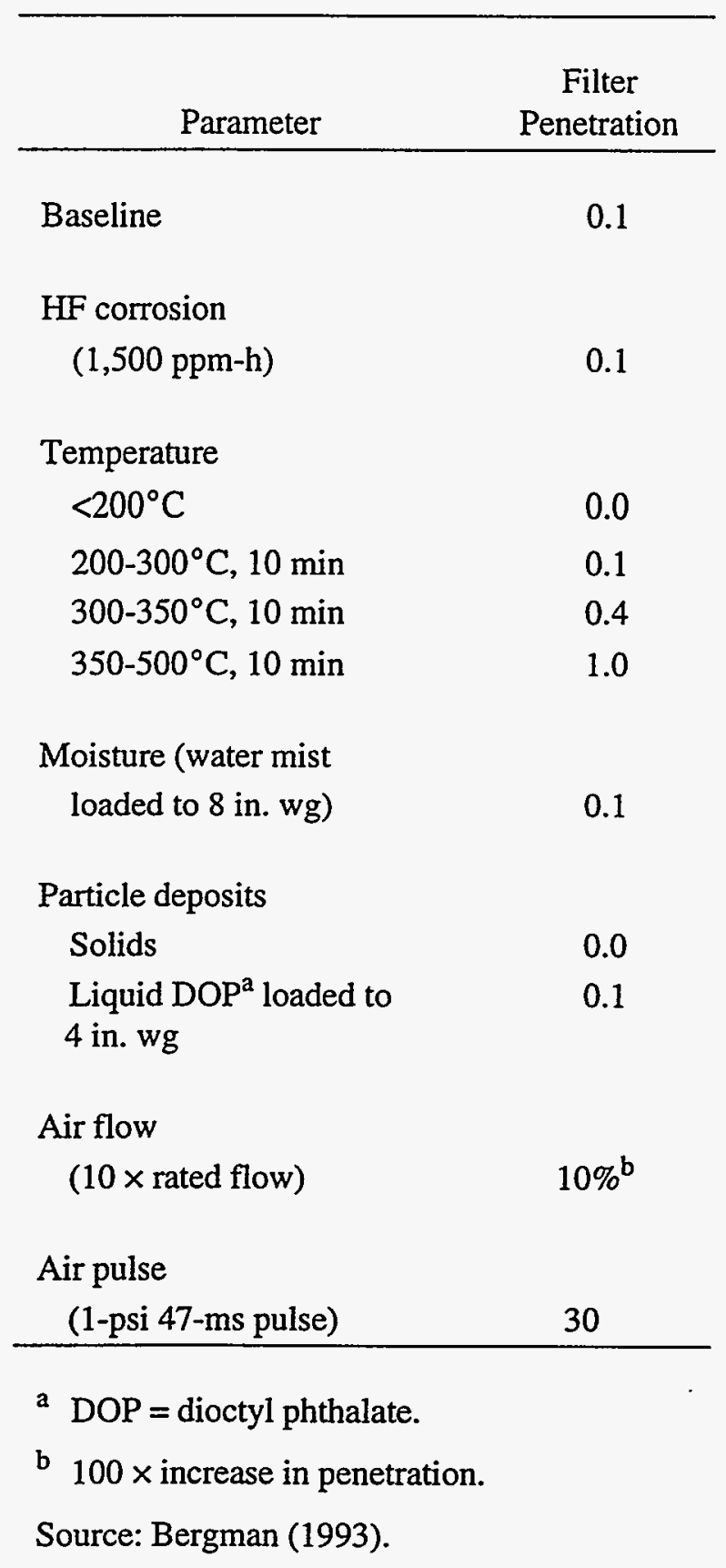


TABLE D.8 Summary of Reduction and Removal Factors Abstracted from Elder et al. (1986)

\begin{tabular}{|c|c|c|c|c|}
\hline Release Mechanism & Safety Analysis Parameter & $\begin{array}{c}\text { Range of } \\
\text { Observation }\end{array}$ & $\begin{array}{l}\text { Current } \\
\text { Practice }\end{array}$ & $\begin{array}{l}\text { Recommended } \\
\text { Value }\end{array}$ \\
\hline $\begin{array}{l}\text { Particulate filters } \\
\text { (\% efficiency) }\end{array}$ & $\begin{array}{l}\text { (a) HEPA : Ist stage } \\
\text { 2nd stage } \\
\text { 3rd stage } \\
\text { 4th stage } \\
\text { (b) Sand filter bed } \\
\text { (c) Fiber glass (deep bed) }\end{array}$ & $\begin{array}{c}96.0-99.999 \\
99.976- \\
99.992 \\
99.49-99.99+ \\
-\mathrm{b} \\
99.60-99.999 \\
70-99.995\end{array}$ & $\begin{array}{c}99.0-99.99 \\
99.0-99.9 \\
94.0-99.8 \\
83.0 \\
99.0 \\
90.0\end{array}$ & $\begin{array}{l}99.9^{\mathrm{a}} \\
99.0^{\mathrm{a}} \\
99.0^{\mathrm{a}} \\
83.0^{\mathrm{a}} \\
99.0 \\
90.0\end{array}$ \\
\hline $\begin{array}{l}\text { Noble gas traps } \\
\text { (\% efficiency) }\end{array}$ & $\begin{array}{l}\text { (a) Refrigerant } \\
\text { (b) Cryogenic }\left(\mathrm{CO}_{2}\right)\end{array}$ & $\begin{array}{l}75.0-99.99+ \\
90.0-99.993\end{array}$ & - & $\begin{array}{l}\mathrm{NR}^{\mathrm{c}} \\
\mathrm{NR}\end{array}$ \\
\hline $\begin{array}{l}\text { Halogen filters } \\
\text { (\% efficiency for bed } \\
\text { depth } 25 \mathrm{~cm} \text { ) }\end{array}$ & $\begin{array}{l}\text { (a) Activated charcoal } \\
\mathrm{I}_{2} \text { at } \mathrm{RH}<70 \% \text { d } \\
\mathrm{I}_{2} \text { at } \mathrm{RH}>70 \% \\
\mathrm{CH}_{3} \mathrm{I} \text { at } \mathrm{RH}<70 \% \\
\mathrm{CH}_{3} \mathrm{I} \text { at } \mathrm{RH}>70 \% \\
\text { (b) Inorganic adsorber } \\
\mathrm{I}_{2}: \text { low loadinge } \\
\mathrm{I}_{2}: \text { high loading } \\
\mathrm{CH}_{3} \mathrm{I} \text { : low loading } \\
\mathrm{CH}_{3} \mathrm{I} \text { : high loading } \\
\text { (c) Silver zeolite } \\
\mathrm{I}_{2} \\
\mathrm{CH}_{3} \mathrm{I}\end{array}$ & $\begin{array}{c}81.9-99.999 \\
>90.0- \\
99.9997 \\
50.25- \\
99.999+ \\
8.77-99.99 \\
\\
99.0-99.9997 \\
57.0-76.0 \\
80.0-99.9997 \\
45.9-99.0 \\
\\
99.0-99.99+ \\
90.0-99.999\end{array}$ & $\begin{array}{c}95.0-99.99 \\
90.0 \\
85.0-99.0 \\
30.0-98.0\end{array}$ & $\begin{array}{l}99.0 \\
50.0 \\
99.0 \\
50.0 \\
\\
99.0 \\
99.0\end{array}$ \\
\hline
\end{tabular}

a Alternate values may be appropriate, depending on accident scenario and more detailed information on filtration systems.

b A hyphen indicates data not available.

c $\mathrm{NR}=$ no recommendation.

d $\mathrm{RH}=$ relative humidity.

e Low loading $=<50 \mathrm{mg}$ of $\mathrm{I}_{2}$ or $\mathrm{CH}_{3} \mathrm{I}$ of adsorber.

Source: Adapted from Elder et al. (1986). 


\section{TABLE D.9 Mapping of WM PEIS Treatability Categories for LLW with Accident Analysis Physical Forms ${ }^{\mathrm{a}}$}

\begin{tabular}{|c|c|c|c|c|}
\hline $\begin{array}{l}\text { WM PEIS Treatability } \\
\text { Category }\end{array}$ & Technology & Form $^{b}$ & $\begin{array}{l}\text { Accident Physical } \\
\text { Form }\end{array}$ & Comments/Assumptions \\
\hline \multirow[t]{2}{*}{ Aqueous liquids } & $\begin{array}{l}\text { General aqueous } \\
\text { treatment }\end{array}$ & Product & Aqueous solution & Output waste form is a dilute aqueous LLW solution. \\
\hline & & Solid residual & Aqueous slurry & Solid residual is an aqueous slurry to be sent for solidification. \\
\hline Aqueous liquids & Current storage & Input & Aqueous solution & Input waste form is a dilute aqueous LLW solution. \\
\hline \multirow[t]{2}{*}{ Aqueous liquids } & Evaporation & Product & $\begin{array}{l}\text { Superheated aqueous } \\
\text { solution }\end{array}$ & $\begin{array}{l}\text { Assumes dominant accident scenarios involve release of evaporator } \\
\text { contents (at high temperature and pressure) and radionuclide } \\
\text { composition of product stream similar to evaporator contents. }\end{array}$ \\
\hline & & Solid residual & Aqueous slurry & $\begin{array}{l}\text { Evaporator residual is aqueous slurry with a high solids concentration } \\
\text { to be sent for solidification. }\end{array}$ \\
\hline Aqueous liquids & Solidification & Product & $\begin{array}{l}\text { Noncombustible } \\
\text { aggregated solids }\end{array}$ & $\begin{array}{l}\text { Noncombustible aggregated solids surrogate for grout monolithic } \\
\text { product. }\end{array}$ \\
\hline Combustible solids & Current storage & Input & DAW & Based on waste form description given in Goyette and Dolak (1996). \\
\hline \multirow[t]{2}{*}{ Combustible solids } & Incineration & Product & $\begin{array}{l}\text { Noncombustible } \\
\text { powder }\end{array}$ & \\
\hline & & Liquid residual & Aqueous solution & $\begin{array}{l}\text { Slurry blowdown from off-gas treatment is an aqueous solution } \\
\text { (Goyette and Dolak 1996). }\end{array}$ \\
\hline Combustible solids & Packaging & Product & DAW & Assumes packaging does not affect physical form. \\
\hline Combustible solids & Solidification & Product & $\begin{array}{l}\text { Noncombustible } \\
\text { aggregated solids }\end{array}$ & $\begin{array}{l}\text { Noncombustible aggregated solids surrogate for grout monolithic } \\
\text { product. }\end{array}$ \\
\hline \multirow[t]{2}{*}{ Combustible solids } & $\alpha$-incineration & Product & $\begin{array}{l}\text { Noncombustible } \\
\text { powder }\end{array}$ & \\
\hline & & Liquid residual & Aqueous solution & \\
\hline
\end{tabular}




\section{TABLE D.9 (Cont.)}

\begin{tabular}{|c|c|c|c|c|}
\hline $\begin{array}{l}\text { WM PEIS Treatability } \\
\text { Category }\end{array}$ & Technology & Form $^{b}$ & $\begin{array}{l}\text { Accident Physical } \\
\text { Form }\end{array}$ & Comments/Assumptions \\
\hline Combustible solids & $\alpha$-solidification & Product & $\begin{array}{l}\text { Noncombustible } \\
\text { aggregated solid }\end{array}$ & $\begin{array}{l}\text { Noncombustible aggregated solids surrogate for grout monolithic } \\
\text { product. }\end{array}$ \\
\hline Activated metals & Current storage & Input & Inert metal & Based on waste form description given in Goyette and Dolak (1996). \\
\hline Activated metals & Packaging & Product & Inert metal & Assumes packaging does not affect physical form. \\
\hline Activated metals & Size reduction & Product & Inert metal & $\begin{array}{l}\text { Assumes production of noncombustible powder during size reduction } \\
\text { is negligible, based on release fraction information for normal } \\
\text { operations (Goyette and Dolak 1996). }\end{array}$ \\
\hline Sfc-contaminated metals & Current storage & Input & $\begin{array}{l}\text { Noncombustible } \\
\text { powder }\end{array}$ & $\begin{array}{l}\text { Noncombustible powder assumed to contaminate outer surfaces of } \\
\text { waste. }\end{array}$ \\
\hline \multirow[t]{2}{*}{ Sfc-contaminated metals } & Decontamination & Product & Inert metal & $\begin{array}{l}\text { Assumes decontamination removes surface contamination resulting in a } \\
\text { potentially activated metal. }\end{array}$ \\
\hline & & Liquid residual & Aqueous slurry & Based on waste form description given in Goyette and Dolak (1996). \\
\hline \multirow[t]{2}{*}{ Sfc-contaminated metals } & Metal melting & Product & $\begin{array}{l}\text { Viscous (molten) } \\
\text { liquid }\end{array}$ & $\begin{array}{l}\text { Assumes dominant accident scenario involves process upset during } \\
\text { melting stage and radionuclide composition of product stream similar } \\
\text { to molten material. }\end{array}$ \\
\hline & & Liquid residual & Aqueous slurry & Based on waste form description given in Goyette and Dolak (1996). \\
\hline Sfc-contaminated metals & Packaging & Product & Inert metal & Assumes packaging does not affect physical form. \\
\hline Slc-contaminated metals & Size reduction & Product & Inert metal & Based on waste form description given in Goyette and Dolak (1996). \\
\hline Sfc-contaminated metals & $\alpha$-size reduction & Product & Inert metal & Based on waste form description given in Goyelte and Dolak (1996). \\
\hline $\begin{array}{l}\text { Noncombustible- } \\
\text { noncompactible solids }\end{array}$ & Current storage & Input & Inert metal & Based on waste form description given in Goyelte and Dolak (1996). \\
\hline
\end{tabular}


TABLE D.9 (Cont.)

\begin{tabular}{|c|c|c|c|c|}
\hline $\begin{array}{l}\text { WM PEIS Treatability } \\
\text { Category }\end{array}$ & Technology & Form $^{b}$ & $\begin{array}{l}\text { Accident Physical } \\
\text { Form }\end{array}$ & Comments/Assumptions \\
\hline $\begin{array}{l}\text { Noncombustible- } \\
\text { noncompactible solids }\end{array}$ & Packaging & Product & Inert metal & Assumes packaging does not affect physical form. \\
\hline $\begin{array}{l}\text { Noncombustible- } \\
\text { noncompactible solids }\end{array}$ & Solidification & Product & $\begin{array}{l}\text { Noncombustible } \\
\text { aggregated solid }\end{array}$ & $\begin{array}{l}\text { Noncombustible aggregated solids surrogate for grout monolithic } \\
\text { product. }\end{array}$ \\
\hline $\begin{array}{l}\text { Noncombustible- } \\
\text { noncompactible solids }\end{array}$ & $\alpha$-solidification & Product & $\begin{array}{l}\text { Noncombustible } \\
\text { aggregated solid }\end{array}$ & $\begin{array}{l}\text { Noncombustible aggregated solids surrogate for grout monolithic } \\
\text { product. }\end{array}$ \\
\hline $\begin{array}{l}\text { Noncombustible- } \\
\text { noncompactible solids }\end{array}$ & Supercompaction & $\begin{array}{l}\text { Product } \\
\text { liquid residual }\end{array}$ & $\begin{array}{l}\text { Inert metal } \\
\text { aqueous solution }\end{array}$ & $\begin{array}{l}\text { Assumes supercompaction does not affect initial physical form. } \\
\text { Fugitive liquids from supercompaction stated to be an aqueous solution } \\
\text { (Feizollahi and Shropshire 1992). }\end{array}$ \\
\hline $\begin{array}{l}\text { Noncombustible- } \\
\text { noncompactible solids }\end{array}$ & $\alpha$-supercompaction & $\begin{array}{l}\text { Product } \\
\text { Liquid residual }\end{array}$ & $\begin{array}{l}\text { Inert metal } \\
\text { Aqueous solution }\end{array}$ & $\begin{array}{l}\text { Assumes } \alpha \text {-supercompaction does not affect initial physical form. } \\
\text { Fugitive liquids from } \alpha \text {-supercompaction stated to be an aqueous } \\
\text { solution (Feizollahi and Shropshire 1992). }\end{array}$ \\
\hline Organic liquids & Current storage & Input & $\begin{array}{l}\text { Organic combustible } \\
\text { liquid }\end{array}$ & Based on waste form description given in Goyette and Dolak (1996). \\
\hline \multirow[t]{2}{*}{ Organic liquids } & Incineration & Product & $\begin{array}{l}\text { Noncombustible } \\
\text { powder }\end{array}$ & $\begin{array}{l}\text { Assumes organic liquids contain both suspended and dissolved solids, } \\
\text { so that incinerator ash is a noncombustible powder. }\end{array}$ \\
\hline & & Liquid residual & Aqueous solution & $\begin{array}{l}\text { Assumes slurry blowdown from off-gas treatment is an aqueous } \\
\text { solution. }\end{array}$ \\
\hline \multirow[t]{2}{*}{ Organic liquids } & $\alpha$-incineration & Product & $\begin{array}{l}\text { Noncombustible } \\
\text { powder }\end{array}$ & $\begin{array}{l}\text { Assumes organic liquids contain both suspended and dissolved solids, } \\
\text { so that incinerator ash is a noncombustible powder. }\end{array}$ \\
\hline & & Liquid residual & Aqueous solution & $\begin{array}{l}\text { Slurry blowdown from off-gas treatment is an aqueous solution } \\
\text { (Goyette and Dolak 1996). }\end{array}$ \\
\hline Organic liquids & Solidification & Product & $\begin{array}{l}\text { Noncombustible } \\
\text { aggregated solid }\end{array}$ & $\begin{array}{l}\text { Assumes product from solidification process is a nonflammable } \\
\text { monolithic solid. }\end{array}$ \\
\hline
\end{tabular}




\section{TABLE D.9 (Cont.)}

\begin{tabular}{|c|c|c|c|c|}
\hline $\begin{array}{l}\text { WM PEIS Treatability } \\
\text { Category }\end{array}$ & Technology & Form $^{b}$ & $\begin{array}{l}\text { Accident Physical } \\
\text { Form }\end{array}$ & Comments/Assumptions \\
\hline Organic liquids & $\alpha$-solidification & Product & $\begin{array}{l}\text { Noncombustible } \\
\text { aggregated solid }\end{array}$ & $\begin{array}{l}\text { Assumes product from } \alpha \text {-solidification process is a nonflammable } \\
\text { monolithic solid. }\end{array}$ \\
\hline Organic liquids & Packaging & Product & $\begin{array}{l}\text { Organic combustible } \\
\text { liquid }\end{array}$ & $\begin{array}{l}\text { Assumes packaging does not affect physical form although packaging } \\
\text { of liquid generally involves addition of absorbent to remove excess free } \\
\text { liquids prior to shipment. }\end{array}$ \\
\hline Other/special case & Current storage & Input & Inert metal & $\begin{array}{l}\text { Accident analysis assumption due to lack of information about this } \\
\text { waste form. }\end{array}$ \\
\hline Other/special case & Packaging & Product & Inert metal & Assumes packaging does not affect physical form. \\
\hline Remote-handled & Current storage & Input & Inert metal & Typically activated metal waste. \\
\hline Remote-handled & Packaging & Product & Inert metal & Assumes packaging does not affect physical form. \\
\hline Sludge/resin & Current storage & Input & Aqueous slurry & Sludge/resin form stated to be "wet solid" (Goyette and Dolak 1996). \\
\hline Sludge/resin & Solidification & Product & $\begin{array}{l}\text { Noncombustible } \\
\text { aggregated solid }\end{array}$ & $\begin{array}{l}\text { Noncombustible aggregated solids surrogate for grout monolithic } \\
\text { product. }\end{array}$ \\
\hline Sludge/resin & $\alpha$-solidification & Product & $\begin{array}{l}\text { Noncombustible } \\
\text { aggregated solid }\end{array}$ & $\begin{array}{l}\text { Noncombustible aggregated solids surrogate for grout monolithic } \\
\text { product. }\end{array}$ \\
\hline Sludge/resin & Vitrification & $\begin{array}{l}\text { Product } \\
\text { Liquid residual }\end{array}$ & $\begin{array}{l}\text { Brittle solid (glass) } \\
\text { aqueous slurry }\end{array}$ & $\begin{array}{l}\text { Slurry blowdown from off-gas treatment is an aqueous solution } \\
\text { (Goyette and Dolak 1996). }\end{array}$ \\
\hline Sludge/resin & $\alpha$-vitrification & $\begin{array}{l}\text { Product } \\
\text { Liquid residual }\end{array}$ & $\begin{array}{l}\text { Brittle solid (glass) } \\
\text { aqueous slurry }\end{array}$ & $\begin{array}{l}\text { Slurry blowdown from off-gas treatment is an aqueous solution } \\
\text { (Goyette and Dolak 1996). }\end{array}$ \\
\hline
\end{tabular}

a Abbreviations: $\alpha=$ alpha, DAW = dry active waste, and Sfc $=$ surface.

b Waste form divided into input, product, liquid residual, and solid residual waste forms.

c General aqueous treatment typically involves removal of suspended and dissolved solids. 


\section{TABLE D.10 Mapping of WM PEIS Treatability Categories for TRUW with Accident Analysis Physical Forms}

\begin{tabular}{|c|c|c|}
\hline $\begin{array}{l}\text { WM PEIS Treatability } \\
\text { Category }\end{array}$ & Accident Physical Form & Comments/Assumptions \\
\hline Organic liquid & $\begin{array}{l}\text { Organic combustible } \\
\text { solution }\end{array}$ & $\begin{array}{l}\text { Input waste form consists of flammable components (i.e, petroleum distillates, solvents) with low } \\
\text { amounts of suspended solids. }\end{array}$ \\
\hline Aqueous liquid & Aqueous solution & Input waste form is a dilute aqueous TRUW solution. \\
\hline $\begin{array}{l}\text { Organic sludges/ } \\
\text { particulates }\end{array}$ & Organic combustible slurry & $\begin{array}{l}\text { Assumes a homogeneous mixture of solid particulates and an organic solution, with the } \\
\text { particulate surfaces "wetted" by the solution. If, however, the particulates are not in intimate } \\
\text { contact with the solution so that they can be considered easily dispersible, then the accident } \\
\text { category of "Combustible Powder" may be more appropriate. }\end{array}$ \\
\hline $\begin{array}{l}\text { Inorganic sludges/ } \\
\text { particulates }\end{array}$ & Aqueous slurry & $\begin{array}{l}\text { Based on logic of previous treatability category. If, however the particulates are not in intimate } \\
\text { contact with the solution so that they can be considered easily dispersible, then the accident } \\
\text { category of "Noncombustible Powder" may be more appropriate. }\end{array}$ \\
\hline Cemented solids & $\begin{array}{l}\text { Noncombustible aggregated } \\
\text { solid }\end{array}$ & $\begin{array}{l}\text { Noncombustible aggregated solids surrogate for cemented solids; would expect minimal risk from } \\
\text { any potential current storage accidents, unless the cohesiveness of the cement has been degraded. }\end{array}$ \\
\hline Organic debris & Dry active waste & Based on waste form description (Oak Ridge National Laboratory 1994). \\
\hline Inorganic debris & Inert metal & $\begin{array}{l}\text { Waste includes construction materials, equipment, and structures. Assumes that decontamination } \\
\text { of waste has been performed so that the remaining radioactivity is due to induced activity. }\end{array}$ \\
\hline Heterogeneous debris & Inert metal & Logic used for "Inorganic Debris" also applied to this treatability category. \\
\hline Soils with $<50 \%$ debris & Noncombustible powder & $\begin{array}{l}\text { Based on Mishima's original accident categories which were taken from the WRAP II safety } \\
\text { documentation (Westinghouse Hanford Company 1991). }\end{array}$ \\
\hline Soils without debris & Noncombustible powder & As above. \\
\hline Lab packs with metals & Dry active waste & $\begin{array}{l}\text { Mishima's RARFs for dry active waste were developed from available data for combustible trash } \\
\text { and "lab packs;" assume that the presence of RCRA toxic metals will not significantly affect the } \\
\text { release characteristics of this treatability category (DOE 1994a). }\end{array}$ \\
\hline
\end{tabular}

and "lab packs;" assume that the presence of RCRA toxic metals will not significantly affect the release characteristics of this treatability category (DOE 1994a). 
TABLE D.10 (Cont.)

\begin{tabular}{ccc}
\hline $\begin{array}{c}\text { WM PEIS Treatability } \\
\text { Category }\end{array}$ & Accident Physical Form & Comments/Assumptions \\
\hline
\end{tabular}

Lab packs without metals Dry active waste

Reactive metals

- Explosives

Compressed gases

Mercury, liquid

Lead, elemental
Reactive metal

Combustible powder

Waste-form dependent: see comments/ assumptions

Waste-form dependent: see comments/ assumptions

Waste-form dependent: see comments/ assumptions
Mishima's RARFs (DOE 1994a) for dry active waste were developed from available data for combustible trash and "lab packs."

By definition.

When the accident physical forms were initially developed, the WM PEIS treatability categories for TRUW did not include this treatability category. Further information on the nature of contamination is required; it may, however, be expected that the explosive material has a fine layer of surface contamination. In this case, the "Combustible Powder" accident physical form may be applicable. For assessment of shock-induced explosions, the TNT equivalence of various explosives given in Table 3.4 of NUREG-1320 (NRC 1988) may be used. However, it should be noted that the release of energy may be great enough to cause failure of containment boundaries and lead to opening of alternative flow paths during an accident, affecting the LPF.

The release category is dependent on the compressed gas(es); if the gas is a noncondensible or a noble gas, then the "Noble Gas" category should be applied. A similar situation applies for halogens and condensible vapors.

When the accident physical forms were initially developed, the WM PEIS treatability categories for TRUW did not include this treatability category. It is assumed that the solution and not the mercury itself is radioactively contaminated. One significant mercury-containing solution is the LLMW stream generated at the Savannah River Site (SRS) during reprocessing and other waste processing steps. The SRS stream is an organic liquid containing small amounts of mercury; in this case, the "Organic Combustible Solution" accident physical form may be applicable. Aqueous solutions containing mercury are also present; in this case,, the appropriate accident physical form would be "Aqueous Liquids, Solutions."

When the accident physical forms were initially developed, the WM PEIS treatability categories for TRUW did not include this treatability category. This treatability category may in general contain both surface contamination and induced lead. In the case of surface contamination (of radionuclides other than lead), then the "Noncombustible Powder" accident physical form may be applied. If however, this stream contains significant amounts of induced activity, then the "Inert Metal" physical form may be more appropriate for accident stresses that do not involve high temperatures (e.g., mechanical releases). 
TABLE D.10 (Cont.)

\begin{tabular}{|c|c|c|}
\hline $\begin{array}{c}\text { WM PEIS Treatability } \\
\text { Category }\end{array}$ & Accident Physical Form & Comments/Assumptions \\
\hline Beryllium, dust & $\begin{array}{l}\text { Waste-form dependent: see } \\
\text { comments/ assumptions }\end{array}$ & See above. \\
\hline $\begin{array}{l}\text { Batteries, lead-acid, } \\
\text { cadmium }\end{array}$ & Noncombustible powder & $\begin{array}{l}\text { Assumes that neither the lead nor cadmium are radioactive, and that the majority of the } \\
\text { radioactivity is associated with surface contamination. }\end{array}$ \\
\hline Other/multiple & $\begin{array}{l}\text { Waste-form dependent: see } \\
\text { comments/ assumptions }\end{array}$ & $\begin{array}{l}\text { Limited information is available on the physical properties of this treatability category. The } \\
\text { appropriate accident physical form would be determined from the treatment processes used to } \\
\text { immobilize this waste stream; if supercompaction is used, then "Inert Metal" may be appropriate. } \\
\text { If liquid/solid separation is required, the waste may be considered to be an "Organic Solution" if } \\
\text { combustible liquids are present, or an "Aqueous Slurry" if the liquid is not combustible. }\end{array}$ \\
\hline
\end{tabular}




\section{TABLE D.11 Mapping of WM PEIS Treatability Categories for HLW with Accident Analysis Physical Forms}

\begin{tabular}{|c|c|c|c|c|}
\hline Site $^{\mathrm{a}}$ & TSD Function & $\begin{array}{l}\text { Material at Risk Based on the Contents } \\
\text { of: }\end{array}$ & Accident Physical Form & Comments/Assumptions \\
\hline Hanford & Current tank storage & One double-shell tank (DST) & Aqueous slurry & $\begin{array}{l}\text { DST waste consists of mixtures of HLW, TRUW, and LLW } \\
\text { existing as crystallized salts or oxides and is considered to be } \\
\text { aqueous slurry (ORNL 1992). }\end{array}$ \\
\hline Hanford & Retrieval & Retrieval line & Aqueous solution & $\begin{array}{l}\text { Hydraulic retrieval assumed, which involves adding water to } \\
\text { mobilize waste prior to transport. }\end{array}$ \\
\hline Hanford & Pretreatment & Conceptual Pretreatment Facility & Aqueous solution & $\begin{array}{l}\text { Review of conceptual Hanford pretreatment facility design } \\
\text { (Boomer 1992) indicated that the majority of the HLW within the } \\
\text { facility is an aqueous solution. }\end{array}$ \\
\hline Hanford & Pretreatment & $\begin{array}{l}\text { Fully-loaded cesium ion-exchange } \\
\text { column }\end{array}$ & $\begin{array}{l}\text { Combustible solids - } \\
\text { polyethylene }\end{array}$ & $\begin{array}{l}\text { Radioactive cesium assumed to be removed by a Duolite-like ion- } \\
\text { exchange resin made of polyethylene. }\end{array}$ \\
\hline Hanford & Pretreatment & $\begin{array}{l}\text { 1,000-gal double-containment receiver } \\
\text { tank (DCRT) }\end{array}$ & Aqueous slurry & $\begin{array}{l}\text { Slurry is formed from retrieved waste due to recirculation } \\
\text { (concentration factor of approximately three times). }\end{array}$ \\
\hline Hanford & Treatment & Vitrification melter & $\begin{array}{l}\text { Viscous (molten) } \\
\text { liquid }\end{array}$ & $\begin{array}{l}\text { Molten glass spill due to failure of melter drain system, material } \\
\text { at risk consists of borosilicate glass similar in behavior to molten } \\
\text { lava. }\end{array}$ \\
\hline Hanford & Treatment & Vitrification melter & $\begin{array}{l}\text { Viscous (molten) } \\
\text { liquid }\end{array}$ & $\begin{array}{l}\text { Steam-glass explosion due to failure of cooling system, material } \\
\text { at risk consists of borosilicate glass similar in behavior to molten } \\
\text { lava. }\end{array}$ \\
\hline
\end{tabular}




\section{TABLE D.11 (Cont.)}

\begin{tabular}{|c|c|c|c|c|}
\hline Site ${ }^{a}$ & TSD Function & $\begin{array}{l}\text { Material at Risk Based on the Contents } \\
\text { of: }\end{array}$ & Accident Physical Form & Comments/Assumptions \\
\hline Hanford & Treatment & $\begin{array}{l}\text { Hanford Waste Vitrification Plant } \\
\text { (HWVP) }\end{array}$ & Aqueous slurty & $\begin{array}{l}\text { External event assumed to result in rupture of all waste holding } \\
\text { tanks and spillage of molten glass; molten glass spill neglected } \\
\text { based on Herborn and Smith (1990) due to low inventory in } \\
\text { comparison with entire facility and low release fraction. }\end{array}$ \\
\hline Hanford & Glass canister storage & One HLW glass canister & Brittle solids (glass) & $\begin{array}{l}\text { Brittle (glass) solids surrogate for borosilicate-type glass } \\
\text { produced during vitrification. }\end{array}$ \\
\hline SRS & Current tank storage & One Type-III tank & Aqueous solution & $\begin{array}{l}\text { Majority of the SRS HLW inventory }(\approx 45 \%) \text { associated with the } \\
\text { alkaline liquid, which has a high salt content solution with many } \\
\text { crystallized salt solids. }\end{array}$ \\
\hline SRS & Retrieval & Retrieval line & Aqueous solution & $\begin{array}{l}\text { Hydraulic retrieval assumed, which involves adding water to } \\
\text { mobilize waste prior to transport. }\end{array}$ \\
\hline SRS & Pretreatment & One Type-III tank & Aqueous solution & $\begin{array}{l}\text { Based on material characteristics for in-tank precipitation process } \\
\text { given in Choi and Fowler (1990). }\end{array}$ \\
\hline SRS & Pretreatment & Salt cake tank & Aqueous slurry & $\begin{array}{l}\text { Salt cake tank contains washed sludge waste assumed to be } \\
\text { equivalent in physical form to an aqueous slurry. }\end{array}$ \\
\hline SRS & Treatment & Slurry mix evaporator (SRE) & $\begin{array}{l}\text { Superheated aqueous } \\
\text { solution }\end{array}$ & $\begin{array}{l}\text { Dominant accident scenario in literature involves release of } \\
\text { evaporator contents at high pressure and temperature (WSRC } \\
\text { 1990; WSRC 1991). }\end{array}$ \\
\hline SRS & Treatment & $\begin{array}{l}\text { Slurry receipt and adjustment Tank } \\
\text { (SRAT) }\end{array}$ & Aqueous slurry & $\begin{array}{l}\text { SRAT contains washed sludge, which is assumed to be equivalent } \\
\text { in physical form to an aqueous slurry. }\end{array}$ \\
\hline
\end{tabular}




\section{TABLE D.11 (Cont.)}

\begin{tabular}{|c|c|c|c|c|}
\hline Site $^{\mathfrak{a}}$ & TSD Function & $\begin{array}{l}\text { Material at Risk Based on the Contents } \\
\text { of: }\end{array}$ & Accident Physical Form & Comments/Assumptions \\
\hline SRS & Treatment & Vitrification melter & Viscous (molten) liquid & $\begin{array}{l}\text { Steam-glass explosion due to failure of cooling system, material- } \\
\text { at-risk consists of borosilicate glass similar in behavior to molten } \\
\text { lava. }\end{array}$ \\
\hline SRS & Treatment & $\begin{array}{l}\text { Defense Waste Processing Facility } \\
\text { (DWPF) }\end{array}$ & Aqueous slurry & $\begin{array}{l}\text { External event assumed to result in rupture of all waste holding } \\
\text { tanks and spillage of molten glass; molten glass spill neglected } \\
\text { based on WSRC (1993) due to low inventory in comparison with } \\
\text { entire facility and low release fraction. }\end{array}$ \\
\hline SRS & Glass canister storage & One HLW glass canister & Brittle solids (glass) & $\begin{array}{l}\text { Brittle (glass) solids surrogate for borosilicate-type glass } \\
\text { produced during vitrification. }\end{array}$ \\
\hline WVDP ${ }^{b}$ & Pretreatment & Tank 8D-2 & Aqueous slurry & $\begin{array}{l}\text { Tank } 8 D-2 \text { contains washed sludge waste assumed to be } \\
\text { equivalent in physical form to an aqueous slurry. }\end{array}$ \\
\hline WVDP & Treatment & $\begin{array}{l}\text { Concentrator feed makeup } \\
\text { tank (CFMUT) }\end{array}$ & Aqueous slurry & Based on waste description given in Barnes et al. (1988). \\
\hline WVDP & Treatment & Vitrification melter & Viscous (molten) liquid & $\begin{array}{l}\text { Steam-glass explosion due to failure of cooling system, material } \\
\text { at risk consists of borosilicate glass similar in behavior to molten } \\
\text { lava. }\end{array}$ \\
\hline WVDP & Treatment & Vitrification Facility & Aqueous slurry & $\begin{array}{l}\text { External event assumed to result in rupture of all waste holding } \\
\text { tanks and spillage of molten glass; molten glass spill neglected } \\
\text { due to low inventory in comparison with entire facility and low } \\
\text { release fraction. }\end{array}$ \\
\hline WVDP & Glass canister storage & One HLW glass canister & Brittle solids (glass) & $\begin{array}{l}\text { Brittle (glass) solids surrogate for borosilicate-type glass } \\
\text { produced during vitrification. }\end{array}$ \\
\hline
\end{tabular}

a HLW accident analysis for Idaho National Engineering Laboratory (INEL) not included because of nonexistent safety documentation for the immobilization process and possible conflicts with the accident analysis for the INEL site-wide EIS.

b $W V D P=$ West Valley Demonstration Project. 


\section{D.4 REFERENCES}

Ayer, J.E., et al., 1988, Nuclear Fuel Cycle Accident Analysis Handbook, NUREG-1320, U.S. Nuclear Regulatory Commission, Washington, D.C., May.

Ballinger, M.Y., and W.H. Hodgson, 1986 Aerosols Generated by Spills of Viscous Solutions and Slurries, NUREG/CR-4658, Pacific Northwest Laboratory, Richland, Wash.

Barnes, S.M., et al., 1988, "Three Year's Progress of the West Valley Demonstration Project Vitrification System," in Proceedings of Waste Management '88, R. Post and M. Walks (editors), Laser Options, Inc., Tucson, Ariz., pp. 195-202.

Bergman, W., 1993, Efficiency of HEPA Filtration Systems during and after Design Basis Accidents, Draft, Lawrence Livermore Laboratory, Livermore, Calif.

Boomer, K.D., 1992, Tank Waste Systems Engineering Study, WHC-EP-0405, rev. 0, prepared by Westinghouse Hanford Co., Richland, Wash., for U.S. Department of Energy, Office of Environmental Restoration and Waste Management, Oct.

Choi, A.S., and J.R. Fowler, 1990, Material Balance Tables for the DWPF Basic Data Report. Revision 138: Appendix G, Table 19-1, WSRC-TR-90-93, Westinghouse Savannah River Co., Aiken, S.C., Feb.

DOE. See U.S. Department of Energy.

Elder, J.C., et al., 1986, A Guide to Radiological Accident Considerations for Siting and Design of DOE Nonreactor Nuclear Facilities, LA-10294-MS/UC-41, Los Alamos National Laboratory, Los Alamos, N.M.

Feizollahi, F., and D. Shropshire, 1992, Waste Management Facilities Cost Information Report, EGG-WTD-10443, EG\&G Idaho, Inc., Idaho Falls, Idaho, Oct.

Goyette, M.L., and D.A. Dolak, 1996, Low-Level Waste Inventory, Characteristics, Generation, and Facility Assessment for Treatment, Storage, and Disposal Alternatives Considered in the U.S. Department of Energy Waste Management Programmatic Environmental Impact Statement, ANL/EAD/TM-20, Argonne National Laboratory, Argonne, Ill.

Herborn, D.I., and D.A. Smith, 1990, Hanford Waste Vitrification Plant Preliminary Safety Analysis Report, WHC-EP-0250, rev. B, Draft, Westinghouse Hanford Company, Richland, Wash., July. 
Mishima, J., et al., 1968, Plutonium Release Studies III. Release from Heated Plutonium Bearing Powders, BNWL-786, Pacific Northwest Laboratory, Richland, Wash.

NRC. See U.S. Nuclear Regulatory Commission.

Oak Ridge National Laboratory, 1992, Integrated Data Base for 1992: U.S. Spent Fuel and Radioactive Waste Inventories, Projections, and Characteristics, DOE/RW-0006, rev. 8, prepared for U.S. Department of Energy, Oak Ridge, Tenn., Oct.

Oak Ridge National Laboratory, 1994, Integrated Data Base for 1993: U.S. Spent Fuel and Radioactive Waste Inventories, Projections, and Characteristics, DOE/RW-0006, rev. 9, U.S. Department of Energy, Oak Ridge, Tenn., March.

Restrepo, L.F., 1992, The Annular Core Research Reactor (ACRR) Limiting Event for Worker and Public Consequences, SAND91-0572, Sandia National Laboratories, Albuquerque, N.M.

Roblyer, S.P., and P.C. Owczarski, 1992, "Determining Wind Spray Release from Effluent Disposal Ponds," presented at Hazmacon '92, Long Beach, Calif., March 30-April 2.

Soffer, L., 1993, "Review of Reactor Accident Source Terms and Implications for Nuclear Air Cleaning Requirements," Proceedings of the 22nd DOE/NRC Nuclear Air Cleaning Conference, NUREG-CP-0130, U.S. Nuclear Regulatory Commission, Washington, D.C.

Steindler, M.J., and W.H. Seefeldt, 1980, "A Method for Estimating the Challenge to an Air Cleaning System," in Proceedings of the 16th DOE Air Cleaning Conference, CONF-801038, Harvard Air Cleaning Laboratory, Boston, Mass.

Sutter, S.L., 1983, Aerosols Generated by Release of Pressurized Powders and Solutions in Static Air, NUREG/CR-3093, Pacific Northwest Laboratory, Richland, Wash.

Teleyarkhan, R.P., 1992, "Analysis and Modeling of Fission Product Release from Various Uranium-Aluminum Plate-Type Reactors Fuels," Nuclear Safety 33(1):6-22.

U.S. Department of Energy, 1994, Airborne Release Fractions/Rates and Respirable Fractions at DOE Nonreactor Nuclear Facilities, DOE-STD-3010-94, Office of Scientific and Technical Information, Oak Ridge, Tenn.

U.S. Department of Energy, 1996, Waste Management Programmatic Environmental Impact Statement for Managing Treatment, Storage, and Disposal of Radioactive and Hazardous Waste, DOE/EIS-0200-PF, Office of Environmental Management, Washington, D.C. 
U.S. Nuclear Regulatory Commission (NRC), 1977a, "Assumptions Used for Evaluating the Potential Radiological Consequences of Accidental Nuclear Criticality in a Fuel Reprocessing Plant," NRC Regulatory Guide 3.33.

U.S. Nuclear Regulatory Commission, 1977b, "Assumptions Used for Evaluating the Potential Radiological Consequences of Accidental Nuclear Criticality in a Plutonium Processing and Fuel Fabrication Plant," NRC Regulatory Guide 3.35.

U.S. Nuclear Regulatory Commission, 1977c, "Assumptions Used for Evaluating Radiological Consequences of Accidental Nuclear Criticality in a Uranium Fuel Fabrication Plant," NRC Regulatory Guide 3.34.

U.S. Nuclear Regulatory Commission, 1988, Nuclear Fuel Cycle Facility Accident Analysis Handbook, NUREG-1320, Washington, D.C., May.

Walker, E., 1987, A Summary of Parameters Affecting the Release and Transport of Radioactive Material from an Unplanned Incident, BNFO-81-2, Bechtel Nuclear Fuels, San Francisco, Calif., Sept.

Westinghouse Hanford Company, 1993, Preliminary Safety Analysis Report for Hanford Waste Vitrification Plant, WHC-SD-HWV-PSAR-001, rev. 1, (draft), Richland, Wash.

Westinghouse Savannah River Company (WSRC), 1990, Safety Analysis - 200-S Area Savannah River Site Defense Waste Processing Facility Operations (U), DPSTSA-200-10, rev. 1 SUP-20, Aiken, S.C., Feb.

Westinghouse Savannah River Company, 1991, Support Facilities Descriptions for the New Production Reactor at Savannah River, Volume 1, Heavy Water Reactor (U), WSRC-RP-89-263, vol. 1, version 4, Aiken, S.C.

Westinghouse Savannah River Company, 1993, Final Safety Analysis, Defense Waste Processing Facility. Chapter 9, Analysis of Operation, DPSTA-200-10 SUP.20 rev. 9, Westinghouse Savannah River Co., Aiken, S.C.

WSRC. See Westinghouse Savannah River Co. 
APPENDIX E:

REFERENCE DATA ON NATURAL PHENOMENA FREQUENCIES AND RELATED DESIGN SPECIFICATIONS OF DOE FACILITIES 


$$
E-2
$$




\section{CONTENTS}

NOTATION

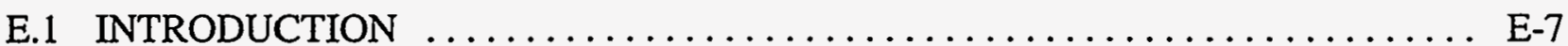

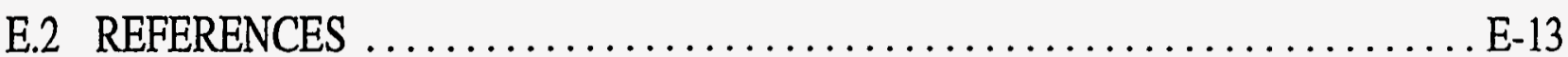

\section{FIGURE}

E.1 Relationship among Hazard Class/Category, SSC Performance Category, and Pertinent DOE Orders and Standards $\ldots \ldots \ldots \ldots \ldots \ldots \ldots$ E-8

\section{TABLES}

E.1 Natural Phenomena Hazards Performance Goals for Systems, Structures,

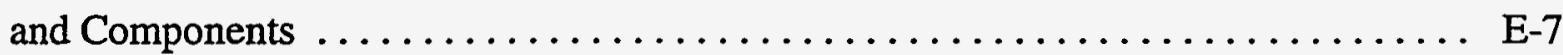

E.2 Natural Phenomena Frequency and Intensity Data for DOE Sites $\ldots \ldots \ldots \ldots \ldots$ E-9 
$E-4$ 


\section{NOTATION}

The following is a list of acronyms, initialisms, and abbreviations (including units of measure) used in this appendix.

\section{ACRONYMS, INITIALISMS, AND ABBREVIATIONS}

$\begin{array}{ll}\text { ANL-E } & \text { Argonne National Laboratory-East } \\ \text { ANL-W } & \text { Argonne National Laboratory-West } \\ \text { BNL } & \text { Brookhaven National Laboratory } \\ \text { CFA } & \text { Central Facilities Area } \\ \text { CPP } & \text { Chemical Processing Plant } \\ \text { DOE } & \text { U.S. Department of Energy } \\ \text { DWPF } & \text { Defense Waste Processing Facility } \\ \text { ETEC } & \text { Energy Technology Engineering Center } \\ \text { FEMP } & \text { Fernald Environmental Management Project } \\ \text { HWHF } & \text { High-Level Waste Handling Facility } \\ \text { INEL } & \text { Idaho National Engineering Laboratory } \\ \text { KCP } & \text { Kansas City Plant } \\ \text { LANL } & \text { Los Alamos National Laboratory } \\ \text { LBL } & \text { Lawrence Berkeley National Laboratory } \\ \text { LLNL } & \text { Lawrence Livermore National Laboratory } \\ \text { NTS } & \text { Nevada Test Site } \\ \text { ORR } & \text { Oak Ridge National Laboratory } \\ \text { PBF } & \text { Power Burst Facility } \\ \text { PGDP } & \text { Paducah Gaseous Diffusion Plant } \\ \text { PORTS } & \text { Portsmouth Gaseous Diffusion Plant } \\ \text { RFETS } & \text { Rocky Flats Environmental Technology Site } \\ \text { RWMC } & \text { Radioactive Waste Management Complex } \\ \text { RWMS } & \text { Radioactive Waste Management Site } \\ \text { SLAC } & \text { Stanford Linear Accelerator Center } \\ \text { SNL-CA } & \text { Sandia National Laboratories (California) } \\ \text { SNL-NM } & \text { Sandia National Laboratories (New Mexico) } \\ \text { SRS } & \text { Savannah River Site } \\ \text { SSC } & \text { system, structure, and component } \\ \text { TA } & \text { Technical Area } \\ \text { WIPP } & \text { Waste Isolation Pilot Plant }\end{array}$




\section{UNITS OF MEASURE}

$\mathrm{ft}$

g

m

$\mathrm{m}^{3}$

$\mathrm{mi} / \mathrm{h}$ foot (feet)

gram(s)

meter(s)

cubic meter(s)

mile(s) per hour 


\section{APPENDIX E:}

\section{REFERENCE DATA ON NATURAL PHENOMENA FREQUENCIES AND RELATED DESIGN SPECIFICATIONS OF DOE FACILITIES}

\section{E.1 INTRODUCTION}

This appendix provides data developed to correlate the magnitude and frequencies of severe natural phenomena that may challenge the facilities at U.S. Department of Energy (DOE) waste management sites. Natural phenomena frequencies were obtained following a two-step process:

1. Performance goals for structures, systems, and components (SSCs) published in DOE 5480.28 (DOE 1993) and summarized in a revised nomenclature in the DOE standard for performance categorization (DOE 1992) are shown in Figure E.1 and summarized in Table E.1 Figure E.1 shows the equivalency between performance categories and hazard categories.

2. The frequencies of varying levels of intensity for natural phenomena at the DOE sites were compiled from the DOE Natural Phenomena Hazards Modeling Project (Coats and Murray 1984, 1985; Savy and Murray 1985). The annual frequencies of exceedance associated with the performance goals were then compared with the published site-specific hazards data to map natural phenomena loadings with these frequencies. The results are shown in Table E.2.

TABLE E.1 Natural Phenomena Hazards Performance Goals for Systems, Structures, and Components

\begin{tabular}{lcccc}
\hline & High & Moderate & Low & General \\
Hazard & Hazard & Hazard & Use \\
Hazard Category & 1 & 2 & 3 & 4 \\
\hline $\begin{array}{l}\text { Performance goal (mean annual } \\
\text { probability of exceedance of } \\
\text { acceptable behavior limits) }\end{array}$ & $10^{-5}$ & $10^{-4}$ & $5 \times 10^{-4}$ & $10^{-3}$ \\
\hline
\end{tabular}




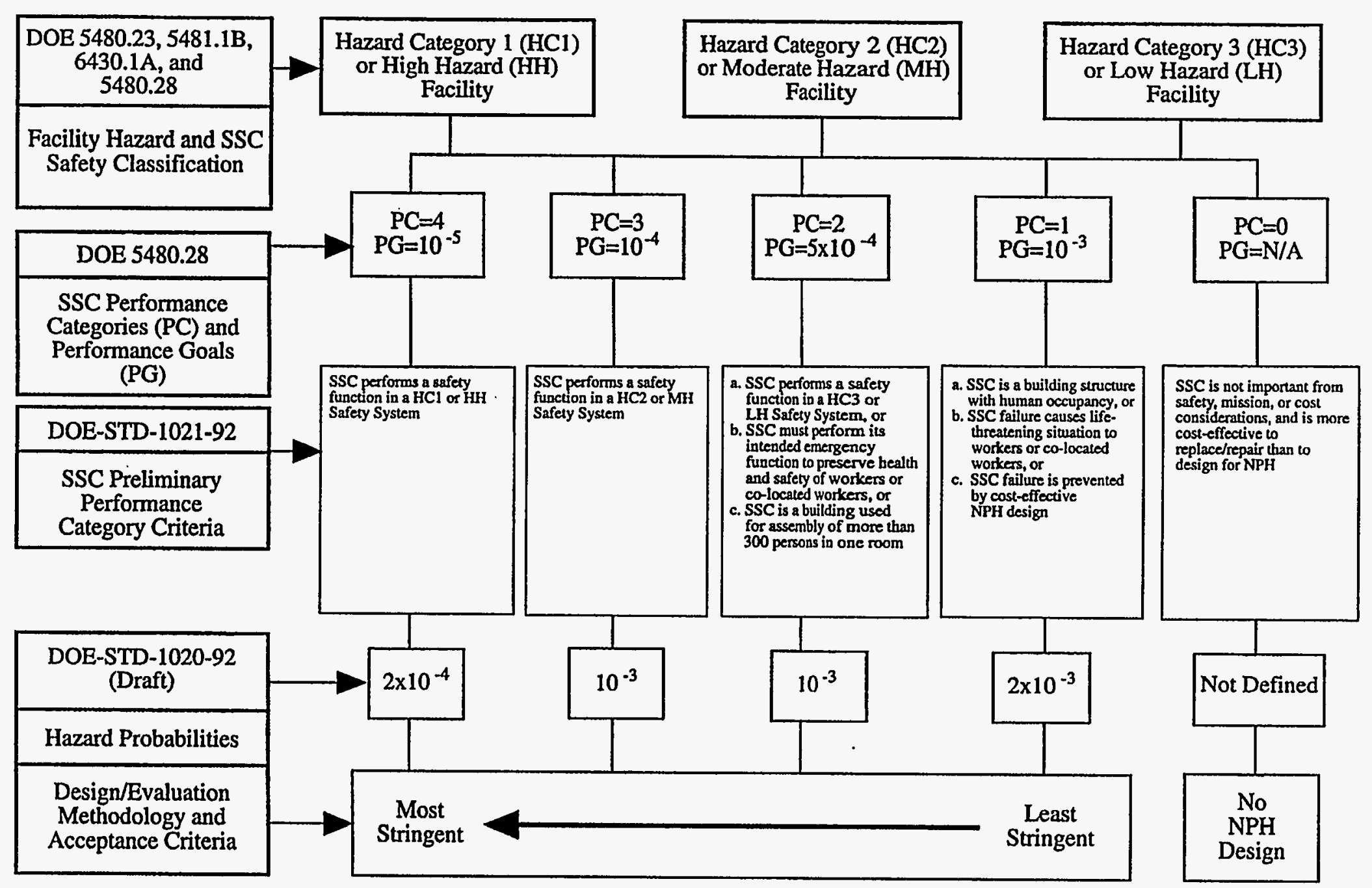

FIGURE E.1 Relationship among Hazard Class/Category, SSC Performance Category, and Pertinent DOE Orders and Standards 
TABLE E.2 Natural Phenomena Frequency and Intensity Data for DOE Sites ${ }^{\mathrm{a}}$

\begin{tabular}{|c|c|c|c|c|c|c|c|c|c|c|c|c|c|c|c|c|}
\hline \multirow[b]{2}{*}{ Site } & \multicolumn{3}{|c|}{$\begin{array}{l}\text { Escimated Hortzantul Selismlc Losd (g) by DOE } \\
\text { S480.28 Pcrformance Calegory (PC) }\end{array}$} & \multicolumn{6}{|c|}{ Wind and Tomado Loads (mi/h) by DOE 5480.28 Performanse Categorfs } & \multicolumn{4}{|c|}{ Flood (n above facility gradc) } & \multirow[b]{2}{*}{$\begin{array}{c}\text { Demography } \\
\text { (50-mi radius } \\
\text { poppulation) }\end{array}$} & \multirow[b]{2}{*}{$\begin{array}{l}\text { Silc Arca } \\
\left(\mathrm{m}^{2}\right)\end{array}$} & \multirow[b]{2}{*}{$\begin{array}{c}\text { Sourcic. } \\
\text { Receptor } \\
\text { Distance (m) } \\
\end{array}$} \\
\hline & $\begin{array}{c}\mathrm{PC} 1 \\
(2.0 \mathrm{E}-03 / \mathrm{yt}) \\
\end{array}$ & $\begin{array}{c}\mathrm{PC} 2,3 \\
(1,0 \mathrm{E}-03 / y \mathrm{y})\end{array}$ & $\begin{array}{c}\mathrm{PC4} \\
(2.0 \mathrm{E}-04 \mathrm{yr}) \\
\end{array}$ & $\begin{array}{c}\text { PC 1 } \\
\text { Wind } \\
(2,0 \mathrm{E}-02 / y r) \\
\end{array}$ & 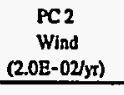 & 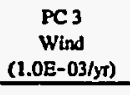 & $\begin{array}{c}\mathrm{PC} 3 \\
\text { Tomado } \\
(2.0 \mathrm{E}-05 / \mathrm{yr}) \\
\end{array}$ & $\begin{array}{c}\text { PC4 } \\
\text { Wind } \\
(1.0 \mathrm{E}-04 / \mathrm{yr}) \\
\end{array}$ & $\begin{array}{c}\text { PC 4 } \\
\text { Turnado } \\
\text { (2.0E-05/yt) } \\
\end{array}$ & $\begin{array}{c}P C 1 \\
(1.0 E-03 / y t) \\
\end{array}$ & $\begin{array}{c}\mathrm{PC} 2 \\
(5.0 \mathrm{E}-04 / \mathrm{y \tau}) \\
\end{array}$ & $\begin{array}{c}\mathrm{PC} 3 \\
(1.0 \mathrm{E}-04 / \mathrm{yt}) \\
\end{array}$ & $\begin{array}{c}\mathrm{PC} 4 \\
(5.0 \mathrm{E}-05 / \mathrm{yt}) \\
\end{array}$ & & & \\
\hline ANLBB & 0.09 & 0.12 & 0.21 & 70 & 70 & $\mathbf{N A}^{\mathrm{d}}$ & 142 & NA & 142 & NA & NA & NA & NA & $\begin{array}{l}7,9(x),(1 \times 1) \\
(1983)\end{array}$ & $6.9 \mathrm{~B} 06$ & $\begin{array}{l}800 \text { Arcx: } \\
240 ; 300 \\
\text { Arca: } 170\end{array}$ \\
\hline ANLWW & 0.12 & 0.14 & 0.21 & 70 & 70 & 83 & NA & 95 & NA & NA & $\mathrm{NA}$ & $\mathrm{NA}$ & NA & $\begin{array}{l}110,000 \\
(1983)\end{array}$ & 2.3 E0y & $\begin{array}{l}\text { To Hwy 20: } \\
\text { 4.850 }\end{array}$ \\
\hline BNL & 0.12 & 0.15 & 0.25 & 70 & 70 & NA & 95 & $\mathrm{NA}$ & 95 & NA & NA & $\mathrm{NA}$ & NA & $\begin{array}{l}4,800,000 \\
(1983)\end{array}$ & $2.2 \mathrm{E07}$ & $\begin{array}{l}\text { Arez 4t5 } \\
\text { Waste nigl: } \\
900\end{array}$ \\
\hline ETEC & 0.53 & 0.59 & NA & 70 & 70 & NA & 95 & $\mathrm{NA}$ & 95 & NA & NA & NA & NA & $\begin{array}{l}8.100,000 \\
(1983)\end{array}$ & $1.1 \mathrm{E07}$ & NA \\
\hline FEMP & 0.10 & 0.13 & 0.20 & 70 & 70 & $\mathrm{NA}$ & 139 & NA & 139 & NA & $\mathrm{NA}$ & NA & NA & $\begin{array}{l}2,600,000 \\
(1983)\end{array}$ & $4.3 \mathrm{E} 06$ & $\begin{array}{c}\text { Tanks and } \\
\text { chem waste } \\
\text { pils: } 225 \\
\text { Relention } \\
\text { basin: } 490 \\
\text { Product arca: } \\
610\end{array}$ \\
\hline Hanfoud & 0.09 & 0.12 & 0.17 & 70 & 70 & 80 & NA & 90 & $\mathrm{NA}$ & $\begin{array}{c}<-9 \\
\text { (N- } \\
\text { Reactor) }\end{array}$ & $\stackrel{-1}{\stackrel{-1}{(N-}}$ & 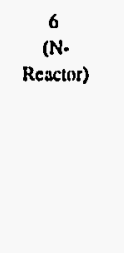 & $\begin{array}{c}27 \\
\text { (N- } \\
\text { Reactor) }\end{array}$ & $\begin{array}{l}340,000 \\
(1983)\end{array}$ & $1.5 \mathrm{E} 09$ & $\begin{array}{c}\text { To liwy 24 } \\
\text { or Barricade } \\
\text { to 200 W: } \\
8,050 ; 200 \mathrm{E}: \\
3,200 \\
\text { Nonradlo- } \\
\text { active } \\
\text { storage } 616: \\
6,400\end{array}$ \\
\hline INEL & 0.12 & 0.14 & 0.21 & 70 & 70 & 84 & NA & 95 & NA & $\mathrm{NA}$ & NA & $\mathrm{NA}$ & $\mathrm{NA}$ & $\begin{array}{l}110,000 \\
(1983)\end{array}$ & $2.3 \mathrm{E} 09$ & $\begin{array}{l}\text { Hwy } 20 \mathrm{lu} \\
\text { RWMCl } \\
\text { CPPPBPF: } \\
\text { S,6000 } \\
\text { CFA: } 1850\end{array}$ \\
\hline KCP & 0.08 & 0.10 & 0.17 & 72 & 72 & $\mathrm{NA}$ & 144 & NA & 144 & 12 & 15 & 18 & 19 & & $3.0 \mathrm{E} 0 \mathrm{~S}$ & $\begin{array}{l}\text { Oil storage: } \\
\quad 100\end{array}$ \\
\hline LBL & 0.55 & 0.64 & NA & 72 & 72 & 95 & NA & 111 & NA & $\mathrm{NA}$ & NA & $\mathrm{NA}$ & 19 & $\begin{array}{l}5,200,00 \\
(1983)\end{array}$ & 5.3 Eos & BIdg 75: 25 \\
\hline LNL & 0.41 & 0.48 & 0.68 & 72 & 72 & 96 & $\mathrm{NA}$ & 113 & NA & $\mathrm{NA}$ & $\mathrm{NA}$ & $\mathrm{NA}$ & $\mathrm{NA}$ & $\begin{array}{l}6,0000,0000 \\
(1988)\end{array}$ & $2.6 \mathrm{E} 06$ & $\begin{array}{l}\text { Bs 13: } 82 \\
\text { B949: } 190 \\
\text { B643: } 130\end{array}$ \\
\hline
\end{tabular}


TABLE E.2 (Cont.)

\begin{tabular}{|c|c|c|c|c|c|c|c|c|c|c|c|c|c|c|c|c|}
\hline \multirow[b]{2}{*}{ Sile } & \multicolumn{3}{|c|}{$\begin{array}{l}\text { Estumaled Horl zontal Selsmalc Load (g) by DOE } \\
\text { S480.28 Performance Calegory (PC) }\end{array}$} & \multicolumn{6}{|c|}{ 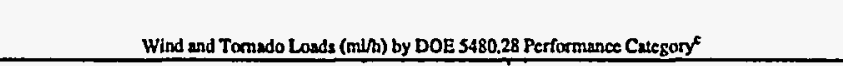 } & \multicolumn{4}{|c|}{ Flood (a above facility grade) } & \multirow[b]{2}{*}{$\begin{array}{l}\text { Demougraphy } \\
\text { (50-ni ratius } \\
\text { populatilun) }\end{array}$} & \multirow[b]{2}{*}{$\begin{array}{l}\text { Sile Area } \\
\left(m^{2}\right)^{2}\end{array}$} & \multirow[b]{2}{*}{$\begin{array}{c}\text { Source. } \\
\text { Recepus } \\
\text { Distaxie (ni) }\end{array}$} \\
\hline & $\begin{array}{c}P C 1 \\
(2.0203 / y 0) \\
\end{array}$ & $\begin{array}{c}\mathrm{PC} 2,3 \\
(1.0 \mathrm{E}-03 / \mathrm{yt})\end{array}$ & $\begin{array}{c}\mathrm{PC} 4 \\
(2.0 \mathrm{E}-(04 / \mathrm{yt})\end{array}$ & $\begin{array}{c}P C I \\
\text { Wind } \\
(2.0 \mathrm{E}-02 / \mathrm{yr})\end{array}$ & $\begin{array}{c}\mathrm{PC} 2 \\
\text { Wind } \\
(2.0 \mathrm{E}-02 / \mathrm{yr})\end{array}$ & $\begin{array}{c}\mathrm{PC}_{3} \\
\text { Wind } \\
(1.0 \mathrm{E}-03 / \mathrm{yr})\end{array}$ & $\begin{array}{c}\mathrm{PC}_{3} \\
\text { Tomado } \\
\text { (2.0E-0S/yr) }\end{array}$ & $\begin{array}{c}\text { PC4 } \\
\text { Wind } \\
(1.0 \mathrm{E}-04 / \mathrm{yr})\end{array}$ & $\begin{array}{c}\mathrm{PC}_{4} \\
\text { Tomado } \\
\text { (2.0E-05/yx) }\end{array}$ & $\begin{array}{c}P C 1 \\
(1.0 \mathrm{E}-03 / y t)\end{array}$ & $\begin{array}{c}\mathrm{PC} 2 \\
(5,0 \mathrm{E}-0.04 / \mathrm{yt}) \\
\end{array}$ & $\begin{array}{c}\mathrm{PC} 3 \\
(1,0 \mathrm{E} \cdot 04 / \mathrm{yr}) \\
\end{array}$ & $\begin{array}{c}\mathrm{PCA} \\
(5.0 \mathrm{E}-0 \mathrm{0S} / \mathrm{yr}) \\
\end{array}$ & & & \\
\hline $\begin{array}{l}\text { LLNL, } \\
\text { Site } 300\end{array}$ & 0.32 & 0.38 & 0.56 & 80 & 80 & 104 & NA & 125 & NA & $\mathrm{NA}$ & NA & NA & NA & NA & $2.9 \mathrm{E} 07$ & B883: 200 \\
\hline LANL. & 0.18 & 0.22 & 0.38 & 77 & 77 & 93 & NA & 107 & NA & $\begin{array}{c}1 \\
(T A-4)\end{array}$ & $\begin{array}{c}2 \\
(T A-4)\end{array}$ & $\begin{array}{c}3 \\
(\pi A-4)\end{array}$ & $\begin{array}{c}5 \\
(2 A-4)\end{array}$ & $\begin{array}{l}160,000 \\
(1983)\end{array}$ & $1.1 \mathrm{E} 08$ & $\begin{array}{c}\text { TA-S0 waste } \\
\text { mgl: 1,800; } \\
\text { TA-St: } \\
\text { 2.600; TA-3: } \\
900\end{array}$ \\
\hline Mound & 0.12 & 0.15 & 0.23 & 73 & 73 & $\mathrm{NA}$ & 136 & $\mathrm{NA}$ & 136 & -5 & -3 & -1 & 0 & $\begin{array}{l}3,400,000 \\
(1983)\end{array}$ & $1.2 \mathrm{E} 06$ & $\begin{array}{c}\text { Main arca: } \\
\text { 120; PP arca: } \\
\text { G0 Test fire } \\
\text { arca: } 230\end{array}$ \\
\hline NTS & 0.21 & 0.27 & 0.46 & 72 & 72 & 87 & $\mathrm{NA}$ & 100 & $\mathrm{NA}$ & $\mathrm{NA}$ & NA & $\mathrm{NA}$ & NA & $\begin{array}{l}4,600 \\
(1983)\end{array}$ & 3.5 E.0Y & $\begin{array}{c}\text { Arcas } \\
\text { RWMS: } \\
\text { 20,300 } \\
\text { Arce 3 } \\
\text { RWMS: } \\
\text { 41,300 } \\
\text { ReMAD: } \\
17,500 \\
\text { Arca 26 } \\
\text { Sthaft: } 17,000\end{array}$ \\
\hline ORR & 0.15 & 0.19 & 0.32 & 70 & 70 & NA & 113 & $\mathrm{NA}$ & 113 & NA & $\mathrm{NA}$ & NA & NA & $\begin{array}{l}840,000 \\
(1983)\end{array}$ & $1.2 \mathrm{E} 07$ & \\
\hline K.25 & 0.15 & 0.19 & 0.32 & 70 & 70 & NA & 113 & $\mathrm{NA}$ & 113 & NA & NA & NA & NA & $\begin{array}{l}840,000 \\
(1983)\end{array}$ & $\begin{array}{l}6.1 \\
\text { E06 }\end{array}$ & \\
\hline$Y \cdot 12$ & 0.15 & 0.19 & 0.32 & 70 & 70 & NA & 113 & $\mathrm{NA}{ }^{\circ}$ & 113 & $\mathrm{NA}$ & NA & $\mathrm{NA}$ & NA & $\begin{array}{l}840,000 \\
(1983)\end{array}$ & $\begin{array}{l}3.3 \\
\mathbf{E 0 6}\end{array}$ & \\
\hline PODP & 0.33 & 0.45 & $\mathrm{NA}$ & 70 & 70 & $\mathrm{NA}$ & 144 & $\mathrm{NA}$ & 144 & $\mathrm{NA}$ & NA & $\mathrm{NA}$ & NA & $\begin{array}{l}500,000 \\
(1983)\end{array}$ & 1.4 E07 & \\
\hline Pantex & 0.08 & 0.10 & 0.17 & 78 & 78 & NA & 132 & $\mathrm{NA}$ & 132 & NA & NA & NA & NA & $\begin{array}{l}259,300 \\
(1980)\end{array}$ & $0.5 E 07$ & $\begin{array}{c}\text { Zunc } 4 \\
\text { burid: } 1,800 \\
\text { Zune } 13 \\
\text { Sewage } \\
\text { teeanumant: } \\
110\end{array}$ \\
\hline Pincllas & 0.04 & 0.05 & 0.09 & 93 & 93 & $130^{\circ}$ & $\mathrm{NA}$ & 150 & NA & -2 & -1 & 5 & 17 & $\begin{array}{c}2,000,000 \\
(1983)\end{array}$ & $4.0 \mathrm{E} 0 \mathrm{~S}$ & \\
\hline
\end{tabular}




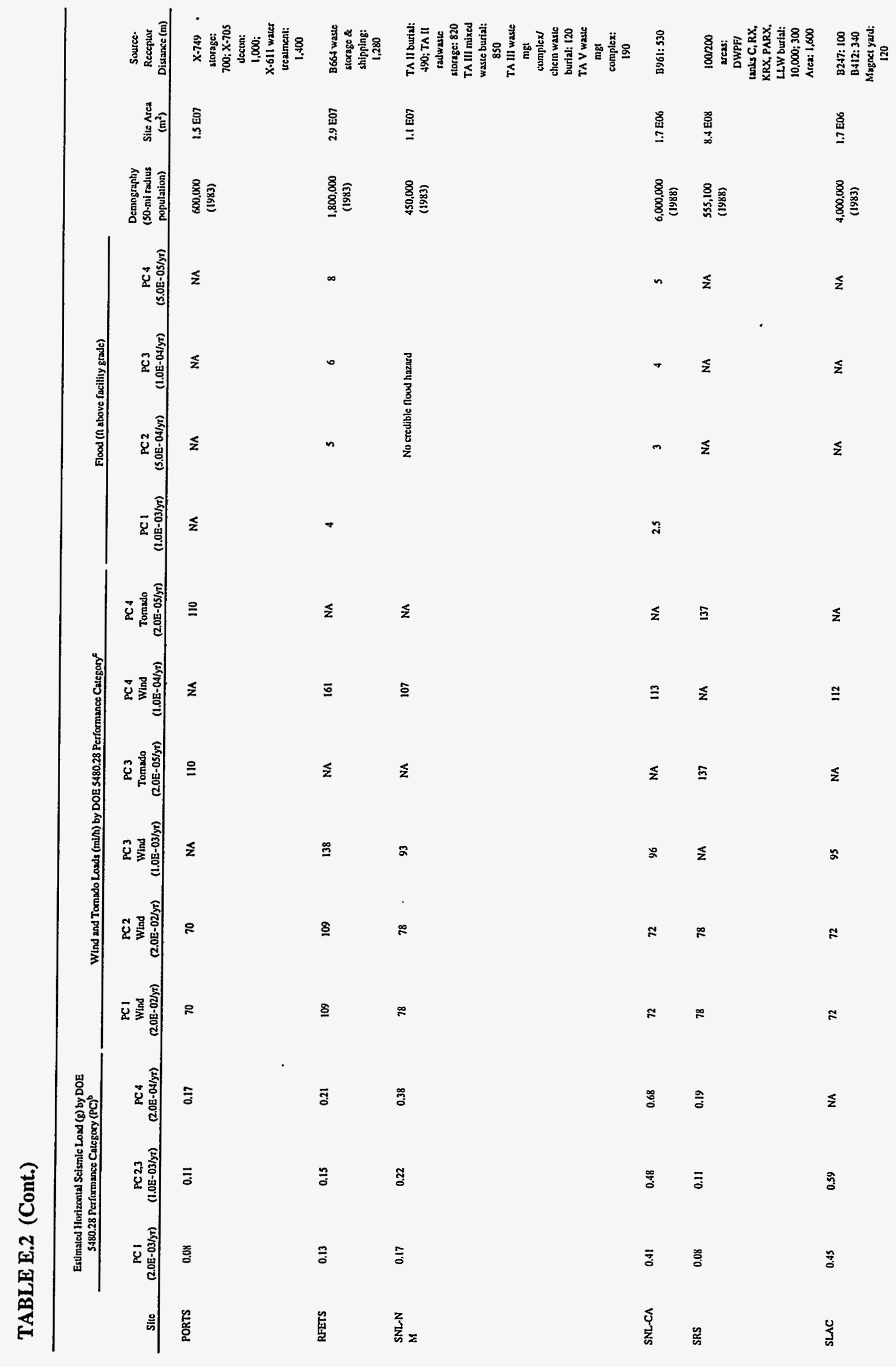


TABLE E.2 (Cont.)

\begin{tabular}{|c|c|c|c|c|c|c|c|c|c|c|c|c|c|c|c|c|}
\hline \multirow[b]{2}{*}{ Site } & \multicolumn{3}{|c|}{$\begin{array}{l}\text { Esumated Hortzontel S Selsmlc Lowd (g) by DOE } \\
\text { S480.28 Performance Category (PC) }\end{array}$} & \multicolumn{6}{|c|}{ Wind and Tornado Loads (milh) by DOE 5480.28 Performance Categorf } & \multicolumn{4}{|c|}{ Food ( $\mathrm{n}$ above facilly graule) } & \multirow[b]{2}{*}{$\begin{array}{l}\text { Demogranhy } \\
\text { (50-mi radius } \\
\text { population) }\end{array}$} & \multirow[b]{2}{*}{$\begin{array}{l}\text { Sul Area } \\
\left(\mathrm{uin}^{2}\right)\end{array}$} & \multirow[b]{2}{*}{$\begin{array}{c}\text { Sinurce- } \\
\text { Receppur } \\
\text { Distancec (min) }\end{array}$} \\
\hline & $\begin{array}{c}P C 1 \\
\text { (2.0E 03/yr) } \\
\end{array}$ & $\begin{array}{c}\mathrm{PC} 2,3 \\
(1,0 \mathrm{E}-03 / \mathrm{yr}) \\
\end{array}$ & $\begin{array}{c}P C 4 \\
(2.08-04 / y r) \\
\end{array}$ & $\begin{array}{c}\mathrm{PC}_{1} \\
\text { Wind } \\
(2.0 \mathrm{E}-02 / \mathrm{yr}) \\
\end{array}$ & $\begin{array}{c}\text { PC2 } \\
\text { Wind } \\
(2,0 \mathrm{~g}-02 / y z) \\
\end{array}$ & $\begin{array}{c}\text { PC3 } \\
\text { Wind } \\
(1,0 \mathrm{E}-03 / \mathrm{yz}) \\
\end{array}$ & $\begin{array}{c}\mathrm{PC3} \\
\text { Tommido } \\
\text { (2.0E-0S/yr) } \\
\end{array}$ & $\begin{array}{c}\text { PC4 } \\
\text { Wind } \\
(1.0 \mathrm{E}-04 / \mathrm{yr}) \\
\end{array}$ & $\begin{array}{c}\text { PC 4 } \\
\text { Tormadu } \\
(2.0 \mathrm{E}-05 / y t)\end{array}$ & $\begin{array}{c}\mathrm{PC}_{1} \\
\left(1.0 E^{-033 / y z)}\right. \\
\end{array}$ & $\begin{array}{c}\mathrm{PC2} \\
(5,0 \mathrm{E}-0.4 \mathrm{yr}) \\
\end{array}$ & $\begin{array}{c}\mathrm{PC} 3 \\
\text { (1.0E (NA/yT) } \\
\end{array}$ & $\begin{array}{c}\text { PC4 } \\
\text { (5.0E 05/yr) } \\
\end{array}$ & & & \\
\hline WIPP & $\mathrm{NA}$ & NA & NA & 80 & 80 & NA & $<183$ & NA & $>183$ & NA & NA & NA & NA & $\begin{array}{l}113,(100) \\
(1990)\end{array}$ & $5.9 \mathrm{E} 016$ & $\begin{array}{c}\text { B411 waste } \\
\text { landling \& } \\
\text { B } 474 \text { heast } \\
\text { waste } \\
\text { storage: } 950\end{array}$ \\
\hline
\end{tabular}

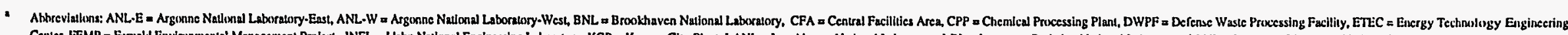

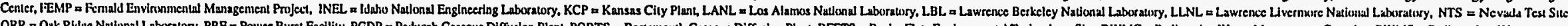

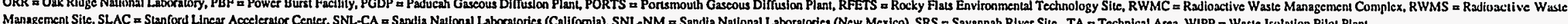

From Table 4-4, Kennely et al. (1990).

c From Table S-3, Kennely et al. (1990)

- NA = not appllicable 


\section{E.2 REFERENCES}

Coats, D.W., and R.C. Murray, 1984, Natural Phenomena Hazards Modeling Project: Seismic Models for Department of Energy Sites, UCRL-53582, rev. 1, Lawrence Livermore National Laboratory, Livermore, Calif.

Coats, D.W., and R.C. Murray, 1985, Natural Phenomena Hazards Modeling Project: Wind/ Tornado Hazard Models for Department of Energy Sites, UCRL-53526, rev. 1, Lawrence Livermore National Laboratory, Livermore, Calif.

Kennedy, R.P., et al., 1990, Design and Evaluation Guidelines for Department of Energy Facilities Subjected to Natural Phenomena Hazards, UCRL-15910, Lawrence Livermore National Laboratory, Livermore, Calif.

Savy, J.B., and R.C. Murray, 1985, Natural Phenomena Hazards Modeling Project: Flood Hazard Models for Department of Energy Sites, UCRL-53851, Lawrence Livermore National Laboratory, Livermore, Calif.

U.S. Department of Energy, 1992, "Natural Phenomena Hazards Performance Categorization Criteria for Structures, Systems, and Components," DOE-STD-1021-92.

U.S. Department of Energy, 1993, "Natural Phenomena Hazards Mitigation," DOE Order 5480.28. 
E-14 


\section{$F-1$}

\section{APPENDIX F:}

EVALUATION OF AIR CRASH ACCIDENTS FOR U.S. DEPARTMENT OF ENERGY WASTE MANAGEMENT FACILITIES 


\section{CONTENTS}

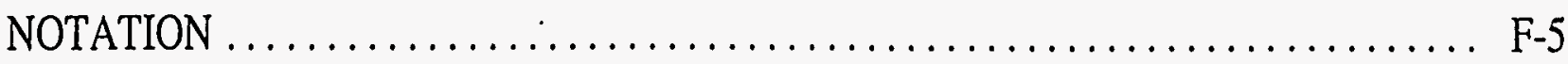

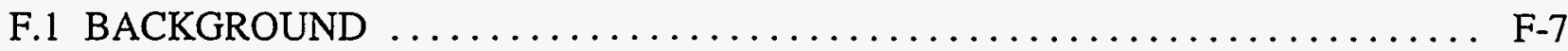

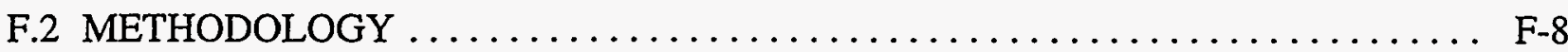

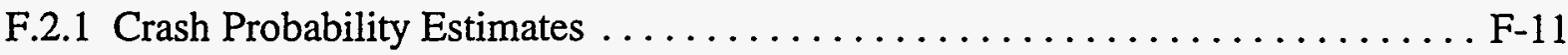

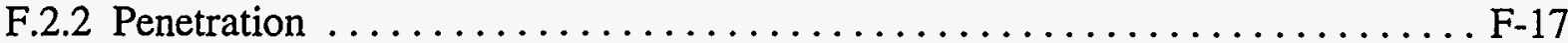

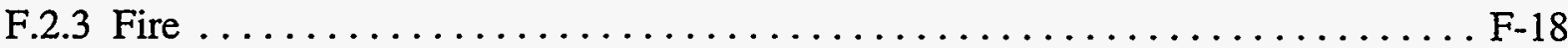

F.2.4 Presence of Radioactive Material . . . . . . . . . . . . . . . . . . F-19

F.3 SUMMARY OF AIRCRAFT CRASH FREQUENCIES PER UNIT

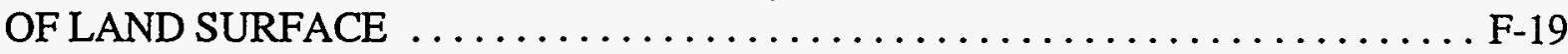

F.4 AIRCRAFT CRASH FREQUENCY FOR WM PEIS FACILITIES $\ldots \ldots \ldots \ldots \ldots$ F-19

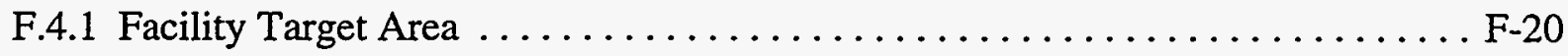

F.4.2 Frequency of Aircraft Crashes against Facilities at DOE Sites .......... F-23

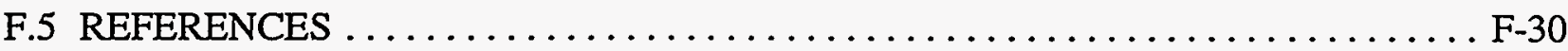

\section{FIGURES}

F.1 Generic Representation of Takeoff and Landing Sectors $\ldots \ldots \ldots \ldots \ldots \ldots \ldots$ F-9

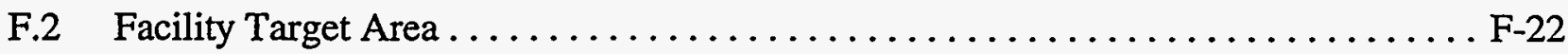

\section{TABLES}

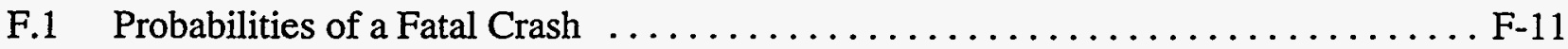

F.2 Principal DOE Waste Management Sites $\ldots \ldots \ldots \ldots \ldots \ldots \ldots \ldots \ldots \ldots \ldots \ldots \ldots \ldots$

F.3 Airports near DOE Sites and their Potentials to Increase Aircraft Accident Frequencies ........................... F 14

F.4 Estimated Annual Overflight Frequencies of DOE Sites $\ldots \ldots \ldots \ldots \ldots \ldots \ldots$ F-15 


\section{TABLES (Cont.)}

F.5 Estimated Annual Crash Probabilities at DOE Sites from Commercial

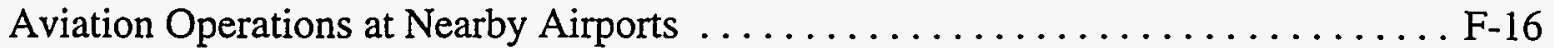

F.6 Estimated Annual Federal Airway Commercial Crash Probabilities ........... F-16

F.7 Estimated Annual Crash Probabilities at DOE Sites from General Aviation Operations at Nearby Airports $\ldots \ldots \ldots \ldots \ldots \ldots \ldots \ldots \ldots$ F-18

F.8 General Aviation Building Penetration Probabilities $\ldots \ldots \ldots \ldots \ldots \ldots \ldots$ F-18

F.9 Summary of Annual Aircraft Crash Frequencies for DOE Sites $\ldots \ldots \ldots \ldots \ldots$ F-20

F.10 Summary of Annual Aircraft Crash Frequency per Square

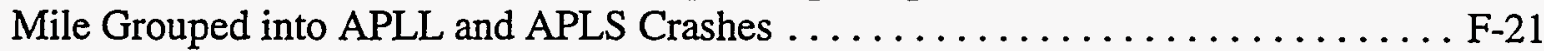

F.11 Effective Area Estimates for LLW, LLMW, TRUW, HLW,

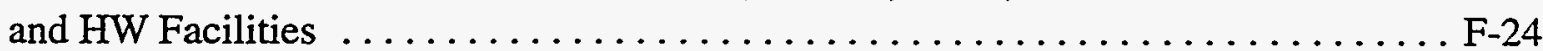

F.12 Airplane Impacts Initiating Event Frequency: LLW Storage . . . . . . . . . F F-25

F.13 Airplane Impacts Initiating Event Frequency: LLW Incineration Facilities . . . . . . F-26

F.14 Airplane Impacts Initiating Event Frequency: HLW Facilities $\ldots \ldots \ldots \ldots \ldots \ldots$ F-26

F.15 Airplane Impacts Initiating Event Frequency: HW Storage Facilities . . . . . . . F-27

F.16 Airplane Impacts Initiating Event Frequency: HW Treatment Facilities . . . . . . . . F-27

F.17 Airplane Impacts Initiating Event Frequency: LLMW Storage Facilities . . . . . . . F-28

F.18 Airplane Impacts Initiating Event Frequency: LLMW Treatment Facilities . . . . . . F-29

F.19 Airplane Impacts Initiating Event Frequency: TRUW Storage Facilities . . . . . . . F-29

F.20 Airplane Impacts Initiating Event Frequency: TRUW Treatment Facilities . . . . . . F-30 


\section{NOTATION}

The following is a list of the acronyms, initialisms, and abbreviations (including units of measure) used in this appendix.

\section{ACRONYMS, INITIALISMS, AND ABBREVIATIONS}

$\begin{array}{ll}\text { AEC } & \text { Atomic Energy Commission } \\ \text { ANL-E } & \text { Argonne National Laboratory-East } \\ \text { APLL } & \text { large aircraft crash } \\ \text { APLS } & \text { small aircraft crash } \\ \text { BNL } & \text { Brookhaven National Laboratory } \\ \text { CFR } & \text { Code of Federal Regulations } \\ \text { DOE } & \text { U.S. Department of Energy } \\ \text { DST } & \text { double-shell tank } \\ \text { EM } & \text { Environmental Management } \\ \text { ETEC } & \text { Energy Technology Engineering Center } \\ \text { FEMP } & \text { Fernald Environmental Management Project } \\ \text { Fermi } & \text { Fermi National Accelerator Laboratory } \\ \text { Hanford } & \text { Hanford Site } \\ \text { HLW } & \text { high-level waste } \\ \text { HW } & \text { hazardous waste } \\ \text { INEL } & \text { Idaho National Engineering Laboratory } \\ \text { KAPL-S } & \text { Knolls Atomic Power Laboratory (Schenectady) } \\ \text { KCP } & \text { Kansas City Plant } \\ \text { LANL } & \text { Los Alamos National Laboratory } \\ \text { LBL } & \text { Lawrence Berkeley National Laboratory } \\ \text { LLMW } & \text { low-level mixed waste } \\ \text { LLNL } & \text { Lawrence Livermore National Laboratory } \\ \text { LLW } & \text { low-level waste } \\ \text { Middlesex } & \text { Middlesex Sampling Plant } \\ \text { Mound } & \text { Mound Plant } \\ \text { NPIAS } & \text { National Plan for Integrated Airport Systems } \\ \text { NRC } & \text { U.S. Nuclear Regulatory Commission } \\ \text { NTS } & \text { Nevada Test Site } \\ \text { NTSB } & \text { National Transportation Safety Board } \\ \text { ORR } & \text { Oak Ridge National Laboratory } \\ \text { Pantex } & \text { Pantex Plant } \\ \text { PEIS } & \text { Programmatic Environmental Impact Statement } \\ \text { PGDP } & \text { Paducah Gaseous Diffusion Plant } \\ \text { PORTS } & \text { Portsmouth Gaseous Diffusion Plant } \\ \text { RFETS } & \text { Rocky Flats Environmental Technology Site } \\ & \end{array}$


SAIC Science Applications International Corporation

SNL-NM Sandia National Laboratories (New Mexico)

SRS Savannah River Site

TRUW transuranic waste

WAC world aeronautical chart

WIPP Waste Isolation Pilot Plant

WM Waste Management

WVDP West Valley Demonstration Project

\section{UNITS OF MEASURE}

$\begin{array}{ll}\mathrm{cm} & \text { centimeter(s) } \\ \mathrm{ft} & \text { foot(feet) } \\ \mathrm{in} . & \text { inch(es) } \\ \mathrm{km} & \text { kilometer(s) } \\ \mathrm{m} & \text { meter(s) } \\ \mathrm{m}^{2} & \text { square meter(s) } \\ \mathrm{mi}^{2} & \text { mile(s) } \\ \mathrm{mi}^{2} & \text { square mile(s) } \\ \mathrm{yr} & \text { year(s) }\end{array}$




\section{APPENDIX F:}

\section{EVALUATION OF AIR CRASH ACCIDENTS FOR U.S. DEPARTMENT OF ENERGY WASTE MANAGEMENT FACILITIES}

\section{F.1 BACKGROUND}

Both the U.S. Department of Energy (DOE) and the U.S. Nuclear Regulatory Commission (NRC) require that the hazards and risks intrinsic to the operation of their facilities be analyzed and documented in safety analysis reports. These documents describe the effects of failed safety-related plant equipment and structures and of external hazards such as tornados, tidal waves, floods, extreme heat or cold, and aircraft impacts.

The accident scenarios in safety analyses evaluate the limiting effects that can result from natural phenomena, system failures, and operator errors, that is, the maximum hazard that could result from facility operation. In the DOE system, facilities are classified as producing a negligible, low (Category 3), moderate (Category 2), or high (Category 1) hazard with respect to the worst-case accident effects on other site employees, the public, and environment. External events, such as an aircraft crash into a facility, can initiate these worst-case accidents and must therefore be considered in the analysis. This appendix summarizes the aircraft impact initiator frequencies estimated for various Waste Management (WM) Programmatic Environmental Impact Statement (PEIS) (DOE 1996) facilities at different DOE sites.

Various authors have developed extensive aircraft operational data and compiled crash statistics. Many of these studies have been performed to support the design and siting of nuclear power plants. These estimates are used to estimate the risk of aircraft crashes at facilities in different locations.

Aircraft crash analyses have historically divided crash data into three groups: commercial, military, and general aviation. By far the most complete records of aircraft operational data and crash information are available for commercial carriers. The National Transportation Safety Board (NTSB) publishes detailed annual reports of the number of commercial flights; distances flown; numbers of takeoffs and landings for each airport; and types of aircraft in use, their capacities, loadings, numbers of passengers, and other data. Detailed reviews of all crashes and accidents are also available.

Less detailed information is available for general aviation operations. Larger airports tabulate operational information on private aircraft that is reported by the NTSB in its annual reports. General aviation crash data are obtained and recorded by the NTSB. These reports are not as detailed or as voluminous as those for commercial carriers, but each crash is investigated and the data are tabulated. 
Military aircraft operations and crash data are generally not publicly available. Some information on hours flown and accidents for the various types of military aircraft has been published; however, use of this information in the present analysis is complicated by a lack of information about which data apply to the public at large. For this study, the frequency of military air crashes was assumed to be equal to the frequency of commercial air carriers for those DOE sites with significant military operations nearby. Although these data are incomplete, some general conclusions can be drawn.

\section{F.2 METHODOLOGY}

Safety assessments were performed for commercial nuclear power stations to estimate the risk from their operation and to ensure that these risks were reduced to a level acceptable to the public. As part of these assessments, the Atomic Energy Commission (AEC) examined the probabilities of aircraft impacts on power plants that could result in a release of radioactive material. In the 1960s, the AEC compiled data on aircraft crashes and found that an increased strike probability was observed within $8 \mathrm{~km}(5 \mathrm{mi})$ of airports, with an approximate $1 / r^{2}$ relationship, where $r$ is the distance from the airport. It was noted further that most crashes occurred within the $60^{\circ}$ arcs centered on the centerline of each end of airport runways. For general aviation aircraft, these arcs extend $8 \mathrm{~km}(5 \mathrm{mi})$ from the end of the runway; for commercial aircraft, they extend $16 \mathrm{~km}(10 \mathrm{mi})$. Beyond this distance, the probabilities of crashes were lower and essentially constant. A method for estimating this risk was developed by Wall $(1974)$ and Eisenhut $(1972,1973)$ and implemented by the AEC. This method is still used by the NRC, with some modifications, and is formalized in NUREG-0800 (NRC 1981), which is used to review license applications, and in WASH-1400 (NRC 1975), the Reactor Safety Study.

The NUREG-0800 method determines the probability of an aircraft crash per square mile per aircraft movement. General aviation movement and crash data accumulated and involving approximately $3.2 \mathrm{E}+08$ movements and $4.0 \mathrm{E}+03$ crashes were reviewed. Air carrier (commercial) data were based on $8.0 \mathrm{E}+07$ movements, and military data were based on $9.4 \mathrm{E}+07$ movements. No dates for the collection of these data are provided in the references of NUREG-0800. It was concluded that only fatal accidents were significant with respect to aircraft crashes into buildings. Wall $(1974)$ and Eisenhut $(1972,1973)$ identified a strong correlation between accidents involving fatalities and those destroying the aircraft. In addition, it was assumed that an aircraft striking a building would generally involve fatalities and destruction of the airframe.

Probabilities were provided only for general aviation and military aircraft crashes within $8 \mathrm{~km}$ ( $5 \mathrm{mi}$ ) of the end of airfield runways and for air carriers (commercial aviation) within $16 \mathrm{~km}(10 \mathrm{mi})$ of the end of the respective runway and within a $60^{\circ}$ arc at the extended centerline of the runway (Figure F.1). The method was originally a comparison of crashes per unit area with the effective target area. 


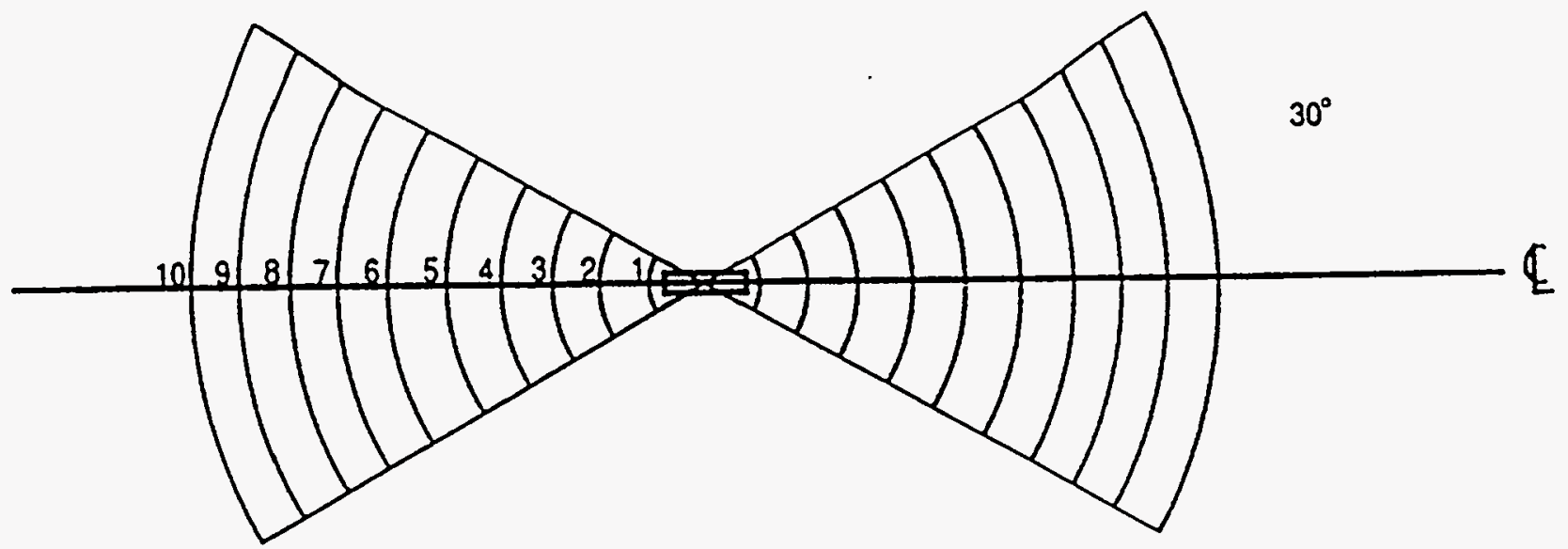

FIGURE F.1 Generic Representation of Takeoff and Landing Sectors

The crash probability equation is

$$
P_{A}=\Sigma_{j} N_{j} \times A_{j} \times f_{j}
$$

$=$ Probability of an aircraft accident resulting in structural damage,

where

$N=$ number of airport runway operations affecting the target;

$A=$ target vulnerable area $\left(\mathrm{mi}^{2}\right)$;

$f=$ fatal crash probability per operation $\left(\mathrm{mi}^{2}\right) ;$ and

$j=$ aircraft type identifier: commercial, military, and general.

The NUREG-0800 crash probability equation was modified to consider proximity to designated federal airways:

$$
P_{N R C}=P_{A}+P_{F A},
$$




$$
\begin{aligned}
& \left.=\int_{i=1}^{L} \sum_{j=1}^{M} \sum \mathrm{C}_{\mathrm{j}} \times \mathrm{N}_{\mathrm{ij}} \times \mathrm{A}_{\mathrm{j}}\right]+\sum_{k=1}^{Q} \sum_{j=1}^{M} \sum \mathrm{C}_{\mathrm{FA}} \times \mathrm{N}_{\mathrm{FAkj}} \times \mathrm{A}_{\mathrm{j}} / \mathrm{w}_{\mathrm{k}} \\
& =\text { total aircraft hazard probability, }
\end{aligned}
$$

where

$$
\begin{aligned}
P_{A} & =\text { probability per year of an aircraft crashing into a site near an airport, } \\
P_{F A}= & \text { probability per year of an aircraft crashing into a site near a federal airway, } \\
M= & \text { number of different types of aircraft using the airport, } \\
L= & \text { number of flight trajectories affecting the site, } \\
Q= & \text { number of airways affecting the site, } \\
C_{j}= & \text { probability per square mile of a crash per aircraft movement, } \\
N_{i j}= & \text { number of movements per year by the } j \text { th aircraft along the } i \text { th flight path, } \\
A_{j}= & \text { effective target area in square miles for the } j \text { th aircraft considering shadow area } \\
& \text { and skid area, } \\
w_{k}= & \text { width of the } k \text { th airway in miles (plus twice the distance from the airway edge } \\
C_{F A}= & \text { in-flight crash rate per mile for aircraft on an airway, } \\
N_{F A k j}= & \text { number of flights per year of } j \text { th aircraft along the } k \text { th airway, } \\
& =\text { aircraft path identifier, }
\end{aligned}
$$

NUREG-0800 uses a value of $4.0 \mathrm{E}-10$ per mile for $C_{F A}$ for commercial aircraft on airways with fewer than 100 flights per day. For heavily traveled corridors (greater than 100 flights per day), 
TABLE F.1 Probabilities of a Fatal Crash

\begin{tabular}{|c|c|c|c|c|}
\hline \multirow{2}{*}{$\begin{array}{l}\text { Distance } \\
\text { from } \\
\text { End of } \\
\text { Runway } \\
\text { (mi) }\end{array}$} & \multicolumn{4}{|c|}{$\begin{array}{c}\text { Probability }\left(\times 10^{8}\right) \text { of a Fatal Crash per Square Mile per } \\
\text { Aircraft Movement }\end{array}$} \\
\hline & $\begin{array}{l}\text { U.S. Air } \\
\text { Carrier }\end{array}$ & $\begin{array}{l}\text { General } \\
\text { Aviation }\end{array}$ & $\begin{array}{c}\text { U.S. Navy/ } \\
\text { U.S. Marine Corps }\end{array}$ & U.S. Air Force \\
\hline $0-1$ & 16.7 & 84 & 8.3 & 5.7 \\
\hline $1-2$ & 4.0 & 15 & 1.1 & 2.3 \\
\hline $2-3$ & 0.96 & 6.2 & 0.33 & 1.1 \\
\hline $3-4$ & 0.68 & 3.8 & 0.31 & 0.42 \\
\hline $4-5$ & 0.27 & 1.2 & 0.20 & 0.40 \\
\hline $5-6$ & 0 & $-a$ & - & - \\
\hline $6-7$ & 0 & - & - & - \\
\hline $7-8$ & 0 & - & - & - \\
\hline $8-9$ & 0.14 & - & - & - \\
\hline $9-10$ & 0.12 & - & - & - \\
\hline
\end{tabular}

a A hyphen indicates data not available for this distance.

Source: Eisenhut (1973).

a more detailed analysis is suggested to obtain a proper value for $C_{F A}$. Table F.1 summarizes the values of $C_{j}$ suggested in NUREG-0800.

The NUREG-0800 method is applied in accordance with Title 10 of the Code of Federal Regulations (CFR), Part 100, which, in conjunction with other criteria, assures that a proposed reactor site will involve a low risk to the public. This requirement is met when the probability of aircraft accidents resulting in radiological consequences greater than the criteria in 10 CFR 100 is less than approximately $1.0 \mathrm{E}-07$ per year.

\section{F.2.1 Crash Probability Estimates}

In this section, a crash probability estimation method is developed specific to DOE waste management facilities utilizing the previous methods as guides and applying DOE site data obtained during the study. The method selected for DOE waste management facilities parallels that used by the NRC (NRC 1981) and is based on the methods of Wall (1974) and Eisenhut $(1972,1973)$. 
The total probability of an aircraft crash into a DOE waste management facility is considered the sum of the probabilities for each category of aircraft examined:

$$
P_{\text {total }}=P_{c}+P_{m}+P_{g} \text {, }
$$

where

$$
\begin{aligned}
& P_{c}=\text { commercial carrier probability per year, } \\
& P_{m}=\text { military probability per year, and } \\
& P_{g}=\text { general aviation probability per year. }
\end{aligned}
$$

The probability of an aircraft crash by aircraft category is estimated by examining two phases of aircraft flight: takeoffs/landings and en route crashes. Consistent with the NUREG-0800 methodology, takeoff and landing aircraft crashes are significant within $8 \mathrm{~km}(5 \mathrm{mi})$ of an airport for general aviation and within $16 \mathrm{~km}(10 \mathrm{mi})$ for commercial and military aviation.

The sites listed in Table F.2 have been identified as the principal DOE waste management sites. For each of these sites, world aeronautical charts (WACs) and the National Plan for Integrated Airport Systems (NPIAS) were examined to estimate the locations of the nearest commercial and general aviation airports. The WACs and NPIAS were reviewed to determine runway orientation with respect to DOE facilities.

Table F.3 summarizes data on each of the DOE facilities and nearby airports. The table provides the estimated distance to the airport and the number of airport runways that potentially result in increased overflights of the DOE facility. (The NUREG-0800 methodology recognizes an increased aircraft crash probability in a $60^{\circ}$ arc extending $30^{\circ}$ in each direction from the runway centerline.) The runway orientation and distance to the nearest facility are used to determine whether a DOE site has the potential for a significant increase in the probability of takeoff/landing aircraft crashes. Table F.3 identifies the following five sites as having the potential for significant takeoff/landing crashes: Lawrence Livermore National Laboratory (LLNL) Site 300, Paducah Gaseous Diffusion Plant (PGDP), Pantex Plant (Pantex), Rocky Flats Environmental Technology Site (RFETS), and Sandia National Laboratories (New Mexico) (SNL-NM). Of these five sites, two have only general aviation service (LLNL Site 300 and RFETS). Airports near the PGDP site provide both commercial and general aviation service. Airports near the Pantex and SNL-NM sites have commercial, general aviation service, and military operations. 
TABLE F.2 Principal DOE Waste Management Sites

\begin{tabular}{lc}
\hline \multicolumn{1}{c}{ DOE Site } & Abbreviation \\
\hline Fernald Environmental Management Project & FEMP \\
Idaho National Engineering Laboratory & INEL \\
Hanford Site & Hanford \\
Kansas City Plant & KCP \\
Lawrence Livermore National Laboratory & LLNL \\
(Main Site and Site 300) & \\
Los Alamos National Laboratory & LANL \\
Nevada Test Site & NTS \\
Oak Ridge National Laboratory (Y-12, K-25) & ORR \\
Paducah Gaseous Diffusion Plant & PGDP \\
Pantex Plant & Pantex \\
Portsmouth Gaseous Diffusion Plant Project & PORTS \\
Rocky Flats Environmental Technology Site & RFETS \\
Sandia National Laboratories (New Mexico) & SNL-NM \\
Savannah River Site & SRS \\
West Valley Demonstration Project & WVDP \\
\hline
\end{tabular}

The four DOE sites listed in Table F.4 are located beneath federal airways. These four sites have the potential for increased en route aircraft crashes. The four affected DOE sites are Pantex, SRS, INEL, and Hanford. At INEL, the federal airway crosses the southwest corner of the site. No facilities are located in this portion of the INEL site. Table F.4 also provides estimated overflight frequencies for these sites.

\section{F.2.1.1 Commercial Aviation}

For each site, the probability of a commercial aviation crash was estimated according to the following equation:

$$
P_{\text {total }}=P_{c}+P_{m}+P_{g} \text {, }
$$

where

$$
P_{e}=\begin{aligned}
& \text { probability of crash per square mile per year at a } \\
& \text { specified DOE site, }
\end{aligned}
$$


TABLE F.3 Airports near DOE Sites and their Potentials to Increase Aircraft Accident Frequencies

\begin{tabular}{|c|c|c|c|c|}
\hline DOE Site & Airfield & $\begin{array}{c}\text { Facility } \\
\text { Distance } \\
(\mathrm{mi})\end{array}$ & $\begin{array}{c}\text { Sectors } \\
\text { Affecting } \\
\text { DOE } \\
\end{array}$ & $\begin{array}{c}\text { Airport } \\
\text { Accidents } \\
\text { Significant? }\end{array}$ \\
\hline FEMP & Hamilton & 10 & 0 & No \\
\hline FEMP & Harrison & 5 & 0 & No \\
\hline Hanford & Richland & 5 & 1 & $\mathrm{No}^{\mathrm{a}}$ \\
\hline Hanford & Pasco & 8 & 1 & $\mathrm{No}^{\mathrm{a}}$ \\
\hline INEL & Mud Lake & 12 & 0 & No \\
\hline INEL & Midway & 10 & 1 & No \\
\hline INEL & Arco & 15 & 0 & No \\
\hline INEL & Howe & 13 & 0 & No \\
\hline $\mathrm{KCP}$ & Richards-Gebaur & 8 & 1 & No \\
\hline $\mathrm{KCP}$ & Lee's Summit & 12 & 0 & No \\
\hline $\mathrm{KCP}$ & Downtown & 11 & 0 & No \\
\hline $\mathrm{KCP}$ & Heart & 8 & 1 & No \\
\hline LLNL & Livermore & 7 & 2 & No \\
\hline LLNL Site 300 & Tracy & 4 & 1 & No \\
\hline LANL & Los Alamos & 1 & 0 & No \\
\hline NTS & Pahute Mesa & 12 & 0 & No \\
\hline NTS & Desert Rock & 15 & 0 & No \\
\hline ORR, Y-12, K-25 & None & & & No \\
\hline Pantex & Amarillo International & 5 & 1 & Yes \\
\hline Pantex & Skellytown & 9 & 0 & No \\
\hline PGDP & Barkley & 3 & 1 & Yes \\
\hline PORTS & Greater Portsmouth & 10 & 0 & No \\
\hline PORTS & Pike County & 6 & 0 & No \\
\hline RFETS & Boulder & 15 & 0 & No \\
\hline RFETS & Jefferson County & 5 & 2 & Yes \\
\hline RFETS & Tri-County & 13 & 0 & No \\
\hline SNL-NM & Albuquerque International & 2 & 2 & Yes \\
\hline SRS & Barnwell & 6 & 0 & No \\
\hline
\end{tabular}

a No waste management activities take place within the area of the Hanford Site that is within $16 \mathrm{~km}(10 \mathrm{mi})$ of the Pasco Airport and $8 \mathrm{~km}(5 \mathrm{mi})$ of the Richland Airport. 
TABLE F.4 Estimated Annual Overflight Frequencies of DOE Sites

\begin{tabular}{lccl}
\hline DOE Site & Commercial & General & Basis of Estimate \\
\hline Hanford & 6,450 & 22,500 & $\begin{array}{l}15 \% \text { of Pasco } \\
15 \% \text { of Richland } \\
\end{array}$ \\
INEL & 1,500 & 2,900 & $20 \%$ of Pocatello \\
Pantex & 3,800 & 15,300 & $15 \%$ of Amarillo \\
SRS & 6,300 & 21,700 & $\begin{array}{l}20 \% \text { of Allendale } \\
10 \% \text { of Savannah } \\
10 \% \text { of Augusta }\end{array}$ \\
\hline
\end{tabular}
$P_{a}=$ probability of crash per square mile per year from nearby airfield operations, and
$P_{F A}=$ probability of crash per square mile per year from operations on a federal airway.

Table F.5 gives the estimated values of $P_{a}$ for the two DOE sites with airports with commercial operations in their vicinities.

Four DOE sites are located under federal airways; however, the estimated overflight rate for commercial aircraft is fewer than 100 flights per day at each site. Assuming that airways are $6 \mathrm{~km}(4 \mathrm{mi})$ wide, an upper-bound estimate of the probability of a crash per square mile from federal airway activities is found using the following equation:

$$
P_{F A}=4.0 \times 10^{-10} / \mathrm{mi} / \text { flight } \times \mathrm{N} \text { flights } / \mathrm{yx} / 4-\mathrm{mi} \text { width }
$$

Table F.6 summarizes estimates of crash probabilities from commercial aviation federal airway flights. Only the four DOE sites listed in Table F.6 are considered to be affected by commercial aircraft operations. This is because the NUREG- 0800 methodology states that accidents are not credible at DOE sites located at distances greater than $16 \mathrm{~km}(10 \mathrm{mi})$ from an airport if the sites are not crossed by a federal airway. 
TABLE F.5 Estimated Annual Crash Probabilities at DOE Sites from Commercial Aviation Operations at Nearby Airports

\begin{tabular}{|c|c|c|c|c|c|c|c|}
\hline DOE Site & Airfield & $\begin{array}{l}\text { Facility } \\
\text { Distance } \\
\text { (mi) }\end{array}$ & Runways & $\begin{array}{l}\text { Sectors } \\
\text { Affecting } \\
\text { DOE }\end{array}$ & $\begin{array}{l}\text { Commercial } \\
\text { Operations/yr }\end{array}$ & $\begin{array}{l}\text { Crash Rate } \\
\text { per Movement } \\
\left(\mathrm{mi}^{2} / \mathrm{yr}\right)\end{array}$ & $\begin{array}{c}\text { Crash Rate } \\
\left(\mathrm{mi}^{2} / \mathrm{yr}\right)\end{array}$ \\
\hline Pantex & $\begin{array}{l}\text { Amarillo } \\
\text { International }\end{array}$ & 5 & 1 & 2 & 25,000 & $6.8 \mathrm{E}-10$ & $1.7 \mathrm{E}-05$ \\
\hline SNL-NM & $\begin{array}{l}\text { Albuquerque } \\
\text { International }\end{array}$ & 2 & 2 & 4 & 161,000 & $1.0 \mathrm{E}-08$ & $1.6 \mathrm{E}-03$ \\
\hline
\end{tabular}

TABLE F.6 Estimated Annual Federal Airway Commercial Crash Probabilities

\begin{tabular}{lcc}
\hline DOE Site & $\begin{array}{c}\text { Number of } \\
\text { Overflights }\end{array}$ & $\begin{array}{c}\text { Federal Airway } \\
\text { Crash Probability } \\
\left(\mathrm{mi}^{2} / \mathrm{yr}\right)\end{array}$ \\
\hline Hanford & 6,450 & $6.5 \mathrm{E}-07$ \\
INEL & 1,500 & $1.5 \mathrm{E}-07$ \\
Pantex & 3,800 & $3.8 \mathrm{E}-07$ \\
SRS & 6,300 & $6.3 \mathrm{E}-07$ \\
\hline
\end{tabular}

\section{F.2.1.2 Military Aviation}

The method for estimating military aviation accidents is identical to that for commercial aircraft. Only two DOE sites, SNL-NM and Pantex, have nearby military airfields, training areas, or operations areas within $16 \mathrm{~km}(10 \mathrm{mi})$. Military aircraft do not routinely use the commercial airways adjacent to DOE facilities but may occasionally fly in their proximity. The local military crash information obtained during this study was not sufficient to develop local crash statistics. Previous studies (Wall 1974) indicate that when operating as an air carrier, military aircraft have accident rates (per mile flown) approximately the same as those of commercial air carriers. These accident rates, however, may significantly overestimate the risk from military aircraft at DOE waste management facilities. The estimated risk from commercial aircraft is primarily due to the relatively heavy commercial traffic on airways adjacent to some DOE facilities. No such heavy military air traffic exists close to DOE facilities. For this study, the military accident probability, $P_{m}$, is estimated to be equivalent to the commercial probability for sites with nearby military air operations. Because the number of military operations is believed to be significantly less than the commercial 
operations in the vicinities of DOE facilities, this is a conservative assumption; however, adequate data were not available to quantify the degree of conservatism.

\section{F.2.1.3 General Aviation}

The probability of general aviation accidents is estimated in a manner similar to that of NUREG-0800 (NRC 1981). According to the NUREG-0800 method, the probability of an aircraft crash within $8 \mathrm{~km}(5 \mathrm{mi})$ of an airport, $P_{G}$, will consist of two factors - aircraft operations within and beyond distances $8 \mathrm{~km}(5 \mathrm{mi})$ from an airport - according to the following equation:

$$
P_{G}=P_{A}+P_{F A} \text {. }
$$

Table F.7 summarizes the number of general aviation aircraft movements and crash frequencies for the five DOE sites with nearby general aviation airfields.

To estimate the probability of general aviation en route accidents resulting in a release from a DOE facility, a method similar to the take-off and landing method was used. A general aviation accident frequency of $1.0 \mathrm{E}-04 / \mathrm{mi}^{2} / \mathrm{yr}$ (Wall 1974) was used for all sites.

After the frequency of the aircraft impact has been established, the likelihood of a hazardous material release will depend on the probability of containment breach. Fires can enhance the possibility for release of material. All these considerations are facility- and waste-dependent and are accounted for in the event trees developed to define the accident sequences. Although this appendix is concerned only with the frequency of the initiating event (the aircraft crash against the facility), source background information is provided in the following paragraphs on the effects of a crash on a generic facility.

\section{F.2.2 Penetration}

The significant missile associated with a small aircraft accident is assumed to be the aircraft engine. This assumption is consistent with the analysis of Chelapati et al. (1972), who note that other parts of the aircraft, such as wings and fuselage, offer less resistance and are assumed to break up on impact. The frame and wings of general aviation aircraft do not penetrate minimal thicknesses of reinforced concrete, they have low densities relative to the engine, and they crumple on impact, exhausting their kinetic energy in structural deformation. Larger aircraft airframes may offer greater resistance to crushing under impact. Chelapati et al. (1972) developed a distribution frequency for small aircraft engine weights and effective diameters and perforation and penetration estimates. On 
TABLE F.7 Estimated Annual Crash Probabilities at DOE Sites from General Aviation Operations at Nearby Airports

\begin{tabular}{llcccccc}
\hline DOE Site & \multicolumn{1}{c}{ Airfield } & $\begin{array}{c}\text { Facility } \\
\text { Distance } \\
(\mathrm{mi})\end{array}$ & Runways & $\begin{array}{c}\text { Sectors } \\
\text { Affecting } \\
\text { DOE }\end{array}$ & $\begin{array}{c}\text { General } \\
\text { Aviation } \\
\text { Operations/yr }\end{array}$ & $\begin{array}{c}\text { Crash Rate/ } \\
\text { Movement } \\
\left(\mathrm{mi}^{2} / \mathrm{yr}\right)\end{array}$ & $\begin{array}{c}\text { Crash } \\
\text { Rate } \\
\left(\mathrm{mi}^{2} / \mathrm{yr}\right)\end{array}$ \\
\hline LLNL Site 300 & Tracy & 4 & 1 & 2 & 63,000 & $9.5 \mathrm{E}-09$ & $6.0 \mathrm{E}-04$ \\
Pantex & $\begin{array}{l}\text { Amarillo } \\
\text { International }\end{array}$ & 5 & 1 & 2 & 102,000 & $3.0 \mathrm{E}-08$ & $9.6 \mathrm{E}-04$ \\
PGDP & $\begin{array}{l}\text { Barkley } \\
\text { RFETS }\end{array}$ & 3 & 1 & 2 & 62,000 & $1.6 \mathrm{E}-08$ & $9.6 \mathrm{E}-04$ \\
\multirow{2}{*}{ SNL-NM } & $\begin{array}{l}\text { Jefferson } \\
\text { County }\end{array}$ & 5 & 2 & 3 & 190,000 & $4.0 \mathrm{E}-09$ & $7.6 \mathrm{E}-04$ \\
& $\begin{array}{l}\text { Albuquerque } \\
\text { International }\end{array}$ & 2 & 2 & 4 & 225,000 & $3.8 \mathrm{E}-08$ & $8.4 \mathrm{E}-03$ \\
\hline
\end{tabular}

TABLE F.8 General Aviation Building Penetration Probabilities

\begin{tabular}{ccc}
$\begin{array}{c}\text { Accident } \\
\text { Type }\end{array}$ & $\begin{array}{c}\text { Category } \\
\text { Facility }\end{array}$ & $\begin{array}{c}\text { Category 2 } \\
\text { Facility }\end{array}$ \\
\hline $\begin{array}{l}\text { Takeoff/ } \\
\text { landing }\end{array}$ & 0.01 & 0.17 \\
En route & 0.34 & 0.69 \\
\hline
\end{tabular}

the basis of their analysis, estimates of the probability of light aircraft penetrating a hardened structure can be developed. For purposes of this analysis, it is assumed that a Category 2 facility will have a "hardness" that is equivalent to a minimum wall thickness of $20.3 \mathrm{~cm}$ (8 in.) of reinforced concrete. A Category 1 facility is assumed to have a minimum wall thickness of $30.5 \mathrm{~cm}(12 \mathrm{in}$.) of reinforced concrete. Table F. 8 summarizes the probability of penetrating Category 1 and 2 facilities. For outdoor storage facilities, the penetration probability is conservatively assumed to be 1.0 .

\section{F.2.3 Fire}

The occurrence of a fire subsequent to crash can have a significant impact on accident consequences. A fire could be a major factor in the spread of any radioactive material in a facility hit by aircraft. Without a fire, the spread of radioactive material would be significantly reduced and probably limited to only the vicinity of impact. A review of 108 aircraft crashes in northern 
California indicated that 36 had subsequent fires. This provides a probability of fire, $P_{f}$, of $3.3 \mathrm{E}-01$, which is consistent with the approximate $30 \%$ post-crash fire rate identified by Wall (1974) for general aviation craft.

\section{F.2.4 Presence of Radioactive Material}

The probability that an aircraft crash penetrating a structure will damage an area that contains radioactive material depends on facility layout and operating characteristics. For example, a facility that stores radioactive material will likely have a 1.0 probability of having radioactive material present $\left(P_{m}\right)$. A facility that requires significant supporting equipment to process radioactive material may have a value of $P_{m}=1.0 \mathrm{E}-02$. In this analysis, it is conservatively estimated that radioactive material will always be present at the crash location when an aircraft penetrates a structure, $P_{m}=1.0$.

\section{F.3 SUMMARY OF AIRCRAFT CRASH FREQUENCIES PER UNIT OF LAND SURFACE}

Table F.9 summarizes estimated aircraft crash frequencies for all DOE sites and aircraft types.

\section{F.4 AIRCRAFT CRASH FREQUENCY FOR WM PEIS FACILITIES}

The methodology presented in Section F.2 is used to calculate the annual aircraft crash frequency per unit of ground surface. To estimate the frequency of an aircraft impact at a facility; it is necessary to calculate the effective area of the facility in question. The aircraft impact frequency at a facility can be estimated by multiplying the crash frequency per unit area summarized in Table F. 9 by the effective facility area.

For the purpose of the WM PEIS (DOE 1996), two types of airplane crash accidents are considered: those involving large commercial airplanes and those involving small or general aviation aircraft. Military aircraft accidents, relevant only for two of the DOE sites considered, have been lumped with general aviation accidents because many of the reported crashes involve helicopters or training flights.

Table F.10 groups the air crash data presented in Table F.9 into large and small aircraft crashes. The annual frequency per square mile of a large aircraft crash (APLL), as shown in Table F.10, includes the contribution of nearby airports, and the contribution of the proximity to federal airways. The annual frequency for small aircraft crash (APLS) includes the en route general 
TABLE F.9 Summary of Annual Aircraft Crash Frequencies for DOE Sites

\begin{tabular}{|c|c|c|c|c|c|}
\hline \multirow[b]{2}{*}{ DOE Site } & \multicolumn{2}{|c|}{$\begin{array}{c}\text { Commercial } \\
\text { Crash Frequencies } \\
\left(\mathrm{crash} / \mathrm{yr}-\mathrm{mi}^{2}\right) \\
\end{array}$} & \multirow[b]{2}{*}{$\begin{array}{c}\text { Military } \\
\text { Crash } \\
\text { Frequencies }\end{array}$} & \multicolumn{2}{|c|}{$\begin{array}{l}\text { General Aviation } \\
\text { Crash Frequencies } \\
\left(\mathrm{crash} / \mathrm{yr}-\mathrm{mi}^{2}\right)\end{array}$} \\
\hline & $\begin{array}{l}\text { Nearby } \\
\text { Airport }\end{array}$ & $\begin{array}{c}\text { Federal } \\
\text { Airways }\end{array}$ & & $\begin{array}{l}\text { Nearby } \\
\text { Airport }\end{array}$ & En Route \\
\hline FEMP & $\mathrm{NA}^{\mathrm{a}}$ & NA & NA & NA & $1.0 \mathrm{E}-04$ \\
\hline Hanford & NA & $6.5 \mathrm{E}-07$ & NA & NA & $1.0 \mathrm{E}-04$ \\
\hline INEL & NA & $1.5 \mathrm{E}-07$ & NA & NA & $1.0 \mathrm{E}-04$ \\
\hline $\mathrm{KCP}$ & NA & NA & $\mathrm{NA}$ & NA & $1.0 \mathrm{E}-04$ \\
\hline LANL & NA & NA & NA & NA & $1.0 \mathrm{E}-04$ \\
\hline LLNL & NA & NA & NA & NA & $1.0 \mathrm{E}-04$ \\
\hline LLNL Site 300 & $\mathrm{NA}$ & NA & NA & $6.0 \mathrm{E}-04$ & NA \\
\hline NTS & NA & NA & NA & $\mathrm{NA}$ & $1.0 \mathrm{E}-04$ \\
\hline ORR & $\mathrm{NA}$ & $\mathrm{NA}$ & $\mathrm{NA}$ & NA & $1.0 \mathrm{E}-04$ \\
\hline Pantex & $1.7 \mathrm{E}-05$ & $3.8 \mathrm{E}-07$ & $1.7 \mathrm{E}-05$ & $3.1 E-04$ & $\mathrm{NA}$ \\
\hline PGDP & NA & NA & NA & $9.6 \mathrm{E}-04$ & NA \\
\hline PORTS & NA & NA & NA & NA & $1.0 \mathrm{E}-04$ \\
\hline RFETS & NA & NA & NA & $7.6 \mathrm{E}-04$ & NA \\
\hline SNL-NM & $1.6 \mathrm{E}-03$ & NA & $1.6 \mathrm{E}-03$ & $8.4 \mathrm{E}-03$ & $\mathrm{NA}$ \\
\hline SRS & NA & $6.3 \mathrm{E}-07$ & NA & NA & $1.0 \mathrm{E}-04$ \\
\hline
\end{tabular}

a $\mathrm{NA}=$ not applicable.

aviation crash frequency, the proximity of airports, and the contribution of military aircraft. Two DOE sites not mentioned in Section F.2, Argonne National Laboratory-East (ANL-E) and the Fermi National Accelerator Laboratory (Fermi), are included in Table F.10 because they were considered in the hazardous waste storage analysis (90-day storage facility or staging area) in Section 7 of this report. Since the two sites are not listed among the DOE sites affected by proximity to airports or by federal airways, the contribution to aircraft risk is by general aviation en route crashes $\left(10^{-4} / \mathrm{yr}-\mathrm{mi}^{2}\right)$.

\section{F.4.1 Facility Target Area}

The calculation of effective facility area also follows the methodology of NUREG-0800 (NRC 1981). The target area offered by a facility is usually estimated as an effective area that takes into consideration the facility plan (horizontal projection) area, a shadow area, and a skid area. 
TABLE F.10 Summary of Annual Aircraft Crash Frequency per Square Mile Grouped into APLL and APLS Crashes

\begin{tabular}{|c|c|c|c|c|c|c|c|}
\hline \multirow[b]{2}{*}{ DOE Site } & \multicolumn{2}{|c|}{ Commercial Aircraft } & \multirow{2}{*}{$\begin{array}{l}\text { Military } \\
\text { Aviation }\end{array}$} & \multicolumn{2}{|c|}{ General Aviation } & \multirow[b]{2}{*}{ APLL } & \multirow{2}{*}{ APLS } \\
\hline & Airport & Airways & & Airport & Airways & & \\
\hline ANL-E & NA & $\mathrm{NA}$ & NA & NA & $1.0 \mathrm{E}-04$ & $\mathrm{NA}$ & $1.0 \mathrm{E}-04$ \\
\hline FEMP & $N A^{a}$ & NA & NA & NA & $1.0 \mathrm{E}-04$ & NA & $1.0 \mathrm{E}-04$ \\
\hline Fermi & $\mathrm{NA}$ & NA & NA & NA & $1.0 \mathrm{E}-04$ & $\mathrm{NA}$ & $1.0 \mathrm{E}-04$ \\
\hline Hanford & NA & $6.5 \mathrm{E}-07$ & NA & NA & $1.0 \mathrm{E}-04$ & $6.5 \mathrm{E}-07$ & $1.0 \mathrm{E}-04$ \\
\hline INEL & NA & $1.5 \mathrm{E}-07$ & NA & NA & $1.0 \mathrm{E}-04$ & $1.5 \mathrm{E}-07$ & $1.0 \mathrm{E}-04$ \\
\hline $\mathrm{KCP}$ & NA & NA & NA & NA & $1.0 \mathrm{E}-04$ & NA & $1.0 \mathrm{E}-04$ \\
\hline LANL & NA & NA & NA & NA & NA & NA & $1.0 \mathrm{E}-04$ \\
\hline LLNL & NA & NA & NA & NA & $1.0 \mathrm{E}-04$ & NA & $1.0 \mathrm{E}-04$ \\
\hline NTS & NA & NA & NA & NA & $1.0 \mathrm{E}-04$ & NA & $1.0 \mathrm{E}-04$ \\
\hline ORR & NA & NA & NA & NA & $1.0 \mathrm{E}-04$ & $\mathrm{NA}$ & $1.0 \mathrm{E}-04$ \\
\hline Pantex & $1.7 \mathrm{E}-05$ & $3.8 \mathrm{E}-07$ & $1.7 \mathrm{E}-05$ & $3.1 E-04$ & NA & $1.7 \mathrm{E}-05$ & $3.3 \mathrm{E}-04$ \\
\hline PGDP & NA & NA & NA & $9.6 \mathrm{E}-04$ & $\mathrm{NA}$ & NA & $9.6 \mathrm{E}-04$ \\
\hline PORTS & NA & NA & NA & NA & $1.0 \mathrm{E}-04$ & $\mathrm{NA}$ & $1.0 \mathrm{E}-04$ \\
\hline RFETS & NA & NA & NA & $7.6 \mathrm{E}-04$ & NA & NA & $7.6 \mathrm{E}-04$ \\
\hline SNL & $1.6 \mathrm{E}-03$ & NA & $1.6 \mathrm{E}-03$ & $8.4 \mathrm{E}-03$ & NA & $1.6 \mathrm{E}-03$ & $1.0 \mathrm{E}-02$ \\
\hline SRS & NA & $6.3 \mathrm{E}-07$ & NA & NA & $1.0 \mathrm{E}-04$ & $6.3 E-07$ & $1.0 \mathrm{E}-04$ \\
\hline
\end{tabular}

a $\mathrm{NA}=$ not applicable.

Figure F.2 shows a representation of these three components of the effective area (Kot et al. 1982). For particular facilities, there will be additional considerations, like the possible shielding by adjacent buildings or hills. The effect of the wingspan of the aircraft is also considered.

For a facility with dimensions $L$ (length), $W$ (width), and $H$ (height), the effective plan area can be estimated as

$$
A_{p}=(L+d) W
$$

where $d$ is the wingspan of the incoming aircraft. The average wingspan for small airplanes is approximately $12 \mathrm{~m}(39.4 \mathrm{ft})$, with $6 \mathrm{~m}(19.7 \mathrm{ft})$ between engines. For a large commercial aircraft, average wingspan is $50 \mathrm{~m}$ (164 ft), with $30 \mathrm{~m}$ (98ft) between engines. The distance between engines is relevant for hardened structures, because the engines are more likely to penetrate them. 


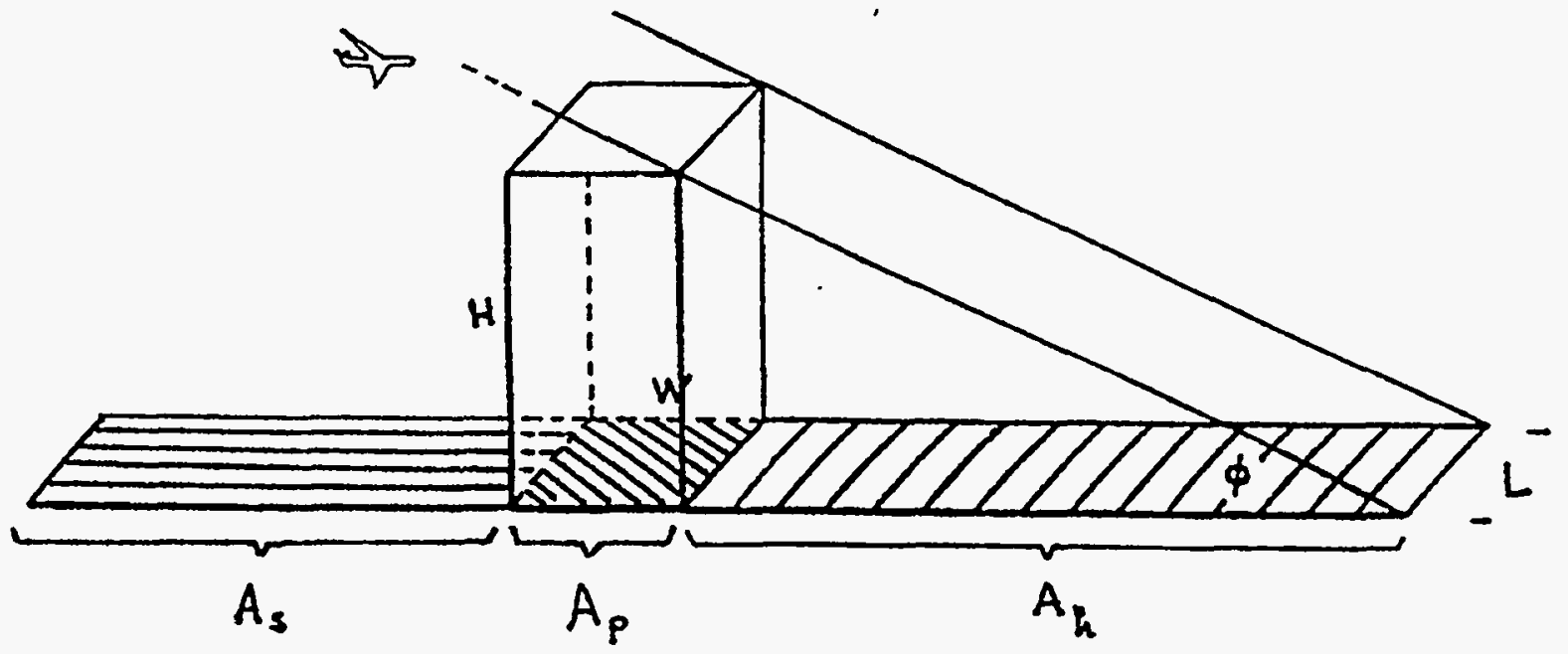

FIGURE F.2 Facility Target Area (Source: Adapted from Kot et al. 1982)

The skid area can be estimated as

$$
A_{s}=(L+d) s
$$

where $s$ is the skid length, $100 \mathrm{~m}(328.1 \mathrm{ft})$ for small and $300 \mathrm{~m}(984.3 \mathrm{ft})$ for large airframes.

The shadow area can be estimated as

$$
A_{h}=(L+d) H / \tan \phi
$$

where $\phi$ is the glide angle, usually assumed to be $20^{\circ}$.

The effective target area, $A_{\text {eff }}$ is the addition of the three components:

$$
A_{\text {eff }}=A_{p}+A_{s}+A_{h}
$$


Some reports have estimated the shadow area in terms of the longest facility dimension, rather than in terms of the length, that is,

$$
A_{h}=\left(\left(L^{2}+W^{2}\right)^{0.5}+d\right) H / \tan \phi
$$

For the facility dimensions used in the WM PEIS, there is no appreciable difference in the effective area between the two equations, and the initial equation for the shadow area is used. Table F.11 shows the effective facility areas for low-level waste (LLW), low-level mixed waste (LLMW), transuranic waste (TRUW), high-level waste (HLW), and hazardous waste (HW) facilities.

The dimensions of the LLW storage facility were supplied by Science Applications International Corporation (SAIC) (based on WM PEIS information developed by INEL [Feizollahi and Shropshire 1992]) for the generic facility size to be used for LLW storage. The incineration (or treatment) facilities for LLW, HLW and HW, although processing different throughput at different sites, have been assumed to be of a single size for the purpose of evaluating the effective area. The size of a medium WM PEIS incineration facility, as reported in Feizollahi and Shropshire (1992), has been used as the basis for the size. The dimensions reported have been increased and rounded up to account for the additional areas (e.g., waste staging area, stack exhaust system, electrical substation) attached to the main building. The same facility sizes used in LLW facilities were used for LLMW and TRUW facilities.

The size of the generic storage facility for hazardous waste, which is in fact a staging area, has been assumed to be one-quarter that of the generic LLW storage facility. The height of the facility has been assumed to be a more realistic $5 \mathrm{~m}(16 \mathrm{ft})$. Even with this reduction, the size selected conservatively envelops the Hazardous Waste Storage Facility at INEL, for example. For $\mathrm{HLW}$, current storage takes place in underground tanks, so the effective area does not include skidor shadow-area considerations. There will also be areas between the tanks where a crash would not be as harmful as a direct hit. The effective shape and dimensions of a tank farm have been assumed to be a square with a side of $100 \mathrm{~m}(328 \mathrm{ft})$.

\section{F.4.2 Frequency of Aircraft Crashes against Facilities at DOE Sites}

Combining the estimated annual frequency of a crash per square mile with the calculated effective areas for the different facilities, the annual frequency of the initiating events for crashes of large and small aircraft (APLL and APLS, respectively) at different facilities can be estimated. The following tables list the frequencies of these two initiators by waste type, function, and DOE site. Only the sites considered for each waste and function have an associated initiating event frequency. 
TABLE F.11 Effective Area Estimates for LLW, LLMW, TRUW, HLW, and HW Facilities

\begin{tabular}{|c|c|c|c|c|c|c|c|c|c|c|c|c|c|}
\hline Facility & $\begin{array}{c}\text { Size of } \\
\text { Aircraft }\end{array}$ & $\begin{array}{l}\text { Length } \\
(\mathrm{m})\end{array}$ & $\begin{array}{c}\text { Width } \\
(\mathrm{m})\end{array}$ & $\begin{array}{l}\text { Height } \\
\text { (m) }\end{array}$ & $\begin{array}{l}\text { Skid } \\
(m)\end{array}$ & $\begin{array}{c}\text { Wingspan } \\
(\mathrm{m})\end{array}$ & $\begin{array}{l}\text { Plan } \\
\text { Area } \\
\left(\mathrm{m}^{2}\right) \\
\end{array}$ & $\begin{array}{l}\text { Skid } \\
\text { Area } \\
\left(\mathrm{m}^{2}\right) \\
\end{array}$ & $\begin{array}{c}\text { Shadow } \\
\text { Area } \\
\left(\mathrm{m}^{2}\right) \\
\end{array}$ & $\begin{array}{l}\text { Total } \\
\text { Area } \\
\left(\mathrm{m}^{2}\right)\end{array}$ & $\begin{array}{l}\text { Total } \\
\text { Area } \\
\left(\mathrm{mi}^{2}\right)\end{array}$ & SAIC Value $\left(\mathrm{mi}^{2}\right)$ & $\begin{array}{c}\text { Effective } \\
\text { Area } \\
\left(\mathrm{ni}^{2}\right)\end{array}$ \\
\hline \multicolumn{14}{|l|}{$\begin{array}{l}\text { LLW, LLMW, } \\
\text { TRUW }\end{array}$} \\
\hline Storage & APLL & 100 & 50 & 3 & 300 & 50 & 7,500 & 45,000 & 1.236 & 53,736 & 2.1E-02 & $6.8 \mathrm{E}-03 / 1.9 \mathrm{E}-02$ & $2.1 E-02$ \\
\hline Storage & APLS & 100 & 50 & 3 & 100 & 12 & 5,600 & 11,200 & 923 & 17,723 & $6.9 \mathrm{E}-03$ & $6.8 \mathrm{E}-03 / 5.6 \mathrm{E}-03$ & $7.0 \mathrm{E}-03$ \\
\hline Incinerator & APLL & 100 & 50 & 10 & 300 & 30 & 6,500 & 39,000 & 3,572 & 49,072 & $1.9 \mathrm{E}-02$ & $6.8 \mathrm{E}-03 / 1.7 \mathrm{E}-02$ & $1.8 \mathrm{E}-02$ \\
\hline Incinerator & APLS & 100 & 50 & 10 & 100 & 3 & 5,300 & 10,600 & 2,912 & 18,812 & $7.4 \mathrm{E}-03$ & $6.8 \mathrm{E}-03 / 5.3 \mathrm{E}-03$ & $7.0 \mathrm{E}-03$ \\
\hline \multicolumn{14}{|l|}{ HLW } \\
\hline DST $^{\mathrm{a}}$ & APLL & 100 & 100 & $N A^{b}$ & NA & $\mathrm{NA}$ & 10,000 & 0 & 0 & 10,000 & $3.9 \mathrm{E}-03$ & NA & $4.0 \mathrm{E}-03$ \\
\hline DST & APLS & 100 & 100 & NA & NA & $\mathrm{NA}$ & 10,000 & 0 & 0 & 10,000 & $3.9 \mathrm{E}-03$ & NA & $4.0 \mathrm{E}-03$ \\
\hline Other & APLL & 100 & 50 & 10 & 300 & 30 & 6,500 & 39,000 & 3,572 & 49,072 & $1.9 \mathrm{E}-02$ & $1.8 \mathrm{E}-02$ & $1.8 \mathrm{E}-02$ \\
\hline Other & APLS & 100 & 50 & 10 & 100 & 6 & 5,300 & 10,600 & 2,912 & 18,812 & $7.4 \mathrm{E}-03$ & $6.5 \mathrm{E}-03$ & $7.0 \mathrm{E}-03$ \\
\hline \multicolumn{14}{|l|}{ HW } \\
\hline Storage & APLL & 50 & 25 & 5 & 300 & 50 & 2,500 & 30,000 & 1,374 & 33,874 & 1.3E- 02 & NA & $1.3 \mathrm{E}-02$ \\
\hline Stonge & APLS & 50 & 25 & 5 & 100 & 12 & 1,550 & 6,200 & 852 & 8.602 & $3.4 E-03$ & NA & $3.0 \mathrm{E}-03$ \\
\hline Treatment & APLL & 100 & 50 & 10 & 300 & 30 & 6,500 & 39,000 & 3,572 & 49,072 & $1.9 \mathrm{E}-02$ & NA & $1.8 \mathrm{E}-02$ \\
\hline Treatment & APLS & 100 & 50 & 10 & 100 & 6 & 5,300 & 10,600 & 2,912 & 18,812 & 7.4E -03 & $\mathrm{NA}$ & $7.0 \mathrm{E}-03$ \\
\hline
\end{tabular}

abbreviation: DST $=$ double-shell tank.

b $N A=$ not applicable. 
Table F. 12 lists the frequencies for LLW storage at the 11 DOE sites considered in the WM PEIS alternative 9. The 11 sites cover the 11 major storage sites and, because the size of the facility is generic, storage facilities under other alternatives are also covered. Table F.13 provides the annual frequencies for APLL and APLS at the LLW incineration facilities at the relevant sites.

Table F.14 shows the initiating event frequencies for HLW facilities at the two sites for which aircraft crashes were originally considered in screening accidents but were not analyzed (Hanford and SRS). Tables F.15 and F.16 provide the annual frequencies for hazardous waste storage and treatment facilities, respectively. The storage sites cover the 11 major locations (all alternatives covered). For treatment facilities, sites under Alternatives 2 and 3 are distinguished in the table. Tables F.17 and F.18 list the annual frequency of aircraft impacts on LLMW storage and treatment facilities at the relevant DOE sites; Tables F.19 and F.20 list similar information for TRUW facilities.

TABLE F.12 Airplane Impacts Initiating Event Frequency: LLW Storage

\begin{tabular}{|c|c|c|c|c|c|c|}
\hline \multirow[b]{2}{*}{$\begin{array}{c}\text { DOE } \\
\text { Site } \\
\end{array}$} & \multicolumn{3}{|c|}{ APLL } & \multicolumn{3}{|c|}{ APLS } \\
\hline & $\begin{array}{c}\text { Crash } \\
\text { Frequency } \\
\left(\text { crash/yr-mi }{ }^{2}\right)\end{array}$ & $\begin{array}{l}\text { Area } \\
\left(\mathrm{mi}^{2}\right)\end{array}$ & $\begin{array}{l}\text { Initiating } \\
\text { Event } \\
\text { Frequency } \\
\left(\mathrm{yr}^{-1}\right)\end{array}$ & $\begin{array}{c}\text { Crash } \\
\text { Frequency } \\
\left.\text { (crash/yr-mi }{ }^{2}\right)\end{array}$ & $\begin{array}{l}\text { Area } \\
\left(\mathrm{mi}^{2}\right)\end{array}$ & $\begin{array}{c}\text { Initiating } \\
\text { Event } \\
\text { Frequency } \\
\left(\mathrm{yr}^{-1}\right)\end{array}$ \\
\hline ANL-E & NA & NA & NA & $1.0 \mathrm{E}-04$ & NA & NA \\
\hline FEMP & $N^{a}$ & $2.1 \mathrm{E}-02$ & $\mathrm{NA}$ & $1.0 \mathrm{E}-04$ & $7.0 \mathrm{E}-03$ & 7.E-07 \\
\hline Fermi & NA & NA & NA & $1.0 \mathrm{E}-04$ & NA & $\mathrm{NA}$ \\
\hline Hanford & $6.5 \mathrm{E}-07$ & $2.1 \mathrm{E}-02$ & $1.4 \mathrm{E}-08$ & $1.0 \mathrm{E}-04$ & $7.0 \mathrm{E}-03$ & $7.0 \mathrm{E}-07$ \\
\hline INEL & $1.5 \mathrm{E}-07$ & $2.1 \mathrm{E}-02$ & $3.2 \mathrm{E}-09$ & $1.0 \mathrm{E}-04$ & $7.0 \mathrm{E}-03$ & 7.E-07 \\
\hline $\mathrm{KCP}$ & NA & $\mathrm{NA}$ & NA & $1.0 \mathrm{E}-04$ & NA & NA \\
\hline LANL & NA & $2.1 \mathrm{E}-02$ & $\mathrm{NA}$ & $1.0 \mathrm{E}-04$ & $7.0 \mathrm{E}-03$ & 7.E-07 \\
\hline LLNL & $\mathrm{NA}$ & $2.1 \mathrm{E}-02$ & $\mathrm{NA}$ & $1.0 \mathrm{E}-04$ & $7.0 \mathrm{E}-03$ & 7.E-07 \\
\hline NTS & NA & $\mathrm{NA}$ & $\mathrm{NA}$ & $1.0 \mathrm{E}-04$ & $\mathrm{NA}$ & NA \\
\hline ORR & $\mathrm{NA}$ & $2.1 \mathrm{E}-02$ & $\mathrm{NA}$ & $1.0 \mathrm{E}-04$ & $7.0 \mathrm{E}-03$ & $7.0 \mathrm{E}-07$ \\
\hline Pantex & $1.7 \mathrm{E}-05$ & $2.1 \mathrm{E}-02$ & 3.7E-07 & $3.3 E-04$ & $7.0 \mathrm{E}-03$ & $2.3 \mathrm{E}-06$ \\
\hline PGDP & NA & 2.1E-02 & NA & $9.6 \mathrm{E}-04$ & $7.0 \mathrm{E}-03$ & $6.7 \mathrm{E}-06$ \\
\hline PORTS & NA & 2.1E-02 & NA & $1.0 \mathrm{E}-04$ & $7.0 \mathrm{E}-03$ & $7.0 \mathrm{E}-07$ \\
\hline RFETS & $\mathrm{NA}$ & $2.1 \mathrm{E}-02$ & $\mathrm{NA}$ & $7.6 \mathrm{E}-04$ & $7.0 \mathrm{E}-03$ & $5.3 \mathrm{E}-06$ \\
\hline SNL-NM & $1.6 \mathrm{E}-03$ & NA & NA & $1.0 \mathrm{E}-02$ & NA & $\mathrm{NA}$ \\
\hline SRS & $6.3 E-07$ & 2.1E-02 & $1.3 \mathrm{E}-08$ & $1.0 \mathrm{E}-04$ & $7.0 \mathrm{E}-03$ & $7.0 \mathrm{E}-07$ \\
\hline
\end{tabular}

a $\mathrm{NA}=$ not applicable. 
TABLE F.13 Airplane Impacts Initiating Event Frequency: LLW Incineration Facilities

\begin{tabular}{|c|c|c|c|c|c|c|}
\hline \multirow[b]{2}{*}{ DOE Site } & \multicolumn{3}{|c|}{ APLL } & \multicolumn{3}{|c|}{ APLS } \\
\hline & $\begin{array}{c}\text { Crash } \\
\text { Frequency } \\
\text { (crash/yr-mi }{ }^{2} \text { ) }\end{array}$ & $\begin{array}{l}\text { Area } \\
\left(\mathrm{mi}^{2}\right)\end{array}$ & $\begin{array}{l}\text { Initiating } \\
\text { Event } \\
\text { Frequency } \\
\left(y r^{-1}\right)\end{array}$ & $\begin{array}{c}\text { Crash } \\
\text { Frequency } \\
\left(\text { crash/yr-mi }{ }^{2}\right)\end{array}$ & $\begin{array}{l}\text { Area } \\
\left(\mathrm{mi}^{2}\right)\end{array}$ & $\begin{array}{c}\text { Initiating } \\
\text { Event } \\
\text { Frequency } \\
\left(\mathrm{yr}^{-1}\right)\end{array}$ \\
\hline ANL-E & NA & NA & NA & $1.0 \mathrm{E}-04$ & NA & NA \\
\hline FEMP & NA & $1.8 \mathrm{E}-02$ & NA & $1.0 \mathrm{E}-04$ & $7.0 \mathrm{E}-03$ & $7.0 \mathrm{E}-07$ \\
\hline Fermi & NA & NA & NA & $1.0 \mathrm{E}-04$ & NA & NA \\
\hline Hanford & $6.5 E-07$ & $1.8 \mathrm{E}-02$ & $1.2 \mathrm{E}-08$ & $1.0 \mathrm{E}-04$ & $7.0 \mathrm{E}-03$ & $7.0 \mathrm{E}-07$ \\
\hline INEL & $1.5 \mathrm{E}-07$ & $1.8 \mathrm{E}-02$ & $2.7 \mathrm{E}-09$ & $1.0 \mathrm{E}-04$ & $7.0 \mathrm{E}-03$ & $7.0 \mathrm{E}-07$ \\
\hline $\mathrm{KCP}$ & NA & NA & NA & $1.0 \mathrm{E}-04$ & NA & $\mathrm{NA}$ \\
\hline LANL & NA & $1.8 \mathrm{E}-02$ & NA & $1.0 \mathrm{E}-04$ & $7.0 \mathrm{E}-03$ & $7.0 \mathrm{E}-07$ \\
\hline LLNL & NA & $1.8 \mathrm{E}-02$ & $\mathrm{NA}$ & $1.0 \mathrm{E}-04$ & $7.0 \mathrm{E}-03$ & $7.0 \mathrm{E}-07$ \\
\hline NTS & NA & NA & NA & $1.0 \mathrm{E}-04$ & NA & $\mathrm{NA}$ \\
\hline ORR & NA & $1.8 \mathrm{E}-02$ & NA & $1.0 \mathrm{E}-04$ & 7.0E-03 & $7.0 \mathrm{E}-07$ \\
\hline Pantex & $1.7 \mathrm{E}-05$ & $1.8 \mathrm{E}-02$ & $3.1 E-07$ & $3.3 \mathrm{E}-04$ & $7.0 \mathrm{E}-03$ & $2.3 \mathrm{E}-06$ \\
\hline PGDP & NA & $1.8 \mathrm{E}-02$ & NA & $9.6 \mathrm{E}-04$ & $7.0 \mathrm{E}-03$ & $6.7 \mathrm{E}-06$ \\
\hline PORTS & NA & $1.8 \mathrm{E}-02$ & $\mathrm{NA}$ & $1.0 \mathrm{E}-04$ & $7.0 \mathrm{E}-03$ & $7.0 \mathrm{E}-07$ \\
\hline RFETS & NA & $1.8 \mathrm{E}-02$ & NA & $7.6 \mathrm{E}-04$ & $7.0 \mathrm{E}-03$ & $5.3 \mathrm{E}-06$ \\
\hline SNL-NM & $1.6 \mathrm{E}-03$ & NA & NA & $1.0 \mathrm{E}-02$ & $\mathrm{NA}$ & NA \\
\hline SRS & $6.3 E-07$ & $1.8 \mathrm{E}-02$ & $1.1 E-08$ & $1.0 \mathrm{E}-04$ & $7.0 \mathrm{E}-03$ & $7.0 \mathrm{E}-07$ \\
\hline
\end{tabular}

2 NA = not applicable.

TABLE F.14 Airplane Impacts Initiating Event Frequency: HLW Facilities

\begin{tabular}{|c|c|c|c|c|c|c|}
\hline \multirow[b]{2}{*}{ Facility } & \multicolumn{3}{|c|}{ APLL } & \multicolumn{3}{|c|}{ APLS } \\
\hline & $\begin{array}{c}\text { Crash } \\
\text { Frequency } \\
\text { (crash-mi }{ }^{2} \text { ) }\end{array}$ & $\begin{array}{l}\text { Area } \\
\left(\mathrm{mi}^{2}\right)\end{array}$ & $\begin{array}{l}\text { Initiating } \\
\text { Event } \\
\text { Frequency } \\
\left(\mathrm{yr}^{-1}\right)\end{array}$ & $\begin{array}{c}\text { Crash } \\
\text { Frequency } \\
\left(\text { crash/yr-mi }{ }^{2}\right)\end{array}$ & $\begin{array}{l}\text { Area } \\
\left(\mathrm{mi}^{2}\right)\end{array}$ & $\begin{array}{l}\text { Initiating } \\
\text { Event } \\
\text { Frequency } \\
\left(y r^{-1}\right)\end{array}$ \\
\hline \multicolumn{7}{|l|}{ Hanford } \\
\hline DST & $6.5 \mathrm{E}-07$ & $4.0 \mathrm{E}-03$ & $2.6 \mathrm{E}-09$ & $1.0 \mathrm{E}-04$ & $4.0 \mathrm{E}-03$ & $4.0 \mathrm{E}-07$ \\
\hline Pretreatment & $6.5 E-07$ & $1.8 \mathrm{E}-02$ & $1.2 \mathrm{E}-08$ & $1.0 \mathrm{E}-04$ & $7.0 \mathrm{E}-03$ & $7.0 \mathrm{E}-07$ \\
\hline Treatment & $6.5 \mathrm{E}-07$ & $1.8 \mathrm{E}-02$ & $1.2 \mathrm{E}-08$ & $1.0 \mathrm{E}-04$ & $7.0 \mathrm{E}-03$ & $7.0 \mathrm{E}-07$ \\
\hline Glass storage & $6.5 \mathrm{E}-07$ & $1.8 \mathrm{E}-02$ & $1.2 \mathrm{E}-08$ & $1.0 \mathrm{E}-04$ & $7.0 \mathrm{E}-03$ & $7.0 \mathrm{E}-07$ \\
\hline \multicolumn{7}{|l|}{ SRS } \\
\hline DST & $6.3 E-07$ & $1.8 \mathrm{E}-02$ & $2.5 \mathrm{E}-09$ & $1.0 \mathrm{E}-04$ & $4.0 \mathrm{E}-03$ & $4.0 \mathrm{E}-07$ \\
\hline Pretreatment & $6.3 E-07$ & $1.8 \mathrm{E}-02$ & $1.1 \mathrm{E}-08$ & $1.0 \mathrm{E}-04$ & $7.0 \mathrm{E}-03$ & $7.0 \mathrm{E}-07$ \\
\hline Treatment & $6.3 E-07$ & $1.8 \mathrm{E}-02$ & $1.1 \mathrm{E}-08$ & $1.0 \mathrm{E}-04$ & $7.0 \mathrm{E}-03$ & $7.0 \mathrm{E}-07$ \\
\hline Glass storage & $6.3 \mathrm{E}-07$ & $1.8 \mathrm{E}-02$ & $1.1 \mathrm{E}-08$ & $1.0 \mathrm{E}-04$ & $7.0 \mathrm{E}-03$ & $7.0 \mathrm{E}-07$ \\
\hline
\end{tabular}


TABLE F.15 Airplane Impacts Initiating Event Frequency: HW Storage Facilities

\begin{tabular}{|c|c|c|c|c|c|c|}
\hline \multirow[b]{2}{*}{$\begin{array}{c}\text { DOE } \\
\text { Site } \\
\end{array}$} & \multicolumn{3}{|c|}{ APLL } & \multicolumn{3}{|c|}{ APLS } \\
\hline & $\begin{array}{c}\text { Crash } \\
\text { Frequency } \\
\left.\text { (crash/yr- } \mathrm{mi}^{2}\right)\end{array}$ & $\begin{array}{l}\text { Area } \\
\left(\mathrm{mi}^{2}\right)\end{array}$ & $\begin{array}{l}\text { Initiating } \\
\text { Event } \\
\text { Frequency } \\
\left(\mathrm{yr}^{-1}\right)\end{array}$ & $\begin{array}{c}\text { Crash } \\
\text { Frequency } \\
\text { (crash/yr-mi }{ }^{2} \text { ) }\end{array}$ & $\begin{array}{l}\text { Area } \\
\left(\mathrm{mi}^{2}\right)\end{array}$ & $\begin{array}{c}\text { Initiating } \\
\text { Event } \\
\text { Frequency } \\
\left(\mathrm{yr}^{-1}\right)\end{array}$ \\
\hline ANL-E & $\mathrm{NA}$ & $1.3 \mathrm{E}-02$ & NA & $1.0 \mathrm{E}-04$ & $3.0 \mathrm{E}-03$ & $3.0 \mathrm{E}-07$ \\
\hline FEMP & $N A^{a}$ & NA & NA & $1.0 \mathrm{E}-04$ & NA & NA \\
\hline Fermi & $\mathrm{NA}$ & $1.3 \mathrm{E}-02$ & $\mathrm{NA}$ & $1.0 \mathrm{E}-04$ & $3.0 \mathrm{E}-03$ & $3.0 \mathrm{E}-07$ \\
\hline Hanford & $6.5 \mathrm{E}-07$ & $1.3 \mathrm{E}-02$ & 8.5E-08 & $1.0 \mathrm{E}-04$ & $3.0 \mathrm{E}-03$ & $3.0 \mathrm{E}-07$ \\
\hline INEL & $1.5 \mathrm{E}-07$ & $1.3 \mathrm{E}-02$ & $2.0 \mathrm{E}-09$ & $1.0 \mathrm{E}-04$ & $3.0 \mathrm{E}-03$ & $3.0 \mathrm{E}-07$ \\
\hline $\mathrm{KCP}$ & $\mathrm{NA}$ & $1.3 \mathrm{E}-02$ & $\mathrm{NA}$ & $1.0 \mathrm{E}-04$ & $3.0 \mathrm{E}-03$ & $3.0 \mathrm{E}-07$ \\
\hline LANL & $\mathrm{NA}^{\circ}$ & $1.3 \mathrm{E}-02$ & $\mathrm{NA}$ & $1.0 \mathrm{E}-04$ & $3.0 \mathrm{E}-03$ & $3.0 \mathrm{E}-07$ \\
\hline LLNL & NA & $1.3 \mathrm{E}-02$ & $\mathrm{NA}$ & $1.0 \mathrm{E}-04$ & $3.0 \mathrm{E}-03$ & $3.0 \mathrm{E}-07$ \\
\hline NTS & $\mathrm{NA}$ & NA & NA & $1.0 E-04$ & $\mathrm{NA}$ & $\mathrm{NA}$ \\
\hline ORR & $\mathrm{NA}$ & $1.3 \mathrm{E}-02$ & $\mathrm{NA}$ & $1.0 \mathrm{E}-04$ & $3.0 \mathrm{E}-03$ & $3.0 \mathrm{E}-07$ \\
\hline Pantex & $1.7 \mathrm{E}-05$ & $1.3 \mathrm{E}-02$ & $2.3 \mathrm{E}-07$ & $3.3 E-04$ & $3.0 \mathrm{E}-03$ & $9.8 \mathrm{E}-07$ \\
\hline PGDP & $\mathrm{NA}$ & NA & $\mathrm{NA}$ & $9.6 \mathrm{E}-04$ & NA & $\mathrm{NA}$ \\
\hline PORTS & NA & NA & NA & $1.0 \mathrm{E}-04$ & NA & NA \\
\hline RFETS & $\mathrm{NA}$ & NA & NA & $7.6 \mathrm{E}-04$ & $\mathrm{NA}$ & NA \\
\hline SNL-NM & $1.6 \mathrm{E}-03$ & $1.3 \mathrm{E}-02$ & $2.1 \mathrm{E}-05$ & $1.0 \mathrm{E}-02$ & $3.0 \mathrm{E}-03$ & $3.0 \mathrm{E}-05$ \\
\hline SRS & $6.3 \mathrm{E}-07$ & $1.3 \mathrm{E}-02$ & $8.2 \mathrm{E}-09$ & $1.0 E-04$ & $3.0 \mathrm{E}-03$ & $3.0 \mathrm{E}-07$ \\
\hline
\end{tabular}

2 NA = not applicable.

TABLE F.16 Airplane Impacts Initiating Event Frequency: HW Treatment Facilities

\begin{tabular}{|c|c|c|c|c|c|c|}
\hline \multirow[b]{2}{*}{$\begin{array}{c}\text { DOE } \\
\text { Site }\end{array}$} & \multicolumn{3}{|c|}{ APLL } & \multicolumn{3}{|c|}{ APLS } \\
\hline & $\begin{array}{c}\text { Crash } \\
\text { Frequency } \\
\left.\text { (crash/yr-mi }{ }^{2}\right)\end{array}$ & $\begin{array}{l}\text { Area } \\
\left(\mathrm{mi}^{2}\right)\end{array}$ & $\begin{array}{c}\text { Initiating } \\
\text { Event } \\
\text { Frequency } \\
\left(\mathrm{yr}^{-1}\right)\end{array}$ & $\begin{array}{c}\text { Crash } \\
\text { Frequency } \\
\left(\text { crash/yr-mi }{ }^{2}\right)\end{array}$ & $\begin{array}{l}\text { Area } \\
\left(\mathrm{mi}^{2}\right)\end{array}$ & $\begin{array}{c}\text { Initiating } \\
\text { Event } \\
\text { Frequency } \\
\left(y r^{-1}\right)\end{array}$ \\
\hline \multicolumn{7}{|c|}{ Alternative 2} \\
\hline Hanford & $6.5 E-07$ & $1.8 \mathrm{E}-02$ & $1.2 \mathrm{E}-08$ & $1.0 E-04$ & $7.0 \mathrm{E}-03$ & $7.0 \mathrm{E}-07$ \\
\hline INEL & $1.5 \mathrm{E}-07$ & $1.8 \mathrm{E}-02$ & $2.7 E-09$ & $1.0 \mathrm{E}-04$ & $7.0 \mathrm{E}-03$ & $7.0 \mathrm{E}-07$ \\
\hline LANL & $N A^{a}$ & $1.8 \mathrm{E}-02$ & NA & $1.0 \mathrm{E}-04$ & $7.0 \mathrm{E}-03$ & $7.0 \mathrm{E}-07$ \\
\hline ORR & $\mathrm{NA}$ & $1.8 \mathrm{E}-02$ & NA & $1.0 \mathrm{E}-04$ & $7.0 E-03$ & $7.0 E-07$ \\
\hline SRS & $6.3 E-07$ & $1.8 \mathrm{E}-02$ & $1.1 E-09$ & $1.0 \mathrm{E}-04$ & $7.0 \mathrm{E}-03$ & $7.0 \mathrm{E}-07$ \\
\hline \multicolumn{7}{|c|}{ Alternative 3} \\
\hline INEL & $1.5 \mathrm{E}-07$ & $1.8 \mathrm{E}-02$ & $2.7 E-09$ & $1.00 \mathrm{E}-04$ & $7.00 \mathrm{E}-03$ & $7.0 \mathrm{E}-07$ \\
\hline ORR & NA & $1.8 \mathrm{E}-02$ & NA & $1.00 \mathrm{E}-04$ & $7.00 \mathrm{E}-03$ & $7.0 \mathrm{E}-07$ \\
\hline
\end{tabular}

a $\mathrm{NA}=$ not applicable. 
TABLE F.17 Airplane Impacts Initiating Event Frequency: LLMW Storage Facilities $^{\mathbf{a}}$

\begin{tabular}{|c|c|c|c|c|c|c|}
\hline \multirow[b]{2}{*}{ DOE Site } & \multicolumn{3}{|c|}{ APLL } & \multicolumn{3}{|c|}{ APLS } \\
\hline & $\begin{array}{c}\text { Crash } \\
\text { Frequency } \\
\left(\text { crash/yr-mi }{ }^{2}\right)\end{array}$ & $\begin{array}{l}\text { Area } \\
\left(\mathrm{mi}^{2}\right)\end{array}$ & $\begin{array}{l}\text { Initiating } \\
\text { Event } \\
\text { Frequency } \\
\text { (yr-1) }\end{array}$ & $\begin{array}{c}\text { Crash } \\
\text { Frequency } \\
(\text { crash/yr-mi })\end{array}$ & $\begin{array}{l}\text { Area } \\
\left(\mathrm{mi}^{2}\right)\end{array}$ & $\begin{array}{l}\text { Initiating } \\
\text { Event } \\
\text { Frequency } \\
\left(\mathrm{yr}^{-1}\right)\end{array}$ \\
\hline ANL-E & NA & $2.1 \mathrm{E}-02$ & NA & $1.0 \mathrm{E}-0.4$ & $7.0 \mathrm{E}-03$ & $7.0 \mathrm{E}-07$ \\
\hline BNL & NA & $2.1 \mathrm{E}-02$ & NA & $1.0 \mathrm{E}-04$ & $7.0 \mathrm{E}-03$ & $7.0 \mathrm{E}-07$ \\
\hline ETEC & NA & $2.1 \mathrm{E}-02$ & NA & $1.0 \mathrm{E}-04$ & $7.0 \mathrm{E}-03$ & $7.0 \mathrm{E}-07$ \\
\hline FEMP & $N A^{b}$ & $2.1 \mathrm{E}-02$ & NA & $1.0 \mathrm{E}-04$ & $7.0 E-03$ & $7.0 \mathrm{E}-07$ \\
\hline Hanford & $6.5 \mathrm{E}-07$ & $2.1 E-02$ & $1.4 \mathrm{E}-08$ & $1.0 \mathrm{E}-04$ & $7.0 \mathrm{E}-03$ & $7.0 \mathrm{E}-07$ \\
\hline INEL & $1.5 \mathrm{E}-07$ & $2.1 \mathrm{E}-02$ & $3.2 \mathrm{E}-09$ & $1.0 \mathrm{E}-04$ & $7.0 \mathrm{E}-03$ & $7.0 \mathrm{E}-07$ \\
\hline KAPL-S & NA & $2 \mathrm{IE}-02$ & NA & $1.0 \mathrm{E}-04$ & $7.0 \mathrm{E}-03$ & $7.0 \mathrm{E}-07$ \\
\hline LANL & NA & $2.1 E-02$ & NA & $1.0 \mathrm{E}-04$ & $7.0 \mathrm{E}-03$ & $7.0 \mathrm{E}-07$ \\
\hline LBL & NA & $2.1 \mathrm{E}-02$ & NA & $1.0 \mathrm{E}-04$ & $7.0 \mathrm{E}-03$ & $7.0 \mathrm{E}-07$ \\
\hline LLNL & NA & 2.1E-02 & NA & $1.0 \mathrm{E}-04$ & $7.0 \mathrm{E}-03$ & $7.0 \mathrm{E}-07$ \\
\hline Middlesex & NA & 2.1E-02 & NA & $1.0 \mathrm{E}-04$ & $7.0 \mathrm{E}-03$ & $7.0 \mathrm{E}-07$ \\
\hline NTS & NA & $2.1 \mathrm{E}-02$ & NA & $1.0 \mathrm{E}-04$ & $7.0 \mathrm{E}-03$ & $7.0 \mathrm{E}-07$ \\
\hline ORR & NA & $2.1 \mathrm{E}-02$ & NA & $1.0 \mathrm{E}-04$ & $7.0 \mathrm{E}-03$ & $7.0 \mathrm{E}-07$ \\
\hline Pantex & $1.7 \mathrm{E}-05$ & $2.1 E-02$ & $3.7 \mathrm{E}-07$ & $3.3 E-04$ & $7.0 \mathrm{E}-03$ & $2.3 E-06$ \\
\hline PGDP & NA & $2.1 \mathrm{E}-02$ & NA & $9.6 \mathrm{E}-04$ & $7.0 \mathrm{E}-03$ & $6.7 E-06$ \\
\hline PORTS & NA & $2.1 E-02$ & NA & $1.0 \mathrm{E}-04$ & $7.0 \mathrm{E}-03$ & $7.0 \mathrm{E}-07$ \\
\hline RFETS & NA & $2.1 E-02$ & NA & $7.6 \mathrm{E}-04$ & $7.0 \mathrm{E}-03$ & $5.3 \mathrm{E}-06$ \\
\hline SNL-NM & $1.6 \mathrm{E}-03$ & $2.1 \mathrm{E}-02$ & $3.4 \mathrm{E}-05$ & $1.0 \mathrm{E}-02$ & $7.0 \mathrm{E}-03$ & $7.0 \mathrm{E}-05$ \\
\hline SRS & $6.3 E-07$ & $2.1 \mathrm{E}-02$ & $1.3 E-08$ & $1.0 E-04$ & $7.0 \mathrm{E}-03$ & $7.0 \mathrm{E}-07$ \\
\hline
\end{tabular}

a Abbreviations: $\mathrm{BNL}=$ Brookhaven National Laboratory, ETEC $=$ Energy Technology Engineering Center, KAPL-S = Knolls Atomic Power Laboratory (Schenectady), LBL = Lawrence Berkeley Laboratory, and Middlesex $=$ Middlesex Sampling Plant.

b $\mathrm{NA}=$ not applicable. 
TABLE F.18 Airplane Impacts Initiating Event Frequency: LLMW Treatment Facilities

\begin{tabular}{|c|c|c|c|c|c|c|}
\hline \multirow[b]{2}{*}{$\begin{array}{l}\text { DOE } \\
\text { Site }\end{array}$} & \multicolumn{3}{|c|}{ APLL } & \multicolumn{3}{|c|}{ APLS } \\
\hline & $\begin{array}{c}\text { Crash } \\
\text { Frequency } \\
\text { (crash/yr- } \mathrm{mi}^{2} \text { ) }\end{array}$ & $\begin{array}{l}\text { Area } \\
\left(\mathrm{mi}^{2}\right)\end{array}$ & $\begin{array}{c}\text { Initiating } \\
\text { Event } \\
\text { Frequency } \\
\left(\mathrm{yr}^{-1}\right)\end{array}$ & $\begin{array}{c}\text { Crash } \\
\text { Frequency } \\
\text { (crash/yr- } \mathrm{mi}^{2} \text { ) }\end{array}$ & $\begin{array}{l}\text { Area } \\
\left(\mathrm{mi}^{2}\right)\end{array}$ & $\begin{array}{c}\text { Initiating } \\
\text { Event } \\
\text { Frequency } \\
\left(\mathrm{yr}^{-1}\right)\end{array}$ \\
\hline FEMP & $N A^{a}$ & $1.8 \mathrm{E}-02$ & NA & $1.0 \mathrm{E}-04$ & $7.0 \mathrm{E}-03$ & $7.0 \mathrm{E}-07$ \\
\hline Hanford & $6.5 \mathrm{E}-07$ & $1.8 \mathrm{E}-02$ & $1.2 \mathrm{E}-08$ & $1.0 \mathrm{E}-04$ & $7.0 \mathrm{E}-03$ & $7.0 \mathrm{E}-07$ \\
\hline INEL & $1.5 \mathrm{E}-07$ & $1.8 \mathrm{E}-02$ & 2.7E-09 & $1.0 \mathrm{E}-04$ & $7.0 \mathrm{E}-03$ & $7.0 \mathrm{E}-07$ \\
\hline LANL & $\mathrm{NA}$ & $1.8 \mathrm{E}-02$ & NA & $1.0 \mathrm{E}-04$ & $7.0 \mathrm{E}-03$ & $7.0 \mathrm{E}-07$ \\
\hline LLNL & NA & $1.8 \mathrm{E}-02$ & NA & $1.0 \mathrm{E}-04$ & $7.0 \mathrm{E}-03$ & $7.0 \mathrm{E}-07$ \\
\hline ORR & NA & $1.8 \mathrm{E}-02$ & NA & $1.0 \mathrm{E}-04$ & $7.0 \mathrm{E}-03$ & $7.0 \mathrm{E}-07$ \\
\hline Pantex & $1.7 \mathrm{E}-05$ & $1.8 \mathrm{E}-02$ & $3.1 \mathrm{E}-07$ & $3.3 \mathrm{E}-04$ & $7.0 \mathrm{E}-03$ & $2.3 \mathrm{E}-06$ \\
\hline PGDP & NA & $1.8 \mathrm{E}-02$ & NA & $9.6 \mathrm{E}-04$ & $7.0 \mathrm{E}-03$ & $6.7 \mathrm{E}-06$ \\
\hline PORTS & NA & $1.8 \mathrm{E}-02$ & NA & $1.0 \mathrm{E}-04$ & $7.0 \mathrm{E}-03$ & 7.0E-07 \\
\hline RFETS & NA & $1.8 \mathrm{E}-02$ & NA & $7.6 \mathrm{E}-04$ & 7.0E-03 & $5.3 \mathrm{E}-06$ \\
\hline SRS & $6.3 \mathrm{E}-07$ & $1.8 \mathrm{E}-02$ & $1.1 E-08$ & $1.0 \mathrm{E}-04$ & $7.0 \mathrm{E}-03$ & $7.0 \mathrm{E}-07$ \\
\hline
\end{tabular}

a $\mathrm{NA}=$ not applicable.

TABLE F.19 Airplane Impacts Initiating Event Frequency: TRUW Storage Facilities

\begin{tabular}{|c|c|c|c|c|c|c|}
\hline \multirow[b]{2}{*}{$\begin{array}{l}\text { DOE } \\
\text { Site }^{\mathbf{a}}\end{array}$} & \multicolumn{3}{|c|}{ APLL } & \multicolumn{3}{|c|}{ APLS } \\
\hline & $\begin{array}{c}\text { Crash } \\
\text { Frequency } \\
\left(\text { crash/yr-mi }{ }^{2}\right)\end{array}$ & $\begin{array}{l}\text { Area } \\
\left(\mathrm{mi}^{2}\right)\end{array}$ & $\begin{array}{l}\text { Initiating } \\
\text { Event } \\
\text { Frequency } \\
\left(\mathrm{yr}^{-1}\right)\end{array}$ & $\begin{array}{c}\text { Crash } \\
\text { Frequency } \\
\left(\text { crash/yr-mi }{ }^{2}\right)\end{array}$ & $\begin{array}{l}\text { Area } \\
\left(\mathrm{mi}^{2}\right)\end{array}$ & $\begin{array}{c}\text { Initiating } \\
\text { Event } \\
\text { Frequency } \\
\left(\mathrm{yr}^{-1}\right)\end{array}$ \\
\hline ANL-E & $N A^{b}$ & $2.1 \mathrm{E}-02$ & $\mathrm{NA}$ & $1.0 \mathrm{E}-04$ & $7.0 \mathrm{E}-03$ & $7.0 \mathrm{E}-07$ \\
\hline Hanford & $6.5 \mathrm{E}-07$ & $2.1 \mathrm{E}-02$ & $1.4 \mathrm{E}-08$ & $1.0 \mathrm{E}-04$ & $7.0 \mathrm{E}-03$ & $7.0 \mathrm{E}-07$ \\
\hline INEL & $1.5 E-07$ & $2.1 \mathrm{E}-02$ & $3.2 \mathrm{E}-09$ & $1.0 \mathrm{E}-04$ & $7.0 \mathrm{E}-03$ & $7.0 \mathrm{E}-07$ \\
\hline LANL & NA & $2.1 E-02$ & NA & $1.0 \mathrm{E}-04$ & $7.0 \mathrm{E}-03$ & $7.0 \mathrm{E}-07$ \\
\hline LLNL & NA & $2.1 \mathrm{E}-02$ & NA & $1.0 \mathrm{E}-04$ & $7.0 \mathrm{E}-03$ & $7.0 \mathrm{E}-07$ \\
\hline Mound & NA & $2.1 \mathrm{E}-02$ & $\mathrm{NA}$ & $1.0 \mathrm{E}-04$ & $7.0 \mathrm{E}-03$ & $7.0 \mathrm{E}-07$ \\
\hline NTS & NA & $2.1 \mathrm{E}-02$ & NA & $1.0 \mathrm{E}-04$ & $7.0 \mathrm{E}-03$ & $7.0 \mathrm{E}-07$ \\
\hline ORR & $\mathrm{NA}$ & $2.1 E-02$ & NA & $1.0 \mathrm{E}-04$ & $7.0 \mathrm{E}-03$ & $7.0 \mathrm{E}-07$ \\
\hline RFETS & NA & $2.1 E-02$ & $\mathrm{NA}$ & $7.6 \mathrm{E}-04$ & $7.0 \mathrm{E}-03$ & $5.3 \mathrm{E}-06$ \\
\hline SRS & $6.3 E-07$ & $2.1 E-02$ & $1.3 E-08$ & $1.0 \mathrm{E}-04$ & $7.0 \mathrm{E}-03$ & $7.0 \mathrm{E}-07$ \\
\hline
\end{tabular}

a Abbreviation: Mound = Mound Plant.

b $\mathrm{NA}=$ not applicable. 
TABLE F.20 Airplane Impacts Initiating Event Frequency: TRUW Treatment Facilities

\begin{tabular}{|c|c|c|c|c|c|c|}
\hline \multirow[b]{2}{*}{$\begin{array}{l}\text { DOE } \\
\text { Site }^{\mathbf{a}}\end{array}$} & \multicolumn{3}{|c|}{ APLL } & \multicolumn{3}{|c|}{ APLS } \\
\hline & $\begin{array}{c}\text { Crash } \\
\text { Frequency } \\
\text { (crash/yr-mi }{ }^{2} \text { ) }\end{array}$ & $\begin{array}{l}\text { Area } \\
\left(\mathrm{mi}^{2}\right)\end{array}$ & $\begin{array}{l}\text { Initiating } \\
\text { Event Frequency } \\
\left(\mathrm{yr}^{-1}\right)\end{array}$ & $\begin{array}{c}\text { Crash } \\
\text { Frequency } \\
\text { (crash/yr-mi }{ }^{2} \text { ) }\end{array}$ & $\begin{array}{l}\text { Area } \\
\left(\mathrm{mi}^{2}\right)\end{array}$ & $\begin{array}{l}\text { Initiating } \\
\text { Event } \\
\text { Frequency/yr }\end{array}$ \\
\hline Hanford & $6.5 E-07$ & $1.8 \mathrm{E}-02$ & $1.2 \mathrm{E}-08$ & $1.0 \mathrm{E}-04$ & $7.0 \mathrm{E}-03$ & $7.0 \mathrm{E}-07$ \\
\hline INEL & $1.5 \mathrm{E}-07$ & $1.8 \mathrm{E}-02$ & 2.7E-09 & $1.0 \mathrm{E}-04$ & $7.0 \mathrm{E}-03$ & $7.0 \mathrm{E}-07$ \\
\hline LANL & $\mathrm{NA}^{\mathrm{b}}$ & $1.8 \mathrm{E}-02$ & $\mathrm{NA}$ & $1.0 \mathrm{E}-04$ & $7.0 \mathrm{E}-03$ & $7.0 \mathrm{E}-07$ \\
\hline RFETS & $\mathrm{NA}$ & $1.8 \mathrm{E}-02$ & $\mathrm{NA}$ & $7.6 E-04$ & $7.0 \mathrm{E}-03$ & $5.3 \mathrm{E}-06$ \\
\hline SRS & $6.3 \mathrm{E}-07$ & $1.8 \mathrm{E}-02$ & $1.1 \mathrm{E}-08$ & $1.0 \mathrm{E}-04$ & $7.0 \mathrm{E}-03$ & $7.0 \mathrm{E}-07$ \\
\hline WIPP & NA & $1.8 \mathrm{E}-02$ & NA & $1.0 \mathrm{E}-04$ & $7.0 \mathrm{E}-03$ & $7.0 \mathrm{E}-07$ \\
\hline
\end{tabular}

a Abbreviation: WIPP $=$ Waste Isolation Pilot Plant.

b $\mathrm{NA}=$ not applicable.

\section{F.5 REFERENCES}

Chelapati, C.V., et al., 1972, "Probabilistic Assessment of Aircraft Hazards for Nuclear Power Plants," Nuclear Engineering and Design 19:333-346.

Eisenhut, D.G., 1972, General Aviation Fatal Crash Probability Distribution for Use in Nuclear Reactor Siting, U.S. Atomic Energy Commission, Washington D.C.

Eisenhut, D.G., 1973, "Reactor Siting in the Vicinity of Airfields," in Transactions of the American Nuclear Society 1973 Annual Meeting, American Nuclear Society, La Grange, IIl.

Feizollahi, F., and D. Shropshire, 1992, Waste Management Facilities Cost Information Report, EGG-WTD-10443, EG\&G Idaho, Idaho Falls, Idaho, Oct.

Kot, C.A., et al., 1982, Evaluation of Aircraft Crash Hazards Analyses for Nuclear Power Plants, NUREG/CR-2859, ANL-CT-81-32, U.S. Nuclear Regulatory Commission, Washington, D.C.

U.S. Department of Energy, 1996, Waste Management Programmatic Environmental Impact Statement for Managing Treatment, Storage, and Disposal of Radioactive and Hazardous Waste, DOE/EIS-0200-PF, Office of Environmental Management, Washington, D.C.

U.S. Nuclear Regulatory Commission, 1975, Reactor Safety Study, WASH-1400, Washington, D.C. 
U.S. Nuclear Regulatory Commission, 1981, Standard Review Plan: Aircraft Hazards, Section 3.5.1.6, rev. 2, NUREG-0800, Washington, D.C.

Wall, I.B., 1974, "Probabilistic Assessment of Aircraft Risk for Nuclear Power Plants," Nuclear Safety 15(3):276-284. 
F-32 
$G-1$

APPENDIX G:

MODELING OF EXTERNAL EVENTS 


\section{CONTENTS}

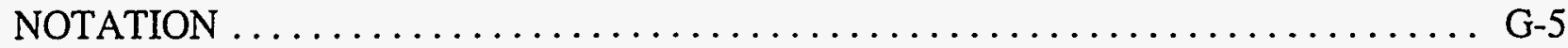

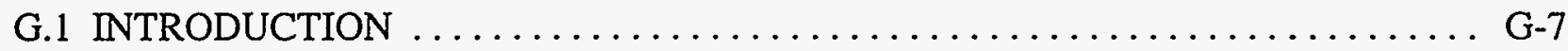

G.2 STORAGE FACILITY ACCIDENTS $\ldots \ldots \ldots \ldots \ldots \ldots \ldots \ldots \ldots \ldots$ G 8

G.2.1 Specification and Frequency Evaluation of Accident Sequences .......... G-8

G.2.2 Evaluation of Source Term Parameters .................... G-16

G.3 TREATMENT FACILITY ACCIDENTS $\ldots \ldots \ldots \ldots \ldots \ldots \ldots \ldots \ldots$ G-17

G.3.1 Specification and Frequency Evaluation of Accident Sequences .......... G-17

G.3.2 Evaluation of Source Term Parameters for Treatment Facilities ......... G-23

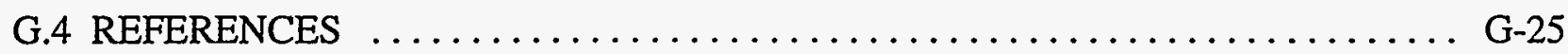

\section{TABLE}

G.1 Approximate Distribution of Incinerator Ash in the Generic Facility . . . . . . . G-24

\section{FIGURES}

G.1 Event Tree for Small-Aircraft Impact on Generic Storage Facility

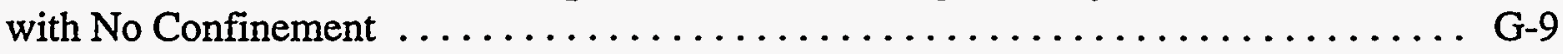

G.2 Event Tree for Large-Aircraft Impact on Generic Storage Facility

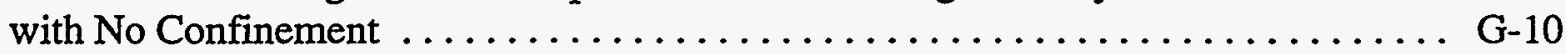

G.3 Event Tree for Seismic Challenge to Generic Storage Facility

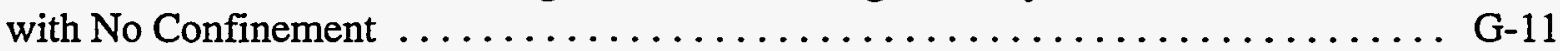

G.4 Event Tree for Small-Aircraft Impact on Generic DOE Hazard

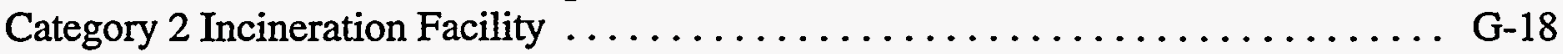

G.5 Event Tree for Large-Aircraft Impact on Generic DOE Hazard

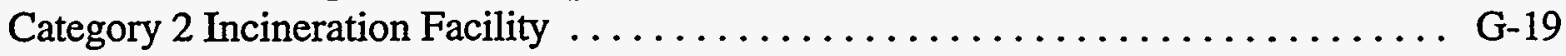

G.6 Event Tree for Seismic Challenge to Generic DOE Hazard Category 2 Incineration Facility 
$G-4$ 


\section{NOTATION}

The following is a list of acronyms, initialisms, and abbreviations (including units of measure) used in this appendix.

\section{ACRONYMS, INITIALISMS, AND ABBREVIATIONS}

CBD integrity of secondary containment

CIF Consolidated Incineration Facility

DET severity of explosion

DF damage fraction

DOE U.S. Department of Energy

EXP occurrence of explosions involving waste

FR occurrence of fire

HEPA high-efficiency particulate air (filter)

HW hazardous waste

LLMW low-level mixed waste

LLW low-level waste

MAR material at risk

PBB integrity of primary containment

PRL pressurized release

PRP propagation to adjacent area

RARF respirable airborne release fraction

SCC secondary combustion chamber

SFR severity of fire

TRUW transuranic waste

WERF Waste Experimental Reduction Facility

\section{UNITS OF MEASURE}

$\begin{array}{ll}\mathrm{h} & \text { hour(s) } \\ \mathrm{kg} & \text { kilogram(s) } \\ \mathrm{lb} & \text { pound(s) }\end{array}$


$G \cdot \sigma$ 


\section{APPENDIX G:}

\section{MODELING OF EXTERNAL EVENTS}

\section{G.1 INTRODUCTION}

This appendix evaluates the frequencies and source terms for the accidents caused by external initiators. External event challenges are important to the human health risk from radiological releases insofar as they have the potential to create major spills, fires, or explosions that can disperse and render airborne radioactive waste materials. Plausible external accident initiators leading to direct fire and explosion scenarios include impacts from military, general aviation, or commercial aircraft; impacts from large trucks carrying fuel or chemicals; and fuel or process chemical fires and explosions in nearby facilities or storage tanks. Natural phenomena such as earthquakes can cause waste spills and natural gas, fuel, or process chemical fires and explosions in nearby facilities. The severity of such phenomena makes mitigation by on-site fire brigades unlikely.

Event trees are used to model the accidents and to project the progression of the accidents through plausible generic sequences. These sequences are developed for aircraft impacts (small and large aircraft are considered separately) and seismic events. The safety impacts of aircraft accidents envelop impacts for other man-made severe external challenges; the damage and safety impacts from seismic events envelop effects from other natural phenomena. These accident initiators and the associated accident sequences are developed for the designs for a generic storage facility and treatment facility as described in Section 2.5 of this document. The event trees presented in this section are generally applicable to low-level mixed waste (LLMW), low-level waste (LLW), and transuranic waste (TRUW); however, the values for conditional failure probability are those for LLW. The appropriate adjustments for the conditional failure probabilities needed to address LLMW and TRUW are discussed in the text or noted on the event trees. A single sequence from the event trees was selected for analysis for hazardous waste (HW). External event results are covered in the sections addressing specific waste types.

The event trees presented in this section are based on accepted probabilistic risk assessment methods and are consistent with methods prescribed by the U.S. Nuclear Regulatory Commission, the American Institute of Chemical Engineers, and the U.S. Department of Energy (DOE). Because the event trees are generic, all of the top (conditional) events that are used for all types of accidents are included in all of the event trees. Top events that are not developed (i.e., no branch exists) are either not applicable or effectively assumed to occur in the sequence (i.e., the conditional failure probability is 1.0). As shown in the event trees, the individual sequences are named, and the associated conditional failure probabilities and damage fractions are also given. A release class that is used for "bookkeeping" in handling the results is also included. The accident sequence column is used to show which conditional failure events (e.g., integrity of secondary containment [CBD1], 
integrity of primary containment [PBB2], etc.) are included in the sequence. The success events are not shown; however, the frequencies of accident sequences include the probabilities of the success branches. The lower (failure) branch generally indicates that the failure or higher consequence of the top event occurs, while the upper (success) branch indicates that the top event does not occur or occurs with lesser consequence.

\section{G.2 STORAGE FACILITY ACCIDENTS}

\section{G.2.1 Specification and Frequency Evaluation of Accident Sequences}

Event trees were developed to structure and facilitate the evaluation of the external event sequences for storage facilities. The first group of sequences considered is shown in Figure G.1, which illustrates the accident progression for the initiation of major fires in storage areas hit by small aircraft. These event trees also apply to impacts from large trucks carrying fuel or chemicals or from propagation of fires or explosions from nearby facilities. Sequences from these initiators would tend to have similar likelihoods of accident progression and lead to similar source term releases.

The second set of sequences is shown in Figure G.2, which illustrates the accident progression for the initiation of major accidents in storage areas hit by large commercial aircraft. The third set of sequences is shown in Figure G.3, which illustrates the accident sequences in storage areas for accidents initiated by seismic events. As discussed in Section 2.3 of the main text, effects from other dominant natural phenomena, like severe winds and tornadoes, can be enveloped by effects depicted for seismic events. The initiating frequencies for external event sequences are site-dependent for natural phenomena. For aircraft impacts, initiating frequencies are both site- and facility-dependent.

As discussed in Section 2.5 of the text of this document, containment systems for generic storage facilities do not conform to any of the standard DOE structural performance goals; consequently, it has been assumed that natural phenomena will have the potential to cause damage and release hazardous materials. Because the same generic design is assumed to be used at all DOE sites and because the frequency of natural phenomena of a particular severity varies from site to site, the frequency of damage from seismic and wind events is site-dependent. The frequency of aircraft impacts is also site-dependent because the frequency is a function of the proximity to general and commercial airways and airports.

The probabilities assigned to the various accident progression branches are a function of (1) the initiating event and its magnitude and corresponding impact on the storage facility and material at risk (MAR) and (2) the sequence of events preceding the branch to be evaluated, and its 


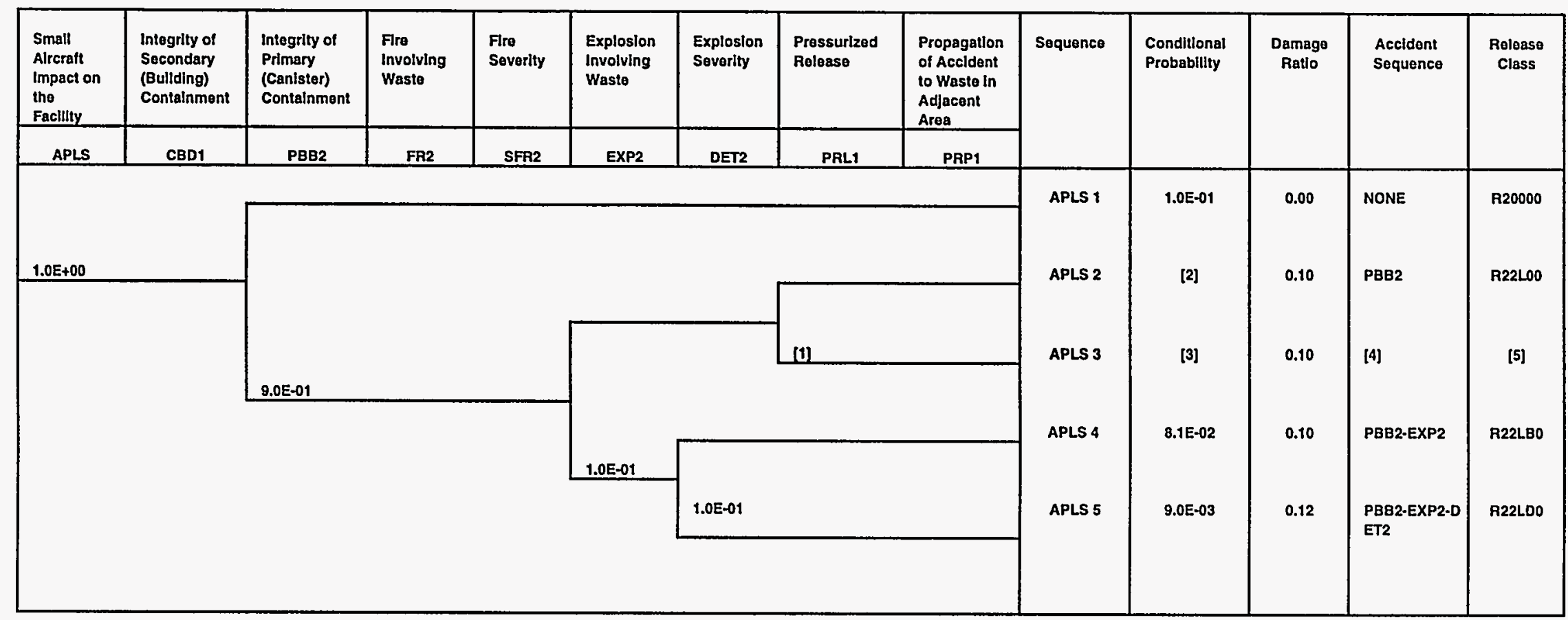

\section{FIGURE G.1 Event Tree for Small-Aircraft Impact on Generic Storage Facility with No Confinement [6]}

[1] Because of the general absence of liquids in storage, the estimated probability of a pressurized release for LLW and TRUW is assumed to be 0. For LLMW, where liquids (many organic-based) are present in general, the likelihood of a pressurized release with a severe fire is estimated to be 0.01 .

[2] The conditional probability depends on waste type.

[3] The conditional probability depends on waste form and does not apply to LLW and TRUW.

[4] This accident sequence does not occur for LLW and TRUW. The sequence is PBB2-PRLI for LLMW.

[5] The release class is only relevant for LLMW and is R22L01.

[6] A single sequence, APLS-2, was used for hazardous waste. 


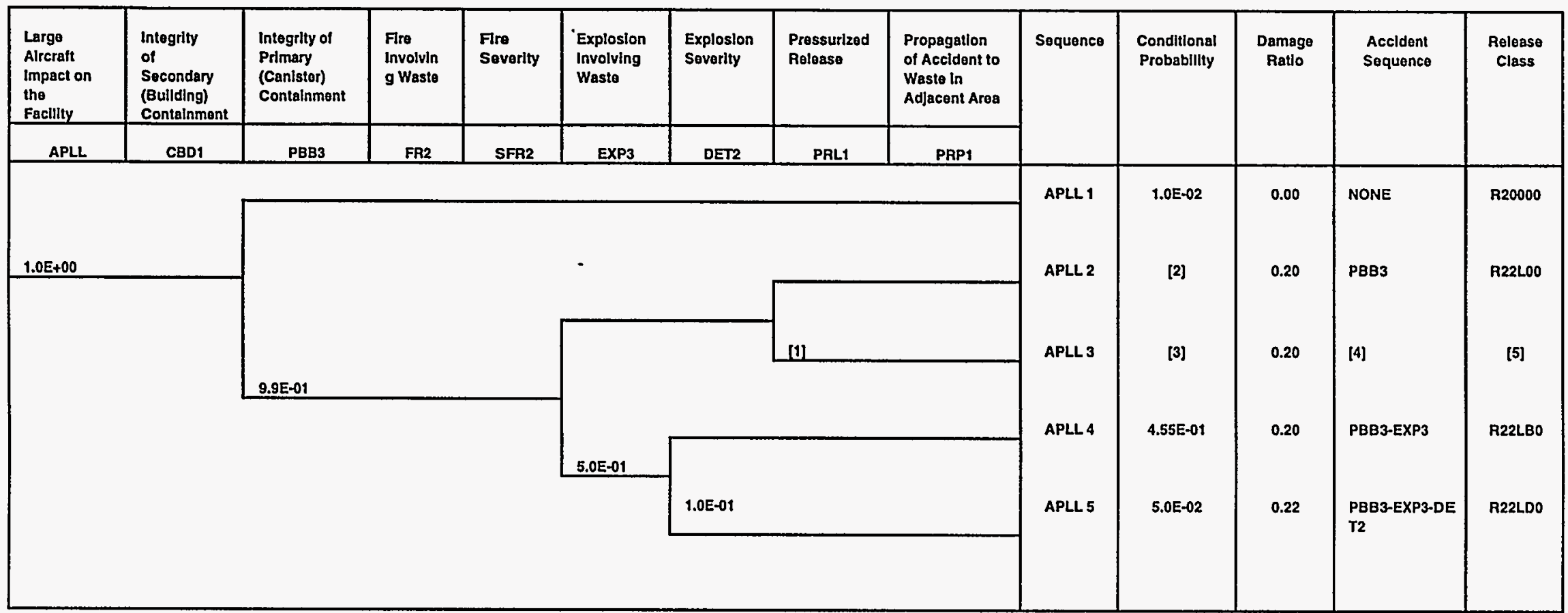

\section{FIGURE G.2 Event Tree for Large-Aircraft Impact on Generic Storage Facility with No Confinement [6]}

[1] Because of the general absence of liquids in storage, the estimated probability of a pressurized release for LLW and TRUW is assumed to be 0 . For LLMW, where liquids (many organic-based) are present in general, the likelihood of a pressurized release with a severe fire is estimated to be 0.01 .

[2] The conditional probability depends on waste type.

[3] The conditional probability depends on waste form and does not apply to LLW and TRUW.

[4] This accident sequence does not occur for LLW and TRUW. The sequence is PBB3-PRL1 for LLMW.

[5] The release class is only relevant for LLMW and is R22L01.

[6] A single sequence, APLL-2, was used for hazardous waste. 


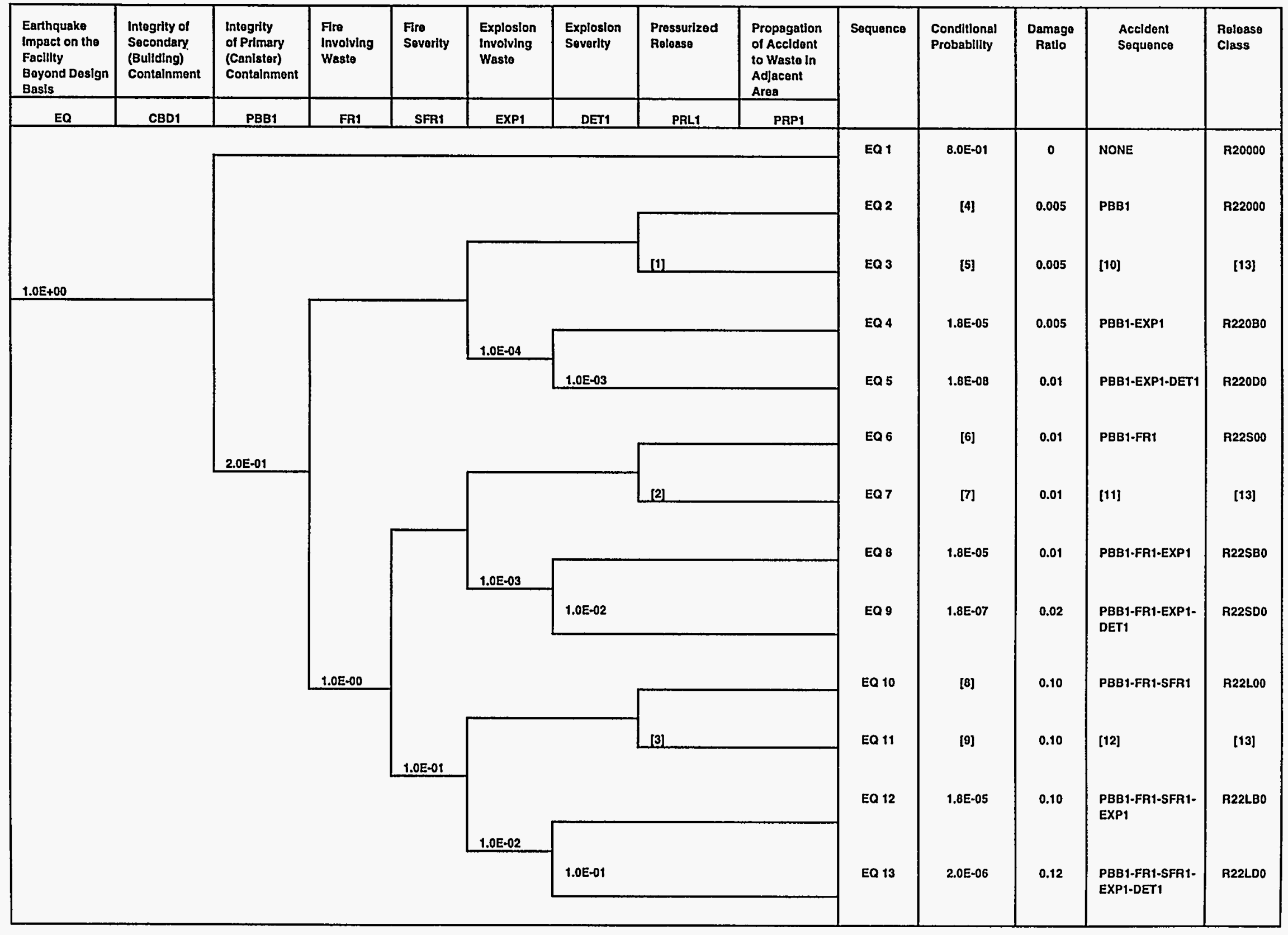

FIGURE G.3 Event Tree for Seismic Challenge to Generic Storage Facility with No Confinement [14]

See next page for footnotes. 
[1] Because of the general absence of liquids in storage, the estimated probability of a pressurized release for LLW and TRUW is assumed to be 0 . For LLMW, where liquids (many organic-based) are present in general, the likelihood of a pressurized release with no fire is estimated at 1.0E-04.

[2] The probability of a pressurized release is 0 for LLW and TRUW because the absence of liquids in storage. For LLMW, the probability is estimated at $1.0 \mathrm{E}-03$ in the presence of a moderate fire.

[3] The probability of a pressurized release is still 0 for LLW and TRUW because of the absence of liquids in storage. For LLMW, the probability is estimated at 0.01 in the presence of a severe fire.

[4] The conditional probability depends on waste type.

[5] The conditional probability depends on waste form and is not applicable to LLW and TRUW.

[6] The conditional probability depends on waste type.

[7] The conditional probability depends on waste type and can range from -0 to $1.8 \mathrm{E}-05$.

[8] The conditional probability depends on waste type.

[9] The conditional probability depends on waste type and can range from 0 to $2.0 \mathrm{E}-05$.

[10] This accident sequence does not occur for LLW and TRUW. The sequence is PBB1-PRL3 for LLMW.

[11] This accident sequence does not occur for LLW and TRUW. The sequence is PBB1-FR1-PRL3 for LLMW.

[12] This accident sequence does not occur for LLW and TRUW. The sequence is PBB 1-FR1-SFR1-PRL3 for LLMW.

[13] The release class is only relevant for LLMW and is R22001 for EQ3, R22S01 for EQ7, and R22L01 for EQ11.

[14] A single sequence, equivalent to EQ-2, is used for hazardous waste. 
expected impact on the facility and MAR. In general, conservative but reasonable assumptions have been made. The probabilities assigned are shown on the event trees and are discussed subsequently.

\section{G.2.1.1 Integrity of Secondary Containment (CBD)}

Storage facilities have been assumed to lack formal containment; the implied probability of the failure of the secondary confinement is 1.0 for all three types of external event initiators.

\section{G.2.1.2 Integrity of Primary Containment (PBB)}

For events caused by natural phenomena, it has been assumed that drums drop to the floor, either because of the direct impact of the initiator or because of the impact of structural elements falling on the drums. While the actual probability would strongly depend on the storage array and the details of the structure, it has been assumed that, on average, the probability that drums fall to the floor and leak is 0.1 and the probability that structural elements or projectiles puncture one or more drums is 0.1 . Thus, the conditional probability assigned is 0.2 . For aircraft impacts or nearby explosions, the likelihood of drum breach is very high. It has been assumed that the likelihood is 0.9 for small aircraft (very likely) and 0.99 for large aircraft (almost certain).

\section{G.2.1.3 Occurrence of Fire (FR)}

For aircraft-crash external events, fires have been assumed to occur. For earthquakes, the conditional probability for the occurrence of a sustained fire in a storage facility is obviously a function of the content of the waste containers and the physical characteristics of the facility. Containers of TRUW already under pressure from gas buildup would have a finite probability of spontaneous ignition under shock from impact or crushing events associated with seismic shaking. For LLMW and LLW containers, for which such mechanistic forces are hard to identify, the probability would be much less. Similarly, unless the affected waste is combustible, the ability of a fire to sustain itself in the absence of a combustible source is hard to rationalize.

Important facility characteristics include the presence of (1) natural-gas or chemical process piping that could be sheared during the seismic event; (2) fuel or chemical process storage tanks that could be ignited and are located in or near the storage facility; (3) vehicles with fuel tanks that could be ignited under crush or impact. In the absence of site-specific information, the following assumptions were used to generically assess the likelihood of fires in storage facilities. Facilities storing combustibles in packaged containers or drums were assigned a minimum probability of 0.1 of having a fire initiated by seismic shaking. General purpose buildings used for storage of combustibles were assigned a minimum probability of 0.2 for fires to account for the greater 
likelihood of coherent sources of combustible materials in the facility. For storage pads or general purpose buildings storing noncombustibles, the minimum probabilities of fire were reduced by a factor of 10 to 0.01 and 0.02 , respectively. For aircraft crashes, with the additional source for fuel, a fire was assumed to occur.

\section{G.2.1.4 Severity of Fire (SFR)}

Fire resistant packaging is used for combustibles of all types. Thus, for a severe fire to sustain itself, large sources of fuel from within or nearby, (e.g., large fuel tanks or chemical process tanks) are required. To account for this possibility, the conservative assumption was made that a minimum of $10 \%$ of the sustained fire sequences in storage facilities storing combustibles would involve severe fire that would challenge the entire facility after an earthquake. All sustained fires in facilities storing noncombustibles were assumed to arise from ignition of external fuel or chemical sources, and thus the conditional probability that the fire was severe was conservatively assumed to be 1.0 for aircraft crashes.

\section{G.2.1.5 Occurrence of Explosions Involving Waste (EXP)}

The event trees for natural phenomena show the occurrence of an explosion in the absence of a fire, in the presence of a small fire, and in the presence of a severe fire. The conditional probabilities have been assigned as a function of these three situations, assuming that the higher the stresses (presence and severity of a fire), the higher the probability of inducing an explosion in the waste containers. Almost no information exists on the probability of induced explosions in storage facilities. In storage of $\mathrm{HW}$, an estimated $2 \%$ chance that a large fire will induce a large explosion has been reported (EG\&G 1990). In LLW storage, where a large fraction of the waste may be noncombustible, the probability would be expected to be lower. A value of 0.01 in the presence of a severe fire has been conservatively assigned. In the presence of small fires, the value is reduced by an order of magnitude; for no fires, the number is reduced by a factor of 100 . The situation changes for aircraft or fuel truck impacts, where a large fire is assumed to take place and where the incoming vehicle adds fuel materials that are likely to increase the probability of explosions. A value of 0.1 is used for small aircraft and 0.5 for large aircraft, to account for the possibility that the explosion will occur in the fuel tanks of the airplane.

\section{G.2.1.6 Severity of Explosion (DET)}

The severity of the explosion refers to the differentiation between a deflagration or a detonation. Unfortunately, no generic or facility-specific information has been found to assess the likelihood of a detonation given that an explosion has occurred. A detonation is thought to be more 
capable of dispersing material than a deflagration. The expectation is that the likelihood of a detonation will be a function of the material involved in the explosion and the type of container in use. While differentiation of these two characteristics is beyond the scope of a generic analysis for an environmental impact statement, the selection of the explosion severity affects the respirable airborne release fraction (RARF) for the accident. It has been assumed that the probability of a detonation depends on the severity of the accident leading to the explosion, and 1 in 10 explosions is likely to be a detonation in the presence of a large fire. The likelihood is decreased by one and two orders of magnitude for small fires and for no fires, respectively; both of these situations appear for natural phenomena.

\section{G.2.1.7 Pressurized Release (PRL)}

Pressurized releases apply only to liquids that can be vaporized and released in vapor or aerosol form from their containers. For solid waste, an accident stress from impact is analogous to the liquid pressurized release. The inventory data for LLW and TRUW storage and generation indicated that liquid LLW and TRUW are rarely found in storage facilities. Liquid LLW was only a very small fraction of the total $L L W$ sent to storage areas. In the very few places where the amount of liquid LLW in long-term storage was significant, it amounted to no more than $10 \%$ of the total LLW in volume and less than $30 \%$ in radioactivity. Pressurized release in LLW and TRUW was assigned a probability of 0 .

For LLMW, a large fraction of the volume in storage is in liquid form, with many waste streams containing organic liquids. For LLMW, therefore, pressurized releases are possible. Because the likelihood of the pressurized release will depend on the heat stress applied to the waste container, the probability of pressurized release is proportional to the accident stress. In the absence of a fire, the probability is considered very unlikely; a value of 1.0E-04 has been assigned. In the presence of a fire, the probability is higher $-1.0 \mathrm{E}-03$ for small fires and $1.0 \mathrm{E}-02$ for severe fires.

For HW, where liquid wastes (often organic liquids) are the norm, pressurized releases have been included in the scenarios identified (miscellaneous accidents that include container pressurization caused by loading errors; see Section 8 of main text). The pressurized releases for $\mathrm{HW}$ are therefore limited to the handling accidents. For external events, a single sequence for source term characterization has been chosen for each initiator (namely a fire after aircraft crashes and a spill after an earthquake); pressurized releases have not been included.

\section{G.2.1.8 Propagation to Adjacent Area (PRP)}

For a generic storage facility, no decisions on the number of pads and the distance between the pads will be made. Therefore, the assumptions are that all of the waste is stored in the same pad 
and that propagation is irrelevant. The amount of material affected is accounted for by the selection of the MAR, and the event tree parameters (damage ratio, release class) apply to the entire facility MAR.

\section{G.2.2 Evaluation of Source Term Parameters}

The storage source term calculation for TRUW, LLW, and LLMW have been performed on the basis of a generic unit inventory of $2,000 \mathrm{~m}^{3}$ (10,000 55-gal drums equivalent). The facilitywide accidents will therefore be based on the unit inventory. To address the variability in storage capacity different sites, a set of scaling factors were developed (see Section 2, and Table 2.4 in particular, for the development of the scaling factors). A scaling factor has been estimated for each major site in TRUW (Table 4.2), LLW (Table 5.2) and LLMW (Table 6.3). The unit size source term estimated in the storage facility-wide accidents is scaled with the appropriate site scaling factor before health effects consequences are estimated.

For outdoor pads or weather protection facilities, the MAR is essentially the inventory at the pad. The damage fractions (DFs) are a function of the accident sequence, with greater stresses resulting in higher DFs. Severe fire sequences would be likely to involve all of the packages; the DF would then be influenced by the frequency of package breach and the combustibility of the waste product. Explosions would be expected to cause drum or package breach but would tend to disperse the packages. These factors would have conflicting impacts on DFs. The RARFs are a function of the accident sequences and the physical form of the waste and are discussed in Appendix D. The estimated DFs for the various sequences are summarized on the event trees. The justification for the numbers used is provided in the following paragraphs.

\section{G.2.2.1 Seismic Events}

For sequences with only mechanical stresses, it has been assumed that $10 \%$ of the drums may fall or be impacted by structural elements (the actual value would strongly depend on the storage configuration and the severity of the accident stress). For containers that are dropped or impacted, it has been assumed that $10 \%$ will be breached and that on average, $50 \%$ of the contents of breached drums will be spilled. Thus, the DF is 0.005 . For sequences with an explosion (in the absence of a fire), it has been assumed that containers near those that have ruptured can also be breached if the explosion is severe enough. Thus, the DF was increased to 0.01 for detonation sequences without a fire. If a small fire occurs, adjacent containers can also be affected; thus, the damage fraction was increased to 0.01 . If, in addition to the small fire, a detonation occurs, additional nearby containers are assumed to be breached; the damage fraction was increased to 0.02 . For sequences with large fires, a significant number of containers are likely to be involved. The damage fraction assigned is 0.1 (and 0.12 if a detonation also occurs). 


\section{G.2.2.2 Small Aircraft}

The relevant sequences involve severe fires, which have been assumed to involve a significant fraction $(0.1)$ of the facility. If a detonation occurs, an additional $2 \%$ of the waste containers have been assumed to be breached, for a total damage ratio of 0.12 .

\section{G.2.2.3 Large Aircraft}

Because of the possible large amount of fuel provided by the aircraft, a larger fraction of the facility has been assumed to be affected by the severe fire. The damage fraction is estimated to be 0.2 . As with the other initiators, an additional $2 \%$ of containers have been assumed to be affected by a detonation.

\section{G.3 TREATMENT FACILITY ACCIDENTS}

\section{G.3.1 Specification and Frequency Evaluation of Accident Sequences}

Event trees were developed to structure and facilitate the evaluation of the external event sequences for incineration facilities. As for storage facilities, the first set of sequences (Figure G.4) corresponds to accident sequences initiated by impacts with small aircraft. Impacts caused by large aircraft result in the sequences shown in Figure G.5. Seismic event sequences are shown in Figure G.6 and are assumed to envelop the risk of sequences from other natural phenomena.

As discussed in Section 2.5 of this report, all incineration facilities have been assumed to meet the requirements of a Hazard Category 2 facility and to have the same performance goal (i.e., same building and equipment response to a natural phenomena) and exceedance frequency for external events, independent of the site. Thus, the initiating event frequency used for natural phenomena will be independent of the sites; however, the natural phenomenon severity for which the facility will be designed will be site-dependent. The frequency of aircraft impacts is sitedependent. The probabilities assigned to the various accident progression branches are a function of the initiating event and the sequence of events preceding the branches to be evaluated. The probabilities assigned are summarized on the event trees. The rationale for these values is given in the following paragraphs. 


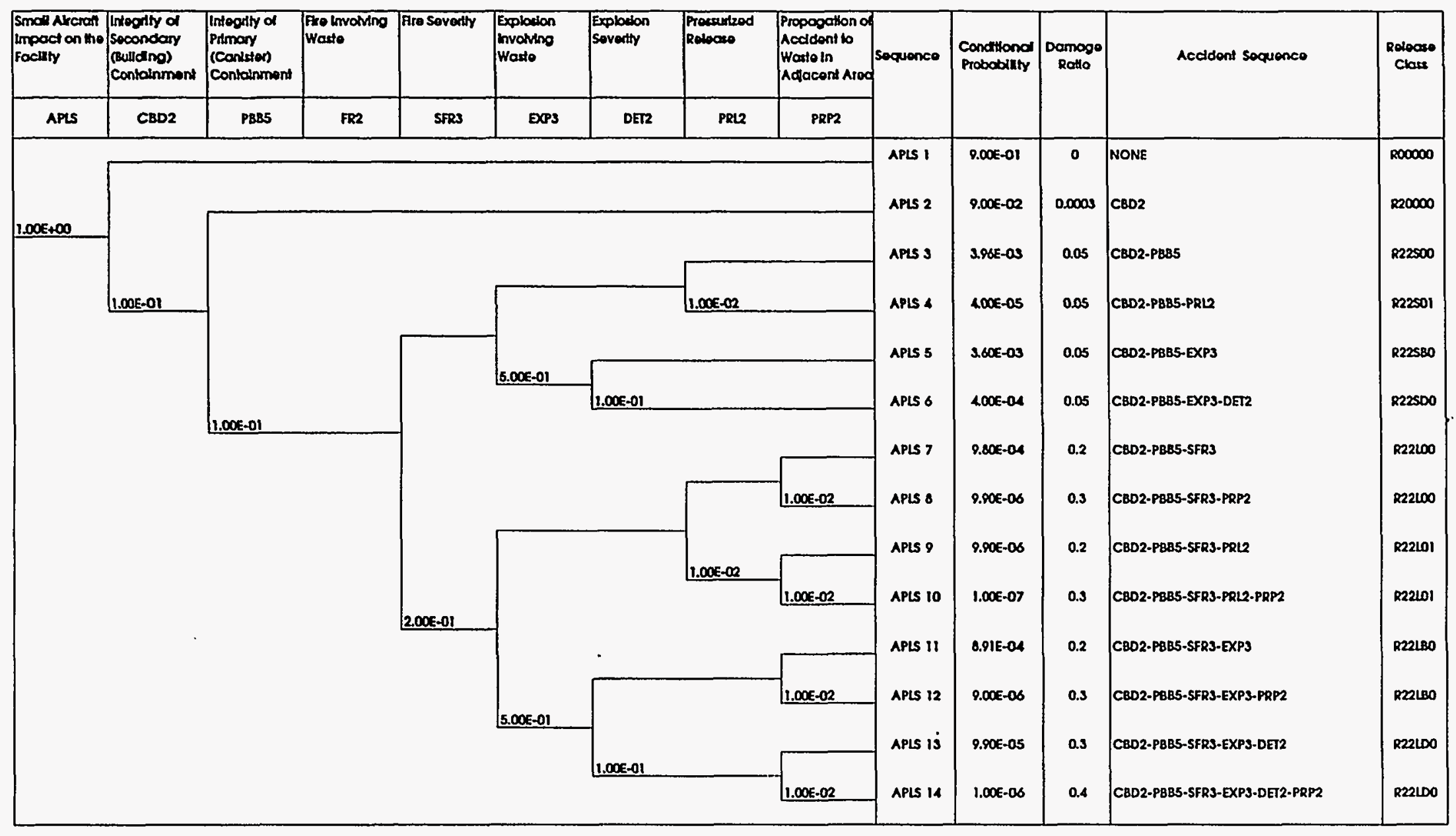

FIGURE G.4 Event Tree for Small-Aircraft Impact on Generic DOE Hazard Category 2 Incineration Facility 


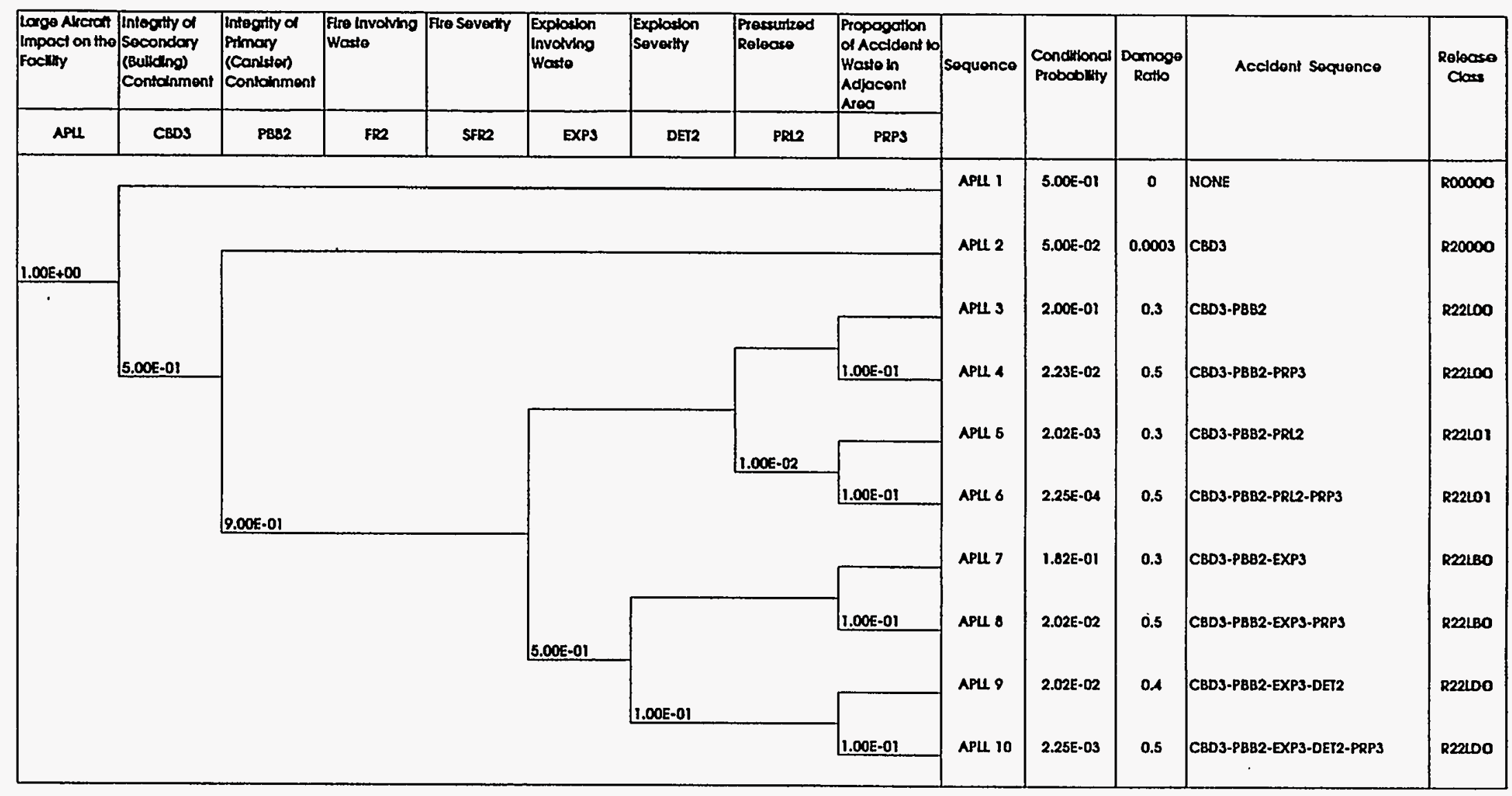

FIGURE G.5 Event Tree for Large-Aircraft Impact on Generic DOE Hazard Category 2 Incineration Facility 


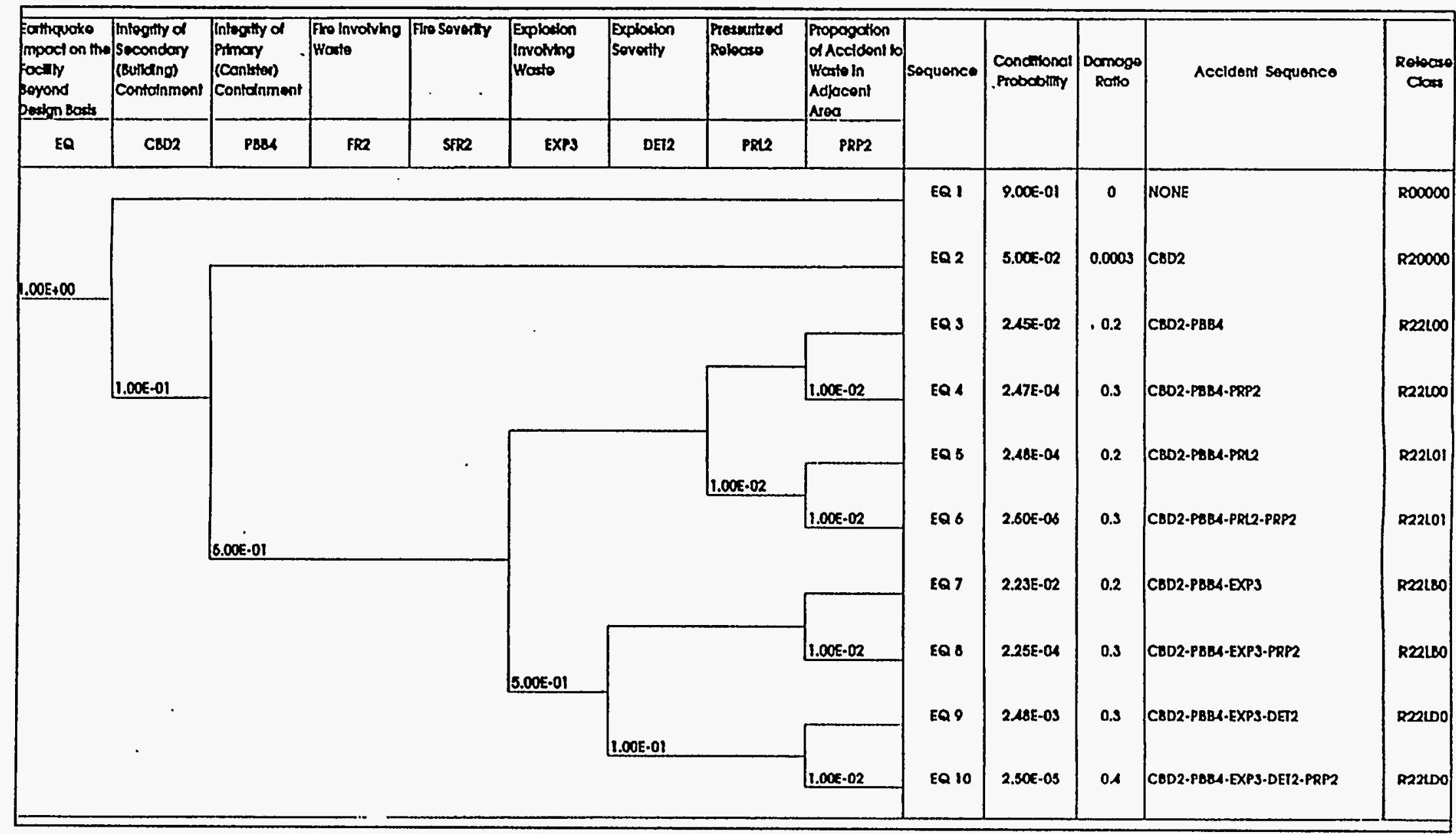

FIGURE G.6 Event Tree for Seismic Challenge to Generic DOE Hazard Category 2 Incineration Facility 


\section{G.3.1.1 Integrity of Secondary Containment (CBD)}

The performance goal (i.e., the annual probability of exceedance of facility damage as a result of a natural phenomena event) is a function of the annual probability of the exceedance of the event and the safety factors included in the facility design. For the incineration facility, which is assumed to be a Hazard Category 2 facility, the conditional probability of containment failure under natural phenomena has been assigned such that, when multiplied by the recommended design-basis frequency from Kennedy et al. (1990), the performance goal is met. For seismic events, the frequency is $1.0 \mathrm{E}-03 / \mathrm{yr}$ and the performance goal is $1.0 \mathrm{E}-04 / \mathrm{yr}$. Therefore, a conditional probability of 0.1 is used for seismic events. It has been assumed that the stresses on the structure caused by small-aircraft impacts are similar to those of natural phenomena and the same value of 0.1 has been used for the failure of the confinement. The probability of containment breach in this case is expected to be dominated by the massive airplane parts (mostly the engines) because lighter aircraft components may or may not penetrate the building (in general, the reinforced concrete walls of a Hazard Category 2 facility will protect the facility from projectiles and fuel fires, except for a direct crash onto the roof); however, for large aircraft, the likelihood of containment breach is assumed to be higher, and a conditional probability of 0.5 has been assigned.

\section{G.3.1.2 Integrity of Primary Containment (PDB)}

The major pieces of equipment (which form the primary containment) in this facility are the rotary kiln and the secondary combustion chamber. It has been assumed that these components will be designed to the same performance goals as the facility. Because the failure of the equipment is evaluated for the case of containment breach, as indicated by the event tree, the probability of equipment failure for the same seismic design goals, knowing that the containment building has failed, will be expected to be higher than the independent equipment failure probability. A value of 0.5 was used for the primary containment failure under seismic conditions; a probability of 0.1 was used for small-aircraft impacts; for large aircraft, a high probability of primary rupture (0.9) was used under the situation of a breached building.

\section{G.3.1.3 Occurrence of Fire (FR)}

All three types of initiating events were assumed to result in fires.

\section{G.3.1.4 Severity of Fire (SFR)}

The large aircraft and seismic initiating events were assumed to result in severe fires. For small aircraft, only one in five fires was assumed to be severe. 


\section{G.3.1.5 Occurrence of Explosions Involving Waste (EXP)}

Little or no information exists on external events inducing explosions in an incineration facility; however, an accident involving explosion of a kiln or secondary combustion chamber (SCC) is considered possible in this type of facility. Incinerators were assumed to have fuel supplies to aid in the combustion of some waste. The same conditional probability $(0.5)$ was assigned for all accident initiators and branches.

\section{G.3.1.6 Severity of Explosion (DET)}

The severity of the explosion refers to the differentiation between a deflagration and a detonation; the shock waves associated with detonation are capable of dispersing material beyond those of a deflagration. While no generic or facility-specific information exists to precisely quantify their relative frequencies, the likelihood of a detonation will be much smaller, given the absence of material associated with known detonations for all plausible initiators. Accordingly, the value of 0.1 was assigned as the conditional probability of a detonation, given that an explosion occurs.

\section{G.3.1.7 Pressurized Release (PRL)}

The percentage of liquid waste in the incineration facility is likely to be smaller than the $10 \%$ assumed for some storage facilities, although some aqueous liquids occur as incineration residues from off-gas treatment. In the absence of specific information on facility designs, it was assumed that these liquid residues are collected and can be released in a pressurized manner. The probability is estimated as the same order of magnitude as for a release of LLMW in the presence of fire for storage facilities. The value of 0.01 applies for all initiators.

\section{G.3.1.8 Propagation to Next Area (PRP)}

The propagation event in the incineration facility represents the spread of the accident from the incineration rooms to the areas where the front-end storage or the off-gas and ash treatment take place. Propagation takes place only with a severe fire; the fire-suppression systems, fire brigades, and fire barriers must fail for the propagation to take place. The combined failure probability of all of these actions or systems would be expected to be on the order of the facility's performance goal $(1.0 \mathrm{E}-04)$ or lower if one considered their failure to be independent. However, under external accident conditions, the failure probability must be higher because of the assumed loss of integrity for the facility. The combined failure probability was assumed to be 0.01 for natural phenomena and small-aircraft impacts and 0.1 for large-aircraft impacts. 


\section{G.3.2 Evaluation of Source Term Parameters for Treatment Facilities}

Information on incineration facilities (i.e., the consolidated Incineration Facility [CIF] [DuPont 1987], a conceptual facility [Feizollahi and Shropshire 1992c], and the Waste Experimental Reduction Facility [WERF] [EG\&G 1992]) was reviewed; each document provided part of the required data for the accident analysis. As discussed in Section 2.5 of this report, the incineration facilities considered here have the following general areas: the receiving, storage, and feed area; the rotary kiln; the off-gas SCC; the off-gas treatment area; the liquid treatment area; the solidification area; and the high-efficiency particulate air (HEPA) filtration systems. The receiving, storage, and feed area contains waste in various (but mostly solid) physical forms. The liquid treatment area contains the liquid residue generated in the incineration process. The solidification system consists of mixing the ash resulting from the incineration with a solidification agent, such as concrete, for immobilization. Radioactive waste in the other areas is in the form of ash. Although wet ash is found in all CIF ash areas except the two combustion chambers, dry ashes are apparently found in the other facilities and are assumed for source term development here.

To simplify the source term evaluation for radioactive waste, the ash in the facility was used to derive ratio estimates for the MAR, DF, and RARF. The material in the storage area and in the liquid and solidification treatment areas was considered for chemical waste (LLMW and HW), but can be neglected for radiological releases because incineration ashes are in the most dispersible (i.e., particulate) form and also contain the highest concentration of radionuclides. The storage area, which tends to be separated from the rest of the facility, contains only a small number of drums compared with the on-site storage facilities. The MAR in the liquid streams (of small volume) and solidified product is expected to be in a significantly less releasable form than the ash.

The radiological MAR (i.e., the ash) is located in four major areas in the facility: primary incinerator (kiln and ash-out zone); SCC; off-gas treatment areas; and HEPA filtration system area. The total amount of ash in the facility will, in general, be a function of the process rate of the facility, depending on the DOE site and EM PEIS alternative. The only information relating the process rate to the ash inventory is provided in the CIF documentation (DuPont 1987). The average process rate for LLW solids in the facility is about $330 \mathrm{~kg} / \mathrm{h}(720 \mathrm{lb} / \mathrm{h})$, and the total (solids and liquids) averages about $450 \mathrm{~kg} / \mathrm{h}(1,000 \mathrm{lb} / \mathrm{h})$. The total amount of ash in the CIF facility is about $1,600 \mathrm{~kg}(3,500 \mathrm{lb})$, excluding the ashcrete (solidified form) and particulates in the liquid storage tanks.

To determine the locations of the MAR, information from the CIF and other incineration facilities in the design phase was used. The approximate average distribution of the incinerator ash in the generic facility is as shown in Table G.1.

For radiological releases, the DFs were estimated as follows. For all accident sequences with only mechanical breach of the secondary confinement (but no breach of primary confinement), it was assumed that flow disturbances affect only the filtration system and that $1 \%$ of the material 
TABLE G.1 Approximate Distribution of Incinerator Ash in the Generic Facility

\begin{tabular}{lc}
\hline \multicolumn{1}{c}{ Location } & $\begin{array}{c}\text { Fraction of Total } \\
\text { Ash Inventory } \\
\text { of Facility }\end{array}$ \\
\hline Kiln & 0.12 \\
Ash-out area & 0.36 \\
Total of kiln and ash-out & 0.48 \\
$\quad$ area & \\
SCC & 0.12 \\
Off-gas treatment area & 0.37 \\
Total of SCC and off-gas & 0.49 \\
$\quad$ treatment area & \\
HEPA filtration system & 0.03 \\
Total of HEPA & 0.03 \\
$\quad$ filtration system & \\
\hline
\end{tabular}

in the filters is spilled, for a DF (of the total facility ash inventory) of 3.0E-04. In sequences involving small fires (small-aircraft crashes only), the area containing the highest fraction (0.49) of ashes (i.e., the off-gas treatment area) was assumed to be affected. Because Hazard Category 2 facilities are expected to have fire-suppression systems, $10 \%$ of the material in this area was assumed to be involved, resulting in a DF of 0.05 . Small-fire sequences involving explosions or pressurized releases were also assumed to be bounded by a DF of 0.05 .

Severe fires for all sequences have been assumed to start in the rotary kiln area because of the presence of fuel. For natural phenomena and small-aircraft crashes, the severe fire is generally confined to this area, with low-probability propagation sequences accounting for the fire spreading to the off-gas treatment area. The DFs were estimated by assuming that $50 \%$ of the material in the kiln area (48\% of the facility ash inventory) is affected, for a DF of 0.24 . In fire-propagation sequences, $50 \%$ of the material in the SCC (12\% of facility ash) and $10 \%$ of the material in the offgas treatment equipment (10\% of facility ash) was added to the damaged material, for an estimated DF of 0.34 . For sequences involving detonation explosions, the ash in the HEPA filters (3\% facility ash) was added, resulting in analogous DFs of 0.27 and 0.37 .

For large-aircraft impacts, the initial severe fire (fed with additional fuel) was assumed to engulf the kiln and off-gas treatment areas and to involve $50 \%$ of the material in the kiln area and the SCC and $10 \%$ of the off-gas treatment equipment ash contents (DF of 0.34 ). With propagation, up to $50 \%$ of the off-gas treatment material will be involved, with a total DF of 0.48 . For explosion 
sequences involving detonations, the ash in the HEPA filters was added, resulting in analogous DFs of 0.37 and 0.51 .

For chemical source terms, the material in the feedstock area was assumed to be involved. On the basis of information from commercial incineration facilities, it was assumed that there would be three times the daily processing rate for the MAR. A DF of 0.2 has been assigned for seismic events and small-aircraft impacts and a DF of 0.3 for large-aircraft impacts.

\section{G.4 REFERENCES}

EG\&G, 1990, Safety Analysis Report for the Hazardous Waste Storage Facility, EG\&G-WM-PD-88-014, rev. 1, EG\&G Idaho, Inc., Idaho Falls, Idaho, Nov.

EG\&G, 1992, Draft Environmental Assessment: Idaho National Laboratory Low-Level and Mixed Waste Processing, EG\&G Idaho, Inc., Idaho Falls, Idaho, Dec.

E.I. Du Pont de Nemours \& Co., 1987, Safety Assessment Document: Consolidated Incineration Facility, approved draft, DPSTAD-200-6, Savannah River Laboratory, Aiken, S.C., Oct.

Feizollahi, F., and D. Shropshire, 1992, Waste Management Facilities Cost Information (WMFCI) Report, EGG-WID-10433, draft, EG\&G Idaho, Inc., Idaho Falls, Idaho.

Kennedy, R.P., et. al., 1990, Design and Evaluation Guidelines for Department of Energy Facilities Subjected to Natural Phenomena Hazards, UCRL-15910, Lawrence Livermore National Laboratory, Livermore, Calif. 


$$
\text { G-26 }
$$




\section{APPENDIX H:}

REFERENCE DATA ON AIRBORNE RELEASES FOR ACCIDENTS INVOLVING HAZARDOUS CHEMICALS 
H-2 


\section{CONTENTS}

NOTATION

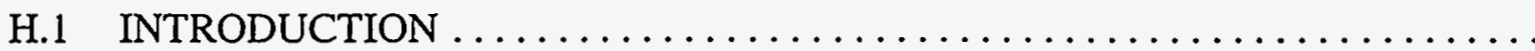

H.2 HANDLING ACCIDENT IN WHICH AQUEOUS AMMONIA

IS SPILLED

H.3 HANDLING ACCIDENT IN WHICH HYDROCHLORIC ACID

IS SPILLED

H.4 HANDLING ACCIDENT IN WHICH AQUEOUS HYDROGEN

FLUORIDE IS SPILLED

H.5 HANDLING ACCIDENT IN WHICH NITRIC ACID IS SPLLED $\ldots \ldots \ldots \ldots$ H-10

H.6 HANDLING ACCIDENT IN WHICH AN AROMATIC HYDROCARBON SPILLS AND BURNS

H.7 HANDLING ACCIDENT IN WHICH A FLAMMABLE LIQUID SPILLS, IGNITES, AND BURNS, CAUSING THE RUPTURE OF OTHER CONTAINERS

H.8 HANDLING ACCIDENT IN WHICH A FLAMMABLE LIQUID SPILLS AND IGNITES; THE FIRE ENGULFS NEARBY DRUMS AND INITIATES REACTIONS THAT RELEASE HIGHLY TOXIC VAPORS $\mathrm{H}-13$

H.9 LARGER ACCIDENT IN WHICH A FLAMMABLE LIQUID SPLLLS AND IGNITES; THE FIRE ENGULFS NEARBY DRUMS AND INITIATES REACTIONS THAT RELEASE TOXIC VAPORS

H.10 HEAT FROM THE FIRE CAUSES AN EXPLOSION IN A COMPRESSED GAS CONTAINER, RESULTING IN VENTING OF A TOXIC GAS . ........ H-14

H.11 ACCIDENTAL CO-CONFINEMENT OF OXIDIZING AND REDUCING AGENTS, LEADING TO A REACTION GENERATING HEAT THAT IGNITES PACKAGING AND BREACHES A NEARBY DRUM 
H.12 ACCIDENTAL CONFINEMENT OF WATER WITH ALKALI METALS, ALKALI-METAL HYDRIDES, OR ALKALINE-EARTH OXIDES, GIVING REACTIONS GENERATING HEAT, IGNITING PACKAGING, AND BREACHING NEARBY DRUMS $\ldots \ldots \ldots \ldots \ldots \ldots \ldots \ldots \ldots \ldots \ldots \ldots \ldots \ldots \ldots$

H.13 ACCIDENTAL RUPTURE OF COMPRESSED GAS DUE TO VALVE FAILURE, RESULTING IN RELEASES OF TOXIC GAS $\ldots \ldots \ldots \ldots \ldots \ldots \mathrm{H}-16$

H.14 EXPLOSION OF A STORED CHEMICAL $\ldots \ldots \ldots \ldots \ldots \ldots \ldots \ldots \ldots$ H-16

H.15 HANDLING ACCIDENTS IN WHICH A SPILLED WASTE RELEASES A MUTAGENIC, TERATOGENIC, OR CARCINOGENIC SUBSTANCE $\mathrm{H}-17$

H.16 HANDLING ACCIDENT SPILL THAT IGNITES FLAMMABLE LIQUIDS, THEREBY BREACHING NEARBY DRUMS WITH CADMIUM-CONTAINING COMPOUNDS $\mathrm{H}-17$

H.17 HANDLING ACCIDENT SPILL THAT IGNITES FLAMMABLE LIQUID; THE FIRE BREACHES NEARBY DRUMS CONTAINING DICHROMATE SALTS $\mathrm{H}-18$ 


\section{NOTATION}

The following is a list of acronyms, initialisms, and abbreviations (including units of measure) used in this appendix.

\section{ACRONYMS, INITIALISMS, AND ABBREVIATIONS}

$\begin{array}{ll}a q & \text { aqueous } \\ \text { bp } & \text { boiling point } \\ \mathrm{C}_{2} \mathrm{H}_{5}-\mathrm{O}-\mathrm{C}_{2} \mathrm{H}_{5} & \text { diethyl ether } \\ \mathrm{C}_{3} \mathrm{H}_{6} \mathrm{O} & \text { acetone } \\ \mathrm{C}_{6} \mathrm{H}_{10} \mathrm{O}_{5} & \text { cellulose monomer unit } \\ \mathrm{C}_{6} \mathrm{H}_{6} & \text { benzene } \\ \mathrm{C}_{8} \mathrm{H}_{18} & \text { octane } \\ \mathrm{Ca}(\mathrm{ClO})_{2} & \text { calcium hypochlorite } \\ \mathrm{Ca}(\mathrm{OH})_{2} & \text { calcium hydroxide } \\ \mathrm{C}_{20} \mathrm{H}_{12} & \text { benzo[a]pyrene } \\ \mathrm{CaO} & \text { quicklime } \\ \mathrm{Cd} & \text { cadmium } \\ \mathrm{CH} \mathrm{COOH}_{3} \mathrm{CO} & \text { glacial acetic acid } \\ \mathrm{Cl} \mathrm{C}_{3} \mathrm{C}-\mathrm{CH}_{3} & \text { 1,1,1-trichloroethane } \\ \mathrm{CO} & \text { carbon dioxide } \\ \mathrm{Cs} & \text { cesium } \\ \mathrm{CS} & \text { carbon disulfide } \\ \mathrm{DOE} & \text { U.S. Department of Energy } \\ g & \text { gas } \\ \mathrm{H}_{2} & \text { hydrogen } \\ \mathrm{H}_{2} \mathrm{O} & \text { water } \\ \mathrm{H}_{2} \mathrm{SO}{ }_{4} & \text { sulfuric acid } \\ \mathrm{HBr} & \text { hydrobromic acid } \\ \mathrm{HCl}(a q) & \text { hydrochloric acid } \\ \mathrm{HCl}(g) & \text { hydrogen chloride } \\ \mathrm{HCN} & \text { hydrogen cyanide } \\ \mathrm{HF} & \text { hydrofluoric acid } \\ \mathrm{Hg} & \text { mercury } \\ \mathrm{HI} & \text { hydroiodic acid } \\ \mathrm{HNO} & \text { nitric acid } \\ \mathrm{HWSF} & \text { hazardous waste storage facility } \\ \mathrm{K} & \text { potassium } \\ \mathrm{K}_{2} \mathrm{Cr} \mathrm{O}_{2} & \text { potassium dichromate } \\ \mathrm{K}_{2} \mathrm{O} & \text { potassium oxide } \\ \mathrm{KCN} & \text { potassium cyanide } \\ \mathrm{KMnO} & \text { potassium permanganate } \\ \mathrm{KOH} & \text { potassium hydroxide } \\ & \end{array}$




$\begin{array}{ll}l & \text { liquid } \\ \mathrm{Li} & \text { lithium } \\ \mathrm{MH} & \text { metal hydride } \\ \mathrm{MOnO}_{2} & \text { manganese (IV) oxide } \\ \mathrm{N}_{2} & \text { nitrogen } \\ \mathrm{N}_{2} \mathrm{O} & \text { nitrous oxide } \\ \mathrm{Na} & \text { sodium } \\ \mathrm{Na}_{2} \mathrm{SO}_{4} & \text { sodium sulfate } \\ \mathrm{NaCn} & \text { sodium cyanide } \\ \mathrm{NH}_{3}(a q) & \text { ammonia - in water } \\ \mathrm{NH}_{3}(g) & \text { ammonia - gas } \\ \mathrm{NH}_{4} & \text { ammonium ion } \\ \mathrm{NO} & \text { nitric oxide } \\ \mathrm{NO}_{2} & \text { nitrogen dioxide } \\ \mathrm{NO}_{\mathrm{x}} & \text { mixed oxides of nitrogen } \\ \mathrm{PAH} & \text { polycyclic aromatic hydrocarbon } \\ \mathrm{Rb}_{\mathrm{RCRA}} & \text { rubidium } \\ \mathrm{RC} & \text { Resource Conservation and Recovery Act } \\ \Delta H^{\circ} & \text { solid } \\ & \text { standard change in enthalpy }\end{array}$

\section{UNITS OF MEASURE}

$\begin{array}{ll}{ }^{\circ} \mathrm{C} & \text { atmosphere(s) } \\ { }^{\circ} \mathrm{F} & \text { degree(s) Celsius } \\ \mathrm{g} & \text { degree(s) Fahrenheit } \\ \mathrm{kJ} & \text { gram(s) } \\ \mathrm{mol} & \text { kilojoule(s) } \\ & \text { mole(s) }\end{array}$




\section{APPENDIX H:}

\section{REFERENCE DATA ON AIRBORNE RELEASES FOR ACCIDENTS INVOLVING HAZARDOUS CHEMICALS}

\section{H.1 INTRODUCTION}

All accidents were divided into three general categories, each having subcategories and including potentials for any adverse effects and potential life-threatening endpoints:

1. Spills resulting in partial vaporization of the waste ("spill only");

2. Spills followed by ignition of the waste ("spill plus fire"); and

3. "Other event combinations"

- spills followed by ignition of the waste and an induced explosion in a waste container ("spill plus fire plus explosion"),

- facility fires resulting in a waste container breach ("fire only"),

- mechanical failure of a compressed gas container resulting in an explosion ("spill and explosion"),

- explosion from exposure of reactive material to air followed by fire ("fire and explosion").

Table 8.4 in Volume 1 of this report lists the representative accidents chosen to serve as surrogates for all risk dominant sequences. The first 13 accidents involve the release of potentially lifethreatening toxic gases; the remaining accidents involve the release of gas with only carcinogenic or sublethal impacts. In the development of these accidents, the following considerations were taken into account:

1. Proximity of classes of chemicals to each other in the storage facilities;

2. Typical designs of the storage facilities and the required separation of such groups of chemicals as flammable liquids, acids, caustics, combustibles, oxidizers, etc;

3. Ninety-day residence limit for Resource Conservation and Recovery Act (RCRA) hazardous waste in a storage facility.

The accident scenarios include a range of high-probability, low-consequence accidents and high-consequence, low-probability accidents. In general, these accidents involve chemical or 
physical changes in stored materials subsequent to an initial incident. Equations were derived to represent the changes anticipated to occur during the accidents. Toxic gaseous products were identified, and their masses estimated from the mass of the reactants and the stoichiometry of the reactions. Rates of releases were estimated on the basis of engineering judgment and the recognition that such rates often decay exponentially with time. Obviously, the exact course of an accident is shaped by a multitude of factors, including (but not limited to) temperature, humidity, pooling versus spreading of spills, the exact composition/concentration of reactive materials, (often unknown), and the proximity and nature of nearby reactive materials (including packaging, shelving, and flooring).

This appendix provides details on the selection of the accident scenarios, on the chemistry involved in their progression, and on the estimation of the rates of release of the toxic gases.

\section{H.2 HANDLING ACCIDENT IN WHICH AQUEOUS AMMONIA IS SPILLED}

This scenario was developed because large amounts of aqueous ammonia pass through U.S. Department of Energy (DOE) storage facilities and because of the well-known hazards of exposure to ammonia $\left(\mathrm{NH}_{3}\right)$.

Ammonia, a gas at ordinary conditions, is quite soluble in water. Chemically, it is a base. Solutions of ammonia in water $\left(\mathrm{NH}_{3}[a q]\right)$ are often called ammonium hydroxide (formula $\mathrm{NH}_{4} \mathrm{OH}$ ). Solutions of aqueous ammonia vary in concentration. Standard "concentrated ammonium hydroxide," which is widely distributed and used, consists of $28 \% \mathrm{NH}_{3}$ by mass. Although it is probable that most waste ammonia is at least partly neutralized before disposal (by reaction with an acid in use), the scenario makes the conservative assumption that concentrated aqueous ammonia is spilled.

Concentrated aqueous ammonia evaporates and releases gaseous ammonia $\left(\mathrm{NH}_{3}[g]\right)$ according to the following equation:

$$
\begin{gathered}
\mathrm{NH}_{3}(a q) \rightarrow \mathrm{NH}_{3}(g) \quad \Delta \mathrm{H}^{\circ}=+34.18 \mathrm{~kJ} / \mathrm{mol} \\
\Delta \mathrm{H}^{\circ}=+2.0 \mathrm{~kJ} / \mathrm{g} \mathrm{NH} \mathrm{NH}_{3},
\end{gathered}
$$

which is equivalent to

$$
\mathrm{NH}_{4}{ }^{+}(a q)+\mathrm{OH}^{-}(a q) \rightarrow \mathrm{NH}_{3}(g)+\mathrm{H}_{2} \mathrm{O}(l) .
$$

Essentially all of the ammonia evaporates before the evaporation of any of the solvent water. Ammonia is far more volatile than water (the vapor pressure of $\mathrm{NH}_{3}$ at $25^{\circ} \mathrm{C}\left[77^{\circ} \mathrm{F}\right]$ is $10 \mathrm{~atm}$, whereas that of water is $0.030 \mathrm{~atm}$ ).

The quantity to the right of Equation $\mathrm{H} .1$ is the standard change in enthalpy $\left(\Delta \mathrm{H}^{\circ}\right)$ for the process. A positive $\Delta \mathrm{H}^{\circ}$ means that the reaction is endothermic (withdraws heat from the surroundings); a negative $\Delta \mathrm{H}^{\circ}$ means that it is exothermic (generates heat in the surroundings). The 
$\Delta \mathrm{H}^{\circ}$ is given per mol of reaction as written and, in the second line, per gram of reactant. Thus, $1 \mathrm{~mol}$ of aqueous ammonia in its standard state takes up $34.18 \mathrm{~kJ}$ of energy to yield $1 \mathrm{~mol}$ of gaseous ammonia under standard conditions. Because evaporation is endothermic, the scenario envisages an early, more rapid release of $\mathrm{NH}_{3}(g)$ as spilled $\mathrm{NH}_{3}(a q)$ spreads out and is maintained at ambient temperature by contact with fresh warm surfaces. This is succeeded by a falling rate of release as the spill puddles and experiences local evaporative cooling. The times proposed for the two phases of the release of the toxic gas are reasonable estimates; actual times would range quite widely depending on the evolution, size, and shape of the evaporating surface of the spill. The proposed rates of evaporation of the ammonia are also reasonable estimates. Rates would depend strongly on the ambient temperature. An exponential decay in the rate of release is assumed to set in as the spill attains its full extent, as the exposed $\mathrm{NH}_{3}(a q)$ reaches a steady-state temperature, and as the solution dwindles in concentration.

The generation of gaseous ammonia is greatly accelerated if a spill encounters another base (e.g., lime or sodium hydroxide). Such compounds supply $\mathrm{OH}^{-}$ion to drive the evaporation strongly to the right.

$$
\mathrm{NH}_{4}^{+}(a q)+\mathrm{OH}^{-}(a q) \rightarrow \mathrm{NH}_{3}(g)+\mathrm{H}_{2} \mathrm{O}(l)
$$

Plans for the segregation of reactive materials in hazardous waste storage facilities (HWSFs) put acids and bases far apart, whereas weak volatile bases and strong bases are in close proximity.

The release of gaseous ammonia is representative of releases of amines, a numerous and important class of compounds. Amines are organic derivatives of ammonia that vary in toxicity and volatility. The release of amines from aqueous solution is also accelerated by contact with a strong base.

\section{H.3 HANDLING ACCIDENT IN WHICH HYDROCHLORIC ACID IS SPILLED}

This scenario is a chemical reversal (acid rather than base) of the ammonia spill just described. Hydrogen chloride $(\mathrm{HCl})$ is gaseous at room conditions but dissolves readily in water to yield hydrochloric acid ( $\mathrm{HCI}[a q]$, sometimes called muriatic acid). Hydrochloric acid is commonly shipped as a 12.1 molar solution (concentrated hydrochloric acid). This mixture contains $37 \% \mathrm{HCl}$ by mass. Aqueous solutions of $\mathrm{HCl}$ evaporate when not confined. $\mathrm{Because} \mathrm{HCl}$ is more volatile than water, it predominates in the first vapors emitted:

$$
\begin{gathered}
\mathrm{H}^{+}(a q)+\mathrm{Cl}^{-}(a q) \rightarrow \mathrm{HCl}(g) \Delta \mathrm{H}^{\circ}=+74.85 \mathrm{~kJ} / \mathrm{mol} \\
\Delta \mathrm{H}^{\circ}=2.1 \mathrm{~kJ} / \mathrm{g} \mathrm{HCl} .
\end{gathered}
$$

The other details in this scenario were developed in the same way as those in the ammonia spill. A slower outflux of gas in the second stage of the $\mathrm{HCl}(a q)$ spill is assumed because $\Delta \mathrm{H}^{\circ}$ for the evaporation of $\mathrm{HCl}(a q)$ exceeds $\Delta \mathrm{H}^{\circ}$ for the evaporation of $\mathrm{NH}_{3}(a q)$. 
Concentrated $\mathrm{HCl}(a q)$ reacts with many metals, including iron and steel, to generate gaseous hydrogen:

$$
\begin{gathered}
2 \mathrm{H}^{+}(a q)+\mathrm{Fe}(s)-\mathrm{H}_{2}(g)+\mathrm{Fe}^{2+}(a q) \Delta \mathrm{H}^{\circ}=-89.1 \mathrm{~kJ} / \mathrm{mol} \\
\Delta \mathrm{H}^{\circ}=-1.22 \mathrm{~kJ} / \mathrm{g} \mathrm{HCl}
\end{gathered}
$$

This reaction is not a "spill alone" and was not considered in that category.

Also, the generation of $\mathrm{HCl}(g)$ from $\mathrm{HCl}(a q)$ is greatly favored both thermodynamically and kinetically by contact of the hydrochloric acid with a strong non-volatile acid (the best example is sulfuric acid $\left.\left[\mathrm{H}_{2} \mathrm{SO}_{4}\right]\right)$. Strong acid drives the evaporation reaction strongly to the right.

The scenario developed here is representative of accidental spills of all volatile acids (such as hydrobromic acid [HBr(aq)], hydroiodic acid [HI(aq)], and hydrofluoric acid [HF(aq)]).

\section{H.4 HANDLING ACCIDENT IN WHICH AQUEOUS HYDROGEN FLUORIDE IS SPILLED}

This scenario was developed because $\mathrm{HF}(g)$ is much more toxic than $\mathrm{HCl}(g)$. Otherwise, it is similar to the $\mathrm{HCl}(a q)$ spill. The evaporation reaction is as follows:

$$
\begin{gathered}
\mathrm{HF}(a q) \rightarrow \mathrm{HF}(g) \quad \Delta \mathrm{H}^{\circ}=+49.0 \mathrm{~kJ} / \mathrm{mol} \\
\Delta \mathrm{H}^{\circ}=2.45 \mathrm{~kJ} / \mathrm{g} \mathrm{HF} .
\end{gathered}
$$

$\mathrm{HF}$ is a weak acid in aqueous solution; that is, ionization to $\mathrm{H}^{+}(a q)$ and $\mathrm{F}^{-}(a q)$ ions is only slight, whereas $\mathrm{HCl}$ and the other hydrohalic acids ( $\mathrm{HBr}$ and $\mathrm{HI}$ ) are strong acids (completely ionized). This fact is sometimes erroneously advanced as mitigating the hazards of $\operatorname{HF}(a q)$. In fact, it has little influence on the events projected in the scenario.

The above reaction, like the evaporation of $\mathrm{HCl}$, is driven to the right by the presence in the system of a strong nonvolatile acid (such as $\mathrm{H}_{2} \mathrm{SO}_{4}$ ).

\section{H.5 HANDLING ACCIDENT IN WHICH NITRIC ACID IS SPILLED}

This scenario is a case in which a noxious gaseous compound is generated by chemical action subsequent to a spill.

The nitric acid $\left(\mathrm{HNO}_{3}[a q]\right)$ is assumed to be commercial concentrated nitric acid (approx. $70 \%$ by mass). Concentrated nitric acid has great power as an oxidizing agent. Spills of $\mathrm{HNO}_{3}(a q)$ would generate clouds of $\mathrm{NO}_{x}$ (mixed oxides of nitrogen) containing a large proportion of brown nitrogen dioxide $\left(\mathrm{NO}_{2}\right)$ as the advancing spill would touch various more or less easily oxidized 
materials. Indeed, concentrated nitric acid is likely to cause ignitions of wood, excelsior, and other cellulose products, particularly when the cellulosic material is finely divided or porous. A typical reaction of concentrated nitric acid with a metal is as follows:

$$
\begin{gathered}
\mathrm{Fe}(s)+3 \mathrm{HNO}_{3}(a q)+3 \mathrm{H}^{+}(a q) \rightarrow \mathrm{Fe}^{3+}(a q)+3 \mathrm{NO}_{2}(g)+3 \mathrm{H}_{2} \mathrm{O}(l) \\
\Delta \mathrm{H}^{\circ}=-191.5 \mathrm{~kJ} / \mathrm{mol} \\
\Delta \mathrm{H}^{\circ}=-1.01 \mathrm{~kJ} / \mathrm{g} \mathrm{HNO}
\end{gathered}
$$

The chemistry of nitric acid oxidations is much more complex than this. For example, the reaction of nitric acid with iron also yields nitric oxide $(\mathrm{NO}[g])$, nitrous oxide $\left(\mathrm{N}_{2} \mathrm{O}[g]\right)$, nitrogen $\left(\mathrm{N}_{2}[g]\right)$, hydrogen $\left(\mathrm{H}_{2}[g]\right)$, and ammonium ion $\left(\mathrm{NH}_{4}{ }^{+}[a q]\right)$, depending on the exact temperature and concentration of the acid. The acid would react similarly with most of the many materials it might encounter during a spill.

The scenario assumes that all the nitrogen in the $\mathrm{HNO}_{3}$ goes off as brown gaseous $\mathrm{NO}_{2}$. This amounts to $46 / 63$ (the ratio of the molar mass of $\mathrm{NO}_{2}$ to that of $\mathrm{HNO}_{3}$ ) of the mass of the $\mathrm{HNO}_{3}$, which is about $3 / 4$ of that mass. The scenario takes the mass of $\mathrm{NO}_{2}(\mathrm{~g})$ as simply equal to the mass of $\mathrm{HNO}_{3}$ in the spill.

The pattern for the rate of release of the $\mathrm{NO}_{2}$ in this scenario purposely resembles that chosen in the three previous scenarios: strong at the start then dying down exponentially over time.

\section{H.6 HANDLING ACCIDENT IN WHICH AN AROMATIC HYDROCARBON SPILLS AND BURNS}

This scenario posits a fire in aromatic hydrocarbon wastes because such wastes are common in the HWSFs.

Aromatic hydrocarbons include benzene $\left(\mathrm{C}_{6} \mathrm{H}_{6}\right)$ and its derivatives (such as toluene and xylene). The complete combustion of benzene generates innocuous products and considerable heat:

$$
\begin{gathered}
\mathrm{C}_{6} \mathrm{H}_{6}(l)+15 / 2 \mathrm{O}_{2}(g) \rightarrow 6 \mathrm{CO}_{2}(g)+3 \mathrm{H}_{2} \mathrm{O}(g) \quad \Delta \mathrm{H}^{\circ}=-3135 \mathrm{~kJ} / \mathrm{mol} \\
\Delta \mathrm{H}^{\circ}=-40.2 \mathrm{~kJ} / \mathrm{g} \mathrm{C}_{6} \mathrm{H}_{6} .
\end{gathered}
$$

The combustion of benzene (or other aromatic hydrocarbons) in a pool in the open air does not proceed according to Equation H.8. Instead, oxidation is incomplete and produces quantities of carbon monoxide and soot. The soot is a mixture of elemental carbon and many compounds, 
including polycyclic aromatic hydrocarbons (PAHs) such as benzo[a]pyrene $\left(\mathrm{C}_{20} \mathrm{H}_{12}\right)$. Thus, a range of concurrent oxidation reactions takes place. Representative reactions include the following:

$$
\begin{gathered}
2 \mathrm{C}_{6} \mathrm{H}_{6}(l)+9 \mathrm{O}_{2}(g)-12 \mathrm{CO}(g)+6 \mathrm{H}_{2} \mathrm{O}(g) \\
2 \mathrm{C}_{6} \mathrm{H}_{6}(l)+3 \mathrm{O}_{2}(g)-12 \mathrm{C}(s)+6 \mathrm{H}_{2} \mathrm{O}(g) \\
10 \mathrm{C}_{6} \mathrm{H}_{6}(l)+6 \mathrm{O}_{2}(g)-3 \mathrm{C}_{20} \mathrm{H}_{12}(s)+12 \mathrm{H}_{2} \mathrm{O}(g) .
\end{gathered}
$$

The molar ratio of oxygen to benzene decreases from $9 / 2$ to $6 / 10$ going down the list of three partial oxidations. All three reactions consume less oxygen than complete combustion, which uses oxygen in a $15 / 2$ molar ratio.

The heat of combustion of the first portions of the hydrocarbon evaporates other portions as shown in the following equation:

$$
\mathrm{C}_{6} \mathrm{H}_{6}(l) \rightarrow \mathrm{C}_{6} \mathrm{H}_{6}(g) \quad \Delta \mathrm{H}^{\circ}=+33.9 \mathrm{~kJ} / \mathrm{mol} .
$$

The unburned vapors present an inhalation hazard.

The total mass of the products of combustion of a quantity of a hydrocarbon exceeds that of the hydrocarbon by an amount equal to the mass of the oxygen that is taken up. A stoichiometric calculation shows that complete combustion (to $\mathrm{CO}_{2}$ and $\mathrm{H}_{2} \mathrm{O}$ ) of $m$ pounds of benzene requires $3.08 \mathrm{~m}$ pounds of oxygen. (Benzene has $78 \mathrm{~g} / \mathrm{mol}$ and oxygen has $32 \mathrm{~g} / \mathrm{mol}$. Thus, complete combustion of $2 \mathrm{~mol}$ of benzene by $15 \mathrm{~mol}$ of oxygen implies a mass ratio for the two reactants of $15 \times 32 / 2 \times 78$.) Incomplete combustion naturally uses less oxygen. The scenario assumes that $12 \%$ of the hydrocarbon is evaporated; $40 \%$ is converted to soot having approximately the same mass as the hydrocarbon reacted; and the rest is converted to water, carbon monoxide, and carbon dioxide. This distribution of products is representative but would vary greatly with the actual circumstances of the fire.

\section{H.7 HANDLING ACCIDENT IN WHICH A FLAMMABLE LIQUID SPILLS, IGNITES, AND BURNS, CAUSING THE RUPTURE OF OTHER CONTAINERS}

This scenario hinges on a contingent event. It points out that (1) oxygen is not the only oxidizing agent that might become involved in a fire in a HWSF and (2) an otherwise ordinary fire can be intensified by involvement of neighboring chemically active wastes.

Flammable organic solvents (e.g., acetone) are reducing agents that tend to react with oxidizing agents such as $\mathrm{Ca}(\mathrm{ClO})_{2}$ (calcium hypochlorite). For example,

$$
\begin{gathered}
\mathrm{C}_{3} \mathrm{H}_{6} \mathrm{O}(l)+4 \mathrm{Ca}(\mathrm{ClO})_{2} \rightarrow 4 \mathrm{CaCl}_{2}(s)+3 \mathrm{CO}_{2}(g)+3 \mathrm{H}_{2} \mathrm{O}(\mathrm{g}) \\
\Delta \mathrm{H}^{\circ}=-2159 \mathrm{~kJ} / \mathrm{mol} \\
\Delta \mathrm{H}^{\circ}=-37.2 \mathrm{~kJ} / \mathrm{g} \mathrm{C}_{3} \mathrm{H}_{6} \mathrm{O}
\end{gathered}
$$


The rate of generation of the heat would depend on the details of the contact between the reactants. However, involvement of stored oxidizing agents could aggravate an otherwise ordinary solvent fire in a HWSF, as shown by comparing the preceding $\Delta \mathrm{H}^{\circ}$ to the $\Delta \mathrm{H}^{\circ}$ for the simple combustion of a mol of acetone:

$$
\begin{gathered}
\mathrm{C}_{3} \mathrm{H}_{6} \mathrm{O}(l)+4 \mathrm{O}_{2}(g)-3 \mathrm{CO}_{2}(g)+3 \mathrm{H}_{2} \mathrm{O}(g) \Delta \mathrm{H}^{\circ}=-1689 \mathrm{~kJ} / \mathrm{mol} \\
\Delta \mathrm{H}^{\circ}=-29.1 \mathrm{~kJ} / \mathrm{g} \mathrm{C}_{3} \mathrm{H}_{6} \mathrm{O} .
\end{gathered}
$$

The reaction of acetone with $\mathrm{Ca}(\mathrm{ClO})_{2}$ could also proceed faster, leading to higher local temperatures.

In this scenario, it is suggested that the heat ruptures a nearby container of $\mathrm{HF}(a q)$, causing dispersal of $\operatorname{HF}(g)$ into the air (see above). The estimated rate of release in this puff is meant as a single intense spurt of $\mathrm{HF}$ when the container ruptures following strong heating.

\section{H.8 HANDLING ACCIDENT IN WHICH A FLAMMABLE LIQUID SPILLS AND IGNITES; THE FIRE ENGULFS NEARBY DRUMS AND INITIATES REACTIONS THAT RELEASE HIGHLY TOXIC VAPORS}

Like the previous scenario, this scenario hinges on contingent events. A solvent catches fire:

$$
\mathrm{C}_{3} \mathrm{H}_{6} \mathrm{O}(l)+4 \mathrm{O}_{2}(g) \rightarrow 3 \mathrm{CO}_{2}(g)+3 \mathrm{H}_{2} \mathrm{O}(g) \quad \Delta \mathrm{H}^{\circ}=-1689 \mathrm{~kJ} \text {. }
$$

Heat from the fire is assumed to rupture nearby or engulfed containers. The released materials react among themselves (apart from the fire) to generate toxic gases. The simultaneous release of a waste acid (such as $\mathrm{H}_{2} \mathrm{SO}_{4}, \mathrm{HCl}$, or $\mathrm{HNO}_{3}$, which are common in the HWSFs) and a cyanide salt (such as sodium cyanide [NaCN] or potassium cyanide [KCN]) could then lead to the release of very toxic $\mathrm{HCN}(g)$ from the reaction:

$$
\mathrm{H}_{2} \mathrm{SO}_{4}(a q)+2 \mathrm{NaCN}(s, \text { or } a q) \rightarrow 2 \mathrm{HCN}(g)+\mathrm{Na}_{2} \mathrm{SO}_{4}(a q) \text {. }
$$

The preceding reaction is essentially instantaneous once the reactants are in contact. The scenario assumes that contact between the acid and the cyanide salt occurs rapidly. The yield of $\mathrm{HCN}(g)$ (assuming an excess of acid) would be 0.55 pounds per pound of $\mathrm{NaCN}$. For simplicity, the mass of the $\mathrm{HCN}(\mathrm{g})$ is assumed to equal the mass of the cyanide salt in the hazardous waste container. 


\section{H.9 LARGER ACCIDENT IN WHICH A FLAMMABLE LIQUID SPILLS AND IGNITES; THE FIRE ENGULFS NEARBY DRUMS AND INITIATES REACTIONS THAT RELEASE TOXIC VAPORS}

The occasional presence of large quantities of flammables in HWSFs prompted the development of this scenario. A burning tank-car of naphtha (the $C_{4}$ to $C_{10}$ fraction from petroleum used to make gasoline) is a serious fire in any setting:

$$
\begin{gathered}
\mathrm{C}_{8} \mathrm{H}_{18}+25 / 2 \mathrm{O}_{2} \rightarrow 8 \mathrm{CO}_{2}(\mathrm{~g})+9 \mathrm{H}_{2} \mathrm{O}(\mathrm{g}) \quad \Delta \mathrm{H}^{\circ}=-5450 \mathrm{~kJ} / \mathrm{mol} \\
\Delta \mathrm{H}^{\circ}=-44.8 \mathrm{~kJ} / \mathrm{g} \mathrm{C}_{8} \mathrm{H}_{18} .
\end{gathered}
$$

In a HWSF, the fire might engulf stored oxidizing agents, which would intensify the fire. For example,

$$
\begin{gathered}
\mathrm{C}_{8} \mathrm{H}_{18}+25 / 2 \mathrm{Ca}(\mathrm{ClO})_{2} \rightarrow 25 / 2 \mathrm{CaCl}_{2}(s)+8 \mathrm{CO}_{2}(g)+9 \mathrm{H}_{2} \mathrm{O}(\mathrm{g}) \\
\Delta \mathrm{H}^{\circ}=-6586 \mathrm{~kJ} / \mathrm{mol} \\
\Delta \mathrm{H}^{\circ}=-57.8 \mathrm{~kJ} / \mathrm{g} \mathrm{C}_{8} \mathrm{H}_{18} .
\end{gathered}
$$

Further, it might cause release of toxic vapors as in scenarios 7 and 8.

Such a fire could cause the release of toxic materials from objects generally thought to have a low hazard (such as mercury cells). A hot fire vaporizes mercury (bp $357^{\circ} \mathrm{C}\left[675^{\circ} \mathrm{F}\right]$ ) easily according to the following equation:

$$
\mathrm{Hg}(l) \rightarrow \mathrm{Hg}(g) \quad \Delta \mathrm{H}^{\circ}=61.32 \mathrm{~kJ} / \mathrm{mol} .
$$

The release of $\mathrm{Hg}$ in such an event would be intermittent, as the cells ruptured.

\section{H.10 HEAT FROM THE FIRE CAUSES AN EXPLOSION IN A COMPRESSED GAS CONTAINER, RESULTING IN VENTING OF A TOXIC GAS}

This scenario is included because the inventories of the HWSFs include containers of pressurized gases or liquid/gas mixtures. Such systems are liable to rupture if heated.

The precipitating event here is the combustion of a spilled flammable liquid, as in preceding scenarios. This generates enough heat to cause explosive failure of a container of confined toxic gas. In this case., the gas is taken to be ammonia $\left(\mathrm{NH}_{3}[g]\right)$. The release of the contents in a single burst is a representative result in the catastrophic failure of pressurized gas containers. 


\section{H.11 ACCIDENTAL CO-CONFINEMENT OF OXIDIZING AND REDUCING AGENTS, LEADING TO A REACTION GENERATING HEAT THAT IGNITES PACKAGING AND BREACHES A NEARBY DRUM}

This class of accidents hinges on the large amounts of heat released by many redox (oxidation-reduction) reactions. These accidents are considered separate from the ubiquitous case of combustion, in which the fuel is the reducing agent and oxygen (air) is the oxidizing agent The HWSF inventories include numerous oxidizing agents such as chlorates, perchlorates, persulfates, chromates and dichromates, and permanganates. Reducing agents are also found in the inventories and in packing and other everyday materials as well. Wood, paper, paint, film, and plastics can all serve as reducing agents. A possible reaction would be the following:

$$
8 \mathrm{KMnO}_{4}+\left(\mathrm{C}_{6} \mathrm{H}_{10} \mathrm{O}_{5}\right)-6 \mathrm{CO}_{2}+5 \mathrm{H}_{2} \mathrm{O}+4 \mathrm{~K}_{2} \mathrm{O}+8 \mathrm{MnO}_{2} \text {, }
$$

where $\mathrm{C}_{6} \mathrm{H}_{10} \mathrm{O}_{5}$ is the cellulose monomer unit.

A chemical reaction does not occur automatically on contact between a good reducing agent and good oxidizing agent. For example, newspaper (a reducing agent) lasts more or less indefinitely in air. Still, some redox reactions are immediate upon mixing the reactants; others can set in and occur rapidly after a long induction period.

In this scenario, a case is visualized in which commingled oxidizing and reducing agents ultimately react and generate either enough heat to start a fire or cause rupture of a nearby container holding pressurized toxic gas. It is assumed that the toxic gas is released in a single burst upon decompression.

\section{H.12 ACCIDENTAL CONFINEMENT OF WATER WITH ALKALI METALS, ALKALI-METAL HYDRIDES, OR ALKALINE-EARTH OXIDES, GIVING REACTIONS GENERATING HEAT, IGNITING PACKAGING, AND BREACHING NEARBY DRUMS}

Part of this scenario (the reaction of water with alkali metals and alkali-metal hydrides) is a special case of the previous redox scenario; it is distinguished from the redox scenario by the particularly violent and rapid nature of the reactions. The last part (reaction of water with alkalineearth oxides) is included because of the strong generation of heat from an acid-base reaction.

The alkali metals (lithium [Li], sodium [Na], potassium [K], rubidium [Rb], and cesium [Cs]) all react rapidly with water to generate gaseous hydrogen and a hydroxide:

$$
\begin{gathered}
2 \mathrm{M}(s)+2 \mathrm{H}_{2} \mathrm{O}(l) \rightarrow \mathrm{H}_{2}(g)+2 \mathrm{M}^{+}(a q)+2 \mathrm{OH}^{-}(a q) \\
\Delta \mathrm{H}^{\circ} \text { s approx }-650 \mathrm{~kJ} / \mathrm{mol} .
\end{gathered}
$$


The heat of the reaction melts the metal and usually ignites the hydrogen, which burns rapidly:

$$
2 \mathrm{H}_{2}(g)+\mathrm{O}_{2}(g) \rightarrow 2 \mathrm{H}_{2} \mathrm{O}(g) \Delta \mathrm{H}^{\circ}=-241.8 \mathrm{~kJ} / \mathrm{mol} \text {. }
$$

Any combustible materials would become involved in the fire and the fire would spread.

The alkali metal hydrides $(\mathrm{MH})$ (such as $\mathrm{LiH}, \mathrm{NaH}, \mathrm{RbH}$ ) are also violently oxidized by water:

$$
\begin{gathered}
\mathrm{MH}(s)+\mathrm{H}_{2} \mathrm{O}(l)-1 / 2 \mathrm{H}_{2}(g)+\mathrm{M}^{+}(a q)+\mathrm{OH}^{-}(a q) \\
\Delta \mathrm{H}^{\circ} \text { s spprox }-140 \mathrm{~kJ} / \mathrm{mol}
\end{gathered}
$$

This heat of this reaction also often ignites the hydrogen produced.

The reactions of alkali-metal oxides or alkali-earth oxides with water are acid-base reactions (not oxidation-reduction reactions). Typical equations are as follows:

$$
\begin{gathered}
\mathrm{K}_{2} \mathrm{O}(s)+\mathrm{H}_{2} \mathrm{O}(l)-2 \mathrm{KOH}(a q) \quad \Delta \mathrm{H}^{\circ}=-361.4 \mathrm{~kJ} / \mathrm{mol} \\
\Delta \mathrm{H}^{\circ}=-3.85 \mathrm{~kJ} / \mathrm{g} \mathrm{K}_{2} \mathrm{O} \\
\mathrm{CaO}(s)+\mathrm{H}_{2} \mathrm{O}(l) \rightarrow 2 \mathrm{Ca}(\mathrm{OH})_{2}(s) \Delta \mathrm{H}^{\circ}=-1052 \mathrm{~kJ} / \mathrm{mol} \\
\Delta \mathrm{H}^{\circ}=-18.8 \mathrm{~kJ} / \mathrm{g} \mathrm{CaO} .
\end{gathered}
$$

The heat is generated rapidly enough to ignite paper, wood, or other packing materials. The accidental wetting of paper bags of quicklime $(\mathrm{CaO})$ has caused numerous fires.

\section{H.13 ACCIDENTAL RUPTURE OF COMPRESSED GAS (NOS [NOT OTHERWISE SPECIFIED] FLAMMABLE) DUE TO VALVE FAILURE, RESULTING IN RELEASES OF TOXIC GAS}

This scenario treats a simple failure of confinement of a pressurized gas. The consequences would depend on the identity of the gas, which is often not known ("NOS"). It is assumed here that the toxic gas is ammonia.

The release of compressed gas would be complete essentially immediate; this is not the same as the evaporative release of a dissolved gas from a liquid spill.

\section{H.14 EXPLOSION (WITHOUT PREVIOUS SPILL) OF A STORED CHEMICAL}

This scenario highlights the fact that certain stored chemicals can explode without obvious initiation. The formation of explosive peroxides from ethers in contact with air is well-known.

$$
\mathrm{C}_{2} \mathrm{H}_{5}-\mathrm{O}-\mathrm{C}_{2} \mathrm{H}_{5}+1 / 2 \mathrm{O}_{2} \rightarrow \mathrm{C}_{2} \mathrm{H}_{5}-\mathrm{O}-\mathrm{O}-\mathrm{C}_{2} \mathrm{H}_{5} \text {. }
$$


Such explosions can occur without apparent prompting. The scenario envisages such an event with the following sequelae: (1) a quick fire in the unperoxidized ether and (2) the rupture of a nearby container of a toxic gas (assumed for the sake of illustration to be ammonia). The release of compressed gas would be complete essentially immediate; this is not the same as the evaporative release of a dissolved gas from a liquid spill.

\section{H.15 HANDLING ACCIDENTS IN WHICH A SPILLED WASTE RELEASES A MUTAGENIC, TERATOGENIC, OR CARCINOGENIC SUBSTANCE}

Glacial (pure) acetic acid spills and subsequently evaporates as follows:

$$
\begin{gathered}
\mathrm{CH}_{3} \mathrm{COOH}(l)-\mathrm{CH}_{3} \mathrm{COOH}(\mathrm{g}) \quad \Delta \mathrm{H}^{\circ}=+52.25 \mathrm{~kJ} / \mathrm{mol} \\
\Delta \mathrm{H}^{\circ}=+0.87 \mathrm{~kJ} / \mathrm{g} \text { acetic acid } .
\end{gathered}
$$

Slower rates of release than in previous similar scenarios are proposed because acetic acid is less volatile (bp $118^{\circ} \mathrm{C}\left[244^{\circ} \mathrm{F}\right]$ ) than the other acids.

A similar spill of $\mathrm{CS}_{2}(l)$ (carbon disulfide), a nonacidic liquid, vaporizes as follows:

$$
\begin{gathered}
\mathrm{CS}_{2}(l) \rightarrow \mathrm{CS}_{2}(g) \quad \Delta \mathrm{H}^{\circ}=+27.66 \mathrm{~kJ} / \mathrm{mol} \\
\Delta \mathrm{H}^{\circ}=+0.69 \mathrm{~kJ} / \mathrm{g} \mathrm{CS}
\end{gathered}
$$

The release rate of the vapor is set somewhat higher than for acetic acid because $\mathrm{CS}_{2}$ is more volatile (bp $46.5^{\circ} \mathrm{C}$ ).

A spill of $1,1,1$-trichloroethane $\left(\mathrm{Cl}_{3} \mathrm{CCH}_{3}\right)$, a volatile solvent, in a substantially larger amount evaporates as follows:

$$
\begin{gathered}
\mathrm{Cl}_{3} \mathrm{CCH}_{3}(l) \rightarrow \mathrm{Cl}_{3} \mathrm{CCH}_{3}(g) \quad \Delta \mathrm{H}^{\circ}=+32.8 \mathrm{~kJ} / \mathrm{mol} \\
\Delta \mathrm{H}^{\circ}=+0.25 \mathrm{~kJ} / \mathrm{g} \mathrm{Cl}_{3} \mathrm{CCH}_{3} .
\end{gathered}
$$

The boiling point of 1,1,1-trichloroethane is $74^{\circ} \mathrm{C}\left(165^{\circ} \mathrm{F}\right)$. The rate of release as vapor would diminish as evaporative cooling lowers the vapor pressure of the remaining spill.

\section{H.16 HANDLING ACCIDENT SPILL THAT IGNITES FLAMMABLE LIQUIDS, THEREBY BREACHING NEARBY DRUMS WITH CADMTUM-CONTAINING COMPOUNDS (CD SALTS OR NICAD BATTERIES)}

This scenario uses the motif of an accidental spill escalating to a fire with subsequent involvement of nearby stored materials. In this case, the stored materials are posited to be used Nicad batteries. It is assumed that the heat of the fire is sufficient to cause fumes of Cd metal to escape 
(cadmium melts and boils at the relatively low temperatures of $321^{\circ} \mathrm{C}\left[609^{\circ} \mathrm{F}\right]$ and $765^{\circ} \mathrm{C}$ $\left.\left(1,409^{\circ} \mathrm{F}\right]\right)$.

The rate of release of the cadmium (Cd) would be rapid upon rupture of individual sealed batteries by the heat of the fire.

$$
\begin{gathered}
\mathrm{Cd}(s) \rightarrow \mathrm{Cd}(g) \quad \Delta \mathrm{H}^{\circ}=+112 \mathrm{~kJ} / \mathrm{mol} \\
\Delta \mathrm{H}^{\circ}=+1.0 \mathrm{~kJ} / \mathrm{g} \mathrm{Cd} .
\end{gathered}
$$

Both Cd vapor and $\mathrm{Cd}$-containing particulate matter would be formed.

\section{H.17 HANDLING ACCIDENT SPILL THAT IGNITES FLAMMABLE LIQUID; THE FIRE BREACHES NEARBY DRUMS CONTAINING DICHROMATE SALTS}

This scenario is the same as the previous one, but now a release of the carcinogenic salts of chromium ensues from the spill and fire. A typical fire would be the combustion of acetone.

$$
\mathrm{C}_{3} \mathrm{H}_{6} \mathrm{O}(l)+4 \mathrm{O}_{2}(g)-3 \mathrm{CO}_{2}(g)+3 \mathrm{H}_{2} \mathrm{O}(g)
$$

Once a drum containing the dichromate salts is breached, such a compound could become involved as oxidizers. For example,

$$
\mathrm{C}_{3} \mathrm{H}_{6} \mathrm{O}+8 / 3 \mathrm{~K}_{2} \mathrm{Cr}_{2} \mathrm{O}_{7}-3 \mathrm{CO}_{2}+3 \mathrm{H}_{2} \mathrm{O}+8 / 3 \mathrm{~K}_{2} \mathrm{O}+8 / 3 \mathrm{Cr}_{2} \mathrm{O}_{3} \text {. }
$$

Both the unreacted dichromate salt (e.g., $\mathrm{K}_{2} \mathrm{Cr}_{2} \mathrm{O}_{7}$ in Equation $\mathrm{H} .29$ ) and the chromium (III) oxide $\left(\mathrm{Cr}_{2} \mathrm{O}_{3}\right.$ in Equation H.29) would be dispersed by the fire as particulates. The rate of release of the dusts would be rapid, assuming full involvement in the fire. The mass of the dispersed dusts is taken to equal the mass of the dichromate waste (although, in fact, the preceding reaction would reduce that mass slightly). 